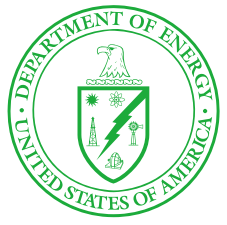

U.S. Department of Energy Idaho Operations Office

\title{
Feasibility Study for Operable Unit 7-13/14
}

May 2007

K. Jean Holdren

Thomas E. Bechtold

Brian D. Preussner 
DOE/ID-11268

Revision 0

\title{
Feasibility Study for Operable Unit 7-13/14
}

\author{
K. Jean Holdren \\ Thomas E. Bechtold \\ Brian D. Preussner \\ Edited by Lynda Nelson and Jan K. Wright
}

May 2007

Prepared for the

U.S. Department of Energy

DOE Idaho Operations Office 



\begin{abstract}
The Subsurface Disposal Area is a radioactive waste landfill located within the Radioactive Waste Management Complex at the Idaho National Laboratory Site in southeastern Idaho. This Feasibility Study for Operable Unit 7-13/14 analyzes options for mitigating risks to human health and the environment associated with the landfill. Analysis is conducted in accordance with the Comprehensive Environmental Response, Compensation, and Liability Act, using nine evaluation criteria to develop detailed and comparative analysis of five assembled alternatives. The five assembled alternatives, named after their featured technology, are Alternative 1-No Action; Alternative 2-Surface Barrier; Alternative 3-In Situ Grouting; Alternative 4-Partial Retrieval, Treatment, and Disposal; and Alternative 5-Full Retrieval, Treatment, and Disposal. Except for Alternative 1, all alternatives satisfy remedial action objectives, primarily because each action alternative includes an evaluation of (1) a surface barrier that controls the source by inhibiting biotic transport of contamination to the surface and by reducing infiltration and resulting contaminant transport into the vadose zone and aquifer, (2) continued operation of the vadose zone vapor vacuum extraction with treatment system, and (3) long-term surveillance, maintenance, monitoring, and institutional controls. Advantages and disadvantages of each alternative are identified and compared to provide a basis for decision-making. Assembled alternatives are composed of discrete modules. Ultimately, decision-makers will select, recombine, and sum various modules into an optimized preferred alternative and final remedial decision. This decision process is implemented through the Federal Facility Agreement and Consent Order among the U.S. Department of Energy, the Idaho Department of Environmental Quality, and the U.S. Environmental Protection Agency.
\end{abstract}





\section{EXECUTIVE SUMMARY}

The Feasibility Study for Operable Unit 7-13/14 is the second of two reports comprising the comprehensive remedial investigation and feasibility study for Operable Unit (OU) 7-13/14 at the Idaho National Laboratory (INL) Site Radioactive Waste Management Complex (RWMC). The first report — the Remedial Investigation and Baseline Risk Assessment (RI/BRA) (Holdren et al. 2006) — estimated risks that could be posed by contaminant waste buried in the Subsurface Disposal Area (SDA) at RWMC in the absence of remedial action. The RI/BRA identified human health and environmental risks greater than threshold values. Human health risks are described using three metrics: (1) excess cancer risk, which is the probability of developing a fatal or nonfatal cancer as a result of exposure to carcinogens; (2) hazard index, an indicator of possible noncarcinogenic effects from exposure to toxic substances; (3) and simulated contaminant concentrations in the aquifer that exceed maximum contaminant levels (MCLs). This feasibility study - the second report — develops and evaluates remedial alternatives to address risks identified in the RI/BRA.

Combined with the RI/BRA, this feasibility study provides a basis for risk management decisions for OU 7-13/14. Risk management decisions will be developed by the U.S. Department of Energy (DOE), the Idaho Department of Environmental Quality (DEQ), and the U.S. Environmental Protection Agency (EPA) - referred to collectively as the Agencies - under the Comprehensive Environmental Response, Compensation, and Liability Act (CERCLA) (42 USC $\S 9601$ et seq., 1980) and the Federal Facility Agreement and Consent Order (DOE-ID 1991).

Developing this comprehensive feasibility study involves integrating remedies for several characteristics of the SDA (e.g., localized subsidence in pits, abovegrade waste on Pad A, and near-surface volatile organic compounds [VOCs]) into fully assembled alternatives that address the entire landfill. The Agencies recognized that each specific characteristic can be addressed several ways; thus, many assembled alternatives composed of different combinations are possible. The Agencies optimized feasibility study development by specifying the combinations that would be evaluated as fully assembled alternatives. To maintain flexibility, each of the various components was developed as a discrete module. The Agencies will be able to mix and match various components, selecting the optimum combination when developing a preferred alternative and finalizing remedial decisions for the SDA.

Six major sections compose the body of the report, and six appendixes provide additional detail for complex elements of the study. The six major sections are summarized as follows:

- Section 1 defines the scope of the study, summarizes important information from the RI/BRA, presents remedial action objectives and preliminary remediation goals, and lists overarching assumptions

- Section 2 evaluates and screens technologies and process options, and identifies a range of viable remediation technologies for developing remedial alternatives

- $\quad$ Section 3 compiles remediation technologies into a range of assembled alternatives

- $\quad$ Section 4 evaluates assembled alternatives in detail, based on CERCLA criteria

- $\quad$ Section 5 compares relative advantages and disadvantages of assembled alternatives

- Section 6 lists all references cited throughout the report. 


\section{ES-1. SUMMARY OF SECTION 1-INTRODUCTION}

Section 1 defines the scope of the feasibility study, summarizes important information from the RI/BRA (e.g., historical background, physical setting, land use, nature and extent of contamination, and contaminants of concern [COCs]), presents remedial action objectives and preliminary remediation goals, and lists overarching assumptions. The following subsections summarize these elements.

\section{ES-1.1 Scope}

Primary scope elements of the OU 7-13/14 feasibility study develop and evaluate a range of remedial alternatives that would satisfy remedial action objectives. Remedial action objectives address risks identified in the RI/BRA (Holdren et al. 2006). Important components of the feasibility study include developing preliminary remediation goals, assembling a range of alternatives, evaluating those alternatives in detail, and comparing their relative advantages and disadvantages based on CERCLA evaluation criteria.

Except for continued operation of the vapor vacuum extraction system, initiated under the OU 7-08 Organic Contamination in the Vadose Zone (OCVZ) Project to collect VOCs from the vadose zone, scope for OU 7-13/14 focuses on measures that deal directly with buried waste. Because contaminant migration has not occurred to a substantial extent (except for VOCs), the objective for remedial action at the SDA is source control. The baseline risk assessment and this feasibility study define the source as the buried waste and associated contaminated soil down to the first basalt layer beneath the landfill. The Agencies identified source control, which can include containment, removal, or treatment of selected areas within the source (EPA 1988), to inhibit future releases from buried waste and to prevent further contamination of the environment. The unsaturated region beneath the source is the vadose zone and below that is the aquifer. Source control, combined with continued operation of the OCVZ system, will protect the vadose zone and aquifer.

One important element of source control is anticipated to be construction of an engineered surface barrier. The Agencies concluded early in the study of the SDA that an engineered surface barrier will be a component of every action alternative evaluated in this feasibility study (Holdren and Broomfield 2004). Coupled with long-term institutional controls (ICs), the surface barrier would preclude inadvertent human intrusion. The surface barrier also would preclude contaminant transport to the surface by plants and animals. Therefore, analysis of long-term effectiveness focuses on groundwater ingestion because an effectively designed surface barrier would satisfy all human health and ecological remedial action objectives at the surface.

Three operable units with existing records of decision (RODs) for Waste Area Group 7 are incorporated into this analysis. The OU 7-13/14 ROD will supersede the previous RODs for OU 7-08, OCVZ (DOE-ID 1994a), and OU 7-12, Pad A (DOE-ID 1994b). The ROD for OU 7-10, the Pit 9 Process Demonstration Interim Action (DOE-ID 1993), will be addressed in future decisions as part of the OU 7-13/14 ROD. Requirements for amendments or explanations of significant difference, if required to address existing RODs in the comprehensive ROD for OU 7-13/14, will be developed in accordance with EPA guidance (EPA 1999). Changes to existing RODs will be presented to stakeholders concurrent with OU 7-13/14 stakeholder involvement activities.

Except for continued operation of the OCVZ system to extract and treat VOCs from the vadose zone, the feasibility study analysis is limited to alternatives that meet objectives through source control (i.e., remediation that focuses on preventing continued release of contaminants into the environment).

Source control can include removing or treating selected areas within the source (EPA 1988). Combined with continued vapor vacuum extraction and treatment of VOCs from the vadose zone, the Agencies identified source control as the only reasonable strategy for the SDA because current contaminant concentrations in the vadose zone and aquifer do not jeopardize human health and the environment. 
However, unmitigated release of contaminants from waste buried in the SDA could generate concentrations in the future that pose risk greater than threshold values (i.e., risk greater than $10^{-6}$ to $10^{-4}$, hazard index greater than or equal to 1, and simulated groundwater concentrations that exceed MCLs). Once released in significant quantities, these contaminants would be extremely difficult to remediate. Therefore, source control in the near term would prevent potential future risks from developing. Based on the conclusion that source control will protect human health and the environment, remediation of the vadose zone and aquifer are not evaluated, other than continued operation of the OCVZ system.

\section{ES-1.2 Contaminants of Concern}

Results of the risk assessment and uncertainty associated with those results were used to transition from the RI/BRA (Holdren et al. 2006) to the feasibility study. Contaminants of potential concern assessed in the RI/BRA (i.e., those contaminants that might cause risk to exceed threshold values if no remediation is implemented) were screened to identify COCs (i.e., those contaminants that warrant risk management decisions). The RI/BRA estimated human health risks for occupational, residential, and inadvertent intruder scenarios. Because residential risks were highest (i.e., are bounding), they are used to identify primary COCs for OU 7-13/14 based on either of two screening criteria:

- Contaminant has a total carcinogenic risk estimate greater than or equal to $1 \mathrm{E}-05$ or a hazard index greater than or equal to 1 within the 1,000-year simulation period for the future residential exposure scenario. (The value of $1 \mathrm{E}-05$ is used to identify COCs to ensure that additive carcinogenic risk from multiple contaminants remains less than $10^{-4}$.)

- Simulated groundwater concentrations exceed the EPA MCLs within the 1,000-year simulation period.

For modeling and risk assessment, a 100-year IC period that prohibits residential land use within the INL Site was simulated. After the end of the simulated IC period (2110), residential land use inside the INL Site was modeled. Therefore, all risk and hazard index graphs show a large increase in risk at 2110, immediately following the end of the simulated IC period because the location of the hypothetical residential receptor is shifted from the INL Site boundary to the SDA boundary. Risks within the SDA boundary are calculated based on an inadvertent intruder scenario. Those risks will be mitigated under all alternatives by a cap designed to deter intruders in combination with institutional controls to limit unauthorized access.

Tables ES-1 and ES-2 identify radionuclide and nonradionuclide COCs, respectively, based on the above criteria, and primary exposure pathways contributing to risk. Data for a few COCs were modified after the RI/BRA because the RI/BRA concluded with recommendations for additional modeling to refine estimates for several contaminants and to provide a better foundation for the feasibility study. Differences are slight; the most significant changes are associated with risk estimates for Tc-99 (and collocated I-129) and tetrachloroethylene. Minor changes also were realized for C-14, nitrate, and VOCs. In total, 18 primary COCs are identified: 12 radionuclides and six nonradionuclides. Figure ES-1 illustrates cumulative risk over time for all COCs for the future residential scenario. Figure ES-1 shows a large increase in risk immediately following the end of the simulated IC period because the location of the hypothetical receptor is shifted from the INL Site boundary to the SDA boundary. Total cumulative risk for all contaminants is at a maximum of $7 \mathrm{E}-03$ at the end of the 1,000 -year simulation period in the year 3010. Surface exposure pathways contribute the most risk throughout the 1,000-year simulation period, with a maximum of 7E-03.

Table ES-3 identifies waste streams associated with the 18 primary COCs. Four COCs (i.e., Pb-210, Ra-226, Ra-228, and Th-228) have very small initial inventories generated at the INL Site; however, risk is driven by inventories generated through ingrowth attributable to Rocky Flats Plant waste streams. 
Table ES-1. Primary radionuclide contaminants of concern based on 1,000-year future residential scenario peak risk estimates and estimated peak groundwater concentrations in the absence of remedial action at the Subsurface Disposal Area boundary.

\begin{tabular}{|c|c|c|c|c|c|c|}
\hline Contaminant & $\begin{array}{l}\text { Peak } \\
\text { Risk }\end{array}$ & Year $^{\mathrm{a}}$ & Primary Exposure Pathways ${ }^{\mathrm{b}}$ & $\begin{array}{c}\text { Peak Aquifer } \\
\text { Concentration } \\
(\mathrm{pCi} / \mathrm{L})\end{array}$ & Year $^{\mathrm{a}}$ & $\begin{array}{c}\text { Maximum } \\
\text { Contaminant } \\
\text { Level } \\
(\mathrm{pCi} / \mathrm{L})\end{array}$ \\
\hline Ac-227 & $5 \mathrm{E}-07$ & 3010 & Groundwater ingestion & $5.30 \mathrm{E}-02$ & 3010 & $15^{\mathrm{c}}$ \\
\hline Am-241 & $3 \mathrm{E}-03$ & 2594 & External exposure, soil ingestion, and inhalation & $6.80 \mathrm{E}-08$ & 3010 & $15^{\mathrm{c}}$ \\
\hline Am-243 & $1 \mathrm{E}-07$ & 3008 & External exposure & 1.29E-09 & 3010 & $15^{\mathrm{c}}$ \\
\hline $\mathrm{C}-14$ & $1 \mathrm{E}-05$ & 2110 & $\begin{array}{l}\text { Groundwater ingestion and inhalation of volatiles } \\
\text { (at the surface) }\end{array}$ & $1.74 \mathrm{E}+02$ & 2145 & 2,000 \\
\hline $\mathrm{Cl}-36$ & $2 \mathrm{E}-06$ & 2384 & Groundwater ingestion and crop ingestion & $2.12 \mathrm{E}+01$ & 2395 & 700 \\
\hline Cs-137 & $2 \mathrm{E}-03$ & 2110 & External exposure and crop ingestion & NA & NA & NA \\
\hline $\mathrm{I}-129$ & $9 \mathrm{E}-06$ & 2870 & Groundwater ingestion & $2.93 \mathrm{E}+00$ & 2870 & 1 \\
\hline $\mathrm{Nb}-94$ & $2 \mathrm{E}-06$ & 3010 & External exposure & NA & NA & NA \\
\hline Np-237 & $7 \mathrm{E}-06$ & 2647 & External exposure & $6.53 \mathrm{E}-02$ & 3010 & $15^{\mathrm{c}}$ \\
\hline $\mathrm{Pa}-231$ & $3 \mathrm{E}-07$ & 3010 & Groundwater ingestion & $8.17 \mathrm{E}-02$ & 3010 & $15^{\mathrm{c}}$ \\
\hline $\mathrm{Pb}-210$ & $3 \mathrm{E}-05$ & 3010 & Crop ingestion and soil ingestion & $1.02 \mathrm{E}-05$ & 3010 & NA \\
\hline $\mathrm{Pu}-238$ & $1 \mathrm{E}-06$ & 2262 & Soil ingestion, crop ingestion, and inhalation & $6.10 \mathrm{E}-19$ & 2920 & $15^{\mathrm{c}}$ \\
\hline $\mathrm{Pu}-239$ & $3 \mathrm{E}-03$ & 3010 & Soil ingestion, crop ingestion, and inhalation & $5.19 \mathrm{E}-10$ & 3010 & $15^{\mathrm{c}}$ \\
\hline $\mathrm{Pu}-240$ & $6 \mathrm{E}-04$ & 3010 & Soil ingestion, crop ingestion, and inhalation & $1.28 \mathrm{E}-10$ & 3010 & $15^{\mathrm{c}}$ \\
\hline $\mathrm{Ra}-226$ & 7E-04 & 3010 & External exposure and crop ingestion & $1.30 \mathrm{E}-05$ & 3010 & 5 \\
\hline Ra-228 & $3 \mathrm{E}-05$ & 3010 & External exposure & $1.97 \mathrm{E}-09$ & 3010 & 5 \\
\hline Sr-90 & $1 \mathrm{E}-03$ & 2110 & $\begin{array}{l}\text { Crop ingestion, external exposure, and soil } \\
\text { ingestion }\end{array}$ & NA & NA & NA \\
\hline Tc-99 & $5 \mathrm{E}-05$ & 2858 & $\begin{array}{l}\text { Groundwater ingestion and crop ingestion } \\
\text { (crops irrigated with contaminated groundwater) }\end{array}$ & $5.34 \mathrm{E}+02$ & 2870 & 900 \\
\hline Th-228 & $5 \mathrm{E}-05$ & 3010 & External exposure & NA & NA & NA \\
\hline Th-229 & 4E-07 & 3010 & Groundwater ingestion and external exposure & $2.64 \mathrm{E}-02$ & 3010 & $15^{\mathrm{c}}$ \\
\hline Th-230 & $1 \mathrm{E}-08$ & 3010 & Crop ingestion, soil ingestion, and inhalation & $3.01 \mathrm{E}-04$ & 3010 & $15^{\mathrm{c}}$ \\
\hline Th-232 & $3 \mathrm{E}-07$ & 3010 & Crop ingestion, soil, ingestion, and inhalation & 2.82E-09 & 3010 & $15^{\mathrm{c}}$ \\
\hline U-233 & $4 \mathrm{E}-06$ & 3010 & Groundwater ingestion & $2.90 \mathrm{E}+00$ & 3010 & $2.9 \mathrm{E}+05^{\mathrm{d}}$ \\
\hline U-234 & $6 \mathrm{E}-07$ & 3010 & Groundwater ingestion & $3.97 \mathrm{E}-01$ & 3010 & $1.87 \mathrm{E}+05^{\mathrm{d}}$ \\
\hline U-235 & 2E-07 & 2286 & External exposure and groundwater ingestion & $1.19 \mathrm{E}-01$ & 3010 & $6.49 \mathrm{E}+01^{\mathrm{d}}$ \\
\hline $\mathrm{U}-236$ & 9E-07 & 3010 & Groundwater ingestion & $6.24 \mathrm{E}-01$ & 3010 & $1.94 \mathrm{E}+03^{\mathrm{d}}$ \\
\hline $\mathrm{U}-238$ & $1 \mathrm{E}-06$ & 2284 & External exposure and groundwater ingestion & $5.52 \mathrm{E}-01$ & 3010 & $1.01 \mathrm{E}+01^{\mathrm{d}}$ \\
\hline \multicolumn{7}{|c|}{$\begin{array}{l}\text { a. Peak years may differ for maximum risk and groundwater concentration because they are computed differently. Risk is averaged over time } \\
\text { (i.e., a } 30 \text {-year rolling average), while simulated aquifer concentrations represent a single year. } \\
\text { b. All complete exposure pathways are assessed in the baseline risk assessment; those contributing most to risk are listed as primary exposure } \\
\text { pathways. For COCs, all exposure pathways with risk greater than } 1 \mathrm{E}-05 \text { are listed from highest to lowest risk. } \\
\text { c. The limit is } 15 \mathrm{pCi} / \mathrm{L} \text { for total alpha ( } 40 \mathrm{CFR} 141) \text {. } \\
\text { d. The limit is } 3 \mathrm{E}-02 \mathrm{mg} / \mathrm{L}(30 \mu \mathrm{g} / \mathrm{L}) \text { for total uranium. To compare concentrations of uranium isotopes, } 3 \mathrm{E}-02 \mathrm{mg} / \mathrm{L} \text { is converted to the equivalent } \\
\text { activity for each isotope. } \\
\text { COC = contaminant of concern }\end{array}$} \\
\hline \multicolumn{3}{|c|}{ Surface exposure pathway COC } & $\begin{array}{l}\text { COC for both surface expo } \\
\text { and groundwater pathways }\end{array}$ & \multicolumn{3}{|c|}{$\begin{array}{l}\text { COC based on potential to exceed } \\
\text { the maximum contaminant level }\end{array}$} \\
\hline
\end{tabular}


Table ES-2. Nonradionuclide contaminants of concern based on 1,000-year future residential scenario peak risk estimates and estimated peak groundwater concentrations in the absence of remedial action at the Subsurface Disposal Area boundary.

\begin{tabular}{|c|c|c|c|c|c|c|c|c|}
\hline Contaminant & Peak Risk & Year $^{\mathrm{a}}$ & $\begin{array}{c}\text { Peak } \\
\text { Hazard } \\
\text { Index }\end{array}$ & Year $^{\mathrm{a}}$ & Primary Exposure Pathways ${ }^{\mathrm{b}}$ & $\begin{array}{c}\text { Peak Aquifer } \\
\text { Concentration } \\
(\mathrm{mg} / \mathrm{L})^{\mathrm{b}}\end{array}$ & Year $^{\mathrm{a}}$ & $\begin{array}{c}\text { Maximum } \\
\text { Contaminant } \\
\text { Level } \\
(\mathrm{mg} / \mathrm{L}) \\
\end{array}$ \\
\hline Carbon tetrachloride & 4E-04 & 2117 & $1 \mathrm{E}+01$ & 2119 & $\begin{array}{l}\text { Groundwater ingestion and inhalation of } \\
\text { volatiles (at the surface) }\end{array}$ & $2.85 \mathrm{E}-01$ & 2133 & $5.00 \mathrm{E}-03$ \\
\hline 1,4-Dioxane & $2 \mathrm{E}-05$ & 2110 & NA & NA & Groundwater ingestion & $1.67 \mathrm{E}-01$ & 2120 & $3.00 \mathrm{E}-03^{\mathrm{c}}$ \\
\hline Methylene chloride & $5 \mathrm{E}-06$ & 2244 & $3 \mathrm{E}-02$ & 2244 & Groundwater ingestion & $5.76 \mathrm{E}-02$ & 2245 & $5.00 \mathrm{E}-03$ \\
\hline Nitrate & NA & NA & 9E-01 & 2283 & Groundwater ingestion & $4.93 \mathrm{E}+01$ & 2295 & 10 \\
\hline Tetrachloroethylene & $4 \mathrm{E}-04$ & 2136 & $3 \mathrm{E}-01$ & 2136 & $\begin{array}{l}\text { Groundwater ingestion and dermal exposure } \\
\text { (e.g., showering) }\end{array}$ & $6.69 \mathrm{E}-02$ & 2145 & $5.00 \mathrm{E}-03$ \\
\hline Trichloroethylene & $2 \mathrm{E}-05$ & 2141 & NA & NA & Groundwater ingestion & $1.15 \mathrm{E}-01$ & 2145 & $5.00 \mathrm{E}-03$ \\
\hline
\end{tabular}

a. Peak years may differ for maximum risk (or hazard index) and groundwater concentration because they are computed differently. Risk (and hazard index) is averaged over time (i.e., a 30 -year rolling average), while simulated aquifer concentrations represent a single year.

b. All complete exposure pathways are assessed in the baseline risk assessment; those contributing most to risk are listed as primary exposure pathways. For COCs, all exposure pathways with risk greater than $1 \mathrm{E}-05$ or a hazard index greater than or equal to 1 are listed from highest to lowest risk.

c. No MCL is given, but a health advisory level is provided for reference.

$\mathrm{COC}=$ contaminant of concern

$\mathrm{MCL}=$ maximum contaminant level

\begin{tabular}{lll}
\hline Surface exposure pathway COC & Groundwater pathway COC & $\begin{array}{l}\text { COC for both surface exposure and } \\
\text { groundwater pathways }\end{array}$
\end{tabular}




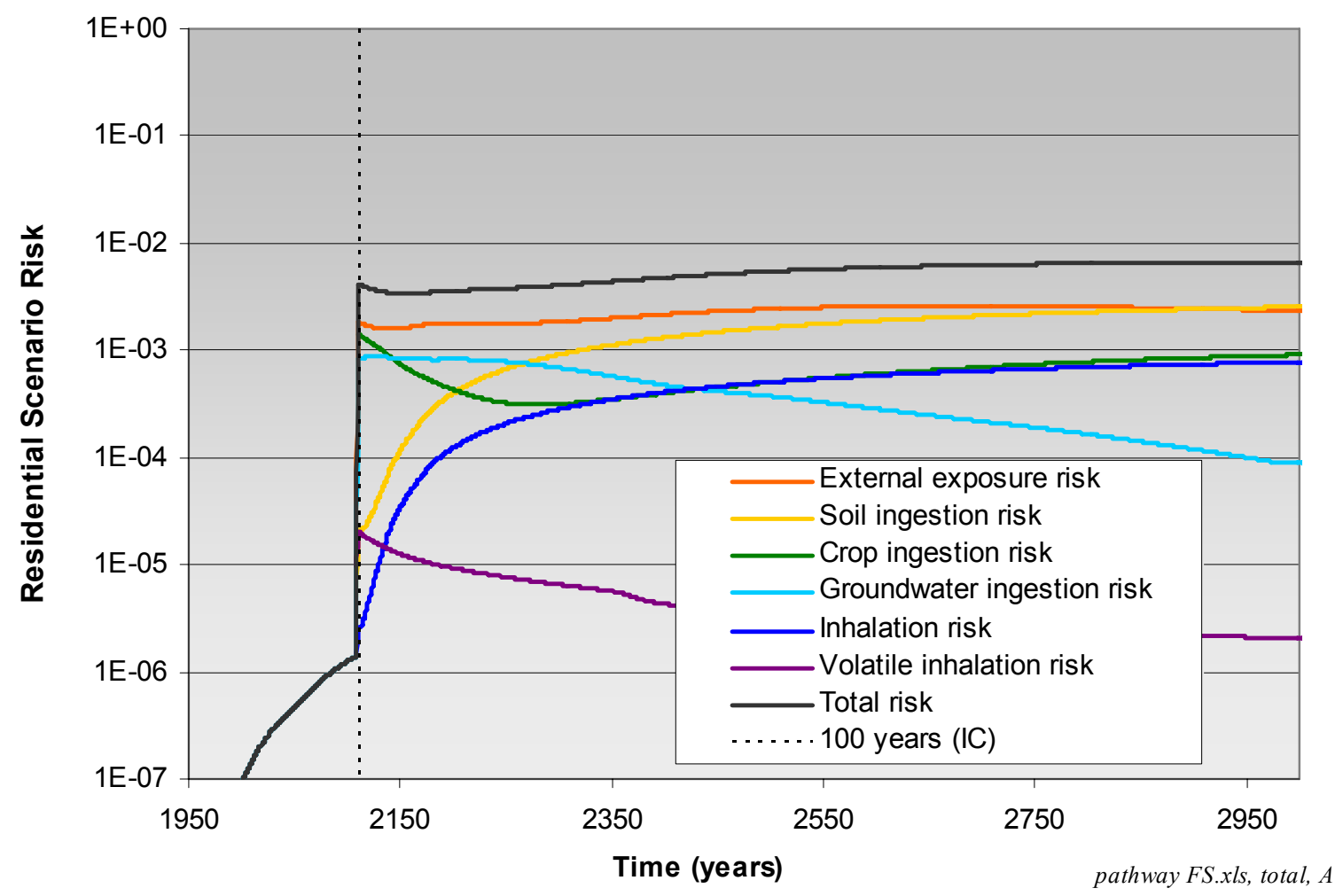

Figure ES-1. Total residential exposure scenario risk by exposure pathway for all radionuclides and nonradionuclides.

Table ES-3. Original waste generators and general locations of primary contaminants of concern in the Subsurface Disposal Area.

\begin{tabular}{llccl}
\hline \multicolumn{1}{c}{ Contaminant } & Waste Generator & $\begin{array}{c}\text { Portion } \\
(\%)\end{array}$ & $\begin{array}{c}\text { Initial } \\
\text { Inventory }^{\mathrm{b}}\end{array}$ & \multicolumn{1}{c}{ Areas of Highest Densities } \\
\hline $\mathrm{Am}-241$ & Rocky Flats Plant & 100.0 & $2.43 \mathrm{E}+05$ & Pits \\
$\mathrm{C}-14$ & INL Site & 100.0 & $7.31 \mathrm{E}+02$ & Trenches and soil vaults \\
$\mathrm{Cs}-137$ & INL Site & 100.0 & $1.68 \mathrm{E}+05$ & Trenches and soil vaults \\
$\mathrm{I}-129$ & INL Site & 100.0 & $1.88 \mathrm{E}-01$ & Trenches and soil vaults \\
$\mathrm{Pb}-210$ & Rocky Flats Plant & $\mathrm{NA}^{\mathrm{c}}$ & $\mathrm{NA}^{\mathrm{c}}$ & Pits \\
$\mathrm{Pb}-210$ & INL Site & $100.0^{\mathrm{c}}$ & $5.62 \mathrm{E}-07^{\mathrm{c}}$ & Trenches \\
$\mathrm{Pu}-238^{\mathrm{d}}$ & Rocky Flats Plant & 88.7 & $1.85 \mathrm{E}+03$ & Pits \\
$\mathrm{Pu}-238^{\mathrm{d}}$ & INL Site & 11.3 & $2.35 \mathrm{E}+02$ & Trenches \\
$\mathrm{Pu}-239$ & Rocky Flats Plant & 98.3 & $6.30 \mathrm{E}+04$ & Pits \\
$\mathrm{Pu}-239$ & INL Site & 1.7 & $1.08 \mathrm{E}+03$ & Trenches \\
$\mathrm{Pu}-240$ & Rocky Flats Plant & 96.6 & $1.40 \mathrm{E}+04$ & Pits \\
$\mathrm{Pu}-240$ & INL Site & 3.4 & $5.03 \mathrm{E}+02$ & Trenches
\end{tabular}


Table ES-3. (continued).

\begin{tabular}{|c|c|c|c|c|}
\hline Contaminant & Waste Generator $^{\mathrm{a}}$ & $\begin{array}{c}\text { Portion } \\
(\%)\end{array}$ & $\begin{array}{c}\text { Initial } \\
\text { Inventory }^{\mathrm{b}}\end{array}$ & Areas of Highest Densities \\
\hline Ra-226 & Rocky Flats Plant & $\mathrm{NA}^{\mathrm{e}}$ & $\mathrm{NA}^{\mathrm{e}}$ & Pits \\
\hline Ra-226 & INL Site & $100.0^{\mathrm{e}}$ & $6.53 \mathrm{E}+01^{\mathrm{e}}$ & Trenches \\
\hline Ra-228 & Rocky Flats Plant & $\mathrm{NA}^{\mathrm{f}}$ & $N A^{f}$ & Pits \\
\hline Ra-228 & INL Site & $100.0^{\mathrm{f}}$ & $3.66 \mathrm{E}-05^{\mathrm{f}}$ & Trenches \\
\hline Sr-90 & INL Site & 100.0 & $1.36 \mathrm{E}+05$ & Trenches and soil vaults \\
\hline Tc-99 & INL Site & 100.0 & $4.23 \mathrm{E}+01$ & Trenches and soil vaults \\
\hline Th-228 & Rocky Flats Plant & $\mathrm{NA}^{\mathrm{g}}$ & $\mathrm{NA}^{\mathrm{g}}$ & Pits \\
\hline Th-228 & INL Site & $100.0^{\mathrm{g}}$ & $1.05 \mathrm{E}+01^{\mathrm{g}}$ & Low-Level Waste Pit \\
\hline Carbon tetrachloride & Rocky Flats Plant & 100.0 & $7.90 \mathrm{E}+08$ & Pits \\
\hline 1,4-Dioxane & Rocky Flats Plant & 96.0 & $1.87 \mathrm{E}+06$ & Pits (with carbon tetrachloride) \\
\hline 1,4-Dioxane & INL Site & 4.0 & $4.24 \mathrm{E}+04$ & Pits, trenches, and soil vaults \\
\hline Methylene chloride & Rocky Flats Plant & 100.0 & $1.41 \mathrm{E}+07$ & Pits \\
\hline Nitrate (as nitrogen) & Rocky Flats Plant & 89.1 & $4.06 \mathrm{E}+08$ & Pits and Pad A \\
\hline Nitrate (as nitrogen) & INL Site & 10.9 & $4.98 \mathrm{E}+07$ & Pits \\
\hline Tetrachloroethylene & Rocky Flats Plant & 100.0 & $9.87 \mathrm{E}+07$ & Pits (with carbon tetrachloride) \\
\hline Trichloroethylene & Rocky Flats Plant & 99.6 & $8.92 \mathrm{E}+07$ & Pits (with carbon tetrachloride) \\
\hline Trichloroethylene & INL Site & 0.4 & $4.07 \mathrm{E}+05$ & Trenches \\
\hline \multicolumn{5}{|c|}{$\begin{array}{l}\text { a. Portions listed for INL Site waste may include small amounts from off-INL Site waste generators, excluding the Rocky } \\
\text { Flats Plant. } \\
\text { b. Initial inventory is inventory at time of disposal with no adjustments for volatile organic compounds released to the } \\
\text { atmosphere, degradation, radioactive decay and ingrowth, or any other mechanism. Units are curies for radionuclides and } \\
\text { grams for nonradionuclides. } \\
\text { c. Risk is attributable to ingrowth of Pb-210 from Pu- } 238 \text { and U-238; initial disposal quantities are not significant. } \\
\text { d. Pu-238 is not, itself, a COC. However, Pu- } 238 \text { decays to two COCs (i.e., Pb-210 and Ra-226). } \\
\text { e. Risk is attributable to ingrowth of Ra-226 from Pu-238 and U-238; initial disposal quantities are not significant. } \\
\text { f. Risk is attributable to ingrowth of Ra-228; initial disposal quantities are not significant. Ingrowth is primarily associated } \\
\text { with Pu-240 from the Rocky Flats Plant. } \\
\text { g. Risk is attributable to ingrowth of Th-228; initial disposal quantities are not significant. Ingrowth is primarily associated } \\
\text { with Pu-240 from the Rocky Flats Plant, though a small portion arises and then decays from U-232. }\end{array}$} \\
\hline
\end{tabular}

To address uncertainties associated with model results, simulations were extended to 10,000 years for long-lived radionuclides that did not reach peak simulated concentrations in 1,000-year simulations. Residential scenario risk estimates are greater than 1E-05 in the 10,000-year simulation period for eight radionuclides: Ac-227, Np-237, Pa-231, U-233, U-234, U-235, U-236, and U-238. Simulated aquifer concentrations for two of these radionuclides, Np-237 and U-238, also exceed MCLs thousands of years in the future. All eight radionuclides, listed in Table ES-4, are identified as secondary COCs for the OU 7-13/14 feasibility study. 
- $\quad$ Reduce infiltration such that COC concentrations in the aquifer are less than MCLs.

In addition, goals identified under OU 7-08 for two depth intervals in the vadose zone immediately beneath the SDA are adopted as preliminary remediation goals to reduce transport of VOCs to the aquifer:

- $\quad$ Maintain concentrations of carbon tetrachloride in vadose zone soil vapor above the B-C interbed (approximately the 9 to $30-\mathrm{m}$ [30 to 100-ft] -depth interval) to less than $190 \mathrm{ppm}$

- $\quad$ Maintain concentrations of carbon tetrachloride in vadose zone soil vapor between the B-C and C-D interbeds (approximately the 30 to $73-\mathrm{m}$ [100 to $240-\mathrm{ft}$ ] -depth interval) to less than $39 \mathrm{ppm}$.

\section{ES-1.4 Assumptions for the Feasibility Study}

Overarching assumptions for this feasibility study are:

- $\quad$ Land use inside the SDA is industrial; residential land use on the SDA itself will not occur.

- $\quad$ Long-term ICs will be established and maintained to restrict land use.

- Environmental monitoring will continue throughout ICs.

- $\quad$ Lockheed Martin Advanced Environmental Systems structures will be removed under another program before SDA remedial action. (Note: These structures must be removed before the surface barrier can be constructed.)

- $\quad$ The OU 7-13/14 ROD will supersede the OU 7-08 ROD (i.e., OCVZ) (DOE-ID 1994a), and OCVZ vapor extraction operations will continue until remediation goals identified and evaluated under OU 7-13/14 are satisfied.

- $\quad$ The OU 7-13/14 ROD will supersede the OU 7-12 ROD (i.e., Pad A) (DOE-ID 1994b).

- $\quad$ The ROD for OU 7-10, Pit 9 Process Demonstration Interim Action (DOE-ID 1993), will be addressed in future decisions as part of the OU 7-13/14 ROD.

- $\quad$ The Low-Level Waste (LLW) Disposal Facility (also known as the LLW Pit) will accept contact-handled waste through 2008 and remote-handled waste through 2009, then will be closed under DOE Order 435.1-1 and transferred to OU 7-13/14 to facilitate remediation under CERCLA. (Note: This assumption was adopted for modeling in this feasibility study; however, operation of the LLW Pit could continue until it interferes with implementation of the OU 7-13/14 ROD.) Projected inventory for the LLW Pit is evaluated in both the baseline risk assessment and this feasibility study.

\section{ES-2. SUMMARY OF SECTION 2-IDENTIFICATION AND SCREENING OF TECHNOLOGIES}

This section of the feasibility study identifies technologies that potentially apply to remedial actions in the SDA. The identification and screening process delineates a range of potentially applicable technologies and then selects a subset of options that merits further analysis. Remedial action objectives and preliminary remediation goals are established to support analysis, and then general response actions are identified to organize the analysis. Technologies and process options that address general response 
actions are identified and screened. Finally, Section 2 summarizes technologies and representative process options retained for detailed analysis.

\section{ES-2.1 General Response Actions}

General response actions are defined as general approaches that can be implemented to achieve remedial action objectives, either individually or in combination. A description of each general response action follows:

- No action-This general response action is required by the National Contingency Plan (40 CFR 300). A no action alternative serves as a baseline for evaluating other remedial action alternatives and is generally retained throughout the feasibility study process. As defined in CERCLA guidance (EPA 1988), environmental monitoring is included in the no action general response action, but actions taken to reduce exposure (e.g., site fences and deed restrictions) are not. The no action general response action serves as a baseline for evaluating other remedial action alternatives.

- Retrieval-This general response action involves physically removing waste and soil. Because of radioactive and hazardous characteristics of SDA waste, retrieval systems must minimize worker exposure while stringently controlling contamination.

- Disposal-This general response action involves placing retrieved waste, contaminated soil, treatment residuals, and investigation-derived waste in permanent waste management facilities.

- In situ treatment-This general response action uses technologies that degrade, immobilize, or destroy contaminants while waste remains in the landfill (in situ). Treatment technologies include physical, chemical, thermal, and biological approaches. In situ treatment limits worker exposure to contaminated media.

- Ex situ treatment-This general response action treats retrieved soil and waste using chemical, physical, thermal, or biological processes. Technologies focus on segregating targeted and nontargeted waste forms, characterizing radiological and hazardous characteristics (e.g., identifying transuranic, mixed transuranic, LLW, and mixed LLW), and processing waste to reduce toxicity, mobility, or volume. Treatment also may be applied to remove a Resource Conservation and Recovery Act (RCRA) (42 USC § 6901 et seq., 1976) hazardous characteristic (i.e., ignitability, corrosivity, reactivity, and toxicity) to meet disposal requirements.

- $\quad$ Containment-This general response action mitigates risk by preventing direct human or biotic contact, precluding contaminant transport to the surface by plants and animals, and minimizing contaminant migration by limiting infiltrating moisture. Containment approaches include surface barriers, lateral barriers, barriers to intrusion (e.g., biointrusion barriers), and impermeable layers immediately beneath buried waste (i.e., bottom sealing).

- Institutional controls-This general response action imposes active or passive measures to prevent or limit access to contaminated areas. Active measures typically involve routine or periodic human presence at the site (e.g., guards and surveillance), while passive measures are largely administrative (e.g., land-use restrictions). Institutional controls include deed restrictions, fences or other barriers, signs, and security. Environmental monitoring typically is included in the ICs general response action. 


\section{ES-2.2 Identification and Screening of Technology Types and Process Options}

This subsection identifies remedial technology types and process options that could be implemented at the SDA and selects representative process options used to assemble alternatives in Section 3 for detailed analysis in Section 4. Technology types are general category treatment approaches, while process options are specific approaches within a general technology type.

Each process option was screened based on effectiveness, implementability, and relative cost. Discussions of effectiveness focus on anticipated success of the technology in meeting remedial action objectives and expected reliability of the technology under SDA conditions. Potential safety issues were identified, as appropriate. The implementability evaluation considered both technical and administrative feasibility, with the intent of eliminating those options that clearly were not implementable at the SDA. Cost evaluations played a limited role in the screening process, incorporating only qualitative descriptions of capital costs and operating and maintenance expenses in terms of low, medium, or high. Appendix A includes a screening evaluation of potentially applicable technology types and process options and the expected effectiveness, implementability, and relative cost of each. Those process options identified as effective and implementable were carried forward into the body of Section 2 and described in greater detail.

Technologies and process options selected as representative are carried forward into Section 3 to support development of remedial alternatives. Table ES-5 summarizes representative process options retained for each general response action.

Table ES-5. General response actions, remedial technologies, and retained process options.

\begin{tabular}{lll}
\multicolumn{1}{c}{$\begin{array}{c}\text { General } \\
\text { Response Action }\end{array}$} & \multicolumn{1}{c}{ Remedial Technology } & \multicolumn{1}{c}{ Retained Process Option } \\
\hline Retrieval & Contamination control & $\begin{array}{l}\text { Confinement } \\
\text { Foams, sprays, misters, fixatives, and } \\
\text { washers } \\
\end{array}$ \\
& & Ventilation and vacuum systems \\
& & Standard construction equipment with \\
& On-INL Site storage and disposal & ICDF \\
& & LLW Pit within the SDA \\
Disposal & & Temporary on-INL Site storage \\
& Off-INL Site storage and disposal & EnergySolutions, Utah \\
& & WIPP, New Mexico \\
\hline In situ treatment & In situ physical treatment & In situ high-pressure jet grouting \\
& & In situ soil-vapor extraction \\
\hline Ex situ treatment & Ex situ physical treatment & Ex situ screening and classification \\
& Ex situ chemical treatment & Ex situ fixation and stabilization \\
\hline Containment & Surface barriers & ET barrier \\
& & Foundation preparation \\
& & Modified RCRA Type C surface barrier \\
\hline
\end{tabular}


Table ES-5. (continued).

\begin{tabular}{|c|c|c|}
\hline $\begin{array}{c}\text { General } \\
\text { Response Action }\end{array}$ & Remedial Technology & Retained Process Option \\
\hline & Subsurface vertical barriers & Slurry wall \\
\hline \multirow[t]{12}{*}{ Institutional controls } & Passive land-use restrictions & Conservation easement \\
\hline & & Covenant \\
\hline & & Deed notice \\
\hline & & Groundwater use restriction \\
\hline & & Public advisory \\
\hline & & Reversionary interest \\
\hline & & State use restriction \\
\hline & & Zoning ordinances and local permit \\
\hline & Active access controls & Perimeter patrols and surveillance \\
\hline & & Security guard \\
\hline & Passive access controls & Fences \\
\hline & & Signs \\
\hline \multicolumn{3}{|c|}{$\begin{array}{l}\text { ET = evapotranspiration } \\
\text { ICDF = Idaho CERCLA Disposal Facility } \\
\text { INL = Idaho National Laboratory } \\
\text { LLW = low-level waste } \\
\text { RCRA = Resource Conservation and Recovery Act } \\
\text { SDA = Subsurface Disposal Area } \\
\text { WIPP = Waste Isolation Pilot Plant }\end{array}$} \\
\hline
\end{tabular}

In addition to technology and process option screening, Section 2 also presents approaches for incorporating Pad A, removing near-surface VOCs, and incorporating ongoing remediation of the vadose zone (i.e., extraction and treatment of VOCs from the vadose zone using the OCVZ system). Process options were specified in the Second Addendum to the Work Plan (Holdren and Broomfield 2004), and thus were not evaluated in the technology screening process. However, because these elements are critical to development of alternatives in Section 3, they were itemized in Section 2 and are listed below for completeness.

- $\quad$ Six options evaluated for managing Pad A waste are:

1. Leave Pad A waste in place and incorporate it into a surface barrier

2. Remove Pad A waste and move it to the LLW Pit without treatment or additional engineering of the pit

3. Remove Pad A waste, grout it ex situ, and move it to a pit on the SDA

4. Remove Pad A waste and send it to Idaho CERCLA Disposal Facility (ICDF) for treatment and disposal

5. Leave Pad A waste in place and apply dynamic compaction to address subsidence (added for Alternative 4b)

6. Remove Pad A waste, send it to ICDF for treatment, and dispose of it off the INL Site. 
- Three approaches evaluated for removing near-surface VOCs released from buried waste are:

1. Active vapor extraction using additional near-surface wells

2. Active vapor extraction from a gas transport layer within the surface barrier

3. Passive vapor extraction from a gas transport layer within the surface barrier.

- $\quad$ Continued remediation of the vadose zone using the existing OCVZ system to extract and treat VOCs is included in all action alternatives; operational timeframes (i.e., durations) vary depending on other factors being evaluated in parallel (e.g., type of surface barrier and amount of waste retrieved).

\section{ES-3. SUMMARY OF SECTION 3-DEVELOPMENT OF ALTERNATIVES}

This section develops specific remedial action alternatives that provide technically sound approaches to address project remedial action objectives. Analysis focuses on source control (i.e., approaches to prevent or substantially reduce release of contamination from buried waste). The five comprehensive remedial alternatives (identified in Section 1.5) are assembled by combining representative process options (identified in Section 2) that provide distinct technical approaches.

All alternatives - except Alternative 1 (No Action) —include three common elements: (1) continued operation of the OCVZ system to extract and treat VOCs that have migrated into the underlying vadose zone; (2) an engineered surface barrier to prevent contaminant transport to the surface by plants and animals, to inhibit infiltration and subsequent transport of contaminants to the vadose zone, and to preclude inadvertent human intrusion (e.g., through overall thickness of the cap coupled with long-term ICs); and (3) long-term stewardship (e.g., long-term surveillance, maintenance, monitoring, and ICs. In addition, all alternatives include strategies to address subsidence, integrate Pad A (an abovegrade disposal area with a preexisting ROD [DOE-ID 1994b]), and manage near-surface VOCs immediately beneath or within the surface barrier. Alternatives were developed to encompass all process options retained for analysis. The five alternatives are listed below:

- Alternative 1-No Action - evaluates the absence of remedial action and provides a baseline for comparison of other alternatives. Environmental monitoring is the only activity evaluated for Alternative 1.

- $\quad$ Alternative 2-Surface Barrier - evaluates containment as the primary means of source control.

- Alternative 3-In Situ Grouting (ISG) - evaluates in situ treatment to immobilize long-lived radioactive contaminants resulting from INL Site reactor operations.

- $\quad$ Alternative 4-Partial Retrieval, Treatment, and Disposal (RTD) — evaluates retrieval of targeted Rocky Flats Plant waste from described areas within the SDA using methods developed for the Accelerated Retrieval Project. ${ }^{\mathrm{a}}$

- $\quad$ Alternative 5-Full RTD — evaluates removing all waste from the SDA.

\footnotetext{
a. The Accelerated Retrieval Project provides a well-supported basis for evaluating this alternative with information generated by operating experience relating to implementability, short-term risks, and cost. Targeted Rocky Flats Plant waste streams are Series 741 sludge, Series 743 sludge, graphite, filters, and roaster oxides. These waste streams contain volatile organic compounds, transuranics, and uranium.
} 
In accordance with the Second Addendum (Holdren and Broomfield 2004), these five assembled alternatives are identified based on the above analysis. Alternatives are evaluated in detail in Section 4 and compared against each other in Section 5. From general descriptions of the assembled alternatives, 20 modularized elements were defined to expedite analysis of the five CERCLA balancing criteria and to facilitate mixing and matching various components into a preferred alternative in the proposed plan. The five assembled alternatives and the 20 modules that evolved from those alternatives are described in the following subsections. Appendix E provides process flow diagrams and additional design details associated with each of the 20 modules. Table ES-6 summarizes the five assembled alternatives that are carried forward to Sections 4 and 5 for detailed and comparative analysis.

\section{ES-3.1.1 Alternative 1-No Action}

Alternative 1 evaluates the absence of remedial action to provide a baseline for comparison of other alternatives. Environmental monitoring is the only activity evaluated for Alternative 1.

\section{ES-3.1.2 Alternative 2-Surface Barrier}

Two types of surface barriers are evaluated in the OU 7-13/14 feasibility study. In addition to continued operation of the OCVZ system and long-term surveillance, maintenance, monitoring, and ICs, assembled alternatives for the two surface barriers incorporate unique approaches to control subsidence, address Pad A waste, and inhibit buildup of organic vapor in the cap. The two approaches, Alternatives 2a and $2 \mathrm{~b}$, are described in the following subsections.

ES-3.1.2.1 Alternative 2a-Modified RCRA Type C Surface Barrier. The modified RCRA Type $\mathrm{C}$ surface barrier is an engineered barrier constructed of an asphalt layer and several thin and thick layers of natural materials. Overall thickness of the barrier, coupled with long-term ICs, would preclude inadvertent human intrusion. The asphalt layer would protect against both biotic intrusion and infiltration. Other enhancements for Alternative 2a include incorporating Pad A into the surface barrier, installing grout columns in waste pits to provide a stable foundation, and expanding the existing OCVZ system with shallow extraction wells. The implementation timeframe for Alternative $2 \mathrm{a}$ would be approximately 7 years.

Pad A would be incorporated into the surface barrier by adding layers over the existing Pad A soil cover. This alternative does not include steps to address subsidence of Pad A waste.

Installing grout columns would provide a stable foundation for the SDA surface barrier. Liquid grout would be injected into buried waste using a probe driven by a rotary percussion drill. High-pressure jet grouting would mix grout with waste and soil to form homogeneous columns, which would be spaced on $3.7-\mathrm{m}(12-\mathrm{ft})$ centers to provide a suitable foundation for the surface barrier. Approximately 7.7 ha (19 acres) of the SDA would be grouted with approximately 5,700 columns.

The existing OCVZ system would continue to extract and treat VOCs that have migrated into the vadose zone. The system would be enhanced with shallow extraction wells to preclude trapping organic vapor beneath asphalt layers of the surface barrier. Gas extraction wells would be installed in

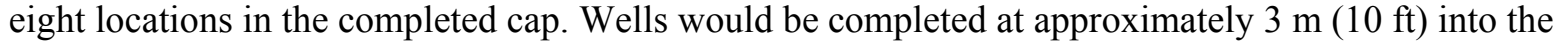
basalt layer immediately beneath the landfill and between pits to avoid intrusion into the buried waste. Risers would extend above the surface barrier and connect to the OCVZ system. Operation and maintenance of the OCVZ system would continue until remediation goals are satisfied (approximately 65 years). The OCVZ system would run longer for the modified RCRA cap (Alternative 2a) than for the evapotranspiration (ET) surface barrier (Alternative 2b) because the Modified RCRA Type C surface barrier includes a low-permeability asphalt layer that would trap VOCs in the subsurface. 
Table ES-6. Summary of five assembled alternatives and major components in each.

\begin{tabular}{|c|c|c|c|c|c|c|c|}
\hline \multirow[b]{2}{*}{ Component } & \multirow[b]{2}{*}{$\begin{array}{c}1 . \\
\text { No Action }\end{array}$} & \multicolumn{2}{|c|}{ 2. Surface Barrier } & \multirow[b]{2}{*}{$\begin{array}{c}3 . \\
\text { In Situ Grouting }\end{array}$} & \multicolumn{2}{|c|}{ 4. Partial Retrieval, Treatment, and Disposal } & \multirow{2}{*}{$\begin{array}{l}5 . \\
\text { Full Retrieval, } \\
\text { Treatment, and } \\
\text { Disposal }\end{array}$} \\
\hline & & $\begin{array}{c}\text { 2a. } \\
\text { Modified RCRA } \\
\text { Type C } \\
\end{array}$ & $\begin{array}{c}2 \mathrm{~b} . \\
\text { Evapotranspiration }\end{array}$ & & $\begin{array}{c}4 \mathrm{a} . \\
4 \text { Acres } \\
\end{array}$ & $\begin{array}{c}4 \mathrm{~b} . \\
2 \text { Acres }\end{array}$ & \\
\hline Monitoring $^{\mathrm{a}}$ & Monitoring & Monitoring & Monitoring & Monitoring & Monitoring & Monitoring & Monitoring \\
\hline $\begin{array}{l}\text { In situ } \\
\text { treatment }\end{array}$ & None & None & None & $\begin{array}{l}\text { ISG-specified Tc-99 and } \\
\text { I-129 }\end{array}$ & None & None & None \\
\hline Retrieval & None & None & None & None & $\begin{array}{l}\text { Retrieve targeted Rocky } \\
\text { Flats Plant waste }\end{array}$ & $\begin{array}{l}\text { Retrieve targeted } \\
\text { Rocky Flats Plant waste }\end{array}$ & $\begin{array}{l}\text { Retrieve all waste in the } \\
\text { SDA }\end{array}$ \\
\hline Pad A & None & $\begin{array}{l}\text { Incorporate Pad A as-is } \\
\text { into cap }\end{array}$ & Relocate to LLW Pit & $\begin{array}{l}\text { Treat ex situ and relocate } \\
\text { to LLW Pit }\end{array}$ & Remove to ICDF & $\begin{array}{l}\text { Dynamically compact } \\
\text { and incorporate into cap }\end{array}$ & $\begin{array}{l}\text { Remove to off-INL Site } \\
\text { disposal facility }\end{array}$ \\
\hline $\begin{array}{l}\text { Subsidence in } \\
\text { pits }\end{array}$ & None & Foundation grouting & Dynamic compaction $^{\mathrm{b}}$ & Dynamic compaction $^{\mathrm{b}}$ & Dynamic compaction $^{\mathrm{b}}$ & Proof-roll & None \\
\hline $\begin{array}{l}\text { Surface } \\
\text { barrier }\end{array}$ & None & $\begin{array}{l}\text { Modified RCRA } \\
\text { Type C surface barrier } \\
\text { with biointrusion layer }\end{array}$ & $\begin{array}{l}\text { ET surface barrier with } \\
\text { biointrusion layer }\end{array}$ & $\begin{array}{l}\text { ET surface barrier with } \\
\text { biointrusion layer }\end{array}$ & $\begin{array}{l}\text { ET surface barrier with } \\
\text { biointrusion layer }\end{array}$ & $\begin{array}{l}\text { ET surface barrier with } \\
\text { biointrusion layer and } \\
\text { slurry perimeter wall }\end{array}$ & $\begin{array}{l}\text { ET surface barrier } \\
\text { without biointrusion } \\
\text { barrier }\end{array}$ \\
\hline $\begin{array}{l}\text { Surface } \\
\text { barrier vapor } \\
\text { extraction }\end{array}$ & None & None & $\begin{array}{l}\text { Active gas collection } \\
\text { layer }\end{array}$ & $\begin{array}{l}\text { Passive gas collection } \\
\text { layer }\end{array}$ & $\begin{array}{l}\text { Passive gas collection } \\
\text { layer }\end{array}$ & $\begin{array}{l}\text { Passive gas collection } \\
\text { layer }\end{array}$ & None \\
\hline $\begin{array}{l}\text { Vadose zone } \\
\text { vapor } \\
\text { extraction }\end{array}$ & None & $\begin{array}{l}\text { Add near-surface } \\
\text { extraction wells; } \\
\text { operate OCVZ system }^{c}\end{array}$ & Operate OCVZ system ${ }^{\mathrm{c}}$ & Operate OCVZ system ${ }^{c}$ & Operate OCVZ system $^{\mathrm{c}}$ & Operate OCVZ system ${ }^{\mathrm{c}}$ & Operate OCVZ system ${ }^{\mathrm{c}}$ \\
\hline $\begin{array}{l}\text { Surveillance } \\
\text { and } \\
\text { maintenance }\end{array}$ & None & $\begin{array}{l}\text { Until eliminated by a } \\
\text { 5-year review } \mathrm{d}\end{array}$ & $\begin{array}{l}\text { Until eliminated by a } \\
5 \text {-year review }{ }^{d}\end{array}$ & $\begin{array}{l}\text { Until eliminated by a } \\
5 \text {-year review } \mathrm{d}\end{array}$ & $\begin{array}{l}\text { Until eliminated by a } \\
5 \text {-year review }{ }^{d}\end{array}$ & $\begin{array}{l}\text { Until eliminated by a } \\
\text { 5-year review }{ }^{d}\end{array}$ & $\begin{array}{l}\text { Until eliminated by a } \\
5 \text {-year review }{ }^{d}\end{array}$ \\
\hline $\begin{array}{l}\text { Institutional } \\
\text { control }\end{array}$ & None & $\begin{array}{l}\text { Until eliminated by a } \\
\text { 5-year review }\end{array}$ & $\begin{array}{l}\text { Until eliminated by a } \\
\text { 5-year review }{ }^{\mathrm{d}}\end{array}$ & $\begin{array}{l}\text { Until eliminated by a } \\
\text { 5-year review }{ }^{d}\end{array}$ & $\begin{array}{l}\text { Until eliminated by a } \\
\text { 5-year review }\end{array}$ & $\begin{array}{l}\text { Until eliminated by a } \\
\text { 5-year review }{ }^{d}\end{array}$ & $\begin{array}{l}\text { Until eliminated by a } \\
\text { 5-year review }{ }^{\mathrm{d}}\end{array}$ \\
\hline \multicolumn{8}{|c|}{$\begin{array}{l}\text { a. Monitoring comprises surface, vadose zone, and aquifer monitoring. Cost estimates include } 100 \text { years of monitoring for No Action and } 100 \text { years of monitoring after the cap is complete for all action alternatives. } \\
\text { b. Dynamic compaction was identified for analysis because it presents the most short-term risk and highest cost among process options that apply surface treatment to address subsidence; thus, it bounds the analysis. } \\
\text { Other process options (e.g., impact rolling) could be substituted during remedial design. } \\
\text { c. Operation of the OCVZ system would continue until eliminated by a } 5 \text {-year review after remediation goals for VOCs in the vadose zone are achieved. } \\
\text { d. Estimates include cost for } 100 \text { years of surveillance, maintenance, and institutional control after the cap is complete. }\end{array}$} \\
\hline \multicolumn{3}{|c|}{$\begin{array}{l}\text { ET = evapotranspiration } \\
\text { ICDF = Idaho CERCLA Disposal Facility } \\
\text { ISG = in situ grouting }\end{array}$} & \multicolumn{2}{|c|}{$\begin{array}{l}\text { INL }=\text { Idaho National Laboratory } \\
\text { LLW = low-level waste } \\
\text { OCVZ = Organic Contamination in the Vadose Zone }\end{array}$} & \multicolumn{3}{|c|}{$\begin{array}{l}\text { RCRA }=\text { Resource Conservation and Recovery Act } \\
\text { SDA }=\text { Subsurface Disposal Area } \\
\text { VOC }=\text { volatile organic compound }\end{array}$} \\
\hline
\end{tabular}


ES-3.1.2.2 Alternative 2b-Evapotranspiration Surface Barrier. The ET surface barrier is an engineered barrier constructed of several layers of natural materials. A biotic barrier would be incorporated to preclude biotic intrusion and transport of contaminants to the surface. Overall thickness of the barrier, coupled with long-term ICs, would preclude inadvertent human intrusion. Other enhancements for Alternative $2 \mathrm{~b}$ include transferring waste from Pad A into the LLW Pit (or another location within the SDA), dynamically compacting waste pits to provide a stable foundation, and incorporating a gas collection system within the surface barrier that would be coupled to the existing OCVZ system. The implementation timeframe for Alternative $2 \mathrm{~b}$ would be approximately 10 years.

Waste from Pad A would be removed under a weather enclosure and would require approximately 5 years to complete. Pad A waste would be placed within new boxes or liners and transferred to the active LLW Pit or other location within the SDA. Waste would not be treated prior to transfer.

Dynamic compaction would be applied to waste pits, before constructing the cap, to reduce subsidence. A heavy weight would be dropped from a height of approximately $18 \mathrm{~m}(60 \mathrm{ft})$ from a crane to compact the waste pits. A layer of soil would be placed over areas before they are compacted to reduce the possibility of exposing waste.

The existing OCVZ system would continue to extract and treat VOCs that have migrated into the vadose zone. To preclude buildup of vapor in the cap a gas collection pipe would be installed during surface barrier construction and connected to the OCVZ system after the cap is constructed. Vapor extraction from the transport layer also would prevent accumulation of landfill gas beneath the surface barrier, including VOCs, C-14, methane, and carbon dioxide. Operation and maintenance of the OCVZ system would continue until remediation goals are satisfied (approximately 45 years). The OCVZ system would not run as long for the ET cap (Alternative 2b) as it would for the Modified RCRA Type C surface barrier (Alternative 2a) because the ET cap would vent gas-phase VOCs to the surface instead of trapping them in the subsurface.

\section{ES-3.1.3 Alternative 3-In Situ Grouting}

Alternative 3 evaluates using in situ grouting of specified waste to retard migration of contaminants generated by INL Site reactor and fuel development operations. Alternative 3 includes the three components common to all action alternatives: (1) continued operation of the OCVZ system to extract and treat VOCs that have migrated into the underlying vadose zone; (2) an engineered surface barrier (i.e., an ET cap) to prevent contaminant transport to the surface by plants and animals, to inhibit infiltration and subsequent transport of contaminants to the vadose zone, and to preclude inadvertent human intrusion through overall thickness of the cap coupled with long-term ICs; and (3) long-term stewardship including surveillance, maintenance, monitoring, and ICs. Additional components of Alternative 3 are (1) removing and ex situ grouting Pad A waste and relocating it to the LLW Pit or other location within the SDA, (2) performing dynamic compaction of pit areas to mitigate future waste subsidence, and (3) passively venting soil vapor from the ET surface barrier. The implementation timeframe for Alternative 3 would be approximately 10 years.

Specified waste in trenches and soil vaults totaling 0.2 acres of INL Site reactor operations waste is evaluated as an example. Specified waste contains releasable Tc-99 and I-129 that would be encapsulated by in situ injection of a cement grout using commercially available equipment. Liquid grout would be injected into buried waste using a probe driven by a rotary percussion drill. High-pressure jet grouting would mix grout with waste and soil to form homogeneous columns. Grout columns would be closely spaced on $0.5-\mathrm{m}$ (20-in.) centers to form consolidated monoliths. Stabilized waste monoliths would be highly impermeable and would reduce contaminant diffusion to moisture that may infiltrate the waste zone. Approximately 3,100 columns would be installed. 
Waste would be retrieved from Pad A in a retrieval enclosure. Bulk waste would be separated into fines (less than 15-cm [6-in.] diameter) and debris (greater than 15-cm [6-in.] diameter). Fines would be mixed with cement grout. Debris would be placed into waste boxes and stabilized with flowable cement grout. Stabilized waste boxes would be transported to the LLW Pit or other location within the SDA. After Pad A waste is removed, the retrieval enclosure would be demobilized and the site prepared for surface barrier construction.

\section{ES-3.1.4 Alternative 4-Partial Retrieval, Treatment, and Disposal}

To facilitate scaling up or down to various retrieval sizes, pit areas totaling 4 and 2 acres, respectively, are evaluated as Alternatives $4 \mathrm{a}$ and $4 \mathrm{~b}$. Analyzing retrievals that vary in size from areas totaling 2 and 4 acres in Alternatives $4 \mathrm{a}$ and $4 \mathrm{~b}$ enables the Agencies to scale and select different sizes of retrieval areas for the final remedy.

Alternatives $4 \mathrm{a}$ and $4 \mathrm{~b}$ both incorporate the targeted waste approach developed for Accelerated Retrieval Project non-time-critical removal actions (DOE-ID 2004; DOE-ID 2006). The Accelerated Retrieval Project provides a well-supported basis for evaluating partial RTD because information relating to implementability, short-term risk, and cost was generated by operating experience. The focused objective of both Accelerated Retrieval Projects is targeted retrieval of certain Rocky Flats Plant waste streams that are highly contaminated with VOCs, transuranics, and uranium. To achieve this objective, the following Rocky Flats Plant waste streams are targeted for retrieval: Series 741 sludge, Series 743 sludge, graphite, filters, and roaster oxides. These waste streams were identified because they contain high concentrations of COCs listed in the Second Addendum (Holdren and Broomfield 2004). Though the list of COCs in the Second Addendum subsequently was refined in the RI/BRA (see Section 1.4.5), the Agencies retained all the original targeted waste types for the Accelerated Retrieval Projects to address uncertainty in model results, especially for uranium isotopes (secondary COCs). Therefore, the same types of targeted waste identified for the Accelerated Retrieval Projects are evaluated for Alternative 4 in this feasibility study.

During the process of excavation, other types of waste could be revealed that are not targeted waste. Nontargeted waste would be removed if the Agencies agree that retrieval is warranted and - as determined through visual inspection or field screening - the subject waste meets the following three criteria: (1) waste poses a potential risk of contamination to the underlying aquifer if left in place, (2) potential risk is sufficient to warrant removal at that time rather than leaving it to be addressed by OU 7-13/14, and (3) waste can be managed safely be retrieval using the personnel, facilities, and equipment readily available at INL for retrieval of targeted waste stream (DOE-ID 2004; DOE-ID 2006).

The same approach identified for the Accelerated Retrieval Projects are evaluated for Alternative 4 in this feasibility study. Removing targeted waste would reduce inventories of VOCs, transuranics, and uranium isotopes. Vadose zone remediation goals for VOCs would be achieved sooner, thus minimizing future OCVZ system operations. In addition, partial retrieval would reduce VOC contamination in the buried waste substantially and would reduce the potential for organics to get into the underlying aquifer.

Operations would be conducted in a large metal-framed fabric retrieval enclosure equipped with airlocks. These airlocks would house drum packaging stations (i.e., glove boxes) for inspecting waste and loading drums. Waste would be retrieved within smaller mobile tents and within the retrieval enclosure. Excavators modified for operation within a contaminated environment, dust-suppression capabilities, and camera optics would be used for retrieval. Whether a waste is targeted or nontargeted would be determined at or near the dig face. Nontargeted waste would be returned to the excavation, while targeted waste would be transferred to the large retrieval enclosure. Targeted waste would be handled in one of two ways: 
- Transuranic waste would be sent to the Waste Isolation Pilot Plant (WIPP). The Second Addendum to the Work Plan (Holdren and Broomfield 2004) specifies that retrieval alternatives will be based on the Accelerated Retrieval Project process. For the Accelerated Retrieval Project, nontransuranic waste (less than $100 \mathrm{nCi} / \mathrm{g}$ ) containing some level of transuranic isotopes is payload-based load-managed, and sent to WIPP. Therefore, an alternate disposal path for this waste type was not evaluated.

- $\quad$ Targeted roaster oxides (uranium oxides) would be moved to drum packaging stations, drummed, and prepared for transfer to the ICDF for treatment and disposal. At ICDF, waste would be stabilized by grouting.

Both partial retrieval alternatives include an ET surface barrier with a passive gas vent layer to dissipate organic vapor and inhibit biotic intrusion. Overall thickness of the barrier, coupled with long-term ICs, would preclude inadvertent human intrusion. The surface barrier would reduce infiltration and contaminant transport into the subsurface and would inhibit biotic transport to the surface. The OCVZ system would continue to extract and treat VOCs from the vadose zone. Both assembled alternatives incorporate long-term surveillance, maintenance, monitoring, and ICs. Unique features of the two partial retrieval alternatives are described in the following subsections.

\section{ES-3.1.4.1 Alternative 4a-4-Acre Partial Retrieval, Treatment, and Disposal.}

Alternative 4a involves retrieval of all waste on Pad A and RTD of targeted waste from pit areas totaling 4 acres using methods described previously. The implementation timeframe for Alternative $4 \mathrm{a}$ would be approximately 16 years.

To provide a stable foundation for the surface barrier and reduce subsidence, all waste pits would be dynamically compacted. Waste retrieved from Pad A would be shipped to ICDF, where fines would be treated (i.e., mixed with grout) and void spaces within debris boxes would be filled with grout, in accordance with ICDF waste acceptance criteria. A multilayered ET surface barrier (see Alternative 2b) would be placed over the entire SDA.

\section{ES-3.1.4.2 Alternative 4b-2-Acre Partial Retrieval, Treatment, and Disposal.}

Alternative $2 \mathrm{~b}$ involves RTD of targeted waste from pit areas totaling 2 acres using methods described previously. The implementation timeframe for Alternative $4 \mathrm{~b}$ would be approximately 12 years.

To provide a stable foundation for the surface barrier and reduce subsidence, Pad A would be dynamically compacted and waste pits would be proof-rolled. The surface barrier would be anchored to a subsurface slurry wall around the perimeter. A multilayered ET surface barrier (see Alternative 2b) incorporating Pad A would be placed over the entire SDA.

\section{ES-3.1.5 Alternative 5-Full Retrieval, Treatment, and Disposal}

Alternative 5 involves retrieving all waste from the SDA and disposal elsewhere. Operations would be conducted within a large metal-framed fabric retrieval enclosure equipped with airlocks. These airlocks would house drum packaging stations (i.e., glove boxes) for inspecting waste and loading drums. In addition, airlocks would be used to control contamination during ingress and egress from retrieval operations. Waste retrieval would occur within this large retrieval enclosure and within three smaller mobile tent structures. Excavators modified for operation within a contaminated environment, dust-suppression capabilities, and camera optics would be used for retrieval. Retrieval areas would be backfilled with noncontaminated soil and compacted. 
Waste would be placed in cargo containers for transfer to the central retrieval enclosure and sorted, based on disposal path. Retrieved waste would be handled in one of the following ways:

- Transuranic waste would be sent to WIPP. The Second Addendum to the Work Plan (Holdren and Broomfield 2004) specifies that retrieval alternatives will be based on the Accelerated Retrieval Project process. For the Accelerated Retrieval Project, nontransuranic waste (less than $100 \mathrm{nCi} / \mathrm{g}$ ) containing some level of transuranic isotopes is payload-based load-managed, and sent to WIPP. Therefore, an alternate disposal path was not evaluated for this waste type.

- $\quad$ Roaster oxides and a portion of the other contact-handled waste meeting waste acceptance criteria would be moved to drum packaging stations, drummed, and transferred to the ICDF for treatment (i.e., grouting) and disposal.

- A portion of the other contact-handled waste would be moved to drum packaging stations, drummed, and sent off the INL Site for treatment, if required to satisfy waste acceptance criteria, and permanent disposal.

- $\quad$ Remote-handled waste would be retrieved using a crane and shielding blocks. Remote-handled waste would be placed in a cask and then sent to a new storage facility on the INL Site for up to 20 years, pending future transport to an off-INL Site facility. Remote-handled waste containing transuranic isotopes would be sent to WIPP.

Following retrieval, a simplified, two-layered ET surface barrier would be placed over the entire SDA to reduce infiltration and inhibit transport of residual contamination in the vadose zone. The implementation timeframe for Alternative 5 would be 30 years. The OCVZ system would continue to extract and treat VOCs that have migrated into the vadose zone throughout construction. Alternative 5 also includes long-term surveillance, maintenance, monitoring, and ICs.

\section{ES-3.1.6 Modules}

To facilitate analysis, 20 distinct modules were defined for the feasibility study, based on elements contained in assembled alternatives. These modules also can be used by the Agencies to compile elements from several alternatives into a preferred alternative for the proposed plan. The modules are described below:

\section{- Retrieval and disposal modules}

- $\quad$ 2-Acre partial RTD-This module consists of retrieving targeted waste from pit areas totaling 2 acres, sorting and packaging waste within a centrally located retrieval enclosure, and transporting waste to either WIPP or ICDF, as appropriate.

- $\quad$ 4-Acre partial RTD-This module consists of retrieving targeted waste from pit areas totaling 4 acres, sorting and packaging waste within a centrally located retrieval enclosure, and transporting waste to either WIPP or ICDF, as appropriate.

- $\quad$ Full RTD-This module consists of retrieving all waste from the SDA. Remote-handled waste containing no transuranic isotopes would be placed in interim storage. All other waste would be sorted and packaged within a centrally located retrieval enclosure and transported to WIPP, ICDF, or another off-INL Site disposal facility, as appropriate. 


\section{- Pad A modules}

Removing Pad A and disposing of waste in the RWMC LLW Pit without treatmentThis module consists of contouring the Pad A berm and building an enclosure over the top to be used for retrieving waste from Pad A. Waste would be retrieved, sorted, placed in bulk containers, and transferred to the LLW Pit (or other location within the SDA) without treatment.

- $\quad$ Removing Pad A and disposing of waste in the RWMC LLW Pit following ex situ treatment-This module consists of contouring the Pad A berm and building an enclosure over the top for retrieving waste from Pad A. Waste would be retrieved, sorted, treated ex situ with grout, placed in waste boxes, and transferred to the LLW Pit (or other location within the SDA).

- $\quad$ Removing Pad A and disposing of and treating waste at the ICDF or similar on-INL Site facility-This module consists of contouring the Pad A berm and building an enclosure over the top for retrieving waste from Pad A. Waste would be retrieved, sorted, visually examined to satisfy ICDF waste acceptance criteria, placed in waste boxes, and transferred to ICDF (or similar facility) for treatment and disposal.

- $\quad$ Removing Pad A and disposing of and treating waste at EnergySolutions or similar off-INL Site facility-This module consists of contouring the Pad A berm and building an enclosure over the top for retrieving waste from Pad A. Waste would be retrieved, placed in containers, and transferred to EnergySolutions (formerly Envirocare) by rail for treatment and disposal.

- Dynamic compaction of Pad A-This module consists of dynamically compacting soil by dropping a heavy weight from a designated height in an engineered pattern. This would prepare the Pad A mound for a surface barrier that would be placed over Pad A.

\section{- Foundation preparation modules}

- Dynamic compaction of pits-This module consists of dynamically compacting pit areas by dropping a heavy weight from a designated height in an engineered pattern and is similar to dynamic compaction of Pad A. Dynamic compaction would mitigate subsidence in SDA pit areas to provide a stable base for a surface barrier. Dynamic compaction was identified because it presents the most short-term risk and highest cost among process options that apply surface treatment to address subsidence, thus bounding the analysis. Other process options (e.g., impact rolling) could be substituted during remedial design.

- $\quad$ Foundation grouting-This module consists of injecting subsurface grout columns at regular intervals using a rotary percussion drill. Foundation grouting would provide a stable base for a cap.

- $\quad$ Proof-rolling-This module consists of compacting SDA pit areas using a roller-compactor. The proof-rolling compaction process would be used to test uniformity and stability of the foundation for the surface barrier. 


\section{- In situ treatment module}

Contaminant grouting-This module consists of installing overlapping subsurface grout columns by injecting grout using a rotary percussion drill. Columns would overlap to fill entire specified areas with grout to encapsulate waste.

\section{- $\quad$ Surface barrier modules}

- Modified RCRA Type $\mathbf{C}$ surface barrier-This module consists of constructing a modified RCRA Type C cap over the entire SDA. This surface barrier would manage moisture and biotic intrusion by incorporating an impermeable asphalt layer. This module also includes installing and demolishing roads and fences, extending wells, installing wells, contouring the SDA, and 100 years of surveillance, maintenance, monitoring, and ICs. Overall thickness of the cap, coupled with long-term ICs, would preclude inadvertent human intrusion.

- $\quad$ ET surface barrier-This module consists of constructing an ET cap, composed of several layers of varying thickness and composition, over the entire SDA. This type of surface barrier would manage moisture through evaporation and transpiration and would include layers to prevent biotic intrusion and collect volatile constituents emitted by buried waste. This module also includes installing and demolishing roads and fences, extending wells, installing wells, contouring the SDA, and 100 years of surveillance, maintenance, monitoring, and ICs. Overall thickness of the cap, coupled with long-term ICs, would preclude inadvertent human intrusion.

- $\quad$ Simplified ET surface barrier with no biointrusion and gas vent layer-This module consists of constructing a simplified ET cap specifically for Alternative 5, where features to address biotic intrusion and gas venting would not be required because all waste would be removed. This module also includes installing and demolishing roads and fences, extending wells, installing wells, contouring the SDA, and 100 years of surveillance, maintenance, monitoring, and ICs. Overall thickness of the cap, coupled with long-term ICs, would preclude inadvertent human intrusion.

- $\quad$ Slurry cut-off wall-This module consists of installing a subsurface slurry cut-off wall by digging a trench around the SDA and immediately filling it with bentonite slurry. This belowgrade barrier would be placed beneath and incorporated into the toe of a surface barrier.

\section{- Volatile organic compound removal modules}

- $\quad$ Near-surface vapor extraction wells-This module consists of installing near-surface vapor extraction wells vertically through the modified RCRA Type C surface barrier, between the waste pits, and into the underlying basalt. Following cap completion, protruding wells would be connected to the OCVZ system.

- Gas vent layer extraction pipe-This module consists of placing sections of horizontal pipe within the ET cap biointrusion and gas vent layer and either connecting the pipe to the OCVZ system or venting the pipe directly to the atmosphere.

- $\quad$ OCVZ system operations and maintenance-This module consists of operating and maintaining the OCVZ system. Three phases associated with this module are (1) operating and maintaining OCVZ treatment units for each 5-year period they operate, (2) replacing OCVZ treatment units for each 20 years they are in service, and (3) shutting down the 
OCVZ system at the end of operation. Because alternatives have different OCVZ system operational timeframes, various combinations of these three phases are used to estimate cost for each alternative.

\section{- Monitoring module}

- Monitoring - This module comprises only environmental monitoring for the No Action alternative. Unlike surface barrier modules, this module does not involve installing new monitoring equipment as a site-preparation activity. This module includes 100 years of monitoring.

\section{ES-4. SUMMARY OF SECTION 4-DETAILED ANALYSIS OF ASSEMBLED ALTERNATIVES}

This section provides detailed analysis of assembled remedial alternatives, developed in Section 3, against CERCLA evaluation criteria. Results of this analysis form the basis for comparative analysis in Section 5 and for future activities that support remedial decision-making (e.g., identifying a preferred alternative, preparing the OU 7-13/14 comprehensive proposed plan, and developing the OU 7-13/14 ROD). Assembled alternatives are constructed using combinations of various elements that were developed as modules in Section 3. During the decision-making process, the Agencies could identify a preferred alternative composed of a different combination of modules. The purpose of this analysis is to present sufficient information to allow the Agencies, in addition to input from the public, to select an alternative.

\section{ES-4.1 Criteria for Detailed Analysis}

The National Contingency Plan specifies nine criteria for analyzing remedial alternatives in detail (40 CFR 300.430). This feasibility study evaluates seven of the nine criteria and defers the last two, in accordance with EPA guidance (EPA 1988). Section 4.1 provides a more detailed description of each of the nine evaluation criteria outlined in the National Contingency Plan (40 CFR 300.430[e][9][iii]) and EPA guidance (EPA 1988). The nine criteria are grouped into three categories as described in the following subsections.

\section{ES-4.1.1 Threshold Criteria}

The first two criteria are (1) overall protection of human health and the environment and (2) compliance with applicable or relevant and appropriate requirements. Threshold criteria relate to statutory findings that ultimately must be included in the OU 7-13/14 ROD. Consequently, remedial action must satisfy these first two criteria to qualify as a preferred alternative. Except for Alternative 1 (No Action), which is included as a basis for comparison, remedial alternatives are not carried forward for detailed analysis unless threshold criteria can be met.

\section{ES-4.1.2 Balancing Criteria}

The five balancing criteria are (3) long-term effectiveness and permanence; (4) reduction of toxicity, mobility, or volume through treatment; (5) short-term effectiveness; (6) implementability; and (7) cost. Balancing criteria are tools for evaluating major characteristics of each alternative and their respective advantages and disadvantages. Appendix $\mathrm{C}$ tabulates alternative-specific information used to evaluate the five balancing criteria. 
Groundwater modeling results for nitrate, three VOCs (i.e., carbon tetrachloride, methylene chloride, and trichloroethylene), and 1,4-dioxane are not used at face value in assessing long-term effectiveness. Simulated concentrations are largely overpredicted compared to detected concentrations in the environment. Though simulated concentrations exceed threshold values for these contaminants, qualitative interpretation of results - after accounting for conservative parameters and uncertainty in modeling - supports the conclusion that all action alternatives would satisfy remedial action objectives and preliminary remediation goals. The following subsections discuss uncertainties relating to interpretation of groundwater simulations for nitrate, VOCs, and 1,4-dioxane.

ES-4.1.2.1 Nitrate. Simulated aquifer concentrations for nitrate are overpredicted, as discussed in detail in Appendix D (see Section D-3.6.1.1). For Alternative 1 (No Action), the numerical model underpredicts observed nitrate concentrations at the few locations in the vadose zone with observed elevated concentrations. The numerical model does, however, produce large overpredictions in the aquifer at Wells M17S, USGS-90, and USGS-117, demonstrating that nitrate simulation results are conservative overall. The majority of other aquifer locations outside this predicted contaminant plume show no simulated impact above local background concentrations. This demonstrated conservatism indicates uncertainty in model results, especially for nitrate. The model predicts a distributed plume of elevated nitrate in the vadose zone and aquifer that is not substantiated by monitoring. Simulations indicate that concentrations would exceed the nitrate MCL of $10 \mathrm{mg} / \mathrm{L}$ before 1980 in the aquifer at the Well M17S monitoring location and would approach $10 \mathrm{mg} / \mathrm{L}$ by 2005 at the Well USGS 119 monitoring location. Neither location has shown monitoring results noticeably different from the regional background concentration of 1 to $2 \mathrm{mg} / \mathrm{L}$. This unsubstantiated plume within the Alternative 1 simulation affects, in turn, simulations that are used to evaluate long-term effectiveness of each action alternative. Though simulated concentrations produce a hazard index less than 1 , they exceed the nitrate MCL of $10 \mathrm{mg} / \mathrm{L}$ for all action alternatives (see Section D-4). These elevated current and future nitrate concentrations are not credible because they are based on simulated release from the source that has not occurred at the predicted magnitude. A consequence of overpredicted nitrate concentrations for this feasibility study is that the model shows a significant mass of nitrate released into the vadose zone that would be beyond the influence of remedial action. In reality, most of this mass is probably still in the buried waste. Remedial action that limits infiltration would effectively reduce transport to the vadose zone and aquifer and would prevent groundwater concentrations that exceed the nitrate MCL.

ES-4.1.2.2 Volatile Organic Compounds. For three VOCs (i.e., carbon tetrachloride, methylene chloride, and trichloroethylene), simulation results meet vadose zone preliminary remediation goals; however, predicted aquifer concentrations are not less than MCLs in the year 2110 for all contaminants and all alternatives. The discrepancy primarily is due to simplifying assumptions used to develop remediation goals for OU 7-08 (which were adopted as preliminary remediation goals for OU 7-13/14) and uncertainties associated with those assumptions. Predicted concentrations do not fall below MCLs by the year 2110 in all cases. However, results for all three contaminants are only slightly greater than MCLs (e.g., maximum simulated carbon tetrachloride concentration of $12 \mu \mathrm{g} / \mathrm{L}$ compared to an MCL of $5 \mu \mathrm{g} / \mathrm{L}$ ); it is reasonable to conclude that MCLs are within the bounds of uncertainty. Appendix D presents details (see Section D-3.6.1.2). Though the modeling goal was to achieve vadose zone remediation goals and not MCLs, it is reasonable to expect, based on professional judgment and interpretation of model results, that achieving MCLs is probable. However, if vadose zone remediation goals are achieved and aquifer concentrations greater than MCLs are persistent, then risk management actions beyond source control measures evaluated in this feasibility study could be identified. Possible approaches include defining a groundwater exclusion zone (i.e., buffer zone), expanding the vapor vacuum extraction with treatment system, or implementing an aquifer pump and treat system.

ES-4.1.2.3 1,4-Dioxane. Aquifer samples have not been analyzed specifically for 1,4-dioxane in the past; however, 1,4-dioxane has never been reported as a tentatively identified compound in routine 
monitoring. This analyte was added recently to the groundwater monitoring program at RWMC. The 1,4-dioxane was on the analyte list for the first time during the November 6, 2006, sampling event; it was not detected. The simulated maximum aquifer concentration for 1,4-dioxane is approximately $120 \mu \mathrm{g} / \mathrm{L}$ in the year 2006 for Alternative 1 (No Action). Because it has not been reported as a tentatively identified compound and was not detected in any of the 15 aquifer monitoring wells sampled on November 6, 2006, 1,4-dioxane is probably overpredicted. However, routine monitoring over time will be necessary to further substantiate the conclusion that modeling overpredicts 1,4-dioxane.

\section{ES-4.1.3 Modifying Criteria}

The last two criteria are (8) state acceptance and (9) community acceptance. Modifying criteria address acceptability of remedial alternatives to stakeholders. The feasibility study does not examine these criteria. Instead, modifying criteria will be analyzed in conjunction with stakeholder comments on the proposed plan that follows completion of the remedial investigation and feasibility study. The proposed plan will summarize the remedial investigation and feasibility study and present the alternative preferred by the Agencies. The Agencies could combine elements (modules) extracted from combinations evaluated in this feasibility study (i.e., assembled alternatives) to compose their preferred alternative.

\section{ES-4.2 Alternative 1-No Action}

Alternative 1 provides a baseline for comparing other alternatives and includes only environmental monitoring with no additional actions to reduce risk. This alternative does not satisfy threshold criteria.

\section{ES-4.3 Alternative 2-Surface Barrier}

Alternative 2 would protect human health and the environment primarily by removing VOCs from the vadose zone and by controlling potential exposure to COCs through containment with a surface barrier and ICs. Under this alternative, a low-permeability surface barrier would be constructed over the SDA. The surface barrier would inhibit transport of contaminants to the surface and infiltration and subsequent migration of contaminants to the vadose zone and aquifer. Overall thickness of the cap, coupled with long-term ICs, would preclude inadvertent human intrusion. The OCVZ system would continue to extract and treat VOCs that have migrated into the vadose zone. Long-term surveillance, maintenance, monitoring, and ICs would ensure continued effectiveness of the remedy.

Alternative 2 comprises two subalternatives: Alternative 2a (Modified RCRA Type C Surface Barrier) and Alternative 2b (ET Surface Barrier). The primary difference between these alternatives is the design of the surface barrier. In addition, because multiple process options were identified in Section 3 to control subsidence, address Pad A, and prevent buildup of volatile contaminants beneath the barrier, the two alternatives incorporate different approaches for these elements (see Table ES-6).

Both types of surface barriers satisfy threshold criteria. With respect to balancing criteria, both surface barriers provide long-term effectiveness and permanence and are fully implementable, though some adjustments may be required to achieve acceptable performance in addressing subsidence and Pad A waste. Short-term risk is very low. Treatment is not a primary element of this alternative, but mobility would be reduced by limiting biotic uptake to the surface and infiltration into the subsurface. The OCVZ system would continue to operate to extract and treat VOCs that have migrated into the vadose zone. Long-term surveillance, maintenance, monitoring, and ICs would be implemented until discontinued through the CERCLA 5-year review process. For Alternatives $2 \mathrm{a}$ and $2 \mathrm{~b}$, respectively, total current value costs are approximately $\$ 344$ million and $\$ 331$ million, with net present values of \$176 million and \$179 million. 


\section{ES-4.4 Alternative 3-In Situ Grouting}

Alternative 3 would protect human health and the environment primarily removing VOCs from the vadose zone and by controlling potential exposure to COCs through containment with an ET surface barrier and ICs. An additional measure of protection would be added by immobilizing Tc-99 (and collocated I-129). Specified Tc-99-containing waste would be encapsulated, in situ, with highly impermeable grout to retard migration. Pad A waste would be excavated, treated with ex situ grouting, and relocated within the SDA.

Alternative 3 satisfies both threshold criteria. With respect to balancing criteria, the cap provides long-term effectiveness and permanence. Alternative 3 is fully implementable, though some adjustments may be required to achieve acceptable performance in addressing Pad A waste. Short-term risk is moderate. Short term risk for Alternative 3 is higher than short-term risk for Alternative 2 because additional time and exposure is incurred during Pad A retrieval activities included within Alternative 3. In situ grouting also increases risk slightly. Treatment is a primary element for a small subset of waste in the SDA (i.e., ISG to immobilize Tc-99 and I-129 and ex situ grouting to decharacterize Pad A waste). In addition, mobility would be reduced by limiting biotic uptake to the surface and infiltration into the subsurface. The OCVZ system would continue to extract and treat VOCs that have migrated into the vadose zone. Long-term surveillance, maintenance, monitoring, and ICs would be implemented until discontinued through the CERCLA 5-year review process. Total current value cost for this alternative is approximately $\$ 385$ million, with a net present value of \$223 million.

\section{ES-4.5 Alternative 4-Partial Retrieval, Treatment, and Disposal}

Alternative 4 would protect human health and the environment primarily by removing VOCs from the vadose zone and by controlling potential exposure to COCs through containment with an ET surface barrier and ICs. An additional measure of protection would be added by removing a portion of the Rocky Flats Plant waste buried in the SDA. Specified targeted waste forms are Series 743 sludge, Series 741 sludge, graphite, filters, and roaster oxide. These waste forms contain high concentrations of VOCs, transuranics, and uranium. The Accelerated Retrieval Project provides a well-supported basis for evaluating this alternative with information generated by operating experience relating to implementability, short-term risk, and cost. This approach focuses on removing primary (e.g., carbon tetrachloride) and secondary (e.g., uranium) COCs for groundwater pathways.

During the process of excavation, other types of waste could be revealed that are not targeted waste. Nontargeted waste would be removed if the Agencies agree that retrieval is warranted and-as determined through visual inspection or field screening - the subject waste meets the following three criteria: (1) waste poses a potential risk of contamination to the underlying aquifer if left in place, (2) potential risk is sufficient to warrant removal at that time rather than leaving it to be addressed by OU 7-13/14, and (3) waste can be managed safely be retrieval using the personnel, facilities, and equipment readily available at INL for retrieval of targeted waste stream (DOE-ID 2004; DOE-ID 2006).

Alternative 4 comprises two subalternatives: Alternative 4a (4-Acre Partial RTD) and Alternative $4 b$ (2-Acre Partial RTD). The primary difference between these alternatives is the amount of excavation. In addition, the two alternatives incorporate different approaches for Pad A: Alternative 4a transfers Pad A waste to ICDF, and Alternative $2 \mathrm{~b}$ applies dynamic compaction to Pad A as a pretreatment for cap construction. Alternative $2 \mathrm{~b}$ also includes a perimeter slurry wall.

Both subalternatives satisfy threshold criteria. With respect to balancing criteria, the cap ensures long-term effectiveness and permanence. Alternatives $4 \mathrm{a}$ and $4 \mathrm{~b}$ are fully implementable, though some uncertainty is associated with treatment of Pad A waste at ICDF under Alternative 4a. Short-term risk 
would be moderate, based on potential worker exposure to radioactive and hazardous materials. Treatment, as traditionally defined, is not a primary element of this alternative, though minor portions of waste would be addressed by treatment at facilities outside the SDA. However, Alternative 4 would remove a substantial amount of waste contaminated with VOCs and transuranics, repackage it, and dispose of it at the Waste Isolation Pilot Plant (WIPP) in New Mexico. WIPP is a deep geologic repository that provides a system that isolates the waste from the environment. In addition, mobility would be reduced by limiting biotic uptake to the surface and infiltration into the subsurface. The OCVZ system would continue to extract and treat VOCs that have migrated into the vadose zone. Long-term surveillance, maintenance, monitoring, and ICs would be implemented until discontinued through the CERCLA 5-year review process. For Alternatives $4 \mathrm{a}$ and $4 \mathrm{~b}$, respectively, total current value costs are approximately \$1,071 million and \$705 million, with net present values of \$756 million and \$486 million.

\section{ES-4.6 Alternative 5-Full Retrieval, Treatment, and Disposal}

Alternative 5 would protect human health and the environment primarily by removing VOCs from the vadose zone and by controlling potential exposure to COCs by removing all waste from the SDA and transferring it elsewhere. An additional measure of protection would be provided by controlling potential exposure to residual COCs through containment with a simplified ET surface barrier. For this alternative, all waste within the SDA (i.e., Pad A, pits, trenches, and soil vaults) would be retrieved and shipped off the SDA. Waste containing transuranic isotopes would be processed for shipment to WIPP, while waste with no transuranic isotopes would be sent to ICDF or an off-INL Site facility (e.g., EnergySolutions) for treatment and disposal. Waste with no current path to disposal (e.g., remote-handled nontransuranic waste) would be placed within shielded casks and stored in a newly constructed facility on the INL Site pending development of a federal or commercial repository.

Alternative 5 satisfies both threshold criteria. With respect to balancing criteria, the cap provides long-term effectiveness and permanence. Implementability of Alternative 5 is uncertain with regard to availability of protective retrieval techniques for remote-handled waste and large objects and with regard to availability of treatment, storage, and disposal facilities. Short-term risk is high because the alternative is complex, with substantial potential for construction accidents and exposure to radioactive and hazardous materials. Treatment is not a primary element of this alternative, though a small subset of the waste would be treated at disposal facilities to meet waste acceptance criteria. In addition, mobility would be reduced by limiting biotic uptake to the surface and infiltration into the subsurface. The OCVZ system would continue to extract and treat VOCs that have migrated into the vadose zone. Long-term surveillance, maintenance, monitoring, and ICs would be implemented until discontinued through the CERCLA 5-year review process. Total current value cost for this alternative is approximately $\$ 13,651$ million, with a net present value of $\$ 8,434$ million.

\section{ES-5. SUMMARY OF SECTION 5-COMPARATIVE ANALYSIS}

This section compares the relative advantages and disadvantages of the five assembled alternatives in achieving remedial action objectives for the SDA. The nine CERCLA criteria provide the basis for comparison. The following summary assesses alternatives - relative to one another-for seven of the nine evaluation criteria (i.e., two threshold and five balancing criteria). The last two criteria (i.e., modifying criteria), state acceptance and community acceptance, will be evaluated in conjunction with the proposed plan and ROD. Detailed analyses in Section 4 evaluated alternatives independently. Comparative analysis presented in this section complements the detailed analysis by identifying key tradeoffs that decision-makers must balance to select a preferred alternative and develop risk management decisions. The five assembled alternatives and comparative analysis are summarized in the following subsections. 


\section{ES-5.1 Summary of Assembled Alternatives}

Except for continued operation of the vapor vacuum extraction system, initiated under OU 7-08 to collect VOCs from the vadose zone, scope for OU 7-13/14 focuses on measures that deal directly with the buried waste. Because contaminant migration has not occurred to a substantial extent (except for VOCs), the objective for remedial action at the SDA is source control (i.e., approaches to prevent contaminant migration). The baseline risk assessment and this feasibility study define the source as the buried waste and associated contaminated soil down to the first basalt layer beneath the landfill. The Agencies identified source control, which can include containment, removal, or treatment of selected areas within the source (EPA 1988), to inhibit future releases from buried waste and to prevent further contamination of the environment. The unsaturated region beneath the source is the vadose zone, and below that is the aquifer. Source control, combined with continued operation of the OCVZ system, will protect the vadose zone and aquifer.

The primary means of source control is construction of an engineered surface barrier and, for Alternatives 4 and 5, removal of a substantial portion of VOC waste via excavation and continued operation of the OCVZ system. The Agencies concluded early in the study of the SDA that an engineered surface barrier will be a component of every action alternative evaluated in this feasibility study (Holdren and Broomfield 2004). Coupled with long-term ICs, the surface barrier would preclude inadvertent human intrusion. The surface barrier also would preclude contaminant transport to the surface by plants and animals.

Developing this comprehensive feasibility study involves integrating remedies for several characteristics of the SDA (e.g., localized subsidence in pits, abovegrade waste on Pad A, and near-surface VOCs) into fully assembled alternatives that address the entire landfill. The Agencies recognized that each specific characteristic can be addressed several ways; thus, many assembled alternatives composed of different combinations are possible. The Agencies optimized feasibility study development by specifying the combinations that would be evaluated as fully assembled alternatives. To maintain flexibility, each of the various components was developed as a discrete module. Each alternative is named after its featured component, though every action alternative includes an engineered surface barrier, continued operation of the OCVZ system, and long-term surveillance, maintenance, monitoring, and ICs. The Agencies will be able to mix and match various components, selecting the optimum combination when developing a preferred alternative and finalizing remedial decisions for the SDA.

The five alternatives are summarized below:

- Alternative 1-No Action-comprises environmental monitoring only, with no measures to reduce risk.

- $\quad$ Alternative 2-Surface Barrier-includes two subalternatives, which are evaluated in detail:

- $\quad$ Alternative 2a-Modified RCRA Type C Surface Barrier-is a surface barrier assembled with additional near-surface vapor vacuum extraction, foundation grouting to address subsidence, continued operation of the OCVZ system, and long-term surveillance, maintenance, monitoring, and ICs. Pad A would be incorporated as-is into the surface barrier.

- $\quad$ Alternative 2b-ET Surface Barrier-is a surface barrier with an active gas collection layer assembled with dynamic compaction to address subsidence, continued operation of the OCVZ system, and long-term surveillance, maintenance, monitoring, and ICs. Pad A waste would be transferred to the LLW Pit or other location within the SDA. 
- $\quad$ Alternative 3-ISG_involves immobilizing Tc-99 and I-129 in place using high-pressure jet grouting. Relevant waste forms are associated with INL Site reactor research and operations. Fully assembled, this alternative includes dynamic compaction of pits to address subsidence, an ET surface barrier with a passive gas collection layer, continued operation of the OCVZ system, and long-term surveillance, maintenance, monitoring, and ICs. Pad A waste would be retrieved, treated ex situ, and transferred to the LLW Pit or other location within the SDA.

- $\quad$ Alternative 4-Partial RTD—includes the following two subalternatives that are evaluated in detail to facilitate scaling for variable sizes of retrieval areas:

- $\quad$ Alternative 4a-4-Acre Partial RTD—addresses removal of targeted Rocky Flats Plant waste from pit areas in the SDA totaling 4 acres. Additional features of this assembled alternative include dynamic compaction of pits to address subsidence, a passively vented ET surface barrier, continued operation of the OCVZ system, and long-term surveillance, maintenance, monitoring, and ICs. Pad A waste would be removed and sent to ICDF for treatment and disposal.

- $\quad$ Alternative 4b-2-Acre Partial RTD—addresses removal of targeted Rocky Flats Plant waste from pit areas in the SDA totaling 2 acres. Additional features of this assembled alternative include proof-rolling of pits to address subsidence, a subsurface slurry wall around the perimeter of the landfill, a passively vented ET surface barrier, continued operation of the OCVZ system, and long-term surveillance, maintenance, monitoring, and ICs. Pad A would be dynamically compacted and incorporated into the surface barrier.

- $\quad$ Alternative 5-Full RTD-includes complete removal of all buried waste in combination with a simplified ET surface barrier, continued operation of the OCVZ system, and long-term surveillance, maintenance, monitoring, and ICs.

In subsections that follow, Alternative 1 (No Action) is discussed first under each criterion. Action alternatives (i.e., Alternatives 2, 3, 4, and 5) then are presented in the relative order in which they perform, beginning with the alternative that provides the best overall performance for the criterion. Table ES-7 provides a matrix of the five assembled alternatives and major components in each. This section concludes with a summary table of the comparative analysis (see Table ES-8).

\section{ES-5.2 Summary of Comparative Analysis}

All action alternatives include a surface barrier that would effectively preclude transport of contaminants to the surface by plants and animals. Overall thickness of the surface barrier, coupled with long-term ICs, would preclude inadvertent human intrusion. Each action alternative also includes elements to reduce concentrations of VOCs at the surface. Thus, each action alternative is relatively equal in terms of satisfying remedial action objectives and mitigating risk attributable to surface exposure pathways for both human health and the environment.

Comparisons of long-term effectiveness for groundwater are based on carcinogenic risk, toxic effects from chemicals (i.e., hazard indexes), and concentrations of contaminants in the aquifer. Each action alternative includes a surface barrier that reduces infiltration and continued operation of the OCVZ system to extract and treat VOCs from the vadose zone - which in turn protects groundwater. Estimates are predicated on models that simulate release of contaminants from buried waste and subsequent transport through the vadose zone and into the aquifer. Instantaneous remediation in 2010 - followed by continued operation of the OCVZ system - was modeled for all action alternatives to facilitate direct comparison of long-term effectiveness. Therefore, contaminant migration occurring during remediation- 
and consequent increase in long-term risk - is not apparent in comparison graphs. Figures ES-2 and ES-3 compare long-term effectiveness for the five alternatives in reducing carcinogenic risk and hazard index for groundwater pathways. Groundwater modeling results for nitrate, three VOCs (i.e., carbon tetrachloride, methylene chloride, and trichloroethylene), and 1,4-dioxane are not used at face value in assessing long-term effectiveness because simulated concentrations are largely overpredicted in comparison to detected concentrations in the environment (see Section ES-4.1.2). Qualitative interpretation of results after accounting for overly conservative parameters (as evidenced by overpredictions) and uncertainty in modeling supports the conclusion that all action alternatives would satisfy remedial action objectives and preliminary remediation goals.

Magnitude of short-term risk for each alternative depends on the amount of time required to implement an action, the degree of potential exposures to hazardous and radioactive materials, and hazards from construction and transport of construction materials. Completion of the surface barrier achieves remedial action objectives for source control, illustrated as construction timeframes for each action alternative in Figure ES-4. Therefore, the construction timeframe is used to define the implementation period and to assess short-term risk. These estimated timeframes are predicated on construction beginning in 2010 and sufficient funding to continue without interruption until work is complete. None of the remedial alternatives evaluated in this feasibility study pose a cumulative hazard index greater than 1, and likelihood of a fatality is extremely low. However, excess cancer risk and injuries are more likely. In general, carcinogenic risk increases with complexity and the amount of retrieval included in each alternative. Workers would not be exposed directly to waste in Alternative 2a; thus, the risk of developing cancer over time as a result of exposure received during remediation is

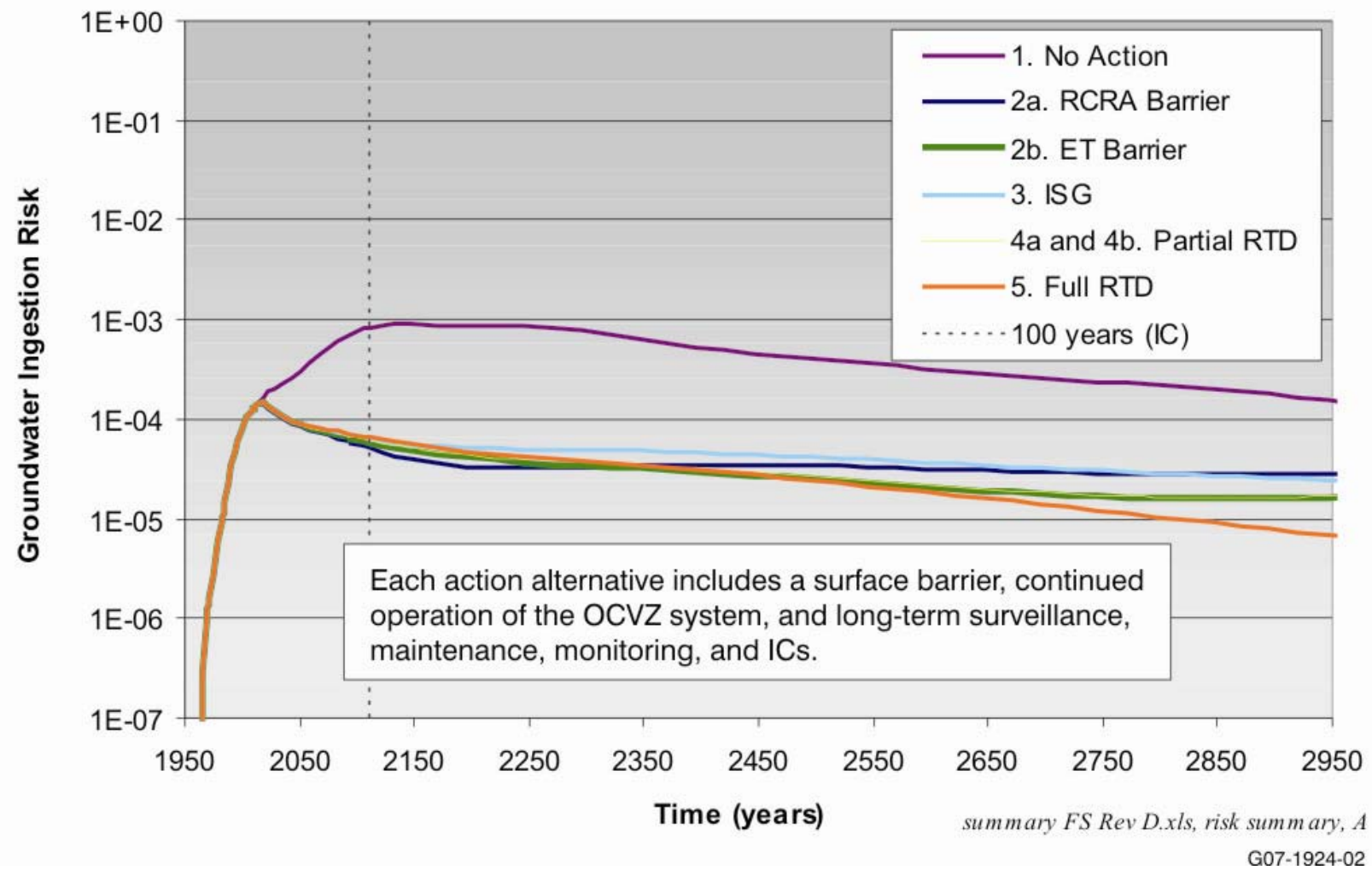

Figure ES-2. Comparison of long-term effectiveness based on cumulative carcinogenic risk for groundwater ingestion provided by each remedial alternative. 


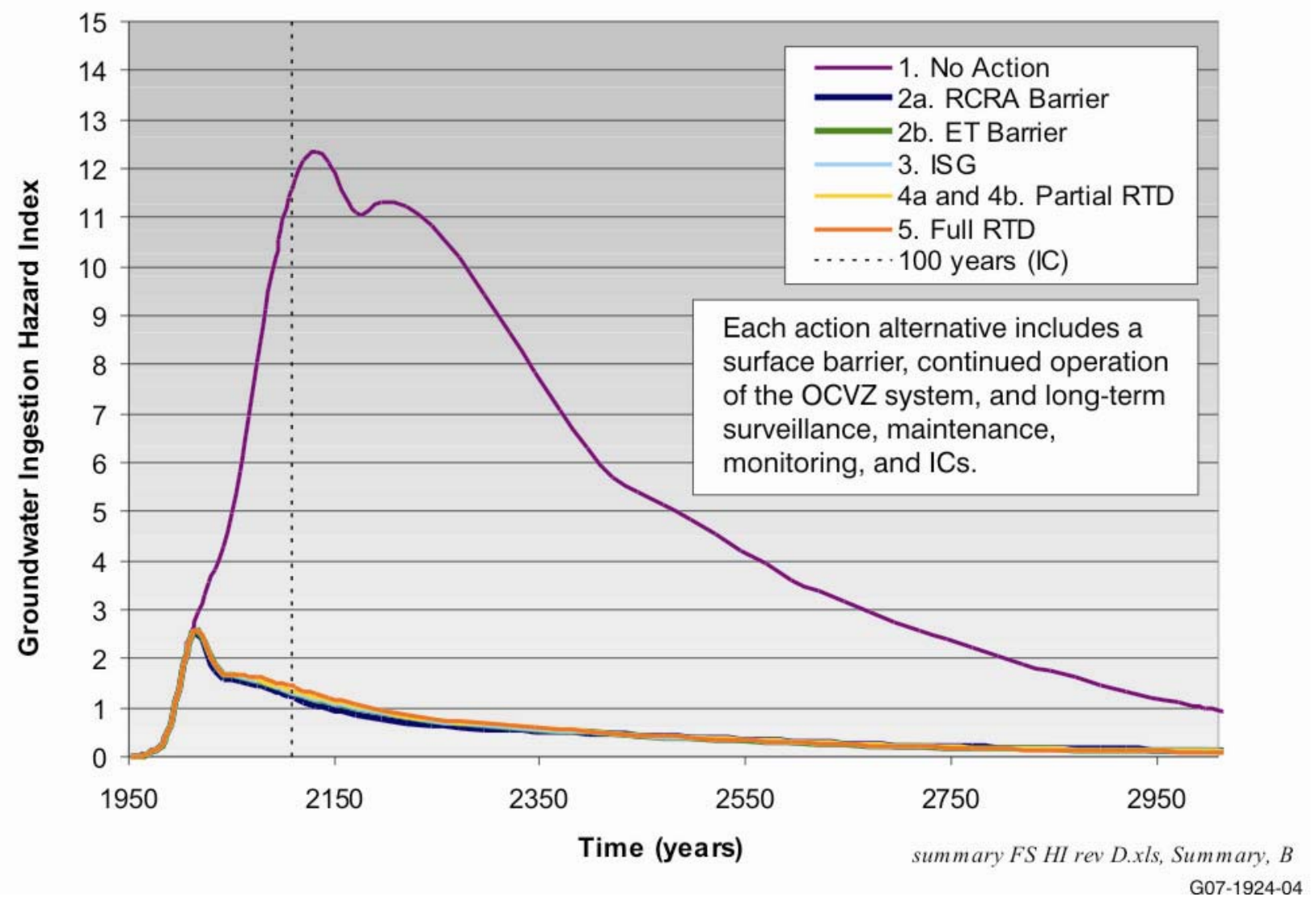

Figure ES-3. Comparison of long-term effectiveness based on cumulative hazard index for groundwater ingestion provided by each remedial alternative; hazard indexes are overestimated for all alternatives.

roughly equivalent to background risk. Alternatives $2 \mathrm{~b}$ and 3 both include retrieval of Pad A, posing a moderately low increase in carcinogenic risk. Workers would incur a moderate increase in risk during targeted waste retrieval in Alternative 4. Alternative 5 would pose relatively high risk to workers, especially during complex elements of the alternative (e.g., retrieving large objects and remote-handled waste). Similarly, risk of injuries increases with complexity and the amount of retrieval. Figure ES-5 shows estimated recordable injuries for each action alternative.

Figure ES-6 shows relative cost estimates for each assembled alternative. Both current value (Fiscal Year 2006 dollars) and net present value are presented. For the proposed plan, the Agencies will likely identify an optimized combination of modules for their preferred alternative that is not an exact match with any one alternative evaluated in this feasibility study. Estimated costs will be a summation of costs for each module included in the preferred alternative. 


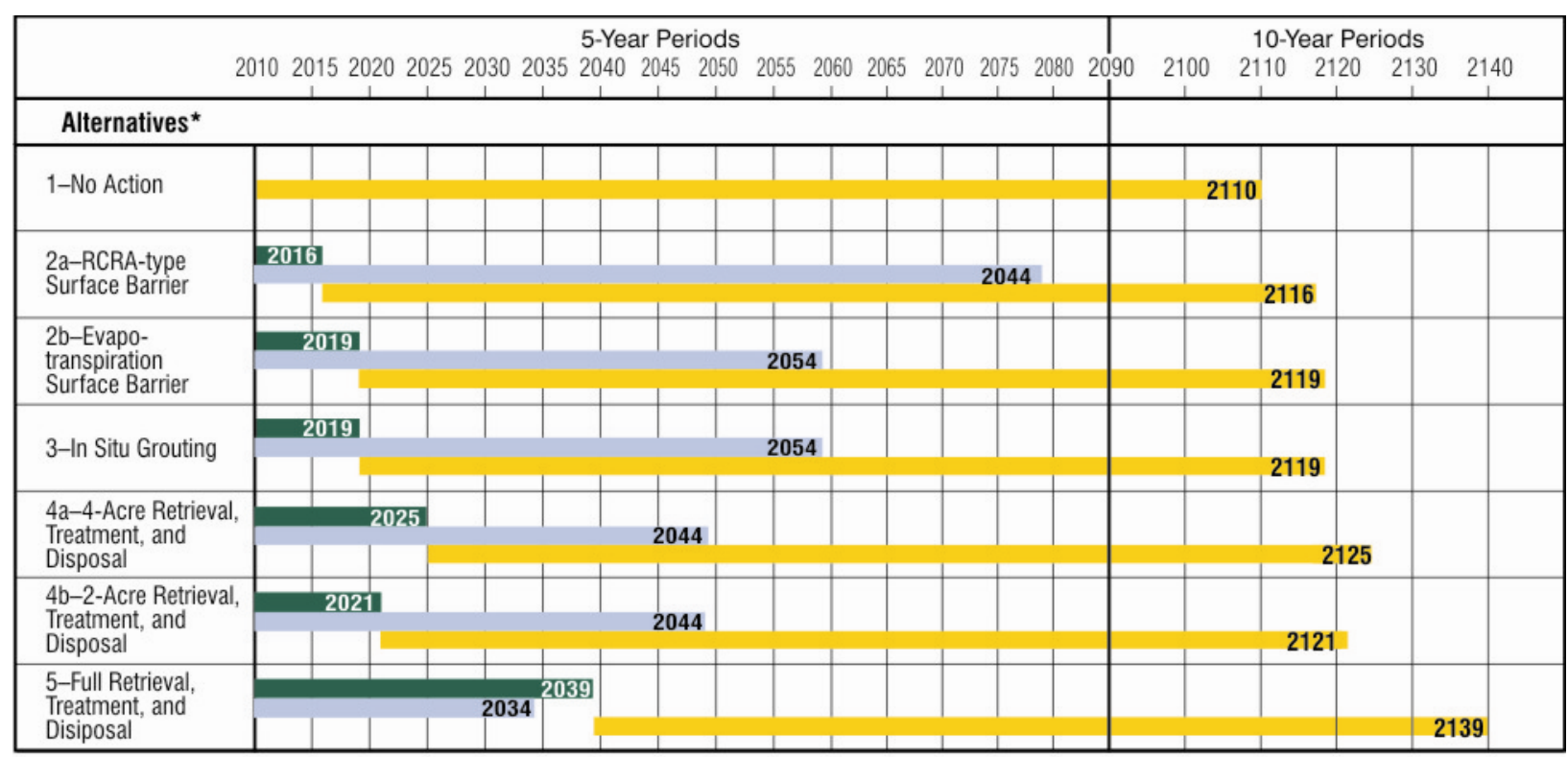

Construction $\square$ Organic Contamination in the Vadose Zone operations and maintenance

Other operations and maintenance * Each action alternative includes a surface barrier, continued operation of the OCVZ system, and long-term surveillance, maintenance, monitoring, and ICs.

G07-1924-14

Figure ES-4. Estimated implementation timeframes for each remedial alternative.

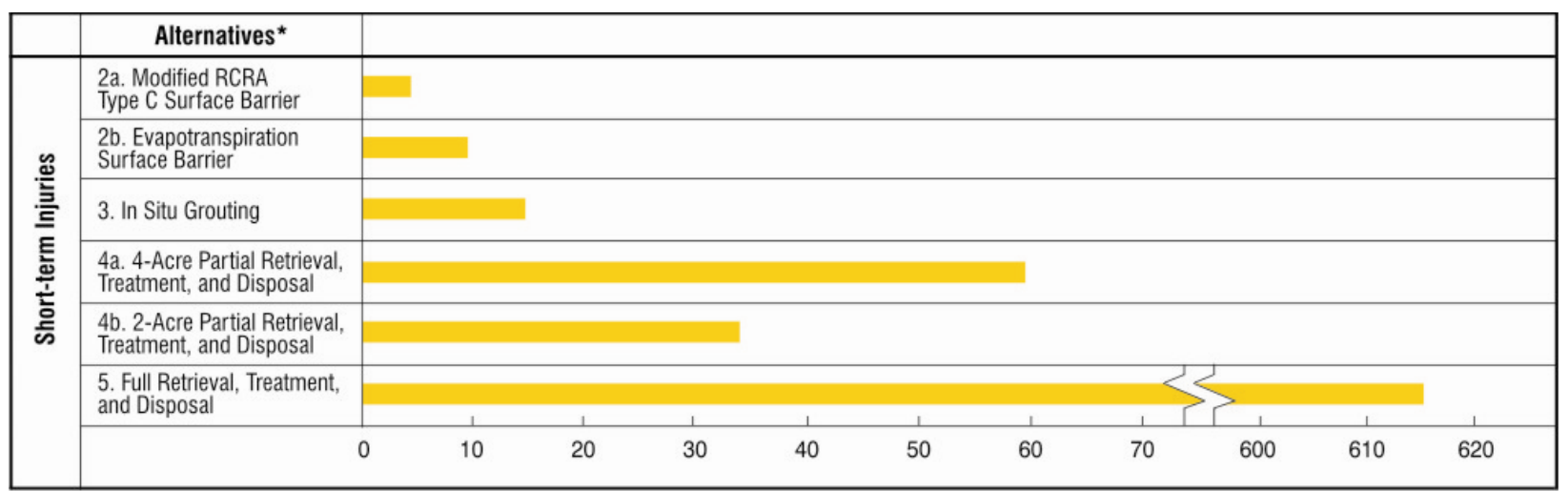

* Each action alternative includes a surface barrier, continued operation of the OCVZ system, and long-term surveillance, maintenance, monitoring, and ICs.

G07-1924-16

Figure ES-5. Estimated recordable injuries for each action alternative. 


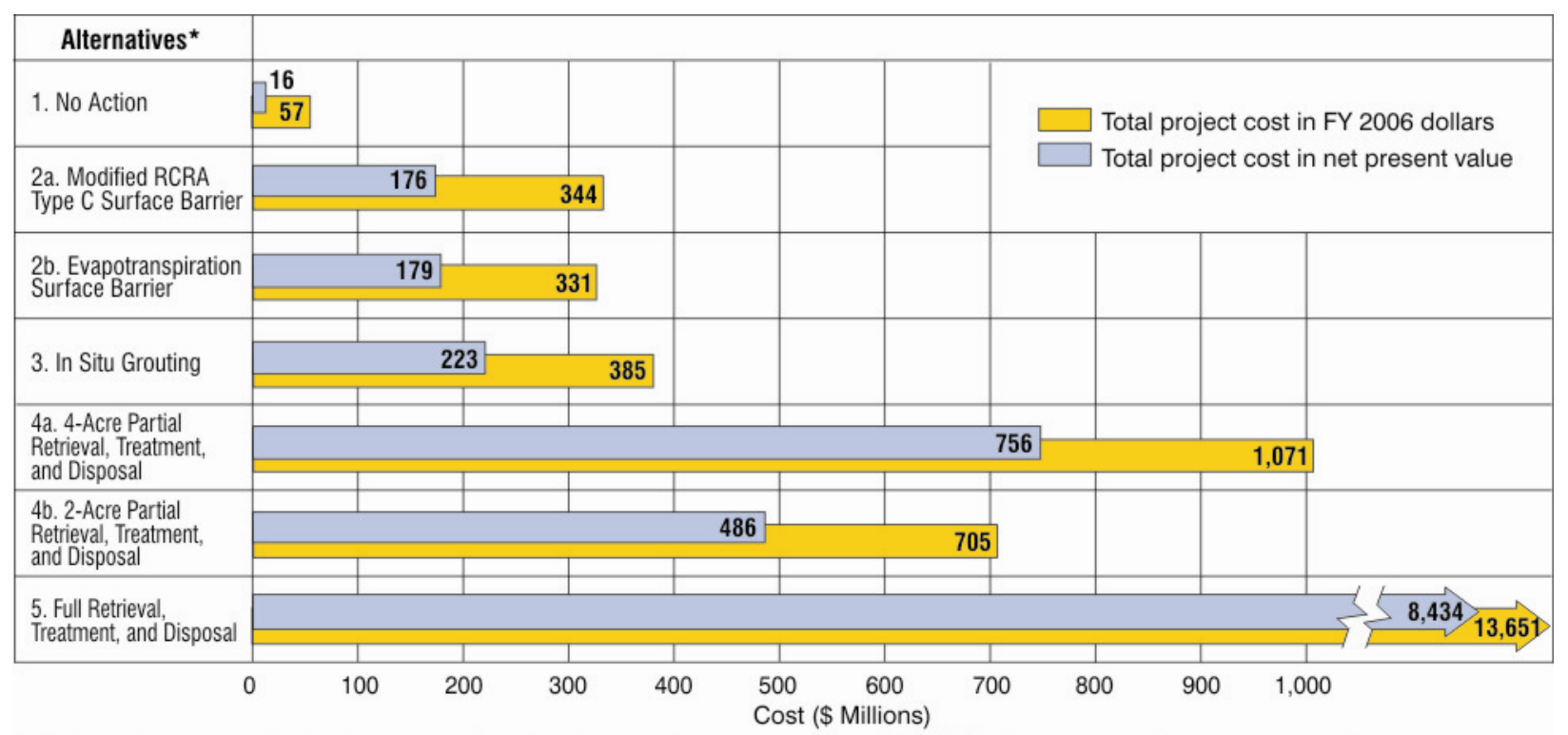

* Each action alternative includes a surface barrier, continued operation of the OCVZ system, and long-term surveillance, maintenance, monitoring, and ICs.

Figure ES-6. Comparison and summary of cost associated with each alternative.

Table ES-7 provides a matrix illustrating the assembled alternatives and the modules that compose them. The Agencies can recombine these modules in a different configuration to develop their preferred alternative in the future proposed plan. Table ES-8 summarizes the comparative analysis of alternatives. The greatest degree of discrimination among alternatives occurs in evaluating short-term effectiveness, implementability, and cost. Excluding Alternative 1 (No Action), long-term effectiveness in the first 100 years after remediation is approximately the same, with all action alternatives satisfying remedial action objectives. In combination with continued operation of the OCVZ system to extract and treat VOCs from the vadose zone, the surface barrier component of each alternative effectively addresses all remedial action objectives. Alternative 5 (Full RTD) in the 1,000-year timeframe and beyond slightly reduces long-term risk (i.e., risk diminishes from the $10^{-5}$ to the $10^{-6}$ order of magnitude), but short-term risk is much higher than for other alternatives, and implementability is uncertain. 
Table ES-7. Matrix of the five assembled alternatives and major components in each.

\begin{tabular}{|c|c|c|c|c|c|c|c|}
\hline \multirow[b]{2}{*}{ Component } & \multirow[b]{2}{*}{$\begin{array}{c}1 . \\
\text { No Action }\end{array}$} & \multicolumn{2}{|c|}{ 2. Surface Barrier } & \multirow[b]{2}{*}{$\begin{array}{c}3 . \\
\text { In Situ Grouting }\end{array}$} & \multicolumn{2}{|c|}{ 4. Partial Retrieval, Treatment, and Disposal } & \multirow{2}{*}{$\begin{array}{c}5 . \\
\text { Full Retrieval, Treatment, } \\
\text { and Disposal }\end{array}$} \\
\hline & & $\begin{array}{l}\text { 2a. } \\
\text { Modified RCRA Type C }\end{array}$ & $\begin{array}{c}2 \mathrm{~b} . \\
\text { Evapotranspiration }\end{array}$ & & $\begin{array}{l}\text { 4a. } \\
4 \text { Acres }\end{array}$ & $\begin{array}{c}4 \mathrm{~b} . \\
2 \text { Acres }\end{array}$ & \\
\hline Monitoring $^{a}$ & Monitoring & Monitoring & Monitoring & Monitoring & Monitoring & Monitoring & Monitoring \\
\hline In situ treatment & None & None & None & ISG-specified Tc-99 and I-129 & None & None & None \\
\hline Retrieval & None & None & None & None & $\begin{array}{l}\text { Retrieve targeted Rocky } \\
\text { Flats Plant waste }\end{array}$ & $\begin{array}{l}\text { Retrieve targeted Rocky Flats } \\
\text { Plant waste }\end{array}$ & Retrieve all waste in the SDA \\
\hline Pad A & None & $\begin{array}{l}\text { Incorporate Pad A as-is into } \\
\text { cap }\end{array}$ & Relocate to LLW Pit & $\begin{array}{l}\text { Treat ex situ and relocate to } \\
\text { LLW Pit }\end{array}$ & Remove to ICDF & $\begin{array}{l}\text { Dynamically compact }{ }^{\mathrm{b}} \text { and } \\
\text { incorporate into cap }\end{array}$ & $\begin{array}{l}\text { Remove to off-INL Site } \\
\text { disposal facility }\end{array}$ \\
\hline $\begin{array}{l}\text { Subsidence in } \\
\text { pits }\end{array}$ & None & Foundation grouting & Dynamic compaction $^{\mathrm{b}}$ & Dynamic compaction $^{\mathrm{b}}$ & Dynamic compaction $^{\mathrm{b}}$ & Proof-roll & None \\
\hline Surface barrier & None & $\begin{array}{l}\text { Modified RCRA Type C } \\
\text { surface barrier with } \\
\text { biointrusion layer }\end{array}$ & $\begin{array}{l}\text { ET surface barrier with } \\
\text { biointrusion layer }\end{array}$ & $\begin{array}{l}\text { ET surface barrier with } \\
\text { biointrusion layer }\end{array}$ & $\begin{array}{l}\text { ET surface barrier with } \\
\text { biointrusion layer }\end{array}$ & $\begin{array}{l}\text { ET surface barrier with } \\
\text { biointrusion layer and slurry } \\
\text { perimeter wall }\end{array}$ & $\begin{array}{l}\text { ET surface barrier without } \\
\text { biointrusion barrier }\end{array}$ \\
\hline $\begin{array}{l}\text { Surface barrier } \\
\text { vapor extraction }\end{array}$ & None & None & Active gas collection layer & Passive gas collection layer & Passive gas collection layer & Passive gas collection layer & None \\
\hline $\begin{array}{l}\text { Vadose zone } \\
\text { vapor extraction }\end{array}$ & None & $\begin{array}{l}\text { Add near-surface extraction } \\
\text { wells; operate OCVZ system } \\
58.5 \text { years after construction }\end{array}$ & $\begin{array}{l}\text { Operate OCVZ system } \\
35 \text { years after construction }\end{array}$ & $\begin{array}{l}\text { Operate OCVZ system } \\
35 \text { years after construction }\end{array}$ & $\begin{array}{l}\text { Operate OCVZ system } \\
19 \text { years after construction }\end{array}$ & $\begin{array}{l}\text { Operate OCVZ system } \\
23 \text { years after construction }\end{array}$ & $\begin{array}{l}\text { Operate OCVZ system } \\
\text { throughout construction }^{\mathrm{c}}\end{array}$ \\
\hline $\begin{array}{l}\text { Surveillance and } \\
\text { maintenance }\end{array}$ & None & $\begin{array}{l}\text { Until eliminated by a } 5 \text {-year } \\
\text { review }^{d}\end{array}$ & $\begin{array}{l}\text { Until eliminated by a } 5 \text {-year } \\
\text { review }^{\mathrm{d}}\end{array}$ & $\begin{array}{l}\text { Until eliminated by a 5-year } \\
\text { review }^{d}\end{array}$ & $\begin{array}{l}\text { Until eliminated by a } 5 \text {-year } \\
\text { review }^{\mathrm{d}}\end{array}$ & $\begin{array}{l}\text { Until eliminated by a } 5 \text {-year } \\
\text { review }^{\mathrm{d}}\end{array}$ & $\begin{array}{l}\text { Until eliminated by a 5-year } \\
\text { review }^{d}\end{array}$ \\
\hline $\begin{array}{l}\text { Institutional } \\
\text { control }\end{array}$ & None & $\begin{array}{l}\text { Until eliminated by a } 5 \text {-year } \\
\text { review }^{\mathrm{d}}\end{array}$ & $\begin{array}{l}\text { Until eliminated by a } 5 \text {-year } \\
\text { review }^{\mathrm{d}}\end{array}$ & $\begin{array}{l}\text { Until eliminated by a } 5 \text {-year } \\
\text { review }^{\mathrm{d}}\end{array}$ & $\begin{array}{l}\text { Until eliminated by a } 5 \text {-year } \\
\text { review }^{\mathrm{d}}\end{array}$ & $\begin{array}{l}\text { Until eliminated by a } 5 \text {-year } \\
\text { review }^{\mathrm{d}}\end{array}$ & $\begin{array}{l}\text { Until eliminated by a } 5 \text {-year } \\
\text { review }^{\mathrm{d}}\end{array}$ \\
\hline \multicolumn{8}{|c|}{$\begin{array}{l}\text { a. Monitoring comprises surface, vadose zone, and aquifer monitoring. Cost estimates include } 100 \text { years of monitoring for No Action and } 100 \text { years of monitoring after the cap is complete for all action alternatives. } \\
\text { b. Dynamic compaction was identified for analysis because it presents the most short-term risk and highest cost among process options that apply surface treatment to address subsidence; thus, it bounds the analysis. Other process options (e.g., impact rolling) could be substituted during remedial } \\
\text { design. } \\
\text { c. Operation of the OCVZ system would continue throughout construction and beyond until eliminated by a } 5 \text {-year review after remediation goals for VOCs in the vadose zone are achieved. Timeframes given are approximations based on modeling. } \\
\text { d. Estimates include cost for } 100 \text { years of surveillance, maintenance, and institutional control after the cap is complete. }\end{array}$} \\
\hline
\end{tabular}




$\begin{array}{ccccc}\text { Evaluation Criteria } & \begin{array}{c}\text { Alternative 1- } \\ \text { No Action }\end{array} & \begin{array}{l}\text { Alternative 2- } \\ \text { Surface Barrier }\end{array} & \begin{array}{c}\text { Alternative 3- } \\ \text { In Situ Grouting }\end{array} & \begin{array}{c}\text { Alternative 4-Partial Retrieval, Treatment, } \\ \text { and Disposal }^{\mathrm{b}}\end{array} \\ \text { Alternative 5-Full Retrieval, } & \text { Treatment, and Disposal }\end{array}$

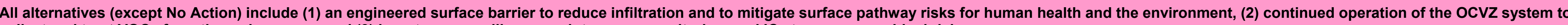
collect and treat VOCs from the vadose zone, and (3) long-term surveillance, maintenance, monitoring, and ICs to manage residual risk.

\section{Threshold Criteria}

Overall protection of

human health

\section{Does not satisfy}

criterion

Meets remedial action objectives and

provides overall protection

Meets remedial action objectives and

provides overall protection

Mect

Compliance with

Does not satisfy

Complies with ARARs

Complies with ARARs

Meets remedial action objectives and

Meets remedial action objectives and

ARARs criterion

Balancing Criteria

Long-term effectiveness Not applicable and permanence
Provides long-term protectiveness and

permanence

Alternative $2 \mathrm{a}$-more susceptible to damage

from subsidence and requires more

maintenance than Alternative $2 b$

Satisfies remedial action objectives at end of

construction relatively quickly (i.e., 7 to

10 years) ${ }^{\circ}$

Alternative 2a-Operates the OCVZ system

for approximately 58.5 years after

construction

Alternative $2 \mathrm{~b}$ - Operates the OCVZ system

for approximately 35 years after constructio

Infiltration continues for 7 to 10 years-

shorter implementation timeframe minimizes

the amount of contamination that migrates

into the vadose zone and reaches the aquifer
Provides long-term protectiveness an permanence

Substantial portion of releasable Tc-99 would be immobilized

Satisfies remedial action objectives at end of construction relatively quickly (i.e., 10 years) $^{c}$

Operates the OCVZ system for approximately 35 years after construction

Infiltration continues for 10 years - shorter mplementation timeframe minimizes the the vadose zone and reaches the ac provides overall protection

Complies with ARARs

provides overall protection

Complies with ARARs

\section{Provides long-term protectiveness and} permanence

Alternative 4a-removes Pad A and targeted waste from pit areas totaling 4 acres

Alternative $4 \mathrm{~b}$ - removes targeted waste from pit areas totaling 2 acres

Alternative $4 \mathrm{a}-$ Satisfies remedial action objectives at end of construction in approximately 16 years $^{\mathrm{c}}$

Alternative $4 \mathrm{~b}$ - Satisfies remedial action objectives at end of construction in approximately 12 years $^{\mathrm{c}}$

Alternative $4 \mathrm{a}-$ Operates the OCVZ system for approximately 19 years after construction Alternative $4 \mathrm{~b}-$ Operates the OCVZ system for approximately 23 years after construction

Infiltration continues for 12 to 16 yearslonger implementation timeframes increase into the vadose zone and aquifer
Provides greatest degree of long-term protectiveness and permanence

Removes all buried waste

Satisfies remedial action objectives at end of construction in approximately 30 years $^{\mathrm{c}}$ Operates the OCVZ system throughout construction

Infiltration continues for 30 years-long implementation timeframe greatly increases mplementation timeframe greatly increases into the vadose zone and aquifer 
All alternatives (except No Action) include (1) an engineered surface barrier to reduce infiltration and to mitigate surface pathway risks for human health and the environment, (2) continued operation of the OcvZ system to

\section{collect and treat VOCs from the vadose zone, and (3) long-term surveillance, maintenance, monitoring, and ICs to manage residual risk.}

\section{Reduction of toxicity, Not applicable}

mobility, or volume

hrough treatment
OCVZ system destroys organic vapors

collected from the vadose zone

Alternative $2 \mathrm{~b}$ - includes additional

near-surface extraction wells
OCVZ system destroys organic vapors

collected from the vadose zone

In situ grouting immobilizes Tc-99 (and

collocated I-129)

Ex situ grouting removes the characteristic of eactivity from uranium waste retrieved from Pad A

Implementability
No additional risk to collocated workers, the public, or the environment

Slightly in Pad A waste to the LLW Pit) than for Alternative 2a (leaves Pad A waste in place)

Fully implementable
No additional risk to collocated workers, the

\section{Fully implementable}

Alternative $2 \mathrm{a}$-rigorous quality control would be required to ensure integrity of the asphalt hydraulic barrier over a large area (e.g., 105 acres)

Alternative $2 b$ - relocating Pad A waste without treatment to the LLW Pit would satisfy ARARs; however:

- This action may not be acceptable to DEQ and EPA

Disposal capacity in the LLW Pit may be limited
Relatively moderate (Alternative $4 \mathrm{~b}$ ) to moderately high risk (Alternative 4a) to remediation workers totaling 4 acres) than for Alternative $4 \mathrm{~b}$ (retrieves targeted waste from pit areas totaling 2 acres)

Relatively moderate risk to remediation SDA), and tred by retrieving, treating (

Very low risk to collocated workers, the public, and the environment

Fully implementable

Fully implementable

Treating Pad A waste would satisfy ARARs, including relevant land disposal requirements Relocating treated waste to the LLW would satisfy ARARs; however:

This action may not be acceptable to DEQ and EPA

- Disposal capacity in the LLW Pit may be limited restart the treatment facility and extend operations beyond 2012 at ICDF
OCVZ system destroys organic vapors

collected from the vadose zon

Transfers some targeted waste elsewhere for potential treatment to satisfy disposal facility aste acceptance criteria

Ex situ grouting removes the characteristic of reactivity from uranium waste retrieved from
Pad A

Higher risk for Alternative 4a (retrieves Pad A waste and targeted waste from pit areas

OCVZ system destroys organic vapors collected from the vadose zon

Transfers waste elsewhere for potential atment to satisfy acceptance criteria

Relatively high risk to remediation workers posed by retrieving all waste, including large objects and remote-handled waste

Administrative action would be required to

\section{Moderate risk to collocated workers,} the public, and the environment

Uncertainty is high, including several issues with respect to retrieval and storage of remote-handled waste and large objects,
posing a large potential for significant delay Could exceed current WIPP disposal capacity, necessitating that Congress modify the WIPP Land Withdrawal Act

Retrieval component of this alternative extends until the year 2037, with WIPP filled to capacity by the year 2034 
Table ES-8. (continued).

Evaluen Citeria

Alternative 1-

Alternative 2-

Alternative 3-

In Situ Grouting Alternative 4-Partial Retrieval, Treatment,
and Disposal $^{\mathrm{b}}$

Alternative 5-Full Retrieval,

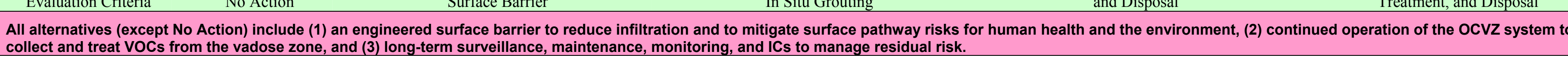

Cost

Current value:

$\$ 57 \mathrm{M}$

Current value:

$2 \mathrm{a}-\$ 344 \mathrm{M}$

urrent value:

Net present value

$\$ 223 \mathrm{M}$

2a-\$176M
Current value:

4a- $\$ 1,071 \mathrm{M}$

$4 \mathrm{~b}-\$ 705 \mathrm{M}$

Net present value:

4a- $\$ 756 \mathrm{M}$
Current value:

$\$ 13,651 \mathrm{M}$

Net present value:

$\$ 8,434 \mathrm{M}$

Modifying Criteria

State acceptance

Community acceptance

$-{ }^{\mathrm{d}}$

d

-

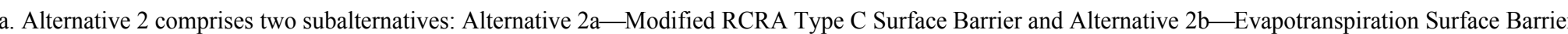

b. Alternative 4 comprises two subalternatives: Alternative $4 a-4$-Acre RTD, and Alternative $4 b-2$-Acre RTD

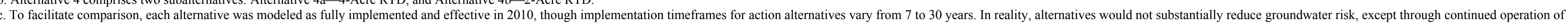

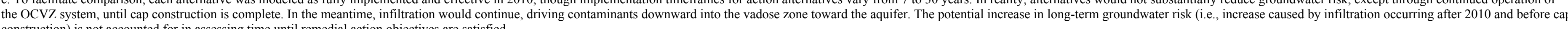

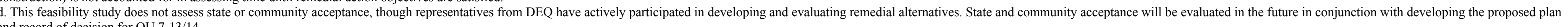

ARAR $=$ applicable or relevant and appropriate requirement

$\mathrm{DEQ}=$ (Idaho) Department of Environmental Quality

IC = institutional contro

CDF = Idaho CERCLA Disposal Facility

$\mathrm{CVZ}=$ Organic $\mathrm{CO}$

RCRA $=$ Resource Conservation and Recovery Act

$\mathrm{RTD}=$ retrieval, treatment, and disposa

VOC $=$ volatile organic compound
WIPP $=$ Waste Isolation Pilot Plant 


\section{ES-6. REFERENCES}

40 CFR 141, 2006, "National Primary Drinking Water Regulations," Code of Federal Regulations, Office of the Federal Register.

40 CFR 300, 2006, "National Oil and Hazardous Substances Pollution Contingency Plan," Code of Federal Regulations, Office of the Federal Register.

40 CFR 300.430, 2006, "Remedial Investigation/Feasibility Study and Selection of Remedy," Code of Federal Regulations, Office of the Federal Register.

42 USC $\S 6901$ et seq., 1976, "Resource Conservation and Recovery Act of 1976 (Solid Waste Disposal Act)," United States Code.

42 USC $\S 9601$ et seq., 1980, "Comprehensive Environmental Response, Compensation and Liability Act of 1980 (CERCLA/Superfund)," United States Code.

DOE O 435.1, 2001, “Radioactive Waste Management," Change 1, U.S. Department of Energy.

DOE-ID, 1991, Federal Facility Agreement and Consent Order for the Idaho National Engineering Laboratory, Administrative Docket No. 1088-06-29-120, U.S. Department of Energy Idaho Operations Office; U.S. Environmental Protection Agency, Region 10; Idaho Department of Environmental Quality.

DOE-ID, 1993, Record of Decision: Declaration for Pit 9 at the Radioactive Waste Management Complex Subsurface Disposal Area at the Idaho National Engineering Laboratory, Administrative Record No. 5569, U.S. Department of Energy Idaho Operations Office; U.S. Environmental Protection Agency, Region 10; Idaho Department of Health and Welfare.

DOE-ID, 1994a, Record of Decision: Declaration for Organic Contamination in the Vadose Zone Operable Unit 7-08, Idaho National Engineering Laboratory, Radioactive Waste Management Complex, Subsurface Disposal Area, Administrative Record No. 5761, U.S. Department of Energy Idaho Operations Office; U.S. Environmental Protection Agency, Region 10; Idaho Department of Health and Welfare.

DOE-ID, 1994b, Record of Decision: Declaration for Pad A at the Radioactive Waste Management Complex Subsurface Disposal Area at the Idaho National Engineering Laboratory, Administrative Record No. 5632, U.S. Department of Energy Idaho Operations Office; U.S. Environmental Protection Agency, Region 10; Idaho Department of Health and Welfare.

DOE-ID, 2004, Action Memorandum for Accelerated Retrieval of a Described Area within Pit 4, DOE/NE-ID-11179, Rev. 0, U.S. Department of Energy Idaho Operations Office.

DOE-ID, 2006, Action Memorandum for the Accelerated Retrieval Project II within Pits 4 and 6 of the Subsurface Disposal Area, DOE/NE-ID-11238, U.S. Department of Energy Idaho Operations Office.

EPA, 1988, Guidance for Conducting Remedial Investigations and Feasibility Studies under CERCLA, Interim Final, EPA/540/G-89-004, OSWER Directive 9355.3-01, U.S. Environmental Protection Agency. 
EPA, 1997, Establishment of Cleanup Levels for CERCLA Sites with Radioactive Contamination, OSWER Directive No. 9200.4-18, U.S. Environmental Protection Agency, Office of Emergency and Remedial Response and Office of Radiation and Indoor Air.

EPA, 1999, A Guide to Preparing Superfund Proposed Plans, Records of Decision, and other Remedy Selection Decision Documents, EPA 540-R-98-031, OSWER 9200.1-23P, U.S. Environmental Protection Agency, Office of Solid Waste and Emergency Response.

Holdren, K. Jean and Barbara J. Broomfield, 2004, Second Addendum to the Work Plan for the OU 7-13/14 Waste Area Group 7 Comprehensive Remedial Investigation/Feasibility Study, DOE/ID-11039, Rev. 0, U.S. Department of Energy Idaho Operations Office.

Holdren, K. Jean, Danny L. Anderson, Bruce H. Becker, Nancy L. Hampton, L. Don Koeppen, Swen O. Magnuson, and A. Jeffrey Sondrup, 2006, Remedial Investigation and Baseline Risk Assessment for Operable Unit 7-13/14, DOE/ID-11241, U.S. Department of Energy Idaho Operations Office.

Public Law 102-579, 1992, “The Waste Isolation Pilot Plant Land Withdrawal Act,” Public Law, 1992. 


\section{ACKNOWLEDGMENTS}

This report embodies years of cooperative effort of many technical and support staff. Without their contributions and commitment to excellence, this work would not have been possible. The authors recognize and express their gratitude to the contributors listed below. Any omissions are accidental. In addition, the authors would like to thank participants from the U.S. Department of Energy, the Idaho Department of Environmental Quality, and the U.S. Environmental Protection Agency, the authors and contributors of the numerous documents cited in this report, and the many reviewers of Waste Area Group 7 products whose comments and insights helped to develop this study.

\begin{tabular}{lll}
\hline \multicolumn{3}{c}{ Technical Contributors } \\
\hline $\begin{array}{l}\text { Danny L. Anderson } \\
\text { Aran T. Armstrong }\end{array}$ & Lancy L. Hampton & M. Doug McKenzie \\
Bruce H. Becker & L. Don Koeppen & Karen A. Taylor \\
Brent N. Burton & Steve L. Lopez & Linda A. Tedrow \\
Kirk M. Green & Swen O. Magnuson & Luke J. White \\
\hline \multicolumn{3}{c}{ Document and Graphic Services Staff } \\
\hline \multicolumn{2}{c}{ Text Processing: Susan M. Harper, Ina M. Moore, Paula Terry } \\
\multicolumn{3}{c}{ Printing: Eric T. English, Terry L. Ferguson } \\
Administrative Record: Joy C. Stuart \\
Draft Editing: Tasha N. Taylor, LauraLee Gourley, Pamela F. Lilburn \\
\multicolumn{3}{c}{ Graphic Design: Jacalyn M. Brower, Stuart C. Hall } \\
\hline \multicolumn{3}{c}{ Waste Area Group 7 Management } \\
\hline \multicolumn{2}{c}{ Frank L. Webber } \\
\hline
\end{tabular}




\section{CONTENTS}

ABSTRACT.

Abstract

EXECUTIVE SUMMARY ES-1

ACKNOWLEDGMENTS

ACRONYMS xiii

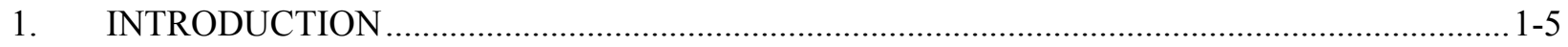

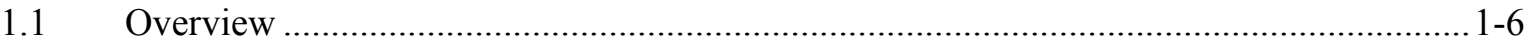

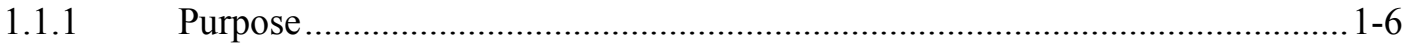

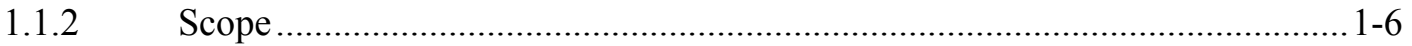

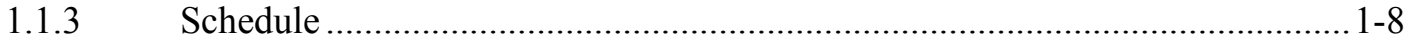

1.1.4 Regulatory Setting ........................................................................... 1-8

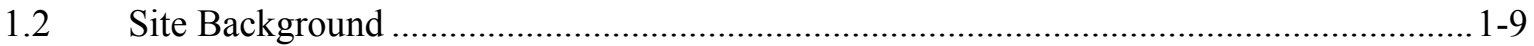

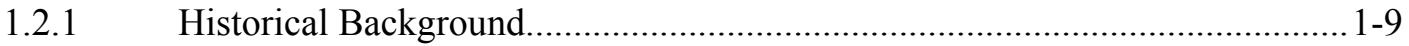

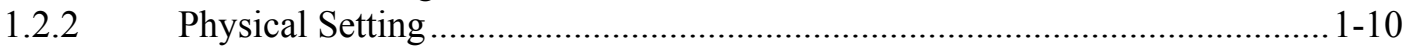

1.2.3 Demography, Flora and Fauna, and Cultural Resources .............................. 1-12

1.2.4 Current and Future Land Use ..................................................................... 1-12

$1.3 \quad$ Nature and Extent of Contamination ..................................................................... 1-13

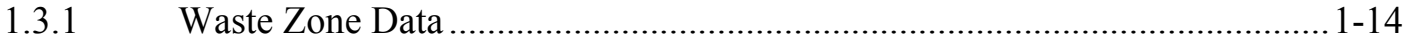

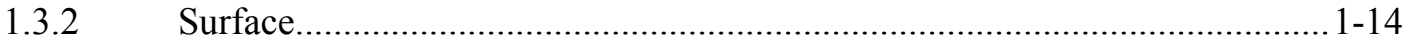

1.3.3 Vadose Zone Soil Moisture, Perched Water, and Vapor ..............................1-15

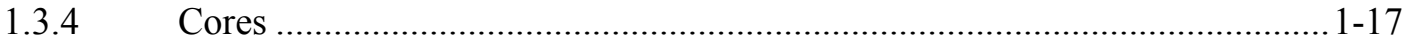

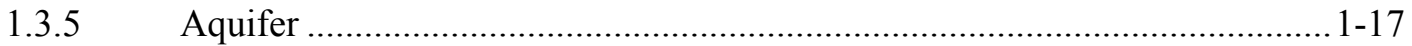

1.3.6 Ecological Contaminants of Potential Concern............................................ 1-20

1.3.7 Nature and Extent of Contamination-Conclusions ...................................... 1-21

$1.4 \quad$ Summary of the Baseline Risk Assessment ............................................................... 1-21

1.4.1 Contaminant Fate and Transport ........................................................... 1-22

1.4.2 Overall Results of the Human Health Baseline Risk Assessment................... 1-27

1.4.3 Ecological Risk Assessment.................................................................. 1-33

1.4.4 Overall Uncertainty in Modeling and Risk Assessment ............................. 1-34

1.4.5 Contaminants of Concern............................................................................. 1-35

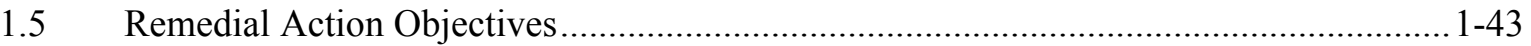

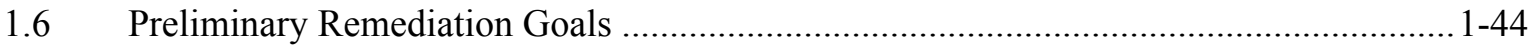

$1.7 \quad$ Assumptions for the Feasibility Study ...................................................................... 1-44

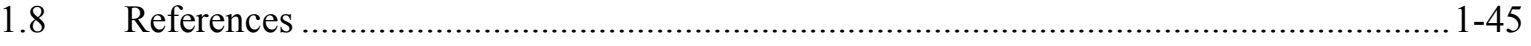




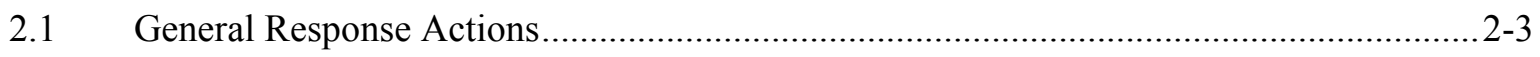

2.2 Identification and Screening of Technology Types and Process Options ........................ 2-4

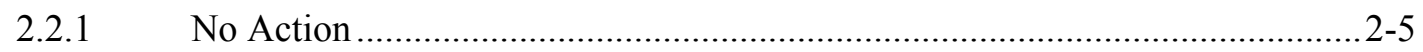

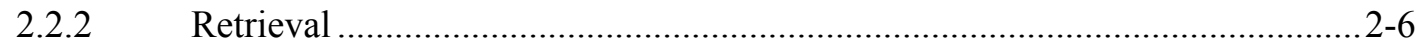

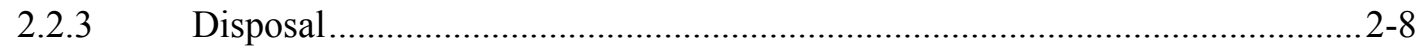

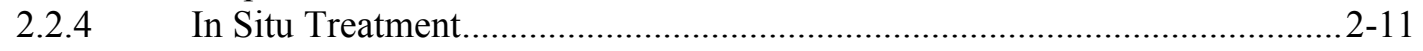

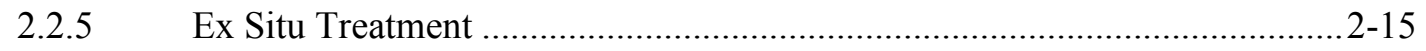

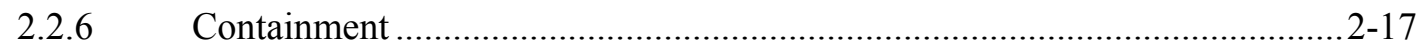

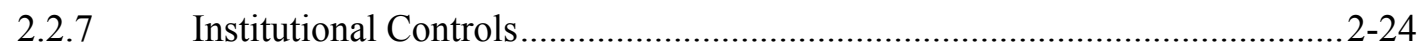

2.2.8 Summary of Representative Process Options ............................................ 2-26

2.2.9 Options for Incorporating Pad A and Removing Near-Surface Volatile Organic Compounds into Alternatives for Operable Unit 7-13/14 ..............2-28

2.2.10 Incorporation of Ongoing Vapor Extraction from the Vadose Zone into Alternatives for Operable Unit 7-13/14 .................................................. 2-29

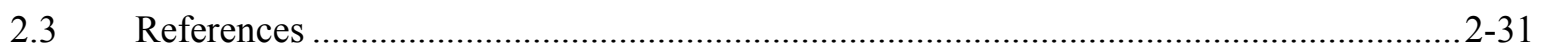

3. DEVELOPMENT OF ALTERNATIVES.............................................................................

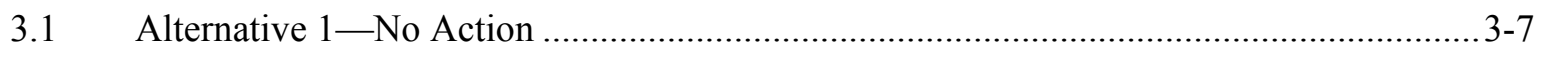

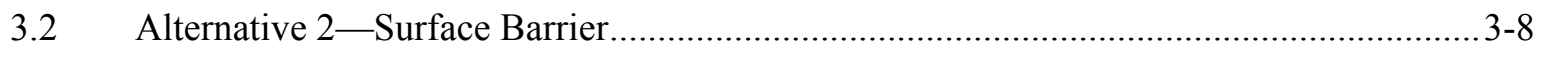

3.2.1 Alternative 2a-Modified RCRA Type C Surface Barrier ............................... 3-8

3.2.2 Alternative 2b-Evapotranspiration Surface Barrier ................................. 3-15

3.3 Alternative 3 - In Situ Grouting ......................................................................... 3-23

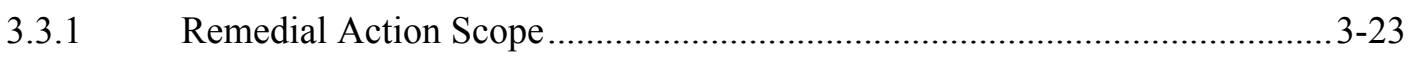

3.3.2 Remedial Action Process …................................................................ 3-24

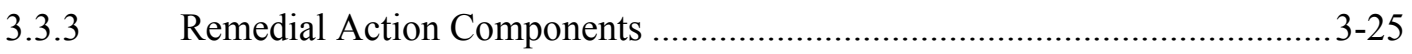

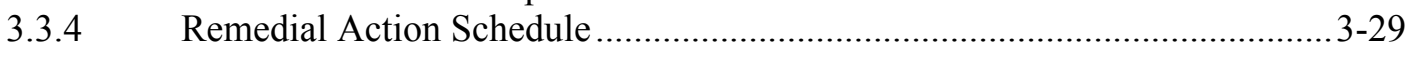

3.4 Alternative 4-Partial Retrieval, Treatment, and Disposal ........................................ 3-31

3.4.1 Alternative 4a-4-Acre Partial Retrieval, Treatment, and Disposal..............3-32

3.4.2 Alternative 4b-2-Acre Partial Retrieval, Treatment, and Disposal.............. 3-42

3.5 Alternative 5-Full Retrieval, Treatment, and Disposal ......................................... 3-48

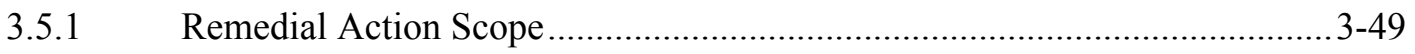

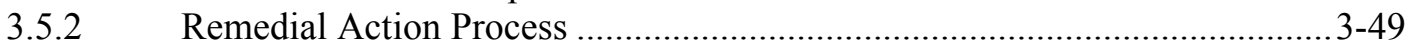

3.5.3 Remedial Action Components ................................................................... 3-50

3.5.4 Remedial Action Schedule ................................................................. $3-55$ 
3.6 Summary of Assembled Alternatives .................................................................... $3-57$

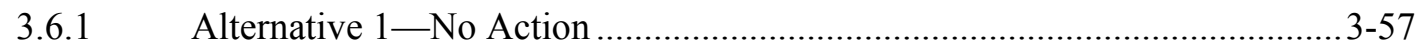

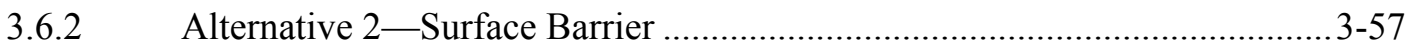

3.6.3 Alternative 3-In Situ Grouting...............................................................59

3.6.4 Alternative 4-Partial Retrieval, Treatment, and Disposal.......................... 3-60

3.6.5 Alternative 5-Full Retrieval, Treatment, and Disposal................................3-61

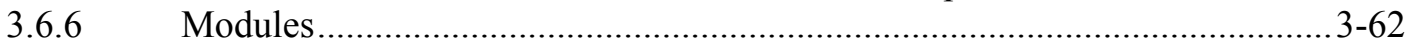

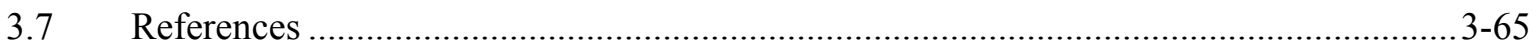

4. DETAILED ANALYSIS OF ASSEMBLED ALTERNATIVES .............................................. $4-5$

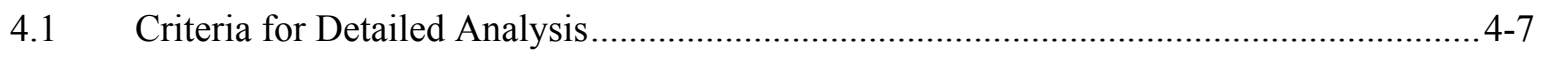

4.1.1 Overall Protection of Human Health and the Environment ............................4-7

4.1.2 Compliance with Applicable or Relevant and Appropriate Requirements ...... 4-7

4.1.3 Long-Term Effectiveness and Permanence.................................................... 4-8

4.1.4 Reduction of Toxicity, Mobility, or Volume through Treatment................... 4-10

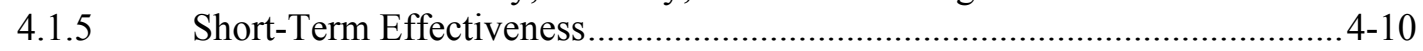

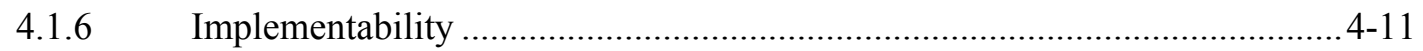

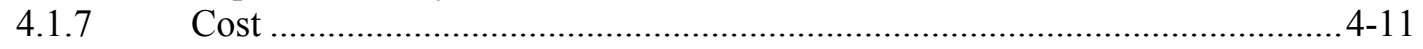

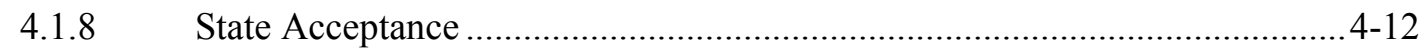

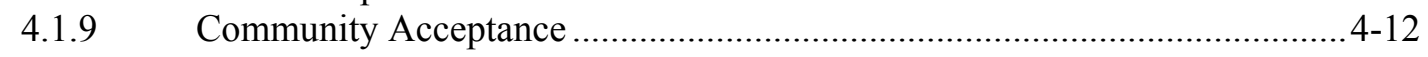

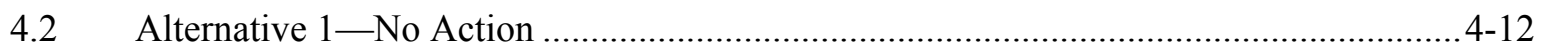

4.2.1 Overall Protection of Human Health and the Environment ..........................4-12

4.2.2 Compliance with Applicable or Relevant and Appropriate Requirements ....4-13

4.2.3 Long-Term Effectiveness and Permanence..................................................4-14

4.2.4 Reduction of Toxicity, Mobility, or Volume through Treatment................... 4-14

4.2.5 Short-Term Effectiveness .....................................................................4-14

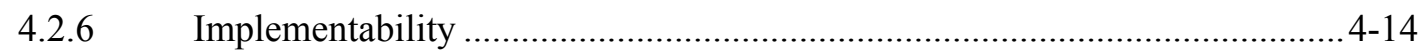

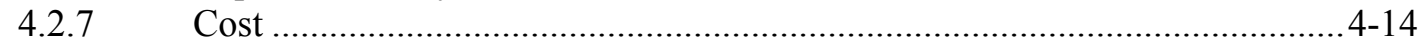

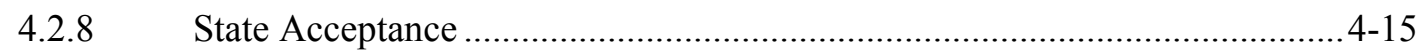

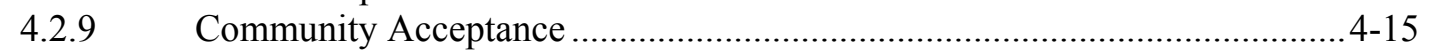

4.3 Alternative 2-Surface Barrier........................................................................... $4-15$

4.3.1 Alternative 2a-Modified Resource Conservation and Recovery Act Type C Surface Barrier ......................................................................4-16

4.3.2 Alternative 2b-Evapotranspiration Surface Barrier ................................... 4-25

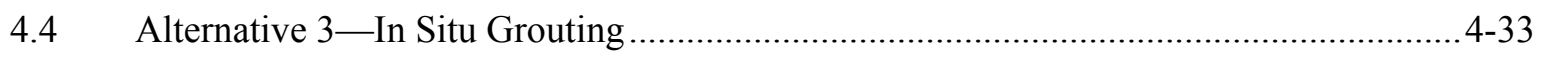

4.4.1 Overall Protection of Human Health and the Environment ...........................4-34

4.4.2 Compliance with Applicable or Relevant and Appropriate Requirements ....4-34

4.4.3 Long-Term Effectiveness and Permanence................................................4-37

4.4.4 Reduction of Toxicity, Mobility, or Volume through Treatment................... 4-40

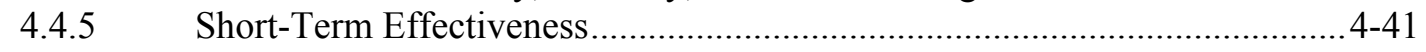

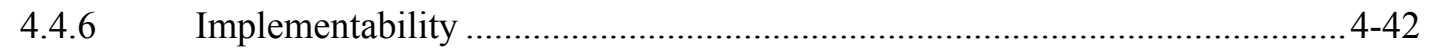


Cost

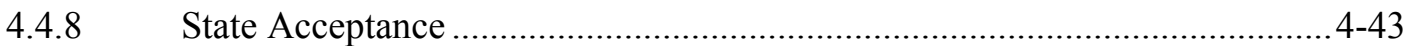

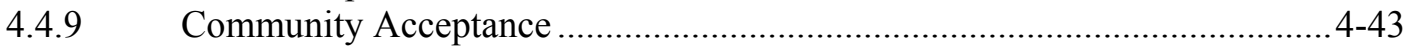

4.5 Alternative 4-Partial Retrieval, Treatment, and Disposal ........................................4-44

4.5.1 Alternative 4a-4-Acre Retrieval, Treatment, and Disposal ........................4-45

4.5.2 Alternative 4b-2-Acre Retrieval, Treatment, and Disposal ......................... 4-54

4.6 Alternative 5-Full Retrieval, Treatment, and Disposal .........................................4-60

4.6.1 Overall Protection of Human Health and the Environment ..........................4-60

4.6.2 Compliance with Applicable or Relevant and Appropriate Requirements ....4-61

4.6.3 Long-Term Effectiveness and Permanence..................................................4-63

4.6.4 Reduction of Toxicity, Mobility, or Volume through Treatment................... 4-66

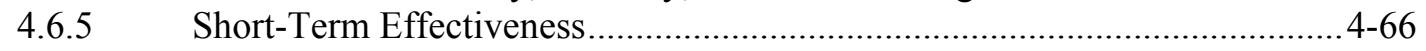

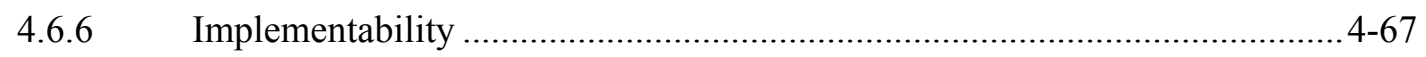

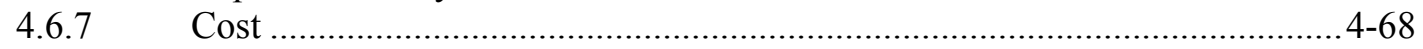

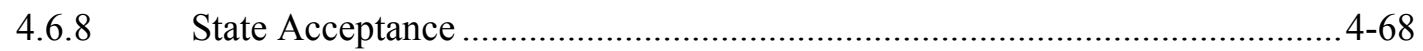

4.6.9 Community Acceptance ….................................................................

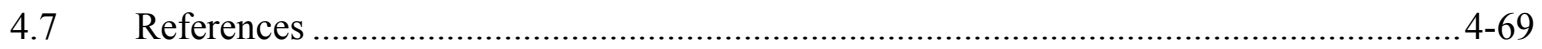

5. COMPARATIVE ANALYSIS OF ALTERNATIVES ........................................................ $5-2$

5.1 Overall Protection of Human Health and the Environment............................................. 5-4

5.2 Compliance with Applicable or Relevant and Appropriate Requirements.......................5-4

5.3 Long-Term Effectiveness and Permanence ............................................................ 5-5

5.3.1 Residual Risks at the Surface .................................................................... $5-5$

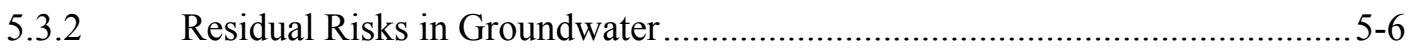

5.3.3 Adequacy and Reliability of Controls ..................................................... $5-9$

5.4 Reduction of Toxicity, Mobility, or Volume through Treatment................................... 5-10

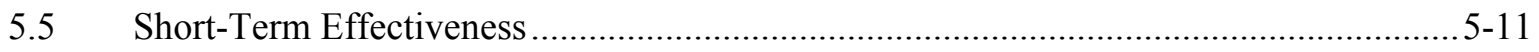

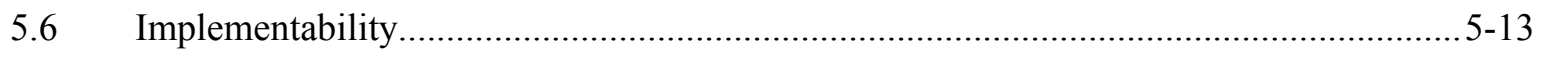

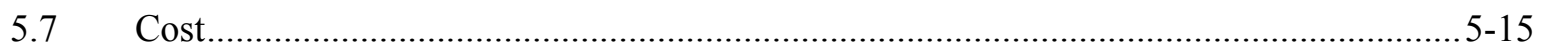

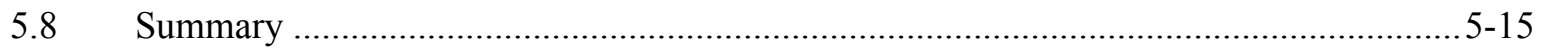

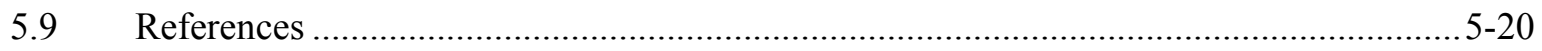

Appendix A—Remedial Technologies Identification and Screening .............................................. A-1

Appendix B —Applicable or Relevant and Appropriate Requirements ............................................. B-1

Appendix C_-Balancing Criteria Detailed Analysis ......................................................................... C-1 


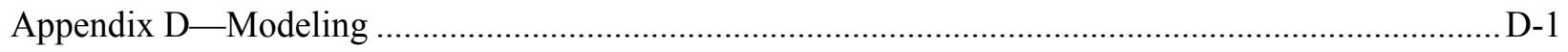

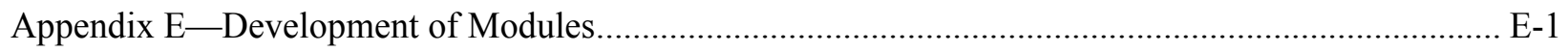

Appendix F-Module Cost Estimates General Information.............................................................

\section{FIGURES}

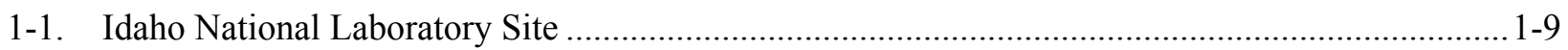

1-2. Radioactive Waste Management Complex........................................................................... 1-11

1-3. Recurring constituents in vadose zone lysimeters .......................................................... 1-15

1-4. Radionuclides detected in core samples between 1971 and 2003 ......................................... 1-18

1-5. Constituents detected in aquifer monitoring wells ............................................................. 1-19

1-6. Eighteen source areas simulated in the source-release model ............................................... 1-23

1-7. Southwest views of base grid (A), first-level refined grid (B), and second-level refined grid (C) beneath the Subsurface Disposal Area showing vertical conformable gridding............. 1-24

1-8. Combined sensitivity results for maximum simulated concentration anywhere in the aquifer for carbon-14, nitrate, and uranium-238 ................................................................ 1-26

1-9. Cumulative risk for the residential exposure scenario for all contaminants of potential

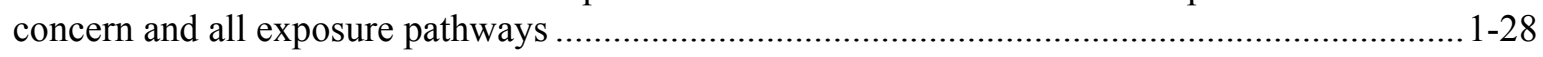

1-10. Cumulative hazard index for the residential exposure scenario ............................................ 1-28

1-11. Total residential exposure scenario risk by exposure pathway for all radionuclides and nonradionuclides

1-12. Major contributors to external exposure risk ................................................................ 1-30

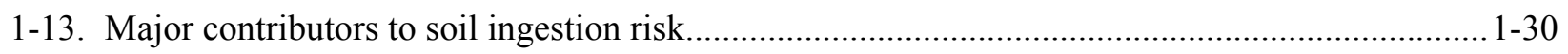

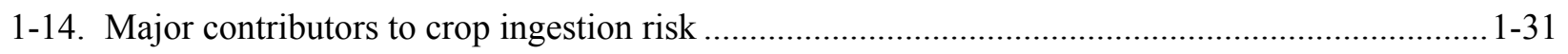

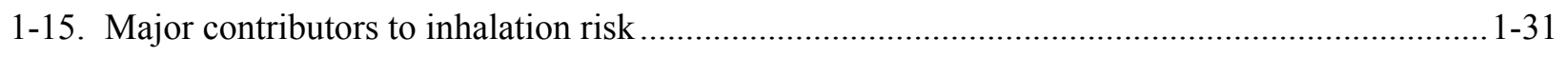

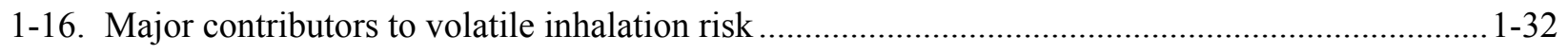

1-17. Major contributors to groundwater ingestion risk ........................................................... 1-32

1-18. Peak cumulative groundwater ingestion risk isopleths for radionuclides for the regional refined grid 


\section{FIGURES (continued)}

1-19. Peak cumulative groundwater ingestion risk isopleths for radionuclides for the aquifer refined grid

1-20. Peak cumulative groundwater ingestion risk isopleths for volatile organic compounds. $1-40$

1-21. Peak cumulative groundwater ingestion hazard index isopleths $1-41$

2-1. Retrieval Enclosure for the Accelerated Retrieval Project.

2-2. Modified excavator at the Accelerated Retrieval Project

2-3. Disposal locations off the Idaho National Laboratory Site

2-4. Cross section of the preconceptual evapotranspiration surface barrier design $2-20$

2-5. Cross section of the modified RCRA Type C surface barrier $2-20$

3-1. Process flow diagram for Alternative 2a-Modified RCRA Type C Surface Barrier $3-10$

3-2. Preconceptual design for Alternative 2a-Modified RCRA Type C Surface Barrier 3-11

3-3. Foundation grouting for Alternative 2a-Modified RCRA Type C Surface Barrier $3-12$

3-4. Summary schedule for Alternative 2a-Modified RCRA Type C Surface Barrier $3-14$

3-5. Process flow diagram for Alternative 2b-Evapotranspiration Surface Barrier $3-16$

3-6. Cross section of surface barrier preconceptual design for Alternative $2 b-$ Evapotranspiration Surface Barrier

3-7. Pad A waste retrieval and Low-Level Waste Pit disposal process for Alternative $2 \mathrm{~b}$ Evapotranspiration Surface Barrier

3-8. Dynamic compaction operation for Alternative $2 b$-Evapotranspiration Surface Barrier

3-9. Summary schedule for Alternative 2b-Evapotranspiration Surface Barrier

3-10. Hypothetical treatment locations for Alternative 3-In Situ Grouting

3-11. Process flow diagram for in situ grouting and containment for Alternative 3In Situ Grouting.

3-12. Rotopercussion grout rig used for Alternative 3-In Situ Grouting

3-13. Remote operation of in situ grouting equipment during the Beryllium Encapsulation Early Actions Project.

3-14. Pad A waste retrieval, ex situ treatment, and Low-Level Waste Pit disposal process for Alternative 3-In Situ Grouting. 


\section{FIGURES (continued)}

3-15. Summary schedule for Alternative 3-In Situ Grouting

3-16. Hypothetical retrieval locations for Alternative 4a-4-Acre Partial Retrieval, Treatment, and Disposal

3-17. Process flow diagram for Alternative 4a-4-Acre Partial Retrieval, Treatment, and Disposal....3-35

3-18. Modifications to the existing Accelerated Retrieval Project Retrieval Enclosure for Alternative 4a-4-Acre Partial Retrieval, Treatment, and Disposal

3-19. Plan view of partial retrieval process for Alternative 4a-4-Acre Partial Retrieval, Treatment, and Disposal.

3-20. Drum packaging system within the Accelerated Retrieval Project

3-21. Waste moved from Pad A to the Idaho CERCLA Disposal Facility for treatment and disposal for Alternative 4a-4-Acre Partial Retrieval, Treatment, and Disposal

3-22. Summary schedule for Alternative 4a - 4-Acre Partial Retrieval, Treatment, and Disposal ........3-41

3-23. Hypothetical retrieval locations for Alternative 4b-2-Acre Partial Retrieval, Treatment, and Disposal

3-24. Process flow diagram for Alternative 4b-2-Acre Partial Retrieval, Treatment, and Disposal....3-45

3-25. Summary schedule for Alternative $4 b$-2-Acre Partial Retrieval, Treatment, and Disposal ........3-47

3-26. Process flow diagram for Alternative 5-Full Retrieval, Treatment, and Disposal

3-27. Preconceptual plan view of full retrieval process and remote-handled storage in the Subsurface Disposal Area for Alternative 5-Full Retrieval, Treatment, and Disposal .....

3-28. Removal of a remote-handled waste drum at the Intermediate-Level Transuranic Storage Facility.

3-29. Pad A waste retrieval and off-Idaho National Laboratory Site disposal process for Alternative 5-Full Retrieval, Treatment, and Disposal

3-30. Cross section of a simplified evapotranspiration surface barrier with no biointrusion and gas vent layer for Alternative 5-Full Retrieval, Treatment, and Disposal

3-31. Summary schedule for Alternative 5-Full Retrieval, Treatment, and Disposal.....

4-1. Cumulative groundwater ingestion risk for Alternative 2a-Modified RCRA Type C Surface Barrier, compared to Alternative $1-$ No Action

4-2. Hazard index for Alternative 2a-Modified RCRA Type C Surface Barrier, compared to Alternative $1-$ No Action 


\section{FIGURES (continued)}

4-3. Cumulative groundwater ingestion risk for Alternative $2 b$-Evapotranspiration Surface

Barrier, compared to Alternative $1-$ No Action

4-4. Hazard index for Alternative 2b-Evapotranspiration Surface Barrier, compared to

Alternative $1-$ No Action

4-5. Cumulative groundwater ingestion risk for Alternative 3-In Situ Grouting, compared to Alternative 1 -No Action and Alternative 2b-Evapotranspiration Surface Barrier

4-6. Hazard index for Alternative 3-In Situ Grouting, compared to Alternative 1-No Action........4-38

4-7. Cumulative groundwater ingestion risk for Alternative 4a-4-Acre Partial Retrieval, Treatment, and Disposal, and Alternative 4b-2-Acre Partial Retrieval, Treatment, and Disposal, compared to Alternative 1-No Action.

4-8. Hazard index for Alternative 4a-4-Acre Partial Retrieval, Treatment, and Disposal, compared to Alternative 1-No Action.

4-9. Cumulative groundwater ingestion risk for Alternative 5-Full Retrieval, Treatment, and Disposal, compared to Alternative 1-No Action.

4-10. Hazard index for Alternative 5-Full Retrieval, Treatment, and Disposal, compared to Alternative $1-$ No Action

5-1. Comparison of long-term effectiveness based on cumulative carcinogenic risk for groundwater ingestion provided by each remedial alternative

5-2. Comparison of long-term effectiveness based on cumulative hazard index for groundwater ingestion provided by each remedial alternative

5-3. Estimated implementation timeframes for each remedial alternative

5-4. Estimated recordable injuries for each action alternative

5-5. Comparison and summary of cost associated with each alternative 


\section{TABLES}

1-1. Primary radionuclide contaminants of concern based on 1,000-year future residential scenario peak risk estimates and estimated peak groundwater concentrations in the absence of remedial action at the Subsurface Disposal Area boundary

1-2. Nonradionuclide contaminants of concern based on 1,000-year future residential scenario peak risk estimates and estimated peak groundwater concentrations in the absence of remedial action at the Subsurface Disposal Area boundary

1-3. Original waste generators and general locations of primary contaminants of concern in the Subsurface Disposal Area.

1-4. Secondary radionuclide contaminants of concern based on 10,000-year future residential scenario groundwater ingestion peak risk estimates and groundwater concentrations $1-43$

2-1. Summary of screening results for the retrieval general response action $2-6$

2-2. Modifications to standard excavation equipment......

2-3. Summary of screening results for the disposal general response action.

2-4. Disposal sites for various waste types

2-5. Summary of screening results for the in situ treatment general response action

2-6. Summary of screening results for the ex situ treatment general response action

2-7. Summary of screening results for the containment general response action......

2-8. General response actions, remedial technologies, and retained process options

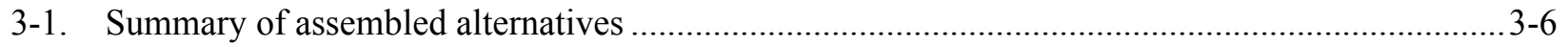

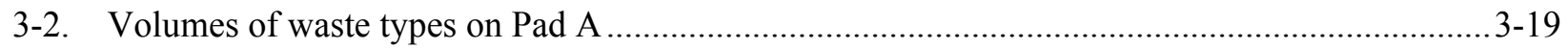

3-3. Summary of five assembled alternatives and major components in each .................................3-58

4-1. Regulatory compliance evaluation for Alternative 1 -No Action ............................................ $4-13$

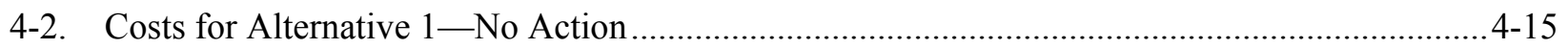

4-3. Regulatory compliance evaluation for Alternative 2a-Modified RCRA Type C Surface Barrier.

4-4. Costs for Alternative 2a-Modified RCRA Type C Surface Barrier.

4-5. Regulatory compliance evaluation for Alternative $2 b$-Evapotranspiration Surface Barrier .......4-26

4-6. Costs for Alternative $2 b$-Evapotranspiration Surface Barrier.

4-7. Regulatory compliance evaluation for Alternative 3-In Situ Grouting. 4-35 


\section{TABLES (continued)}

4-8. Costs for Alternative 3-In Situ Grouting

4-9. Regulatory compliance evaluation for Alternative 4a-4-Acre Partial Retrieval, Treatment,

4-10. Costs for Alternative 4a - 4-Acre Partial Retrieval, Treatment, and Disposal........................... 4-53

4-11. Costs for Alternative 4b-2-Acre Partial Retrieval, Treatment, and Disposal .......................... 4-59

4-12. Regulatory compliance evaluation for Alternative 5-Full Retrieval, Treatment,

4-13. Costs for Alternative 5-Full Retrieval, Treatment, and Disposal...........................................4-69

5-1. Matrix of the five assembled alternatives and major components in each ...............................5-17

5-2. Summary of the comparative analysis of alternatives .......................................................... $5-18$ 


\section{ACRONYMS}

ARAR applicable or relevant and appropriate requirement

CERCLA Comprehensive Environmental Response, Compensation, and Liability Act

COC contaminant of concern

DEQ (Idaho) Department of Environmental Quality

DOE U.S. Department of Energy

EPA U.S. Environmental Protection Agency

ET evapotranspiration

FFA/CO Federal Facility Agreement and Consent Order

HEPA high-efficiency particulate air

IC institutional control

ICDF Idaho CERCLA Disposal Facility

INL Idaho National Laboratory

ISG in situ grouting

LLW low-level waste

MCL maximum contaminant level

OCVZ Organic Contamination in the Vadose Zone

OU operable unit

RCRA Resource Conservation and Recovery Act

RI/BRA Remedial Investigation and Baseline Risk Assessment

RI/FS remedial investigation and feasibility study

ROD record of decision

RTD retrieval, treatment, and disposal

RWMC Radioactive Waste Management Complex

SDA Subsurface Disposal Area

TBC to-be-considered (other information from advisories, criteria, and guidance)

VOC volatile organic compound

WIPP Waste Isolation Pilot Plant 


\section{CONTENTS}

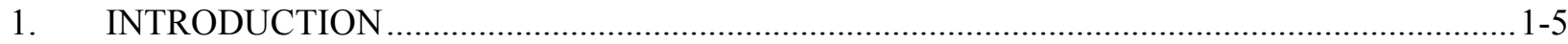

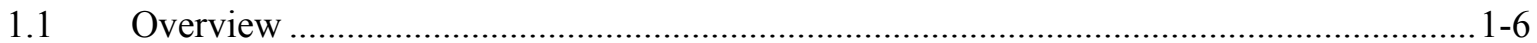

1.1.1 Purpose

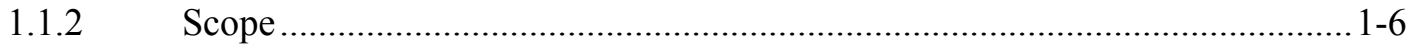

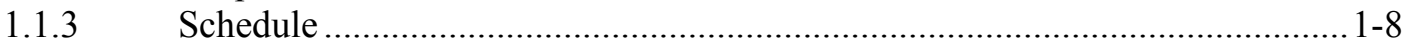

1.1.4 Regulatory Setting................................................................................ $1-8$

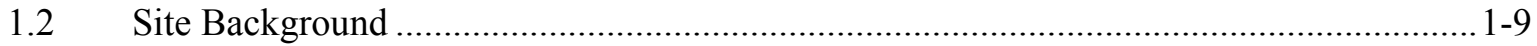

1.2.1 Historical Background...........................................................................1-9

1.2.2 Physical Setting .................................................................................. 1-10

1.2.3 Demography, Flora and Fauna, and Cultural Resources ................................1-12

1.2.4 Current and Future Land Use ..................................................................1-12

$1.3 \quad$ Nature and Extent of Contamination ............................................................................ 1-13

1.3.1 Waste Zone Data ..............................................................................1-14

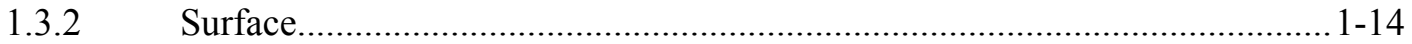

1.3.3 Vadose Zone Soil Moisture, Perched Water, and Vapor ...............................1-15

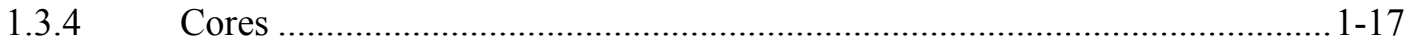

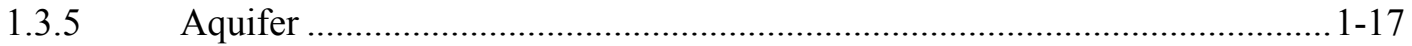

1.3.6 Ecological Contaminants of Potential Concern.............................................. 1-20

1.3.7 Nature and Extent of Contamination-Conclusions ...................................... 1-21

$1.4 \quad$ Summary of the Baseline Risk Assessment …………….........................................1-21

1.4.1 Contaminant Fate and Transport ............................................................... 1-22

1.4.2 Overall Results of the Human Health Baseline Risk Assessment...................1-27

1.4.3 Ecological Risk Assessment.......................................................................1-33

1.4.4 Overall Uncertainty in Modeling and Risk Assessment …………………......1-34

1.4.5 Contaminants of Concern........................................................................... 1-35

$1.5 \quad$ Remedial Action Objectives............................................................................1-43

$1.6 \quad$ Preliminary Remediation Goals ............................................................................. 1-44

$1.7 \quad$ Assumptions for the Feasibility Study....................................................................... 1-44

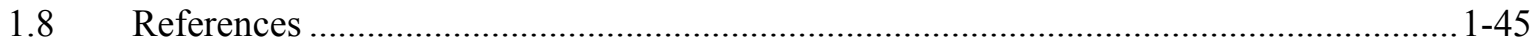




\section{FIGURES}

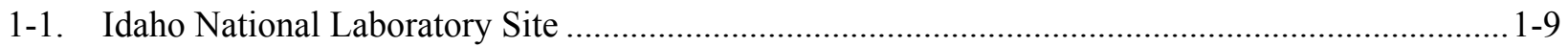

1-2. Radioactive Waste Management Complex......................................................................... 1-11

1-3. Recurring constituents in vadose zone lysimeters ............................................................ 1-15

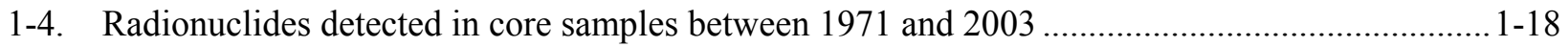

1-5. Constituents detected in aquifer monitoring wells ........................................................... 1-19

1-6. Eighteen source areas simulated in the source-release model .............................................. 1-23

1-7. Southwest views of base grid (A), first-level refined grid (B), and second-level refined grid (C) beneath the Subsurface Disposal Area showing vertical conformable gridding.

1-8. Combined sensitivity results for maximum simulated concentration anywhere in the aquifer for carbon-14, nitrate, and uranium-238

1-9. Cumulative risk for the residential exposure scenario for all contaminants of potential concern and all exposure pathways

1-10. Cumulative hazard index for the residential exposure scenario

1-11. Total residential exposure scenario risk by exposure pathway for all radionuclides and nonradionuclides.

1-12. Major contributors to external exposure risk ................................................................... 1-30

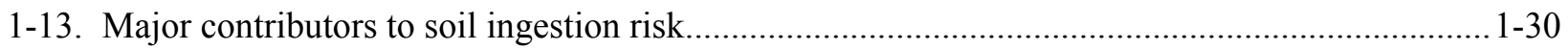

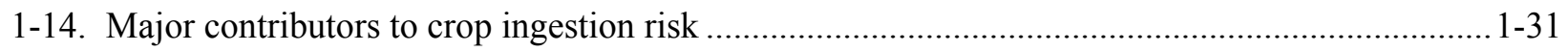

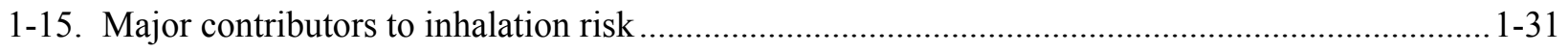

1-16. Major contributors to volatile inhalation risk ................................................................. 1-32

1-17. Major contributors to groundwater ingestion risk ........................................................... 1-32

1-18. Peak cumulative groundwater ingestion risk isopleths for radionuclides for the regional refined grid

1-19. Peak cumulative groundwater ingestion risk isopleths for radionuclides for the aquifer refined grid

1-20. Peak cumulative groundwater ingestion risk isopleths for volatile organic compounds. $1-40$

1-21. Peak cumulative groundwater ingestion hazard index isopleths ...... $1-41$ 


\section{TABLES}

1-1. Primary radionuclide contaminants of concern based on 1,000-year future residential scenario peak risk estimates and estimated peak groundwater concentrations in the absence of remedial action at the Subsurface Disposal Area boundary

1-2. Nonradionuclide contaminants of concern based on 1,000-year future residential scenario peak risk estimates and estimated peak groundwater concentrations in the absence of remedial action at the Subsurface Disposal Area boundary.

1-3. Original waste generators and general locations of primary contaminants of concern in the Subsurface Disposal Area.

1-4. Secondary radionuclide contaminants of concern based on 10,000-year future residential scenario groundwater ingestion peak risk estimates and groundwater concentrations 


\section{Feasibility Study for Operable Unit 7-13/14}

\section{INTRODUCTION}

This feasibility study is the second of two reports comprising the comprehensive remedial investigation and feasibility study (RI/FS) for Operable Unit (OU) 7-13/14 at the Idaho National Laboratory (INL) Site Radioactive Waste Management Complex (RWMC). The first report - the Remedial Investigation and Baseline Risk Assessment (RI/BRA) (Holdren et al. 2006)-estimated risk associated with waste buried in the Subsurface Disposal Area (SDA) at RWMC in the absence of remedial action. The RI/BRA identified human health and environmental risks greater than threshold values. Human health risks are described using three metrics: (1) excess cancer risk, which is the probability of developing a fatal or nonfatal cancer as a result of exposure to carcinogens; (2) hazard index, an indicator of possible noncarcinogenic effects from exposure to toxic substances; (3) and simulated contaminant concentrations in the aquifer that exceed maximum contaminant levels (MCLs). This feasibility study - the second report — develops and evaluates remedial alternatives to address risks identified in the RI/BRA.

Developing this comprehensive feasibility study involves integrating remedies for several characteristics of the SDA (e.g., localized subsidence in pits, abovegrade waste on Pad A, and near-surface volatile organic contaminants [VOCs]) into fully assembled alternatives that address the entire landfill. The Agencies recognized that each specific characteristic can be addressed several ways; thus, many assembled alternatives composed of different combinations are possible. The Agencies optimized feasibility study development by specifying the combinations that would be evaluated as fully assembled alternatives. To maintain flexibility, each of the various components was developed as a discrete module. The Agencies will be able to mix and match various components to select an optimum combination when developing a preferred alternative and finalizing remedial decisions for the SDA. The selected remedy will be a summation of individual modules.

This report is organized as follows:

- $\quad$ Section 1-defines the scope of the feasibility study, summarizes important information from the RI/BRA, presents remedial action objectives and preliminary remediation goals, and lists overarching assumptions

- $\quad$ Section 2-evaluates and screens technologies and process options to establish a range of viable remediation techniques for developing remedial alternatives

- Section 3-compiles remediation techniques into a range of assembled alternatives

- $\quad$ Section 4-evaluates assembled alternatives in detail, based on Comprehensive Environmental Response, Compensation, and Liability Act (CERCLA) (42 USC § 9601 et seq., 1980) criteria

- $\quad$ Section 5-compares relative advantages and disadvantages of assembled alternatives

- $\quad$ Section 6-lists all references cited throughout the report

- $\quad$ Appendix A-tabulates technology and process option screening

- $\quad$ Appendix B-presents preliminary analysis of applicable or relevant and appropriate requirements and other information from advisories, criteria, and guidance to-be-considered 
- $\quad$ Appendix C - tabulates detailed analysis of assembled alternatives based on five balancing criteria specified by CERCLA

- $\quad$ Appendix D-describes modeling to support evaluation of long-term effectiveness of assembled remedial alternatives.

Two additional appendixes are summarized in this report. Complete appendixes are included on the enclosed compact disc:

- $\quad$ Appendix E-describes in detail each of the 20 distinct modules used in the feasibility study to facilitate analysis

- Appendix $\mathbf{F}$-provides details of cost estimates organized in modules.

\subsection{Overview}

This feasibility study is developed to satisfy the purpose, scope, and schedule of the comprehensive RI/FS for OU 7-13/14, as defined within a specific regulatory setting. These requirements are described below.

\subsubsection{Purpose}

The OU 7-13/14 feasibility study, in combination with the RI/BRA (Holdren et al. 2006), provides a basis for risk management decisions for Waste Area Group 7. Risk management decisions will be developed by the U.S. Department of Energy (DOE), the Idaho Department of Environmental Quality (DEQ), and the U.S. Environmental Protection Agency (EPA) — referred to collectively as the Agenciesunder CERCLA and the Federal Facility Agreement and Consent Order (FFA/CO) (DOE-ID 1991).

\subsubsection{Scope}

To fulfill the purpose stated above, primary scope elements of the OU 7-13/14 feasibility study develop and evaluate a range of remedial alternatives that would satisfy remedial action objectives. Remedial action objectives address risks identified in the RI/BRA. Important components of the feasibility study include developing preliminary remediation goals, assembling a range of alternatives, evaluating those alternatives in detail, and comparing their relative advantages and disadvantages based on CERCLA evaluation criteria.

Except for continued operation of the vapor vacuum extraction system, initiated under OU 7-08 to collect VOCs from the vadose zone, scope for OU 7-13/14 focuses on measures that deal directly with the buried waste. Because contaminant migration has not occurred to a substantial extent (except for VOCs), the objective for remedial action at the SDA is source control (i.e., approaches to prevent contaminant migration). The baseline risk assessment and this feasibility study define the source as the buried waste and associated contaminated soil down to the first basalt layer beneath the landfill. The Agencies identified source control, which can include containment, removal, or treatment of selected areas within the source (EPA 1988), to inhibit future releases from buried waste and to prevent further contamination of the environment. The unsaturated region beneath the source is the vadose zone and below that is the aquifer. Source control, combined with continued operation of the OCVZ system, will protect the vadose zone and aquifer. 
One important element of source control is anticipated to be construction of an engineered surface barrier. The Agencies concluded early in the study of the SDA that an engineered surface barrier will be a component of every action alternative evaluated in this feasibility study (Holdren and Broomfield 2004). Coupled with long-term institutional controls (ICs), the surface barrier would preclude inadvertent human intrusion. The surface barrier also would preclude contaminant transport to the surface by plants and animals. Therefore, analysis of long-term effectiveness focuses on groundwater ingestion because an effectively designed surface barrier would satisfy all human health and ecological remedial action objectives at the surface.

Three operable units with existing records of decision (RODs) for Waste Area Group 7 are incorporated into this analysis. The OU 7-13/14 ROD will supersede the previous RODs for OU 7-08, OCVZ (DOE-ID 1994a); and OU 7-12, Pad A (DOE-ID 1994b). The ROD for OU 7-10, the Pit 9 Process Demonstration Interim Action (DOE-ID 1993), will be addressed in future decisions as part of the OU 7-13/14 ROD. Requirements for amendments or explanations of significant difference, if required to address existing RODs in the comprehensive ROD for OU 7-13/14, will be developed in accordance with EPA guidance (EPA 1999). Changes to existing RODs will be presented to stakeholders concurrent with OU 7-13/14 stakeholder involvement activities. The three operable units are addressed as follows:

- Operable Unit 7-08 Organic Contamination in the Vadose Zone (OCVZ) RI/FS (DOE-ID 1994a)-This Feasibility Study for Operable Unit 7-13/14 incorporates continued remediation of organic vapors in the vadose zone through vapor vacuum extraction with treatment. Remediation goals established for OU 7-08 will be replaced with remediation goals in the OU 7-13/14 ROD.

- $\quad$ Operable Unit 7-10 Pit 9 Process Demonstration Interim Action (DOE-ID 1993)-This Feasibility Study for Operable Unit 7-13/14 addresses all waste in Pit 9 along with the waste buried in the remainder of the SDA. The OU 7-10 ROD will be addressed in future decisions as part of the OU 7-13/14 ROD.

- Operable Unit 7-12 Pad A RI/FS (DOE-ID 1994b) - Though a final remedy was implemented for $\mathrm{Pad} \mathrm{A}$ as developed in accordance with CERCLA and the FFA/CO, the OU 7-13/14 RI/BRA included Pad A waste in comprehensive risk estimates. Assembled alternatives in this Feasibility Study for Operable Unit 7-13/14 incorporate several process options for Pad A, ranging from no further action to complete removal.

The Second Addendum to the Work Plan outlined scope for the feasibility study. Except for continued operation of the vapor vacuum extraction with treatment system initiated under OU 7-08 to extract and treat VOCs from the vadose zone, the scope of actions evaluated in the feasibility study is limited to measures that deal directly with buried waste (i.e., alternatives for remediation of the vadose zone and the aquifer are not evaluated). Agencies identified source control as the only reasonable strategy for the SDA because current contaminant concentrations in the vadose zone and aquifer do not jeopardize human health and the environment. However, unmitigated release of contaminants from waste buried in the SDA could generate concentrations in the future that pose risk greater than threshold values (i.e., risk greater than $10^{-6}$ to $10^{-4}$, hazard index greater than or equal to 1 , and simulated groundwater concentrations that exceed MCLs). Once released in significant quantities, these contaminants would be extremely difficult to remediate. Therefore, source control in the near term would prevent potential future risks from developing. Based on the conclusion that source control will protect human health and the environment, remediation of the vadose zone and aquifer are not evaluated, other than continued operation of the OCVZ system. 
The following RWMC facilities, outside the SDA, also are excluded:

- $\quad$ Operable Unit 7-09-No further action is warranted for potential sources within the Transuranic Storage Area (e.g., contaminated soil identified in the FFA/CO as OU 7-09, focusing on potential historical releases from storage Pads 1, 2, 3, R, and the Intermediate Level Transuranic Storage Facility). Resource Conservation and Recovery Act (RCRA) (42 USC $§ 6901$ et seq., 1976) closure of the Intermediate-Level Transuranic Storage Facility has been approved by DEQ, and final decommissioning will be completed as CERCLA non-time-critical removal actions under general decommissioning activities for Idaho Cleanup Project (DOE-ID 2006b). Advanced Mixed Waste Treatment Project facilities will be deactivated, decontaminated, decommissioned, and also closed in accordance with RCRA standards.

- $\quad$ Operable Unit 7-11-Septic tanks at RWMC were evaluated in a Track 1 investigation. The DOE, DEQ, and EPA concluded that RWMC septic tanks are not sources of potential contamination or risk and signed a No Action Determination in 1993 (INEL 1993).

- $\quad$ All other collocated facilities-Sebo and Whittaker (2005) concluded that all collocated facilities and processes are operated under appropriate controls and procedures to manage possible events.

\subsubsection{Schedule}

The draft Feasibility Study for Operable Unit 7-13/14 is a primary document under the FFA/CO, with an enforceable schedule of December 2006.

\subsubsection{Regulatory Setting}

Federal statutes, agreements, and enforceable deadlines govern CERCLA assessments of the INL Site and are the legal basis for remedial decisions. The INL Site was added to the National Priorities List of Superfund Sites (54 FR 48184, 1989) under CERCLA. The FFA/CO (DOE-ID 1991) — a binding agreement between the DOE, DEQ, and EPA — established the procedural framework for identifying appropriate actions that must be implemented to protect human health and the environment, in accordance with the "National Oil and Hazardous Substances Pollution Contingency Plan" (40 CFR 300), CERCLA, RCRA, and the Idaho Hazardous Waste Management Act (Idaho Code § 39-4401 et seq., 1983).

The Action Plan attached to the FFA/CO includes the original schedule for developing, prioritizing, implementing, and monitoring response actions. The FFA/CO Action Plan provides for remediating RWMC under the designation of Waste Area Group 7. For management purposes, the FFA/CO divided the INL Site into 10 waste area groups. Waste Area Group 7, comprising RWMC, is located in the southwestern quadrant of the INL Site (see Figure 1-1). The FFA/CO Action Plan further divided Waste Area Group 7 into numerous operable units. Currently, overall remediation of the SDA within RWMC is being evaluated through a comprehensive CERCLA RI/FS under combined OU 7-13/14.

The comprehensive RI/FS for Waste Area Group 7 is identified as OU 7-13/14 in the FFA/CO. The FFA/CO is a binding agreement between the DOE, DEQ, and EPA. The FFA/CO provides the framework for CERCLA response actions at the INL Site.

In accordance with the decision-making process patterned after CERCLA in the FFA/CO, a proposed plan and ROD will follow the final feasibility study. Subsequent remedial actions will be implemented as specified in the OU 7-13/14 ROD and managed under the 5-year review process. 


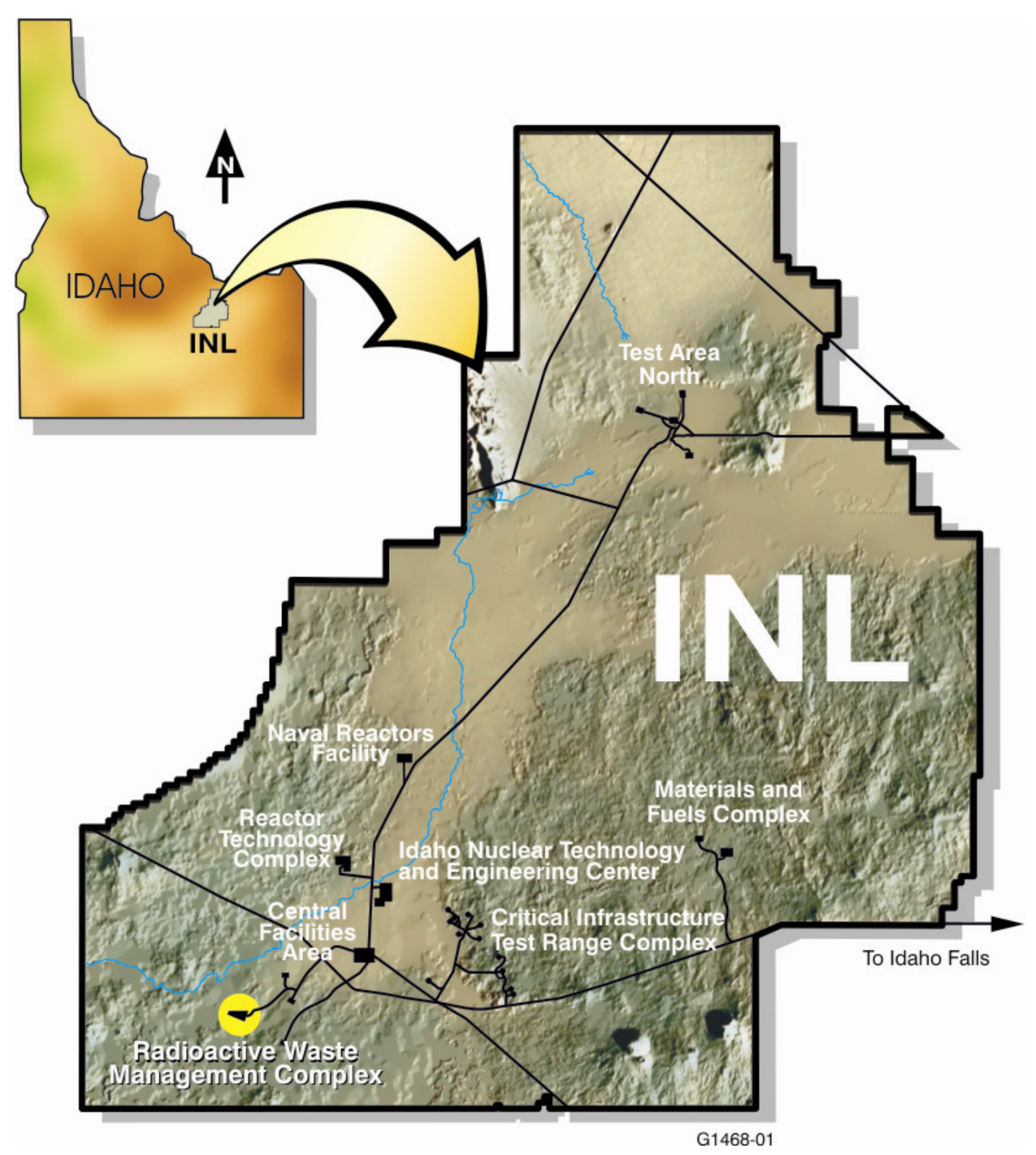

Figure 1-1. Idaho National Laboratory Site.

\subsection{Site Background}

The following subsections describe characteristics of the INL Site and RWMC. Included are the historical background, physical setting (e.g., meteorology, geology, and hydrology), and other important elements (e.g., flora and fauna, demography, land use, and cultural resources) that must be considered when remedial actions for the SDA are evaluated.

\subsubsection{Historical Background}

The INL Site, originally established in 1949, is a DOE-managed reservation that historically has been devoted to energy research and related activities. In mid-2003, the laboratory was restructured into two separate business units: one for laboratory research and development missions (i.e., INL) and one for 
cleanup activities (i.e., Idaho Cleanup Project). In February 2005, two separate contractors assumed management of the two business units. This separation allows each organization to focus on its distinct mission: (a) the INL primary mission as the lead laboratory for U.S. nuclear energy research and (b) the Idaho Cleanup Project mission to remediate the environment and clean up historical contamination at the INL Site as quickly and efficiently as possible (Litus and Shea 2005).

Four federal government contractors operate facilities at the INL Site. Bechtel Bettis operates the Naval Reactors Facility; Bechtel BWXT Idaho, LLC, manages the Advanced Mixed Waste Treatment Project; CH2M-WG, Idaho, LLC, manages the Idaho Cleanup Project; and Battelle Energy Alliance manages national laboratory functions and operates INL Site services. These contractors conduct various programs at the INL Site under the supervision of two DOE offices: the U.S. Department of Energy Idaho Operations Office and the DOE-Pittsburgh Naval Reactors Office. The U.S. Department of Energy Idaho Operations Office authorizes all government contractors to operate at the INL Site.

\subsubsection{Physical Setting}

The INL Site is located in southeastern Idaho (see Figure 1-1) and occupies 2,305 $\mathrm{km}^{2}\left(890 \mathrm{mi}^{2}\right)$ in the northeastern region of the Snake River Plain. Regionally, the INL Site is nearest the cities of Idaho Falls and Pocatello and U.S. Interstate Highways I-15 and I-86. The INL Site extends nearly $63 \mathrm{~km}$ (39 $\mathrm{mi})$ from north to south, is about $58 \mathrm{~km}(36 \mathrm{mi})$ wide at its broadest southern portion, and occupies parts of five southeastern Idaho counties.

The RWMC covers 72 ha (177 acres) (see Figure 1-2), including the operations and administration area (approximately 9 ha [22 acres]), the SDA (39 ha [97 acres]), and the Transuranic Storage Area (23 ha [58 acres]). Burial of radioactive waste in the SDA has resulted from building and operating a wide variety of reactor types at the INL Site and from accepting - for disposal-radioactive and hazardous waste from outside facilities (primarily from the Rocky Flats Plant).

Local elevations across RWMC range from a low of 1,517.3 m (4,978 ft) to a high of 1,544.7 m $(5,068 \mathrm{ft})$. Typically, soil in this southern portion of the INL Site is shallow and consists of fine-grained eolian soil deposits with some fluvial gravels and gravelly sand. Occasional pockets of thicker sediment layers form in depressions. Soil in the RWMC area was formed from several types of soil-genesis cycles, including deposition of loess, leaching of calcium carbonate, accumulation of clay, and erosion. The RWMC lies within a natural topographic depression that is associated with the fluvial systems of the Big Lost River and the Big Southern Butte. Some RWMC soil may be derived from historical stream deposits from the Big Lost River; however, evidence of erosion by these systems during the last 10,000 years is not evident. The RWMC is hydrologically isolated from surface water in the Big Lost River. Though three floods have occurred at the RWMC since disposal operations began, these floods were caused by local runoff generated by snowmelt. Flooding is now prevented by a containment dike around the landfill.

Undisturbed surficial deposits within the RWMC area range in thickness from 0.6 to $7.0 \mathrm{~m}$ ( 2 to $23 \mathrm{ft}$ ) (Anderson, Liszewski, and Ackerman 1996). Irregularities in soil thickness generally reflect the undulating surface of underlying basalt flows. Many physical features are common within the soil stratigraphy of the RWMC area (e.g., pebble layers, freeze-thaw textures, glacial loess deposits, and platy caliche horizons). Surface soil at RWMC has been significantly disturbed and contoured, and additional backfill - in several cases, sediment from the spreading areas - has been added to control subsidence and runoff. RWMC also has been contoured on many occasions to accommodate waste management operations and to implement remedial actions. 


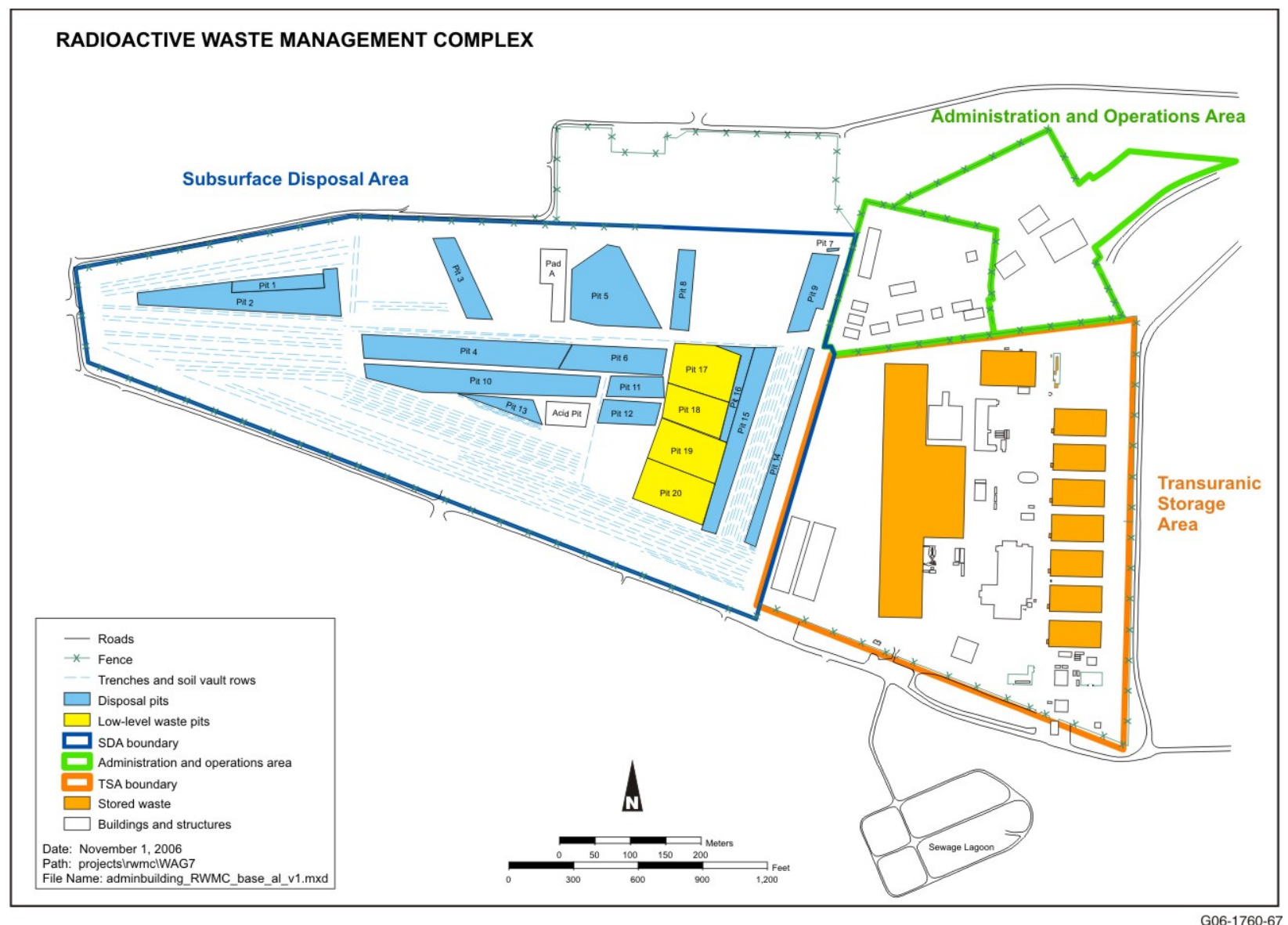

Figure 1-2. Radioactive Waste Management Complex.

The INL Site region is classified as arid to semiarid because of low average rainfall of $22.1 \mathrm{~cm} /$ year ( $8.7 \mathrm{in}$./year). The RWMC has no permanent surface water features; however, the local depression tends to hold precipitation and to collect additional runoff from surrounding slopes. Surface water from episodes of rain or snowmelt eventually either evaporates or infiltrates into the vadose zone (i.e., unsaturated subsurface) and the underlying aquifer (Holdren et al. 2002). Below the shallow surficial sediment is a thick sequence of basalt flows intercalated with thin sedimentary interbeds. The regional subsurface consists mostly of these layered basalt flows with a few comparatively thin layers of sedimentary interbeds. Interbeds tend to retard downward water migration to the aquifer and are important features in assessing the fate and transport of contaminants. Because subsurface formations are unsaturated most of the year, they are characterized as a vadose zone; however, ephemeral lenses of perched water have been detected in association with interbeds.

The Snake River Plain Aquifer underlies RWMC at an approximate depth of $177 \mathrm{~m}(580 \mathrm{ft})$ and flows generally from northeast to southwest. The aquifer is bounded on the north and south by the edge of the Snake River Plain, on the west by surface discharge into the Snake River between King Hill and Twin Falls, Idaho, and on the northeast by the Yellowstone basin. The aquifer consists of a series of water-saturated basalt layers and sediment. Local perturbations and seemingly anomalous behavior are observed for water levels in the RWMC area. Pump-test results from RWMC area wells show that a region of low permeability is present south and southwest of the RWMC area (Wylie and Hubbell 1994; Wylie 1996). 


\subsubsection{Demography, Flora and Fauna, and Cultural Resources}

Populations potentially affected by INL Site or RWMC activities primarily are composed of workers, ranchers, people in neighboring communities, and members of the Shoshone-Bannock Tribes. Approximately 8,000 people currently work at INL Site facilities, though only a fraction of this population visits RWMC (Litus and Shea 2005). Ranchers graze livestock in areas on or near the INL Site; approximately $60 \%$ of the INL Site is used for grazing. Residential populations live in neighboring communities comprising the five Idaho counties bordering the INL Site; populations are sparse, ranging from 15 to 62 residents per square mile. No permanent residents live within the boundaries of the INL Site. Members of the Shoshone-Bannock Tribes are allowed access to areas of cultural and religious significance.

Undeveloped land and restricted access to the INL Site provide and protect important habitats for plants and animals. Large numbers of migratory birds of prey and mammals are funneled onto the INL Site because of its location at the mouth of several mountain valleys. The INL Site was designated as a National Environmental Research Park in 1975 (Bowman et al. 1984), and the Sagebrush-Steppe Ecosystem Reserve was created in 1999, comprising 29,947 ha (74,000 acres) of unique habitat in the northwestern portion of the INL Site. Nearly all avian, reptile, and mammalian species found across the INL Site also can be found at RWMC and are supported by various vegetation communities. Larger mammals (e.g., coyotes and pronghorn) are occasionally seen on facility grounds. No ecologically sensitive areas (i.e., areas of critical habitat) have been identified within RWMC.

All four major types of INL Site cultural resources (i.e., archaeological sites, contemporary Native American cultural resources, historic architectural properties, and paleontological sites) have been identified in the RWMC area. Ten major archaeological survey projects identified an inventory of 13 potentially significant prehistoric sites within a $200-\mathrm{m}$ (656-ft)-wide zone surrounding the fenced perimeter of RWMC and more than 80 additional archaeological resources in the surrounding area. Paleontological remains have been identified in excavations within the facility. Shoshone-Bannock tribal members are consulted about additional resources of Native American concern. In addition, as a result of architectural surveys of 55 buildings administered by DOE within the developed portion of RWMC, three buildings have been identified as potentially eligible for nomination to the National Register of Historic Places.

\subsubsection{Current and Future Land Use}

Land within the INL Site is administered by DOE and is classified by the U.S. Bureau of Land Management as industrial and mixed-use acreage. Approximately $98 \%$ of land on the INL Site is open and undeveloped. Large tracts of land are reserved as buffer and safety zones around the boundary of the INL Site, while portions within the central area are reserved for INL Site operations. Remaining land within the reservation core is largely undeveloped and is used for environmental research and to preserve ecological and cultural resources. Grazing and controlled hunting are permitted. The INL Site is crossed by several highways, a rail system, and a high-voltage power distribution loop. Most work takes place within the primary facility areas (Litus and Shea 2005). Future land use (and aquifer use) is expected to remain essentially the same as current use - a research facility within INL Site boundaries, with agriculture and undeveloped land surrounding the INL Site. 


\subsection{Nature and Extent of Contamination}

The RI/BRA evaluated the nature and extent of contamination for all environmental media associated with the SDA, as summarized below. Section 4 of the RI/BRA report (Holdren et al. 2006) provides further details, and updates are available in the most recent annual monitoring report (Koeppen et al. 2006).

Tens of thousands of samples have been collected near RWMC over the past 3 decades, and more than 100,000 analyses have been performed. The RI/BRA assessed monitoring data to identify distributions of contaminants of potential concern associated with the SDA. Monitoring at RWMC has been conducted over time under a variety of programs and with differing objectives. Though locations for monitoring capabilities (e.g., aquifer monitoring wells, vadose zone lysimeters, and waste zone probes) were chosen based on individual program objectives, the common goal of all programs in choosing locations was to maximize the likelihood of detecting contamination. In other words, the monitoring network at RWMC has grown over time and provides data that are not statistically representative of environmental media. Despite the bias toward detection, detections are generally sparse and sporadic, typically near detection levels, and with only a few trends limited to only a few specific locations in the shallow vadose zone. Migration is very limited, with no imminent threat to the aquifer except for carbon tetrachloride, a VOC associated with Rocky Flats Plant weapons-production waste.

Analytical data associated with contaminants of potential concern at RWMC were compiled and evaluated, encompassing analytical data from 1971 to 2004 and including results obtained by DOE, U.S. Geological Survey, and various INL Site contractors. Detected concentrations are interpreted by assessing them against comparison values. For concentrations in solid media (i.e., soil, core material, and solids filtered from samples), risk-based concentrations for soil are used. For water (i.e., soil moisture, perched water, and aquifer samples), MCLs established by EPA are used. Risk-based concentrations and MCLs provide a scale for interpreting significance of detected concentrations. In addition to soil risk-based concentrations and groundwater MCLs, background concentrations for soil and water provide information useful for evaluating constituents that occur naturally in the environment (e.g., nitrate and uranium isotopes) and for estimating detection frequencies.

Data for assessing the nature and extent of contamination for each contaminant of potential concern are organized as follows:

- Waste zone-Data sources for the waste zone are historical shipment and disposal records (e.g., constituent inventories, physical characteristics of the waste, and waste packaging) and a limited probe network equipped with vapor ports, lysimeters, and tensiometers in several focus areas.

- $\quad$ Surface-Samples of surface soil (typically the top $15 \mathrm{~cm} \mathrm{[6} \mathrm{in.]),} \mathrm{vegetation,} \mathrm{and} \mathrm{run-off} \mathrm{water}$ collected outside the buried waste, but within the interval of shallow surficial sediments (i.e., the region down to the first basalt interface), provide data for the surface interval.

- Vadose zone-Vadose zone samples have been collected from lysimeters and perched water wells up to four times a year since 1997. (The U.S. Geological Survey has regularly collected perched water samples from Well USGS-92 since 1972.) Because of small sample volumes, analysis is conducted in accordance with a predetermined analyte priority. Soil vapor samples also are collected routinely and analyzed primarily for VOCs. 
- Cores-Cores are obtained when wells are drilled, and samples of interbed sediments are collected and analyzed for contaminant concentrations and physical characteristics.

- $\quad$ Aquifer-Samples have been collected from the aquifer by INL Site and U.S. Geological Survey programs since 1972. In 2004, monitoring frequency was reduced from quarterly to semiannually. Typically, a suite of radionuclides and chemicals are comprehensively analyzed.

Monitoring data indicate that some contaminants of potential concern occur in low concentrations in the vadose zone and aquifer and are likely to be attributable to waste buried in the SDA. Volatile organic compounds, particularly carbon tetrachloride, are the only widespread contaminants in the environment. The following subsections summarize the nature and extent of contamination for these intervals.

\subsubsection{Waste Zone Data}

Focus areas for monitoring within the waste zone were carefully selected to maximize the probability of detecting high concentrations of targeted analytes. More than 300 probes have been installed in the SDA since 1998. Most probing was directed at areas containing waste from the Rocky Flats Plant, though some of the probes targeted waste generated by INL Site operations. Sites for probing were based primarily on historical disposal records. Concentrations detected in these focus areas are high for analytes targeted by the probing, thus corroborating disposal records and demonstrating success in choosing locations for waste zone monitoring. The most frequently detected analytes, in order of detection frequency, are VOCs, plutonium isotopes, Am-241, and uranium isotopes.

In general, constituent profiles and ratios confirm successful penetration of waste types targeted in each focus area. For example, organic compounds and radionuclides detected in the Depleted Uranium Focus Area in 2004 were compared to waste-disposal inventories in this area, and good correlation was noted. Analytical indicators (e.g., plutonium isotope activity ratios and ratios of various organic compounds) indicate that areas expected to contain waste from the Rocky Flats Plant are primarily composed of weapons-manufacturing waste.

\subsubsection{Surface}

Hundreds of surface soil, vegetation, and run-off water samples have been collected and analyzed for numerous analytes over the past 10 years. Most constituents at RWMC are measured at concentrations near surficial soil background levels, and none have exceeded soil risk-based concentrations. Of the contaminants of potential concern, $\mathrm{Pu}-239 / 240$ and Am-241 are most frequently detected in surface soil samples (i.e., within the top $15 \mathrm{~cm}$ [6 in.]) inside and outside the SDA, at detection rates of about 22 and $21 \%$, respectively. The high number of $\mathrm{Pu}-239 / 240$ detections compared to $\mathrm{Pu}-238$ suggests the plutonium is either from weapons-manufacturing waste in the SDA or from fallout. Americium-241 and $\mathrm{Pu}-239 / 240$ concentrations generally are low; however, the presence of these contaminants at detectable levels in the surface environment around the RWMC area emphasizes the importance of following radiological control procedures to minimize cross contamination when drilling and installing new monitoring wells and collecting samples. Surface contamination outside the SDA also substantiates the likely origin of $\mathrm{Pu}-239 / 240$ detected during aquifer well drilling, installation, and sampling in the early 1970s. Detections in samples of vegetation and run-off water were few, and their contributions to the assessment of $\mathrm{Pu}-239$ concentrations were insignificant. 


\subsubsection{Vadose Zone Soil Moisture, Perched Water, and Vapor}

Various radionuclides and chemicals are detected in the vadose zone. Except for VOCs, most constituents are detected only sporadically and have no associated temporal or spatial trends. A few constituents are consistently detected in the vadose zone (see Figure 1-3), exhibit concentration trends, and show evidence of migration. Vadose zone constituents that have been identified as contaminants of potential concern, in order of their detection frequency from highest to lowest, are VOCs, uranium isotopes, C-14, nitrate, and Tc-99. The following subsections summarize these constituents.

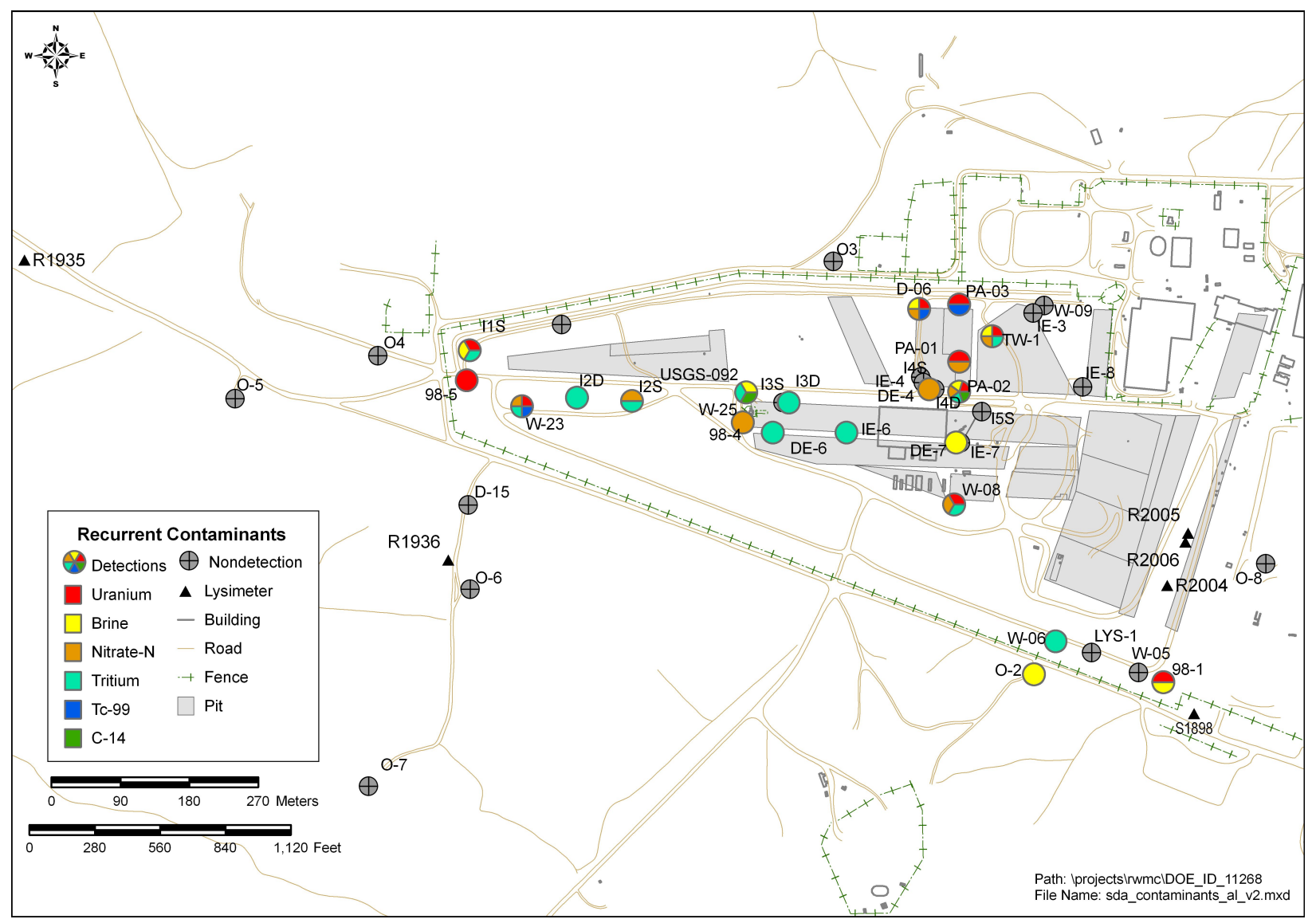

Figure 1-3. Recurring constituents in vadose zone lysimeters.

1.3.3.1 Volatile Organic Compounds. Carbon tetrachloride, tetrachloroethylene, and trichloroethylene are consistently detected in perched water and lysimeter samples. Each has been detected above MCLs in perched water samples and in shallow, intermediate, and deep lysimeter samples. Methylene chloride is detected less frequently and at lower concentrations. Methylene chloride has been detected above the MCL in shallow lysimeter and perched water samples, but has not been detected in any intermediate or deep lysimeter samples.

1.3.3.2 Uranium Isotopes. Uranium concentrations, determined by alpha-spectrometry, are regularly detected in pore water, collected from the vadose zone beneath the SDA (Koeppen et al. 2006). Elevated uranium concentrations could result from contaminant migration from uranium-containing waste or from mobilization of uranium from minerals native to the Snake River Plain. Elevated uranium concentrations are regularly detected in the vadose zone near Pad A (e.g., PA01:L15), Pit 5 (e.g., TW1:DL04), the western end of the SDA (e.g., W23:L07), the Acid Pit (e.g., W13:L29), and the 
western end of Pits 4 and 10 (e.g., IE6:DL34) and are probably indicative of migration from buried waste. Whether from waste or from native minerals, uranium is subject to perturbation of local geochemical conditions (e.g., elevated nitrate or $\mathrm{CO}_{2}$ concentrations). Evaluating isotopic activity ratios (i.e., U-238:U-235 and U-234:U-238) has proven of limited utility for identifying the source of detected uranium. Isotopic activity ratios for most samples are not significantly different from those found in local groundwater (Koeppen et al. 2006). Case-by-case evaluation of four lysimeter samples with elevated uranium concentrations using mass spectrometry confirmed ratios consistent with an anthropogenic source in only one location, TW-1:DL04 (Koeppen et al. 2006; Roback et al. 2001). Uranium ratios for all other locations tested to date exhibit isotope abundances characteristic of natural uranium. Therefore, uranium concentrations significantly greater than upper background concentration limits (e.g., IE6:DL34) are identified as indicators of probable migration from buried waste, regardless of observed isotopic activity ratios.

1.3.3.3 Nitrate. Nitrate concentrations at many monitoring locations are above the local soil-moisture upper background range; however, because of background variability, only five monitoring locations have concentrations high enough above the upper background range to confidently declare that nitrate is likely from anthropogenic sources (i.e., Wells D15, I2S, W08, W25, and 98-4). The high nitrate concentrations are predominantly found in shallow and intermediate-depth intervals. Concentration trends are evident at monitoring Lysimeters I2S, PA02, and W25, which are located by Pad A and in the western part of the SDA, at depths around 30.5, 2.7, and $4.9 \mathrm{~m}$ (100, 9, and $16 \mathrm{ft})$, respectively (see Figure 1-3). Nitrate measured at Lysimeter PA02, by Pad A, appears to be migrating downward because concentrations at Well I4S, about $30.5 \mathrm{~m}(100 \mathrm{ft})$ below Pad A, have started increasing.

1.3.3.4 Technetium-99. Technetium-99 is consistently detected at depths of $27 \mathrm{~m}(88 \mathrm{ft})$ in two locations: Well D06 by Pad A and Well W23 at the western end of the SDA (see Figure 1-3). The concentration associated with Well D06 is increasing. Historically, Tc-99 has not been a priority analyte for vadose zone monitoring; therefore, data are sparse.

1.3.3.5 Carbon-14. Carbon-14 concentrations around beryllium blocks are substantially higher than C-14 concentrations near activated steel or other low-level waste (LLW) disposals. Carbon-14 is detected intermittently in soil-moisture samples (see Figure 1-3), but is readily detected in vapor samples collected near beryllium blocks and activated stainless steel. Carbon-14 also is detected in vapor samples collected from OCVZ vapor ports at depths from 11 to $51 \mathrm{~m}$ (35 to $166 \mathrm{ft}$ ). Collecting samples with suction lysimeters (vacuum) may volatilize C-14 and produce nondetections or biased-low concentrations. This may explain why C-14 is detected only intermittently in soil-moisture samples.

1.3.3.6 Vadose Zone Soil Gas. Volatile organic compounds are consistently detected in soil-gas samples from land surface to the aquifer and as far as $1 \mathrm{~km}(3,281 \mathrm{ft})$ beyond the SDA. Thousands of gas samples have been collected from more than 100 permanent soil-gas sampling ports inside and outside the SDA. Analyzed compounds (i.e., measured concentrations in order of highest-to-lowest average concentration) were carbon tetrachloride, chloroform, tetrachloroethylene, 1,1,1-trichloroethane, and trichloroethylene.

Except for chloroform, these are primary volatile organic constituents in Series 743 sludge received from the Rocky Flats Plant. Very little chloroform was buried in the SDA; but because it is a degradation product of carbon tetrachloride, it is ubiquitous in soil gas. Soil-gas samples are not analyzed for 1,4-dioxane and methylene chloride.

The OCVZ treatment system has reduced concentrations of VOCs in the vadose zone since operations began in 1996. Concentrations near active source areas have been impacted less by the remediation system. 


\subsubsection{Cores}

Few radionuclides are detected in core samples. Most are detected only sporadically and have no associated temporal or spatial trends; however, some radionuclides are consistently detected in RWMC core samples. In order of detection frequency from highest to lowest, these radionuclides are Am-241, $\mathrm{Pu}-238, \mathrm{Pu}-239 / 240, \mathrm{Sr}-90$, and Tc-99.

Sample concentrations generally are very low and below soil risk-based concentrations used for comparison. Americium-241, $\mathrm{Pu}-238$, and $\mathrm{Pu}-239 / 240$ were detected primarily in the 0 to $10.7-\mathrm{m}$ ( 0 to $35-\mathrm{ft}$ ) and 11 to $42.7-\mathrm{m}$ ( 35 to $140-\mathrm{ft}$ ) depth intervals, with very few detections deeper than $43 \mathrm{~m}$ $(140 \mathrm{ft})$, as listed below:

- Am-241 - four detections out of 161 analyses

- Pu-238 - five detections out of 175 analyses

- $\quad \mathrm{Pu}-239 / 240$ - five detections out of 175 analyses

- $\quad$ Sr-90 - nine detections out of 158 analyses

- Tc-99-10 detections out of 28 analyses.

Concentrations of these actinides ranged from 0.002 to $9.6 \mathrm{pCi} / \mathrm{g}$, with a mean concentration around $0.25 \mathrm{pCi} / \mathrm{g}$. Most Am-241 detections were not corroborated with detections of other actinides (e.g., Pu-238 and Pu-239/240), except at monitoring locations in Pit 5, where Pu-238 and Pu-239/240 also were detected. Most valid americium and plutonium detections (i.e., those not taken between 1971 and 1974) are located in the Pit 5 area and the western part of the SDA (see Figure 1-4). All plutonium detections in the B-C interbed occurred between 30 and $34 \mathrm{~m}$ (98 and $111 \mathrm{ft}$ ). This substantiates the conclusion by Batcheller and Redden (2004) that plutonium (and probably other contaminants) is effectively immobilized in sedimentary interbeds.

Detections of Tc-99 in cores from I-series wells in 1999 were not corroborated by detections in the 2003 core sampling campaign. Some evidence supports the conclusion that Tc-99 is present, while some evidence points to the contrary. However, lysimeter data imply Tc-99 transport may be occurring.

\subsubsection{Aquifer}

Very few contaminants of potential concern are detected regularly at levels greater than background concentrations in the aquifer near RWMC. Those frequently detected contaminants of potential concern, in order of detection frequency from highest to lowest, are carbon tetrachloride, trichloroethylene, uranium isotopes, and Cs-137. Other constituents, which are not contaminants of potential concern, are regularly detected in concentrations greater than aquifer background values. Those other constituents, in order of detection frequency from highest to lowest, are tritium, sulfate, chloride, chromium, and toluene. Figure 1-5 illustrates constituents detected in the aquifer near RWMC.

Some constituents are intermittently detected in the aquifer near RWMC. Those intermittently detected constituents, in order of detection frequency from highest to lowest, are bromide (not a contaminant of potential concern), magnesium (not a contaminant of potential concern), C-14, nitrate, $\mathrm{Pu}-238, \mathrm{Am}-241, \mathrm{Pu}-239 / 240$, methylene chloride, and tetrachloroethylene. Detection frequencies are low. For example, $\mathrm{Pu}-238$ plus $\mathrm{Pu}-239 / 240$ are detected at a rate of $1.0 \%$, which is slightly lower than the detection rate of blank samples $(1.2 \%)$ and is also the number of times a result is expected to occur outside the $99.7 \%$ confidence interval (i.e., a false positive detection). 


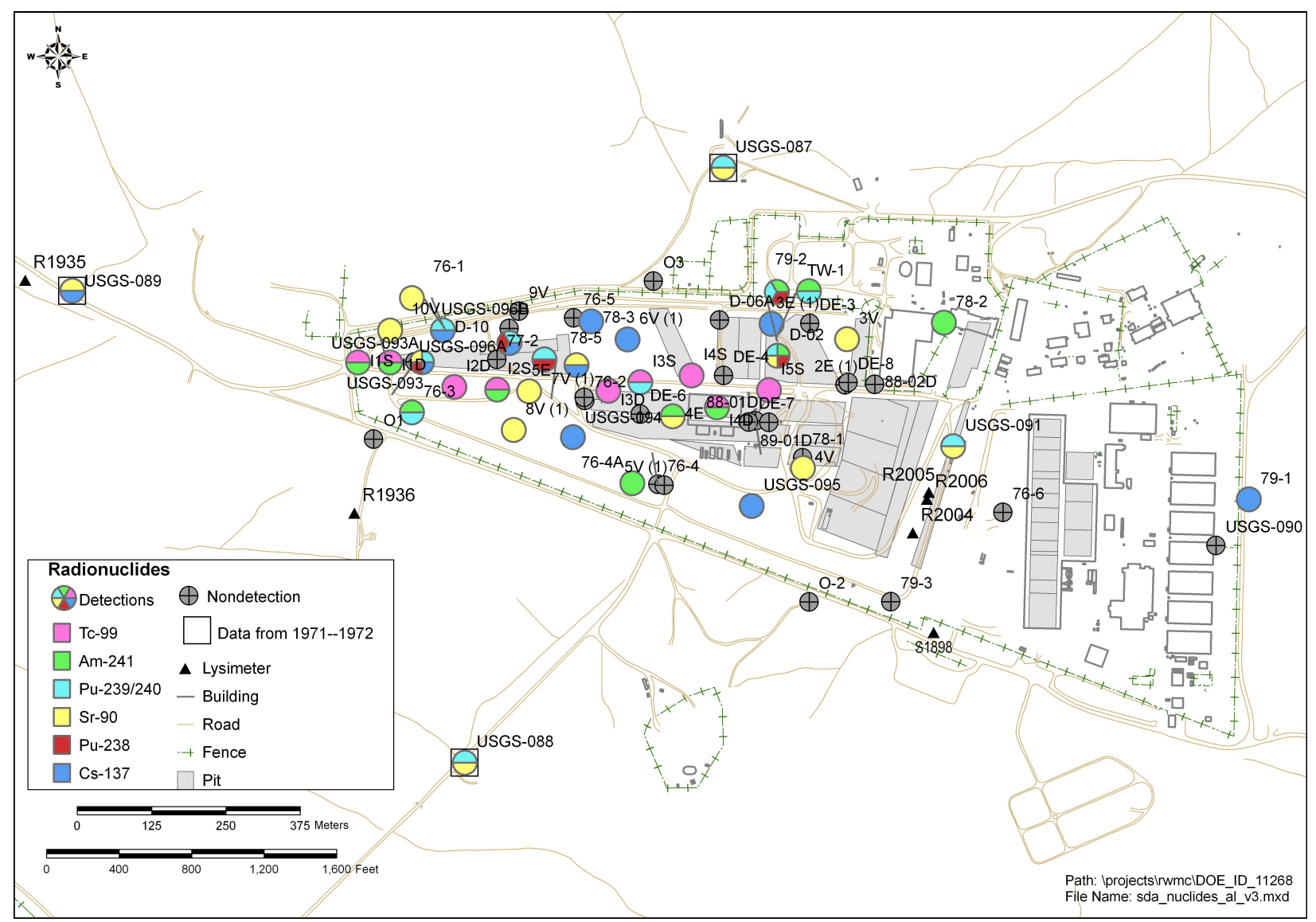

Figure 1-4. Radionuclides detected in core samples between 1971 and 2003. 


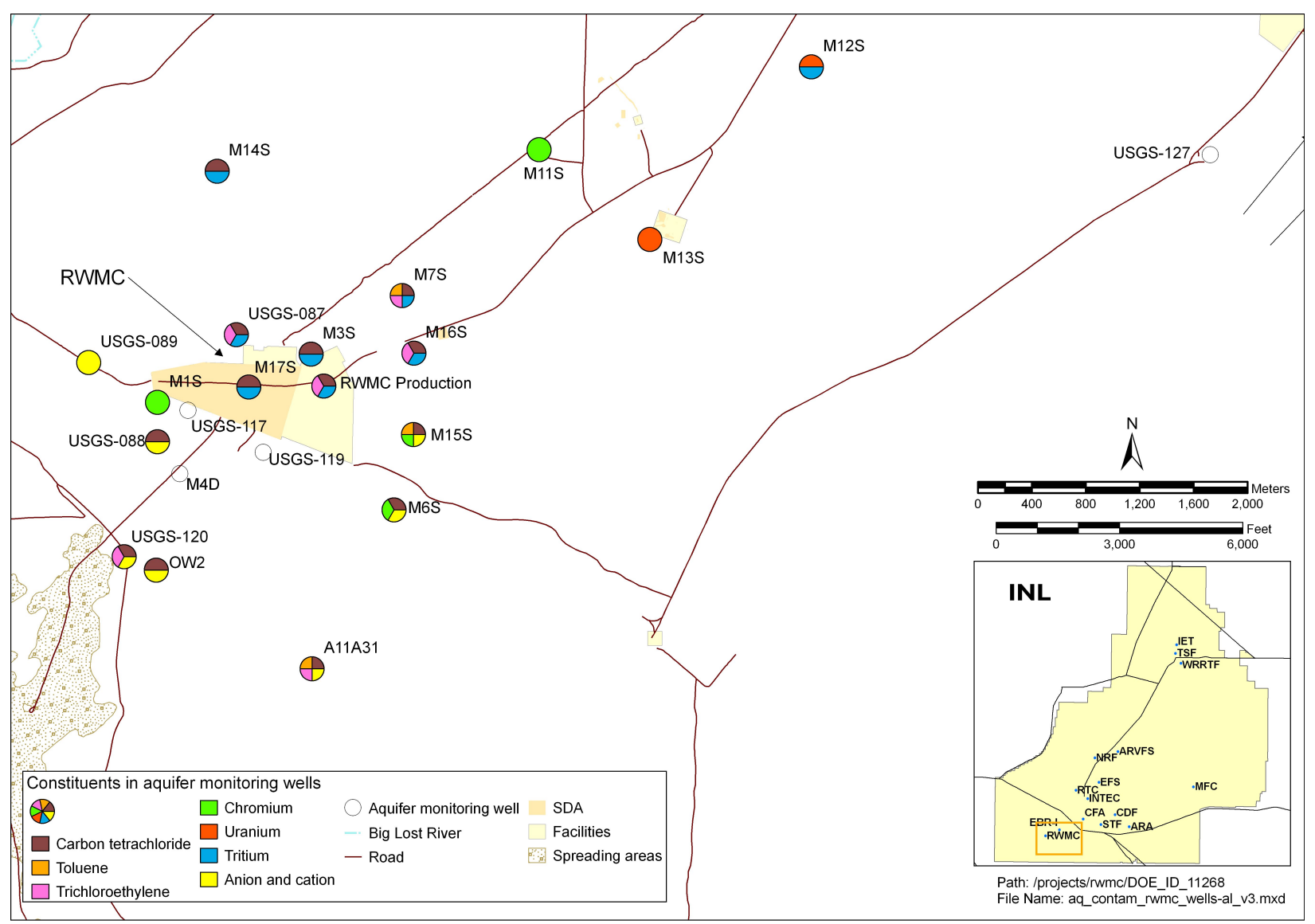

Figure 1-5. Constituents detected in aquifer monitoring wells.

Carbon tetrachloride is the only contaminant of potential concern that exceeds its MCL. Carbon tetrachloride is consistently detected in numerous aquifer monitoring wells at concentrations near and occasionally greater than the MCL of $5 \mu \mathrm{g} / \mathrm{L}$. Toluene and trichloroethylene also are detected frequently at certain locations in the aquifer beneath the SDA, but concentrations are significantly less than MCLs, and concentration trends are not evident. Low levels of chromium, nitrate, and tritium, as well as a few anions and cations, are detected consistently above background levels in the aquifer beneath RWMC; however, the source of these constituents is uncertain. Possible sources could be transported from the SDA, contributions from upgradient facilities, or corroding well construction material.

Analytical evidence shows that intermittently detected contaminants (i.e., Am-241, C-14, methylene chloride, nitrate, $\mathrm{Pu}-238, \mathrm{Pu}-239 / 240$, and tetrachloroethylene) are not widespread in the aquifer near RWMC, and they are not migrating at measurable concentrations. Nitrate concentrations in monitoring Well M6S are higher than all other RWMC aquifer monitoring wells; however, the long-term trend appears to have leveled off at concentrations near the upper background range.

Segregation in the aquifer is observed around RWMC, as described below:

- Tritium is detected only in monitoring wells north of RWMC

- $\quad$ High anions and cations (i.e., bromine, chlorine, nitrate, magnesium, and sulfate) are found in wells south of RWMC 
- $\quad$ Trichloroethylene and toluene are located to the east and south

- High chromium concentrations are isolated to the low-permeability zone beneath the southern RWMC boundary.

Excluding VOCs, upgradient concentrations are attributable to other facilities (see Section 2.3.4 of the RI/BRA report [Holdren et al. 2006]).

1.3.5.1 Carbon Tetrachloride. Low levels of carbon tetrachloride are consistently detected in aquifer monitoring wells in and around RWMC (see Figure 1-5). The maximum concentration was $8 \mu \mathrm{g} / \mathrm{L}$, measured in Well M7S. Concentration trends of carbon tetrachloride in many RWMC aquifer monitoring wells appear to be stabilizing and perhaps declining slightly; however, concentrations in Wells M7S, M16S, RWMC Production Well, and A11A31 continue to fluctuate slightly above and below the MCL of $5 \mu \mathrm{g} / \mathrm{L}$. No wells exhibited an obvious increasing trend over the past few years, but Well USGS-120 has shown a decreasing trend.

1.3.5.2 Trichloroethylene. Trichloroethylene is routinely detected at low levels in aquifer monitoring wells in and around RWMC (see Figure 1-5). The maximum concentration was $3.9 \mu \mathrm{g} / \mathrm{L}$, measured in Well USGS-90 in 1988. Since 2000, the highest concentrations measured were 3.3, 3.2, and $3.0 \mu \mathrm{g} / \mathrm{L}$ in Wells RWMC Production, A11A31, and M7S, respectively. Concentration trends of trichloroethylene in most RWMC aquifer monitoring wells are stable. Trichloroethylene has not been detected in the aquifer above the MCL of $5 \mu \mathrm{g} / \mathrm{L}$.

1.3.5.3 Uranium Isotopes. Concentrations of uranium detected in aquifer monitoring wells are consistent with natural background values and have never approached or exceeded the MCL for total uranium. The number of detections of U-233/234 and U-238 exceeding the upper background comparison concentrations is consistent with expected rates (i.e., less than or equal to $1 \%$ ). The detection rate for U-235/236 is slightly higher than those for U-233/234 and U-238. This is attributed to relatively high measurement uncertainties associated with low-level U-235/236 analyses and a low upper background comparison concentration at RWMC. Ranges at other aquifer monitoring locations around the INL Site are typically a factor of two higher than at RWMC.

1.3.5.4 Cesium-137. The detection rate of Cs-137 for aquifer samples is also very low (i.e., $1.5 \%$ ), but slightly higher than the expected rate. Many detections contributing to the rate occurred in the early 1970s and are artifacts of well drilling and sampling methods employed at the time. The MCL was exceeded in one aquifer sample collected in 1995; however, Cs-137 has not been detected at that sampling location in subsequent sampling events.

\subsubsection{Ecological Contaminants of Potential Concern}

Ecological risk assessments conducted at the INL Site are based on evaluation and interpretation of the nature and extent of contamination conducted for human health (Van Horn, Hampton, and Morris 1995). Samples have not been collected and analyzed to specifically address RWMC ecological receptors, and sampling data collected as part of the human health assessment were not analyzed in terms of nature and extent for individual ecological receptors (e.g., compared to ecologically based screening levels). However, results of INL Site biotic sampling conducted as part of INL Site environmental monitoring programs were used to assess transport of contaminants from subsurface to surface soil, to locations outside the SDA, and into the food web. 


\subsubsection{Nature and Extent of Contamination-Conclusions}

Low concentrations of carbon tetrachloride are affecting the aquifer near the SDA. Carbon tetrachloride has been detected slightly above the MCL, but concentrations appear to be leveling off. This may be the result of vapor vacuum extraction by the OCVZ Project (i.e., OU 7-08).

Several other contaminants buried in the SDA have been detected at low concentrations in the vadose zone and may be migrating. Most vadose zone detections are in the interval above the B-C interbed. Highest frequencies were detected in the vadose zone beneath Pit 5 and Pad A and in the western end of the SDA. The most frequently detected contaminants in the vadose zone are VOCs, C-14, nitrate, Tc-99, and uranium isotopes. In addition, Am-241, Cl-36, I-129, Pu-238, Pu-239/240, and Sr-90 have been detected sporadically at concentrations near detection limits.

The monitoring network has been expanded greatly since 1998. Additions include more than 300 probes in the waste, 62 vadose zone lysimeters, five upgradient aquifer wells, and an aquifer monitoring well inside the SDA. Additional vapor ports also have been installed, bringing the total to 212, 174 of which are sampled routinely. Concentrations in the environment around the SDA will continue to change over time due to such factors as those listed below:

- $\quad$ Remedial actions at the SDA could affect concentrations in the environment (e.g., beryllium block grouting may reduce $\mathrm{C}-14$ concentrations in the vadose zone)

- $\quad$ Continued operation of the OCVZ treatment system removes VOCs from the vadose zone

- $\quad$ Subsidence repairs and surface contouring reduce migration by decreasing the amount of infiltration through the waste and into the subsurface

- $\quad$ Degradation of waste packages influences measured concentrations (e.g., as containers fail over time, more contamination is available for transport to the surface by plants and animals or into the subsurface from infiltration).

\subsection{Summary of the Baseline Risk Assessment}

Unlike a classical analysis, the OU 7-13/14 RI/BRA (Holdren et al. 2006) depends on concentrations of contaminants in environmental media estimated through modeling rather than on currently detected concentrations. The DOE, DEQ, and EPA identified this approach as appropriate for the SDA because of the long half-lives of some radionuclides in the SDA, issues associated with representative sampling (e.g., sampling heterogeneous media such as fractured basalt and landfill waste), and, except for carbon tetrachloride, current contamination in the environment is not widespread and does not exhibit spatial and temporal patterns that provide an adequate basis for risk assessment and remedial decision-making.

The baseline risk assessment (Holdren et al. 2006) and subsequent refinements in the No Action analysis for this feasibility study address potential risk to human health from contaminants buried in the SDA in the absence of further remedial action. Based on EPA and INL guidance (EPA 1988, 1989; Burns 1995), Waste Area Group 7 was comprehensively assessed by evaluating cumulative, simultaneous risk for all complete exposure pathways for all contaminants of potential concern. The risk assessment included exposure and toxicity assessments, risk characterization, parametric sensitivity analysis, and qualitative evaluation of uncertainty. Contaminant screening for the RI/BRA identified 33 human health contaminants of potential concern for quantitative evaluation: 27 radionuclides, five VOCs, and one inorganic chemical. Risk estimates were developed for occupational and residential scenarios for 
complete exposure pathways. The future residential scenario bounds the risk, meaning that risk estimates are higher than for all other exposure scenarios. Therefore, risk estimates for this scenario are the basis for identifying contaminants of concern (COCs) and are the focus of discussions that follow.

Future residential exposures were simulated, beginning in the year 2110, following an assumed 100 -year IC period. Though residential development near the SDA is not expected, analysis of hypothetical residential exposure conservatively assesses residential use immediately adjacent to the SDA with ICs to preclude direct access into the waste. Concentrations and risks were simulated out to 1,000 years for all pathways, except groundwater ingestion. Groundwater risks were simulated until concentrations peaked or to a maximum of 10,000 years.

The RI/BRA concluded with recommendations for additional modeling to refine estimates for several contaminants and to provide a better foundation for the feasibility study. Appendix D presents a summary of additional modeling with comparisons to those results presented originally in the RI/BRA. Details are provided in two modeling reports that support the analysis (i.e., Anderson and Becker [2006] for source-release modeling and Magnuson and Sondrup [2006] for transport modeling). This section incorporates those modifications. Differences are slight; the most significant changes are associated with risk estimates for Tc-99 (and collocated I-129) and tetrachloroethylene. Minor changes also were realized for C-14, nitrate, and VOCs.

The following subsections provide a synopsis of general approaches and results of human health and ecological risk assessments. Potential threats to human health and the environment - in the absence of any remedial action - are evaluated. Modeling for the RI/FS is summarized first, followed by final cumulative risk results used as a basis for this feasibility study.

\subsubsection{Contaminant Fate and Transport}

This section addresses modeling of contaminant source release, potential routes of contaminant migration and persistence for the subsurface pathway, and methodology for determining rate constants used in the biotic model. Complete exposure pathways defined by the conceptual site model led to three types of models: source release, subsurface transport, and biotic transport. Persistence of contaminants in the environment was evaluated based on contaminant mobility controlled by dissolved-phase transport, vapor-phase transport, and biotic transport by animals and plants intruding into the waste.

Modeling uses best-estimate inventories as the basis for analyzing baseline risk. Because uncertainties are and always will be associated with predicting movement of contaminants, conservatism is retained in the modeling and is demonstrated through comparison of predicted-to-monitored concentrations.

Eighteen source areas were defined for implementation in the source-release model (see Figure 1-6). The source-term model simulated release of contaminants into the subsurface from buried waste. The 18 source areas reasonably represent various groups of waste-form and disposal-site types. The DUST-MS code (Sullivan 1992) was used to simulate release of contaminants of potential concern and their long-lived decay-chain products. Simulated mass-release mechanisms comprised surface washoff, diffusion, and dissolution. Release mechanisms were identified based on waste-stream-specific data. Output from the source-release model provided input to both the biotic- and subsurface-transport models. 


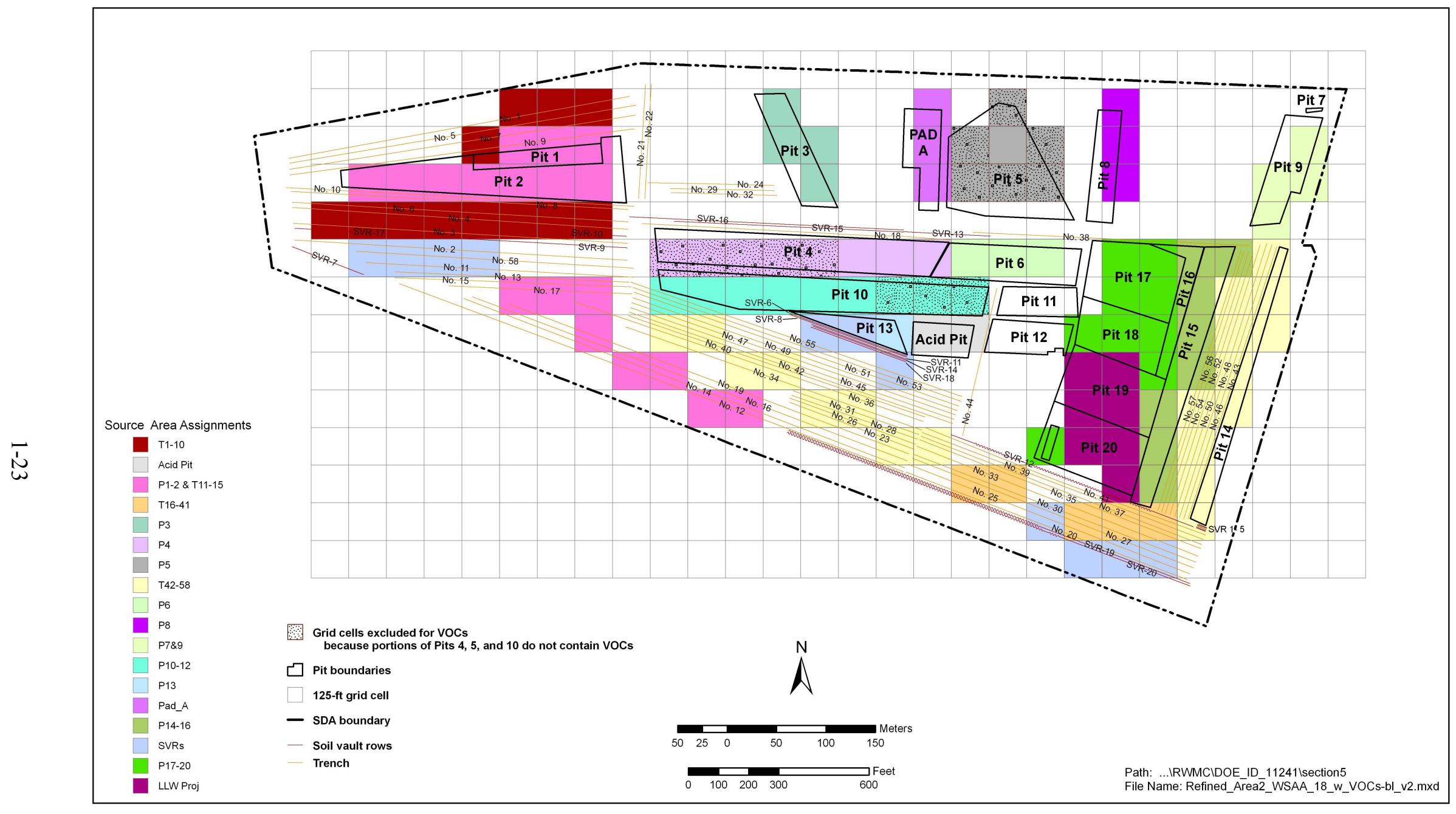

Figure 1-6. Eighteen source areas simulated in the source-release model. 
The three-dimensional TETRAD simulator was used to model fate and transport of both dissolved-phase and vapor-phase contaminants in the SDA subsurface (Shook 1995). Verification and benchmark testing of the TETRAD Version 12.7ms simulator is documented in Martian (2007), which concludes that the simulator is appropriate for environmental transport simulations on the INL Site. Beginning with contaminant fluxes received as input from the source-release model, the TETRAD model simulates movement of contaminants in the vadose zone down to the aquifer and subsequent aquifer transport. Figure 1-7 shows three-dimensional views of the vadose zone base grid and the first and second-level grid refinements. Simulations produced estimates of future contaminant concentrations in groundwater. The model was parameterized in consultation with modeling staff from DEQ and EPA, as reflected in values presented in the Second Addendum to the Work Plan (Holdren and Broomfield 2004). Where available, site-specific data were applied in describing lithology, spatially variable infiltration, sorption, and other characteristics. Contaminant transport in the aquifer was simulated until peak aquifer concentrations were achieved or to a maximum of 10,000 years. Sensitivity cases were modeled to evaluate effects of upper-bound inventories and additional selected parameters on estimated media concentrations and risk.

A
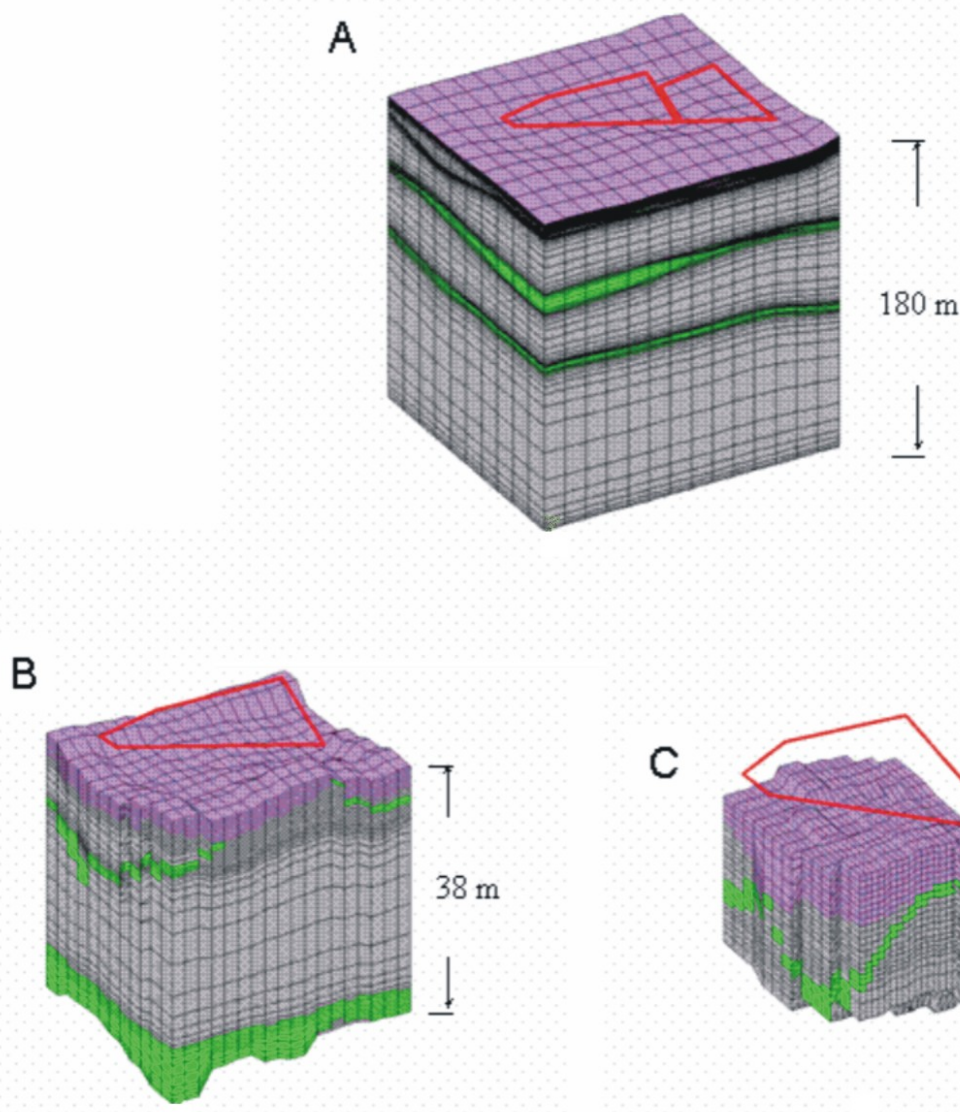

Legend

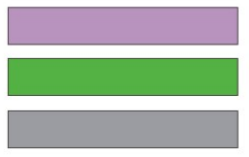

Surficial sediment grids

Interbed grids

Fractured basalt grids

G1569-23

Figure 1-7. Southwest views of base grid (A), first-level refined grid (B), and second-level refined grid (C) beneath the Subsurface Disposal Area showing vertical conformable gridding. The A-B interbed appears black in the base grid as a result of fine vertical discretization. 
The DOSTOMAN code was used to estimate surface soil concentrations produced by biotic transport of contaminants to the surface by plants and animals. Rate constants and other input parameters used in the code (e.g., rooting depths) were selected from current literature, giving preference to site-specific values for the SDA and the INL Site, when available. The biotic model was not calibrated because surface soil at the SDA is routinely redistributed through contouring and operations and because of the fundamental assumption that remedial action at the SDA will include a surface barrier (Holdren and Broomfield 2004). The DOSTOMAN model soil concentrations were estimated for the current timeframe and for future human health and ecological exposure scenarios.

Sensitivity simulations showed that source inventory and the type of mass-release mechanism (i.e., surface washoff, diffusion, and dissolution) have the largest impact on predicted contaminant concentrations in environmental media. The amount of infiltration through the waste and the low-permeability region in the aquifer are two other model features that significantly affect predicted groundwater concentrations. The amount of water that contacts waste influences groundwater pathway concentrations. Water is the driving force that moves aqueous-phase contaminants along the groundwater pathway. Sensitivity simulations show that additional water in the vadose zone, that does not contact waste, primarily dilutes groundwater pathway concentrations. The low-permeability region in the aquifer also substantially impacts predicted concentrations by reducing dilution that would otherwise occur, thus preserving higher concentrations that reflect concentrations influxing from the vadose zone. Figure 1-8 compares results from various sensitivity simulations for U-238 (a long-lived actinide), C-14 (a dual-phase radionuclide), and nitrate (a dissolved-phase nonradionuclide). Maximum concentrations anywhere in the aquifer are presented to facilitate comparison between various sensitivity simulations. The different simulations are identified using the following nomenclature:

- $\quad \mathrm{B}=$ Baseline risk assessment

- $\quad$ Bli $=$ Baseline risk assessment with low infiltration inside the SDA

- $\quad \mathrm{B} 4 \mathrm{ng}=$ Baseline risk assessment with no retrieval and no beryllium block grouting

- $\quad \mathrm{Bu}=$ Baseline risk assessment with upper-bound inventory

- $\quad$ Bhi $=$ Baseline risk assessment with high infiltration inside the SDA

- $\quad$ Bloi $=$ Baseline risk assessment with low background infiltration outside the SDA

- $\quad \mathrm{Bnbc}=$ Baseline risk assessment with no B-C interbed

- $\quad \mathrm{Bnlk}=$ Baseline risk assessment with no low-permeability region.

Best judgment was used to select parameters for the source-release model and the subsurface flow and transport model. Fortunately, from an environmental consequence perspective, movement of contaminants in the vadose zone and aquifer beneath the SDA is slow, and no extensive dissolved-phase contaminant plume is available against which to calibrate. An extensive database exists for contaminants in the waste zone, unsaturated zone, perched groundwater (when and where present), and regional aquifer, but there is no clear general pattern of contaminant detections nor trends in concentrations at this time, except for the volatile contaminants. Results of source-release and dissolved-phase subsurface flow and transport models can be compared only to the presence or absence of contaminants in field monitoring data instead of calibration to a contaminant plume. The ongoing monitoring program and evaluation of monitoring results are time consuming and expensive. Results of these monitoring activities have shown promise in identifying trends in contaminant behavior that are useful for determining the relative conservatism in modeling. 

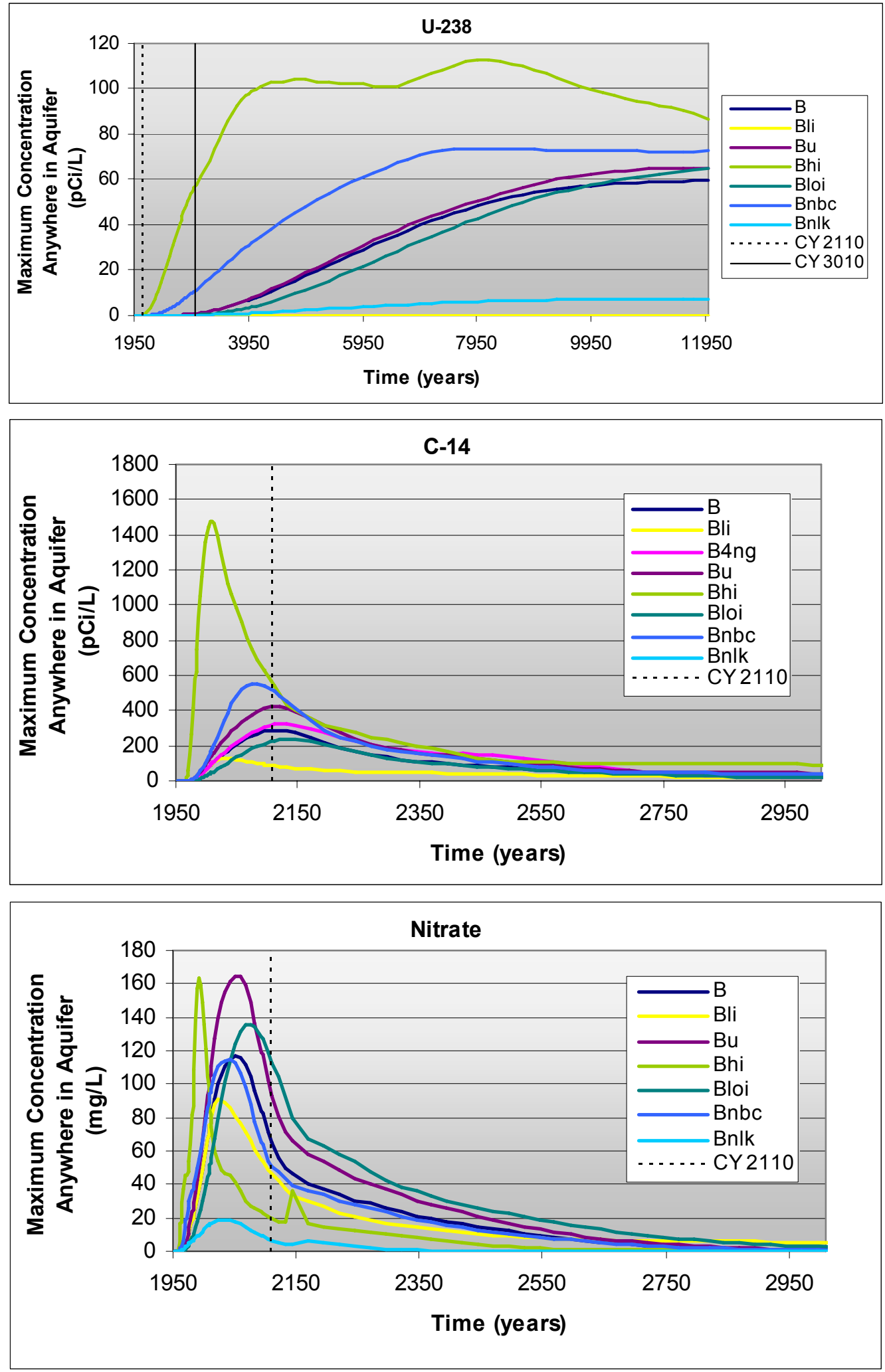

Figure 1-8. Combined sensitivity results for maximum simulated concentration anywhere in the aquifer for carbon-14, nitrate, and uranium-238. 
Limited calibration to vapor-phase carbon tetrachloride was achieved. Particular parameters were adjusted within reasonable uncertainty ranges until model results adequately agreed with observations of carbon tetrachloride in vadose zone soil-gas and aqueous concentrations in the aquifer. The goal of calibration was to match observed general trends and not be overly concerned with matching values at specific points. This goal was achieved. Limited calibration also was achieved in representing spatial distribution of observed soil-water matric potentials in the B-C and C-D interbeds, where wetter conditions are consistently observed within SDA boundaries compared to locations outside the SDA fence.

Personnel from DOE, DEQ, and EPA consider model results a reasonable basis for estimating potential risk to human health and the environment and for assessing appropriate remedial alternatives to mitigate risk. However, results must be considered in light of uncertainties associated with this analysis. Modeling results (i.e., simulated concentrations) are consistently overpredicted in the aquifer (i.e., neglecting sporadic detections), overpredicted at some vadose zone monitoring locations, and underpredicted at other vadose zone monitoring locations. In general, groundwater pathway modeling results are conservative. This conservatism primarily results from overestimating contaminant source release, including rapid vertical transport in the fractured basalt portions of the vadose zone, and including the extensive low-permeability region in the aquifer domain, which limits dilution. Because the model overpredicts current concentrations in the aquifer, it is certain that model results are conservative at present. The amount of uncertainty in the predictive results undoubtedly increases with time, decreasing the level of confidence that the model remains reasonably conservative over time. Monitoring over time and comparing monitoring results against model predictions will be an important aspect of post-ROD monitoring.

\subsubsection{Overall Results of the Human Health Baseline Risk Assessment}

For modeling and risk assessment, a 100-year IC period that prohibits residential land use within the INL Site was simulated. After the end of the simulated ICs (2110), residential land use inside the INL Site was modeled. Therefore, all risk and hazard index graphs show a large increase in risk at 2110 , immediately following the end of the simulated IC period because the location of the hypothetical residential receptor is shifted from the INL Site boundary to the SDA boundary. Risks within the SDA boundary are calculated based on an inadvertent intruder scenario. Those risks will be mitigated under all alternatives by a cap designed to deter intruders in combination with institutional controls to limit unauthorized access.

Figure 1-9 shows cumulative risk for the residential scenario, including refinements implemented for the feasibility study. Cumulative risk peaks at 7E-03 at the end of the 1,000-year simulation period. Because surface pathway results dominate total cumulative risk by a substantial margin, previously discussed modeling refinements did not affect the total peak risk. Figure 1-10 shows the cumulative hazard index for the residential scenario, including refinements. The hazard index peaks at 15 at the end of ICs.

For the future residential scenario, 18 contaminants within the 1,000-year simulation period have cumulative risk greater than or equal to $1 \mathrm{E}-05$, a hazard index greater than or equal to 1 , or simulated groundwater concentrations that exceed MCLs. Residential risk estimates are greater than or equal to 1E-05, or simulated groundwater concentrations are greater than MCLs for eight additional contaminants within the 10,000-year simulation period. 


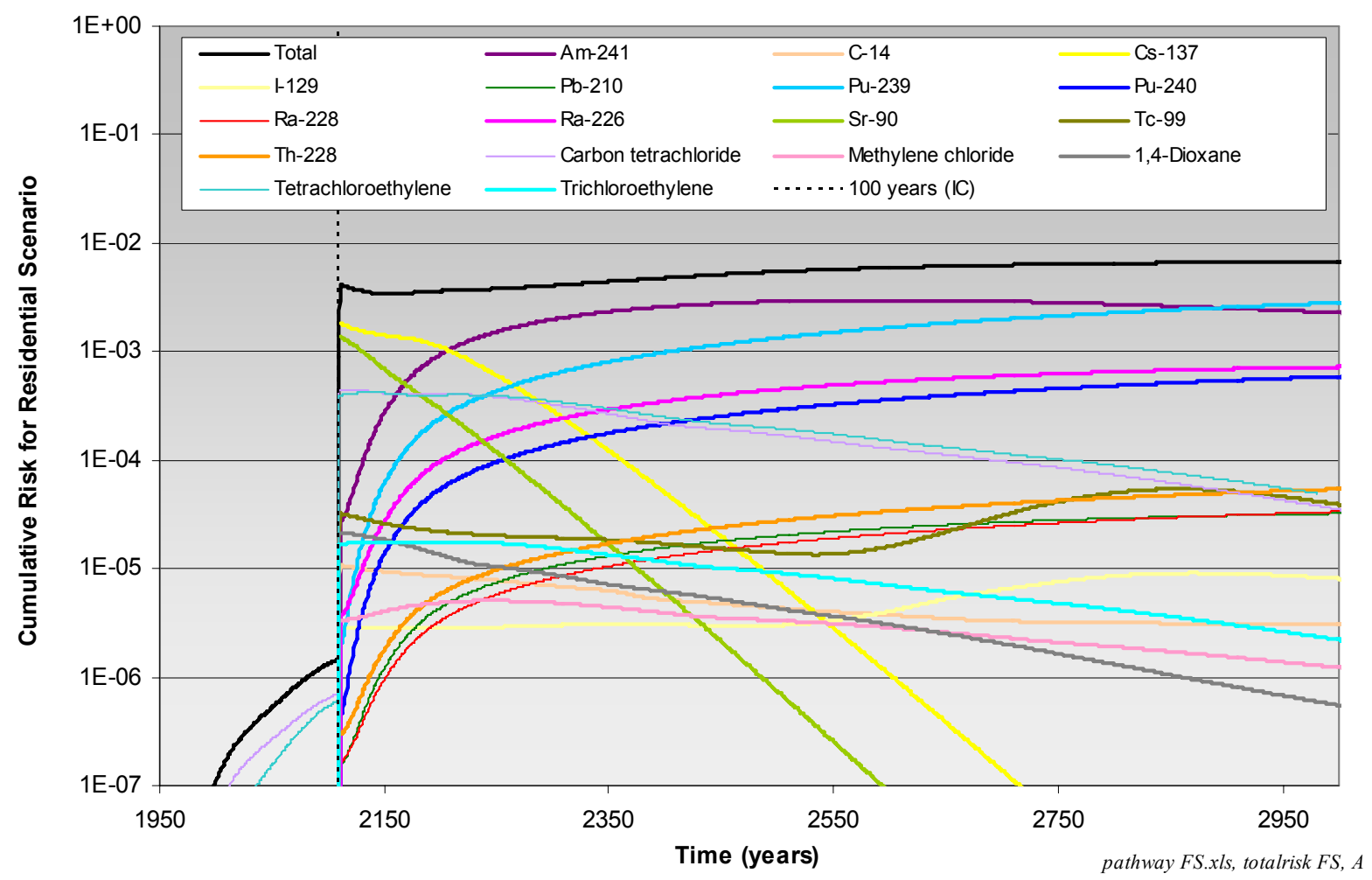

Figure 1-9. Cumulative risk for the residential exposure scenario for all contaminants of potential concern and all exposure pathways.

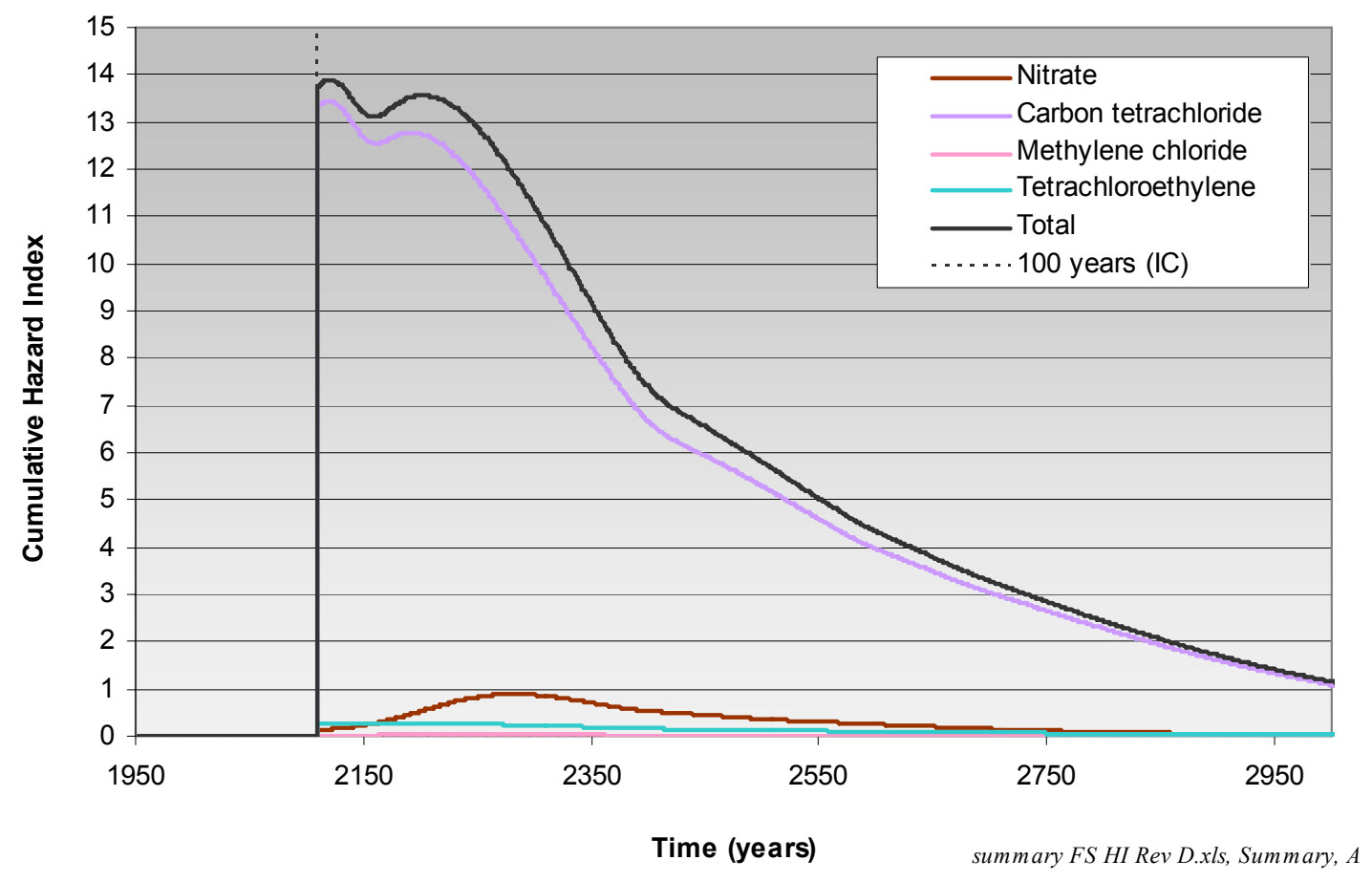

Figure 1-10. Cumulative hazard index for the residential exposure scenario. 
In the 1,000-year simulation period, highest residential risks are driven by biotic uptake and surface pathway exposure from Am-241, Cs-137, Pb-210, Pu-239, Pu-240, Ra-226, Ra-228, Sr-90, Th-228, and trichloroethylene. Risks from 1,4-dioxane, I-129, and nitrate are primarily through groundwater pathway exposures; risks from C-14 and carbon tetrachloride are primarily through groundwater and vapor inhalation (at the surface) exposures, while Tc-99 risk is primarily through groundwater ingestion and irrigating crops with groundwater. Simulated groundwater concentrations for the 1,000-year simulation period exceed MCLs immediately adjacent to the SDA for carbon tetrachloride, 1,4-dioxane, I-129, methylene chloride, nitrate, Tc-99, tetrachloroethylene, and trichloroethylene.

Figure 1-11 shows total risk over time and relative contributions attributable to each exposure pathway for the future residential scenario immediately adjacent to the SDA. Except for inhalation of volatiles, risk remains greater than $1 \mathrm{E}-05$ for each exposure pathway throughout the 1,000-year simulation period, and cumulative risk remains well above 1E-03. External exposure and soil ingestion dominate the risk. Crop ingestion risk is initially higher than soil ingestion risk immediately after ICs. Inhalation risk is less than 1E-05 immediately after ICs but increases rapidly. Volatile inhalation risk is slightly greater than $1 \mathrm{E}-05$ at the end of ICs but decreases to less than $1 \mathrm{E}-05$ within 50 years. Figures 1-12 through 1-17 illustrate individual pathway risks for surface exposure pathways over 1,000 years. Each figure shows the total by pathway, major contributors to the total, and the sum of other contaminants.

Figure 1-17 shows total 1,000-year groundwater ingestion risk for all radionuclides and nonradionuclides, major contributors to the total, and the sum of other contaminants. Carbon tetrachloride and Tc-99 drive the groundwater ingestion risk immediately after the end of ICs. Within the 1,000-year simulation, eight contaminants exceed their respective MCLs: carbon tetrachloride, 1,4-dioxane, I-129, methylene chloride, nitrate, Tc-99, tetrachloroethylene, and trichloroethylene.

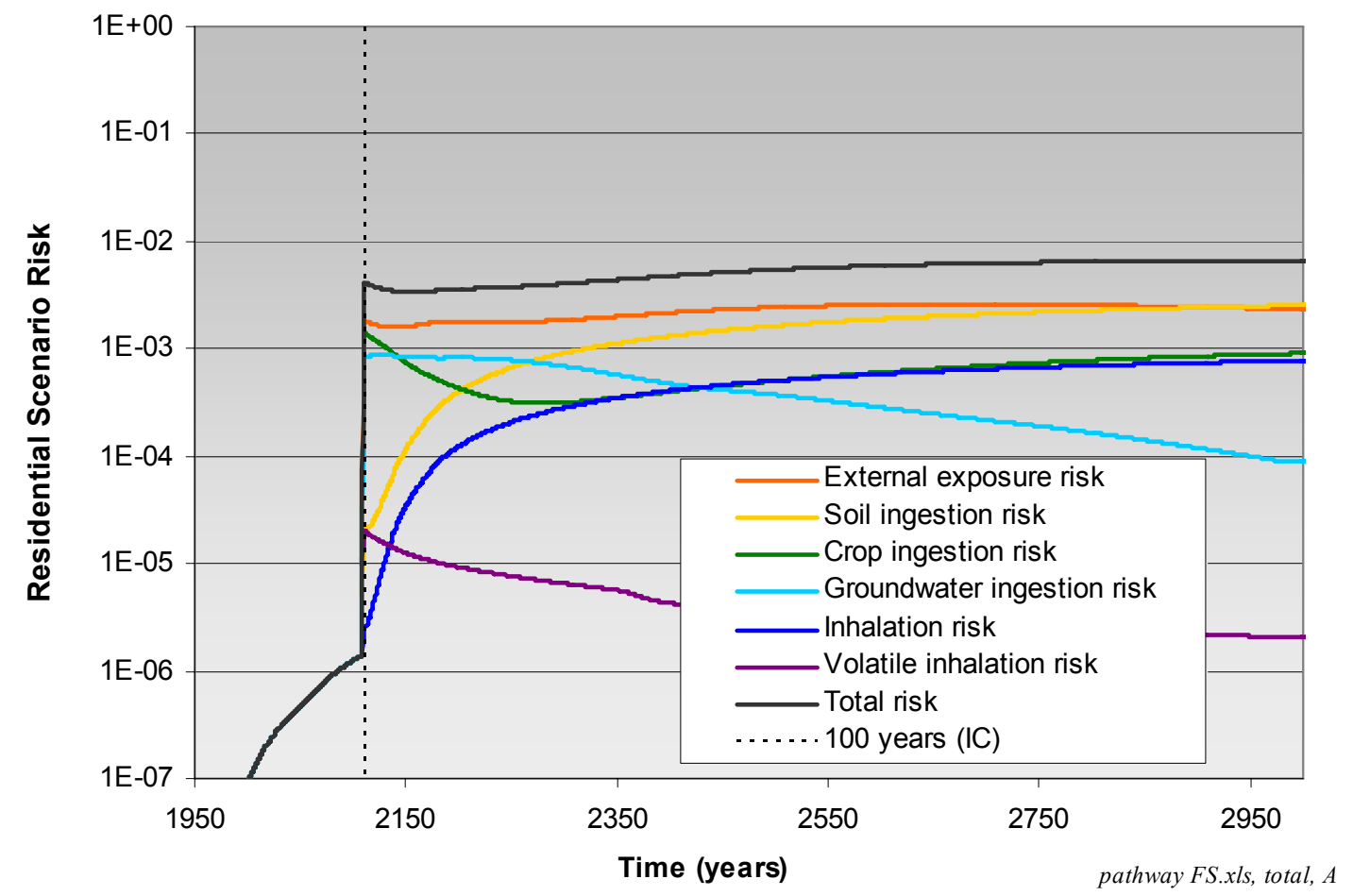

Figure 1-11. Total residential exposure scenario risk by exposure pathway for all radionuclides and nonradionuclides. 


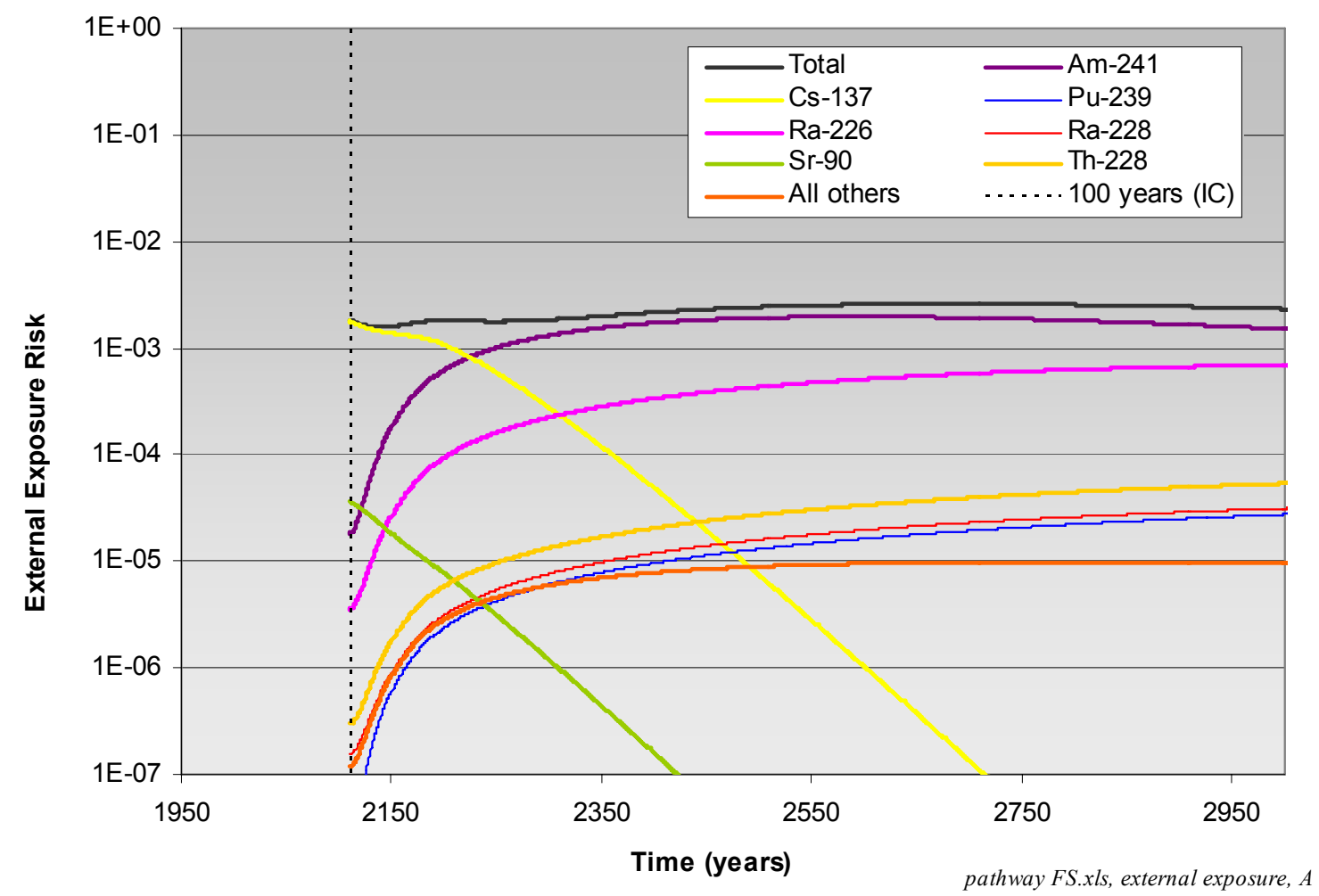

Figure 1-12. Major contributors to external exposure risk.

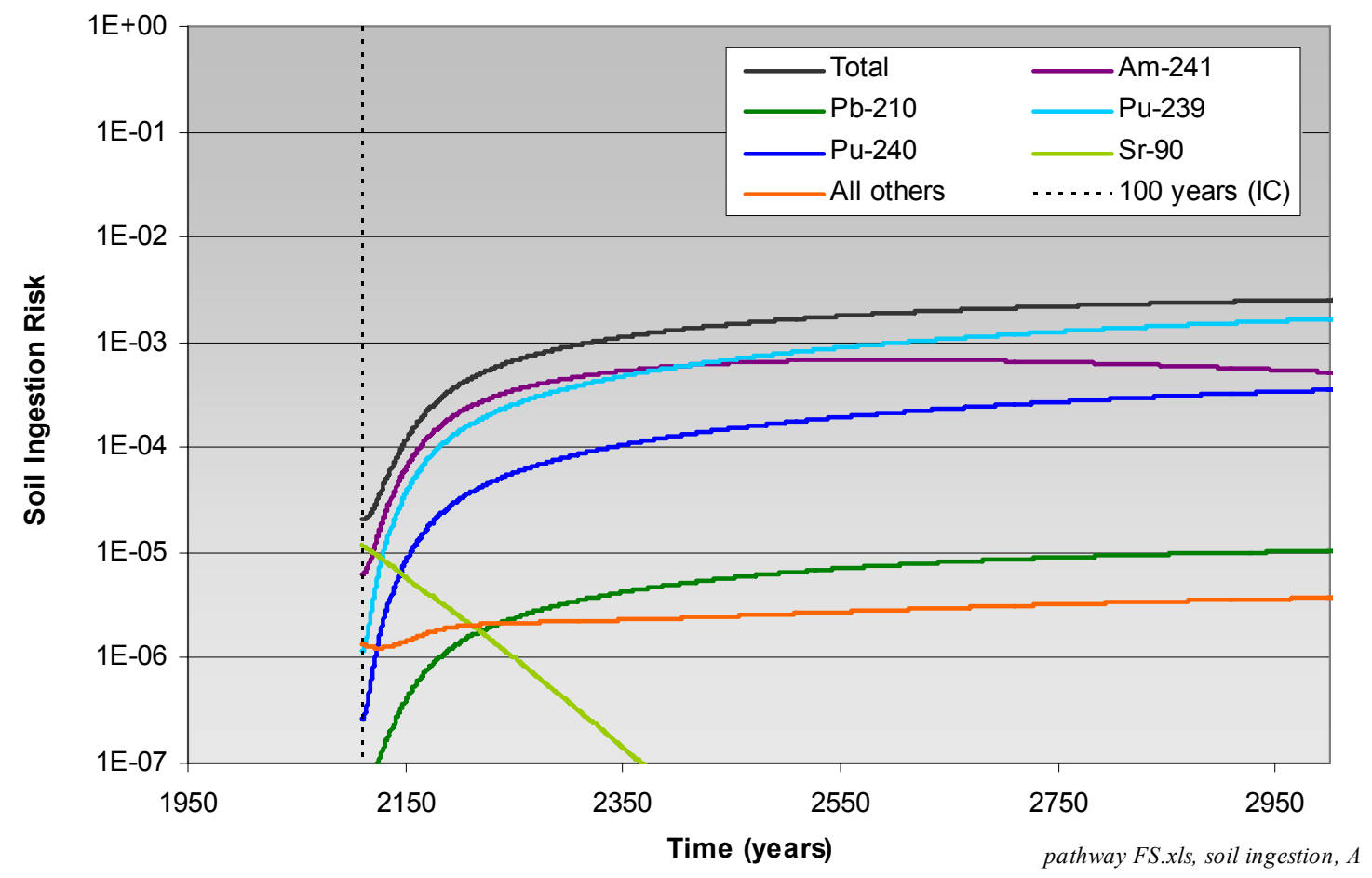

Figure 1-13. Major contributors to soil ingestion risk. 


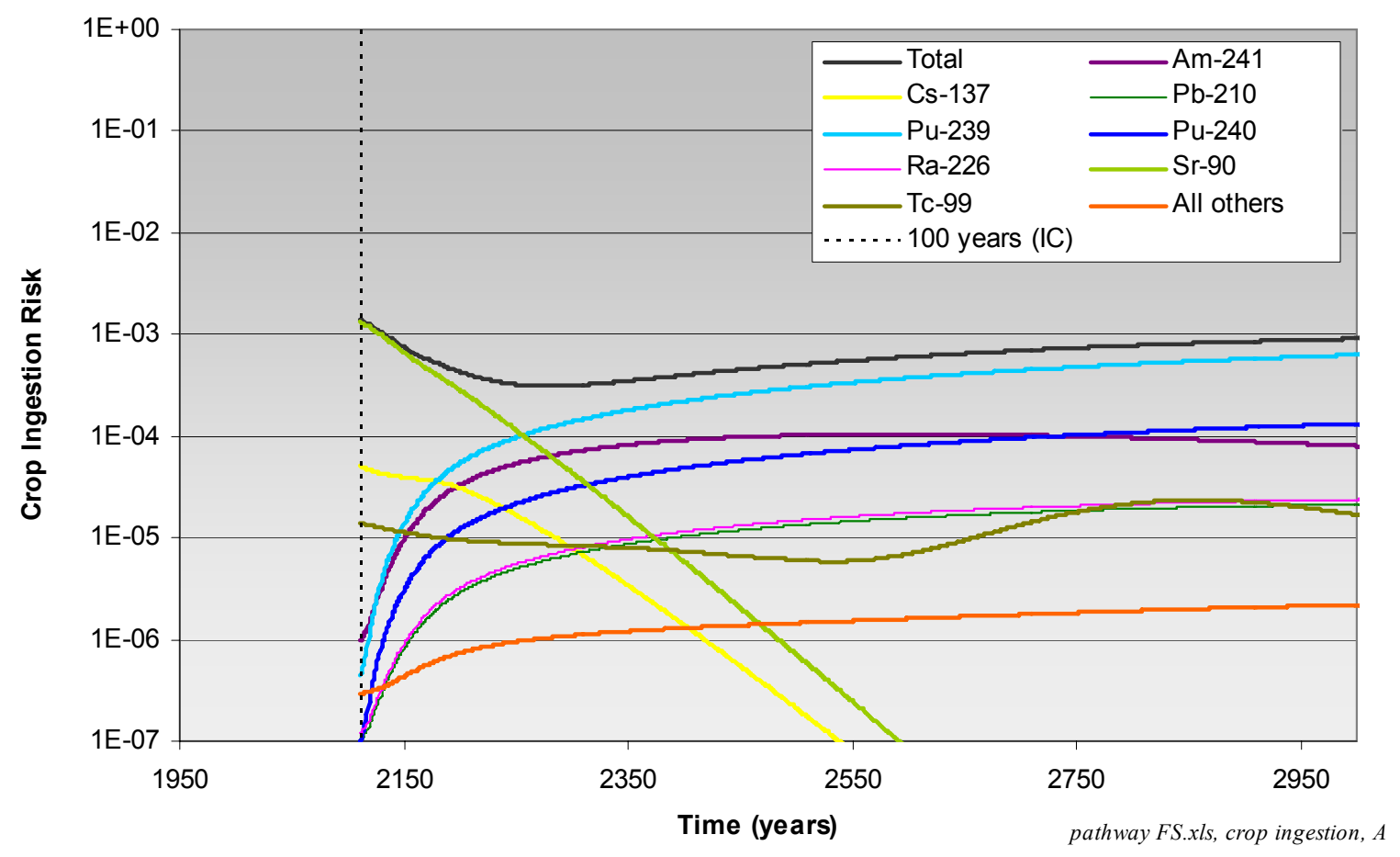

Figure 1-14. Major contributors to crop ingestion risk.

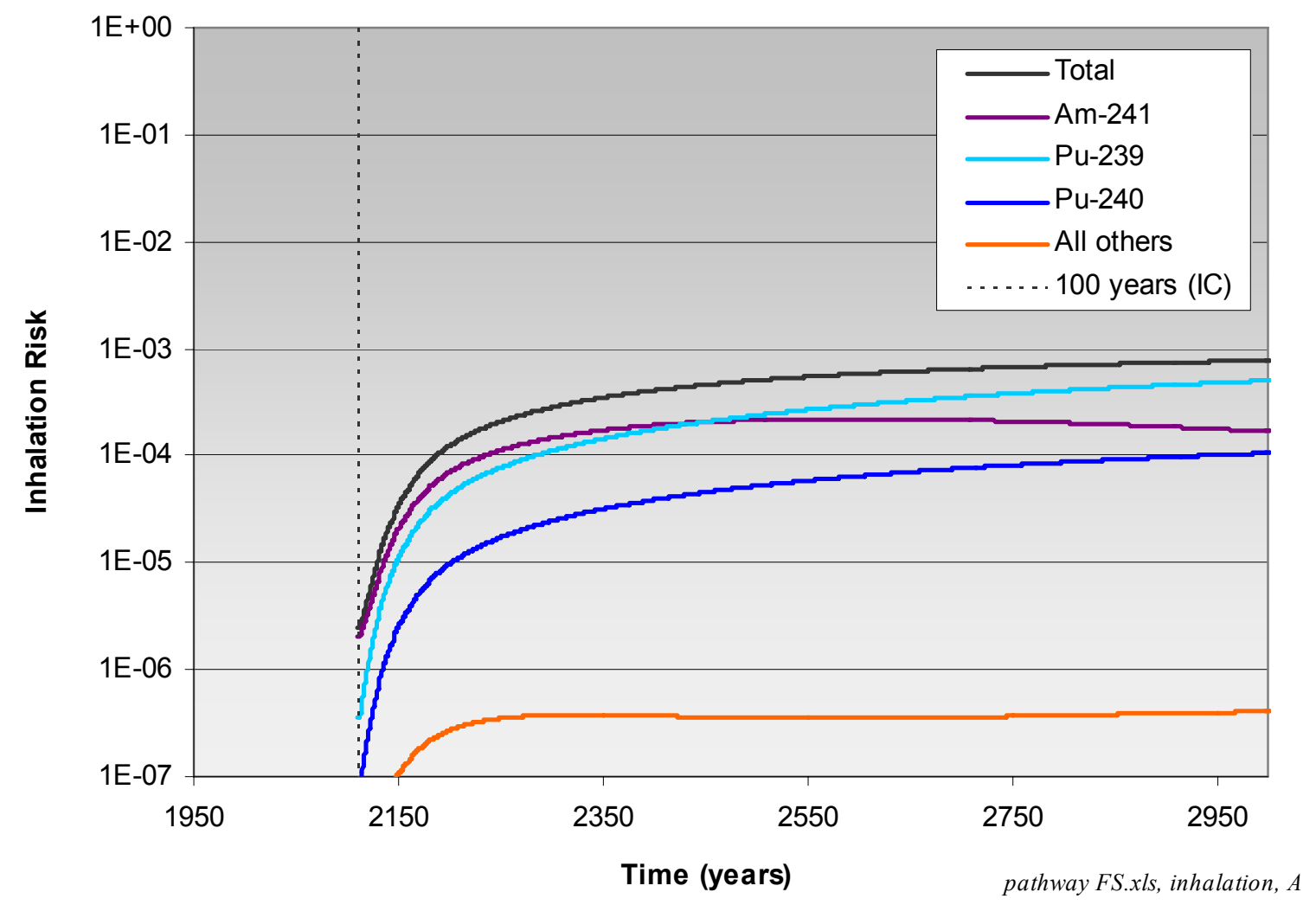

Figure 1-15. Major contributors to inhalation risk. 


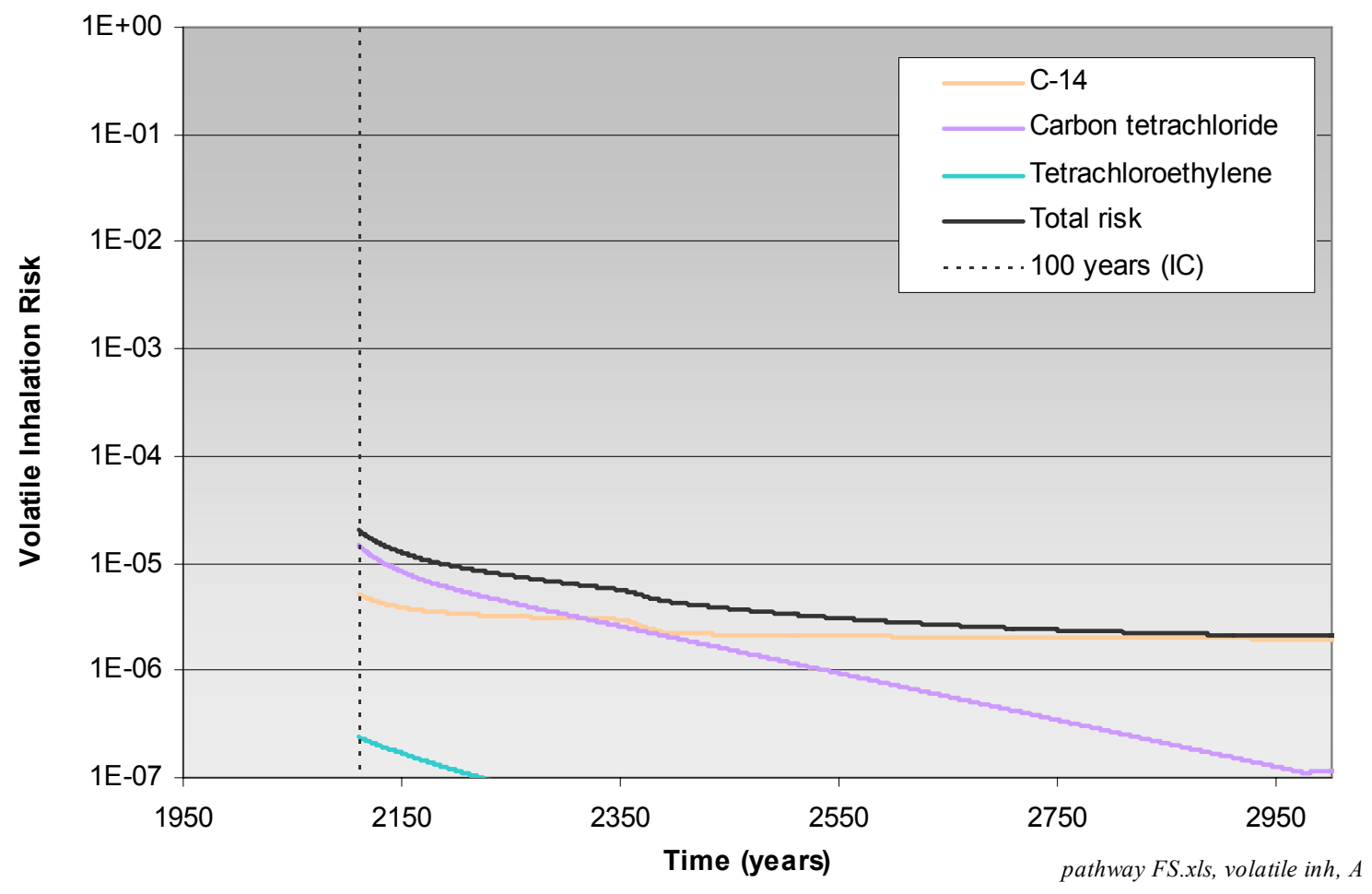

Figure 1-16. Major contributors to volatile inhalation risk.

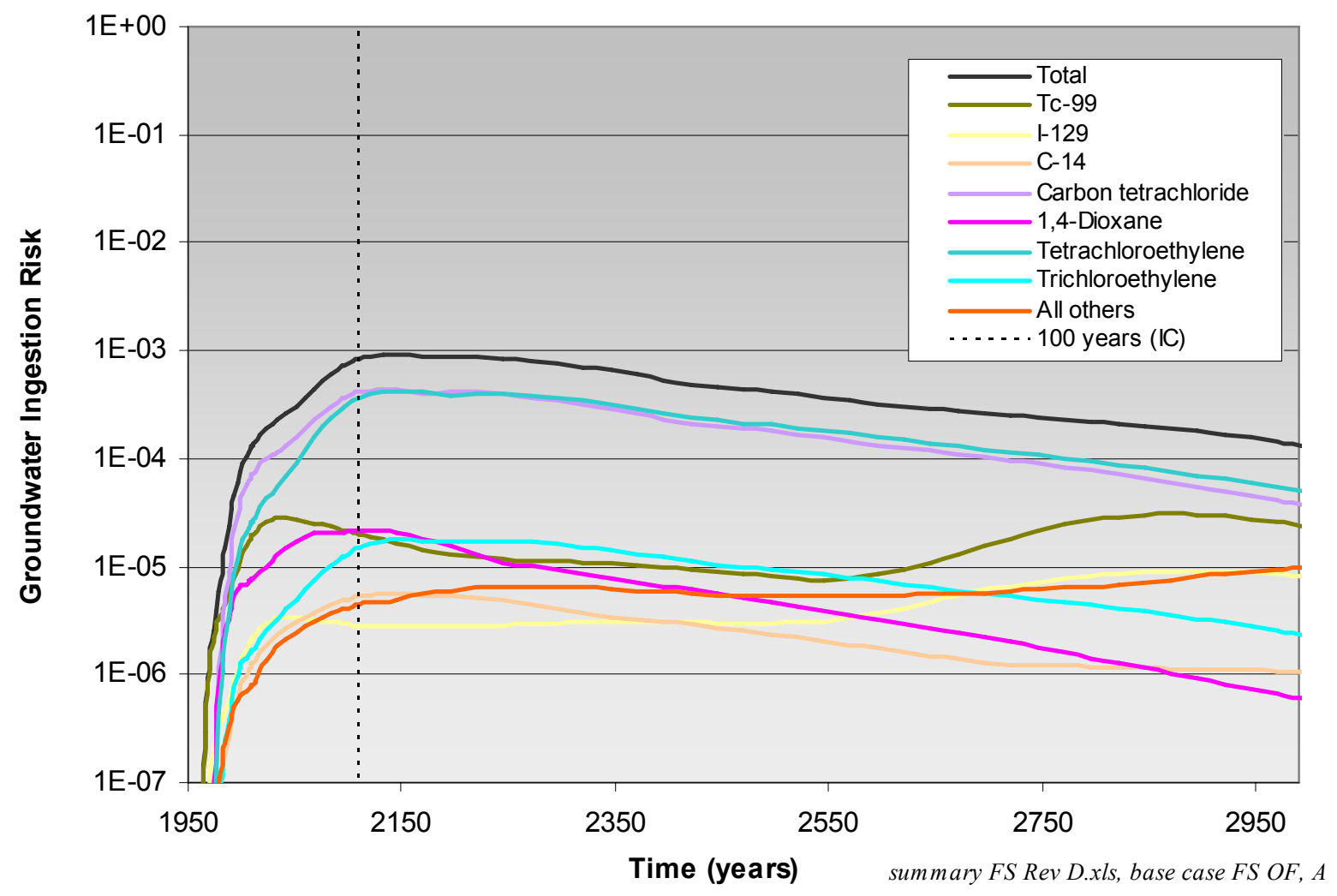

Figure 1-17. Major contributors to groundwater ingestion risk. 
Groundwater simulations were extended to 10,000 years to evaluate long-lived radionuclides that did not achieve peak simulated concentrations in the 1,000-year simulations. Estimated risk is greater than or equal to 1E-05 for eight actinides: Ac-227, Np-237, Pa-231, U-233, U-234, U-235, U-236, and U-238. Primary contributors are Np-237 and U-238. Concentrations exceed MCLs in the 10,000-year simulations for these same two actinides.

Sensitivity and qualitative uncertainty analyses were performed for parameters identified by DOE, DEQ, and EPA as important for understanding uncertainty in base-case risk. The sensitivity analysis shows the effect on predicted risk of changes in selected model inputs. With the exception of inventory sensitivity, sensitivity analysis focused on the groundwater ingestion pathway. The following list summarizes sensitivity cases:

- Inventory-To assess sensitivity to source-term inventory, risk was estimated based on upper-bound inventories. Risk estimates for most contaminants were of the same order of magnitude, with total cumulative risk for all contaminants higher by an approximate factor of 2 .

- Infiltration-Three sensitivity cases addressing infiltration rates were examined: (1) reduced background infiltration outside the SDA, (2) low infiltration inside the SDA, and (3) high uniform infiltration inside the SDA. Reduced background infiltration produced slightly higher risk estimates, while lower and higher infiltration inside the SDA paralleled lower and higher risk.

- Interbed gaps-The effect of neglecting known gaps in the B-C interbed was evaluated by completely eliminating the B-C interbed in the model; negligible effect was noted.

- $\quad$ Pit 4 retrieval and beryllium block grouting-Because the base case incorporated assumptions that beryllium blocks would be grouted and targeted waste retrieval in Pit 4 would be completed, a sensitivity case was performed to examine consequences of not completing these remedial actions. If beryllium blocks are not grouted, $\mathrm{C}-14$ groundwater ingestion risk increases slightly. If the half-acre retrieval in Pit 4 is not completed, groundwater risk shows no discernible change.

- Low-permeability zone-Effects of the postulated low-permeability zone assumed for the base case were evaluated by implementing a sensitivity case that did not include such a region in the aquifer. In the absence of a low-permeability zone, risk estimates are substantially lower (e.g., decrease from 3E-04 to 4E-05 for radionuclides, excluding Tc-99 [and collocated I-129]), further suggesting that base-case model results are conservative.

- No sorption in interbeds-Removing the effects of plutonium sorption in interbed sediment was evaluated by completely eliminating sorption in the B-C and C-D interbeds using an approach roughly equivalent to spreading the plutonium source term into a thin layer (i.e., by advective spreading in the vadose zone) and leaching it directly into the aquifer. Results of this extremely conservative simulation show several orders of magnitude increase in risk.

\subsubsection{Ecological Risk Assessment}

The ecological risk assessment was a screening-level analysis because of the fundamental assumption that the SDA will be covered with a surface barrier (DOE-ID 1998; Holdren and Broomfield 2004). Current and 100-year scenarios were evaluated for representative receptors. Contaminant screening focused evaluation on those contaminants most likely to exceed remedial action objectives; 56 contaminants of potential concern were identified - 16 radionuclides and 40 nonradionuclides. Concentrations in surface soil and subsurface intervals were estimated with the DOSTOMAN biotic uptake model. Receptor exposures were evaluated for all 16 Waste Area Group 7 
radionuclides; 8 of the 40 nonradionuclides were evaluated as indicators of potential risk. Thirteen contaminants, 10 radionuclides (i.e., Am-241, Cs-137, Pu-238, Pu-239, Pu-240, Pu-241, Ra-226, Sr-90, U-234, and U-238), and three nonradionuclides (i.e., beryllium, cadmium, and lead) were shown to pose risk greater than threshold values to Waste Area Group 7 ecological receptors in both current and future scenarios.

\subsubsection{Overall Uncertainty in Modeling and Risk Assessment}

Personnel from DOE, DEQ, and EPA have actively participated throughout development of the $\mathrm{RI} / \mathrm{BRA}$ to produce a mathematical modeling approach useful for predicting release and transport of contaminants from waste buried in the SDA (Holdren and Broomfield 2004; Holdren et al. 2006). The unchanging goal has been to develop a reasonably conservative model - one that is not excessively conservative (overpredicting concentrations) or excessively nonconservative (underpredicting concentrations). This is a difficult goal to achieve in any simulation, but even more difficult for OU 7-13/14 for several reasons, as described in the following subsections.

1.4.4.1 Inventory. The SDA is a landfill that has received thousands of shipments over the past 5 decades. Thousands of records have been researched extensively to verify source-term information for the SDA. Data have been compiled into a database that can query shipments. Though some shipment locations have been verified through probing into a few key areas, absolute certainty is not a practical objective for a 97-acre landfill (containing approximately 35 acres of waste) that has been in service since 1952. However, the database includes inventory estimates (mass or curies), an approximate location, and waste form descriptions for almost every shipment placed in the SDA. This information is used to fulfill modeling requirements for site characterization data. For instance, modeling requires information about inventories of contaminants and the physical form of the waste. Information was developed to address the following:

- Whether contaminants are in solution

- Whether contaminants are sorbed into a matrix in bags inside barrels

- Whether barrels are carbon steel or stainless steel

- Whether waste is in boxes

- Whether boxes are wood or cardboard

- How contaminants are released from waste

- $\quad$ Rate of contaminant release from waste.

1.4.4.2 Infiltration. Movement of dissolved-phase (aqueous) contaminants in the unsaturated zone is controlled by the amount of water moving through the sedimentary layers. Typically, contaminants are transported in the shallow vadose zone in pulses that correlate with precipitation. These pulses are not specifically modeled. This compromise in the temporal effects of water movement causes some uncertainty in the modeling, but was acceptable to DOE, DEQ, and EPA because pulses generally dampen with depth and do not influence long-term simulation results at depth. Water movement through sedimentary features can be described by a nonlinear set of equations, which are computer intensive to solve because the hydraulic conductivity of the layers depends on the moisture content and other characteristics of the materials in the layer. Complexity of variably saturated water movement through fractured basalts is less well understood, but significant insight into this movement and confidence in the equivalent-porous continuum modeling approach was gained by successful inverse modeling of a large-scale infiltration test that was conducted near RWMC in support of the RI/FS. 
1.4.4.3 Sorption. Transport in the vadose zone and aquifer also is controlled by the tendency of each contaminant to adsorb onto sedimentary interbeds and, to a much lesser degree, to fractures in basalt. These contaminants can exist in different forms (e.g., oxidation states) in the environment, which greatly affects sorption. Mineralogy of sedimentary interbeds varies laterally and vertically within each sedimentary feature. An attempt to characterize spatial variability using distribution coefficients measured on corehole samples was unsuccessful in identifying spatial correlation. Therefore, single average values must be used to represent sorption for each contaminant, increasing the uncertainty in modeling results. Site-specific values were applied for sediments, when available; otherwise, conservative values were selected. Sorption of contaminants was conservatively assumed to not occur with fractured basalts.

1.4.4.4 Calibration. Modeling efforts at other INL Site facilities (e.g., Test Area North and Idaho Nuclear Technology and Engineering Center) were facilitated by the presence of contaminants in soil, perched water, or the aquifer from past releases. Characterization data describing spatial and temporal aspects of these releases and presence of plumes within the aquifer provided benchmarks for model development. Fate and transport models could be reasonably calibrated to these plumes. A similar approach could not be implemented for OU 7-13/14 because well-defined plumes, patterns of detection, and consistent trends in concentrations do not exist, except for VOCs. Simulations for dissolved-phase contaminants, therefore, can be compared only to the absence or presence of contaminants in monitoring. The model sometimes predicts the presence of contaminants in the unsaturated zone or in the regional aquifer when those contaminants have not been detected. This modeling effort, except for calibrated VOC modeling, is wholly predictive.

1.4.4.5 Simulation Periods. Because this modeling effort is wholly predictive (except for VOCs), the predictive nature of the modeling for 100-year timeframes (i.e., restoration timeframe) is uncertain, and the degree of uncertainty is much greater for the longer, 1,000-year timeframes. This uncertainty was recognized and accepted by DOE, DEQ, and EPA in the context of developing risk management decisions for OU 7-13/14. Extending groundwater simulations to 10,000 years was identified as necessary to assess potential long-term risk to human health and the environment because of the long-term presence and slow movement of some COCs. However, the level of uncertainty for these predictions is very large. These modeling predictions and the relative degree of uncertainty will be considered by DOE, DEQ, and EPA in developing risk management decisions.

\subsubsection{Contaminants of Concern}

Results of the risk assessment and uncertainty associated with those results were used to transition from the RI/BRA to the feasibility study. Contaminants of potential concern assessed in the RI/BRA (i.e., those contaminants that might cause risk to exceed threshold values if no remediation is implemented) were screened to identify COCs (i.e., those contaminants that might warrant risk management decisions). Contaminants of concern are identified by reviewing human health risk estimates and simulated groundwater concentrations for contaminants of potential concern and applying screening criteria. Contaminants of concern are those individual contaminants that, when combined, cause cumulative risk to exceed threshold values. The EPA established a risk range from $10^{-6}$ to $10^{-4}$ for managing risk and expresses preference for the more protective end of the range (EPA 1991). The presence of multiple contaminants and exposure pathways (EPA 1989), land use projections (EPA 1995), and guidelines for risk management decisions (EPA 1997a) also are important considerations in identifying COCs. Carcinogenic risk of $10^{-4}$ and a hazard index of 1 for a future residential scenario are typical human health threshold values applied by DOE, DEQ, and EPA to support risk management decisions at the INL Site. Contaminants of concern then become the focus of the evaluation of remedial alternatives in this feasibility study and, ultimately, risk management decisions. 
The RI/BRA estimated human health risks for occupational, residential, and inadvertent intruder scenarios. Because residential risks were highest (i.e., are bounding), they are used to identify primary COCs for OU 7-13/14 based on either of two screening criteria:

1. Contaminant has a total carcinogenic risk estimate greater than or equal to $1 \mathrm{E}-05$ or a hazard index greater than or equal to 1 within the 1,000-year simulation period for the future residential exposure scenario. (Note: The value of $1 \mathrm{E}-05$ is used to identify COCs to ensure that additive carcinogenic risk from multiple contaminants remains less than $10^{-4}$.)

2. Simulated groundwater concentrations exceed the EPA MCLs within the 1,000-year simulation period.

Modeling refinements implemented for this feasibility study - subsequent to publication of the RI/BRA - did not modify the list of COCs, though estimated risk, hazard index, or groundwater concentrations were modified for several COCs (i.e., I-129, Tc-99, nitrate, and VOCs). Tables 1-1 and 1-2 identify radionuclide and nonradionuclide COCs, respectively, based on the above criteria. In total, 18 primary COCs are identified: 12 radionuclides and six nonradionuclides. Figure 1-11 illustrates cumulative risk over time for all COCs for the future residential scenario. Total cumulative risk for all contaminants is at a maximum of 7E-03 at the end of the 1,000-year simulation period in the year 3010 . Surface exposure pathways contribute the most risk throughout the 1,000-year simulation period, with a maximum of 7E-03. As shown in Figures 1-12 through 1-17, the most significant contributors to surface pathway risk are Am-241, carbon tetrachloride, Cs-137, Pu-239, and Sr-90.

Cumulative groundwater ingestion risk within the 1,000-year simulation period reaches a peak of 7E-04 at the end of the simulated IC period, when the location for the hypothetical residential receptor shifts from the INL Site boundary to the SDA boundary. Carbon tetrachloride and tetrachloroethylene are the primary groundwater pathway risk drivers in the 1,000-year timeframe. Groundwater ingestion risk steadily diminishes over the 1,000-year simulation period (see Figure 1-17). Figures 1-18, 1-19, and 1-20 provide cumulative groundwater ingestion risk isopleths for the 1,000-year residential scenario. In addition, the groundwater ingestion hazard index for carbon tetrachloride is $1 \mathrm{E}+01$. Figure 1-21 shows maximum hazard index isopleths.

Simulated groundwater concentrations exceed MCLs (EPA 2000) within the 1,000-year simulation period for eight contaminants: two radionuclides and six nonradionuclides. Both radionuclides (i.e., Tc-99 and collocated I-129) and four of the nonradionuclides (i.e., carbon tetrachloride, 1,4-dioxane, nitrate, and trichloroethylene) are identified as COCs because they exceed risk thresholds. Two additional COCs (i.e., methylene chloride and tetrachloroethylene) are identified solely on their potential to exceed their respective MCLs.

In total, 18 primary COCs are identified, based on human health risk estimates or potential to exceed MCLs in the aquifer. Table 1-3 identifies waste streams associated with these primary COCs. Several COCs (i.e., $\mathrm{Pb}-210$, Ra-226, Ra-228, and Th-228) have very small initial inventories generated at the INL Site; however, risk is driven by inventories generated through ingrowth attributable to Rocky Flats Plant waste streams. 
Table 1-1. Primary radionuclide contaminants of concern based on 1,000-year future residential scenario peak risk estimates and estimated peak groundwater concentrations in the absence of remedial action at the Subsurface Disposal Area boundary.

\begin{tabular}{|c|c|c|c|c|c|c|}
\hline Contaminant & $\begin{array}{l}\text { Peak } \\
\text { Risk }\end{array}$ & Year $^{\mathrm{a}}$ & Primary Exposure Pathways ${ }^{b}$ & $\begin{array}{c}\text { Peak Aquifer } \\
\text { Concentration } \\
(\mathrm{pCi} / \mathrm{L})\end{array}$ & Year $^{\mathrm{a}}$ & $\begin{array}{c}\text { Maximum } \\
\text { Contaminant } \\
\text { Level } \\
(\mathrm{pCi} / \mathrm{L})\end{array}$ \\
\hline Ac- 227 & 5E-07 & 3010 & Groundwater ingestion & $5.30 \mathrm{E}-02$ & 3010 & $15^{\mathrm{c}}$ \\
\hline Am-241 & $3 \mathrm{E}-03$ & 2594 & External exposure, soil ingestion, and inhalation & $6.80 \mathrm{E}-08$ & 3010 & $15^{\mathrm{c}}$ \\
\hline Am-243 & $1 \mathrm{E}-07$ & 3008 & External exposure & $1.29 \mathrm{E}-09$ & 3010 & $15^{\mathrm{c}}$ \\
\hline $\mathrm{C}-14$ & $1 \mathrm{E}-05$ & 2110 & $\begin{array}{l}\text { Groundwater ingestion and inhalation of volatiles } \\
\text { (at the surface) }\end{array}$ & $1.74 \mathrm{E}+02$ & 2145 & 2,000 \\
\hline $\mathrm{Cl}-36$ & 2E-06 & 2384 & Groundwater ingestion and crop ingestion & $2.12 \mathrm{E}+01$ & 2395 & 700 \\
\hline Cs-137 & 2E-03 & 2110 & External exposure and crop ingestion & NA & NA & NA \\
\hline $\mathrm{I}-129$ & 9E-06 & 2870 & Groundwater ingestion & $2.93 \mathrm{E}+00$ & 2870 & 1 \\
\hline $\mathrm{Nb}-94$ & $2 \mathrm{E}-06$ & 3010 & External exposure & NA & NA & NA \\
\hline $\mathrm{Np}-237$ & $7 \mathrm{E}-06$ & 2647 & External exposure & $6.53 \mathrm{E}-02$ & 3010 & $15^{\mathrm{c}}$ \\
\hline $\mathrm{Pa}-231$ & $3 \mathrm{E}-07$ & 3010 & Groundwater ingestion & $8.17 \mathrm{E}-02$ & 3010 & $15^{\mathrm{c}}$ \\
\hline $\mathrm{Pb}-210$ & $3 \mathrm{E}-05$ & 3010 & Crop ingestion and soil ingestion & $1.02 \mathrm{E}-05$ & 3010 & NA \\
\hline $\mathrm{Pu}-238$ & $1 \mathrm{E}-06$ & 2262 & Soil ingestion, crop ingestion, and inhalation & $6.10 \mathrm{E}-19$ & 2920 & $15^{\mathrm{c}}$ \\
\hline $\mathrm{Pu}-239$ & 3E-03 & 3010 & Soil ingestion, crop ingestion, and inhalation & $5.19 \mathrm{E}-10$ & 3010 & $15^{\mathrm{c}}$ \\
\hline $\mathrm{Pu}-240$ & $6 \mathrm{E}-04$ & 3010 & Soil ingestion, crop ingestion, and inhalation & $1.28 \mathrm{E}-10$ & 3010 & $15^{\mathrm{c}}$ \\
\hline Ra-226 & 7E-04 & 3010 & External exposure and crop ingestion & $1.30 \mathrm{E}-05$ & 3010 & 5 \\
\hline Ra-228 & $3 \mathrm{E}-05$ & 3010 & External exposure & $1.97 \mathrm{E}-09$ & 3010 & 5 \\
\hline Sr-90 & 1E-03 & 2110 & $\begin{array}{l}\text { Crop ingestion, external exposure, and soil } \\
\text { ingestion }\end{array}$ & NA & NA & NA \\
\hline Tc-99 & $5 \mathrm{E}-05$ & 2858 & $\begin{array}{l}\text { Groundwater ingestion and crop ingestion } \\
\text { (crops irrigated with contaminated groundwater) }\end{array}$ & $5.34 \mathrm{E}+02$ & 2870 & 900 \\
\hline Th-228 & $5 \mathrm{E}-05$ & 3010 & External exposure & NA & NA & NA \\
\hline Th-229 & $4 \mathrm{E}-07$ & 3010 & Groundwater ingestion and external exposure & $2.64 \mathrm{E}-02$ & 3010 & $15^{\mathrm{c}}$ \\
\hline Th-230 & $1 \mathrm{E}-08$ & 3010 & Crop ingestion, soil ingestion, and inhalation & $3.01 \mathrm{E}-04$ & 3010 & $15^{\mathrm{c}}$ \\
\hline Th-232 & $3 \mathrm{E}-07$ & 3010 & Crop ingestion, soil, ingestion, and inhalation & $2.82 \mathrm{E}-09$ & 3010 & $15^{\mathrm{c}}$ \\
\hline $\mathrm{U}-233$ & $4 \mathrm{E}-06$ & 3010 & Groundwater ingestion & $2.90 \mathrm{E}+00$ & 3010 & $2.9 \mathrm{E}+05^{\mathrm{d}}$ \\
\hline $\mathrm{U}-234$ & $6 \mathrm{E}-07$ & 3010 & Groundwater ingestion & $3.97 \mathrm{E}-01$ & 3010 & $1.87 \mathrm{E}+05^{\mathrm{d}}$ \\
\hline $\mathrm{U}-235$ & 2E-07 & 2286 & External exposure and groundwater ingestion & $1.19 \mathrm{E}-01$ & 3010 & $6.49 \mathrm{E}+01^{\mathrm{d}}$ \\
\hline $\mathrm{U}-236$ & 9E-07 & 3010 & Groundwater ingestion & $6.24 \mathrm{E}-01$ & 3010 & $1.94 \mathrm{E}+03^{\mathrm{d}}$ \\
\hline U-238 & $1 \mathrm{E}-06$ & 2284 & External exposure and groundwater ingestion & $5.52 \mathrm{E}-01$ & 3010 & $1.01 \mathrm{E}+01^{\mathrm{d}}$ \\
\hline \multirow{2}{*}{\multicolumn{7}{|c|}{$\begin{array}{l}\text { a. Peak years may differ for maximum risk and groundwater concentration because they are computed differently. Risk is averaged over time } \\
\text { (i.e., a } 30 \text {-year rolling average) while simulated aquifer concentrations represent a single year. } \\
\text { b. All complete exposure pathways are assessed in the baseline risk assessment; those contributing most to risk are listed as primary exposure } \\
\text { pathways. For COCs, all exposure pathways with risk greater than } 1 \mathrm{E}-05 \text { are listed from highest to lowest risk. } \\
\text { c. The limit is } 15 \mathrm{pCi} / \mathrm{L} \text { for total alpha ( } 40 \mathrm{CFR} 141) \text {. } \\
\text { d. The limit is } 3 \mathrm{E}-02 \mathrm{mg} / \mathrm{L}(30 \mu \mathrm{g} / \mathrm{L} \text { ) for total uranium. To compare concentrations of uranium isotopes, } 3 \mathrm{E}-02 \mathrm{mg} / \mathrm{L} \text { is converted to the equivalent } \\
\text { activity for each isotope. }\end{array}$}} \\
\hline & & & & & & \\
\hline \multicolumn{3}{|c|}{ Surface exposure pathway COC } & $\begin{array}{l}\text { COC for both surface expos } \\
\text { and groundwater pathways }\end{array}$ & $\begin{array}{l}\text { COC base } \\
\text { the maxim }\end{array}$ & $\begin{array}{l}\mathrm{d} \text { on poter } \\
\text { um conta }\end{array}$ & $\begin{array}{l}\text { atial to exceed } \\
\text { minant level }\end{array}$ \\
\hline
\end{tabular}


Table 1-2. Nonradionuclide contaminants of concern based on 1,000-year future residential scenario peak risk estimates and estimated peak groundwater concentrations in the absence of remedial action at the Subsurface Disposal Area boundary.

\begin{tabular}{|c|c|c|c|c|c|c|c|c|}
\hline Contaminant & Peak Risk & Year $^{\mathrm{a}}$ & $\begin{array}{c}\text { Peak } \\
\text { Hazard } \\
\text { Index }\end{array}$ & Year $^{\mathrm{a}}$ & Primary Exposure Pathways ${ }^{\mathrm{b}}$ & $\begin{array}{c}\text { Peak Aquifer } \\
\text { Concentration } \\
(\mathrm{mg} / \mathrm{L})^{\mathrm{b}}\end{array}$ & Year $^{\mathrm{a}}$ & $\begin{array}{c}\text { Maximum } \\
\text { Contaminant } \\
\text { Level } \\
(\mathrm{mg} / \mathrm{L}) \\
\end{array}$ \\
\hline Carbon tetrachloride & 4E-04 & 2117 & $1 \mathrm{E}+01$ & 2119 & $\begin{array}{l}\text { Groundwater ingestion and inhalation of } \\
\text { volatiles (at the surface) }\end{array}$ & $2.85 \mathrm{E}-01$ & 2133 & $5.00 \mathrm{E}-03$ \\
\hline 1,4-Dioxane & $2 \mathrm{E}-05$ & 2110 & NA & NA & Groundwater ingestion & $1.67 \mathrm{E}-01$ & 2120 & $3.00 \mathrm{E}-03^{\mathrm{c}}$ \\
\hline Methylene chloride & $5 \mathrm{E}-06$ & 2244 & $3 \mathrm{E}-02$ & 2244 & Groundwater ingestion & $5.76 \mathrm{E}-02$ & 2245 & $5.00 \mathrm{E}-03$ \\
\hline Nitrate & NA & NA & 9E-01 & 2283 & Groundwater ingestion & $4.93 \mathrm{E}+01$ & 2295 & 10 \\
\hline Tetrachloroethylene & $4 \mathrm{E}-04$ & 2136 & $3 \mathrm{E}-01$ & 2136 & $\begin{array}{l}\text { Groundwater ingestion and dermal exposure } \\
\text { (e.g., showering) }\end{array}$ & $6.69 \mathrm{E}-02$ & 2145 & $5.00 \mathrm{E}-03$ \\
\hline Trichloroethylene & $2 \mathrm{E}-05$ & 2141 & NA & NA & Groundwater ingestion & $1.15 \mathrm{E}-01$ & 2145 & $5.00 \mathrm{E}-03$ \\
\hline
\end{tabular}

a. Peak years may differ for maximum risk (or hazard index) and groundwater concentration because they are computed differently. Risk (and hazard index) is averaged over time (i.e., a 30-year rolling average) while simulated aquifer concentrations represent a single year.

b. All complete exposure pathways are assessed in the baseline risk assessment; those contributing most to risk are listed as primary exposure pathways. For COCs, all exposure pathways with risk greater than $1 \mathrm{E}-05$ or a hazard index greater than or equal to 1 are listed from highest to lowest risk.

c. No MCL is given, but a health advisory level is provided for reference.

$\mathrm{COC}=$ contaminant of concern

$\mathrm{MCL}=$ maximum contaminant level

\begin{tabular}{lll}
\hline Surface exposure pathway COC & Groundwater pathway COC & $\begin{array}{l}\text { COC for both surface exposure and } \\
\text { groundwater pathways }\end{array}$
\end{tabular}




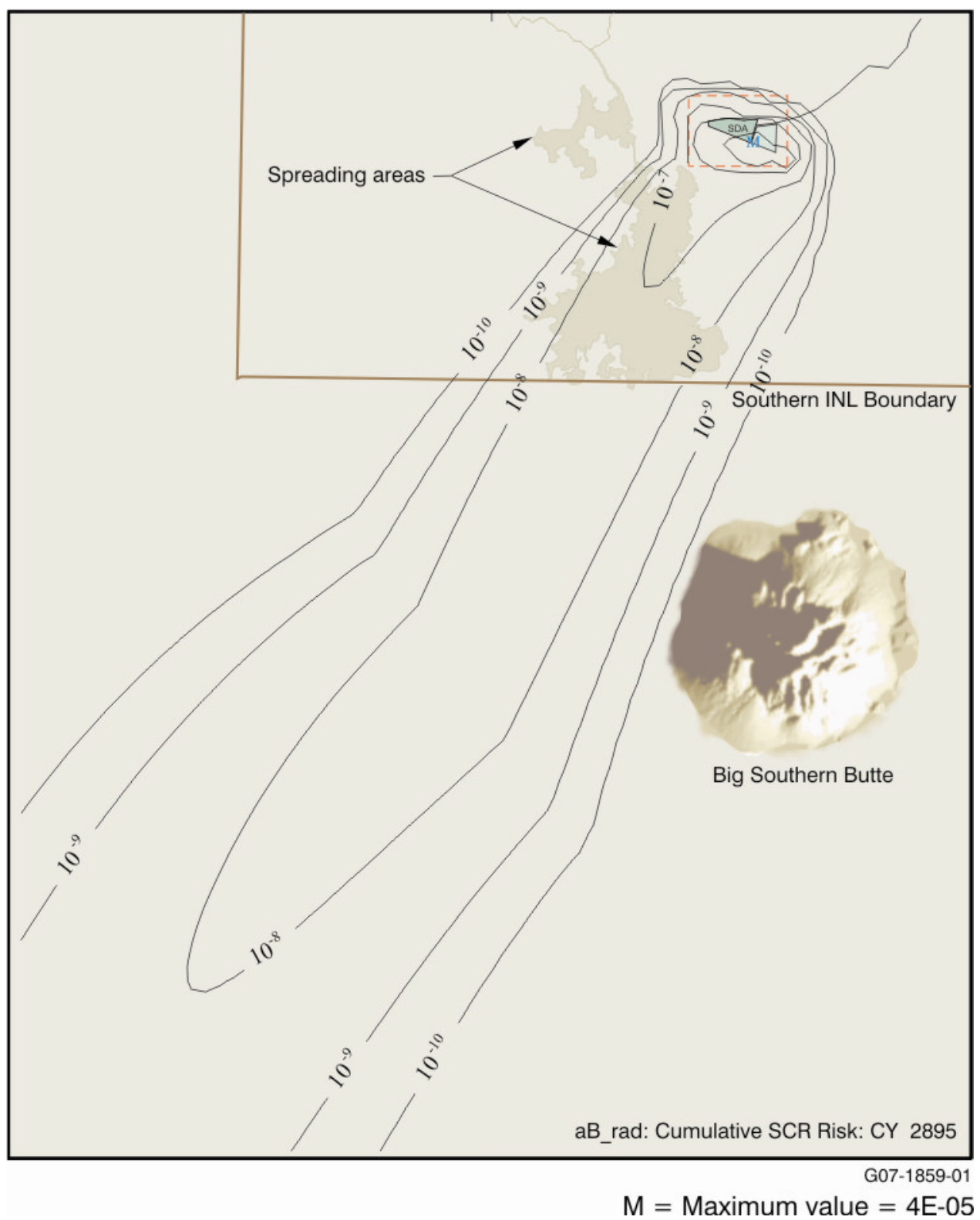

Figure 1-18. Peak cumulative groundwater ingestion risk isopleths for radionuclides for the regional refined grid. 


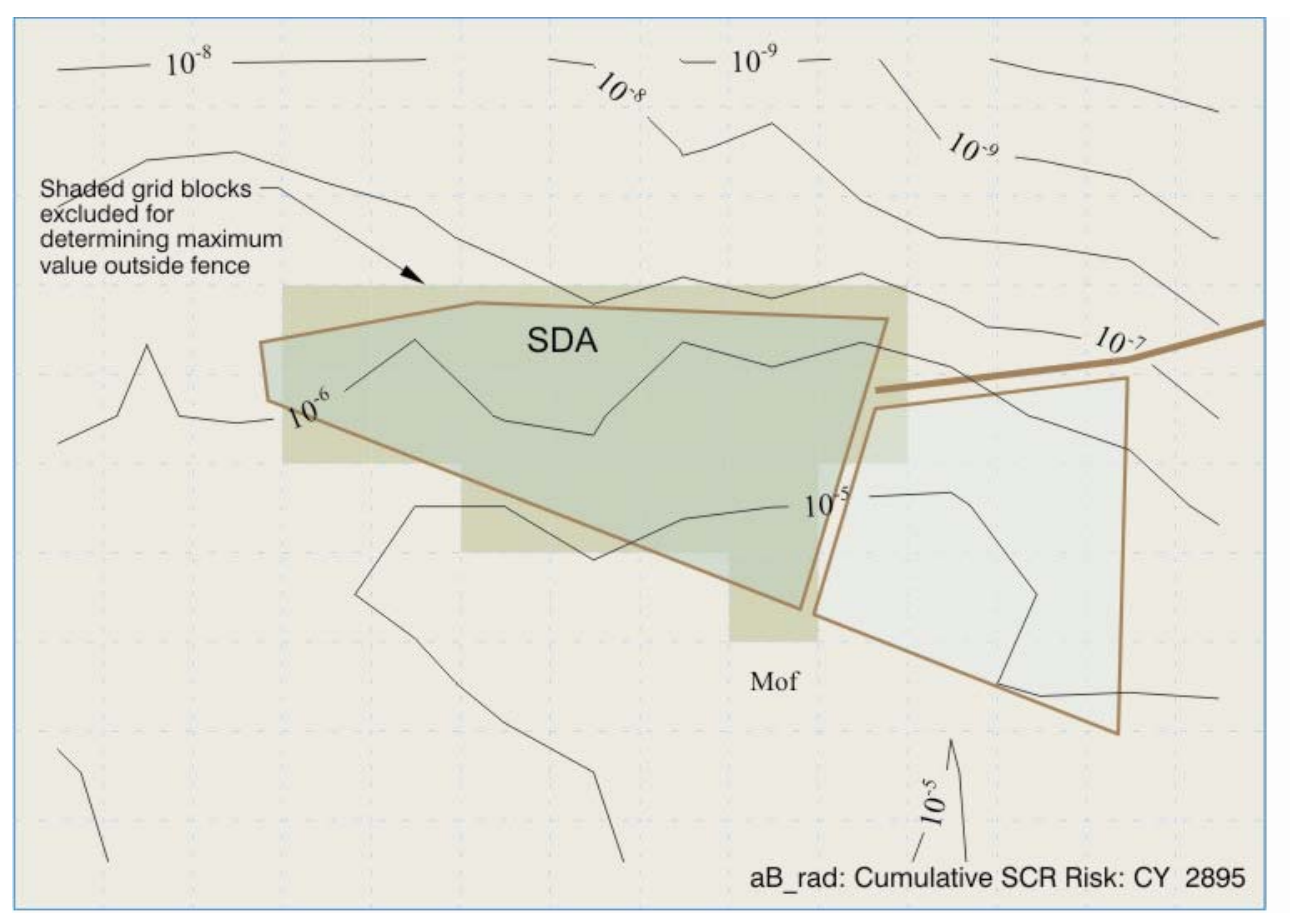

G07-1859-02-65

Mof $=$ Maximum value outside fence $=4 \mathrm{E}-05$

Figure 1-19. Peak cumulative groundwater ingestion risk isopleths for radionuclides for the aquifer refined grid.

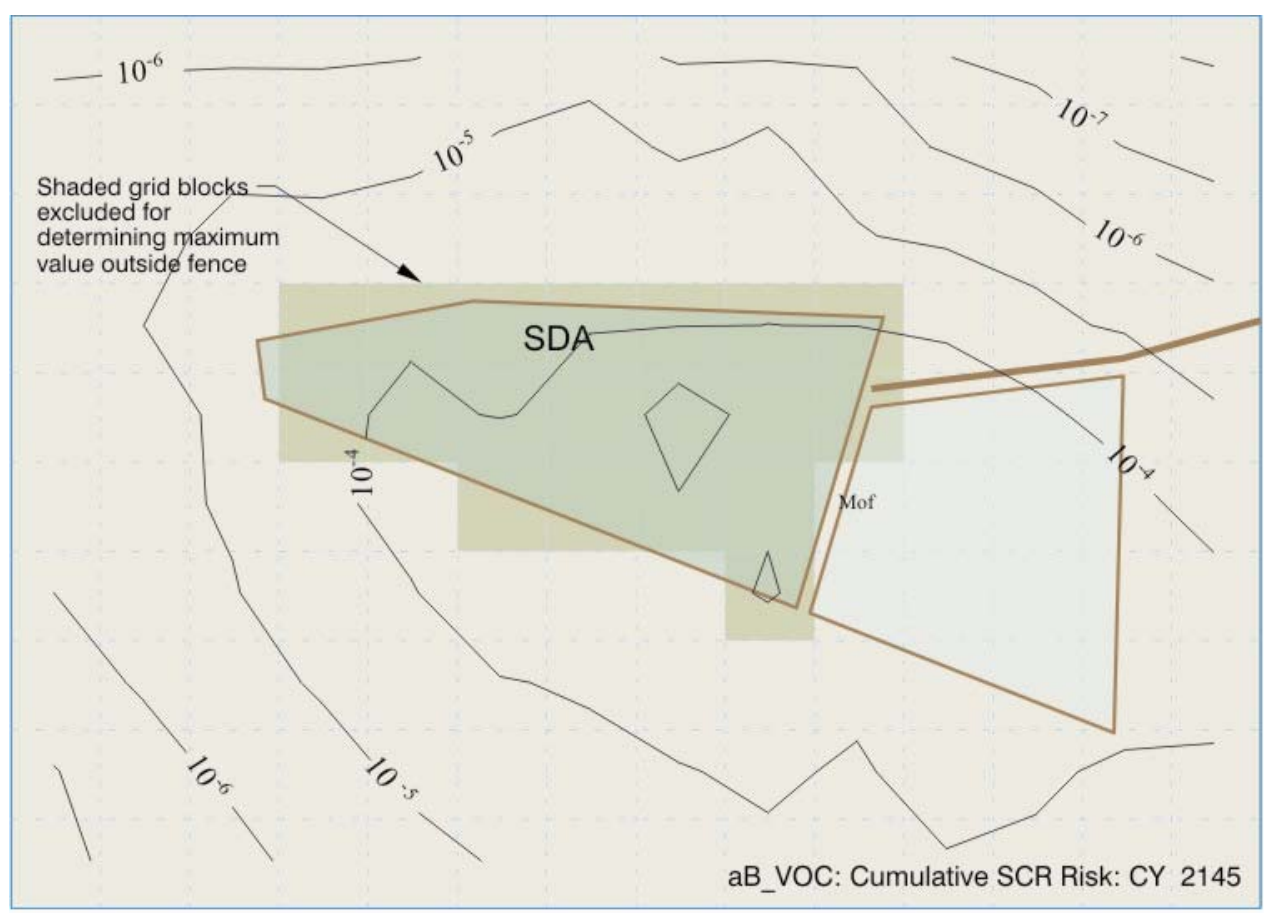

G07-1859-03

Mof $=$ Maximum value outside fence $=9 \mathrm{E}-04$

Figure 1-20. Peak cumulative groundwater ingestion risk isopleths for volatile organic compounds. 


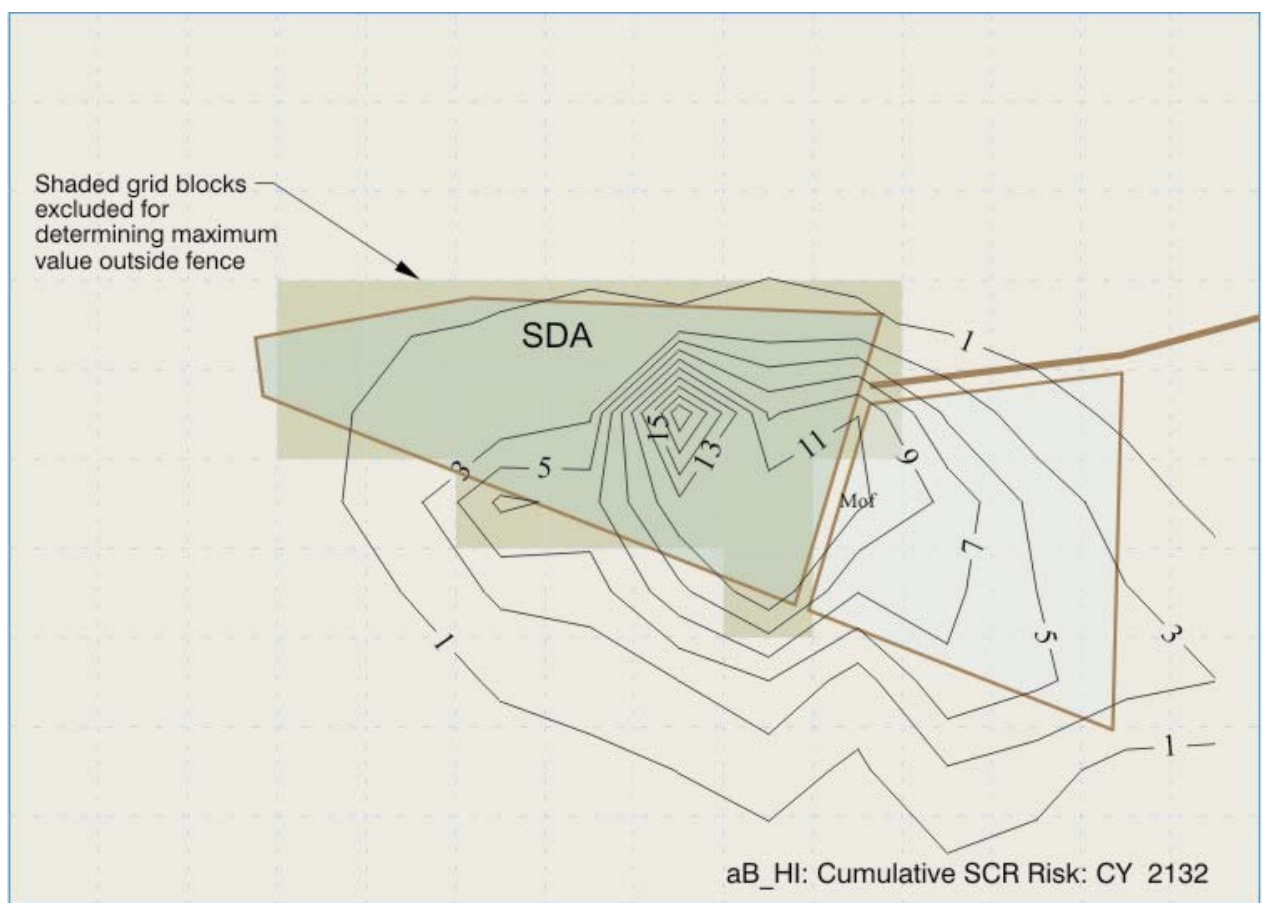

G07-1859-04

Mof $=$ Maximum value outside fence $=1.5 \mathrm{E}-01$

Figure 1-21. Peak cumulative groundwater ingestion hazard index isopleths. 
Table 1-3. Original waste generators and general locations of primary contaminants of concern in the Subsurface Disposal Area.

\begin{tabular}{|c|c|c|c|c|}
\hline Contaminant & Waste Generator $^{\mathrm{a}}$ & $\begin{array}{c}\text { Portion } \\
(\%)\end{array}$ & $\begin{array}{c}\text { Initial } \\
\text { Inventory }^{\mathrm{b}}\end{array}$ & Areas of Highest Densities \\
\hline Am-241 & Rocky Flats Plant & 100.0 & $2.43 \mathrm{E}+05$ & Pits \\
\hline $\mathrm{C}-14$ & INL Site & 100.0 & $7.31 \mathrm{E}+02$ & Trenches and soil vaults \\
\hline Cs-137 & INL Site & 100.0 & $1.68 \mathrm{E}+05$ & Trenches and soil vaults \\
\hline $\mathrm{I}-129$ & INL Site & 100.0 & $1.88 \mathrm{E}-01$ & Trenches and soil vaults \\
\hline $\mathrm{Pb}-210$ & Rocky Flats Plant & $\mathrm{NA}^{\mathrm{c}}$ & $\mathrm{NA}^{\mathrm{c}}$ & Pits \\
\hline $\mathrm{Pb}-210$ & INL Site & $100.0^{\mathrm{c}}$ & $5.62 \mathrm{E}-07^{\mathrm{c}}$ & Trenches \\
\hline $\mathrm{Pu}-238^{\mathrm{d}}$ & Rocky Flats Plant & 88.7 & $1.85 \mathrm{E}+03$ & Pits \\
\hline $\mathrm{Pu}-238^{\mathrm{d}}$ & INL Site & 11.3 & $2.35 \mathrm{E}+02$ & Trenches \\
\hline Pu-239 & Rocky Flats Plant & 98.3 & $6.30 \mathrm{E}+04$ & Pits \\
\hline Pu-239 & INL Site & 1.7 & $1.08 \mathrm{E}+03$ & Trenches \\
\hline $\mathrm{Pu}-240$ & Rocky Flats Plant & 96.6 & $1.40 \mathrm{E}+04$ & Pits \\
\hline $\mathrm{Pu}-240$ & INL Site & 3.4 & $5.03 \mathrm{E}+02$ & Trenches \\
\hline Ra-226 & Rocky Flats Plant & $\mathrm{NA}^{\mathrm{e}}$ & $\mathrm{NA}^{\mathrm{e}}$ & Pits \\
\hline Ra-226 & INL Site & $100.0^{\mathrm{e}}$ & $6.53 \mathrm{E}+01^{\mathrm{e}}$ & Trenches \\
\hline Ra-228 & Rocky Flats Plant & $N A^{f}$ & $N A^{f}$ & Pits \\
\hline Ra-228 & INL Site & $100.0^{\mathrm{f}}$ & $3.66 \mathrm{E}-05^{\mathrm{f}}$ & Trenches \\
\hline Sr-90 & INL Site & 100.0 & $1.36 \mathrm{E}+05$ & Trenches and soil vaults \\
\hline Tc-99 & INL Site & 100.0 & $4.23 \mathrm{E}+01$ & Trenches and soil vaults \\
\hline Th-228 & Rocky Flats Plant & $\mathrm{NA}^{\mathrm{g}}$ & $\mathrm{NA}^{\mathrm{g}}$ & Pits \\
\hline Th-228 & INL Site & $100.0^{\mathrm{g}}$ & $1.05 \mathrm{E}+01^{\mathrm{g}}$ & Low-Level Waste Pit \\
\hline Carbon tetrachloride & Rocky Flats Plant & 100.0 & $7.90 \mathrm{E}+08$ & Pits \\
\hline 1,4-Dioxane & Rocky Flats Plant & 96.0 & $1.87 \mathrm{E}+06$ & Pits (with carbon tetrachloride) \\
\hline 1,4-Dioxane & INL Site & 4.0 & $4.24 \mathrm{E}+04$ & Pits, trenches, and soil vaults \\
\hline Methylene chloride & Rocky Flats Plant & 100.0 & $1.41 \mathrm{E}+07$ & Pits \\
\hline Nitrate (as nitrogen) & Rocky Flats Plant & 89.1 & $4.06 \mathrm{E}+08$ & Pits and Pad A \\
\hline Nitrate (as nitrogen) & INL Site & 10.9 & $4.98 \mathrm{E}+07$ & Pits \\
\hline Tetrachloroethylene & Rocky Flats Plant & 100.0 & $9.87 \mathrm{E}+07$ & Pits (with carbon tetrachloride) \\
\hline Trichloroethylene & Rocky Flats Plant & 99.6 & $8.92 \mathrm{E}+07$ & Pits (with carbon tetrachloride) \\
\hline Trichloroethylene & INL Site & 0.4 & $4.07 \mathrm{E}+05$ & Trenches \\
\hline \multicolumn{5}{|c|}{$\begin{array}{l}\text { a. Portions listed for INL Site waste may include small amounts from off-INL Site waste generators, excluding the Rocky Flats Plant. } \\
\text { b. Initial inventory is inventory at time of disposal with no adjustments for volatile organic compounds released to the atmosphere, } \\
\text { degradation, radioactive decay and ingrowth, or any other mechanism. Units are curies for radionuclides and grams for nonradionuclides. } \\
\text { c. Risk is attributable to ingrowth of Pb-210 from Pu-238 and U-238; initial disposal quantities are not significant. } \\
\text { d. Pu-238 is not, itself, a COC. However, Pu- } 238 \text { decays to two COCs (i.e., Pb-210 and Ra-226). } \\
\text { e. Risk is attributable to ingrowth of Ra-226 from Pu-238 and U-238; initial disposal quantities are not significant. } \\
\text { f. Risk is attributable to ingrowth of Ra-228; initial disposal quantities are not significant. Ingrowth is primarily associated with Pu-240 from } \\
\text { the Rocky Flats Plant. } \\
\text { g. Risk is attributable to ingrowth of Th-228; initial disposal quantities are not significant. Ingrowth is primarily associated with Pu-240 from } \\
\text { the Rocky Flats Plant, though a small portion arises and then decays from U-232. }\end{array}$} \\
\hline \multicolumn{5}{|c|}{$\begin{array}{l}\mathrm{COC}=\text { contaminant of concern } \\
\mathrm{INL}=\text { Idaho National Laboratory }\end{array}$} \\
\hline
\end{tabular}


- Inhibit migration of COCs, as identified in the RI/BRA, into the vadose zone and the underlying aquifer

- $\quad$ Prevent unacceptable exposure to biota from contaminated soil

- Inhibit transport of COCs to the surface by plants and animals.

\subsection{Preliminary Remediation Goals}

Preliminary remediation goals are measurable quantities used to demonstrate that remedial action objectives (see Section 1.5) are satisfied. Because candidate remedial actions for the SDA primarily focus on source control (i.e., methods to prevent or significantly reduce contaminant release from buried waste), performance objectives are defined-instead of contaminant-specific concentrations — as follows:

- Reduce carcinogenic risk at the surface to less than $10^{-6}$ to $10^{-4}$ by maintaining an effective dose equivalent rate at the surface less than $15 \mathrm{mrem} /$ year (EPA 1997b) as a measurable performance objective

- $\quad$ Reduce infiltration such that COC concentrations in the aquifer are less than MCLs.

In addition, goals identified under OU 7-08 for two depth intervals in the vadose zone immediately beneath the SDA are adopted as preliminary remediation goals to reduce transport of VOCs to the aquifer:

- Maintain concentrations of carbon tetrachloride in vadose zone soil vapor above the B-C interbed (approximately the 30 to $100-\mathrm{ft}$ depth interval) to less than $190 \mathrm{ppm}$

- Maintain concentrations of carbon tetrachloride in vadose zone soil vapor between the B-C and C-D interbeds (approximately the 100 to 240 -ft depth interval) to less than $39 \mathrm{ppm}$.

The OU 7-08 Data Quality Objectives Summary Report (INL 2005) explains how carbon tetrachloride remediation goals were determined. Appendix D provides additional information on VOC remediation goals.

\subsection{Assumptions for the Feasibility Study}

The list below represents overarching assumptions for this feasibility study. Subsequent sections address technology and alternative-specific assumptions. The Work Plan (Becker et al. 1996) and its addenda (DOE-ID 1998; Holdren and Broomfield 2004) established many of these assumptions, while others were adopted during development of the feasibility study:

- $\quad$ Land use inside the SDA is industrial; residential land use on the SDA itself will not occur.

- $\quad$ Long-term ICs will be established and maintained to restrict land use.

- $\quad$ Environmental monitoring will continue throughout ICs.

- $\quad$ Lockheed Martin Advanced Environmental Systems structures will be removed under another program before SDA remedial action. (Note: These structures must be removed before the surface barrier can be constructed.) 
- $\quad$ The OU 7-13/14 ROD will supersede the OU 7-08 ROD (i.e., OCVZ) (DOE-ID 1994a) and OCVZ vapor extraction operations will continue until remediation goals identified and evaluated under OU 7-13/14 are satisfied.

- $\quad$ The OU 7-13/14 ROD will supersede the OU 7-12 ROD (i.e., Pad A) (DOE-ID 1994b).

- $\quad$ The ROD for OU 7-10, Pit 9 Process Demonstration Interim Action (DOE-ID 1993), will be addressed in future decisions as part of the OU 7-13/14 ROD.

- $\quad$ The LLW Disposal Facility (also known as the LLW Pit) will accept contact-handled waste through 2008 and remote-handled waste through 2009, then will be closed under DOE Order 435.1-1 and transferred to OU 7-13/14 to facilitate remediation under CERCLA. (Note: this assumption was adopted for modeling in this feasibility study; however, operation of the LLW Pit could continue until it interferes with implementation of the OU 7-13/14 ROD.) Projected inventory for the LLW Pit is evaluated in both the baseline risk assessment and this feasibility study.

\subsection{References}

40 CFR 141, 2006, "National Primary Drinking Water Regulations," Code of Federal Regulations, Office of the Federal Register.

40 CFR 300, 2006, "National Oil and Hazardous Substances Pollution Contingency Plan," Code of Federal Regulations, Office of the Federal Register.

42 USC $\S 6901$ et seq., 1976, "Resource Conservation and Recovery Act of 1976 (Solid Waste Disposal Act)," United States Code.

42 USC $\S 9601$ et seq., 1980, “Comprehensive Environmental Response, Compensation and Liability Act of 1980 (CERCLA/Superfund)," United States Code.

54 FR 48184, 1989, "National Priorities List of Uncontrolled Hazardous Waste Sites; Final Rule," Federal Register.

Anderson, Danny L. and Bruce H. Becker, 2006, Source Release Modeling Report for Operable Unit 7-13/14, ICP/EXT-05-01039, Idaho National Laboratory, Idaho Cleanup Project.

Anderson, S. R., M. J. Liszewski, and D. J. Ackerman, 1996, Thickness of Surficial Sediment at and Near the Idaho National Engineering Laboratory, Idaho, U.S. Geological Survey Open-File Report 96-330, U.S. Geological Survey.

Batcheller, Thomas A. and George D. Redden, 2004, Colloidal Plutonium at the Operable Unit 7-13/14 Subsurface Disposal Area: Estimate of Inventory and Transport Properties, ICP/EXT-04-00253, Idaho National Engineering and Environmental Laboratory, Idaho Completion Project.

Becker, B. H., T. A. Bensen, C. S. Blackmore, D. E. Burns, B. N. Burton, N. L. Hampton, R. M. Huntley, R. W. Jones, D. K. Jorgensen, S. O. Magnuson, C. Shapiro, and R. L. VanHorn, 1996, Work Plan for Operable Unit 7-13/14 Waste Area Group 7 Comprehensive Remedial Investigation/Feasibility Study, INEL-95/0343, Rev. 0, Idaho National Engineering Laboratory. 
Bowman, A. L., W. F. Downs, K. S. Moor, and B. F. Russell, 1984, INEL Environmental Characterization Report, Volume II: Appendices A-C, EGG-NPR-6688, Rev. 0, Idaho National Engineering Laboratory.

Burns, Douglas E., 1995, Guidance Protocol for the Performance of Cumulative Risk Assessments at the INEL, INEL-95/131, Rev. 0, Idaho National Engineering Laboratory.

DOE O 435.1, 2001, "Radioactive Waste Management,” Change 1, U.S. Department of Energy.

DOE-ID, 1991, Federal Facility Agreement and Consent Order for the Idaho National Engineering Laboratory, Administrative Docket No. 1088-06-29-120, U.S. Department of Energy Idaho Operations Office; U.S. Environmental Protection Agency, Region 10; and Idaho Department of Environmental Quality.

DOE-ID, 1993, Record of Decision: Declaration for Pit 9 at the Radioactive Waste Management Complex Subsurface Disposal Area at the Idaho National Engineering Laboratory, Administrative Record No. 5569, U.S. Department of Energy Idaho Operations Office; U.S. Environmental Protection Agency, Region 10; and Idaho Department of Health and Welfare.

DOE-ID, 1994a, Record of Decision: Declaration for Organic Contamination in the Vadose Zone Operable Unit 7-08, Idaho National Engineering Laboratory, Radioactive Waste Management Complex, Subsurface Disposal Area, Administrative Record No. 5761, U.S. Department of Energy Idaho Operations Office; U.S. Environmental Protection Agency, Region 10; and Idaho Department of Health and Welfare.

DOE-ID, 1994b, Record of Decision: Declaration for Pad A at the Radioactive Waste Management Complex Subsurface Disposal Area at the Idaho National Engineering Laboratory, Administrative Record No. 5632, U.S. Department of Energy Idaho Operations Office; U.S. Environmental Protection Agency, Region 10; Idaho Department of Health and Welfare.

DOE-ID, 1998, Addendum to the Work Plan for the Operable Unit 7-13/14 Waste Area Group 7 Comprehensive Remedial Investigation/Feasibility Study, DOE/ID-10622, U.S. Department of Energy Idaho Operations Office.

DOE-ID, 2004, Action Memorandum for Accelerated Retrieval of a Described Area within Pit 4, DOE/NE-ID-11179, Rev. 0, U.S. Department of Energy Idaho Operations Office.

DOE-ID, 2006a, Action Memorandum for the Accelerated Retrieval Project II within Pits 4 and 6 of the Subsurface Disposal Area, DOE/NE-ID-11238, U.S. Department of Energy Idaho Operations Office.

DOE-ID, 2006b, Engineering Evaluation/Cost Analysis for General Decommissioning Activities under the Idaho Cleanup Project, DOE/ID-11291, OSWER Directive 9355.3-01, Rev. 0, U.S. Department of Energy Idaho Operations Office.

EPA, 1988, Guidance for Conducting Remedial Investigations and Feasibility Studies Under CERCLA, Interim Final, EPA/540/G-89/004, U.S. Environmental Protection Agency.

EPA, 1989, Risk Assessment Guidance for Superfund, Vol. I - Human Health Evaluation Manual, Interim Guidance, Part A, EPA/540/1-89/002, U.S. Environmental Protection Agency. 
EPA, 1991, Role of the Baseline Risk Assessment in Superfund Remedy Selection Decisions, OSWER Directive 9355.0-30, U.S. Environmental Protection Agency, Office of Solid Waste and Emergency Response.

EPA, 1995, Land Use in the CERCLA Remedy Selection Process, OSWER Directive No. 9355.7-04, U.S. Environmental Protection Agency, Office of Solid Waste and Emergency Response.

EPA, 1997a, Rules of Thumb for Superfund Remedy Selection, EPA 540-R-97-013, OSWER 9355.0-69, U.S. Environmental Protection Agency, Office of Solid Waste and Emergency Response.

EPA, 1997b, Establishment of Cleanup Levels for CERCLA Sites with Radioactive Contamination, OSWER Directive No. 9200.4-18, U.S. Environmental Protection Agency, Office of Emergency and Remedial Response and Office of Radiation and Indoor Air.

EPA, 2000, Radionuclides Notice of Data Availability Technical Support Document, U.S. Environmental Protection Agency.

Holdren, K. Jean and Barbara J. Broomfield, 2004, Second Addendum to the Work Plan for the OU 7-13/14 Waste Area Group 7 Comprehensive Remedial Investigation/Feasibility Study, DOE/ID-11039, Rev. 0, U.S. Department of Energy Idaho Operations Office.

Holdren, K. Jean, Bruce H. Becker, Nancy L. Hampton, L. Don Koeppen, Swen O. Magnuson, T. J. Meyer, Gail L. Olson, and A. Jeffrey Sondrup, 2002, Ancillary Basis for Risk Analysis of the Subsurface Disposal Area, INEEL/EXT-02-01125, Rev. 0, Idaho National Engineering and Environmental Laboratory.

Holdren, K. Jean, Danny L. Anderson, Bruce H. Becker, Nancy L. Hampton, L. Don Koeppen, Swen O. Magnuson, and A. Jeffrey Sondrup, 2006, Remedial Investigation and Baseline Risk Assessment for Operable Unit 7-13/14, DOE/ID-11241, Idaho National Laboratory, Idaho Cleanup Project.

Idaho Code § 39-4401 et seq., 1983, "Hazardous Waste Management Act of 1983," State of Idaho, Boise, Idaho.

INEL, 1993, Decision Documentation Package for Operable Unit 7-11 Septic Systems, Administrative Record No. 5235, Idaho National Engineering Laboratory.

INL, 2005, Data Quality Objectives Summary Report for the Operable Unit 7-08 Post-Record of Decision Sampling, INEEL/EXT-2000-00814, Rev. 2, Idaho National Laboratory, Idaho Cleanup Project.

Koeppen, L. Don, M. Doug McKenzie, Paul D. Ritter, and William A. Smith, 2006, Fiscal Year 2005 Environmental Monitoring Report for the Radioactive Waste Management Complex, RPT-171, Idaho National Laboratory, Idaho Cleanup Project.

Litus, Marty and Jerry P. Shea, 2005, Summary of Cleanup at the Idaho National Laboratory Site, ICP/EXT-05-00806, Rev. 0, Idaho National Laboratory, Idaho Completion Project.

Magnuson, Swen O. and A. Jeffrey Sondrup, 2006, Subsurface Flow and Transport Model Development for the Operable Unit 7-13/14 Remedial Investigation and Feasibility Study, ICP/EXT-05-01016, Rev. 1, Idaho National Laboratory, Idaho Cleanup Project. 
Martian, Peter, 2007, Verification and Benchmark Testing of the TETRAD Simulator, Version 12.7ms, RPT-335, Idaho National Laboratory, Idaho Cleanup Project.

Roback, Robert C., Deward W. Efurd, Michael T. Murrell, Robert E. Steiner, and Clarence J. Duffy, 2000, Assessment of Uranium and Plutonium in the Saturated and Unsaturated Zones Beneath the Surface Disposal Area, INEEL, LA-UR-00-5471, INEEL/EXT-01-00771, Los Alamos National Laboratory.

Sebo, D. and C. A. Whitaker, 2005, Collocated Facilities Analysis for Waste Area Group 7, Operable Unit 7-13/14, INEEL/EXT-01-00027, Rev. 1, Idaho National Laboratory, Idaho Cleanup Project.

Shook, G. M., 1995, Development of an Environmental Simulator from Existing Petroleum Technology, INEL-94/0283, Idaho National Engineering Laboratory.

Sullivan, T. M., 1992, Development of DUST: A Computer Code That Calculates Release Rates from LLW Disposal Unit, BNL-NUREG-47118, Brookhaven National Laboratory, U.S. Nuclear Regulatory Commission.

Van Horn, R. L., N. L. Hampton, and R. C. Morris, 1995, Guidance Manual for Conducting Screening-Level Ecological Risk Assessments at the INEL, INEL-95/0190, Rev. 0, Idaho National Engineering Laboratory.

Wylie, A. H., 1996, Pumping Test of Pit 9 Production Well, INEL-96/171, Idaho National Engineering Laboratory.

Wylie, A. H. and J. M. Hubbell, 1994, Aquifer Testing of Wells M1S, M3S, M4D, M6S, M7S, and M10S at the Radioactive Waste Management Complex, ER-WAG7-26, Rev. 1, Idaho National Engineering Laboratory. 


\section{CONTENTS}

2. IDENTIFICATION AND SCREENING OF TECHNOLOGIES ...........................................2-3

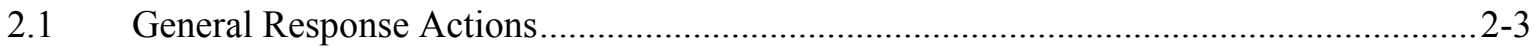

2.2 Identification and Screening of Technology Types and Process Options .........................2-4

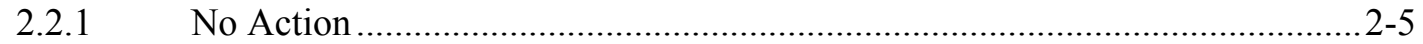

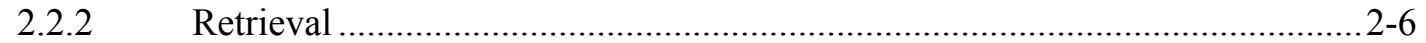

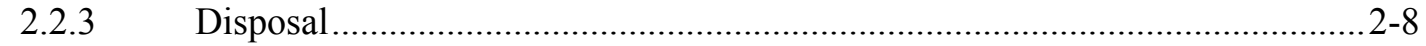

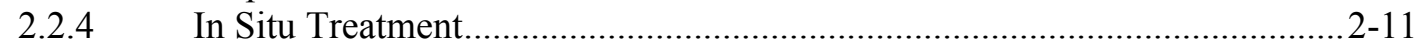

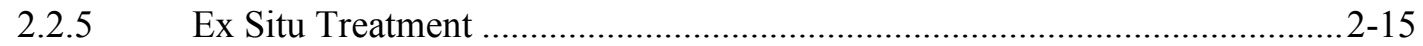

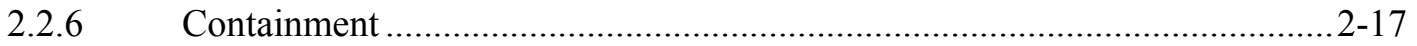

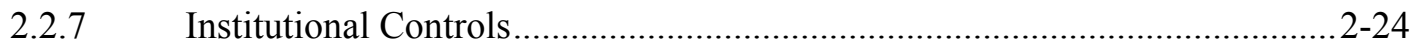

2.2.8 Summary of Representative Process Options ...........................................2-26

2.2.9 Options for Incorporating Pad A and Removing Near-Surface Volatile Organic Compounds into Alternatives for Operable Unit 7-13/14 ...............2-28

2.2.10 Incorporation of Ongoing Vapor Extraction from the Vadose Zone into Alternatives for Operable Unit 7-13/14 .....................................................2-29

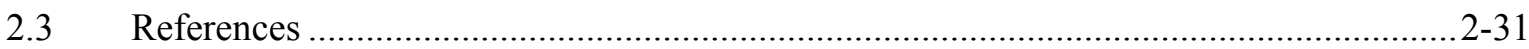

\section{FIGURES}

2-1. Retrieval Enclosure for the Accelerated Retrieval Project ....................................................2-7

2-2. Modified excavator at the Accelerated Retrieval Project ........................................................2-8

2-3. Disposal locations off the Idaho National Laboratory Site …................................................2-11

2-4. Cross section of the preconceptual evapotranspiration surface barrier design ...........................2-20

2-5. Cross section of the modified RCRA Type C surface barrier ................................................2-20 


\section{TABLES}

2-1. Summary of screening results for the retrieval general response action ....................................2-6

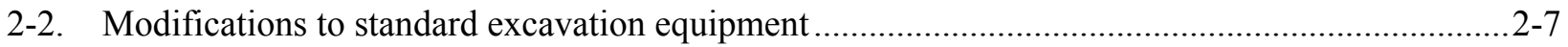

2-3. Summary of screening results for the disposal general response action......................................2-9

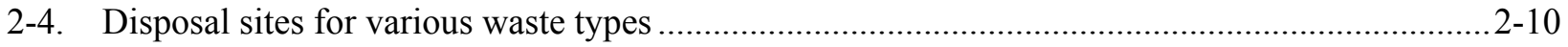

2-5. Summary of screening results for the in situ treatment general response action........................2-12

2-6. Summary of screening results for the ex situ treatment general response action .......................2-15

2-7. Summary of screening results for the containment general response action .............................2-18

2-8. General response actions, remedial technologies, and retained process options .........................2-27 


\section{IDENTIFICATION AND SCREENING OF TECHNOLOGIES}

This section of the Feasibility Study for Operable Unit 7-13/14 identifies technologies that potentially apply to remedial actions in the Subsurface Disposal Area (SDA). The identification and screening process delineates a range of potentially applicable technologies and then selects a subset of process options that merits further analysis. Guidance for Conducting Remedial Investigations and Feasibility Studies Under CERCLA, Interim Final (EPA 1988) and the National Contingency Plan (40 CFR 300) describe the following steps to identify and screen technologies:

1. Establish remedial action objectives (see Section 1.5) that permit development of a range of treatment or containment alternatives. Remedial action objectives are used throughout the technology screening process; first, remedial action objectives are used to identify general response actions and later to identify relevant technologies and evaluate their effectiveness. In general, remedial action objectives can be achieved by removing contaminants (i.e., retrieval), immobilizing contaminants (i.e., in situ treatment), or eliminating exposure paths using physical barriers or access restrictions (i.e., containment or institutional controls [ICs]).

2. Identify general response actions (see Section 2.1) that may meet remedial action objectives, either individually or in combination with other general response actions.

3. Identify areas or specific media to which general response actions might be applied (see Section 2.2).

4. Identify remedial technology types that apply to the site that are expected to be effective and implementable (see Section 2.2).

5. Select a representative process option for each technology type retained for further evaluation (see Section 2.2).

The following steps are performed in accordance with the technology screening process:

1. Assemble representative process options into remedial alternatives (see Section 3)

2. Perform detailed analysis of remedial alternatives (see Section 4)

3. Perform comparative analysis of remedial alternatives (see Section 5).

\subsection{General Response Actions}

General response actions are general approaches that can be implemented to achieve remedial action objectives, either individually or in combination. Seven general response actions were defined in the Preliminary Evaluation of Remedial Alternatives (Zitnik et al. 2002) and incorporated into this feasibility study in accordance with the Second Addendum to the Work Plan (Holdren and Broomfield 2004). A description of each general response action follows:

- No action-This general response action is required by the National Contingency Plan (40 CFR 300). A no action alternative serves as a baseline for evaluating other remedial action alternatives and is generally retained throughout the feasibility study process. As defined in the Comprehensive Environmental Response, Compensation, and Liability Act (CERCLA) (42 USC § 9601 et seq., 1980) guidance (EPA 1988), environmental monitoring is included in the no action general response action, but actions taken to reduce exposure (e.g., site fences and deed restrictions) are not. 
- Retrieval-This general response action involves physically removing waste and soil. Because of radioactive and hazardous characteristics of waste in the SDA, retrieval systems must minimize worker exposure while stringently controlling contamination.

- Disposal-This general response action involves placing retrieved waste, contaminated soil, treatment residuals, and investigation-derived waste in permanent waste management facilities.

- In situ treatment-This general response action uses technologies that degrade, immobilize, or destroy contaminants while waste remains in the landfill (in situ). Treatment technologies include physical, chemical, thermal, and biological approaches. In situ treatment minimizes worker exposure to contaminated media.

- Ex situ treatment-This general response action treats retrieved soil and waste using chemical, physical, thermal, or biological processes. Technologies focus on segregating targeted and nontargeted waste forms, characterizing radiological and hazardous constituents (e.g., classification as transuranic waste, mixed transuranic waste, low-level waste [LLW], and mixed LLW), and processing to reduce contaminant toxicity, mobility, or volume. Treatment also may be applied to remove Resource Conservation and Recovery Act (RCRA) (42 USC § 6901 et seq., 1976) hazardous characteristics (i.e., ignitability, corrosivity, reactivity, and toxicity) to meet disposal requirements.

- $\quad$ Containment-This general response action mitigates risk by preventing direct human or biotic contact with contaminated media, precluding contaminant transport to the surface by plants and animals, and minimizing contaminant migration by limiting infiltrating moisture. Containment approaches include surface barriers, lateral barriers, barriers to intrusion (e.g., biointrusion barriers), and impermeable layers immediately beneath buried waste (i.e., bottom sealing).

- Institutional controls-This general response action imposes active or passive measures to prevent or limit access to contaminated areas. Active measures typically involve routine or periodic human presence at the site (e.g., guards and surveillance), while passive measures are largely administrative (e.g., land-use restrictions). Institutional controls include deed restrictions, fences, barriers, or signs. Environmental monitoring typically is included in the ICs general response action.

\subsection{Identification and Screening of Technology Types and Process Options}

This subsection identifies remedial technology types and process options that would be effective and could be implemented at the SDA and selects representative process options used to assemble alternatives in Section 3. Technology types are general category treatment approaches, while process options are specific approaches within a general technology type. For example, containment is a technology type; both surface barriers and vertical grout curtains are process options under the containment technology type. Because technology screening relies heavily on previously published work (Zitnik et al. 2002), this subsection focuses on selecting representative process options.

Appendix A tabulates potentially applicable technologies and process options, briefly describes each process option, evaluates their potential effectiveness and implementability at the SDA, and assesses their relative costs. Process options considered not implementable at the SDA were eliminated from further consideration. Process options listed in Appendix A, compiled from Zitnik et al. (2002), were updated, considering the most current technology performance and site characterization data. 
Technology performance information was obtained from publicly available technology reviews (FRTR 2002; EPA 2003; CPEO 2002), vendor-provided information, site-specific preremedial design and safety analyses, and any relevant information from other remedial actions, either on or off the Idaho National Laboratory (INL) Site, that share similar characteristics with the SDA. Site-specific information was obtained from Holdren et al. (2006) and the Waste Identification and Location Database, which integrates and validates inventories and waste form descriptions (McKenzie et al. 2005).

Sections 2.2.1 through 2.2.7 present, for each general response action technology, process options identified as applicable to and implementable at the SDA. Process options for environmental monitoring are not evaluated in this feasibility study, but are described under the no action general response action, Section 2.2.1, and are included during development of all alternatives, including a no action alternative, as required by U.S. Environmental Protection Agency (EPA) guidance (EPA 1988). Section 2.2.8 summarizes representative process options retained for further evaluation.

\subsubsection{No Action}

The no action general response action does not include remedial actions; therefore, no remedial technologies or process options are identified. As discussed in EPA guidance (EPA 1988), a no action general response action can include environmental monitoring of potentially affected environmental media. Various types of routine or occasional environmental monitoring implemented at the SDA include the following:

- $\quad$ Air monitoring-Air monitoring uses high- and low-volume air samplers to determine whether contaminated surface soil has been dispersed by wind or surface water.

- Biological monitoring-Animal tissue is analyzed to identify bioaccumulation of contaminants of concern (COCs). Vegetation also is analyzed to evaluate contaminant uptake from the subsurface.

- Groundwater monitoring-The aquifer is monitored to assess effectiveness of waste management processes in preventing contaminant migration. Samples are analyzed for volatile organic compounds (VOCs); metals; nitrates; gross alpha, beta, and gamma; and selected radionuclides. Similar analyses would be used to evaluate the effectiveness of any remedial actions.

- $\quad$ Soil monitoring-Soil monitoring includes radiation surveys over and around sites where contaminated soil and debris are left in place to determine whether plants, insects, or burrowing animals have transported radionuclides to the surface.

- $\quad$ Surface water monitoring-Surface water is sampled to monitor for contaminant transport during seasonal or episodic run-off.

- Vadose zone monitoring-Perched water and soil moisture are monitored to provide early indication of infiltration and contaminant migration. Vapor ports also are used to monitor for vapor-phase transport of C-14 and VOCs. Tensiometers are used to monitor changes in vadose zone moisture content.

These types of environmental monitoring will be evaluated for incorporation into a remedial design following remedy selection. Environmental monitoring assesses current environmental conditions and evaluates effectiveness of action-specific remedial actions and is retained for developing assembled alternatives. 


\subsubsection{Retrieval}

The retrieval general response action is divided into two technology types: contamination control and excavation methods. Table 2-1 lists technology types and process options considered during initial screening (see Appendix A). Specific process options identified as applicable are discussed in the following subsections.

Table 2-1. Summary of screening results for the retrieval general response action.

\begin{tabular}{lll}
\hline Remedial Technology & \multicolumn{1}{c}{$\begin{array}{c}\text { Potentially Applicable } \\
\text { Process Option }\end{array}$} & $\begin{array}{c}\text { Not Potentially Applicable } \\
\text { Process Option }\end{array}$ \\
\hline Contamination control & $\begin{array}{l}\text { Confinement } \\
\text { Foams, sprays, misters, fixatives, } \\
\text { and washers } \\
\text { In situ stabilization } \\
\text { Ventilation and vacuum systems }\end{array}$ & Electrically charged plastic \\
& $\begin{array}{l}\text { Standard construction equipment } \\
\text { Excavation methods }\end{array}$ & None \\
& $\begin{array}{l}\text { Standard construction } \\
\text { Remote-operated equipment }\end{array}$ & \\
\hline Note: Retained for further evaluation. & \\
\hline
\end{tabular}

2.2.2.1 Contamination Control. Methods to control spread of contamination during waste retrieval operations mitigate potential for worker exposure and minimize cost associated with operating, maintaining, and decontaminating equipment. Process options for contamination control consist of the following:

- Confinement-Confinement enclosures constructed of plastic, metal, fiberglass, or other materials inhibit spread of airborne contaminants by enclosing equipment, work areas, or an entire site. Enclosures may be lightweight and portable or sturdier and less portable.

- $\quad$ Foams, sprays, misters, fixatives, and washes-Foams, sprays, misters, fixatives, and washes perform various functions, including controlling odors, VOCs, dust, and other emissions; creating barriers between work surfaces and the atmosphere; settling loose airborne contamination; and decontaminating personnel or equipment. A variety of products is readily available in nonhazardous and biodegradable forms.

- Ventilation and vacuum systems-Ventilation systems direct area-wide airborne contaminants to high-efficiency particulate air filtration units. Vacuum systems remove loose particles from equipment or structures and collect dust and debris near the excavation point.

Confinement systems; foams, sprays, misters, fixatives and washes; and ventilation and vacuum systems are identified as representative process options for contamination control. These process options are effective, based on observation of ongoing Accelerated Retrieval Project operations. 
Figure 2-1 shows the Retrieval Enclosure used to control airborne contamination at the Accelerated Retrieval Project. The Retrieval Enclosure is a temporary modular building with a high-volume ventilation system that captures particulates during excavation. The 4,600- $\mathrm{m}^{2}\left(49,200-\mathrm{ft}^{2}\right)$ Retrieval Enclosure consists of a metal frame with interior and exterior fabric covers. Two smaller $325-\mathrm{m}^{2}$ $\left(3,500-\mathrm{ft}^{2}\right)$ airlocks are used for equipment maintenance and waste packaging.

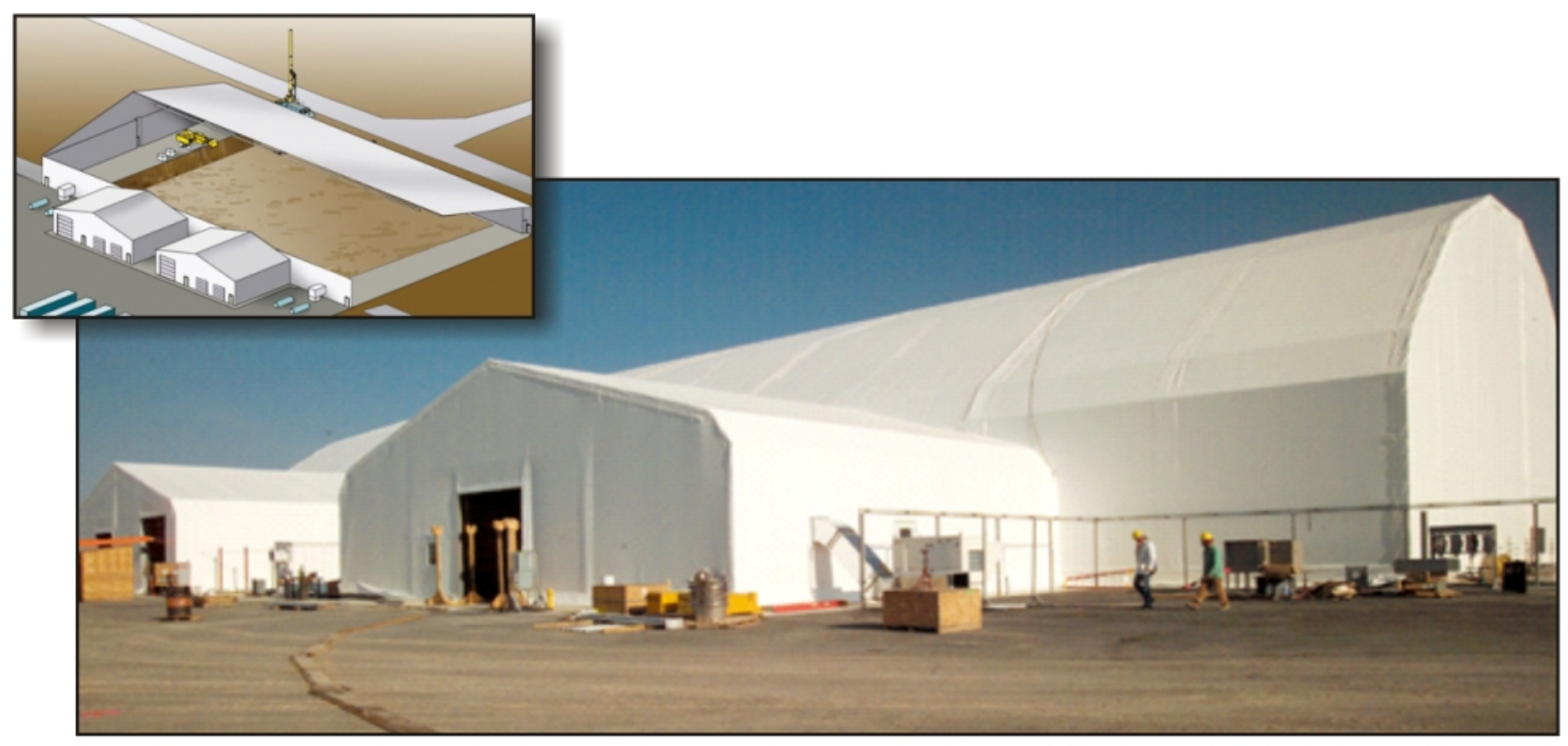

G06-1746-10

Figure 2-1. Retrieval Enclosure for the Accelerated Retrieval Project.

2.2.2.2 Excavation Methods. Technologies for excavating buried waste include conventional construction equipment, modified construction equipment (e.g., sealed cabs with filtered or supplied air), and remote-operated equipment. Table 2-2 lists specific types of applicable excavation equipment (also see Appendix A).

Table 2-2. Modifications to standard excavation equipment.

\begin{tabular}{ll}
\hline \multicolumn{1}{c}{ Modification } & \multicolumn{1}{c}{ Description } \\
\hline $\begin{array}{l}\text { Sealed and pressurized } \\
\text { cab with filtered air }\end{array}$ & $\begin{array}{l}\text { Conventional construction equipment with modified cab } \\
\text { Sealed and pressurized cab uses filtered air (high-efficiency particulate } \\
\text { air filtration) } \\
\text { Conventional construction equipment with modified cab }\end{array}$ \\
$\begin{array}{l}\text { Sealed and pressurized } \\
\text { cab with supplied air }\end{array}$ & \begin{tabular}{l} 
Sealed and pressurized cab uses supplied air \\
\hline
\end{tabular}
\end{tabular}

Because of contaminants at the SDA, potential for airborne release and worker exposure during retrieval is significant. However, a wide range of technologies is available to protect workers in contaminated environments. All conventional construction equipment identified in Appendix A can be modified to be effective and implementable at radioactively contaminated sites. Excavation equipment and its applicability to retrieval operations at the SDA are discussed in Sykes (2002), EPA (1991), INEEL (1997), and BHI (2000). However, many of the remote-operated equipment systems described in Sykes (2002) are one-of-a-kind systems that may not be available. In general, capital costs of remote-operated equipment are greater than those of conventional or modified construction equipment. 
Construction equipment modified to protect the operator from airborne contamination and flying debris has proved reliable in contaminated environments and provides adequate protection for remediation workers (Sykes 2002). Furthermore, observation of ongoing Accelerated Retrieval Project operations suggests that modified construction equipment is effective and implementable at the SDA. For these reasons, modified construction equipment is identified as a representative process option for excavation methods.

Figure 2-2 shows the modified excavator currently deployed at the Accelerated Retrieval Project. Modifications to this excavator include cab air filtration, supplied breathing air, video camera, dust-suppression system, impact-resistant windows, and indoor exhaust management.

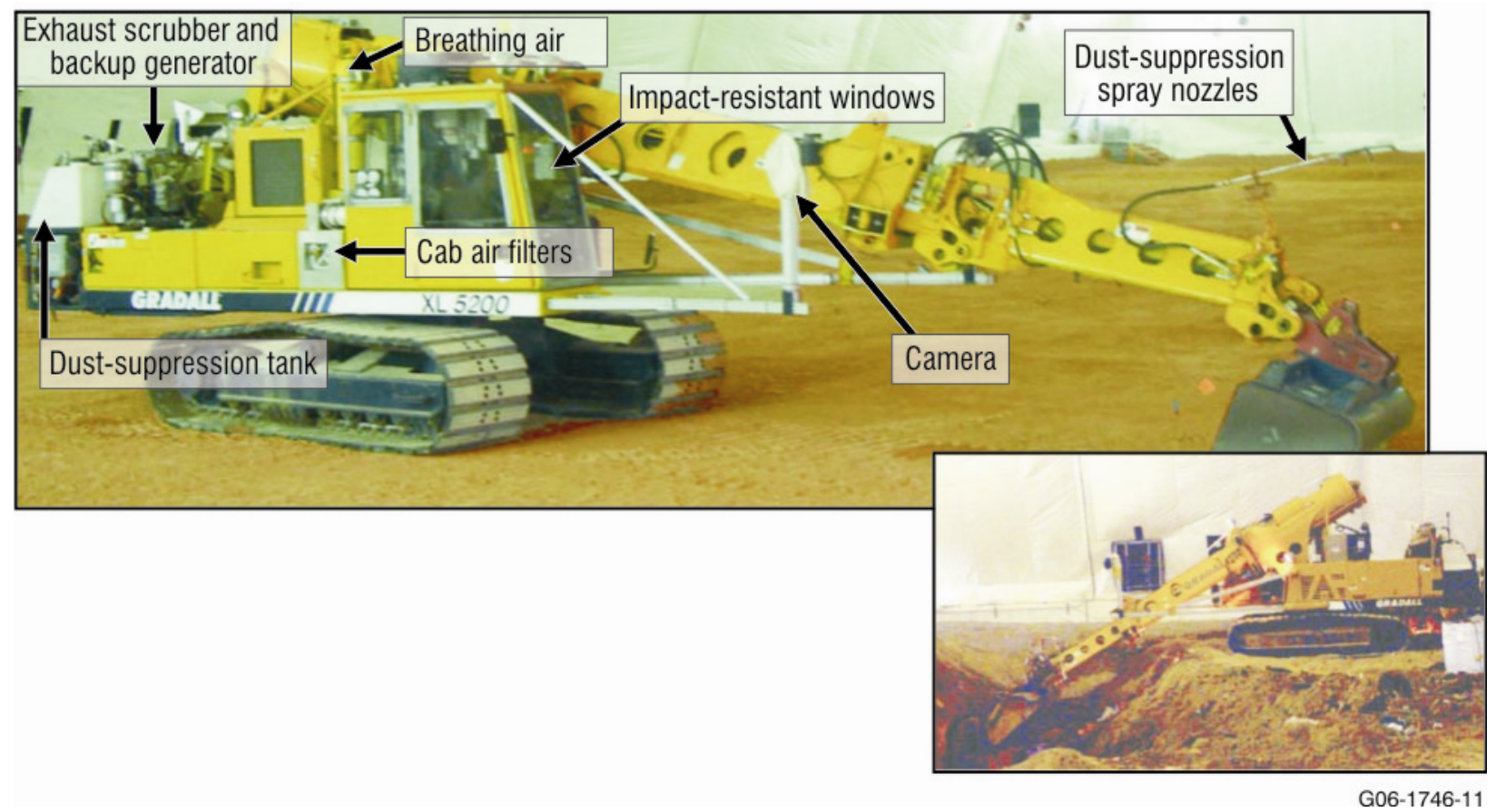

Figure 2-2. Modified excavator at the Accelerated Retrieval Project.

\subsubsection{Disposal}

The disposal general response action is divided into two primary categories: (1) storage and disposal on the INL Site and (2) storage and disposal off the INL Site. Table 2-3 shows disposal options evaluated during screening (see Appendix A). For some waste forms and disposal facilities, treatment would be required to meet waste acceptance criteria. Section 2.2.5 addresses treatment process options. The following subsections discuss specific options identified as applicable for disposal. 
Table 2-3. Summary of screening results for the disposal general response action.

\begin{tabular}{|c|c|c|}
\hline Remedial Technology & $\begin{array}{l}\text { Potentially Applicable } \\
\text { Process Option }\end{array}$ & $\begin{array}{c}\text { Not Potentially Applicable } \\
\text { Process Option }\end{array}$ \\
\hline \multirow{4}{*}{$\begin{array}{l}\text { On-INL Site storage } \\
\text { and disposal }\end{array}$} & ICDF & Central Facilities Area Landfill \\
\hline & LLW Pit within the SDA & \\
\hline & New permanent on-INL Site landfill & \\
\hline & Temporary on-INL Site storage & \\
\hline \multirow[t]{7}{*}{$\begin{array}{l}\text { Off-INL Site storage } \\
\text { and disposal }\end{array}$} & $\begin{array}{l}\text { Barnwell Waste Management } \\
\text { Facility, South Carolina }\end{array}$ & None \\
\hline & EnergySolutions, Utah & \\
\hline & Hanford Site, Washington & \\
\hline & Nevada Test Site, Nevada & \\
\hline & US Ecology, Washington & \\
\hline & Waste Control Specialists, Texas & \\
\hline & WIPP, New Mexico & \\
\hline \multicolumn{3}{|c|}{ Note: Retained for further evaluation. } \\
\hline \multicolumn{3}{|c|}{$\begin{array}{l}\text { ICDF = Idaho CERCLA Disposal Facility } \\
\text { INL = Idaho National Laboratory } \\
\text { LLW = low-level waste } \\
\text { SDA = Subsurface Disposal Area } \\
\text { WIPP = Waste Isolation Pilot Plant }\end{array}$} \\
\hline
\end{tabular}

2.2.3.1 Storage or Disposal on the Idaho National Laboratory Site. Table 2-4 lists facilities and waste types accepted for storage or disposal on the INL Site. Currently, INL Site facilities dispose of LLW and municipal waste and store other types of waste before subsequent disposal. Possible options include the following:

- Idaho CERCLA Disposal Facility (ICDF) - ICDF is located at the Idaho Nuclear Technology and Engineering Center. The ICDF consists of a landfill, evaporation pond, treatment facility, and associated staging and storage annex. This facility accepts contaminated soil and debris generated at the INL Site during CERCLA cleanup actions. If waste is not from within the area of contamination defined by the Operable Unit (OU) 3-13 Record of Decision (ROD)

(DOE-ID 1999a), then waste must meet land disposal restrictions before disposal. The disposal facility is operational and scheduled to continue to accept waste until the year 2012 (DOE-ID 2003); however, future availability of disposal capacity and date for final closure of ICDF are uncertain. If ICDF is not available after 2012, other off-INL Site treatment and disposal services are assumed to be available. 
Table 2-4. Disposal sites for various waste types.

\begin{tabular}{|c|c|c|c|c|}
\hline Disposal Site & $\begin{array}{c}\text { Transuranic } \\
\text { Waste }\end{array}$ & $\begin{array}{c}\text { Mixed } \\
\text { Low-Level } \\
\text { Waste } \\
\end{array}$ & $\begin{array}{c}\text { Low-Level } \\
\text { Waste }\end{array}$ & $\begin{array}{c}\text { Remote-Handled } \\
\text { Waste }\end{array}$ \\
\hline \multicolumn{5}{|l|}{ On-INL Site Storage and Disposal } \\
\hline $\mathrm{ICDF}$ & - & $\mathrm{X}$ & $\mathrm{X}$ & - \\
\hline LLW Pit at the SDA & - & & $\mathrm{X}$ & - \\
\hline Temporary on-INL Site storage & $\mathrm{X}$ & $\mathrm{X}$ & $\mathrm{X}$ & $\mathrm{X}$ \\
\hline \multicolumn{5}{|l|}{ Off-INL Site Disposal } \\
\hline EnergySolutions, Utah & - & $\mathrm{X}$ & $\mathrm{X}$ & - \\
\hline WIPP, New Mexico & $\mathrm{X}$ & - & - & $\mathrm{X}$ \\
\hline $\begin{array}{l}\text { ICDF = Idaho CERCLA Disposal Facility } \\
\text { INL = Idaho National Laboratory } \\
\text { LLW = low-level waste } \\
\text { SDA = Subsurface Disposal Area } \\
\text { WIPP = Waste Isolation Pilot Plant }\end{array}$ & & & & \\
\hline
\end{tabular}

- $\quad$ Low-Level Waste Pit within the SDA-Active cells in the SDA currently accept LLW for disposal. The LLW Pit is not permitted for hazardous or mixed waste, but can accept waste that began as RCRA-characteristic waste and was treated to comply with land disposal restrictions, on a case-by-case basis (40 CFR 268; IDAPA 58.01.05.011; DOE-ID 2005). The LLW Pit will remain open for contact-handled LLW until September 2008 and for remote-handled LLW until September 2009 (PLN-2085). As of January 31, 2006, about 28,000 $\mathrm{m}^{3}\left(36,600 \mathrm{yd}^{3}\right)$ of disposal capacity remains (Parsons and Seitz 2006). Future availability of disposal capacity and date for final closure of the LLW Pit are uncertain; however, it is likely that receipt of LLW will continue beyond 2009 .

- Temporary on-INL Site Storage

- $\quad$ Existing temporary storage facility-Located at the SDA, the CERCLA Storage Enclosure accepts contact-handled waste for temporary storage. Current operations at this storage facility include certification and interim storage of solid, contact-handled waste retrieved during the Accelerated Retrieval Projects (DOE-ID 2004, 2006).

- $\quad$ Additional on-INL Site storage facilities-If substantial portions of buried waste are retrieved from the SDA, construction of additional storage capacity may be required at the Radioactive Waste Management Complex (RWMC). In addition, a specialized facility for interim storage of high-activity waste (i.e., remote-handled waste) may be necessary until appropriate disposal alternatives are identified. Though not identified as targeted waste for Accelerated Retrieval Projects, remote-handled waste could be encountered in other types of retrieval actions evaluated in this feasibility study.

The LLW Pit at the SDA and the ICDF landfill are identified as representative process options for disposal of LLW and soil. However, available disposal capacity at these facilities is uncertain. Existing and additional facilities within RWMC are identified as representative process options for temporary storage of containerized waste resulting from removal actions. In addition, staging areas would be identified to facilitate material handling during retrieval and subsequent treatment, storage, or disposal. 
2.2.3.2 Disposal off the Idaho National Laboratory Site. Off-INL Site disposal involves shipping waste to an approved facility outside the INL Site. As described in Appendix A, several off-INL Site disposal facilities are available that could receive specific subsets of SDA waste. Figure 2-3 shows the general location of each facility. However, the variety of waste types at the SDA, and regulatory requirements associated with disposal of each, limit options for off-INL Site waste disposal. Table 2-4 identifies the disposal facilities and applicable waste types.

- EnergySolutions, Utah-EnergySolutions (formerly Envirocare) is licensed to receive LLW. EnergySolutions has rail access and may be the most practical option for waste shipment. Therefore, EnergySolutions is identified as the representative process option for disposal of LLW off the INL Site (EnergySolutions 2006).

- Waste Isolation Pilot Plant (WIPP), New Mexico - WIPP is currently the only disposal facility that can accept transuranic waste for disposal, including both contact- and remote-handled waste. Therefore, WIPP is identified as the representative process option for disposal of transuranic waste (DOE-CBFO 2002).

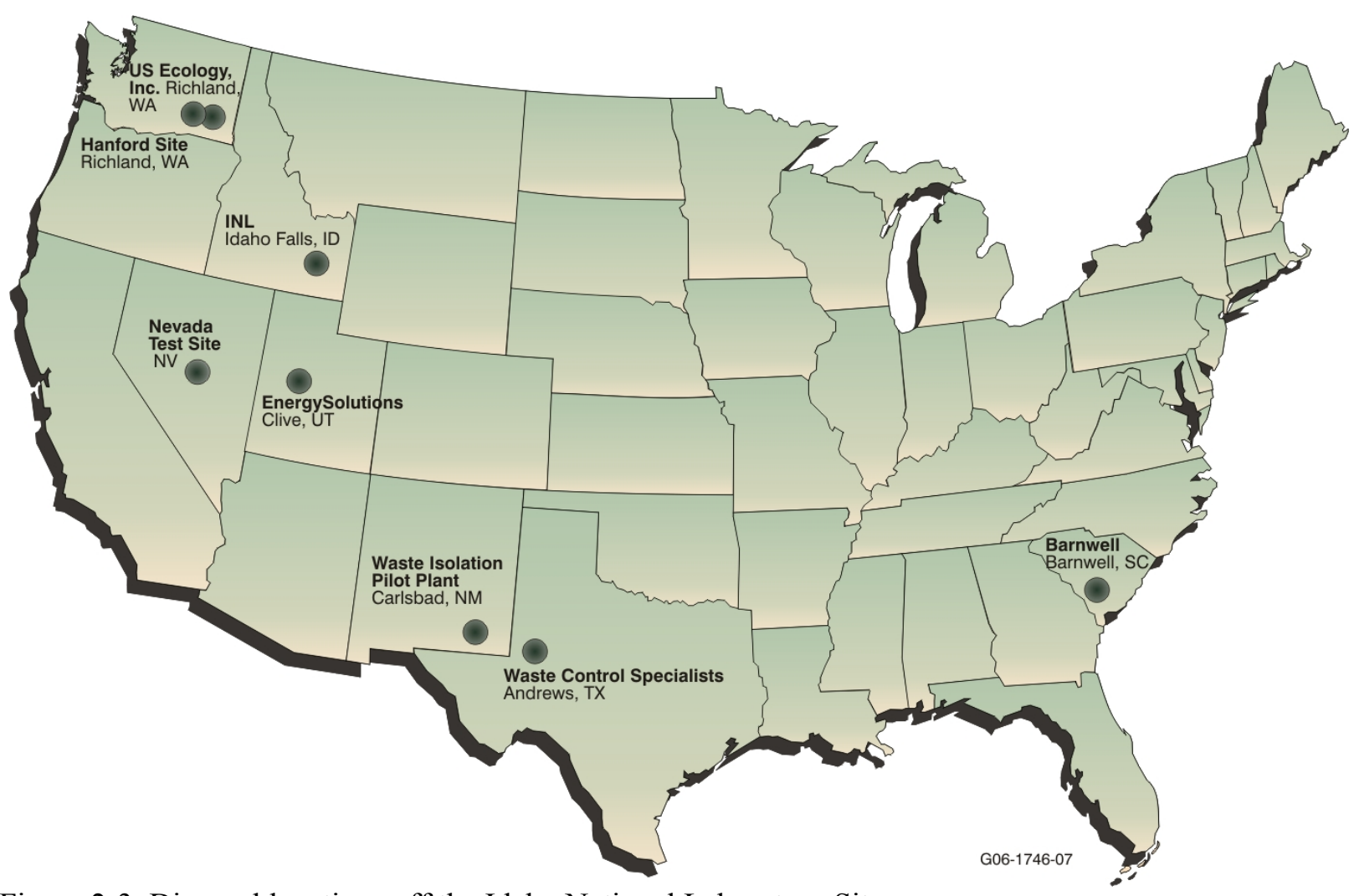

Figure 2-3. Disposal locations off the Idaho National Laboratory Site.

\subsubsection{In Situ Treatment}

In situ treatment technologies have the advantage of reducing toxicity, mobility, or volume of COCs without incurring worker risk associated with retrieval, treatment, and disposal (RTD) of buried waste. As with the other technology types, a wide range of process options was considered during the screening process, many of which were determined to be not implementable under SDA site-specific conditions. Table 2-5 lists in situ treatment technology types and process options evaluated during the screening process. 
Table 2-5. Summary of screening results for the in situ treatment general response action.

\begin{tabular}{lll} 
Remedial Technology & \multicolumn{1}{c}{$\begin{array}{c}\text { Potentially Applicable } \\
\text { Process Option }\end{array}$} & \multicolumn{1}{c}{$\begin{array}{c}\text { Not Potentially Applicable } \\
\text { Process Option }\end{array}$} \\
\hline Physical treatment & $\begin{array}{l}\text { High-pressure jet grouting } \\
\text { Soil-vapor extraction }\end{array}$ & $\begin{array}{l}\text { Enhanced soil mixing } \\
\text { Low-pressure permeation grouting }\end{array}$ \\
\hline Chemical treatment & None & $\begin{array}{l}\text { Chemical leaching } \\
\text { Electrokinetic remediation }\end{array}$ \\
& & $\begin{array}{l}\text { Hydrolysis } \\
\text { Reduction-oxidation manipulation }\end{array}$ \\
& & Soil flushing \\
\hline Thermal treatment & $\begin{array}{l}\text { Thermal desorption (gas-phase } \\
\text { heating) }\end{array}$ & $\begin{array}{l}\text { Thermal desorption (Joule heating) } \\
\text { Thermal desorption (radiant heating) } \\
\text { Viological treatment }\end{array}$ \\
& None & Vitrification \\
\hline
\end{tabular}

Note: Retained for further evaluation.

2.2.4.1 In Situ Physical Treatment. Two in situ treatment technology process options are retained for evaluation in this feasibility study. In situ grouting is a method of encapsulating buried waste to isolate it from the surrounding environment and inhibit contaminant release, while soil-vapor extraction collects contaminated off-gas released by the waste. Both in situ treatments are described in the following subsections.

2.2.4.1.1 In Situ Grouting-Grout mixtures are routinely injected into the subsurface to stabilize soil or reduce infiltration during civil construction. More recently, grouting was used to stabilize contaminated soil and waste in place. This process has the advantage of reducing contaminant mobility without incurring worker risk associated with retrieval. Typically, grout is injected using a modified rotary percussion drill rig. A hollow drill stem is advanced to the bottom of a contaminated area, and grout is pumped into the subsurface formation under high pressure. The grout exits small-diameter jets as the drill stem is slowly rotated and lifted through the contaminated media. Grout jets mix waste and soil to form a dense column. Grout columns are constructed in overlapping patterns to create a subsurface monolith that is highly impervious to infiltrating moisture (see Figure 3-12). Previous field tests demonstrated that when in situ grouting (ISG) is applied to waste and soil types similar to those in the SDA, it creates a relatively homogenous monolith of soil, waste, and grout (Loomis et al. 2003; Loomis, Zdinak, and Bishop 1997; Loomis and Thompson 1995; Loomis, Thompson, and Heiser 1995).

Jet grouting equipment used in conventional civil engineering practice is readily adaptable to stabilize buried waste. Jet grouting systems commonly are configured into single, double, or triple fluid systems. Multifluid systems inject air or water simultaneously with grout to reduce friction between the grout and soil, thereby increasing the diameter of resulting columns. However, single fluid systems are preferred for in situ waste stabilization because they produce a uniform stabilized waste product (Layne GeoConstruction 2006) and do not displace contaminated media to the ground surface (DOE-ID 1999b). With in situ high-pressure jet grouting, overall waste volume remains nearly constant, 
while waste-form density substantially increases. Because single phase, nondisplacement, high-pressure jet grouting minimizes the amount of contaminated material inadvertently brought to the surface, it has been recommended for use at the $\mathrm{SDA}^{\mathrm{a}}$ (Loomis, Zdinak, and Bishop 1997).

A variety of cementitious grouts and one paraffin-based thermoplastic grout (i.e., WAXFIX) were evaluated. These grouts were found suitable for stabilizing several SDA waste forms containing transuranic isotopes or radionuclides resulting from nuclear fission and activation (Shaw 2004a, 2004b; Matthern et al. 2005). These grouts significantly reduce hydraulic conductivity ${ }^{\mathrm{b}}$ and, in the case of cementitious grouts, also may chemically buffer the resulting waste form, reducing the solubility of some radionuclides. Evaluations of long-term durability of cementitious and paraffin-based grouts suggest that they should remain effective for in situ stabilization of SDA waste for at least 10,000 years (Hanson et al. 2005) and 1,000 years (Hanson et al. 2004), respectively. Specific grout formulations would be developed during the design phase of any proposed action that includes ISG.

In situ grouting has been implemented at several small-scale remedial action sites across the U.S. Department of Energy (DOE) complex, including successful deployment at the SDA Acid Pit (Loomis et al. 1998). In 2004, ISG was used to encapsulate beryllium reflector blocks and outer shim control cylinders buried in soil vaults and trenches at 15 separate locations within the SDA (Lopez et al.2005). The objective of this action was to reduce infiltration into trenches and soil vaults, reduce corrosion of the blocks and release of contaminants from the beryllium matrix, and mitigate contaminant transport. This action was implemented without incident by a commercial geotechnical service company (Shropshire 2004). Based on past testing results and results of the Beryllium Block Grouting Project, ISG is retained as a representative process option for further evaluation.

2.2.4.1.2 Soil-Vapor Extraction-Soil-vapor extraction, also known as soil venting or vacuum extraction, is the process of applying a vacuum near or within a contamination source. Volatile contaminants evaporate, and vapors are drawn toward extraction points. Extracted vapors are treated and released to the atmosphere. Vapor extraction wells may be installed either vertically or horizontally, or as commonly implemented at landfills, vapor may be extracted from a vent layer integrated into the cover system.

Soil-vapor extraction has proven effective in reducing VOC concentrations at numerous hazardous waste sites, and EPA identifies soil-vapor extraction as a presumptive remedy for superfund sites with halogenated VOC-contaminated soil. Soil-vapor extraction will not remove heavy oils, metals, polychlorinated biphenyls, or dioxins. According to available historical records and soil gas surveys, soil-vapor extraction would be effective for most organic COCs in the SDA (i.e., carbon tetrachloride, methylene chloride, tetrachloroethylene, and trichloroethylene; but not 1,4-dioxane). Advantages of soil-vapor extraction include ease of installation, minimal disturbance to site operations, and relatively low capital and maintenance costs.

Soil-vapor extraction has been implemented successfully at the SDA as part of the OU 7-08 remedy. The existing OU 7-08 Organic Contamination in the Vadose Zone (OCVZ) treatment system has been removing dispersed VOC contamination from the vadose zone beneath the SDA since 1996. The current OCVZ system consists of multiple vapor extraction wells, an off-gas treatment system to destroy organic contaminants in vapor removed from extraction wells, and soil-vapor monitoring wells to monitor

\footnotetext{
a. Other grout injection methods (e.g., low-pressure or permeation grouting) are available, but are not suitable for use in fine-grained interstitial soil typical of the SDA.

b. Application of ISG in simulated waste forms has demonstrated significant reductions in site permeability. Field-measured hydraulic conductivity for paraffin- and cement-based grout was less than $1 \mathrm{E}-07 \mathrm{~cm} / \mathrm{second}$ (Loomis, Zdinak, and Bishop 1997), which is equivalent to required permeability for bottom liners at RCRA Subtitle C landfills (EPA 1989).
} 
extraction performance. The OU 7-08 remedy is limited to the vadose zone and does not address buried waste or the aquifer. However, the soil-vapor extraction technology also could be configured to remove VOCs as they are released in the buried waste.

To address removal of volatile contaminants as they are released from buried waste, both active and passive soil-vapor extraction approaches could be applied. Active vapor extraction consists of several unit operations: gas extraction, gas transport, gas treatment, or condensate removal and disposal (USACE 1995). A well-designed active collection system is considered the most effective means of gas collection. An active vapor extraction system usually is used when relatively high concentrations of landfill gas are expected, and higher extraction capacity is required. Active collection systems have been effective for managing gas volumes generated by municipal landfills, which contain significantly more degradable organics than the SDA (USACE 1995). An active near-surface vapor extraction system configured for use in the SDA would consist of shallow extraction wells installed into the underlying fractured basalt or perforated pipes installed in a gas-permeable layer incorporated into a future surface barrier. The gas extraction system would be connected to the OCVZ system for treatment.

A passive vapor extraction system uses diurnal variation in atmospheric pressure to remove soil vapor. Generally, passive systems are used when relatively small gas volumes will be generated at the waste site (USACE 1995). Though the extraction rate is less than that for active systems, passive systems have the advantage that they continue to function indefinitely. A passive extraction system configured for use at the SDA would consist of a collection system (i.e., perforated piping), or a gas-permeable layer, integrated into a surface barrier that would collect gas released by buried waste and discharge it to the atmosphere without additional treatment.

2.2.4.2 In Situ Thermal Treatment. In situ thermal desorption and in situ vitrification are two in situ thermal treatment process options that were determined not implementable. Because these technologies were favorably reviewed in the Preliminary Evaluation of Remedial Alternatives (Zitnik et al. 2002), they were thoroughly evaluated during the technology screening process. Appendix A provides additional information on these two technologies.

2.2.4.2.1 In Situ Thermal Desorption-Results of recent EPA testing at a U.S. Department of Defense site indicated that in situ thermal desorption would not be technically feasible at the SDA due to problematic waste types (see Appendix A). Specifically, corrosive effects of (a) acid gases released during decomposition of highly concentrated chlorinated organic waste and (b) molten salts resulting from melting and migration of Rocky Flats Plant Series 745 salts may severely compromise reliability of the in situ thermal desorption system.

2.2.4.2.2 In Situ Vitrification-The in situ vitrification alternative described in the Zitnik (et al. 2002) relied on in situ thermal desorption pretreatment to avoid process upsets by site conditions or risks implicit in the in situ thermal treatment of waste forms unique to the SDA. In situ vitrification would not be technically implementable without prior application of in situ thermal desorption because in situ vitrification would remain subject to the same process upsets, including catastrophic failure of the off-gas system resulting from corrosion or thermal excursions caused by waste reactivity. Neither in situ thermal desorption nor in situ vitrification are retained as representative in situ treatment process options for developing assembled alternatives. 


\subsubsection{Ex Situ Treatment}

Ex situ treatment technologies can reduce toxicity, mobility, or volume of contaminants, or remove hazardous characteristics of waste, if required, to meet specific disposal and transportation requirements. Regulatory requirements for transuranic waste disposal and transportation are different than for nontransuranic waste. Transuranic waste is characterized to meet WIPP waste acceptance criteria. Potential treatments required to prepare waste for shipment to WIPP include removing prohibited items, solidifying free liquids, and eliminating characteristics of ignitability, corrosivity, or reactivity. In addition, transportation requirements for waste shipments to WIPP limit emission of flammable gas from drums in transportation casks. Drums with unacceptable emission rates may require treatment to remove organic compounds. Because WIPP is exempt from RCRA land disposal restrictions, ex situ treatment of mixed transuranic waste is not necessary. However, treatment may be required for retrieved waste that is not characterized as transuranic to immobilize regulated metals or to destroy hazardous organic constituents before disposal. Nontransuranic waste shipped to treatment facilities off the INL Site may require treatment to meet applicable waste disposal criteria, and would be treated at the receiving facility.

Potential process options for ex situ treatment are grouped under four general technology types: physical, chemical, thermal, and biological. Appendix A summarizes evaluations of the effectiveness and implementability of ex situ treatment process options. Several process options were eliminated from further evaluation because they were not applicable to SDA waste types, were technically immature, or were infeasible for expected volumes. Table 2-6 lists the technology types and process options evaluated during the screening process. The following subsections discuss technologies and process options identified as applicable at the SDA.

Table 2-6. Summary of screening results for the ex situ treatment general response action.

\begin{tabular}{cll}
$\begin{array}{c}\text { Remedial } \\
\text { Technology }\end{array}$ & \multicolumn{1}{c}{$\begin{array}{c}\text { Potentially Applicable } \\
\text { Process Option }\end{array}$} & \multicolumn{1}{c}{$\begin{array}{c}\text { Not Potentially Applicable } \\
\text { Process Option }\end{array}$} \\
\hline Physical treatment & $\begin{array}{l}\text { Compaction } \\
\text { Conveyor with gamma monitor and } \\
\text { gate system } \\
\text { Electrostatic separation } \\
\text { Gravity separation }\end{array}$ & Magnetic separation \\
& $\begin{array}{l}\text { Screening and classification } \\
\text { Sizing }\end{array}$ & \\
\hline Chemical treatment & Fixation and stabilization & Acid extraction \\
& Neutralization & Dehalogenation \\
& & Mediated electrochemical oxidation \\
& & Reduction-oxidation manipulation \\
& & Soil washing \\
& & Solvent extraction
\end{tabular}


Table 2-6. (continued).

\begin{tabular}{lll}
$\begin{array}{c}\text { Remedial } \\
\text { Technology }\end{array}$ & \multicolumn{1}{c}{$\begin{array}{c}\text { Potentially Applicable } \\
\text { Process Option }\end{array}$} & \multicolumn{1}{c}{$\begin{array}{c}\text { Not Potentially Applicable } \\
\text { Process Option }\end{array}$} \\
\hline Thermal treatment & Pyrolysis & Incineration \\
& Steam reforming & Molten metal system \\
& Thermal desorption & Molten salt system \\
& Vitrification & Supercritical water oxidation \\
\hline Biological treatment & None & Aerobic bioremediation \\
& & Anaerobic bioremediation \\
\hline Note: Retained for further evaluation. & \\
\hline
\end{tabular}

2.2.5.1 Ex Situ Physical Treatment. Physical treatment consists of sizing and compacting waste, followed by separation by physical or radiological characteristics. Physical treatment process options identified as potentially applicable are:

- Compaction-Compaction applies high pressure to waste to reduce void space and volume.

- Conveyor with gamma monitor and gate system-This process option combines a feed hopper, a conveyor belt, gamma spectroscopy, and a gate to separate soil, based on gamma activity.

- $\quad$ Electrostatic separation-Electrostatic separation is used routinely in mineral processing. Particles are sprayed with electrons from the active electrode and develop a charge that causes them to adhere to a grounded rotor. Conductive particles immediately lose charge and separate from the nonconducting particles.

- Gravity separation-Gravity separation is used to separate solids and liquids by differences in density. Equipment size and effectiveness depend on the settling velocity of solids, which is a function of particle size, particle density, fluid viscosity, and settlement time. Gravity separation also can be used to separate immiscible organic phases.

- $\quad$ Screening and classification-Screening and classification uses different-sized sieves and screens to separate material types. Screening and classification equipment includes grizzly shakers and rotary trommels. The process can be used to exclude oversized material as a pretreatment step for further processing.

- $\quad$ Sizing-Cutting, shredding, or crushing equipment can be used to reduce the size of solid debris. Equipment includes jaw crushers, gyratory crushers, hammermills, shear shredders, and dual-auger shredders.

Waste sent to treatment and disposal facilities either on or off the INL site may require screening and classification prior to further processing; therefore, screening and classification is identified as a representative option. 
2.2.5.2 Ex Situ Chemical Treatment. Chemical treatment consists of binding contaminants in less soluble forms, removing or destroying contaminants, or eliminating reactivity or corrosivity. Chemical treatment process options identified as potentially applicable are:

- $\quad$ Fixation and stabilization-Fixation and stabilization immobilizes radioactive and hazardous constituents by binding or absorbing the contaminants in a less soluble form, or encapsulating them in an impermeable matrix. Matrices commonly used for waste stabilization include Portland cement and organic polymers.

- $\quad$ Neutralization-Neutralization is used to adjust caustic or acidic waste to an acceptable $\mathrm{pH}$.

Fixation and stabilization is identified as a representative process option to treat mixed LLW if any is relocated within the OU 7-13/14 area of contamination. Similar process options have been developed to stabilize soil and debris at ICDF, and while those processes are not in current use, they are assumed to be applicable and adaptable for use in the SDA. Grouts applicable to stabilization of some SDA waste types have been studied at the INL (Loomis et al. 2003; Matthern et al. 2005), but additional studies may be required during remedial design.

2.2.5.3 Ex Situ Thermal Treatment. Thermal treatment is used to desorb or decompose organic contaminants using thermal energy. Products of these process options include gases, refractory residues (e.g., ash, char, and glass), and metals. Thermal treatment also includes removal of organic contaminants using steam or supercritical water. Thermal treatment process options identified as potentially applicable are:

- Pyrolysis-Pyrolysis decomposes organic compounds at high temperature in an oxygen-deficient atmosphere. Inorganic contaminants, including radionuclides and heavy metals, remain in the refractory residue, and may require additional treatment (i.e., fixation or stabilization).

- $\quad$ Steam reforming - Steam reforming uses superheated steam to decompose organics into a hydrogen-rich gas. Resulting gas is subsequently oxidized and released to the atmosphere. The refractory residue may require additional treatment (i.e., fixation or stabilization).

- Thermal desorption-Thermal desorption heats waste to volatilize (but typically not oxidize) organic contaminants. Contaminated materials are fed into dryers, and the volatilized organics are captured or decomposed using an off-gas treatment system.

- Vitrification-Vitrification uses intense heat to destroy organic material and melt the refractory residue into a glass-like waste form. Process options include Joule-heated, plasma torch, and arc melters.

None of the ex situ thermal treatment processes are retained as representative process options for further evaluation. The OU 7-13/14 feasibility study assumes that, if required, waste would be treated at independent on- or off-INL Site treatment facilities. In addition, waste failing WIPP waste acceptance criteria for gas generation (DOE-CBFO 2005) can be managed without resorting to thermal treatment.

\subsubsection{Containment}

Containment technologies isolate waste using surface or subsurface engineered barriers. When properly constructed and maintained, containment technologies can prevent or substantially reduce contaminant migration into the surrounding environment and eliminate or reduce direct exposure to waste. Containment options reduce mobility of contaminants without incurring worker risk associated 
with retrieval and subsequent handling (e.g., packaging, treatment, and shipment) of hazardous waste. Table 2-7 lists technology types and process options evaluated during the screening process (see Appendix A). Four process options are retained for further evaluation and are described in the following subsections. Section 2.2.6.1.2 describes three technologies that could be used to provide a stable foundation for constructing a surface barrier for closure of the SDA.

Table 2-7. Summary of screening results for the containment general response action.

\begin{tabular}{lll} 
Remedial Technology & \multicolumn{1}{c}{$\begin{array}{c}\text { Potentially Applicable } \\
\text { Process Option }\end{array}$} & \multicolumn{1}{c}{$\begin{array}{c}\text { Not Potentially Applicable } \\
\text { Process Option }\end{array}$} \\
\hline Surface barriers & $\begin{array}{l}\text { ET surface barrier } \\
\text { Foundation preparation } \\
\text { Hanford surface barrier } \\
\text { ICDF surface barrier } \\
\text { Modified RCRA Type C surface } \\
\text { barrier } \\
\text { Surface biotic barrier }\end{array}$ & Single-layered surface barrier \\
& Slurry wall & \\
\hline $\begin{array}{l}\text { Subsurface vertical } \\
\text { barriers }\end{array}$ & & Ground-freezing barrier \\
& & Grout curtain \\
& & In-place soil mixing \\
& Sheet-piling barrier \\
\hline Horizontal barriers & Grout injection & Block displacement \\
& & Ground-freezing liner \\
\hline $\begin{array}{l}\text { Note: Retained for further evaluation. } \\
\text { ET = evapotranspiration } \\
\text { ICDF = Idaho CERCLA Disposal Facility } \\
\text { RCRA = Resource Conservation and Recovery Act }\end{array}$ & \\
\hline
\end{tabular}

2.2.6.1 Surface Barriers. All remedial action alternatives evaluated in the OU 7-13/14 feasibility study include an engineered surface barrier (Holdren and Broomfield 2004). The term engineered surface barrier, commonly referred to as a cap or cover, describes a wide range of technologies that covers buried waste to reduce contaminant transport to the ground surface and minimize infiltration of precipitation (e.g., snow and rain). Surface barriers effectively eliminate most surface exposure pathways. Surface barriers meet remedial action objectives by covering contaminated areas with uncontaminated soil, rock, or other media (e.g., asphalt, concrete, or geosynthetic materials). Vegetation may be established on the surface to improve evapotranspiration (ET), reduce infiltration of water, control soil erosion, and improve appearance.

Surface barriers must be designed to mitigate site-specific exposure risks and comply with applicable or relevant and appropriate requirements, taking into account buried waste characteristics, availability of construction materials, and site environmental conditions (e.g., climate and precipitation). Factors considered when defining functional requirements for surface barrier design include:

- $\quad$ Possibility that plant roots, burrowing animals, and insects will penetrate soil and waste

- $\quad$ Site infrastructure that may interfere with construction 
- $\quad$ Climate, including temperature, insulation, precipitation, evaporation, and transpiration

- $\quad$ Stability of the subgrade and the resulting barrier surface and side slopes

- Wind or water erosion

- $\quad$ Catastrophic events (e.g., earthquakes, volcanoes, or floods).

Several surface barrier designs have been evaluated for application at the SDA, based on available performance data and site-specific hydrogeologic and climatic conditions (Golder Associates 1988; Keck 1992; Forman and Anderson 2005; Mattson et al. 2004). The following subsections describe surface barrier types identified during the screening process as applicable for use at the SDA.

2.2.6.1.1 Evapotranspiration Surface Barrier-The primary design element of an ET surface barrier is a water storage layer composed of native soil. The ET surface barrier is designed to manage the water balance of the covered area to minimize infiltration through the barrier to underlying contaminated material. The ET surface barrier design exploits the high evaporation and transpiration rates characteristic of undisturbed soil and vegetation in arid and semiarid environments (e.g., the SDA). Evaporation and transpiration of seasonal precipitation maintains low soil-moisture content in the storage layer, minimizing infiltration and hydraulic conductivity through the underlying waste. The storage layer sustains plant growth during dry periods and prevents infiltration through buried waste when plants are inactive and transpiration rates are low. Incorporating a coarse gravel layer immediately beneath the water storage layer provides a capillary break that can further reduce moisture infiltration (Stormont and Anderson 1999; Porro 2001; Forman and Anderson 2005) and inhibit biotic intrusion.

A capillary break within an ET surface barrier can be actively or passively vented to remove soil vapor, further reducing migration of volatile contaminants (i.e., VOCs and C-14) to the subsurface. This variation has been called a dry barrier (Stormont et al. 1994). The resulting dry zone also may effectively deter plant root intrusion into the underlying waste (Anderson et al. 1993). In addition, an ET surface barrier may incorporate an optional layer of coarse rock (e.g., river cobbles) as an additional deterrent to waste intrusion by plant roots, insects, and burrowing animals (Hakonson 1986; Gaglio et al. 2001; Breshears, Nyman, and Davenport 2005).

Numerous evaluations have advocated using ET barriers instead of conventional multilayered barriers, based on availability of construction materials, ease of construction, and reduced susceptibility to surface barrier failure resulting from differential subsidence of buried waste (Dwyer 1997; Moore and Crowe 1998; ITRC 2003; Breshears, Nyman, and Davenport 2005). Field-scale tests conducted adjacent to the SDA suggest that ET barriers should be equally protective of human health and the environment as conventional multilayered surface barrier designs (Forman and Anderson 2005). Modeling for the preconceptual ET surface barrier design evaluated in the OU 7-13/14 feasibility study suggests that average moisture flux into the underlying waste would be extremely low (on the order of $0.15 \mathrm{~cm} / \mathrm{year}$ [0.06 in./year]), assuming current climatic conditions at the SDA (Mattson et al. 2004).

Based on evaluation of multiple barrier designs, the ET surface barrier was identified as the most applicable design for waste containment at the SDA (Keck 1992; Mattson et al. 2004). The ET surface barrier design is appropriate for SDA site-specific climatic conditions and is expected to effectively meet remedial action objectives for both protection of groundwater and direct exposure pathways. For these reasons, the ET surface barrier is retained as a representative process option for developing assembled alternatives. Figures 2-4 and 2-5 depict the two surface barrier process options (i.e., ET and modified RCRA Type C) retained for assembly and detailed evaluation of remedial alternatives in Sections 3 and 4. Figure 2-4 shows a cross section of a typical ET surface barrier. Consistent with assumptions in the Second Addendum to the Work Plan (Holdren and Broomfield 2004, Table 2-2, Assumption 8), the 
preconceptual ET barrier design evaluated in the OU 7-13/14 feasibility study includes a capillary break and optional coarse rock layer (i.e., biotic barrier) to deter biotic intrusion into buried waste. These design elements (i.e., optional coarse rock layer) were included to compare similar barrier designs; however, specific design elements will not be determined until the barrier design is complete. Several design elements can deter biotic intrusion, including increasing depth of the native soil layer. Individual design elements, alone or in combination, can effectively inhibit burrowing animals as well as penetration by deep-rooting plant species. At the INL Site, burrowing animals have attained measured maximum depths of $1.9 \mathrm{~m}(6.2 \mathrm{ft})$ for the Great Basin pocket mouse (Perognathus parvus), $2.3 \mathrm{~m}(7.5 \mathrm{ft})$ for the badger (Taxidea taxus), and $2.7 \mathrm{~m}(8.9 \mathrm{ft})$ for the harvester ant (Hampton 2006). In addition, sagebrush (Artemisia tridentata) frequently attains depths of more than $2 \mathrm{~m}$ (6.6 ft) (Hampton 2006). An ET surface barrier, modified to meet SDA site conditions, is retained as a representative process option for developing assembled alternatives. The preliminary design for an ET surface barrier evaluated in this feasibility study for OU 7-13/14 (Mattson et al. 2004) is composed of five layers, with a nominal thickness of $2.7 \mathrm{~m} \mathrm{(9.0} \mathrm{ft)} \mathrm{(see} \mathrm{Figure} \mathrm{2-4).} \mathrm{The} \mathrm{area} \mathrm{of} \mathrm{a} \mathrm{surface} \mathrm{barrier} \mathrm{on} \mathrm{the} \mathrm{SDA} \mathrm{would} \mathrm{be} \mathrm{at} \mathrm{least}$ 42.5 ha (105 acres).

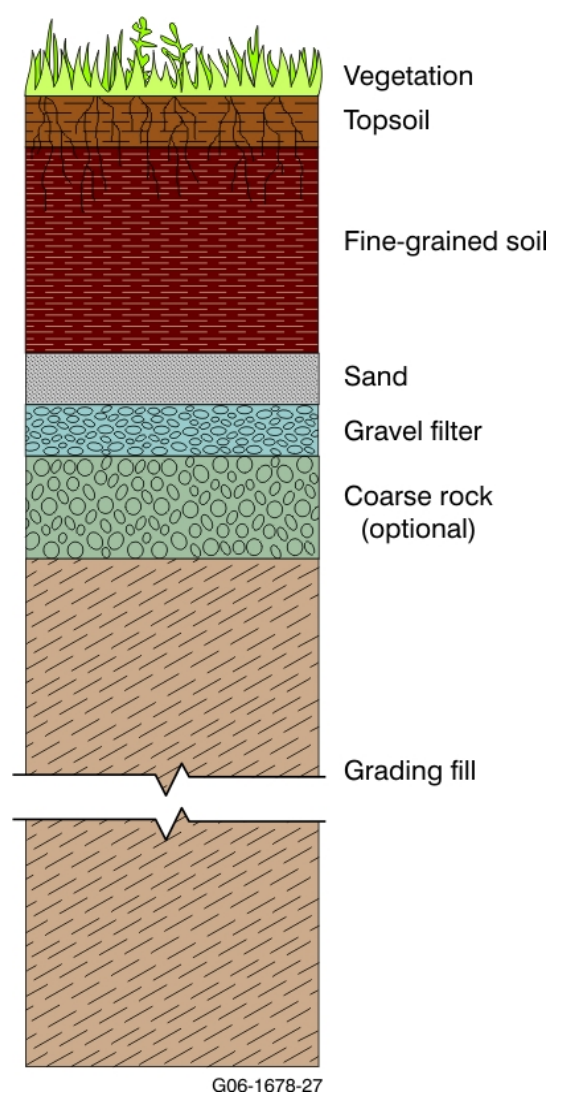

Figure 2-4. Cross section of the preconceptual evapotranspiration surface barrier design.

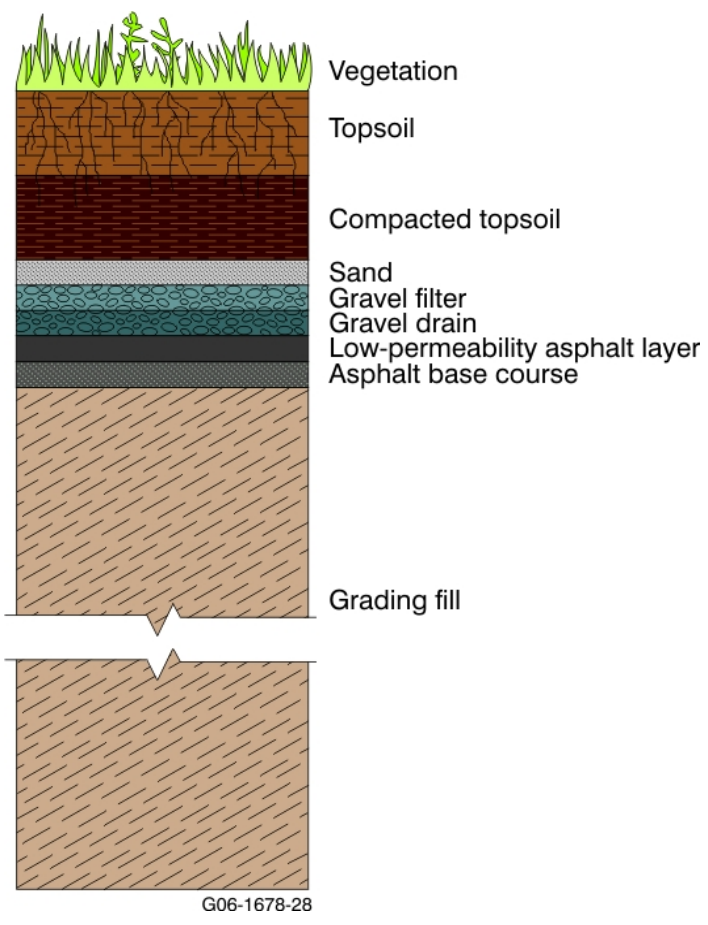

Figure 2-5. Cross section of the modified RCRA Type C surface barrier.

2.2.6.1.2 Foundation Preparation-Using ground improvement technologies in the SDA could enhance physical stability of the surface barrier and increase its long-term effectiveness. Subsidence may be the greatest threat to performance of the surface barrier (Keck and Seitz 2002; Moore and Crowe 1998) because differential settlement could fracture impermeable layers and cause preferential flow of moisture infiltration through underlying waste. Though ET surface barriers are designed to be less susceptible to differential settlement than multilayered surface barriers, pretreatment applications are still 
recommended to create a stable foundation (Mattson et al. 2004). Three process options for foundation preparation were evaluated. Foundation grouting is an intrusive process that injects liquid grout into the subsurface to fill voids or form piles to provide structural support. Dynamic compaction and surface rolling (i.e., proof-rolling) were evaluated to provide a range of ground-improvement processes that could be applied without penetrating the soil layer overlying waste buried in the SDA.

All three process options are retained for use in development of alternatives. Dynamic compaction was retained because it is a bounding and representative process option that poses the highest short-term risk and highest cost for process options applied at the ground surface. Because historical waste disposal methods and the thickness of layers of buried waste varies across the SDA, a combination of process options may be proposed during remedial design. The three retained process options for ground improvement are described below:

- $\quad$ Foundation grouting-Foundation grouting would involve injecting cement grout into the subsurface to fill voids or form columns to support a surface barrier. In situ grouting (see Section 2.2.4) can be used to form discrete grout columns in the subsurface. Columns are installed in a geometric pattern designed to provide sufficient structural support for the overlying surface barrier (Stephens 2004). Foundation grouting design criteria would include field implementability, compressive strength of emplaced columns, grout durability sufficient to provide a design life of 500 to 1,000 years, and waste compatibility with the grout formulation.

- Dynamic compaction-Dynamic compaction is a civil construction process for compacting and strengthening loose or soft soil to support buildings, roadways, and other heavy structures. Richins and Hurst (2004) performed a preliminary evaluation of the potential use of dynamic compaction for foundation preparation at the SDA. This process involves systematically dropping heavy weights, typically 10 to 20 tons, in a pattern designed to consolidate underlying soil and waste. Drop heights vary from 9 to $24 \mathrm{~m}$ (30 to $80 \mathrm{ft}$ ). The crater formed at the impact point is subsequently backfilled with clean soil. Several phases of tamping may be required, depending on underlying media and depth of improvement required. After high-energy tamping, a low-energy or "ironing" phase is performed to compact the upper $1.5 \mathrm{~m}(5 \mathrm{ft})$ of the formation. The ironing phase consists of dropping the weight from a height of 3 to $8 \mathrm{~m}$ (10 to $25 \mathrm{ft})$ on close centers. While dynamic compaction is used routinely to consolidate waste in municipal landfills, it is seldom used for ground improvement during closure of landfills containing radioactive or hazardous waste because of concerns about disrupting waste containers, penetrating buried waste, and potentially spreading surface or airborne contamination. However, engineering and administrative controls can be applied to ensure safety in contaminated environments.

- Proof-rolling-Surface- or proof-rolling uses rubber- or steel-wheeled vehicles to test uniformity and stability of the ground surface. Proof-rolling identifies soft spots in the ground surface that might delay construction of structures (e.g., a surface barrier); however, ground consolidation is limited to the first few feet of soil, especially with compactable silty clay soil, such as that found in the SDA. Effectiveness of proof-rolling at the SDA could be improved by using vibratory rollers or eccentric impact rollers. Effectiveness of impact rolling could be further improved through iterative use when soil conditions are most conducive to plastic flow (i.e., when soil is wet). Iterative use of impact rolling, perhaps integrated with future drainage improvement actions, could substantially extend the effective zone of influence beyond what is typical for proof-rolling.

2.2.6.1.3 Hanford Long-Term Composite Surface Barrier-The Hanford long-term composite surface barrier, referred to as the Hanford barrier, was developed for long-term isolation of transuranic waste and LLW at the Hanford site (Gee, Ward, and Wittreich 2002; Wing and Gee 1994). This surface barrier design uses thick layers of native earthen materials and a composite asphalt layer to 
provide 1,000-year isolation at disposal sites containing greater than Class C LLW or transuranic waste. The Hanford barrier is functionally a water balance system, designed to minimize infiltration of precipitation in semiarid to subhumid environments, combined with a RCRA Subtitle C surface barrier.

The Hanford barrier comprises nine layers, with a nominal thickness of $4.6 \mathrm{~m}(15 \mathrm{ft})$ and surface vegetation to minimize erosion. Layers include upper and lower silt layers, sand filter, gravel filter, fractured basalt, lateral drainage aggregate, asphalt layer, and asphalt base course over a grading fill. The $1.5-\mathrm{m}(5-\mathrm{ft})$ layer of fractured basalt is designed to deter biotic intrusion. This configuration may reduce the likelihood that human intrusion (e.g., excavation of a foundation) would result in inadvertent dispersal of buried waste, consistent with DOE Order 435.1, which requires a total cover thickness of at least $4.5 \mathrm{~m}$ $(15 \mathrm{ft})$ at disposal sites where human intrusion is reasonably anticipated. However, because residential intrusion is not anticipated at the SDA, the Hanford barrier design is not directly applicable. Furthermore, as discussed for the modified RCRA Type $\mathrm{C}$ surface barrier, impermeable layers are not expected to be effective if differential subsidence occurs (Moore and Crowe 1998; Mattson et al. 2004). For these reasons, the Hanford long-term composite barrier is not retained as a representative process option for developing assembled alternatives.

2.2.6.1.4 Idaho CERCLA Disposal Facility Surface Barrier-The ICDF surface barrier is designed to provide containment and hydraulic protection for 1,000 years (Crouse and Watson 2002). This barrier design is based on the Hanford long-term composite barrier. The ICDF barrier comprises nine layers, with a nominal thickness of $5.6 \mathrm{~m}(18.5 \mathrm{ft})$ with surface vegetation to minimize erosion. Layers include topsoil, engineered earth fill, sand filter, gravel filter, biotic intrusion layer, gravel filter, sand filter, geomembrane, and compacted clay layer over a grading fill. This INL Site-specific design includes a $0.75-\mathrm{m}(2.5-\mathrm{ft})$ layer of fractured basalt, to deter biotic intrusion, and a geomembrane, which replaces the asphalt drainage layer in the Hanford design.

As with the Hanford barrier, the thickness of the ICDF surface barrier was designed to comply with requirements allowing future residential use of the surface barrier. However, because residential use of the SDA is not anticipated, this design is not directly applicable. Furthermore, using a geomembrane drainage layer is not expected to be effective if differential subsidence occurs (Moore and Crowe 1998; Mattson et al. 2004). For these reasons, the ICDF surface barrier is not retained as a representative process option for developing assembled alternatives.

2.2.6.1.5 Modified RCRA Type C Surface Barrier-A conventional RCRA Type C surface barrier is designed to meet performance objectives for closure of RCRA Subtitle C landfills under 40 CFR 265.310. U.S. Environmental Protection Agency guidance (EPA 1988, 1989) recommends a surface barrier composed of three layers consisting of a vegetated soil layer, a sand drainage layer, and an impermeable layer comprising a flexible membrane liner overlying a compacted clay layer. A gas-collection layer may be included if gas accumulates in the landfill. Nominal thickness of the conventional RCRA Type $\mathrm{C}$ surface barrier is $1.5 \mathrm{~m}(5.0 \mathrm{ft})$, and adding grading fill to maintain a slope for shedding water would increase overall thickness of the surface barrier. The conventional RCRA Type $\mathrm{C}$ surface barrier has a projected design life of 30 years and would not meet remedial action objectives for the SDA. A modified RCRA Type $\mathrm{C}$ design was evaluated that provides a design life of 500 years to address long-term containment and hydrologic protection requirements for sites containing LLW and mixed LLW (DOE-RL 1996). Because the conventional compacted clay impermeable layer is vulnerable to desiccation and cracking in semiarid environments, an asphalt composite layer was substituted (Daniel and Wu 1993). Layers in the modified RCRA Type C surface barrier include topsoil (with or without pea gravel), sand filter, gravel filter, lateral drainage layer, asphalt, and a base course that overlies the grading fill (see Figure 2-5). The asphalt layer minimizes drainage and deters biotic intrusion. 
The modified RCRA Type $\mathrm{C}$ surface barrier relies on an intact asphalt layer to divert drainage to the edge of the barrier. If differential subsidence occurs in the underlying waste, integrity of the drainage layer could be compromised, accelerating infiltration at localized failures (Moore and Crowe 1998). For this reason, any alternative implementing a modified RCRA Type $\mathrm{C}$ surface barrier, or similar barrier incorporating impermeable layers, would require substantial foundation preparation to minimize this risk.

Modified RCRA Type $\mathrm{C}$ surface barriers deployed to date have been for relatively small areas (e.g., less than 2 ha [5 acres]) (EPA 2006). Because the area of a surface barrier on the SDA would be at least 42.5 ha (105 acres), significant technical and administrative implementability issues may arise. Specifically, staged deployment of an asphalt composite layer over a large area would cause interlift boundaries, which would require construction of sealed staggered joints. Because of previous difficulties in constructing thin impermeable layers (Suter, Luxmore, and Smith 1993), rigorous construction quality control would be required to ensure integrity of a thin asphalt composite hydraulic barrier (Bowders et al. 2003).

Multilayered surface barriers commonly are used to control infiltration at landfills. Design and construction details are well understood and available from commercial contractors. Performance data for these types of surface barrier designs, at least for modern landfills, are well understood. Though long-term effectiveness of the modified RCRA Type C surface barrier under SDA conditions is unclear, this design is considered the most applicable multilayered design. Therefore, the modified RCRA Type C surface barrier is identified as a representative process option for development and evaluation of remedial alternatives. The preliminary design for a modified RCRA Type $\mathrm{C}$ surface barrier evaluated in the feasibility study for OU 7-13/14 is composed of seven layers, with a nominal thickness of $1.7 \mathrm{~m}(5.6 \mathrm{ft})$. The preliminary design for the modified RCRA Type $\mathrm{C}$ surface barrier does not incorporate a separate biotic intrusion barrier because this function is assumed to be provided by the asphalt layers (see Figure 2-5).

2.2.6.1.6 Surface Biotic Barrier-A surface biotic barrier, also referred to as a rock armor cover, is designed to prevent human contact with contaminated media and future intrusions into waste by plants or animals. This type of barrier may include rock armor and compacted clay layers (DOE 1988, 1989). This barrier has been used at uranium mill remediation projects to stabilize tailings. A rock armor barrier was used to close the Stationary Low-Power Reactor-1 burial ground at the INL Site. This barrier was composed of (from top to bottom) layers of basalt boulders, gravel, river cobble, and gravel. Basalt boulders were placed to deter biotic intrusion.

Used alone, a surface biotic barrier may increase infiltration above background rates because of reduced evaporation resulting from lowered surface temperature and wind speed and reduced transpiration resulting from excluding surface vegetation. For these reasons, a surface biotic barrier is not retained for developing assembled alternatives. However, similar subsurface biotic intrusion layers are incorporated into the preliminary design for the ET surface barrier to provide defense-in-depth against biotic intrusion. The asphalt layer in the modified RCRA Type $\mathrm{C}$ surface barrier is assumed to adequately deter biotic intrusion.

2.2.6.2 Subsurface Vertical Barriers. Subsurface vertical barrier technology focuses on controlling lateral movement of moisture into a contaminated area. A vertical barrier can be constructed around the perimeter of a contaminated area without directly disturbing contaminated media. Potentially applicable subsurface vertical barriers include grout injection, soil mixing, sheet-piling barrier, and slurry wall. Grout injection and soil mixing are not selected for developing assembled alternatives because continuity of individually placed barrier elements is difficult to verify, and sheet-piling barriers are unlikely to meet the design life of the associated surface barrier. The slurry wall is retained for developing assembled alternatives. 
2.2.6.2.1 Slurry Wall-Slurry walls are used to contain contaminated groundwater, divert contaminated groundwater from drinking water intakes, divert uncontaminated groundwater flow around contaminated areas, or provide an intake to a groundwater treatment system (EPA 1984; FRTR 2002). At the SDA, a slurry wall could be combined with a surface barrier to provide complete hydraulic isolation of buried waste from either vertical or horizontal infiltration. A slurry wall is typically constructed by excavating a vertical trench through surficial sediments, which is simultaneously backfilled with a low-permeability soil-bentonite mixture. This continuous trenching method allows excavation and backfilling in a single operation, and is the best construction method for the variable basalt surface underlying the SDA. In addition to bentonite clay, Portland cement or organic polymers could be used to reduce penetration of moisture through a slurry wall.

Evaluation of the nature and extent of contamination in the SDA (see Section 1.3) concludes that migration of contaminants from the buried waste has been limited, with the exception of gas-phase transport of volatile organic contaminants. Furthermore, no mechanism has been identified for horizontal migration of precipitation in surficial sediments. Nevertheless, a slurry wall is retained as a representative process option and included in developing Alternative $4 \mathrm{~b}$ so that a cost estimate module would be available if this action is required in the proposed plan.

2.2.6.3 Subsurface Horizontal Barriers. Subsurface horizontal barriers potentially could be used to control vertical movement of moisture from buried waste into the underlying vadose zone. Ideally, a horizontal barrier would be constructed with minimal disruption of the buried waste. However, horizontal barrier construction methods are developmental and have not been used at disposal sites similar to the SDA. For completeness during technology screening, ISG was evaluated as a potential process option. Conceptually, horizontal or vertical drilling might be used to inject a microfine grout to seal fractures in the underlying basalt. However, no practical means are available to verify permeability of the resulting barrier. If the effective permeability of the subsurface barrier exceeds that of the underlying horizontal barrier, moisture could accumulate (i.e., pond) in the buried waste, with the potential to increase contaminant migration. For these reasons, subsurface horizontal barriers are not retained as representative process options for developing assembled alternatives.

\subsubsection{Institutional Controls}

Two means were evaluated for implementing the ICs general response action: passive land-use restrictions and both passive and active access controls. All process options associated with each approach were identified as potentially applicable and were retained for further evaluation, as follows:

- $\quad$ Passive land-use restrictions

- $\quad$ Conservation easement

- Covenant

- $\quad$ Deed notice

- Groundwater-use restriction

- $\quad$ Public advisory

- $\quad$ Reversionary interest

- $\quad$ State use restriction

- $\quad$ Zoning ordinance and local permit 
- $\quad$ Active access controls

- $\quad$ Perimeter patrol and surveillance

- $\quad$ Security guard

- $\quad$ Passive access controls

- $\quad$ Fences

- $\quad$ Signs.

The following subsections provide descriptions and results of preliminary screening for each process option.

2.2.7.1 Passive Land-Use Restrictions. Future land use at the SDA could be controlled using several process options. DOE could use a combination of several of the following measures to implement long-term stewardship of the SDA:

- Conservation easement-A state statute could be imposed to establish an easement to conserve and protect the property and to limit future use. A positive easement could be imposed allowing access for surveillance and environmental monitoring. A negative easement could be imposed to prohibit drilling or other intrusive activities.

- Covenant-Upon conveyance of the property, an agreement could be required specifying future land use.

- $\quad$ Deed notice-A deed notice commonly refers to nonenforceable information filed in public land records. A notice might discourage inappropriate land use, but would have little or no effect on a property owner's legal rights to property use.

- Groundwater use restriction-Restrictions could include limitations or prohibitions on aquifer well drilling in the affected area or buffer zone. In addition, local governments could impose restrictions on, or prohibit use of, groundwater.

- $\quad$ Public advisory-A public advisory could be issued by agencies at federal, state, or local levels warning potential users of the potential risk of using the land, surface water, or aquifer. Such an advisory has no legal or enforceable effect, but might deter inappropriate use.

- Reversionary interest-A clause could be placed in a deed specifying that the property would revert to the original owner under certain conditions. Such a clause might restrict the transferee's right to own and occupy the property and could be binding upon any subsequent purchasers.

- $\quad$ State use restriction-A state statute could be imposed, directing DOE to establish specific restrictions on using contaminated property. Such a statute could override common law impediments and allow long-term enforcement of property interests.

- Zoning ordinance and local permit-These are used by local governments to control land use. A zoning ordinance is not necessarily permanent because it can be repealed, or exemptions can be obtained after public hearings. In addition, a zoning ordinance would not be effective unless monitored and enforced. 
All means of land-use restriction are retained as potential process options to develop assembled alternatives. The retained measures can be used in combination with action-specific technologies to prevent compromise of site controls, minimize future maintenance requirements, and control potential exposure pathways that might result in unacceptable risk to human health. These measures apply to control of human access to the site, but will have little or no impact on ecological exposures.

2.2.7.2 Active Access Control. Process options for active access control include perimeter access patrol and surveillance (remote or manned) and the presence of security guards at entry points. Active security presence is an effective means of excluding human intruders.

Active access controls are retained for developing assembled alternatives. A security presence is readily implementable and significantly increases protectiveness beyond passive access controls.

2.2.7.3 Passive Access Control. Process options for passive access control include fences and signs intended to reduce health risk by inhibiting human intrusion into contaminated areas within the SDA. Fences with locked gates would prevent human access. Signs and monuments would inform potential intruders of dangers within enclosed areas. Process options focus on excluding human intruders, but also would be effective in limiting access by large mammals.

All process options for passive access control are retained for developing assembled alternatives. Fences and signs are readily implementable, and in combination with other ICs, can minimize the probability of site intrusion.

\subsubsection{Summary of Representative Process Options}

In summary, remedial action objectives and preliminary remediation goals were established considering the contaminants of interest, exposure routes, and receptors identified in the Remedial Investigation and Baseline Risk Assessment (Holdren et al. 2006, Section 1). General response actions were identified to encompass a range of remedial actions, including no action, retrieval, disposal, in situ treatment, ex situ treatment, containment, and ICs. Remedial technology types and associated process options then were identified for each general response action.

Each process option was screened based on effectiveness and implementability. Effectiveness evaluations were based largely on a previous screening of available process options (Zitnik et al. 2002), but were updated to include current vendor information, new information on the nature of waste types in the SDA, and lessons learned from implementing similar remedial actions. The implementability evaluation considered both technical and administrative feasibility, with the intent of eliminating those options that clearly were not implementable at the SDA. Appendix A provides a screening evaluation of potentially applicable technology types and process options and the expected implementability of each. Those process options identified as applicable are retained and evaluated further in this section.

Discussions for each process option focus on the anticipated effectiveness of the technology and its expected reliability under SDA conditions. In addition, potential safety issues are identified, as appropriate. Cost evaluations play a limited role in the screening process. Appendix A includes a qualitative description of the relative capital and operating and maintenance costs in terms of low, medium, or high.

Technologies and process options retained as representative process options are carried forward into Section 3 to support developing assembled alternatives.

Table 2-8 summarizes representative process options retained for each general response action. 
Table 2-8. General response actions, remedial technologies, and retained process options.

\begin{tabular}{|c|c|c|}
\hline $\begin{array}{c}\text { General } \\
\text { Response Action }\end{array}$ & Remedial Technology & Retained Process Option \\
\hline \multirow[t]{4}{*}{ Retrieval } & \multirow[t]{3}{*}{ Contamination control } & Confinement \\
\hline & & $\begin{array}{l}\text { Foams, sprays, misters, fixatives, and } \\
\text { washers }\end{array}$ \\
\hline & & Ventilation and vacuum systems \\
\hline & Excavation methods & $\begin{array}{l}\text { Standard construction equipment with } \\
\text { modifications }\end{array}$ \\
\hline \multirow[t]{5}{*}{ Disposal } & \multirow[t]{3}{*}{ On-INL Site storage and disposal } & ICDF \\
\hline & & LLW Pit within the SDA \\
\hline & & Temporary on-INL Site storage \\
\hline & \multirow[t]{2}{*}{ Off-INL Site storage and disposal } & EnergySolutions, Utah \\
\hline & & WIPP, New Mexico \\
\hline \multirow[t]{2}{*}{ In situ treatment } & \multirow[t]{2}{*}{ Physical treatment } & High-pressure jet grouting \\
\hline & & Soil-vapor extraction \\
\hline \multirow[t]{2}{*}{ Ex situ treatment } & \multirow{2}{*}{$\begin{array}{l}\text { Physical treatment } \\
\text { Chemical treatment }\end{array}$} & Screening and classification \\
\hline & & Fixation and stabilization \\
\hline \multirow[t]{4}{*}{ Containment } & \multirow[t]{3}{*}{ Surface barriers } & ET surface barrier \\
\hline & & Foundation preparation \\
\hline & & $\begin{array}{l}\text { Modified RCRA Type C surface } \\
\text { barrier }\end{array}$ \\
\hline & Subsurface vertical barriers & Slurry wall \\
\hline \multirow[t]{12}{*}{ Institutional controls } & \multirow[t]{8}{*}{ Passive land-use restrictions } & Conservation easement \\
\hline & & Covenant \\
\hline & & Deed notice \\
\hline & & Groundwater use restriction \\
\hline & & Public advisory \\
\hline & & Reversionary interest \\
\hline & & State use restriction \\
\hline & & Zoning ordinances and local permit \\
\hline & \multirow[t]{2}{*}{ Active access controls } & Perimeter patrols and surveillance \\
\hline & & Security guard \\
\hline & \multirow[t]{2}{*}{ Passive access controls } & Fences \\
\hline & & Signs \\
\hline \multicolumn{3}{|c|}{$\begin{array}{l}\text { ET = evapotranspiration } \\
\text { ICDF = Idaho CERCLA Disposal Facility } \\
\text { INL = Idaho National Laboratory } \\
\text { LLW = low-level waste }\end{array}$} \\
\hline
\end{tabular}




\subsubsection{Options for Incorporating Pad A and Removing Near-Surface Volatile Organic Compounds into Alternatives for Operable Unit 7-13/14}

During development of the Second Addendum to the Work Plan (Holdren and Broomfield 2004), strategies were developed for incorporating the Pad A ROD (DOE-ID 1994a) and removing VOCs that might accumulate within or beneath a surface barrier. These strategies were refined during subsequent discussions among DOE, the Idaho Department of Environmental Quality, and EPA (the Agencies). In addition, all alternatives developed in Section 3 include continued operation of the OCVZ system, which is used to ensure compliance with remedial objectives for removing VOCs from the vadose zone beneath the SDA (DOE-ID 1994b). Appendix E describe process options for incorporating management of Pad A waste and removing near-surface VOCs into assembled alternative.

2.2.9.1 Options for Incorporating Pad A into Alternatives. The Second Addendum to the Work Plan (Holdren and Broomfield 2004, Subsection A-2.1) specifies five options to be evaluated in the feasibility study for Pad A. Subsequently, the Agencies identified one additional option (i.e., Option 5 listed below). The six options are as follows:

1. Leave Pad A waste in place and incorporate it into a surface barrier (associated with Alternative 2a [Modified RCRA Type C Surface Barrier])

2. Remove Pad A waste and move it to the LLW Pit without treatment or additional engineering of the pit (associated with Alternative 2b [ET Surface Barrier])

3. Remove Pad A waste, grout it ex situ, and move it to a pit on the SDA (associated with Alternative 3 [ISG])

4. Remove Pad A waste and send it to ICDF for treatment and disposal (associated with Alternative 4a [4-Acre RTD])

5. Leave Pad A waste in place and apply dynamic compaction to address subsidence (associated with Alternative $4 \mathrm{~b}$ [2-Acre RTD])

6. Remove Pad A waste, send it to ICDF for treatment, and dispose of it off the INL Site (associated with Alternative 5 [Full RTD]).

Evaluations after publication of the Second Addendum to the Work Plan concluded that it would be infeasible to segregate the small volume of transuranic and larger amount of uranium (e.g., roaster oxide) waste commingled with LLW on Pad A. Previous penetration and inspection of Pad A, summarized in Holdren et al. (2006), Section 3.1.5.5, suggests that waste packages in Pad A are highly degraded, and that it would be infeasible to segregate waste using bulk-handling techniques.

Discriminating the small amount of potentially transuranic waste on Pad A would be technically impracticable. Though roaster oxides are identified as targeted waste for the Accelerated Retrieval Projects (DOE-ID 2004, 2006), roaster oxide on Pad A would not be a worthwhile stand-alone target for retrieval because uranium on Pad A is not advantageously collocated with Rocky Flats Plant transuranic waste, which is the primary focus of the Accelerated Retrieval Projects. Uranium is a secondary COC, and the Agencies are taking the opportunity to remove uranium that is collocated with transuranics to address uncertainty in the risk assessment. Therefore, all retrieval alternatives developed in Section 3 assume that Pad A waste is managed as LLW, consistent with the Pad A ROD (DOE-ID 1994a).

Options for managing Pad A waste assume that commingled waste, debris, and contaminated soil, in composite, will not exhibit the characteristic of an oxidizer. However, Rocky Flats Plant Series 745 
evaporator (nitrate) salts, as packaged at the time of production, do exhibit the characteristic of an oxidizer (Peterson, Johnson, and Peter 1986), and might require treatment before being transported off the SDA. Treatment to immobilize underlying hazardous constituents in Pad A waste (i.e., chromium) is assumed to occur at treatment, storage, and disposal facilities on or off the INL Site (associated with Alternative 5). Treatment (i.e., stabilization with Portland cement) is assumed to not be required for near-term immobilization of nitrates or immobilization of uranium in the distant future (e.g., beyond the year 3010). While not currently used, the stabilization treatment process selected for use at the Staging, Storage, Sizing, and Treatment Facility (Raivo 2001) is assumed to be feasible for stabilizing Pad A waste at ICDF (associated with Alternative 4a) or a similar facility constructed at the SDA (associated with Alternative 3).

\subsubsection{Options for Incorporating Removal of Near-Surface Volatile Organic Compounds into Alternatives. The Second Addendum to the Work Plan (Holdren and} Broomfield 2004, Section A-2.1) specifies options to be evaluated in the feasibility study for removing near-surface VOCs (i.e., VOCs no longer contained in the waste). The three options are listed below:

1. Active vapor extraction using additional, near-surface wells (associated with Alternative 2a [Modified RCRA Type C Surface Barrier])

2. Active vapor extraction from a gas transport layer within the surface barrier (associated with Alternative 2b [ET Surface Barrier])

3. Passive vapor extraction from a gas transport layer within the surface barrier (associated with Alternatives 3 [ISG], 4a [4-Acre Partial RTD], and 4b [2-Acre Partial RTD], which includes ET surface barriers).

Near-surface extraction wells are required with the modified RCRA Type C surface barrier because the asphalt layer would be highly impermeable to volatile contaminants and would effectively prevent diffusion of VOCs and C-14 to the atmosphere (Magnuson and Sondrup 2006). Alternatives incorporating ET surface barriers (i.e., Alternatives $2 \mathrm{~b}, 3,4 \mathrm{a}$, and $4 \mathrm{~b}$ ) would extract volatile contaminants from an integrated gas transport layer. Active extraction of volatile contaminants would be accomplished by coupling shallow extraction wells (i.e., Alternative 2a) or risers from the gas transport layer (i.e., Alternative 2b) to the existing OCVZ system (Housley 2005). Passive extraction would be accomplished by connecting the gas transport layer directly to the atmosphere using open risers (i.e., Alternatives 3, 4a, and 4b). Diurnal variation of atmospheric pressure would be sufficient to maintain contaminant concentrations in the transport layer below remediation goals for alternatives incorporating passive extraction. Features to address vapor build-up are not included in Alternative 5 (Full RTD) because the entire source of volatile contaminants would be removed from the landfill.

\subsubsection{Incorporation of Ongoing Vapor Extraction from the Vadose Zone into Alternatives for Operable Unit 7-13/14}

The Remedial Investigation and Feasibility Study (RI/FS) for OU 7-08 (Duncan, Sondrup, and Troutman 1993) concluded that volatile organic contaminants (e.g., carbon tetrachloride) had migrated from buried waste into fractured basalt and sedimentary interbeds lying beneath the SDA and represented an unacceptable risk to human health and the environment. Most VOCs buried in the SDA are associated with stabilized Series 743 sludge received from the Rocky Flats Plant. The OU 7-08 RI/FS (Duncan, Sondrup, and Troutman 1993) evaluated a range of applicable treatment technologies for treating VOCs that had migrated into the vadose zone, including containment, retrieval, vapor extraction, vapor extraction with thermal enhancements, and in situ remediation. Subsequent evaluation of assembled 
alternatives concluded that phased deployment of vapor extraction with ex situ treatment would be the most effective means to meet OU 7-08 remedial action objectives:

- $\quad$ Prevent inhalation of vapors emanating from the vadose zone from resulting in a total excess cancer risk greater than $10^{-4}$ to $10^{-6}$ (for carcinogens) and from resulting in a hazard index greater than or equal to 1 (for noncarcinogens)

- $\quad$ Prevent migration of vapor- and aqueous-phase COCs in the vadose zone from producing groundwater (i.e., aquifer) contamination concentrations that would result in a future total excess cancer risk greater than $10^{-4}$ to $10^{-6}$ (for carcinogens) and a hazard index greater than or equal to 1 (for noncarcinogens)

- $\quad$ Protect groundwater quality by preventing migration of vapor- and aqueous-phase COCs in the vadose zone from resulting in groundwater contaminant concentrations greater than state and federal maximum contaminant levels.

The OU 7-13/14 ROD will supersede the existing OU 7-08 ROD; therefore, the feasibility study for OU 7-13/14 adopts the OU 7-08 technical approach, and no additional effort is made to identify and screen technologies because evaluations in the OU 7-08 RI/FS are considered adequate. In addition, the OU 7-08 RI/FS includes a successful vapor extraction treatability study (Lodman et al. 1994). The following paragraphs provide an overview of the OU 7-08 ROD and the OCVZ system. Additional alternative-specific preliminary design details are discussed in Sections 3 and 4.

Operable Unit 7-08 extends from the land surface to the top of the Snake River Plain Aquifer, which is approximately $177 \mathrm{~m}(580 \mathrm{ft})$ below ground surface, but excludes the primary contamination source: waste buried in the SDA. The selected remedy identified in the OU 7-08 ROD (DOE-ID 1994b) consists of extraction and destruction of organic contaminant vapors present in the vadose zone beneath and within the immediate vicinity of RWMC and monitoring of vadose zone vapor and the Snake River Plain Aquifer in the vicinity of RWMC. The general objective of the selected remedy is to reduce risk to human health and the environment by removing volatile organic vapors that migrate into the vadose zone and to ensure that federal and state drinking water standards are not exceeded after vapor extraction is discontinued. Monitoring technologies are similar to those described for the No Action general response action (see Section 2.2.1).

Major components of the current OCVZ system include (a) approximately 20 vapor extraction wells with extraction intervals in shallow, intermediate, and deep fractured basalt within the vadose zone; (b) three treatment units that contain a blower and electrically heated catalytic oxidizers (i.e., Units D, E, and F) for removal and destruction of organic vapors; and (c) approximately 170 sample ports used for monitoring the effectiveness of OCVZ operations (Housley 2005; INL 2005). The OU 7-08 ROD specified phased deployment of the OCVZ system because the mass of VOCs remaining in the source term was poorly defined and there was uncertainty about the rate of VOC release from waste packages (e.g., polyethylene liners). Phase I included initial well installation and OCVZ system startup. Phase II is to continue until active vapor extraction is no longer required, ensuring that remedial action objectives are achieved. Phases II and III include options for increasing the number of extraction wells.

Operating experience suggests that original estimates of the time required to achieve preliminary remediation goals for Phase II were overly optimistic (Holdren et al. 2006) (see Section 3.2.8). Operable Unit 7-08 assumed that the selected remedy for OU 7-13/14 would reduce or eliminate the source of VOCs by year 2012, and that active vapor extraction would not be required after 2018 (INL 2005). However, refined two-phase fate and transport modeling included in the OU 7-13/14 feasibility study (see Appendix D, Section D-3.6.1.2) suggests that OCVZ system operations for all alternatives developed in 
Section 3 may have to be continued until 2035 to 2075 to meet remedial action objectives for OU 7-13/14. After applicable remediation goals have been achieved, a compliance verification period (i.e., Phase III) would be initiated to ensure that VOC concentrations in the vadose zone remain below remediation goals after shutdown of the OCVZ system. Long-term monitoring would be initiated following Agency concurrence that remediation goals have been achieved. Subsequent evaluations of remedy effectiveness would be included in the 5-year reviews for OU 7-13/14.

\subsection{References}

40 CFR 265.310, 2006, "Closure and Post-Closure Care," Code of Federal Regulations, Office of the Federal Register.

40 CFR 268, 2006, "Land Disposal Restrictions," Code of Federal Regulations, Office of the Federal Register.

40 CFR 300, 2006, "National Oil and Hazardous Substances Pollution Contingency Plan," Code of Federal Regulations, Office of the Federal Register.

42 USC $\S 6901$ et seq., 1976, "Resource Conservation and Recovery Act of 1976 (Solid Waste Disposal Act)," United States Code.

42 USC § 9601 et seq., 1980, "Comprehensive Environmental Response, Compensation and Liability Act of 1980 (CERCLA/Superfund)," United States Code.

Anderson, J. E., R. S. Nowak, T. D. Ratzlaff, and O. D. Markham, 1993, "Managing Soil Moisture on Waste Burial Sites in Arid Regions," Journal of Environmental Quality, Vol. 22, No. 1, pp. 62-69.

BHI, 2000, Technical Alternatives Baseline Report, Bechtel Hanford, Richland, Washington.

Bowders, John J., J. Erick Loehr, Deepak Neupane, and Abdelmalek Bouassa, 2003, "Construction Quality Control for Asphalt Concrete Hydraulic Barriers," Journal of Geotechnical and Geoenvironmental Engineering, Vol. 129, No. 3, pp. 219-223.

Breshears, David D., John W. Nyhan, and David W. Davenport, 2005, "Ecohydrology Monitoring and Excavation of Semiarid Landfill Covers a Decade after Installation," Vadose Zone Journal, Vol. 4, pp. $798-810$.

CPEO, 2002, Technology Tree, Center for Public Environmental Oversight, URL: http://www.cpeo.org/techtree/ttdescript/index.html, Web site updated November 2002, Web page visited January 30, 2007.

Crouse, Phillip and Montgomery Watson, 2002, "Liner and Final Cover Long Term Performance Evaluation and Final Cover Life Cycle Expectation," EDF-ER-281, Rev. 1, Idaho National Engineering and Environmental Laboratory.

Daniel, David E. and Yung-Kwant Wu, 1993, "Compacted Clay Liners and Covers for Arid Sites," Journal of Geotechnical Engineering, Vol. 199, No. 2, pp. 223-237.

DOE, 1988, Vegetative Covers: Special Study, DOE/UMTRA-400642-0000, U.S. Department of Energy Albuquerque Operations Office. 
DOE, 1989, Technical Approach Document, DOE/UMTRA-050425-0002, U.S. Department of Energy Albuquerque Operations Office.

DOE O 435.1, 2001, "Radioactive Waste Management," Change 1, U.S. Department of Energy.

DOE-CBFO, 2002, National TRU Waste Management Plan, DOE/NTP-96-1204, Rev. 3, U.S. Department of Energy Carlsbad Field Office.

DOE-CBFO, 2005, Contact-Handled Transuranic Waste Authorized Methods for Payload Control (CH-TRAMPAC), NRC Docket 71-9279, Rev. 2, Waste Isolation Pilot Plant, U.S. Department of Energy Carlsbad Field Office.

DOE-ID, 1994a, Record of Decision: Declaration for Pad A at the Radioactive Waste Management Complex Subsurface Disposal Area at the Idaho National Engineering Laboratory, Administrative Record No. 5632, U.S. Department of Energy Idaho Operations Office; U.S. Environmental Protection Agency; Idaho Division of Environmental Quality, Idaho Department of Health and Welfare.

DOE-ID, 1994b, Record of Decision: Declaration for Organic Contamination in the Vadose Zone Operable Unit 7-08, Idaho National Engineering Laboratory, Radioactive Waste Management Complex, Subsurface Disposal Area, Administrative Record No. 5761, U.S. Department of Energy Idaho Operations Office; U.S. Environmental Protection Agency; Idaho Division of Environmental Quality, Idaho Department of Health and Welfare.

DOE-ID, 1999a, Final Record of Decision, Idaho Nuclear Technology and Engineering Center, Operable Unit 3-13, DOE/ID-10660, Rev. 0, Idaho National Engineering and Environmental Laboratory; U.S. Department of Energy Idaho Operations Office; U.S. Environmental Protection Agency; Idaho Department of Health and Welfare.

DOE-ID, 1999b, Operable Unit 7-13/14, In Situ Grouting Treatability Study Work Plan, DOE/ID-10690, U.S. Department of Energy Idaho Operations Office.

DOE-ID, 2003, INEEL CERCLA Disposal Facility Complex Remedial Action Work Plan, DOE/ID-10984, Rev. 0, U.S. Department of Energy Idaho Operations Office.

DOE-ID, 2004, Action Memorandum for Accelerated Retrieval of a Described Area within Pit 4, DOE/NE-ID-11179, Rev. 0, U.S. Department of Energy Idaho Operations Office.

DOE-ID, 2005, Idaho National Engineering and Environmental Laboratory Waste Acceptance Criteria, DOE/ID-10381, Rev. 21, U.S. Department of Energy Idaho Operations Office.

DOE-ID, 2006, Action Memorandum for the Accelerated Retrieval Project II within Pits 4 and 6 of the Subsurface Disposal Area, DOE/NE-ID-11238, U.S. Department of Energy Idaho Operations Office.

DOE-RL, 1996, Focused Feasibility Study of Engineered Barriers for Waste Management Units in 200 Areas, DOE/RL-93-33, Rev. 0, U.S. Department of Energy, Office of Environmental Restoration and Waste Management, Richland, Washington. 
Dwyer, S. F., 1997, "Large-Scale Field Study of Landfill Covers at Sandia National Laboratories," Conference Proceedings of Landfill Capping in the Semi-Arid West: Problems, Perspectives, and Solutions, Grand Teton National Park, Wyoming, pp. 87-107.

EnergySolutions, 2006, Bulk Waste Disposal and Treatment Facilities Waste Acceptance Criteria, Rev. 6, EnergySolutions.

EPA, 1984, Slurry Trench Construction for Pollution Migration Control, EPA/540/2-84-001, U.S. Environmental Protection Agency.

EPA, 1988, Guidance for Conducting Remedial Investigations and Feasibility Studies under CERCLA, Interim Final, EPA/540/G-89-004, OSWER Directive 9355.3-01, U.S. Environmental Protection Agency.

EPA, 1989, Final Covers on Hazardous Waste Landfills and Surface Impoundments, EPA/530-SW-89-047, U.S. Environmental Protection Agency, Office of Solid Waste and Emergency Response.

EPA, 1991, Survey of Materials Handling Technologies Used at Hazardous Waste Site, EPA/540/2-91/010, U.S. Environmental Protection Agency.

EPA, 2003, Superfund Innovative Technology Evaluation Program, Technology Profiles, Eleventh Edition, Volume 1, Demonstration Program, EPA 540/R-03/501, U.S. Environmental Protection Agency.

EPA, 2006, Remediation Technology Descriptions, Alternative Landfill Cover Project Profiles, U.S. Environmental Protection Agency, Technology Innovation Program, URL: http://cluin.org/products/altcovers/, Web page visited January 30, 2007.

Forman, Amy D. and Jay E. Anderson, 2005, "Design and Performance of Four Evapotranspiration Caps," Practice Periodical of Hazardous, Toxic, and Radioactive Waste Management, Vol. 9 , No. 4, pp. 263-272.

FRTR, 2002, Remediation Technologies Screening Matrix and Reference Guide Version 4.0, Federal Remediation Technologies Roundtable, URL: http:/www.frtr.gov/matrix 2/top_page.html, Web page visited January 30, 2007.

Gaglio, Michael D., William P. Mackay, Daniel Padilla, Robert Webb, and David V. LeMone, 2001, "The Effectiveness of Biobarrier Layers within Protective Caps at Preventing Penetration of Waste Sites by the Harvester Ant Pogonomyrmex Salinus Olsen (Hymenoptera: Formicidae)," Waste Management Conference 2001, Tucson Arizona, February 25-March 1, 2001.

Gee, G. W., A. L. Ward, and C. D. Wittreich, 2002, The Hanford Site 1000-Year Cap Design Test, PNNL-14143, Pacific Northwest National Laboratory.

Golder Associates, 1988, Master Evaluation of Cover Alternatives and Surface Drainage Design at the Subsurface Disposal Area, EGG-LLW-8235, Golder Associates, Inc., for the Idaho National Engineering Laboratory.

Hakonson, T. E., 1986, Evaluation of Geologic Materials to Limit Biological Intrusion into Low-Level Radioactive Waste Disposal Sites, LA-10286-MS, Los Alamos National Laboratory. 
Hampton, Nancy L., 2006, Biological Data to Support Operable Unit 7-13/14 Modeling of Plant and Animal Intrusion at Buried Waste Sites, INEEL/EXT-01-00273, Rev. 1, Idaho National Laboratory, Idaho Cleanup Project.

Hanson, D. J., G. E. Matthern, N. A. Yancey, and D. L. Knudson, 2004, Evaluation of the Durability of WAXFIX for Subsurface Applications, ICP/EXT-04-00300, Rev. 0, Idaho National Engineering and Environmental Laboratory, Idaho Completion Project.

Hanson, Duane J., Gretchen E. Matthern, Sylvester J. Losinski, and Jay T. Brown, 2005, Evaluation of Durability of Portland-Cement-Based Grout for Subsurface Applications at OU 7-13/14, ICP/EXT-05-00798, Rev. 0, Idaho National Engineering and Environmental Laboratory, Idaho Cleanup Project.

Holdren, K. Jean and Barbara J. Broomfield, 2004, Second Addendum to the Work Plan for the OU 7-13/14 Waste Area Group 7 Comprehensive Remedial Investigation/Feasibility Study, DOE/ID-11039, Rev. 0, U.S. Department of Energy Idaho Operations Office.

Holdren, K. Jean, Danny L. Anderson, Bruce H. Becker, Nancy L. Hampton, L. Don Koeppen, Swen O. Magnuson, and A. Jeffrey Sondrup, 2006, Remedial Investigation and Baseline Risk Assessment for Operable Unit 7-13/14, DOE/ID-11241, U.S. Department of Energy Idaho Operations Office.

Housley, L. Todd, 2005, Environmental and Operational End-Year Data Report for the OU 7-08 Organic Contamination in the Vadose Zone Project-2004, ICP/EXT-05-00779, Rev. 0, Idaho National Laboratory, Idaho Completion Project.

IDAPA 58.01.05.011, 2006, "Land Disposal Restrictions," Idaho Administrative Procedures Act, Idaho Department of Environmental Quality.

INEEL, 1997, Hot Spot Removal System: System Description, INEEL/EXT-97-00666, Idaho National Engineering and Environmental Laboratory.

INL, 2005, Data Quality Objectives Summary Report for the Operable Unit 7-08 Post-Record of Decision Sampling, INEEL/EXT-2000-00814, Rev. 2, Idaho National Laboratory, Idaho Cleanup Project.

ITRC, 2003, Technical and Regulatory Guidance for Design, Installation, and Monitoring of Alternative Final Landfill Covers, Interstate Technology Regulatory Council, Alternative Landfill Technologies Team, URL: http://www.itrcweb.org/Documents/ALT-2.pdf, Web page last visited February 1, 2007.

Keck, J. F., 1992, "Evaluation of Engineered Barriers for Closure Cover of the Radioactive Waste Management Complex Subsurface Disposal Area," EDF-RWMC-523, Idaho National Engineering Laboratory.

Keck, K. N. and R. R. Seitz, 2002, Potential for Subsidence at the Low-Level Radioactive Waste Disposal Area, INEEL/EXT-02-01154, Idaho National Engineering and Environmental Laboratory.

Layne GeoConstruction, 2006, Jet Grouting Technical Summary, vendor data provided February 2006 by Layne GeoConstruction, a Division of Layne Christensen Company. 
Lodman, David, Steve Dunstan, Wayne Downs, Jeff Sondrup, Dean Miyasaki, Kelly Galloway, and Karen Izbicki, 1994, Treatability Study Report for the Organic Contamination in the Vadose Zone, Operable Unit 7-08, EGG-ER-11121, Rev. 0, Idaho National Engineering Laboratory.

Loomis, G. G. and D. N. Thompson, 1995, Innovative Grout/Retrieval Demonstration Final Report, INEL-95/001, Idaho National Engineering and Environmental Laboratory.

Loomis, Guy G., David N. Thompson, and John H. Heiser, 1995, Innovative Subsurface Stabilization of Transuranic Pits and Trenches, INEL-95/0632, Idaho National Engineering Laboratory.

Loomis, Guy G., Andrew P. Zdinak, and Carolyn W. Bishop, 1997, Innovative Subsurface Stabilization Project - Final Report (Revision 1), INEL-96/0439, Idaho National Engineering Laboratory.

Loomis, Guy G., Andrew P. Zdinak, Mark A. Ewanic, James J. Jessmore, 1998, Acid Pit Stabilization Project (Volume l-Cold Testing), INEEL/EXT-98-00009, Idaho National Engineering and Environmental Laboratory.

Loomis, Guy G., James J. Jessmore, Jerry R. Weidner, Christopher M. Miller, and Allen L. Sehna, 2003, Final Results Report, In Situ Grouting Technology for Application in Buried Transuranic Waste Sites Volume 1, Technology Description and Treatability Study Results for Operable Unit 7-13/14, INEEL/EXT-02-00233, Rev. 1, Idaho National Engineering and Environmental Laboratory.

Lopez, S. L., William H. Landman, Donald E. Sebo, and Vivian G. Schultz, 2005, Summary Report for the OU 7-13/14 Early Actions Beryllium Encapsulation Project, ICP/EXT-04-00646, Rev. 1, Idaho National Engineering and Environmental Laboratory, Idaho Completion Project.

Magnuson, Swen O. and A. Jeffrey Sondrup, 2006, Subsurface Flow and Transport Model Development for the Operable Unit 7-13/14 Remedial Investigation and Feasibility Study, ICP/EXT-05-01016, Rev. 1, Idaho National Laboratory, Idaho Cleanup Project.

Matthern, Gretchen, Neal Yancey, Gregory Hulet, and Peter Shaw, 2005, Preremedial Design Report of Remediation Options for OU 7-13/14, ICP/EXT-04-00330, Rev. 0, Idaho National Laboratory, Idaho Cleanup Project.

Mattson, Earl, Mark Ankeny, Steve Dwyer, Nancy Hampton, Gretchen Matthern, Brenda Pace, Alva Parsons, Mitch Plummer, Steve Reese, and Jody Waugh, 2004, Preliminary Design for an Engineered Surface Barrier at the Subsurface Disposal Area, ICP/EXT-04-00216, Rev. 0, Idaho National Engineering and Environmental Laboratory, Idaho Completion Project.

McKenzie, M. Doug, Donald E. Sebo, Kirk M. Green, and Vivian G. Schultz, 2005, Waste Information and Location Database for the OU 7-13/14 Project, ICP/EXT-04-00271, Rev. 0, Idaho National Laboratory, Idaho Cleanup Project.

Moore, Beth A. and Bruce M. Crowe, 1998, Consequences of Subsidence for the Area 3 and Area 5 Radioactive Waste Management Sites, Nevada Test Site, DOE/NV-502 UC-600, U.S. Department of Energy Nevada Operations Office.

Parsons, Alva M. and Roger R. Seitz, 2006, Annual Performance Assessment and Composite Analysis Review for the RWMC Low-Level Waste Disposal Facility FY 2005, ICP/EXT-06-01131, Rev. 0, Idaho National Laboratory, Idaho Cleanup Project. 
Peterson, R. D., A. J. Johnson, and K. G. Peter, 1986, Nitrate Salt Immobilization Process Development and Implementation, RFP-3919, Rocky Flats Plant.

PLN-2085, 2006, "Project Execution Plan for the ICP Radioactive Waste Management Complex Project," Rev. 2, Idaho National Laboratory, Idaho Cleanup Project.

Porro, Indrik, 2001, "Hydrologic Behavior of Two Engineered Barriers Following Extreme Wetting," Journal of Environmental Quality, Vol. 30, pp. 655-667.

Raivo, B., 2001, "Staging, Storage, Sizing, and Treatment Facility (SSSTF) Stabilization Treatment Process Selection," EDF-1542, Rev. 0, Idaho National Engineering and Environmental Laboratory.

Richins, W. D. and C. J. Hurst, 2004, “Assessment of Dynamic Soil Compaction at SDA,” EDF-4909, Rev. 0, Idaho National Engineering and Environmental Laboratory, Idaho Completion Project.

Shaw, Peter, 2004a, "Grout Selection Criteria and Recommendation for the OU 7-13/14 In Situ Grouting Early Action Project," EDF-4397, Rev. 0, Idaho National Engineering and Environmental Laboratory, Idaho Completion Project.

Shaw, Peter, 2004b, "Grout Selection Criteria and Recommendation for the OU 7-13/14 In Situ Grouting Project,” EDF-5333, Rev. 0, Idaho National Engineering and Environmental Laboratory, Idaho Completion Project.

Shropshire, Karen, 2004, "Lessons Learned from ISG Phase 1-Beryllium Block Wax Grouting in Summer 2004,” EDF-5473, Rev. 0, Idaho National Engineering and Environmental Laboratory, Idaho Completion Project.

Stephens, David L., 2004, “OU 7-13/14 In Situ Grouting Project Foundation Grouting Study,” EDF-5028, Rev. 0, Idaho National Engineering and Environmental Laboratory, Idaho Completion Project.

Stormont, John C. and Clifford E. Anderson, 1999, "Capillary Barrier Effect from Underlying Coarser Soil Layer," Journal of Geotechnical and Geoenvironmental Engineering, Vol. 125, No. 8, pp. 641-648.

Stormont, J. C., M. D. Ankeny, M. E. Burkhard, M. K. Tansey, and J. A. Kelsey, 1994, Assessment of an Active Dry Barrier for a Landfill Cover System, SAND94-0301, Sandia National Laboratories and Daniel B. Stephens \& Associates for the U.S. Department of Energy.

Suter, Glenn W., II, Robert J. Luxmoore, and Ellen D. Smith, 1993, “Compacted Soil Barriers at Abandoned Landfill Sites Are Likely to Fail in the Long Term," Journal of Environmental Quality, Vol. 22, No. 2, pp. 217-226.

Sykes, Kira, 2002, Evaluation of Soil and Buried Waste Retrieval Technologies for Operable Unit 7-13/14, INEEL/EXT-01-00281, CH2MHILL for Bechtel BWXT Idaho, LLC, Idaho National Engineering and Environmental Laboratory.

USACE, 1995, Engineering and Design - Chemical Grouting, EM 1110-1-3500, U.S. Army Corps of Engineers, Waterways Experiment Station, Vichsburg, Mississippi, URL: http://www.usace.army.mil/inet/usace-docs/eng-manuals/em1110-1-3500/toc.htm, published January 31, 1995, Web page visited January 29, 2007. 
Wing, N. R. and G. W. Gee, 1994, "Quest for the Perfect Cap," Civil Engineering, Vol. 64, No. 10, pp. 38-41.

Zitnik, James F., Aran T. Armstrong, Brian K. Corb, Mark H. Edens, Douglas B. Holsten, Patricia M. O'Flaherty, Janet Rodriguez, Tamara N. Thomas, Russell L. Treat, Wayne Schofield, and Kira L. Sykes, 2002, Preliminary Evaluation of Remedial Alternatives for the Subsurface Disposal Area, INEEL/EXT-02-01258, Rev. 0, prepared by CH2MHILL for the Idaho National Engineering and Environmental Laboratory. 
2-38 


\section{CONTENTS}

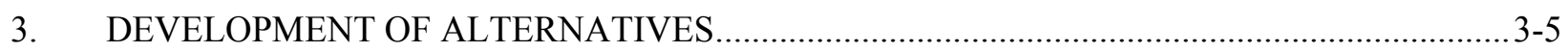

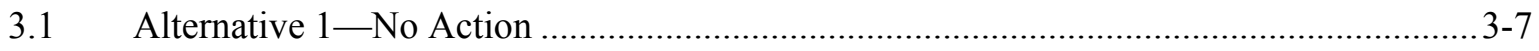

3.2 Alternative 2-Surface Barrier.......................................................................... 3-8

3.2.1 Alternative 2a-Modified RCRA Type C Surface Barrier .............................3-8

3.2.2 Alternative 2b-Evapotranspiration Surface Barrier ................................... 3-15

3.3 Alternative 3 - In Situ Grouting ..................................................................... 3-23

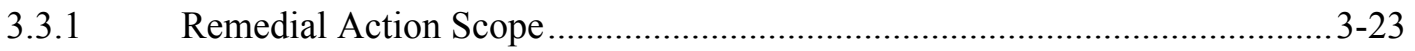

3.3.2 Remedial Action Process …......................................................................... $3-24$

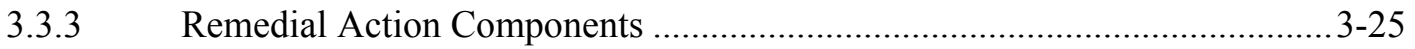

3.3.4 Remedial Action Schedule …................................................................... 3-29

3.4 Alternative 4-Partial Retrieval, Treatment, and Disposal ....................................... 3-31

3.4.1 Alternative 4a-4-Acre Partial Retrieval, Treatment, and Disposal..............3-32

3.4.2 Alternative 4b-2-Acre Partial Retrieval, Treatment, and Disposal...............3-42

3.5 Alternative 5-Full Retrieval, Treatment, and Disposal .............................................. 3-48

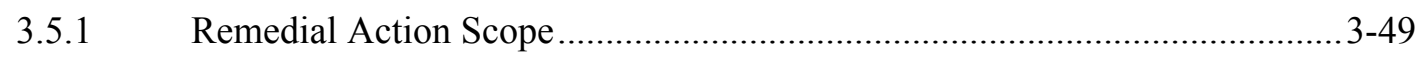

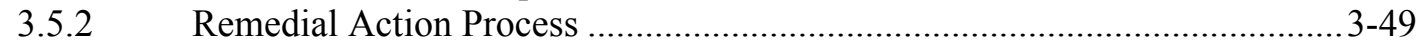

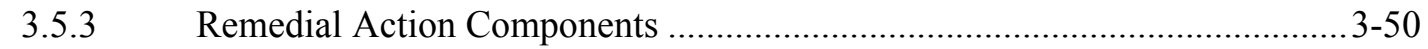

3.5.4 Remedial Action Schedule .................................................................... 3-55

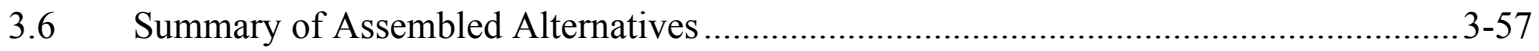

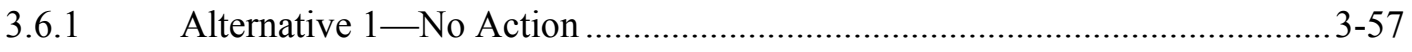

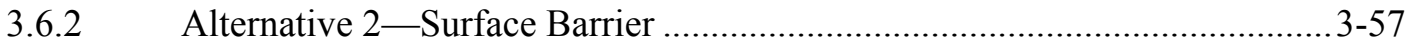

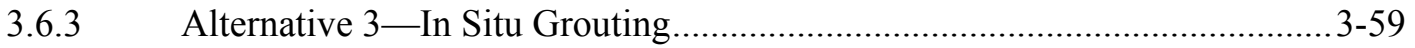

3.6.4 Alternative 4-Partial Retrieval, Treatment, and Disposal .........................3-60

3.6.5 Alternative 5-Full Retrieval, Treatment, and Disposal.............................. 3-61

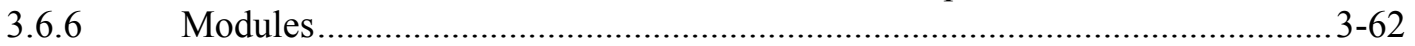

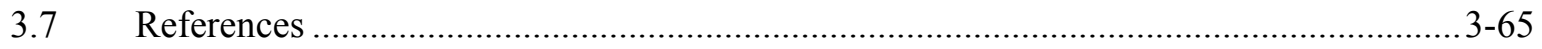




\section{FIGURES}

3-1. Process flow diagram for Alternative 2a-Modified RCRA Type C Surface Barrier .................3-10

3-2. Preconceptual design for Alternative 2a-Modified RCRA Type C Surface Barrier...................3-11

3-3. Foundation grouting for Alternative 2a-Modified RCRA Type C Surface Barrier ....................3-12

3-4. Summary schedule for Alternative 2a-Modified RCRA Type C Surface Barrier .....................3-14

3-5. Process flow diagram for Alternative 2b-Evapotranspiration Surface Barrier .........................3-16

3-6. Cross section of surface barrier preconceptual design for Alternative $2 b-$

Evapotranspiration Surface Barrier

3-7. Pad A waste retrieval and Low-Level Waste Pit disposal process for Alternative $2 \mathrm{~b}$ -

Evapotranspiration Surface Barrier

3-8. Dynamic compaction operation for Alternative $2 \mathrm{~b}$-Evapotranspiration Surface Barrier

3-9. Summary schedule for Alternative $2 b$-Evapotranspiration Surface Barrier

3-10. Hypothetical treatment locations for Alternative 3-In Situ Grouting

3-11. Process flow diagram for in situ grouting and containment for Alternative $3-$ In Situ Grouting....

3-12. Rotopercussion grout rig used for Alternative 3-In Situ Grouting

3-13. Remote operation of in situ grouting equipment during the Beryllium Encapsulation

Early Actions Project.

3-14. Pad A waste retrieval, ex situ treatment, and Low-Level Waste Pit disposal process for Alternative 3-In Situ Grouting.

3-15. Summary schedule for Alternative 3-In Situ Grouting.

3-16. Hypothetical retrieval locations for Alternative 4a-4-Acre Partial Retrieval, Treatment, and Disposal

3-17. Process flow diagram for Alternative 4a-4-Acre Partial Retrieval, Treatment, and Disposal....3-35

3-18. Modifications to the existing Accelerated Retrieval Project Retrieval Enclosure for Alternative 4a-4-Acre Partial Retrieval, Treatment, and Disposal

3-19. Plan view of partial retrieval process for Alternative 4a-4-Acre Partial Retrieval, Treatment, and Disposal.....

3-20. Drum packaging system within the Accelerated Retrieval Project

3-21. Waste moved from Pad A to the Idaho CERCLA Disposal Facility for treatment and disposal for Alternative 4a-4-Acre Partial Retrieval, Treatment, and Disposal 


\section{FIGURES (continued)}

3-22. Summary schedule for Alternative 4a-4-Acre Partial Retrieval, Treatment, and Disposal ........3-41

3-23. Hypothetical retrieval locations for Alternative 4b-2-Acre Partial Retrieval, Treatment,

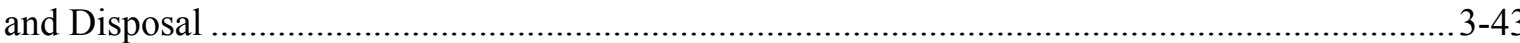

3-24. Process flow diagram for Alternative $4 b-2$-Acre Partial Retrieval, Treatment, and Disposal....3-45

3-25. Summary schedule for Alternative $4 b$-2-Acre Partial Retrieval, Treatment, and Disposal ........3-47

3-26. Process flow diagram for Alternative 5-Full Retrieval, Treatment, and Disposal....................3-50

3-27. Preconceptual plan view of full retrieval process and remote-handled storage in the Subsurface Disposal Area for Alternative 5-Full Retrieval, Treatment, and Disposal

3-28. Removal of a remote-handled waste drum at the Intermediate-Level Transuranic Storage Facility.

3-29. Pad A waste retrieval and off-Idaho National Laboratory Site disposal process for Alternative 5-Full Retrieval, Treatment, and Disposal

3-30. Cross section of a simplified evapotranspiration surface barrier with no biointrusion and gas vent layer for Alternative 5-Full Retrieval, Treatment, and Disposal

3-31. Summary schedule for Alternative 5-Full Retrieval, Treatment, and Disposal $3-56$

\section{TABLES}

3-1. Summary of assembled alternatives $3-6$

3-2. Volumes of waste types on Pad A.......

3-3. Summary of five assembled alternatives and major components in each $3-58$ 


\section{DEVELOPMENT OF ALTERNATIVES}

The National Contingency Plan (40 CFR 300) requires that the remedy selection process for Operable Unit (OU) 7-13/14 identify remedial actions that are protective of human health and the environment, maintain protection over time, and minimize untreated waste (40 CFR 300.430). The purpose of the Feasibility Study for Operable Unit 7-13/14 is to identify a range of remedial action alternatives for the Subsurface Disposal Area (SDA) at the Radioactive Waste Management Complex (RWMC) that, if selected, would meet the national goal. Developing remedial action alternatives to support the detailed analysis is a key element of the feasibility study process. This section develops specific remedial action alternatives that provide technically sound approaches to address project remedial action objectives. Analysis focuses on source control (i.e., approaches to prevent or substantially reduce release of contamination from buried waste). These alternatives were developed in accordance with requirements of the National Contingency Plan and the Second Addendum to the Work Plan (Holdren and Broomfield 2004).

Five remedial alternatives were developed to address remedial action objectives identified in Section 2.1. Alternatives are assembled by combining representative process options (identified in Section 2.3) into distinct technical approaches. Assembled alternatives described in the following subsections are composed of various combinations of 20 distinct modules for the feasibility study to facilitate analysis (see Appendix E). These modules also can be used by the U.S. Department of Energy, the Idaho Department of Environmental Quality, and the U.S. Environmental Protection Agency (referred to as the Agencies) to compile a different combination of elements from several alternatives into a preferred alternative for the proposed plan for OU 7-13/14.

Alternative 1 (No Action) provides a baseline for comparison of other alternatives by evaluating the SDA in the absence of remedial action. Environmental monitoring is the only activity evaluated for this alternative. Alternative 2 (Surface Barrier) evaluates containment as the primary means of source control. Alternative 3 (In Situ Grouting [ISG]) evaluates ISG for immobilizing specified long-lived radioactive contaminants of concern (COCs) originally generated by Idaho National Laboratory (INL) Site reactor operations. Alternative 4 (Partial Retrieval, Treatment, and Disposal [RTD]) evaluates retrieval and management of targeted waste originally received from the Rocky Flats Plant. Alternative 5 (Full RTD) evaluates removing all waste from the SDA. Collectively, Alternatives 2, 3, 4, and 5 are referred to as action alternatives, while Alternative 1 represents no action.

All action alternatives include the following common elements:

- Vapor vacuum extraction and treatment-Continued operation of the ongoing Organic Contamination in the Vadose Zone (OCVZ) system established under OU 7-08 is a primary component in each action alternative. The OCVZ system extracts and treats volatile organic compounds (VOCs) from the vadose zone.

- $\quad$ Engineered surface barrier-Each alternative includes a surface barrier to prevent contaminant transport to the surface by plants and animals and to inhibit infiltration and subsequent transport of contaminants to the vadose zone. Overall thickness of the barrier, coupled with long-term institutional controls (ICs), would preclude inadvertent human intrusion.

- Long-term stewardship-Analysis in this feasibility study for OU 7-13/14 evaluates 100 years of postremediation long-term stewardship as a basis for modeling and cost estimating. However, these activities would be conducted until eliminated through the 5-year review process, in accordance with the Comprehensive Environmental Response, Compensation, and Liability Act (CERCLA) 
(42 USC $\S 9601$ et seq., 1980). These activities include surveillance, maintenance, environmental monitoring, and ICs.

All action alternatives include varying strategies to address several additional elements. These additional elements are the following:

- $\quad$ Pretreatment for subsidence control-Each alternative includes one of three process options evaluated to address subsidence (see Section 2.2.6.1.2) to provide a stable foundation for the surface barrier.

- $\quad$ Pad A-Each alternative incorporates one of six options (see Section 2.2.9.1) to address Pad A-a unique abovegrade disposal area with an existing record of decision (ROD) (DOE-ID 1994) — into the comprehensive remedies.

- $\quad$ Near-surface, released VOCs_Each alternative incorporates one of three options (see Section 2.2.9.2) to preclude buildup of VOCs immediately beneath or within the surface barrier. These options are in addition to continued operation of the existing OCVZ system to extract and treat VOCs from the vadose zone.

Collectively, assembled alternatives include all process options identified for analysis (see Section 2) to provide a full range of remedial approaches. These five alternatives are carried into the detailed analysis in Section 4 and relative comparison of alternatives in Section 5. Table 3-1 summarizes aspects of the five alternatives, and Sections 3.1 through 3.5 discuss the assembled alternatives in detail.

Table 3-1. Summary of assembled alternatives.

Alternative

1. No Action

2. Surface Barrier

3. In Situ Grouting

\section{Description $^{\mathrm{a}}$}

Alternative 1 evaluates the absence of remedial action to provide a baseline for comparison with other alternatives. Environmental monitoring is the only activity evaluated for this alternative.

Alternative 2 involves constructing a low-permeability surface barrier to control exposure to contaminants by suppressing migration and implementing ICs. Two surface barrier alternatives ( $2 \mathrm{a}$ and $2 \mathrm{~b}$ ) have been developed to support the evaluation of two competing surface barriers (i.e., a modified RCRA Type $\mathrm{C}$ surface barrier with active gas extraction through shallow wells and an ET surface barrier with active gas extraction from within the barrier itself). The two surface barrier alternatives differ in foundation stabilization for barrier support (foundation ISG and dynamic compaction) and disposition of Pad A waste (leave in place and relocate within the SDA).

Alternative 3 includes deploying ISG to stabilize select areas within the SDA. Select areas that contain COC-rich waste types (primarily fission products in waste from INL Site reactor operations) would be stabilized. To address remaining untreated waste, the entire SDA would also be covered by an ET surface barrier that incorporates passive gas extraction. Dynamic compaction for foundation support and ex situ grouting of Pad A waste, before disposal in the SDA, also would be evaluated. 
Table 3-1. (continued).

\begin{tabular}{|c|c|}
\hline Alternative & Description $^{\mathrm{a}}$ \\
\hline $\begin{array}{l}\text { 4. Partial Retrieval, } \\
\text { Treatment, and } \\
\text { Disposal }\end{array}$ & $\begin{array}{l}\text { Alternative } 4 \text { evaluates partial removal of buried waste. Select areas that contain } \\
\text { concentrations of Rocky Flats Plant transuranic waste and collocated roaster oxide } \\
\text { (uranium oxide) would be systematically retrieved. Two partial retrieval alternatives } \\
\text { ( } 4 \text { a and } 4 \mathrm{~b} \text { ) have been developed to evaluate retrieval of targeted waste from pit areas } \\
\text { totaling either } 2 \text { or } 4 \text { acres. To address residual waste, the entire SDA would be covered } \\
\text { by an ET surface barrier with passive gas extraction. The two retrieval alternatives differ } \\
\text { in foundation stabilization for barrier support (dynamic compaction and proof-rolling) and } \\
\text { disposition of Pad A waste (relocate to ICDF and dynamically compact in place). In } \\
\text { addition, a perimeter slurry wall would be incorporated in one of the partial retrieval } \\
\text { alternatives. }\end{array}$ \\
\hline $\begin{array}{l}\text { 5. Full Retrieval, } \\
\text { Treatment, and } \\
\text { Disposal }\end{array}$ & $\begin{array}{l}\text { Alternative } 5 \text { provides for removal of all contaminated waste to the maximum extent } \\
\text { possible. All buried waste would be systematically retrieved. Retrieved waste would be } \\
\text { managed using a combination of short-term staging of contact-handled waste, long-term } \\
\text { storage of remote-handled waste, and disposal at commercial and federal disposal sites. To } \\
\text { reduce infiltration and subsequent transport of contaminants left in the vadose zone, a } \\
\text { surface barrier would cover the entire SDA. Pad A waste would be retrieved and shipped } \\
\text { off the INL Site. }\end{array}$ \\
\hline \multicolumn{2}{|c|}{$\begin{array}{l}\text { a. All assembled alternatives, except Alternative 1, include continued operation of the OCVZ system until OU 7-08 remediation goals are } \\
\text { achieved, and long-term surveillance, maintenance, monitoring, and ICs. }\end{array}$} \\
\hline $\begin{array}{l}\mathrm{COC}=\text { contaminant of co } \\
\mathrm{ET}=\text { evapotranspiration } \\
\text { IC }=\text { institutional control } \\
\text { ICDF = Idaho CERCLA } \\
\text { INL = Idaho National Lal } \\
\text { ISG = in situ grouting } \\
\text { OCVZ = Organic Contan } \\
\text { OU = operable unit } \\
\text { RCRA = Resource Conse } \\
\text { SDA = Subsurface Dispo }\end{array}$ & $\begin{array}{l}\text { osal Facility } \\
\text { tory } \\
\text { ion in the Vadose Zone } \\
\text { ion and Recovery Act } \\
\text { trea }\end{array}$ \\
\hline
\end{tabular}

\subsection{Alternative 1-No Action}

Alternative 1 evaluates risk in the absence of remedial action. This evaluation provides a baseline for comparing other alternatives. Environmental monitoring is the only activity included under Alternative 1.

Environmental monitoring evaluated in Alternative 1 is based on the current monitoring network and includes the vadose zone and groundwater. Vadose zone monitoring would assess contaminant migration from buried waste into subsurface soil moisture and vapor. Because soil-moisture sample volumes are limited, vadose zone analytes would be prioritized, as required, and probably would include metals; inorganic compounds; volatile and semivolatile organic compounds; gross alpha, beta, and gamma; and various radioisotopes. Groundwater monitoring would assess migration of contaminants to the aquifer. Though monitoring would continue indefinitely, cost estimates for this alternative are based on 100 years and quantities listed below:

- Groundwater-Semiannual sampling of 20 aquifer monitoring wells for the first 5 years and annual sampling for the next 95 years 


\section{- Vadose zone}

- Annual sampling of 100 lysimeters

- Quarterly sampling of 20 vapor monitoring wells for 5 years and annual sampling for the following 95 years

- $\quad$ Automated continuous monitoring of 50 tensiometers.

\subsection{Alternative 2-Surface Barrier}

Many surface barrier designs are available. The Agencies specified two types of cap for detailed analysis (Holdren and Broomfield 2004) based on technology screening (see Section 2). Because the two surface barriers represent two process options under the same technology, Alternative 2 comprises two subalternatives. Alternative 2a evaluates a modified Resource Conservation and Recovery Act (RCRA) Type $C$ surface barrier, and Alternative $2 b$ evaluates an evapotranspiration (ET) surface barrier. Both cap alternatives include continued operation of the OCVZ system to extract and treat VOCs from the vadose zone and long-term surveillance, maintenance, monitoring, and ICs.

The primary difference between these alternatives is the design of the surface barrier. Section 2 identified multiple process options to mitigate subsidence, address Pad A waste, and prevent buildup of organic vapors beneath the cap. These two alternatives incorporate different approaches for those elements. The following subsections describe the two surface barrier alternatives in detail.

\subsubsection{Alternative 2a-Modified RCRA Type C Surface Barrier}

Alternative 2a is assembled from multiple general response actions, which, when implemented as a comprehensive remedy, would satisfy remedial action objectives. This alternative comprises the following general response actions:

- $\quad$ Containment-A modified RCRA Type C surface barrier (i.e., a cap designed to meet performance objectives for closure of a RCRA Subtitle C landfill under 40 CFR 265.310), constructed of a thin asphalt layer and multiple thin and thick layers of natural materials, would be constructed over the SDA to minimize infiltration and to prevent biotic intrusion into contaminated media. Overall thickness of the barrier, coupled with long-term ICs, would preclude inadvertent human intrusion. Foundation grouting would minimize potential future subsidence. Perimeter grading, cap armament (e.g., sand, gravel, and rock along the edges to minimize erosion), and surface barrier vegetation would mitigate erosion. Periodic surveillance of vegetation growth, subsidence, and animal intrusion would be performed, and the surface barrier would be maintained. Near-surface vapor extraction wells would be installed and integrated into the existing OCVZ system to enhance removal of volatile contaminants from beneath the surface barrier.

- Institutional controls-Active and passive controls would be implemented to prevent or limit access to the SDA. Institutional controls would include restrictions on groundwater use (e.g., well-drilling restrictions), restrictions on land use (e.g., limit to industrial applications), and physical security.

Groundwater, vadose zone, and surface monitoring also would be performed. The following subsections provide detailed descriptions of Alternative 2a, including scope, process, and schedule. 
3.2.1.1 Remedial Action Scope. The Remedial Investigation and Baseline Risk Assessment (RI/BRA) (Holdren et al. 2006) identifies COCs associated with multiple exposure pathways (see Section 1.4.5). Alternative $2 \mathrm{a}$ is assembled specifically to address risk posed by these contaminants and pathways. To minimize potential mobilization of these contaminants, a low-permeability surface barrier would be constructed across the surface of the SDA. This surface barrier would prevent contaminant migration to the surface and subsurface and would address remedial action objectives (see Section 1.5) by the following means:

- Minimize infiltration into and through buried waste remaining in the SDA

- $\quad$ Prevent gas buildup within or beneath the surface barrier

- Inhibit plant, animal, and human intrusion into contaminated media (e.g., soil and waste)

- $\quad$ Maintain performance for at least 1,000 years (Mattson et al. 2004).

Volatile COCs (e.g., C-14 and carbon tetrachloride) migrate by gas diffusion in all directions through the subsurface. A network of vadose zone vapor extraction wells, integrated into the existing OCVZ system and coupled with the surface barrier, would mitigate groundwater ingestion risk associated with these gas-phase contaminants. The surface barrier would retard migration of COCs to the aquifer. Concurrently, the OCVZ system would collect and treat volatile COCs from the vadose zone, thereby reducing amounts that reach the aquifer. The surface barrier asphalt layer would prevent gas-phase contaminants from reaching the surface and creating a volatile inhalation risk. A network of near-surface vapor extraction wells would remove and treat volatiles that collect beneath the impermeable barrier, further reducing the amount of contaminants that reach the aquifer.

In addition, Alternative $2 \mathrm{a}$ would provide active and passive controls to prevent or limit access to the site because unrestricted land use is expected to be prohibited in future 5-year reviews.

3.2.1.2 Remedial Action Process. As illustrated in Figure 3-1, grout columns would be injected throughout the SDA in pit disposal areas, using high-pressure jet grouting, to provide a stable foundation for surface barrier construction. Near-surface vapor extraction wells would then be installed to mitigate buildup of landfill gases (e.g., C-14, carbon tetrachloride, and methylene chloride). Finally, contaminants remaining in the SDA would be contained by completion of a modified RCRA Type C surface barrier. Surface barrier surveillance, maintenance, monitoring, and ICs would continue until eliminated through the CERCLA 5-year review process. The following subsections describe the technical approach, equipment, and construction details for remedial action components included in Alternative 2a.

3.2.1.3 Remedial Action Components. The following paragraphs describe the technical approach, equipment, and construction details for remedial action components included in Alternative 2a (Modified RCRA Type C Surface Barrier).

Continued operation of the existing OCVZ system is included in every action alternative. Major components of the current OCVZ system include approximately 20 vapor extraction wells with ports in shallow, intermediate, and deep fractured basalt within the vadose zone; three electrically heated catalytic oxidizers (i.e., Units D, E, and F) that remove and destroy organic vapors; and approximately 170 sample ports used for monitoring the effectiveness of OCVZ operations. The OCVZ system uses a vacuum blower to draw air and VOCs from subsurface extraction wells into electrically heated catalytic oxidizers (treatment units), where spontaneous reaction with air and water vapor (in the presence of a reactive solid surface) occurs. Primary products of oxidation are carbon dioxide and hydrochloric acid. Exhaust gas is expelled through a stack and dispersed into the atmosphere. 


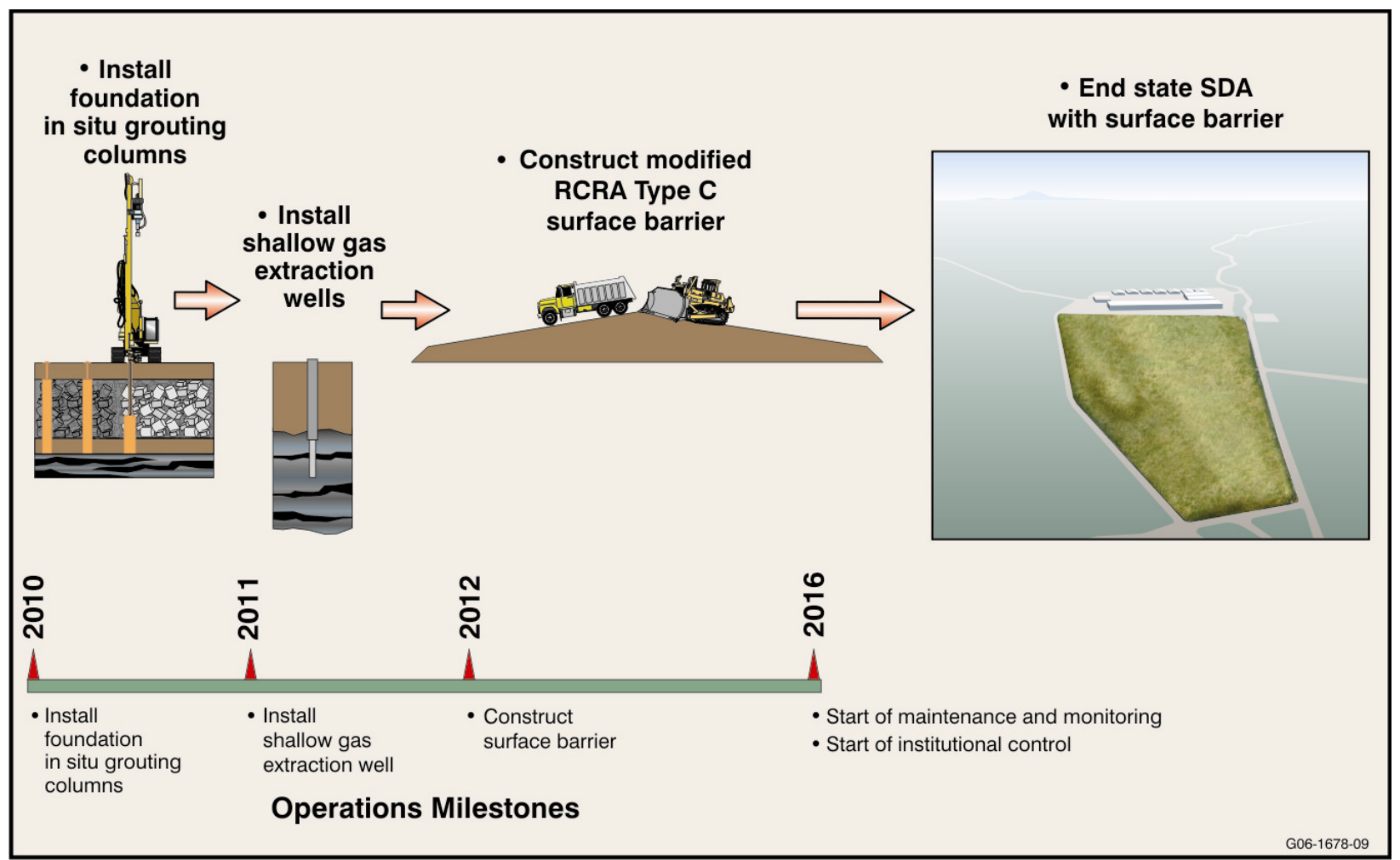

Figure 3-1. Process flow diagram for Alternative 2a-Modified RCRA Type C Surface Barrier.

Many surface barrier designs were evaluated and tested for application at the INL Site (Mattson et al. 2004; Anderson and Forman 2003; DOE-ID 1997; Magnuson 1993; Porro 2001; Zitnik et al. 2002; Keck and Seitz 2002). The modified RCRA Type C surface barrier was identified during technology screening as a representative process option (see Section 2). This design includes a continuous layer of sloped, low-permeability asphalt to divert infiltrating water to edges of the surface barrier, where it would evaporate or infiltrate to the subsurface at some distance beyond the SDA boundary. The asphalt layer also would serve as a biotic barrier, precluding intrusion of plants and animals into the waste and subsequent transport of contaminants to the surface. Overall thickness of the cap, coupled with long-term ICs, would preclude inadvertent human intrusion. Figure 3-2 illustrates a preconceptual design of the assembled alternative. The surface barrier would be constructed in a series of steps, including preparing the foundation and infrastructure, installing near-surface vapor extraction wells, and emplacing surface barrier materials. 


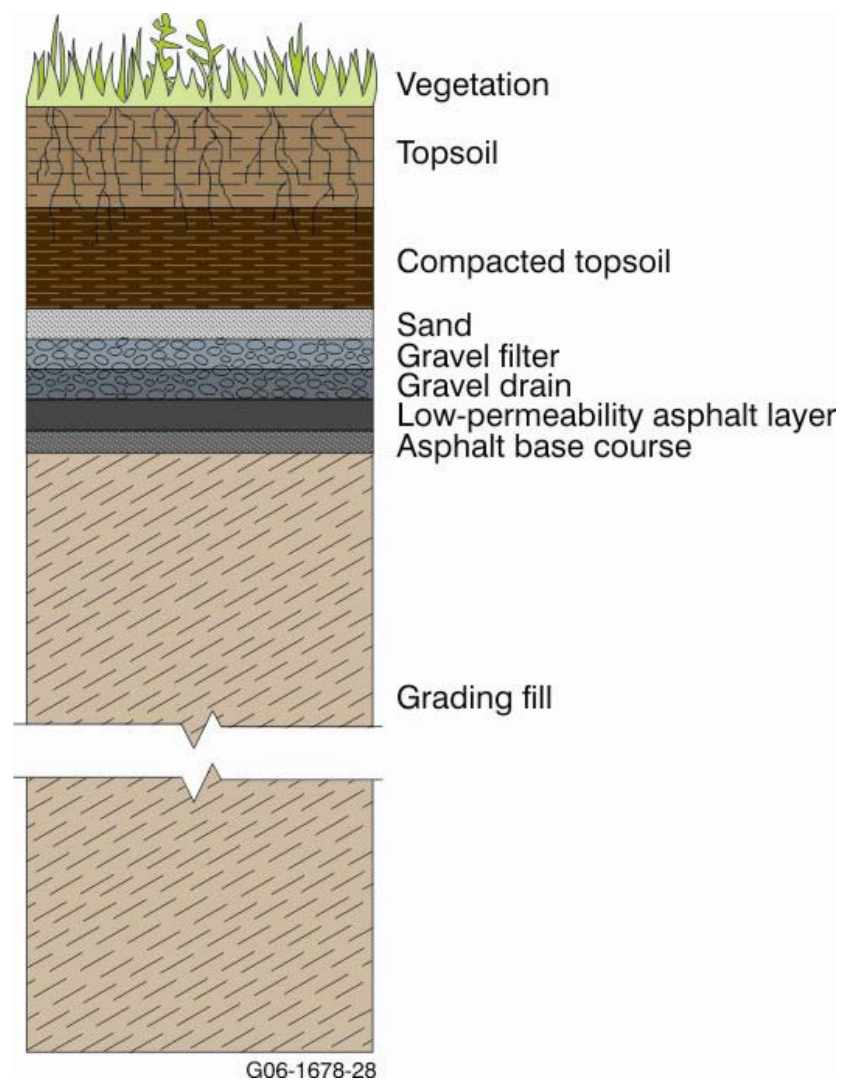

Figure 3-2. Preconceptual design for Alternative 2aModified RCRA Type C Surface Barrier.
Preparing the foundation would be a critical construction activity because differential settlement occurs routinely at the SDA. As described in Mattson et al. (2004), the modified RCRA Type C surface barrier relies on an asphalt drainage layer to minimize infiltration. The continuous slope and integrity of the drainage layer could be compromised by differential subsidence. In Alternative $2 \mathrm{a}$, foundation grouting is evaluated as the process option to mitigate differential settlement. High-pressure ISG rigs would be used to install columns of grout from the underlying basalt up to near the surface of the SDA. Figure 3-3 provides a schematic of the foundation grouting conceptual approach. Foundation grouting would be appropriate within Pits 1 through 6 and 8 through 16 , areas totaling approximately 7.7 ha (19 acres) (Stephens 2004). Pit 7 is too small to realize any benefit from foundation grouting. Approximately 5,700 columns would be constructed on $3.7-\mathrm{m}$ (12-ft) centers, with a triangular grid pattern. As shown in Figure 3-3, contamination from grout returns ${ }^{\mathrm{a}}$ would be controlled by removing approximately $0.6 \mathrm{~m}(2 \mathrm{ft})$ of overburden

soil from identified treatment areas to form depressions that would retain grout that may be displaced to the ground surface. Immediately following completion of grout injection, the surface area above the ISG columns (and potential grout returns) would be covered with clean soil up to grade.

Under Alternative 2a, Pad A would be incorporated into the surface barrier by adding layers over the existing Pad A soil cover. Doing so, however, would present some design and construction challenges. Pad A waste currently sits on an asphalt pad. More than 20,000 waste containers, including 55-gal drums and plywood boxes, were placed on the pad. In 1994, the Pad A soil cover was reinforced with a vegetated soil layer ( 0.9 to $1.2 \mathrm{~m} \mathrm{[3}$ to $5 \mathrm{ft}$ thick) with rock armor on the southern face, as a remedial action, in accordance with the OU 7-12 ROD (DOE-ID 1994). The covered waste area extends to an average height of $9 \mathrm{~m}(29.5 \mathrm{ft})$. Annual maintenance includes repairing subsidence-related damage to the soil cover.

a. Grout returns would flow to the surface during drilling operations - a condition seen in normal grouting operations and testing performed under low pressure at the INL Site and elsewhere. The volume is proportional to density of the waste matrix or soil into which the grout is being injected. Returns would be allowed to ooze around the drill-to-soil interface and flow out horizontally. 


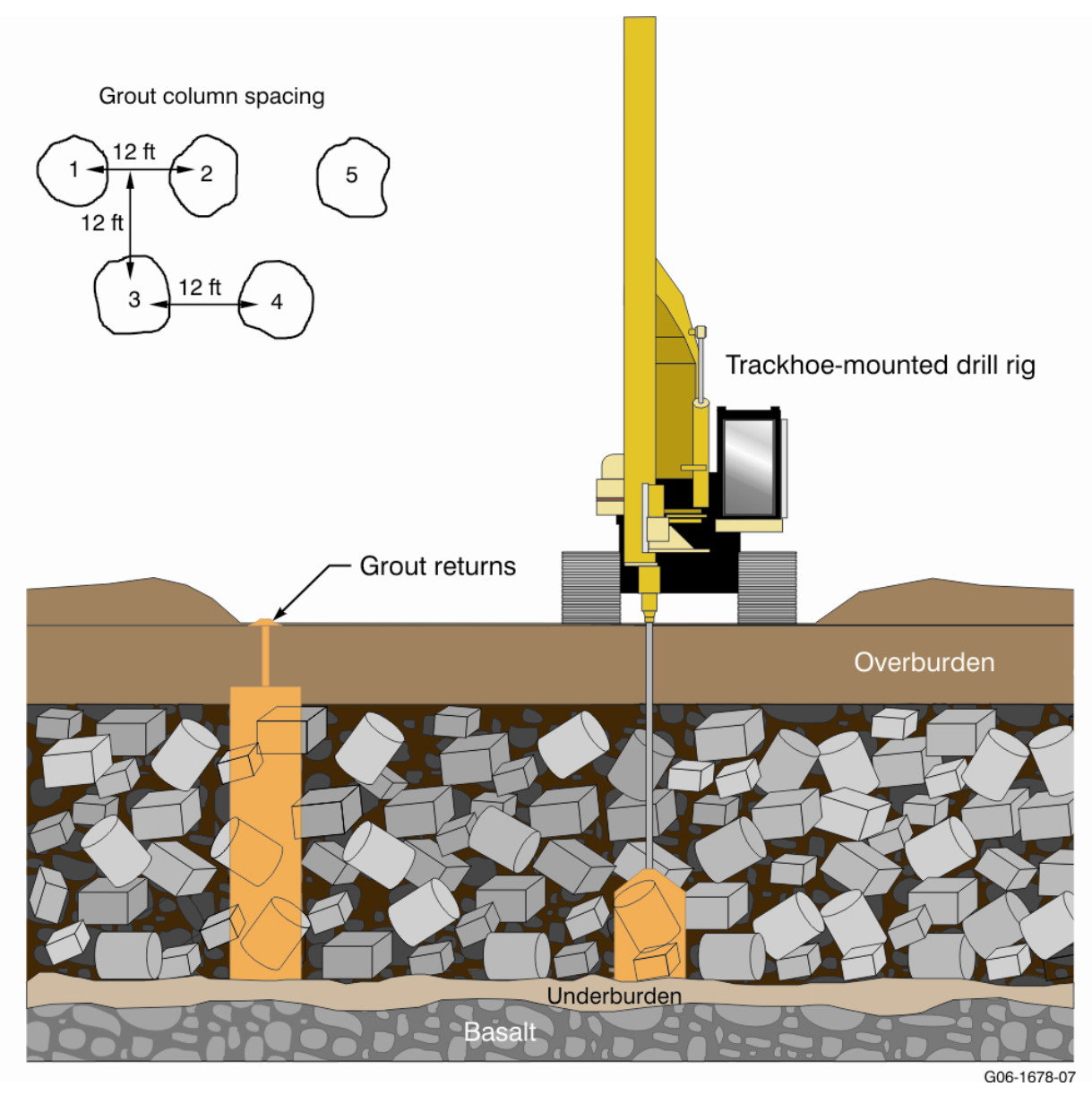

Figure 3-3. Foundation grouting for Alternative 2a-Modified RCRA Type C Surface Barrier.

Volatile contaminants (e.g., C-14 and carbon tetrachloride) are present in significant quantities in the SDA. Constructing the modified RCRA Type C surface barrier, with its low-permeability asphalt layer, would prevent natural venting from the shallow waste zone and potentially would increase transport of volatile contaminants to the aquifer. To prevent buildup of landfill gas beneath the asphalt drainage layer, eight near-surface vapor extraction wells would be installed through the surficial soil and partially into the basalt bedrock. Wells would be installed between pits to avoid intrusion into buried waste. Risers would extend through the surface barrier and connect to OCVZ treatment units.

Constructing a modified RCRA Type $\mathrm{C}$ surface barrier would be accomplished using conventional construction techniques. Existing infrastructure (e.g., utilities and monitoring equipment) at the SDA would be abandoned, relocated, or reconfigured to accommodate construction. The following activities would be performed before constructing the surface barrier:

- Install a temporary water storage tank

- Construct a new perimeter access road

- Install a new perimeter fence (including demolishing the old one)

- $\quad$ Abandon half the 50 existing monitoring wells (i.e., 25)

- Double the current network of 50 advanced tensiometers to monitor surface barrier performance (i.e., 100) 
- $\quad$ Relocate the three existing OCVZ treatment units to an area outside the future surface barrier perimeter

- $\quad$ Extend (upward through the surface barrier) $18 \mathrm{OCVZ}$ wells, 100 advanced tensiometers, and 25 monitoring wells.

Because the multilayered design is continuous, this surface barrier would be installed across the SDA in a sequential approach. Continuous construction of each layer of the surface barrier across the entire SDA would be achieved through the following steps:

- $\quad$ Prepare subgrade

- $\quad$ Remove surface infrastructure

- Haul soil and rock material from local borrow sources to the SDA

- $\quad$ Apply and compact soil material

- $\quad$ Produce and lay asphalt

- $\quad$ Apply and compact soil and rock material.

Modified RCRA Type $\mathrm{C}$ surface barriers deployed to date have been for relatively small areas (e.g., less than 5 acres) (EPA 2006). For a large area, such as the SDA (i.e., 97 acres), significant technical and administrative implementability issues may arise. Specifically, staged deployment of an asphalt composite layer over a large area would cause interlift boundaries, which would require constructing sealed staggered joints. Because of previous difficulties in constructing thin impermeable layers (Suter, Luxmore, and Smith 1993), rigorous construction quality control would be required to ensure integrity of a thin asphalt composite hydraulic barrier (Bowders et al. 2003).

Three additional construction activities would follow surface barrier completion. First, preexisting OCVZ wells and shallow gas extraction wells that were installed to collect gas trapped beneath the surface barrier would extend into the air after the barrier is completed. Connecting these wells to the relocated OCVZ treatment units would be required for continued operation of the OCVZ system and active gas extraction. The second and third construction activities involve installing six additional sampling wells outside the barrier perimeter and contouring the SDA for drainage.

Following the construction phase of Alternative 2a, long-term surveillance, maintenance, monitoring, and ICs would be conducted to enforce land-use restrictions and ensure effectiveness of the completed surface barrier. Surveillance and maintenance would include inspecting and repairing the surface barrier and peripheral components (e.g., fences and signs) to address observable degradation (e.g., subsidence, erosion, loss of vegetative cover, and biotic intrusion). Monitoring would include collecting samples and analyzing data from the vadose zone (i.e., soil moisture, soil vapor, perched water, and changes in moisture content) and from the aquifer. In addition, the INL Sitewide monitoring program would conduct radiological monitoring of air, surface water, surface soil, and biota. Active and passive ICs would include access restrictions, restrictions on groundwater use (e.g., well-drilling restrictions), restrictions on land use (e.g., limit to industrial applications), and physical security.

3.2.1.4 Remedial Action Schedule. Figure 3-4 provides a summary schedule for Alternative 2a, based on a hypothetical start date in year 2010. Modules 5, 7, 10, and 20 (described in Appendix F) provide a detailed schedule of each activity. The OCVZ system would operate throughout construction and for approximately 58.5 years after completion of the surface barrier to achieve preliminary remediation goals for the vadose zone and aquifer. 


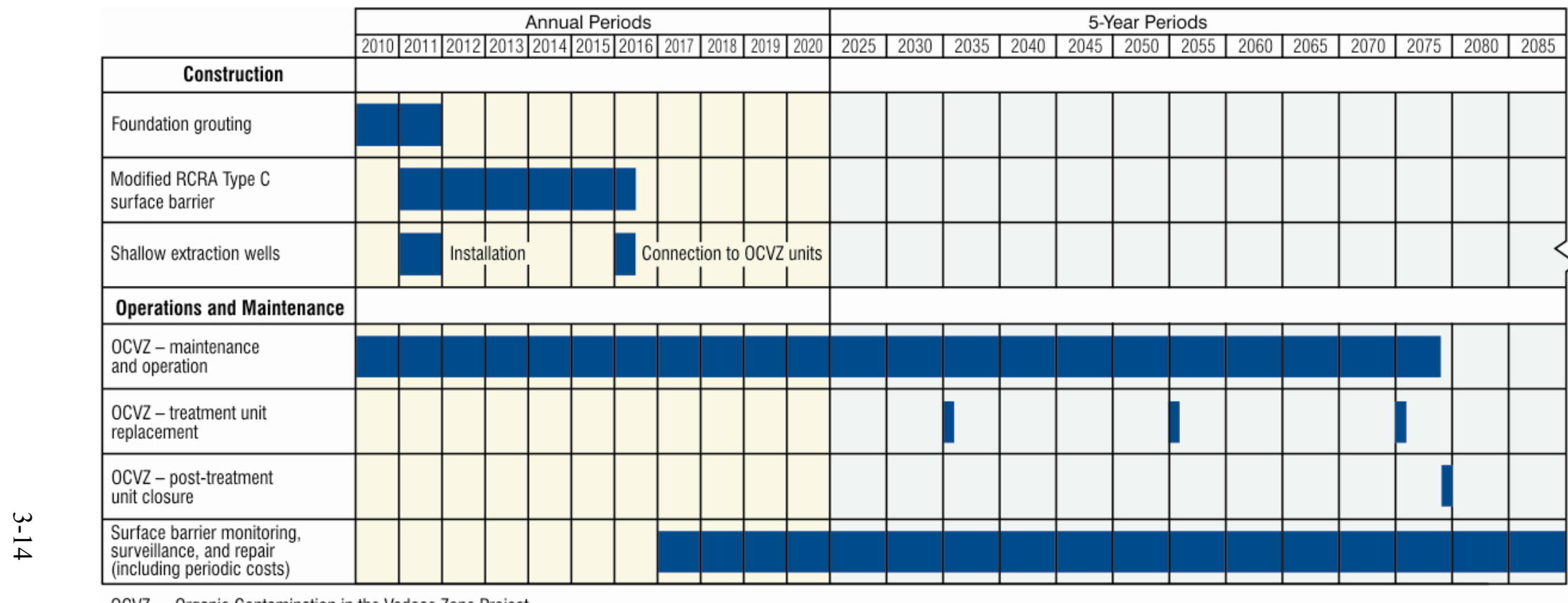

OCVZ $=$ Organic Contamination in the Vadose Zone Project

$\mathrm{RCRA}=$ Resource Conservation and Recovery Act

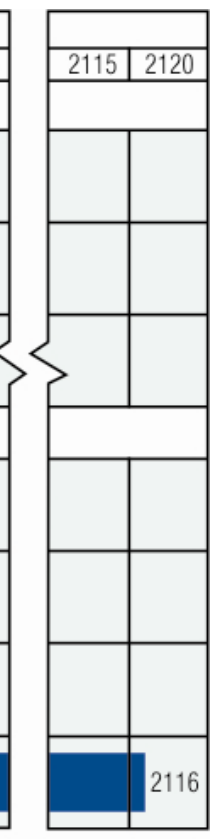

G06-1760-23

Figure 3-4. Summary schedule for Alternative 2a-Modified RCRA Type C Surface Barrier. 
For comparison, OCVZ system operational timeframes (required to achieve preliminary remediation goals for the vadose zone and aquifer) were based on the assumption that instantaneous remediation occurred in year 2010. (Section 4.1.3 and Appendix D provide further detail.) Operations and maintenance would start at surface barrier completion and would include groundwater monitoring, vadose zone monitoring, other environmental monitoring, surface barrier surveillance (e.g., visual inspection of vegetation growth, subsidence, and animal intrusion), and maintenance (e.g., subsidence repair). Periodic costs would parallel the operation and maintenance schedule and would include a remedial action report, an annual summary report, 5-year reviews, and a final operations and maintenance report.

\subsubsection{Alternative 2b-Evapotranspiration Surface Barrier}

Alternative $2 \mathrm{~b}$ is assembled from multiple general response actions that, when implemented as a comprehensive remedy, would satisfy remedial action objectives. This alternative comprises the following general response actions:

- $\quad$ Retrieval-Pad A waste would be retrieved and temporarily staged within the SDA until disposal. Waste would be retrieved using a standard excavator modified for use in a contaminated environment. Waste-retrieval operations would be conducted within fabric enclosures equipped with high-efficiency particulate air (HEPA) -filtered ventilation systems.

- $\quad$ Disposal-Staged Pad A waste would be transferred to the Low-Level Waste (LLW) Disposal Facility at the SDA (i.e., LLW Pit) or other location within the SDA to facilitate construction of the surface barrier.

- Containment-An ET surface barrier, consisting primarily of a vegetated soil layer and a coarse rock (e.g., cobble) layer, would be constructed over the SDA to minimize infiltration and to prevent biotic intrusion into contaminated media. Overall thickness of the barrier, coupled with long-term ICs, would preclude inadvertent human intrusion. The coarse rock layer would be vented to prevent buildup of landfill gases beneath the surface barrier. Dynamic compaction would be used before construction to minimize potential for future subsidence. Perimeter grading, cap armament, and surface barrier vegetation would mitigate erosion. Periodic surveillance of vegetation growth, subsidence, and animal intrusion would be performed, and the surface barrier would be maintained. A gas collection pipe would be installed within the gas collection layer of the surface barrier and integrated into the existing OCVZ system.

- Institutional controls-Active and passive controls would be implemented to prevent or limit access to the SDA. Institutional controls would include restrictions on groundwater use (e.g., well-drilling restrictions), restrictions on land use (e.g., limit to industrial applications), and physical security.

Groundwater, vadose zone, and radiological surface monitoring and surveillance for subsidence and animal intrusion would be performed. The following subsections provide detailed descriptions of Alternative $2 b$, including scope, process, and schedule.

3.2.2.1 Remedial Action Scope. The RI/BRA (Holdren et al. 2006) identifies COCs associated with multiple exposure pathways (see Section 1.4.5). Alternative $2 \mathrm{~b}$ is assembled specifically to address risk posed by these contaminants and pathways. To minimize potential mobilization of these contaminants, a low-permeability surface barrier would be constructed across the SDA surface. The surface barrier would prevent migration of contaminants to the surface and subsurface and would address remedial action objectives (see Section 1.5) by the following means: 
- Minimize infiltration into and through contaminated media in the SDA

- $\quad$ Prevent vapor buildup within the surface barrier

- Inhibit plant, animal, and human intrusion into the remaining waste

- $\quad$ Maintain performance for at least 1,000 years (Mattson et al. 2004).

Volatile COCs (e.g., C-14 and carbon tetrachloride) migrate in all directions through the subsurface by gas diffusion. A gas collection system and OCVZ system integrated with the surface barrier would mitigate the potential for buildup of these vapor-phase contaminants. The surface barrier would retard migration of COCs to the aquifer. Concurrently, the OCVZ system would collect and treat volatile COCs from the vadose zone, thereby reducing the amount that reaches the aquifer.

In addition, Alternative $2 \mathrm{~b}$ would provide active and passive controls to prevent or limit access to the site because unrestricted land use is expected to be prohibited in future 5-year reviews.

3.2.2.2 Remedial Action Process. As illustrated in Figure 3-5, Pad A waste would be removed and relocated within the SDA LLW Pit or other location within the SDA. Dynamic compaction would be applied to pit disposal areas (not including relocated Pad A waste) to provide a stable foundation for surface barrier construction. Finally, contaminants remaining in the SDA would be contained by completion of an ET surface barrier. Surface barrier surveillance, maintenance, monitoring, and ICs would continue until eliminated through the CERCLA 5-year review process. The following subsections describe the technical approach, equipment, and construction details for remedial action components included in Alternative $2 \mathrm{~b}$.

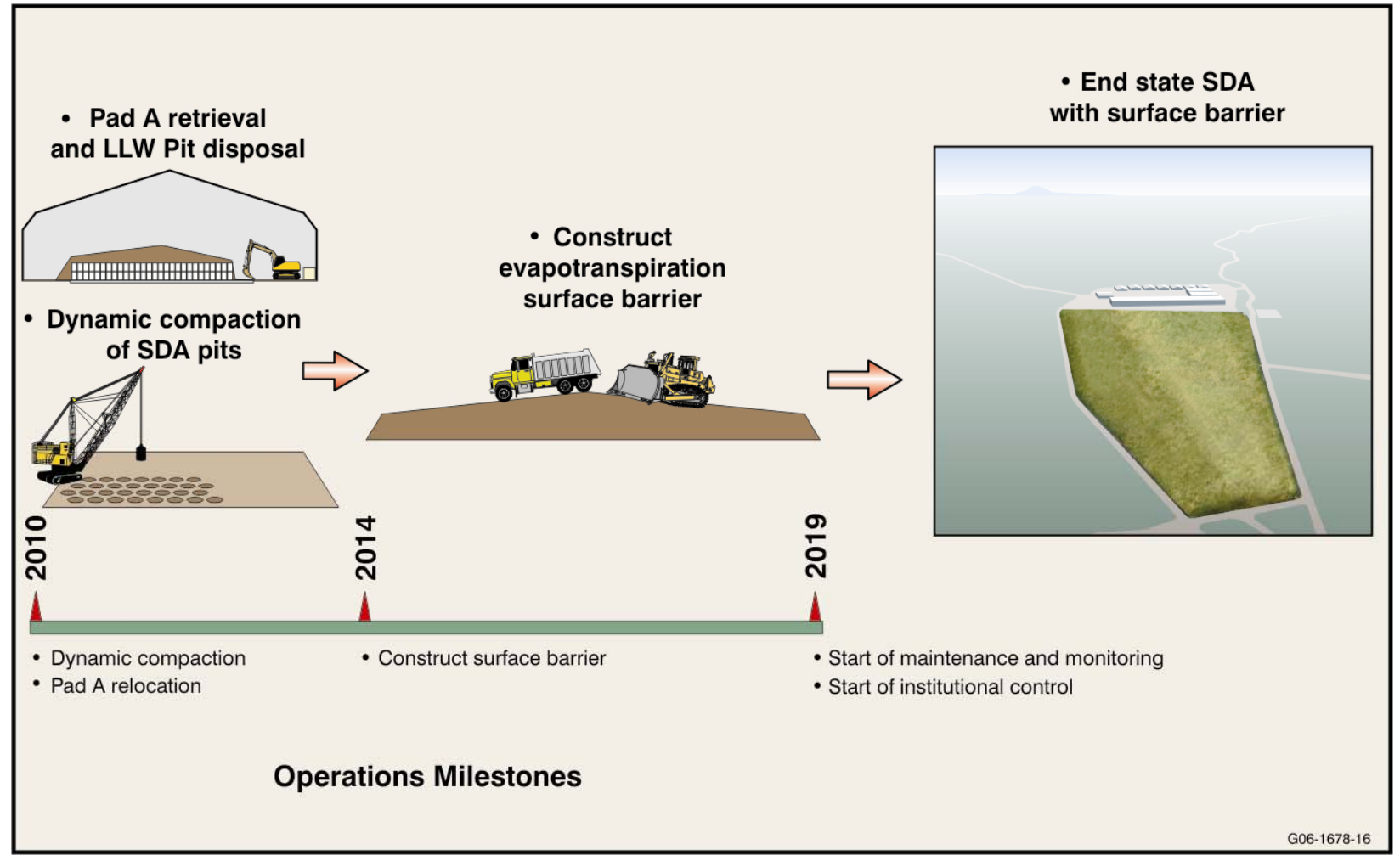

Figure 3-5. Process flow diagram for Alternative $2 b$-Evapotranspiration Surface Barrier. 
3.2.2.3 Remedial Action Components. This subsection describes the technical approach, equipment, and construction details for remedial action components included in Alternative $2 \mathrm{~b}$ (ET Surface Barrier).

Existing OCVZ extraction wells, treatment units, and sample ports for this alternative are identical to those for Alternative 2a (Modified RCRA Type C Surface Barrier).

Many surface barrier designs were evaluated and tested for application at the SDA (Mattson et al. 2004; Anderson and Forman 2003; DOE-ID 1997; Magnuson 1993; Porro 2001; Zitnik et al. 2002; Keck and Seitz 2002). Most recently, Mattson et al. (2004) conducted a comprehensive evaluation of available surface barrier designs and developed a site-specific preconceptual design for an ET surface barrier to support alternatives evaluated in this feasibility study. Design information presented here was derived primarily from that work. Figure 3-6 illustrates the conceptual design for the SDA ET surface barrier.

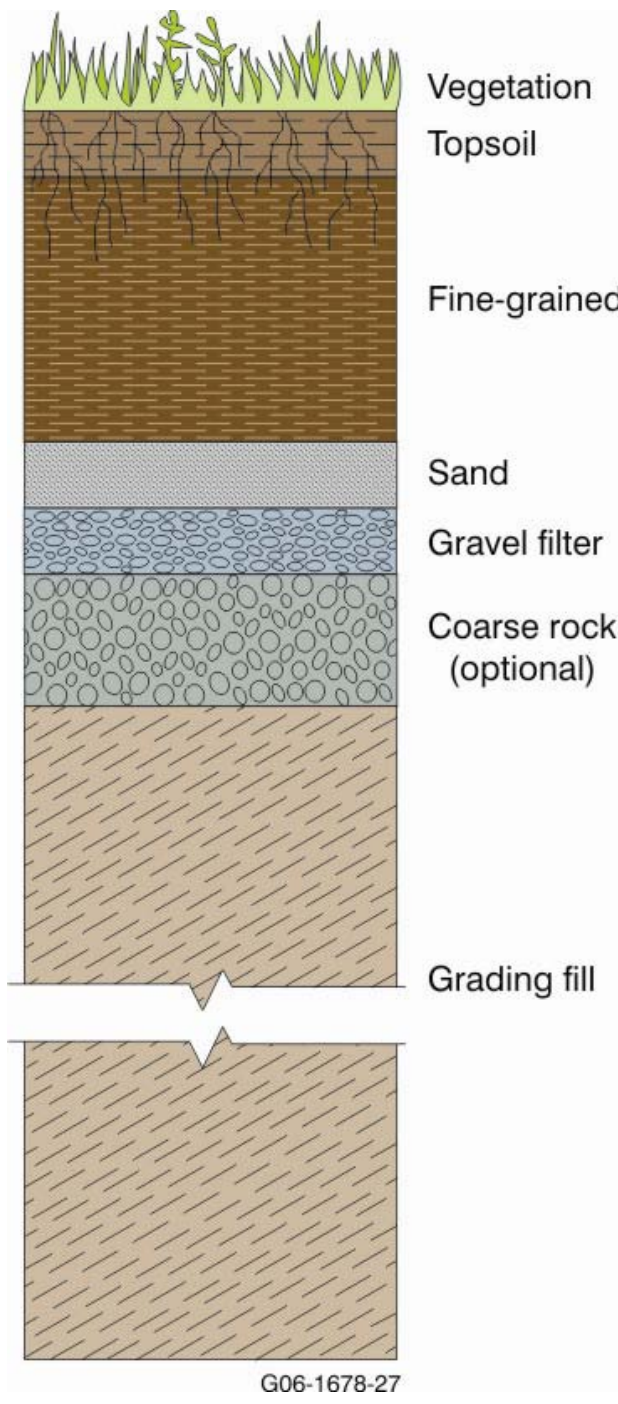

Figure 3-6. Cross section of surface barrier preconceptual design for Alternative $2 \mathrm{~b}-$ Evapotranspiration Surface Barrier.
The ET surface barrier is a multilayered cap composed of natural materials. Overall thickness of the cap, coupled with long-term ICs, would preclude inadvertent human intrusion. The primary component of any ET surface barrier is a vegetated fine-grained soil layer that retains infiltrated water until it is removed by the combined effects of evaporation and transpiration (Dwyer 1997) (see Figure 3-6). Design of the ET surface barrier for the SDA includes a water storage layer of fine-grained soil approximately $1 \mathrm{~m}$ (3.3 ft) thick. Thickness of the water storage layer has been optimized for SDA site-specific conditions (i.e., thick enough to accommodate storage of water while the plants are dormant, yet thin enough to be compatible with expected root dynamics of the vegetative community). A water storage layer that is too thick (i.e., thicker than the root distribution of vegetation on the barrier surface) does not improve performance because the ET surface barrier relies on plants to remove water from the water storage layer. Water that infiltrates below the root zone has little chance of removal and eventually could infiltrate through the barrier. The soil layer also incorporates gravel in the topsoil for erosion control.

The secondary component of the ET surface barrier is a layer of coarse rock that underlies the vegetated soil layer. Layers of gravel and sand would be placed between the fine-grained soil and coarse rock layers to minimize filtering of soil into the coarse rock layer. The first function of this coarse rock layer would be to deter animals from burrowing into the underlying waste and potentially bringing contamination to the surface. The second function of would be venting to prevent buildup of landfill gases (e.g., C-14, carbon tetrachloride, and methylene 
chloride). In Alternative 2b, piping would be installed within the coarse rock layer and connected to the existing OCVZ treatment units to actively extract volatile contaminants. After a period of active extraction, the coarse rock layer would continue to function as a passive venting system for the surface barrier. A vent layer also tends to create a dry barrier (Ankeny et al. 1997), further inhibiting downward growth of plant roots.

Two adjacent layers of material with differing pore structure (e.g., fine-grained soil and coarse rock) would create a capillary break where, under unsaturated conditions, water is held in the fine-grained layer by capillary forces (ITRC 2003). The capillary break would tend to decrease water flux through the surface barrier.

Because leaving Pad A on the surface of the SDA would hamper construction of an ET surface barrier, Alternative $2 \mathrm{~b}$ includes relocating Pad A waste. In its current configuration, Pad A is a mound

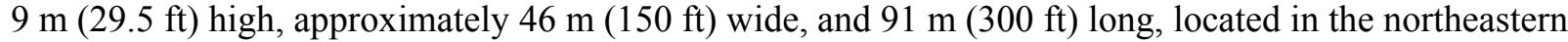
portion of the SDA. More than 20,000 waste containers, including 55-gal drums and plywood boxes, were placed on an asphalt pad and covered with soil. In 1994, the Pad A soil cover was reinforced-with a vegetated soil layer ( 0.9 to $1.2 \mathrm{~m}$ [ 3 to $5 \mathrm{ft}$ ] thick) and a rock armor barrier on the southern face - as a remedial action in accordance with the OU 7-12 ROD (DOE-ID 1994). Since that time, annual maintenance activities have included repairing subsidence-related damage to the soil cover.

Figure 3-7 illustrates the process that would be used for removing waste from Pad A. Table 3-2 provides the volumes of the various waste types within Pad A. After removing clean soil currently surrounding Pad A waste, the entire area of Pad A would be enclosed with a modular structure to provide weather protection and to confine airborne contaminants. The enclosure would be similar to that used for the Accelerated Retrieval Project. Excavation equipment modified for operation within a contaminated environment and modified for dust-suppression capabilities would be used to remove waste from Pad A. All intact-drum waste would be placed in new boxes. All loose waste would be placed in new lift liners. These boxes and liners then would be transferred to a staging area and eventually relocated to the LLW Pit or other location within the SDA. Placing this waste in an unlined pit (e.g., LLW Pit) may not be acceptable to the U.S. Environmental Protection Agency, even though risk-based criteria (i.e., remedial action objectives) and applicable or relevant and appropriate requirements would be satisfied. After Pad A waste has been removed, the retrieval enclosure would be demobilized, and the site would be prepared for surface barrier construction.

Constructing the surface barrier would be accomplished in a series of steps, including foundation preparation, infrastructure preparation, and placement of surface barrier materials and vegetation. Preparing the foundation would be a critical construction activity. Differential settlement occurs routinely at the SDA. While ET surface barriers are, by design, less susceptible to differential settlement, construction techniques that minimize future subsidence ultimately would reduce maintenance requirements for the surface barrier. In Alternative $2 b$, dynamic compaction would be used to mitigate subsidence before placing surface barrier materials; routine inspections and monitoring would be performed after construction.

Dynamic compaction was chosen to address subsidence and provide a stable foundation for the surface barrier. This technology was identified because it presents the highest short-term risk and cost among process options that apply surface treatment, thus bounding the analysis. Other process options (e.g., impact rolling) could be substituted during remedial design. 


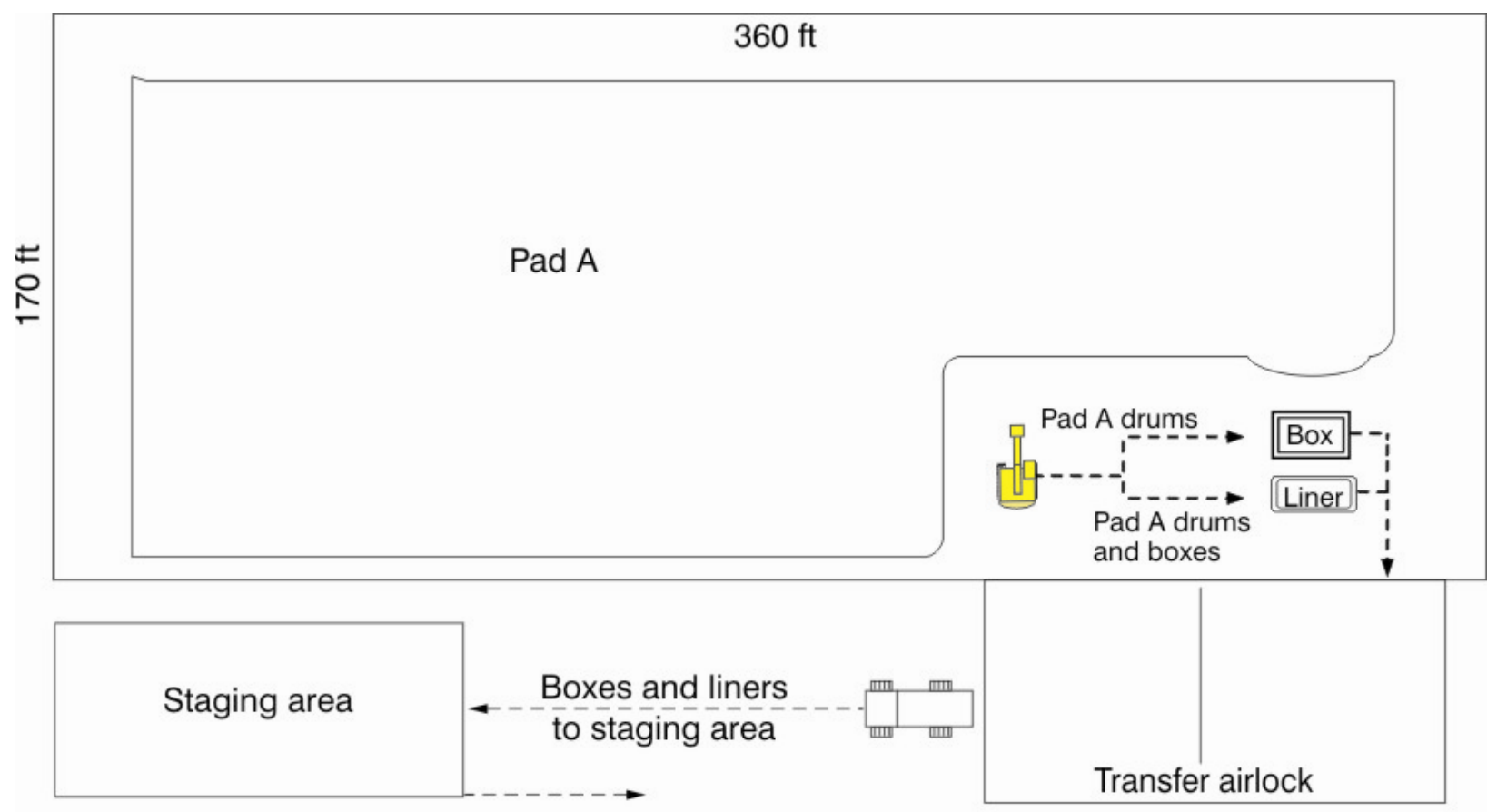

To Low-Level Waste Pit

G06-1760-10

Figure 3-7. Pad A waste retrieval and Low-Level Waste Pit disposal process for Alternative $2 \mathrm{~b}$ Evapotranspiration Surface Barrier.

Table 3-2. Volumes of waste types on Pad A.

\begin{tabular}{lc}
\hline \multicolumn{1}{c}{ Waste Type } & $\begin{array}{c}\text { Pad A } \\
\text { Waste Volume } \\
\left(\mathrm{ft}^{3}\right)\end{array}$ \\
\hline $\begin{array}{l}\text { Miscellaneous INL Site-generated } \\
\text { Series 745 sludge }\end{array}$ & $5.2 \mathrm{E}+02$ \\
Series 995 sludge & $2.6 \mathrm{E}+05$ \\
Rocky Flats Plant combustible and & $5.2 \mathrm{E}+03$ \\
noncombustible waste & $9.7 \mathrm{E}+04$ \\
Roaster oxide & \\
Loose overburden and sideburden soil & $7.7 \mathrm{E}+03$ \\
\hline $\begin{array}{l}\text { a. As disposed of. } \\
\text { INL= Idaho National Laboratory }\end{array}$ & \\
\hline
\end{tabular}

Dynamic compaction is a standard construction technique for compacting soft soil to support buildings, roadways, and surface barriers. This method involves systematically dropping a heavy weight (i.e., 10 to $40,000 \mathrm{~kg}$ ) from a height of 5 to $25 \mathrm{~m}$ (16 to $82 \mathrm{ft})$ in a pattern designed to improve the underlying density of soil (see Figure 3-8). In areas of soft ground, dynamic compaction has proven to be an effective and economical alternative to proof-rolling, foundation piling, deep vibratory compaction, or soil undercutting and replacement. Energy delivered to the soil, per blow, can exceed 12,000 kNm. Shock waves can penetrate to a depth of $10 \mathrm{~m}$ (33 ft). In coarser soil, shock waves

create liquefaction that leads to compaction. In finer textured soil, shock waves create positive pore-water pressures, followed by soil consolidation (Richins and Hurst 2004). A layer of soil would be placed over areas at the SDA and would be compacted, before treatment, to maintain overburden integrity during the dynamic compaction process. 


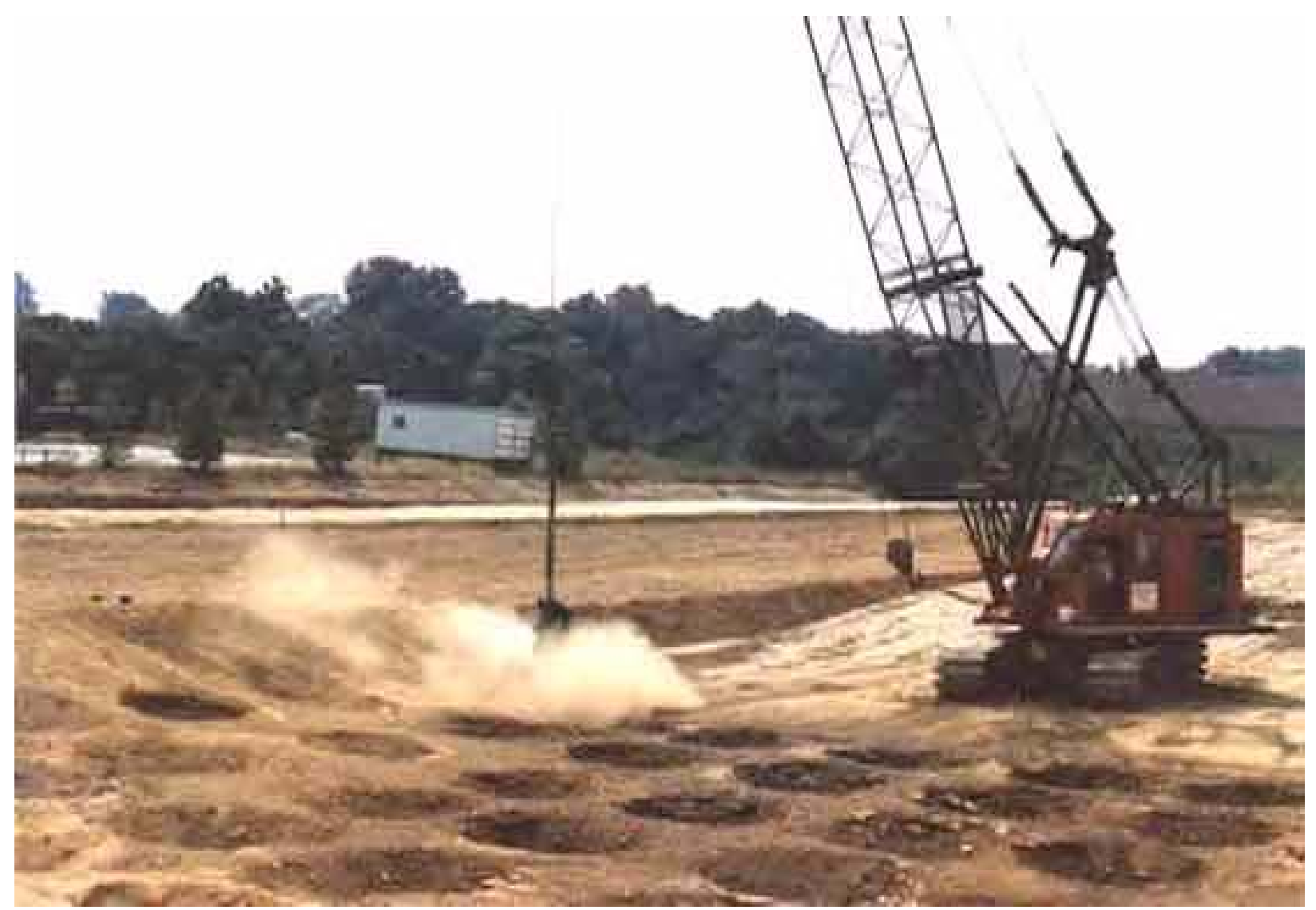

Figure 3-8. Dynamic compaction operation for Alternative 2b-Evapotranspiration Surface Barrier.

Existing infrastructure (e.g., utilities and monitoring equipment) at the SDA would be abandoned, relocated, or reconfigured to accommodate construction. The following activities would be performed before constructing the surface barrier:

- Install a temporary water storage tank

- $\quad$ Construct a new perimeter access road

- Install a new perimeter fence after demolishing the old one

- $\quad$ Abandon half the 50 existing monitoring wells (i.e., 25)

- Double the current network of 50 advanced tensiometers to monitor surface barrier performance (i.e., 100)

- $\quad$ Relocate the three existing OCVZ treatment units to an area outside the future surface barrier perimeter

- $\quad$ Extend (upward through the surface barrier) 18 OCVZ wells, 100 advanced tensiometers, and 25 monitoring wells. 
After preparing the subgrade and removing surface infrastructure, soil and rock material would be hauled to the SDA from local borrow sources. The ET surface barrier could be constructed in a phased approach where it could be substantially completed over sections of the SDA at one period of time while other areas would be covered at a later date. Such an approach could be used to accommodate ongoing landfill operations or other remediation activities (e.g., Accelerated Retrieval Project).

Three additional construction activities would follow surface barrier completion. First, both the existing OCVZ wells and the gas collection pipes installed within the coarse rock gas collection layer would extend into the air following completion of the barrier. Connecting the wells and pipes to the relocated OCVZ treatment units would be required for continued operation of the OCVZ system and active gas extraction. The second and third construction activities involve installing six additional sampling wells outside the barrier perimeter and contouring the SDA for drainage.

Following the construction phase of Alternative 2b, long-term surveillance, maintenance, monitoring, and ICs would be conducted to enforce land-use restrictions and ensure effectiveness of the completed surface barrier. Surveillance and maintenance would include inspecting and repairing the surface barrier and peripheral components (e.g., fences and signs) to address observable degradation (e.g., subsidence, erosion, loss of vegetative cover, and biotic intrusion). Monitoring would include collecting samples and analyzing data from the vadose zone (i.e., soil moisture, soil vapor, perched water, and changes in moisture content) and from the aquifer. In addition, the INL Sitewide monitoring program would conduct radiological monitoring of air, surface water, surface soil, and biota. Active and passive ICs would include access restrictions, restrictions on groundwater use (e.g., well-drilling restrictions), restrictions on land use (e.g., limit to industrial applications), and physical security.

3.2.2.4 Remedial Action Schedule. Figure 3-9 provides a summary schedule for Alternative $2 b$ based on a hypothetical start date in year 2010. Modules 3, 6, 8, 15, and 20 (described in Appendix F) provide a detailed schedule of each activity. The OCVZ system would operate throughout construction and for approximately 35 years after completion of the surface barrier to achieve preliminary remediation goals for the vadose zone and aquifer.

For comparison, OCVZ system operational timeframes (required to achieve preliminary remediation goals for the vadose zone and aquifer) were based on the assumption that instantaneous remediation occurred in year 2010. (Section 4.1.3 and Appendix D provide further detail.) The duration the OCVZ system would operate is shorter than for the Modified RCRA Type C surface barrier alternative (Alternative 2a). The difference in duration is due to the ability of the ET cap to vent gas-phase VOCs to the surface instead of trapping them below the asphalt layer, which is part of the Modified RCRA Type C surface barrier. Operations and maintenance would start at surface barrier completion and would include groundwater monitoring, vadose zone monitoring,) other environmental monitoring, surface barrier surveillance (e.g., visual inspection of vegetation growth, subsidence, and animal intrusion), and maintenance (e.g., subsidence repair). Periodic cost would parallel the operation and maintenance schedule and would include a remedial action report, an annual summary report, 5-year reviews, and a final operations and maintenance report. 

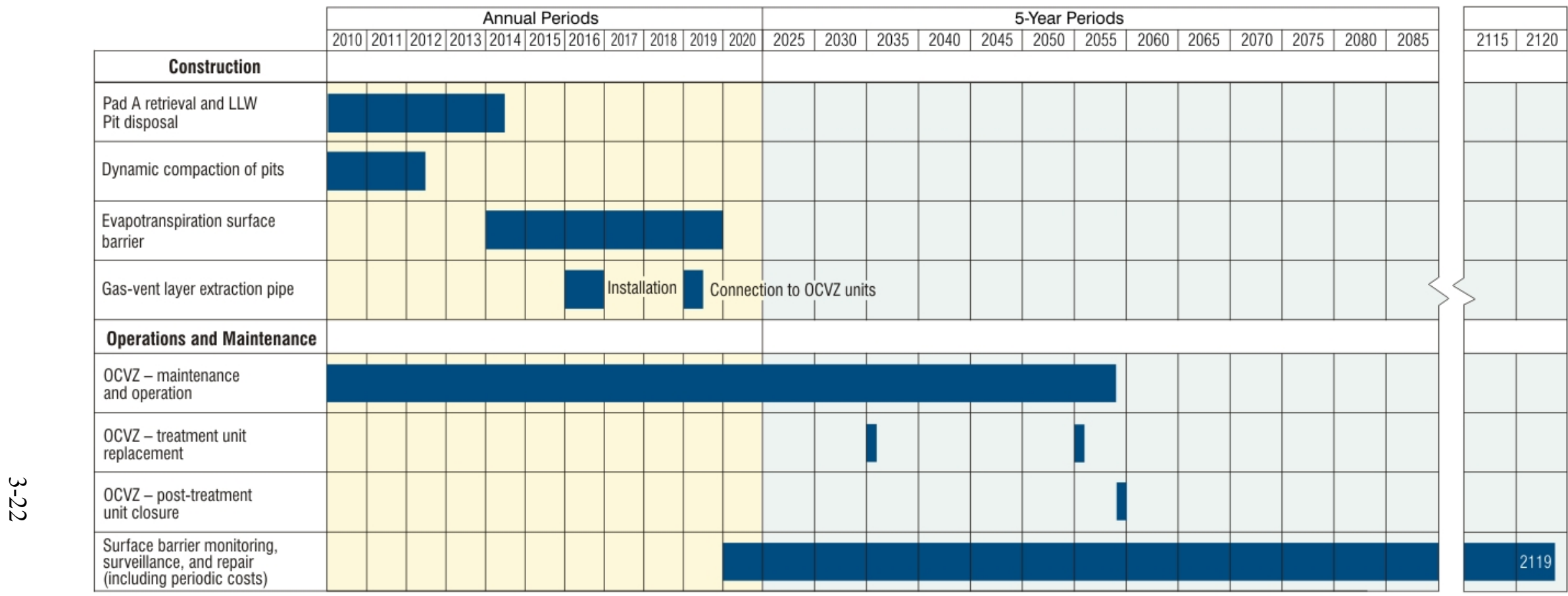

$\mathrm{LLW}=$ low-level waste
$\mathrm{OCVZ}=$ Organic Contamination in the Vadose Zone Project

Figure 3-9. Summary schedule for Alternative 2b-Evapotranspiration Surface Barrier. 


\subsection{Alternative 3-In Situ Grouting}

Alternative 3 is assembled from multiple general response actions, which, when implemented as a comprehensive remedy, would satisfy remedial action objectives. This alternative comprises the following general response actions:

- $\quad$ Retrieval-Pad A waste would be retrieved, segregated by size, and transferred to a treatment area. Waste would be retrieved using a standard excavator modified for use in a contaminated environment. Waste-retrieval operations would be conducted within fabric enclosures equipped with HEPA-filtered ventilation systems.

- $\quad$ Ex situ Treatment-Pad A waste of sufficiently small size would be placed within a mixer and combined with Portland cement grout. All other Pad A waste would be stabilized by a flowable cement grout. Treated waste would be staged temporarily within the SDA prior to disposal.

- Disposal-Treated Pad A waste would be shipped to the LLW Pit or other location within the SDA to facilitate construction of the surface barrier.

- In situ treatment-Alternative 3 would include ISG of buried waste containing long-lived radioisotopes where the unmitigated risk associated with groundwater ingestion is estimated to be greater than 1E-05. Grout would be emplaced around and within specified waste disposals using conventional civil engineering equipment and techniques. Hypothetical waste locations include approximately 0.2 acres of the SDA where INL Site reactor operations waste, containing releasable Tc-99 and I-129, were buried.

- Containment-An ET surface barrier, consisting primarily of a vegetated soil layer and a coarse rock layer, would be constructed over the SDA to minimize infiltration and to prevent biotic intrusion into contaminated media. Overall thickness of the barrier, coupled with long-term ICs, would preclude inadvertent human intrusion. The coarse rock layer would be vented to prevent buildup of landfill gases beneath the surface barrier. Dynamic compaction would be performed before construction to minimize the potential for future subsidence. Perimeter grading, cap armament, and surface barrier vegetation would be provided to mitigate erosion. Vegetation growth, subsidence, and animal intrusion would be monitored and the surface barrier would be maintained. A gas collection pipe would be installed within the gas collection layer of the surface barrier and directly vented, without treatment, into the atmosphere.

- Institutional controls-Active and passive controls would be implemented to prevent or limit access to the SDA. Institutional controls would include restrictions on groundwater use (e.g., well-drilling restrictions), restrictions on land use (e.g., limit to industrial applications), and physical security.

Groundwater, vadose zone, and radiological surface monitoring (described under Alternative 1) and surveillance for subsidence and animal intrusion would be performed. The following subsections provide detailed descriptions of Alternative 3, including scope, process, and schedule.

\subsubsection{Remedial Action Scope}

The RI/BRA (Holdren et al. 2006) identifies COCs associated with multiple exposure pathways (see Section 1.4.5). Alternative 3 is assembled to specifically address risk posed by these contaminants and pathways. Groundwater pathway COCs include Tc-99 (and collocated I-129). In situ grouting by high-pressure jet grouting would effectively immobilize Tc-99 and I-129. In combination with an 
ET surface barrier, ISG of specified waste forms would satisfy all remedial action objectives. Waste types specified for ISG are INL Site reactor operations waste expected to contain releasable or mobile Tc-99 (i.e., resins, fuel examination, or surface-contaminated waste). For purposes of the feasibility study, 1,000 linear feet of trenches and soil vault rows, containing 39 specified waste shipments and approximately $50 \%$ (by activity) of the mobile Tc-99 source term, are evaluated as an example. Areas would be grouted using a generic Portland cement-based grout. Figure 3-10 shows hypothetical treatment locations for Tc-99 waste shipments evaluated for ISG.

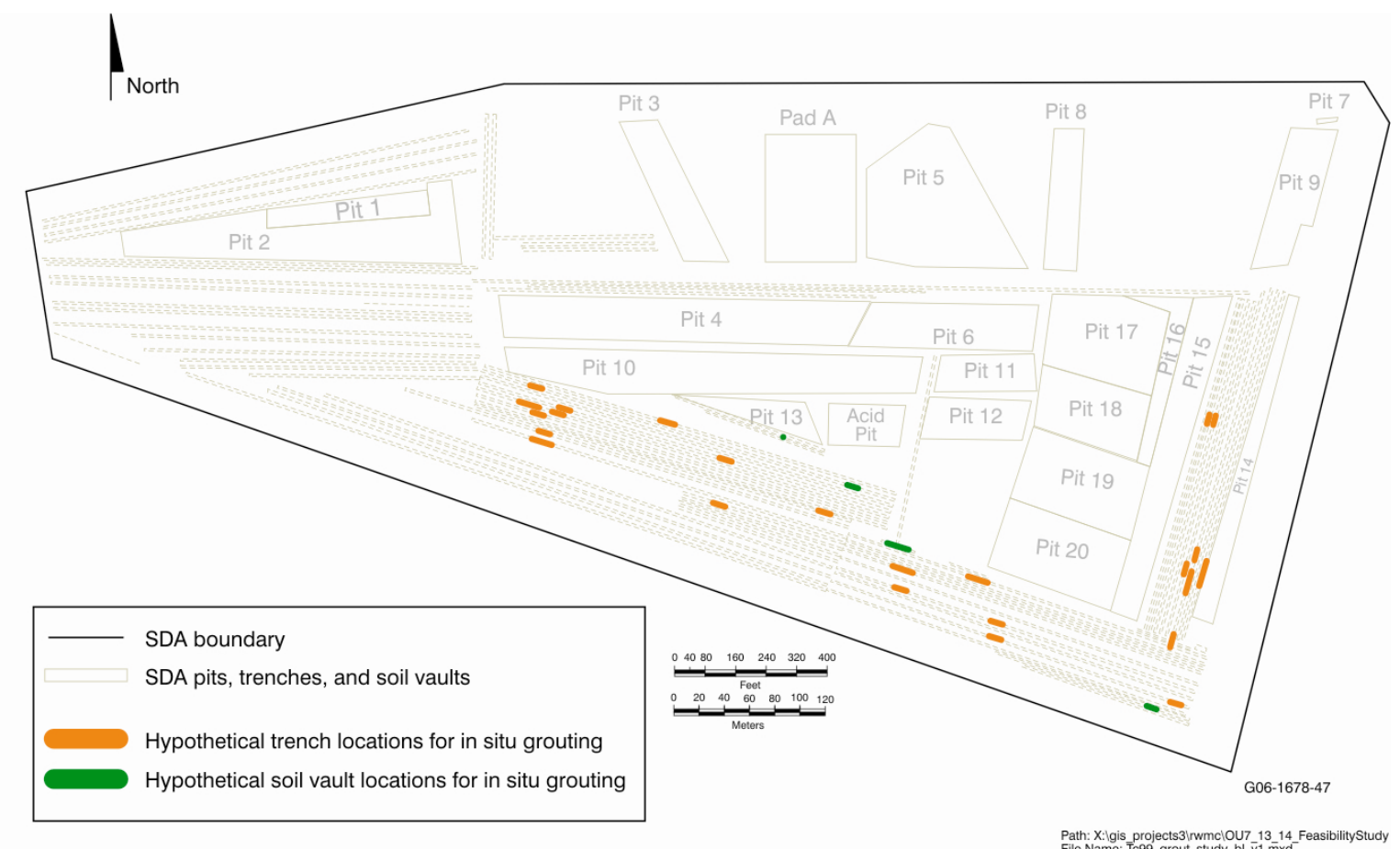

Figure 3-10. Hypothetical treatment locations for Alternative 3-In Situ Grouting.

After ISG of specified waste, an ET surface barrier - with an integrated biointrusion and gas vent layer-would be constructed over the entire SDA to achieve the following:

- Minimize infiltration into and through contaminated media remaining in the SDA

- $\quad$ Prevent vapor buildup within the surface barrier

- Inhibit plant and animal intrusion into the remaining waste

- $\quad$ Maintain performance for 1,000 years (Mattson et al. 2004).

Alternative 3 (ISG) would provide active and passive controls to prevent or limit access to the waste because unrestricted land use is expected to be prohibited in future 5-year reviews. Institutional controls for Alternative 3 include restrictions on groundwater use (e.g., well-drilling restrictions), restrictions on land use (e.g., limit to industrial applications), and physical security.

\subsubsection{Remedial Action Process}

Alternative 3 assumes that targeted Rocky Flats Plant waste would be removed from the first Accelerated Retrieval Project retrieval area (DOE-ID 2004a) and that all other waste would remain in the SDA. As illustrated in Figure 3-11, Pad A waste would be removed, treated ex situ, and relocated below 
grade within the SDA LLW pit or other location within the SDA. In situ grouting of buried waste, using high-pressure jet grouting, would be applied to specified trench and soil vault areas. Dynamic compaction would be applied to the same pit disposal areas as identified in the previous alternatives. Finally, contaminants remaining in the SDA would be contained by completion of an ET surface barrier. Surface barrier maintenance, surveillance, monitoring, and ICs would be maintained until discontinued through the CERCLA 5-year review process. The following subsections describe the technical approach, equipment, and construction details for remedial action components included in Alternative 3.

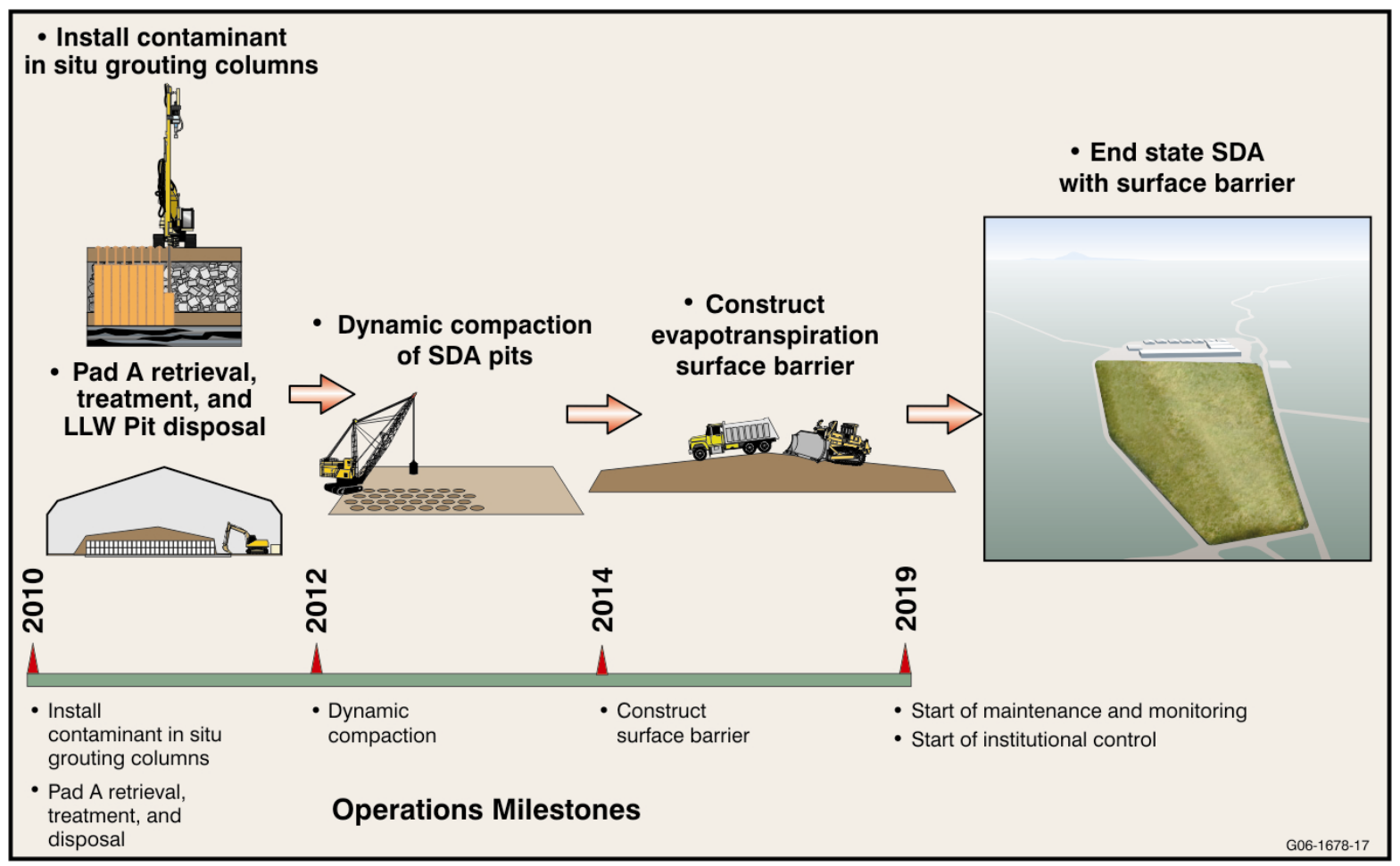

Figure 3-11. Process flow diagram for in situ grouting and containment for Alternative 3-In Situ Grouting.

\subsubsection{Remedial Action Components}

Existing OCVZ extraction wells, treatment units, and sample ports for this alternative are identical to those of Alternative $2 \mathrm{a}$.

Specified waste types identified for ISG would be encapsulated by injecting Portland cement grout (Jensen 2004; Shaw 2004; Matthern et al. 2005) using commercially available equipment (Raivo 2004). Liquid grout would be injected into the buried waste using a probe driven by a rotopercussion drill (see Figures 3-12 and 3-13). High-pressure jet-grouting mixes grout with waste and soil to form consolidated monoliths. Grout columns would be closely spaced on $0.5-\mathrm{m}$ (20-in.) centers. Stabilized waste monoliths would be highly impermeable and would reduce contaminant diffusion into moisture that may infiltrate the waste zone. Accurately defined waste perimeters, coupled with detailed disposal records and grout injection beyond the specified footprint, would provide good confidence in specified waste encapsulation. Figure 3-13 shows remote operation of vendor-owned ISG equipment used in the SDA during the Beryllium Encapsulation Early Actions Project (Lopez 2004). 
Grout column spacing

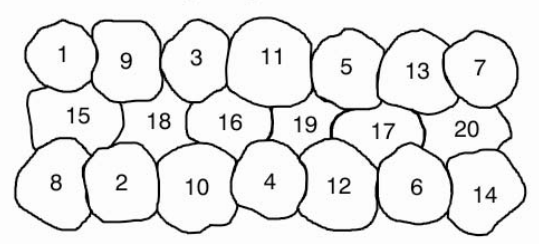

(Numbers indicate order of injection)

Trackhoe-mounted drill rig

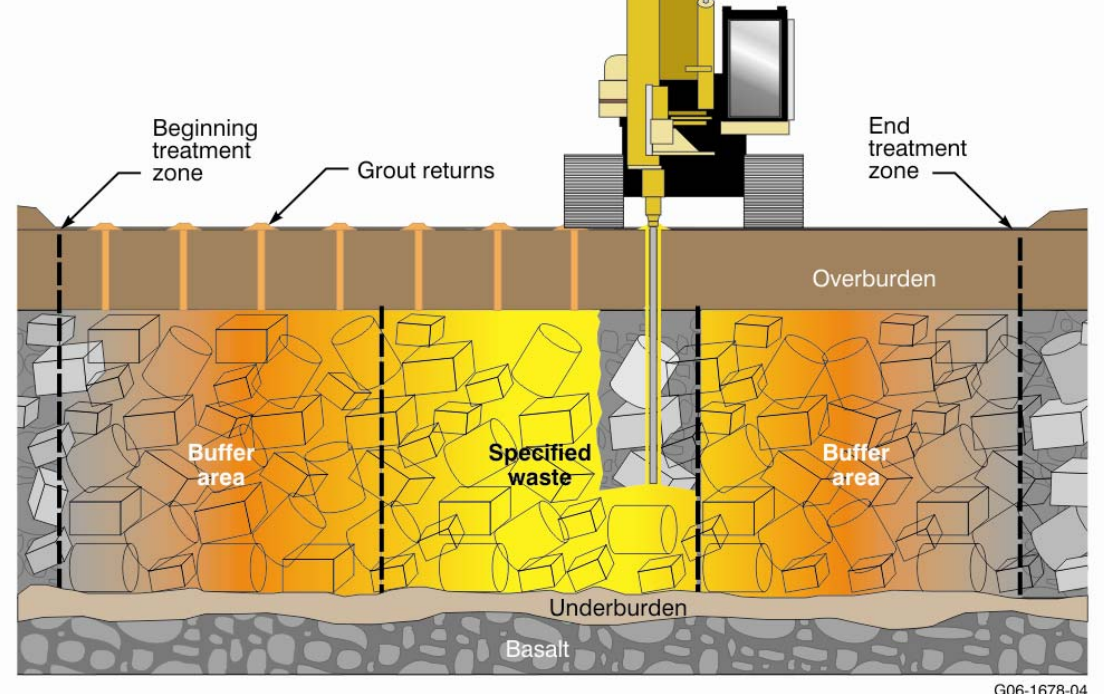

Figure 3-12. Rotopercussion grout rig used for Alternative 3-In Situ Grouting.

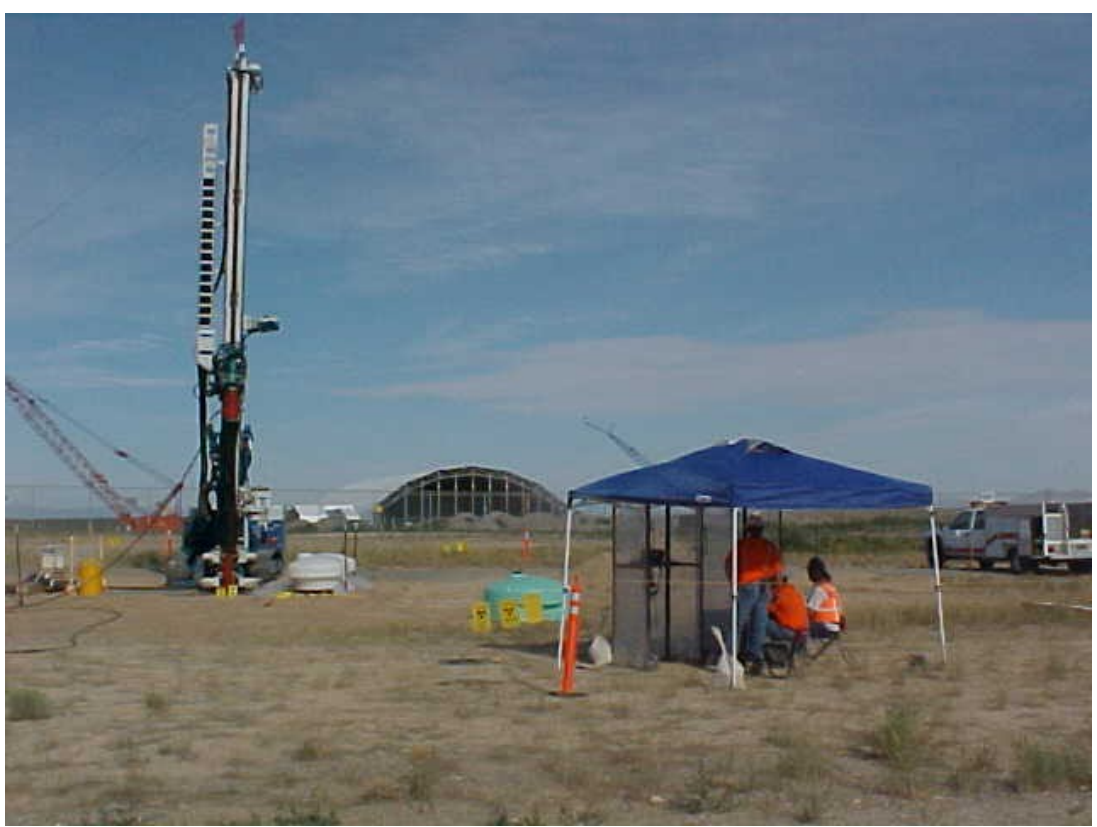

Figure 3-13. Remote operation of in situ grouting equipment during the Beryllium Encapsulation Early Actions Project. 
Grout returns are not expected to flow to the ground surface during routine ISG operations. A single-phase nondisplacement grouting approach was demonstrated at the INL Site (Loomis, Zdinak, and Bishop 1997). However, engineering controls would be included to provide additional protection against spread of contamination. Experience gained during the Beryllium Encapsulation Early Action Project suggests that grout would be effective in containing any contaminants displaced to the ground surface and that additional containment would not be required. As shown in Figure 3-12, contamination from grout

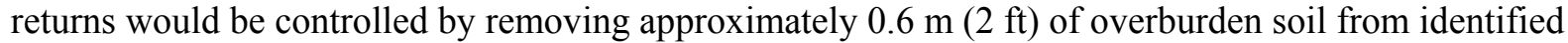
treatment areas to form depressions to retain any contaminated grout that may be displaced to the ground surface. Immediately following completion of grout injection, the in situ treatment area (including grout returns and any contamination brought to the surface by the drill stem) would be covered with clean soil up to grade.

After ISG of specified waste forms in trenches and soil vault rows, the SDA would be covered by an ET surface barrier. Figure 3-6 presents a cross section of an ET surface barrier. The primary component of any ET surface barrier is a vegetated fine-grained soil layer that retains infiltrated water until it is removed by evaporation and transpiration (Dwyer 1997). Design of the ET surface barrier for the SDA includes a water storage layer of fine-grained soil approximately $1 \mathrm{~m}(3.3 \mathrm{ft})$ thick. Thickness of the water storage layer was optimized for SDA site-specific conditions (i.e., thick enough to accommodate storage of water while plants are dormant, yet thin enough to be compatible with expected root dynamics of the vegetative community). The soil layer also incorporates a gravel admixture in the topsoil for erosion control.

The secondary component of the ET surface barrier is a layer of coarse rock, approximately $1.2 \mathrm{~m}$ $(3.9 \mathrm{ft})$ thick that underlies the vegetated soil layer. Note that layers of gravel and sand would be placed between the fine-grained soil and the coarse rock layers to minimize filtering of soil into the coarse rock layer. The first function of this coarse rock layer is to deter animals from burrowing into the underlying waste and potentially bringing contamination to the surface. The second function of the coarse rock layer is to provide a means of venting to prevent buildup of landfill gases (e.g., C-14, carbon tetrachloride, and methylene chloride). In Alternative 3, piping would be installed within the coarse rock layer and allowed to passively vent. The coarse rock layer also would create a capillary barrier that would tend to decrease the flow of water through the surface barrier and create a dry barrier (Ankeny et al. 1997), which would further inhibit downward growth of plant roots.

Because leaving Pad A on the surface of the SDA would hamper construction of an ET surface barrier, this alternative includes treating and relocating Pad A waste.

Figure 3-14 illustrates processes that would be used for removing waste from Pad A. Following removal of clean soil — currently surrounding the Pad A waste - the entire area of Pad A would be enclosed with a modular structure to provide weather protection and to confine airborne contaminants. The enclosure would be similar to that used for the Accelerated Retrieval Project. Excavation equipment modified for operation within a contaminated environment and modified for dust-suppression capabilities would be used to remove waste from Pad A. Because waste containers are expected to be highly degraded, no attempt would be made to segregate Pad A waste types. Bulk waste would be separated into fines (i.e., less than 7.6-cm [6-in.] diameter) and debris (i.e., greater than 7.6-cm [6-in.] diameter). Fines would be treated by mixing them with a Portland cement grout. Debris would be placed into waste boxes and stabilized with flowable cement grout. Stabilized waste boxes would be transported to the active LLW Pit or another location within the OU 7-13/14 area of contamination. Placing this waste in an unlined pit (e.g., LLW Pit) may not be acceptable to the U.S. Environmental Protection Agency, even though risk-based criteria (i.e., remedial action objectives) and applicable or relevant and appropriate requirements would be satisfied. On completion of Pad A waste removal, the retrieval enclosure would be demobilized, and the site would be prepared for surface barrier construction. 


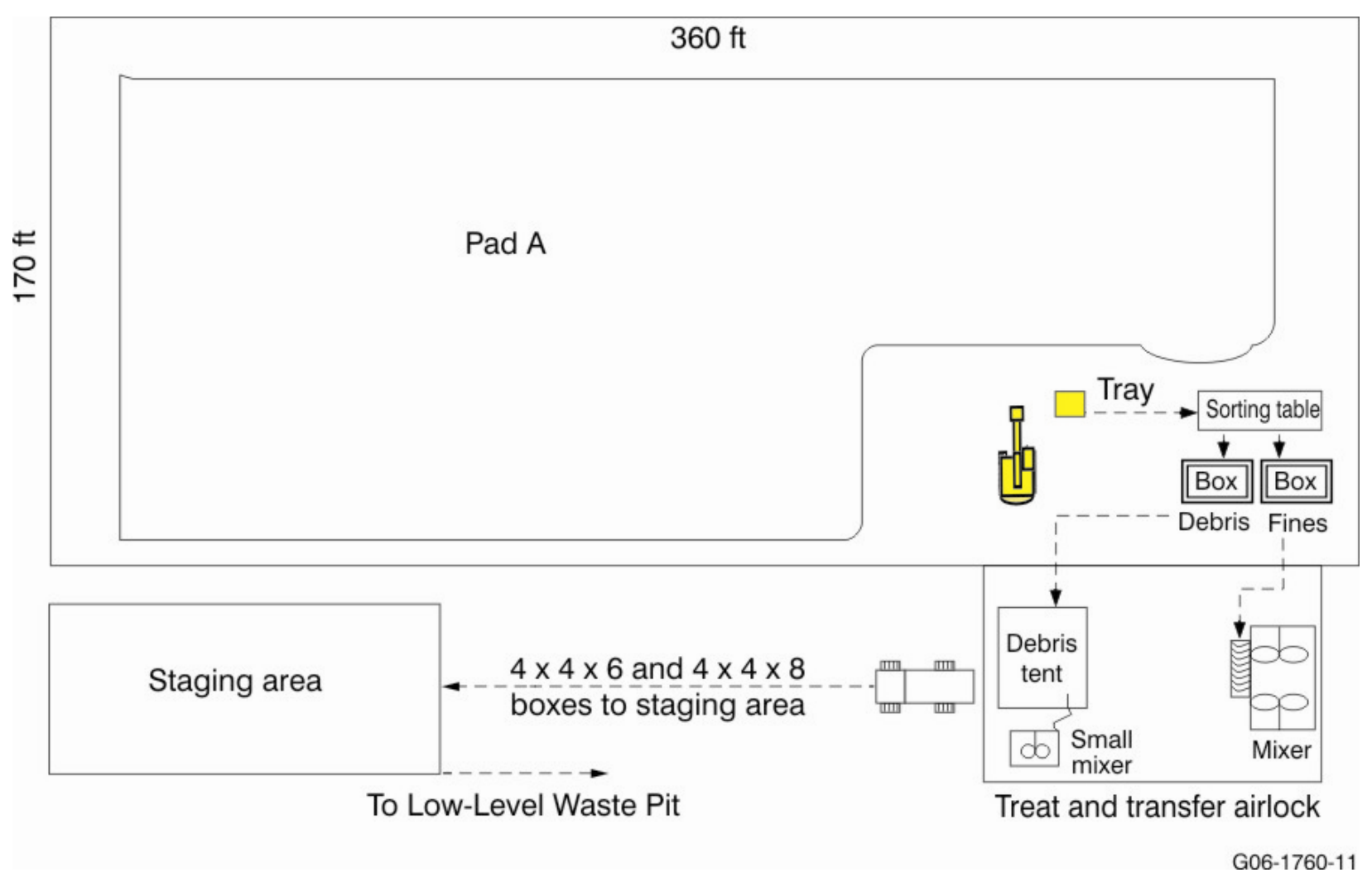

Figure 3-14. Pad A waste retrieval, ex situ treatment, and Low-Level Waste Pit disposal process for Alternative 3-In Situ Grouting.

Constructing the surface barrier would be accomplished in a series of steps: preparing the foundation, preparing the infrastructure, and emplacing surface barrier materials and vegetation. Preparing the foundation would be a critical construction activity. Differential settlement occurs routinely at the SDA. While ET surface barriers are, by design, less susceptible to differential settlement, construction techniques that minimize future subsidence ultimately would reduce maintenance requirements for the surface barrier. In Alternative 3, dynamic compaction would be used to mitigate differential settlement (described in Section 3.2.2.3) before placing surface barrier materials; routine inspections and monitoring would be performed after construction. This technology was chosen because it presents the highest short-term risk and cost among process options that apply surface treatment, thus bounding the analysis. Other process options (e.g., impact rolling) could be substituted during remedial design.

Existing infrastructure (e.g., utilities and monitoring equipment) at the SDA would be abandoned, relocated, or reconfigured to accommodate construction. The following activities would be performed before constructing the surface barrier:

- Install a temporary water storage tank

- Construct a new perimeter access road

- Install a new perimeter fence (including demolishing the old one)

- $\quad$ Abandon half the 50 existing monitoring wells (i.e., 25) 
- Double the current network of 50 advanced tensiometers to monitor surface barrier performance (i.e., 100)

- $\quad$ Relocate the three existing OCVZ treatment units to an area outside the future surface barrier perimeter

- $\quad$ Extend (upward through the surface barrier) $18 \mathrm{OCVZ}$ wells, 100 advanced tensiometers, and 25 monitoring wells.

After preparing the subgrade and removing surface infrastructure, soil and rock material would be hauled to the SDA from local borrow sources. The ET surface barrier could be constructed in a phased approach where it could be substantially completed over sections of the SDA at one period of time while other areas would be covered at a later date. Such an approach could be used to accommodate ongoing landfill operations or other remediation activities (e.g., the Accelerated Retrieval Project retrieval).

Two additional construction activities follow completion of the surface barrier. First, the existing OCVZ wells would extend into the air after the barrier is complete. Connecting these wells to the relocated OCVZ treatment units would be required for continued operation of the OCVZ system. The second and third construction activities involve installing six additional sampling wells outside the barrier perimeter and contouring the southern and eastern ends of the SDA for drainage.

Following the construction phase of Alternative 3, long-term surveillance, maintenance, monitoring, and ICs would be conducted to enforce land-use restrictions and ensure effectiveness of the completed surface barrier. Surveillance and maintenance would include inspecting and repairing the surface barrier and peripheral components (e.g., fences and signs) to address observable degradation (e.g., subsidence, erosion, loss of vegetative cover, and biotic intrusion). Monitoring would include collecting samples and analyzing data from the vadose zone (i.e., soil moisture, soil vapor, perched water, and changes in moisture content) and from the aquifer. In addition, the INL Sitewide monitoring program would conduct radiological monitoring of air, surface water, surface soil, and biota. Active and passive ICs would include access restrictions, restrictions on groundwater use (e.g., well-drilling restrictions), restrictions on land use (e.g., limit to industrial applications), and physical security.

\subsubsection{Remedial Action Schedule}

Figure 3-15 provides a summary schedule for Alternative 3 based on a hypothetical start date in year 2010. Modules 3, 6, 8, 11, 18, and 20 (see Appendix F) provide a detailed schedule of each activity. The OCVZ system would operate throughout construction. Because release of VOCs is dependent on the rate of diffusion from intact waste packages, the OCVZ system would operate for an additional 35 years after completion of the surface barrier to achieve preliminary remediation goals for the vadose zone and aquifer. For comparison, OCVZ system operational timeframes (required to achieve preliminary remediation goals for the vadose zone and aquifer) were based on the assumption that instantaneous remediation occurred in year 2010. Section 4.1.3 and Appendix D provide further detail. Operations and maintenance would start at surface barrier completion and would include groundwater monitoring, vadose zone monitoring, other environmental monitoring, surface barrier surveillance (e.g., monitoring vegetation growth, subsidence, and animal intrusion), and maintenance (e.g., subsidence repair). Periodic costs would parallel the operation and maintenance schedule and would include a remedial action report, an annual summary report, 5-year reviews, and a final operations and maintenance report. 

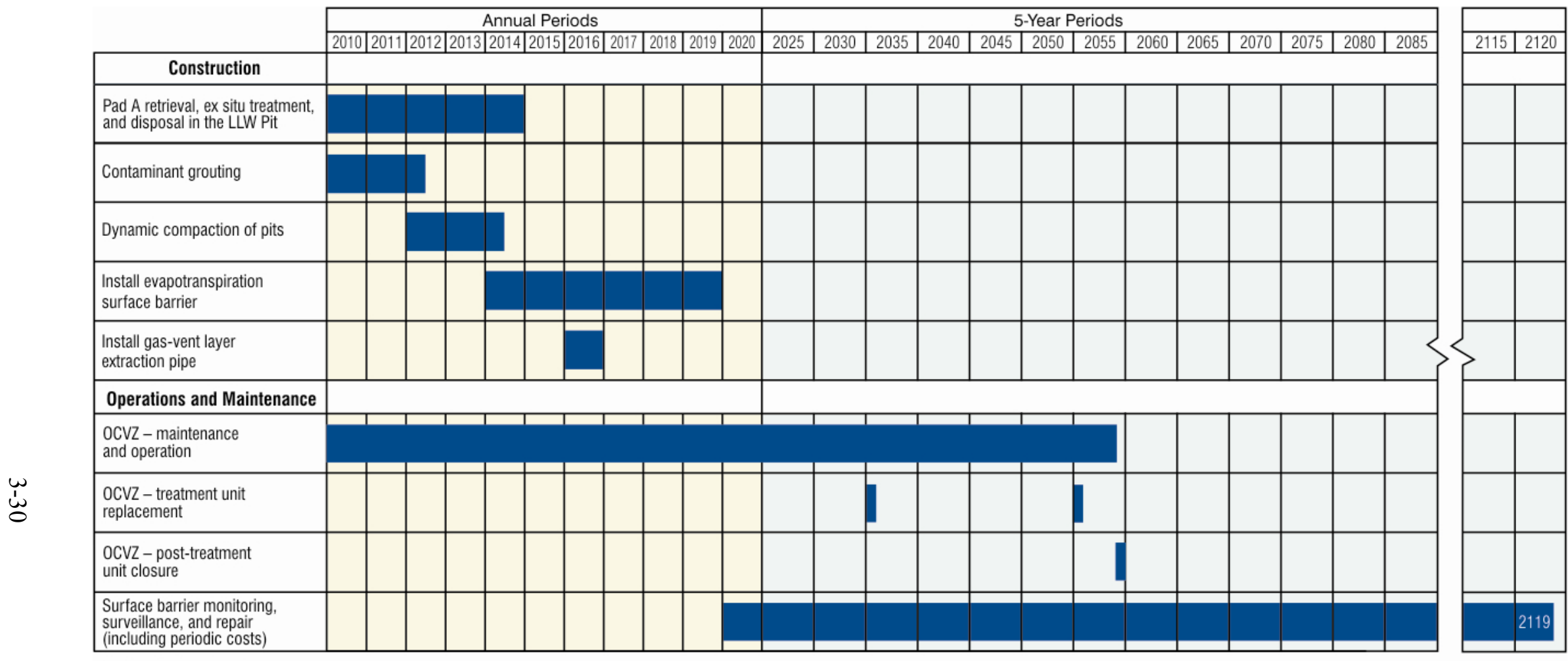

$\mathrm{LLW}=$ low-level waste
$\mathrm{OCVZ}=$ Organic Contamination in the Vadose Zone Project

Figure 3-15. Summary schedule for Alternative 3-In Situ Grouting. 


\subsection{Alternative 4-Partial Retrieval, Treatment, and Disposal}

Alternative 4 is divided into two partial RTD subalternatives. Alternative 4a is the partial RTD alternative specified in the Second Addendum (Holdren and Broomfield 2004). Alternative 4b was added when the Agencies identified advantages in examining various sizes of retrieval areas. Analyzing retrievals that vary in size from areas totaling 4 and 2 acres in Alternatives $4 \mathrm{a}$ and $4 \mathrm{~b}$, respectively, enables the Agencies to scale and select different sizes of retrieval areas for the final remedy. Alternative $4 \mathrm{~b}$ examines leaving Pad A waste in place and retrieving a total of 2 acres of Rocky Flats Plant waste. In combination, the two subalternatives facilitate scaling up or down to various retrieval area sizes, including or excluding Pad A.

Alternatives $4 \mathrm{a}$ and $4 \mathrm{~b}$ both incorporate the targeted waste approach developed for the Accelerated Retrieval Project non-time-critical removal actions (DOE-ID 2004a; DOE-ID 2006). The Accelerated Retrieval Project is a well-supported basis for evaluating partial RTD because information relating to implementability, short-term risk, and cost was generated by operating experience. Methods are founded on important observations from the OU 7-10 Glovebox Excavator Method Project (i.e., limited retrieval demonstration in Pit 9) (DOE-ID 2004b) and on substantially improved tools for characterizing the source term and identifying locations of specific waste streams in the SDA (McKenzie et al. 2005).

The retrieval demonstration in Pit 9 produced critical observations fundamental to developing and deploying targeted waste retrieval. For example, many Rocky Flats Plant waste streams were readily identified by visual observation in Pit 9. Workers were trained to recognize specific waste types, based on containers, color, form, and other visual cues. Waste types associated with high concentrations of transuranics (e.g., graphite molds and fines) were easily identified. In addition, specific waste types were found in locations consistent with improved waste zone mapping. Another critical observation concerned containers. Though drums had degraded significantly, many polyethylene drum liners were intact, containing VOCs and other contaminants decades after disposal.

Waste zone mapping has evolved into a sophisticated tool used to support characterizing and remediating the SDA. As summarized in Section 3.3 of the RI/BRA (Holdren et al. 2006), the SDA source term was initially described beginning in the early 1990s as total inventories ascribed to waste streams buried throughout the entire SDA. Estimates were reasonable for inventories in whole pits and trenches, but not for specific locations within those pits and trenches. Today, inventories are assigned to individual waste shipments, rather than entire waste streams, using sophisticated database tools to automate mapping. Coupled with refined information about historical waste-generating processes (e.g., acceptable knowledge and source-term reconstruction), shipments are described by waste generator, waste form, container type, inventories, volumes, and locations. This ability facilitates targeted waste retrieval.

The focused objective of both Accelerated Retrieval Projects is targeted retrieval of certain Rocky Flats Plant waste streams that are highly contaminated with VOCs, transuranics, and uranium. To achieve this objective, both actions involve removal of the following Rocky Flats Plant targeted waste streams: Series 741 sludge, Series 743 sludge, graphite, filters, and roaster oxides. These waste streams were identified because they contain high concentrations of COCs listed in the Second Addendum (Holdren and Broomfield 2004). Though the list of COCs in the Second Addendum subsequently was refined in the RI/BRA (see Section 1.4.5), the Agencies retained all of the original targeted waste types for the Accelerated Retrieval Projects to address uncertainty in model results, especially for uranium isotopes (secondary COCs). Therefore, the same types of targeted waste identified for the Accelerated Retrieval Projects are evaluated for Alternative 4 in this feasibility study. Removing targeted waste would reduce inventories of VOCs, transuranics, and uranium isotopes. Vadose zone remediation goals would be achieved sooner, thus minimizing future OCVZ system operations. 
During the process of excavation, other types of waste could be revealed that are not targeted waste. Nontargeted waste would be removed if the Agencies agree that retrieval is warranted and-as determined through visual inspection or field screening - the subject waste meets the following three criteria: (1) waste poses a potential risk of contaminating the underlying aquifer if left in place, (2) potential risk is sufficient to warrant removal at that time rather than leaving waste to be addressed by OU 7-13/14, and (3) waste can be managed safely by retrieval, using personnel, facilities, and equipment readily available at the INL Site for retrieval of targeted waste streams (DOE-ID 2004; DOE-ID 2006).

The same approach identified for the Accelerated Retrieval Projects is evaluated for Alternative 4 in this feasibility study. Removing targeted waste would reduce inventories of VOCs, transuranics, and uranium isotopes. Vadose zone remediation goals for VOCs would be achieved sooner, thus minimizing future OCVZ system operations. In addition, partial retrieval would reduce VOC contamination in the buried waste substantially and would reduce the potential for organics to get into the underlying aquifer.

The Agencies chose locations for the two ongoing Accelerated Retrieval Projects (DOE-ID 2004a; DOE-ID 2006) to maximize the amount of targeted waste that would be exhumed. Identified areas are sizable portions of pits that contain relatively significant amounts of targeted waste and present few obstacles to safe retrieval (e.g., large objects and waste with high exposure rates). Identifying specific retrieval areas is not critical to the analysis. Figure 3-16 shows example locations that illustrate the approach.

In addition to differences in the size of retrieval areas, Alternatives $4 \mathrm{a}$ and $4 \mathrm{~b}$ adopt different approaches for subsidence control in pits and Pad A remediation. Alternative 4a includes removing Pad A waste to the Idaho CERCLA Disposal Facility (ICDF) and dynamically compacting pits. Alternative 4b evaluates dynamically compacting Pad A before incorporating it into the surface barrier. Proof-rolling is evaluated to address subsidence. In addition, Alternative $4 \mathrm{~b}$ includes a lateral subsurface barrier (i.e., slurry cut-off wall). Both subalternatives include continued operation of the OCVZ system, to extract and treat VOCs from the vadose zone; an ET surface barrier; and long-term maintenance, surveillance, monitoring, and ICs.

\subsubsection{Alternative 4a-4-Acre Partial Retrieval, Treatment, and Disposal}

Alternative 4a is the partial RTD alternative defined in the Second Addendum (Holdren and Broomfield 2004), with one minor deviation relating to Pad A. Because it would be technically impracticable to segregate the very small amount of potentially transuranic waste on Pad A from other waste streams, segregation was eliminated from analysis. Alternative $4 \mathrm{a}$ is assembled from multiple general response actions that, when implemented as a comprehensive remedy, would satisfy remedial action objectives. This alternative comprises the following general response actions:

- $\quad$ Retrieval-Alternative 4a would retrieve targeted waste (i.e., Series 741 sludge, Series 743 sludge, graphite, filters, and roaster oxides) from pit areas totaling 4 acres and all waste from Pad A. Waste would be retrieved using a standard excavator modified for use in a contaminated environment. Waste-retrieval operations would be conducted within fabric enclosures equipped with HEPA-filtered ventilation systems.

- $\quad$ Ex situ treatment-Most waste retrieved from SDA pit areas would be transferred to the Waste Isolation Pilot Plant (WIPP) for disposal; treatment would not be required. For disposal at WIPP, waste must meet WIPP waste acceptance criteria. Note that, unlike other off-INL Site disposal locations for mixed LLW streams, the WIPP Land Withdrawal Act of 1992 (Public Law 102-579, 1992) exempts WIPP from the requirement to satisfy RCRA land-disposal restrictions. Thus, WIPP waste acceptance criteria would be satisfied through visual examination, sorting, packaging, and 
assaying. Waste that fails gas-generation testing for transportation would be stored until a disposition path is determined by the Accelerated Retrieval Project. However, quantities of this waste type, if any, would be minor, and treatment cost is within the contingency applied to off-INL Site treatment and disposal. Roaster oxide waste from SDA pit areas and all waste from Pad A would be transferred to ICDF for treatment and disposal. Treatment would consist of mixing fines with grout and filling void spaces within boxes of debris with grout, in accordance with ICDF waste acceptance criteria.

- Disposal-Packaged waste, meeting WIPP waste acceptance criteria, would be certified for disposal at WIPP. Packaged roaster oxide waste and all waste from Pad A would be transferred to ICDF for disposal.

- Containment-An ET surface barrier, consisting primarily of a vegetated soil layer and a coarse rock layer, would be constructed over the SDA to minimize infiltration and to prevent biotic intrusion into contaminated media. Overall thickness of the barrier, coupled with long-term ICs, would preclude inadvertent human intrusion. The coarse rock layer would be passively vented through vent pipes to prevent buildup of landfill gases beneath the surface barrier. Dynamic compaction would be used before construction to minimize potential for future subsidence. Perimeter grading, cap armament, and surface barrier vegetation would be provided to mitigate erosion. Surveillance and maintenance, monitoring, and ICs would be maintained until discontinued through the CERCLA 5-year review process.

- Institutional controls-Active and passive controls would be implemented to prevent or limit access to the SDA. Institutional controls would include restrictions on groundwater use (e.g., well-drilling restrictions), restrictions on land use (e.g., limit to industrial applications), and physical security.

Groundwater, vadose zone, and radiological surface monitoring (described under Alternative 1) as well as surveillance for subsidence and animal intrusion also would be performed. The following subsections provide detailed descriptions of Alternative 4a, including scope, process, and schedule.

3.4.1.1 Remedial Action Scope. Targeted waste would be removed from pit areas totaling 4 acres. Pad A waste would be removed from the SDA and sent to ICDF for treatment and disposal. Dynamic compaction would be applied in pit disposal areas to provide a stable foundation for surface barrier construction. Finally, an ET surface barrier would be constructed to contain contaminants remaining in the SDA and to achieve source control.

Figure 3-16 identifies hypothetical waste retrieval locations for Alternative 4a; these locations enclose areas that bound the uncertainties implicit in historical disposal records (i.e., recorded locations plus surrounding buffer areas). Waste types evaluated for removal are identical to targeted waste types for the Accelerated Retrieval Project (i.e., Series 741 sludge, Series 743 sludge, graphite, filters, and roaster oxides). Retrieval of these waste types would remove some of the radiological groundwater COCs and a larger portion of the nonradiological groundwater COCs from the SDA. Risk associated with surface exposure COCs would be mitigated by the ET surface barrier included with Alternative 4a. Tables 1-1 and 1-2 list radiological and nonradiological COCs, respectively. 


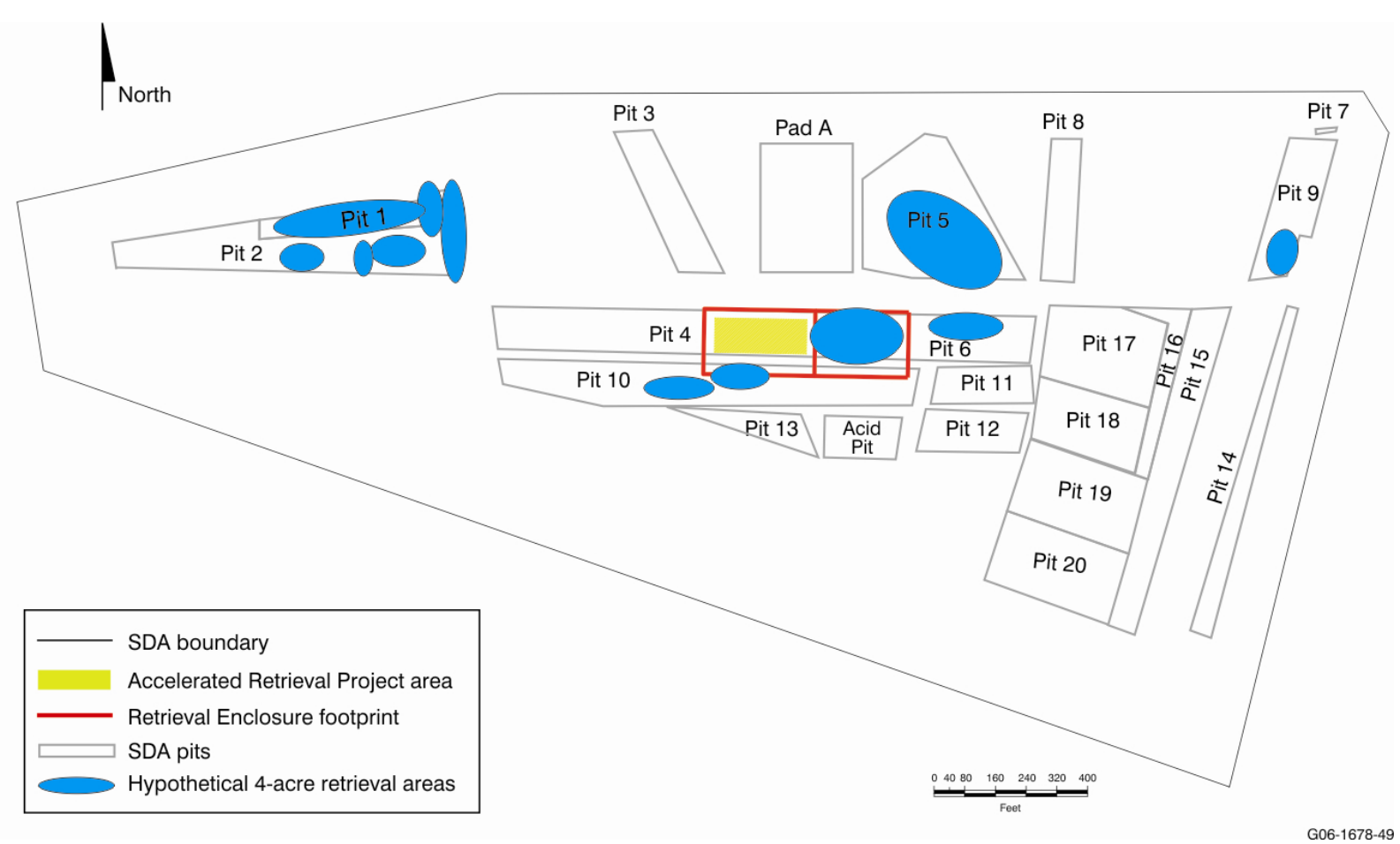

Figure 3-16. Hypothetical retrieval locations for Alternative 4a-4-Acre Partial Retrieval, Treatment, and Disposal.

After retrieval of targeted waste from pit areas and all waste from Pad A, pit areas would be dynamically compacted to address subsidence. An ET surface barrier with a biointrusion and gas vent layer would be constructed over the entire SDA to achieve the following:

- Minimize infiltration into and through waste remaining in the SDA

- $\quad$ Prevent vapor buildup within the surface barrier

- Inhibit plant and animal intrusion into contaminated media

- $\quad$ Maintain performance for 1,000 years (Mattson et al. 2004).

Alternative 4a would provide active and passive controls to prevent or limit access to the SDA because unrestricted land use is expected to be prohibited in future 5-year reviews. Institutional controls for Alternative 4a would include restrictions on groundwater use (e.g., well-drilling restrictions), restrictions on land use (e.g., limit to industrial applications), and physical security. Long-term activities would include environmental monitoring (e.g., groundwater, vadose zone, and surface) and surface barrier surveillance (e.g., animal intrusion, subsidence, and vegetation growth).

3.4.1.2 Remedial Action Process. Alternative 4a (4-Acre Partial RTD) involves removing all Pad A waste and specific waste types from pit areas totaling 4 acres, and placing a surface barrier over the entire SDA. Figure 3-17 illustrates the general process. Pad A waste would be excavated and shipped to ICDF for treatment and disposal. All SDA pit areas would be dynamically compacted to provide a stable foundation for surface barrier construction. Finally, contaminants remaining in the SDA would be contained by an ET surface barrier (i.e., achieve source control). Surface barrier maintenance, surveillance, monitoring, and ICs would be maintained until discontinued through the CERCLA 5-year review process. 


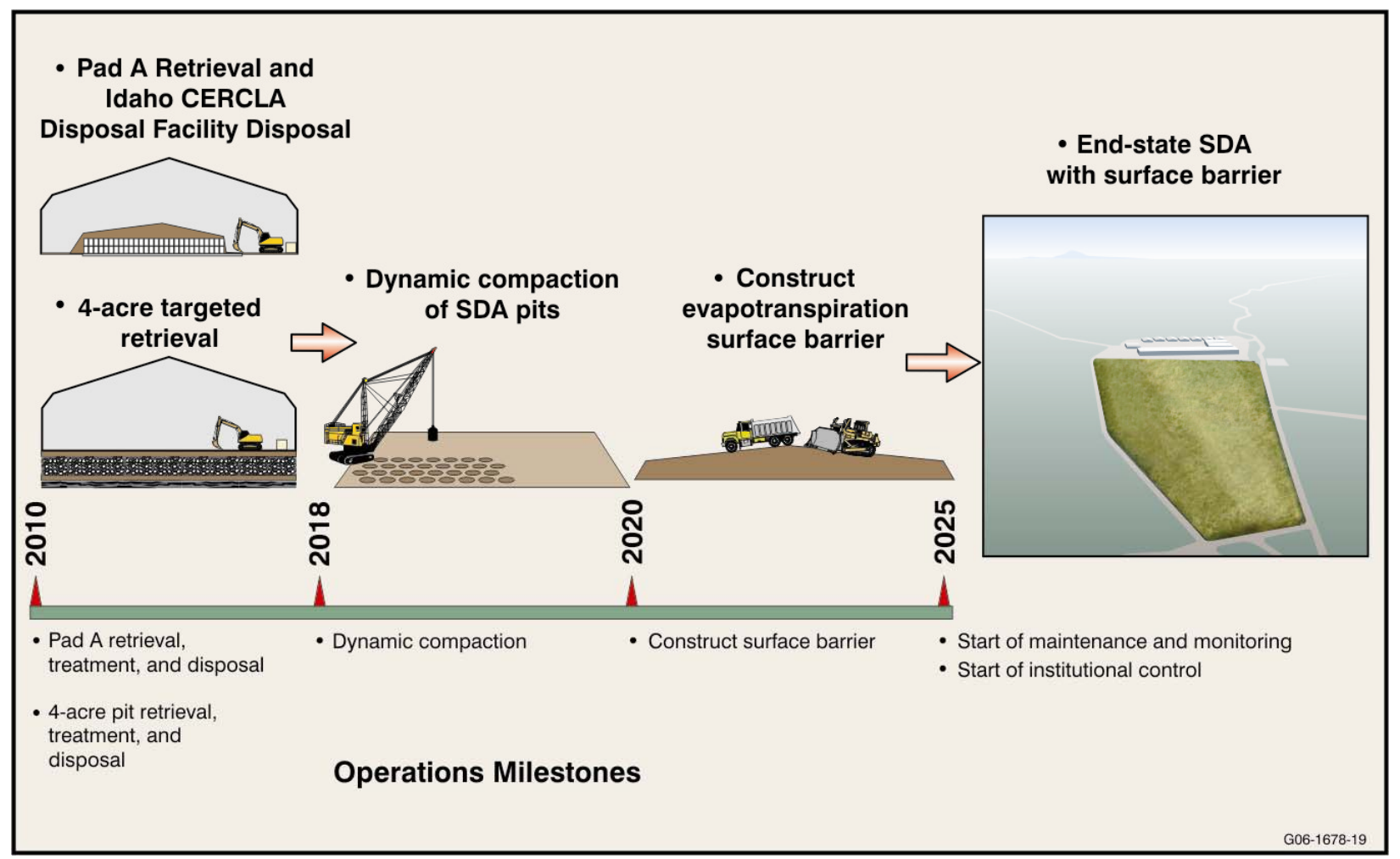

Figure 3-17. Process flow diagram for Alternative 4a-4-Acre Partial Retrieval, Treatment, and Disposal.

3.4.1.3 Remedial Action Components. The following paragraphs describe the technical approach, equipment, and construction details for remedial action components included in Alternative 4a.

Existing OCVZ extraction wells, treatment units, and sample ports for this alternative are as described for Alternative 2a.

Site preparation for the 4-acre alternative would start with a land survey of the SDA retrieval locations followed by construction of access roads and associated ground contouring for site drainage and new building foundations. A $73-\mathrm{m}(240-\mathrm{ft})$ extension would be added to the existing Accelerated Retrieval Project Retrieval Enclosure. As shown on Figure 3-18, modifications to the existing Retrieval Enclosure include building a new extension onto the eastern end of the existing enclosure and removing half the existing enclosure and an attached equipment maintenance bay airlock. The adjoining wall between the two enclosures would be removed to form a single retrieval enclosure with two attached airlocks, housing multiple drum packaging stations. Additional site-preparation activities within the enclosure would include cutting probes off at ground level and treating the top layer of soil with a polymer to create a durable, dust-free surface.

Three smaller (i.e., $33.5 \times 30.5 \mathrm{~m}[110 \times 100 \mathrm{ft}])$ retrieval tents also would be constructed during this period. These smaller tents would be designed for dragging between locations. Each tent would include a filtered exhaust system and two detachable waste transport containers. Site preparation also would involve preparing an existing staging area to facilitate movement of packaged waste from the retrieval enclosure to the final disposal area. 


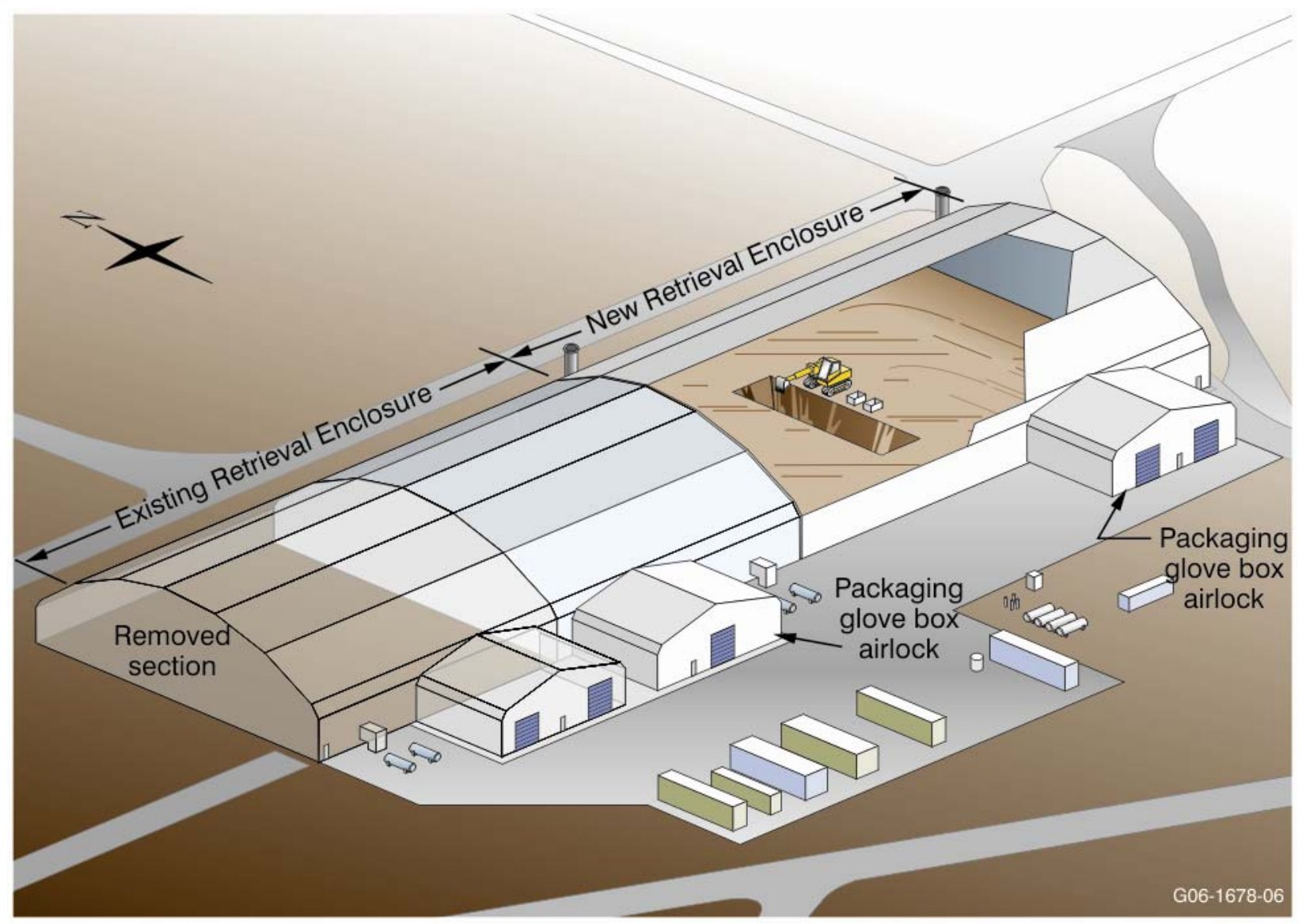

Figure 3-18. Modifications to the existing Accelerated Retrieval Project Retrieval Enclosure for Alternative 4a-4-Acre Partial Retrieval, Treatment, and Disposal.

As shown on Figure 3-19, retrieval of targeted waste (i.e., Series 741 sludge, Series 743 sludge, graphite, filters, and roaster oxides) would be performed within the large, centrally located retrieval enclosure and within the three smaller mobile tent structures, using excavators modified for operation within a contaminated environment, dust-suppression capabilities, and camera optics. An operator at or near the dig face would determine whether waste is targeted or nontargeted. Following waste determination, nontargeted waste would be returned to the exhumation area while targeted waste would be retrieved. Retrieved waste would be transported (inside cargo containers) to the centrally located retrieval enclosure, loaded into WIPP-certified drums within the drum packaging station (see Figure 3-20), and assayed to verify that the fissile gram loading is less than 380 fissile gram equivalents. Drums measuring less than 380 fissile gram equivalents would be transported to an existing SDA staging area, while drums measuring greater than 380 fissile gram equivalents would require special precautions and staging requirements for criticality safety. 


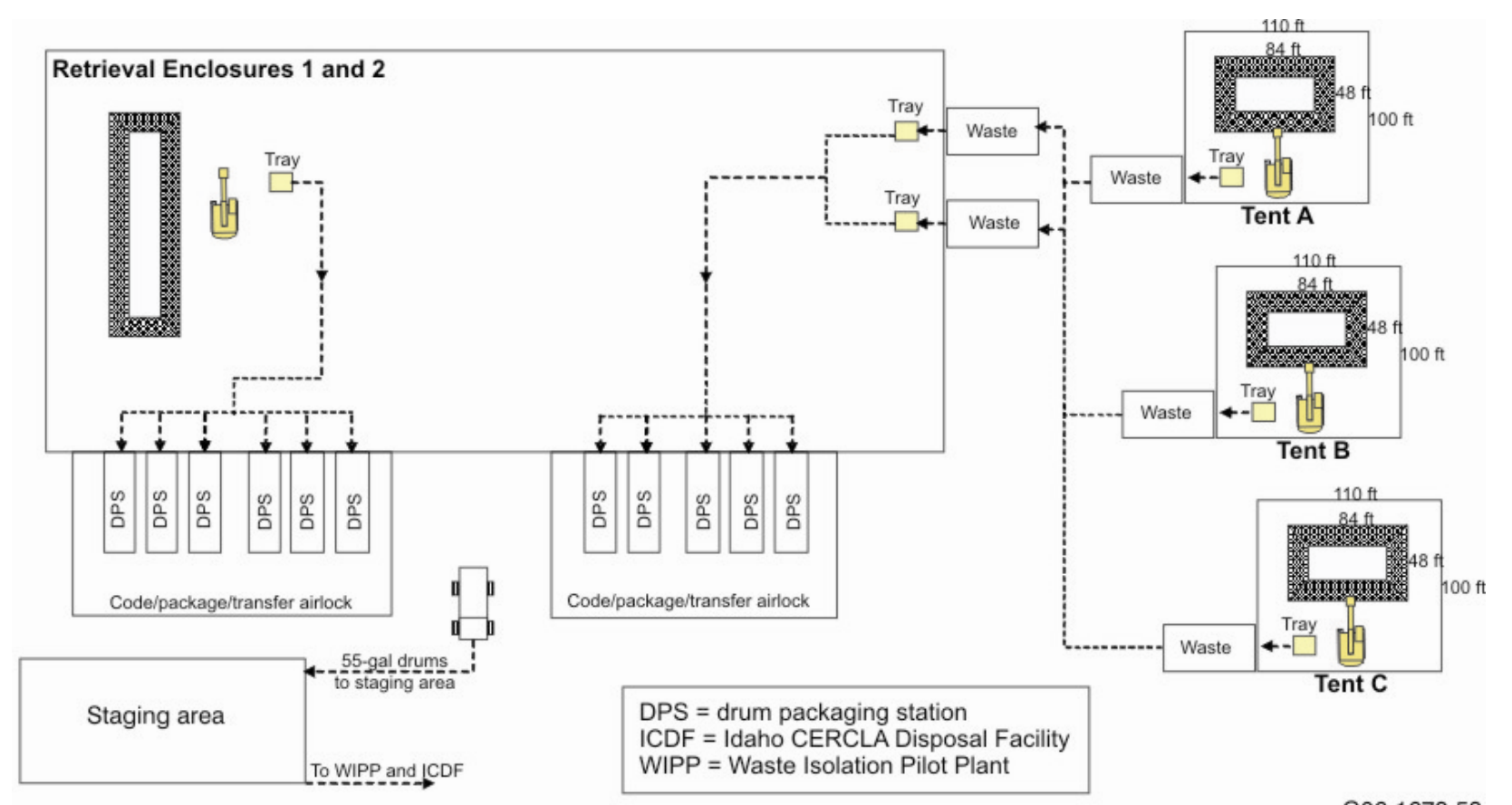

Figure 3-19. Plan view of partial retrieval process for Alternative 4a-4-Acre Partial Retrieval, Treatment, and Disposal.

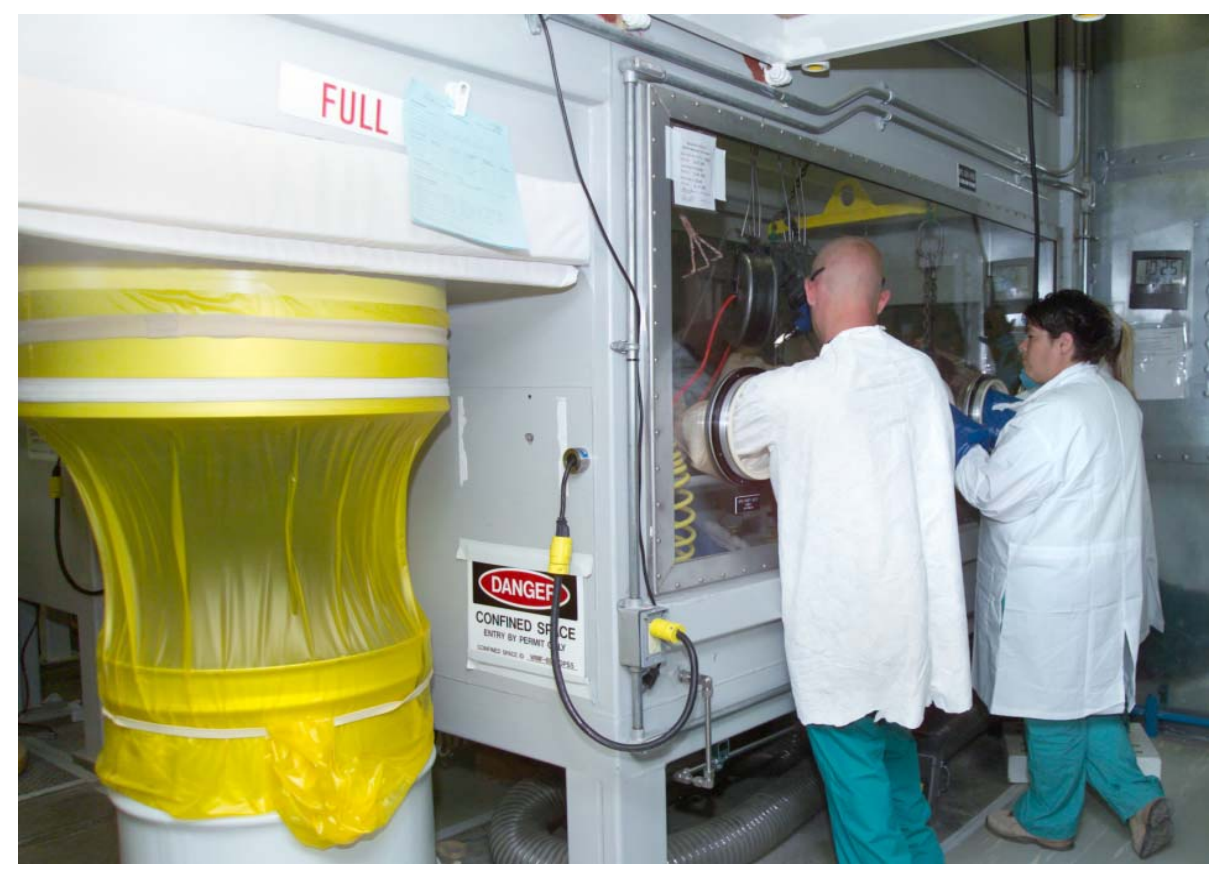

Figure 3-20. Drum packaging system within the Accelerated Retrieval Project. 
Drums containing roaster oxides would be extracted from the staging area and transferred to ICDF for treatment and disposal. Drums containing all other waste types would be processed for shipment to WIPP. Processing for WIPP involves assaying to measure transuranic concentrations and headspace gas sampling for hydrogen, methane, and volatile organic gases. Depending on sampling results, gas-generation testing also may be required. Gas-generation testing involves placing a vented drum inside a heated and vented canister. Heat would be applied, and vapors would be collected and analyzed. If hydrogen or flammable VOC concentrations exceed the limits, the drum would be removed from the canister, packaged, and stored until a disposition path is determined by the Accelerated Retrieval Project. However, quantities of this waste type, if any, would be minor, and treatment cost is within the contingency applied to off-INL Site treatment and disposal. After headspace gas sampling and, potentially, gas-generation testing, waste drums would be loaded into transuranic package containers and transported to WIPP.

Figure 3-21 illustrates the process that would be used for removing waste from Pad A for transfer to ICDF. After removing clean soil that currently surrounds Pad A waste, the entire area of Pad A would be enclosed with a modular structure (separate from the three mobile structures and one large structure used for previously defined SDA pit retrievals) to provide weather protection and to confine airborne contaminants, similar to the process used for the Accelerated Retrieval Project. Excavation equipment (modified for operation within a contaminated environment and modified for dust-suppression capabilities) would be used to transfer Pad A waste to a sorting table where waste would be segregated by size into fines and debris. Segregated waste then would be moved to standard waste box packaging stations and loaded into boxes for shipment to ICDF. Pad A waste would be held in a temporary staging area pending transport to ICDF for stabilization and disposal in accordance with ICDF waste acceptance criteria.

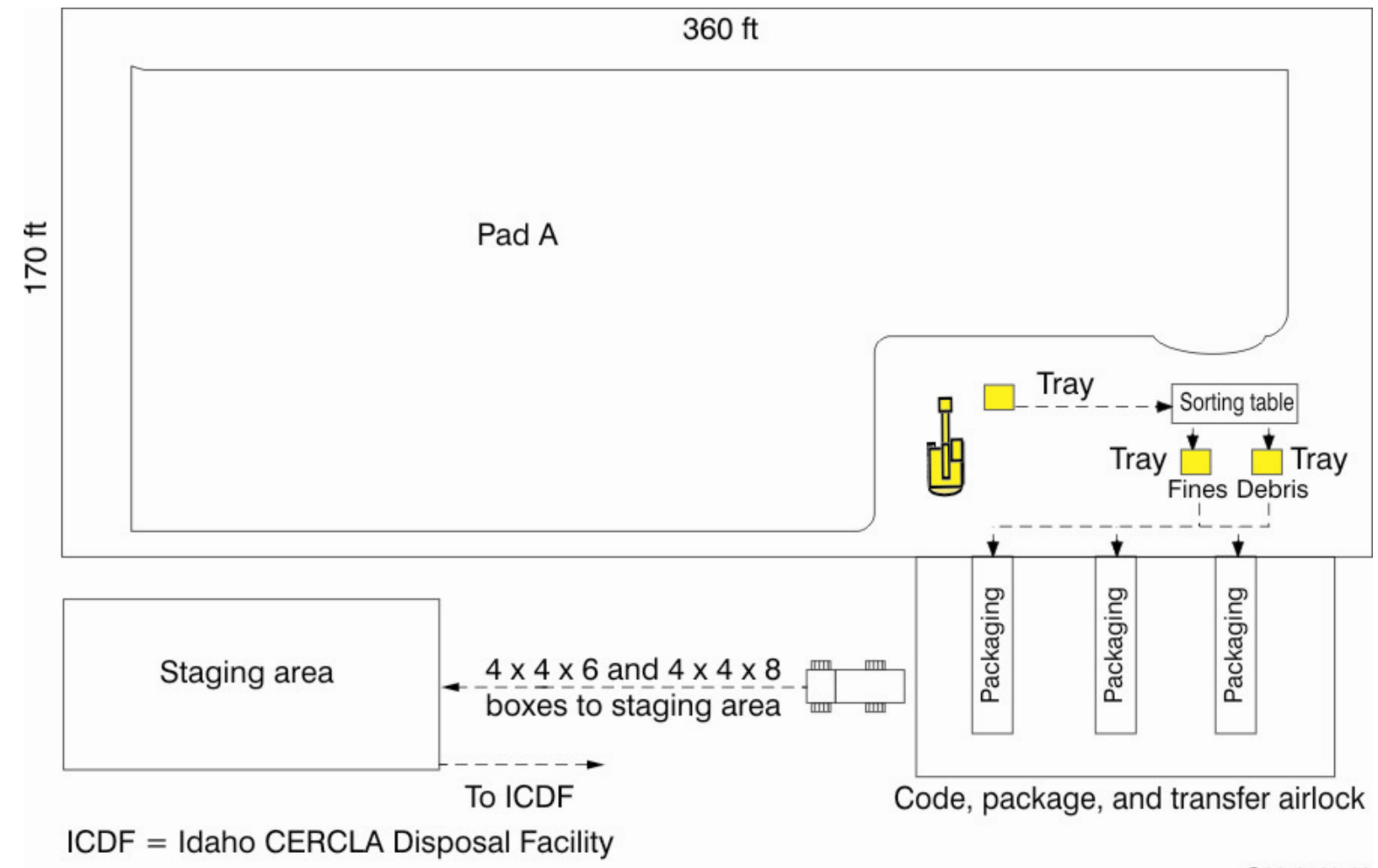

G06-1760-12

Figure 3-21. Waste moved from Pad A to the Idaho CERCLA Disposal Facility for treatment and disposal for Alternative 4a-4-Acre Partial Retrieval, Treatment, and Disposal. 
After retrieving and disposing of specified belowground (i.e., from pit areas totaling 4 acres) and aboveground (i.e., Pad A) waste, equipment would be demobilized, and the retrieval enclosure, mobile tent structures, and associated infrastructure would be dismantled. The SDA then would be covered by an ET surface barrier. Figure 3-6 presents a cross section of an ET surface barrier. The primary component of any ET surface barrier is a vegetated fine-grained soil layer that retains infiltrated water until it is removed by evaporation and transpiration (Dwyer 1997). Section 3.2.2 describes the ET surface barrier

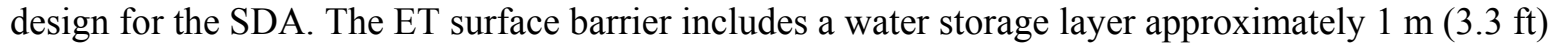
thick. Mattson et al. (2004) defined this thickness as optimal for SDA site-specific conditions (i.e., thick enough to accommodate storage of water while the plants are dormant, yet thin enough to be compatible with the expected root dynamics of the vegetative community). The soil layer also incorporates a gravel admixture in the topsoil for erosion control.

The secondary component of the ET surface barrier would be a layer of coarse rock beneath the vegetated soil layer. Note that layers of gravel and sand would be placed between the fine-grained soil and the coarse rock layers to minimize filtering of soil into the coarse rock layer. The first function of this layer would be to deter animals from burrowing into the underlying waste and potentially bringing contamination to the surface. The second function of the coarse rock layer would be to provide a means of venting to prevent buildup of landfill gases (e.g., C-14, carbon tetrachloride, and methylene chloride). The coarse rock layer also would create a capillary barrier that would tend to decrease the flow of water through the surface barrier and create a dry barrier (Ankeny et al. 1997), further inhibiting downward growth of plant roots. Piping would be installed within this coarse rock layer to allow passive venting of volatile contaminants to the atmosphere.

Construction of the surface barrier would be accomplished in a series of steps, including preparing the foundation and infrastructure and emplacing surface barrier materials and vegetation. Preparing the foundation would be a critical construction activity. Differential settlement occurs routinely at the SDA. While ET surface barriers are, by design, less susceptible to differential settlement, construction techniques that minimize future subsidence ultimately would reduce maintenance requirements for the surface barrier. In Alternative 4a, differential settlement would be mitigated by dynamically compacting SDA pit areas (described in Section 3.2.2.3) prior to placing surface barrier materials. This technology was identified because it presents the highest short-term risk and cost among process options that apply surface treatment, thus bounding the analysis. Other process options (e.g., impact rolling) could be substituted during remedial design. In addition, routine inspections and subsidence repair would be performed after construction is complete.

Existing infrastructure (i.e., utilities and monitoring equipment) at the SDA would be abandoned, relocated, or reconfigured to accommodate construction. Activities to be performed prior to surface barrier construction include:

- Install a temporary water storage tank

- $\quad$ Construct a new perimeter access road

- Install a new perimeter fence (including demolishing the old one)

- $\quad$ Abandon half the 50 existing monitoring wells (i.e., 25)

- Double the current network of 50 advanced tensiometers to monitor surface barrier performance (i.e., 100)

- $\quad$ Relocate the three existing OCVZ treatment units to an area outside the future surface barrier perimeter 
- $\quad$ Extend (upward through the surface barrier) 18 OCVZ wells, 100 advanced tensiometers, and 25 monitoring wells.

After preparing the subgrade and removing surface infrastructure, soil and rock material would be hauled to the SDA from local borrow sources. The ET surface barrier could be constructed in a phased approach where it could be substantially completed over sections of the SDA at one period of time, while other areas would be covered at a later date. Such an approach could be used to accommodate ongoing landfill operations or other remediation activities (e.g., the Accelerated Retrieval Project retrieval).

Three additional construction activities follow surface barrier completion. First, the existing OCVZ wells would extend into the air following completion of the barrier. Connecting these wells to the relocated OCVZ treatment units would be required for continued operation of the OCVZ system. The second and third construction activities involve installing six additional sampling wells outside the barrier perimeter and contouring the southern and eastern ends of the SDA for drainage.

Following the construction phase of Alternative 4a, long-term surveillance, maintenance, monitoring, and ICs would be conducted to enforce land-use restrictions and ensure effectiveness of the completed surface barrier. Surveillance and maintenance would include inspecting and repairing the surface barrier and peripheral components (e.g., fences and signs) to address observable degradation (e.g., subsidence, erosion, loss of vegetative cover, and biotic intrusion). Monitoring would include collecting samples and analyzing data from the vadose zone (i.e., soil moisture, soil vapor, perched water, and changes in moisture content) and from the aquifer. In addition, the INL Sitewide monitoring program would conduct radiological monitoring of air, surface water, surface soil, and biota. Active and passive ICs would include access restrictions, restrictions on groundwater use (e.g., well-drilling restrictions), restrictions on land use (e.g., limit to industrial applications), and physical security.

3.4.1.4 Remedial Action Schedule. Figure 3-22 provides a summary schedule for Alternative 4a, based on a hypothetical start date in year 2010. Modules 3, 6, 8, 13, 16, and 20 (see Appendix F) provide a detailed schedule of each activity. The OCVZ system would operate throughout construction. Because release of VOCs from unretrieved waste depends on the rate of diffusion from intact waste packages, the OCVZ system would operate for an additional 19 years after completion of the surface barrier to achieve preliminary remediation goals for the vadose zone and aquifer. For comparison, OCVZ system operational timeframes (required to achieve preliminary remediation goals for the vadose zone and aquifer) were based on the assumption that instantaneous remediation occurred in year 2010 . (Section 4.1.3 and Appendix D provide further detail.) Operations and maintenance would start at surface barrier completion and would include groundwater monitoring, vadose zone monitoring, other environmental monitoring, surface barrier surveillance (e.g., monitoring vegetation growth, subsidence, and animal intrusion), and maintenance (e.g., subsidence repair). Periodic costs would parallel the operation and maintenance schedule and would include a remedial action report, an annual summary report, 5-year reviews, and a final operations and maintenance report. 


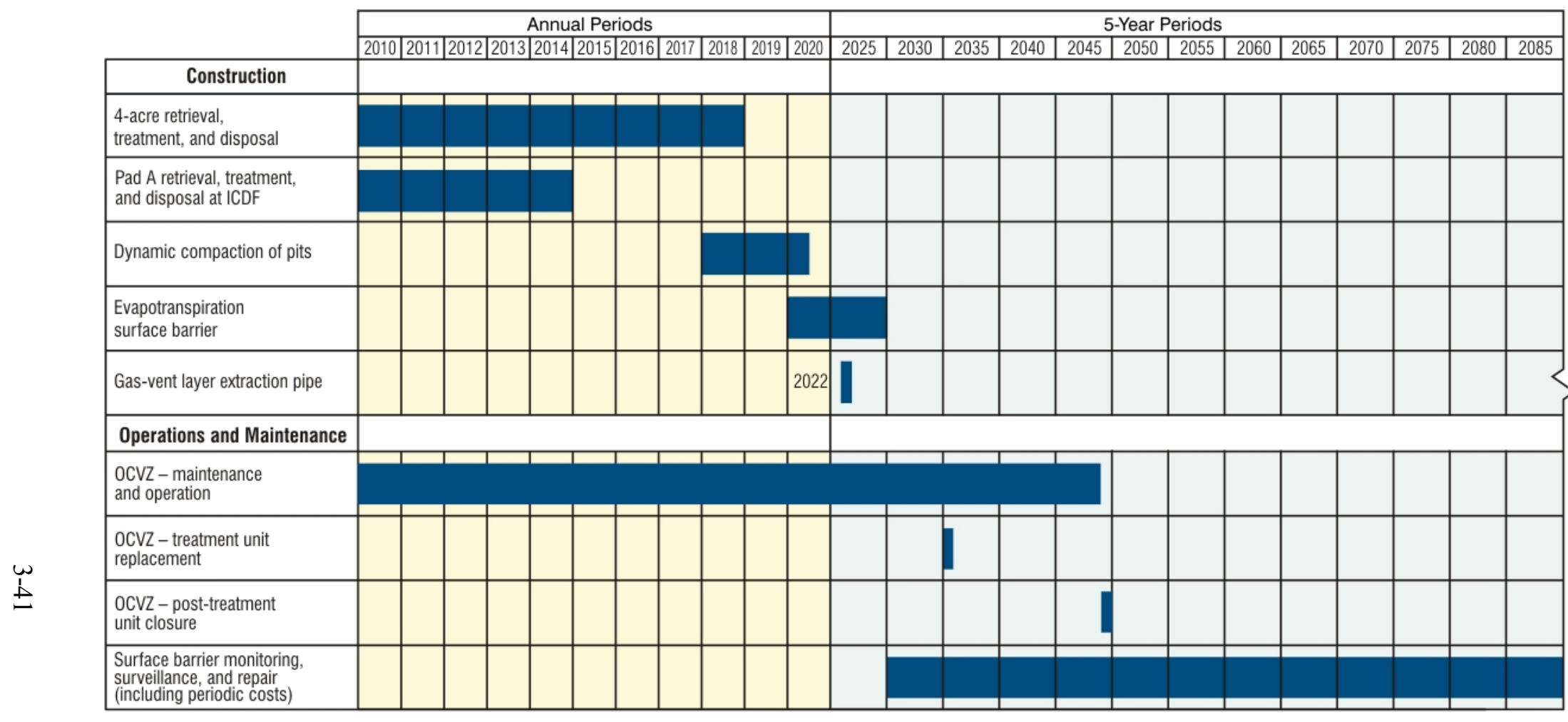

ICDF = Idaho CERCLA Disposal Facility

$\mathrm{OCVZ}=$ Organic Contamination in the Vadose Zone Project

Figure 3-22. Summary schedule for Alternative 4a-4-Acre Partial Retrieval, Treatment, and Disposal.

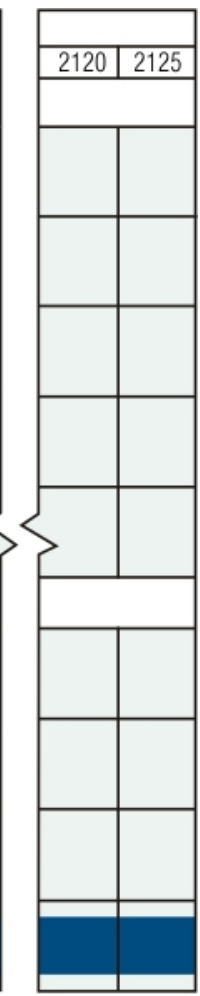




\subsubsection{Alternative 4b-2-Acre Partial Retrieval, Treatment, and Disposal}

Alternative $4 \mathrm{~b}$ is assembled from multiple general response actions, which, when implemented as a comprehensive remedy, would satisfy remedial action objectives. This alternative comprises the following general response actions:

- $\quad$ Retrieval-Alternative 4b would retrieve targeted waste (i.e., Series 741 sludge, Series 743 sludge, graphite, filters, and roaster oxides) from SDA pit areas totaling 2 acres. Waste would be retrieved using a standard excavator modified for use in a contaminated environment. Waste-retrieval operations would be conducted within fabric enclosures equipped with HEPA-filtered ventilation systems.

- $\quad$ Ex situ treatment-Most waste retrieved from SDA pit areas would be transferred to WIPP for disposal; treatment would not be required. For disposal at WIPP, waste must meet WIPP waste acceptance criteria. Note that, unlike other off-INL Site disposal locations for mixed LLW streams, the WIPP Land Withdrawal Act of 1992 (Public Law 102-579, 1992) exempts WIPP from the requirement to satisfy RCRA land disposal restrictions. Thus, WIPP waste acceptance criteria would be met through visual examination, sorting, packaging, and assaying. Waste that fails gas-generation testing for transportation would be stored until a disposition path is determined by the Accelerated Retrieval Project. However, quantities of this waste type, if any, would be minor, and treatment cost is within the contingency applied to off-INL Site treatment and disposal. Packaged roaster oxide (uranium oxide) waste from SDA pit areas would be transferred to ICDF for treatment and disposal.

- Disposal-Contact-handled waste would be removed to glove boxes for visual characterization and packaging. Packaged waste, meeting WIPP waste acceptance criteria, would be certified for disposal at WIPP. Packaged roaster oxide waste would be transferred to ICDF for treatment and disposal.

- $\quad$ Containment-An ET surface barrier, consisting primarily of a vegetated soil layer and a coarse rock layer, would be constructed over the SDA to minimize infiltration and to prevent biotic intrusion into contaminated media. Overall thickness of the barrier, coupled with long-term ICs, would preclude inadvertent human intrusion. The coarse rock layer would be passively vented through vent pipes to prevent buildup of landfill gases beneath the surface barrier. Proof-rolling of SDA pit areas and dynamic compaction of Pad A would be implemented before construction to minimize potential for future subsidence. Alternative $4 \mathrm{~b}$ also includes construction of a soil-bentonite slurry wall inside the perimeter of the surface barrier. Perimeter grading, cap armament, and surface barrier vegetation would mitigate erosion. Vegetation growth, subsidence, and animal intrusion would be monitored, and the surface barrier would be maintained.

- Institutional controls-Active and passive controls would be implemented to prevent or limit access to the SDA. Institutional controls would include restrictions on groundwater use (e.g., well-drilling restrictions), restrictions on land use (e.g., limit to industrial applications), and physical security.

Groundwater, vadose zone, and radiological surface monitoring also would be performed. The following subsections provide detailed descriptions of Alternative $4 \mathrm{~b}$, including scope, process, and schedule. 
3.4.2.1 Remedial Action Scope. Targeted waste would be removed from pit areas totaling 2 acres. Pad A waste would be left in place, and dynamic compaction would be applied to mitigate future waste subsidence. During surface barrier construction, proof-rolling would be applied across the SDA to reduce the risk of waste zone subsidence. Finally, contaminants remaining in the SDA would be contained by construction of an ET surface barrier (i.e., achieve source control).

Figure 3-23 identifies hypothetical waste retrieval locations for Alternative 4b. Anecdotal information from ongoing operations at the Accelerated Retrieval Project suggests that targeted waste could be located, based on disposal records, with much more precision than originally anticipated. This reduced uncertainty in waste disposal locations allows for analysis of an optimized retrieval approach of smaller regions (totaling 2 acres) within the same areas (totaling 4 acres) evaluated in Alternative 4a. This optimized approach focuses retrieval on areas containing higher concentrations of targeted waste.

Retrieval of targeted waste in optimized areas minimizes short-term risk associated with waste handling, because less material is handled, while maximizing the objectives of waste removal by acquiring high concentrations of targeted waste. As retrieval expands over less-concentrated areas, diminishing returns are realized in removing targeted waste. Thus, Alternative $4 b$ (2-acre RTD) would remove more than half the targeted waste that Alternative $4 \mathrm{a}$ (4-acre RTD) would address.

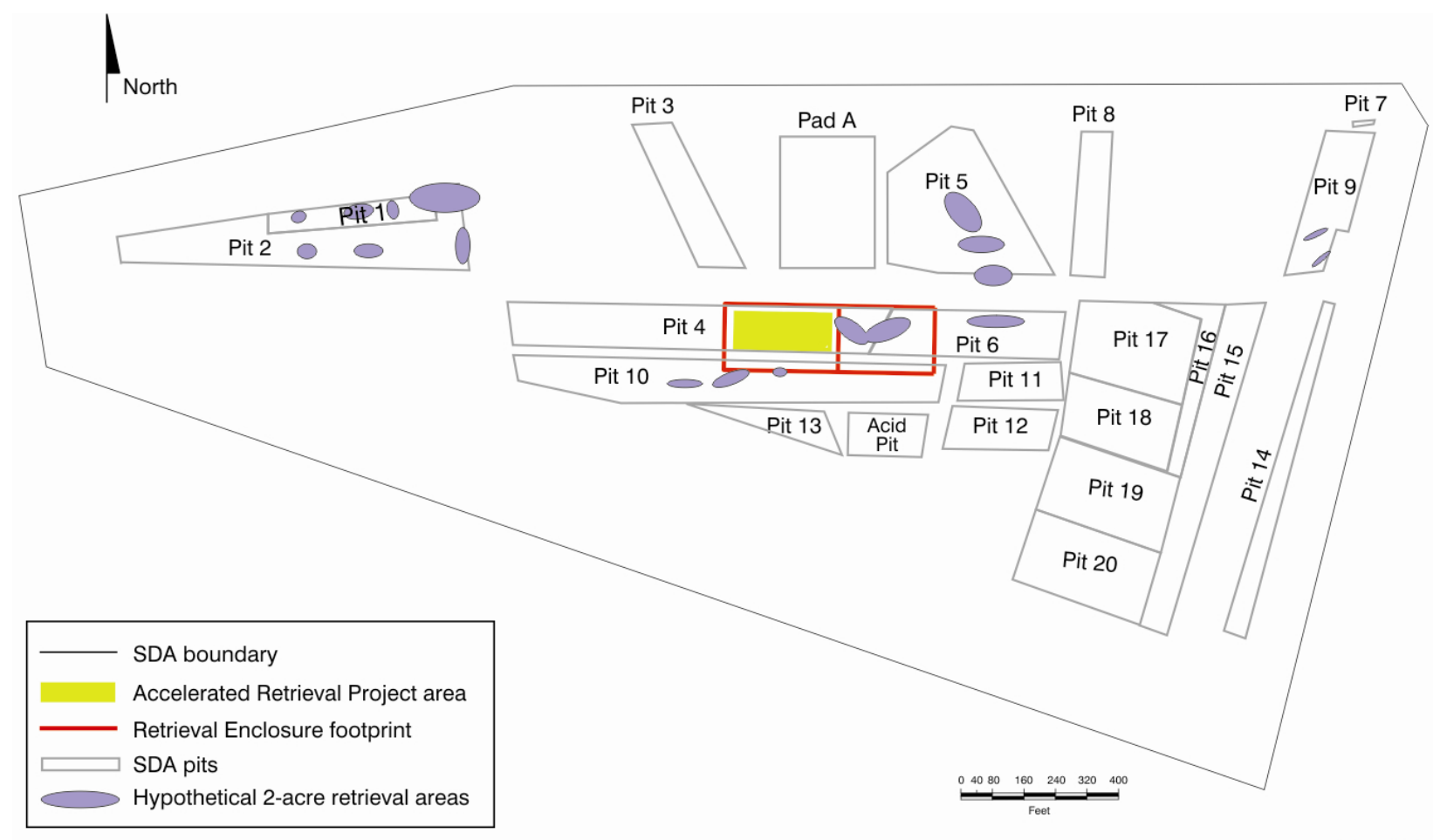

Figure 3-23. Hypothetical retrieval locations for Alternative 4b-2-Acre Partial Retrieval, Treatment, and Disposal. 
Waste types evaluated for removal are identical to targeted waste types for the Accelerated Retrieval Project (i.e., Series 741 sludge, Series 743 sludge, graphite, filters, and roaster oxides). Retrieval of these waste types would remove some of the radiological and nonradiological groundwater COCs. Risk associated with surface exposure COCs would be mitigated by the ET surface barrier included with Alternative 4b. Tables 1-1 and 1-2 list radiological and nonradiological COCs, respectively.

Slight differences in long-term effectiveness between Alternatives $4 \mathrm{a}$ and $4 \mathrm{~b}$ pertain to $\mathrm{Pad} \mathrm{A}-$ Alternative 4a transfers Pad A waste outside of the SDA, while Alternative 4b leaves Pad A in place. This aboveground waste pad contains approximately $50 \%$ of the nitrate and $17 \%$ of the U-238 in the SDA. Nitrate is a groundwater COC based on its potential to exceed the MCL, and U-238 is a secondary groundwater ingestion risk COC (see Section 1.4). Groundwater concentrations for Alternative 4b would be slightly more than for Alternative 4a, where Pad A would be removed completely from the SDA. However, differences are so slight as to be nearly indiscernible at the scales presented on groundwater concentration and risk graphs (see Appendix D).

After retrieval of targeted waste, an ET surface barrier with a biointrusion and gas vent layer would be constructed over the entire SDA to achieve the following:

- $\quad$ Minimize infiltration into and through contaminated media remaining in the SDA

- $\quad$ Prevent vapor buildup within the surface barrier

- Inhibit plant and animal intrusion into the remaining waste

- $\quad$ Maintain performance for 1,000 years (Mattson et al. 2004).

Pad A waste would be left in place and dynamically compacted to mitigate subsidence.

Proof-rolling would be applied across the SDA to mitigate the risk of waste zone subsidence after surface barrier construction. Dynamic compaction of Pad A, proof-rolling before surface barrier construction, and construction of a soil-bentonite slurry cut-off wall would not contribute directly to meeting remedial action objectives for the SDA.

Alternative $4 \mathrm{~b}$ would provide active and passive controls to prevent or limit access to the SDA because unrestricted land use is expected to be prohibited in future 5-year reviews. Institutional controls for Alternative $4 \mathrm{~b}$ include restrictions on groundwater use (e.g., well-drilling restrictions), restrictions on land use (e.g., limit to industrial applications), and physical security. Long-term monitoring activities would include environmental monitoring (e.g., groundwater and vadose zone), radiological surface monitoring, and surface barrier surveillance (e.g., animal intrusion, subsidence detection, and vegetation growth).

3.4.2.2 Remedial Action Process. Alternative $4 \mathrm{~b}$ involves removing specific waste types from pits areas totaling 2 acres and placing a surface barrier over the entire SDA. Figure 3-24 illustrates the general process. Pad A waste would be dynamically compacted to minimize the potential for future subsidence. Specific waste types would be retrieved and shipped to ICDF or WIPP for treatment and disposal. A subsurface bentonite slurry wall would be installed around the perimeter of the SDA. Proof-rolling would be applied to pit disposal areas to provide a stable foundation for surface barrier construction. Finally, contaminants remaining in the SDA would be contained by completion of an ET surface barrier (i.e., achieve source control). Surface barrier maintenance, surveillance, monitoring, and ICs would be maintained until discontinued through the CERCLA 5-year review process. 


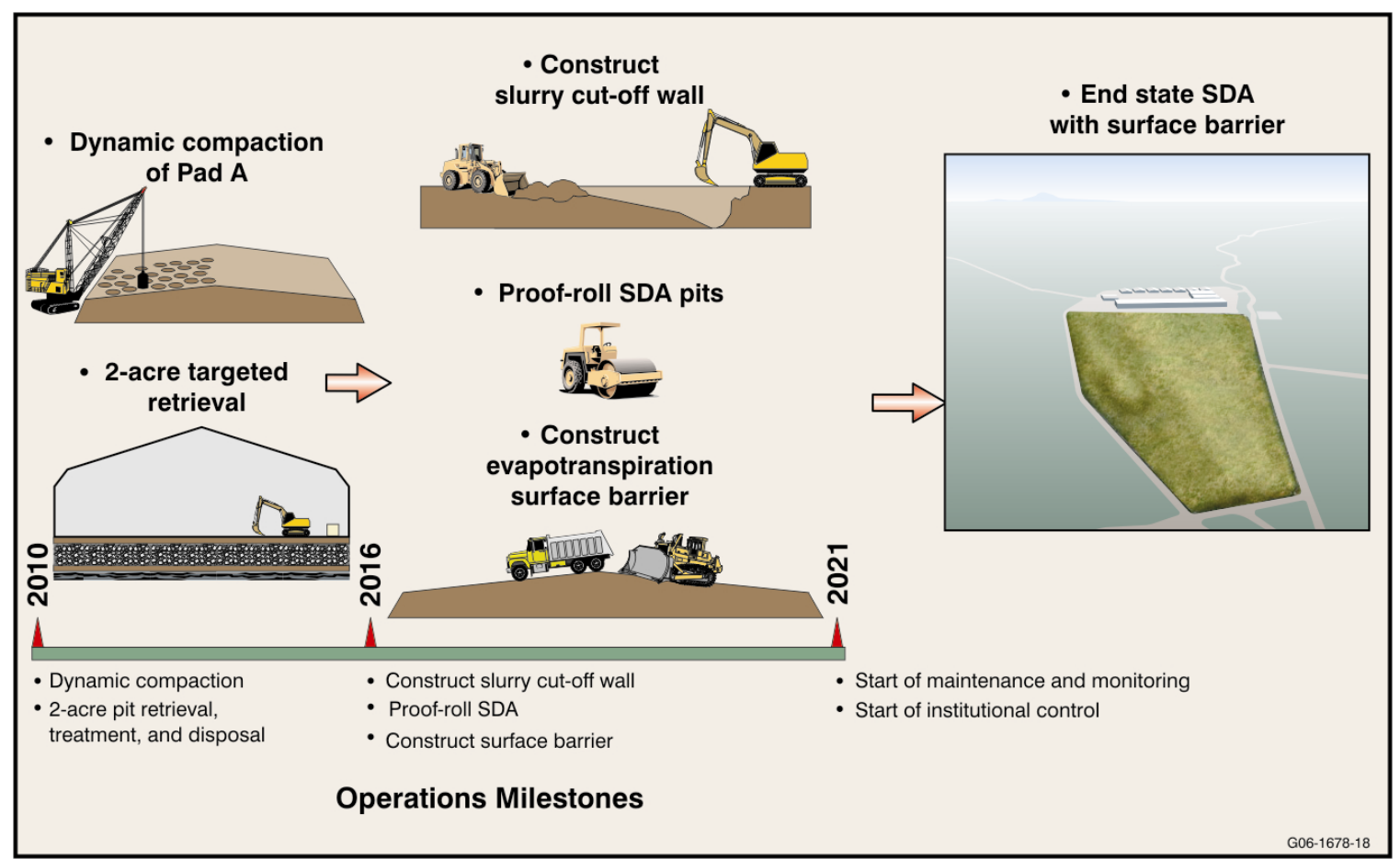

Figure 3-24. Process flow diagram for Alternative 4b-2-Acre Partial Retrieval, Treatment, and Disposal.

3.4.2.3 Remedial Action Components. The following paragraphs describe the technical approach, equipment, and construction details for remedial action components included in Alternative $4 \mathrm{~b}$.

Existing OCVZ extraction wells, treatment units, and sample ports for this alternative are identical to those of Alternative $2 \mathrm{a}$.

Design, mobilization, site preparation, readiness demonstration, remediation, demobilization, and reporting for the 2-acre alternative are identical to those mentioned in the 4-acre alternative (see Section 3.4.1). Discriminating factors between Alternatives $4 \mathrm{a}$ and $4 \mathrm{~b}$ include the total area for targeted waste retrieval, Pad A management, foundation preparation techniques, and construction of a belowgrade perimeter slurry grout wall. Figure 3-23 shows hypothetical retrieval locations, which are smaller regions within the same locations evaluated for the 4-acre partial RTD alternative described in Section 3.4.1. Anecdotal information from ongoing operations at the Accelerated Retrieval Project suggests that targeted waste could be located based on disposal records with much more precision than originally anticipated. This reduced uncertainty in waste disposal location allows for analysis of an optimized retrieval approach.

Alternative $4 \mathrm{~b}$ also includes construction of a continuous slurry wall around the perimeter of the SDA. The slurry wall was retained and included in assembled Alternative $4 \mathrm{~b}$ so that a cost estimate module would be available if this action was required in the proposed plan. In general, slurry walls are constructed in a two-step process. First, a trench would be excavated, and bentonite slurry would be placed in the trench to maintain trench stability. Next, the trench would be excavated to the designated depth and width, and a permanent backfill material - comprising bentonite slurry mixed with excavated soil - would be placed back in the trench, displacing the slurry and forming a hydraulic barrier. 
After retrieving targeted waste and constructing the slurry wall, the entire SDA would be covered by an ET surface barrier. The ET surface barrier preconceptual design for this alternative-including work performed before and after surface barrier construction (e.g., road, fence, wells, treatment unit transfer, and contouring) - is identical to that of Alternative 4a, except for foundation preparation. Preparing the foundation would be a critical construction activity. Differential settlement occurs routinely at the SDA. While ET barriers are, by design, less susceptible to differential settlement, construction techniques that minimize future subsidence ultimately would reduce maintenance requirements for the surface barrier. In Alternative $4 \mathrm{~b}$, differential settlement would be mitigated by dynamically compacting $\mathrm{Pad} \mathrm{A}$ and by proof-rolling pit areas of the SDA before emplacing surface barrier materials. Dynamic compaction of Pad A was chosen because it presents the highest short-term risk and cost among process options that apply surface treatment, thus bounding the analysis. Other process options (e.g., impact rolling) could be substituted during remedial design. The surface barrier perimeter toe would tie into the preinstalled perimeter slurry wall.

Following the construction phase of Alternative 4b, long-term surveillance, maintenance, monitoring, and ICs would be conducted to enforce land-use restrictions and ensure effectiveness of the completed surface barrier. Surveillance and maintenance would include inspecting and repairing the surface barrier and peripheral components (e.g., fences and signs) to address observable degradation (e.g., subsidence, erosion, loss of vegetative cover, and biotic intrusion). Monitoring would include collecting samples and analyzing data from the vadose zone (i.e., soil moisture, soil vapor, perched water, and changes in moisture content) and from the aquifer. In addition, the INL Sitewide monitoring program would conduct radiological monitoring of air, surface water, surface soil, and biota. Active and passive ICs would include access restrictions, restrictions on groundwater use (e.g., well-drilling restrictions), restrictions on land use (e.g., limit to industrial applications), and physical security.

3.4.2.4 Remedial Action Schedule. Figure 3-25 provides a summary schedule for Alternative 4b based on a hypothetical start date in year 2010. Modules 1, 2, 3, 6, 9, 12, and 20 (see Appendix F) provide a detailed schedule of each activity. The OCVZ system would operate throughout construction. Because release of VOCs from unretrieved waste is dependent on the rate of diffusion from intact waste packages, the OCVZ system would operate for an additional 23 years after completion of the surface barrier to achieve preliminary remediation goals for the vadose zone and aquifer. For comparison, OCVZ operational timeframes (required to achieve preliminary remediation goals for the vadose zone and aquifer) were based on the assumption that instantaneous remediation occurred in year 2010.

(Section 4.1.3 and Appendix D provide further detail.) Operations and maintenance would start at surface barrier completion and would include groundwater monitoring, vadose zone monitoring, other environmental monitoring, surface barrier surveillance (e.g., monitoring vegetation growth, subsidence, and animal intrusion), and maintenance (e.g., subsidence repair). Periodic costs would parallel the operation and maintenance schedule and would include a remedial action report, an annual summary report, 5-year reviews, and a final operations and maintenance report. 


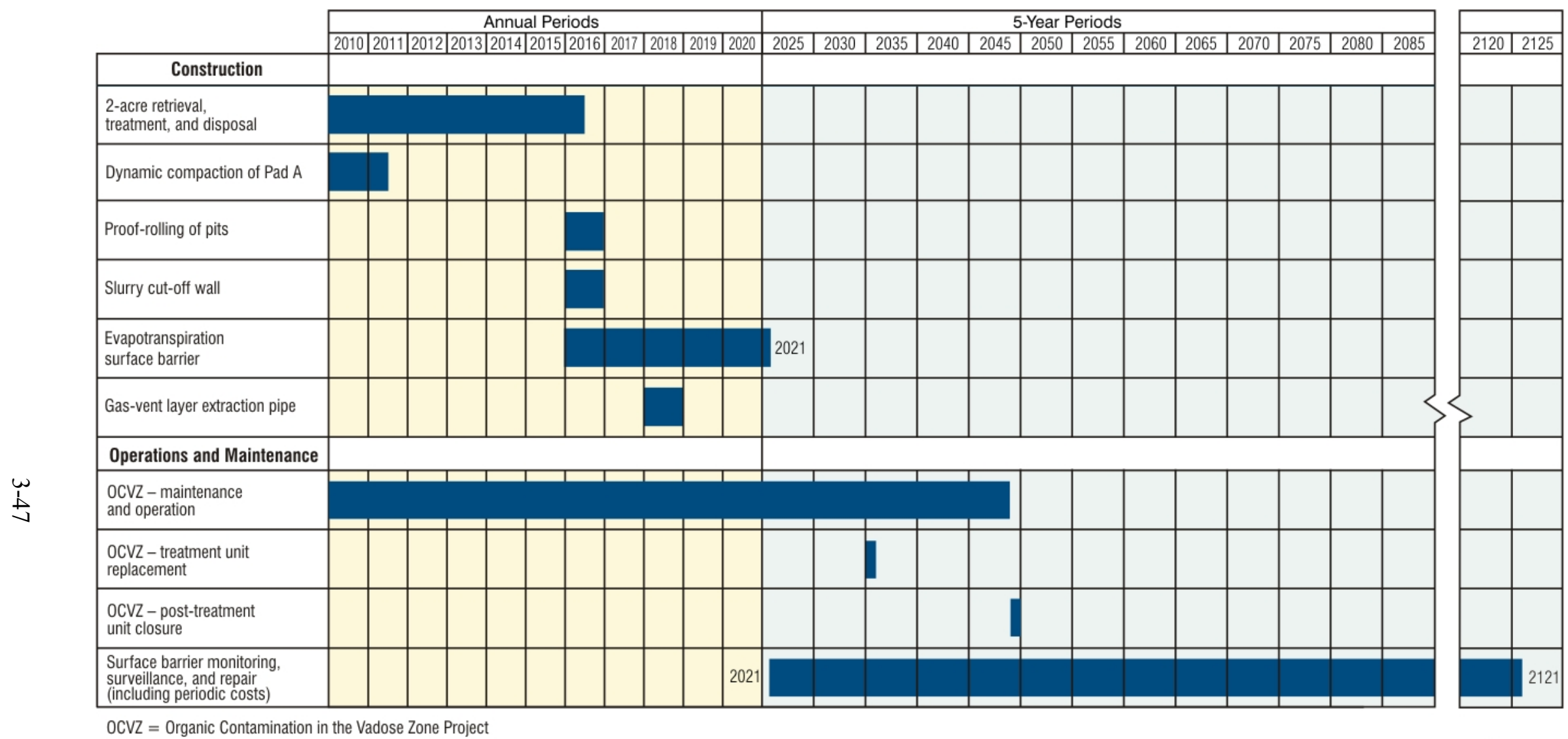

$\mathrm{OCVZ}=$ Organic Contamination in the Vadose Zone Project

Figure 3-25. Summary schedule for Alternative 4b-2-Acre Partial Retrieval, Treatment, and Disposal. 


\subsection{Alternative 5-Full Retrieval, Treatment, and Disposal}

Alternative 5 is assembled from multiple general response actions which, when implemented as a comprehensive remedy, would satisfy remedial action objectives. This alternative comprises the following general response actions:

- Retrieval-Alternative 5 would provide for retrieval of all waste buried within SDA pits, trenches, and soil vaults (e.g., waste containing transuranic isotopes, LLW with no transuranic isotopes, and remote-handled waste). To simplify development of this alternative, approaches used by the Accelerated Retrieval Project for containment, retrieval, and waste packaging are evaluated for removing all contact-handled waste in the SDA. Remote-handled waste would be safely grappled from the excavation, placed in shielded containers, and removed from the retrieval enclosure. Waste-retrieval operations would be conducted in fabric retrieval enclosures equipped with HEPA-filtered ventilation systems. Waste would be retrieved using commercially available excavation equipment modified for use in a contaminated environment.

- Ex situ treatment-Waste retrieved from SDA pit, trench, and soil vault areas would be transferred to WIPP, ICDF, remote-handled waste interim storage, or an off-INL Site commercial facility. For disposal at WIPP, waste must meet WIPP waste acceptance criteria. Note that, unlike other off-INL Site disposal locations for mixed LLW streams, the WIPP Land Withdrawal Act of 1992 (Public Law 102-579, 1992) exempts WIPP from the requirement to satisfy RCRA land disposal restrictions. Thus, WIPP waste acceptance criteria would be satisfied through visual examination, sorting, packaging, and assaying. Waste that fails gas-generation testing for transportation would be stored until the Accelerated Retrieval Project determines a disposition path. However, quantities of this waste type, if any, would be minor, and treatment cost is within the contingency applied to off-INL Site treatment and disposal. Packaged roaster oxide (uranium oxide) waste and a portion of the SDA waste with no transuranic isotopes, would be transferred to ICDF for treatment and disposal. Remote-handled waste with no transuranic isotopes would be placed in a newly constructed interim storage facility pending development of an appropriate federal or commercial repository. The balance of waste with no transuranic isotopes would be transferred to an off-INL Site commercial treatment facility (e.g., EnergySolutions) for treatment and disposal.

- Disposal-Contact-handled waste would be removed to glove boxes for visual characterization and packaging. Packaged waste meeting WIPP waste acceptance criteria would be shipped to WIPP for disposal. Roaster oxide waste and a portion of the SDA waste with no transuranic isotopes would be shipped to ICDF. Nontransuranic remote-handled waste would be packaged and stored at a newly constructed interim storage facility on the INL Site until a national repository becomes available. All other waste with no transuranic isotopes, including waste from Pad A, would be disposed of outside the INL Site (e.g., EnergySolutions).

- Containment-Alternative 5 would provide for closing the SDA using a simplified ET surface barrier after all other remediation activities are completed. The surface barrier would be constructed on packed backfill used to replace retrieved waste and contaminated soil. The surface barrier for Alternative 5 would not include a biointrusion and gas vent layer because all contaminated media would have been removed from the waste zone. Perimeter grading and surface barrier vegetation would be provided to mitigate erosion. Vegetation growth, subsidence, and animal intrusion would be monitored, and the surface barrier would be maintained. 
- Institutional controls-Active and passive controls would be implemented to prevent or limit access to the SDA. Institutional controls would include restrictions on groundwater use (e.g., well-drilling restrictions), restrictions on land use (e.g., limit to industrial applications), and physical security.

Groundwater, vadose zone, and surface monitoring (described under Alternative 1) also would be performed. The following subsections provide detailed descriptions of Alternative 5, including scope, process, and schedule.

\subsubsection{Remedial Action Scope}

Alternative 5 evaluates removal of all waste from the SDA. The majority of waste would be disposed of at an off-INL Site location with a smaller portion of waste disposal at ICDF. Migration of any contaminants that may already have reached the vadose zone would be minimized by construction of a simplified ET surface barrier and continued operation of the existing OCVZ system.

The RI/BRA (Holdren et al. 2006) identifies COCs associated with multiple exposure pathways (see Section 1.4.5). Alternative 5 is assembled to specifically address risk posed by these contaminants and pathways. Removal of all waste and most of the contaminated soil from the SDA would remove the primary source of contaminants from above the underlying basalt, but would not remove any contaminants that have migrated into the vadose zone. The surface barrier would prevent migration of contaminants to the surface and subsurface and would address remedial action objectives (see Section 1.5).

\subsubsection{Remedial Action Process}

Figure 3-26 illustrates the remedial action process under Alternative 5. Starting in year 2010, Pad A waste would be removed and shipped to an off-INL Site facility for treatment and disposal. Concurrently, all other waste would be retrieved and shipped to an on-INL-Site remote-handled storage facility, ICDF, WIPP, or applicable off-INL Site facilities for treatment and disposal. After all waste has been retrieved, an ET surface barrier would be constructed over the site. Surface barrier maintenance, surveillance, monitoring, and ICs would be maintained until discontinued through the 5-year review process. 


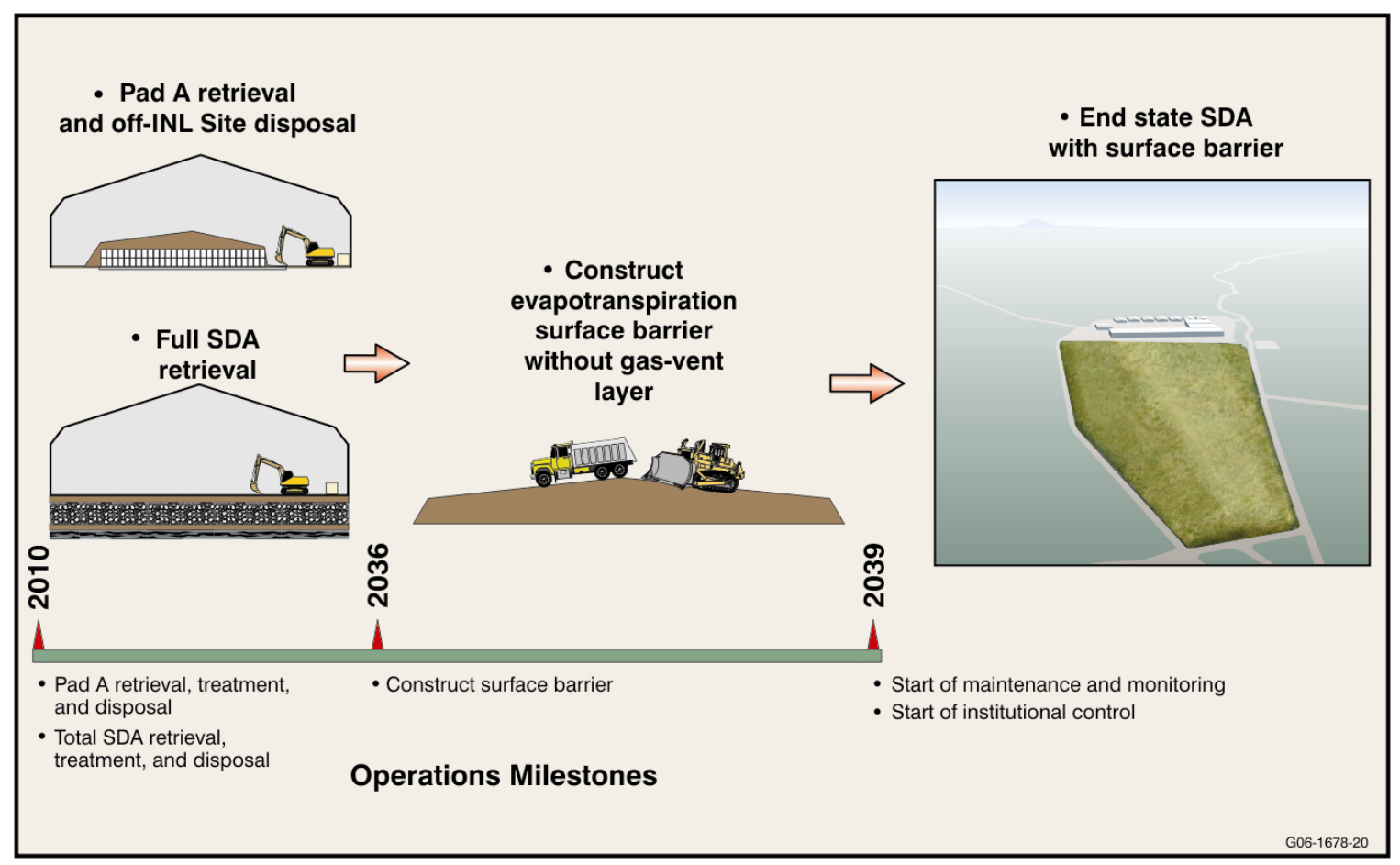

Figure 3-26. Process flow diagram for Alternative 5-Full Retrieval, Treatment, and Disposal.

\subsubsection{Remedial Action Components}

Existing OCVZ extraction wells, treatment units, and sample ports for this alternative are identical to those of Alternative $2 \mathrm{a}$.

Site preparation for full retrieval would start with a land survey of SDA retrieval locations (i.e., all SDA pits, trenches, and soil vaults) followed by construction of access roads and associated ground contouring for site drainage. As with 2- and 4-acre partial RTD alternatives, utility lines would be installed, probes would be cut off at ground level, surface soil would be treated, and a new 73-m (240-ft) extension would be added to the existing Accelerated Retrieval Project Retrieval Enclosure. Six smaller $(33.5 \times 30.1 \mathrm{~m}[110 \times 100 \mathrm{ft}])$ retrieval tents also would be constructed during this period. The large retrieval enclosure extension and the small retrieval tents are identical to designs outlined in the 2- and 4-acre partial RTD descriptions (see Sections 3.4.1 and 3.4.2). A staging area for waste with no transuranic isotopes and a storage facility for remote-handled waste also would be required. The remote-handled waste facility would be designed to store all remote-handled nontransuranic waste until a national repository becomes available.

Conducting a management self-assessment would demonstrate readiness for full SDA waste retrieval and disposal, followed by an operational readiness review to ensure that a deliberate and managed approach was used to perform operations safely. 
As shown in Figure 3-27, waste retrieval would be performed within the large, centrally located Retrieval Enclosure and within the six smaller mobile tent structures using excavators modified for operation within a contaminated environment, dust-suppression capabilities, and camera optics. After all waste has been retrieved (under a mobile tent), clean backfill would be placed within the excavated cavity, then the tent would be moved to the next location. Waste retrieved within mobile tent structures would be transported (inside cargo containers) to the centrally located retrieval enclosure. Inside the retrieval enclosure, waste segregation (i.e., placing waste into appropriate packaging for destination disposal location), visual examination, and drum packaging steps are identical to those described within the 2- and 4-acre partial RTD alternatives (see Section 3.4.1 and 3.4.2). Waste meeting WIPP waste acceptance criteria would be processed for shipment and sent to WIPP for disposal. Roaster oxide and a fraction of SDA waste with no transuranic isotopes would be sent to ICDF for treatment and disposal. The balance of waste with no transuranic isotopes would be sent to an off-INL Site facility for treatment and disposal.

As shown in Figure 3-28, remote-handled waste would be retrieved from the SDA using a method previously used at the Intermediate-Level Transuranic Storage Facility. Site preparation for remote-handled waste removal would include placing shielding blocks and a shielded transport cask between the open pit perimeter and personnel. A crane grappling device would be lowered through a slot in the tent roof. The remote-handled waste then would be retrieved from the waste zone and placed within the transport cask for shipment to a new on-INL Site remote-handled waste storage facility. The waste would be stored at this facility until a national repository becomes available.

On completion of full SDA waste retrieval and disposal, equipment would be demobilized, and the retrieval enclosure, mobile tent structures, and associated infrastructure would be dismantled.

Because full retrieval includes aboveground Pad A waste, this alternative includes relocation of Pad A waste to an off-INL Site facility. Figure 3-29 illustrates the process that would be used for removing waste from Pad A. Following removal of clean soil currently surrounding Pad A waste, a modular structure, similar to that used for the Accelerated Retrieval Project, would enclose the entire area of Pad A to provide weather protection and confine airborne contaminants. Excavation equipmentmodified for operation within a contaminated environment and modified for dust-suppression capabilities - would be used to remove waste from Pad A. Retrieved waste would be dropped into an enclosed chute that would unload into a lined Sea-Land container staged within an attached airlock. Full Sea-Land containers would be closed, decontaminated, and transferred to the Pad A staging area until they could be transferred to the Central Facilities Area and loaded onto intermodal rail cars. The rail cars then would be shipped to a commercial facility (e.g., EnergySolutions) for treatment and disposal of the waste (see Section 2.2.3.2). After Pad A waste has been removed, the retrieval enclosure and associated infrastructure would be dismantled, and the site would be prepared for surface barrier construction. 


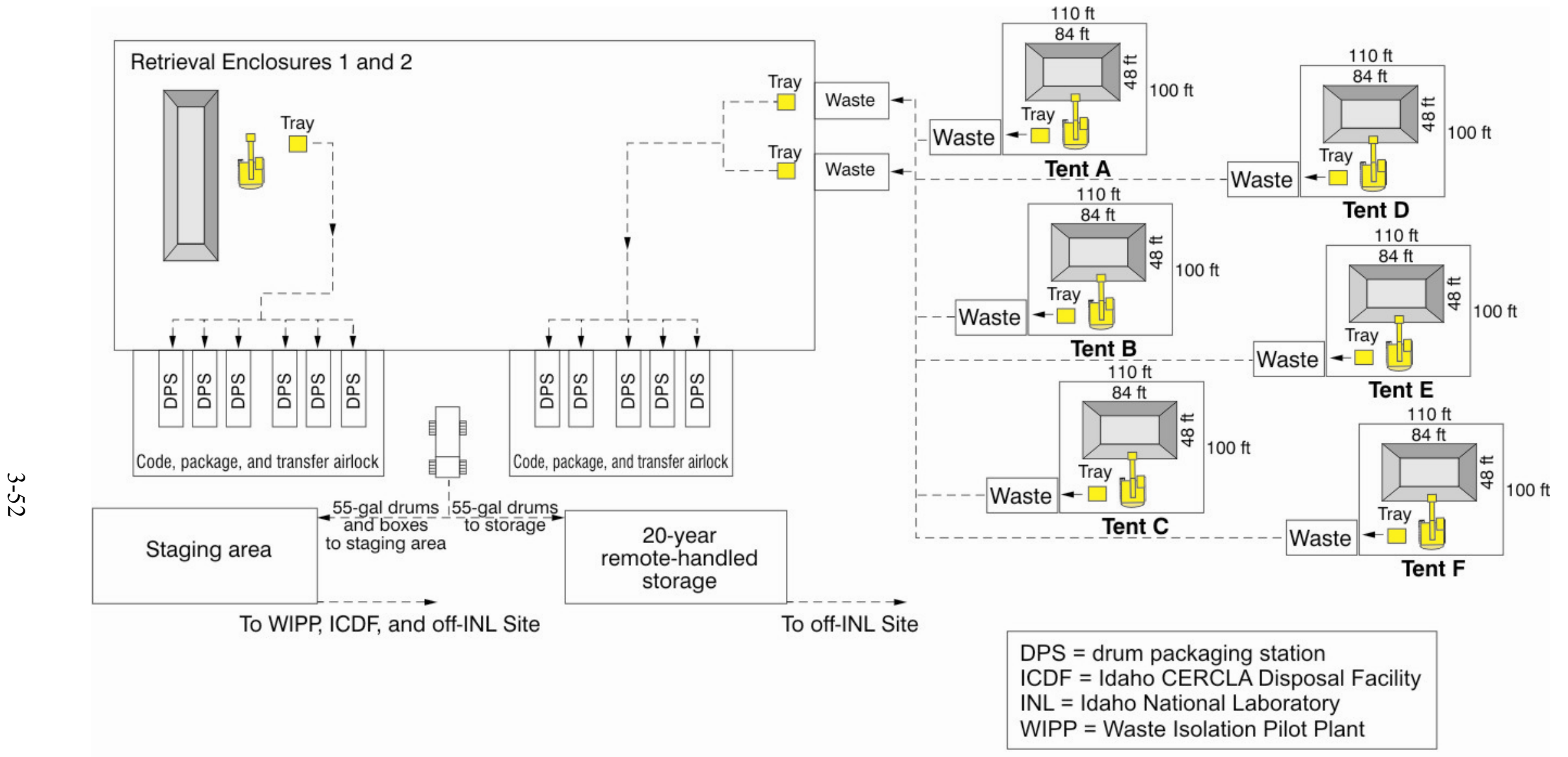

G06-1678-54

Figure 3-27. Preconceptual plan view of full retrieval process and remote-handled storage in the Subsurface Disposal Area for Alternative 5-Full Retrieval, Treatment, and Disposal. 


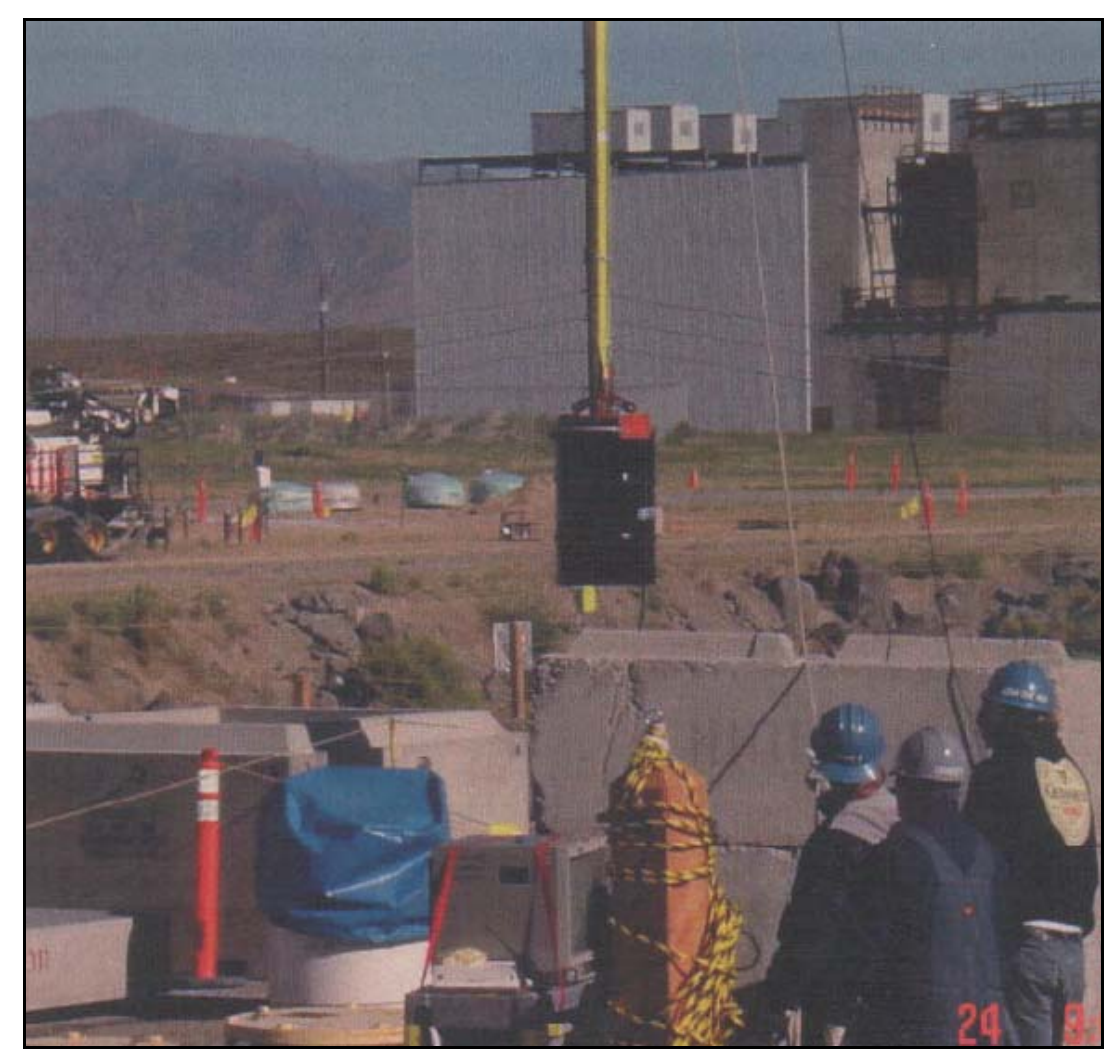

Figure 3-28. Removal of a remote-handled waste drum at the Intermediate-Level Transuranic Storage Facility.

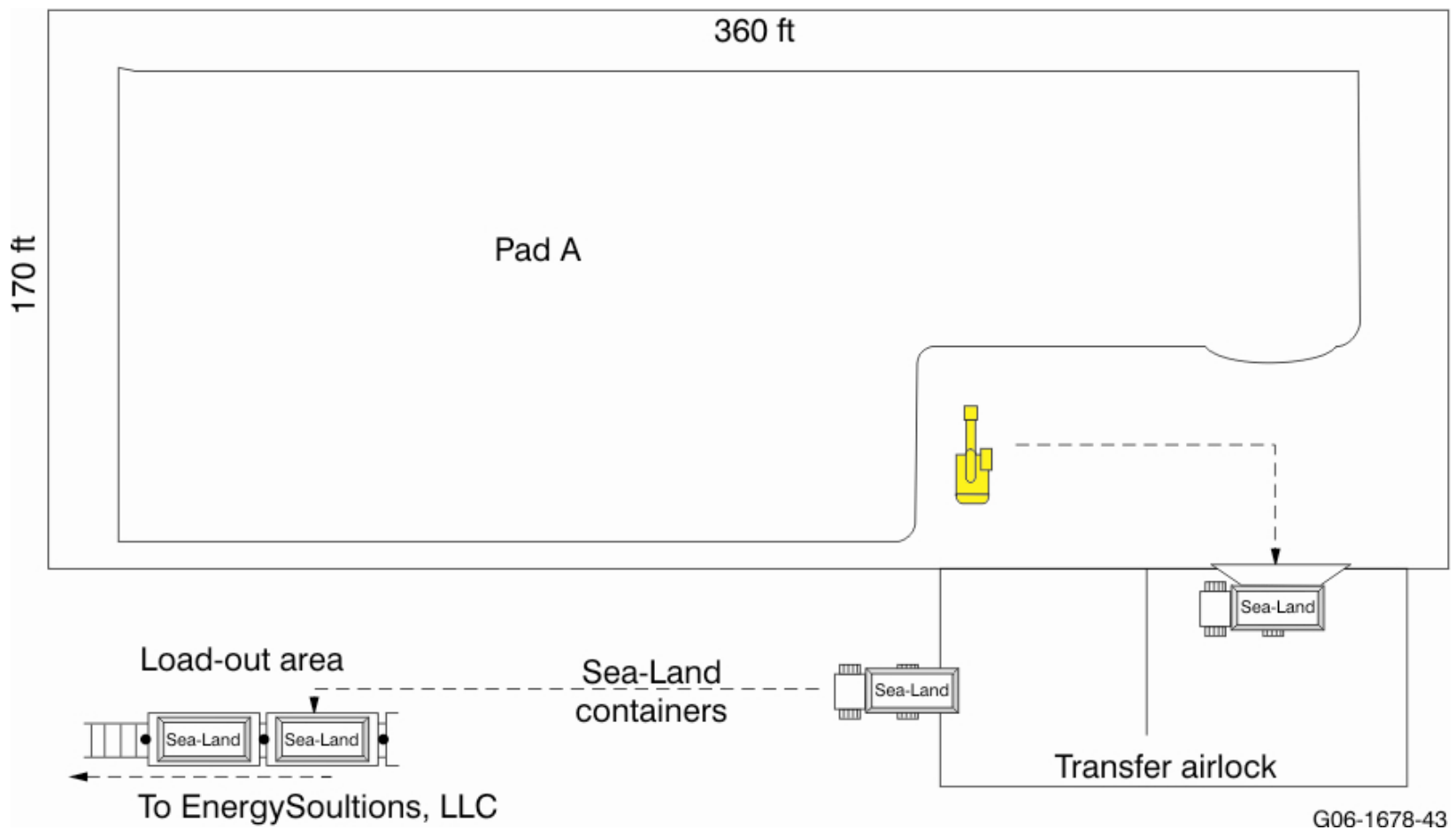

Figure 3-29. Pad A waste retrieval and off-Idaho National Laboratory Site disposal process for Alternative 5-Full Retrieval, Treatment, and Disposal. 
As part of surface barrier site-preparation, the existing infrastructure (e.g., utilities and monitoring equipment) at the SDA would be abandoned, relocated, or reconfigured to accommodate surface barrier construction. Activities to be performed before surface barrier construction include:

- Install a temporary water storage tank

- $\quad$ Construct a new perimeter access road

- Install a new perimeter fence (including demolishing the old one)

- $\quad$ Abandon half the 50 existing monitoring wells (i.e., 25)

- $\quad$ Double the current network of 50 advanced tensiometers to monitor surface barrier performance (i.e., 100)

- Relocate the three existing OCVZ treatment units to an area outside the future surface barrier perimeter

- $\quad$ Extend (upward through the surface barrier) 18 OCVZ wells, 100 advanced tensiometers, and 25 monitoring wells.

Design requirements for the full-retrieval surface barrier would be significantly reduced, compared to the previously defined ET surface barrier because all waste would be removed and replaced by clean backfill. Therefore, the biointrusion and gas vent layer (i.e., coarse rock layer), overlying gravel and sand layers, the fine soil layer, and armament would not be required. The fine soil grading fill of the ET surface barrier would provide moisture storage capacity until evaporation and transpiration removed the water. This soil, in combination with grading fill placed over the soil, would provide the necessary moisture storage capacity. Furthermore, because the simplified ET surface barrier is relatively thin, the perimeter slope for Alternative 5 would match the grading fill slope (i.e., 3\% slope); side-slope armor would not be required.

Figure 3-30 shows the surface barrier for the full retrieval alternative. This barrier would comprise a $0.3-\mathrm{m}$ (1-ft) -thick topsoil layer placed on a bed of grading fill. The topsoil layer would be contoured to achieve a slope of approximately $3 \%$ to facilitate runoff.

Following the construction phase of Alternative 5, long-term surveillance, maintenance, monitoring, and ICs would be conducted to enforce land-use restrictions and ensure effectiveness of the completed surface barrier. Surveillance and maintenance would include inspecting and repairing the surface barrier and peripheral components (e.g., fences and signs) to address observable degradation (e.g., subsidence, erosion, loss of vegetative cover, and biotic intrusion). Monitoring would include collecting samples and analyzing data from the vadose zone (i.e., soil moisture, soil vapor, perched water, and changes in moisture content) and from the aquifer. In addition, the INL Sitewide monitoring program would conduct radiological monitoring of air, surface water, surface soil, and biota. Active and passive ICs would include access restrictions, restrictions on groundwater use (e.g., well-drilling restrictions), restrictions on land use (e.g., limit to industrial applications), and physical security. 


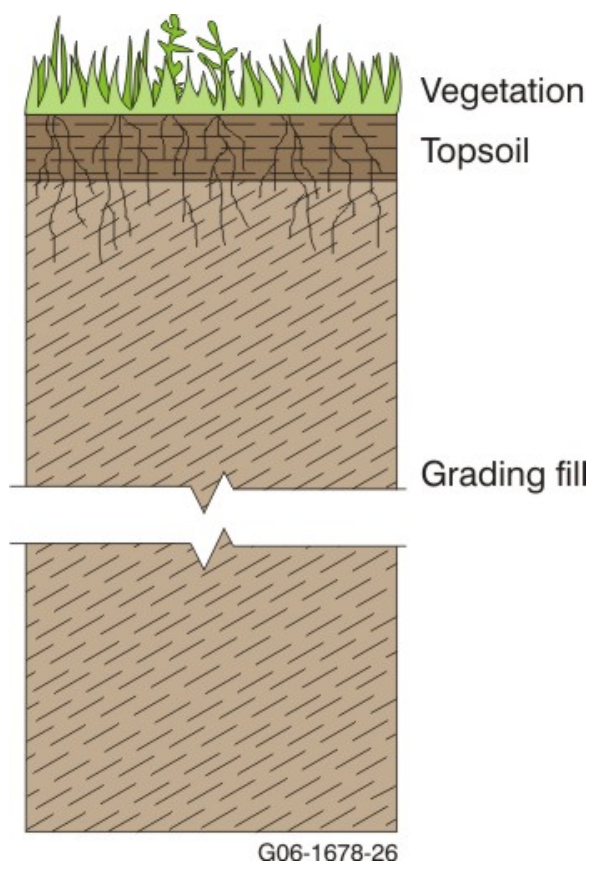

Figure 3-30. Cross section of a simplified evapotranspiration surface barrier with no biointrusion and gas vent layer for Alternative 5Full Retrieval, Treatment, and Disposal.

\subsubsection{Remedial Action Schedule}

Figure 3-31 provides a summary schedule for Alternative 5 based on a hypothetical start date in year 2010. Modules 4, 14, 17, and 20 (see Appendix F) provide a detailed schedule of each activity. The OCVZ system would operate throughout construction. For comparison, OCVZ system operational timeframes (required to achieve preliminary remediation goals for the vadose zone and aquifer) were based on the assumption that instantaneous remediation occurred in year 2010. (Section 4.1.3 and Appendix D provide further detail.) Operations and maintenance would start at surface barrier completion and would include groundwater monitoring, vadose zone monitoring, other environmental monitoring, surface barrier surveillance (e.g., monitoring vegetation growth, subsidence, and animal intrusion), and maintenance (e.g., subsidence repair). Periodic costs would parallel the operation and maintenance schedule and would include a remedial action report, an annual summary report, 5-year reviews, and a final operations and maintenance report. 

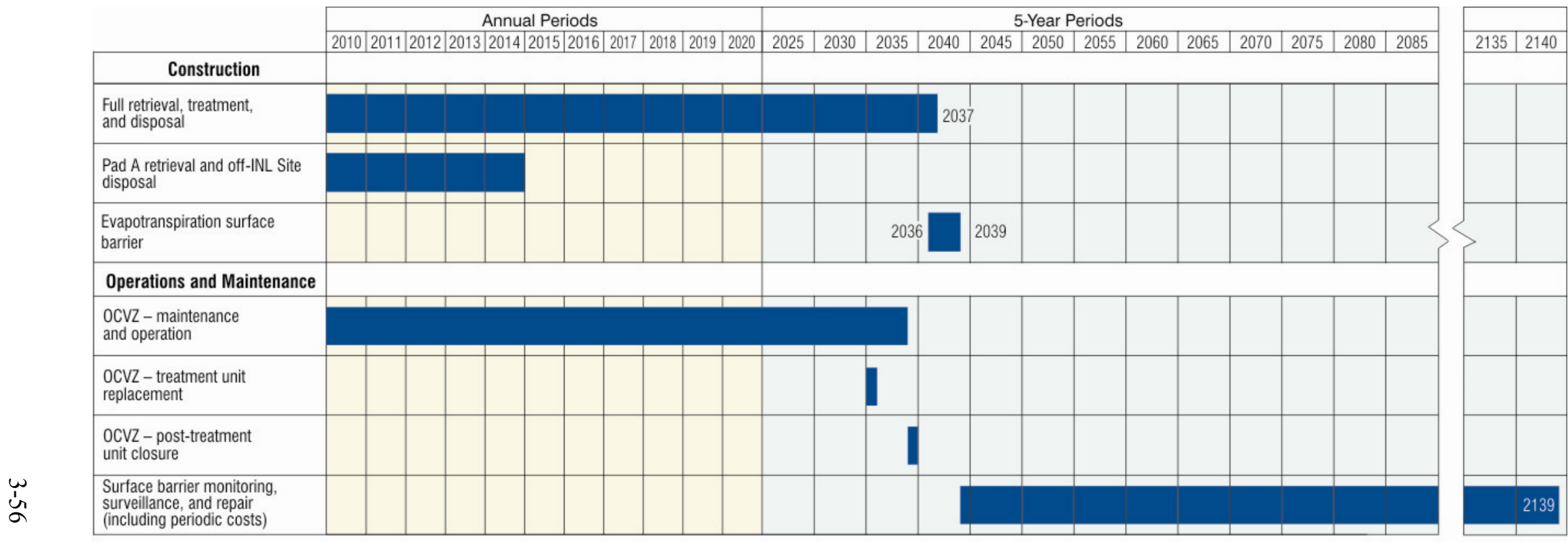

$\mathrm{OCVZ}=$ Organic Contamination in the Vadose Zone Project

G06-1760-21

Figure 3-31. Summary schedule for Alternative 5-Full Retrieval, Treatment, and Disposal. 


\subsection{Summary of Assembled Alternatives}

In accordance with the Second Addendum to the Work Plan (Holdren and Broomfield 2004), five assembled alternatives are identified, based on the above analysis, and are evaluated in detail in Section 4 and compared against each other in Section 5. From general descriptions of the assembled alternatives, 20 modularized elements were defined to expedite analysis of the five CERCLA balancing criteria and to facilitate mixing and matching various components into a preferred alternative in the proposed plan. The five assembled alternatives and the 20 modules that evolved from those alternatives are described in the following subsections. Appendix E provides process flow diagrams and additional preconceptual design details associated with each of the 20 modules. Table 3-3 summarizes the five assembled alternatives that are forwarded to Sections 4 and 5 for detailed and comparative analysis.

\subsubsection{Alternative 1-No Action}

Alternative 1 evaluates the absence of remedial action to provide a baseline against which to compare the other alternatives. Environmental monitoring is the only activity included in the No Action alternative.

\subsubsection{Alternative 2-Surface Barrier}

Two types of surface barriers are evaluated in the Feasibility Study for Operable Unit 7-13/14. In addition to postconstruction maintenance, long-term ICs, and environmental monitoring, assembled alternatives for the two surface barriers incorporate unique approaches to control subsidence, address Pad A waste, and inhibit buildup of organic vapors in the cap. The two surface barrier approaches are described below, as Alternatives $2 \mathrm{a}$ and $2 \mathrm{~b}$.

\subsubsection{Alternative 2a-Modified Resource Conservation and Recovery Act Type C}

Surface Barrier. The modified RCRA Type $\mathrm{C}$ surface barrier is an engineered barrier constructed of an asphalt layer and multiple thin and thick layers of natural materials. The asphalt layer protects against biotic and moisture intrusion. Other enhancements for Alternative 2a include incorporating Pad A into the surface barrier, installing grout columns in waste pits to provide a stable foundation, and expanding the existing OCVZ system with near-surface vapor extraction wells. The implementation timeframe for Alternative 2a is approximately 7 years.

Pad A would be incorporated into the surface barrier by adding additional layers over the existing Pad A surface barrier. This alternative does not include steps to address subsidence of Pad A waste.

Installing grout columns would provide a stable foundation for the SDA surface barrier. Liquid grout would be injected into buried waste using a probe driven by a rotopercussion drill. High-pressure jet grouting would mix grout with waste and soil to form homogeneous columns, which would be spaced on 3-7 m (12-ft) centers to provide a stable foundation for the surface barrier. Approximately $7.7 \mathrm{ha}$ (19 acres) of the SDA would be grouted with approximately 5,700 columns deployed over a period of about 8-1/2 months, using two drill rigs and about 1 million gallons of grout.

The existing OCVZ treatment system would be enhanced with near-surface vapor extraction wells to preclude trapping organic vapors beneath asphalt layers of the cap. Vapor extraction wells would be installed in eight locations in the completed cap. Wells would be completed at approximately $3 \mathrm{~m} \mathrm{(10} \mathrm{ft)}$ into the basalt layer immediately beneath the landfill and between pits to avoid intrusion into the buried waste. Risers would extend above the surface barrier and connect to the OCVZ system. Operations and maintenance of the OCVZ system would continue for approximately 65 years until remediation goals are satisfied. 
Table 3-3. Summary of five assembled alternatives and major components in each.

\begin{tabular}{|c|c|c|c|c|c|c|c|}
\hline \multirow[b]{2}{*}{ Component } & \multirow[b]{2}{*}{$\begin{array}{c}1 . \\
\text { No Action }\end{array}$} & \multicolumn{2}{|c|}{ 2. Surface Barrier } & \multirow[b]{2}{*}{$\begin{array}{c}3 . \\
\text { In Situ Grouting }\end{array}$} & \multicolumn{2}{|c|}{ 4. Partial Retrieval, Treatment, and Disposal } & \multirow{2}{*}{$\begin{array}{l}5 . \\
\text { Full Retrieval, } \\
\text { Treatment, and } \\
\quad \text { Disposal }\end{array}$} \\
\hline & & $\begin{array}{c}\text { 2a. } \\
\text { Modified RCRA } \\
\text { Type C } \\
\end{array}$ & $\begin{array}{c}2 \mathrm{~b} . \\
\text { Evapotranspiration }\end{array}$ & & $\begin{array}{c}4 a . \\
4 \text { Acres }\end{array}$ & $\begin{array}{c}4 \mathrm{~b} . \\
2 \text { Acres }\end{array}$ & \\
\hline Monitoring $^{\mathrm{a}}$ & Monitoring & Monitoring & Monitoring & Monitoring & Monitoring & Monitoring & Monitoring \\
\hline $\begin{array}{l}\text { In situ } \\
\text { treatment }\end{array}$ & None & None & None & $\begin{array}{l}\text { ISG-specified Tc-99 and } \\
\text { I-129 }\end{array}$ & None & None & None \\
\hline Retrieval & None & None & None & None & $\begin{array}{l}\text { Retrieve targeted Rocky } \\
\text { Flats Plant waste }\end{array}$ & $\begin{array}{l}\text { Retrieve targeted } \\
\text { Rocky Flats Plant waste }\end{array}$ & $\begin{array}{l}\text { Retrieve all waste in the } \\
\text { SDA }\end{array}$ \\
\hline Pad A & None & $\begin{array}{l}\text { Incorporate Pad A as-is } \\
\text { into cap }\end{array}$ & Relocate to LLW Pit & $\begin{array}{l}\text { Treat ex situ and relocate } \\
\text { to LLW Pit }\end{array}$ & \begin{tabular}{|l|} 
Remove to ICDF \\
\end{tabular} & $\begin{array}{l}\text { Dynamically compact } \\
\text { and incorporate into cap }\end{array}$ & $\begin{array}{l}\text { Remove to off-INL Site } \\
\text { disposal facility }\end{array}$ \\
\hline $\begin{array}{l}\text { Subsidence in } \\
\text { pits }\end{array}$ & None & Foundation grouting & Dynamic compaction $^{\mathrm{b}}$ & Dynamic compaction $^{\mathrm{b}}$ & Dynamic compaction $^{\text {b }}$ & Proof-roll & None \\
\hline $\begin{array}{l}\text { Surface } \\
\text { barrier }\end{array}$ & None & $\begin{array}{l}\text { Modified RCRA } \\
\text { Type C surface barrier } \\
\text { with biointrusion layer }\end{array}$ & $\begin{array}{l}\text { ET surface barrier with } \\
\text { biointrusion layer }\end{array}$ & $\begin{array}{l}\text { ET surface barrier with } \\
\text { biointrusion layer }\end{array}$ & $\begin{array}{l}\text { ET surface barrier with } \\
\text { biointrusion layer }\end{array}$ & $\begin{array}{l}\text { ET surface barrier with } \\
\text { biointrusion layer and } \\
\text { slurry perimeter wall }\end{array}$ & $\begin{array}{l}\text { ET surface barrier } \\
\text { without biointrusion } \\
\text { barrier }\end{array}$ \\
\hline $\begin{array}{l}\text { Vadose zone } \\
\text { vapor } \\
\text { extraction }\end{array}$ & None & $\begin{array}{l}\text { Add near-surface } \\
\text { extraction wells; } \\
\text { operate OCVZ system }^{\mathrm{c}}\end{array}$ & Operate OCVZ system $^{\mathrm{c}}$ & 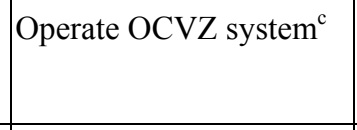 & Operate OCVZ system ${ }^{\mathrm{c}}$ & Operate OCVZ system ${ }^{\mathrm{c}}$ & Operate OCVZ system ${ }^{\mathrm{c}}$ \\
\hline $\begin{array}{l}\text { Surveillance } \\
\text { and } \\
\text { maintenance }\end{array}$ & None & $\begin{array}{l}\text { Until eliminated by a } \\
\text { 5-year review }\end{array}$ & $\begin{array}{l}\text { Until eliminated by a } \\
\text { 5-year review }\end{array}$ & $\begin{array}{l}\text { Until eliminated by a } \\
\text { 5-year review }\end{array}$ & $\begin{array}{l}\text { Until eliminated by a } \\
\text { 5-year review }\end{array}$ & $\begin{array}{l}\text { Until eliminated by a } \\
5 \text {-year review }\end{array}$ & $\begin{array}{l}\text { Until eliminated by a } \\
5 \text {-year review }\end{array}$ \\
\hline $\begin{array}{l}\text { Institutional } \\
\text { controls }\end{array}$ & None & $\begin{array}{l}\text { Until eliminated by a } \\
5 \text {-year review }\end{array}$ & $\begin{array}{l}\text { Until eliminated by a } \\
5 \text {-year review }\end{array}$ & $\begin{array}{l}\text { Until eliminated by a } \\
\text { 5-year review }\end{array}$ & $\begin{array}{l}\text { Until eliminated by a } \\
5 \text {-year review }\end{array}$ & $\begin{array}{l}\text { Until eliminated by a } \\
5 \text {-year review }\end{array}$ & $\begin{array}{l}\text { Until eliminated by a } \\
\text { 5-year review }\end{array}$ \\
\hline \multicolumn{8}{|c|}{$\begin{array}{l}\text { a. Monitoring comprises surface, vadose zone, and aquifer monitoring. Cost estimates include } 100 \text { years of monitoring for No Action and } 100 \text { years of monitoring after the cap is complete for all action alternatives. } \\
\text { b. Dynamic compaction was identified for analysis because it presents the most short-term risk and highest cost among process options that apply surface treatment to address subsidence; thus, it bounds the analysis. } \\
\text { Other process options (e.g., impact rolling) could be substituted during remedial design. } \\
\text { c. Operation of the OCVZ system would continue until eliminated by a } 5 \text {-year review after remediation goals for VOCs in the vadose zone are achieved. } \\
\text { d. Estimates include cost for } 100 \text { years of surveillance, maintenance, and institutional control after the cap is complete. }\end{array}$} \\
\hline \multicolumn{3}{|c|}{$\begin{array}{l}\text { ET = evapotranspiration } \\
\text { ICDF = Idaho CERCLA Disposal Facility } \\
\text { ISG = in situ grouting }\end{array}$} & \multicolumn{2}{|c|}{$\begin{array}{l}\text { INL = Idaho National Laboratory } \\
\text { LLW = low-level waste } \\
\text { OCVZ = Organic Contamination in the Vadose Zone }\end{array}$} & \multicolumn{3}{|c|}{$\begin{array}{l}\text { RCRA = Resource Conservation and Recovery Act } \\
\text { SDA = Subsurface Disposal Area } \\
\text { VOC }=\text { volatile organic compound }\end{array}$} \\
\hline
\end{tabular}


3.6.2.2 Alternative 2b-Evapotranspiration Surface Barrier. The ET surface barrier is an engineered barrier constructed of several layers of natural materials. A biotic barrier would be incorporated into the surface barrier to preclude biotic intrusion and transport of contaminants to the surface. Other enhancements for Alternative $2 \mathrm{~b}$ include transferring waste from Pad A into the LLW Pit, dynamically compacting waste pits to provide a stable foundation, and incorporating a gas collection system, within the surface barrier, that would be coupled to the existing OCVZ system. The implementation timeframe for Alternative $2 b$ is approximately 10 years.

Removal of waste from Pad A would be performed under a weather enclosure and would require approximately 5 years to complete. Almost 600 boxes containing intact drums of Pad A waste and more than 3,000 lift liners containing loose Pad A waste would be transferred to a staging area and then transported to the active LLW Pit. Waste would not be treated before disposal.

Dynamic compaction would be applied to waste pits before constructing the cap to reduce subsidence. A heavy weight would be dropped from a height of approximately $18 \mathrm{~m}(60 \mathrm{ft})$ from a crane to compact the existing waste pits. A $0.3-\mathrm{m}(1-\mathrm{ft})$-thick layer of soil would be placed over areas to be compacted prior to treatment to reduce the possibility of exposing waste.

To preclude buildup of vapor in the cap that could be detrimental to vegetation on the surface, a gas collection pipe would be installed during surface barrier construction. Approximately 3,600 linear feet of 12-in. pipe would be installed in the biointrusion and gas vent layer and connected to 37 vertical pipes protruding out of the surface barrier crest. The risers would be connected to the OCVZ system following completion of cap construction. Operation and maintenance of the OCVZ system would continue for approximately 45 years until remediation goals are satisfied.

\subsubsection{Alternative 3-In Situ Grouting}

Alternative 3 evaluates using in situ stabilization of waste to retard migration of contaminants generated by INL Site reactor and fuel development operations. Alternative 3 also includes removing and ex situ grouting Pad A waste, with subsequent relocation within the OU 7-13/14 area of contamination; performing dynamic compaction of pit areas to mitigate future waste subsidence; constructing an ET surface barrier with a biotic intrusion and gas vent layer; and passively extracting soil vapor from the surface barrier. Alternative 3 also includes postconstruction maintenance, long-term ICs, and environmental monitoring. The implementation timeframe for Alternative 3 would be approximately 10 years.

Specified waste contains releasable Tc-99 and I-129 that would be encapsulated by in situ injection of a Portland cement grout using commercially available equipment. Liquid grout would be injected into buried waste using a probe driven by a rotopercussion drill. High-pressure jet grouting would mix grout with waste and soil to form homogeneous columns. Grout columns would be closely spaced on $0.5-\mathrm{m}$ (20-in.) centers to form consolidated monoliths. Stabilized waste monoliths would be highly impermeable and would reduce contaminant diffusion into moisture that may infiltrate the waste zone. Approximately 3,100 columns would be installed.

Waste would be retrieved from Pad A in a retrieval enclosure. Bulk waste would be separated into fines (less than $15.2 \mathrm{~cm}$ [6 in.] in diameter) and debris (greater than $15 \mathrm{~cm}$ [6 in.] in diameter). Fines would be mixed with Portland cement grout. Debris would be placed into waste boxes and stabilized with flowable cement grout. Stabilized waste boxes would be transported to the LLW Pit or another location within the OU 7-13/14 area of contamination. On completion of Pad A waste removal, the retrieval enclosure would be demobilized and the site would be prepared for surface barrier construction. 
Dynamic compaction would be applied to SDA pit areas to provide a stable foundation for the engineered barrier.

Alternative 3 includes an ET surface barrier with a passive gas vent layer that dissipates organic vapors and inhibits biotic intrusion. The surface barrier would reduce infiltration and contaminant transport into the subsurface and inhibit biotic transport to the surface.

\subsubsection{Alternative 4-Partial Retrieval, Treatment, and Disposal}

To facilitate scaling up or down to various retrieval sizes, two partial retrieval areas are evaluated as Alternatives $4 \mathrm{a}$ and $4 \mathrm{~b}$, representing 4 acres and 2 acres, respectively. These alternatives evaluate identical methods of RTD, but vary in their approaches to subsidence control and Pad A waste.

Operations would be conducted within a large metal-framed, fabric retrieval enclosure equipped with airlocks. Airlocks house glove boxes for inspecting waste and loading drums and also control contamination during ingress to and egress from retrieval operations. Retrievals also would occur within smaller mobile tent structures. Excavation equipment would be modified for operation within a contaminated environment, dust-suppression capabilities, and camera optics. Whether a waste is targeted or nontargeted would be determined at or near the dig face. Nontargeted waste would be returned to the excavation, while targeted waste would be transferred to the central retrieval enclosure.

Targeted waste would be handled in one of two ways:

- $\quad$ Transuranic waste would be sent to WIPP. The Second Addendum to the Work Plan (Holdren and Broomfield 2004) specifies that retrieval alternatives will be based on the Accelerated Retrieval Project process. For the Accelerated Retrieval Project, nontransuranic waste (less than $100 \mathrm{nCi} / \mathrm{g}$ ) containing some level of transuranic isotopes is payload-based load-managed and sent to WIPP. Therefore, an alternate disposal path for this waste type was not evaluated.

- $\quad$ Targeted roaster oxides (uranium oxides) would be drummed and prepared for transfer to ICDF for treatment and disposal.

Both partial retrieval alternatives include an ET surface barrier with a passive gas vent layer to dissipate organic vapor and inhibit biotic intrusion. Overall thickness of the barrier, coupled with long-term ICs, would preclude inadvertent human intrusion. The surface barrier would reduce infiltration and contaminant transport into the subsurface and would inhibit biotic transport to the surface. Alternative $4 \mathrm{~b}$ anchors the surface barrier to a subsurface slurry wall around the perimeter. Both assembled alternatives incorporate long-term maintenance, ICs, and environmental monitoring. The OCVZ system would continue to extract and treat VOCs from the vadose zone. The following subsections describe unique features of the two partial retrieval alternatives.

3.6.4.1 Alternative 4a-4-Acre Partial Retrieval, Treatment, and Disposal. The 4-acre partial retrieval alternative involves RTD of targeted waste from pit areas totaling 4 acres using methods described above. Implementation timeframe for Alternative 4 a would be approximately 16 years.

All waste pits would be dynamically compacted to provide a stable foundation for the surface barrier and to reduce subsidence. Waste would be retrieved from Pad A and shipped to ICDF for treatment (i.e., grouting) and disposal. A multilayered ET surface barrier (see Alternative 2b) would be placed over the entire SDA. 
3.6.4.2 Alternative 4b-2-Acre Partial Retrieval, Treatment, and Disposal. Alternative 4b involves RTD of targeted waste from pit areas totaling 2 acres using methods described above. The implementation timeframe for Alternative $4 \mathrm{~b}$ would be approximately 12 years.

Pad A would be dynamically compacted and waste pits would be proof-rolled to provide a stable foundation for the surface barrier and to reduce subsidence. A slurry cut-off wall would be installed in surficial sediments around the perimeter of the SDA. A multilayered ET surface barrier (see Alternative 2b) incorporating Pad A would be placed over the entire SDA.

\subsubsection{Alternative 5-Full Retrieval, Treatment, and Disposal}

Alternative 5 involves retrieval of all waste from the SDA (including remote-handled objects and oversized objects) and disposal outside the SDA. Operations would be conducted within a large metal-framed fabric retrieval enclosure equipped with airlocks. Airlocks would house glove boxes for inspecting waste and loading drums. In addition, the airlocks would be used to control contamination during ingress to and egress from retrieval operations. Waste retrieval would occur within this large enclosure and within three smaller mobile tent structures. Excavation equipment would be modified for operation within a contaminated environment, dust-suppression capabilities, and camera optics.

Waste retrieved within the smaller mobile tent structures would be placed in cargo containers for transfer to the centrally located retrieval enclosure and would be sorted, based on disposal path. Retrieved waste would be handled in one of the following ways:

- $\quad$ Transuranic waste would be sent to WIPP. The Second Addendum to the Work Plan (Holdren and Broomfield 2004) specifies that retrieval alternatives will be based on the Accelerated Retrieval Project process. For the Accelerated Retrieval Project, nontransuranic waste (less than $100 \mathrm{nCi} / \mathrm{g}$ ) containing some level of transuranic isotopes is payload-based, load-managed, and sent to WIPP. Therefore, an alternate disposal path for this waste type was not evaluated.

- Roaster oxides and a portion of contact-handled waste meeting waste acceptance criteria would be drummed and transferred to ICDF for treatment (i.e., grouting) and disposal.

- A portion of the other contact-handled waste (with the exception of roaster oxide) would be sent to an off-INL Site facility for treatment and permanent disposal.

- $\quad$ Remote-handled waste would be retrieved using a crane and shielding blocks. Remote-handled waste devoid of transuranic isotopes would be placed in a cask, then sent to a new storage facility on the INL Site pending future transport to an off-INL Site repository. Remote-handled waste with transuranic isotopes would be sent to WIPP.

After retrieval is complete, a simplified, two-layer ET surface barrier would be placed over the entire SDA to reduce infiltration and inhibit transport of residual contamination in the vadose zone. Implementation timeframe for Alternative 5 would be 30 years. The OCVZ system would extract and treat VOCs that have migrated into the vadose zone during construction. Alternative 5 also includes long-term surveillance, maintenance, monitoring, and ICs. 


\subsubsection{Modules}

To facilitate analysis, 20 distinct modules (see Appendix F) for the feasibility study were defined, based on elements contained in assembled alternatives. These modules also can be used by the Agencies to compile elements from several alternatives into a preferred alternative for the proposed plan. The modules are described in the following subsections.

\subsubsection{Retrieval and Disposal Modules}

- $\quad$ 2-Acre partial RTD-This module consists of retrieving targeted waste from pit areas totaling 2 acres, sorting and packaging waste within a centrally located retrieval enclosure, and transporting waste to either WIPP or ICDF, as appropriate.

- $\quad$ 4-Acre partial RTD-This module consists of retrieving targeted waste from pit areas totaling 4 acres, sorting and packaging waste within a centrally located retrieval enclosure, and transporting waste to either the WIPP or ICDF, as appropriate.

- $\quad$ Full RTD-This module consists of retrieving all waste from the SDA. Remote-handled waste containing no transuranic isotopes would be placed in interim storage. All other waste would be sorted and packaged within a centrally located retrieval enclosure and transported to WIPP, ICDF, or another off-INL Site disposal facility, as appropriate.

\subsubsection{Pad A Modules}

- Removing Pad A and disposing of waste in the RWMC LLW Pit without treatment-This module consists of contouring the Pad A berm and building an enclosure over the top to be used for retrieving waste from Pad A. Waste would be retrieved, sorted, placed in bulk containers, and transferred to the LLW Pit (or other location within the SDA) without treatment.

- $\quad$ Removing Pad A and disposing of waste in the RWMC LLW Pit following ex situ treatmentThis module consists of contouring the Pad A berm and building an enclosure over the top for retrieving waste from Pad A. Waste would be retrieved, sorted, treated ex situ with grout, placed in waste boxes, and transferred to the LLW Pit (or other location within the SDA).

- $\quad$ Removing Pad A and disposing of and treating waste at ICDF or similar on-INL Site facilityThis module consists of contouring the Pad A berm and building an enclosure over the top for retrieving waste from Pad A. Waste would be retrieved, sorted, visually examined to satisfy ICDF waste acceptance criteria, placed in waste boxes, and transferred to ICDF (or similar facility) for treatment and disposal.

- $\quad$ Removing Pad A and disposing of and treating waste at EnergySolutions or similar off-INL Site facility-This module consists of contouring the Pad A berm and building an enclosure over the top for retrieving waste from Pad A. Waste would be retrieved, placed in containers, and transferred to EnergySolutions by rail for treatment and disposal.

- Dynamic compaction of Pad A-This module consists of dynamically compacting soil by dropping a heavy weight from a designated height in an engineered pattern. This would prepare the Pad A mound for a surface barrier that would be placed over Pad A. 


\subsubsection{Foundation Preparation Modules}

- Dynamic compaction of pits-This module consists of dynamically compacting pit areas by dropping a heavy weight from a designated height in an engineered pattern and is similar to dynamic compaction of Pad A. Dynamic compaction would mitigate subsidence in SDA pit areas to provide a stable base for a surface barrier. Dynamic compaction was identified because it presents the most short-term risk and highest cost among process options that apply surface treatment to address subsidence, thus bounding the analysis. Other process options (e.g., impact rolling) could be substituted during remedial design.

- $\quad$ Foundation grouting-This module consists of injecting subsurface grout columns at regular intervals using a rotary percussion drill. Foundation grouting would provide a stable base for a cap.

- Proof-rolling-This module consists of compacting SDA pit areas using a roller-compactor. The proof-rolling compaction process would be used to test uniformity and stability of the foundation for the surface barrier.

\subsubsection{In Situ Treatment Module}

- Contaminant grouting-This module consists of installing overlapping subsurface grout columns by injecting grout using a rotary percussion drill. Columns would overlap to fill entire specified areas with grout to encapsulate waste.

\subsubsection{Surface Barrier Modules}

- $\quad$ Modified RCRA Type $\mathbf{C}$ surface barrier-This module consists of constructing a modified RCRA Type $\mathrm{C}$ cap over the entire SDA. This surface barrier would manage moisture and biotic intrusion by incorporating an impermeable asphalt layer. This module also includes installing and demolishing roads and fences, extending wells, installing wells, contouring the SDA, and 100 years of surveillance, maintenance, monitoring, and ICs. Overall thickness of the cap, coupled with long-term ICs, would preclude inadvertent human intrusion.

- $\quad$ ET surface barrier-This module consists of constructing an ET cap, composed of several layers of varying thickness and composition, over the entire SDA. This type of surface barrier would manage moisture through evaporation and transpiration and would include layers to prevent biotic intrusion and collect volatile constituents emitted by buried waste. This module also includes installing and demolishing roads and fences, extending wells, installing wells, contouring the SDA, and 100 years of surveillance, maintenance, monitoring, and ICs. Overall thickness of the cap, coupled with long-term ICs, would preclude inadvertent human intrusion.

- $\quad$ Simplified ET surface barrier with no biointrusion and gas vent layer-This module consists of constructing a simplified ET cap specifically for Alternative 5, where features to address biotic intrusion and gas venting would not be required because all waste would be removed. This module also includes installing and demolishing roads and fences, extending wells, installing wells, contouring the SDA, and 100 years of surveillance, maintenance, monitoring, and ICs. Overall thickness of the cap, coupled with long-term ICs, would preclude inadvertent human intrusion.

- $\quad$ Slurry cut-off wall-This module consists of installing a subsurface slurry cut-off wall by digging a trench around the SDA and immediately filling it with bentonite slurry. This belowgrade barrier would be placed beneath and incorporated into the toe of a surface barrier. 


\subsubsection{Volatile Organic Compound Removal Modules}

- Near-surface vapor extraction well-This module consists of installing near-surface vapor extraction wells vertically through the modified RCRA Type C surface barrier, between the waste pits, and into the underlying basalt. Following cap completion, protruding wells would be connected to the OCVZ system.

- Gas vent layer extraction pipe-This module consists of placing sections of horizontal pipe within the ET cap biointrusion and gas vent layer and either connecting the pipe to the OCVZ system or venting the pipe directly to the atmosphere.

- OCVZ system operations and maintenance-This module consists of operating and maintaining the OCVZ system. Three phases associated with this module are (1) operating and maintaining OCVZ treatment units for each 5-year period they operate, (2) replacing OCVZ treatment units for each 20 years they are in service, and (3) shutting down the OCVZ system at the end of operation. Because alternatives have different OCVZ system operational timeframes, various combinations of these three phases are used to estimate cost for each alternative.

\subsubsection{Monitoring Module}

- $\quad$ Monitoring-This module comprises only environmental monitoring for the No Action alternative. Unlike surface barrier modules, this module does not involve installing new monitoring equipment as a site-preparation activity. This module includes 100 years of monitoring. 


\subsection{References}

40 CFR 265.310, 2006, "Closure and Post-Closure Care," Code of Federal Regulations, Office of the Federal Register.

40 CFR 300, 2006, "National Oil and Hazardous Substances Pollution Contingency Plan," Code of Federal Regulations, Office of the Federal Register.

42 USC $\S 6901$ et seq., 1976, "Resource Conservation and Recovery Act of 1976 (Solid Waste Disposal Act)," United States Code.

42 USC $\S 9601$ et seq., 1980, "Comprehensive Environmental Response, Compensation and Liability Act of 1980 (CERCLA/Superfund)," United States Code.

Anderson, J. E. and A. D. Forman, 2003, Evapotranspiration Caps for the Idaho National Engineering and Environmental Laboratory: A Summary of Research and Recommendations, STOLLER-ESER-56, Stoller Corporation and Idaho State University for the U.S. Department of Energy.

Ankeny, M. D., L. M. Coons, N. Majumdar, J. Kelsey, and M. Miller, 1997, "Performance and Cost Considerations for Landfill Caps in Semi-Arid Climates," Proceedings of Landfill Capping in the Semi-Arid West: Problems, Perspectives, and Solutions, Grand Teton National Park, Wyoming, May 21-22.

Bowders, John J., J. Erick Loehr, Deepak Neupane, and Abdelmalek Bouassa, 2003, "Construction Quality Control for Asphalt Concrete Hydraulic Barriers," Journal of Geotechnical and Geoenvironmental Engineering, Vol. 129, No. 3, pp. 219-223.

DOE-ID, 1994, Record of Decision: Declaration for Pad A at the Radioactive Waste Management Complex Subsurface Disposal Area at the Idaho National Engineering Laboratory, Administrative Record No. 5632, U.S. Department of Energy Idaho Operations Office; U.S. Environmental Protection Agency, Region 10; Idaho Department of Health and Welfare.

DOE-ID, 1997, Remedial Action Report for CFA Landfills I, II, and III Native Soil Cover Project Operable Unit 4-12, DOE/ID-10589, Rev. 0, U.S. Department of Energy Idaho Operations Office.

DOE-ID, 2004a, Action Memorandum for Accelerated Retrieval of a Described Area within Pit 4, DOE/NE-ID-11179, Rev. 0, U.S. Department of Energy Idaho Operations Office.

DOE-ID, 2004b, Remedial Action Report for the Operable Unit 7-10 Glovebox Excavator Method Project, DOE/NE-ID-11155, Rev. 0, U.S. Department of Energy Idaho Operations Office.

DOE-ID, 2006, Action Memorandum for the Accelerated Retrieval Project II within Pits 4 and 6 of the Subsurface Disposal Area, DOE/NE-ID-11238, U.S. Department of Energy Idaho Operations Office.

Dwyer, S. F., 1997, "Large-scale Field Study of Landfill Covers at Sandia National Laboratories," Conference Proceedings: Landfill Capping in the Semi-Arid West: Problems, Perspectives, and Solutions, held in Grand Teton National Park, Wyoming, pp. 87-107. 
EPA, 2006, Remediation Technology Descriptions, Alternative Landfill Cover Project Profiles, U.S. Environmental Protection Agency, Technology Innovation Program, URL: http://cluin.org/products/altcovers/, Web page visited January 30, 2007.

Holdren, K. Jean and Barbara J. Broomfield, 2004, Second Addendum to the Work Plan for the OU 7-13/14 Waste Area Group 7 Comprehensive Remedial Investigation/Feasibility Study, DOE/ID-11039, Rev. 0, U.S. Department of Energy Idaho Operations Office.

Holdren, K. Jean, Danny L. Anderson, Bruce H. Becker, Nancy L. Hampton, L. Don Koeppen, Swen O. Magnuson, and A. Jeffrey Sondrup, 2006, Remedial Investigation and Baseline Risk Assessment for Operable Unit 7-13/14, DOE/ID-11241, U.S. Department of Energy Idaho Operations Office.

ITRC, 2003, Technical and Regulatory Guidance for Design, Installation, and Monitoring of Alternative Final Landfill Covers, Interstate Technology Regulatory Council, Alternative Landfill Technologies Team, URL: http://www.itrcweb.org/Documents/ALT-2.pdf, Web page last visited February 1, 2007.

Jensen, Scott, 2004, “OU 7-13/14 In Situ Grouting Project Grout Selection,” EDF-5146, Rev. 0, Idaho National Engineering and Environmental Laboratory, Idaho Completion Project.

Keck, K. N. and R. R. Seitz, 2002, Potential for Subsidence at the Low-Level Radioactive Waste Disposal Area, INEEL/EXT-02-01154, Idaho National Engineering and Environmental Laboratory.

Lopez, Steve L., 2004, Action Memorandum for the Operable Unit 7-13/14 Early Actions Beryllium Encapsulation Project, DOE/NE-ID-11162, U.S. Department of Energy Idaho Operations Office.

Loomis, Guy G., Andrew P. Zdinak, and Carolyn W. Bishop, 1997, Innovative Subsurface Stabilization Project - Final Report (Revision 1), INEL-96/0439, Idaho National Engineering Laboratory.

Magnuson, S. O., 1993, A Simulation Study of Moisture Movement in Proposed Barriers for the Subsurface Disposal Area, EGG-WM-10974, Idaho National Engineering Laboratory.

Magnuson, Swen O. and A. Jeffrey Sondrup, 2006, Subsurface Flow and Transport Model Development for the Operable Unit 7-13/14 Remedial Investigation and Feasibility Study, ICP/EXT-05-01016, Rev. 1, Idaho National Laboratory, Idaho Cleanup Project.

Matthern, Gretchen, Neal Yancey, Gregory Hulet, and Peter Shaw, 2005, Preremedial Design Report of Remediation Options for OU 7-13/14, ICP/EXT-04-00330, Rev. 0, Idaho National Laboratory, Idaho Cleanup Project.

Mattson, Earl, Mark Ankeny, Steve Dwyer, Nancy Hampton, Gretchen Matthern, Brenda Pace, Alva Parsons, Mitch Plummer, Steve Reese, and Jody Waugh, 2004, Preliminary Design for an Engineered Surface Barrier at the Subsurface Disposal Area, ICP/EXT-04-00216, Rev. 0, Idaho National Engineering and Environmental Laboratory, Idaho Completion Project.

McKenzie, M. Doug, Donald E. Sebo, Kirk M. Green, and Vivian G. Schultz, 2005, Waste Information and Location Database for the OU 7-13/14 Project, ICP/EXT-04-00271, Rev. 0, Idaho National Laboratory, Idaho Cleanup Project. 
Porro, Indrik, 2001, "Hydrologic Behavior of Two Engineered Barriers Following Extreme Wetting," Journal of Environmental Quality, Vol. 30, pp. 655-667.

Public Law 102-579, 1992, "Waste Isolation Pilot Plant Land Withdrawal Act," U.S. Environmental Protection Agency.

Raivo, Brian D., 2004, "OU 7-13/14 In Situ Grouting Project Hydraulic Excavator and Drill-Injection Rig,” EDF-5153, Rev. 0, Idaho National Engineering and Environmental Laboratory, Idaho Completion Project.

Richins, W. D. and C. J. Hurst, 2004, “Assessment of Dynamic Soil Compaction at SDA,” EDF-4909, Rev. 0, Idaho National Engineering and Environmental Laboratory, Idaho Completion Project.

Shaw, Peter, 2004, "Grout Selection Criteria and Recommendation for the OU 7-13/14 In Situ Grouting Project," EDF-5333, Rev. 0, Idaho National Engineering and Environmental Laboratory, Idaho Completion Project.

Stephens, David L., 2004, “OU 7-13/14 In Situ Grouting Project Foundation Grouting Study,” EDF-5028, Rev. 0, Idaho National Engineering and Environmental Laboratory, Idaho Completion Project.

Suter, Glenn W. II, Robert J. Luxmoore, and Ellen D. Smith, 1993, "Compacted Soil Barriers at Abandoned Landfill Sites Are Likely to Fail in the Long Term," Journal of Environmental Quality, Vol. 22, No. 2, pp. 217-226.

Zitnik, James F., Aran T. Armstrong, Brian K. Corb, Mark H. Edens, Douglas B. Holsten, Patricia M. O'Flaherty, Janet Rodriguez, Tamara N. Thomas, Russell L. Treat, Wayne Schofield, and Kira L. Sykes, 2002, Preliminary Evaluation of Remedial Alternatives for the Subsurface Disposal Area, INEEL/EXT-02-01258, Rev. 0, prepared by CH2MHILL for the Idaho National Engineering and Environmental Laboratory. 


\section{CONTENTS}

4. DETAILED ANALYSIS OF ASSEMBLED ALTERNATIVES …........................................ $4-5$

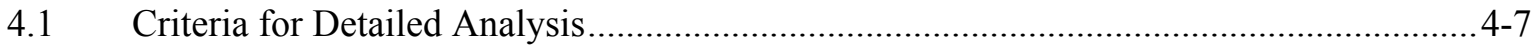

4.1.1 Overall Protection of Human Health and the Environment .............................4-7

4.1.2 Compliance with Applicable or Relevant and Appropriate Requirements .......4-7

4.1.3 Long-Term Effectiveness and Permanence........................................................4-8

4.1.4 Reduction of Toxicity, Mobility, or Volume through Treatment................... 4-10

4.1.5 Short-Term Effectiveness................................................................... $4-10$

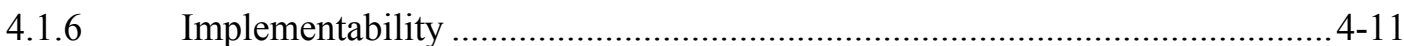

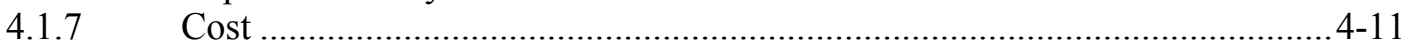

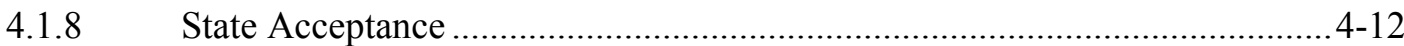

4.1.9 Community Acceptance .................................................................. 4-12

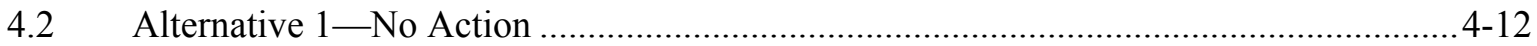

4.2.1 Overall Protection of Human Health and the Environment ..........................4-12

4.2.2 Compliance with Applicable or Relevant and Appropriate Requirements .... 4-13

4.2.3 Long-Term Effectiveness and Permanence....................................................4-14

4.2.4 Reduction of Toxicity, Mobility, or Volume through Treatment....................4-14

4.2.5 Short-Term Effectiveness..................................................................... 4-14

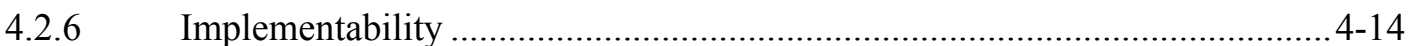

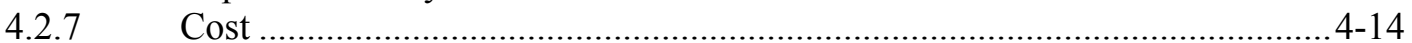

4.2.8 State Acceptance ......................................................................... 4 -15

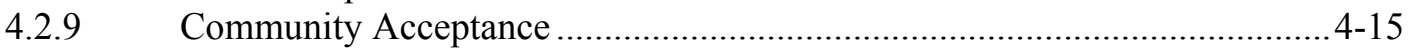

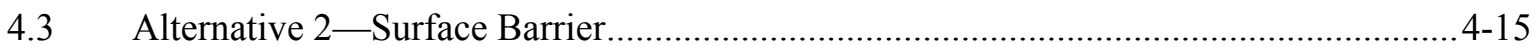

4.3.1 Alternative 2a-Modified Resource Conservation and Recovery Act Type C Surface Barrier .................................................................................4-16

4.3.2 Alternative 2b-Evapotranspiration Surface Barrier ...................................4-25

4.4 Alternative 3 - In Situ Grouting ......................................................................... 4-33

4.4.1 Overall Protection of Human Health and the Environment ............................4-34

4.4.2 Compliance with Applicable or Relevant and Appropriate Requirements ....4-34

4.4.3 Long-Term Effectiveness and Permanence.....................................................4-37

4.4.4 Reduction of Toxicity, Mobility, or Volume through Treatment................... 4-40

4.4.5 Short-Term Effectiveness .......................................................................4-41

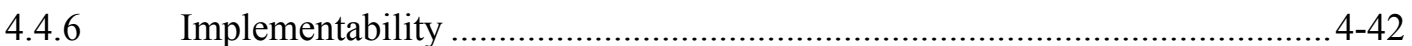

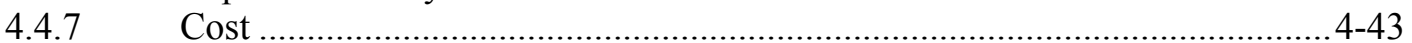

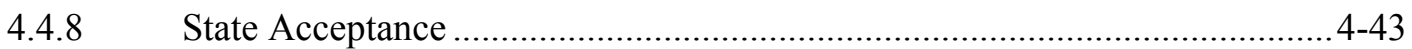

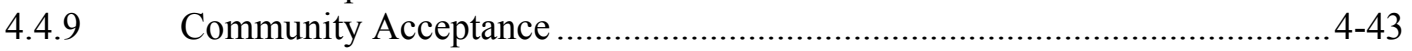

4.5 Alternative 4 Partial Retrieval, Treatment, and Disposal .......................................4-44

4.5.1 Alternative 4a-4-Acre Retrieval, Treatment, and Disposal ........................4-45

4.5.2 Alternative 4b-2-Acre Retrieval, Treatment, and Disposal ........................4-54 
4.6 Alternative 5-Full Retrieval, Treatment, and Disposal ..........................................4-60

4.6.1 Overall Protection of Human Health and the Environment ..........................4-60

4.6.2 Compliance with Applicable or Relevant and Appropriate Requirements ....4-61

4.6.3 Long-Term Effectiveness and Permanence....................................................4-63

4.6.4 Reduction of Toxicity, Mobility, or Volume through Treatment................... 4-66

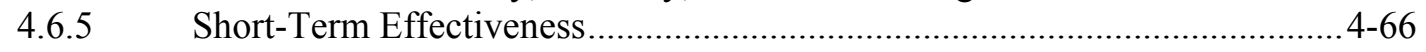

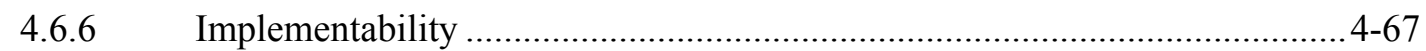

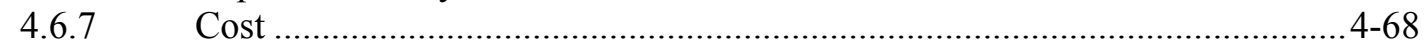

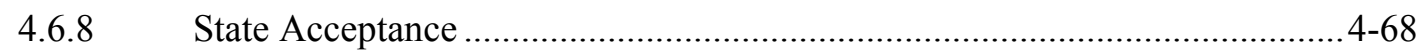

4.6.9 Community Acceptance ............................................................................. 4-68

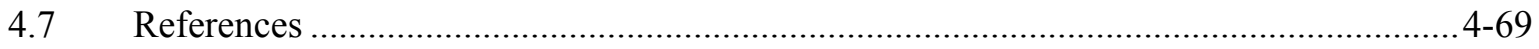

\section{FIGURES}

4-1. Cumulative groundwater ingestion risk for Alternative 2a-Modified RCRA Type C Surface Barrier, compared to Alternative $1-$ No Action ....

4-2. Hazard index for Alternative 2a-Modified RCRA Type C Surface Barrier, compared to Alternative $1-$ No Action

4-3. Cumulative groundwater ingestion risk for Alternative $2 b$-Evapotranspiration Surface Barrier, compared to Alternative 1-No Action

4-4. Hazard index for Alternative 2b-Evapotranspiration Surface Barrier, compared to Alternative $1-$ No Action

4-5. Cumulative groundwater ingestion risk for Alternative 3-In Situ Grouting, compared to Alternative 1-No Action and Alternative 2b-Evapotranspiration Surface Barrier....

4-6. Hazard index for Alternative 3-In Situ Grouting, compared to Alternative 1-No Action........4-38

4-7. Cumulative groundwater ingestion risk for Alternative 4a-4-Acre Partial Retrieval, Treatment, and Disposal, and Alternative 4b-2-Acre Partial Retrieval, Treatment, and Disposal, compared to Alternative 1-No Action.

4-8. Hazard index for Alternative 4a-4-Acre Partial Retrieval, Treatment, and Disposal, compared to Alternative 1-No Action.

4-9. Cumulative groundwater ingestion risk for Alternative 5-Full Retrieval, Treatment, and Disposal, compared to Alternative 1-No Action.

4-10. Hazard index for Alternative 5-Full Retrieval, Treatment, and Disposal, compared to Alternative $1-$ No Action 


\section{TABLES}

4-1. Regulatory compliance evaluation for Alternative 1 -No Action .......................................... 4-13

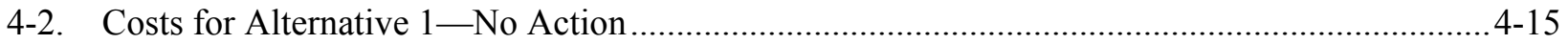

4-3. Regulatory compliance evaluation for Alternative 2a-Modified RCRA Type C Surface Barrier.

4-4. Costs for Alternative 2a-Modified RCRA Type C Surface Barrier.......................................... $4-25$

4-5. Regulatory compliance evaluation for Alternative $2 b$-Evapotranspiration Surface Barrier.......4-26

4-6. Costs for Alternative 2b—Evapotranspiration Surface Barrier ................................................ 4-33

4-7. Regulatory compliance evaluation for Alternative 3 - In Situ Grouting .................................. 4-35

4-8. Costs for Alternative 3 - In Situ Grouting …....................................................................... $4-43$

4-9. Regulatory compliance evaluation for Alternative 4a-4-Acre Partial Retrieval, Treatment,

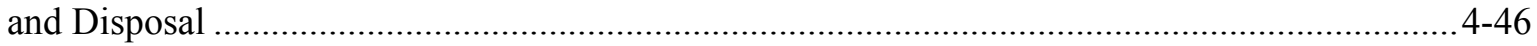

4-10. Costs for Alternative 4a-4-Acre Partial Retrieval, Treatment, and Disposal.......................... 4-53

4-11. Costs for Alternative 4b-2-Acre Partial Retrieval, Treatment, and Disposal ..........................4-59

4-12. Regulatory compliance evaluation for Alternative 5-Full Retrieval, Treatment,

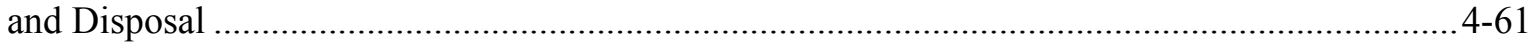

4-13. Costs for Alternative 5-Full Retrieval, Treatment, and Disposal............................................4-69 


\section{DETAILED ANALYSIS OF ASSEMBLED ALTERNATIVES}

This section provides detailed analysis of assembled remedial alternatives, specified by the Agencies and developed in Section 3, against Comprehensive Environmental Response, Compensation, and Liability Act (CERCLA) (42 USC § 9601 et seq., 1980) criteria prescribed by the National Contingency Plan (40 CFR 300.430). Results of this analysis form the basis for comparative analysis in Section 5 and for future activities that support the decision process (e.g., identifying a preferred alternative, preparing the Operable Unit [OU] 7-13/14 comprehensive proposed plan, and developing a record of decision [ROD]). This analysis presents sufficient information, in addition to input from the public, to provide a basis for remedial decision-making by the U.S. Department of Energy (DOE), Idaho Department of Environmental Quality (DEQ), and U.S. Environmental Protection Agency (EPA).

Alternatives were developed by combining various modules into assembled alternatives. Though each alternative is named after its featured component, all action alternatives include the following common elements:

- Vapor vacuum extraction and treatment-Continued operation of the ongoing Organic Contamination in the Vadose Zone (OCVZ) system established under OU 7-08 is a primary component in each action alternative. The OCVZ system extracts and treats volatile organic compounds (VOCs) from the vadose zone.

- $\quad$ Engineered surface barrier-Each alternative includes a surface barrier to prevent contaminant transport to the surface by plants and animals and to inhibit infiltration and subsequent transport of contaminants to the vadose zone. Overall thickness of the barrier, coupled with long-term institutional controls (ICs), would preclude inadvertent human intrusion.

- $\quad$ Long-term stewardship_Analysis in this feasibility study for OU 7-13/14 evaluates 100 years of postremediation long-term stewardship as a basis for modeling and cost estimating. However, these activities would be conducted until eliminated through the 5-year review process, in accordance with CERCLA (42 USC $\S 9601$ et seq., 1980). These activities include surveillance, maintenance, environmental monitoring, and ICs.

All action alternatives include varying strategies to address several additional elements. These additional elements are the following:

- $\quad$ Pretreatment for subsidence control-Each alternative includes one of three process options evaluated to address subsidence (see Section 2.2.6.1.2) to provide a stable foundation for the surface barrier.

- $\quad$ Pad A-Each alternative incorporates one of six options (see Section 2.2.9.1) to address Pad A-a unique abovegrade disposal area with an existing record of decision (ROD) (DOE-ID 1994) - into the comprehensive remedies.

- $\quad$ Near-surface, released VOCs_Each alternative incorporates one of three options (see Section 2.2.9.2) to preclude buildup of VOCs immediately beneath or within the surface barrier. These options are in addition to continued operation of the existing OCVZ system to extract and treat VOCs from the vadose zone. 
The five assembled alternatives developed in Section 3 to address the Subsurface Disposal Area (SDA) are summarized below:

- Alternative 1-No Action-comprises environmental monitoring only, with no measures to reduce risk.

- $\quad$ Alternative 2-Surface Barrier-includes two subalternatives that are evaluated in detail:

- $\quad$ Alternative 2a-Modified Resource Conservation and Recovery Act (RCRA) Type C Surface Barrier-is a surface barrier assembled with additional near-surface vapor vacuum extraction; foundation grouting to address subsidence; continued operation of the OCVZ system; and long-term surveillance, maintenance, monitoring, and ICs. Pad A would be incorporated as-is into the surface barrier.

- $\quad$ Alternative 2b-Evapotranspiration (ET) Surface Barrier-is a surface barrier with an active gas collection layer assembled with dynamic compaction to address subsidence, continued operation of the OCVZ system, and long-term surveillance, maintenance, monitoring, and ICs. Pad A waste would be transferred to the Low-Level Waste (LLW) Pit or other location within the SDA.

- $\quad$ Alternative 3-In Situ Grouting (ISG)—involves immobilizing Tc-99 and I-129 in place using high-pressure jet grouting. Relevant waste forms are associated with Idaho National Laboratory (INL) Site reactor research and operations. Fully assembled, this alternative includes dynamic compaction of pits to address subsidence, an ET surface barrier with a passive gas collection layer, continued operation of the OCVZ system, and long-term surveillance, maintenance, monitoring, and ICs. Pad A waste would be retrieved, treated ex situ, and transferred to the LLW Pit or other location within the SDA.

- $\quad$ Alternative 4-Partial Retrieval, Treatment, and Disposal (RTD)—includes the following two subalternatives that are evaluated in detail to facilitate scaling for variable sizes of retrieval areas:

- $\quad$ Alternative 4a-4-Acre Partial RTD—addresses removal of targeted Rocky Flats Plant waste from pit areas in the SDA totaling 4 acres. Additional features of this assembled alternative include dynamic compaction of pits to address subsidence, a passively vented ET surface barrier, continued operation of the OCVZ system, and long-term surveillance, maintenance, monitoring, and ICs. Pad A waste would be removed and sent to the Idaho CERCLA Disposal Facility (ICDF) for treatment and disposal.

- $\quad$ Alternative 4b-2-Acre Partial RTD—addresses removal of targeted Rocky Flats Plant waste from pit areas in the SDA totaling 2 acres. Additional features of this assembled alternative include proof-rolling of pits to address subsidence, a subsurface slurry wall around the perimeter of the landfill, a passively vented ET surface barrier, continued operation of the OCVZ system, and long-term site maintenance, monitoring, and ICs. Pad A would be dynamically compacted and incorporated into the surface barrier.

- $\quad$ Alternative 5-Full RTD—includes complete removal of all buried waste in combination with a simplified ET surface barrier, continued operation of the OCVZ system, and long-term surveillance, maintenance, monitoring, and ICs.

Subsections that follow describe the nine CERCLA criteria and evaluate the five assembled alternatives against those criteria. 


\subsection{Criteria for Detailed Analysis}

The National Contingency Plan (40 CFR 300.430) specifies nine criteria for analyzing remedial alternatives in detail. This feasibility study evaluates seven of the nine criteria and defers the last two in accordance with EPA guidance (EPA 1988). The nine criteria are grouped into three categories as follows:

- Threshold criteria-The first two criteria are (1) overall protection of human health and the environment, and (2) compliance with applicable or relevant and appropriate requirements (ARARs). Threshold criteria relate to statutory findings that must ultimately be included in the ROD. Consequently, remedial action must satisfy these first two criteria to qualify as a preferred alternative. Except for Alternative 1, which is included as a basis for comparison, remedial alternatives are not forwarded to detailed analysis unless threshold criteria can be met.

- Balancing criteria-The five balancing criteria are (3) long-term effectiveness and permanence; (4) reduction of toxicity, mobility, or volume through treatment; (5) short-term effectiveness;

(6) implementability; and (7) cost. Balancing criteria are tools for evaluating major characteristics of each alternative and their respective advantages and disadvantages. Balancing criteria also facilitate comparison of alternatives. Appendix $\mathrm{C}$ tabulates alternative-specific information used to evaluate the five balancing criteria.

- Modifying criteria-The last two criteria are (8) state acceptance and (9) community acceptance. Modifying criteria address acceptability of remedial alternatives to stakeholders. The feasibility study does not examine these criteria. Instead, modifying criteria are analyzed in conjunction with stakeholder comments on the proposed plan that follows completion of the remedial investigation and feasibility study. The proposed plan will summarize the remedial investigation and feasibility study and present the alternative preferred by DOE, DEQ, and EPA. The agencies could recombine elements (modules) extracted from combinations evaluated in this feasibility study (i.e., assembled alternatives) to compose their preferred alternative.

A description of each of the nine evaluation criteria outlined in the National Contingency Plan (40 CFR 300.430[e][9][iii]) and EPA guidance (EPA 1988) is presented in the following subsections. Characteristics of remedial alternatives that are addressed within each criterion also are described.

\subsubsection{Overall Protection of Human Health and the Environment}

This threshold criterion addresses how an alternative, as a whole, protects human health and the environment. Evaluating overall protection draws on assessments of other criteria, especially compliance with ARARs, long-term effectiveness and permanence, and short-term effectiveness.

\subsubsection{Compliance with Applicable or Relevant and Appropriate Requirements}

Compliance with ARARs is a threshold criterion. The National Contingency Plan (40 CFR 300.430[e][9][B]) requires that alternatives “. . . be assessed to determine whether they need to attain applicable or relevant and appropriate requirements under federal environmental laws and state environmental or facility siting laws or provide grounds for invoking one of the waivers under paragraph (f)(1)(ii)(c) of this section." Cleanup of a CERCLA site must meet requirements or standards promulgated by federal laws and more stringent state laws that relate as ARARs (42 USC § 9621[d][2]). In addition to ARARs, compliance is analyzed for other criteria, advisories, DOE orders, and guidance identified as materials to-be-considered (TBCs) if they help ensure protectiveness or are otherwise useful in assessing a specific alternative. 
The ARARs apply to both environmental regulations that direct site cleanup and environmental media criteria that protect human health and the environment. These regulations also promulgate protective requirements for natural, historical, and archaeological resources. However, ARARs do not encompass worker protection requirements addressed under the "Occupational Safety and Health Administration Act" (29 CFR 1910). While Section 300.150, "Worker Health and Safety," of the National Contingency Plan does require compliance with general Occupational Safety and Health Administration Act workplace standards, such standards do not fall within the scope of ARARs under CERCLA (42 USC § 9621[d][2]).

Preliminary ARARs are identified in Appendix B and are summarized in the discussions within the following subsections for each alternative. A table is provided for each alternative that identifies potential requirements by (a) type (i.e., chemical, location, or action-specific), (b) relevance (i.e., applicable, relevant and appropriate, or TBC), (c) regulatory source citation, and (d) whether the alternative would satisfy a corresponding requirement. In general, the National Contingency Plan requires that onsite actions (i.e., at the INL Site) must comply with substantive provisions of identified ARARs. Portions of alternatives that occur off the INL Site, must comply with all legally applicable requirements, both substantive and administrative (i.e., ARARs are pertinent only to onsite portions of remedial alternatives). Thus, CERCLA hazardous substances, once they are sent offsite for treatment, storage, or disposal, must comply with all environmental regulations normally applicable to the treatment, storage, and disposal facility outside the INL Site that receives them (e.g., 40 CFR Part 191 compliance by Waste Isolation Pilot Plant [WIPP]). Final determination of ARARs would be completed as part of remedy selection and documented in the OU 7-13/14 ROD.

\subsubsection{Long-Term Effectiveness and Permanence}

Evaluation of alternatives under this criterion addresses risk remaining at the site after remedial actions are complete. Factors considered include magnitude of residual risk and adequacy and reliability of controls. The extent that residual contamination (i.e., untreated waste or treatment residuals at conclusion of remedial action) remains hazardous is considered, taking volume, toxicity, mobility, and propensity to bioaccumulate into account. This factor addresses, in particular, uncertainties associated with land disposal for providing long-term protection from residual contamination; potential need to replace technical components of the alternative (e.g., a surface barrier or treatment system); and potential exposure pathways and risk posed if replacing the remedial action becomes necessary. Measures that are considered include containment systems and ICs that are necessary to manage treatment residuals and untreated waste.

Long-term effectiveness is qualitatively evaluated for human health surface exposure pathways and ecological receptors. This approach is adopted because each action alternative includes an engineered surface barrier that precludes biotic intrusion and subsequent contaminant transport to the surface, thus interrupting surface exposure pathways for all receptors. As a result, effectiveness in addressing surface exposure pathways is not a discriminating factor among alternatives. Adequacy and reliability of controls are dominating factors for evaluating performance of the surface barrier against remedial action objectives (Section 1.5) and preliminary remediation goals (Section 1.6).

Conversely, long-term effectiveness relating to groundwater is quantitatively evaluated. Estimates of contaminant concentrations in the aquifer were modeled for each alternative (see Appendix D). All primary and secondary contaminants of concern (COCs) were simulated. Resultant concentrations are addressed in two ways: (1) they are assessed for risk and compared to risk thresholds and remedial action objectives, and (2) they are compared directly to maximum contaminant levels (MCLs). The magnitude of residual concentrations and risk are dominating factors in assessing long-term effectiveness for groundwater. 
To facilitate comparison, each alternative was modeled as fully implemented and effective in 2010 , though implementation timeframes for action alternatives vary from 7 to 30 years. The surface barrier in each action alternative is the primary element that addresses groundwater risk. Continued operation of the OCVZ system also is a critical element. Alternatives would not substantially reduce groundwater risk, except through continued operation of the OCVZ system, until cap construction is complete. In the meantime, infiltration would continue, driving contaminants downward into the vadose zone toward the aquifer. The potential increase in long-term groundwater risk (i.e., increase caused by infiltration occurring after 2010 and before cap construction) is not shown in graphs that illustrate groundwater concentrations and risk. Similarly, release of VOCs would continue throughout implementation. However, the OCVZ system would operate throughout construction and beyond until remediation goals are satisfied. Thus, it may be necessary to extend OCVZ operations beyond those timeframes that were estimated based on instantaneous remediation in 2010 .

Groundwater modeling results for nitrate, three VOCs, and 1,4-dioxane are not used at face value in assessing long-term effectiveness. Though modeling results suggest otherwise, analysis concludes that all action alternatives would satisfy remedial action objectives and preliminary remediation goals for these COCs. The following subsections discuss uncertainties relating to interpretation of groundwater simulations for nitrate, VOCs, and 1,4-dioxane.

4.1.3.1 Nitrate. Simulated aquifer concentrations for nitrate are overpredicted, as discussed in detail in Appendix D (see Section D-3.6.1.1). For Alternative 1 (No Action), the numerical model underpredicts observed nitrate concentrations at the few locations in the vadose zone with observed elevated concentrations. The numerical model does, however, produce large overpredictions in the aquifer at Wells M17S, USGS-90, and USGS-117, demonstrating that nitrate simulation results are conservative overall. The majority of other aquifer locations outside this predicted contaminant plume show no simulated impact above local background concentrations. This demonstrated conservatism indicates uncertainty in model results, especially for nitrate. The model predicts a distributed plume of elevated nitrate in the vadose zone and aquifer that is not substantiated by monitoring. Simulations indicate that concentrations would exceed the nitrate MCL of $10 \mathrm{mg} / \mathrm{L}$ before 1980 in the aquifer at the Well M17S monitoring location and would approach $10 \mathrm{mg} / \mathrm{L}$ by 2005 at the Well USGS-119 monitoring location. However, neither location has shown monitoring results noticeably different from the regional background concentration of 1 to $2 \mathrm{mg} / \mathrm{L}$. This unsubstantiated plume within the Alternative 1 simulation affects, in turn, simulations that are used to evaluate long-term effectiveness of each action alternative. Though simulated concentrations produce a hazard index less than 1, they exceed the nitrate MCL of 10 $\mathrm{mg} / \mathrm{L}$ for all action alternatives (see Section D-4). These elevated current and future nitrate concentrations are not credible because they are based on simulated release from the source that has not occurred at the predicted magnitude. A consequence of overpredicted nitrate concentrations for this feasibility study is that the model shows a significant mass of nitrate released into the vadose zone that would be beyond the influence of remedial action. In reality, most of this mass is probably still in the buried waste. Remedial action that limits infiltration would effectively reduce transport to the vadose zone and aquifer and would prevent groundwater concentrations that exceed the nitrate MCL.

4.1.3.2 Volatile Organic Compounds. For three VOCs (i.e., carbon tetrachloride, methylene chloride, and trichloroethylene), simulation results meet vadose zone preliminary remediation goals; however, predicted aquifer concentrations are not less than MCLs in the year 2110 for all contaminants and all alternatives. The discrepancy primarily is due to simplifying assumptions used to develop remediation goals for OU 7-08 (which were adopted as preliminary remediation goals for OU 7-13/14) and uncertainties associated with those assumptions. Predicted concentrations do not fall below MCLs by the year 2110 in all cases. However, results for all three contaminants are only slightly greater than MCLs (e.g., maximum simulated carbon tetrachloride concentration of $12 \mu \mathrm{g} / \mathrm{L}$ compared to an MCL of $5 \mu \mathrm{g} / \mathrm{L}$ ); it is reasonable to conclude that MCLs are within the bounds of uncertainty. Appendix D presents details 
(see Section D-3.6.1.2). Though the modeling goal was to achieve vadose zone remediation goals and not MCLs, it is reasonable to expect, based on professional judgment and interpretation of model results, that achieving MCLs is probable. However, if vadose zone remediation goals are achieved and aquifer concentrations greater than MCLs are persistent, then risk management actions beyond source control measures evaluated in this feasibility study could be identified. Possible approaches include defining a groundwater exclusion zone (i.e., buffer zone), expanding the vapor vacuum extraction with treatment system, or implementing an aquifer pump and treat system.

4.1.3.3 1,4-Dioxane. Aquifer samples have not been analyzed specifically for 1,4-dioxane in the past; however, 1,4-dioxane has never been reported as a tentatively identified compound in routine monitoring. This analyte was added recently to the groundwater monitoring program at RWMC. The November 6, 2006, sampling event, is the first time 1,4-dioxane was on the analyte list. It was not detected. The simulated maximum aquifer concentration for 1,4-dioxane is approximately $120 \mu \mathrm{g} / \mathrm{L}$ in the year 2006 for Alternative 1 (No Action). Because it has not been reported as a tentatively identified compound and was not detected in any of the 15 aquifer monitoring wells sampled on November 6, 2006, 1,4-dioxane is probably overpredicted. However, routine monitoring over time will be necessary to further substantiate the conclusion that modeling overpredicts 1,4-dioxane.

\subsubsection{Reduction of Toxicity, Mobility, or Volume through Treatment}

The degree at which remedial action alternatives employ recycling or treatment that reduces toxicity, mobility, or volume is assessed, including how treatment addresses principal threats posed by a site. Approaches that do not involve treatment to reduce toxicity, mobility, or volume (e.g., surface barriers and retrieval) are not evaluated as treatment in assessing this criterion. Factors that may be considered include (a) treatment or recycling processes that the alternatives employ and materials they would treat; (b) amount of hazardous substances, pollutants, or contaminants that would be destroyed or recycled; (c) degree of expected reduction in toxicity, mobility, or volume of waste because of treatment or recycling and specification of which reductions are occurring; (d) degree to which treatment is irreversible; (e) types and quantities of residual contamination that would remain following treatment, taking into consideration persistence, toxicity, mobility, and propensity to bioaccumulate; and (f) degree to which treatment reduces inherent hazards posed by principal threats at the site.

\subsubsection{Short-Term Effectiveness}

Short-term effects, defined as risk incurred during implementation of a remedial action, include (a) risk to the community, (b) risk to workers and effectiveness and reliability of protective measures during implementation, (c) potential environmental impacts and effectiveness and reliability of mitigative measures, and (d) time until remedial action objectives are achieved. Implementation timeframes for each action alternative were estimated through completion of the surface barrier. The OCVZ system would continue to operate throughout construction except for limited downtime to modify the system for cap construction. Though all action alternatives include extended operation (e.g., decades) of the OCVZ system after construction of the surface barrier, it is an alternative-specific activity under annual operations and maintenance. Therefore, postconstruction OCVZ operation is not included in the estimated implementation timeframe for each alternative and is not evaluated as an element of short-term effectiveness.

A short-term risk assessment for each alternative was developed to quantitatively and qualitatively evaluate potential impacts to remediation workers, collocated workers, and members of the public (Wheldon et al. 2006). Hazards addressed in the assessment include construction accidents, transportation accidents, and exposures to carcinogenic and noncarcinogenic substances. The risk assessment provides a basis for ranking hazards from extremely low to high. Transportation accidents include transport of 
construction material to the SDA from sources within and outside of the INL Site. For those alternatives involving retrieval, risk associated with transport of waste outside the INL Site is incurred by the receiving facility (i.e., WIPP) and is not double-counted for OU 7-13/14, while transport within the INL Site (i.e., to ICDF) is considered. This assessment also estimated recordable injury and fatality frequencies for the public and collocated workers from transportation accidents, and injury and fatality frequencies for remediation workers based on industrial accidents.

Carcinogenic and noncarcinogenic risk estimates for remediation workers (Wheldon et al. 2006) are grossly overpredicted because they are based on the assumption that that same worker is involved throughout the entire implementation phase in whatever activity poses the highest risk. Furthermore, for retrieval alternatives, the same remediation worker is assumed to incur the maximum administrative dose during retrieval activities (both below grade and above grade). Operating experience gained during the ongoing Accelerated Retrieval Project suggests that waste from SDA pits and Pad A could be excavated and managed without exposing remediation workers to the maximum allowable administrative dose. Therefore, quantified results presented in Wheldon et al. (2006) are highly conservative. These results are interpreted qualitatively for purposes of assessing short-term risk in this feasibility study.

Radiological risk estimates for collocated workers and the public are relevant only for alternatives that include retrieval. The collocated worker is assumed to be present at the point of highest modeled dose, and the public member is assumed to be living at the southern INL Site boundary during retrieval (Wheldon et al. 2006).

\subsubsection{Implementability}

Ease or difficulty of implementing remedial alternatives is assessed by considering technical feasibility, administrative feasibility, and availability of services and materials. Aspects of technical feasibility include technical difficulties and unknowns associated with construction and operation of the technology, reliability of technology, ease of undertaking additional remedial actions, and ability to monitor effectiveness of the remedy. Administrative feasibility encompasses activities required to coordinate with other offices and agencies and acquire approvals and permits. Elements of availability of services and materials include abundance of adequate treatment, storage, and disposal services, necessary equipment and specialists, construction materials, and any additional resources.

\subsubsection{Cost}

Cost estimates developed for this feasibility study are for evaluating and comparing alternatives and are not suitable for budgetary, planning, or funding purposes. Estimates have an approximate range of accuracy of +50 to $-30 \%$, in accordance with EPA guidance (EPA 1988). Estimates are provided for both current value (2006 dollars) and net present value (future dollars). Net present value, also called present worth value, is the projected value of a future dollar after accounting for return and inflation. Present worth costs are estimated by using annual inflation factors provided within the latest revision of federal guidance (OMB 2006). Using currently estimated factors for future inflation, discount rates, and return on investment, present worth values are substantially lower than current value estimates.

Appendix F describes general methodology, assumptions, and derivations of cost estimates. Types of costs include capital costs, operations and maintenance costs, and periodic costs. Capital costs represent the construction phase of remedial action. Postconstruction operations and maintenance costs and periodic costs are estimated for 100 years after construction is complete; however, postconstruction activities (e.g., maintenance, monitoring, and ICs) would continue until terminated by the 5-year review process, which could occur well beyond 100 years. 
Capital cost factors include (a) mobilizing equipment and generating operational plans (e.g., operations and layout plans, radiation monitoring plan, quality control plan, and management self-assessment plan); (b) preparing the site; (c) implementing the remedial action (e.g., constructing a cap); (d) providing professional and technical services (e.g., remedial design, construction management, and project management); and (e) demobilizing equipment and generating final inspection reports.

Operations and maintenance costs include (a) groundwater and vadose zone monitoring, (b) observing and maintaining the surface barrier, (c) providing professional and technical services, and (d) operating the OCVZ system. Periodic costs include reporting for 100 years (e.g., annual summary reports) and support for 5-year reviews.

\subsubsection{State Acceptance}

Though representatives from the State of Idaho DEQ have actively participated in developing and evaluating remedial alternatives in this feasibility study, state acceptance is not evaluated. In keeping with guidance (EPA 1988), state acceptance will be addressed in the ROD after comments on the proposed plan are received. The proposed plan and ROD for OU 7-13/14 will be developed through consensus by DOE, DEQ, and EPA participants.

\subsubsection{Community Acceptance}

This feasibility study does not assess community acceptance. Instead, community acceptance will be evaluated based on responses to the preferred alternative identified by DOE, DEQ, and EPA in the proposed plan. Stakeholders' comments will be addressed in a responsiveness summary attached to the subsequent ROD. Assessing community acceptance includes determining which components of the remedial action alternatives interested persons in the community support, have reservations about, or oppose.

\subsection{Alternative 1-No Action}

Alternative 1 (No Action) provides a baseline for comparing other alternatives and includes only environmental monitoring with no additional actions to reduce risk. As assumed for the baseline risk assessment, retrieval of targeted waste would be completed in the described area of Pit 4 (DOE-ID 2004) and ongoing vapor vacuum extraction would be discontinued in the year 2010. Even though this alternative excludes maintenance and ICs, projected land use at the Radioactive Waste Management Complex (RWMC) is industrial. Consequently, this alternative represents an end state that is equivalent to exposure scenarios and risk estimates developed in the baseline risk assessment and its refinements (see Section 1.4).

\subsubsection{Overall Protection of Human Health and the Environment}

Alternative 1 provides no control of exposure to COCs in the SDA. Risk would not be reduced because transport to the surface by plants and animals would not be controlled and leaching into the subsurface, and ultimately to the aquifer, would be unabated. Therefore, this alternative does not satisfy this threshold criterion. 


\subsubsection{Compliance with Applicable or Relevant and Appropriate Requirements}

Long-term monitoring defined for Alternative 1 involves use of existing systems to collect samples and data from environmental media (e.g., air, soil, perched water, vadose zone soil moisture, and the aquifer). The ARARs are limited to specific requirements for monitoring undisturbed waste. Table 4-1 summarizes major substantive ARARs for Alternative 1. Overall, Alternative 1 would not satisfy this threshold criterion.

Table 4-1. Regulatory compliance evaluation for Alternative 1-No Action.

\begin{tabular}{|c|c|c|c|c|}
\hline ARAR or TBC & Type & Relevance & Citation & $\begin{array}{c}\text { Meets } \\
\text { Evaluation? }\end{array}$ \\
\hline $\begin{array}{l}\text { Idaho groundwater quality } \\
\text { standards }\end{array}$ & $\begin{array}{l}\text { Chemical } \\
\text { and action }\end{array}$ & A & IDAPA 58.01.11.200 & No \\
\hline $\begin{array}{l}\text { Safe Drinking Water Act } \\
\text { maximum contaminant levels }\end{array}$ & Chemical & RA & 40 CFR 141 & No \\
\hline $\begin{array}{l}\text { Idaho control of fugitive dust } \\
\text { emissions }\end{array}$ & $\begin{array}{l}\text { Chemical } \\
\text { and action }\end{array}$ & $\mathrm{A}$ & $\begin{array}{l}\text { IDAPA } 58.01 .01 .650 \\
\text { and } 651\end{array}$ & No \\
\hline $\begin{array}{l}\text { Radionuclide emissions from } \\
\text { DOE facilities }\end{array}$ & Action & A & 40 CFR 61.92 & Yes \\
\hline $\begin{array}{l}\text { Standards for Inactive Asbestos } \\
\text { Disposal Sites }\end{array}$ & Action & A & 40 CFR 61.151 & No \\
\hline $\begin{array}{l}\text { Radiation protection of the } \\
\text { public and the environment }\end{array}$ & $\begin{array}{l}\text { Chemical } \\
\text { and action }\end{array}$ & TBC & DOE Order 5400.5 & No \\
\hline \multicolumn{5}{|c|}{$\begin{array}{l}\mathrm{A}=\text { applicable } \\
\text { ARAR = applicable or relevant and appropriate requirement } \\
\text { CFR = Code of Federal Regulations } \\
\text { DOE = U.S. Department of Energy } \\
\text { IDAPA = Idaho Administrative Procedures Act } \\
\text { RA = relevant and appropriate } \\
\text { TBC = to-be-considered (other information from advisories, }\end{array}$} \\
\hline
\end{tabular}

Action-specific ARARs are not specifically pertinent to Alternative 1 because no remedial action is involved. This alternative would not fulfill DOE Order 5400.5, "Radiation Protection of the Public and the Environment," which is TBC. DOE Order 5400.5 provides standards for protecting the public and the environment from radioactive contamination from all routine DOE activities.

Contaminants would continue to leach from the SDA at rates that may affect groundwater and pose potential future risk to human health. Although technology applications for remediating area groundwater are not directly addressed, objectives associated with the action must ensure releases are mitigated to protect groundwater quality (i.e., source control is effective). Therefore, criteria (e.g., MCLs and MCL goals) established under the "National Primary Drinking Water Standards" (40 CFR 141) and groundwater quality standards, as adopted by the "Ground Water Quality Rule" (IDAPA 58.01.11), are applicable or relevant and appropriate standards for OU 7-13/14. Remedial actions at the SDA must take into consideration these criteria and address estimated groundwater risk to ensure compliance with remedial action objectives. 
Alternative 1 would not comply with Idaho rules for control of fugitive dust emissions (IDAPA 58.01.01.650 and 651), which apply to any source of fugitive dust. Because no effort would be made to mitigate or control dust that might occur over time, this alternative might result in future noncompliance with this standard. Further, diffuse radiological emissions from the undisturbed site must not exceed National Emission Standards for radionuclide emissions from DOE facilities (found in 40 CFR 61, Subpart H). Gaseous radionuclides are expected from some buried waste as a diffuse emissions source; however, past monitoring and reporting information indicates that such emissions would not exceed the applicable effective dose equivalent value of $10 \mathrm{mrem}$ at the nearest public receptor location. Because the LLW Pit in the SDA is currently an active asbestos waste disposal site, 40 CFR 154(g) requires that the closed site would have to meet standards for inactive asbestos waste disposal sites found in 40 CFR 61.151. Requirements involve performance criteria for emissions, surface cover, and controls (e.g., fencing, signs, and deed notifications) to warn of the presence of asbestos.

\subsubsection{Long-Term Effectiveness and Permanence}

Alternative 1 does not reduce long-term risk; therefore, the baseline risk assessment (as refined in Section 1.4) represents long-term effectiveness for this alternative. Because risk associated with the SDA would not be addressed, long-term effectiveness is low.

Current methods for monitoring and managing vegetation and animal intrusion in the SDA would continue. Risk to plant and animal receptors through ingestion or contact with surface and subsurface soil would remain at current levels or increase above levels identified in the 100 -year scenario. Therefore, environmental effectiveness of this alternative over the long term is low.

\subsubsection{Reduction of Toxicity, Mobility, or Volume through Treatment}

Because Alternative 1 does not include treatment, it does not address this criterion.

\subsubsection{Short-Term Effectiveness}

Overall, short-term effectiveness is high for human health and low for the environment. Monitoring poses negligible risk to monitoring staff, collocated workers, and off-INL Site populations. Typical environmental samples are either uncontaminated or have very low concentrations of hazardous or radioactive constituents. Sampling protocols ensure that samples are handled safely and managed in accordance with requirements. The baseline risk assessment showed risk to ecological receptors from exposure to surface and subsurface soil. Current ICs do not eliminate potential risk to plant and animal receptors.

\subsubsection{Implementability}

Alternative 1 is highly implementable because environmental monitoring is an ongoing, well-established activity at RWMC and across the INL Site. Both technical and administrative resources are readily available and technical procedures and administrative protocols are mature.

\subsubsection{Cost}

Cost estimates for Alternative 1 comprise monitoring and related expenses for 100 years. Estimates are based on the existing monitoring system, with a small allowance for replacing parts and equipment. Related expenses include labor, analytical costs, project management, preparing an annual report, and support for 5-year reviews throughout the 100-year timeframe. Table 4-2 summarizes costs for this alternative. 
Table 4-2. Costs for Alternative 1-No Action.

\begin{tabular}{|c|c|c|}
\hline Activity & $\begin{array}{l}\text { Current Value } \\
(\$ M)\end{array}$ & $\begin{array}{l}\text { Net Present Value } \\
(\$ \mathrm{M})\end{array}$ \\
\hline Capital costs & NA & NA \\
\hline \multicolumn{3}{|l|}{ Operations and maintenance costs } \\
\hline $\begin{array}{l}\text { Monitoring, sampling, testing, and analysis } \\
\text { (2010 through } 2110 \text { ) }\end{array}$ & 52.3 & 14.8 \\
\hline Total operations and maintenance cost & 52.3 & 14.8 \\
\hline \multicolumn{3}{|l|}{ Periodic costs } \\
\hline $\begin{array}{l}\text { Professional and technical services for annual reporting } \\
\text { and 5-year reviews ( } 2010 \text { through } 2110)\end{array}$ & 4.7 & 1.0 \\
\hline Total periodic cost & 4.7 & 1.0 \\
\hline Total cost & $\mathbf{5 7 . 0}$ & 15.8 \\
\hline
\end{tabular}

\subsubsection{State Acceptance}

State acceptance will be evaluated in conjunction with the future proposed plan and ROD for OU 7-13/14.

\subsubsection{Community Acceptance}

Community acceptance will be evaluated in conjunction with the future proposed plan and ROD for OU 7-13/14.

\subsection{Alternative 2-Surface Barrier}

Alternative 2 (Surface Barrier) would protect human health and the environment primarily by removing VOCs from the vadose zone and controlling potential exposure to COCs through containment with a surface barrier and ICs. Under this alternative, a low-permeability surface barrier would be constructed across the SDA. The surface barrier would inhibit biotic transport of contaminants to the surface and infiltration of precipitation and subsequent contaminant migration to the vadose zone and aquifer. Overall thickness of the cap, coupled with long-term ICs, would preclude inadvertent human intrusion. The OCVZ system would continue to extract and treat VOCs that have migrated into the vadose zone. Long-term surveillance, maintenance, monitoring, and ICs would ensure continued effectiveness of the remedy.

Alternative 2 comprises two subalternatives: Alternative 2a-Modified RCRA Type C Surface Barrier, and Alternative 2b-ET Surface Barrier. The primary difference between these alternatives is the design of the surface barrier. In addition, because multiple process options were identified in Section 3 to control subsidence, address Pad A, and prevent buildup of volatile contaminants beneath the surface barrier, the two subalternatives incorporate differing approaches for these elements. The two containment approaches are evaluated in detail in the following subsections. 


\subsubsection{Alternative 2a-Modified Resource Conservation and Recovery Act Type C Surface Barrier}

Alternative 2a includes a modified RCRA Type C surface barrier. As described in Section 3, this barrier design is similar to a standard RCRA surface barrier used at Subtitle C licensed disposal facilities across the country; however, it incorporates a sloped, low-permeability asphalt layer near the base of the surface barrier to divert infiltrating water to the edges of the barrier. Because the asphalt layer would be particularly susceptible to damage from differential subsidence, foundation grouting would be performed before surface barrier construction. Pad A would be left in its current configuration, and the surface barrier would be designed to address elevation difference. The existing OCVZ system would be enhanced with several near-surface vapor extraction wells near buried waste containing high concentrations of VOCs to mitigate buildup of volatile contaminants beneath the surface barrier.

4.3.1.1 Overall Protection of Human Health and the Environment. Alternative 2a would be fully protective of human health and the environment. Upon completion of the surface barrier (e.g., in the year 2016), this alternative would achieve all remedial action objectives (see uncertainties discussed in Section 4.1.3 relating to groundwater simulations for nitrate, VOCs, and 1,4-dioxane). The multilayer, low-permeability surface barrier would control and minimize contaminant migration by reducing surface water infiltration, thus impeding contaminant transport to the aquifer. In addition, the surface barrier would effectively isolate buried waste, prevent ecological receptor exposures, and prevent transport of contaminants by plants and animals to the surface, thus mitigating surface exposure risk for human and ecological receptors. Overall thickness of the cap, coupled with long-term ICs, would preclude inadvertent human intrusion. Continued operation of the OCVZ system, expanded by installing nearsurface extraction wells, would collect and treat VOCs that have migrated into the vadose zone or that could accumulate within and immediately beneath the impermeable asphalt layer and potentially increase contaminant migration to the vadose zone and aquifer. Long-term surveillance, maintenance, monitoring, and ICs would be conducted to ensure that the remedy remained protective.

4.3.1.2 Compliance with Applicable or Relevant and Appropriate Requirements. The most significant components of this alternative that relate to ARARs identification are design, construction, and operation and maintenance of the surface barrier, and operation of OCVZ treatment systems (i.e., treatment component). Table 4-3 provides an evaluation summary of the major substantive ARARs for Alternative 2a. Overall, Alternative 2a would satisfy this threshold criterion.

Alternative 2a includes a multilayer surface barrier that would mitigate potential exposure from radioactive and hazardous chemical contaminants, thus fulfilling DOE Order 5400.5. DOE Order 5400.5 provides TBCs for protecting the public and the environment from radioactive contamination from all routine DOE activities.

Air emissions associated with Alternative 2 a involve both point-source (e.g., operation of the OCVZ treatment system) and fugitive or diffuse emissions sources (e.g., generation of dust) during construction. This alternative would be designed and operated to comply with Idaho rules for control of fugitive dust emissions (IDAPA 58.01.01.650 and 651) that apply to any source of fugitive dust during construction and operation and maintenance. Further, point-source and diffuse radiological emissions from the INL Site must not exceed the National Emission Standards for radionuclide emissions from DOE facilities (found in 40 CFR 61, Subpart H). Gaseous radionuclides (e.g., C-14) are expected from some buried waste as a diffuse emissions source; however, past monitoring and reporting (Staley 2006) indicates that diffuse emissions would result in a very small fraction of the applicable effective dose equivalent value of $10 \mathrm{mrem}$ at the nearest public receptor location. In addition, remedial components 
Table 4-3. Regulatory compliance evaluation for Alternative 2a-Modified RCRA Type C Surface Barrier.

\begin{tabular}{|c|c|c|c|c|}
\hline ARAR or TBC & Type & Relevancy & Citation & $\begin{array}{c}\text { Meets } \\
\text { Evaluation? }\end{array}$ \\
\hline Idaho toxic air pollutants & Chemical & A & IDAPA 58.01 .01 .585 and 586 & Yes \\
\hline $\begin{array}{l}\text { Idaho ambient air quality standards } \\
\text { for specific air pollutants }\end{array}$ & Chemical & A & IDAPA 58.01.01.577 & Yes \\
\hline $\begin{array}{l}\text { National emission standards for } \\
\text { hazardous air pollutants }\end{array}$ & Chemical & A & 40 CFR 61.92 through 94 & Yes \\
\hline $\begin{array}{l}\text { Standards for Inactive Asbestos } \\
\text { Disposal Sites }\end{array}$ & Action & A & 40 CFR 61.151 & Yes \\
\hline $\begin{array}{l}\text { Idaho Groundwater Quality } \\
\text { Standards }\end{array}$ & $\begin{array}{l}\text { Chemical } \\
\text { and action }\end{array}$ & A & IDAPA 58.01.11.200 & Yes \\
\hline $\begin{array}{l}\text { Safe Drinking Water Act } \\
\text { maximum contaminant levels }\end{array}$ & Chemical & RA & 40 CFR 141 & Yes \\
\hline $\begin{array}{l}\text { Native American graves protection } \\
\text { and repatriation regulations }\end{array}$ & Location & A & 43 CFR 10 & $\begin{array}{l}\text { Yes-if } \\
\text { encountered }\end{array}$ \\
\hline $\begin{array}{l}\text { Preservation of historic, } \\
\text { prehistoric, and archeological data }\end{array}$ & Location & A & $\begin{array}{l}36 \text { CFR } 800 \text { and } \\
40 \text { CFR } 6.301(b) \text { and (c) }\end{array}$ & $\begin{array}{l}\text { Yes-if } \\
\text { encountered }\end{array}$ \\
\hline $\begin{array}{l}\text { Protection of archaeological } \\
\text { resources }\end{array}$ & Location & A & 43 CFR 7 & $\begin{array}{l}\text { Yes-if } \\
\text { encountered }\end{array}$ \\
\hline $\begin{array}{l}\text { Compliance with environmental } \\
\text { review requirements for } \\
\text { floodplains and wetlands }\end{array}$ & Location & A & 10 CFR 1022 & Yes \\
\hline $\begin{array}{l}\text { Treatment, storage, and disposal } \\
\text { facilities located within floodplains }\end{array}$ & Location & RA & 40 CFR 264.18(b) & Yes \\
\hline $\begin{array}{l}\text { Standards for owners and operators } \\
\text { of treatment, storage, and disposal } \\
\text { facilities-general groundwater } \\
\text { monitoring requirements }\end{array}$ & Action & RA & 40 CFR 264.97 & Yes \\
\hline $\begin{array}{l}\text { Standards for owners and operators } \\
\text { of treatment, storage, and disposal } \\
\text { facilities - closure and postclosure }\end{array}$ & Action & RA & $\begin{array}{l}\text { IDAPA 58.01.05 } \\
\text { (40 CFR 264.111; } \\
\text { 40 CFR 264.114; } \\
\text { 40 CFR 264.117) }\end{array}$ & Yes \\
\hline $\begin{array}{l}\text { Standards for owners and operators } \\
\text { of treatment, storage, and disposal } \\
\text { facilities - landfills }\end{array}$ & Action & RA & $\begin{array}{l}\text { IDAPA 58.01.05 } \\
(40 \text { CFR 264.310(a)(1) through } \\
(5),(b)(1),(4) \text { through (6) }\end{array}$ & $\mathrm{Yes}^{\mathrm{a}}$ \\
\hline $\begin{array}{l}\text { Standards for owners and operators } \\
\text { of treatment, storage, and disposal } \\
\text { facilities - use and management of } \\
\text { containers }\end{array}$ & Action & A & $\begin{array}{l}\text { IDAPA 58.01.05 } \\
\text { (40 CFR 264, Subpart I) }\end{array}$ & Yes \\
\hline $\begin{array}{l}\text { Generator standards - hazardous } \\
\text { waste determination }\end{array}$ & Action & A & $\begin{array}{l}\text { IDAPA 58.01.05.006 } \\
\text { (40 CFR 262.11) }\end{array}$ & Yes \\
\hline Idaho toxic substances & Action & A & IDAPA 58.01.01.161 & Yes \\
\hline Idaho visible emissions & Action & A & IDAPA 58.01.01.625 & Yes \\
\hline
\end{tabular}


Table 4-3. (continued).

\begin{tabular}{|c|c|c|c|c|}
\hline ARAR or TBC & Type & Relevancy & Citation & $\begin{array}{c}\text { Meets } \\
\text { Evaluation? }\end{array}$ \\
\hline $\begin{array}{l}\text { Idaho control of fugitive dust } \\
\text { emissions }\end{array}$ & Action & A & IDAPA 58.01.01.650 and 651 & Yes \\
\hline $\begin{array}{l}\text { Radiation protection of the public } \\
\text { and the environment }\end{array}$ & $\begin{array}{l}\text { Chemical } \\
\text { and action }\end{array}$ & $\mathrm{TBC}$ & DOE Order 5400.5 & Yes \\
\hline \multicolumn{5}{|c|}{$\begin{array}{l}\text { A }=\text { applicable } \\
\text { ARAR = applicable or relevant and appropriate requirement } \\
\text { CFR = Code of Federal Regulations } \\
\text { DOE = U.S. Department of Energy } \\
\text { IDAPA = Idaho Administrative Procedures Act } \\
\text { RA = relevant and appropriate } \\
\text { TBC = to-be-considered (other information from advisories, criteria, and guidance) }\end{array}$} \\
\hline
\end{tabular}

(e.g., operation of foundation grouting and OCVZ systems) may result in point-source radiological emissions that would be designed to comply with National Emission Standards for Hazardous Air Pollutants criteria. Chemical-specific requirements of pertinent air quality standards would be met during both construction and remediation, including controlling toxic air pollutants (IDAPA 58.01.01.585 and 586), ambient air quality standards for specific air pollutants (e.g., as particulate matter) (IDAPA 58.01.01.577), and visible emissions criteria (IDAPA 58.01.01.625).

Because the LLW Pit in the SDA is currently an active asbestos waste disposal site, 40 CFR 154(g) requires that the closed site would have to meet standards for inactive asbestos waste disposal sites found in 40 CFR 61.151. Requirements involve performance criteria for emissions, surface cover, and controls (e.g., fencing, signs, and deed notifications) to warn of the presence of asbestos.

Alternative 2a applies source-control measures to address remedial action objectives that protect groundwater resources. Therefore, criteria (e.g., MCLs and MCL goals) established under the "National Primary Drinking Water Standards" (40 CFR 141) and groundwater quality standards, as adopted by the "Ground Water Quality Rule" (IDAPA 58.01.11), are applicable or relevant and appropriate for OU 7-13/14. Alternative 2a would ensure compliance with these standards by extracting vapors from the vadose zone, reducing infiltration through the waste, and environmental monitoring.

Archeological artifacts have been found in surficial sediment near RWMC. If regulated artifacts or sites are encountered, applicable federal and state preservation requirements would be met. These include the Native American Graves Protection and Repatriation Regulations (43 CFR 10), Protection of Historic Properties (36 CFR 800 and 40 CFR 6.301[b]), and Preservation of Historical Sites (Idaho Statute 67-4601 et seq., 2005).

Though RWMC is not in the Big Lost River floodplain, it is located within a local topographic basin. The most recent study regarding potential for flooding at RWMC concludes that areas outside the SDA could flood as a result of overland flow of surface water (Mitchell et al. 2001). These conditions indicate that floodplain protection measures are applicable or relevant and appropriate, as indicated in Table 4-3. Requirements for federal agencies to comply with floodplain management (10 CFR 1022), to protect floodplains (40 CFR 6), and to implement protective measures at RCRA treatment, storage, and disposal facilities (40 CFR 264.18 [b]) are included. Design of the surface barrier must meet these requirements and would include appropriate engineering controls to prevent washout of hazardous waste by a 100 -year flood event. 
For RCRA requirements to be applicable to a CERCLA site, two conditions must be present: (1) materials at the site must be listed or exhibit a characteristic of hazardous waste, and (2) activity at the CERCLA site must constitute treatment, storage, or disposal as defined by RCRA (EPA 1988).

Hazardous waste would not be actively generated or placed based on remedial approaches associated with Alternative 2a, because the alternative leaves the waste in place. Consequently, RCRA requirements related to managing treatment, storage, and disposal facilities are identified as relevant and appropriate rather than as applicable for Alternative 2a.

"General Groundwater Monitoring Requirements" (40 CFR 264.97), specified in RCRA for the underlying aquifer, is relevant and appropriate to this alternative. Furthermore, because Alternative 2a leaves waste in place, various substantive RCRA Subtitle $\mathrm{C}$ requirements for closure and postclosure (40 CFR 264, Subpart G) may be relevant and appropriate, but not applicable because the SDA is not a new or existing RCRA-regulated unit. Likewise, various RCRA requirements for landfills (40 CFR 264, Subpart N) are relevant and appropriate for designing and operating the surface barrier. These requirements are adopted by reference in the State of Idaho "Rules and Standards for Hazardous Waste" (IDAPA 58.01.05). Design, construction, and operation of the surface barrier would meet these substantive state requirements. Requirements for design and construction of an underlying liner and leachate collection system are neither applicable nor relevant and appropriate for the SDA because waste was buried before the effective date of RCRA regulations.

The RCRA generator requirements for hazardous waste determination and management (40 CFR 262.11) would be applicable to newly generated waste resulting from remediation (e.g., secondary waste streams that result from foundation grouting) because potentially hazardous material may be generated. The RCRA container storage requirements also are identified as applicable to address potential temporary storage of small quantities of hazardous waste at the INL Site (e.g., secondary waste to be disposed of at an off-INL Site treatment, storage, and disposal facility) that could be generated during remedial action (e.g., OCVZ operations and sampling debris).

Institutional controls, including security measures, access controls, fencing, and land-use restrictions, are components of Alternative 2a. These controls would help prevent possible exposure to waste by human intruders and biota. Institutional controls also would meet applicable DOE requirements for residual radioactivity left in place, including related provisions of DOE Order 5400.5.

The SDA is an existing disposal site rather than a new radioactive waste disposal facility. Therefore, substantive waste disposal requirements contained in DOE Order 435.1 do not apply to Alternative $2 \mathrm{a}$ because the waste is left in place.

4.3.1.3 Long-Term Effectiveness and Permanence. Implementation of this alternative would control contaminant migration so that remedial action objectives are satisfied by the end of ICs (see uncertainties discussed in Section 4.1.3 relating to groundwater simulations for nitrate, VOCs, and 1,4-dioxane). The surface barrier would preclude direct exposure to buried waste by human or ecological receptors via surface exposure pathways. Overall thickness of the cap, coupled with long-term ICs, would preclude inadvertent human intrusion. Groundwater-pathway risk would be mitigated by combined effects of the OCVZ vapor extraction system and the low permeability of the surface barrier. All remedial elements included in Alternative 2a, with the exception of OCVZ operations, would be permanent and expected to remain functional into the indefinite future. The following subsections discuss the magnitude of residual risk and reliability of long-term controls.

4.3.1.3.1 Magnitude of Residual Risk-Based on qualitative analysis of the expected performance of the surface barrier, all surface exposure pathways would be interrupted, satisfying all remedial action objectives at the surface for both human and ecological receptors. 
Quantitative results of modeling discussed below are based on a conservative infiltration rate of $0.1 \mathrm{~cm} /$ year; however, studies performed for similar designs show that infiltration would be less than $0.05 \mathrm{~cm} /$ year (Gee, Ward, and Wittreich 2002).

Figure 4-1 compares cumulative groundwater ingestion risk for Alternative 2a to Alternative 1 (No Action). Alternative 2a clearly reduces the magnitude of residual risk to less than 1E-04 by controlling infiltration (see Appendix D for more details). Residual risk for groundwater use is highest in the immediate future (approximately the year 2010) and drops significantly during the simulated 100-year IC period. Risk remains fairly level at approximately 3E-05 until the year 2500 when it begins to decline again. After approximately year 4000, risk falls below 1E-05, where it remains over the duration of the 10,000-year simulation period (see Section 5, Figure 5-1).

Figure 4-2 compares the cumulative groundwater hazard index for Alternative $2 \mathrm{a}$ to Alternative 1. Results are based on overpredicted concentrations of carbon tetrachloride in the aquifer (see Section 4.1.3). Alternative 2a clearly reduces the magnitude of the hazard index by controlling infiltration and would satisfy remedial action objectives.

This alternative also would prevent groundwater concentrations from exceeding MCLs. Monitoring would be established to address uncertainties, especially for nitrate, VOCs, and 1,4-dioxane (see Section 4.1.3).

4.3.1.3.2 Reliability of Long-Term Controls-As illustrated in Figure 4-1, some level of residual risk would remain indefinitely after implementation of this remedial alternative. However, the magnitude of risk resulting from combined radiological and chemical hazards would be within the acceptable risk range established in the National Contingency Plan (40 CFR 300.430). A low-permeability surface barrier over the SDA would effectively reduce risk. For this alternative, the more significant questions for detailed analysis relate to long-term durability of the surface barrier and requirements for long-term monitoring and management to maintain its effectiveness.

In general, surface barriers, such as this one that incorporates continuous drainage layers, are susceptible to damage by differential settlement. The modified RCRA Type C surface barrier, which incorporates a thin, sloped layer of low-permeability asphalt to form a drainage layer could be broken or shifted out of plane by high-tensile stresses caused by subsidence. Such damage could funnel surface water into the landfill if not repaired. Surface barriers incorporating synthetic layers (e.g., asphalt) should not be applied in the SDA without substantial subsurface preparation because the potential for subsidence is significant (Mattson et al. 2004). Therefore, this alternative includes foundation grouting in pits to develop a stable base for the surface barrier. Foundation grouting, essentially installing a pattern of concrete pillars using an ISG rig, is described in detail in Section 3. Preliminary calculations indicate that installing columns on approximately $3.7-\mathrm{m}(12-\mathrm{ft})$ centers would effectively minimize differential settlement across pits. However, some uncertainty remains related to subsidence in other parts of the SDA. Though subsidence in trenches would be less severe than in pits, subsidence does occur. Pad A, which is neither removed nor grouted under this alternative is very susceptible to subsidence (Holdren et al. 2006), and its configuration is not conducive to foundation grouting. Subsidence would increase the need for future maintenance and repair of the surface barrier. 


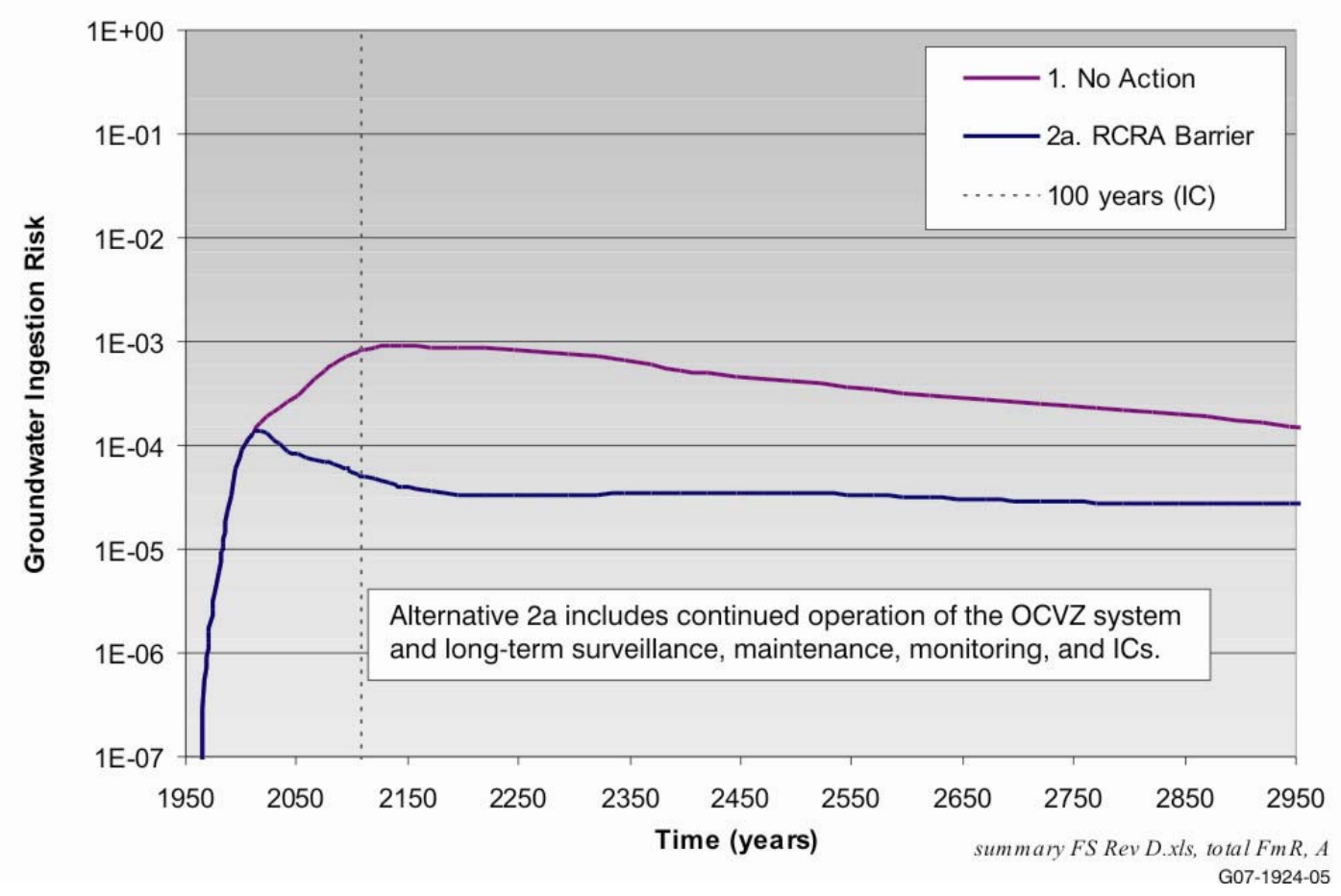

Figure 4-1. Cumulative groundwater ingestion risk for Alternative 2a-Modified RCRA Type C Surface Barrier, compared to Alternative 1-No Action.

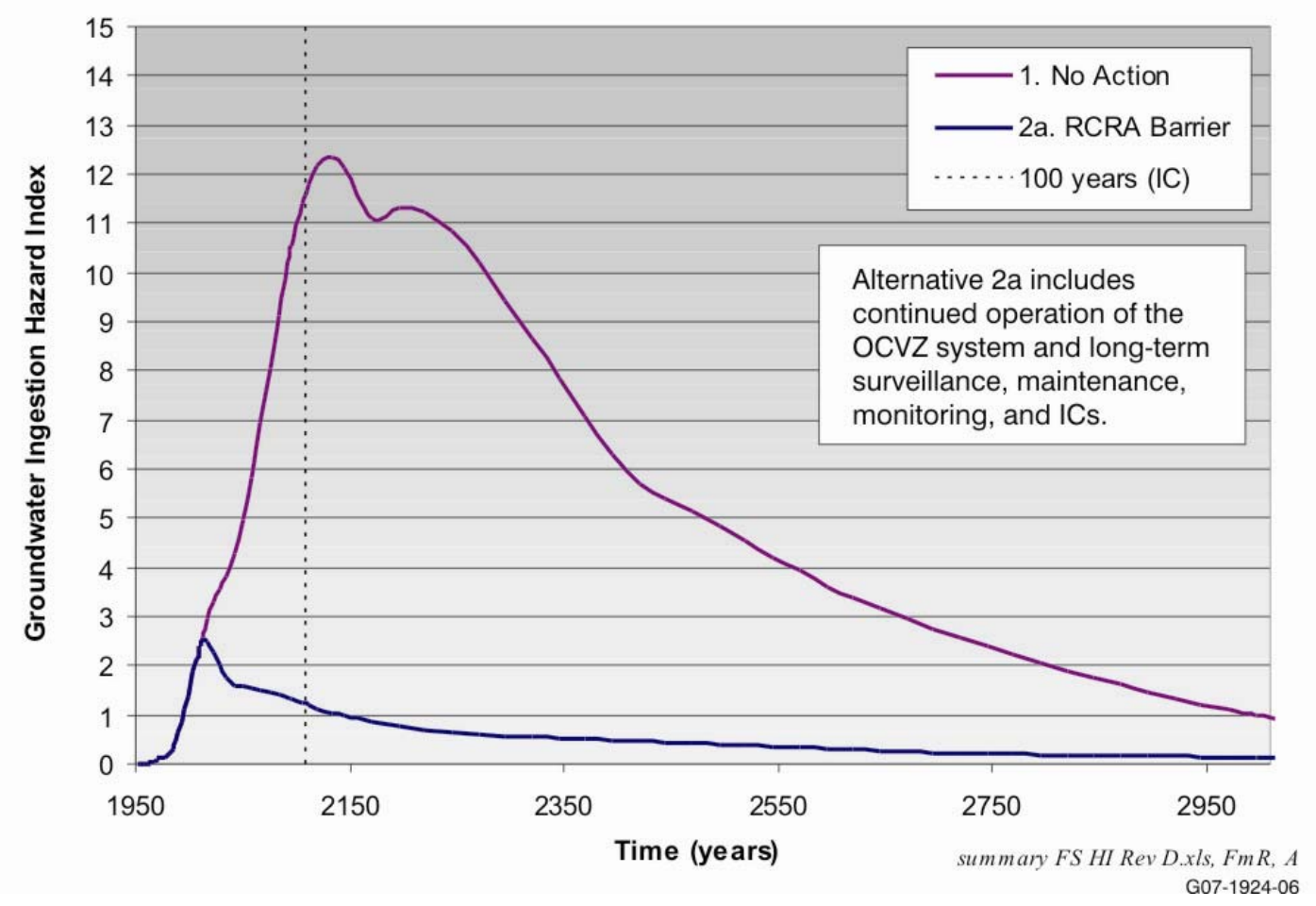

Figure 4-2. Hazard index for Alternative 2a-Modified RCRA Type C Surface Barrier, compared to Alternative $1-$ No Action. 
The surface barrier implemented in this alternative is potentially susceptible to intrusion by burrowing animals and deep-rooted plants over the long term, which, left uncontrolled, would result in redevelopment of exposure pathways through biotic transport from subsurface to surface. Smith, Luxmore, and Suter (1997) estimate that without regular maintenance, compacted soil caps supporting vegetation in semiarid environments could be breached by plant roots in 10 to 50 years and indicate that burrowing animals can be expected to inhabit a newly constructed surface barrier as soon as vegetation is established. Short-term effects of burrowing have been shown to be negligible in increasing penetration of water deeper into the profile (Gee and Ward 1997); however, extensive burrowing by rodents into archaeological mounds has been shown to substantially alter the original forms of the structures over hundreds of years (Suter, Luxmore, and Smith 1993). The asphalt base included as part of this alternative acts as a barrier to reduce potential intrusion by burrowing animals and plant roots. Though the asphalt layer would also reduce potential for exposure to VOCs, inhalation risk remains in the upper profile. Foundation grouting would potentially improve protection of the surface barrier perimeter from biological intrusion (i.e., issues with barrier configuration on edges). Areas of the SDA where intrusion could result in biotic transport of contaminants to the surface are relatively small (size of pits and trenches plus buffer), but horizontal intrusion and transport also are a concern.

Long-term management would be required to confirm performance of the assembled remedial components. Environmental monitoring would include routine collection and analysis of multimedia samples for all COCs. Because levels of untreated residual contamination would not allow unrestricted future use of the SDA site, 5-year reviews would be conducted indefinitely. Surveillance also would be conducted to identify differential settlement, inadequate drainage, or other observable degradation of the surface barrier. Institutional controls and long-term activities would be managed by a federal agency (e.g., DOE or the Bureau of Land Management) to ensure that effective protection is maintained.

4.3.1.4 Reduction of Toxicity, Mobility, or Volume through Treatment. This alternative does not include treatment as a source-control measure, though the surface barrier would substantially reduce mobility. The surface barrier would effectively mitigate all risk associated with exposure to COCs caused by biotic transport to the surface and would substantially reduce contaminant migration into the vadose zone and underlying aquifer.

Treatment is applied to VOCs collected from the vadose zone. A portion of VOCs released from source materials would be removed from the vadose zone beneath the surface barrier and thermally oxidized using the OCVZ treatment system.

4.3.1.5 Short-Term Effectiveness. Potential risk to the public and workers during implementation of remedial components included in Alternative 2a would be extremely low when controls typical of DOE waste management operations are used (Wheldon et al. 2006). Operating experience suggests that all aspects of remedial action could be conducted without exposing members of the public to significant amounts of hazardous or radioactive contaminants. Approximately one public injury might be incurred in an accident involving transport of construction materials to the SDA over public thoroughfares (Wheldon et al. 2006). However, engineering and administrative controls would minimize potential short-term risk to the public (e.g., transportation schedules and routes would be designed to minimize interference with public traffic patterns). A fatality involving transport of construction materials for Alternative 2a would be highly unlikely (Wheldon et al. 2006).

Short-term risk to workers also is very low for this alternative. Remediation workers would be protected by maintaining exposure to penetrating radiation as low as reasonably achievable, using personal protective equipment to limit risk associated with inhalation or dermal adsorption of radionuclides or chemicals, and promoting a safety culture that creates a work environment free from occupational injury or illness. A maximally exposed worker involved in construction would incur a 
negligible increase in lifetime cancer risk relative to a worker involved in routine construction activities in the SDA (Wheldon et al. 2006). Chemical risk and hazards for a remediation worker and collocated worker would be negligible based on qualitative analysis of the absence of an identified exposure pathway. All physical and chemical risk to remediation workers could be readily controlled through engineered or administrative controls, or personal protective equipment. Workers implementing remedial components included in Alternative 2a could incur as many as five recordable industrial accidents (Wheldon et al. 2006). A worker fatality would be highly unlikely during implementation of this alternative.

Immediate risk to the environment as a result of exposure to contaminants would remain at or below those identified in the baseline risk assessment during implementation of this alternative. Fencing around the expanded perimeter is a component of this alternative and would continue to reduce, but not entirely exclude, access to the area by larger animals. Biotic transport through plant uptake and exposure of animal receptors as a result of contact and ingestion of surface and subsurface soil would decrease during the first year construction of the surface barrier begins (i.e., once the asphalt layer is complete). Upon completion of the surface barrier, exposure pathways for ecological receptors would be eliminated.

Potential short-term impacts to the environment for this alternative include disturbances to plant and animal communities resulting from construction of the surface barrier. Surface barrier design and construction of a new access road would expand the active area of the SDA up to $30.5 \mathrm{~m}(100 \mathrm{ft})$ beyond current boundaries, impacting approximately 49 ha (120 acres). Much of the area immediately surrounding the SDA has been previously disturbed by construction and management activities. Fewer than 16.2 ha (40 acres) of undisturbed native vegetation would be affected. No sensitive plant species are known in the area, and the number of individual plants lost would be small relative to the overall area of native communities found at the INL Site. Areas where vegetation and soil are disturbed are at increased risk for invasion by exotic weeds and could act as conduits for expansion of invasive species into native communities. Large weed infestations can potentially increase the hazard of fires but would be mitigated through weed control measures. Minor leaks or spills of oil or gasoline could result in small areas that cannot be vegetated without replacing or remediating affected soil.

Dust created by construction activities and heavy equipment traffic can reduce photosynthesis and otherwise damage plants and, in particular, biotic crusts (Trombulak and Frissell 2000), which are important components of native shrub-steppe communities. Blowing or drifting dust and other pollutants (e.g., vehicle exhaust) can affect vegetation growth at substantial distances beyond active construction areas (Auerbach, Walker, and Walker 1997). Disturbance of current grading and compaction of roadways could reduce drainage, rechannel surface water, and increase erosion. Surface water management and dust suppression measures along roadways and in construction areas would be implemented to mitigate environmental impacts to adjacent vegetation and reduce erosion.

Some small mammals, birds, and reptiles, both on and around the SDA, would be displaced during implementation of this alternative. Noise and ground vibration from construction activities and heavy equipment traffic could disturb resident wildlife and drive some species from the area (Manci et al. 1988). While no threatened or endangered species are resident on or immediately adjacent to the SDA, several species of concern, including the pygmy rabbit, loggerhead shrike, and burrowing owls, have been observed in the vicinity. Construction activities carried into the fall and winter could disturb resident animals (e.g., marmots and reptiles) hibernating near the SDA; night-time activity and lighting could disrupt feeding behavior of some nocturnal species (e.g., owls, reptiles, and bats). Mobile species are likely to leave the areas of activity. Deaths of individual animals are probable in the active areas and along roadways, but losses of small numbers would have little overall effect on local or regional populations. 
Remedial action objectives would be met within 7 years upon completion of the surface barrier. The environment immediately adjacent to the active area would be highly impacted during construction, but overall, short-term effectiveness of this alternative is high to moderate.

4.3.1.6 Implementability. Alternative 2a is technically and administratively implementable. No specialized equipment, personnel, or services are required, and construction materials are readily available on the INL Site or from local sources. However, modified RCRA Type C surface barriers to date have been deployed for relatively small areas (e.g., less than 5 acres) (EPA 2006), and significant implementability issues may be anticipated during construction of a larger surface barrier, such as that required for the SDA (e.g., greater than 97 acres). Specifically, staged deployment of an asphalt composite layer over a large area would require construction of sealed joints at intermediate boundaries. Because of previous difficulties experienced in construction of thin impermeable layers (Suter, Luxmore, and Smith 1993), rigorous construction quality control would be required to ensure integrity of a thin asphalt composite hydraulic surface barrier (Bowders et al. 2003). Other components of this remedial action (e.g., the OCVZ system, environmental monitoring, and ICs) have been routinely implemented at the INL Site. Subgrade stabilization by ISG has not been used for long-term support of a surface barrier, and it would be necessary to demonstrate implementability and effectiveness before use in the SDA.

This alternative has no significant administrative feasibility issues. Concurrent operations (e.g., foundation grouting) would require careful planning and deployment to reduce the likelihood of construction flaws in the surface barrier. Expansion or development of new borrow areas may be necessary to obtain sufficient surface barrier materials. Currently, eight permitted gravel and borrow sources are available to support maintenance operations, new construction, and environmental restoration and waste management activities (Minkin et al. 1994). The potential total amount of soil available for INL Site use from these sources is in excess of 13 million cubic yards (DOE-ID 1997), which would be sufficient for construction of a surface barrier over the SDA (Mattson et al. 2004). Nevertheless, availability of borrow materials and requirements for other construction projects competing for material at the INL Site must be coordinated to support timely construction of the surface barrier.

Available services and materials are ample. Multiple vendors are available for all aspects of the work. Elements of surface barrier construction, including development of borrow areas, hauling, and placement of surface barrier materials, could be accomplished by a number of local construction firms. Several specialized firms with specific geotechnical experience are available to provide foundation grouting.

4.3.1.7 Cost. Capital, operations and maintenance, and periodic costs for Alternative 2a are provided as current value and net present value in Table 4-4. The base year in calculating net present value is 2006, with construction beginning in the year 2010 and ending in 2016. Estimates include costs for 100 years of surveillance and maintenance, monitoring, and ICs following construction. Appendix F provides additional details.

4.3.1.8 State Acceptance. State acceptance will be evaluated in conjunction with the future proposed plan and ROD for OU 7-13/14.

4.3.1.9 Community Acceptance. Community acceptance will be evaluated in conjunction with the future proposed plan and ROD for OU 7-13/14. 
Table 4-4. Costs for Alternative 2a-Modified RCRA Type C Surface Barrier.

$$
\text { Activity }
$$

\section{Current Value Net Present Value}

(\$M)

$(\$ M)$

\section{Capital costs}

RCRA Type C surface barrier (2011 through 2016)

119.4

94.9

Foundation grouting (2010 through 2011)

14.9

12.8

Expansion of OCVZ system with shallow extraction wells

(2011 and 2016)

Replace OCVZ treatment units every 20 years

6.8

(2031, 2051, and 2071)

Total capital cost

144.6

112.5

\section{Operations and maintenance costs}

Surface barrier maintenance and monitoring

(2017 through 2116)

OCVZ operations, maintenance, and monitoring

111.0

43.5

(2010 through 2074)

Total operations and maintenance cost

193.9

62.5

\section{Periodic costs}

Final remedial action report, annual summary reports,

1.1

5 -year reviews, and final operations and maintenance report

(2017 through 2116)

Total periodic cost

5.2

1.1

Total cost

343.7

176.1

OCVZ $=$ Organic Contamination in the Vadose Zone

RCRA = Resource Conservation and Recovery Act

\subsubsection{Alternative 2b-Evapotranspiration Surface Barrier}

Alternative $2 b$ includes an ET surface barrier. This surface barrier would not be particularly susceptible to damage from differential subsidence; however, dynamic compaction would be performed in pit areas before surface barrier construction to minimize the need for future maintenance. Dynamic compaction was identified because it presents the most short-term risk and highest cost among process options that apply surface treatment to address subsidence, thus bounding the analysis. Other process options, such as impact rolling, could be substituted during remedial design. Waste would be removed from Pad A and transferred to the LLW Pit or other location within the SDA to facilitate surface barrier construction. A gas-collection system would be integrated into the ET surface barrier to prevent buildup of volatile contaminants beneath the surface barrier.

4.3.2.1 Overall Protection of Human Health and the Environment. Alternative $2 \mathrm{~b}$ would be fully protective of human health and the environment. Upon completion of the surface barrier in the year 2019, this alternative would achieve all remedial action objectives (see uncertainties discussed in Section 4.1.3 relating to groundwater simulations for nitrate, VOCs, and 1,4-dioxane). The ET surface barrier would minimize contaminant migration by reducing surface water infiltration rates, thus impeding 
further release of contamination into the vadose zone and aquifer. In addition, the surface barrier would effectively isolate buried waste, thus mitigating surface exposure risk for human and ecological receptors. Overall thickness of the cap, coupled with long-term ICs, would preclude inadvertent human intrusion. Continued operation of the existing OCVZ system, enhanced with an active vapor extraction layer in the surface barrier, would collect and treat VOCs from the vadose zone to reduce transport to the aquifer. Long-term surveillance, maintenance, monitoring, and ICs would be conducted to ensure that the remedy remained protective.

\subsubsection{Compliance with Applicable or Relevant and Appropriate Requirements.}

Because of the many common features between Alternatives $2 a$ and $2 b$, the ARARs analysis also is similar. Table 4-5 provides an evaluation summary of the major substantive ARARs for Alternative $2 \mathrm{~b}$, which are the same as identified for Alternative 2a in Table 4-3. Nuances relative to approaches for Pad A, subsidence, and the OCVZ system are addressed in the following paragraphs. See Section 4.3.1.2 for a more detailed discussion regarding other elements of ARARs analysis. Overall, Alternative 2b would satisfy this threshold criterion.

Table 4-5. Regulatory compliance evaluation for Alternative 2b-Evapotranspiration Surface Barrier.

\begin{tabular}{|c|c|c|c|c|}
\hline ARAR or TBC & Type & Relevancy & Citation & $\begin{array}{c}\text { Meets } \\
\text { Evaluation? }\end{array}$ \\
\hline Idaho toxic air pollutants & Chemical & A & IDAPA 58.01 .01 .585 and 586 & Yes \\
\hline $\begin{array}{l}\text { Idaho ambient air quality standards } \\
\text { for specific air pollutants }\end{array}$ & Chemical & $\mathrm{A}$ & IDAPA 58.01.01.577 & Yes \\
\hline $\begin{array}{l}\text { National emission standards for } \\
\text { hazardous air pollutants }\end{array}$ & Chemical & A & 40 CFR 61.92 through 94 & Yes \\
\hline $\begin{array}{l}\text { Standards for Inactive Asbestos } \\
\text { Disposal Sites }\end{array}$ & Action & A & 40 CFR 61.151 & Yes \\
\hline $\begin{array}{l}\text { Idaho Groundwater Quality } \\
\text { Standards }\end{array}$ & $\begin{array}{l}\text { Chemical } \\
\text { and action }\end{array}$ & A & IDAPA 58.01.11.200 & Yes \\
\hline $\begin{array}{l}\text { Safe Drinking Water Act } \\
\text { maximum contaminant levels }\end{array}$ & Chemical & RA & 40 CFR 141 & Yes \\
\hline $\begin{array}{l}\text { Native American graves protection } \\
\text { and repatriation regulations }\end{array}$ & Location & A & 43 CFR 10 & $\begin{array}{l}\text { Yes-if } \\
\text { encountered }\end{array}$ \\
\hline $\begin{array}{l}\text { Preservation of historic, } \\
\text { prehistoric, and archeological data }\end{array}$ & Location & A & $\begin{array}{l}36 \text { CFR } 800 \text { and } \\
40 \text { CFR } 6.301(b) \text { and (c) }\end{array}$ & $\begin{array}{l}\text { Yes-if } \\
\text { encountered }\end{array}$ \\
\hline $\begin{array}{l}\text { Protection of archaeological } \\
\text { resources }\end{array}$ & Location & A & 43 CFR 7 & $\begin{array}{l}\text { Yes-if } \\
\text { encountered }\end{array}$ \\
\hline $\begin{array}{l}\text { Compliance with environmental } \\
\text { review requirements for } \\
\text { floodplains and wetlands }\end{array}$ & Location & A & 10 CFR 1022 & Yes \\
\hline $\begin{array}{l}\text { Treatment, storage, and disposal } \\
\text { facilities located within floodplains }\end{array}$ & Location & RA & 40 CFR 264.18(b) & Yes \\
\hline $\begin{array}{l}\text { Standards for owners and operators } \\
\text { of treatment, storage, and disposal } \\
\text { facilities-general groundwater } \\
\text { monitoring requirements }\end{array}$ & Action & RA & 40 CFR 264.97 & Yes \\
\hline
\end{tabular}


Table 4-5. (continued).

\begin{tabular}{|c|c|c|c|c|}
\hline ARAR or TBC & Type & Relevancy & Citation & $\begin{array}{c}\text { Meets } \\
\text { Evaluation? }\end{array}$ \\
\hline $\begin{array}{l}\text { Standards for owners and operators } \\
\text { of treatment, storage, and disposal } \\
\text { facilities_closure and postclosure }\end{array}$ & Action & RA & $\begin{array}{l}\text { IDAPA 58.01.05 } \\
\text { (40 CFR 264.111; } \\
\text { 40 CFR 264.114; } \\
40 \text { CFR 264.117) }\end{array}$ & Yes \\
\hline $\begin{array}{l}\text { Standards for owners and operators } \\
\text { of treatment, storage, and disposal } \\
\text { facilities_-landfills }\end{array}$ & Action & RA & $\begin{array}{l}\text { IDAPA 58.01.05 } \\
(40 \text { CFR 264.310(a)(1) } \\
\text { through }(5),(\mathrm{b})(1),(4) \\
\text { through }(6)\end{array}$ & Yes $^{\mathrm{a}}$ \\
\hline $\begin{array}{l}\text { Standards for owners and operators } \\
\text { of treatment, storage, and disposal } \\
\text { facilities — use and management of } \\
\text { containers }\end{array}$ & Action & A & $\begin{array}{l}\text { IDAPA } 58.01 .05 \\
\text { (40 CFR 264, Subpart I) }\end{array}$ & Yes \\
\hline $\begin{array}{l}\text { Generator standards - hazardous } \\
\text { waste determination }\end{array}$ & Action & A & $\begin{array}{l}\text { IDAPA 58.01.05.006 } \\
(40 \text { CFR 262.11) }\end{array}$ & Yes \\
\hline Idaho toxic substances & Action & A & IDAPA 58.01.01.161 & Yes \\
\hline Idaho visible emissions & Action & A & IDAPA 58.01.01.625 & Yes \\
\hline $\begin{array}{l}\text { Idaho control of fugitive dust } \\
\text { emissions }\end{array}$ & Action & A & IDAPA 58.01.01.650 and 651 & Yes \\
\hline $\begin{array}{l}\text { Radiation protection of the public } \\
\text { and the environment }\end{array}$ & $\begin{array}{l}\text { Chemical } \\
\text { and action }\end{array}$ & $\mathrm{TBC}$ & DOE Order 5400.5 & Yes \\
\hline \multicolumn{5}{|c|}{$\begin{array}{l}\text { A }=\text { applicable } \\
\text { ARAR = applicable or relevant and appropriate requirement } \\
\text { CFR = Code of Federal Regulations } \\
\text { DOE = U.S. Department of Energy } \\
\text { IDAPA = Idaho Administrative Procedures Act } \\
\text { RA = relevant and appropriate } \\
\text { TBC = to-be-considered (other information from advisories, }\end{array}$} \\
\hline
\end{tabular}

The difference between Subalternatives $2 \mathrm{a}$ and $2 \mathrm{~b}$ in handling Pad A waste was assessed regarding potential impact on identified ARARs. Alternative 2a incorporates Pad A into the surface barrier while Alternative $2 \mathrm{~b}$ transfers Pad A waste to the LLW Pit or other area within the SDA. Transfer of Pad A waste within the area of contamination would not impact RCRA treatment, storage, and disposal ARARs. Consolidating or moving waste within an area of contamination does not constitute treatment, storage, or disposal of a hazardous waste. Temporary staging of Pad A waste in containers within the area of contamination would not necessitate management of a RCRA storage area and, as such, would not constitute placement of the containers in a separate hazardous waste management unit (i.e., would not trigger applicability of land disposal restrictions before disposal). The identified RCRA treatment, storage, and disposal requirements for closure and postclosure of the landfill are identified as relevant and appropriate; the ET surface barrier would satisfy these requirements.

Because the LLW Pit in the SDA is currently an active asbestos waste disposal site, 40 CFR 154(g) requires that the closed site would have to meet standards for inactive asbestos waste disposal sites found in 40 CFR 61.151. Requirements involve performance criteria for emissions, surface cover, and controls (e.g., fencing, signs, and deed notifications) to warn of the presence of asbestos. 
Dynamic compaction of pits in Alternative $2 b$ (instead of foundation grouting in Alternative 2a) would be bound within the scope of the previously identified ARARs and does not trigger applicability of additional ARARs. Similarly, though Alternative 2a includes installation of additional near-surface extraction wells, OCVZ treatment components of the two subalternatives are relatively consistent with the same basis for requirements.

4.3.2.3 Long-Term Effectiveness and Permanence. Implementation of this alternative would control contaminant migration so that remedial action objectives are satisfied by the end of ICs (see uncertainties discussed in Section 4.1.3 relating to groundwater simulations for nitrate, VOCs, and 1,4-dioxane). The surface barrier would preclude direct exposure to buried waste by human or ecological receptors via surface exposure pathways. Overall thickness of the cap, coupled with long-term ICs, would preclude inadvertent human intrusion. Groundwater-pathway risk would be mitigated by combined effects of the OCVZ vapor extraction system and the low permeability of the surface barrier. All remedial elements included in Alternative $2 b$, with the exception of OCVZ operations, would be permanent and expected to remain functional into the indefinite future. The following subsections discuss the magnitude of residual risk and reliability of long-term controls.

4.3.2.3.1 Magnitude of Residual Risk-Based on qualitative analysis of the expected performance of the surface barrier, all surface exposure pathways would be interrupted, satisfying all remedial action objectives at the surface for both human and ecological receptors.

Magnuson (1993) modeled performance of a number of surface barriers, including the ET, or capillary, barrier design described in Section 3, using historical climatic data from the local region. Results indicated that drainage through the ET, or capillary, barrier would be extremely low. Annual drainage through the capillary barrier for the 10-year period of the simulation ranged from 0.5 to $0.03 \mathrm{~cm}$, with an average annual drainage of $0.1 \mathrm{~cm} /$ year. These and other modeling results, as well as field scale tests conducted at the INL Site, demonstrate that an ET surface barrier would sufficiently control infiltration. Contaminant fate and transport modeling discussed below applied a total infiltration through the barrier of $0.1 \mathrm{~cm} /$ year.

Figure 4-3 compares cumulative groundwater ingestion risk for Alternative $2 b$ to Alternative 1 (No Action). Alternative $2 \mathrm{~b}$ clearly reduces the magnitude of residual risk to less than 1E-04 by controlling infiltration (see Appendix D for more details). Residual risk for groundwater use is highest in the immediate future (approximately the year 2010), but declines steadily over the initial 1,000-year simulation period. After approximately year 4000, residual risk falls below $1 \mathrm{E}-05$ where it remains over the duration of the 10,000-year simulation period (see Section 5, Figure 5-1).

Figure 4-4 compares the cumulative groundwater hazard index for Alternative $2 \mathrm{~b}$ to Alternative 1. Results are based on overpredicted concentrations of carbon tetrachloride in the aquifer (see Section 4.1.3). Alternative $2 \mathrm{~b}$ clearly reduces the magnitude of the hazard index by controlling infiltration and would satisfy remedial action objectives.

Alternative $2 \mathrm{~b}$ also would prevent groundwater concentrations from exceeding MCLs. Monitoring would be established to address uncertainties, especially for nitrate, VOCs, and 1,4-dioxane (see Section 4.1.3). 


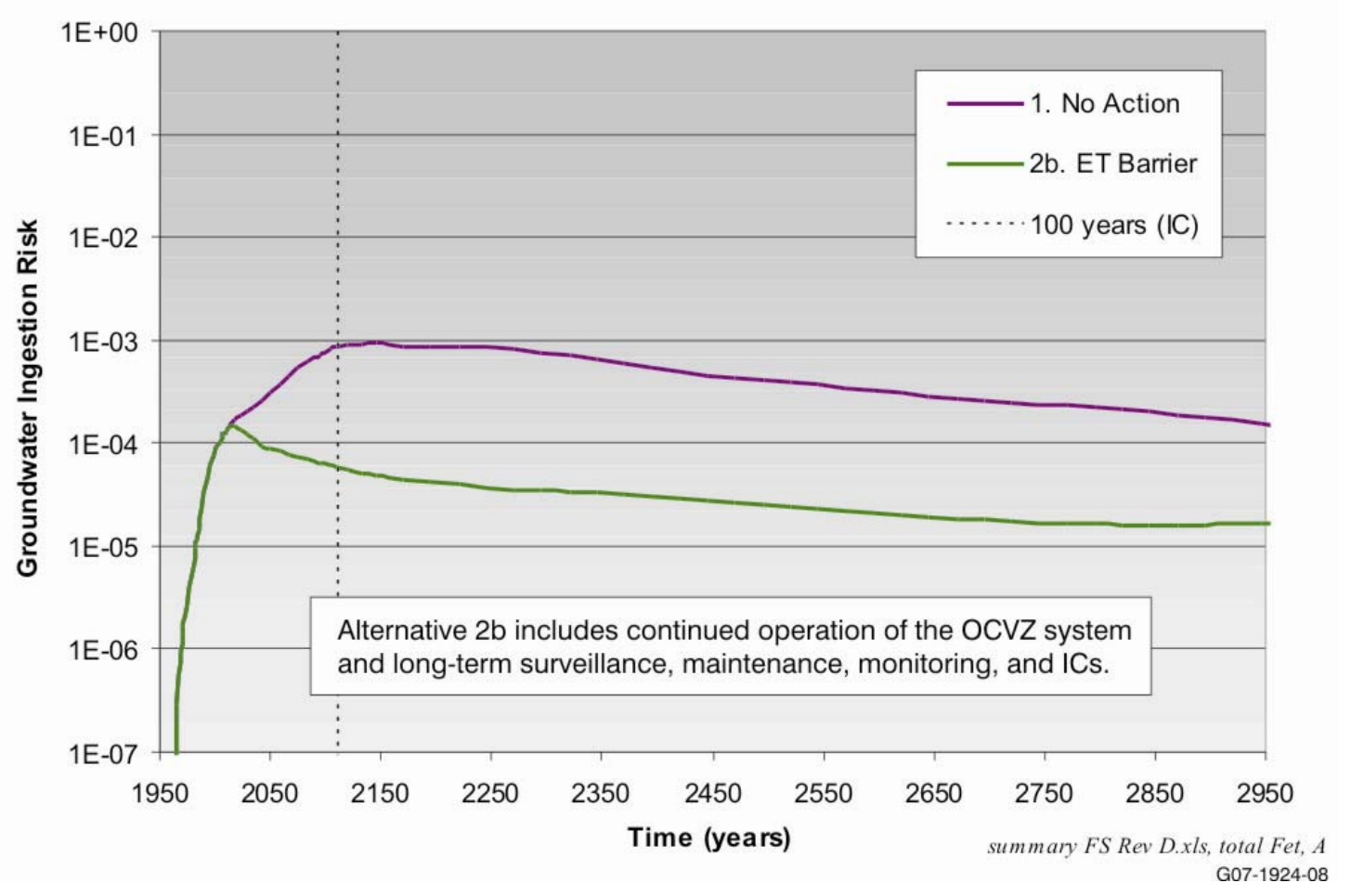

Figure 4-3. Cumulative groundwater ingestion risk for Alternative $2 \mathrm{~b}$-Evapotranspiration Surface Barrier, compared to Alternative 1-No Action.

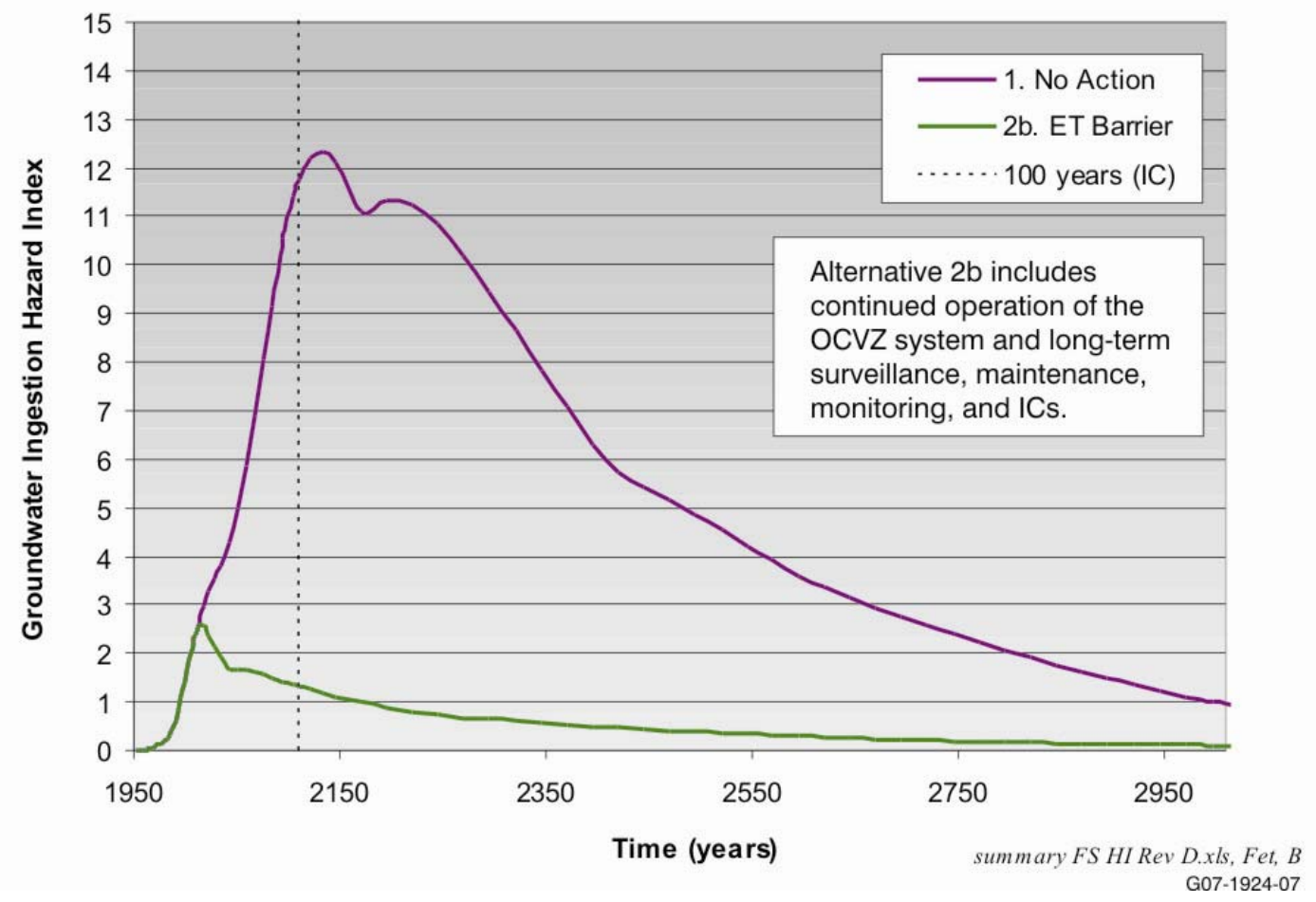

Figure 4-4. Hazard index for Alternative 2b-Evapotranspiration Surface Barrier, compared to Alternative $1-$ No Action. 
4.3.2.3.2 Reliability of Long-Term Controls-As illustrated in Figure 4-3, some level of residual risk would remain indefinitely after implementation of this remedial alternative. However, the magnitude of risk resulting from combined radiological and chemical hazards would be within the acceptable risk range established in the National Contingency Plan (40 CFR 300.430). A low-permeability surface barrier over the SDA would effectively reduce risk. For this alternative, the more significant question for detailed analysis relates to long-term durability of the surface barrier; long-term monitoring and management would be required to maintain its effectiveness.

In general, ET surface barriers are not as susceptible to damage by differential settlement as are barriers that incorporate a continuous drainage layer (Mattson et al. 2004). However, potential exists that deep subsidence events (e.g., collapse of a large metal waste box) could disrupt the contour of the barrier surface and potentially cause increased infiltration. Therefore, this alternative includes dynamic compaction to develop a stable base for construction of the surface barrier. Dynamic compaction (repeatedly dropping a heavy weight onto the ground surface using a modified crane) is described in Section 3. Dynamic compaction would effectively minimize future subsidence (Mattson et al. 2004).

As discussed in Section 4.3.1.3, surface barriers are potentially susceptible to intrusion by burrowing animals and deep-rooted plants over the long term, which could result in redevelopment of subsurface to surface exposure pathways. Overall depths of material above the biointrusion layer for this alternative decrease the likelihood of plant roots and burrowing animals reaching buried waste. Potential for biotic intrusion is further reduced by a coarse rock layer, which would also reduce potential inhalation exposures (i.e., organic vapor) for animals burrowing in the upper surface barrier profile.

Long-term management would be required to confirm performance of the assembled remedial components. Environmental monitoring would include routine collection and analysis of multimedia samples for all COCs. Because levels of untreated residual contamination would not allow unrestricted future use of the SDA site, 5-year reviews would be conducted indefinitely. Surveillance also would be conducted to identify differential settlement, inadequate drainage, or other observable degradation of the surface barrier. Institutional controls and long-term activities would be managed by a federal agency (e.g., DOE or the Bureau of Land Management) to ensure that effective protection is maintained.

4.3.2.4 Reduction of Toxicity, Mobility, or Volume through Treatment. This alternative does not include treatment as a source-control measure, though the surface barrier would substantially reduce mobility. The surface barrier would effectively mitigate all risk associated with exposure to COCs caused by biotic transport to the surface and would substantially reduce contaminant migration into the vadose zone and underlying aquifer.

Treatment is applied to VOCs collected from the vadose zone. A portion of VOCs released from source materials would be removed from the vadose zone beneath the surface barrier and thermally oxidized using the OCVZ treatment system.

4.3.2.5 Short-Term Effectiveness. Potential risk to the public and workers during implementation of remedial components included in Alternative $2 \mathrm{~b}$ would be extremely low when controls typical of DOE waste management operations are used (Wheldon et al. 2006). Operating experience at the INL Site suggests that all aspects of remedial action could be conducted without exposing members of the public to significant amounts of hazardous or radioactive contaminants. Approximately one public injury might be incurred in an accident involving transport of construction materials to the SDA over public thoroughfares (Wheldon et al. 2006). However, engineering and administrative controls would minimize potential short-term risk to the public (e.g., transportation schedules and routes would be designed to minimize interference with public traffic patterns). A fatality 
involving transport of construction materials for Alternative $2 \mathrm{~b}$ would be highly unlikely (Wheldon et al. 2006).

Short-term risk to workers is very low for this alternative. Remediation workers would be protected by maintaining exposure to penetrating radiation as low as reasonably achievable, using personal protective equipment to limit risk associated with inhalation or dermal adsorption of radionuclides or chemicals, and promoting a safety culture that creates a work environment free from occupational injury or illness. A maximally exposed worker involved in construction activities would incur a negligible increase in lifetime cancer risk relative to a worker involved in routine construction activities in the SDA (Wheldon et al. 2006) with the exception of Pad A retrieval. A low radiological risk would be accrued by a remediation worker during retrieval and transfer of Pad A waste. An even lower risk would be incurred by a collocated worker. Chemical risk and hazards for a remediation worker and collocated worker would be negligible based on qualitative analysis or absence of an identified exposure pathway. All physical and chemical risk to remediation workers could be readily controlled through use of engineered or administrative controls, or use of personal protective equipment. Workers implementing remedial components included in Alternative $2 \mathrm{~b}$ would incur as many as seven recordable industrial accidents (Wheldon et al. 2006). A worker fatality would be highly unlikely during implementation of this alternative.

Immediate risk to the environment as a result of exposure to contaminants would remain at or below those identified in the baseline risk assessment during implementation of this alternative. Fencing around the construction perimeter is a component of the alternative and would continue to reduce, although not entirely exclude, access to the active area by larger animals. Biotic transport through plant uptake and exposure of animal receptors (i.e., contact and ingestion of surface and subsurface soil) would decrease during the first year after construction of the surface barrier begins (i.e., once grading fill and cobble vent or biointrusion layers are completed). Upon completion of the surface barrier, existing exposure pathways for ecological receptors would be eliminated.

Short-term impacts to the environment for this alternative are primarily associated with construction of an ET surface barrier. Effects of noise, dust, and physical disturbance from construction activities on habitat and organisms immediately surrounding the SDA are similar to those discussed for Alternative 2a (Section 4.3.1.5). Greater impacts to animals from vibration and noise would result from the extended time (i.e., 1 year) required for dynamic compaction of SDA pits.

This alternative includes mining surface barrier construction materials from on-INL Site borrow areas. Topsoil, graded fill, gravel, and rock for this alternative would be obtained from the INL Site and could require expansion of currently active borrow areas (see Section 4.3.1.6). Implementation of this alternative would require less topsoil than would be required for Alternative 2a; however, more total material would be required.

All remedial components would be completed within 10 years of project inception. Remedial action objectives would be met upon completion of the surface barrier. Impacts to the environment immediately adjacent to the SDA would be high during construction, but overall, short-term environmental effectiveness for this alternative is moderate.

4.3.2.6 Implementability. Alternative $2 \mathrm{~b}$ is technically and administratively implementable. No specialized equipment, personnel, or services are required to construct the ET surface barrier. Several (monolithic) ET surface barriers have been planned for, or constructed on sites as large as the SDA (EPA 2006). In addition, the absence of a thin impermeable layer would simplify construction and allow implementation in stages to accommodate concurrent activities or early drainage control over portions of the SDA. Other components of the remedy (e.g., the OCVZ system, environmental monitoring, and ICs) 
have been routinely implemented at the INL Site. Dynamic compaction has not been used in the SDA; therefore, some uncertainty is associated with the level of radiological control that would be required during compaction. Potential problems could be mitigated by adding soil before compaction.

Construction techniques for surface barriers are common practice. Schedule delays are unlikely to occur because of technical problems. However, transfer of Pad A waste to facilitate construction of the surface barrier has a low probability that schedule delays could occur. Experience during the Accelerated Retrieval Project suggests that excavation of Pad A waste could be complicated and delayed by the presence of Rocky Flats Plant roaster oxides, which may contain pyrophoric material.

Multiple vendors are available for all aspects of the work. All elements of surface barrier construction, including development of borrow areas, hauling, and placement of surface barrier materials, could be accomplished by a number of local construction firms. Several specialized firms with specific geotechnical experience are available to provide dynamic compaction. The INL Site resources are adequate for planning, design, and implementation of Pad A waste excavation and relocation within the OU 7-13/14 area of contamination.

Because the ET surface barrier does not rely on continuous (i.e., seamless) layers of low-permeability material, the surface barrier could be constructed in sections. Constructing the surface barrier in sections would accommodate concurrent operations (e.g., retrieval of Pad A waste and dynamic compaction) and facilitate future maintenance.

This alternative assesses transferring Pad A waste into the LLW Pit. Disposal of Pad A waste in the LLW Pit could arise as an administrative implementability issue based on one of two factors. First, space may not be available in the LLW Pit. Second, placing this waste in an unlined pit may not be acceptable to DEQ and EPA, even though risk-based criteria (i.e., remedial action objectives) and ARARs would be satisfied. In either case, alternative disposal options could be identified for Pad A waste. Options include disposal at ICDF, outside of the INL Site, or in a newly constructed location within the SDA.

Dynamic compaction has not been used in the SDA; therefore, the level of radiological control required for implementation in open-air situations is uncertain. Potential approaches to minimize the spread of airborne contamination include placing additional overburden before compaction and using geotextiles, soil binders, or misters to suppress dust generation. A field demonstration of dynamic compaction may be required during the operational readiness review.

No other significant administrative feasibility issues are identified with this alternative. Expanding or developing new borrow areas may be necessary to obtain sufficient surface barrier materials. Currently, eight permitted gravel and borrow sources are available to support maintenance operations, new construction, and environmental restoration and waste management activities (Minkin et al. 1994). The potential total amount of soil available for INL Site use from these sources is in excess of 13 million cubic yards (DOE-ID 1997), which would be sufficient for construction of a surface barrier over the SDA (Mattson et al. 2004). Nevertheless, availability of borrow materials and requirements for other construction projects competing for material at the INL Site must be coordinated to support timely construction of the surface barrier.

4.3.2.7 Cost. Capital, operations and maintenance, and periodic costs for Alternative $2 \mathrm{~b}$ are provided as current value and net present value in Table 4-6. The base year in calculating net present value is 2006, with construction beginning in the year 2010 and ending in 2019. Estimates include costs for 100 years of surveillance and maintenance, monitoring, and ICs following construction. Appendix F provides additional details. 
Table 4-6. Costs for Alternative 2b-Evapotranspiration Surface Barrier.

Activity

Current Value Net Present Value

$(\$ M)$

$(\$ M)$

\section{Capital costs}

Evapotranspiration surface barrier (2014 through 2019)

$94.0 \quad 67.4$

Dynamic compaction (2010 through 2012)

$5.5 \quad 4.8$

Transfer Pad A waste to Low-Level Waste Pit

$56.3 \quad 46.7$

(2010 through 2014)

Installation of gas collection system (2016 and 2019)

$2.1 \quad 1.4$

Replace OCVZ treatment units every 20 years

$4.5 \quad 1.7$

(2031 and 2051)

Total capital cost

162.5

122.0

\section{Operations and maintenance costs}

Surface barrier maintenance and monitoring (2020 through 2119)

OCVZ operations, maintenance, and monitoring

(2010 through 2054)

Total operations and maintenance cost

86.6

18.2

$77.1 \quad 37.6$

\section{Periodic costs}

Final remedial action report, annual summary reports, 5-year reviews, and final operations and maintenance report

(2020 through 2119)

Total periodic cost

5.2

1.0

Total cost

331.4

178.8

OCVZ = Organic Contamination in the Vadose Zone

4.3.2.8 State Acceptance. State acceptance will be evaluated in conjunction with the future proposed plan and ROD for OU 7-13/14.

4.3.2.9 Community Acceptance. Community acceptance will be evaluated in conjunction with the future proposed plan and ROD for OU 7-13/14.

\subsection{Alternative 3-In Situ Grouting}

Alternative 3 (In Situ Grouting) would protect human health and the environment primarily by removing VOCs from the vadose zone and controlling potential exposure to COCs through containment with an ET surface barrier similar to that described for Alternative $2 \mathrm{~b}$ (see Section 4.3.2). Alternative 3 would provide an additional measure of protection by encapsulating specified waste with highly impermeable grout to retard migration of Tc-99 and I-129 from specified soil vault and trench areas totaling 0.2 acres. These two contaminants are primary COCs associated with waste from INL reactor operations. In addition, waste on Pad A would be excavated, treated with ex situ grouting, and relocated to the LLW Pit or other area in the SDA. 
The ET surface barrier and remaining components for this alternative are nearly identical to those described for Alternative $2 \mathrm{~b}$. The surface barrier would prevent human and ecological receptors from direct contact with buried waste and inhibit infiltration of precipitation and subsequent contaminant migration to the vadose zone and aquifer. Overall thickness of the cap, coupled with long-term ICs, would preclude inadvertent human intrusion. The only difference in the surface barrier compared to Alternative $2 \mathrm{~b}$ is to evaluate a passive gas-collection layer instead of an active gas-collection component. Pits would be dynamically compacted in advance of surface barrier construction to address potential subsidence. Dynamic compaction was identified because it presents the most short-term risk and highest cost among process options that apply surface treatment to address subsidence, thus bounding the analysis. Other process options, such as impact rolling, could be substituted during remedial design. Additional elements include continued operation of the OCVZ system to address VOCs in the vadose zone and long-term surveillance, maintenance, monitoring, and ICs.

\subsubsection{Overall Protection of Human Health and the Environment}

Alternative 3 would be fully protective of human health and the environment. Upon completion of the surface barrier in the year 2019, this alternative would achieve all remedial action objectives (see uncertainties discussed in Section 4.1.3 relating to groundwater simulations for nitrate, VOCs, and 1,4-dioxane). The ET surface barrier would minimize contaminant migration by reducing surface water infiltration rates, thus impeding further release of contamination into the vadose zone and aquifer. In addition, the surface barrier would effectively isolate buried waste, thus mitigating surface exposure risk for human and ecological receptors. Overall thickness of the cap, coupled with long-term ICs, would preclude inadvertent human intrusion. In situ grouting of specified waste would provide an additional measure of protection against migration of Tc-99 and I-129, and treatment of Pad A waste before transfer to the LLW Pit, or other location in the SDA, would reduce subsidence and enhance long-term performance of the surface barrier. Continued operation of the existing OCVZ system would collect and treat VOCs from the vadose zone and reduce transport to the aquifer. Passive vapor extraction from the transport layer would prevent accumulation of landfill gases, including VOCs, C-14, methane, and carbon dioxide, beneath the surface barrier. Long-term surveillance, maintenance, monitoring, and ICs would be conducted to ensure that the remedy remained protective.

\subsubsection{Compliance with Applicable or Relevant and Appropriate Requirements}

Table 4-7 provides an evaluation summary of the major substantive ARARs for Alternative 3. Chemical and location-specific ARARs for Alternative 3 would be the same as for Alternative 2 given that the site setting and chemical characteristics of the waste do not change. In addition, both alternatives include a surface barrier. Differences relate to in situ treatment of specified waste forms and ex situ treatment and relocation of Pad A waste in the SDA. Overall, Alternative 3 would satisfy this threshold criterion.

Action-specific ARARs vary primarily because of the difference in handling Pad A waste (i.e., ex situ treatment component). In situ grouting associated with Alternative 3 would not change action-specific ARARs when compared to those identified under Alternatives 2a and $2 \mathrm{~b}$. Though not focused on the same objective, the foundation grouting component of Alternative 2a would trigger an essentially identical set of ARARs as the contaminant grouting component under Alternative 3 . Performance requirements for the grouting operation do not stem from identified ARARs. Minor air emissions would be anticipated from the operation, which would be designed and operated to comply with pertinent air emission ARARs identified in Table 4-7. 
Table 4-7. Regulatory compliance evaluation for Alternative 3-In Situ Grouting.

\begin{tabular}{|c|c|c|c|c|}
\hline ARAR or TBC & Type & Relevancy & Citation & $\begin{array}{c}\text { Meets } \\
\text { Evaluation? }\end{array}$ \\
\hline Idaho toxic air pollutants & Chemical & A & IDAPA 58.01 .01 .585 and 586 & Yes \\
\hline $\begin{array}{l}\text { Idaho ambient air quality standards } \\
\text { for specific air pollutants }\end{array}$ & Chemical & A & IDAPA 58.01.01.577 & Yes \\
\hline $\begin{array}{l}\text { National emission standards for } \\
\text { hazardous air pollutants }\end{array}$ & Chemical & A & 40 CFR 61.92 through 94 & Yes \\
\hline $\begin{array}{l}\text { Standards for Inactive Asbestos } \\
\text { Disposal Sites }\end{array}$ & Action & A & 40 CFR 61.151 & Yes \\
\hline $\begin{array}{l}\text { Idaho Groundwater Quality } \\
\text { Standards }\end{array}$ & $\begin{array}{l}\text { Chemical } \\
\text { and action }\end{array}$ & A & IDAPA 58.01.11.200 & Yes \\
\hline $\begin{array}{l}\text { Safe Drinking Water Act } \\
\text { maximum contaminant levels }\end{array}$ & Chemical & RA & 40 CFR 141 & Yes \\
\hline $\begin{array}{l}\text { Native American graves protection } \\
\text { and repatriation regulations }\end{array}$ & Location & A & 43 CFR 10 & $\begin{array}{l}\text { Yes-if } \\
\text { encountered }\end{array}$ \\
\hline $\begin{array}{l}\text { Preservation of historic, } \\
\text { prehistoric, and archeological data }\end{array}$ & Location & A & $\begin{array}{l}36 \text { CFR } 800 \text { and } \\
40 \text { CFR } 6.301(b) \text { and (c) }\end{array}$ & $\begin{array}{l}\text { Yes-if } \\
\text { encountered }\end{array}$ \\
\hline $\begin{array}{l}\text { Protection of archaeological } \\
\text { resources }\end{array}$ & Location & A & 43 CFR 7 & $\begin{array}{l}\text { Yes-if } \\
\text { encountered }\end{array}$ \\
\hline $\begin{array}{l}\text { Compliance with environmental } \\
\text { review requirements for } \\
\text { floodplains and wetlands }\end{array}$ & Location & A & 10 CFR 1022 & Yes \\
\hline $\begin{array}{l}\text { Treatment, storage, and disposal } \\
\text { facilities located within floodplains }\end{array}$ & Location & A & 40 CFR 264.18(b) & Yes \\
\hline $\begin{array}{l}\text { General treatment, storage, and } \\
\text { disposal facility standards }\end{array}$ & Action & A & $\begin{array}{l}\text { IDAPA 58.01.05 40, } \\
\text { CFR 264.13(a)(1)(2), } \\
\text { 264.15(a)(c), and 264.17(a)(c) }\end{array}$ & Yes \\
\hline $\begin{array}{l}\text { Preparedness and prevention } \\
\text { standards of treatment, storage, and } \\
\text { disposal facilities }\end{array}$ & Action & A & $\begin{array}{l}\text { IDAPA 58.01.05, } \\
\text { 40 CFR 264.31 through } 35\end{array}$ & Yes \\
\hline $\begin{array}{l}\text { Standards for owners and operators } \\
\text { of treatment, storage, and disposal } \\
\text { facilities - general groundwater } \\
\text { monitoring requirements }\end{array}$ & Action & A & 40 CFR 264.97 & $\mathrm{Yes}^{\mathrm{a}}$ \\
\hline $\begin{array}{l}\text { Standards for owners and operators } \\
\text { of treatment, storage, and disposal } \\
\text { facilities - closure and postclosure }\end{array}$ & Action & A & $\begin{array}{l}\text { IDAPA 58.01.05 } \\
\text { (40 CFR 264.111; } \\
\text { 40 CFR 264.114; } \\
40 \text { CFR 264.117) }\end{array}$ & Yes \\
\hline $\begin{array}{l}\text { Standards for owners and operators } \\
\text { of treatment, storage, and disposal } \\
\text { facilities - landfills }\end{array}$ & Action & A & $\begin{array}{l}\text { IDAPA } 58.01 .05 \\
(40 \text { CFR } 264.310(a)(1) \\
\text { through(5),(b)(1), (4) through } \\
(6)\end{array}$ & $\mathrm{Yes}^{\mathrm{a}}$ \\
\hline $\begin{array}{l}\text { Standards for owners and operators } \\
\text { of treatment, storage, and disposal } \\
\text { facilities - use and management of } \\
\text { containers }\end{array}$ & Action & A & $\begin{array}{l}\text { IDAPA 58.01.05 } \\
\text { (40 CFR 264, Subpart I) }\end{array}$ & Yes \\
\hline $\begin{array}{l}\text { Generator standards - hazardous } \\
\text { waste determination }\end{array}$ & Action & A & $\begin{array}{l}\text { IDAPA 58.01.05.006 } \\
(40 \text { CFR 262.11) }\end{array}$ & Yes \\
\hline
\end{tabular}


Table 4-7. (continued).

\begin{tabular}{|c|c|c|c|c|}
\hline ARAR or TBC & Type & Relevancy & Citation & $\begin{array}{l}\text { Meets } \\
\text { Evaluation? }\end{array}$ \\
\hline Miscellaneous units & Action & A & $\begin{array}{l}\text { IDAPA 58.01.05, } \\
(40 \text { CFR 264.600) }\end{array}$ & Yes \\
\hline Land disposal restrictions & Action & A & $\begin{array}{l}\text { IDAPA 58.01.05.011 } \\
(40 \text { CFR 268) }\end{array}$ & Yes \\
\hline Idaho toxic substances & Action & A & IDAPA 58.01.01.161 & Yes \\
\hline Idaho visible emissions & Action & A & IDAPA 58.01.01.625 & Yes \\
\hline $\begin{array}{l}\text { Idaho control of fugitive dust } \\
\text { emissions }\end{array}$ & Action & A & IDAPA 58.01.01.650 and 651 & Yes \\
\hline $\begin{array}{l}\text { Polychlorinated biphenyls, Toxic } \\
\text { Substances Control Act }\end{array}$ & Action & A & 40 CFR 761, Subpart D & Yes \\
\hline Radioactive waste management & Action & $\mathrm{TBC}$ & DOE Order 435.1 & Yes \\
\hline $\begin{array}{l}\text { Radiation protection of the public } \\
\text { and the environment }\end{array}$ & $\begin{array}{l}\text { Chemical } \\
\text { and action }\end{array}$ & $\mathrm{TBC}$ & DOE Order 5400.5 & Yes \\
\hline \multicolumn{5}{|c|}{$\begin{array}{l}\text { A }=\text { applicable } \\
\text { ARAR = applicable or relevant and appropriate requirement } \\
\text { CFR }=\text { Code of Federal Regulations } \\
\text { DOE }=\text { U.S. Department of Energy } \\
\text { IDAPA = Idaho Administrative Procedures Act } \\
\text { RA = relevant and appropriate } \\
\text { TBC = to-be-considered (other information from advisories, criteria, and guidance) }\end{array}$} \\
\hline
\end{tabular}

Because the LLW Pit in the SDA is currently an active asbestos waste disposal site, 40 CFR 154(g) requires that the closed site would have to meet standards for inactive asbestos waste disposal sites found in 40 CFR 61.151. Requirements involve performance criteria for emissions, surface cover, and controls (e.g., fencing, signs, and deed notifications) to warn of the presence of asbestos.

Transfer of Pad A waste within the area of contamination is supplemented with an ex situ treatment component for Alternative 3. Treatment (i.e., ex situ grouting) influences analysis of RCRA treatment, storage, and disposal ARARs that were identified in Table 4-3 for Alternative 2a. Consequently, Table 4-7 identifies an alternate set of requirements. Grouting would constitute treatment of hazardous waste in a separate hazardous waste management unit and, therefore, leads to requirements to comply with land disposal restrictions for treated Pad A waste before disposal in the LLW Pit or other area in the SDA. The treatment process must be designed to satisfy relevant land disposal requirement treatment standards for both characteristic and listed hazardous waste (e.g., remove oxidizer characteristics of nitrate salts, if present, and meet concentration-based standards for listed hazardous waste and associated underlying hazardous constituents). Based on preconceptual design of the treatment unit, RCRA (40 CFR 264, Subpart X) is the substantive regulatory standard that would be appropriate for the treatment system. As such, appropriate substantive provisions of 40 CFR 264, Subparts I through O and Subparts AA through CC, would be identified as necessary to ensure protective management of the unit. Identification of particular provisions of 40 CFR 264, Subparts I through O and Subparts AA through CC that are appropriate would be dependent on system design, operation, and construction and is beyond the scope of preliminary ARARs evaluation for this feasibility study.

Consistent with Alternative $2 \mathrm{~b}$ (Section 4.3.2), short-term staging of containers holding Pad A waste may be implemented as part of the process for moving waste from Pad A to the LLW Pit, or other location within the SDA. In this case, staging would occur before and after ex situ treatment. Temporary staging of containers within the area of contamination would not necessitate management of a RCRA 
storage area and as such would not constitute placement of the containers in a separate hazardous waste management unit. Because of the treatment component, substantive RCRA treatment, storage, and disposal facility standards and preparedness and prevention requirements from 40 CFR 264, Subparts B and $\mathrm{C}$, were included as ARARs.

The identified RCRA treatment, storage, and disposal requirements for closure and postclosure of the landfill would be applicable requirements because the waste exhibits RCRA characteristics and is RCRA listed, and grouting constitutes treatment as defined by RCRA. Potential applicability of the RCRA landfill design and operating requirements for construction of an underlying liner and leachate collection system, often referred to as minimum technology requirements, was evaluated. Because the action would not involve establishment of a new landfill, a lateral expansion of an existing landfill, or a replacement unit, the requirement to install a liner and leachate collection system was not applicable (EPA 1988 and 1989). While requirements may be viewed as relevant and appropriate, depending on circumstances of the release and the site, closure associated with Alternative 3 (i.e., waste generally left in place in the SDA with the exception of Pad A) would not support identification of the minimum technology requirements as relevant and appropriate. Other conclusions reached under Alternatives $2 \mathrm{a}$ and $2 \mathrm{~b}$ (e.g., for dynamic compaction and OCVZ operations) also are appropriate for Alternative 3.

\subsubsection{Long-Term Effectiveness and Permanence}

Implementation of Alternative 3 would control contaminant migration so that remedial action objectives are satisfied by the end of ICs (see uncertainties discussed in Section 4.1.3 relating to groundwater simulations for nitrate, VOCs, and 1,4-dioxane). The ET surface barrier would preclude direct exposure to buried waste by human or ecological receptors via surface exposure pathways. Overall thickness of the cap, coupled with long-term ICs, would preclude inadvertent human intrusion.

Groundwater-pathway risk would be mitigated by combined effects of the OCVZ vapor extraction system and low permeability of the surface barrier. In situ grouting would provide an additional measure of groundwater protection to inhibit leaching from specified waste forms. Pad A remediation would improve surface barrier performance by reducing the likelihood of subsidence and minimizing the surface barrier profile. All remedial elements included in Alternative 3, with the exception of OCVZ operations, would be permanent and expected to remain functional into the indefinite future. The following subsections discuss the magnitude of residual risk and reliability of long-term controls.

4.4.3.1 Magnitude of Residual Risk. Based on qualitative analysis of the expected performance of the surface barrier, all surface exposure pathways would be interrupted, satisfying all remedial action objectives at the surface for both human and ecological receptors. Magnitude of residual risk would be about the same as described for Alternative 2b. At the surface, risk to human and ecological receptors would be at background values because the ET surface barrier would inhibit intrusion of plant roots and animals, thus mitigating potential transport to the surface.

Alternative 3 uses ISG, in addition to an ET surface barrier, to reduce groundwater risk associated with migration of Tc-99 and I-129 from specified disposals of INL reactor operations' waste. Figure 4-5 compares cumulative groundwater ingestion risk for Alternative 3 to Alternative 1 (No Action).

Cumulative groundwater ingestion risk for Alternative 3 would be less than $1 \mathrm{E}-04$ well before the end of the IC period and would continue to diminish over time (see Appendix D for more details). Risk would eventually diminish to less than $1 \mathrm{E}-05$ in less than 3,000 years (see Section 5, Figure 5-1).

Figure 4-6 compares cumulative groundwater hazard index for Alternative 3 to Alternative 1. Results are based on overpredicted concentrations of carbon tetrachloride in the aquifer (see Section 4.1.3). Alternative 3 clearly reduces the magnitude of the hazard index by controlling infiltration and would satisfy remedial action objectives. 


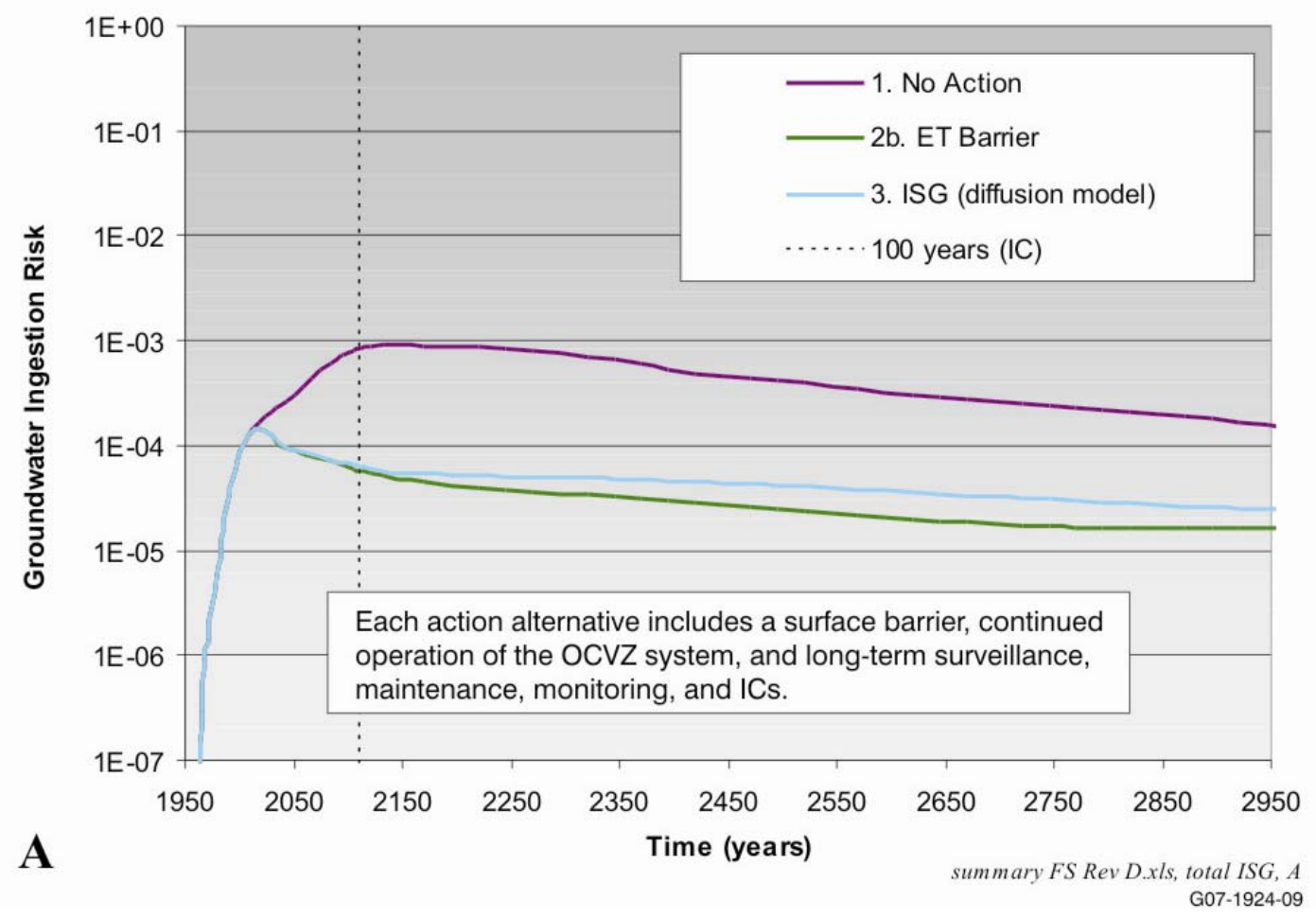

Figure 4-5. Cumulative groundwater ingestion risk for Alternative 3-In Situ Grouting, compared to Alternative 1-No Action and Alternative 2b-Evapotranspiration Surface Barrier.

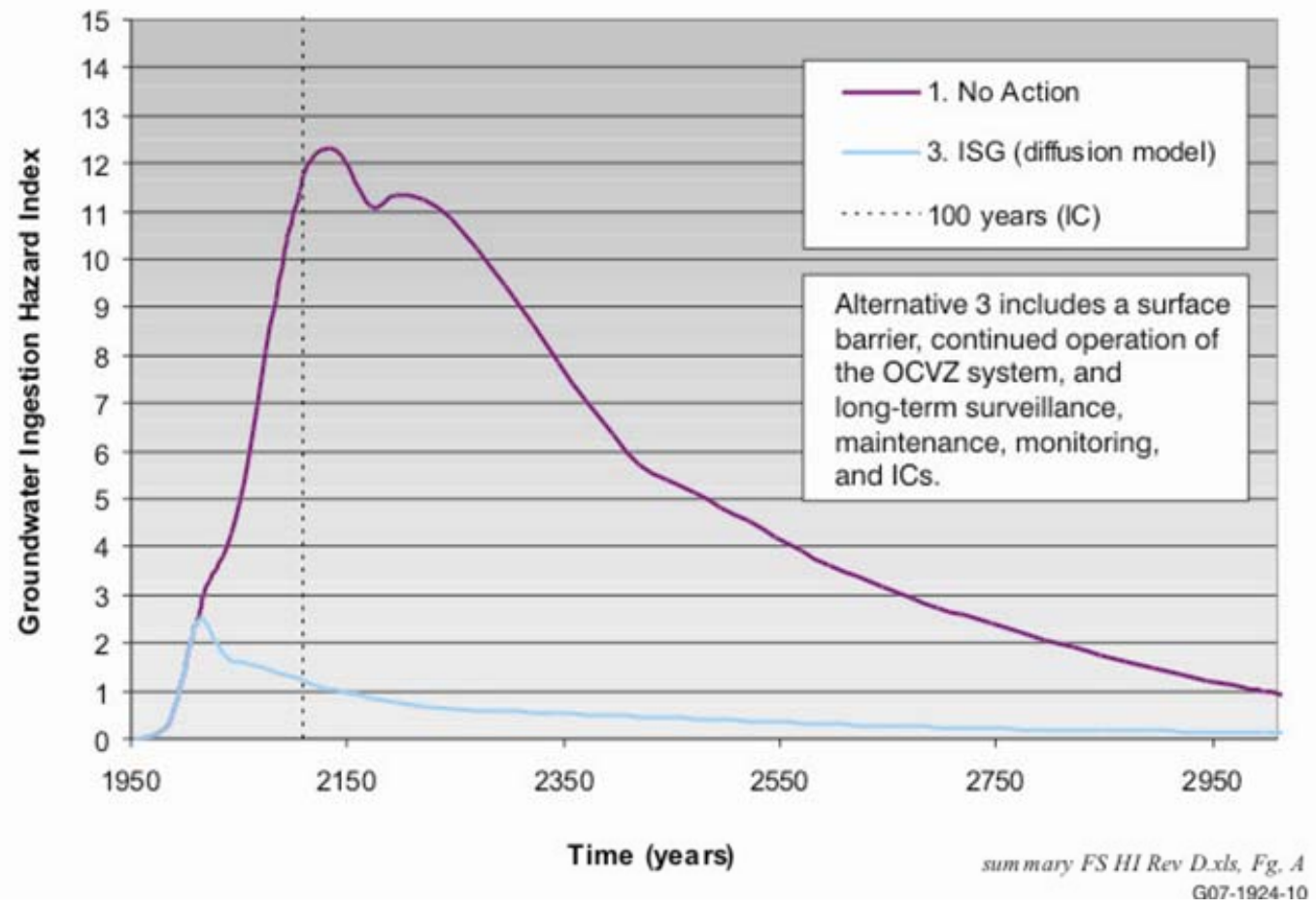

Figure 4-6. Hazard index for Alternative 3-In Situ Grouting, compared to Alternative 1-No Action. 
This alternative also would prevent groundwater concentrations from exceeding MCLs. Monitoring would be established to address uncertainties, especially for nitrate, VOCs, and 1,4-dioxane (see Section 4.1.3).

Figure 4-5 shows that simulated groundwater ingestion risk for Alternative 3 would slightly exceed that for the ET surface barrier alone (i.e., Alternative 2b) for approximately the first 2,000 years after the end of ICs, when cumulative risk for both would be less than 1E-05. Complexity in leach characteristics and packaging for waste types identified for in situ treatment of Tc-99 required that several simulations be run to estimate cumulative groundwater ingestion risk, as described in Appendix D. Parameters for these simulations were selected prospectively, with the most representative results shown in Figure 4-5.

Appendix D provides more details. Figure D-17A in Appendix D shows the groundwater ingestion risk curve for instantaneous release of Tc-99 and I-129 from specified waste disposals, where subsequent migration is controlled solely by diffusion from the encapsulating grout matrix. In contrast, Figure D-17B in Appendix D shows the groundwater ingestion risk curve for simulations that take into account limits (diffusion coefficients and corrosion rate, respectively) on the release of Tc-99 and I-129 from resins and fuel examination debris. In both simulations, all waste packaging is assumed to fail instantaneously during ISG operations (i.e., are disrupted by high pressure grout), though disposal records indicate that these waste types were contained in durable packages (e.g., concrete casks and welded stainless steel cans). Furthermore, literature suggests that treating resins with cementitious grouts should have little or no effect on release of Tc-99 (Morgan and Bostick 1992); though less is known about Tc-99 and I-129 release from fuel examination waste stabilized in cement grout, it is likely that the most representative groundwater ingestion risk curve for Alternative 3 would approximate or be less than the curve for use of an ET surface barrier alone (see Figure 4-3). In summary, while modeling results do not illustrate reduced groundwater ingestion risk associated with ISG of specified waste, bench-scale tests suggest that grout would effectively retard diffusion of Tc-99 and I-129 (Matthern et al. 2005), and no adverse chemical incompatibilities are anticipated. Similarly, while modeling for Alternative 3 suggests that groundwater concentrations for I-129 would exceed the MCL (i.e., 1 pCi/L) for nearly 1,000 years (see Figure D-53 in Appendix D), this also is a consequence of conservative modeling assumptions discussed above.

4.4.3.2 Reliability of Long-Term Controls. As illustrated in Figure 4-5, some level of residual risk would remain indefinitely after implementation of Alternative 3. However, the magnitude of risk resulting from combined radiological and chemical hazards would be within the acceptable risk range established in the National Contingency Plan (40 CFR 300.430). Effectiveness of Alternative 3 depends on surface barrier performance. The ET surface barrier would significantly reduce groundwater infiltration into the indefinite future. Evapotranspiration surface barriers are specifically designed to accommodate some differential subsidence within the underlying buried waste (Moore and Crowe 1998); dynamic compaction of pit areas would enhance long-term surface barrier performance.

In general, ET surface barriers are not as susceptible to damage by differential settlement as are barriers that incorporate continuous impermeable layers (Moore and Crowe 1998). However, potential exists that deep subsidence events (e.g., collapse of a large metal waste box) could disrupt the contour of the barrier surface and potentially cause increased infiltration. Therefore, this alternative includes dynamic compaction to develop a stable base for construction of the surface barrier. Dynamic compaction (repeatedly dropping a heavy weight onto the ground surface using a modified crane) is described in Section 3. Dynamic compaction will likely reduce, but not eliminate, future subsidence in the SDA (Mattson et al. 2004); therefore, surface barrier maintenance is provided for during the 100-year administrative control period. In addition, Pad A waste would be retrieved, treated ex situ, and transferred to the LLW Pit or other location in the SDA. Pad A retrieval would further reduce the potential for significant subsidence deleterious to surface barrier integrity. 
As discussed in Section 4.3.1.3, surface barriers are potentially susceptible to intrusion by burrowing animals and deep-rooted plants over the long term, which could result in redevelopment of subsurface to surface exposure pathways. Overall depths of material above the biointrusion layer for this alternative decrease the likelihood of plant roots and burrowing animals reaching buried waste. An optional coarse rock biointrusion and gas vent layer, also would reduce potential inhalation exposures (i.e., organic vapor) for animals burrowing in the upper surface barrier profile.

Long-term management would be required to confirm performance of the assembled remedial components. Environmental monitoring would include routine collection and analysis of multimedia samples for all COCs. Because levels of untreated residual contamination would not allow unrestricted future use of the SDA site, 5-year reviews would be conducted indefinitely. Surveillance also would be conducted to identify differential settlement, inadequate drainage, or other observable degradation of the surface barrier. Institutional controls and long-term activities would be managed by a federal agency (e.g., DOE or the Bureau of Land Management) to ensure that effective protection is maintained.

\subsubsection{Reduction of Toxicity, Mobility, or Volume through Treatment}

Alternative 3 would provide an additional measure of protection by treating small, specified areas within the waste zone using ISG to reduce mobility of releasable Tc-99 and I-129. In situ grouting would lower hydraulic conductivity of the treated waste, which, in combination with decreased infiltration provided by the surface barrier, would greatly reduce release of Tc-99 and I-129. Treatment of specified disposal areas would immobilize approximately $50 \%$ of the Tc-99 that might readily migrate from source materials (i.e., surface-contaminated debris, resins, and fuel examination waste). Approximately 1,000 linear feet of trench would be grouted from the underlying basalt to within $0.6 \mathrm{~m}(2 \mathrm{ft})$ of the ground surface. In situ grouting substantially increases the volume of contaminated media, but produces a cohesive waste form in the subsurface that would be resistant to leaching. High pressure jet grouting would disrupt soft waste packaging; however, waste disposal records indicate that waste specified for ISG is contained in durable containers (e.g., cement casks and sealed stainless steel cans) that would be less susceptible to disruption. Furthermore, even if waste packages were disrupted, interaction with cement grout would not adversely impact contaminant release from specified waste forms (e.g., ion exchange resins) (Morgan and Bostick 1992).

Alternative 3 would remove all waste from Pad A, treat it with cement grout (ex situ), and relocate stabilized waste to the LLW Pit or other location in the SDA. Treatment of Pad A waste before relocation in the SDA might reduce groundwater concentrations by retarding migration of nitrate. However, given uncertainties for performance of waste forms containing high salt contents, modeling did not include retardation of nitrate in the environment. The primary benefits of ex situ grouting would be to reduce subsidence associated with the relocated waste and to satisfy ARARs. Ex situ treatment would not reduce toxicity, would achieve limited reduction in mobility, and would substantially increase volume. Pad A waste includes approximately 4.6 million kilograms ( 10 million pounds) of Rocky Flats Plant Series 745 evaporator salts (Halford et al. 1993), which contain 235,000 kg of nitrate (i.e., approximately one-half of the original nitrate mass buried in the SDA) (Holdren et al. 2006). Ex situ treatment also would address RCRA characteristics (i.e., decharacterize) if commingled Pad A waste were determined to exhibit the characteristic of an oxidizer (i.e., ignitability) (Peterson, Johnson, and Peter 1986). Ex situ stabilization of Pad A waste may be effective for long-term immobilization of RCRA metal (e.g., chromium and cadmium).

Pad A contains approximately $17 \%$ of the total U-238 originally disposed of in the SDA (Holdren et al. 2006). Nearly all (greater than 99\%) of the U-238 on Pad A is associated with roaster oxides from the Rocky Flats Plant (Halford et al. 1993). Disposal records indicate that approximately 227 drums of roaster oxides were disposed of on Pad A, representing less than $0.5 \%$ of the total waste 
volume on Pad A; therefore, it would be infeasible to selectively remove and treat roaster oxides. In addition, roaster oxides retrieved during the Accelerated Retrieval Project have exhibited the characteristic of pyrophoricity (ICP 2006), which could greatly complicate material handling during waste treatment. Ex situ grouting of Pad A waste would double the original waste volume (approximately $725,000 \mathrm{ft}^{3}$ ). Grout alone (i.e., without a surface barrier) may not effectively immobilize secondary COCs (e.g., uranium isotopes), but would satisfy remedial action objectives in combination with a surface barrier.

Actions included in Alternative 3 focus on reducing the mobility of Tc-99 and I-129 in the buried waste source, consistent with the Second Addendum to the Work Plan (Holdren and Broomfield 2004), and as reflected in remedial action objectives and general assumptions in Section 1. While several approaches for mitigation of Tc-99 migration in the vadose zone have been proposed, they are not evaluated in this feasibility study. A recent evaluation of in situ treatment technologies for the Hanford groundwater remediation project (Kaback, Fogwell, and Peterson 2005) recommended that implementation of surface infiltration control, using a surface barrier, would be the most effective means for limiting Tc-99 flux to the aquifer. Most methods of in situ immobilization would have limited effectiveness if large amounts of oxidizer were present (e.g., nitrate) (Szecsody et al. 2005).

\subsubsection{Short-Term Effectiveness}

Potential risk to the public and workers during implementation of remedial components included in Alternative 3 would be extremely low when controls typical of DOE waste management operations are used (Wheldon et al. 2006). Operating experience in the SDA suggests that ISG could be conducted without exposing members of the public to significant amounts of hazardous or radioactive contaminants. Similarly, operating experience gained during the ongoing Accelerated Retrieval Project suggests that Pad A waste could be excavated, treated, and relocated within the SDA without exposing members of the public to significant amounts of hazardous or radioactive contaminants. Approximately one public injury might be incurred in an accident involving transport of construction materials to the SDA over public thoroughfares. However, engineering and administrative controls would minimize potential short-term risk to the public (e.g., transportation schedules and routes would be designed to minimize interference with public traffic patterns). A fatality involving transport of construction materials for Alternative 3 would be highly unlikely.

Short-term risk to remediation workers would be moderate and could be readily mitigated. Risk would be addressed by maintaining exposure to penetrating radiation as low as reasonably achievable through engineering and administrative controls, using personal protective equipment to limit risk associated with inhalation or dermal adsorption, and promoting a safety culture that creates a work environment free from occupational injury or illness. A maximally exposed worker involved in implementation of remedial components included in Alternative 3 would incur a small increase in lifetime cancer risk relative to a worker involved in routine construction activities at the SDA (Wheldon et al. 2006). Most cancer risk would be associated with excavation, treatment, and relocation of Pad A waste. Collocated workers would incur less risk. Chemical hazards would be negligible for both remediation and collocated workers based on qualitative analysis or the absence of an identified exposure pathway. Workers implementing remedial components included in Alternative 3 may incur as many as 12 recordable industrial accidents. A worker fatality would be highly unlikely during implementation of this alternative.

Risk to the environment during implementation of Alternative 3 would remain at or below those identified in the baseline risk assessment. Minimal or no environmental impacts are anticipated from ISG, addressing Pad A, or dynamic compaction of SDA pits. Contaminated media would not be exposed during construction of the ET surface barrier; therefore, contamination of adjacent areas is not anticipated. 
Fencing around the construction perimeter would reduce, although not entirely exclude, access to the active area by larger animals. Biotic transport through plant uptake and exposure of animal receptors (i.e., contact and ingestion of surface and subsurface soil) would decrease as soon as construction of the surface barrier begins. Upon completion of the surface barrier, existing exposure pathways for ecological receptors would be eliminated. Noise, dust, and physical disturbance from grouting, dynamic compaction, and surface barrier construction would be significant, and impacts to the habitat and organisms immediately surrounding the SDA would be high during implementation. Conventional suppression measures would be used to minimize fugitive dust.

All components of Alternative 3, including the ET surface barrier, would be completed within 10 years of project inception. Overall, short-term effectiveness for this alternative is moderate.

\subsubsection{Implementability}

All remedial components in Alternative 3 are technically mature and commercially available. In situ grouting has previously been used in the SDA to encapsulate irradiated beryllium reflector blocks using a molten paraffin grout (Lopez et al. 2005). In situ grouting equipment using cement grout would be even more reliable because civil applications routinely use cement grouts. Additional design and demonstration of operational readiness may be required before in situ treatment of trenches and soil vaults with cement grout; however, use of cement grout would provide adequate contamination control and produce small volumes of secondary waste (e.g., grout spoils or returns). Pad A excavation methods are based on those currently used by the Accelerated Retrieval Project. Ex situ stabilization of Pad A waste is based on processes currently used at ICDF. Methods for construction of the ET surface barrier are commonly used in civil engineering practice.

Experience with ISG in the SDA suggests that this remedial component is reliable and that minimal schedule delays would be anticipated; however, exact locations of specified waste disposals evaluated for ISG have not been validated using geophysical methods. In addition, procedures would be needed to address large, dense objects that could result in probe refusal before reaching the underlying basalt.

Experience during the Accelerated Retrieval Project suggests that excavation of Pad A waste could be complicated by the presence of Rocky Flats Plant roaster oxides, which may contain pyrophoric material. Observation of pyrophoric material could significantly delay Pad A waste excavation and treatment. Furthermore, roaster oxides and large amounts of Rocky Flats Plant Series 745 evaporator salts may present significant difficulties in maintaining product consistency during ex situ grouting.

The ex situ grouting method included in the cost estimate for Alternative 3 is based on that used at the ICDF Staging, Storage, Sizing, and Treatment Facility (Raivo 2001).Treatability testing would be required to adapt this process to roaster oxides and nitrate salts.

Relocating treated Pad A waste to the LLW Pit, or other area in the SDA, could raise two administrative implementability issues. First, space may not be available in the LLW Pit at the time of implementation, and second, relocation of treated Pad A waste to an unlined pit may not be acceptable to DEQ and EPA, even though risk-based criteria (i.e., remedial action objectives) would be satisfied. In either case, it would be necessary to identify alternative disposal options, which could include disposal at ICDF, disposal off the INL Site, or construction of a new LLW disposal facility within the SDA or on the INL Site.

Implementability issues associated with dynamic compaction and construction of an ET surface barrier are addressed under Alternative $2 \mathrm{~b}$ (Section 4.3.2). The only notable issues relate to dynamic compaction and administratively coordinating demands on borrow sources. 
Multiple vendors are available for implementation of remedial elements included in Alternative 3. All aspects of surface barrier construction, including development of borrow areas, hauling, and placement of surface barrier materials, could be accomplished by any of several local construction firms. Several specialty firms with geotechnical experience required to implement ISG and dynamic compaction are available. INL Site resources are adequate to plan, design, and implement Pad A remediation.

\subsubsection{Cost}

Table 4-8 provides the cost summary for Alternative 3. Capital, operations and maintenance, and periodic costs are provided as current value and net present value. The base year in calculating net present value is 2006, with construction beginning in the year 2010 and ending in 2019. Estimates include costs for 100 years of surveillance and maintenance, monitoring, and ICs following construction. Appendix F contains additional details.

\subsubsection{State Acceptance}

State acceptance will be evaluated in conjunction with the future proposed plan and ROD for OU 7-13/14.

\subsubsection{Community Acceptance}

Community acceptance will be evaluated in conjunction with the future proposed plan and ROD for OU 7-13/14.

Table 4-8. Costs for Alternative 3-In Situ Grouting.

Activity

Current Value Net Present Value $(\$ \mathrm{M})$

$(\$ \mathrm{M})$

\section{Capital costs}

Pad A retrieval and relocation (2010 through 2014)

99.9

82.1

Contaminant grouting (2010 through 2012)

11.6

9.9

Dynamic compaction of pits (2012 through 2014)

5.5

Containment with evapotranspiration surface barrier with

94.0

67.4

biotic barrier and vented gas transport layer

(2014 through 2019)

Gas vent layer extraction pipe installation within surface barrier (2016)

Replace OCVZ treatment units every 20 years (2035 and 2051) 
Table 4-8. (continued).

Current Value Net Present Value

Activity

$(\$ M)$

$(\$ \mathrm{M})$

Operations and maintenance costs

OCVZ operations, maintenance, and monitoring

77.1

37.6

(2010 through 2054)

Surface barrier maintenance, environmental monitoring,

86.6

18.2

project management and technical support

(2019 through 2119)

Total operations and maintenance cost

163.6

55.8

\section{Periodic costs}

Final remedial action report, annual summary reports, 5-year

1.0

reviews, and final operations and maintenance report

(2019 through 2119)

Total periodic cost

5.2

1.0

Total cost

385.0

222.7

OCVZ $=$ Organic Contamination in the Vadose Zone

\subsection{Alternative 4-Partial Retrieval, Treatment, and Disposal}

Alternative 4 (Partial Retrieval, Treatment, and Disposal) would protect human health and the environment primarily by removing VOCs from the vadose zone and by controlling potential exposure to COCs through containment with an ET surface barrier and ICs similar to that described for Alternative $2 b$ (see Section 4.3.2). Alternative 4 would provide an additional measure of protection by implementing targeted waste retrieval using methods established by the ongoing Accelerated Retrieval Projects (DOE-ID 2004, DOE-ID 2006).

The focused objective of both Accelerated Retrieval Projects is targeted waste retrieval of certain Rocky Flats Plant waste streams that contain high concentrations of transuranic radionuclides, VOCs, and isotopes of uranium. To achieve this objective, both actions target removal of the following Rocky Flats Plant waste streams: Series 741 sludge, Series 743 sludge; graphite; filters; and roaster oxide waste. These waste forms contain high concentrations of VOCs, transuranics, and uranium. The same targeted waste types identified for the Accelerated Retrieval Projects are evaluated for Alternative 4 in this feasibility study. Retrieved waste satisfying the WIPP waste acceptance criteria would be shipped to WIPP while the balance of the retrieved waste would be sent to ICDF for treatment and disposal.

During the process of excavation, other types of waste could be revealed that are not targeted waste. Nontargeted waste would be removed if the Agencies agree that retrieval is warranted and-as determined through visual inspection or field screening - the subject waste meets the following three criteria: (1) waste poses a potential risk of contamination to the underlying aquifer if left in place, (2) potential risk is sufficient to warrant removal at that time rather than leaving it to be addressed by OU 7-13/14, and (3) waste can be managed safely be retrieval using the personnel, facilities, and equipment readily available at INL for retrieval of targeted waste stream (DOE-ID 2004; DOE-ID 2006). 
Alternative 4 comprises two subalternatives: Alternative 4a-4-Acre Retrieval, Treatment, and Disposal, and Alternative 4b-2-Acre Retrieval, Treatment, and Disposal. Alternative 4a is the Partial RTD alternative specified in the Second Addendum (Holdren and Broomfield 2004) and evaluates retrieving Pad A and targeted waste retrieval in pit areas totaling 4 acres. Alternative $4 \mathrm{~b}$ was added when the agencies identified advantages in examining various sizes of retrieval areas. It leaves Pad A in place and examines targeted waste retrieval in pit areas totaling 2 acres. In combination, the two subalternatives facilitate scaling up or down to various retrieval area sizes, including or excluding Pad A.

Both subalternatives include continued operation of the OCVZ system to extract and treat VOCs from the vadose zone, an ET surface barrier, and long-term surveillance, maintenance, monitoring, and ICs. The ET surface barrier is nearly identical to that described for Alternative $2 b$; the only significant difference is that Alternative 4 evaluates a passive gas-collection layer instead of an active gas-collection layer in the surface barrier. The surface barrier would prevent human and ecological receptors from direct contact with buried waste and would inhibit infiltration and subsequent contaminant migration to the vadose zone and aquifer. Overall thickness of the cap, coupled with long-term ICs, would preclude inadvertent human intrusion.

The primary difference between the two subalternatives is the total retrieval area. However, because multiple process options were identified in Section 3 to control subsidence and address Pad A, the two alternatives incorporate differing approaches for these elements. Alternative 4a includes removing Pad A waste to ICDF and dynamically compacting pits. Alternative $4 \mathrm{~b}$ evaluates dynamically compacting Pad A before incorporating it into the surface barrier. Proof-rolling is evaluated to address subsidence in pits. Alternative $4 \mathrm{~b}$ also includes a lateral subsurface barrier (i.e., slurry cut-off wall). The two partial retrieval alternatives are described in detail in the following subsections.

\subsubsection{Alternative 4a-4-Acre Retrieval, Treatment, and Disposal}

This alternative evaluates targeted waste retrieval within pit areas totaling 4 acres. Dynamic compaction of pits would be implemented to inhibit subsidence. Dynamic compaction was identified because it presents the most short-term risk and highest cost among process options that apply surface treatment to address subsidence, thus bounding the analysis. Other process options, such as impact rolling, could be substituted during remedial design. Pad A waste would be removed and sent to ICDF for treatment and disposal.

4.5.1.1 Overall Protection of Human Health and the Environment. Alternative 4a would be fully protective of human health and the environment. Upon completion of the surface barrier in the year 2025, this alternative would achieve all remedial action objectives (see uncertainties discussed in Section 4.1.3 relating to groundwater simulations for nitrate, VOCs, and 1,4-dioxane). The ET surface barrier would minimize contaminant migration by reducing surface water infiltration rates, thus impeding further release of contamination into the vadose zone and aquifer. In addition, the surface barrier would effectively isolate remaining buried waste, thus mitigating surface exposure risk for human and ecological receptors. Overall thickness of the cap, coupled with long-term ICs, would preclude inadvertent human intrusion.

Targeted waste retrieval from pits and removal of Pad A would provide an additional measure of protection by reducing the inventory of COCs. Continued operation of the existing OCVZ system, enhanced with a passive vapor extraction layer in the barrier, would collect and treat VOCs from the vadose zone and reduce transport of volatile COCs to the aquifer. Long-term surveillance, maintenance, monitoring, and ICs would be conducted to ensure that the remedy remained protective. 
Implementing this alternative would increase the threat of exposure in the short term (i.e., during remediation). Engineering and administrative controls would readily address potential risk to workers, the public, and the environment.

\subsubsection{Compliance with Applicable or Relevant and Appropriate Requirements.}

Table 4-9 provides an evaluation summary of the major substantive ARARs for Alternative 4a. Chemical and location-specific ARARs would be the same among all action alternatives given that the setting and chemical characteristics of the waste do not change. For Alternative 4a, identification of action-specific ARARs is impacted primarily because of RTD of waste from pits and shipment of Pad A waste to ICDF. Dynamic compaction would not invoke a unique set of ARARs and would primarily involve ensuring compliance with air-emissions standards, including fugitive dust control, during implementation.

Table 4-9. Regulatory compliance evaluation for Alternative 4a-4-Acre Partial Retrieval, Treatment, and Disposal.

\begin{tabular}{|c|c|c|c|c|}
\hline ARAR or TBC & Type & Relevancy & Citation & $\begin{array}{c}\text { Meets } \\
\text { Evaluation? }\end{array}$ \\
\hline Idaho toxic air pollutants & Chemical & A & IDAPA 58.01.01.585 and 586 & Yes \\
\hline $\begin{array}{l}\text { Idaho ambient air quality standards } \\
\text { for specific air pollutants }\end{array}$ & Chemical & A & IDAPA 58.01.01.577 & Yes \\
\hline $\begin{array}{l}\text { National emission standards for } \\
\text { hazardous air pollutants }\end{array}$ & Chemical & A & 40 CFR 61.92 through 94 & Yes \\
\hline $\begin{array}{l}\text { Standards for Inactive Asbestos } \\
\text { Disposal Sites }\end{array}$ & Action & A & 40 CFR 61.151 & Yes \\
\hline $\begin{array}{l}\text { Idaho groundwater quality } \\
\text { standards }\end{array}$ & $\begin{array}{l}\text { Chemical } \\
\text { and action }\end{array}$ & A & IDAPA 58.01.11.200 & Yes \\
\hline $\begin{array}{l}\text { Safe Drinking Water Act } \\
\text { maximum contaminant levels }\end{array}$ & Chemical & RA & 40 CFR 141 & Yes \\
\hline $\begin{array}{l}\text { Native American graves protection } \\
\text { and repatriation regulations }\end{array}$ & Location & A & 43 CFR 10 & $\begin{array}{l}\text { Yes-if } \\
\text { encountered }\end{array}$ \\
\hline $\begin{array}{l}\text { Preservation of historic, } \\
\text { prehistoric, and archeological data }\end{array}$ & Location & A & $\begin{array}{l}36 \text { CFR } 800 \text { and } \\
40 \text { CFR } 6.301(b) \text { and (c) }\end{array}$ & $\begin{array}{l}\text { Yes-if } \\
\text { encountered }\end{array}$ \\
\hline $\begin{array}{l}\text { Protection of archaeological } \\
\text { resources }\end{array}$ & Location & A & 43 CFR 7 & $\begin{array}{l}\text { Yes-if } \\
\text { encountered }\end{array}$ \\
\hline $\begin{array}{l}\text { Compliance with environmental } \\
\text { review requirements for } \\
\text { floodplains and wetlands }\end{array}$ & Location & A & 10 CFR 1022 & Yes \\
\hline $\begin{array}{l}\text { Treatment, storage, and disposal } \\
\text { facilities located within floodplains }\end{array}$ & Location & A & $\begin{array}{l}\text { IDAPA } 58.01 .05 \\
\text { [40 CFR 264.18(b)] }\end{array}$ & Yes \\
\hline $\begin{array}{l}\text { General treatment, storage, and } \\
\text { disposal facility standards }\end{array}$ & Action & A & $\begin{array}{l}\text { IDAPA } 58.01 .0540 \text {, } \\
\text { CFR 264.13(a)(1)(2), } \\
264.15(\mathrm{a})(\mathrm{c}) \text {, and } 264.17(\mathrm{a})(\mathrm{c})\end{array}$ & Yes \\
\hline $\begin{array}{l}\text { Preparedness and prevention } \\
\text { standards of treatment, storage, and } \\
\text { disposal facilities }\end{array}$ & Action & A & $\begin{array}{l}\text { IDAPA } 58.01 .0540 \text { and } \\
\text { CFR 264.31 through } 35\end{array}$ & Yes \\
\hline
\end{tabular}


Table 4-9. (continued).

\begin{tabular}{|c|c|c|c|c|}
\hline ARAR or TBC & Type & Relevancy & Citation & $\begin{array}{c}\text { Meets } \\
\text { Evaluation? }\end{array}$ \\
\hline $\begin{array}{l}\text { Standards for owners and operators } \\
\text { of treatment, storage, and disposal } \\
\text { facilities_-general groundwater } \\
\text { monitoring requirements }\end{array}$ & Action & A & $\begin{array}{l}\text { IDAPA 58.01.05 } \\
\text { (40 CFR 264.97) }\end{array}$ & $\mathrm{Yes}^{\mathrm{a}}$ \\
\hline $\begin{array}{l}\text { Standards for owners and operators } \\
\text { of treatment, storage, and disposal } \\
\text { facilities_closure and postclosure }\end{array}$ & Action & A & $\begin{array}{l}\text { IDAPA 58.01.05 } \\
\text { (40 CFR 264.111, } \\
\text { 40 CFR 264.114, } \\
\text { 40 CFR 264.117) }\end{array}$ & Yes \\
\hline $\begin{array}{l}\text { Standards for owners and operators } \\
\text { of treatment, storage, and disposal } \\
\text { facilities_-landfills }\end{array}$ & Action & A & $\begin{array}{l}\text { IDAPA 58.01.05 } \\
(40 \text { CFR 264.310(a)(1) } \\
\text { through }(5),(\mathrm{b})(1),(4) \\
\text { through }(6)\end{array}$ & $\mathrm{Yes}^{\mathrm{a}}$ \\
\hline $\begin{array}{l}\text { Standards for owners and operators } \\
\text { of treatment, storage, and disposal } \\
\text { facilities - use and management of } \\
\text { containers }\end{array}$ & Action & A & $\begin{array}{l}\text { IDAPA } 58.01 .05 \\
\text { (40 CFR 264, Subpart I) }\end{array}$ & Yes \\
\hline $\begin{array}{l}\text { Generator standards-hazardous } \\
\text { waste determination }\end{array}$ & Action & $\mathrm{A}$ & $\begin{array}{l}\text { IDAPA 58.01.05.006 } \\
(40 \text { CFR 262.11) }\end{array}$ & Yes \\
\hline Land disposal restrictions & Action & A & $\begin{array}{l}\text { IDAPA 58.01.05.011 } \\
(40 \text { CFR 268) }\end{array}$ & Yes \\
\hline Idaho toxic substances & Action & A & IDAPA 58.01.01.161 & Yes \\
\hline $\begin{array}{l}\text { Polychlorinated biphenyls-Toxic } \\
\text { Substances Control Act }\end{array}$ & Action & A & 40 CFR 761, Subpart D & Yes \\
\hline Idaho visible emissions & Action & A & IDAPA 58.01.01.625 & Yes \\
\hline $\begin{array}{l}\text { Idaho control of fugitive dust } \\
\text { emissions }\end{array}$ & Action & A & IDAPA 58.01.01.650 and 651 & Yes \\
\hline Radioactive waste management & Action & $\mathrm{TBC}$ & DOE Order 435.1 & Yes \\
\hline $\begin{array}{l}\text { Radiation protection of the public } \\
\text { and the environment }\end{array}$ & $\begin{array}{l}\text { Chemical } \\
\text { and action }\end{array}$ & $\mathrm{TBC}$ & DOE Order 5400.5 & Yes \\
\hline \multicolumn{5}{|c|}{$\begin{array}{l}\text { A }=\text { applicable } \\
\text { ARAR = applicable or relevant and appropriate requirements } \\
\text { CFR = Code of Federal Regulations } \\
\text { DOE = U.S. Department of Energy } \\
\text { IDAPA = Idaho Administrative Procedures Act } \\
\text { RA = relevant and appropriate } \\
\text { TBC }=\text { to-be-considered (other information form advisories, criteria, and guidance) }\end{array}$} \\
\hline
\end{tabular}

Provisions of the Toxic Substances Control Act (40 CFR 761, Subpart D) for storage and disposal of polychlorinated biphenyls would be an ARAR for Alternative 4a. Elevated concentrations of polychlorinated biphenyls have been observed in various SDA waste streams as part of previous removal operations to date (Burton 2006). Storage facilities that comply with requirements of the Toxic Substances Control Act would be required.

For RCRA purposes, Alternative 4a treatment, storage, and disposal ARARs are identified primarily to address the storage facility because the alternative does not involve treatment on the INL Site. Also, shipment of Pad A waste to ICDF would necessitate compliance with RCRA land disposal 
restrictions given the removal of hazardous waste from the RWMC area of contamination and disposal in the ICDF landfill. Meeting ICDF waste acceptance criteria for polychlorinated biphenyls also would be required for Pad A waste that is transferred to ICDF for treatment and disposal.

Air emissions associated with Alternative 4 a involve both point-source (e.g., operation of the OCVZ treatment system) and fugitive or diffuse emissions sources (e.g., generation of dust during construction and dynamic compaction). If implemented, this alternative would be designed and operated to comply with the Idaho rules for control of fugitive dust emissions (IDAPA 58.01.01.650 and 651) that apply to any source of fugitive dust during construction and operations and maintenance activities. Further, point-source and diffuse radiological emissions from the site must not exceed the National Emission Standards (40 CFR 61, Subpart H) for radionuclide emissions from DOE facilities. Point-source emissions monitoring for the Accelerated Retrieval Project has shown that abated radiological emissions fall well within the applicable effective dose equivalent value of $10 \mathrm{mrem}$ at the nearest public receptor location (Staley 2004). Volatile organic compound emissions also must fall within chemical-specific requirements of pertinent air quality standards during remediation, including controlling toxic air pollutants (IDAPA 58.01.01.585 and 586), ambient air quality standards for specific air pollutants (e.g., as particulate matter) (IDAPA 58.01.01.577), and visible emissions criteria (IDAPA 58.01.01.625). Operational experience under the Accelerated Retrieval Project to date provides a reasonable basis to conclude that these criteria would be satisfied for retrieval under Alternative 4a.

Because the LLW Pit in the SDA is currently an active asbestos waste disposal site, 40 CFR 154(g) requires that the closed site would have to meet standards for inactive asbestos waste disposal sites found in 40 CFR 61.151. Requirements involve performance criteria for emissions, surface cover, and controls (e.g., fencing, signs, and deed notifications) to warn of the presence of asbestos.

4.5.1.3 Long-Term Effectiveness and Permanence. Targeted waste removal combined with surface barrier placement would inhibit exposure of humans, plants, and animals to contaminants and would minimize contaminant migration to groundwater. Alternative 4a would provide additional protection by removing COCs from the SDA, including a portion of those in buried Rocky Flats Plant targeted waste and all those in Pad A waste. All remedial action objectives would be satisfied by the end of the simulated IC period (see uncertainties discussed in Section 4.1.3 relating to groundwater simulations for nitrate, VOCs, and 1,4-dioxane). The surface barrier would preclude direct exposure to buried waste by human or ecological receptors via surface exposure pathways. Overall thickness of the cap, coupled with long-term ICs, would preclude inadvertent human intrusion. Groundwater-pathway risk would be mitigated by combined effects of the OCVZ vapor extraction system and low permeability of the surface barrier. All remedial elements included in Alternative 4a, with exception of OCVZ operations, would be permanent and expected to remain functional into the indefinite future.

This alternative would remove approximately 138,000 $\mathrm{ft}^{3}$ of waste (as disposed of) from pits and approximately $360,000 \mathrm{ft}^{3}$ of waste (as disposed of) from Pad A. Retrieval would increase these volumes to approximately $266,000 \mathrm{ft}^{3}$ and $779,000 \mathrm{ft}^{3}$, respectively, because of expansion, soil retrieved with waste, and other factors. Expansion factors are provided in Appendix E (see Table E-5 for pits and Table E-11 for Pad A).

The following subsections discuss the magnitude of residual risk and reliability of long-term controls.

4.5.1.3.1 Magnitude of Residual Risk-Based on qualitative analysis of the expected performance of the surface barrier, all surface exposure pathways would be interrupted, satisfying all remedial action objectives at the surface for both human and ecological receptors. Long-term modeling indicates the effectiveness of Alternative $4 \mathrm{a}$ in retarding migration of COCs remaining in the SDA. 
Results show that this alternative would effectively reduce contaminant migration and cumulative groundwater pathway risk to less than 1E-04. See Section 4.1.3 for additional discussion of limitations associated with groundwater modeling for nitrate, VOCs, and 1,4-dioxane.

Alternatives $4 \mathrm{a}$ and $4 \mathrm{~b}$ reduce groundwater risk by the same amount for two reasons:

- $\quad$ Both subalternatives include a surface barrier and continued operation of the OCVZ system, the primary means for reducing groundwater risk

- $\quad$ The amount of targeted waste containing VOCs (the only groundwater risk driver in targeted waste) would be approximately the same for both subalternatives.

Figure 4-7 compares groundwater ingestion carcinogenic risk for Alternative 4 to Alternative 1 (No Action). Risk would peak slightly above and then fall below 1E-04 before the end of the simulated IC period. Risk would decrease further in subsequent years, eventually falling below 1E-05 in less than 3,000 years (see Section 5, Figure 5-1). Peak groundwater risk for this alternative is significantly less than peak risk for Alternative 1. Long-term groundwater ingestion risk for Alternative 4 is approximately the same as for Alternative 2b (ET Surface Barrier) (see Figure 4-3), indicating that partial RTD, which includes an ET surface barrier, does not further reduce groundwater risk. Risk is reduced primarily by the surface barrier and operation of the OCVZ system. However, though it would have little or no effect on groundwater risk after the IC period, retrieval of targeted waste containing VOCs would reduce the operational period of the OCVZ system.

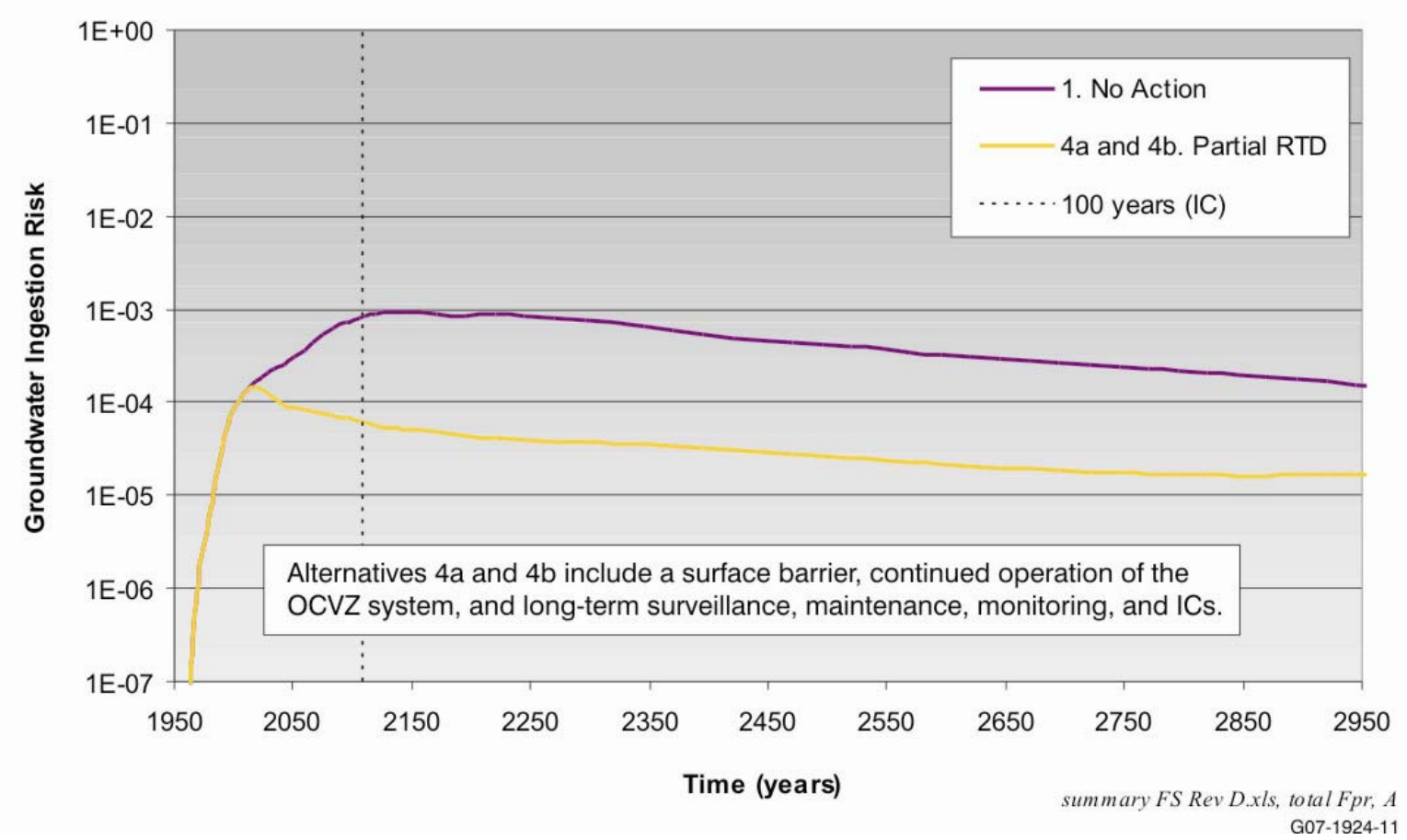

Figure 4-7. Cumulative groundwater ingestion risk for Alternative 4a-4-Acre Partial Retrieval, Treatment, and Disposal, and Alternative 4b-2-Acre Partial Retrieval, Treatment, and Disposal, compared to Alternative 1-No Action. 
Radiological groundwater ingestion COCs (i.e., C-14, I-129, and Tc-99) are not affected by targeted waste retrieval. Neither I-129 nor Tc-99 partition into vapor and, therefore, would not be extracted from the vadose zone through the OCVZ system before reaching the aquifer. These radiological contaminants are not present in targeted waste (i.e., Series 741 aqueous treatment sludge, Series 743 organic setup sludge, graphite, filters, and roaster oxides) and, therefore, Alternative 4a would leave these contaminants in place, though their transport to the aquifer would be reduced by the surface barrier.

Figure 4-8 compares cumulative groundwater hazard index for Alternative 4a (and 4b) to Alternative 1. The hazard index graphs for Alternatives $4 \mathrm{a}$ and $4 \mathrm{~b}$ are identical because the OCVZ system removes most of the carbon tetrachloride (primary driver) from the vadose zone before reaching the aquifer regardless of the mass removed from the waste zone. Results shown in Figure 4-8 are based on overpredicted concentrations of carbon tetrachloride in the aquifer (see Section 4.1.3).

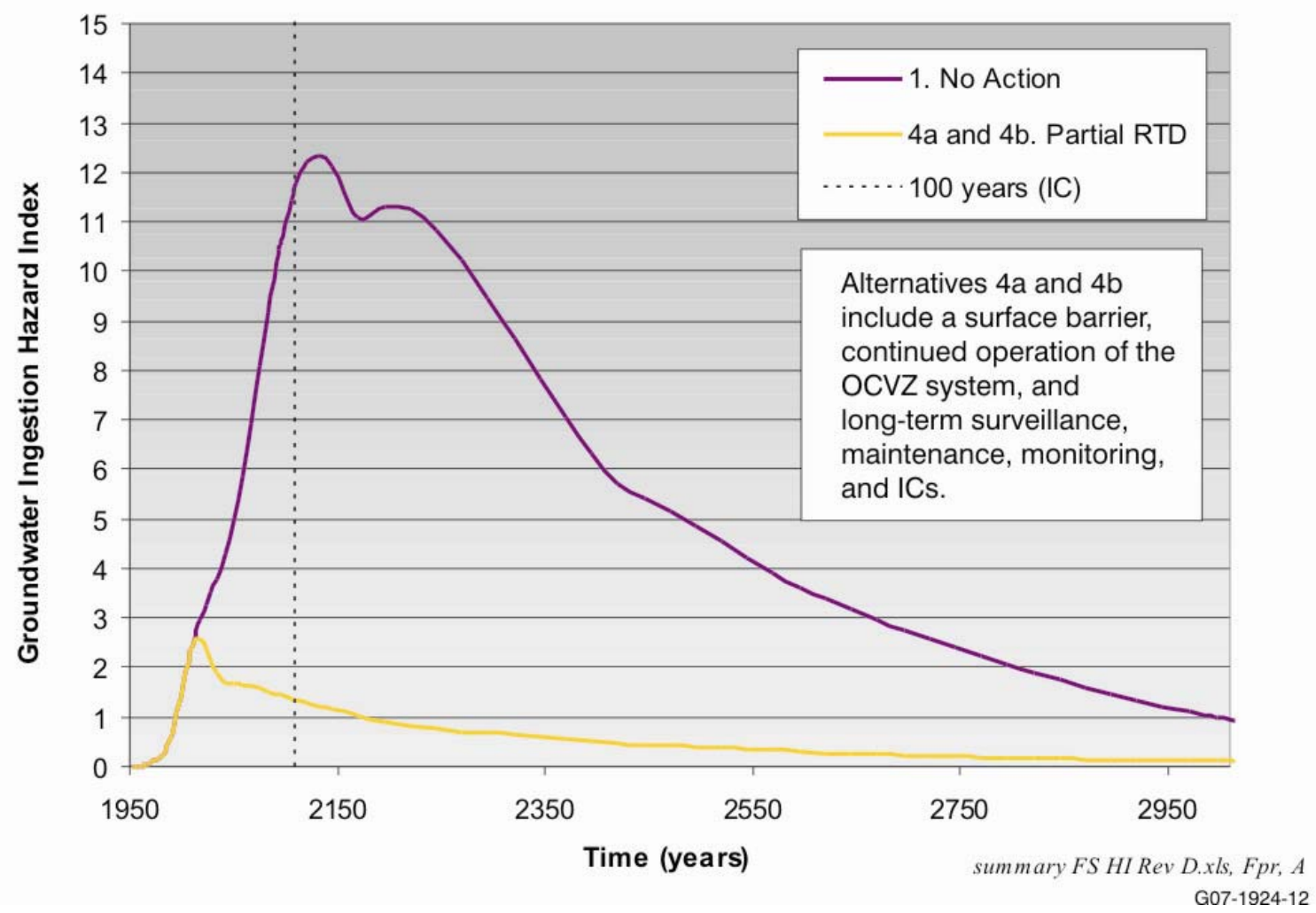

Figure 4-8. Hazard index for Alternative 4a-4-Acre Partial Retrieval, Treatment, and Disposal, compared to Alternative $1-$ No Action.

Alternative 4a also would prevent groundwater concentrations from exceeding MCLs. Monitoring would be established to address uncertainties, especially for nitrate, VOCs, and 1,4-dioxane (see Section 4.1.3).

4.5.1.3.2 Reliability of Long-Term Controls-As illustrated in Figure 4-7, some level of residual risk would remain indefinitely after implementation of this remedial alternative. However, the magnitude of risk resulting from combined radiological and chemical hazards would be within the acceptable risk range established in the National Contingency Plan (40 CFR 300.430). A low-permeability surface barrier over the SDA would effectively reduce risk. For this alternative, the 
more significant question for detailed analysis relates to long-term durability of the surface barrier; long-term monitoring and management would be required to maintain its effectiveness.

In general, ET surface barriers are not susceptible to damage by differential settlement as are barriers that incorporate a continuous drainage layer (Mattson et al. 2004). However, potential exists that deep subsidence events (e.g., collapse of a large metal waste box) could disrupt the contour of the barrier surface and potentially cause increased infiltration. Therefore, this alternative includes dynamic compaction to develop a stable base for construction of the surface barrier. Dynamic compaction (repeatedly dropping a heavy weight onto the ground surface using a modified crane) is described in Section 3. Dynamic compaction would effectively minimize future subsidence (Mattson et al. 2004).

As discussed in Section 4.3.2.3, overall depths of material above the biointrusion layer for this alternative decrease the likelihood of plant roots and burrowing animals reaching buried waste. Potential for biotic intrusion is further reduced by a coarse rock layer, which also would reduce potential inhalation exposures (i.e., organic vapor) for animals burrowing in the upper surface barrier profile.

Long-term management would be required to confirm performance of the assembled remedial components. Environmental monitoring would include routinely collecting and analyzing multimedia samples for all COCs. Because levels of untreated residual contamination would not allow unrestricted future land use of the SDA, 5-year reviews would be conducted indefinitely. Surveillance also would be conducted to identify differential settlement, inadequate drainage, or other observable degradation of the surface barrier. Institutional controls and long-term activities would be managed by a federal agency (e.g., DOE or the Bureau of Land Management) to ensure that effective protection is maintained.

\subsubsection{Reduction of Toxicity, Mobility, or Volume through Treatment. Treatment, as} traditionally defined, is not a primary element of Alternative 4a, though minor treatment elements are included for Pad A waste, targeted uranium waste, and organic vapors collected from the vadose zone. However, Alternative 4a would remove a substantial amount of waste contaminated with VOCs and transuranics, repackage it, and dispose of it at WIPP in New Mexico. WIPP is a deep geologic repository that provides a system that isolates the waste from the environment. All Pad A waste and uranium waste retrieved from pit areas would be sent to ICDF for ex situ treatment and disposal. Treatment would not substantially reduce toxicity or mobility and would increase volume. In addition, treatment may be required based on results from gas generation testing to satisfy shipping criteria for some retrieved waste. Soil vapors extracted using the OCVZ system are treated; toxicity is irreversibly reduced by thermal oxidization.

Though treatment is not a component of the surface barrier, contaminant mobility to the underlying aquifer would be mitigated by reducing infiltration through the waste. Contaminant mobility to the surface would be prevented through the use of the surface barrier's gas collection layer directing off gas away from the surface soil and a biointrusion layer preventing plant roots and burrowing animals from transporting contamination to the surface.

4.5.1.5 Short-Term Effectiveness. Potential risk to the public and workers during implementation of remedial components included in Alternative 4a would be moderate when controls typical of DOE waste management operations are used (Wheldon et al. 2006). Chemical exposures and radiological risk to a public member would be moderately low based on quantitative analysis of assumed emission rates from retrieval structures. Previous operating experience suggests that all aspects of remedial action could be conducted without exposing members of the public to significant amounts of hazardous or radioactive contaminants. Approximately four public injuries may be incurred in an accident involving transport of construction materials to the SDA over public thoroughfares (Wheldon et al. 2006). However, engineering and administrative controls would minimize potential short-term risk to the public 
(e.g., transportation schedules and routes would be designed to minimize interference with public traffic patterns). A fatality involving a member of the public and transport of construction materials for Alternative $4 \mathrm{a}$ would be highly unlikely (Wheldon et al. 2006).

Short-term risk to workers would be moderate and could be readily mitigated. Risk would be addressed by maintaining exposure to penetrating radiation as low as reasonably achievable, using personal protective equipment to limit risk associated with inhalation or dermal adsorption of radionuclides or chemicals, and promoting a safety culture that creates a work environment free from occupational injury or illness. A maximally exposed worker involved in implementation of remedial components included in Alternative 4a would incur a moderate increase in lifetime cancer risk relative to a worker involved in routine construction activities in the SDA (Wheldon et al. 2006). Most cancer risk would be associated with handling waste (e.g., retrieval and packaging) during retrieval of the Pad A and subgrade pit areas. Chemical hazards for workers not directly involved with the alternative but near retrieval would be moderately low based on quantitative analysis. Workers implementing remedial components included in Alternative 4a could incur as many as 56 recordable industrial accidents (Wheldon et al. 2006). A worker fatality would be highly unlikely during implementation of this alternative.

Risk to the environment during implementation of Alternative 4a would remain at or below those identified in the baseline risk assessment. Fencing around the construction perimeter is a component of this alternative and would continue to reduce, although not entirely exclude, access to the active area by larger animals. Biotic transport through plant uptake and exposure of animal receptors (i.e., contact and ingestion of surface and subsurface soil) would decrease as buried waste is progressively removed and as grading fill and biointrusion layers are completed. With completion of the surface barrier, existing exposure pathways for ecological receptors would be eliminated. Remediation activities would be largely confined to the current footprint of the SDA. Short-term impacts to the environment for this alternative would be similar to those described for implementing a surface barrier in Alternative 2 (see Section 4.3). Noise, dust, and physical disturbance from retrieval activities (e.g., structure construction, waste transfer, and retrieval tent moves), dynamic compaction of pit areas, and surface barrier construction would be significant, and impacts to the habitat and organisms immediately surrounding the SDA would be high during the active construction timeline for this alternative.

All components of Alternative 4a, including the ET surface barrier, would be completed with 16 years of project inception. Overall, short-term effectiveness of this alternative is moderate.

4.5.1.6 Implementability. All remedial components included in Alternative 4a are well understood and commercially available. The excavation of pit areas totaling 4 acres and Pad A retrieval methods are based on those currently used by the Accelerated Retrieval Project. Methods for construction of the ET surface barrier are commonly used in civil engineering practice.

Experience during the Accelerated Retrieval Project suggests that excavation of SDA waste could be complicated by the presence of Rocky Flats Plant roaster oxides, which may contain pyrophoric material. Observation of pyrophoric material could significantly delay excavation of pit areas and retrieval of Pad A waste.

All Pad A waste and roaster oxide waste removed from pits would be sent to ICDF for treatment and disposal. Although treatment at ICDF is feasible for this waste, the treatment facility has not been used for treatment of radioactively contaminated waste in the past. Large quantities of radioactive waste sent to ICDF for treatment could prove challenging. In addition, administrative action to restart the treatment facility and extend operations beyond 2012, at ICDF would be required. The ICDF is scheduled 
for closure in the year 2012 and retrieval activates associated with this alternative are anticipated to last through the year 2018 (see Figure 3-22).

Currently WIPP is the only facility that can receive transuranic waste for disposal. The volume of waste containerized by Alternative 4a and shipped to WIPP would be approximately $9,700 \mathrm{yd}^{3}$ (i.e., 36,000 drums). Total capacity of WIPP as currently designed is $175,600 \mathrm{~m}^{3}\left(229,676 \mathrm{yd}^{3}\right)$; WIPP is expected to be filled to capacity by the year 2034 .

If portions of some targeted waste forms (i.e., Series 741 aqueous treatment sludge, Series 743 organic setup sludge, graphite, filters, and roaster oxides) do not contain transuranic radionuclides (i.e., cannot be sent to WIPP), treatment for volatiles may be applicable at the appropriate off-INL Site treatment and disposal facility in order to satisfy land disposal requirements. Acceptance of this waste type depends on the capacity and treatment process available at the treatment and disposal facility.

Equipment and specialists required for SDA waste retrieval and construction of an ET surface barrier are available at the INL Site and within the commercial sector and have been sufficiently demonstrated at either the INL Site or within the DOE complex. In addition, these technologies are sufficiently developed to allow full-scale deployment within the SDA. Based on common commercial equipment and remediation methods used in this alternative, lack of equipment or specialists would not prevent implementation of remedial components. An exception could potentially be availability of a modified crane used for dynamic compaction (Richins and Hurst 2004).

Based on previous responses to requests for proposals, several qualified vendors would bid to retrieve or dynamically compact waste in the SDA. Several commercial firms likely would respond to requests for proposals for design and construction of an ET surface barrier.

4.5.1.7 Cost. Table 4-10 provides the cost summary for Alternative 4a. Capital, operations and maintenance, and periodic costs are provided as current value and net present value. The base year in calculating net present value is 2006, with construction beginning in the year 2010 and ending in 2025 . Estimates include costs for 100 years of surveillance and maintenance, monitoring, and ICs following construction. Appendix F contains additional details.

Table 4-10. Costs for Alternative 4a-4-Acre Partial Retrieval, Treatment, and Disposal.

\begin{tabular}{lcr}
\multicolumn{1}{c}{ Activity } & $\begin{array}{c}\text { Current Value } \\
(\text { SM })\end{array}$ & $\begin{array}{r}\text { Net Present Value } \\
(\$ \mathrm{M})\end{array}$ \\
\hline Capital costs & & \\
Excavation of pit areas totaling 4 acres (2010 through 2018) & 693.8 & 543.8 \\
Pad A retrieval and ICDF disposal (2010 through 2014) & 122.9 & 100.9 \\
Dynamic compaction of disposal pits (2018 through 2020) & 5.5 & 3.8 \\
Containment with evapotranspiration surface barrier with & 94.0 & 56.6 \\
biotic barrier and vented gas transport layer & & \\
(2020 through 2025) & 0.5 & 0.3 \\
Gas vent layer extraction pipe installation within surface & & \\
barrier (2022 through 2023) & 2.3 & 1.1 \\
Replace OCVZ treatment units every 20 years (2030) & $\mathbf{9 1 9 . 1}$ & $\mathbf{7 0 6 . 5}$ \\
Total capital cost & & \\
\hline
\end{tabular}


Table 4-10. (continued).

Current Value Net Present Value

Activity

(\$M)

$(\$ \mathrm{M})$

Operations and maintenance costs

OCVZ operations, maintenance, and monitoring

60.1

33.1

(2010 through 2044)

Surface barrier maintenance, environmental monitoring,

86.6

15.1

project management and technical support

(2025 through 2125)

Total operations and maintenance cost

146.7

48.2

\section{Periodic costs}

Final remedial action report, annual summary reports,

0.8

5 -year reviews, and final operations and maintenance report

(2025 through 2125)

Total periodic cost

5.2

0.8

Total cost

$1,071.0$

755.5

ICDF = Idaho CERCLA Disposal Facility

OCVZ $=$ Organic Contamination in the Vadose Zone

4.5.1.8 State Acceptance. State acceptance will be evaluated in conjunction with the future proposed plan and ROD for OU 7-13/14.

4.5.1.9 Community Acceptance. Community acceptance will be evaluated in conjunction with the future proposed plan and ROD for OU 7-13/14.

\subsubsection{Alternative 4b-2-Acre Retrieval, Treatment, and Disposal}

This alternative evaluates targeted waste retrieval in pit areas totaling 2 acres. Waste would be retrieved, packaged, stored, and shipped for treatment and disposal using the same methods previously described for Alternative 4a. Pits would be proof-rolled to reduce subsidence. Proof-rolling was identified because it presents the least short-term risk and lowest cost among process options that apply surface treatment to address subsidence, while Alternative 4a includes dynamic compaction, the most rigorous surface treatment. Pad A would be dynamically compacted and incorporated into the ET surface barrier. Dynamic compaction was identified because it presents the most short-term risk and highest cost among process options that apply surface treatment to address subsidence, thus bounding the analysis. Other process options, such as impact rolling, could be substituted during remedial design. A belowgrade slurry perimeter wall would be installed around the entire SDA and integrated with the ET surface barrier.

4.5.2.1 Overall Protection of Human Health and the Environment. Alternative $4 \mathrm{~b}$ would be fully protective of human health and the environment. Upon completion of the surface barrier in the year 2021, this alternative would achieve all remedial action objectives (see uncertainties discussed in Section 4.1.3 relating to groundwater simulations for nitrate, VOCs, and 1,4-dioxane). The ET surface barrier would minimize contaminant migration by reducing surface water infiltration rates, thus impeding further release of contamination into the vadose zone and aquifer. In addition, the surface barrier would effectively isolate remaining buried waste, thus mitigating surface exposure risk for human and ecological receptors. Overall thickness of the cap, coupled with long-term ICs, would preclude inadvertent human intrusion. 
Targeted waste retrieval from pits would provide an additional measure of protection by reducing the inventory of COCs. Continued operation of the existing OCVZ system, enhanced with a passive vapor extraction layer in the surface barrier, would collect and treat VOCs from the vadose zone and reduce transport of volatile COCs to the aquifer. Long-term surveillance, maintenance, monitoring, and ICs would be conducted to ensure that the remedy remained protective.

Implementing this alternative would increase the threat of exposure in the short term (during remediation). Engineering and administrative controls would readily address potential risk to workers, the public, and the environment.

\subsubsection{Compliance with Applicable or Relevant and Appropriate Requirements.}

Because of similarity in scope, the ARARs analysis for Alternatives $4 \mathrm{a}$ and $4 \mathrm{~b}$ is essentially equivalent. The most significant components that differ between the two alternatives are installation of the slurry cut-off wall tied to the ET surface barrier and implementation of proof-rolling rather than dynamic compaction to address subsidence. Analysis did not identify unique ARARs for these activities as compared with Alternative 4a. Consequently, Table 4-9 (see Section 4.5.1.2) also provides an evaluation summary of the major substantive ARARs for Alternative 4b. Land disposal restriction applicability for Alternative $4 \mathrm{~b}$ relates only to waste that would be disposed of outside of the RWMC at a facility other than WIPP. The most likely example of this type of waste stream is uranium roaster oxide waste that is targeted for removal.

4.5.2.3 Long-Term Effectiveness and Permanence. Targeted waste removal combined with surface barrier placement would inhibit exposure of humans, plants, and animals to contaminants and would minimize contaminant migration to groundwater. Alternative $4 \mathrm{~b}$ would provide additional protection by removing a portion of COCs in buried Rocky Flats Plant targeted waste. (Unlike for Alternative 4a, Alternative 4b leaves Pad A in place.) All remedial action objectives would be satisfied by the end of the simulated IC period (see uncertainties discussed in Section 4.1.3 relating to groundwater simulations for nitrate, VOCs, and 1,4-dioxane). The surface barrier would preclude direct exposure to buried waste by human or ecological receptors via surface exposure pathways. Overall thickness of the cap, coupled with long-term ICs, would preclude inadvertent human intrusion. Groundwater-pathway risk would be mitigated by combined effects of the OCVZ vapor extraction system and low permeability of the surface barrier. All remedial elements included in Alternative 4b, with exception of OCVZ operations, would be permanent and expected to remain functional into the indefinite future.

This alternative would remove approximately $107,000 \mathrm{ft}^{3}$ of waste (as disposed of) from pit areas. Retrieval would increase this volume to approximately $208,000 \mathrm{ft}^{3}$ because of expansion, soil retrieved with waste, and other factors. Expansion factors are provided in Appendix E (see Table E-3). The majority of the retrieved waste would be transferred to WIPP for disposal, and a much smaller portion would be sent to ICDF for treatment and disposal.

The following subsections discuss the magnitude of residual risk and reliability of long-term controls.

4.5.2.3.1 Magnitude of Residual Risk-Based on qualitative analysis of the expected performance of the surface barrier, all surface exposure pathways would be interrupted, satisfying all remedial action objectives at the surface for both human and ecological receptors. Long-term modeling indicates the effectiveness of Alternative 4a (4-acre partial RTD) in retarding migration of COCs remaining in the SDA burial zone (see Section 4.5.1.3.1). Results are essentially the same for Alternative $4 \mathrm{~b}$ (2-acre partial RTD). A separate set of model runs was not implemented. Like Alternative $4 \mathrm{a}$, Alternative $4 \mathrm{~b}$ would effectively reduce contaminant migration and cumulative groundwater pathway risk to less than 1E-04. See Section 4.1.3 for additional discussion of limitations 
associated with groundwater modeling for nitrate, VOCs, and 1,4-dioxane. Alternatives $4 \mathrm{a}$ and $4 \mathrm{~b}$ reduce groundwater risk by the same amount for two reasons:

- $\quad$ Both subalternatives include a surface barrier and continued operation of the OCVZ system, the primary means for reducing groundwater risk

- $\quad$ The amount of targeted waste containing VOCs (the only groundwater risk driver in targeted waste) would be approximately the same for both subalternatives.

As stated above, risk modeling was not performed for this alternative because it is essentially the same as for Alternative 4a (see Figures 4-7 and 4-8 in Section 4.5.1.3.1). As shown, long-term groundwater ingestion risk and hazard index are not affected by targeted waste retrieval. Risk is reduced primarily by the surface barrier and operation of the OCVZ system. However, though it would have little or no effect on groundwater risk after the IC period, retrieval of targeted waste containing VOCs would reduce the operational period of the OCVZ system.

Like Alternative $4 \mathrm{a}$, Alternative $4 \mathrm{~b}$ also would prevent groundwater concentrations from exceeding MCLs. Monitoring would be established to address uncertainties, especially for nitrate, VOCs, and 1,4-dioxane (see Section 4.1.3). An additional factor present in this alternative that was not present in Alternative 4a pertains to Pad A, because in Alternative 4b, Pad A is left in place. This aboveground waste pad contains approximately $50 \%$ of SDA nitrate waste (a groundwater COC based on its potential to exceed the MCL). As a result, the groundwater concentration for Alternative $4 \mathrm{~b}$ would be slightly more than for Alternative 4a, where Pad A was completely removed from the SDA.

4.5.2.3.2 Reliability of Long-Term Controls-Like Alternative 4a, Alternative $4 \mathrm{~b}$ also has some level of residual risk that would remain indefinitely after implementation of this remedial alternative. However, the magnitude of risk resulting from combined radiological and chemical hazards would be within the acceptable risk range established in the National Contingency Plan

(40 CFR 300.430). In general, the discussion for Alternative 4a (Section 4.5.1.3.2) also applies to Alternative $4 \mathrm{~b}$.

The few differences are the slurry cut-off wall, approaches to address subsidence, and Pad A. Addition of the slurry cut-off wall would not enhance protectiveness to any appreciable degree. Therefore, this component is not a discriminating feature among alternatives. Conversely, approaches to subsidence in pits in Alternative $4 \mathrm{~b}$ could diminish long-term reliability. Proof-rolling to address subsidence would provide only limited effectiveness and could increase maintenance requirements and reduce long-term performance of the surface barrier. However, dynamic compaction would be adequate to address these same issues for Pad A.

Long-term management would be required for Alternative $4 b$ to confirm performance of the assembled remedial components. Environmental monitoring would include routinely collecting and analyzing multimedia samples for all COCs. Because levels of untreated residual contamination would not allow unrestricted future land use of the SDA, 5-year reviews would be conducted indefinitely. Surveillance also would be conducted to identify differential settlement, inadequate drainage, or other observable degradation of the surface barrier. Institutional controls and long-term activities would be managed by a federal agency (e.g., DOE or the Bureau of Land Management) to ensure that effective protection is maintained.

4.5.2.4 Reduction of Toxicity, Mobility, or Volume through Treatment. Treatment, as traditionally defined, is not a primary element of Alternative $4 \mathrm{~b}$, though minor treatment elements are included for targeted uranium waste and organic vapors collected from the vadose zone. However, 
Alternative $4 \mathrm{~b}$ would remove a substantial amount of waste contaminated with VOCs and transuranics, repackage it, and dispose of it at WIPP in New Mexico. WIPP is a deep geologic repository that provides a system that isolates the waste from the environment. Uranium waste retrieved from pit areas would be sent to ICDF for ex situ treatment and disposal. In addition, treatment may be required based on results from gas generation testing to satisfy shipping criteria for some retrieved waste. Soil vapors extracted using the OCVZ system would be treated; toxicity is irreversibly reduced by thermal oxidization.

Though treatment is not a component of the surface barrier, contaminant mobility to the underlying aquifer would be mitigated by reducing infiltration through the waste. Contaminant mobility to the surface would be prevented through the use of (1) the surface barrier's gas collection layer directing off gas away from the surface soil and (2) a biointrusion layer preventing plant roots and burrowing animals from transporting contamination to the surface.

4.5.2.5 Short-Term Effectiveness. Potential risk to the public and workers during implementation of remedial components included in Alternative $4 \mathrm{~b}$ would be moderate when controls typical of DOE waste management operations are used (Wheldon et al. 2006). Chemical exposures and radiological risk to a public member would be moderately low based on quantitative analysis of assumed emission rates from retrieval structures. Previous operating experience suggests that all aspects of remedial action could be conducted without exposing members of the public to significant amounts of hazardous or radioactive contaminants. Approximately, four public injuries may be incurred in an accident involving transport of construction materials to the SDA over public thoroughfares (Wheldon et al. 2006). However, engineering and administrative controls would minimize potential short-term risk to the public (e.g., transportation schedules and routes would be designed to minimize interference with public traffic patterns). A fatality involving a member of the public and transport of construction materials for Alternative $4 \mathrm{~b}$ would be highly unlikely (Wheldon et al. 2006).

Short-term risk to workers would be moderate and could be readily mitigated. Risk would be addressed by (1) maintaining exposure to penetrating radiation as low as reasonably achievable, (2) using personal protective equipment to limit risk associated with inhalation or dermal adsorption of radionuclides or chemicals, and (3) promoting a safety culture that creates a work environment free from occupational injury or illness. A maximally exposed worker involved in implementation of remedial components included in Alternative $4 \mathrm{~b}$ would incur a moderate increase in lifetime cancer risk relative to a worker involved in routine construction activities at the SDA (Weldon et al. 2006). Most cancer risk would be associated with handling waste (e.g., retrieval and packaging) during retrieval of subgrade pit areas. Chemical hazards for workers not directly involved with the alternative but near retrieval would be moderately low based on quantitative analysis. Workers implementing remedial components included in Alternative $4 \mathrm{~b}$ could incur as many as 32 recordable industrial accidents (Wheldon et al. 2006). A worker fatality would be highly unlikely during implementation of this alternative.

Risk to the environment during implementation of Alternative $4 \mathrm{~b}$ would remain at or below those identified in the baseline risk assessment. Fencing around the construction perimeter is a component of this alternative and would continue to reduce, although not entirely exclude, access to the active area by larger animals. Biotic transport through plant uptake and exposure of animal receptors (i.e., contact and ingestion of surface and subsurface soil) would decrease as buried waste is progressively removed and as grading fill and biointrusion layers are completed. With completion of the surface barrier, existing exposure pathways for ecological receptors would be eliminated. Remediation activities would be largely confined to the current footprint of the SDA. Short-term impacts to the environment for this alternative would be similar to those described for implementing a surface barrier in Alternative 2 (see Section 4.3). Noise, dust, and physical disturbance from retrieval activities (e.g., structure construction, waste transfer, and retrieval tent moves), dynamic compaction of pit areas, and surface barrier construction would be 
significant; and impacts to the habitat and organisms immediately surrounding the SDA would be high during the active construction timeline for this alternative.

All components of Alternative 4b, including the ET surface barrier, would be completed within 12 years of project inception. Overall, short-term effectiveness of this alternative is moderate.

4.5.2.6 Implementability. All remedial components included in Alternative $4 \mathrm{~b}$ are well understood and commercially available. The excavation and retrieval methods for areas totaling 2 acres are based on those currently used by the Accelerated Retrieval Project. Methods for construction of the slurry cut-off wall and the ET surface barrier are commonly used in civil engineering practice.

During dynamic compaction of Pad A, ground vibrations could breach containers in buried waste, releasing contaminants to the air. Modeling, mockup testing, monitoring, and demonstration would likely be required to establish safety protocols. Results would be used to define operating parameters (e.g., soil cover thickness and drop height). Risk of nitrate salt deflagration, though low (Beitel 2000), also would be defined and mitigated.

Experience during the Accelerated Retrieval Project suggests that excavation of SDA waste could be complicated by the presence of Rocky Flats Plant roaster oxides, which may contain pyrophoric material. Observation of pyrophoric material could significantly delay excavation.

Roaster oxide waste removed from pits would be sent to ICDF for treatment and disposal. Although treatment at ICDF is feasible, the treatment facility has not been used for treatment of radioactively contaminated waste in the past. If quantities of radioactive waste sent to ICDF for treatment are high, then treatment could prove challenging. In addition, administrative action to restart the treatment facility and extend operations beyond 2012 at ICDF would be required. The ICDF is scheduled for closure in the year 2012, and retrieval activates associated with this alternative are anticipated to last halfway through the year 2016 (see Figure 3-25).

Currently, WIPP is the only facility that can receive transuranic waste for disposal. The volume of waste containerized by Alternative $4 \mathrm{~b}$ and shipped to WIPP would be approximately $8,000 \mathrm{yd}^{3}$ (i.e., 28,000 drums). Total capacity of WIPP as currently designed, is $175,600 \mathrm{~m}^{3}\left(229,676 \mathrm{yd}^{3}\right)$; WIPP is expected to be filled to capacity by the year 2034 .

If portions of some targeted waste forms (i.e., Series 741 aqueous treatment sludge, Series 743 organic setup sludge, graphite, filters, and roaster oxides) do not contain transuranic radionuclides (i.e., cannot be sent to WIPP), treatment for volatiles may be applicable at the appropriate off-INL Site treatment and disposal facility in order to satisfy land disposal requirements. Acceptance of this waste type depends on the capacity and treatment process available at the treatment and disposal facility.

Equipment and specialists required for SDA waste retrieval, construction of a slurry cut-off wall, and construction of an ET surface barrier are available at the INL Site and within the commercial sector, and have been sufficiently demonstrated at either the INL Site or within the DOE complex. In addition, these technologies are sufficiently developed to allow full-scale deployment in the SDA. Based on common commercial equipment and remediation methods used within this alternative, lack of equipment or specialists would not prevent implementation of remedial components. As stated previously, an exception to this could potentially be availability of a modified crane used for dynamic compaction.

Based on previous responses to requests for proposals, several qualified vendors would bid to retrieve waste from pits or dynamically compact Pad A. Several commercial firms would respond to requests for proposals for design and construction of a slurry cut-off wall and an ET surface barrier. 
4.5.2.7 Cost. Table 4-11 provides the cost summary for Alternative 4b. Capital, operations and maintenance, and periodic costs are provided as current value and net present value. The base year in calculating net present value is 2006, with construction beginning in the year 2010 and ending in 2021 . Estimates include costs for 100 years of surveillance and maintenance, monitoring, and ICs following construction. Appendix F contains additional details.

Table 4-11. Costs for Alternative 4b-2-Acre Partial Retrieval, Treatment, and Disposal.

\section{Activity}

\section{Capital costs}

Excavation of pit areas totaling 2 acres (2010 through 2016)

Dynamic compaction of Pad A (2010 through 2011)

Proof-rolling of disposal pits (2016 through 2017)

Slurry cut-off wall installation around SDA perimeter (2016 through 2017)

Containment with evapotranspiration surface barrier with biotic barrier and vented gas transport layer (2016 through 2021)

Gas vent layer extraction pipe installation within surface barrier (2017 through 2018)

Replace OCVZ treatment units every 20 years (2030)

Total capital cost

\section{Operations and maintenance costs}

OCVZ operations, maintenance, and monitoring (2010 through 2044)

Surface barrier maintenance, environmental monitoring, project management, and technical support

(2021 through 2121)

Total operations and maintenance cost

146.7

$\begin{array}{rr}449.2 & 363.5 \\ 3.3 & 2.9 \\ 2.0 & 1.5 \\ 1.9 & 1.4 \\ 94.0 & 63.8\end{array}$

\begin{tabular}{cc}
$\begin{array}{c}\text { Current Value } \\
(\$ M)\end{array}$ & Net Present Value \\
\hline
\end{tabular}

\section{Periodic costs}

Final remedial action report, annual summary reports, 5.2 1.0 5-year reviews, and final operations and maintenance report (2021 through 2121)
60.1

86.6

17.1

33.1
1.1
0.5

434.5

63.8

$2.3 \quad 1.1$

553.2

50.2

$5.2 \quad 1.0$

5.2

1.0

705.1

485.6

OCVZ $=$ Organic Contamination in the Vadose Zone $\mathrm{SDA}=$ Subsurface Disposal Area 
4.5.2.8 State Acceptance. State acceptance will be evaluated in conjunction with the future proposed plan and ROD for OU 7-13/14.

4.5.2.9 Community Acceptance. Community acceptance will be evaluated in conjunction with the future proposed plan and ROD for OU 7-13/14.

\subsection{Alternative 5-Full Retrieval, Treatment, and Disposal}

Alternative 5 (Full Retrieval, Treatment, and Disposal) would protect human health and the environment primarily by removing VOCs from the vadose zone and removing all waste from the SDA and transferring it elsewhere. An additional measure of protection would be provided by controlling potential exposure to residual COCs through containment with a simplified ET surface barrier. For this alternative, all waste within the SDA (i.e., Pad A, pits, trenches, and soil vaults) would be retrieved and shipped off the SDA. Retrieved transuranic waste would be processed for shipment to WIPP, while nontransuranic waste would be sent to ICDF or an off-INL Site facility (e.g., EnergySolutions) for treatment and disposal. Waste with no current path to disposal (e.g., remote-handled nontransuranic waste) would be placed within shielded casks and stored in a newly constructed facility on the INL Site pending development of a federal or commercial repository. Following retrieval, the SDA would be backfilled with uncontaminated soil. Long-term activities for Alternative 5 include operation of the OCVZ system, surveillance and maintenance, ICs, and environmental monitoring.

\subsubsection{Overall Protection of Human Health and the Environment}

Alternative 5 would be fully protective of human health and the environment. Upon completion of the surface barrier in the year 2039, this alternative would achieve all remedial action objectives (see uncertainties discussed in Section 4.1.3 relating to groundwater simulations for nitrate, VOCs, and 1,4-dioxane). The ET surface barrier would minimize residual contaminant migration by reducing surface water infiltration rates.

This alternative would remove and relocate approximately $8,297,000 \mathrm{ft}^{3}$ of waste from the SDA. Retrieval would increase this volume to approximately 13,707,000 $\mathrm{ft}^{3}$ because of expansion, soil retrieved with waste, and other factors. Expansion factors are provided in Appendix E (see Table E-7). Four general types of waste would be handled: (1) LLW, (2) mixed LLW, (3) waste containing transuranic isotopes, and (4) remote-handled nontransuranic waste. The majority of waste would be LLW and would be transferred to waste disposal facilities outside of the INL Site. A relatively small quantity of LLW would be mixed waste, which would be transferred to ICDF for treatment. An even smaller amount would contain transuranic isotopes and would be sent to WIPP. The smallest amount of waste, remote-handled nontransuranic waste, would have no identified path to disposal and would be placed in interim storage.

Retrieval of all waste would greatly reduce contaminant inventories in the SDA, though residual contamination would remain in soil and the underlying vadose zone. Subsequent construction of a surface barrier and continued operation of the existing OCVZ system would address residual contamination. Long-term surveillance and maintenance, monitoring, and ICs would be conducted to ensure that the remedy remained protective.

Implementing this alternative would greatly increase the threat of exposure in the short term (i.e., during remediation). Complex engineering controls and administrative controls would address potential risk to workers, the public, and the environment. 


\subsubsection{Compliance with Applicable or Relevant and Appropriate Requirements}

Table 4-12 provides an evaluation summary of the major substantive ARARs for Alternative 5. Chemical and location-specific ARARs would be the same among all action alternatives given that the setting and chemical characteristics of the waste do not change. The most significant components of this alternative that relate to ARARs identification are design, installation, and operation of retrieval systems and requirements for long-term storage of waste.

Action-specific ARARs identification focuses on RTD of waste and shipping waste off the INL Site. Off-INL Site disposal requires satisfaction of all applicable administrative and substantive provisions that apply to the particular disposal situation. Thus, ARARs in Table 4-14 relate to on-INL Site remedial activities, chemicals, and setting.

Table 4-12. Regulatory compliance evaluation for Alternative 5-Full Retrieval, Treatment, and Disposal.

\begin{tabular}{|c|c|c|c|c|}
\hline ARAR or TBC & Type & Relevancy & Citation & $\begin{array}{c}\text { Meets } \\
\text { Evaluation? }\end{array}$ \\
\hline Idaho toxic air pollutants & Chemical & A & IDAPA 58.01 .01 .585 and 586 & Yes \\
\hline $\begin{array}{l}\text { Idaho ambient air quality } \\
\text { standards for specific air } \\
\text { pollutants }\end{array}$ & Chemical & A & IDAPA 58.01.01.577 & Yes \\
\hline $\begin{array}{l}\text { National emission standards for } \\
\text { hazardous air pollutants }\end{array}$ & Chemical & A & 40 CFR 61.92 through 94 & Yes \\
\hline $\begin{array}{l}\text { Idaho groundwater quality } \\
\text { standards }\end{array}$ & $\begin{array}{l}\text { Chemical } \\
\text { and action }\end{array}$ & A & IDAPA 58.01.11.200 & Yes \\
\hline $\begin{array}{l}\text { Safe Drinking Water Act } \\
\text { maximum contaminant levels }\end{array}$ & Chemical & RA & 40 CFR 141 & Yes \\
\hline $\begin{array}{l}\text { Native American graves } \\
\text { protection and repatriation } \\
\text { regulations }\end{array}$ & Location & A & 43 CFR 10 & $\begin{array}{l}\text { Yes-if } \\
\text { encountered }\end{array}$ \\
\hline $\begin{array}{l}\text { Preservation of historic, } \\
\text { prehistoric, and archeological } \\
\text { data }\end{array}$ & Location & A & $\begin{array}{l}36 \text { CFR } 800 \text { and } \\
40 \text { CFR } 6.301(b) \text { and (c) }\end{array}$ & $\begin{array}{l}\text { Yes-if } \\
\text { encountered }\end{array}$ \\
\hline $\begin{array}{l}\text { Protection of archaeological } \\
\text { resources }\end{array}$ & Location & A & 43 CFR 7 & $\begin{array}{l}\text { Yes-if } \\
\text { encountered }\end{array}$ \\
\hline $\begin{array}{l}\text { Compliance with environmental } \\
\text { review requirements for } \\
\text { floodplains and wetlands }\end{array}$ & Location & A & 10 CFR 1022 & Yes \\
\hline $\begin{array}{l}\text { Treatment, storage, and disposal } \\
\text { facilities located within } \\
\text { floodplains }\end{array}$ & Location & A & $\begin{array}{l}\text { IDAPA 58.01.05 } \\
\text { [40 CFR 264.18(b]) }\end{array}$ & Yes \\
\hline $\begin{array}{l}\text { General treatment, storage, and } \\
\text { disposal facility standards }\end{array}$ & Action & A & $\begin{array}{l}\text { IDAPA 58.01.05, } \\
\text { 40 CFR 264.13(a)(1)(2), } \\
\text { 264.15(a)(c), and 264.17(a)(c) }\end{array}$ & Yes \\
\hline $\begin{array}{l}\text { Preparedness and prevention } \\
\text { standards of treatment, storage, } \\
\text { and disposal facilities }\end{array}$ & Action & A & $\begin{array}{l}\text { IDAPA 58.01.05, } \\
\text { 40 CFR 264.31 through } 35\end{array}$ & Yes \\
\hline
\end{tabular}


Table 4-12. (continued).

\begin{tabular}{|c|c|c|c|c|}
\hline ARAR or TBC & Type & Relevancy & Citation & $\begin{array}{c}\text { Meets } \\
\text { Evaluation? }\end{array}$ \\
\hline $\begin{array}{l}\text { Standards for owners and } \\
\text { operators of treatment, storage, } \\
\text { and disposal facilities-general } \\
\text { groundwater monitoring } \\
\text { requirements }\end{array}$ & Action & A & 40 CFR 264.97 & $\mathrm{Yes}^{\mathrm{a}}$ \\
\hline $\begin{array}{l}\text { Standards for owners and } \\
\text { operators of treatment, storage, } \\
\text { and disposal facilities - closure } \\
\text { and postclosure }\end{array}$ & Action & $\mathrm{A}$ & $\begin{array}{l}\text { IDAPA 58.01.05 } \\
\text { (40 CFR 264.111, } \\
\text { 40 CFR 264.114, } \\
\text { 40 CFR 264.117) }\end{array}$ & Yes \\
\hline $\begin{array}{l}\text { Standards for owners and } \\
\text { operators of treatment, storage, } \\
\text { and disposal facilities-landfills }\end{array}$ & Action & $\mathrm{A}$ & $\begin{array}{l}\text { IDAPA 58.01.05 } \\
(40 \text { CFR 264.310(a)(1) } \\
\text { through }(5),(b)(1), \\
\text { (4) through (6) }\end{array}$ & Yes $^{\mathrm{a}}$ \\
\hline $\begin{array}{l}\text { Standards for owners and } \\
\text { operators of treatment, storage, } \\
\text { and disposal facilities-use and } \\
\text { management of containers }\end{array}$ & Action & $\mathrm{A}$ & $\begin{array}{l}\text { IDAPA 58.01.05 } \\
\text { (40 CFR 264, Subpart I) }\end{array}$ & Yes \\
\hline $\begin{array}{l}\text { Generator standards-hazardous } \\
\text { waste determination }\end{array}$ & Action & A & $\begin{array}{l}\text { IDAPA 58.01.05.006 } \\
(40 \text { CFR 262.11) }\end{array}$ & Yes \\
\hline Land disposal restrictions & Action & $\mathrm{A}$ & $\begin{array}{l}\text { IDAPA 58.01.05.011 } \\
\text { (40 CFR 268) }\end{array}$ & Yes \\
\hline Idaho toxic substances & Action & A & IDAPA 58.01.01.161 & Yes \\
\hline $\begin{array}{l}\text { Polychlorinated biphenyls-- } \\
\text { Toxic Substances Control Act }\end{array}$ & Action & $\mathrm{A}$ & 40 CFR 761, Subpart D & Yes \\
\hline Idaho visible emissions & Action & A & IDAPA 58.01.01.625 & Yes \\
\hline $\begin{array}{l}\text { Idaho control of fugitive dust } \\
\text { emissions }\end{array}$ & Action & A & IDAPA 58.01.01.650 and 651 & Yes \\
\hline Radioactive waste management & Action & $\mathrm{TBC}$ & DOE Order 435.1 & Yes \\
\hline $\begin{array}{l}\text { Radiation protection of the public } \\
\text { and the environment }\end{array}$ & $\begin{array}{l}\text { Chemical } \\
\text { and action }\end{array}$ & $\mathrm{TBC}$ & DOE Order 5400.5 & Yes \\
\hline $\begin{array}{l}\text { a. Evaluation criteria met, excluding contan } \\
\text { A }=\text { applicable } \\
\text { ARAR }=\text { applicable or relevant and approp } \\
\text { CFR = Code of Federal Regulations } \\
\text { DOE = U.S. Department of Energy } \\
\text { IDAPA = Idaho Administrative Procedures } \\
\text { RA = relevant and appropriate } \\
\text { TBC = to-be-considered (other information }\end{array}$ & $\begin{array}{l}\text { nation that may } \\
\text { ate requirement } \\
\text { ct } \\
\text { rom advisories, }\end{array}$ & ye already migra & ed into the vadose zone. & \\
\hline
\end{tabular}

Provisions of the Toxic Substances Control Act (40 CFR 761, Subpart D) for storage and disposal of polychlorinated biphenyls have been added as an ARAR for Alternative 5. Elevated concentrations of polychlorinated biphenyls have been observed in various SDA waste streams as part of previous removal operations to date. Toxic Substances Control Act-compliant storage facilities are assumed to be required.

For RCRA purposes, a set of ARARs similar to Alternatives 3 and 4 is identified, primarily because each of these alternatives involve treatment, storage, or disposal of hazardous waste. Consequently, RCRA treatment, storage, and disposal requirements are similarly identified. Treatment, storage, and disposal ARARs primarily address the storage facility because Alternative 5 does not involve on-INL Site treatment of waste. Also, shipment to ICDF of roaster oxides and other waste with no 
transuranics would necessitate compliance with RCRA land disposal restrictions given removal of hazardous waste from the RWMC area of contamination and disposal in the ICDF landfill. The ICDF waste acceptance criteria for polychlorinated biphenyls would also have to be met for waste that is transferred to ICDF for treatment and disposal.

Air emissions associated with Alternative 5 involve both point-source (e.g., from the retrieval enclosure stack) and fugitive or diffuse emissions sources (e.g., generation of dust during construction). This alternative would be designed and operated to comply with Idaho rules for control of fugitive dust emissions (IDAPA 58.01.01.650 and 651) that apply to any source of fugitive dust during construction and operations and maintenance activities. Further, point-source and diffuse radiological emissions must not exceed National Emission Standards (located in 40 CFR 61, Subpart H) for radionuclide emissions from DOE facilities. Point-source emissions monitoring for the Accelerated Retrieval Project has shown that abated radiological emissions fall well within the applicable effective dose equivalent value of $10 \mathrm{mrem}$ at the nearest public receptor location. Volatile organic compound emissions must also fall within chemical-specific requirements of pertinent air quality standards during remediation, including controlling toxic air pollutants (IDAPA 58.01.01.585 and 586), ambient air quality standards for specific air pollutants (e.g., as particulate matter) (IDAPA 58.01.01.577), and visible emissions criteria (IDAPA 58.01.01.625). To date, operational experience under the Accelerated Retrieval Project provides a reasonable basis to conclude that these criteria would also be satisfied for retrieval under Alternative 5.

All asbestos waste would be removed from the SDA under Alternative 5; therefore, inactive waste disposal standards of 40 CFR 61.151 would not apply.

\subsubsection{Long-Term Effectiveness and Permanence}

Implementation of Alternative 5 would control contaminant migration so that remedial action objectives are satisfied by the end of ICs (see uncertainties discussed in Section 4.1.3 relating to groundwater simulations for nitrate, VOCs, and 1,4-dioxane). Complete removal of all buried waste, followed by construction of an ET surface barrier, would preclude direct exposure to residual contamination by human or ecological receptors via surface exposure pathways. Overall thickness of the cap, coupled with long-term ICs, would preclude inadvertent human intrusion. Groundwater-pathway risk would be mitigated by combined effects of the OCVZ vapor extraction system and low permeability of the surface barrier. All remedial elements included in Alternative 5, with the exception of OCVZ operations, would be permanent and expected to remain functional into the indefinite future. The following subsections discuss magnitude of residual risk and reliability of long-term controls.

4.6.3.1 Magnitude of Residual Risk. Based on qualitative analysis of the expected performance of the surface barrier, all surface exposure pathways would be interrupted, satisfying all remedial action objectives at the surface for both human and ecological receptors. At the surface, risk to human and ecological receptors would be at background values because all buried waste would be transferred to a waste management facility, and the ET surface barrier would inhibit intrusion of plant roots and animals, thus mitigating potential transport of residual contamination to the surface.

Figure 4-9 compares carcinogenic groundwater risk to Alternative 1 (No Action). Carcinogenic risk would peak slightly above and then fall below 1E-04 before the end of the IC period and would decrease further in subsequent years, eventually falling below 1E-06 in less than 2,000 years (see Section 5, Figure 5-1). Peak groundwater risk for Alternative 5 is significantly lower than peak risk for Alternative 1. Reduction in risk is attributable to reduction in contaminant migration and presence of an OCVZ system. Migration of contaminants into the underlying aquifer would be reduced in two ways. First, a surface barrier over the SDA would limit migration of water percolating through the vadose zone, thereby slowing migration of contaminants to the aquifer. Second, the OCVZ treatment system would 
extract volatile COCs from the vadose zone until remediation goals are achieved (approximately 25 years from 2010), thus reducing the amount of contaminants that reach the aquifer. The risk curve in Figure 4-9 for Alternative 5 differs somewhat from risk curves shown for the partial retrieval (see Figure 4-7) and surface barrier alternatives (see Figures 4-1 and 4-3) after about 500 years. This indicates that long-term carcinogenic risk eventually would be affected by full retrieval.

Figure 4-10 compares the cumulative groundwater hazard index for Alternative 5 to Alternative 1. Results are based on overpredicted concentrations of carbon tetrachloride in the aquifer (see Section 4.1.3). Alternative 5 clearly reduces the magnitude of the hazard index, primarily by operating the OCVZ system and controlling infiltration and, secondarily by removing the source. Alternative 5 would satisfy remedial action objectives. Alternative 5 also would prevent groundwater concentrations from exceeding MCLs. Monitoring would be established to address uncertainties, especially for nitrate, VOCs, and 1,4-dioxane (see Section 4.1.3).

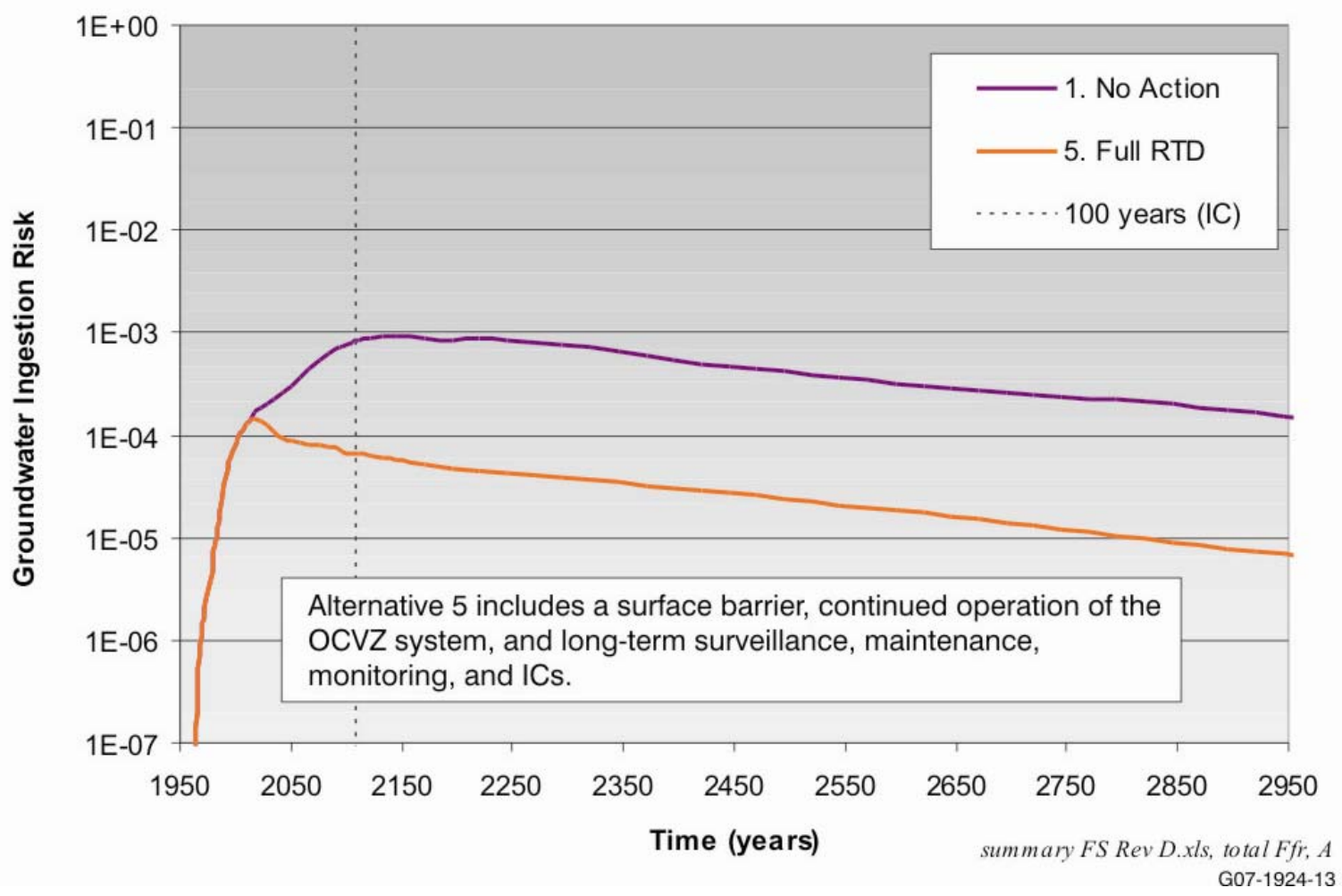

Figure 4-9. Cumulative groundwater ingestion risk for Alternative 5-Full Retrieval, Treatment, and Disposal, compared to Alternative 1-No Action. 


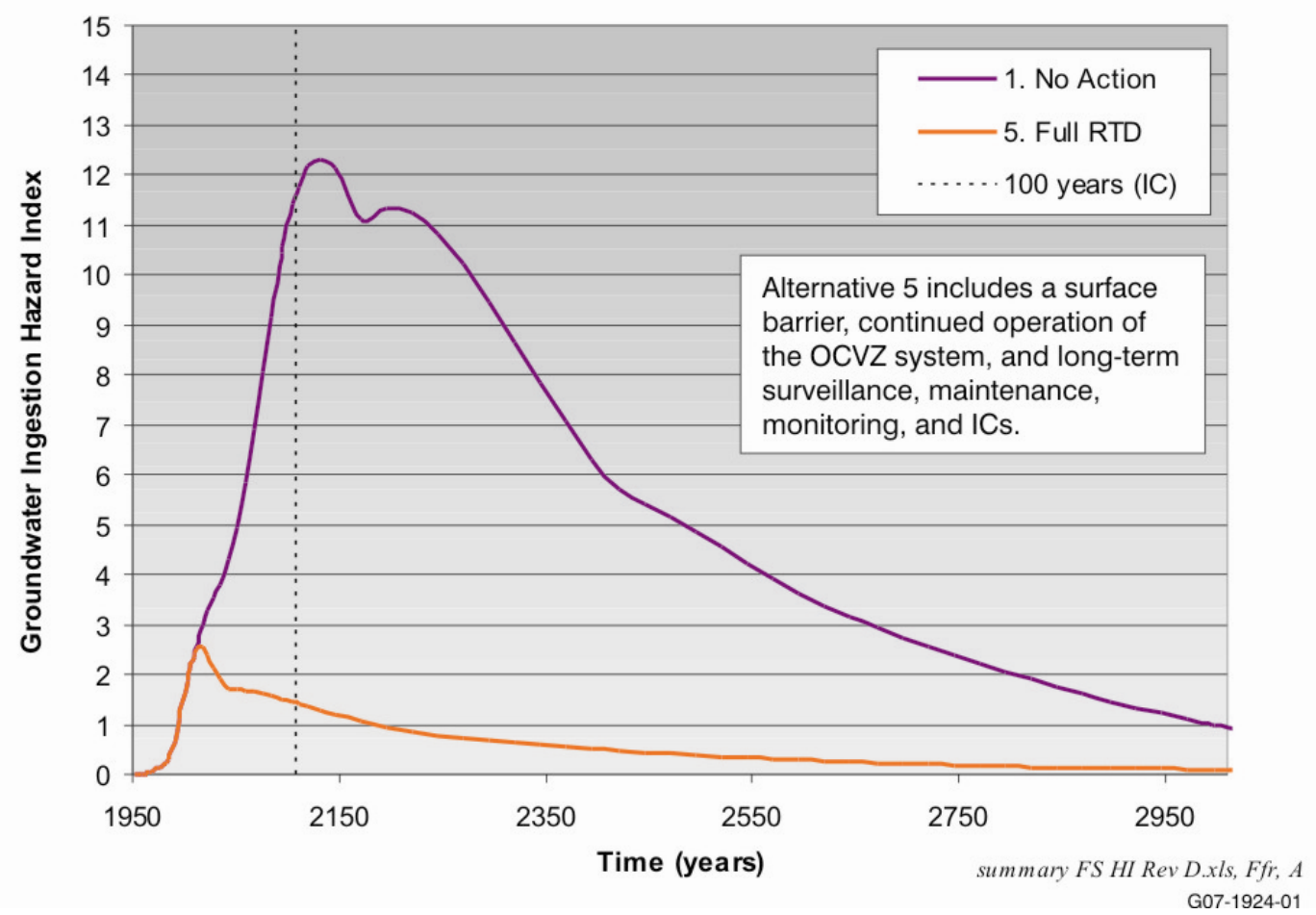

Figure 4-10. Hazard index for Alternative 5-Full Retrieval, Treatment, and Disposal, compared to Alternative 1 -No Action.

4.6.3.2 Reliability of Long-Term Controls. Some level of residual risk would remain indefinitely after implementation of this remedial alternative. However, the magnitude of risk resulting from combined radiological and chemical hazards would be within the acceptable risk range established in the National Contingency Plan (40 CFR 300.430). Effectiveness of Alternative 5 partially depends on surface barrier performance. The ET surface barrier would significantly reduce groundwater infiltration into the indefinite future.

As discussed in Section 4.3.1.3, surface barriers are potentially susceptible to intrusion by burrowing animals and deep-rooted plants over the long term, which could result in redevelopment of subsurface to surface exposure pathways. Overall thicknesses of cap material for this alternative decrease the likelihood of plant roots and burrowing animals reaching residual contamination. Potential for biotic intrusion is further reduced by bedrock underlying the INL Site.

Long-term management would be required to confirm performance of the assembled remedial components. Environmental monitoring would include routine collection and analysis of multimedia samples for all COCs. Because levels of untreated residual contamination would not allow unrestricted future use of the SDA site, 5-year reviews would be conducted indefinitely. Surveillance also would be conducted to identify differential settlement, inadequate drainage, or other observable degradation of the surface barrier. Institutional controls and long-term activities would be managed by a federal agency (e.g., DOE or the Bureau of Land Management) to ensure that effective protection is maintained. 


\subsubsection{Reduction of Toxicity, Mobility, or Volume through Treatment}

Treatment is not a primary element of Alternative 5, though treatment would be required for some waste forms to satisfy shipping requirements and to meet waste acceptance criteria for treatment, storage, and disposal facilities. Soil vapors extracted from the vadose zone using the OCVZ system would be treated; toxicity is irreversibly reduced by thermal oxidization. Though treatment is not a component of the surface barrier, contaminant mobility to the underlying aquifer would be mitigated by reducing infiltration through residual contamination in the vadose zone.

\subsubsection{Short-Term Effectiveness}

Potential risk to the public and workers during implementation of remedial components included in Alternative 5 would be high when controls typical of DOE waste management operations are used (Wheldon et al. 2006). Chemical and radiological risk to a public member living at the INL Site boundary would be moderate based on quantitative analysis of assumed emission rates from retrieval structures. Operating experience suggests that all aspects of remedial action could be conducted without exposing members of the public to significant amounts of hazardous or radioactive contaminants. Because of the large amount of transportation involved in full retrieval, approximately 30 public injuries may be incurred in an accident involving transport of construction materials to the SDA over public thoroughfares (Wheldon et al. 2006). However, engineering and administration controls would minimize potential short-term risk to the public (e.g., transportation schedules and routes would be designed to minimize interference with public traffic patterns). A fatality involving a member of the public and transport of construction materials for Alternative 5 would be highly unlikely (Wheldon et al. 2006).

Short-term risk to workers is relatively high for this alternative. Remediation workers would be protected by maintaining exposure to penetrating radiation as low as reasonably achievable, using personal protective equipment to limit risk associated with inhalation or dermal adsorption of radionuclides or chemicals, and promoting a safety culture that creates a work environment free from occupational injury or illness. A maximally exposed worker would incur an increase in lifetime cancer risk relative to a worker involved in routine construction activities in the SDA (Wheldon et al. 2006). Most radiological risk accrued by a remediation worker would be associated with handling waste (e.g., retrieval and packaging) for long periods of time during extensive retrieval activities (e.g., Pad A and subgrade pits, trenches, and soil vaults). Radiological risk to workers during these activities would be higher than risk to workers performing standard construction activities. Chemical risk and hazards for collocated workers would be moderate based on quantitative analysis of assumed emission rates from the retrieval structures. Workers implementing remedial components included in Alternative 5 could incur as many as 616 recordable industrial accidents (Wheldon et al. 2006). A worker fatality would be highly unlikely during implementation of this alternative.

Immediate risk to the environment, as a result of exposure to contaminants, would remain at or below those identified in the baseline risk assessment during implementation of Alternative 5. Fencing around the construction perimeter is a component of this alternative and would continue to reduce, although not entirely exclude, access to the active area by larger animals. Biotic transport through plant uptake and exposure of animal receptors (i.e., contact and ingestion of surface and subsurface soil) would decrease as buried waste is progressively removed and as grading fill and the surface barrier layers are completed. With completion of the surface barrier, existing exposure pathways for ecological receptors would be eliminated.

Remediation activities would be largely confined to the current footprint of the SDA. Short-term impacts to the environment for this alternative would be similar to those described for implementing a surface barrier in Alternative 2b. Noise, dust, and physical disturbance from retrieval activities 
(e.g., structure construction, waste transfer, and retrieval tent moves) would be significant, and impacts to habitat and organisms immediately surrounding the SDA would be high during active construction. Relative to environmental impacts short-term effectiveness is low for this alternative because of the extended timeframe for retrieval.

All components of Alternative 5, including the simplified ET surface barrier, would be completed within 30 years of project inception. Overall, short-term effectiveness of this alternative is low.

\subsubsection{Implementability}

Though remedial components associated with retrieval of most of the waste buried in the SDA and construction of a surface barrier are well understood and commercially available, the Full RTD Alternative would encounter several significant implementability issues. Technologies that deal with retrieval and storage of remote-handled waste have high potential for construction difficulties. This alternative would remove remote-handled waste using the method applied to remove waste from the Intermediate-Level Transuranic Storage Facility. This method entails transferring waste from the pit area into a shielded cask using a crane. The cask would then be stored within a newly constructed remote-handled interim storage facility pending development of an appropriate federal or commercial repository. Storage up to 20 years is assumed. Using this method within smaller retrieval tent structures would present significant challenges. First, crane height would be limited by the height of the retrieval enclosure. In addition, the Intermediate-Level Transuranic Storage Facility extracted intact drums from belowground vaults. Waste containers buried within the SDA would be in various states of decomposition. Construction of a remote-handled storage facility to store and package waste for shipment would also present additional construction challenges.

Experience during the Accelerated Retrieval Project suggests that excavation of SDA waste could be complicated by presence of Rocky Flats Plant roaster oxides, which may contain pyrophoric material. Observation of pyrophoric material could significantly delay excavation. Similar delays would likely be incurred during removal of highly radioactive material and during sizing of large objects.

All roaster oxide waste and $25 \%$ of all other waste with no transuranics would be sent to ICDF for treatment and disposal. Although treatment at ICDF is feasible for this type of waste, the treatment facility has not been used for treatment of radioactively contaminated waste in the past. If quantities of radioactive waste sent to ICDF for treatment are high, then treatment could prove challenging. Additional implementation issues are associated with the anticipated ICDF closure date; administrative action to restart the treatment facility and extend operations beyond 2012 at ICDF would be required. The ICDF is scheduled for closure in the year 2012, and retrieval activities associated with this alternative would last through the year 2037 (see Figure 3-31).

Currently, WIPP is the only facility that can receive transuranic waste for disposal. Total capacity of WIPP as currently designed is $175,600 \mathrm{~m}^{3}\left(229,676 \mathrm{yd}^{3}\right)$; WIPP may not have sufficient capacity to receive 242,000 drums or $50,000 \mathrm{~m}^{3}\left(66,000 \mathrm{yd}^{3}\right)$ of potentially acceptable waste from the SDA, necessitating that Congress modify the WIPP Land Withdrawal Act. In addition, WIPP is expected to be filled to capacity by the year 2034. The retrieval component of this alternative would last until the year 2037, which could pose a problem if WIPP is filled to capacity by the year 2034 .

If portions of some waste forms (e.g., Series 741 aqueous treatment sludge, Series 743 organic setup sludge, graphite, filters, and roaster oxides) do not contain transuranic radionuclides (i.e., cannot be sent to WIPP), treatment for volatiles may be applicable at the appropriate off-INL Site treatment and disposal facility in order to satisfy land disposal requirements. Acceptance of this waste type depends on the capacity and treatment process available at the treatment and disposal facility. 
EnergySolutions (formerly known as Envirocare) in Utah, accepts low-level radioactive waste, mixed low-level radioactive waste, and radioactive polychlorinated biphenyl waste. Treatment options available at EnergySolutions include stabilization, solidification, adsorption, reduction and oxidation, deactivation, neutralization, and macroencapsulation and microencapsulation. In addition, EnergySolutions carries the stipulation of accepting Class A mixed LLW only. EnergySolutions currently has 543 acres for three waste disposal cells, but, as of August 2005, they acquired an additional 536 acres to expand disposal operations with expectations of disposing of radiologically contaminated waste for the next 20 years.

Currently, no disposal path exists for some waste forms, especially remote-handled nontransuranic waste. This alternative assumes that waste with no path to disposal would be stored for a period of up to 20 years at which time a federal or commercial repository would be available. In view of the difficulties experienced with opening WIPP and Yucca Mountain, 20 years may not be sufficient.

Equipment and specialists required for SDA waste retrieval and construction of an ET surface barrier are available at the INL Site and within the commercial sector and have been adequately demonstrated at either the INL Site or within the DOE complex. In addition, these technologies are sufficiently developed to allow full-scale deployment within the SDA. Based on common commercial equipment and remediation methods used within this alternative, lack of equipment or specialists would not prevent implementation of remedial components.

Based on previous responses to requests for proposals, several qualified vendors would bid to retrieve waste in the SDA. Several commercial firms would respond to requests for proposals for design and construction of an ET surface barrier.

\subsubsection{Cost}

Table 4-13 provides the cost summary for Alternative 5. Capital, operations and maintenance, and periodic costs are provided as current value and net present value. The base year in calculating net present value is 2006, with construction beginning in the year 2010 and ending in 2039. Estimates include costs for 100 years of surveillance and maintenance, monitoring, and ICs following construction. Appendix F contains additional details.

\subsubsection{State Acceptance}

State acceptance will be evaluated in conjunction with the future proposed plan and ROD for OU 7-13/14.

\subsubsection{Community Acceptance}

Community acceptance will be evaluated in conjunction with the future proposed plan and ROD for OU 7-13/14. 
Table 4-13. Costs for Alternative 5-Full Retrieval, Treatment, and Disposal.

Activity

Current Value

(\$M)

$\begin{array}{rr}13,068.0 & 8,047.5 \\ 412.6 & 334.3\end{array}$

(2010 through 2014)

Containment with simplified evapotranspiration surface barrier (2036 through 2039)

Replace OCVZ treatment units every 20 years (2030)

Total capital cost
37.3

2.3

$13,520.2$
Net Present Value

$(\$ \mathrm{M})$

\section{Operations and maintenance costs}

OCVZ operations, maintenance, and monitoring

(2010 through 2034)

Surface barrier maintenance, environmental monitoring, and project management and technical support

(2039 through 2139)

Total operations and maintenance cost

27.0

82.9

9.6

\section{Periodic costs}

Final remedial action report, annual summary reports, 5 -year reviews, and final operations and maintenance report (2039 through 2139)

Total periodic cost

5.2

0.6

Total cost

$13,651.4$

36.6

126.0

5.2

0.6

$\mathrm{INL}=$ Idaho National Laboratory

OCVZ $=$ Organic Contamination in the Vadose Zone

\subsection{References}

10 CFR 1022, 2003, "Compliance with Floodplain and Wetland Environmental Review Requirements," Code of Federal Regulations, Office of the Federal Register.

29 CFR 1910, 2006, “Occupational Safety and Health Standards," Code of Federal Regulations, Office of the Federal Register, July 2006.

36 CFR 800, 2004, "Protection of Historic Properties," Code of Federal Regulations, Office of the Federal Register.

40 CFR 6, 2002, "Procedures for Implementing the Requirements of the Council on Environmental Quality on the National Environmental Policy Act," Code of Federal Regulations, Office of the Federal Register.

40 CFR 61, 2006, "National Emission Standards for Hazardous Air Pollutants," Code of Federal Regulations, Office of the Federal Register. 
40 CFR 141, 2006, "National Primary Drinking Water Regulations," Code of Federal Regulations, Office of the Federal Register.

40 CFR 154, 2006, “Special Review Procedures,” Code of Federal Regulations, Office of the Federal Register.

40 CFR 262, 2006, "Standards Applicable to Generators of Hazardous Waste," Code of Federal Regulations, Office of the Federal Register.

40 CFR 264, 2006, "Standards for Owners and Operators of Hazardous Waste Treatment, Storage, and Disposal Facilities," Code of Federal Regulations, Office of the Federal Register.

40 CFR 300, 2006, "National Oil and Hazardous Substances Pollution Contingency Plan," Code of Federal Regulations, Office of the Federal Register.

40 CFR 761, Subpart D, 2006, "Storage and Disposal," Code of Federal Regulations, Office of the Federal Register.

43 CFR 7, 2006, "Protection of Archaeological Resources," Code of Federal Regulations, Office of the Federal Register.

43 CFR 10, 2006, "Native American Graves Protection and Repatriation Regulations," Code of Federal Regulations, Office of the Federal Register.

42 USC § 9601 et seq., 1980, "Comprehensive Environmental Response, Compensation and Liability Act of 1980 (CERCLA/Superfund)," United States Code.

42 USC $§ 9621$ et seq., 2004, “Cleanup Standards,” United States Code.

Auerbach, N. A., M. D. Walker, and D. A. Walker, 1997, "Effects of Roadside Disturbance on Substrate and Vegetation Properties in Arctic Tundra," Ecological Applications, Vol. 7, No. 1, pp. 218-235.

Beitel, George A., 2000, Independent Technical Review Panel Safety Review of Proposed Stage I Drilling Activities, INEEL/EXT-2000-00185, EDF-ER-143, Idaho National Engineering and Environmental Laboratory.

Bowders, John J., J. Erick Loehr, Deepak Neupane, and Abdelmalek Bouassa, 2003, "Construction Quality Control for Asphalt Concrete Hydraulic Barriers," Journal of Geotechnical and Geoenvironmental Engineering, Vol. 129, No. 3, pp. 219-223.

Burton, Brent, 2006, "Emissions pf Radionuclides from the Accelerated Retrieval Project During Calendar Year 2005," EDF-6763, Rev. 0, Idaho National Laboratory, Idaho Cleanup Project.

DOE-ID, 1997, Environmental Assessment and Plan for New Silt/Clay Source Development and Use at the Idaho National Engineering and Environmental Laboratory, DOE/EA-1083, U.S. Department of Energy Idaho Operations Office.

DOE-ID, 2004, Action Memorandum for Accelerated Retrieval of a Described Area within Pit 4, DOE/NE-ID-11179, Rev. 0, U.S. Department of Energy Idaho Operations Office. 
DOE-ID, 2006, Action Memorandum for the Accelerated Retrieval Project II within Pits 4 and 6 of the Subsurface Disposal Area, DOE/NE-ID-11238, U.S. Department of Energy Idaho Operations Office.

DOE O 435.1, 2001, "Radioactive Waste Management,” Change 1, U.S. Department of Energy.

DOE O 5400.5, 1993, "Radiation Protection of the Public and the Environment," U.S. Department of Energy.

EPA, 1988, Guidance for Conducting Remedial Investigations and Feasibility Studies Under CERCLA, Interim Final, EPA/540/G-89/004, OSWER Directive 9355.3-01, U.S. Environmental Protection Agency.

EPA, 1989, Superfund LDR Guide \#5 Determining When Land Disposal Restrictions (LDRs) Are Applicable to CERCLA Response Actions, OSWER Directive 9347.3-05FS, U.S. Environmental Protection Agency, Office of Solid Waste and Emergency Response.

EPA, 2006, Remediation Technology Descriptions, Alternative Landfill Cover Project Profiles, U.S. Environmental Protection Agency, Technology Innovation Program, URL: http://cluin.org/products/altcovers/, Web page visited January 30, 2007.

Gee, G. W. and A. L. Ward, 1997, "Still in Quest for the Perfect Cap," edited by T. D. Reynolds and R. C. Morris, Conference Proceedings-Landfill Capping in the Semi-Arid West: Problems, Perspectives, and Solutions, Environmental Science and Research Foundation, Vol. ESRF-019.

Gee, G. W., A. L. Ward, and C. D. Wittreich, 2002, The Hanford Site 1000-Year Cap Design Test, PNNL-14143, Pacific Northwest National Laboratory.

Halford, V. E., D. R. Perry, W. C. Craft III, J. J. King, J. M. McCarthy, I. D. Figueroa, and Y. McClellan, 1993, Remedial Investigation/Feasibility Study for Pad A Operable Unit 7-12, Waste Area Group 7, Radioactive Waste Management Complex, Idaho National Engineering Laboratory, EGG-WM-9967, Vol. 1, Idaho National Engineering Laboratory.

Holdren, K. Jean and Barbara J. Broomfield, 2004, Second Addendum to the Work Plan for the OU 7-13/14 Waste Area Group 7 Comprehensive Remedial Investigation/Feasibility Study, DOE/ID-11039, Rev. 0, U.S. Department of Energy Idaho Operations Office.

Holdren, K. Jean, Danny L. Anderson, Bruce H. Becker, Nancy L. Hampton, L. Don Koeppen, Swen O. Magnuson, and A. Jeffrey Sondrup, 2006, Remedial Investigation and Baseline Risk Assessment for Operable Unit 7-13/14, DOE/ID-11241, U.S. Department of Energy Idaho Operations Office.

ICP, 2006, Independent Investigation Report of the November 2005 Drum Fire at the Idaho National Laboratory Site, RPT-190, Idaho National Laboratory, Idaho Cleanup Project.

Idaho Statute 67-4601 et seq., 2005, Preservation of Historic Sites, State of Idaho.

IDAPA 58.01.01.161, 1995, “Toxic Substances,” Idaho Administrative Procedures Act, Idaho Department of Environmental Quality. 
IDAPA 58.01.01.577, 1994, “Ambient Air Quality Standards for Specific Air Pollutants,” Idaho Administrative Procedures Act, Idaho Department of Environmental Quality.

IDAPA 58.01.01.585, 1995, “Toxic Air Pollutants Non-Carcinogenic Increments," Idaho Administrative Procedures Act, Idaho Department of Environmental Quality.

IDAPA 58.01.01.586, 2001, “Toxic Air Pollutants Carcinogenic Increments,” Idaho Administrative Procedures Act, Idaho Department of Environmental Quality.

IDAPA 58.01.01.625, 2000, “Visible Emissions," Idaho Administrative Procedures Act, Idaho Department of Environmental Quality.

IDAPA 58.01.01.650, 1994, "Rules for Control of Fugitive Dust," Idaho Administrative Procedures Act, Idaho Department of Environmental Quality.

IDAPA 58.01.01.651, 1994, “General Rules,” Idaho Administrative Procedures Act, Idaho Department of Environmental Quality.

IDAPA 58.01.05, 1993, "Rules and Standards for Hazardous Waste," Idaho Administrative Procedures Act, Idaho Department of Environmental Quality.

IDAPA 58.01.05.011, 2006, "Land Disposal Restrictions," Idaho Administrative Procedures Act, Idaho Department of Environmental Quality.

IDAPA 58.01.11, 1997, “Ground Water Quality Rule,” Idaho Administrative Procedures Act, Idaho Department of Environmental Quality.

IDAPA 58.01.11.200, 1997, "Ground Water Quality Standards,” Idaho Administrative Procedures Act, Idaho Department of Environmental Quality.

Kaback, D. S., T. W. Fogwell, and S. W. Peterson, 2005, Evaluation of Vadose Zone Treatment Technologies to Immobilize Technetium-99, WMP-27397, Fluor Hanford.

Lopez, S. L., William H. Landman, Donald E. Sebo, and Vivian G. Schultz, 2005, Summary Report for the OU 7-13/14 Early Actions Beryllium Encapsulation Project, ICP/EXT-04-00646, Rev. 1, Idaho National Engineering and Environmental Laboratory, Idaho Completion Project.

Magnuson, S. O., 1993, A Simulation Study of Moisture Movement in Proposed Barriers for the Subsurface Disposal Area, EGG-WM-10974, Idaho National Engineering Laboratory.

Manci, K. M., D. N. Gladwin, R. Villella, and M. G. Cavendish, 1988, Effects of Aircraft Noise and Sonic Booms on Domestic Animals and Wildlife: A Literature Synthesis, NERC-88/29, U.S. Fish and Wildlife Service, National Ecology Research Center, Ft. Collins, Colorado, pp. 88.

Matthern, Gretchen, Neal Yancey, Gregory Hulet, and Peter Shaw, 2005, Preremedial Design Report of Remediation Options for OU 7-13/14, ICP/EXT-04-00330, Rev. 0, Idaho National Laboratory, Idaho Cleanup Project. 
Mattson, Earl, Mark Ankeny, Steve Dwyer, Nancy Hampton, Gretchen Matthern, Brenda Pace, Alva Parsons, Mitch Plummer, Steve Reese, and Jody Waugh, 2004, Preliminary Design for an Engineered Surface Barrier at the Subsurface Disposal Area, ICP/EXT-04-00216, Rev. 0, Idaho National Engineering and Environmental Laboratory, Idaho Completion Project.

Minkin, S. C., M. R. Jackson, C. Knutson, P. N. Middleston, B. L. Ringe, R. C. Rope, and R. P. Smith, 1994, INEL Gravel/Borrow Resources and Compliance Assessment, EGG-FM-1126, Idaho National Engineering Laboratory.

Mitchell, T., S. Mitchell, J. Humphrey, D. Kennedy, and T. Funderburg, 2001, 100-Year Floodplain and 25-Year Runoff Analyses for the Radioactive Waste Management Complex Area at the Idaho National Engineering and Environmental Laboratory, INEEL/EXT-02-00093, Idaho National Engineering and Environmental Laboratory.

Moore, Beth A. and Bruce M. Crowe, 1998, Consequences of Subsidence for the Area 3 and Area 5 Radioactive Waste Management Sites, Nevada Test Site, DOE/NV-502 UC-600, U.S. Department of Energy Nevada Operations Office.

Morgan, I. L. and W. D. Bostick, 1992, "Performance Testing of Grout-Based Waste Forms for the Solidification of Anion Exchange Resins," Stabilization and Solidification of Hazardous, Radioactive, and Mixed Wastes, 2nd Volume, STP 1123, ASTM, Philadelphia, pp. 133-145.

OMB, 2006, Guidelines and Discount Rates for Benefit-Cost Analysis of Federal Programs, Appendix C, "Discount Rates for Cost-Effectiveness, Lease Purchase, and Related Analysis," OMB Circular No. A-94, Office of Management and Budget, URL: http://www.whitehouse.gov/omb/circulars/a094/a94_appx-c.html, Web page last visited June 12, 2006.

Peterson, R. D., A. J. Johnson, and K. G. Peter, 1986, Nitrate Salt Immobilization Process Development and Implementation, RFP-3919, Rocky Flats Plant.

Raivo, B., 2001, "Staging, Storage, Sizing, and Treatment Facility (SSSTF) Stabilization Treatment Process Selection," EDF-1542, Rev. 0, Idaho National Engineering and Environmental Laboratory.

Richins, W. D. and C. J. Hurst, 2004, “Assessment of Dynamic Soil Compaction at SDA,” EDF-4909, Rev. 0, Idaho National Engineering and Environmental Laboratory, Idaho Completion Project.

Smith, E. D., R. J. Luxmore, and G. W. Suter, 1997, "Natural Physical and Biological Processes Compromise the Long Term Integrity of Compacted Clay Caps," Barrier Technologies for Environmental Management, National Research Council, Washington, D.C.: National Academies Press.

Staley, Chris, 2004, "Air Emissions Evaluation for the Accelerated Retrieval Project for a Described Area within Pit 4," EDF-4692, Rev. 0, Idaho National Engineering and Environmental Laboratory, Idaho Completion Project.

Staley, Chris, 2006, “2005 INEEL Emissions Standards for Hazardous Air Pollutants (NESHAP)— Compilation of Radiological Releases from Idaho Completion Project Activities and Sites for CY 2004,” EDF-5846, Rev. 0, Idaho National Laboratory, Idaho Cleanup Project. 
Suter, Glenn W. II, Robert J. Luxmoore, and Ellen D. Smith, 1993, "Compacted Soil Barriers at Abandoned Landfill Sites Are Likely to Fail in the Long Term," Journal of Environmental Quality, Vol. 22, No. 2, pp. 217-223.

Szecsody, J. E., J. L. Phillips, V. R. Vermeul, J. S. Fruchter, and M. D. Williams, 2005, Influence of Nitrate on the Hanford 100D Area in Situ Redox Manipulation Barrier Longevity, PNNL-15262, Pacific Northwest National Laboratory.

Trombulak, S. C. and C. Frissell, 2000, "A Review of the Ecological Effects of Roads on Terrestrial and Aquatic Ecosystems," Conservation Biology, Vol. 14, pp. 18-30.

Wheldon, Nathan M., Gary J. McManus, Jeffrey A. Towers, and David J. Thorne, 2006, Short-Term Risk Assessment for the Operable Unit 7-13/14 Feasibility Study, RPT-188, Rev. 0, Idaho National Laboratory, Idaho Cleanup Project. 


\section{CONTENTS}

5. COMPARATIVE ANALYSIS OF ALTERNATIVES............................................................

5.1 Overall Protection of Human Health and the Environment...........................................5-5

5.2 Compliance with Applicable or Relevant and Appropriate Requirements....................... 5-5

5.3 Long-Term Effectiveness and Permanence …..........................................................5-6

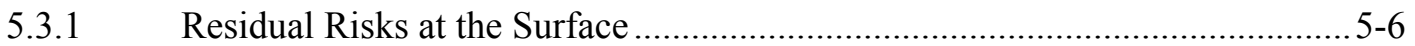

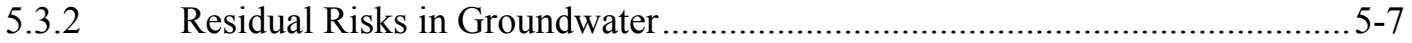

5.3.3 Adequacy and Reliability of Controls .......................................................5-10

5.4 Reduction of Toxicity, Mobility, or Volume through Treatment ...................................5-11

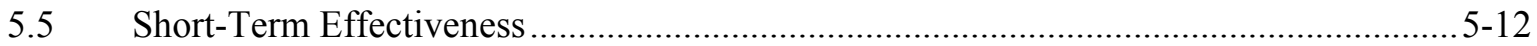

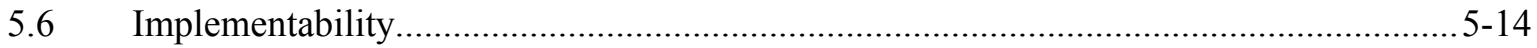

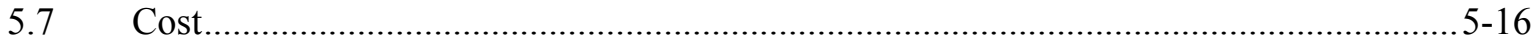

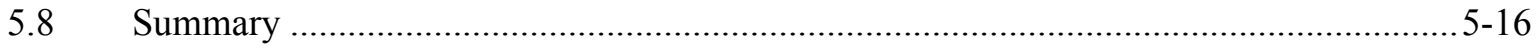

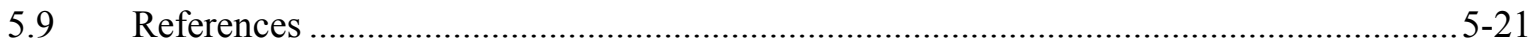

\section{FIGURES}

5-1. Comparison of long-term effectiveness based on cumulative carcinogenic risk for groundwater ingestion provided by each remedial alternative

5-2. Comparison of long-term effectiveness based on cumulative hazard index for groundwater ingestion provided by each remedial alternative

5-3. Estimated implementation timeframes for each remedial alternative

5-4. Estimated recordable injuries for each action alternative

5-5. Comparison and summary of cost associated with each alternative

\section{TABLES}

5-1. Matrix of the five assembled alternatives and major components in each 


$$
\text { 5-2 }
$$




\section{COMPARATIVE ANALYSIS OF ALTERNATIVES}

This section compares relative advantages and disadvantages of the five assembled alternatives in achieving remedial action objectives for the Subsurface Disposal Area (SDA). The nine Comprehensive Environmental Response, Compensation, and Liability Act (CERCLA) (42 USC § 9601 et seq., 1980) criteria provide the basis for comparison. The following analysis assesses alternatives - relative to one another - for seven of the nine evaluation criteria (i.e., two threshold and five balancing criteria). The last two criteria (i.e., modifying criteria), state acceptance and community acceptance, will be evaluated in conjunction with the proposed plan and record of decision.

Except for continued operation of the vapor vacuum extraction system, initiated under Operable Unit (OU) 7-08 to collect volatile organic compounds (VOCs) from the vadose zone, scope for OU 7-13/14 focuses on measures that deal directly with the buried waste. Because contaminant migration has not occurred to a substantial extent (except for VOCs), the objective for remedial action at the SDA is source control (i.e., approaches to prevent contaminant migration). The baseline risk assessment and this feasibility study define the source as the buried waste and associated contaminated soil down to the first basalt layer beneath the landfill. The Agencies identified source control, which can include containment, removal, or treatment of selected areas within the source (EPA 1988), to inhibit future releases from buried waste and to prevent further contamination of the environment. The unsaturated region beneath the source is the vadose zone, and below that is the aquifer. Source control, combined with continued operation of the OCVZ system, will protect the vadose zone and aquifer.

The primary means of source control is construction of an engineered surface barrier and, for Alternatives 4 and 5, removal of a substantial portion of VOC waste via excavation and continued operation of the OCVZ system. The Agencies concluded early in the study of the SDA that an engineered surface barrier will be a component of every action alternative evaluated in this feasibility study (Holdren and Broomfield 2004). Coupled with long-term institutional controls (ICs), the surface barrier would preclude inadvertent human intrusion. The surface barrier also would preclude contaminant transport to the surface by plants and animals.

Developing this comprehensive feasibility study involves integrating remedies for several characteristics of the SDA (e.g., localized subsidence in pits, above-grade waste on Pad A, and near-surface VOCs) into fully assembled alternatives that address the entire landfill. The Agencies recognized that each specific characteristic can be addressed several ways; thus, many assembled alternatives composed of different combinations are possible. The Agencies optimized feasibility study development by specifying the combinations that would be evaluated as fully assembled alternatives. To maintain flexibility, each component was developed as a discrete module. Each alternative is named after its featured component, though every action alternative includes an engineered surface barrier, continued operation of the OCVZ system, and long-term surveillance, maintenance, monitoring, and ICs. The Agencies will be able to mix and match various components, selecting the optimum combination when developing a preferred alternative and finalizing remedial decisions for the SDA.

Detailed analyses in Section 4 evaluated alternatives for the SDA independently. Comparative analysis presented in this section complements the detailed analysis by identifying key tradeoffs that DOE, DEQ, and EPA must balance to select a preferred alternative and develop risk management decisions for the SDA. The summary of the five assembled alternatives developed in Section 3 and analyzed in detail in Section 4 is repeated below to facilitate comparative analysis in subsections that follow.

- $\quad$ Alternative 1-No Action-comprises environmental monitoring only, with no measures to reduce risk. 
- $\quad$ Alternative 2-Surface Barrier-includes two subalternatives, which are evaluated in detail:

- $\quad$ Alternative 2a-Modified Resource Conservation and Recovery Act (RCRA) Type C Surface Barrier-is a surface barrier assembled with additional near-surface vapor vacuum extraction, foundation grouting to address subsidence, continued operation of the OCVZ system, and long-term surveillance, maintenance, monitoring, and ICs. Pad A would be incorporated as-is into the surface barrier.

- $\quad$ Alternative 2b-Evapotranspiration (ET) Surface Barrier-is a surface barrier with an active gas collection layer assembled with dynamic compaction to address subsidence, continued operation of the OCVZ system, and long-term surveillance, maintenance, monitoring, and ICs. Pad A waste would be transferred to the Low-Level Waste (LLW) Pit or other location within the SDA.

- $\quad$ Alternative 3-In Situ Grouting (ISG)—involves immobilizing Tc-99 and I-129 in place using high-pressure jet grouting. Relevant waste forms are associated with Idaho National Laboratory (INL) Site reactor research and operations. Fully assembled, this alternative includes dynamic compaction of pits to address subsidence, an ET surface barrier with a passive gas collection layer, continued operation of the OCVZ system, and long-term surveillance, maintenance, monitoring, and ICs. Pad A waste would be retrieved, treated ex situ, and transferred to the LLW Pit or other location within the SDA.

- $\quad$ Alternative 4-Partial Retrieval, Treatment, and Disposal (RTD)—includes the following two subalternatives that are evaluated in detail to facilitate scaling for variable sizes of retrieval areas:

- $\quad$ Alternative 4a-4-Acre Partial RTD—addresses removal of targeted Rocky Flats Plant waste from pit areas in the SDA totaling 4 acres. Additional features of this assembled alternative include dynamic compaction of pits to address subsidence, a passively vented ET surface barrier, continued operation of the OCVZ system, and long-term surveillance, maintenance, monitoring, and ICs. Pad A waste would be removed and sent to the Idaho CERCLA Disposal Facility (ICDF) for treatment and disposal.

- $\quad$ Alternative 4b-2-Acre Partial RTD—addresses removal of targeted Rocky Flats Plant waste from pit areas in the SDA totaling 2 acres. Additional features of this assembled alternative include proof-rolling of pits to address subsidence, a subsurface slurry wall around the perimeter of the landfill, a passively vented ET surface barrier, continued operation of the OCVZ system, and long-term surveillance, maintenance, monitoring, and ICs. Pad A would be dynamically compacted and incorporated into the surface barrier.

- $\quad$ Alternative 5-Full RTD-includes complete removal of all buried waste in combination with a simplified ET surface barrier, continued operation of the OCVZ system, and long-term surveillance, maintenance, monitoring, and ICs.

In subsections that follow, Alternative 1 (No Action) is discussed first under each criterion. Action alternatives (i.e., Alternatives 2, 3, 4, and 5) then are presented in the relative order in which they perform, beginning with the alternative that provides the best overall performance for the criterion. Table 5-1 provides a matrix of the five assembled alternatives and major components in each. This section concludes with a summary table of the comparative analysis (see Table 5-2). 


\subsection{Overall Protection of Human Health and the Environment}

All alternatives, except No Action, provide overall protection of human health and the environment. Alternative 1, which includes environmental monitoring with no other steps to reduce exposure, does not satisfy this criterion. Over time, plants and animals would transport contaminants to the surface, and moisture would continue to infiltrate through buried waste, resulting in contaminant concentrations in surface soil and groundwater that could exceed preliminary remediation goals.

Alternative 5 would perform marginally better than other alternatives because all buried waste would be removed. However, all four action alternatives would provide adequate and relatively equivalent protection and would satisfy this threshold criterion, primarily because a surface barrier and extraction of VOCs from the vadose zone are components of each. A surface barrier would constrain intrusion by plants and animals, thus preventing transport of contaminants to the surface in concentrations that could exceed preliminary remediation goals. Infiltration of moisture into buried waste would be greatly diminished, reducing contaminant release into the vadose zone and retarding transport to the underlying aquifer. Overall thickness of the surface barrier, coupled with long-term ICs, would preclude inadvertent human intrusion.

Implementation time for each alternative provides some slight discrimination between alternatives. To provide a balanced analysis, the year 2010 was used as the effective date for modeling long-term risk. Thus, as modeled, each alternative instantaneously reduces biotic intrusion and moisture infiltration in 2010. In reality, alternatives that require shorter implementation times also provide more overall protection by reducing infiltration and leaching into the subsurface sooner. Therefore, Alternatives 2 and 3 (i.e., surface barrier and ISG alternatives) perform best for this criterion because they require the least amount of time to implement. The construction period for Alternative 2a (Modified RCRA Type C Surface Barrier) would require approximately 7 years, while Alternative 2b (ET Surface Barrier) and Alternative 3 (ISG) would require approximately 10 years. The additional 3 years for Alternatives $2 \mathrm{~b}$ and 3 comprise the time required to relocate Pad A waste. Construction periods for Alternatives 4 and 5 require increasingly more implementation time. Construction periods for the subalternatives under Alternative 4 (Partial RTD) would require approximately 16 years (i.e., Alternative 4a, 4-acre RTD) and 12 years (i.e., Alternative 4b, 2-acre RTD) to implement. The construction period for Alternative 5 (Full RTD) would require approximately 30 years.

\subsection{Compliance with Applicable or Relevant and Appropriate Requirements}

All alternatives, except No Action, would comply with associated applicable or relevant and appropriate requirements (ARARs). Alternative 1 (No Action) would fail to satisfy this criterion because it offers no measures to reduce contaminant concentrations or preclude exposures. Specifically, Alternative 1 does not address ARARs relating to radiation protection, groundwater quality, maximum contaminant levels (MCLs), and fugitive dust emissions.

All four action alternatives would comply with ARARs, and would, therefore, be eligible for selection, based on this threshold criterion. Each alternative addresses ARARs relating to radiation protection, airborne concentrations, groundwater quality, MCLs, archeological artifacts, and other chemical, action, and location-specific regulations. Limited discrimination is provided by considering two factors: the number of ARARs associated with each alternative and implementation timeframes. 
The increasing complexity of each alternative would invoke an increasing number of ARARs. Consequently, the Alternative 2 (Surface Barrier) would comply with all associated ARARs more readily, while subsequent alternatives, in sequence, require more. Relative to Alternative 5 (Full RTD), some uncertainty is associated with the ability to fully evaluate compliance with ARARs. Approaches developed for the Accelerated Retrieval Project were used as a basis for evaluating Alternative 5, as specified in the Second Addendum to the Work Plan (Holdren and Broomfield 2004). Realistically, these approaches may not sufficiently address all waste forms that would be generated.

\subsection{Long-Term Effectiveness and Permanence}

Evaluation of alternatives under this criterion addresses anticipated results of remedial action in terms of risk remaining after response objectives have been met. This evaluation focuses primarily on the extent and effectiveness of controls that may be required to manage residual risk. Consideration is based on factors that describe the magnitude of residual risks and the adequacy and reliability of controls.

Alternative 1 (No Action) would not reduce long-term risk; therefore, the magnitude of residual risk is equivalent to that described by the refined baseline risk assessment (see Section 1.4). Because controls are not included in No Action, this alternative also would fail to provide adequacy and reliability of controls.

Implementation time for each alternative provides some discrimination between action alternatives based on standards for owners and operators of treatment, storage, and disposal facilities, and long-term effectiveness. To provide a balanced analysis, the year 2010 was used as the effective date for each alternative to model long-term risk. Thus, as modeled, each alternative instantaneously reduces moisture infiltration. In reality, alternatives that require shorter implementation timeframes also reduce the amount of contamination that could accumulate in the vadose zone and reach the aquifer (i.e., alternatives with shorter timeframes provide better protection because they allow less time for water to infiltrate). Alternatives 2 and 3 require the least amount of time to implement (i.e., 7 to 10 years) Alternative 4 requires more (i.e., 12 to 16 years), and Alternative 5 requires the most time (i.e., 30 years).

Conversely, despite allowing more release into the vadose zone because of longer implementation times, alternatives that remove waste from the SDA reduce the amount of contamination that is available to migrate. Alternative 5 (Full RTD) would be most effective because all waste would be removed, followed by Alternative $4 \mathrm{a}$, which removes Pad A and targeted waste from 4 acres, and Alternative $4 \mathrm{~b}$, which removes targeted waste from 2 acres. Alternatives 2 and 3 would leave all waste in place. However, the surface barrier would substantially reduce migration in all action alternatives, effectively equalizing their long-term performance. The following subsections present more details regarding long-term effectiveness and permanence.

\subsubsection{Residual Risks at the Surface}

All action alternatives include a surface barrier that would effectively preclude transport of contaminants to the surface by plants and animals. Each action alternative also includes elements to reduce concentrations of VOCs at the surface. Thus, once cap construction is complete, each action alternative is relatively equal in terms of satisfying remedial action objectives and mitigating risk attributable to surface exposure pathways for both human health and the environment. 


\subsubsection{Residual Risks in Groundwater}

Comparisons of long-term effectiveness for groundwater are based on carcinogenic risk, hazard indexes, and concentrations of contaminants in the aquifer. Each action alternative includes a surface barrier that reduces infiltration and continued operation of the OCVZ system to extract and treat VOCs for the vadose zone. Estimates are predicated on models that simulate release of contaminants from buried waste and subsequent transport through the vadose zone and into the aquifer. Instantaneous remediation in 2010 - followed by continued operation of the OCVZ system - was modeled for all action alternatives to facilitate direct comparison of long-term effectiveness. Therefore, contaminant migration occurring during remediation - and consequent increase in long-term risk - is not apparent in comparison graphs. Three timeframes are described for the four action alternatives: 100 years, 1,000 years, and 10,000 years from 2010.

5.3.2.1 Carcinogenic Risk. Figure 5-1 illustrates risk over time attributable to groundwater ingestion over all three timeframes. The threshold for cumulative risk is $10^{-6}$ to $10^{-4}$. As modeled (i.e., with instantaneous remediation in 2010), all four action alternatives show substantial improvement over No Action. Each action alternative would reduce cumulative risk to less than $1 \mathrm{E}-04$ by the end of the 100 -year hypothetical IC period in 2110 . However, modeling instantaneous remediation does not account for implementation timeframes. In reality, alternatives that require shorter implementation timeframes also reduce the amount of contamination that could accumulate in the vadose zone and potentially reach the aquifer. Thus, Alternative 2 (Surface Barrier) would perform slightly better within 100 years because it has the shortest implementation timeframe. Alternative $2 \mathrm{~b}$ (ET Surface Barrier) would perform better than Alternative 2a because the ET surface barrier is more robust. Alternative 2a (Modified RCRA Type C Surface Barrier) would likely require substantial maintenance other alternatives because the cap would be susceptible to damage by subsidence. This vulnerability would be exacerbated for Alternative $2 \mathrm{a}$ because measures to mitigate subsidence of Pad A are not included. Alternatives 3 (ISG), 4 (Partial RTD), and 5 (Full RTD) require increasingly more implementation time and follow in sequence in their respective abilities to achieve remedial action objectives in the first 100 years.

Results for the 1,000-year timeframe are less sensitive to implementation periods for the respective alternatives. All action alternatives would satisfy remedial action objectives by the end of 100 years and would continue to reduce risk at a roughly equivalent rate until part way through the 1,000-year period when Alternative 5 (Full RTD) begins to outperform other alternatives. By end of the 1,000-year simulation period, cumulative groundwater ingestion risk for Alternative 5 would be approximately 6E-06, while cumulative risk for Alternatives 2 (Surface Barrier), 3 (ISG), and 4 (Partial RTD) would be about $2 \mathrm{E}-05$. Alternative 5 provides the best performance in this timeframe because all the buried waste would be transferred elsewhere for long-term management.

Risk continues to diminish over time in the 10,000-year timeframe, and any initial sensitivity to implementation timeframes is no longer significant. Alternative 5, with cumulative risk below $1 \mathrm{E}-06$ in approximately 2,000 years, continues to perform somewhat better than other action alternatives. Cumulative risk for Alternatives 2, 3, and 4 decline to 1E-05 in approximately 2,000 years. 


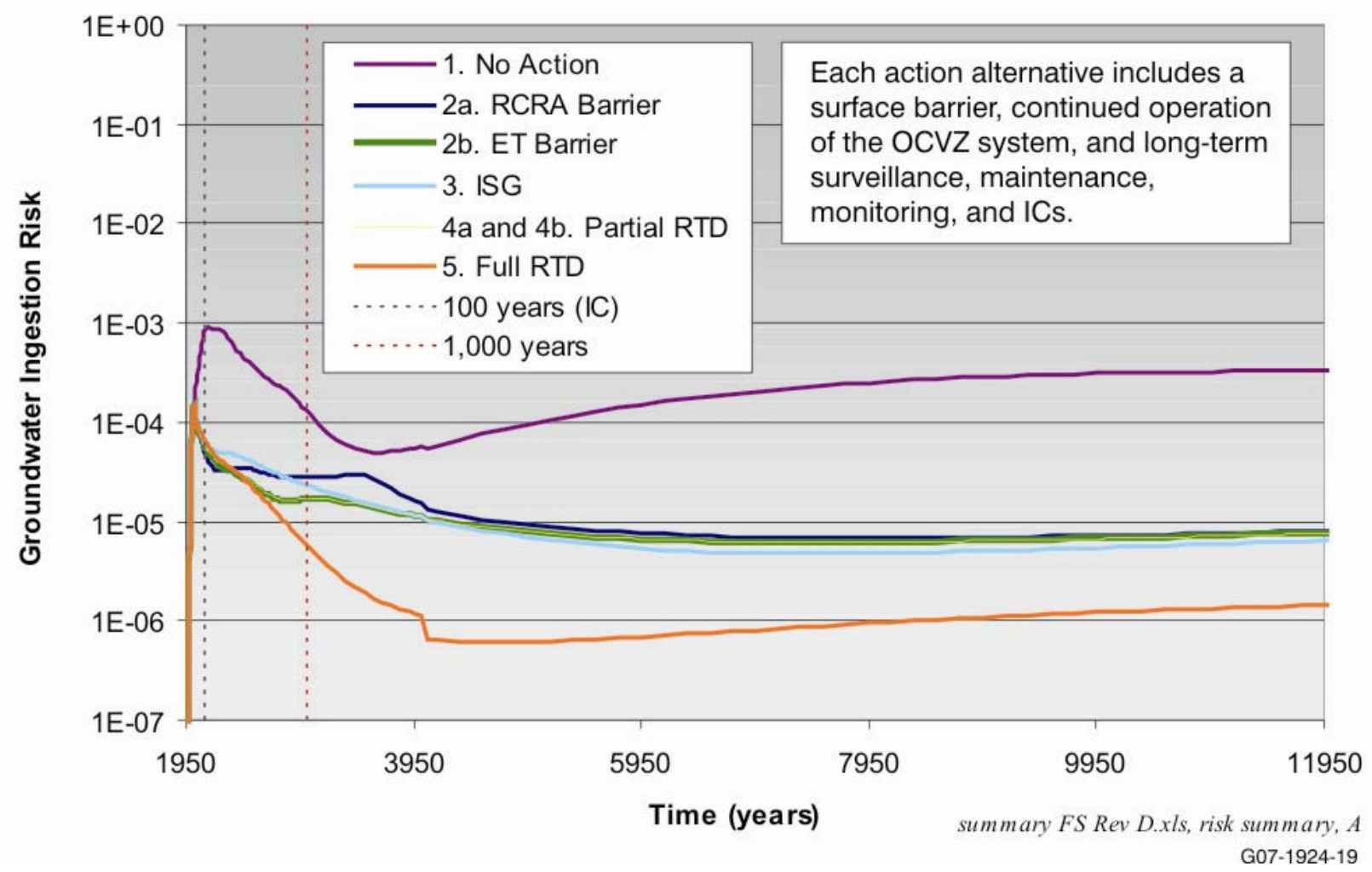

Figure 5-1. Comparison of long-term effectiveness based on cumulative carcinogenic risk for groundwater ingestion provided by each remedial alternative.

5.3.2.2 Hazard Index. Maximum hazard indexes were simulated for a period of 1,000 years, not 10,000 years, because the hazard index is associated primarily with chemicals, while risk is dominated by radionuclides. Chemicals are not as persistent in the environment as radionuclides. The threshold value for the cumulative hazard index is 1 .

As shown on Figure 5-2, results over time for the cumulative hazard index exhibit the same trend as carcinogenic risk shown in Figure 5-1. The peak occurs for all action alternatives within the first 100 years and diminishes rapidly, showing substantial improvement over No Action. The slight advantage Alternative 5 has over other alternatives is less pronounced than for carcinogenic risk because the hazard index is primarily associated with chemicals instead of radionuclides.

An initial conclusion, based on results shown in Figure 5-2, is that the threshold hazard index of 1 is not satisfied. The cumulative hazard index, attributable to carbon tetrachloride, is slightly greater than 1 at the end of the simulated 100-year IC period. However, results shown in Figure 5-2 are based on overpredicted aquifer concentrations of carbon tetrachloride. Even a slight downward adjustment in simulated aquifer concentrations would reduce the cumulative hazard index to less than 1 . The next subsection discusses overpredicted aquifer concentrations and model uncertainty. 


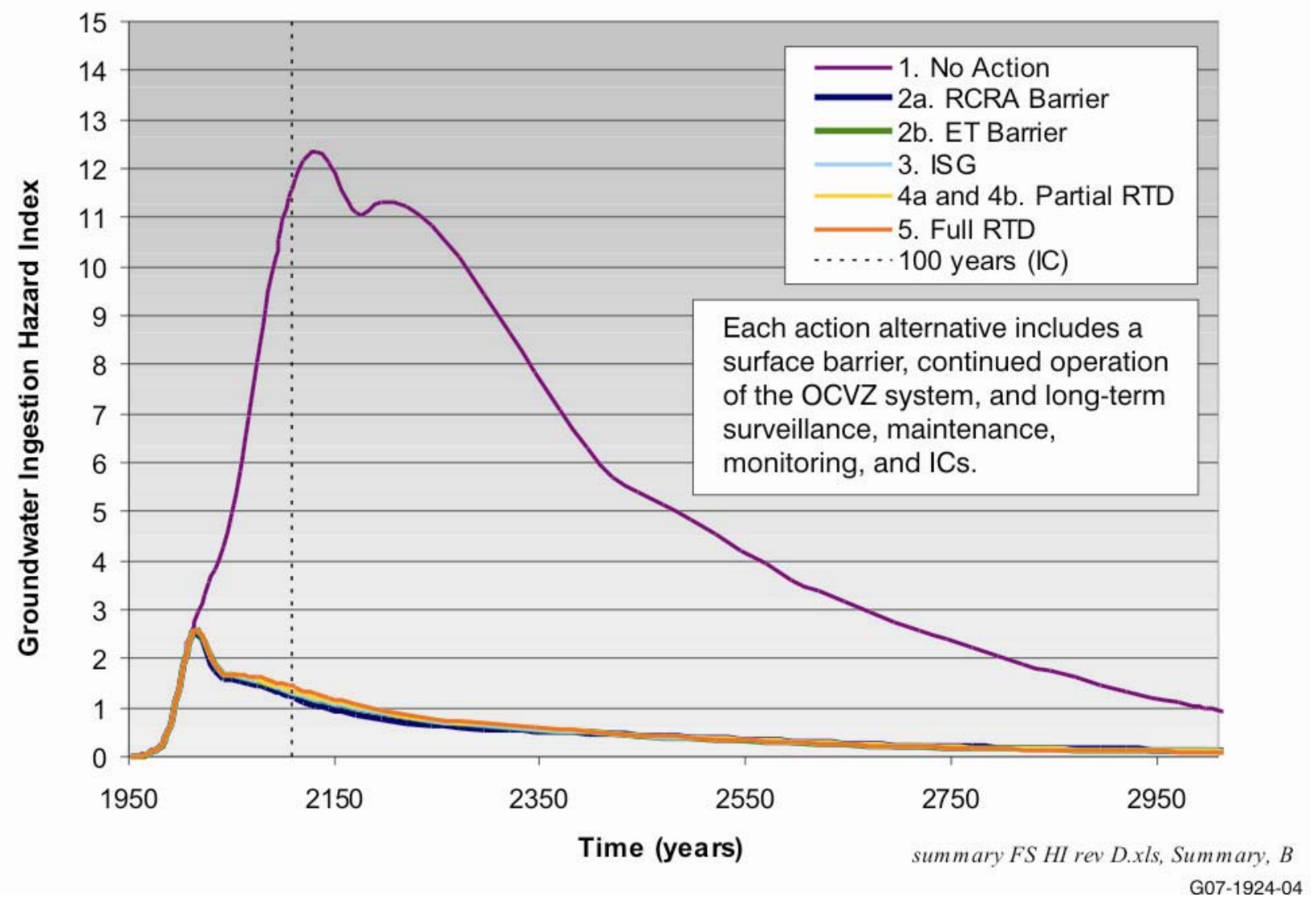

Figure 5-2. Comparison of long-term effectiveness based on cumulative hazard index for groundwater ingestion provided by each remedial alternative.

5.3.2.3 Aquifer Concentrations and Model Uncertainty. Remedial action at the SDA must inhibit migration of contaminants of concern (COCs) into the vadose zone and the underlying aquifer by two means: (1) reducing infiltration such that COC concentrations in the aquifer remain less than MCLs and (2) continuing to extract volatile COCs from the vadose zone to satisfy preliminary remediation goals for vadose zone vapor concentrations, which in turn protects groundwater. To evaluate effectiveness in these terms, simulated aquifer concentrations were compared to MCLs for each COC.

Performance of each action alternative is roughly equivalent to results presented for carcinogenic risk (see Section 5.3.2.1). Alternatives 2, 3, 4, and 5 show about the same level of effectiveness through the 100-year period and part way through the 1,000-year period when Alternative 5 begins to show a slight advantage over other alternatives. An initial conclusion, based on comparing simulated aquifer concentrations to MCLs, indicates that action alternatives would not maintain aquifer concentrations less than MCLs for five primary COCs: 1,4-dioxane, nitrate, and three VOCs (i.e., carbon tetrachloride, methylene chloride, and trichloroethylene). However, simulated aquifer concentrations for these COCs are overpredicted, as summarized below and discussed in detail in Appendix D.

5.3.2.3.1 Nitrate-Simulated aquifer concentrations for nitrate are overpredicted, as discussed in detail in Appendix D (see Section D-3.6.1.1). For Alternative 1 (No Action), the numerical model underpredicts observed nitrate concentrations at the few locations in the vadose zone with observed elevated concentrations. The numerical model does, however, produce large overpredictions in the aquifer at Wells M17S, USGS-90, and USGS-117, demonstrating that nitrate simulation results are conservative 
overall. The majority of other aquifer locations outside this predicted contaminant plume show no simulated impact above local background concentrations. This demonstrated conservatism indicates uncertainty in model results, especially for nitrate. The model predicts a distributed plume of elevated nitrate in the vadose zone and aquifer that is not substantiated by monitoring. Simulations indicate that concentrations would exceed the nitrate MCL of $10 \mathrm{mg} / \mathrm{L}$ before 1980 in the aquifer at the M17S monitoring location and would approach $10 \mathrm{mg} / \mathrm{L}$ by 2005 at the USGS-119 monitoring location. However, neither location has shown monitoring results noticeably different from the regional background concentration of 1 to $2 \mathrm{mg} / \mathrm{L}$. This unsubstantiated plume (within the Alternative 1 simulation) affects, in turn, simulations that are used to evaluate effectiveness of each action alternative. Simulated concentrations exceed the nitrate MCL of $10 \mathrm{mg} / \mathrm{L}$ for all action alternatives (see Section D-4 in Appendix D). These elevated current and future nitrate concentrations are not credible because they are based on simulated release from the source that has not occurred at the predicted magnitude. A consequence of overpredicted nitrate concentrations for this feasibility study is that the model shows a significant mass of nitrate released into the vadose zone that would be beyond the influence of remedial action. In reality, most of this mass is probably still in the buried waste. Remedial action that limits infiltration would effectively reduce transport to the vadose zone and aquifer and would prevent groundwater concentrations that exceed the nitrate MCL.

5.3.2.3.2 Volatile Organic Compounds-For three VOCs, simulation results meet vadose zone preliminary remediation goals; however, predicted aquifer concentrations are not less than MCLs in the year 2110 for all contaminants and all alternatives. This discrepancy is primarily due to simplifying assumptions used to develop remediation goals for OU 7-08 (which were adopted as preliminary remediation goals for OU 7-13/14) and uncertainties associated with those assumptions. Predicted concentrations do not fall below MCLs by the year 2110 in all cases. However, results for all three contaminants are only slightly greater than MCLs (e.g., maximum simulated carbon tetrachloride concentration of $12 \mu \mathrm{g} / \mathrm{L}$ compared to an MCL of $5 \mu \mathrm{g} / \mathrm{L}$ ), and it is reasonable to conclude that MCLs are within the bounds of uncertainty. Appendix D presents details (see Section D-3.6.1.2). Though the modeling goal was to achieve vadose zone remediation goals and not MCLs, it is reasonable to expect, based on professional judgment and interpretation of model results, that achieving MCLs is probable. However, if vadose zone remediation goals are achieved and aquifer concentrations greater than MCLs are persistent, then risk management actions beyond source control measures evaluated in this feasibility study could be identified. Possible approaches include defining a groundwater exclusion zone (i.e., buffer zone), expanding the OCVZ vapor vacuum extraction with treatment system, or implementing an aquifer pump and treat system.

5.3.2.3.3 1,4-Dioxane-Aquifer samples have not been analyzed specifically for 1,4-dioxane in the past; however, it has never been reported as a tentatively identified compound in routine monitoring. This analyte has been added recently to the groundwater monitoring program at RWMC. The simulated maximum aquifer concentration for 1,4-dioxane is approximately $120 \mu \mathrm{g} / \mathrm{L}$ in the year 2006 for Alternative 1 (No Action). Because it has not been reported as a tentatively identified compound, 1,4-dioxane is probably overpredicted. Monitoring results soon will be available to assess this conclusion.

\subsubsection{Adequacy and Reliability of Controls}

In terms of adequacy and reliability of controls, all action alternatives are nearly equivalent. Alternative 5 would seem to provide an advantage in terms of adequacy and reliability of controls because all buried waste would be gone. However, residual contamination would preclude unrestricted land use. Therefore, the same controls would be required for Alternative 5 (Full RTD) as for the other action alternatives. Alternative $2 \mathrm{a}$ would incorporate Pad A into a surface barrier without addressing its potential subsidence; therefore, an increased level of maintenance to ensure cap integrity could be required for 
some years until subsidence no longer occurred on Pad A. In addition, the surface barrier in Alternative 2a (Modified RCRA Type C Surface Barrier) is more susceptible to damage from differential subsidence than the ET surface barrier included in all other action alternatives. Most subsidence would occur during the first 100 years. Long-term ICs, maintenance, and monitoring would be required for all alternatives because of the long half-lives associated with radionuclides in the buried waste. Control would be required indefinitely, involving a combination of active and passive measures to protect human health and the environment. Active controls include routine site maintenance, monitoring, site surveys, and access restrictions that require routine or periodic human presence at the site. Passive controls are administrative measures (e.g., deed restrictions) that do not require routine human presence.

\subsection{Reduction of Toxicity, Mobility, or Volume through Treatment}

This evaluation criterion addresses the statutory preference for actions that incorporate treatment that permanently and significantly reduces toxicity, mobility, or volume of hazardous substances as their principal element. This preference is satisfied when treatment is used to reduce principal threats by destroying toxic contaminants, reducing total mass of toxic contaminants, irreversibly reducing contaminant mobility, or reducing total volume of contaminated media. The SDA does not contain any waste that is unambiguously identified as principal threat waste (i.e., source materials containing liquids or highly mobile materials posing a risk potential of 1E-03 [EPA 1991]). Waste types that contain VOCs (e.g., carbon tetrachloride, tetrachloroethylene, and trichloroethylene) comprise the only potential principal threat waste. Though risk from VOCs is less than 1E-03 (see Section 1.4), these contaminants are mobile, toxic, and affect the aquifer. However, VOCs already are being destroyed through treatment by the OCVZ system. Because continued operation of the OCVZ system to collect and treat VOCs is a component of each action alternative, treatment of (potential) principal threat waste is not a discriminating factor in the relative comparison.

Alternative 1 does not include treatment, offering no features relative to this criterion. Each action alternative employs a surface barrier to reduce infiltration and thermal treatment to destroy VOCs extracted from the vadose zone. The surface barrier would reduce mobility by limiting the amount of precipitation infiltrating into the waste but would not employ treatment as a principal element. Though thermal treatment is an important element in reducing toxicity, mobility, and volume of vapors collected from the vadose zone, it does not address the source of contamination in buried waste. Because each action alternative includes both a surface barrier and treatment of VOCs, these components do not offer any discrimination among alternatives.

Alternative 5 (Full RTD) ranks best for this criterion because treatments that may be required to meet waste acceptance criteria for treatment, storage, and disposal facilities outside the SDA would be applied. Alternative 3 and 4 are roughly equivalent for this criterion. Alternative 3 (ISG) treats Tc-99 (and collocated I-129) to inhibit transport into the vadose zone and aquifer. Alternative 3 also includes retrieval and ex situ grouting of Pad A waste; however, treatment of Pad A waste would not affect toxicity, would provide only limited reduction in mobility, and would increase volume. Alternative 4 (Partial RTD) incorporates limited treatment of targeted uranium waste (grouting at an off-SDA treatment and disposal facility to immobilize waste before disposal). Other treatments that may be required to meet waste acceptance criteria for treatment, storage, and disposal facilities outside the SDA are assumed to occur at such facilities and are not included in this analysis. Alternative 2 does not include treatment, except as noted above for VOCs extracted from the vadose zone. 


\subsection{Short-Term Effectiveness}

This evaluation criterion addresses risk incurred during implementation of a remedy. Completion of the surface barrier achieves remedial action objectives for source control, illustrated as construction timeframes for each action alternative in Figure 5-3. Therefore, the construction timeframe is used to define the implementation period and to assess short-term risk. These estimated timeframes are predicated on construction beginning in 2010 , sufficient funding to continue without interruption until work is complete. Alternatives are evaluated in terms of hazards to remediation workers, collocated workers, and members of the public. Environmental impacts also are considered. Types of risk that can be incurred include construction hazards and exposures to chemicals and radionuclides. In general, short-term effectiveness diminishes with increasing complexity of the alternative and the amount of time required for implementation.

Alternative 1 (No Action) performs very well with respect to this criterion. Waste would be left undisturbed and would not become a potential exposure hazard to workers collecting environmental samples at the site. Construction is not an element. Thus, exposures and construction hazards would not increase.

None of the remedial alternatives evaluated in this feasibility study pose a short-term cumulative hazard index greater than 1, and likelihood of a fatality is extremely low. However, excess cancer risk and injuries are more probable. In general, carcinogenic risk increases with complexity and the amount of retrieval included in each alternative. Workers would not be exposed directly to waste in Alternative 2a; thus the risk of developing cancer over time as a result of exposures received during remediation is roughly equivalent to background risk. Alternative $2 \mathrm{~b}$ and 3 both include retrieval of Pad A, posing a moderately low increase in carcinogenic risk. Workers would incur a moderate increase in risk during targeted waste retrieval in Alternative 4. Alternative 5 would pose relatively high risk to workers, especially during complex elements of the alternative such as retrieving large objects and remote-handled waste. Similarly, risk of injuries increases with complexity and the amount of retrieval. Figure 5-4 shows estimated recordable injuries for each action alternative.

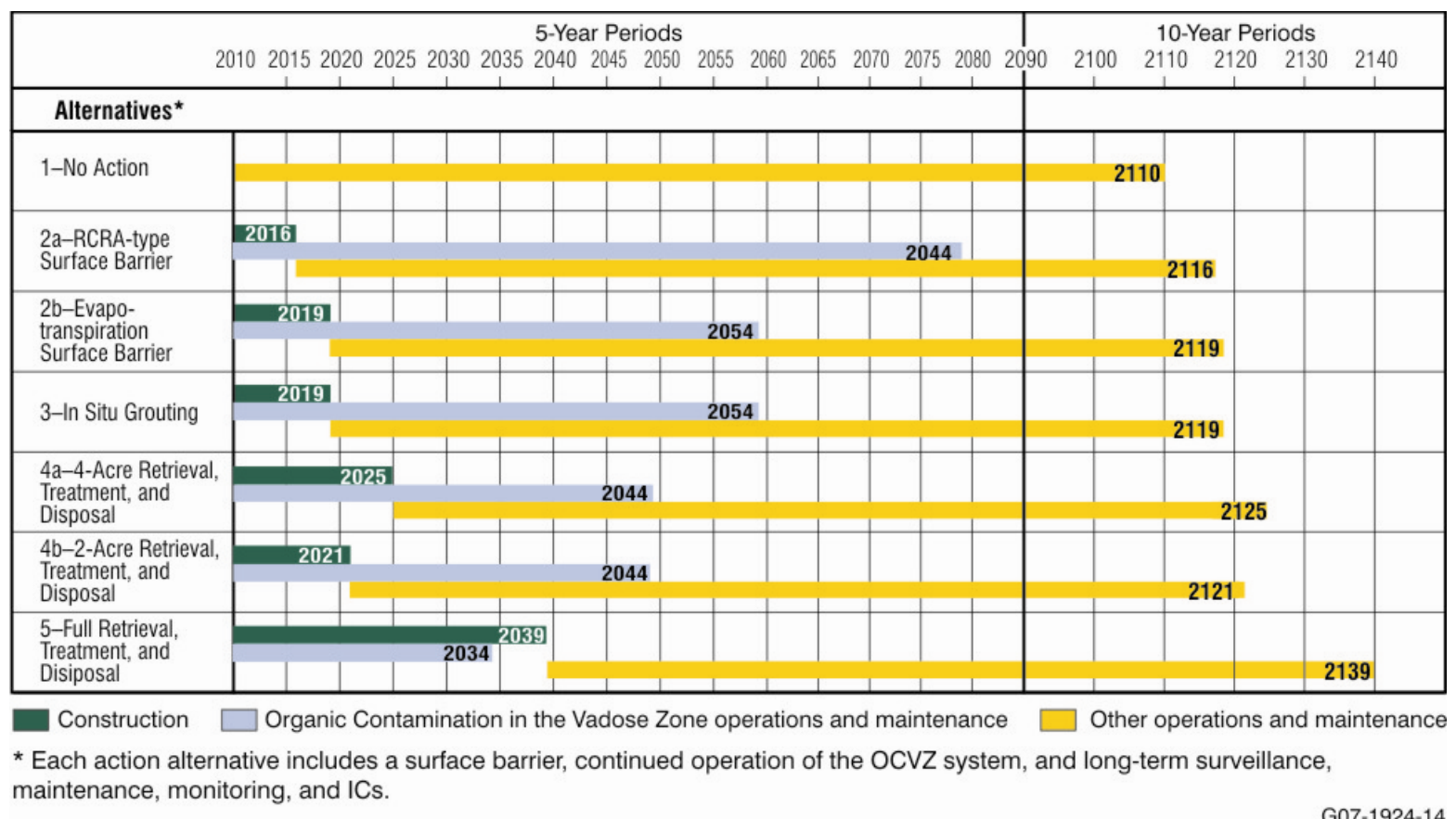

Figure 5-3. Estimated implementation timeframes for each remedial alternative. 


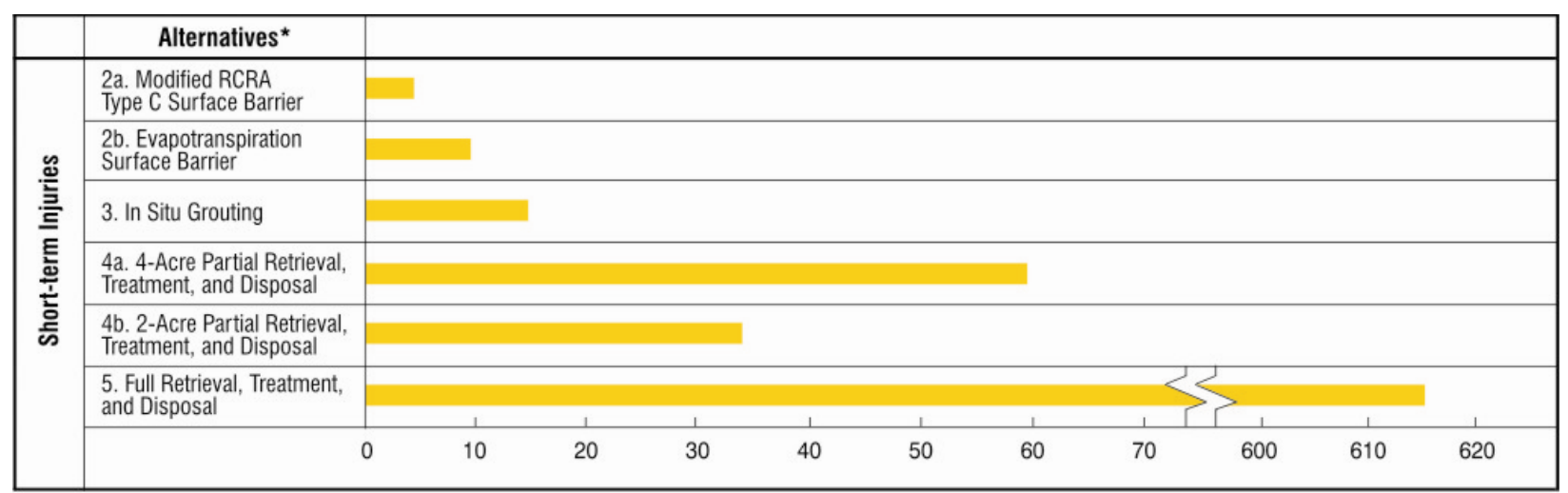

* Each action alternative includes a surface barrier, continued operation of the OCVZ system, and long-term surveillance, maintenance, monitoring, and ICs.

Figure 5-4. Estimated recordable injuries for each action alternative.

Overall, Alternative 2 (Surface Barrier) performs best in terms of this criterion. It is the least complex and would require the least amount of time. Though some element of risk to workers would be associated with cap construction, such risks are routine industrial hazards that would be readily mitigated through engineering and administrative controls. Effects on collocated workers, the environment, and members of the public would be minimal. Alternative 2a (Modified RCRA Type C Surface Barrier) does not include retrieval of Pad A waste, so it may be slightly better than Alternative 2b (ET Surface Barrier) because potential exposures to Pad A waste would not be incurred. However, the Accelerated Retrieval Project is providing good experience in exhuming waste below grade, and techniques for retrieving abovegrade Pad A waste would be readily adaptable for safe implementation. Alternative 2a employs ISG to provide a stable foundation for cap construction, while Alternative $2 b$ includes dynamic compaction of pits. Additional risks from these activities are roughly equivalent. Installation of additional near-surface vapor extraction wells under Alternative 2a involves standard construction techniques that would not substantially influence short-term effectiveness. Implementation timeframes are 7 and 10 years for Alternatives $2 \mathrm{a}$ and $2 \mathrm{~b}$, respectively. These relatively short implementation periods also reduce the probability that a serious accident would occur.

Alternative 3 (ISG) is next best. Elements of risk associated with cap construction, Pad A retrieval, and dynamic compaction of pits are the same as for Alternative 2. Effects on collocated workers, the environment, and members of the public would be minimal. A moderate amount of additional risk would be incurred by remediation workers compared to Alternative $2 \mathrm{~b}$ as a consequence of additional waste handling required to treat Pad A waste and to deploy ISG in highly contaminated areas. Experience gained by ISG of beryllium blocks in the SDA would reduce risk associated with grouting. The implementation timeframe for Alternative 3 is 10 years, the same as Alternative $2 b$. Implementation timeframes for Alternatives $2 \mathrm{~b}$ and 3 are 3 years longer than for Alternative 2a because of Pad A waste retrieval.

Short-term risk associated with Alternative 4 (Partial RTD) is significantly greater compared to Alternative 3 (ISG). In general, Alternative 4 is more complex and would require longer implementation times, though engineering and administrative controls would mitigate risks associated with this alternative. Potential exposure during retrieval and handling of buried waste is the primary feature that would increase risk. Because waste would be disturbed, some potential for airborne release would be incurred, with moderate risk to remediation workers and a slight increase in risk to collocated workers and members of the public. Alternative 4a (4-Acre Retrieval) would pose slightly more risk than Alternative $4 \mathrm{~b}$ (2-Acre Retrieval) because of the larger excavation area. Elements of risk associated with cap construction would be the same as for Alternatives 2 and 3. Alternative 4a includes Pad A retrieval 
and dynamic compaction of pits; this would pose a slight increase in risk compared to Alternative $4 \mathrm{~b}$ and risk equivalent to that described for the same activities in Alternative 3. Risk of environmental impacts also is slightly higher compared to Alternatives 2 and 3. Implementation timeframes for Alternatives 4a and 4b, 16 and 12 years, respectively, are somewhat longer than for Alternatives 2 and 3.

Alternative 5 (Full RTD), by a significant margin, poses the greatest short-term risk to remediation workers, collocated workers, members of the public, and the environment. Alternative 5 is highly complex, incorporating substantially more construction, retrieval, handling, and storage. Quantified risk estimates are probably low for Alternative 5 because they are based on contact-handled retrieval of targeted waste (i.e., Alternative 4 retrieval methods) and open-air retrieval of well-contained remote-handled waste (i.e., as implemented at the Intermediate-Level Transuranic Storage Facility). Though probably underestimated, risk estimates for retrieving 14 ha (35 acres) of waste are much greater compared to the 4-acre retrieval described in Alternative 4a. Techniques developed for the Accelerated Retrieval Project would not be completely adequate, and remote retrieval techniques would be required for some waste forms. Complex engineering and administrative controls would be necessary to manage risk. This alternative would require 3 decades to implement, nearly twice as long as Alternative 4 and four times longer than Alternatives 2 and 3.

\subsection{Implementability}

The implementability criterion addresses technical and administrative feasibility of implementing an alternative and availability of required services and materials. All alternatives would be technically and administratively feasible, with sufficient availability of required services and materials. However, levels of ease vary between alternatives, offering some discrimination among them.

Alternative 1 is completely implementable, with no anticipated obstacles. Environmental monitoring has been a routine activity for many years. Standard protocols are in place, and services and materials are readily available.

All action alternatives include a surface barrier. Construction of a surface barrier is completely implementable, involving well-developed standard techniques. Competition for borrow source material may require administrative attention to prioritize projects and obtain permit modifications. In particular, topsoil for establishing vegetation on the surface barrier and coarse rock material for the capillary break (i.e., biotic barrier) within the surface barrier may be in short supply on the INL Site. Such materials can be transported from sources outside the INL Site, if necessary.

Alternatives 2, 3, and 4 are technically and administratively feasible, with only a few discriminating trade-offs. Services, materials, and vendors for each technical component are generally available.

For Alternatives $2 \mathrm{~b}$ and 3 , which involve transferring Pad A waste into the LLW Pit (without and with treatment, respectively), potential administrative complications could arise. Transferring Pad A waste into an unlined disposal cell may not be acceptable to DEQ and EPA. Furthermore, ongoing waste disposal operations could consume all space in the LLW Pit, precluding transfer of Pad A waste. These potential issues could be addressed by using an alternative disposal facility outside the SDA or by constructing a new engineered disposal cell within the SDA. Both approaches are technically and administratively feasible, though construction of a new cell within the SDA could be more difficult to design and obtain approval for compared to disposal at an existing facility. 
A field-scale demonstration of dynamic compaction of pits could be required to develop safety protocols for Alternatives $2 \mathrm{~b}, 3$, and $4 \mathrm{a}$, a task that is technically and administratively feasible. Similarly, field-scale testing to develop safe approaches to dynamically compact Pad A (Alternative 4b) could be required. Some modification to techniques for belowgrade retrieval within a retrieval enclosure could be required to customize the Accelerated Retrieval Project approach to abovegrade retrieval of Pad A waste (Alternatives 2b, 3, and 4a). All other aspects of Alternatives 2, 3, and 4 are sufficiently developed, both technically and administratively, such that significant implementability issues or lack of required services and materials would not be anticipated.

Alternatives involving treatment or disposal at ICDF (Alternatives 4a, 4b, and potentially 5) could encounter two minor administrative implementability issues; both could be readily resolved. First, the treatment facility at ICDF presently is not used to stabilize INL Site CERCLA waste. Though administrative action would be required to start up the facility, sufficient time would be available during remedial design to achieve startup without delaying construction. Second, ICDF is scheduled to close by 2012. Administrative action to defer closure would be required to accommodate remediation of the SDA. However, extending operations at ICDF would be relatively straightforward and would not impede retrieval alternatives.

Alternatives 4 and 5 would encounter waste with transuranic concentrations less than $100 \mathrm{nCi} / \mathrm{g}$. The Second Addendum to the Work Plan (Holdren and Broomfield 2004) specifies that retrieval alternatives will be based on the Accelerated Retrieval Project process. The Accelerated Retrieval Project assumes that nontransuranic waste (less than $100 \mathrm{nCi} / \mathrm{g}$ ) containing some level of transuranic isotopes would be payload-based load-managed and sent to the Waste Isolation Pilot Plant (WIPP). Therefore, an alternate disposal path for this waste type was not evaluated.

Alternative 5 (Full RTD) could encounter several implementability obstacles. This alternative was developed based on the same technical approaches being deployed at the Accelerated Retrieval Project. These techniques would not be adequate to safely retrieve high-exposure-rate waste forms (i.e., remote-handled waste) and large objects. Additional strategies (e.g., remote retrieval, in situ size reduction [perhaps remotely], and handling deteriorated containers) would be needed. Alternative 5 incorporates methods developed by the Remote-Handled Transuranic Project to transfer high-integrity containers of waste into and out of the Intermediate-Level Transuranic Storage Facility. These transfers were conducted in open air, with no restriction on the height of the crane used to provide distance between workers and the waste (i.e., distances to reduce exposures to gamma radiation). A similar operation within a retrieval enclosure would be challenging. Administratively, a potential difficulty is that a path to disposal would not be available for some retrieved waste forms. This analysis incorporates use of a temporary (i.e., less than 20 years) storage facility constructed at the SDA to house such waste until an appropriate facility is developed by another program (e.g., a repository constructed and managed by the U.S. Nuclear Regulatory Commission or other federal agency). Historically, obtaining approvals for federal waste repositories has not been straightforward, as evidenced by delays encountered for WIPP and Yucca Mountain. Other administrative issues relate to disposal at WIPP. The facility may not have sufficient capacity to receive an additional 242,000 drums or $50,000 \mathrm{~m}^{3}\left(66,000 \mathrm{yd}^{3}\right)$ of potentially acceptable waste from the SDA. Congress would have to modify the WIPP Land Withdrawal Act to expand capacity. In addition, WIPP is expected to be filled to capacity by the year 2034 . The retrieval component of this alternative would last until the year 2037, which could pose a problem if WIPP is filled to capacity by the year 2034 . 


\subsection{Cost}

Figure 5-5 provides a comparison and summary of costs associated with each alternative. Alternative 1, which includes 100 years of environmental monitoring using the existing monitoring system, is the lowest cost alternative. Costs increase for each subsequent alternative, consistent with increasing complexity and implementation timeframes. For the proposed plan, the Agencies likely will identify an optimized combination of modules for their preferred alternative that is not an exact match with any one alternative evaluated in this feasibility study. Estimated costs will be a summation of costs for each module included in the preferred alternative.

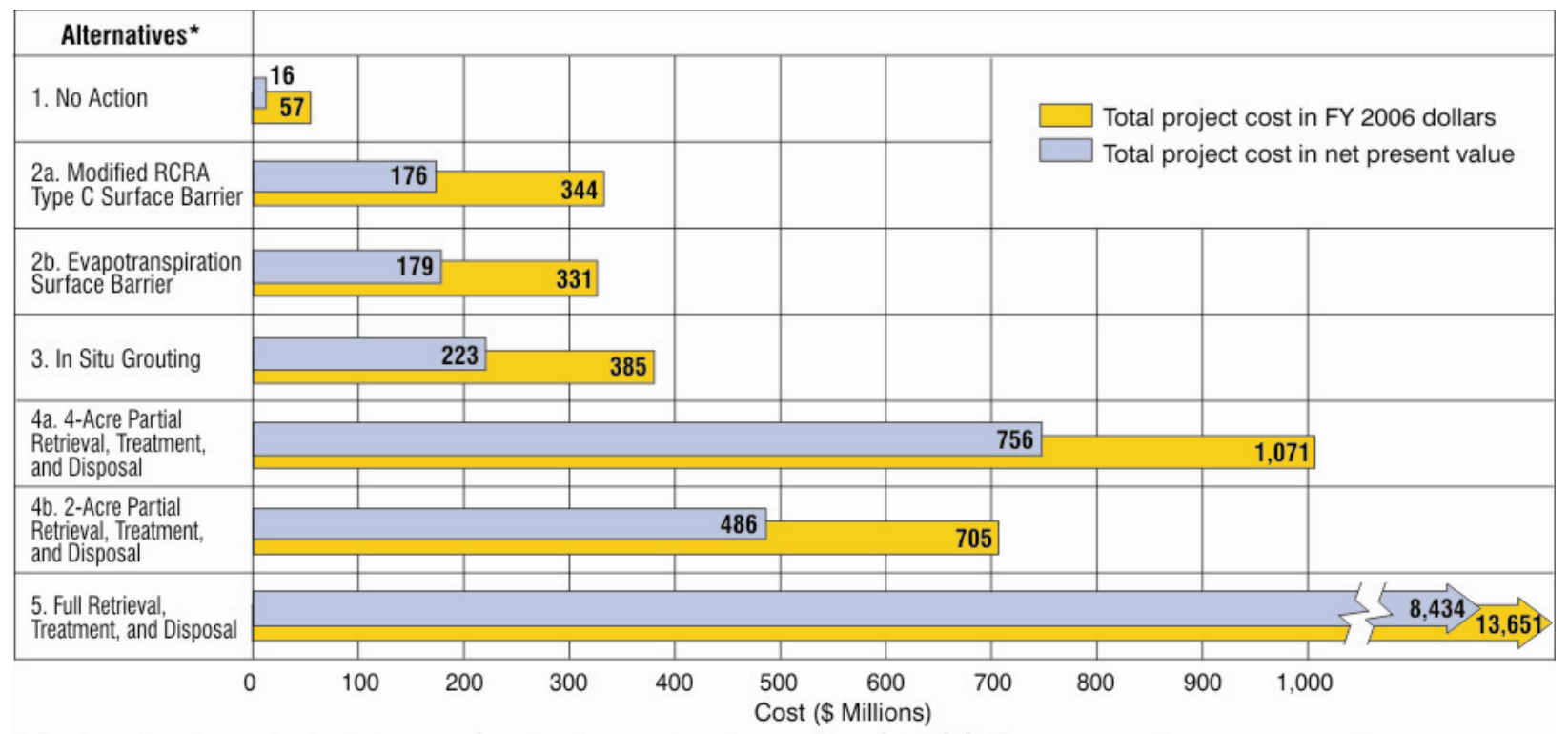

* Each action alternative includes a surface barrier, continued operation of the OCVZ system, and long-term surveillance, maintenance, monitoring, and ICs.

G07-1924-15

Figure 5-5. Comparison and summary of cost associated with each alternative.

\subsection{Summary}

Table 5-1 provides a matrix illustrating the assembled alternatives and the modules that comprise them. The Agencies can recombine these modules in a different configuration to develop their preferred alternative in the future proposed plan. Table 5-2 provides a summary of the comparative analysis of alternatives. In combination with continued operation of the OCVZ system to extract and treat VOCs from the vadose zone, the surface barrier component of each action alternative effectively addresses all remedial action objectives. The greatest degree of discrimination among alternatives occurs in evaluating short-term effectiveness, implementability, and cost. Excluding the No Action alternative, long-term effectiveness in the first 100 years after remediation is approximately the same, with all action alternatives satisfying remedial action objectives. The full retrieval alternative in the 1,000-year timeframe and beyond shows a slight improvement in long-term risk reduction (i.e., diminishes from the $10^{-5}$ to the $10^{-6}$ order of magnitude), but short-term risk is much higher than for other alternatives, and implementability is uncertain. 
Table 5-1. Matrix of the five assembled alternatives and major components in each

\begin{tabular}{|c|c|c|c|c|c|c|c|}
\hline \multirow[b]{2}{*}{ Component } & \multirow[b]{2}{*}{$\begin{array}{c}1 . \\
\text { No Action }\end{array}$} & \multicolumn{2}{|c|}{ 2. Surface Barrier } & \multirow[b]{2}{*}{$\begin{array}{c}3 . \\
\text { In Situ Grouting }\end{array}$} & \multicolumn{2}{|c|}{ 4. Partial Retrieval, Treatment, and Disposal } & \multirow{2}{*}{$\begin{array}{c}5 . \\
\text { Full Retrieval, Treatment, } \\
\text { and Disposal }\end{array}$} \\
\hline & & $\begin{array}{l}\text { 2a. } \\
\text { Modified RCRA Type C }\end{array}$ & $\begin{array}{c}2 \mathrm{~b} . \\
\text { Evapotranspiration }\end{array}$ & & $\begin{array}{l}4 \mathrm{a} . \\
4 \text { Acres }\end{array}$ & $\begin{array}{c}4 \mathrm{~b} . \\
2 \text { Acres }\end{array}$ & \\
\hline Monitoring $^{\mathrm{a}}$ & Monitoring & Monitoring & Monitoring & Monitoring & Monitoring & Monitoring & Monitoring \\
\hline In situ treatment & None & None & None & ISG-specified Tc-99 and I-129 & None & None & None \\
\hline Retrieval & None & None & None & None & $\begin{array}{l}\text { Retrieve targeted Rocky } \\
\text { Flats Plant waste }\end{array}$ & $\begin{array}{l}\text { Retrieve targeted Rocky Flats } \\
\text { Plant waste }\end{array}$ & Retrieve all waste in the SDA \\
\hline Pad A & None & $\begin{array}{l}\text { Incorporate Pad A as-is into } \\
\text { cap }\end{array}$ & Relocate to LLW Pit & $\begin{array}{l}\text { Treat ex situ and relocate to } \\
\text { LLW Pit }\end{array}$ & Remove to ICDF & $\begin{array}{l}\text { Dynamically compact }{ }^{\mathrm{b}} \text { and } \\
\text { incorporate into cap }\end{array}$ & $\begin{array}{l}\text { Remove to off-INL Site } \\
\text { disposal facility }\end{array}$ \\
\hline $\begin{array}{l}\text { Subsidence in } \\
\text { pits }\end{array}$ & None & Foundation grouting & Dynamic compaction $^{\text {b }}$ & Dynamic compaction $^{\mathrm{b}}$ & Dynamic compaction $^{\mathrm{b}}$ & Proof-roll & None \\
\hline Surface barrier & None & $\begin{array}{l}\text { Modified RCRA Type C } \\
\text { surface barrier with } \\
\text { biointrusion layer }\end{array}$ & $\begin{array}{l}\text { ET surface barrier with } \\
\text { biointrusion layer }\end{array}$ & $\begin{array}{l}\text { ET surface barrier with } \\
\text { biointrusion layer }\end{array}$ & $\begin{array}{l}\text { ET surface barrier with } \\
\text { biointrusion layer }\end{array}$ & $\begin{array}{l}\text { ET surface barrier with } \\
\text { biointrusion layer and slurry } \\
\text { perimeter wall }\end{array}$ & $\begin{array}{l}\text { ET surface barrier without } \\
\text { biointrusion barrier }\end{array}$ \\
\hline $\begin{array}{l}\text { Surface barrier } \\
\text { vapor extraction }\end{array}$ & None & None & Active gas collection layer & Passive gas collection layer & Passive gas collection layer & Passive gas collection layer & None \\
\hline $\begin{array}{l}\text { Vadose zone } \\
\text { vapor extraction }\end{array}$ & None & $\begin{array}{l}\text { Add near-surface extraction } \\
\text { wells; operate OCVZ system } \\
58.5 \text { years after construction }\end{array}$ & $\begin{array}{l}\text { Operate OCVZ system } \\
35 \text { years after construction }\end{array}$ & $\begin{array}{l}\text { Operate OCVZ system } \\
35 \text { years after construction }\end{array}$ & $\begin{array}{l}\text { Operate OCVZ system } \\
19 \text { years after construction }\end{array}$ & $\begin{array}{l}\text { Operate OCVZ system } \\
23 \text { years after construction }\end{array}$ & $\begin{array}{l}\text { Operate OCVZ system } \\
\text { throughout construction }^{\mathrm{c}}\end{array}$ \\
\hline $\begin{array}{l}\text { Surveillance and } \\
\text { maintenance }\end{array}$ & None & $\begin{array}{l}\text { Until eliminated by a } 5 \text {-year } \\
\text { review }^{d}\end{array}$ & $\begin{array}{l}\text { Until eliminated by a } 5 \text {-year } \\
\text { review }^{d}\end{array}$ & $\begin{array}{l}\text { Until eliminated by a } 5 \text {-year } \\
\text { review }^{d}\end{array}$ & $\begin{array}{l}\text { Until eliminated by a } 5 \text {-year } \\
\text { review }^{\mathrm{d}}\end{array}$ & $\begin{array}{l}\text { Until eliminated by a } 5 \text {-year } \\
\text { review }^{d}\end{array}$ & $\begin{array}{l}\text { Until eliminated by a } 5 \text {-year } \\
\text { review }^{d}\end{array}$ \\
\hline $\begin{array}{l}\text { Institutional } \\
\text { control }\end{array}$ & None & $\begin{array}{l}\text { Until eliminated by a } 5 \text {-year } \\
\text { review }^{\mathrm{d}}\end{array}$ & $\begin{array}{l}\text { Until eliminated by a } 5 \text {-year } \\
\text { review }^{d}\end{array}$ & $\begin{array}{l}\text { Until eliminated by a } 5 \text {-year } \\
\text { review }^{\mathrm{d}}\end{array}$ & $\begin{array}{l}\text { Until eliminated by a } 5 \text {-year } \\
\text { review }^{d}\end{array}$ & $\begin{array}{l}\text { Until eliminated by a } 5 \text {-year } \\
\text { review }^{\mathrm{d}}\end{array}$ & $\begin{array}{l}\text { Until eliminated by a } 5 \text {-year } \\
\text { review }^{d}\end{array}$ \\
\hline \multicolumn{8}{|c|}{$\begin{array}{l}\text { a. Monitoring comprises surface, vadose zone, and aquifer monitoring. Cost estimates include } 100 \text { years of monitoring for No Action and } 100 \text { years of monitoring after the cap is complete for all action alternatives. } \\
\text { b. Dynamic compaction was identified for analysis because it presents the most short-term risk and highest cost among process options that apply surface treatment to address subsidence; thus, it bounds the analysis. Other process options (e.g., impact rolling) could be substituted during remedial } \\
\text { design. } \\
\text { c. Operation of the OCVZ system would continue throughout construction and beyond until eliminated by a } 5 \text {-year review after remediation goals for VOCs in the vadose zone are achieved. Timeframes given are approximations based on modeling. } \\
\text { d. Estimates include cost for } 100 \text { years of surveillance, maintenance, and institutional control after the cap is complete. }\end{array}$} \\
\hline \multicolumn{8}{|c|}{$\begin{array}{l}\text { ET = evapotranspiration } \\
\text { ICDF = Idaho CERCLA Disposal Facility } \\
\text { ISG = in situ grouting } \\
\text { INL = Idaho National Laboratory } \\
\text { LLW = low-level waste } \\
\text { OCVZ = Organic Contamination in the Vadose Zone } \\
\text { RCRA = Resource Conservation and Recovery Act } \\
\text { SDA = Subsurface Disposal Area } \\
\text { VOC = volatile organic compound }\end{array}$} \\
\hline
\end{tabular}




\begin{tabular}{|c|c|c|c|c|c|}
\hline Fvaluation Criteria & Alternative 1- & Alternative 2-- & $\begin{array}{l}\text { Alternative 3- } \\
\text { In Situ Groutino }\end{array}$ & Alternative 4-Partial Retrieval, Treatment, & Alternative 5-Full Retrieval, \\
\hline
\end{tabular}

All alternatives (except No Action) include (1) an engineered surface barrier to reduce infiltration and to mitigate surface pathway risks for human health and the environment, (2) continued operation of the OCVZ system to collect and treat VOCs from the vadose zone, and (3) long-term surveillance, maintenance, monitoring, and ICs to manage residual risk.

Threshold Criteria

\begin{tabular}{|c|c|c|c|c|c|}
\hline $\begin{array}{l}\text { Overall protection of } \\
\text { human health and the } \\
\text { environment }\end{array}$ & $\begin{array}{l}\text { Does not satisfy } \\
\text { criterion }\end{array}$ & $\begin{array}{l}\text { Meets remedial action objectives and } \\
\text { provides overall protection }\end{array}$ & $\begin{array}{l}\text { Meets remedial action objectives and } \\
\text { provides overall protection }\end{array}$ & $\begin{array}{l}\text { Meets remedial action objectives and } \\
\text { provides overall protection }\end{array}$ & $\begin{array}{l}\text { Meets remedial action objectives and } \\
\text { provides overall protection }\end{array}$ \\
\hline $\begin{array}{l}\text { Compliance with } \\
\text { ARARs }\end{array}$ & $\begin{array}{l}\text { Does not satisfy } \\
\text { criterion }\end{array}$ & Complies with ARARs & Complies with ARARs & Complies with ARARs & Complies with ARARs \\
\hline \multicolumn{6}{|l|}{ Balancing Criteria } \\
\hline \multirow[t]{7}{*}{$\begin{array}{l}\text { Long-term effectiveness } \\
\text { and permanence }\end{array}$} & \multirow[t]{7}{*}{ Not applicable } & $\begin{array}{l}\text { Provides long-term protectiveness and } \\
\text { permanence }\end{array}$ & $\begin{array}{l}\text { Provides long-term protectiveness and } \\
\text { permanence }\end{array}$ & $\begin{array}{l}\text { Provides long-term protectiveness and } \\
\text { permanence }\end{array}$ & $\begin{array}{l}\text { Provides greatest degree of long-term } \\
\text { protectiveness and permanence }\end{array}$ \\
\hline & & $\begin{array}{l}\text { Alternative } 2 \mathrm{a}-\text { more susceptible to damage } \\
\text { from subsidence and requires more } \\
\text { maintenance than Alternative } 2 \mathrm{~b}\end{array}$ & $\begin{array}{l}\text { Substantial portion of releasable Tc- } 99 \text { would } \\
\text { be immobilized }\end{array}$ & $\begin{array}{l}\text { Alternative } 4 \mathrm{a}-\text { removes Pad } \mathrm{A} \text { and targeted } \\
\text { waste from pit areas totaling } 4 \text { acres } \\
\text { Alternative } 4 \mathrm{~b}-\text { removes targeted waste from } \\
\text { pit areas totaling } 2 \text { acres }\end{array}$ & Removes all buried waste \\
\hline & & \multirow{2}{*}{$\begin{array}{l}\text { Satisfies remedial action objectives at end of } \\
\text { construction relatively quickly (i.e., } 7 \text { to } \\
10 \text { years) } \\
\text { Alternative } 2 \text { a-Operates the OCVZ system } \\
\text { for approximately } 58.5 \text { years after } \\
\text { construction }\end{array}$} & \multirow{5}{*}{$\begin{array}{l}\text { Satisfies remedial action objectives at end } \\
\text { of construction relatively quickly } \\
\text { (i.e., } 10 \text { years) }^{\mathrm{c}} \\
\text { Operates the OCVZ system for approximately } \\
35 \text { years after construction } \\
\text { Infiltration continues for } 10 \text { years-shorter } \\
\text { implementation timeframe minimizes the } \\
\text { amount of contamination that migrates into } \\
\text { the vadose zone and reaches the aquifer }\end{array}$} & $\begin{array}{l}\text { Alternative } 4 \mathrm{a}-\text { Satisfies remedial action } \\
\text { objectives at end of construction in } \\
\text { approximately } 16 \text { years }{ }^{\mathrm{c}}\end{array}$ & \multirow{5}{*}{$\begin{array}{l}\text { Satisfies remedial action objectives at end } \\
\text { of construction in approximately } 30 \text { years } \\
\text { Operates the OCVZ system throughout } \\
\text { construction } \\
\text { Infiltration continues for } 30 \text { years-long } \\
\text { implementation timeframe greatly increases } \\
\text { the amount of contamination that migrates } \\
\text { into the vadose zone and aquifer }\end{array}$} \\
\hline & & & & $\begin{array}{l}\text { Alternative } 4 \mathrm{~b}-\text { Satisfies remedial action } \\
\text { objectives at end of construction in } \\
\text { approximately } 12 \text { years }^{\mathrm{c}}\end{array}$ & \\
\hline & & \multirow{3}{*}{$\begin{array}{l}\text { Alternative } 2 \mathrm{~b}-\text { Operates the OCVZ system } \\
\text { for approximately } 35 \text { years after construction } \\
\text { Infiltration continues for } 7 \text { to } 10 \text { years-- } \\
\text { shorter implementation timeframe minimizes } \\
\text { the amount of contamination that migrates } \\
\text { into the vadose zone and reaches the aquifer }\end{array}$} & & $\begin{array}{l}\text { approximately } 12 \text { years }{ }^{\mathrm{c}} \\
\text { Alternative } 4 \mathrm{a}-\text { Operates the OCVZ system } \\
\text { for approximately } 19 \text { years after construction }\end{array}$ & \\
\hline & & & & $\begin{array}{l}\text { Alternative } 4 \mathrm{~b}-\text { Operates the OCVZ system } \\
\text { for approximately } 23 \text { years after construction }\end{array}$ & \\
\hline & & & & $\begin{array}{l}\text { Infiltration continues for } 12 \text { to } 16 \text { years-- } \\
\text { longer implementation timeframes increase } \\
\text { the amount of contamination that migrates } \\
\text { into the vadose zone and aquifer }\end{array}$ & \\
\hline
\end{tabular}


Evaluation Criteria

Alternatives (except No Action) include (1) an engineered surface barrier to reduce infiltration and to mitigate surface pathway risks for human health and the environment, (2) continued operation of the OcVZ system to

collect and treat VOCs from the vadose zone, and (3) long-term surveillance, maintenance, monitoring, and ICs to manage residual risk.

Reduction of toxicity, Not applicable

OCVZ system destroys organic vapor

collected from the vadose zone

Alternative $2 b$-includes additiona

OCVZ system destroys organic vapors

collected from the vadose zone
In situ grouting immobilizes Tc-99 (and

collocated I-129)

Ex situ grouting removes the characteristic of aste retrieved from $\operatorname{Pad} \mathrm{A}$

OCVZ system destroys organic vapors collected from the vadose zone

Transfers some targeted waste elsewhere for potential treatment to satisfy disposal facility waste acceptance criteria

Ex situ grouting removes the characteristic of eactivity from uranium waste retrieved from Pad A
Short-term effectiveness Very low risk to workers, the public and the environme

Relatively low risk to remediation workers Slightly more risk for Alternative $2 \mathrm{~b}$ (moves Pad A waste to the LLW Pit) than for Alternative 2a (leaves Pad A waste in place)

No additional risk to collocated workers, the public, or the environment

Implementability Fully implementable Fully implementable

Alternative 2a-rigorous quality contro would be required to ensure integrity of the asphalt hydraulic barrier over a large area (e.g., 105 acres)

Alternative $2 \mathrm{~b}$ - relocating Pad A waste

- This action may not be acceptable to DEQ and EPA

- Disposal capacity in the LLW Pit may b limited without treatment to the LLW Pit would satisfy ARARs; however:
Relatively moderate risk to remediation workers posed by retrieving, treating (at SDA), and transferring to the LLW Pit

Relatively moderate (Alternative 4b) to moderately high risk (Alternative 4a) to remediation workers

Higher risk for Alternative $4 \mathrm{a}$ (retrieves Pad A waste and targeted waste from pit areas otaling 4 acres) than for Alternative $4 \mathrm{~b}$ totaling 2 acres)

No additional risk to collocated workers, the Very low risk to collocated workers, the public, or the environment

Fully implementable public, and the environment

Fully implementable

Treating Pad A waste would satisfy ARARs, including relevant land disposal requirements Relocating treated waste to the LLW would atisfy ARARs; however:

- This acion may not be acceptable to DEQ and EPA limited the action would be required to A operations beyond 2012 at ICDF
OCVZ system destroys organic vapors collected from the vadose zone

Transfers waste elsewhere for potential reatment to satisfy disposal facility waste acceptance criteria
Relatively high risk to remediation worker posed by retrieving all waste, including large objects and remote-handled waste

Moderate risk to collocated workers, the public, and the environment

Uncertainty is high, including several issues with respect to retrieval and storage of remote-handled waste and large objects,
posing a large potential for significant delays Could exceed current WIPP disposal capacity, necessitating that Congress modify the WIPP Land Withdrawal Act

Retrieval component of this alternative extends until the year 2037, with WIPP filled to capacity by the year 2034 
Table 5-2. (continued)

Evaluation Criteria Alternative 1Alternative 2-

Alternative 3

and Disposal
alternative artial Retrieval, Treatment,

Alternative 5-Full Retrieval Treatment, and Disposal

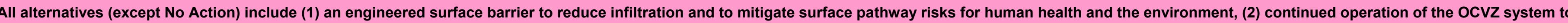
collect and treat VOCs from the vadose zone, and (3) long-term surveillance, maintenance, monitoring, and ICs to manage residual risk.

Cost

$\begin{array}{cr}\text { Current value: } & \text { Current value: } \\ \$ 57 \mathrm{M} & 2 \mathrm{a}-\$ 344 \mathrm{M} \\ & 2 \mathrm{~b}-\$ 331 \mathrm{M}\end{array}$

\section{Current value:}

$\$ 385 \mathrm{M}$

$2 \mathrm{~b}-\$ 331 \mathrm{M}$
Current value:

4a- $\$ 1,071 \mathrm{M}$

$4 \mathrm{~b}-\$ 705 \mathrm{M}$

Net present value

$4 \mathrm{a}-\$ 756 \mathrm{M}$

$\mathrm{b}-\$ 486 \mathrm{M}$
Current value:

$\$ 13,651 \mathrm{M}$

Net present value:

$\$ 8,434 \mathrm{M}$

\begin{tabular}{|c|c|c|c|c|c|}
\hline \multicolumn{6}{|l|}{ Modifying Criteria } \\
\hline State acceptance & $-^{\mathrm{d}}$ & $-^{\mathrm{d}}$ & ${ }^{\mathrm{d}}$ & ${ }^{\mathrm{d}}$ & $-^{\mathrm{d}}$ \\
\hline Community acceptance & $-^{\mathrm{d}}$ & $\sim^{\mathrm{d}}$ & - $^{\mathrm{d}}$ & - $^{\mathrm{d}}$ & - $^{\mathrm{d}}$ \\
\hline
\end{tabular}

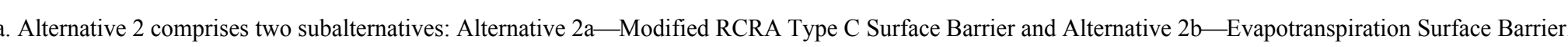

b. Alternative 4 comprises two subalternatives: Alternative $4 a-4$-Acre RTD, and Alternative $4 b-2$-Acre RTD.

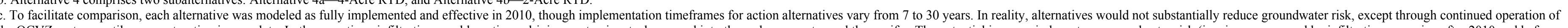
occurring after 2010 and before cap and record of decision for OU 7-13/14.

ARAR $=$ applicable or relevant and appropriate requirement

$\mathrm{DEQ}=$ (Idaho) Department of Environmental Quality
$\mathrm{EPA}=$ U.S. Environmental Protection Agency IC = institutional control LLW $=$ low-level waste
$\mathrm{OCVZ}=$ Organic Contamination in the Vadose Zone $\mathrm{OU}=$ operable uni RCRA $=$ Resource Conservation and Recovery Act
$\mathrm{RTD}=$ retrieval, treatment, and disposa VOC $=$ volatile organic compound
WIPP = Waste Isolation Pilot Plant 


\subsection{References}

42 USC § 9601 et seq., 1980, "Comprehensive Environmental Response, Compensation and Liability Act of 1980 (CERCLA/Superfund)," United States Code.

DOE-ID, 1994, Record of Decision: Declaration for Organic Contamination in the Vadose Zone Operable Unit 7-08, Idaho National Engineering Laboratory, Radioactive Waste Management Complex, Subsurface Disposal Area, Administrative Record No. 5761, U.S. Department of Energy Idaho Operations Office; U.S. Environmental Protection Agency; Idaho Division of Environmental Quality, Idaho Department of Health and Welfare.

EPA, 1991, A Guide to Principal Threat and Low Level Threat Wastes, OSWER Directive 9380.3-06FS, U.S. Environmental Protection Agency, Office of Solid Waste and Emergency Response.

Holdren, K. Jean and Barbara J. Broomfield, 2004, Second Addendum to the Work Plan for the OU 7-13/14 Waste Area Group 7 Comprehensive Remedial Investigation/Feasibility Study, DOE/ID-11039, Rev. 0, U.S. Department of Energy Idaho Operations Office. 


\section{REFERENCES}

10 CFR 1022, 2003, "Compliance with Floodplain and Wetland Environmental Review Requirements," Code of Federal Regulations, Office of the Federal Register.

29 CFR 1910, 2006, "Occupational Safety and Health Standards," Code of Federal Regulations, Office of the Federal Register, July 2006.

36 CFR 800, 2004, "Protection of Historic Properties," Code of Federal Regulations, Office of the Federal Register.

40 CFR 6, 2002, "Procedures for Implementing the Requirements of the Council on Environmental Quality on the National Environmental Policy Act," Code of Federal Regulations, Office of the Federal Register.

40 CFR 61, 2006, "National Emission Standards for Hazardous Air Pollutants," Code of Federal Regulations, Office of the Federal Register.

40 CFR 141, 2006, "National Primary Drinking Water Regulations," Code of Federal Regulations, Office of the Federal Register.

40 CFR 154, 2006, "Special Review Procedures," Code of Federal Regulations, Office of the Federal Register.

40 CFR 262, 2006, "Standards Applicable to Generators of Hazardous Waste," Code of Federal Regulations, Office of the Federal Register.

40 CFR 264, 2006, "Standards for Owners and Operators of Hazardous Waste Treatment, Storage, and Disposal Facilities," Code of Federal Regulations, Office of the Federal Register.

40 CFR 265.310, 2006, "Closure and Post-Closure Care," Code of Federal Regulations, Office of the Federal Register.

40 CFR 268, 2006, "Land Disposal Restrictions," Code of Federal Regulations, Office of the Federal Register.

40 CFR 300, 2006, "National Oil and Hazardous Substances Pollution Contingency Plan," Code of Federal Regulations, Office of the Federal Register.

40 CFR 300.430, 2006, "Remedial Investigation/Feasibility Study and Selection of Remedy," Code of Federal Regulations, Office of the Federal Register.

40 CFR 761, Subpart D, 2006, "Storage and Disposal," Code of Federal Regulations, Office of the Federal Register.

43 CFR 7, 2006, "Protection of Archaeological Resources," Code of Federal Regulations, Office of the Federal Register.

43 CFR 10, 2006, "Native American Graves Protection and Repatriation Regulations," Code of Federal Regulations, Office of the Federal Register. 
42 USC $§ 6901$ et seq., 1976, "Resource Conservation and Recovery Act of 1976 (Solid Waste Disposal Act)," United States Code.

42 USC $§ 9601$ et seq., 1980, “Comprehensive Environmental Response, Compensation and Liability Act of 1980 (CERCLA/Superfund)," United States Code.

42 USC § 9621 et seq., 2004, “Cleanup Standards,” United States Code.

54 FR 48184, 1989, "National Priorities List of Uncontrolled Hazardous Waste Sites; Final Rule," Federal Register.

Anderson, Danny L. and Bruce H. Becker, 2006, Source Release Modeling Report for Operable Unit 7-13/14, ICP/EXT-05-01039, Idaho National Laboratory, Idaho Cleanup Project.

Anderson, J. E. and A. D. Forman, 2003, Evapotranspiration Caps for the Idaho National Engineering and Environmental Laboratory: A Summary of Research and Recommendations, STOLLER-ESER-56, Stoller Corporation and Idaho State University for the U.S. Department of Energy.

Anderson, J. E., R. S. Nowak, T. D. Ratzlaff, and O. D. Markham, 1993, "Managing Soil Moisture on Waste Burial Sites in Arid Regions," Journal of Environmental Quality, Vol. 22, No. 1, pp. 62-69.

Anderson, S. R., M. J. Liszewski, and D. J. Ackerman, 1996, Thickness of Surficial Sediment at and Near the Idaho National Engineering Laboratory, Idaho, U.S. Geological Survey Open-File Report 96-330, U.S. Geological Survey.

Ankeny, M. D., L. M. Coons, N. Majumdar, J. Kelsey, and M. Miller, 1997, "Performance and Cost Considerations for Landfill Caps in Semi-Arid Climates," Proceedings of Landfill Capping in the Semi-Arid West: Problems, Perspectives, and Solutions, Grand Teton National Park, Wyoming, May 21-22.

Auerbach, N. A., M. D. Walker, and D. A. Walker, 1997, "Effects of Roadside Disturbance on Substrate and Vegetation Properties in Arctic Tundra," Ecological Applications, Vol. 7, No. 1, pp. 218-235.

Batcheller, Thomas A. and George D. Redden, 2004, Colloidal Plutonium at the Operable Unit 7-13/14 Subsurface Disposal Area: Estimate of Inventory and Transport Properties, ICP/EXT-04-00253, Idaho National Engineering and Environmental Laboratory, Idaho Completion Project.

Becker, B. H., T. A. Bensen, C. S. Blackmore, D. E. Burns, B. N. Burton, N. L. Hampton, R. M. Huntley, R. W. Jones, D. K. Jorgensen, S. O. Magnuson, C. Shapiro, and R. L. VanHorn, 1996, Work Plan for Operable Unit 7-13/14 Waste Area Group 7 Comprehensive Remedial Investigation/Feasibility Study, INEL-95/0343, Rev. 0, Idaho National Engineering Laboratory.

Beitel, George A., 2000, Independent Technical Review Panel Safety Review of Proposed Stage I Drilling Activities, INEEL/EXT-2000-00185, EDF-ER-143, Idaho National Engineering and Environmental Laboratory.

BHI, 2000, Technical Alternatives Baseline Report, Bechtel Hanford, Richland, Washington. 
Bowders, John J., J. Erick Loehr, Deepak Neupane, and Abdelmalek Bouassa, 2003, “Construction Quality Control for Asphalt Concrete Hydraulic Barriers," Journal of Geotechnical and Geoenvironmental Engineering, Vol. 129, No. 3, pp. 219-223.

Bowman, A. L., W. F. Downs, K. S. Moor, and B. F. Russell, 1984, INEL Environmental Characterization Report, Volume II: Appendices A-C, EGG-NPR-6688, Rev. 0, Idaho National Engineering Laboratory.

Breshears, David D., John W. Nyhan, and David W. Davenport, 2005, "Ecohydrology Monitoring and Excavation of Semiarid Landfill Covers a Decade after Installation,” Vadose Zone Journal, Vol. 4, pp. $798-810$.

Burns, Douglas E., 1995, Guidance Protocol for the Performance of Cumulative Risk Assessments at the INEL, INEL-95/131, Rev. 0, Idaho National Engineering Laboratory.

Burton, Brent, 2006, "Emissions pf Radionuclides from the Accelerated Retrieval Project During Calendar Year 2005,” EDF-6763, Rev. 0, Idaho National Laboratory, Idaho Cleanup Project.

CPEO, 2002, Technology Tree, Center for Public Environmental Oversight,

URL: http://www.cpeo.org/techtree/ttdescript/index.html, Web site updated November 2002, Web page visited January 30, 2007.

Crouse, Phillip and Montgomery Watson, 2002, "Liner and Final Cover Long Term Performance Evaluation and Final Cover Life Cycle Expectation," EDF-ER-281, Rev. 1, Idaho National Engineering and Environmental Laboratory.

Daniel, David E. and Yung-Kwant Wu, 1993, "Compacted Clay Liners and Covers for Arid Sites," Journal of Geotechnical Engineering, Vol. 199, No. 2, pp. 223-237.

DOE, 1988, Vegetative Covers: Special Study, DOE/UMTRA-400642-0000, U.S. Department of Energy Albuquerque Operations Office.

DOE, 1989, Technical Approach Document, DOE/UMTRA-050425-0002, U.S. Department of Energy Albuquerque Operations Office.

DOE O 435.1, 2001, "Radioactive Waste Management,” Change 1, U.S. Department of Energy.

DOE O 5400.5, 1993, "Radiation Protection of the Public and the Environment," U.S. Department of Energy.

DOE-CBFO, 2002, National TRU Waste Management Plan, DOE/NTP-96-1204, Rev. 3, U.S. Department of Energy Carlsbad Field Office.

DOE-CBFO, 2005, Contact-Handled Transuranic Waste Authorized Methods for Payload Control (CH-TRAMPAC), NRC Docket 71-9279, Rev. 2, Waste Isolation Pilot Plant, U.S. Department of Energy Carlsbad Field Office.

DOE-ID, 1991, Federal Facility Agreement and Consent Order for the Idaho National Engineering Laboratory, Administrative Docket No. 1088-06-29-120, U.S. Department of Energy Idaho Operations Office; U.S. Environmental Protection Agency, Region 10; Idaho Department of Environmental Quality. 
DOE-ID, 1993, Record of Decision: Declaration for Pit 9 at the Radioactive Waste Management Complex Subsurface Disposal Area at the Idaho National Engineering Laboratory, Administrative Record No. 5569, U.S. Department of Energy Idaho Operations Office; U.S. Environmental Protection Agency, Region 10; Idaho Department of Health and Welfare.

DOE-ID, 1994, Record of Decision: Declaration for Organic Contamination in the Vadose Zone Operable Unit 7-08, Idaho National Engineering Laboratory, Radioactive Waste Management Complex, Subsurface Disposal Area, Administrative Record No. 5761, U.S. Department of Energy Idaho Operations Office; U.S. Environmental Protection Agency, Region 10; Idaho Department of Health and Welfare.

DOE-ID, 1994, Record of Decision: Declaration for Pad A at the Radioactive Waste Management Complex Subsurface Disposal Area at the Idaho National Engineering Laboratory, Administrative Record No. 5632, U.S. Department of Energy Idaho Operations Office; U.S. Environmental Protection Agency, Region 10; Idaho Department of Health and Welfare.

DOE-ID, 1997, Environmental Assessment and Plan for New Silt/Clay Source Development and Use at the Idaho National Engineering and Environmental Laboratory, DOE/EA-1083, U.S. Department of Energy Idaho Operations Office.

DOE-ID, 1997, Remedial Action Report for CFA Landfills I, II, and III Native Soil Cover Project Operable Unit 4-12, DOE/ID-10589, Rev. 0, U.S. Department of Energy Idaho Operations Office.

DOE-ID, 1998, Addendum to the Work Plan for the Operable Unit 7-13/14 Waste Area Group 7 Comprehensive Remedial Investigation/Feasibility Study, DOE/ID-10622, U.S. Department of Energy Idaho Operations Office.

DOE-ID, 1999, Final Record of Decision, Idaho Nuclear Technology and Engineering Center, Operable Unit 3-13, DOE/ID-10660, Rev. 0, Idaho National Engineering and Environmental Laboratory; U.S. Department of Energy Idaho Operations Office; U.S. Environmental Protection Agency; Idaho Department of Health and Welfare.

DOE-ID, 1999, Operable Unit 7-13/14, In Situ Grouting Treatability Study Work Plan, DOE/ID-10690, U.S. Department of Energy Idaho Operations Office.

DOE-ID, 2003, INEEL CERCLA Disposal Facility Complex Remedial Action Work Plan, DOE/ID-10984, Rev. 0, U.S. Department of Energy Idaho Operations Office.

DOE-ID, 2004, Action Memorandum for Accelerated Retrieval of a Described Area within Pit 4, DOE/NE-ID-11179, Rev. 0, U.S. Department of Energy Idaho Operations Office.

DOE-ID, 2004, Remedial Action Report for the Operable Unit 7-10 Glovebox Excavator Method Project, DOE/NE-ID-11155, Rev. 0, U.S. Department of Energy Idaho Operations Office.

DOE-ID, 2005, Idaho National Engineering and Environmental Laboratory Waste Acceptance Criteria, DOE/ID-10381, Rev. 21, U.S. Department of Energy Idaho Operations Office.

DOE-ID, 2006, Action Memorandum for the Accelerated Retrieval Project II within Pits 4 and 6 of the Subsurface Disposal Area, DOE/NE-ID-11238, U.S. Department of Energy Idaho Operations Office. 
DOE-ID, 2006, Engineering Evaluation/Cost Analysis for General Decommissioning Activities under the Idaho Cleanup Project, DOE/ID-11291, OSWER Directive 9355.3-01, Rev. 0, U.S. Department of Energy Idaho Operations Office.

DOE-RL, 1996, Focused Feasibility Study of Engineered Barriers for Waste Management Units in 200 Areas, DOE/RL-93-33, Rev. 0, U.S. Department of Energy, Office of Environmental Restoration and Waste Management, Richland, Washington.

Dwyer, S. F., 1997, "Large-Scale Field Study of Landfill Covers at Sandia National Laboratories," Conference Proceedings of Landfill Capping in the Semi-Arid West: Problems, Perspectives, and Solutions, Grand Teton National Park, Wyoming, pp. 87-107.

EnergySolutions, 2006, Bulk Waste Disposal and Treatment Facilities Waste Acceptance Criteria, Rev. 6, EnergySolutions.

EPA, 1984, Slurry Trench Construction for Pollution Migration Control, EPA/540/2-84-001, U.S. Environmental Protection Agency.

EPA, 1988, Guidance for Conducting Remedial Investigations and Feasibility Studies under CERCLA, Interim Final, EPA/540/G-89-004, OSWER Directive 9355.3-01, U.S. Environmental Protection Agency.

EPA, 1989, Final Covers on Hazardous Waste Landfills and Surface Impoundments, EPA/530-SW-89-047, U.S. Environmental Protection Agency, Office of Solid Waste and Emergency Response.

EPA, 1989, Risk Assessment Guidance for Superfund, Vol. I - Human Health Evaluation Manual, Interim Guidance, Part A, EPA/540/1-89/002, U.S. Environmental Protection Agency.

EPA, 1989, Superfund LDR Guide \#5 Determining When Land Disposal Restrictions (LDRs) Are Applicable to CERCLA Response Actions, OSWER Directive 9347.3-05FS, U.S. Environmental Protection Agency, Office of Solid Waste and Emergency Response.

EPA, 1991, A Guide to Principal Threat and Low Level Threat Wastes, OSWER Directive 9380.3-06FS, U.S. Environmental Protection Agency, Office of Solid Waste and Emergency Response.

EPA, 1991, Role of the Baseline Risk Assessment in Superfund Remedy Selection Decisions, OSWER Directive 9355.0-30, U.S. Environmental Protection Agency, Office of Solid Waste and Emergency Response.

EPA, 1991, Survey of Materials Handling Technologies Used at Hazardous Waste Site, EPA/540/2-91/010, U.S. Environmental Protection Agency.

EPA, 1995, Land Use in the CERCLA Remedy Selection Process, OSWER Directive No. 9355.7-04, U.S. Environmental Protection Agency, Office of Solid Waste and Emergency Response.

EPA, 1997, Establishment of Cleanup Levels for CERCLA Sites with Radioactive Contamination, OSWER Directive No. 9200.4-18, U.S. Environmental Protection Agency, Office of Emergency and Remedial Response and Office of Radiation and Indoor Air. 
EPA, 1997, Rules of Thumb for Superfund Remedy Selection, EPA 540-R-97-013, OSWER 9355.0-69, U.S. Environmental Protection Agency, Office of Solid Waste and Emergency Response.

EPA, 1999, A Guide to Preparing Superfund Proposed Plans, Records of Decision, and other Remedy Selection Decision Documents, EPA 540-R-98-031, OSWER 9200.1-23P, U.S. Environmental Protection Agency, Office of Solid Waste and Emergency Response.

EPA, 2000, Radionuclides Notice of Data Availability Technical Support Document, U.S. Environmental Protection Agency.

EPA, 2003, Superfund Innovative Technology Evaluation Program, Technology Profiles, Eleventh Edition, Volume 1, Demonstration Program, EPA 540/R-03/501, U.S. Environmental Protection Agency.

EPA, 2006, Remediation Technology Descriptions, Alternative Landfill Cover Project Profiles, U.S. Environmental Protection Agency, Technology Innovation Program, URL: http://cluin.org/products/altcovers/, Web page visited January 30, 2007.

Forman, Amy D. and Jay E. Anderson, 2005, "Design and Performance of Four Evapotranspiration Caps," Practice Periodical of Hazardous, Toxic, and Radioactive Waste Management, Vol. 9, No. 4, pp. 263-272.

FRTR, 2002, Remediation Technologies Screening Matrix and Reference Guide Version 4.0, Federal Remediation Technologies Roundtable, URL: http:/www.frtr.gov/matrix 2/top page.html, Web page visited January 30, 2007.

Gaglio, Michael D., William P. Mackay, Daniel Padilla, Robert Webb, and David V. LeMone, 2001, "The Effectiveness of Biobarrier Layers within Protective Caps at Preventing Penetration of Waste Sites by the Harvester Ant Pogonomyrmex Salinus Olsen (Hymenoptera: Formicidae)," Waste Management Conference 2001, Tucson Arizona, February 25-March 1, 2001.

Gee, G. W. and A. L. Ward, 1997, "Still in Quest for the Perfect Cap," edited by T. D. Reynolds and R. C. Morris, Conference Proceedings-Landfill Capping in the Semi-Arid West: Problems, Perspectives, and Solutions, Environmental Science and Research Foundation, Vol. ESRF-019.

Gee, G. W., A. L. Ward, and C. D. Wittreich, 2002, The Hanford Site 1000-Year Cap Design Test, PNNL-14143, Pacific Northwest National Laboratory.

Golder Associates, 1988, Master Evaluation of Cover Alternatives and Surface Drainage Design at the Subsurface Disposal Area, EGG-LLW-8235, Golder Associates, Inc., for the Idaho National Engineering Laboratory.

Hakonson, T. E., 1986, Evaluation of Geologic Materials to Limit Biological Intrusion into Low-Level Radioactive Waste Disposal Sites, LA-10286-MS, Los Alamos National Laboratory.

Halford, V. E., D. R. Perry, W. C. Craft III, J. J. King, J. M. McCarthy, I. D. Figueroa, and Y. McClellan, 1993, Remedial Investigation/Feasibility Study for Pad A Operable Unit 7-12, Waste Area Group 7, Radioactive Waste Management Complex, Idaho National Engineering Laboratory, EGG-WM-9967, Vol. 1, Idaho National Engineering Laboratory. 
Hampton, Nancy L., 2006, Biological Data to Support Operable Unit 7-13/14 Modeling of Plant and Animal Intrusion at Buried Waste Sites, INEEL/EXT-01-00273, Rev. 1, Idaho National Laboratory, Idaho Cleanup Project.

Hanson, D. J., G. E. Matthern, N. A. Yancey, and D. L. Knudson, 2004, Evaluation of the Durability of WAXFIX for Subsurface Applications, ICP/EXT-04-00300, Rev. 0, Idaho National Engineering and Environmental Laboratory, Idaho Completion Project.

Hanson, Duane J., Gretchen E. Matthern, Sylvester J. Losinski, and Jay T. Brown, 2005, Evaluation of Durability of Portland-Cement-Based Grout for Subsurface Applications at OU 7-13/14, ICP/EXT-05-00798, Rev. 0, Idaho National Engineering and Environmental Laboratory, Idaho Cleanup Project.

Holdren, K. Jean and Barbara J. Broomfield, 2004, Second Addendum to the Work Plan for the OU 7-13/14 Waste Area Group 7 Comprehensive Remedial Investigation/Feasibility Study, DOE/ID-11039, Rev. 0, U.S. Department of Energy Idaho Operations Office.

Holdren, K. Jean, Bruce H. Becker, Nancy L. Hampton, L. Don Koeppen, Swen O. Magnuson, T. J. Meyer, Gail L. Olson, and A. Jeffrey Sondrup, 2002, Ancillary Basis for Risk Analysis of the Subsurface Disposal Area, INEEL/EXT-02-01125, Rev. 0, Idaho National Engineering and Environmental Laboratory.

Holdren, K. Jean, Danny L. Anderson, Bruce H. Becker, Nancy L. Hampton, L. Don Koeppen, Swen O. Magnuson, and A. Jeffrey Sondrup, 2006, Remedial Investigation and Baseline Risk Assessment for Operable Unit 7-13/14, DOE/ID-11241, U.S. Department of Energy Idaho Operations Office.

Housley, L. Todd, 2005, Environmental and Operational End-Year Data Report for the OU 7-08 Organic Contamination in the Vadose Zone Project-2004, ICP/EXT-05-00779, Rev. 0, Idaho National Laboratory, Idaho Completion Project.

ICP, 2006, Independent Investigation Report of the November 2005 Drum Fire at the Idaho National Laboratory Site, RPT-190, Idaho National Laboratory, Idaho Cleanup Project.

Idaho Code § 39-4401 et seq., 1983, "Hazardous Waste Management Act of 1983," State of Idaho, Boise, Idaho.

Idaho Statute 67-4601 et seq., 2005, Preservation of Historic Sites, State of Idaho.

IDAPA 58.01.01.161, 1995, “Toxic Substances,” Idaho Administrative Procedures Act, Idaho Department of Environmental Quality.

IDAPA 58.01.01.577, 1994, “Ambient Air Quality Standards for Specific Air Pollutants,” Idaho Administrative Procedures Act, Idaho Department of Environmental Quality.

IDAPA 58.01.01.585, 1995, “Toxic Air Pollutants Non-Carcinogenic Increments," Idaho Administrative Procedures Act, Idaho Department of Environmental Quality.

IDAPA 58.01.01.586, 2001, “Toxic Air Pollutants Carcinogenic Increments," Idaho Administrative Procedures Act, Idaho Department of Environmental Quality. 
IDAPA 58.01.01.625, 2000, "Visible Emissions," Idaho Administrative Procedures Act, Idaho Department of Environmental Quality.

IDAPA 58.01.01.650, 1994, "Rules for Control of Fugitive Dust," Idaho Administrative Procedures Act, Idaho Department of Environmental Quality.

IDAPA 58.01.01.651, 1994, “General Rules,” Idaho Administrative Procedures Act, Idaho Department of Environmental Quality.

IDAPA 58.01.05, 1993, "Rules and Standards for Hazardous Waste," Idaho Administrative Procedures Act, Idaho Department of Environmental Quality.

IDAPA 58.01.05.011, 2006, "Land Disposal Restrictions," Idaho Administrative Procedures Act, Idaho Department of Environmental Quality.

IDAPA 58.01.11, 1997, “Ground Water Quality Rule,” Idaho Administrative Procedures Act, Idaho Department of Environmental Quality.

IDAPA 58.01.11.200, 1997, “Ground Water Quality Standards,” Idaho Administrative Procedures Act, Idaho Department of Environmental Quality.

INEEL, 1997, Hot Spot Removal System: System Description, INEEL/EXT-97-00666, Idaho National Engineering and Environmental Laboratory.

INEL, 1993, Decision Documentation Package for Operable Unit 7-11 Septic Systems, Administrative Record No. 5235, Idaho National Engineering Laboratory.

INL, 2005, Data Quality Objectives Summary Report for the Operable Unit 7-08 Post-Record of Decision Sampling, INEEL/EXT-2000-00814, Rev. 2, Idaho National Laboratory, Idaho Cleanup Project.

ITRC, 2003, Technical and Regulatory Guidance for Design, Installation, and Monitoring of Alternative Final Landfill Covers, Interstate Technology Regulatory Council, Alternative Landfill Technologies Team, URL: http://www.itrcweb.org/Documents/ALT-2.pdf, Web page last visited February 1, 2007.

Jensen, Scott, 2004, “OU 7-13/14 In Situ Grouting Project Grout Selection,” EDF-5146, Rev. 0, Idaho National Engineering and Environmental Laboratory, Idaho Completion Project.

Kaback, D. S., T. W. Fogwell, and S. W. Peterson, 2005, Evaluation of Vadose Zone Treatment Technologies to Immobilize Technetium-99, WMP-27397, Fluor Hanford.

Keck, J. F., 1992, "Evaluation of Engineered Barriers for Closure Cover of the Radioactive Waste Management Complex Subsurface Disposal Area,” EDF-RWMC-523, Idaho National Engineering Laboratory.

Keck, K. N. and R. R. Seitz, 2002, Potential for Subsidence at the Low-Level Radioactive Waste Disposal Area, INEEL/EXT-02-01154, Idaho National Engineering and Environmental Laboratory. 
Koeppen, L. Don, M. Doug McKenzie, Paul D. Ritter, and William A. Smith, 2006, Fiscal Year 2005 Environmental Monitoring Report for the Radioactive Waste Management Complex, RPT-171, Idaho National Laboratory, Idaho Cleanup Project.

Layne GeoConstruction, 2006, Jet Grouting Technical Summary, vendor data provided February 2006 by Layne GeoConstruction, a Division of Layne Christensen Company.

Litus, Marty and Jerry P. Shea, 2005, Summary of Cleanup at the Idaho National Laboratory Site, ICP/EXT-05-00806, Rev. 0, Idaho National Laboratory, Idaho Completion Project.

Lodman, David, Steve Dunstan, Wayne Downs, Jeff Sondrup, Dean Miyasaki, Kelly Galloway, and Karen Izbicki, 1994, Treatability Study Report for the Organic Contamination in the Vadose Zone, Operable Unit 7-08, EGG-ER-11121, Rev. 0, Idaho National Engineering Laboratory.

Loomis, G. G. and D. N. Thompson, 1995, Innovative Grout/Retrieval Demonstration Final Report, INEL-95/001, Idaho National Engineering and Environmental Laboratory.

Loomis, Guy G., Andrew P. Zdinak, and Carolyn W. Bishop, 1997, Innovative Subsurface Stabilization Project - Final Report (Revision 1), INEL-96/0439, Idaho National Engineering Laboratory.

Loomis, Guy G., Andrew P. Zdinak, Mark A. Ewanic, James J. Jessmore, 1998, Acid Pit Stabilization Project (Volume l-Cold Testing), INEEL/EXT-98-00009, Idaho National Engineering and Environmental Laboratory.

Loomis, Guy G., David N. Thompson, and John H. Heiser, 1995, Innovative Subsurface Stabilization of Transuranic Pits and Trenches, INEL-95/0632, Idaho National Engineering Laboratory.

Loomis, Guy G., James J. Jessmore, Jerry R. Weidner, Christopher M. Miller, and Allen L. Sehna, 2003, Final Results Report, In Situ Grouting Technology for Application in Buried Transuranic Waste Sites Volume 1, Technology Description and Treatability Study Results for Operable Unit 7-13/14, INEEL/EXT-02-00233, Rev. 1, Idaho National Engineering and Environmental Laboratory.

Lopez, S. L., William H. Landman, Donald E. Sebo, and Vivian G. Schultz, 2005, Summary Report for the OU 7-13/14 Early Actions Beryllium Encapsulation Project, ICP/EXT-04-00646, Rev. 1, Idaho National Engineering and Environmental Laboratory, Idaho Completion Project.

Lopez, Steve L., 2004, Action Memorandum for the Operable Unit 7-13/14 Early Actions Beryllium Encapsulation Project, DOE/NE-ID-11162, U.S. Department of Energy Idaho Operations Office.

Magnuson, Swen O. and A. Jeffrey Sondrup, 2006, Subsurface Flow and Transport Model Development for the Operable Unit 7-13/14 Remedial Investigation and Feasibility Study, ICP/EXT-05-01016, Rev. 1, Idaho National Laboratory, Idaho Cleanup Project.

Magnuson, S. O., 1993, A Simulation Study of Moisture Movement in Proposed Barriers for the Subsurface Disposal Area, EGG-WM-10974, Idaho National Engineering Laboratory.

Manci, K. M., D. N. Gladwin, R. Villella, and M. G. Cavendish, 1988, Effects of Aircraft Noise and Sonic Booms on Domestic Animals and Wildlife: A Literature Synthesis, NERC-88/29, U.S. Fish and Wildlife Service, National Ecology Research Center, Ft. Collins, Colorado, pp. 88. 
Martian, Peter, 2007, Verification and Benchmark Testing of the TETRAD Simulator, Version 12.7ms, RPT-335, Idaho National Laboratory, Idaho Cleanup Project.

Matthern, Gretchen, Neal Yancey, Gregory Hulet, and Peter Shaw, 2005, Preremedial Design Report of Remediation Options for OU 7-13/14, ICP/EXT-04-00330, Rev. 0, Idaho National Laboratory, Idaho Cleanup Project.

Mattson, Earl, Mark Ankeny, Steve Dwyer, Nancy Hampton, Gretchen Matthern, Brenda Pace, Alva Parsons, Mitch Plummer, Steve Reese, and Jody Waugh, 2004, Preliminary Design for an Engineered Surface Barrier at the Subsurface Disposal Area, ICP/EXT-04-00216, Rev. 0, Idaho National Engineering and Environmental Laboratory, Idaho Completion Project.

McKenzie, M. Doug, Donald E. Sebo, Kirk M. Green, and Vivian G. Schultz, 2005, Waste Information and Location Database for the OU 7-13/14 Project, ICP/EXT-04-00271, Rev. 0, Idaho National Laboratory, Idaho Cleanup Project.

Minkin, S. C., M. R. Jackson, C. Knutson, P. N. Middleston, B. L. Ringe, R. C. Rope, and R. P. Smith, 1994, INEL Gravel/Borrow Resources and Compliance Assessment, EGG-FM-1126, Idaho National Engineering Laboratory.

Mitchell, T., S. Mitchell, J. Humphrey, D. Kennedy, and T. Funderburg, 2001, 100-Year Floodplain and 25-Year Runoff Analyses for the Radioactive Waste Management Complex Area at the Idaho National Engineering and Environmental Laboratory, INEEL/EXT-02-00093, Idaho National Engineering and Environmental Laboratory.

Moore, Beth A. and Bruce M. Crowe, 1998, Consequences of Subsidence for the Area 3 and Area 5 Radioactive Waste Management Sites, Nevada Test Site, DOE/NV-502 UC-600, U.S. Department of Energy Nevada Operations Office.

Morgan, I. L. and W. D. Bostick, 1992, "Performance Testing of Grout-Based Waste Forms for the Solidification of Anion Exchange Resins," Stabilization and Solidification of Hazardous, Radioactive, and Mixed Wastes, 2nd Volume, STP 1123, ASTM, Philadelphia, pp. 133-145.

OMB, 2006, Guidelines and Discount Rates for Benefit-Cost Analysis of Federal Programs, Appendix C, "Discount Rates for Cost-Effectiveness, Lease Purchase, and Related Analysis," OMB Circular No. A-94, Office of Management and Budget, URL: http://www.whitehouse.gov/omb/circulars/a094/a94_appx-c.html, Web page last visited June 12, 2006.

Parsons, Alva M. and Roger R. Seitz, 2006, Annual Performance Assessment and Composite Analysis Review for the RWMC Low-Level Waste Disposal Facility FY 2005, ICP/EXT-06-01131, Rev. 0, Idaho National Laboratory, Idaho Cleanup Project.

Peterson, R. D., A. J. Johnson, and K. G. Peter, 1986, Nitrate Salt Immobilization Process Development and Implementation, RFP-3919, Rocky Flats Plant.

PLN-2085, 2006, "Project Execution Plan for the ICP Radioactive Waste Management Complex Project," Rev. 2, Idaho National Laboratory, Idaho Cleanup Project.

Porro, Indrik, 2001, "Hydrologic Behavior of Two Engineered Barriers Following Extreme Wetting," Journal of Environmental Quality, Vol. 30, pp. 655-667. 
Public Law 102-579, 1992, “The Waste Isolation Pilot Plant Land Withdrawal Act,” Public Law, 1992.

Raivo, B., 2001, "Staging, Storage, Sizing, and Treatment Facility (SSSTF) Stabilization Treatment Process Selection," EDF-1542, Rev. 0, Idaho National Engineering and Environmental Laboratory.

Raivo, Brian D., 2004, "OU 7-13/14 In Situ Grouting Project Hydraulic Excavator and Drill-Injection Rig,” EDF-5153, Rev. 0, Idaho National Engineering and Environmental Laboratory, Idaho Completion Project.

Richins, W. D. and C. J. Hurst, 2004, “Assessment of Dynamic Soil Compaction at SDA,” EDF-4909, Rev. 0, Idaho National Engineering and Environmental Laboratory, Idaho Completion Project.

Roback, Robert C., Deward W. Efurd, Michael T. Murrell, Robert E. Steiner, and Clarence J. Duffy, 2000, Assessment of Uranium and Plutonium in the Saturated and Unsaturated Zones Beneath the Surface Disposal Area, INEEL, LA-UR-00-5471, INEEL/EXT-01-00771, Los Alamos National Laboratory.

Sebo, D. and C. A. Whitaker, 2005, Collocated Facilities Analysis for Waste Area Group 7, Operable Unit 7-13/14, INEEL/EXT-01-00027, Rev. 1, Idaho National Laboratory, Idaho Cleanup Project.

Shaw, Peter, 2004, "Grout Selection Criteria and Recommendation for the OU 7-13/14 In Situ Grouting Early Action Project,” EDF-4397, Rev. 0, Idaho National Engineering and Environmental Laboratory, Idaho Completion Project.

Shaw, Peter, 2004, "Grout Selection Criteria and Recommendation for the OU 7-13/14 In Situ Grouting Project," EDF-5333, Rev. 0, Idaho National Engineering and Environmental Laboratory, Idaho Completion Project.

Shook, G. M., 1995, Development of an Environmental Simulator from Existing Petroleum Technology, INEL-94/0283, Idaho National Engineering Laboratory.

Shropshire, Karen, 2004, "Lessons Learned from ISG Phase 1-Beryllium Block Wax Grouting in Summer 2004,” EDF-5473, Rev. 0, Idaho National Engineering and Environmental Laboratory, Idaho Completion Project.

Smith, E. D., R. J. Luxmore, and G. W. Suter, 1997, "Natural Physical and Biological Processes Compromise the Long Term Integrity of Compacted Clay Caps," Barrier Technologies for Environmental Management, National Research Council, Washington, D.C.: National Academies Press.

Staley, Chris, 2004, "Air Emissions Evaluation for the Accelerated Retrieval Project for a Described Area within Pit 4," EDF-4692, Rev. 0, Idaho National Engineering and Environmental Laboratory, Idaho Completion Project.

Staley, Chris, 2006, “2005 INEEL Emissions Standards for Hazardous Air Pollutants (NESHAP)— Compilation of Radiological Releases from Idaho Completion Project Activities and Sites for CY 2004," EDF-5846, Rev. 0, Idaho National Laboratory, Idaho Cleanup Project.

Stephens, David L., 2004, “OU 7-13/14 In Situ Grouting Project Foundation Grouting Study,” EDF-5028, Rev. 0, Idaho National Engineering and Environmental Laboratory, Idaho Completion Project. 
Stormont, John C. and Clifford E. Anderson, 1999, "Capillary Barrier Effect from Underlying Coarser Soil Layer," Journal of Geotechnical and Geoenvironmental Engineering, Vol. 125, No. 8, pp. 641-648.

Stormont, J. C., M. D. Ankeny, M. E. Burkhard, M. K. Tansey, and J. A. Kelsey, 1994, Assessment of an Active Dry Barrier for a Landfill Cover System, SAND94-0301, Sandia National Laboratories and Daniel B. Stephens \& Associates for the U.S. Department of Energy.

Sullivan, T. M., 1992, Development of DUST: A Computer Code That Calculates Release Rates from LLW Disposal Unit, BNL-NUREG-47118, Brookhaven National Laboratory, U.S. Nuclear Regulatory Commission.

Suter, Glenn W., II, Robert J. Luxmoore, and Ellen D. Smith, 1993, "Compacted Soil Barriers at Abandoned Landfill Sites Are Likely to Fail in the Long Term," Journal of Environmental Quality, Vol. 22, No. 2, pp. 217-226.

Sykes, Kira, 2002, Evaluation of Soil and Buried Waste Retrieval Technologies for Operable Unit 7-13/14, INEEL/EXT-01-00281, CH2MHILL for Bechtel BWXT Idaho, LLC, Idaho National Engineering and Environmental Laboratory.

Szecsody, J. E., J. L. Phillips, V. R. Vermeul, J. S. Fruchter, and M. D. Williams, 2005, Influence of Nitrate on the Hanford 100D Area in Situ Redox Manipulation Barrier Longevity, PNNL-15262, Pacific Northwest National Laboratory.

Trombulak, S. C. and C. Frissell, 2000, "A Review of the Ecological Effects of Roads on Terrestrial and Aquatic Ecosystems," Conservation Biology, Vol. 14, pp. 18-30.

USACE, 1995, Engineering and Design - Chemical Grouting, EM 1110-1-3500, U.S. Army Corps of Engineers, Waterways Experiment Station, Vichsburg, Mississippi, URL: http://www.usace.army.mil/inet/usace-docs/eng-manuals/em1110-1-3500/toc.htm, published January 31, 1995, Web page visited January 29, 2007.

Van Horn, R. L., N. L. Hampton, and R. C. Morris, 1995, Guidance Manual for Conducting Screening-Level Ecological Risk Assessments at the INEL, INEL-95/0190, Rev. 0, Idaho National Engineering Laboratory.

Wheldon, Nathan M., Gary J. McManus, Jeffrey A. Towers, and David J. Thorne, 2006, Short-Term Risk Assessment for the Operable Unit 7-13/14 Feasibility Study, RPT-188, Rev. 0, Idaho National Laboratory, Idaho Cleanup Project.

Wing, N. R. and G. W. Gee, 1994, "Quest for the Perfect Cap," Civil Engineering, Vol. 64, No. 10, pp. 38-41.

Wylie, A. H., 1996, Pumping Test of Pit 9 Production Well, INEL-96/171, Idaho National Engineering Laboratory.

Wylie, A. H. and J. M. Hubbell, 1994, Aquifer Testing of Wells M1S, M3S, M4D, M6S, M7S, and M10S at the Radioactive Waste Management Complex, ER-WAG7-26, Rev. 1, Idaho National Engineering Laboratory. 
Zitnik, James F., Aran T. Armstrong, Brian K. Corb, Mark H. Edens, Douglas B. Holsten, Patricia M. O'Flaherty, Janet Rodriguez, Tamara N. Thomas, Russell L. Treat, Wayne Schofield, and Kira L. Sykes, 2002, Preliminary Evaluation of Remedial Alternatives for the Subsurface Disposal Area, INEEL/EXT-02-01258, Rev. 0, prepared by CH2MHILL for the Idaho National Engineering and Environmental Laboratory. 
6-14 


\section{Appendix A}

\section{Remedial Technologies Identification and Screening}




$$
\text { A-2 }
$$




\section{CONTENTS}

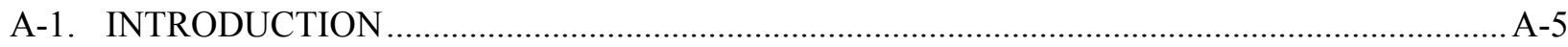

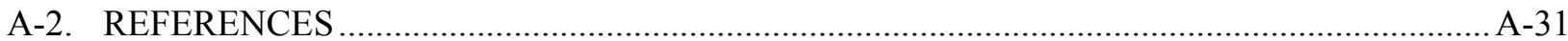

TABLES

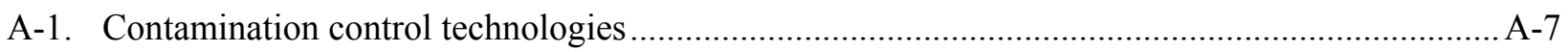

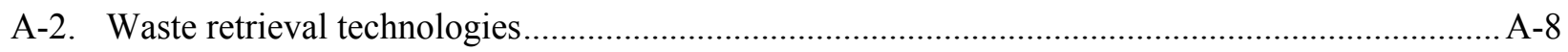

A-3. Treatment, storage, and disposal options on the Idaho National Laboratory Site ........................ A-9

A-4. Treatment, storage, and disposal options off the Idaho National Laboratory Site ..................... A-10

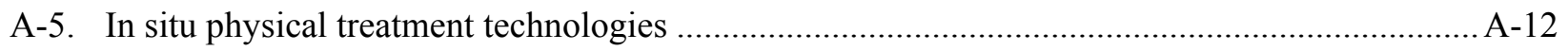

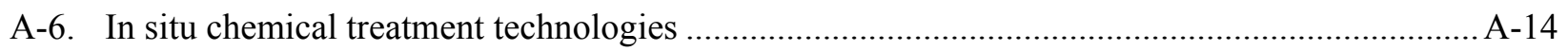

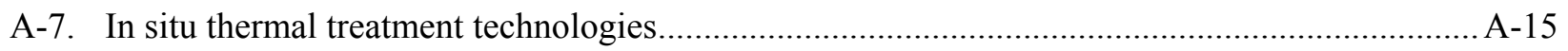

A-8. In situ biological treatment technologies............................................................................... A-17

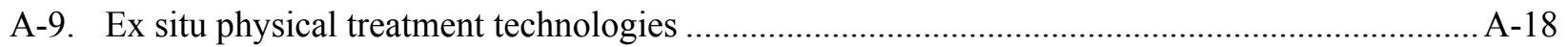

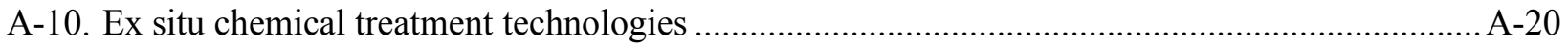

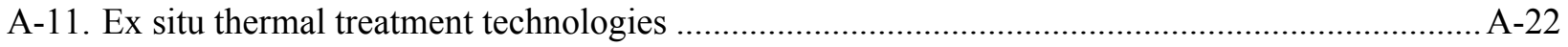

A-12. Ex situ biological treatment technologies ...............................................................................

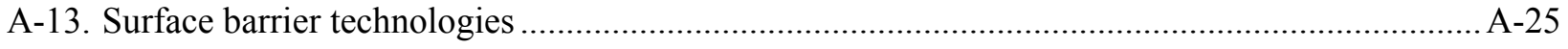

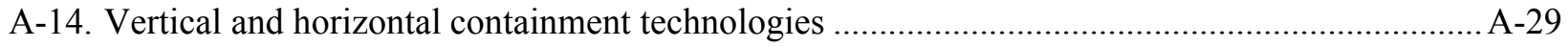




\section{Appendix A}

\section{Remedial Technologies Identification and Screening \\ A-1. INTRODUCTION}

The Feasibility Study for Operable Unit 7-13/14 identifies remedial technology types and process options that could be implemented at the Subsurface Disposal Area (SDA). Applied methodology is consistent with U.S. Environmental Protection Agency Guidance for Conducting Remedial Investigations and Feasibility Studies Under CERCLA (EPA 1988). Appendix A tabulates potential process options for 15 general technology types applicable to implementing general response actions identified in Section 2.2. Tables A-1 through A-15 briefly describe each process option, evaluate their potential effectiveness and implementability at the SDA, and assess the relative cost of construction and operation.

Section 4.1 describes criteria used for evaluations and detailed analysis of assembled alternatives. However, screening evaluations focus on effectiveness, potential impacts to human health and the environment during construction and implementation, and how proven or reliable a process is, considering site conditions. Gray shading in the tables identifies process options that are not implementable at the SDA and were not retained for further evaluation. Representative process options retained in Section 2 for development of remedial alternatives for Operable Unit (OU) 7-13/14 in Section 3 are shown in tables that follow as bolded colored text. Process options that are neither shaded nor in bolded colored text may be implementable at the SDA, but were not identified as representative process options for detailed analysis because - in comparison to other process options within the same technology - they are not applicable; are less optimal, less effective, or more costly; or would require further development.

Process options listed in Appendix A were compiled from Zitnik et al. (2002) and updated, considering the most current technology performance and site characterization data. Technology performance information was obtained from publicly available technology reviews (FRTR 2002; EPA 2003a, 2003b; CPEO 2002), vendor-provided information, site-specific preremedial design and safety analyses, and relevant information from other remedial actions, either on or off the Idaho National Laboratory (INL) Site, that share similar characteristics with the SDA. Site-specific information also was obtained from Holdren et al. (2006) and the Waste Identification and Location Database, which integrates and validates inventories and waste form descriptions (McKenzie et al. 2005). 
Table A-1. Contamination control technologies.

\begin{tabular}{|c|c|c|c|c|}
\hline Process Option & Description & Effectiveness & Implementability & Relative Cost \\
\hline Confinement & $\begin{array}{l}\text { Confinement enclosures prevent the spread of airborne } \\
\text { contaminants by surrounding or enclosing a piece of equipment, } \\
\text { decontamination pad, or an entire site. Enclosures are made of } \\
\text { plastic, metal, fiberglass, or other material. These enclosures may } \\
\text { be relatively lightweight and portable, or may be substantially } \\
\text { sturdier and less portable. Enclosures must be compatible with the } \\
\text { technologies used during remediation. }\end{array}$ & $\begin{array}{l}\text { The confinement option is effective at preventing } \\
\text { the spread of airborne contaminants during } \\
\text { retrieval operations if designed, constructed, and } \\
\text { operated correctly. }\end{array}$ & $\begin{array}{l}\text { Confinement is implementable and readily } \\
\text { available. Rigorous engineering and administrative } \\
\text { controls would be required for application at a } \\
\text { radioactive waste disposal site. A site-specific } \\
\text { enclosure may be required. }\end{array}$ & Cost depends on specific design requirements. \\
\hline $\begin{array}{l}\text { Ventilation and } \\
\text { vacuum systems }\end{array}$ & $\begin{array}{l}\text { Ventilation systems use laminar airflow at the digface of an } \\
\text { excavation and within enclosures to direct dust to high-efficiency } \\
\text { particulate air filter units. Ventilation systems would be designed } \\
\text { for site-specific conditions and may be used in conjunction with } \\
\text { other technologies to minimize the spread of airborne } \\
\text { contaminants. Vacuum systems remove loose particles from } \\
\text { equipment and structures and draw in dust and debris generated } \\
\text { during excavation. Vacuum systems, used to control dust close to } \\
\text { the vacuum, are readily available. }\end{array}$ & $\begin{array}{l}\text { This is a proven process option. It is effective at } \\
\text { controlling and directing airborne contaminants } \\
\text { and dust away from work areas if designed, } \\
\text { constructed, and operated correctly. }\end{array}$ & $\begin{array}{l}\text { This option is implementable. Rigorous } \\
\text { engineering and administrative controls would be } \\
\text { required for application at a radioactive waste } \\
\text { disposal site. Site-specific design is required. A } \\
\text { wide variety of equipment is readily available. } \\
\text { Off-gas treatability testing is required to ensure } \\
\text { compliance with remedial action objectives. }\end{array}$ & Cost is expected to be relatively low. \\
\hline $\begin{array}{l}\text { Foams, sprays, } \\
\text { misters, fixatives, } \\
\text { and washes }\end{array}$ & $\begin{array}{l}\text { These processes could be applied quickly and remotely to perform } \\
\text { a variety of functions-including controlling odors, vOCs, dust, } \\
\text { and other emissions-by creating a barrier between the work } \\
\text { surface and atmosphere, fixing loose airborne or settling } \\
\text { contamination to a surface, and decontaminating personnel, } \\
\text { atmosphere, or equipment. These processes are readily available in } \\
\text { nontoxic, nonhazardous, nonflammable, and biodegradable forms } \\
\text { and range from water to polymeric mixtures. Commonly used } \\
\text { fixatives include aerosol fogs and strippable coatings, which can be } \\
\text { used to either secure contamination or decontaminate the } \\
\text { atmosphere or equipment. Aerosol fogs are used to capture and } \\
\text { hold airborne contaminants and prevent contaminants on the } \\
\text { surface from becoming airborne. Strippable coatings can be } \\
\text { applied to clean or dirty surfaces. When applied to contaminated } \\
\text { surfaces, the coating attracts, absorbs, and chemically binds the } \\
\text { contaminants in its polymeric structure. When applied to clean } \\
\text { surfaces, the coating protects the area from contamination. Other } \\
\text { common methods of decontamination include sprays and washes, } \\
\text { which are chemicals that can be sprayed on and then wiped off. }\end{array}$ & $\begin{array}{l}\text { This is a proven process option. Foams, sprays, } \\
\text { misters, fixatives, and washers are effective at } \\
\text { controlling emissions, dust, and source material; } \\
\text { they also are effective at decontaminating } \\
\text { equipment. }\end{array}$ & $\begin{array}{l}\text { This option is implementable. Rigorous } \\
\text { engineering and administrative controls would be } \\
\text { required for application at a radioactive waste } \\
\text { disposal site. Systems are readily available, and } \\
\text { many technologies are well developed. Foams, } \\
\text { sprays, misters, fixatives, and washers can be } \\
\text { effectively applied remotely. }\end{array}$ & Cost is expected to be relatively low. \\
\hline $\begin{array}{l}\text { Electrostatically } \\
\text { charged plastic }\end{array}$ & $\begin{array}{l}\text { Electrostatically charged plastic and electrostatic curtains can be used } \\
\text { as barrier walls to minimize the spread of contamination from one } \\
\text { location to another, but do not collect dust once it becomes airborne. } \\
\text { The curtains can be used upstream of emission-filtering systems to } \\
\text { neutralize charged dust particles. Electrostatically charged plastic can } \\
\text { be used in enclosures to minimize airborne particles in dust. }\end{array}$ & $\begin{array}{l}\text { Electrostatically charged plastic is effective at } \\
\text { minimizing the spread of contamination from one } \\
\text { location to another, but not in collecting dust once it } \\
\text { becomes airborne. }\end{array}$ & $\begin{array}{l}\text { The electrostatically charged plastic option is difficult } \\
\text { to implement. Rigorous engineering and } \\
\text { administrative controls would be required for } \\
\text { application at a radioactive waste disposal site. Plastic } \\
\text { sheets would be cumbersome in an excavation and } \\
\text { would collect only dust generated near the sheet. }\end{array}$ & Cost is expected to be relatively low. \\
\hline In situ stabilization & $\begin{array}{l}\text { In situ soil stabilization controls contamination in the soil and waste } \\
\text { matrix. Portland cement grout or organic polymer could be injected } \\
\text { into waste to solidify it before retrieval. Ground freezing is another } \\
\text { stabilizing technology that could be used. }\end{array}$ & $\begin{array}{l}\text { ISG and ground freezing are effective at stabilizing } \\
\text { waste and soil in place and minimizing } \\
\text { contaminant-control requirements during retrieval } \\
\text { actions. }\end{array}$ & $\begin{array}{l}\text { In situ stabilization is implementable. Rigorous } \\
\text { engineering and administrative controls would be } \\
\text { required for application at a radioactive waste disposal } \\
\text { site. This table discusses implementability of ISG and } \\
\text { ground freezing technologies. Retrieval actions and } \\
\text { equipment must be specifically designed to address } \\
\text { removal of stabilized matrix. }\end{array}$ & $\begin{array}{l}\text { Cost varies widely, depending on the stabilization } \\
\text { technology used. }\end{array}$ \\
\hline
\end{tabular}


Table A-2. Waste retrieval technologies.

\begin{tabular}{|c|c|c|c|c|}
\hline Process Option & Description & Effectiveness & Implementability & Relative Cost \\
\hline $\begin{array}{l}\text { Standard } \\
\text { construction } \\
\text { equipment }\end{array}$ & $\begin{array}{l}\text { A variety of standard heavy construction equipment is available to } \\
\text { remove buried waste and overburden soil. Front-end loaders, } \\
\text { backhoes, and trenchers are three common types of excavation } \\
\text { equipment that have been used to remove buried hazardous waste } \\
\text { (Sykes 2002). Front-end loaders are used for digging, lifting, } \\
\text { dumping, and hauling. The backhoe is used for trench digging and } \\
\text { small area excavations and is frequently used in a backhoe and } \\
\text { front-end loader combination. Trenchers are similar to backhoes in } \\
\text { their function, but have a smaller carrying capacity and, thus, would } \\
\text { be used in smaller excavation and grading applications. Dozers are } \\
\text { used to remove soil covers. In addition, standard cranes have been } \\
\text { used to provide distance from radioactive materials during cask } \\
\text { loading (a method previously used at the INL Intermediate-Level } \\
\text { Transuranic Storage Facility). }\end{array}$ & $\begin{array}{l}\text { Standard construction equipment is effective at } \\
\text { performing material-handling tasks for which it was } \\
\text { designed, but is not effective at protecting workers } \\
\text { from airborne contaminants. In contamination areas, } \\
\text { standard equipment must be combined with other } \\
\text { protective process options. }\end{array}$ & $\begin{array}{l}\text { This option is implementable. Rigorous engineering } \\
\text { and administrative controls would be required for } \\
\text { application at a radioactive waste disposal site. A wide } \\
\text { range of equipment is readily available for the wide } \\
\text { range of tasks required. }\end{array}$ & $\begin{array}{l}\text { Capital and operating costs are expected to be low, } \\
\text { relative to other retrieval process options. }\end{array}$ \\
\hline $\begin{array}{l}\text { Standard } \\
\text { construction } \\
\text { equipment with } \\
\text { modification }\end{array}$ & $\begin{array}{l}\text { Standard equipment (e.g., front-end loaders, backhoes, and } \\
\text { trenchers) can be modified in a variety of ways to better protect } \\
\text { the operator in highly contaminated environments (Sykes 2002). } \\
\text { Modifications may include (but are not limited to) a shielded } \\
\text { cabin, a sealed and pressurized cabin with filtered air, or a sealed } \\
\text { and pressurized cabin with supplied air. Shielded excavators have } \\
\text { been used successfully (i.e., Hanford), and equipment with } \\
\text { pressurized and sealed cabs has been used successfully (with } \\
\text { supplied air at Niagara Falls and filtered air at Maralinga). The } \\
\text { Accelerated Retrieval Project has successfully used modified } \\
\text { manned excavators and telehandlers for SDA waste retrieval. } \\
\text { Modifications include (among other adaptations) shielding, } \\
\text { supplied breathing air, and filtered cab air. }\end{array}$ & $\begin{array}{l}\text { Standard construction equipment with } \\
\text { modification is effective at performing } \\
\text { material-handling tasks and also at protecting } \\
\text { workers when combined with contamination } \\
\text { control. }\end{array}$ & $\begin{array}{l}\text { This option is implementable. Rigorous } \\
\text { engineering and administrative controls would be } \\
\text { required for application at a radioactive waste } \\
\text { disposal site }\end{array}$ & $\begin{array}{l}\text { Capital and operating costs are expected to be } \\
\text { medium, relative to other retrieval process options. }\end{array}$ \\
\hline $\begin{array}{l}\text { Remote-operated } \\
\text { equipment }\end{array}$ & $\begin{array}{l}\text { Remote-operated excavators have been used to remove hazardous, } \\
\text { pyrophoric, and radioactive waste with remote controls and remote } \\
\text { end-effectors that maintain distance between the source and the } \\
\text { operator. The technology to modify standard heavy equipment is } \\
\text { available, and remote excavators have been demonstrated } \\
\text { (Sykes 2002). }\end{array}$ & $\begin{array}{l}\text { Remote-operated equipment is effective at removing } \\
\text { buried waste, as demonstrated in cold tests. However, } \\
\text { experience with this option as a digging device to } \\
\text { remove buried waste is limited. }\end{array}$ & $\begin{array}{l}\text { This option is implementable and recently has become } \\
\text { more available for purchase rather than for lease or by } \\
\text { special design. Rigorous engineering and } \\
\text { administrative controls would be required for } \\
\text { application at a radioactive waste disposal site. }\end{array}$ & $\begin{array}{l}\text { Capital and operating costs are expected to be medium } \\
\text { to high, relative to other retrieval process options. }\end{array}$ \\
\hline \multicolumn{5}{|c|}{$\begin{array}{l}\text { Note: Technology retained in Section } 2 \text { for developing assembled alternatives in Section } 3 . \\
\text { IN = Idaho National Laboratory } \\
\text { SDA = Subsurface Disposal Area }\end{array}$} \\
\hline
\end{tabular}


Table A-3. Treatment, storage, and disposal options on the Idaho National Laboratory Site

\begin{tabular}{|c|c|c|c|c|}
\hline Process Option & Description & Effectiveness & Implementability & Relative Cost \\
\hline $\begin{array}{l}\text { Temporary on-INL } \\
\text { Site storage }\end{array}$ & $\begin{array}{l}\text { Either an existing containment structure could be used or a } \\
\text { containment structure could be constructed for onsite staging and } \\
\text { storage of waste retrieved from the SDA before the waste is } \\
\text { transported to either an off- or on-INL Site facility for treatment } \\
\text { and disposal. Design would be in accordance with state and federal } \\
\text { requirements for temporary storage facilities and would be sized } \\
\text { as required to meet processing requirements. }\end{array}$ & $\begin{array}{l}\text { A structure would be designed to effectively } \\
\text { contain waste and COCs during staging between } \\
\text { retrieval and treatment or disposal. Existing SDA } \\
\text { facilities could be used for storing transuranic } \\
\text { waste and some nontransuranic waste. If large } \\
\text { quantities of nontransuranic waste or any quantity } \\
\text { of remote-handled waste requires temporary } \\
\text { storage, construction of a short-term storage } \\
\text { facility would be required. }\end{array}$ & $\begin{array}{l}\text { Temporary onsite storage is implementable. } \\
\text { Rigorous engineering and administrative controls } \\
\text { would be required for application at a radioactive } \\
\text { waste disposal site. }\end{array}$ & $\begin{array}{l}\text { Cost for using existing SDA storage facilities is } \\
\text { expected to be low. } \\
\text { Cost for constructing a new storage facility is } \\
\text { expected to be medium. } \\
\text { Cost for constructing a temporary storage facility } \\
\text { for remote-handled waste is expected to be high, } \\
\text { relative to other onsite storage options. }\end{array}$ \\
\hline $\begin{array}{l}\text { LLW Pit within the } \\
\text { SDA }\end{array}$ & $\begin{array}{l}\text { A shallow landfill that currently accepts LLW for disposal is } \\
\text { located within the SDA. The LLW Pit can receive decharacterized } \\
\text { RCRA waste on a case-by-case basis. The SDA is not permitted for } \\
\text { disposal of mixed waste. Upon arrival, waste is examined and } \\
\text { radiological surveys are performed to ensure that waste meets } \\
\text { disposal requirements. }\end{array}$ & $\begin{array}{l}\text { The LLW Pit within the SDA would be effective for } \\
\text { disposal of LLW generated during remedial } \\
\text { actions in the SDA. However, because remedial } \\
\text { actions within the SDA will be performed under } \\
\text { CERCLA, it may be appropriate to close the LLW } \\
\text { Pit under DOE Order } 435.1 \text { before relocating } \\
\text { CERCLA waste within the area of contamination. }\end{array}$ & $\begin{array}{l}\text { The LLW Pit within the SDA is implementable. } \\
\text { The landfill is currently planned to remain open } \\
\text { for disposal of contact-handled LLW until } \\
\text { September } 2008 \text { and remote-handled LLW until } \\
\text { September } 2009 \text {. As of January } 31,2006 \text {, } \\
\text { approximately } 28,000 \mathrm{~m}^{3}\left(36,600 \text { yd }{ }^{3}\right) \text { of disposal } \\
\text { capacity remained in the open pit. Future } \\
\text { availability of disposal capacity and the date for } \\
\text { final closure of the LLW Pit are uncertain; } \\
\text { however, it is likely that receipt of LLW will } \\
\text { continue beyond } 2009 \text {. }\end{array}$ & $\begin{array}{l}\text { Cost is expected to be low, relative to other disposal } \\
\text { options. }\end{array}$ \\
\hline ICDF & $\begin{array}{l}\text { The ICDF is located on the INL Site near the Idaho Nuclear } \\
\text { Technology and Engineering Center. The ICDF is permitted for } \\
\text { disposal of contaminated soil and debris resulting from INL } \\
\text { CERCLA cleanup actions. The ICDF includes a landfill, an } \\
\text { evaporation pond, a treatment facility, and an associated staging } \\
\text { and storage annex. Accepted waste forms include characteristic } \\
\text { and listed remediation waste in accordance with specified waste } \\
\text { acceptance criteria. If waste is not from within the area of } \\
\text { contamination as defined by the OU 3-13 ROD (DOE-ID 1999, } \\
\text { 2005), then the waste must meet land disposal restrictions before } \\
\text { disposal. }\end{array}$ & $\begin{array}{l}\text { The ICDF is effective for long-term disposal of } \\
\text { CERCLA waste. The facility is designed with a } \\
\text { triple liner and other features for low-level } \\
\text { radioactive waste and mixed LLW. }\end{array}$ & $\begin{array}{l}\text { The ICDF is potentially implementable for limited } \\
\text { volume of radioactive LLW and mixed waste, } \\
\text { depending on available capacity for non-Waste } \\
\text { Area Group } 3 \text { waste. Mixed LLW must be treated } \\
\text { to meet the waste acceptance criteria. Though } \\
\text { treatment at ICDF is feasible for nontransuranic } \\
\text { and Pad A waste, it has not been used for } \\
\text { treatment of radioactively contaminated waste. If } \\
\text { large quantities of radioactive waste were sent to } \\
\text { the ICDF for treatment, then treatment could be } \\
\text { challenging. The ICDF is currently operating and } \\
\text { is planned to continue operations until the year } \\
\text { 2012; however, future availability of disposal } \\
\text { capacity and date for final closure of ICDF are } \\
\text { uncertain. If ICDF is not available after 2012, it is } \\
\text { assumed that other off-SDA treatment and disposal } \\
\text { services would be available. }\end{array}$ & $\begin{array}{l}\text { Cost is expected to be low, relative to off-INL Site } \\
\text { disposal options. }\end{array}$ \\
\hline $\begin{array}{l}\text { Central Facilities } \\
\text { Area Landfill }\end{array}$ & $\begin{array}{l}\text { The Central Facilities Area Landfill is located near the Central } \\
\text { Facilities Area on the INL Site. This unlined landfill accepts } \\
\text { nonhazardous industrial waste from INL sites. }\end{array}$ & $\begin{array}{l}\text { The Central Facilities Area Landfill is effective for } \\
\text { disposal of nonhazardous industrial waste. }\end{array}$ & $\begin{array}{l}\text { The Central Facilities Area Landfill cannot accept } \\
\text { contaminated waste generated during remediation of } \\
\text { the SDA. }\end{array}$ & Not applicable. \\
\hline $\begin{array}{l}\text { New permanent INL } \\
\text { Site landfill }\end{array}$ & $\begin{array}{l}\text { A new engineered facility could be constructed within the SDA to } \\
\text { dispose of LLW and mixed LLW. The facility would be designed in } \\
\text { accordance with requirements for RCRA Subtitle C lined landfills. } \\
\text { This facility would be designed similar to the INL CERCLA Disposal } \\
\text { Facility landfill. }\end{array}$ & $\begin{array}{l}\text { An engineered on-INL Site facility is effective for } \\
\text { disposal of LLW and mixed LLW. } \\
\text { The facility is not effective for disposal of transuranic } \\
\text { waste. }\end{array}$ & $\begin{array}{l}\text { A new permanent INL Site landfill is potentially } \\
\text { implementable and uses standard construction with } \\
\text { available materials. Lead time would be required for } \\
\text { permitting, design, and construction. }\end{array}$ & $\begin{array}{l}\text { Cost for permitting and constructing a new engineered } \\
\text { disposal facility at the INL Site is highly uncertain and } \\
\text { may exceed disposal cost at facilities off the INL Site. }\end{array}$ \\
\hline \multicolumn{4}{|c|}{$\begin{array}{l}\text { Note: Technology retained in Section } 2 \text { for developing assembled alternatives in Section } 3 . \\
\text { CERCLA = Comprenensive Environmental Response, Compensation, and Liability Act } \\
(42 \text { USC } \$ 9601 \text { et sen, } 1,1980) \\
\text { COC = contaminant of concern }\end{array}$} & $\begin{array}{l}\text { ROD }=\text { record of decision } \\
\text { RWM }=\text { Radioactive Waste Management Complex } \\
\text { SDA }=\text { Subsurface Disposal Area }\end{array}$ \\
\hline
\end{tabular}


Table A-4. Treatment, storage, and disposal options off the Idaho National Laboratory Site.

\begin{tabular}{|c|c|c|c|c|}
\hline Process Option & Description & Effectiveness & Implementability & Relative Cost \\
\hline $\begin{array}{l}\text { Waste Isolation } \\
\text { Pilot Plant }\end{array}$ & $\begin{array}{l}\text { WIPP, located near Carlsbad, New Mexico, is a deep geologic } \\
\text { repository that accepts defense-generated transuranic waste for } \\
\text { disposal. Mixed transuranic waste is acceptable under specified } \\
\text { waste codes. WIPP can accept both contact-handled and } \\
\text { remote-handled transuranic waste. A public highway provides } \\
\text { access to the facility. }\end{array}$ & $\begin{array}{l}\text { The WIPP is an effective option for disposal of } \\
\text { defense-generated transuranic waste. } \\
\text { The WIPP does not accept waste that exhibits } \\
\text { RCRA characteristics of ignitability, corrosivity, } \\
\text { or reactivity. }\end{array}$ & $\begin{array}{l}\text { The WIPP is implementable. Acceptance of SDA } \\
\text { waste depends on approval of INL waste } \\
\text { characterization procedures. } \\
\text { Total capacity of WIPP is approximately } 175,600 \mathrm{~m}^{3} \\
\left(229,676 \mathrm{yd}^{3}\right) \text {. WIPP is expected to be filled to } \\
\text { capacity by the year } 2034 \text { (DOE-CBFO 2002). }\end{array}$ & $\begin{array}{l}\text { Costs for preparing transuranic waste from the } \\
\text { SDA for shipment to WIPP are expected to be } \\
\text { high. Shipping and disposal costs would be } \\
\text { incurred by WIPP and are not included in cost } \\
\text { estimates for this feasibility study. }\end{array}$ \\
\hline $\begin{array}{l}\text { Waste Control } \\
\text { Specialists, Texas }\end{array}$ & $\begin{array}{l}\text { Waste Control Specialists, located in Andrews County, Texas, is a } \\
\text { planned treatment, storage, and disposal facility that is applying for a } \\
\text { permit for treatment and disposal of radioactive LLW and mixed } \\
\text { waste under RCRA and the Toxic Substances Control Act } \\
\text { (15 USC \& } 2601 \text { et seq., 1976). The facility can accept greater than } \\
\text { Class C LLW and transuranic waste for storage and treatment. The } \\
\text { LLW permit is pending. Disposal units are RCRA-compliant, with } \\
\text { independent liner and leachate collection systems. Cells are enclosed } \\
\text { in a natural clay barrier. Rail access and a public highway are } \\
\text { available directly to the INL Site (WCS 2005). }\end{array}$ & $\begin{array}{l}\text { Waste Control Specialists would be highly effective } \\
\text { because the facility can treat incoming waste at the } \\
\text { disposal site and accept a wide range of waste. } \\
\text { Once permitted and licensed, the facility will accept } \\
\text { LLW and mixed LLW from DOE facilities across } \\
\text { the country. } \\
\text { Waste Control Specialists currently is available to } \\
\text { treat only LLW waste. transuranic waste disposal is } \\
\text { not available (WCS 2005). }\end{array}$ & $\begin{array}{l}\text { Implementability depends on approval of INL Site } \\
\text { waste characterization procedures. } \\
\text { Total capacity is approximately } 4.6 \text { million } \mathrm{m}^{3} \\
\left(6 \text { million yd } \mathrm{d}^{3}\right) \text {, which is expected to be filled by } \\
\text { year } 2042 \text { (WCS 2005). }\end{array}$ & $\begin{array}{l}\text { Cost is expected to be high, relative to other LLW } \\
\text { disposal options. }\end{array}$ \\
\hline $\begin{array}{l}\text { EnergySolutions, } \\
\text { Utah (formerly } \\
\text { Envirocare) }\end{array}$ & $\begin{array}{l}\text { EnergySolutions, located in Clive, Utah, accepts low-level } \\
\text { radioactive waste, mixed low-level radioactive waste, and } \\
\text { radioactive soil contaminated with polychlorinated biphenyls. } \\
\text { Treatment options available at the site include stabilization, } \\
\text { solidification, adsorption, reduction and oxidation, deactivation, } \\
\text { neutralization, macroencapsulation, and micreoncapsulation. A } \\
\text { public highway and rail provide access to the facility } \\
\text { (EnergySolutions 2006a). }\end{array}$ & $\begin{array}{l}\text { EnergySolutions would be highly effective } \\
\text { because it can treat incoming waste at the } \\
\text { disposal site. } \\
\text { EnergySolutions currently has } 543 \text { acres for three } \\
\text { waste disposal cells; however, as of August } 2005 \text {, } \\
\text { they have acquired an additional } 536 \text { acres to } \\
\text { expand the disposal operations, with expectations } \\
\text { of disposing of radiologically contaminated waste. } \\
\text { EnergySolutions accepts only Class A mixed } \\
\text { LLW (EnergySolutions 2006a). }\end{array}$ & $\begin{array}{l}\text { Implementability depends on approval of INL waste } \\
\text { characterization procedures. } \\
\text { EnergySolutions expects to be available for LLW } \\
\text { disposal for at least the next 20 years (until } \\
\text { approximately 2026) (EnergySolutions 2006a). }\end{array}$ & $\begin{array}{l}\text { Cost is expected to be high, relative to other } \\
\text { disposal options. }\end{array}$ \\
\hline $\begin{array}{l}\text { Nevada Test Site, } \\
\text { Nevada }\end{array}$ & $\begin{array}{l}\text { The Nevada Test Site, located in southwestern Nevada, accepts LLW } \\
\text { and mixed LLW from DOE Nevada activities and other approved } \\
\text { generators. Approved generators are generally those defined as DOE } \\
\text { sites and contractors that historically shipped waste to the Nevada } \\
\text { Test Site. A public highway provides access to the facility } \\
\text { (DOE-NV 2005). }\end{array}$ & $\begin{array}{l}\text { The Nevada Test Site is an effective option for } \\
\text { disposal of LLW and mixed LLW. } \\
\text { Waste accepted at the Nevada Test Site is required to } \\
\text { meet the waste acceptance criteria and the State of } \\
\text { Nevada land disposal requirements. Waste profiles } \\
\text { must be approved by DOE Nevada for each waste } \\
\text { stream before disposal. }\end{array}$ & $\begin{array}{l}\text { Implementability depends on approval of INL Site } \\
\text { waste characterization procedures. } \\
\text { The mixed LLW pit at the Nevada Test Site is } \\
\text { scheduled for closure by December } 1,2010 \text {, or when } \\
\text { filled, whichever comes first. } \\
\text { The current LLW pit life span is through the year } 2027 \\
\text { under DOE Environmental Management operational } \\
\text { agreement with National Nuclear Security } \\
\text { Administrtation. Capacity is not expected to be reached } \\
\text { in this lifetime and disposal operations may extend past } \\
2027 \text { with National Nuclear Security Administration } \\
\text { approval (DOE-NV 2005). }\end{array}$ & $\begin{array}{l}\text { Costs for disposal of LLW and mixed LLW at the } \\
\text { Nevada Test Site are expected to be high, relative to } \\
\text { disposal options on the INL Site. }\end{array}$ \\
\hline
\end{tabular}


Table A-4. (continued).

\begin{tabular}{|c|c|c|c|c|}
\hline Process Option & Description & Effectiveness & Implementability & Relative Cost \\
\hline $\begin{array}{l}\text { Hanford Site, } \\
\text { Washington }\end{array}$ & $\begin{array}{l}\text { The Hanford Site, located near Richland, Washington, has accepted } \\
\text { waste from the INL Site in the past at the Low-Level Waste Burial } \\
\text { Ground. Both a public highway and rail provide access to the facility. }\end{array}$ & $\begin{array}{l}\text { The Hanford Site Low-Level Burial Ground is } \\
\text { effective for disposal of low-level radioactive waste. } \\
\text { Mixed low-level radioactive waste material requires } \\
\text { treatment or segregation or both before shipment. }\end{array}$ & $\begin{array}{l}\text { The Hanford Site disposal option is implementable for } \\
\text { Idaho low-level radioactive waste only if the State of } \\
\text { Washington, EPA, and DOE resolve pending litigation } \\
\text { that currently prevents radioactive waste shipments to } \\
\text { Washington State. } \\
\text { Implementability depends on approval of INL Site } \\
\text { waste characterization procedures. } \\
\text { The Hanford Site Low-Level Burial Ground is } \\
\text { scheduled to remain open through FY } 2035 \\
\text { (69 FR 39446, 2004). }\end{array}$ & $\begin{array}{l}\text { Cost is expected to be high, relative to other LLW } \\
\text { disposal options. }\end{array}$ \\
\hline $\begin{array}{l}\text { US Ecology, } \\
\text { Washington }\end{array}$ & $\begin{array}{l}\text { US Ecology, located near Richland, Washington, is a } 100 \text {-acre } \\
\text { commercial facility that accepts LLW for disposal in shallow } \\
\text { trenches. Since } 1993 \text {, the site has been the regional commercial LLW } \\
\text { disposal site for } 11 \text { western states (northwest and Rocky Mountain } \\
\text { compact states). A public highway provides access to the facility } \\
\text { (State of Washington 2005). }\end{array}$ & $\begin{array}{l}\text { US Ecology is effective for disposal of low-level } \\
\text { radioactive waste. } \\
\text { Mixed LLW is not accepted, and treatment is } \\
\text { unavailable at US Ecology (State of Washington } \\
\text { 2005). }\end{array}$ & 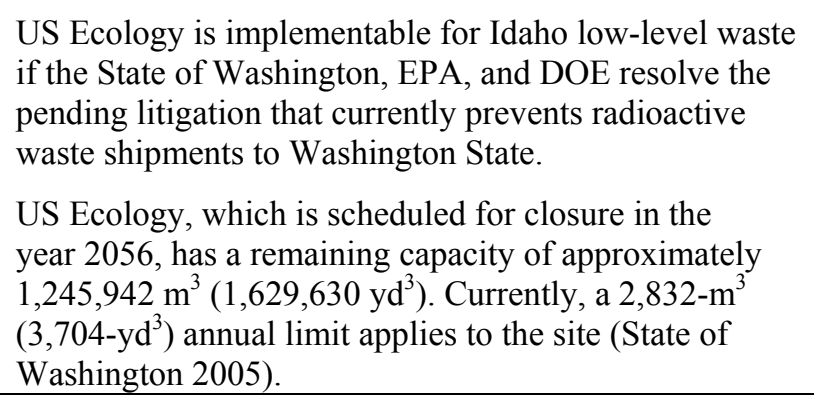 & $\begin{array}{l}\text { Cost is expected to be high, relative to other LLW } \\
\text { disposal options. }\end{array}$ \\
\hline $\begin{array}{l}\text { Barnwell Waste } \\
\text { Management } \\
\text { Facility, South } \\
\text { Carolina }\end{array}$ & $\begin{array}{l}\text { The Barnwell Waste Management Facility, located near } \\
\text { Barnwell, South Carolina, is a } 235 \text {-acre commercial operation that } \\
\text { accepts LLW. Site disposal consists of shallow land burial in concrete } \\
\text { vaults located in engineered earthen trenches. A public highway } \\
\text { provides access to the facility (DHEC 2005). }\end{array}$ & $\begin{array}{l}\text { The Barnwell Waste Management Facility is } \\
\text { moderately effective due to concrete vault } \\
\text { containment before direct burial. } \\
\text { Mixed LLW is not accepted, and treatment is } \\
\text { unavailable at the facility. } \\
\text { Stabilization requirements apply to disposal of all } \\
\text { LLW types. Treatment is unavailable } \\
\text { (EnergySolutions 2006b). }\end{array}$ & $\begin{array}{l}\text { In } 2000 \text {, South Carolina passed a law limiting annual } \\
\text { volume of waste accepted at Barnwell from any } \\
\text { generator through June } 30,2008 \text {. Limits are based on a } \\
\text { declining annual volume of } 2,265 \mathrm{~m}^{3}\left(2,963 \mathrm{yd}^{3}\right) \text { in } \\
2002 \text { to } 991 \mathrm{~m}^{3}\left(1,296 \mathrm{yd}^{3}\right) \text { in } 2008 \text {. After } \\
\text { June } 30,2008 \text {, only waste generated by the Atlantic } \\
\text { Compact Region will be accepted for disposal at } \\
\text { Barnwell (DHEC 2005; EnergySolutions 2006b). }\end{array}$ & $\begin{array}{l}\text { Cost is expected to be high, relative to other LLW } \\
\text { disposal options. }\end{array}$ \\
\hline $\begin{array}{l}\text { Note: Technology retai } \\
\text { DOE = U.S. Departmen } \\
\text { EPA = U.S. Environmer } \\
\text { FY = fiscal year } \\
\text { INL = Idaho National L } \\
\text { LLW = low-level waste } \\
\text { RCRA = Resource Cons } \\
\text { SDA = Subsurface Disp } \\
\text { WIPP = Waste Isolation }\end{array}$ & $\begin{array}{l}\text { in Section } 2 \text { for developing assembled alternatives in Section } 3 . \\
\text { Energy } \\
\text { rotection Agency } \\
\text { tory } \\
\text { tion and Recovery Act (42 USC } \$ 6901 \text { et seq., 1976) } \\
\text { Area } \\
\text { tPlant }\end{array}$ & & & \\
\hline
\end{tabular}


Table A-5. In situ physical treatment technologies.

\begin{tabular}{|c|c|c|c|c|}
\hline Process Option & Description & Effectiveness & Implementability & Relative Cost \\
\hline $\begin{array}{l}\text { Soil-vapor } \\
\text { extraction }\end{array}$ & $\begin{array}{l}\text { Soil-vapor extraction consists of an array of extraction wells, } \\
\text { screened within the zone of contamination, that are equipped with } \\
\text { an extraction pump that can pull enough air to maintain a vacuum } \\
\text { within the zone of influence (FRTR 2002; Freeman and } \\
\text { Harris } 1995 \text { ). Soil gas is pulled off and directed into a process } \\
\text { train, which treats the gas before emission to the atmosphere, as } \\
\text { required to meet emission control requirements. The system can be } \\
\text { run intermittently (pulsed) after the extracted mass-removal rate } \\
\text { has leveled off. Pulsed operation can increase the effectiveness of } \\
\text { the process. Vertical extraction wells typically are used at depths } \\
\text { of } 1.52 \mathrm{~m}(5 \mathrm{ft}) \text { or greater and have been applied successfully as } \\
\text { deep as } 91.4 \mathrm{~m}(300 \mathrm{ft}) \text {. }\end{array}$ & $\begin{array}{l}\text { Soil-vapor extraction is a presumptive remedy } \\
\text { at superfund sites with halogenated } \\
\text { vOC contaminated soil. Soil-vapor extraction } \\
\text { potentially is effective at reducing volatile and } \\
\text { semivolatile organic contaminants in the source } \\
\text { term within the SDA. It preferentially removes } \\
\text { materials from high-permeability zones, but can be } \\
\text { pulse-operated to allow diffusion to increase } \\
\text { removal. Soil-vapor extraction is not effective for } \\
\text { nonvolatilie organics, most inorganics, and } \\
\text { radionuclides. Soil-vapor extraction addresses only } \\
\text { volatile and some semivolatile contaminants and } \\
\text { may enhance biodegradation of low-volatility } \\
\text { organic compounds. A geosynthetic material may } \\
\text { be required over the surface of the area being } \\
\text { remediated to prevent short circuiting } \\
\text { (breakthrough at the ground surface). Soil with a } \\
\text { high percentage of fines and a high saturation level } \\
\text { would require higher vacuum rates or would } \\
\text { hinder operation of the process. Soil-vapor } \\
\text { extraction in soil with highly variable } \\
\text { permeabilities may induce uneven gas flow, } \\
\text { reducing effectiveness in the lower permeability } \\
\text { areas. } \\
\text { Soil-vapor extraction is not effective for buried, } \\
\text { containerized waste. Soil-vapor extraction in the } \\
\text { SDA may require preconditioning of the source } \\
\text { term to breach intact containers. }\end{array}$ & $\begin{array}{l}\text { Soil-vapor extraction is implementable. Rigorous } \\
\text { engineering and administrative controls would be } \\
\text { required for application at a radioactive waste } \\
\text { disposal site. A soil-vapor extraction system } \\
\text { currently is operating at the site in the underlying } \\
\text { vadose zone soil. }\end{array}$ & $\begin{array}{l}\text { Capital and operating costs are expected to be low, } \\
\text { relative to other in situ treatment options. }\end{array}$ \\
\hline $\begin{array}{l}\text { Low-pressure } \\
\text { permeation grouting }\end{array}$ & $\begin{array}{l}\text { Permeation grouting can be used to solidify waste in situ. Permeation } \\
\text { grouting reduces hydraulic conductivity through the waste } \\
\text { (Karol 2003; EPA 1998, 2003a; CPEO 2002), and may retard diffusion } \\
\text { of some COCs from the grout matrix. Grouts suitable for permeation } \\
\text { grouting, such as thermoset chemical grouts (e.g., polyacrylamide), } \\
\text { colloidal silica, and ultrafine cement, have low viscosity at the time of } \\
\text { emplacement (Kalb et al. 1997; USACE 1995). The grout is injected at } \\
\text { low pressure and permeates the waste and surrounding soil. } \\
\text { Subsequent setting of the grout yields a solidified monolith of waste } \\
\text { and interstitial soil in a grout matrix. Grout performance for specific } \\
\text { waste forms is usually determined during the feasibility study or } \\
\text { remedial design phase. }\end{array}$ & $\begin{array}{l}\text { Permeation grouting has been effective for in situ } \\
\text { stabilization of some buried waste. However, } \\
\text { chemical grouts have limited permanence, restricting } \\
\text { their use to mitigation of near-term contaminant } \\
\text { migration. Ultrafine cementitious grouts provide } \\
\text { longer-term durability; however, their effectiveness is } \\
\text { limitited by soil impermeability to particulate grouts. } \\
\text { Permeation grouting, using a microfine cementitious } \\
\text { grout, has been ineffective for stabilization of } \\
\text { simulated INL Site buried waste (Loomis and } \\
\text { Low 1988). }\end{array}$ & $\begin{array}{l}\text { Permeation grouting for in situ stabilization of buried } \\
\text { waste is technically implementable; however, grouts } \\
\text { suitable for emplacement using low-pressure } \\
\text { permeation methods are not suitable for long-term } \\
\text { stabilization of waste at the SDA. Rigorous } \\
\text { engineering and administrative controls would be } \\
\text { required for application at a radioactive waste disposal } \\
\text { site. }\end{array}$ & $\begin{array}{l}\text { Capital and operating costs are expected to be low to } \\
\text { medium relative to other in situ treatment options. }\end{array}$ \\
\hline
\end{tabular}


Table A-5. (continued).

\begin{tabular}{|c|c|c|c|c|}
\hline Process Option & Description & Effectiveness & Implementability & Relative Cost \\
\hline $\begin{array}{l}\text { High-pressure jet } \\
\text { grouting }\end{array}$ & $\begin{array}{l}\text { High-pressure ISG uses the energy of a high-pressure grout jet to } \\
\text { disrupt buried waste and mix it into an impermeable waste form } \\
\text { (FRTR 2002; CPEO 2002; Kalb et al. 1997; Armstrong, Arrenholz, } \\
\text { and Weidner 2002). Because the waste, interstitial soill, and grout } \\
\text { are physically mixed, effectiveness of ISG is not limited by } \\
\text { variations in soil permeability. Jet grouting pumps and drill rigs } \\
\text { used in conventional civil engineering practice are readily } \\
\text { adaptable for emplacing thermoplastic (e.g., paraffin-based) or } \\
\text { cementitious grouts suitable for in situ stabilization. Grout } \\
\text { performance for specific waste forms is usually determined during } \\
\text { the feasibility study or remedial design phase. Selection criteria } \\
\text { and recommendations have been developed for grouts suitable for } \\
\text { in situ waste stabilization within the SDA (Shaw 2004a, 2004b; } \\
\text { Matthern et al. 2005). } \\
\text { For the purpose of contaminant immobilization, it is assumed that } \\
\text { ISG in the SDA will be focused on those waste forms determined to } \\
\text { pose an unacceptable human health risk by contaminant release by } \\
\text { the surface wash mechanism (Holdren et al. 2006; Holdren and } \\
\text { Broomfield 2004). }\end{array}$ & $\begin{array}{l}\text { High-pressure ISG has been demonstrated to be } \\
\text { effective for in situ stabilization of heterogeneous } \\
\text { buried waste in SDA soil (Loomis, Zdinak, and } \\
\text { Bishop 1997; Loomis et al. 2003). Hydraulic } \\
\text { conductivity of simulated waste stabilized by } \\
\text { high-pressure ISG was more than two orders of } \\
\text { magnitude less than for unstabilized waste and is } \\
\text { comparable to permeability criteria for engineered } \\
\text { clay liners used in construction of hazardous waste } \\
\text { landfills (EPA 1989). Cementitious grouts, both } \\
\text { commercially available and nonproprietary, and a } \\
\text { paraffin-based thermoplastic grout have been } \\
\text { evaluated for stabilization of several SDA waste } \\
\text { forms containing transuranic isotopes or } \\
\text { radionuclides resulting from nuclear fission and } \\
\text { activation (Matthern et al. 2005). Chemical } \\
\text { buffering provided by cementitious grouts may } \\
\text { reduce the solubility of some radionuclides. } \\
\text { Interactions between waste forms and grouts were } \\
\text { evaluated to avoid incompatibilities that might } \\
\text { compromise grout performance. Evaluations of } \\
\text { long-term durability of paraffin-based and } \\
\text { cementitious grouts suggest that they should be } \\
\text { effective for in situ stabilization of SDA waste for } \\
\text { at least } 1,000 \text { years (Hanson et al. 2004) and } \\
\text { 10,000 years (Hanson et al. 2005), respectively. }\end{array}$ & $\begin{array}{l}\text { High-pressure ISG for waste stabilization is } \\
\text { technically implementable at the SDA. Rigorous } \\
\text { engineering and administrative controls would be } \\
\text { required for application at a radioactive waste } \\
\text { disposal site. A preliminary documented safety } \\
\text { analysis of high-pressure ISG for use in the SDA } \\
\text { concluded that ISG could be safely implemented in } \\
\text { the SDA with no additional technical safety } \\
\text { requirements beyond those required for the } \\
\text { pressurized subsystems of the grout injection rig } \\
\text { (Abbott and Santee 2004). High-pressure iSG } \\
\text { using paraffin-based grout subsequently was } \\
\text { shown to be implementable in the SDA during the } \\
\text { Early Actions Beryllium Encapsulation Project } \\
\text { (Lopez et al. 2005; Shropshire 2004). } \\
\text { Cement-based grouts may not be applicable to in } \\
\text { situ treatment of some waste forms in the SDA } \\
\text { (e.g., Series 743 organic sludge, nitrate salts, and } \\
\text { uranium-containing roaster oxides). }\end{array}$ & $\begin{array}{l}\text { Capital and operating costs are expected to be low } \\
\text { to medium relative to other in situ treatment } \\
\text { options. }\end{array}$ \\
\hline $\begin{array}{l}\text { Enhanced soil } \\
\text { mixing }\end{array}$ & $\begin{array}{l}\text { In situ enhanced soil mixing uses a crane-suspended auger to disrupt } \\
\text { contaminated soil and mix soil with reagents for in situ treatment } \\
\text { (FRTR 2002; EPA 2003a; CPEO 2002; Kalb et al. 1997). In situ soil } \\
\text { mixing has been used for in situ stabilization of contaminated soil } \\
\text { using cementitious grout. It also has been used to improve in situ vapor } \\
\text { extraction and in situ chemical oxidation. }\end{array}$ & $\begin{array}{l}\text { In situ enhanced soil mixing has been proved effective } \\
\text { at sites where contaminants are associated with } \\
\text { fine-grained soil but is not applicable to use at sites } \\
\text { (e.g., SDA) that contain highly contaminated } \\
\text { heterogeneous debris, large metal objects, or cement } \\
\text { stabilized waste forms. }\end{array}$ & $\begin{array}{l}\text { Enhanced soil mixing is not technically } \\
\text { implementable at the SDA. }\end{array}$ & $\begin{array}{l}\text { Capital and operating costs are expected to be } \\
\text { medium relative to other in situ treatment options. }\end{array}$ \\
\hline $\begin{array}{l}\text { Note: Technology retai } \\
C O C=\text { contaminant of } c \\
\text { INL = Idaho National L: } \\
\text { ISG }=\text { in situ grouting } \\
\text { SDA = Subsurface Disn }\end{array}$ & $\begin{array}{l}\text { in Section } 2 \text { for developing assembled alternatives in Section } 3 . \\
\text { eern }\end{array}$ & & & \\
\hline
\end{tabular}


Table A-6. In situ chemical treatment technologies.

\begin{tabular}{|c|c|c|c|c|}
\hline Process Option & Description & Effectiveness & Implementability & Relative Cost \\
\hline In situ soil flushing & $\begin{array}{l}\text { Because of difficulties in solution recovery, extracting contaminants by } \\
\text { flushing soil or debris with aqueous solutions is performed most } \\
\text { commonly ex situ (Freeman and Harris 1995; FRTR 2002; } \\
\text { EPA 2003b; CPEO 2002). For in situ applications, flushing solutions } \\
\text { are removed using extraction wells or subsurface drains. Soil flushing } \\
\text { solutions can incorporate miscible organic solvents for removal of both } \\
\text { organic and inorganic contaminants. }\end{array}$ & $\begin{array}{l}\text { Though soil flushing is effective for contaminant } \\
\text { removal in ex situ applications, it is not effective for } \\
\text { in situ treatment of waste buried in the SDA. The } \\
\text { heterogeneous nature of the waste and the uneven } \\
\text { surface of the underlying basalt make it extremely } \\
\text { difficult to recover the flushing solutions. } \\
\text { Unrecovered solutions might penetrate through the } \\
\text { basalt and into the underlying vadose zone. } \\
\text { Furthermore, a significant portion of target } \\
\text { contaminants may be in intact containers and not } \\
\text { available to flushing solutions. }\end{array}$ & $\begin{array}{l}\text { In situ soil flushing is not technically implementable } \\
\text { at the SDA. }\end{array}$ & $\begin{array}{l}\text { Capital and operating costs are expected to be } \\
\text { medium relative to other in situ treatment options. }\end{array}$ \\
\hline $\begin{array}{l}\text { In situ chemical } \\
\text { leaching }\end{array}$ & $\begin{array}{l}\text { Because of difficulties in solution recovery, extracting contaminants by } \\
\text { chemical leaching is performed most commonly ex situ (CPEO 2002). } \\
\text { For in situ applications, leach solutions are removed using extraction } \\
\text { wells or subsurface drains. }\end{array}$ & $\begin{array}{l}\text { Though chemical leaching is effective for } \\
\text { contaminant removal in ex situ applications, it is not } \\
\text { effective for in situ treatment of waste buried in the } \\
\text { SDA. The heterogeneous nature of the waste and the } \\
\text { uneven surface of the underlying basalt make it } \\
\text { extremely difficult to recover the leaching solutions. } \\
\text { Unrecovered solutions might penetrate through the } \\
\text { basalt and into the underlying vadose zone. } \\
\text { Furthermore, a significant portion of target } \\
\text { contaminants may be in intact containers and not } \\
\text { available to leaching solutions. }\end{array}$ & $\begin{array}{l}\text { In situ chemical leaching is not technically } \\
\text { implementable at the SDA. }\end{array}$ & $\begin{array}{l}\text { Capital and operating costs are expected to be } \\
\text { medium relative to other in situ treatment options. }\end{array}$ \\
\hline In situ hydrolysis & $\begin{array}{l}\text { Some volatile organic compounds spontaneously degrade in the } \\
\text { presence of water (McBride 1994). Hydrolysis rates can be increased } \\
\text { by raising soil temperature, adding chemical reactants, or adding } \\
\text { nutrients to increase native biological activity. This process is a } \\
\text { component of in situ thermal desorption, in situ reduction-oxidation } \\
\text { manipulation, and in situ biologic treatment and not a unique process } \\
\text { option. In situ hydrolysis also could affect the mobility of inorganic } \\
\text { contaminants. }\end{array}$ & Not applicable. & Not applicable. & Not applicable. \\
\hline $\begin{array}{l}\text { In situ } \\
\text { reduction-oxidation } \\
\text { manipulation }\end{array}$ & $\begin{array}{l}\text { In situ reduction-oxidation manipulation involves injecting chemical } \\
\text { reactants into the subsurface or waste zone to (a) oxidize organic } \\
\text { contaminants or (b) reduce toxic metals to less soluble chemical } \\
\text { compounds (FRTR 2002; EPA 2003a; CPEO 2002). Reagents for } \\
\text { in situ reduction-oxidation manipulation (e.g., hydrogen sulfide, iron } \\
\text { particles, and potassium permanganate) are injected into the subsurface } \\
\text { as gas, solution, or liquid suspension, or in combination with grouts } \\
\text { used for waste stabilization. }\end{array}$ & $\begin{array}{l}\text { In situ reduction-oxidation manipulation is potentially } \\
\text { effective for treating contaminants in soil, but is not } \\
\text { effective for near-term treatment of waste in intact } \\
\text { containers. Furthermore, little information is available } \\
\text { on the long-term performance of in situ treatments } \\
\text { that immobilize toxic metals (e.g., Tc-99) by } \\
\text { providing a reducing environment (Kaback, Fogwell, } \\
\text { and Peterson 2005; Szecsody et al. 2005). }\end{array}$ & $\begin{array}{l}\text { In situ reduction-oxidation manipulation is not a } \\
\text { mature in situ treatment method for heterogeneous } \\
\text { buried waste and would not be implementable at the } \\
\text { SDA without further development. }\end{array}$ & $\begin{array}{l}\text { Capital and operating costs are expected to be } \\
\text { medium relative to other in situ treatment options. }\end{array}$ \\
\hline $\begin{array}{l}\text { In situ electrokinetic } \\
\text { remediation }\end{array}$ & $\begin{array}{l}\text { Electrokinetic remediation is used to remove inorganic cations from } \\
\text { contaminated soil (FRTR 2002; EPA 2003b; CPEO 2002). A low-level } \\
\text { direct current is applied to the contamination zone using fluid-filled } \\
\text { electrodes. Ionic species, including heavy metal contaminants, migrate } \\
\text { within the soil matrix and are collected in the electrolytes within the } \\
\text { electrodes. }\end{array}$ & $\begin{array}{l}\text { Though in situ electrokinetic remediation has proved } \\
\text { effective in fine-grained soil, it has not been } \\
\text { demonstrated at a buried waste site containing large } \\
\text { amounts of metallic waste. Furthermore, its ability to } \\
\text { maintain adequate current densities without adding } \\
\text { water to the unsaturated soil has not been } \\
\text { demonstrated. }\end{array}$ & $\begin{array}{l}\text { In situ electrokinetic remediation is not a mature in } \\
\text { situ treatment method for heterogeneous buried waste } \\
\text { and would not be implementable at the SDA without } \\
\text { further development. }\end{array}$ & $\begin{array}{l}\text { Capital and operating costs are expected to be } \\
\text { moderate relative to other in situ treatment proces: } \\
\text { options. }\end{array}$ \\
\hline
\end{tabular}


Table A-7. In situ thermal treatment technologies.

\begin{tabular}{|c|c|c|c|c|}
\hline Process Option & Description & Effectiveness & Implementability & Relative Cost \\
\hline $\begin{array}{l}\text { In situ thermal } \\
\text { desorption by in situ } \\
\text { radiant heating }\end{array}$ & $\begin{array}{l}\text { In situ thermal desorption by radiant or conduction (Stegemeier and } \\
\text { Vinegar 2001) heating improves removal of buried organic waste by } \\
\text { applying heat and vacuum (FRTR 2002; EPA 2003a; CPEO 2002). } \\
\text { Encased radiant heater wells are installed through contaminated waste } \\
\text { and soil. Heated extraction wells are installed throughout the waste } \\
\text { volume, and a slight tacuum is applied to extract soil vapors. When the } \\
\text { heaters are energized, organic contaminants are (a) hydrolyzed by } \\
\text { interstitial water, (b) boiled-off with interstitial water, or (c) pyrolyzed } \\
\text { if the waste and interstitial soil are heated to a sufficiently high } \\
\text { temperature. Temperatures immediately adjacent to heated extraction } \\
\text { wells are sufficient to pyrolyze most organic materials. Depending on } \\
\text { the spacing of heater wells, it can take several months for the entire } \\
\text { waste zone to reach temperatures sufficient to destroy semivolatile } \\
\text { organic compounds, heavy hydrocarbons (e.g., machine oil in Rocky } \\
\text { Flats Plant Series } 743 \text { sludge), or combustibles. Organic vapors that are } \\
\text { not destroyed in situ are collected by the extraction wells and } \\
\text { transported to an off-gas treatment system. }\end{array}$ & $\begin{array}{l}\text { In situ thermal desorption by radiant heating is } \\
\text { effective for removing volatile organic compounds } \\
\text { from heterogeneous waste buried in the SDA. It also } \\
\text { is effective for in situ destruction of semivolatile } \\
\text { organic compounds, heavy hydrocarbons } \\
\text { (e.g., machine oil in Rocky Flats Plant Series } 743 \\
\text { sludge), and combustibles. }\end{array}$ & $\begin{array}{l}\text { In situ thermal desorption is not technically } \\
\text { implementable at the SDA. Rigorous engineering and } \\
\text { administrative controls would be required for } \\
\text { application at a radioactive waste disposal site. A } \\
\text { failure assessment in an EPA site demonstration } \\
\text { report (EPA 2004) for deploying in situ thermal } \\
\text { desorption at a site similar to the SDA raised concerns } \\
\text { that acid gas resulting from destruction of chlorinated } \\
\text { hydrocarbons might make it impossible to maintain } \\
\text { vapor extraction wells, collection manifoldss, and } \\
\text { off-gas treatment system components. Failure of the } \\
\text { off-gas treatment system would pose unacceptable } \\
\text { health risk to collocated workers (Abbott 2003). In } \\
\text { addition, bench-scale and field studies using surrogate } \\
\text { waste similar to that buried in the SDA suggest that } \\
\text { uncontrollable reactions may occur between nitrate } \\
\text { salts (i.e., Rocky Flats Plant Series } 745 \text { evaporator } \\
\text { salts) and pyrolyzed organic waste (e.g., Rocky Flats } \\
\text { Plant combustible waste) (Matthern et al. 2005). } \\
\text { These reactions are most likely to initiate immediately } \\
\text { adjacent to heater wells, but may spread into the } \\
\text { surrounding waste (Evans 2003). }\end{array}$ & $\begin{array}{l}\text { Capital and operating costs are expected to be high, } \\
\text { relative to other in situ treatment options. }\end{array}$ \\
\hline $\begin{array}{l}\text { In situ thermal } \\
\text { desorption by in situ } \\
\text { gas-phase heating } \\
\text { (e.g., steam } \\
\text { injection, dynamic } \\
\text { underground } \\
\text { stripping, and hot air } \\
\text { injection) }\end{array}$ & $\begin{array}{l}\text { In situ thermal desorption by gas-phase heating improves removal of } \\
\text { buried organic waste by injecting hot gas directly into the } \\
\text { contaminated media (FRTR 2002; EPA 2003a; CPEO 2002). Waste } \\
\text { heating by injecting steam or hot air has been deployed successfully at } \\
\text { several contaminated soil sites. Organic contaminants are } \\
\text { (a) hydrolyzed by interstitial water or (b) boiled-off with interstitial } \\
\text { water. Though the waste matrix may reach temperatures sufficient to } \\
\text { melt plastics, these methods are not applicable to heating soil to } \\
\text { temperatures sufficient to destroy semivolatile organic compounds, } \\
\text { heavy hydrocarbons (e.g., machine oil in Rocky Flats Plant Series } 743 \\
\text { sludge), or combustibles. Volatile soil vapors are removed using } \\
\text { extraction wells and transported to an off-gas treatment system. }\end{array}$ & $\begin{array}{l}\text { In situ thermal desorption by in situ heating using } \\
\text { steam or hot air is effective for removing some } \\
\text { volatile organic compounds from heterogeneous waste } \\
\text { buried in the SDA. However, waste matrix } \\
\text { temperatures in some areas may not be sufficient to } \\
\text { degrade polyethylene bags enclosing Rocky Flats } \\
\text { Plant Series } 743 \text { sludge that did not rupture at the time } \\
\text { of disposal. If these bags remain intact, they may } \\
\text { provide a diffusion barrier that would limit the rate of } \\
\text { volatile organic compound removal, thus prolonging } \\
\text { treatment. This in situ thermal desorption process } \\
\text { option would be ineffective for heating buried waste } \\
\text { to temperatures sufficient for in situ destruction of } \\
\text { semivolatile organic compounds, heavy hydrocarbons } \\
\text { (e.g., machine oil in Rocky Flats Plant Series } 743 \\
\text { sludge), or combustibles. Incomplete destruction of } \\
\text { organic contaminants in situ may place an increased } \\
\text { load on the off-gas treatment system. }\end{array}$ & $\begin{array}{l}\text { This in situ thermal desorption process option would } \\
\text { not be implementable at the SDA without further } \\
\text { development. Rigorous engineering and } \\
\text { administrative controls would be required for } \\
\text { application at a radioactive waste disposal site. } \\
\text { Temperatures achieved from heating with steam or } \\
\text { hot air would not decompose chlorinated } \\
\text { hydrocarbons, reducing corrosion in extraction wells } \\
\text { and collection manifolds. }\end{array}$ & $\begin{array}{l}\text { Capital and operating costs are expected to be high, } \\
\text { relative to other in situ treatment options. }\end{array}$ \\
\hline
\end{tabular}


Table A-7. (continued).

\begin{tabular}{|c|c|c|c|c|}
\hline Process Option & Description & Effectiveness & Implementability & Relative Cost \\
\hline $\begin{array}{l}\text { In situ thermal } \\
\text { desorption by } \\
\text { induction or Joule } \\
\text { heating } \\
\text { (e.g., microwave, } \\
\text { radio frequency, } \\
\text { six-phase heating, } \\
\text { and electrical } \\
\text { resistance heating) }\end{array}$ & $\begin{array}{l}\text { In situ thermal desorption by induction or Joule heating improves the } \\
\text { removal of buried organic waste by adding heat using microwave or } \\
\text { radio frequency radiation, or by passing an electrical current directly } \\
\text { through the waste matrix (FRTR } 2002 \text {; EPA } 2003 a \text {; CPEO } 2002 \text { ). } \\
\text { Resistance to induced or applied electric currents results in direct } \\
\text { heating of the waste matrix and interstitial soil. Organic contaminants } \\
\text { are (a) hydrolyzed by interstitial water or (b) boiled-off with interstitial } \\
\text { water. While the waste matrix may reach temperatures sufficient to } \\
\text { melt plastics, these methods are not applicable to heating soil to } \\
\text { temperatures sufficient to destroy semivolatile organic compounds, } \\
\text { heavy hydrocarbons (e.g., machine oil in Rocky Flats Plant Series } 743 \\
\text { sludge), or combustibles. Volatile soil vapors are removed using } \\
\text { extraction wells and transported to an off-gas treatment system. }\end{array}$ & $\begin{array}{l}\text { In situ thermal desorption by induction or joule } \\
\text { heating is effective for removing some volatile } \\
\text { organic compounds from heterogeneous waste buried } \\
\text { in the SDA. However, waste matrix temperatures in } \\
\text { most areas may not be sufficient to degrade } \\
\text { polyethylene bags enclosing Rocky Flats Plant } \\
\text { Series } 743 \text { sludge that did not rupture at the time of } \\
\text { disposal. If these bags remain intact, they may provide } \\
\text { a diffusion barrier that would limit the rate of volatile } \\
\text { organic compound removal, prolonging treatment. } \\
\text { This in situ thermal desorption process option would } \\
\text { not be effective for heating buried waste to } \\
\text { temperatures sufficient for in situ destruction of } \\
\text { semivolatile organic compounds, heavy hydrocarbons } \\
\text { (e.g., machine oil in Rocky Flats Plant Series } 743 \\
\text { sludge), or combustible materials. Incomplete } \\
\text { destruction of organic contaminants in situ may place } \\
\text { an increased load on the off-gas treatment system. }\end{array}$ & $\begin{array}{l}\text { This in situ thermal desorption process option would } \\
\text { not be implementable at the SDA without further } \\
\text { development. Rigorous engineering and } \\
\text { administrative controls would be required for } \\
\text { application at a radioactive waste disposal site. Large } \\
\text { amounts of buried metal debris may increase waste } \\
\text { conductivity, reducing effective heating rates. } \\
\text { Furthermore, currents induced in or passed through } \\
\text { metal debris could result in electrical arcs that could } \\
\text { initiate reactions between incompatible waste types } \\
\text { (e.g., Rocky Flats Plant Series } 745 \text { nitrate salts and } \\
\text { organic waste). Temperatures normally achieved } \\
\text { during in situ thermal desorption using inductive or } \\
\text { Joule heating would not destroy chlorinated } \\
\text { hydrocarbons completely, reducing the risk of } \\
\text { corrosion in extraction wells and collection manifolds. }\end{array}$ & $\begin{array}{l}\text { Capital and operating costs are expected to be high, } \\
\text { relative to other in situ treatment options. }\end{array}$ \\
\hline In situ vitrification & $\begin{array}{l}\text { In situ vitrification uses heat to destroy organic waste and melt the } \\
\text { remaining inorganic residues and interstitial soil into a waste form that } \\
\text { resembles volcanic glass (FRTR 2002; EPA 2003a; CPEO 2002; } \\
\text { Thomas and Treat 2002 Kalb et al. 1997). Electric current is passed } \\
\text { through the buried waste and interstitial soil using carbon electrodes } \\
\text { inserted directly through the overburden. Additional soil must be added } \\
\text { during the in situ vitrification process to maintain the overburden, } \\
\text { because waste volume reductions of approximately } 60 \% \text { are commonly } \\
\text { observed. Process vapors and off-gases are collected using an } \\
\text { abovegrade hood and then treated to remove hazardous or radioactive } \\
\text { material. In situ vitrification treatment areas can be as large as } 13.7 \mathrm{~m} \\
\text { (45 ft) in diameter. Larger areas can be treated by intersecting several } \\
\text { in situ vitrification melts. }\end{array}$ & $\begin{array}{l}\text { In situ vitrification is effective for destroying organic } \\
\text { waste and stabilizing most metal oxides, including } \\
\text { transuranic contaminants, in a durable glass ceramic } \\
\text { waste form. However, contaminants in activated metal } \\
\text { components (i.e., C-14 and Tc-99) may partition into } \\
\text { a separate metal phase that may not be as resistant to } \\
\text { corrosion as the in situ vitrification glass, or even the } \\
\text { original untreated metal components. In addition, } \\
\text { some fission and activation products (i.e., C-14, I-129, } \\
\text { and Tc-99) may volatilize at the in situ vitrification } \\
\text { melt front, recondense in adjacent soil, and remain } \\
\text { available for immediate release to infiltrating surface } \\
\text { water. }\end{array}$ & $\begin{array}{l}\text { In situ vitrification is not technically implementable at } \\
\text { the SDA without pretreating buried waste to remove } \\
\text { water and reduce the mass of combustible materials } \\
\text { (Kalb et al. 1997). Rigorous engineering and } \\
\text { administrative controls would be required for } \\
\text { application at a radioactive waste disposal site. A risk } \\
\text { of steam explosion would exist if molten glass } \\
\text { contacts water-saturated waste. Furthermore, release } \\
\text { of steam and combustion gas from the waste could } \\
\text { result in an explosive atmosphere within the hood } \\
\text { containing the in situ vitrification treatment area. } \\
\text { Detonation of this atmosphere could displace the } \\
\text { hood. The resulting loss of confinement would pose } \\
\text { unacceptable health and safety risks to collocated } \\
\text { workers and unacceptable health risks to the off-INL } \\
\text { Site public (Santee 2003). }\end{array}$ & $\begin{array}{l}\text { Capital and operating costs are expected to be high, } \\
\text { relative to other in situ treatment options. }\end{array}$ \\
\hline
\end{tabular}


Table A-8. In situ biological treatment technologies.

\begin{tabular}{|c|c|c|c|c|}
\hline Process Option & Description & Effectiveness & Implementability & Relative Cost \\
\hline $\begin{array}{l}\text { In situ aerobic } \\
\text { bioremediation }\end{array}$ & $\begin{array}{l}\text { In situ aerobic bioremediation most commonly is used to decompose } \\
\text { nonchlorinated organic contaminants in soil (FRTR 2002; EPA 2003a, } \\
2003 \text { b } \text { CPEO 2002; Freeman and Harris 1995). It also can be used to } \\
\text { mobilize or immobilize inorganic contaminants. Active } \\
\text { microorganisms can be either native to the waste site or introduced } \\
\text { using characterized cultures. Specific microorganisms and culture } \\
\text { conditions can be adapted to treat individual contaminants of concern. } \\
\text { However, using in situ bioremediation at complex buried waste sites } \\
\text { can lead to inadvertent consequences (e.g., enhanced migration of } \\
\text { heavy metals). }\end{array}$ & $\begin{array}{l}\text { Though in situ aerobic bioremediation is applicable to } \\
\text { in situ degradation of organic contaminants in soil in } \\
\text { the SDA, it is not directly applicable to organic } \\
\text { contaminants that remain in intact containers } \\
\text { (e.g., Series } 743 \text { sludge drums). Furthermore, any } \\
\text { manipulation of waste zone conditions in the SDA } \\
\text { with the intent of optimizing the metabolism of } \\
\text { aerobic organisms may adversely impact the mobility } \\
\text { of heavy metal contaminants (e.g., uranium). }\end{array}$ & $\begin{array}{l}\text { In situ aerobic bioremediation is a mature in situ } \\
\text { treatment method that is technically implementable. } \\
\text { However, it is not directly applicable to waste } \\
\text { packaging and contaminant types in the SDA. }\end{array}$ & $\begin{array}{l}\text { Capital and operating costs are expected to be low, } \\
\text { relative to other in situ treatment options. }\end{array}$ \\
\hline $\begin{array}{l}\text { In situ anaerobic } \\
\text { bioremediation }\end{array}$ & $\begin{array}{l}\text { In situ anaerobic bioremediation most commonly is used to treat } \\
\text { organic contaminants that are not easily decomposed by aerobic } \\
\text { organisms (FRTR 2002; EPA 2003a; CPEO 2002). Organic } \\
\text { compounds most commonly targeted for treatment using in situ } \\
\text { anaerobic bioremediation include chlorinated hydrocarbons, such as } \\
\text { those in Rocky Flats Plant Series } 743 \text { sludge (i.e., carbon tetrachloride } \\
\text { and tetrachloroethylene). In situ anaerobic bioremediation typically } \\
\text { involves injecting aqueous solutions containing nutrients that stimulate } \\
\text { the metabolic activity of native anaerobic organisms. }\end{array}$ & $\begin{array}{l}\text { Though in situ anaerobic bioremediation is applicable } \\
\text { to in situ degradation of chlorinated organic } \\
\text { contaminants in soil in the SDA, it is not directly } \\
\text { applicable to organic contaminants that remain in } \\
\text { intact containers (e.g., Rocky Flats Plant Series } 743 \\
\text { sludge drums). It is unknown what effect injection of } \\
\text { nutrient solutions, with the intent of optimizing the } \\
\text { metabolic activity of anaerobic organisms, may have } \\
\text { on mobility of inorganic contaminants. }\end{array}$ & $\begin{array}{l}\text { In situ anaerobic bioremediation is a mature in situ } \\
\text { treatment method that is technically implementable. } \\
\text { However, it is not directly applicable to waste } \\
\text { packaging in the SDA. }\end{array}$ & $\begin{array}{l}\text { Capital and operating costs are expected to be low, } \\
\text { relative to other in situ treatment options. }\end{array}$ \\
\hline
\end{tabular}


Table A-9. Ex situ physical treatment technologies.

\begin{tabular}{|c|c|c|c|c|}
\hline Process Option & Description & Effectiveness & Implementability & Relative Cost \\
\hline Ex situ sizing & $\begin{array}{l}\text { Sizing consists of reducing the size of larger pieces of soil, rock, or } \\
\text { other materials using cutting, shredding, or crushing machinery } \\
\text { (Perry, Green, and Maloney 1997). Various types of equipment } \\
\text { standard to the waste processing, recovery, mining, and demolition } \\
\text { industries may be used. This equipment includes jaw crushers, } \\
\text { gyratory crushers, hammerrills, shear shredders, and dual-auger } \\
\text { shredders. Standard industrial equipment is robust and proven. }\end{array}$ & $\begin{array}{l}\text { Ex situ sizing is effective at reducing the size of larger } \\
\text { soil and rock particles, concrete, wood, some metals, } \\
\text { construction debris, and many other waste materials. } \\
\text { It is important as a pretreatment step for some process } \\
\text { technologies. }\end{array}$ & $\begin{array}{l}\text { Sizing is implementable for certain portions of the } \\
\text { waste stream. Rigorous engineering and } \\
\text { administrative controls would be required for } \\
\text { application at a radioactive waste disposal site. }\end{array}$ & Capital and operating costs are expected to be low. \\
\hline Ex situ compaction & $\begin{array}{l}\text { Compaction is the process of applying high pressure to waste to reduce } \\
\text { void space and reduce volume (EPRI 1988; EPA 1972). The reduced } \\
\text { volume is a function of void space in the waste, force applied by the } \\
\text { press, bulk density of the material, and spring-back characteristics of } \\
\text { the waste. Supercompactors can achieve a two-to-four-volume } \\
\text { reduction factor for noncompactible waste and six-to-seven-volume } \\
\text { reduction factor for compactable waste. Volume reduction can be } \\
\text { improved by preshredding the waste. }\end{array}$ & $\begin{array}{l}\text { Effectiveness of compaction depends on } \\
\text { characteristics of the waste material. Compaction is a } \\
\text { well-proven treatment technology in both nuclear and } \\
\text { nonnuclear industries. }\end{array}$ & $\begin{array}{l}\text { Compaction is implementable for certain portions of } \\
\text { the waste stream. Rigorous engineering and } \\
\text { administrative controls would be required for } \\
\text { application at a radioactive waste disposal site. }\end{array}$ & Capital and operating costs are expected to be low. \\
\hline $\begin{array}{l}\text { Ex situ screening } \\
\text { and classification }\end{array}$ & $\begin{array}{l}\text { Different sized sieves and screens separate material types by } \\
\text { particle size. Screening and classification equipment includes } \\
\text { grizzly shakers and rotary trommels. The process can separate } \\
\text { oversized material as a pretreatment step for further processing. } \\
\text { To separate contaminants, excavated soil can be passed through } \\
\text { progressively finer screen sizes to separate fine-grained from } \\
\text { coarse-grained fractions. Most contaminants tend to bind to soil } \\
\text { fines (e.g., silts and clays) rather than to coarse components } \\
\text { (coarse types of sand, gravel, and cobble). This process option may } \\
\text { be used alone or in combination with other treatment process } \\
\text { options. Standard process equipment or remotely operable, } \\
\text { specially designed equipment may be used in this option. Screening } \\
\text { processes are well-established technologies used in many } \\
\text { applications. }\end{array}$ & $\begin{array}{l}\text { Screening and classification are effective at } \\
\text { separating soil or other material by size. It is a } \\
\text { well-established technology for treating } \\
\text { wastewater, soil, sediments, and sludge, and as a } \\
\text { pretreatment step for waste processing. Its value as } \\
\text { the sole method of contaminant separation is } \\
\text { limited. }\end{array}$ & $\begin{array}{l}\text { Screening and classification are implementable. } \\
\text { Rigorous engineering and administrative controls } \\
\text { would be required for application at a radioactive } \\
\text { waste disposal site. Design considerations include } \\
\text { means to prevent and clear clogging of the } \\
\text { equipment. }\end{array}$ & Capital and operating costs are expected to be low. \\
\hline $\begin{array}{l}\text { Ex situ gravity } \\
\text { separation }\end{array}$ & $\begin{array}{l}\text { Gravity separation is a solid-liquid separation process that exploits a } \\
\text { density difference between the solid and liquid phases (FRTR 2002). } \\
\text { Equipment size and effectiveness of gravity separation depend on the } \\
\text { solids' settling velocity, which is a function of the particles' size, } \\
\text { density difference, fluid viscosity, and concentration. Gravity } \\
\text { separation also is used to remove immiscible oil phases and to classify } \\
\text { where particles of different sizes are separated. This technology is } \\
\text { often preceded by coagulation and flocculation to increase particle } \\
\text { size, thereby allowing the removal of fine particles. }\end{array}$ & $\begin{array}{l}\text { Effectiveness of gravity separation depends on } \\
\text { settling velocities. Gravity separation is a } \\
\text { well-established process for treating wastewater, soil, } \\
\text { sediment, and sludge. }\end{array}$ & $\begin{array}{l}\text { Gravity separation is implementable. Rigorous } \\
\text { engineering and administrative controls would be } \\
\text { required for application at a radioactive waste disposal } \\
\text { site. This option requires slurry formation with waste. } \\
\text { It generates secondary waste in the form of } \\
\text { wastewater. }\end{array}$ & $\begin{array}{l}\text { Capital and operating costs are expected to be low to } \\
\text { medium relative to other ex situ treatment options. }\end{array}$ \\
\hline $\begin{array}{l}\text { Ex situ magnetic } \\
\text { separation }\end{array}$ & $\begin{array}{l}\text { Magnetic separation is used to extract slightly magnetic radioactive } \\
\text { particles and metals from host materials (e.g., water, soil, or air) } \\
\text { (FRTR 2002). Uranium and plutonium compounds are slightly } \\
\text { magnetic, while most host materials are not magnetic. The process } \\
\text { operates by passing contaminated fluid or slurry through magnetized } \\
\text { media. The magnetized media contain a magnetized matrix (e.g., steel } \\
\text { wool) that extracts the slightly magnetic contamination particles from } \\
\text { the slurry. Magnetic separation is a new technology to remove } \\
\text { radioactive contaminants from soil and has been bench-scale tested at } \\
\text { DOE sites. }\end{array}$ & $\begin{array}{l}\text { Magnetic separation is effective at removing slightly } \\
\text { magnetic radioactive and metal particles from water, } \\
\text { soil, or air, as shown in the bench-scale test. This } \\
\text { technology has not been tested at full scale. }\end{array}$ & $\begin{array}{l}\text { Magnetic separation is not implementable without } \\
\text { further development because SDA waste contains } \\
\text { large amounts of ferrous metal debris (e.g., corroded } \\
\text { waste drums). Rigorous engineering and } \\
\text { administrative controls would be required for } \\
\text { application at a radioactive waste disposal site. This } \\
\text { option requires slurry formation with waste. It } \\
\text { generates secondary waste in the form of wastewater. }\end{array}$ & $\begin{array}{l}\text { Capital and operating costs are expected to be low to } \\
\text { medium relative to other ex situ treatment options. }\end{array}$ \\
\hline
\end{tabular}


Table A-9. (continued).

\begin{tabular}{|c|c|c|c|c|}
\hline Process Option & Description & Effectiveness & Implementability & Relative Cost \\
\hline $\begin{array}{l}\text { Ex situ electrostatic } \\
\text { separation }\end{array}$ & $\begin{array}{l}\text { Electrostatic separation of materials is based on differences in surface } \\
\text { conductivity and preferential charging and attraction of materials to an } \\
\text { electric field of opposite charge (Perry, Green, and Maloney 1997). A } \\
\text { variety of electrostatic separation equipment is available, depending on } \\
\text { the type of material to be separated. The process can be used for } \\
\text { nonconductors, mineral processing, recycling, and laboratory or } \\
\text { pilot-scale devices. For mineral processing, minerals are sprayed with } \\
\text { electrons from the active electrode and develop a charge that pins them } \\
\text { to the grounded rotor. Conductors, however, immediately lose the } \\
\text { charge and drop straight down. Semiconductors and nonconductors } \\
\text { stay pinned longer, thus separating. }\end{array}$ & $\begin{array}{l}\text { Electrostatic separation is effective at separating } \\
\text { different types of materials. It is a proven, } \\
\text { commercially available process. }\end{array}$ & $\begin{array}{l}\text { Electrostatic separation is implementable. Rigorous } \\
\text { engineering and administrative controls would be } \\
\text { required for application at a radioactive waste disposal } \\
\text { site. Materials would require screening and sizing. }\end{array}$ & $\begin{array}{l}\text { Capital and operating costs are expected to be low to } \\
\text { medium relative to other ex situ treatment options. }\end{array}$ \\
\hline $\begin{array}{l}\text { Ex situ conveyor } \\
\text { with gamma } \\
\text { monitor and gate } \\
\text { system }\end{array}$ & $\begin{array}{l}\text { This process option combines a feed hopper, a conveyor belt, gamma } \\
\text { spectroscopy, and a gate to separate soil into categories based on } \\
\text { gamma activity (Patteson 2000). }\end{array}$ & $\begin{array}{l}\text { This option is effective at sorting radioactive materials } \\
\text { from nonemitting or low-emitting materials. Materials } \\
\text { must be sized to }<5 \mathrm{~cm}(<2 \text { in.) in diameter. The } \\
\text { system was used successfully at Sandia National } \\
\text { Laboratory in } 1998 \text { (Patteson 2000); however, it was } \\
\text { not useful for sorting contaminated soil at the INL } \\
\text { Site (Giles 1999). }\end{array}$ & $\begin{array}{l}\text { This option is implementable if combined with sizing } \\
\text { process options. Rigorous engineering and } \\
\text { administrative controls would be required for } \\
\text { application at a radioactive waste disposal site. }\end{array}$ & $\begin{array}{l}\text { Capital and operating costs are expected to be } \\
\text { medium relative to other ex situ treatment options. }\end{array}$ \\
\hline
\end{tabular}


Table A-10. Ex situ chemical treatment technologies.

\begin{tabular}{|c|c|c|c|c|}
\hline Process Option & Description & Effectiveness & Implementability & Relative Cost \\
\hline $\begin{array}{l}\text { Ex situ fixation and } \\
\text { stabilization }\end{array}$ & $\begin{array}{l}\text { Chemical fixation and stabilization process options immobilize } \\
\text { radioactive and hazardous constituents in waste by mixing in } \\
\text { additives that bind or absorb the waste into a solid waste form } \\
\text { (EPA 2000, 2003a, 2003b; Freeman and Harris 1995). This option } \\
\text { may be required before waste storage or shipment to immobilize } \\
\text { liquids and contaminants. Processes use either organic or } \\
\text { inorganic additives, which either bind or absorb contaminants or } \\
\text { provide for containment. Additives include Portland cement, } \\
\text { modified sulfur cement, and organic polymers. }\end{array}$ & $\begin{array}{l}\text { Fixation and stabilization are effective at } \\
\text { absorbing liquids and immobilizing contaminants } \\
\text { in a solid waste form. }\end{array}$ & $\begin{array}{l}\text { Fixation and stabilization are implementable. } \\
\text { Rigorous engineering and administrative controls } \\
\text { would be required for application at a radioactive } \\
\text { waste disposal site. Treatability studies would be } \\
\text { required to define process variables (e.g., binder } \\
\text { composition and mixing times). }\end{array}$ & $\begin{array}{l}\text { Capital and operating costs are expected to be } \\
\text { medium relative to other ex situ treatment options. }\end{array}$ \\
\hline Ex situ soil washing & $\begin{array}{l}\text { Soil washing uses an aqueous solution and surfactants to remove } \\
\text { organic material from the surface of soil particles (EPA 2003a, 2003b; } \\
\text { Freeman and Harris } 1995 \text { ). Soil washing does not destroy the organic } \\
\text { material, but produces three products: (1) a wastewater stream, (2) a } \\
\text { sludge of contaminated fine particulates, and (3) soil that may contain } \\
\text { regulated levels of heavy metals and radionuclides. Soil washing is } \\
\text { applicable to soil contaminated with a wide variety of heavy metals, } \\
\text { radionuclides, and organic contaminants. Additional treatment may be } \\
\text { required to remove residual surfactant from treatment residuals. } \\
\text { Equipment and space requirements for soil washing systems are } \\
\text { extensive, and soil-washing operations tend to be complex. }\end{array}$ & $\begin{array}{l}\text { Effectiveness of removing contaminants and } \\
\text { fine-grained material from coarse-grained material } \\
\text { depends on contaminant solubility in the wash } \\
\text { solution, residence time, and affinity for the matrix. } \\
\text { The system may not be applicable to waste streams } \\
\text { containing both metals and organics. Removing } \\
\text { organics adsorbed onto clay-size particles may be } \\
\text { difficult. }\end{array}$ & $\begin{array}{l}\text { Soil washing is moderately implementable. Rigorous } \\
\text { engineering and administrative controls would be } \\
\text { required for application at a radioactive waste disposal } \\
\text { site. Waste must be sized before processing and } \\
\text { treatment would be required for separated } \\
\text { contaminants. A treatability study would be required } \\
\text { to formulate surfactant. } \\
\text { This process generates secondary waste in the form of } \\
\text { wastewater. }\end{array}$ & $\begin{array}{l}\text { Capital and operating costs are expected to be } \\
\text { medium to high, relative to other ex situ treatment } \\
\text { options. }\end{array}$ \\
\hline $\begin{array}{l}\text { Ex situ acid } \\
\text { extraction }\end{array}$ & $\begin{array}{l}\text { Acid extraction uses hydrochloric acid to extract heavy metals } \\
\text { (e.g., uranium and transuranic elements) from soil (FRTR } 2002 \text {; } \\
\text { EPA 2003a, 2003b). In this process, soil is first screened to remove } \\
\text { coarse solids. Hydrochloric acid then is introduced to the soil in the } \\
\text { extraction unit. Residence time in the unit varies, depending on the soil } \\
\text { type, contaminants, and contaminant concentrations. Soil and } \\
\text { extractant are separated with hydrocyclones. When extraction is } \\
\text { complete, the solids are rinsed with water to remove entrained acid and } \\
\text { metals. The extraction solution and rinse waters are regenerated, and } \\
\text { the heavy metals are concentrated in a form potentially suitable for } \\
\text { recovery. During the final step, soil is dewatered and mixed with lime } \\
\text { and fertilizer to neutralize any residual acid. }\end{array}$ & $\begin{array}{l}\text { Acid extraction is effective at removing metals from } \\
\text { soil and sludge (FRTR 2002). However, bench-scale } \\
\text { studies using SDA soil have shown that acid leaching } \\
\text { can result in dissolution of a large portion of the soil } \\
\text { matrix (e.g., } 15-30 \mathrm{wt} \% \text { ), which would result in } \\
\text { unacceptable volumes of secondary waste } \\
\text { (Gombert, Karraker, and Drake 2006). }\end{array}$ & $\begin{array}{l}\text { Acid extraction is implementable. Rigorous } \\
\text { engineering and administrative controls would be } \\
\text { required for application at a radioactive waste disposal } \\
\text { site. It requires physical separation, which may } \\
\text { include screening, density separation, flotation, and } \\
\text { magnetic separation as a pretreatment. Acid extraction } \\
\text { generates secondary waste that may require additional } \\
\text { treatment. }\end{array}$ & $\begin{array}{l}\text { Capital and operating costs are expected to be } \\
\text { medium to high, relative to other ex situ treatment } \\
\text { options. }\end{array}$ \\
\hline $\begin{array}{l}\text { Ex situ solvent } \\
\text { extraction }\end{array}$ & $\begin{array}{l}\text { Organic solvents are used commonly to extract contaminants from soil. } \\
\text { Solvent extraction uses an organic solvent to remove organic } \\
\text { contaminants (e.g., semivolatile organic compounds) from the waste } \\
\text { (EPA 2003a, 2003b; Freeman and Harris } 1995) \text {. Depending on } \\
\text { site-specific conditions, the process may function as a stand-alone } \\
\text { option or in combination with other options (e.g., soil washing, } \\
\text { solidification/stabilization, and thermal oxidation.) Removal efficiency } \\
\text { is highly variable, depending on the individual contaminant solubility } \\
\text { in the solvent, residence time, affinity to the matrix, and moisture } \\
\text { content. Solvent may be difficult to remove from the waste matrix. } \\
\text { Spent solvent may require treatment or stabilization prior to disposal. }\end{array}$ & $\begin{array}{l}\text { Solvent extraction has proved effective in treating soil } \\
\text { containing primarily organic contaminants } \\
\text { (e.g., polychlorinated biphenyls, VOCs, halogenated } \\
\text { solvents, and petroleum waste). This option is difficult } \\
\text { to use on waste containing multiple complex } \\
\text { contaminants. }\end{array}$ & $\begin{array}{l}\text { Solvent extraction is moderately implementable. } \\
\text { Rigorous engineering and administrative controls } \\
\text { would be required for application at a radioactive } \\
\text { waste disposal site. Waste must be sized before } \\
\text { processing; separated contaminants require treatment. } \\
\text { A treatability study is required to select an appropriate } \\
\text { extractant. This process may generate less secondary } \\
\text { waste than soil washing. }\end{array}$ & $\begin{array}{l}\text { Capital and operating costs are expected to be } \\
\text { medium to high, relative to other ex situ treatment } \\
\text { options. }\end{array}$ \\
\hline
\end{tabular}


Table A-10. (continued).

\begin{tabular}{|c|c|c|c|c|}
\hline Process Option & Description & Effectiveness & Implementability & Relative Cost \\
\hline $\begin{array}{l}\text { Ex situ } \\
\text { dehalogenation }\end{array}$ & $\begin{array}{l}\text { Dehalogenation involves adding reagents to soil contaminated with } \\
\text { halogenated organics and heating the mixture (Freeman and } \\
\text { Harris 1995). Dehalogenation is achieved by either replacing the } \\
\text { halogen molecules or decomposing and partially volatilizing the } \\
\text { contaminants. This option is potentially applicable if combined with } \\
\text { other processes to address inorganic and radionuclide COCC. This } \\
\text { relatively mature and simple technology operates at a low temperature } \\
\text { with low off-gas and good destruction efficiencies for chlorinated } \\
\text { compounds. }\end{array}$ & $\begin{array}{l}\text { Dehalogenation has been field tested successfully in } \\
\text { treating polychlorinated biphenyls. The process option } \\
\text { can be used, but may be less effective against selected } \\
\text { halogenated VOCs. This process option meets } \\
\text { regulatory requirements for treating polychlorinated } \\
\text { biphenyl-contaminated soil, but remaining chlorinated } \\
\text { organics may require further treatment. } \\
\text { Potential concerns include (a) treatment of } \\
\text { nonchlorinated organics required, (b) amount of } \\
\text { pretreatment required, (c) ability to treat diverse waste } \\
\text { types (e.g., sensitivity to pH and moisture content), } \\
\text { and (d) safety (e.g., high pressure process using } \\
\text { sodium metal and anhydrous ammonia). }\end{array}$ & $\begin{array}{l}\text { Dehalogenation is moderately implementable. } \\
\text { Rigorous engineering and administrative controls } \\
\text { would be required for application at a radioactive } \\
\text { waste disposal site. Treatability tests may be required } \\
\text { to determine the operating parameters of the unit. } \\
\text { Off-gas treatment is required for VOCs and dust. } \\
\text { Chemical dehalogenation may produce explosive } \\
\text { atmospheres in process equipment (FRTR 2002). }\end{array}$ & $\begin{array}{l}\text { Capital and operating costs are expected to be high, } \\
\text { relative to other ex situ treatment options. }\end{array}$ \\
\hline $\begin{array}{l}\text { Ex situ } \\
\text { reduction-oxidation } \\
\text { manipulation }\end{array}$ & $\begin{array}{l}\text { Ex situ reduction-oxidation reactions can be used to decompose } \\
\text { hazardous organic contaminants or to immobilize toxic metals } \\
\text { (i.e., chromium) or radioisotopes (i.e., Tc-99) (EPA 2003a, 2003b; } \\
\text { Freeman and Harris 1995). Chemical reduction-oxidation is a } \\
\text { full-scale, well-established process option. This option can be operated } \\
\text { with standard process equipment in batch or continuous modes. } \\
\text { However, process control is difficult if waste composition varies } \\
\text { significantly. }\end{array}$ & $\begin{array}{l}\text { Effectiveness of chemical oxidation destruction } \\
\text { depends on the organic material treated, oxidizing } \\
\text { agent used, and residence time. Effectiveness of } \\
\text { reduction-oxidation processes in treating waste also } \\
\text { depends on system design and operating parameters. }\end{array}$ & $\begin{array}{l}\text { Reduction-oxidation manipulation is moderately } \\
\text { implementable. Rigorous engineering and } \\
\text { administrative controls would be required for } \\
\text { application at a radioactive waste disposal site. The } \\
\text { waste stream would require demonstration to } \\
\text { determine efficiency. Waste would require } \\
\text { pretreatment for size reduction and slurry formation. } \\
\text { Wastewater and precipitated sludge would require } \\
\text { treatment. } \\
\text { Treatability studies would be required for a particular } \\
\text { waste stream. }\end{array}$ & $\begin{array}{l}\text { Capital and operating costs are expected to be } \\
\text { medium to high, relative to other ex situ treatment } \\
\text { options. }\end{array}$ \\
\hline $\begin{array}{l}\text { Ex situ } \\
\text { neutralization }\end{array}$ & $\begin{array}{l}\text { Neutralization may be required to remove the corrosivity characteristic } \\
\text { from alkaline or acidic waste (Manahan 1990). The process is reliable, } \\
\text { readily available, and uses standard process equipment. }\end{array}$ & $\begin{array}{l}\text { Neutralization is effective for decharacterizing } \\
\text { corrosive waste. }\end{array}$ & $\begin{array}{l}\text { Neutralization is implementable. Rigorous } \\
\text { engineering and administrative controls would be } \\
\text { required for application at a radioactive waste disposal } \\
\text { site. Construction materials must be resistant to } \\
\text { corrosive waste and reagents. }\end{array}$ & $\begin{array}{l}\text { Capital and operating costs are expected to be low to } \\
\text { medium relative to other ex situ treatment options. }\end{array}$ \\
\hline $\begin{array}{l}\text { Ex situ mediated } \\
\text { electrochemical } \\
\text { oxidation }\end{array}$ & $\begin{array}{l}\text { Mediated electrochemical oxidation is an aqueous, low-temperature } \\
\left.\text { (i.e.e., }<80^{\circ} \mathrm{C}\right) \text { process that treats mixed waste by electrochemically } \\
\text { oxidizing the organic contaminants to yield carbon dioxide and water } \\
\text { (Schwinkendorf, Musgrave, and Drake } 1997 \text {; Balazs et al. 1997). The } \\
\text { remaining inorganic waste components are then stabilized. This } \\
\text { process would require recovering and reusing nitric acid and metal } \\
\text { catalysts (e.g., silver or cerium) to be economical. }\end{array}$ & $\begin{array}{l}\text { Mediated electrochemical oxidation can be highly } \\
\text { effective for destruction of organic contaminants; } \\
\text { however, treating waste containing high } \\
\text { concentrations of chlorinated organics can cause } \\
\text { unacceptable loss of catalyst (e.g., precipitation of } \\
\text { silver chloride, which is a RCRA metal). }\end{array}$ & $\begin{array}{l}\text { Mediated electrochemical oxidation is an } \\
\text { experimental technology that has had limited use at } \\
\text { production scale and would not be implementable at } \\
\text { the SDA without further development. }\end{array}$ & $\begin{array}{l}\text { Capital and operating costs are expected to be high, } \\
\text { relative to other ex situ treatment options. }\end{array}$ \\
\hline $\begin{array}{l}C O C=\text { contaminanto } \\
R C R A=R e s o u r e e ~ C\end{array}$ & $\begin{array}{l}\text { Section } 2 \text { for developing assembled alternatives in Section } 3 . \\
\text { and Recovery Act ( } 42 \text { USC } \$ 6901 \text { et seq., 1976) } \\
\text { aa } \\
\text { nd }\end{array}$ & & & \\
\hline
\end{tabular}


Table A-11. Ex situ thermal treatment technologies.

\begin{tabular}{|c|c|c|c|c|}
\hline Process Option & Description & Effectiveness & Implementability & Relative Cost \\
\hline Ex situ incineration & $\begin{array}{l}\text { Incineration is used to thermally destroy organic constituents of a } \\
\text { waste, both to reduce the volume and to produce more readily } \\
\text { stabilized product (Gill and Quiel 1 1993; Freeman and Harris 1995). } \\
\text { Typical process configurations include rotary kilns, multiple hearth } \\
\text { incinerators, fluidized bed combustors, and liquid injection } \\
\text { incineration. Secondary thermal oxidizers can be incorporated in } \\
\text { off-gas treatment systems to ensure that products of incomplete } \\
\text { combustion are not released to the atmosphere. Refractory treatment } \\
\text { residuals may require stabilization. }\end{array}$ & $\begin{array}{l}\text { Incineration is effective for destruction of organic } \\
\text { contaminants, including polychlorinated biphenyls, } \\
\text { and reduction of waste volume. Incineration is a } \\
\text { well-understood process and has been used in DOE } \\
\text { and U.S. Department of Defense operations. }\end{array}$ & $\begin{array}{l}\text { Because of concern about dioxins produced from } \\
\text { thermal treatment of waste containing chlorine or } \\
\text { chlorinated hydrocarbons (Schwinkendorf, Musgrave, } \\
\text { and Drake 1997), incineration has low public } \\
\text { acceptance and would not be implementable at the } \\
\text { SDA. }\end{array}$ & $\begin{array}{l}\text { Capital and operating costs are expected to be } \\
\text { medium to high, relative to other ex situ treatment } \\
\text { options. }\end{array}$ \\
\hline Ex situ pyrolysis & $\begin{array}{l}\text { Pyrolysis decomposes organic waste and contaminants under high } \\
\text { temperature in an oxygen-deficient environment (Mason et al. 2003; } \\
\text { Freeman and Harris 1995). Inorganic components, including heavy } \\
\text { metals, remain in the char residue, which may require stabilization. A } \\
\text { thermal oxidizer is used to treat product gas before release to the } \\
\text { atmosphere. Advantages over incineration are lower off-gas volume } \\
\text { and less particulate carryover. Refractory treatment residuals may } \\
\text { require stabilization. }\end{array}$ & $\begin{array}{l}\text { Pyrolysis is highly effective for removing organic } \\
\text { contaminants from many waste forms. However, } \\
\text { overall treatment efficiency depends on subsequent } \\
\text { oxidation of the product gas (e.g., catalytic oxidizer or } \\
\text { steam reformer). }\end{array}$ & $\begin{array}{l}\text { Pyrolysis is technically implementable and applies to } \\
\text { many waste forms. Rigorous engineering and } \\
\text { administrative controls would be required for } \\
\text { application at a radioactive waste disposal site. } \\
\text { Secondary waste is generated in the form of char. } \\
\text { Pyrolysis may have greater public acceptance than } \\
\text { incineration because rigorous treatment (i.e., steam } \\
\text { reforming) can be applied before release of gaseous } \\
\text { products (Schwinkendorf, Musgrave, and } \\
\text { Drake 1997). }\end{array}$ & $\begin{array}{l}\text { Capital and operating costs are expected to be } \\
\text { medium to high, relative to other ex situ treatment } \\
\text { options. }\end{array}$ \\
\hline Ex situ vitrification & $\begin{array}{l}\text { Ex situ vitrification uses heat to destroy organic waste and } \\
\text { contaminants, and melt the remaining inorganic material into a glass or } \\
\text { slag (EPA 2003a, 2003b; Freeman and Harris 1995). Products of } \\
\text { combustion and particulates are captured and treated using a secondary } \\
\text { off-gas management system. Hazardous metals and refractory } \\
\text { radioisotopes are stabilized in the resulting glass, which is highly } \\
\text { resistant to leaching. This process can be applied to waste liquids, wet } \\
\text { or dry sludge, and combustible materials. Viable system configurations } \\
\text { include joule-heated, plasma torch, and direct-current arc melters. }\end{array}$ & $\begin{array}{l}\text { Ex situ vitrification is highly effective for destroying } \\
\text { organic contaminants, immobilizing inorganic } \\
\text { contaminants, and it significantly reduces volume. } \\
\text { Some system configurations can treat heterogeneous } \\
\text { waste without extensive pretreatment. Overall system } \\
\text { effectiveness depends on subsequent off-gas } \\
\text { treatment. }\end{array}$ & $\begin{array}{l}\text { Ex situ vitrification is a commercially available } \\
\text { technology. Though technically mature for some } \\
\text { waste types, it has proved difficult to implement in the } \\
\text { DOE complex. Rigorous engineering and } \\
\text { administrative controls would be required for } \\
\text { application at a radioactive waste disposal site. }\end{array}$ & $\begin{array}{l}\text { Capital and operating costs are expected to be } \\
\text { medium to high, relative to other ex situ treatment } \\
\text { options. }\end{array}$ \\
\hline $\begin{array}{l}\text { Ex situ molten metal } \\
\text { system }\end{array}$ & $\begin{array}{l}\text { Molten metal treatment systems use the thermal energy in a molten } \\
\text { metal bath to decompose organic waste and contaminants } \\
\text { (Nagel et al. 1996). While molten metal systems might be applicable to } \\
\text { treat more diverse waste types, complex systems would be required to } \\
\text { be developed to separate and remove ceramic and metal waste forms. } \\
\text { Extensive off-gas treatment is required. }\end{array}$ & $\begin{array}{l}\text { Molten metal treatment systems have been shown to } \\
\text { be highly effective for destruction of organic waste } \\
\text { that contains little or no inorganic residue (e.g., ion } \\
\text { exchange resins). }\end{array}$ & $\begin{array}{l}\text { Molten metal treatment would not be feasible for most } \\
\text { waste types in the SDA without significant waste } \\
\text { preparation. There is currently no commercial vendor } \\
\text { of this technology. }\end{array}$ & $\begin{array}{l}\text { Capital and operating costs are expected to be high, } \\
\text { relative to other ex situ treatment options. }\end{array}$ \\
\hline $\begin{array}{l}\text { Ex situ molten salt } \\
\text { system }\end{array}$ & $\begin{array}{l}\text { Molten salt treatment systems use the thermal energy in a molten salt } \\
\text { bath to decompose organic waste and contaminants (Hsu et al. 1998). } \\
\text { Molten salt treatment systems can tolerate waste containing significant } \\
\text { amounts of refractory elements; however, the resulting secondary } \\
\text { waste can be difficult to stabilize. Extensive off-gas treatment is } \\
\text { required. }\end{array}$ & $\begin{array}{l}\text { Molten salt treatment systems have been } \\
\text { demonstrated to be highly effective for destruction of } \\
\text { organic waste containing small amounts of } \\
\text { radioisotopes. }\end{array}$ & $\begin{array}{l}\text { Molten salt oxidation of organic waste has been } \\
\text { demonstrated at pilot scale; however, no commercial } \\
\text { capability has been developed for treating waste types } \\
\text { typical of those in the SDA. }\end{array}$ & $\begin{array}{l}\text { Capital and operating costs are expected to be high, } \\
\text { relative to other ex situ treatment options. }\end{array}$ \\
\hline
\end{tabular}


Table A-11. (continued).

\begin{tabular}{|c|c|c|c|c|}
\hline Process Option & Description & Effectiveness & Implementability & Relative Cost \\
\hline $\begin{array}{l}\text { Ex situ steam } \\
\text { reforming }\end{array}$ & $\begin{array}{l}\text { Steam reforming uses superheated steam to convert organics to a } \\
\text { hydrogen-rich synthesis gas (Schwinkendorf, Musgrave, and } \\
\text { Drake 1997). A thermal oxidizer then filters and oxidizes product gas } \\
\text { before discharge to the atmosphere. Destroying organic debris can } \\
\text { significantly reduce volume. Most radionuclides and heavy metals are } \\
\text { retained in the remaining ash. Steam reforming can use a heated } \\
\text { shredder, heated screw, or fluidized bed for material feed, or it can } \\
\text { directly volatilize organics from drummed waste contained in an } \\
\text { autoclave (Mason et al. 2003). Steam reforming is a commercially } \\
\text { available process option applicable to a wide variety of waste streams. } \\
\text { Waste preparation requirements depend on equipment configuration, } \\
\text { and can be complex. Refractory treatment residuals may require } \\
\text { stabilization. }\end{array}$ & $\begin{array}{l}\text { Steam reforming is highly effective for destruction of } \\
\text { organic contaminants. This process option is } \\
\text { applicable to a wide variety of waste forms. }\end{array}$ & $\begin{array}{l}\text { Steam reforming is implementable for removal and } \\
\text { destruction of organic contaminants in SDA waste } \\
\text { types. Rigorous engineering and administrative } \\
\text { controls would be required for application at a } \\
\text { radioactive waste disposal site. While it might be } \\
\text { feasible to remove organic contaminants from } \\
\text { drummed waste using an autoclave-based approach, } \\
\text { greatly simplifying material preparation, there is } \\
\text { presently no facility planned to offer treatment of } \\
\text { mixed transuranic waste. }\end{array}$ & $\begin{array}{l}\text { Capital and operating costs are expected to be } \\
\text { medium to high, relative to other ex situ treatment } \\
\text { options. }\end{array}$ \\
\hline $\begin{array}{l}\text { Ex situ supercritical } \\
\text { water oxidation }\end{array}$ & $\begin{array}{l}\text { Supercritical water oxidation destroys organic waste using oxidizing } \\
\text { properties of water heated and maintained at pressures greater than its } \\
\text { critical point (e.g., } 705^{\circ} \mathrm{F} \text { at } 3,202 \text { psi) (Schwinkendorf, Musgrave, and } \\
\text { Drake } 1997 ; \text { Freeman and Harris } 1995 \text { ). Under these conditions, } \\
\text { organic contaminants become highly soluble in water, enabling rapid, } \\
\text { complete oxidation. This process option is applicable to treatment of } \\
\text { liquid waste feeds, but extensive pretreatment would be required to } \\
\text { treat solids. Supercritical water oxidation units are subject to mineral } \\
\text { fouling and accelerated corrosion, requiring frequent maintenance and } \\
\text { use of specialized construction materials. This is an emerging } \\
\text { technology with limited commercial application and availability. } \\
\text { Refractory treatment residuals may require stabilization. }\end{array}$ & $\begin{array}{l}\text { Supercritical water oxidation is highly effective for } \\
\text { destroying liquid organic contaminants, but is not } \\
\text { applicable to treating solids and debris. }\end{array}$ & $\begin{array}{l}\text { Supercritical water oxidation is moderately } \\
\text { implementable for treating liquid waste. However, } \\
\text { this option is impractical for treating waste retrieved } \\
\text { from the SDA because solids and debris would } \\
\text { require extensive pretreatment. Rigorous engineering } \\
\text { and administrative controls would be required for } \\
\text { application at a radioactive waste disposal site. }\end{array}$ & $\begin{array}{l}\text { Capital and operating costs are expected to be high, } \\
\text { relative to other ex situ treatment options. }\end{array}$ \\
\hline $\begin{array}{l}\text { Ex situ thermal } \\
\text { desorption }\end{array}$ & $\begin{array}{l}\text { Thermal desorption heats waste to remove water and volatile organic } \\
\text { contaminants from soil, sludge, or debris (EPA } 2003 \mathrm{a}, 2003 \mathrm{~b} \text {; Freeman } \\
\text { and Harris } 1995 \text { ). Thermal desorption routinely is performed using } \\
\text { heated dryers or screw feeds, but can also be directly applied to } \\
\text { drummed waste using autoclaves. A carrier gas or vacuum gradient is } \\
\text { used to transport volatilized organics to a collection or treatment } \\
\text { system. Secondary treatment systems can include absorption beds or a } \\
\text { thermal oxidizer. Refractory treatment residuals may require } \\
\text { stabilization. }\end{array}$ & $\begin{array}{l}\text { Thermal desorption is very effective for removing } \\
\text { volatile organic contaminants from soil or debris; } \\
\text { however, it is not applicable to destruction of } \\
\text { semivolatile organic contaminants } \\
\text { (e.g., polychlorinated biphenyls) unless operated at } \\
\text { temperatures sufficient to pyrolyze the waste. }\end{array}$ & $\begin{array}{l}\text { Thermal desorption is a commercially available } \\
\text { technology. Rigorous engineering and administrative } \\
\text { controls would be required for application at a } \\
\text { radioactive waste disposal site. }\end{array}$ & $\begin{array}{l}\text { Capital and operating costs are expected to be } \\
\text { medium to high, relative to other ex situ treatment } \\
\text { options. }\end{array}$ \\
\hline
\end{tabular}


Table A-12. Ex situ biological treatment technologies.

\begin{tabular}{|c|c|c|c|c|}
\hline Process Option & Description & Effectiveness & Implementability & Relative Cost \\
\hline $\begin{array}{l}\text { Ex situ aerobic } \\
\text { bioremediation }\end{array}$ & $\begin{array}{l}\text { Bacteria indigenous to the soil or specific bacterial cultures are used to } \\
\text { degrade organic contaminants (Freeman and Harris 1995; EPA 1994). } \\
\text { Aerobic degradation, performed by microorganisms that require } \\
\text { oxygen for growth, is commonly used to degrade toxic organic } \\
\text { petroleum contaminants to nontoxic by-products, thereby reducing the } \\
\text { waste volume requiring disposal. Aerobic process residues are usually } \\
\text { carbon monoxide, carbon dioxide, water, salts, and biomass sludge } \\
\text { (dead cell material). Because contaminants must be available to the } \\
\text { microorganisms, contaminants that are not water soluble are more } \\
\text { difficult to treat. Though chlorinated organics are difficult to treat, } \\
\text { some bacteria do degrade chlorinated organics in the course of } \\
\text { metabolizing other more easily degraded compounds. Several } \\
\text { processes for ex situ aerobic degradation exist (e.g., containment cells, } \\
\text { land farming, and bioreactors). Aerobic degradation is a } \\
\text { well-developed, highly effective method to treat organic contaminants. }\end{array}$ & $\begin{array}{l}\text { Effectiveness of aerobic bioremediation depends on } \\
\text { contaminant susceptibility to biologic degradation, } \\
\text { nutrient availability, oxygen concentration, } \\
\text { temperature, and pH. }\end{array}$ & $\begin{array}{l}\text { Aerobic bioremediation is potentially implementable. } \\
\text { Rigorous engineering and administrative controls } \\
\text { would be required for application at a radioactive } \\
\text { waste disposal site. Microbe populations are easily } \\
\text { upset by contaminant toxicity, nutrient availability, } \\
\text { oxygen concentration, temperature, and pH. Waste } \\
\text { must be sized. Biomass, wastewater, and off-gas may } \\
\text { require additional treatment. A large system is } \\
\text { required due to slow process time (EPA 1994). }\end{array}$ & $\begin{array}{l}\text { Capital and operating costs are expected to be } \\
\text { medium relative to other ex situ treatment options. }\end{array}$ \\
\hline $\begin{array}{l}\text { Ex situ anaerobic } \\
\text { bioremediation }\end{array}$ & $\begin{array}{l}\text { Bacteria indigenous to the soil or specific bacterial cultures are used to } \\
\text { degrade organic contaminants (DOE-RL 1997; EPA 1994). Anaerobic } \\
\text { degradation is carried out in the absence of oxygen and yields methane, } \\
\text { carbon dioxide, and biomass. Because the contaminants must be } \\
\text { available to the microorganisms, contaminants that are not water } \\
\text { soluble e.g., solids and immiscible organics) are more difficult to } \\
\text { treat. Chlorinated organics are difficult to treat because their } \\
\text { degradation is not a significant source of energy for the bacteria. } \\
\text { Several options for ex situ anaerobic degradation exist, including } \\
\text { containment cells and bioreactors. }\end{array}$ & $\begin{array}{l}\text { Effectiveness of anaerobic bioremediation depends on } \\
\text { contaminant susceptibility to biologic degradation, } \\
\text { nutrient availability, oxygen concentration, } \\
\text { temperature, and pH. }\end{array}$ & $\begin{array}{l}\text { Anaerobic bioremediation is potentially } \\
\text { implementable. Rigorous engineering and } \\
\text { administrative controls would be required for } \\
\text { application at a radioactive waste disposal site. } \\
\text { Microbe populations are easily upset by contaminant } \\
\text { toxicity, nutrient availability, oxygen concentration, } \\
\text { temperature, and pH. Waste must be sized. Biomass, } \\
\text { wastewater, and off-gases may require additional } \\
\text { treatment. A large system is required because process } \\
\text { times are generally slower than for aerobic } \\
\text { degradation (EPA 1994). }\end{array}$ & $\begin{array}{l}\text { Capital and operating costs are expected to be } \\
\text { medium relative to other ex situ treatment options. }\end{array}$ \\
\hline
\end{tabular}


Table A-13. Surface barrier technologies.

\begin{tabular}{|c|c|c|c|c|}
\hline Process Option & Description & Effectiveness & Implementability & Relative Cost \\
\hline $\begin{array}{l}\text { Single-layered } \\
\text { surface barrier }\end{array}$ & $\begin{array}{l}\text { A single-layered surface barrier consists of a designed thickness of a } \\
\text { single type of material, which could include compacted soil, concrete, } \\
\text { asphalt, or geomembrane. Descriptions of different types of } \\
\text { single-layered surface barriers follow: } \\
\text { - Soil cover-Soil layer composed of either natural clay or a } \\
\text { bentonite-soil blend. Clay properties (e.g.,. plasticity index and } \\
\text { particle size gradation) would be specified to achieve permeability } \\
\text { requirements. Soil would be compacted, as required, to provide } \\
\text { consistency and achieve performance requirements. Granular soil } \\
\text { (i.e., sand and gravel) also could be used to provide a physical } \\
\text { barrier. } \\
\text { - Concrete-based cap -A single-layered cover composed of a } \\
\text { reinforced concrete slab placed over a prepared subgrade above the } \\
\text { contaminated material. Concrete also could be considered as a } \\
\text { surface barrier to prevent direct access to waste. Several } \\
\text { engineering controls could be used to reduce the potential for } \\
\text { cracking and increase the effective life of the cap. } \\
\text { - Conventional asphalt cap-A single-layered cap composed of } \\
\text { asphalt pavement placed over a prepared subgrade above the } \\
\text { contaminated material. Asphalt is a common cover used to control } \\
\text { and minimize surface water infiltration. } \\
\text { - Geomembrane-A single layer of flexible, polymeric plastic. } \\
\text { Geomembranes include several commercially available synthetic } \\
\text { materials that could be used to prevent surface water infiltration. } \\
\text { The effective life of geosynthetics exposed to weather generally } \\
\text { does not exceed } 20 \text { years. }\end{array}$ & $\begin{array}{l}\text { A single-layered surface barrier is marginally } \\
\text { effective at achieving the project remedial action } \\
\text { objectives. Single-layered surface barriers generally } \\
\text { are not durable over the long term. Soil covers are } \\
\text { susceptible to biointrusion and desiccation cracking; } \\
\text { concrete covers potentially will crack with differential } \\
\text { settlement of the subgrade; asphalt covers and } \\
\text { geomembranes, though flexible, require periodic } \\
\text { replacement. }\end{array}$ & $\begin{array}{l}\text { A single-layered surface barrier is technically and } \\
\text { administratively implementable. The various types of } \\
\text { single-layered surface barriers are routinely used; the } \\
\text { necessary materials are readily available. }\end{array}$ & $\begin{array}{l}\text { Capital cost is expected to be low to medium relative } \\
\text { to other surface barrier options. However, operating } \\
\text { costs are expected to be high because the surface } \\
\text { barrier requires periodic replacement. }\end{array}$ \\
\hline $\begin{array}{l}\text { Surface biotic } \\
\text { barrier }\end{array}$ & $\begin{array}{l}\text { A biotic barrier generally consists of one or more layers of coarse } \\
\text { gravel or cobbles or both compacted to maximum density, which is } \\
\text { intended to impede burrowing animals and human penetration } \\
\text { (Breshears, Nyhan, and Davenport 2005; Gaglio et al. 2001; } \\
\text { Hakonson 1986). Several potential biotic barrier designs are available, } \\
\text { but the Stationary Low-Power Reactor No. } 1 \text { cap was selected as the } \\
\text { representative process option for this feasibility study. The Stationary } \\
\text { Low-Power Reactor No. } 1 \text { cap, designed for Waste Area Group } 5 \\
\text { Power Burst Facility, consists of layers of basalt cobbles underlain and } \\
\text { overlain by gravel, with a rock armor surface. This cap, with a total } \\
1.8 \mathrm{~m} \text { ( } 6 \text { ft) minimum thickness, was designed to control surface } \\
\text { exposures to radionuclides and to inhibit biotic intrusion for } \\
\text { approximately } 400 \text { years (INEL 1996). }\end{array}$ & $\begin{array}{l}\text { A biotic barrier is effective at providing a barrier } \\
\text { between contaminants and humans and burrowing } \\
\text { animals, but is not effective at minimizing infiltration. } \\
\text { Rock armor caps without low-permeability layers } \\
\text { increase infiltration rates relative to background } \\
\text { conditions because (a) evaporation demand is reduced } \\
\text { due to the temperature and wind speed reduction at } \\
\text { the soil surface afforded by the rock armor and } \\
\text { (b) lack of transpiration demand in the absence of } \\
\text { plants. }\end{array}$ & $\begin{array}{l}\text { The biotic barrier is technically and administratively } \\
\text { implementable. This option is a well-known process } \\
\text { option that uses available materials. A borrow source } \\
\text { evaluation would be required during design to verify } \\
\text { availability of onsite sources for rock. }\end{array}$ & $\begin{array}{l}\text { Capital and operating costs are expected to be low to } \\
\text { medium relative to other surface barrier options. }\end{array}$ \\
\hline
\end{tabular}


Table A-13. (continued).

\begin{tabular}{|c|c|c|c|c|}
\hline Process Option & Description & Effectiveness & Implementability & Relative Cost \\
\hline $\begin{array}{l}\text { Modified RCRA } \\
\text { Type C surface } \\
\text { barrier }\end{array}$ & $\begin{array}{l}\text { The modified RCRA Type C surface barrier is based on the } \\
\text { conventional RCRA Type C surface barrier. A conventional } \\
\text { RCRA Type C surface barrier consists of a vegetated soil layer } \\
\text { and a thin impermeable layer constructed of compacted clay and a } \\
\text { flexible geomembrane (EPA 1989; Golder Associates 1988). The } \\
\text { conventional RCRA Type C surface barrier was designed to meet } \\
\text { performance objectives for RCRA Subtitle C landfill closures } \\
\text { under } 40 \text { CFR 265.310, which assumes a performanee period of } \\
\text { approximately } 30 \text { years. Agency guidance (EPA 1989) also } \\
\text { recognized that alternative designs might be applicable to closure } \\
\text { of hazardous sites (e.g., the SDA). } \\
\text { The modified RCRA Type C surface barrier (DOE-RL 1996) was } \\
\text { designed to contain and hydrologically isolate hazardous and } \\
\text { radioactive waste for at least 500 years. The primary difference } \\
\text { between the conventional and modified RCRA Type C surface } \\
\text { barriers is the modified barrier substitutes an asphalt composite } \\
\text { layer for the conventional compacted clay layer, which is subject to } \\
\text { desiccation in semiarid environments (Daniel and Wu 1993). } \\
\text { Optional gas collection and biotic barrier layers can be added, } \\
\text { depending on site conditions. }\end{array}$ & $\begin{array}{l}\text { The modified RCRA Type C surface barrier is } \\
\text { effective at minimizing surface exposure to } \\
\text { humans and the environment and groundwater } \\
\text { infiltration; however, the impermeable asphalt } \\
\text { layer can restrict release of volatile contaminants } \\
\text { (e.g., VOCs and C-14) to the atmosphere, } \\
\text { increasing contaminant transport to the vadose } \\
\text { zone and underlying aquifer. Effectiveness can be } \\
\text { monitored using soil moisture monitoring } \\
\text { equipment installed within or beneath the surface } \\
\text { barrier. However, thin impermeable layers } \\
\text { (e.g., the asphalt composite layer in the modified } \\
\text { RCRA Type C surface barrier) are susceptible to } \\
\text { localized failure resulting from differential } \\
\text { settlement in the underlying buried waste (Moore } \\
\text { and Crowe 1998). Groundwater infiltration } \\
\text { through failed seams in the thin impermeable layer } \\
\text { could cause contaminants to migrate from areas of } \\
\text { differential settlement (e.g., collapsed filters or fire } \\
\text { waste). The composite asphalt layer is assumed to } \\
\text { provide adequate protection against biotic } \\
\text { intrusion by plant roots or burrowing animals } \\
\text { (DOE-RL 1996). }\end{array}$ & $\begin{array}{l}\text { The modified RCRA Type C surface barrier is } \\
\text { technically and administratively implementable. } \\
\text { No specialized equipment, personnel, or services } \\
\text { are required to construct the modified RCRA } \\
\text { Type C surface barrier. Construction materials are } \\
\text { readily available on the INL Site or from local } \\
\text { sources. A borrow source evaluation would be } \\
\text { required during design to verify availability of } \\
\text { onsite soil and rock sources. However, modified } \\
\text { RCRA Type C surface barriers deployed to date } \\
\text { have been for relatively small areas (e.g., <5 acres) } \\
\text { (EPA 2006). For a large area, such as the SDA } \\
\text { (i.e.e., 97 acres), significant technical and } \\
\text { administrative implementability issues may arise. } \\
\text { Specifically, staged deployment of an asphalt } \\
\text { composite layer over a large area would cause } \\
\text { interlift boundaries, which would require } \\
\text { construction of sealed staggered joints. Because of } \\
\text { previous difficulties in constructing thin } \\
\text { impermeable layers (Suter, Luxmore, and Smith } \\
\text { 1993), rigorous construction quality control would } \\
\text { be required to ensure integrity of a thin asphalt } \\
\text { composite hydraulic barrier (Bowders et al. 2003). }\end{array}$ & $\begin{array}{l}\text { Capital and operating costs are expected to be } \\
\text { medium relative to other surface barrier options. }\end{array}$ \\
\hline $\begin{array}{l}\text { Evapotranspiration } \\
\text { surface barrier }\end{array}$ & $\begin{array}{l}\text { An ET surface barrier primarily consists of a vegetated soil layer } \\
\text { and may include a capillary break or biobarrier (Mattson et al. } \\
\text { 2004; Forman and Anderson 2005; Golder Associates 1988). The } \\
\text { ET barrier is designed to manage water balance over a capped } \\
\text { area such that deep infiltration is minimized. Precipitation that } \\
\text { does not run off is stored within the soil porosity and later } \\
\text { removed by ET. Primarily built using earthen materials, with } \\
\text { minimimal use of geosynthetics, ET barriers exhibit long functional } \\
\text { life. Vegetation is selected to transition to a natural sagebrush } \\
\text { steppe community. Evapotranspiration barriers are best suited to } \\
\text { arid and semiarid climates. }\end{array}$ & $\begin{array}{l}\text { The ET barrier is effective at minimizing } \\
\text { infiltration and, thereby, contaminant flux from } \\
\text { the vadose zone to groundwater, reducing or } \\
\text { eliminating diret radiation exposures, and } \\
\text { providing a barrier between contaminants and } \\
\text { humans. Evapotranspiration barriers are expected } \\
\text { to provide performance equivalent to RCRA } \\
\text { surface barriers in arid climates } \\
\text { (Mattson et al. 2004; ITRC 2003; Magnuson 1993). } \\
\text { These barrier types are built almost entirely using } \\
\text { native earthen materials; therefore, service life is } \\
\text { estimated to exceed that of RCRA Type C barriers. } \\
\text { Design performance margins are expected to be } \\
\text { sufficient to accommodate a wide variety of } \\
\text { transient climatic conditions and provide } \\
\text { long-term reliability (Keck et al. 1992). } \\
\text { Effectiveness can be monitored using soil moisture } \\
\text { monitoring equipment installed in or under the } \\
\text { surface barrier. } \\
\text { A biobarrier may be required to prevent } \\
\text { biointrusion. A capillary barrier may further } \\
\text { reduce infiltration. Evapotranspiration barriers } \\
\text { are designed to be less susceptible to damage by } \\
\text { differential settlement than other multilayered } \\
\text { barriers (Mattson et al. 2004; Keck and Seitz 2002; } \\
\text { Moore and Crowe 1998). }\end{array}$ & $\begin{array}{l}\text { The ET barrier is technically and administratively } \\
\text { implementable. The ET barrier is a } \\
\text { well-established process option (EPA 2006). The } \\
\text { constructability of the ET surface barrier is high. } \\
\text { Lack of geosynthetic materials simplifies } \\
\text { construction of an ET surface barrier in stages. No } \\
\text { specialized equipment, personnel, or services are } \\
\text { required to implement this option. Construction } \\
\text { materials are readily available at the INL Site or } \\
\text { from local sources. A borrow source evaluation } \\
\text { would be required during design to verify } \\
\text { availability of onsite soil and rock sources. }\end{array}$ & $\begin{array}{l}\text { Capital and operating costs are expected to be } \\
\text { medium relative to other surface barrier options. }\end{array}$ \\
\hline
\end{tabular}


Table A-13. (continued).

\begin{tabular}{|c|c|c|c|c|}
\hline Process Option & Description & Effectiveness & Implementability & Relative Cost \\
\hline ICDF surface barrier & $\begin{array}{l}\text { The ICDF barrier (DOE-ID 2003; Crouse and Watson 2002) is a } \\
\text { variation of the Hanford barrier, consisting of (top to bottom) an upper } \\
\text { vegetated ET layer, a biobarrier/capillary break layer, a geomembrane, } \\
\text { and a low-permeability soil layer. This barrier is designed to meet } \\
\text { technical and functional requirements for closure of the ICDF, a mixed } \\
\text { LLW landfill on the INL Site. }\end{array}$ & $\begin{array}{l}\text { Model results for average annual infiltration through } \\
\text { an ICDF surface barrier reported in DOE-ID (1999) } \\
\text { and DOE-ID (2003) would be less than } 0.1 \mathrm{~mm} / \text { year } \\
\text { (0.004 in./year), effectively reducing or eliminating } \\
\text { dissolved contaminant flux to groundwater by } \\
\text { infiltration. The barrier incorporates a } 1.5-\mathrm{m} \\
\text { (5.0-ft) -thick biobarrier to eliminate biointrusion into } \\
\text { underlying waste. The surface barrier would eliminate } \\
\text { contaminant exposure routes, including direct } \\
\text { radiation exposures to surface receptors, soil } \\
\text { ingestion, dermal exposure, and inhalation. Overall } \\
\text { effectiveness for protection of human health and the } \\
\text { environment is high. }\end{array}$ & $\begin{array}{l}\text { The ICDF barrier is technically implementable, but } \\
\text { would be more complex than thinner, single, and } \\
\text { multilayered caps. More material would be required, } \\
\text { including geosynthetics and compacted clay, which } \\
\text { require careful quality control during installation. } \\
\text { More foundation preparation would be required to } \\
\text { prevent damage by future subsidence of the subgrade. }\end{array}$ & $\begin{array}{l}\text { Capital costs for the ICDF barrier would be high, } \\
\text { relative to thinner, single- and multilayered surface } \\
\text { barriers due to the greater material volumes required, } \\
\text { use of geosynthetics, and increased foundation } \\
\text { preparation requirements. Operating costs are } \\
\text { expected to be low. }\end{array}$ \\
\hline $\begin{array}{l}\text { Hanford surface } \\
\text { barrier }\end{array}$ & $\begin{array}{l}\text { The Hanford surface barrier consists of an ET storage layer, capillary } \\
\text { break, and asphalt layer. It is designed to isolate high-activity } \\
\text { low-level, greater-than-Class C, mixed, and transuranic waste. }\end{array}$ & $\begin{array}{l}\text { The Hanford barrier is designed as a water balance } \\
\text { system for long-term (>1,000 years) survivability in } \\
\text { semiarid to subhumid environments and is designed to } \\
\text { meet RCRA Subtitle C performance objectives } \\
\text { (Gee, Ward, and Wittreich 2002; Gee et al. 1995; } \\
\text { Wing and Gee 1994). The Hanford barrier would limit } \\
\text { moisture infiltration and resist erosion by wind and } \\
\text { water for its design life. Design performance margins } \\
\text { are expected to be sufficient to accommodate a wide } \\
\text { variety of transient climatic conditions and provide } \\
\text { long-term reliability. Effectiveness can be monitored } \\
\text { using soil moisture monitoring equipment installed in } \\
\text { or under the barrier. } \\
\text { The Hanford barrier is not in as widespread use as } \\
\text { other multilayered caps, but sufficient design and } \\
\text { testing work has been completed to establish its } \\
\text { effectiveness. Design life is expected to be } \\
1,000 \text { years. Maintenance requirements are expected } \\
\text { to be minimal. }\end{array}$ & $\begin{array}{l}\text { The Hanford barrier is technically and } \\
\text { administratively implementable. The Hanford barrier } \\
\text { is not in as widespread use as other multilayered caps, } \\
\text { but sufficient design and testing work has been } \\
\text { completed to establish its implementability. Because } \\
\text { of the thickness of the cap }(4.6 \mathrm{~m}[15 \mathrm{ft}]) \text {, enough } \\
\text { materials may not be available in the immediate } \\
\text { vicinity of the SDA. Borrow source evaluation would } \\
\text { be required during design to verify availability of } \\
\text { onsite soil and rock sources. }\end{array}$ & $\begin{array}{l}\text { Capital and operating costs are expected to be } \\
\text { medium relative to other surface barrier options. }\end{array}$ \\
\hline $\begin{array}{l}\text { Foundation } \\
\text { preparation by } \\
\text { dynamic } \\
\text { compaction }\end{array}$ & $\begin{array}{l}\text { Dynamic compaction is a construction technology used for } \\
\text { compacting soft soil to support buildings, roadways, etc. The } \\
\text { option involves systematically dropping a heavy weight, } \\
\mathbf{1 0 , 0 0 0} \text { to } 40,000 \mathrm{~kg}(22,000 \text { to } 88,184 \mathrm{lb}) \text {, from a height of } 5 \text { to } 25 \mathrm{~m} \\
(16.4 \text { to } 82 \mathrm{ft} \text { ) in a pattern designed to improve the density of the } \\
\text { underlying material. Though not considered a remedial } \\
\text { technology, dynamic compaction has been evaluated to provide } \\
\text { foundation preparation prior to construction of a surface barrier } \\
\text { at the SDA (Richins and Hurst 2004). }\end{array}$ & $\begin{array}{l}\text { Dynamic compaction has proved to be an effective } \\
\text { and economical alternative to preloading, } \\
\text { foundation piling, deep vibratory compaction, and } \\
\text { soil undercutting and replacement. Energy } \\
\text { delivered to the soil per blow can exceed } \\
12,000 \mathrm{kNm} \text {. Shock waves can penetrate to a depth } \\
\text { of } 10 \mathrm{~m}(33 \mathrm{ft} \text { ). In coarser soil, the shock waves } \\
\text { create liquefaction that leads to compaction. In } \\
\text { finer textured soil, shock waves create positive } \\
\text { pore water pressures and are followed by soil } \\
\text { consolidation. }\end{array}$ & $\begin{array}{l}\text { Dynamic compaction is technically implementable } \\
\text { at the SDA. Rigorous engineering and } \\
\text { administrative controls would be required for } \\
\text { application at a radioactive waste disposal site. } \\
\text { Dynamic compaction has been used successfully to } \\
\text { reduce voids in municipal landfills and DOE burial } \\
\text { sites with conditions similar to those at the SDA. } \\
\text { However, dynamic compaction has the potential to } \\
\text { disrupt containers, penetrate buried waste, and } \\
\text { spread surface and airborne contamination, which } \\
\text { may raise significant administrative barriers for } \\
\text { use at the SDA. Dust suppression and atmospheric } \\
\text { monitoring have proven to be effective controls at } \\
\text { other radioactive-contaminated sites where } \\
\text { dynamic compaction has been performed without } \\
\text { containment. }\end{array}$ & $\begin{array}{l}\text { Capital and operating costs for dynamic } \\
\text { compaction are low to medium relative to other } \\
\text { foundation preparation options. }\end{array}$ \\
\hline
\end{tabular}


Table A-13. (continued).

\begin{tabular}{|c|c|c|c|c|}
\hline Process Option & Description & Effectiveness & Implementability & Relative Cost \\
\hline $\begin{array}{l}\text { Foundation } \\
\text { preparation by } \\
\text { grout injection }\end{array}$ & $\begin{array}{l}\text { Foundation preparation by grout injection (foundation grouting) } \\
\text { would involve injection of Portland cement grout into the buried } \\
\text { waste to fill voids or form free-standing columns to support } \\
\text { surface barrier construction (Stephens 2004). Columns would be } \\
\text { installed using high-pressure jet grouting equipment described in } \\
\text { Section 2.2.4.1. }\end{array}$ & $\begin{array}{l}\text { While grout columns are routinely used for ground } \\
\text { improvement during construction of civil facilities, } \\
\text { they have rarely been used to support structures } \\
\text { constructed over waste landfills. However, } \\
\text { foundation grouting has not been used to support } \\
\text { earthen surface barriers, which must survive } \\
\text { hundreds to thousands of years. }\end{array}$ & $\begin{array}{l}\text { Foundation grouting is implementable at the SDA. } \\
\text { Rigorous engineering and administrative controls } \\
\text { would be required for application at a radioactive } \\
\text { waste disposal site. }\end{array}$ & $\begin{array}{l}\text { Capital and operating costs for foundation } \\
\text { grouting are low to medium relative to other } \\
\text { foundation preparation options. }\end{array}$ \\
\hline $\begin{array}{l}\text { Foundation } \\
\text { preparation by } \\
\text { proof-rolling }\end{array}$ & $\begin{array}{l}\text { Proof-rolling tests the uniformity and stability of a ground surface. } \\
\text { Surficial soil is tested using a wheeled roller or heavy vehicle. } \\
\text { Proof-rolling allows early identification of soft soil and shallow } \\
\text { voids. }\end{array}$ & $\begin{array}{l}\text { Proof-rolling would be effective in identification of } \\
\text { soft soil and shallow voids that could potentially } \\
\text { delay surface barrier construction (e.g., stop work } \\
\text { associated with overburden subsidence and } \\
\text { exposure of buried waste); however, it provides } \\
\text { only shallow soil consolidation and would provide } \\
\text { only a minimal improvement in foundation for a } \\
\text { surface barrier. }\end{array}$ & $\begin{array}{l}\text { Proof-rolling is implementable at the SDA with few } \\
\text { technical or administrative barriers to } \\
\text { implementation. }\end{array}$ & $\begin{array}{l}\text { Capital and operating costs for proof-rolling are } \\
\text { low, relative to other foundation preparation } \\
\text { options. }\end{array}$ \\
\hline 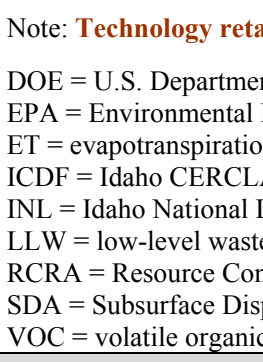 & $\begin{array}{l}\text { in Section } 2 \text { for developing assembled alternatives in Section } 3 . \\
\text { Energy } \\
\text { cction Agency } \\
\text { sposal Facility } \\
\text { ratory } \\
\text { ation and Recovery Act (42 USC } \$ 6901 \text { et seq., 1976) } \\
\text { 1 Area } \\
\text { apound }\end{array}$ & & & \\
\hline
\end{tabular}


Table A-14. Vertical and horizontal containment technologies.

\begin{tabular}{|c|c|c|c|c|}
\hline Process Option & Description & Effectiveness & Implementability & Relative Cost \\
\hline Slurry wall & $\begin{array}{l}\text { A slurry wall consists of a backhoe or excavator-constructed } \\
\text { trench held open with a colloidal clay and water slurry, then } \\
\text { backfilled with a low-permeability material (Freeman and Harris } \\
1995 \text {; EPA 1984). Types of backfill include soil-clay mixtures and } \\
\text { soil-cement mixtures. The primary construction method is } \\
\text { continuous-trenching. This process option can be combined with } \\
\text { other types of lateral barriers. Slurry walls are generally } 1 \mathrm{~m}(3 \mathrm{ft}) \\
\text { thick, with attainable depths of over } 30.5 \mathrm{~m} \text { (100 ft). }\end{array}$ & $\begin{array}{l}\text { The slurry wall is a proven technology that is } \\
\text { effective at minimizing migration of groundwater } \\
\text { across the barrier. Permeability can be reduced } \\
\text { significantly, depending on the slurry type and } \\
\text { construction method. However, in situ } \\
\text { permeability and continuity are not easily } \\
\text { monitored. }\end{array}$ & $\begin{array}{l}\text { The slurry wall is readily implementable. } \\
\text { Excavation of a continuous trench, with } \\
\text { subsequent backfill, is the preferred construction } \\
\text { method at sites with uneven underlying rock or } \\
\text { impermeable layers. The slurry wall uses standard } \\
\text { earthwork equipment and commercially available } \\
\text { and onsite materials. }\end{array}$ & $\begin{array}{l}\text { Capital cost is expected to be low to medium } \\
\text { relative to other lateral barrier options. }\end{array}$ \\
\hline Grout curtain & $\begin{array}{l}\text { Jet and permeability grouting technologies are used to inject grout at } \\
\text { high pressures into sides of a borehole to create columns of modified } \\
\text { soil that overlap to form a low-permeability wall. Grout is installed } \\
\text { through a tube drilled to depth in the soil to form a column by grouting } \\
\text { from the bottom up with an ultrafine Portland cement. Multiple layers } \\
\text { of columns form the wall. This process option for groundwater cutoff } \\
\text { has been used for decades in dam construction and has been used with } \\
\text { success at some sites, but is relatively new for environmental } \\
\text { contamination applications (CH2M HILL 1996). } \\
\text { Grout curtains may be } 1 \mathrm{~m}(3.3 \mathrm{ft} \text { ) or more in thickness, depending on } \\
\text { the number of layers of columns used to create the barrier. Depths over } \\
23 \mathrm{~m}(75 \mathrm{ft} \text { ) are attainable. }\end{array}$ & $\begin{array}{l}\text { The grout curtain is a proven technology that is } \\
\text { effective at minimizing migration of groundwater } \\
\text { across the barrier. Permeability can be reduced } \\
\text { significantly, depending on grout type and } \\
\text { construction method. However, in situ permeability } \\
\text { and continuity are not easily monitored. .ack of } \\
\text { continuity in the barrier could substantially reduce } \\
\text { effectiveness. }\end{array}$ & $\begin{array}{l}\text { The grout curtain is a proven technology and can be } \\
\text { installed with conventional equipment and } \\
\text { commercially available materials. Jet grouting can be } \\
\text { used effectively in soil types ranging from gravel to } \\
\text { heavy clays (Mutch, Ash, and Caputi 1997) and has } \\
\text { been deployed at several soil and waste sites. } \\
\text { However, potential discontinuities resulting from } \\
\text { imprecision in grout column installation can result in } \\
\text { barrier ineffectiveness. }\end{array}$ & $\begin{array}{l}\text { Capital cost is expected to be medium relative to other } \\
\text { lateral barrier options. }\end{array}$ \\
\hline In-place soil mixing & $\begin{array}{l}\text { Multiaxis augers and mixing paddles are used to construct overlapped } \\
\text { columns that form a continuous wall of mixed soil and cement, } \\
\text { bentonite, or other admixture. Barrier walls can be constructed in any } \\
\text { thickness, but generally are } 0.5 \text { to } 1 \mathrm{~m} \text { (1.5 to } 3.3 \mathrm{ft} \text { ) thick and up to } \\
\text { over } 12 \mathrm{~m} \text { ( } 40 \mathrm{ft} \text { ) deep, depending on soil conditions. }\end{array}$ & $\begin{array}{l}\text { Soil mixing is a proven technology that is effective at } \\
\text { minimizing migration of groundwater across the } \\
\text { barrier. Permeability can be reduced significantly, } \\
\text { depending on slurry type and construction method. } \\
\text { However, in situ permeability and continuity are not } \\
\text { easily monitored. Lack of continuity in the barrier } \\
\text { could substantially reduce effective permeability. }\end{array}$ & $\begin{array}{l}\text { In-place soil mixing is implementable. Multiple auger } \\
\text { systems are expected to be implementable in surface } \\
\text { soil in the SDA vicinity. However, potential } \\
\text { discontinitities resulting from imprecision in soil } \\
\text { column installation can result in barrier } \\
\text { ineffectiveness. }\end{array}$ & $\begin{array}{l}\text { Capital cost is expected to be medium to high, relative } \\
\text { to other lateral barrier options. }\end{array}$ \\
\hline Sheet-piling barrier & $\begin{array}{l}\text { Steel sheet-pile technology has evolved to contain contamination. } \\
\text { Sheet piles are driven, vibrated, or jetted to depth and are constructed } \\
\text { with sealable joints to reduce leakage through the sheet pile interlocks. } \\
\text { Sheet pile panels vary in thickness by } 1 \mathrm{~cm}(0.4 \text { in.). Depths up to } 23 \mathrm{~m} \\
(75 \mathrm{ft} \text { typically are attainable, depending on the soil type and density. } \\
\text { Depths of } 91.4 \mathrm{~m} \text { ( } 300 \mathrm{ft}) \text { are possible in unconsolidated deposits } \\
\text { lacking boulders. }\end{array}$ & $\begin{array}{l}\text { Sheet piles are commonly used in geotechnical } \\
\text { applications. A sheet-piling barrier can be effective } \\
\text { at minimizing migration of groundwater across the } \\
\text { barrier. }\end{array}$ & $\begin{array}{l}\text { Sheet piling is a common technology using standard } \\
\text { equipment and commercially available materials. } \\
\text { Piling could be installed in the near surface soil within } \\
\text { the SDA. However, steel sheet piles may not form an } \\
\text { effective interface with underlying rock and have a } \\
\text { limited service life (e.g., decades). }\end{array}$ & $\begin{array}{l}\text { Capital cost is expected to be high, relative to other } \\
\text { lateral barrier options. }\end{array}$ \\
\hline $\begin{array}{l}\text { Ground-freezing } \\
\text { barrier }\end{array}$ & $\begin{array}{l}\text { A ground-freezing barrier is implemented by drilling rows of pipes to } \\
\text { depth around the containment area. Cooled brine freezes the area } \\
\text { between the pipes. A refrigeration plant cools the brine and keeps the } \\
\text { system frozen. The refrigeration must be maintained as long as the } \\
\text { barrier is required. Ground freezing has been used successfully for } \\
\text { several applications, including drilled shaft construction in high water } \\
\text { table areas (temporary applications). The barrier is usually } 9 \text { to } 12 \mathrm{~m} \\
\text { ( } 30 \text { to } 40 \mathrm{ft} \text { ) thick. Depths up to } 23 \mathrm{~m} \text { ( } 75 \mathrm{ft} \text { ) are attainable, but are } \\
\text { limited by cooling system capacity. }\end{array}$ & $\begin{array}{l}\text { The ground-freezing barrier potentially is effective. If } \\
\text { properly designed and operated, the process option } \\
\text { can be effective at minimizing migration of } \\
\text { groundwater across the barrier. }\end{array}$ & $\begin{array}{l}\text { The ground-freezing barrier is not implementable at } \\
\text { the SDA. The ground-freezing barrier has been } \\
\text { demonstrated at Oak Ridge National Laboratory to } \\
\text { divert groundwater around a contaminated site } \\
\text { (DOE-OR 1999); however, ground-freezing barriers } \\
\text { have not been demonstrated for use in semiarid } \\
\text { environments. }\end{array}$ & $\begin{array}{l}\text { Capital cost is expected to be high, relative to other } \\
\text { subsurface containment options. Operating costs are } \\
\text { expected to be high. }\end{array}$ \\
\hline
\end{tabular}


Table A-14. (continued).

\begin{tabular}{|c|c|c|c|c|}
\hline Process Option & Description & Effectiveness & Implementability & Relative Cost \\
\hline Block displacement & $\begin{array}{l}\text { Block displacement vertically displaces a large mass of earth with a } \\
\text { low-permeability material. This process forms a horizontal barrier } \\
\text { below the surface by using a slurry or grout. To create a horizontal } \\
\text { barrier, high-pressure air is pumped through a notching nozzle } \\
\text { extended to the bottom of a borehole drilled to the depth of the barrier. } \\
\text { The air displaces mud and groundwater. Then, sand is injected through } \\
\text { the nozzle to erode a notch radially out from the base of the borehole. } \\
\text { When the desired notch size has been created, slurry is pumped } \\
\text { through the line until the entire notch and casing are filled. Then, } \\
\text { additional slurry is pumped under low pressure to lift the ground. The } \\
\text { subsurface barrier thickness is generally about } 15 \mathrm{~cm}(6 \text { in.) to } \\
0.3 \mathrm{~m}(1 \mathrm{ft}) \text {. }\end{array}$ & $\begin{array}{l}\text { Block displacement is effective in certain geologic } \\
\text { conditions; however, this option is not applicable to } \\
\text { the SDA due to the presence of the basalt layer, which } \\
\text { immediately underlies the source term. A pilot test } \\
\text { would be required to determine whether the zone } \\
\text { beneath the waste could be adequately separated for } \\
\text { grouting using air pressure or cutting methods. }\end{array}$ & $\begin{array}{l}\text { The availability of block displacement and } \\
\text { experienced contractors is limited. The option is not } \\
\text { expected to be implementable due to subsurface } \\
\text { conditions within the SDA. }\end{array}$ & $\begin{array}{l}\text { Capital cost is expected to be high, relative to other } \\
\text { subsurface containment options. }\end{array}$ \\
\hline $\begin{array}{l}\text { Grout-injection } \\
\text { horizontal barrier }\end{array}$ & $\begin{array}{l}\text { The grout-injection horizontal barrier is similar to block displacement, } \\
\text { in that grout is pushed through a borehole and injected at depth in a } \\
\text { gridded pattern with overlap to achieve horizontal continuity. Viscous } \\
\text { liquid barrier is another low-pressure technology that injects } \\
\text { low-viscosity liquid across the interval of the barrier in a similar grid } \\
\text { pattern. The viscous liquid flows into pore space in the formation } \\
\text { before setting up and sealing off the waste zone. Jet grouting uses a } \\
\text { high-pressure pump to inject various grouts radially into the formation } \\
\text { across a given interval and again at gridded locations across the zone to } \\
\text { be sealed. }\end{array}$ & $\begin{array}{l}\text { The grout-injection horizontal barrier option is } \\
\text { potentially effective in basalt materials underlying the } \\
\text { SDA. Low hydraulic conductivities have been } \\
\text { demonstrated with grouted barriers. However, it is } \\
\text { difficult to verify that the subsurface area has been } \\
\text { uniformly treated. }\end{array}$ & $\begin{array}{l}\text { The grout-injection horizontal barrier option is } \\
\text { potentially implementable. Rigorous engineering and } \\
\text { administrative controls would be required for } \\
\text { application at a radioactive waste disposal site. This } \\
\text { option requires drilling through the waste. Most } \\
\text { grouting technologies could be implemented through } \\
\text { drill strings or boreholes, which can be drilled through } \\
\text { most areas of the waste. Waste obstruction could limit } \\
\text { spacing between boreholes. }\end{array}$ & $\begin{array}{l}\text { Capital cost is expected to be high, relative to other } \\
\text { subsurface containment options. }\end{array}$ \\
\hline
\end{tabular}




\section{A-2. REFERENCES}

40 CFR 265.310, 2006, "Closure and Post-Closure Care," Code of Federal Regulations, Office of the Federal Register.

69 FR 39446, 2004, "Revision to the Record of Decision for the Department of Energy's Waste Management Program: Treatment and Storage of Transuranic Waste," Federal Register.

15 USC $§ 2601$ et seq., 1976, “The Toxic Substances Control Act (TSCA) of 1976,” United States Code.

42 USC $\S 6901$ et seq., 1976, "Resource Conservation and Recovery Act of 1976 (Solid Waste Disposal Act)," United States Code.

42 USC $\S 9601$ et seq., 1980, "Comprehensive Environmental Response, Compensation and Liability Act of 1980 (CERCLA/Superfund)," United States Code.

Abbott, David G., 2003, Feasibility Study Preliminary Documented Safety Analysis for In Situ Thermal Desorption in the Subsurface Disposal Area, INEEL/EXT-03-00962, Rev. 0, Idaho National Engineering and Environmental Laboratory, Idaho Completion Project.

Abbott, David and George Santee, 2004, Feasibility Study Preliminary Documented Safety Analysis for In Situ Grouting in the Subsurface Disposal Area, INEEL/EXT-03-00316, Rev. 1, Idaho National Engineering and Environmental Laboratory, Idaho Completion Project.

Armstrong, Aran T., Daniel A. Arrenholz, and Jerry R. Weidner, 2002, Evaluation of In Situ Grouting for OU 7 13/14, INEEL/EXT-01-00278, Rev. 0, North Wind Environmental under subcontract to CH2MHILL, Idaho National Engineering and Environmental Laboratory.

Balazs, B., Z. Chiba, P. Hsu, P. Lewis, L. Murguia, and M. Adamson, 1997, Destruction of Hazardous and Mixed Wastes Using Mediated Electrochemical Oxidation in a $\mathrm{Ag}(\mathrm{II}) \mathrm{HNO}_{3}$ Bench Scale System, UCRL-JC-126754, Lawrence Livermore National Laboratory.

Bowders, John J., J. Erick Loehr, Deepak Neupane, and Abdelmalek Bouassa, 2003, "Construction Quality Control for Asphalt Concrete Hydraulic Barriers," Journal of Geotechnical and Geoenvironmental Engineering, Vol. 129, No. 3, pp. 219-223.

Breshears, David D., John W. Nyhan, and David W. Davenport, 2005, "Ecohydrology Monitoring and Excavation of Semiarid Landfill Covers a Decade after Installation," Vadose Zone Journal, Vol. 4, pp. $798-810$.

CH2M HILL, 1996, Feasibility Study for the Groundwater OU at the Wyckoff Superfund Site, Bainbridge Island, Washington, prepared for the U.S. Environmental Protection Agency.

CPEO, 2002, Technology Tree, Center for Public Environmental Oversight, URL: http://www.cpeo.org/techtree/ttdescript/index.html, Web site updated November 2002, Web page visited January 30, 2007.

Crouse, Phillip and Montgomery Watson, 2002, "Liner and Final Cover Long Term Performance Evaluation and Final Cover Life Cycle Expectation,” EDF-ER-281, Rev. 1, Idaho National Engineering and Environmental Laboratory. 
Daniel, David E. and Yung-Kwant Wu, 1993, "Compacted Clay Liners and Covers for Arid Sites," Journal of Geotechnical Engineering, Vol. 199, No. 2, pp. 223-237.

DHEC, 2005, "South Carolina Department of Health and Environmental Control Radioactive Material License," License No. 097," Amendment No. 50, South Carolina Department of Health and Environmental Control.

DOE O 435.1, 2001, "Radioactive Waste Management,” Change 1, U.S. Department of Energy.

DOE-CBFO, 2002, National TRU Waste Management Plan, DOE/NTP-96-1204, Rev. 3, U.S. Department of Energy Carlsbad Field Office.

DOE-ID, 1999, Final Record of Decision, Idaho Nuclear Technology and Engineering Center, OU 3-13, DOE/ID-10660, Rev. 0, Idaho National Engineering and Environmental Laboratory;

U.S. Department of Energy Idaho Operations Office; U.S. Environmental Protection Agency; Idaho Department of Health and Welfare.

DOE-ID, 2003, INEEL CERCLA Disposal Facility Complex Remedial Action Work Plan, DOE/ID-10984, Rev. 0, U.S. Department of Energy Idaho Operations Office.

DOE-ID, 2005, ICDF Complex Waste Acceptance Criteria, DOE/ID-10881, Rev. 2, U.S. Department of Energy Idaho Operations Office.

DOE-NV, 2005, Nevada Test Site Waste Acceptance Criteria, DOE/NV-325, Rev. 6., U.S. Department of Energy Nevada Site Office.

DOE-OR, 1999, Innovative Technology Summary Report, Frozen Soil Barrier, DOE/EM-0483, OST Reference \#51, U.S. Department of Energy Oak Ridge National Laboratory.

DOE-RL, 1996, Focused Feasibility Study of Engineered Barriers for Waste Management Units in 200 Areas, DOE/RL-93-33, Rev. 0, U.S. Department of Energy, Office of Environmental Restoration and Waste Management, Richland, Washington.

EnergySolutions, 2006a, Bulk Waste Disposal and Treatment Facilities Waste Acceptance Criteria, Rev. 6, EnergySolutions.

EnergySolutions, 2006b, Barnwell Waste Management Facility Site Disposal Criteria Chem-Nuclear Systems Barnwell Office, S20-AD-010, Rev. 22, EnergySolutions.

EPA, 1972, High-Pressure Compaction and Baling of Solid Waste, Washington, D.C.: U.S. Government Printing Office.

EPA, 1984, Slurry Trench Construction for Pollution Migration Control, EPA/540/2-84-001, U.S. Environmental Protection Agency.

EPA, 1988, Guidance for Conducting Remedial Investigations and Feasibility Studies Under CERCLA, Interim Final, EPA/540/G-89/004, OSWER Directive 9355.3-01, U.S. Environmental Protection Agency. 
EPA, 1989, Final Covers on Hazardous Waste Landfills and Surface Impoundments, EPA/530-SW-89-047, U.S. Environmental Protection Agency, Office of Solid Waste and Emergency Response.

EPA, 1994, ARCS Remediation Guidance Document, EPA 905-B94-003, U.S. Environmental Protection Agency, Great Lakes National Program Office, Chicago, Illinois.

EPA, 1998, Evaluation of Subsurface Engineered Barriers at Waste Sites, EPA 542-R-98-005, U.S. Environmental Protection Agency.

EPA, 2000, Solidification/Stabilization Use at Superfund Sites, EPA-542-R-00-010, U.S. Environmental Protection Agency.

EPA, 2003a, Superfund Innovative Technology Evaluation Program, Technology Profiles, Eleventh Edition, Volume 1, Demonstration Program, EPA 540/R-03/501, U.S. Environmental Protection Agency.

EPA, 2003b, Superfund Innovative Technology Evaluation Program, Technology Profiles, Eleventh Edition, Volume 2, Emerging Technologies Program, EPA 540/R-03/501A, U. S. Environmental Protection Agency.

EPA, 2004, Field Evaluation of TerraTherm In Situ Thermal Destruction (ISTD) Treatment of Hexachlorocyclopentadiene - Innovative Technology Evaluation Report, EPA 540-R-05-007, U.S. Environmental Protection Agency.

EPA, 2006, Remediation Technology Descriptions, Alternative Landfill Cover Project Profiles, U.S. Environmental Protection Agency, Technology Innovation Program, URL: http://cluin.org/products/altcovers/, Web page visited January 30, 2007.

EPRI, 1988, Advanced Radioactive Waste Compaction Techniques, EPRI NP-5838, Electric Power Research Institute.

Evans, Dennis, 2003, "Subsurface Processes During In-Situ Thermal Desorption of Buried Wastes at the SDA," EDF-3699, Rev. 0, Idaho National Engineering and Environmental Laboratory.

Forman, Amy D. and Jay E. Anderson, 2005, "Design and Performance of Four Evapotranspiration Caps," Practice Periodical of Hazardous, Toxic, and Radioactive Waste Management, Vol. 9, No. 4, pp. 263-272.

Freeman, Harry M. and Eugene F. Harris (editors), 1995, Hazardous Waste Remediation: Innovative Treatment Technologies, Lancaster, Pennsylvania: Technomic Publishing Co.

FRTR, 2002, Remediation Technologies Screening Matrix and Reference Guide Version 4.0, Federal Remediation Technologies Roundtable, URL: http://www.frtr.gov/matrix2/top page.html, Web page visited January 30, 2007.

Gaglio, Michael D., William P. Mackay, Daniel Padilla, Robert Webb, and David V. LeMone, 2001, "The Effectiveness of Biobarrier Layers within Protective Caps at Preventing Penetration of Waste Sites by the Harvester Ant Pogonomyrmex Salinus Olsen (Hymenoptera: Formicidae)," Waste Management Conference 2001, Tucson, Arizona, February 25-March 1, 2001. 
Gee, G. W., A. L. Ward, and C. D. Wittreich, 2002, The Hanford Site 1000-Year Cap Design Test, PNNL-14143, Pacific Northwest National Laboratory.

Gee, G. W., A. L. Ward, B. G. Gilmore, M. W. Ligotke, and S. O. Link, 1995, Hanford Prototype-Barrier Status Report: FY 1995, PNL-10872, Pacific Northwest Laboratory.

Giles, John R., 1999, Summary Report for Segmented Gate System Treatability Study, INEEL/EXT-99-00733, Rev. 0, Idaho National Engineering and Environmental Laboratory.

Gill, James H. and John M. Quiel, 1993, Incineration of Hazardous, Toxic, and Mixed Wastes, Cleveland, Ohio: North American Manufacturing Co.

Golder Associates, 1988, Master Evaluation of Cover Alternatives and Surface Drainage Design at the Subsurface Disposal Area, EGG-LLW-8235, Golder Associates, for the Idaho National Engineering Laboratory.

Gombert, Dirk, David Karraker, and Ron Drake, 2006, "Evaluation of Cerium (IV) Catalyzed Remediation of Plutonium Contaminated Soils at the Idaho Cleanup Project," Radiochimica Acta, Vol. 94, pp. 167-173.

Hakonson, T. E., 1986, Evaluation of Geologic Materials to Limit Biological Intrusion into Low-Level Radioactive Waste Disposal Sites, LA-10286-MS, Los Alamos National Laboratory.

Hanson, D. J., G. E. Matthern, N. A. Yancey, and D. L. Knudson, 2004, Evaluation of the Durability of WAXFIX for Subsurface Applications, ICP/EXT-04-00300, Rev. 0, Idaho National Engineering and Environmental Laboratory, Idaho Completion Project.

Hanson, Duane J., Gretchen E. Matthern, Sylvester J. Losinski, and Jay T. Brown, 2005, Evaluation of Durability of Portland-Cement-Based Grout for Subsurface Applications at OU 7-13/14, ICP/EXT-05-00798, Rev. 0, Idaho National Laboratory, Idaho Cleanup Project.

Holdren, K. Jean and Barbara J. Broomfield, 2004, Second Addendum to the Work Plan for the OU 7-13/14 Waste Area Group 7 Comprehensive Remedial Investigation/Feasibility Study, DOE/ID-11039, Rev. 0, U.S. Department of Energy Idaho Operations Office.

Holdren, K. Jean, Danny L. Anderson, Bruce H. Becker, Nancy L. Hampton, L. Don Koeppen, Swen O. Magnuson, and A. Jeffrey Sondrup, 2006, Remedial Investigation and Baseline Risk Assessment for OU 7-13/14, DOE/ID-11241, U.S. Department of Energy Idaho Operations Office.

Hsu, P. C., D. L. Hipple, K. G. Foster, T. D. Ford, R. W. Hopper, and M. G. Adamson, 1998, Molten Salt Oxidation for Treating Low-Level Mixed Wastes, UCRL-JC-131718, Lawrence Livermore National Laboratory.

INEL, 1996, Record of Decision, Stationary Low-Power Reactor-1 and Boiling Water Reactor Experiment-I Burial Grounds (OUs 5-05 and 6-01), and 10 No Action Sites (OUs 5-01, 5-03, 5-04, and 5-11), INEL-95/0282, Idaho National Engineering and Environmental Laboratory; U.S. Department of Energy; U.S. Environmental Protection Agency; Idaho Division of Environmental Quality, Idaho Department of Health and Welfare. 
ITRC, 2003, Technical and Regulatory Guidance for Design, Installation, and Monitoring of Alternative Final Landfill Covers, Interstate Technology Regulatory Council, Alternative Landfill Technologies Team.

Kaback, D. S., T. W. Fogwell, and S. W. Peterson, 2005, Evaluation of Vadose Zone Treatment Technologies to Immobilize Technetium-99, WMP-27397, Fluor Hanford.

Kalb, Paul D., Jesse R. Conner, John L. Mayberry, Bhavesh R. Patel, Joseph M. Perez, and Russell L. Treat, 1997, Innovative Site Remediation Technology: Design and Application-Stabilization/Solidification, Annapolis, Maryland: American Academy of Environmental Engineers.

Karol, Reuben H., 2003, Chemical Grouting and Soil Stabilization, $3^{\text {rd }}$ Edition, New York: Marcel Dekker.

Keck, J. F., S. O. Magnuson, K. N. Keck, and J. I. Sipos, 1992, "Evaluation of Engineered Barriers for Closure Cover of the RWMC SDA," EDF-RWMC-523, Idaho National Engineering Laboratory.

Keck, K. N. and R. R. Seitz, 2002, Potential for Subsidence at the Low-Level Radioactive Waste Disposal Area, INEEL/EXT-02-01154, Idaho National Engineering and Environmental Laboratory.

Loomis, Guy G. and James O. Low, 1988, Annual Technology Assessment and Progress Report for the Buried Transuranic Waste Studies Program at the Idaho National Engineering Laboratory (1987), EGG-2525, Idaho National Engineering Laboratory.

Loomis, Guy G., Andrew P. Zdinak, and Carolyn W. Bishop, 1997, Innovative Subsurface Stabilization Project - Final Report (Revision 1), INEL-96/0439, Idaho National Engineering Laboratory.

Loomis, Guy G., James J. Jessmore, Jerry R. Weidner, Christopher M. Miller, and Allen L. Sehn, 2003, Final Results Report, In Situ Grouting Technology for Application in Buried Transuranic Waste Sites, Volume 1, Technology Description and Treatability Study Results for OU 7-13/14, INEEL/EXT-02-00233, Rev. 1, Idaho National Engineering and Environmental Laboratory.

Lopez, Steve L., William H. Landman, Donald E. Sebo, and Vivian G. Schultz, 2005, Summary Report for the OU 7-13/14 Early Actions Beryllium Encapsulation Project, ICP/EXT-04-00646, Rev. 1, Idaho National Engineering and Environmental Laboratory, Idaho Completion Project.

Magnuson, S. O., 1993, A Simulation Study of Moisture Movement in Proposed Barriers for the Subsurface Disposal Area, EGG-WM-10974, Idaho National Engineering Laboratory.

Manahan, Stanley E., 1990, Hazardous Waste Chemistry, Toxicology, and Treatment, Chelsea, Michigan: Lewis Publishers.

Mason, J. Bradley, John McKibbin, Duane Schmoker, and Pat Bacala, 2003, "Pyrolysis/Steam Reforming Technology for Treatment of TRU Orphan Wastes," Proceedings of Waste Management 2003 (WM '03) Conference, Tucson, Arizona, February 23-27, 2003.

Matthern, Gretchen E., Neal Yancey, Gregory Hulet, and Peter Shaw, 2005, Preremedial Design Report of Remediation Options for OU 7-13/14, ICP/EXT-04-00330, Rev. 0, Idaho National Laboratory, Idaho Cleanup Project. 
Mattson, Earl, Mark Ankeny, Steve Dwyer, Nancy Hampton, Gretchen Matthern, Brenda Pace, Alva Parsons, Mitch Plummer, Steve Reese, and Jody Waugh, 2004, Preliminary Design for an Engineered Surface Barrier at the Subsurface Disposal Area, ICP/EXT-04-00216, Rev. 0, Idaho National Engineering and Environmental Laboratory, Idaho Completion Project.

McBride, M. B., 1994, Environmental Chemistry of Soils, New York: Oxford University Press.

McKenzie, M. Doug, Donald E. Sebo, Kirk M. Green, and Vivian G. Schultz, 2005, Waste Information and Location Database for the OU 7-13/14 Project, ICP/EXT-04-00271, Rev. 0, Idaho National Laboratory, Idaho Cleanup Project.

Moore, Beth A. and Bruce M. Crowe, 1998, Consequences of Subsidence for the Area 3 and Area 5 Radioactive Waste Management Sites, Nevada Test Site, DOE/NV-502 UC-600, U.S. Department of Energy Nevada Operations Office.

Mutch, R. D., R. E. Ash, and J. R. Caputi, 1997, “Contain Contaminated Groundwater,” Chemical Engineering, Vol. 104, No. 5, pp. 114-119.

Nagel, Christopher J., Claire A. Chanenchuk, Esther W. Wong, and Robert D. Bach, 1996, "Catalytic Extraction Processing: An Elemental Recycling Technology," Environmental Science and Technology, Vol. 30, No. 7, pp. 2155-2167.

Patteson, Ray, 2000, “The Accelerated Site Technology Deployment Program/Segmented Gate System Project," Spectrum 2000 Conference, Chattanooga, Tennessee, September 24-28, 2000.

Perry, R. H., Don W. Green, and James O. Maloney (editors), 1997, Perry's Chemical Engineers' Handbook, 7th Edition, New York: McGraw-Hill.

Richins, W. D. and C. J. Hurst, 2004, “Assessment of Dynamic Soil Compaction at SDA,” EDF-4909, Rev. 0, Idaho National Engineering and Environmental Laboratory, Idaho Completion Project.

Santee, George Jr., 2003, Feasibility Study Preliminary Documented Safety Analysis for In Situ Vitrification at the Radioactive Waste Management Complex Subsurface Disposal Area, INEEL/EXT-03-00317, Rev. 0, Science Applications International Corporation for Idaho National Engineering and Environmental Laboratory.

Schwinkendorf, W. E., B. C. Musgrave, R. N. Drake, 1997, Evaluation of Alternative Nonflame Technologies for Destruction of Hazardous Organic Waste, INEL/EXT-97-00123, Idaho National Engineering Laboratory.

Shaw, Peter, 2004a, "Grout Selection Criteria and Recommendation for the OU 7-13/14 In Situ Grouting Early Action Project,” EDF-4397, Rev. 0, Idaho National Engineering and Environmental Laboratory, Idaho Completion Project.

Shaw, Peter, 2004b, "Grout Selection Criteria and Recommendation for the OU 7-13/14 In Situ Grouting Project," EDF-5333, Rev. 0, Idaho National Engineering and Environmental Laboratory, Idaho Completion Project.

Shropshire, Karen, 2004, "Lessons Learned from ISG Phase 1-Beryllium Block Wax Grouting in Summer 2004,” EDF-5473, Rev. 0, Idaho National Engineering and Environmental Laboratory, Idaho Completion Project. 
State of Washington, 2005, "State of Washington Radioactive Materials License," License No. WN-1019-2, Amendment No. 32, State of Washington Department of Health.

Stegemeier, George L. and Harold J. Vinegar, 2001, “Thermal Conduction Heating for In-Situ Thermal Desorption of Soils," Hazardous \& Radioactive Waste Treatment Technologies Handbook, Boca Raton, Florida: CRC Press.

Stephens, David L., 2004, “OU 7-13/14 In Situ Grouting Project Foundation Grouting Study,” EDF-5028, Rev. 0, Idaho National Engineering and Environmental Laboratory, Idaho Completion Project.

Suter, Glenn W., II, Robert J. Luxmoore, and Ellen D. Smith, 1993, "Compacted Soil Barriers at Abandoned Landfill Sites Are Likely to Fail in the Long Term," Journal of Environmental Quality, Vol. 22, No. 2, pp. 217-226.

Sykes, Kira, 2002, Evaluation of Soil and Buried Waste Retrieval Technologies for OU 7-13/14, INEEL/EXT-01-00281, CH2MHILL for Bechtel BWXT Idaho, LLC, Idaho National Engineering and Environmental Laboratory.

Szecsody, J. E., J. L. Phillips, V. R. Vermeul, J. S. Fruchter, and M. D. Williams, 2005, Influence of Nitrate on the Hanford 100D Area in Situ Redox Manipulation Barrier Longevity, PNNL-15262, Pacific Northwest National Laboratory.

Thomas, T. N. and Russell L. Treat, 2002, Evaluation of In Situ Vitrification for OU 7-13/14, INEEL/EXT-01-00279, Rev. 0, CH2MHILL and Dade Moeller and Associates for the Idaho National Engineering and Environmental Laboratory.

USACE, 1995, Engineering and Design - Chemical Grouting, EM 1110-1-3500, U.S. Army Corps of Engineers, Waterways Experiment Station, Vichsburg, Mississippi, URL: http://www.usace.army.mil/inet/usace-docs/eng-manuals/em1110-1-3500/toc.htm, published January 31, 1995, Web page visited January 30, 2007.

WCS, 2005, Application for License to Authorize Near-Surface Land Disposal of Low-Level Radioactive Waste, Rev. 9, Waste Control Specialists.

Wing, N. R. and G. W. Gee, 1994, "Quest for the Perfect Cap," Civil Engineering, Vol. 64, No. 10, pp. 38-41.

Zitnik, James F., Aran T. Armstrong, Brian K. Corb, Mark H. Edens, Douglas B. Holsten, Patricia M. O'Flaherty, Janet Rodriguez, Tamara N. Thomas, Russell L. Treat, Wayne Schofield, and Kira L. Sykes, 2002, Preliminary Evaluation of Remedial Alternatives for the Subsurface Disposal Area, INEEL/EXT-02-01258, Rev. 0, prepared by CH2MHILL for the Idaho National Engineering and Environmental Laboratory. 


$$
\text { A-38 }
$$




\section{Appendix B}

\section{Applicable or Relevant and Appropriate Requirements}


B-2 


\section{CONTENTS}

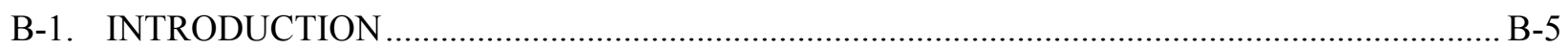

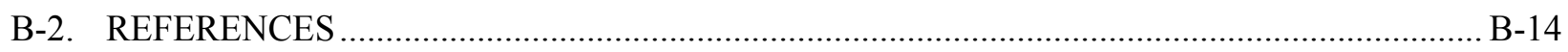

TABLES

B-1. Potential chemical-specific applicable or relevant and appropriate requirements........................ B-6

B-2. Potential location-specific applicable or relevant and appropriate requirements ........................ B-7

B-3. Potential action-specific applicable or relevant and appropriate requirements ........................... B-9

B-4. Potential to-be-considered information from advisories, criteria, and guidance ........................ B-12 
B-4 


\section{Appendix B}

\section{Applicable or Relevant and Appropriate Requirements}

\section{B-1. INTRODUCTION}

Appendix B presents an overall summary of the applicable or relevant and appropriate requirements (ARARs) and other information from advisories, criteria, and guidance to-be-considered (TBCs) that define the potential location, chemical, and action-specific environmental requirements for the remedial alternatives considered in the feasibility study.

The ARARs identification process involved consideration of the Radioactive Waste Management Complex physical setting, composition of the Subsurface Disposal Area waste inventory, and work scope of remedial alternatives being evaluated in the feasibility study. Chemical-specific ARARs are usually health or risk-based numerical values or methodologies that apply to site-specific conditions.

Location-specific ARARs are restrictions placed on the concentration of hazardous substances or the conduct of activities solely because of specific locations involved. Action-specific ARARs are usually technology or activity-based requirements or limitations on actions taken with respect to hazardous waste. Particular remedial activities selected to accomplish the remedy would trigger these requirements.

TBCs are nonpromulgated advisories or guidance that are not legally binding and do not have the status of potential ARARs. As is appropriate for the feasibility study ARARs analysis, generic identification of several U.S. Department of Energy (DOE) orders dealing with radioactive waste management is presented in the table. Identification of the specific provisions of the cited DOE orders that apply to the scope of the selected remedial alternative will be presented in the Operable Unit 7-13/14 record of decision. 
Table B-1. Potential chemical-specific applicable or relevant and appropriate requirements.

\begin{tabular}{|c|c|c|c|}
\hline Category/Statute & Citation & Identification of Requirement & Rationale for Use \\
\hline $\begin{array}{l}\text { Idaho Code, } \\
\text { Sections } 39-105 \\
\text { and } 39-107\end{array}$ & $\begin{array}{l}\text { Idaho Toxic Air } \\
\text { Pollutants } \\
\text { IDAPA 58.01.01.161 } \\
\text { IDAPA } \\
58.01 .01 .210 .16(\mathrm{a}) \\
\text { (IDAPA 58.01.01.585 } \\
\text { and 586) }\end{array}$ & $\begin{array}{l}\text { Applies to CERCLA-related construction, } \\
\text { maintenance, and remediation activities. Compliance } \\
\text { with IDAPA 58.01.01.161 requires that the release of } \\
\text { noncarcinogenic and carcinogenic contaminants into } \\
\text { the air must be estimated in accordance with } \\
\text { IDAPA 58.01.01.210 before the start of construction, } \\
\text { controlled, if necessary, and monitored. If these } \\
\text { increments cannot be met for remediation sources, } \\
\text { compliance with IDAPA 58.01.01.161 will be met in } \\
\text { accordance with IDAPA 58.01.01.210.16(a), } \\
\text { "Environmental Remediation Source. }\end{array}$ & $\begin{array}{l}\text { Idaho's toxic air pollutants requirements have } \\
\text { been determined to be applicable because } \\
\text { carcinogenic and noncarcinogenic air } \\
\text { contaminants are present. }\end{array}$ \\
\hline $\begin{array}{l}\text { Idaho Code, } \\
\text { Sections } 39-105 \\
\text { and } 39-107\end{array}$ & $\begin{array}{l}\text { Ambient Air Quality } \\
\text { Standards for Specific } \\
\text { Air Pollutants } \\
\text { (IDAPA 58.01.01.577) }\end{array}$ & $\begin{array}{l}\text { IDAPA 58.01.01.577 incorporates the National } \\
\text { Ambient Air Quality Standards for particulate matter, } \\
\text { sulfur oxides, ozone, nitrogen dioxide, carbon } \\
\text { monoxide, fluorides, and lead. }\end{array}$ & $\begin{array}{l}\text { Substantive requirements are applicable to } \\
\text { regulated sources of criteria pollutants if the } \\
\text { source has potential to release a significant } \\
\text { quantity of a criteria pollutant as defined in } \\
\text { IDAPA 58.01.01.006.90. Remediation } \\
\text { activities would comply with applicable } \\
\text { emission standards and would not cause or } \\
\text { significantly contribute to a violation of an } \\
\text { ambient air quality standard. Modeling would } \\
\text { be performed if deemed necessary. }\end{array}$ \\
\hline $\begin{array}{l}\text { National Emission } \\
\text { Standards for Hazardous } \\
\text { Air Pollutants } \\
\text { (42 USC } 7412 \text { et seq.) }\end{array}$ & $\begin{array}{l}\text { Radionuclide Emissions } \\
\text { from DOE Facilities } \\
\text { (40 CFR 61.92) }\end{array}$ & $\begin{array}{l}\text { Applies to CERCLA-related construction, } \\
\text { maintenance, and remediation activities. Note: This } \\
\text { requirement is part of } 40 \text { CFR 61, Subpart H, "National } \\
\text { Emission Standards for Emissions of Radionuclides } \\
\text { other than Radon from Department of Energy } \\
\text { Facilities." This standard limits annual emissions of } \\
\text { radionuclides to the ambient air to any member of the } \\
\text { public to an effective dose equivalent of } 10 \mathrm{mrem} / \mathrm{year} \text {. }\end{array}$ & $\begin{array}{l}\text { Substantive requirements for radionuclide } \\
\text { emissions are applicable because radionuclide } \\
\text { contaminants are present that may become } \\
\text { airborne through remedial activities. }\end{array}$ \\
\hline $\begin{array}{l}\text { ARAR }=\text { applicable or relevant } \\
\text { CERCLA = Comprehensive En } \\
\text { DOE }=\text { U.S. Department of Ene } \\
\text { EPA }=\text { U.S. Environmental Pro } \\
\text { INL = Idaho National Laborato }\end{array}$ & $\begin{array}{l}\text { d appropriate requirement } \\
\text { onmental Response, Compensati } \\
\text { y } \\
\text { tion Agency }\end{array}$ & , and Liability Act & \\
\hline
\end{tabular}


Table B-2. Potential location-specific applicable or relevant and appropriate requirements.

\begin{tabular}{|c|c|c|c|}
\hline Category/Statute & Citation & Identification of Requirement & Rationale for Use \\
\hline $\begin{array}{l}\text { Native American Graves } \\
\text { Protection and } \\
\text { Repatriation Act of } 1990 \\
\text { (25 USC } 3001 \text { et seq., } \\
\text { P.L. 101-601) }\end{array}$ & $\begin{array}{l}\text { Native American } \\
\text { Graves Protection and } \\
\text { Repatriation } \\
\text { Regulations } \\
(43 \text { CFR 10) }\end{array}$ & $\begin{array}{l}\text { These regulations require protection of Native American } \\
\text { burial sites and funerary objects. If Native American graves } \\
\text { are discovered within remediation areas, project activities } \\
\text { must cease, and consultation must take place between the } \\
\text { U.S. Department of Interior and the affected tribe. }\end{array}$ & $\begin{array}{l}\text { These regulations are applicable if Native } \\
\text { America human remains or burial objects a } \\
\text { discovered where remedial activities are } \\
\text { being conducted. }\end{array}$ \\
\hline $\begin{array}{l}\text { National Historic } \\
\text { Preservation Act of } 1966 \\
\text { (16 USC } 470 \text { et seq.) }\end{array}$ & $\begin{array}{l}\text { Protection of Historic } \\
\text { Properties } \\
\text { (36 CFR 800; } \\
\text { 40 CFR 6.301(b); } \\
\text { Executive Order 11593) } \\
\text { National Historic } \\
\text { Landmarks Program } \\
\text { (36 CFR 65); National } \\
\text { Register of Historic } \\
\text { Places (36 CFR 60) }\end{array}$ & $\begin{array}{l}\text { The National Historic Preservation Act and its } \\
\text { implementing regulations require that historically } \\
\text { significant properties be protected. The act requires that } \\
\text { agencies undertaking projects must evaluate impacts to } \\
\text { properties listed on or eligible for inclusion on the National } \\
\text { Register of Historic Places. The National Register of } \\
\text { Historic Places is a list of sites, buildings, or other resources } \\
\text { identified as significant to United States history. An } \\
\text { eligibility determination provides a site the same level of } \\
\text { protection as a site listed on the National Register of } \\
\text { Historic Places. Regulations implementing the act require } \\
\text { that the lead agency for a project identify, evaluate, and } \\
\text { determine effects of the project on any cultural resource } \\
\text { sites (including artifacts and remains) that may be within } \\
\text { the area impacted by the project. Implementing regulations } \\
\text { require that negative impacts be resolved. }\end{array}$ & $\begin{array}{l}\text { This regulation is applicable to remedial } \\
\text { actions at Waste Area Group } 7 \text { if buildings } \\
\text { structures, or objects of cultural or religiou } \\
\text { significance near Waste Area Group } 7 \text { are } \\
\text { eligible for the National Register of Histori } \\
\text { Places. Potential for such sites is primarily } \\
\text { limited to the area outside the RWMC } \\
\text { facility fence. }\end{array}$ \\
\hline $\begin{array}{l}\text { Archeological and } \\
\text { Historic Preservation } \\
\text { Act of } 1974 \\
\text { (16 USC } 469 \text { et seq.) }\end{array}$ & $\begin{array}{l}\text { Preservation of } \\
\text { Historic, Prehistoric, } \\
\text { and Archeological Data } \\
(40 \text { CFR } 6.301[\mathrm{c}])\end{array}$ & $\begin{array}{l}\text { This act requires that actions conducted at the site must not } \\
\text { cause loss of any archeological and historical data. This act } \\
\text { mandates preservation of data and does not require } \\
\text { protection of the actual facility. Where a site is determined } \\
\text { to be eligible for the National Register and mitigation is } \\
\text { unavailable, artifacts and data would be recovered and } \\
\text { preserved before commencement of remedial action. }\end{array}$ & $\begin{array}{l}\text { This requirement is applicable if } \\
\text { archeological or historic sites are identifiec } \\
\text { within Waste Area Group } 7 .\end{array}$ \\
\hline $\begin{array}{l}\text { Archaeological } \\
\text { Resources Protection } \\
\text { Act of } 1979 \\
\text { (16 USC } 470 \text { aa-ii) }\end{array}$ & $\begin{array}{l}\text { Protection of } \\
\text { Archaeological } \\
\text { Resources } \\
\text { (43 CFR 7) }\end{array}$ & $\begin{array}{l}\text { Federal agencies must identify possible effects of remedial } \\
\text { activities on archaeological resources. Regulation prohibits } \\
\text { excavation, removal, damage, or other alteration of an } \\
\text { archaeological resource located on public lands. }\end{array}$ & $\begin{array}{l}\text { This regulation is applicable to remedial } \\
\text { actions at Waste Area Group } 7 \text { if there is } \\
\text { potential to impact an archaeological } \\
\text { resource. Consultation with appropriate } \\
\text { personnel is required in the event that a } \\
\text { defined archaeological resource is } \\
\text { encountered during remedial work. }\end{array}$ \\
\hline
\end{tabular}


Table B-2. (continued).

\begin{tabular}{|c|c|c|c|}
\hline Category/Statute & Citation & Identification of Requirement & Rationale for Use \\
\hline $\begin{array}{l}\text { Executive Order } 11988 \\
\text { Flood Plain Management } \\
\text { (May 24, 1997) }\end{array}$ & $\begin{array}{l}\text { Compliance with } \\
\text { Flood-Plain/Wetlands } \\
\text { Environmental Review } \\
\text { Requirements } \\
(10 \text { CFR 1022) }\end{array}$ & $\begin{array}{l}\text { This regulation requires DOE and other federal agencies to } \\
\text { comply with requirements of Executive Order } 11990, \\
\text { "Protection of Wetlands," and Executive Order 11988, } \\
\text { "Flood-Plain Management." Executive Order } 11988 \\
\text { requires DOE procedures to ensure that any actions } \\
\text { conducted in a flood plain consider flood hazards. } \\
\text { Executive Order } 11990 \text { requires protection of wetlands } \\
\text { from destruction. The executive orders require that federal }\end{array}$ & $\begin{array}{l}\text { Flooding from overland flow that historically } \\
\text { occurred at RWMC demonstrates that these } \\
\text { regulations may be applicable. The most } \\
\text { recent study regarding potential for overland } \\
\text { flow surface water flooding at RWMC and in } \\
\text { the Subsurface Disposal Area is provided by } \\
\text { Mitchell et. al. (2001). No wetlands exist on } \\
\text { the INL Site. }\end{array}$ \\
\hline
\end{tabular}
agencies implement these considerations through existing federal requirements such as National Environmental Policy Act requirements. This regulation specifies that DOE prepare a flood plain and wetlands assessment that includes a discussion of purpose and need, a project description, location of wetlands with respect to the project, high hazard areas located in the flood plain, and potential positive and negative effects on flood plains and wetlands. Also, the assessment would include descriptions of alternatives to the action that may be necessary to avoid potential negative impacts.

RCRA

(42 USC 6901)
Location Standards for

Treatment, Storage, and Disposal Facilities

Located within Flood

Plains

(40 CFR 264.18[b])
Regulations require that waste management facilities located within a 100 -year flood plain meet specific design standards for protection against floods. Facility operators have the option to demonstrate that facility procedures ensure waste would be removed before flood waters reach the facility or that no adverse effects to human health or the environment would result if the facility floods.

DOE $=$ U.S. Department of Energy

INL $=$ Idaho National Laboratory

RCRA $=$ Resource Conservation and Recovery Act

RWMC $=$ Radioactive Waste Management Complex 
Table B-3. Potential action-specific applicable or relevant and appropriate requirements.

Category/Statute Citation Identification of Requirement

Idaho Code,

Sections 39-105, 39-107, Rule IDAPA 58.01.11.200

$39-120$, and 39-126

Idaho Code,

Section $42-238$

Idaho Code,

Sections 39-105 and 39-107

Idaho Code,

Sections 39-105 and 39-107

Idaho Code,

Sections 39-105 and

39-107
Idaho Groundwater Quality Groundwater quality and existing and future

beneficial uses of groundwater would be maintained and protected. Degradation that would impair existing and future beneficial uses of groundwater and interconnected surface water would not be allowed

This rule contains provisions for water well construction. The rule contains minimum standards for constructing and abandoning groundwater wells, monitoring wells, and shallow injection wells.

Any contaminant that is toxic to human or animal life or vegetation would not be emitted in quantities or concentrations that would injure or affect human or construction, maintenance, and remediation activities. Compliance with IDAPA 58.01.01.161 requires that the release of noncarcinogenic and carcinogenic contaminants into the air must be estimated in accordance with IDAPA 58.01.01.210 before the start of construction, controlled, if necessary, and monitored. If these increments cannot be met for remediation sources, compliance with

IDAPA 58.01.01.161 will be met in accordance with IDAPA 58.01.01.210.16(a), "Environmental

Remediation Source,"

Idaho Visible Emissions (IDAPA 58.01.01.625)

Idaho Fugitive Dust and 651) from any point of emission for a period, or periods, aggregating more than 3 minutes in any 60-minute period, which is greater than $20 \%$ opacity, is prohibited.

These standards require control of dust. (IDAPA 58.01.01.650 animal life or vegetation. Applies to CERCLA-related

Rationale for Use

Idaho's groundwater quality standards, based on Safe Drinking Water Act maximum contaminan levels, are relevant and appropriate as in situ cleanup standards.

This rule is applicable if regulated wells are constructed as part of remedial actions.

This requirement is applicable because toxic air pollutants are present in Waste Area Group 7 and are subject to potential release because of remedial activities.

This requirement is applicable if remedial action results in visible emissions from a point source.
Fugitive dust requirements are applicable if fugitive dust is generated during remediation. 
Table B-3. (continued).

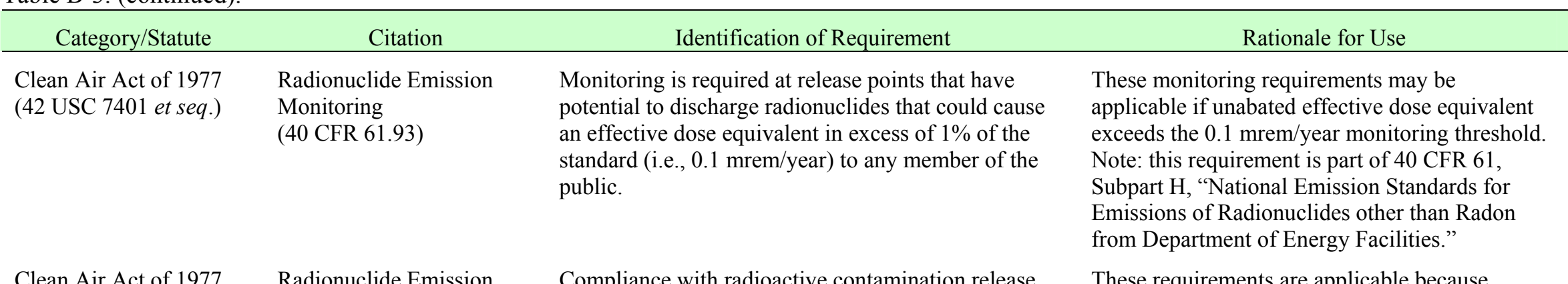

Clean Air Act of $1977 \quad$ Radionuclide Emission Compliance with radioactive contamination release (42 USC 7401 et seq.) Compliance standards would be determined by calculating the (40 CFR 61.94[a]) highest effective dose equivalent to any member of the public at any offsite point where there is a residence, school, business, or office.

Clean Air Act of $1977 \quad$ National Emission

(42 USC 7401 et seq.) Standards for Asbestos

These standards control inactive asbestos waste Standards for Asbestos disposal sites.

\section{RCRA}

(42 USC 6901),

Hazardous Waste

Management Act of 1983

(Idaho Code

39-4401 et seq.) and

Hazardous Waste Facility

Siting Act of 1985 (Idaho

Code 39-5801 et seq.)

Toxic Substances

Control Act of 1976

(15 USC 2601 et seq.)
Land Disposal Restrictions These requirements prohibit placement of restricted (40 CFR 268 and IDAPA 58.01.05.011)

PCBs Manufacturing, Processing, Distribution in Commerce, and Use Prohibitions (40 CFR 761) RCRA hazardous waste in land-based units, such as landfills, surface impoundments, and waste piles, until treated to standards considered protective for disposal. Specific treatment standards are included in the requirements.

These requirements identify standards for storage, treatment, disposal, and characterization of materials containing PCBs, including PCB remediation waste management requirements.
These requirements are applicable because radionuclide contaminants are present. Note: this requirement is part of $40 \mathrm{CFR}$ 61, Subpart $\mathrm{H}$.

Because the active Low-Level Waste Pit is currently receiving regulated asbestos-containing materials, 40 CFR 61.154(g) mandates application of the standards for an inactive asbestos waste site following closure of the Low-Level Waste Pit.

These requirements are applicable to treatment and disposal of RCRA hazardous waste from Waste Area Group 7 if placement of restricted waste occurs. Land disposal requirements generally apply to any off-INL Site disposal of restricted hazardous waste with exception of the Waste Isolation Pilot Plant.

These requirements are applicable to various management activities conducted during remedial response for materials contaminated with PCBs greater than relevant threshold concentrations (i.e., generally 50 parts per million for $\mathrm{PCB}$ remediation waste). 
Table B-3. (continued).

\begin{tabular}{|c|c|c|c|c|}
\hline Category/Statute & Citation & \multicolumn{2}{|r|}{ Identification of Requirement } & Rationale for Use \\
\hline $\begin{array}{l}\text { RCRA } \\
(42 \text { USC 6901) }\end{array}$ & $\begin{array}{l}\text { Hazardous Waste } \\
\text { Identification and Listing } \\
\text { of Hazardous Waste } \\
\text { (40 CFR 261) }\end{array}$ & \multicolumn{2}{|c|}{$\begin{array}{l}\text { These requirements specify that solid waste is } \\
\text { hazardous if it exhibits any characteristics of } \\
\text { hazardous waste (i.e., ignitability, corrosivity, } \\
\text { reactivity, and toxicity) as determined by a toxicity } \\
\text { characteristic leaching procedure. Solid waste is } \\
\text { managed as hazardous waste if it is a "listed" waste } \\
\text { under } 40 \text { CFR 261, Subpart D. }\end{array}$} & $\begin{array}{l}\text { These requirements may be applicable if } \\
\text { hazardous waste is generated. }\end{array}$ \\
\hline $\begin{array}{l}\text { RCRA } \\
(42 \text { USC 6901) }\end{array}$ & $\begin{array}{l}\text { Generator Standards- } \\
\text { Hazardous Waste } \\
\text { Determination } \\
\text { IDAPA 58.01.05.006 } \\
\text { (40 CFR 262.11) }\end{array}$ & \multicolumn{2}{|c|}{$\begin{array}{l}\text { These requirements specify hazardous waste } \\
\text { determination, temporary accumulation, packaging, } \\
\text { and other hazardous waste management requirements } \\
\text { relevant to on and off-INL Site waste management. } \\
\text { Applies to OU } 7-13 / 14 \text { waste that has been placed, } \\
\text { stored, or is being sent to an off-INL Site facility for } \\
\text { treatment or disposal. }\end{array}$} & $\begin{array}{l}\text { Regulatory requirements for facilities that } \\
\text { generate hazardous waste are ARARs if Waste } \\
\text { Area Group } 7 \text { remedial actions involve generation } \\
\text { of hazardous waste. }\end{array}$ \\
\hline $\begin{array}{l}\text { RCRA } \\
(42 \text { USC 6901) }\end{array}$ & $\begin{array}{l}\text { Standards for Owners and } \\
\text { Operators of Treatment, } \\
\text { Storage, and Disposal } \\
\text { Facilities } \\
\text { (40 CFR 264) } \\
\text { (IDAPA-58.01.05) }\end{array}$ & \multicolumn{2}{|c|}{$\begin{array}{l}\text { This regulation sets standards for owners and } \\
\text { operators of hazardous waste treatment, storage, and } \\
\text { disposal facilities. Standards include general facility } \\
\text { requirements (Subpart B), preparedness and } \\
\text { prevention (Subpart C), contingency plan and } \\
\text { emergency procedures (Subpart D), releases from } \\
\text { Solid Waste Management Units (Subpart F), closure } \\
\text { and postclosure requirements (Subpart G), use and } \\
\text { management of containers (Subpart I), tank systems } \\
\text { (Subpart J), waste piles (Subpart L), landfills } \\
\text { (Subpart N), corrective action for solid waste } \\
\text { management units (Subpart S), miscellaneous units } \\
\text { (Subpart X), and containment building (Subpart DD) } \\
\text { standards that may be ARARs based on remedial } \\
\text { alternatives. }\end{array}$} & $\begin{array}{l}\text { Substantive regulatory requirements for owners } \\
\text { and operators of hazardous waste storage, } \\
\text { treatment, or disposal facilities are applicable if a } \\
\text { new hazardous waste treatment facility would be } \\
\text { constructed on the INL Site and may be relevant } \\
\text { and appropriate for other on-INL Site remedial } \\
\text { activities. }\end{array}$ \\
\hline \multicolumn{3}{|c|}{$\begin{array}{l}\text { ARAR = applicable or relevant and appropriate requirement } \\
\text { CERCLA = Comprehensive Environmental Response, Compensation, and Liability Act } \\
\text { CFR }=\text { Code of Federal Regulations }\end{array}$} & $\begin{array}{l}\text { DOE }=\text { U.S. Department of Energy } \\
\text { EPA }=\text { U.S. Environmental Protection Agency } \\
\mathrm{INL}=\text { Idaho National Laboratory }\end{array}$ & $\begin{array}{l}\mathrm{OU}=\text { operable unit } \\
\mathrm{PCB}=\text { polychlorinated biphenyl } \\
\text { RCRA = Resource Conservation and Recovery Act }\end{array}$ \\
\hline
\end{tabular}


Table B-4. Potential to-be-considered information from advisories, criteria, and guidance.

\begin{tabular}{|c|c|c|c|}
\hline Category/Statute & Citation & Summary of TBCs & Rationale for Use \\
\hline Institutional Controls & $\begin{array}{l}\text { EPA Region } 10 \text { Final } \\
\text { Policy on Institutional } \\
\text { Controls at Federal } \\
\text { Facilities }\end{array}$ & $\begin{array}{l}\text { Regional guidance on implementation of institutional } \\
\text { control provisions at Federal Facility Sites. }\end{array}$ & $\begin{array}{l}\text { Policy provisions would be consulted given that } \\
\text { contamination may be left in place after } \\
\text { remediation greater than levels that would allow } \\
\text { for unrestricted use and access. }\end{array}$ \\
\hline Radiological protection & $\begin{array}{l}\text { Radioactive Waste } \\
\text { Management } \\
\text { (DOE O 435.1) }\end{array}$ & $\begin{array}{l}\text { The objective of this DOE order is to ensure that all } \\
\text { DOE radioactive waste is managed in a manner that is } \\
\text { protective of the worker, public health and safety, and } \\
\text { the environment. The Radioactive Waste } \\
\text { Management Manual (DOE M 435.1) establishes } \\
\text { specific responsibilities for implementing radioactive } \\
\text { waste management practices for DOE's high-level } \\
\text { waste, transuranic waste, low-level waste, and the } \\
\text { radioactive component of mixed waste. The Waste } \\
\text { Management Manual catalog's existing procedures } \\
\text { and practices that ensure all DOE elements and } \\
\text { contractors continue to manage DOE's radioactive } \\
\text { waste in a manner protective of the worker, public } \\
\text { health and safety, and the environment. The } \\
\text { Radioactive Waste Management Guide } \\
\text { (DOE G 435.1-1) provides suggestions and } \\
\text { acceptable ways of implementing DOE O } 435.1 \text {. }\end{array}$ & $\begin{array}{l}\text { The DOE order is a TBC because it addresses } \\
\text { management requirements for low-level and } \\
\text { transuranic waste. Disposal requirements apply to } \\
\text { new radioactive waste disposal rather than waste } \\
\text { previously disposed of before the effective date of } \\
\text { the order. }\end{array}$ \\
\hline Radiological protection & $\begin{array}{l}\text { Radiation Protection } \\
\text { of the Public and the } \\
\text { Environment } \\
\text { (DOE O 5400.5) }\end{array}$ & $\begin{array}{l}\text { This DOE order establishes standards for DOE } \\
\text { operations with respect to protection of the public and } \\
\text { the environment against undue risk to radiation. This } \\
\text { DOE order sets limits for annual effective dose } \\
\text { equivalent at } 100 \text { mrem from all exposure pathways, } \\
\text { but allows } 500 \text { mrem if avoidance of higher exposure } \\
\text { is impractical. Annual effective dose equivalent from } \\
\text { drinking water supplies operated by DOE is set at } \\
4 \text { mrem and states that liquid effluent from DOE } \\
\text { activities would not cause public drinking water } \\
\text { systems to exceed EPA maximum contaminant levels. }\end{array}$ & $\begin{array}{l}\text { This DOE order is a TBC because it addresses } \\
\text { radioactive contaminants of concern at the INL } \\
\text { Site and is not an ARAR because it is not a } \\
\text { formally promulgated regulation. }\end{array}$ \\
\hline
\end{tabular}


Table B-4. (continued).

\begin{tabular}{|c|c|c|c|c|}
\hline Category/Statute & Citation & \multicolumn{2}{|l|}{ Summary of TBCs } & Rationale for Use \\
\hline Radiological protection & $\begin{array}{l}\text { Joint NRC/EPA Guidance } \\
\text { on Testing Requirements } \\
\text { for Mixed Radioactive } \\
\text { and Hazardous Waste } \\
\text { (62 FR 224, } \\
\text { November 20, 1997) }\end{array}$ & \multicolumn{2}{|c|}{$\begin{array}{l}\text { This guidance document specifies testing } \\
\text { requirements for mixed low-level radioactive and } \\
\text { hazardous waste. The guidance emphasizes use of } \\
\text { process knowledge to determine if a waste is } \\
\text { hazardous and offers two strategies for helping to } \\
\text { maintain radiation exposure as low as reasonably } \\
\text { achievable if testing is required. }\end{array}$} & $\begin{array}{l}\text { This guidance document is a TBC intended for } \\
\text { NRC licensees. However, the guidance document } \\
\text { also can be used to address testing requirements } \\
\text { for mixed low-level waste present on the INL } \\
\text { Site. }\end{array}$ \\
\hline \multicolumn{2}{|c|}{$\begin{array}{l}\text { ARAR }=\text { applicable or relevant and appropriate requirement } \\
\text { CFR = code of federal regulations } \\
\text { DOE }=\text { U.S. Department of Energy }\end{array}$} & $\begin{array}{l}\mathrm{EPA}=\text { U.S. Environmental Protection Agency } \\
\mathrm{INL}=\text { Idaho National Laboratory } \\
\text { NRC }=\text { Nuclear Regulatory Commission }\end{array}$ & \multicolumn{2}{|c|}{$\begin{array}{l}\mathrm{PCB}=\text { polychlorinated biphenyl } \\
\mathrm{RCRA}=\text { Resource Conservation and Recovery Act } \\
\mathrm{TBC}=\text { to-be-considered (other information from advisories, criteria, and guidance) }\end{array}$} \\
\hline
\end{tabular}




\section{B-2. REFERENCES}

10 CFR 1022, 2003, "Compliance with Floodplain and Wetland Environmental Review Requirements," Code of Federal Regulations, Office of the Federal Register.

36 CFR 60, 2002, "National Register of Historic Places," Code of Federal Regulations, Office of the Federal Register.

36 CFR 65, 2002, "National Historic Landmarks Program," Code of Federal Regulations, Office of the Federal Register.

36 CFR 800, 2004, "Protection of Historic Properties," Code of Federal Regulations, Office of the Federal Register.

40 CFR 6.301(b), 2002, "Historic, architectural, archeological, and cultural sites," Code of Federal Regulations, Office of the Federal Register.

40 CFR 6.301(c), 2002, "Historic, prehistoric and archeological data," Code of Federal Regulations, Office of the Federal Register.

40 CFR 61, 2006, "National Emission Standards for Hazardous Air Pollutants," Code of Federal Regulations, Office of the Federal Register.

40 CFR 61.92, 2006, "Standard," Code of Federal Regulations, Office of the Federal Register.

40 CFR 61.93, 2006, "Emission monitoring and test procedures," Code of Federal Regulations, Office of the Federal Register.

40 CFR 61.94, 2006, “Compliance and reporting," Code of Federal Regulations, Office of the Federal Register.

40 CFR 61.151, 2006, "Standard for inactive waste disposal sites for asbestos mills and manufacturing and fabricating operations," Code of Federal Regulations, Office of the Federal Register.

40 CFR 61.154, 2006, "Standard for active waste disposal sites," Code of Federal Regulations, Office of the Federal Register.

40 CFR 141, 2006, "National Primary Drinking Water Regulations," Code of Federal Regulations, Office of the Federal Register.

40 CFR 154, 2006, "Special Review Procedures," Code of Federal Regulations, Office of the Federal Register.

40 CFR 261, 2006, "Identification and Listing of Hazardous Waste," Code of Federal Regulations, Office of the Federal Register.

40 CFR 262, 2006, "Standards Applicable to Generators of Hazardous Waste," Code of Federal Regulations, Office of the Federal Register.

40 CFR 264, 2006, "Standards for Owners and Operators of Hazardous Waste Treatment, Storage, and Disposal Facilities," Code of Federal Regulations, Office of the Federal Register. 
40 CFR 264, Subpart B, 2006, "General Facility Standards," Code of Federal Regulations, Office of the Federal Register.

40 CFR 264, Subpart C, 2006, "Preparedness and Prevention," Code of Federal Regulations, Office of the Federal Register.

40 CFR 264, Subpart D, 2006, “Contingency Plan and Emergency Procedures," Code of Federal Regulations, Office of the Federal Register.

40 CFR 264, Subpart F, 2006, "Releases from Solid Waste Management Units," Code of Federal Regulations, Office of the Federal Register.

40 CFR 264, Subpart G, 2006, "Closure and Post-Closure," Code of Federal Regulations, Office of the Federal Register.

40 CFR 264, Subpart I, 2006, "Use and Management of Containers," Code of Federal Regulations, Office of the Federal Register.

40 CFR 264, Subpart J, 2006, “Tank Systems,” Code of Federal Regulations, Office of the Federal Register.

40 CFR 264, Subpart L, 2001, "Waste Piles," Code of Federal Regulations, Office of the Federal Register.

40 CFR 264, Subpart N, 2006, "Landfills," Code of Federal Regulations, Office of the Federal Register.

40 CFR 264, Subpart S, 2006, "Special Provisions for Cleanup," Code of Federal Regulations, Office of the Federal Register.

40 CFR 264, Subpart X, 2006, "Miscellaneous Units," Code of Federal Regulations, Office of the Federal Register.

40 CFR 264, Subpart DD, 2006, "Containment Buildings," Code of Federal Regulations, Office of the Federal Register.

40 CFR 264.18, 2006, "Location standards," Code of Federal Regulations, Office of the Federal Register.

40 CFR 268, 2006, "Land Disposal Restrictions," Code of Federal Regulations, Office of the Federal Register.

40 CFR 761, Subpart D, 2006, "Storage and Disposal," Code of Federal Regulations, Office of the Federal Register.

43 CFR 7, 2006, "Protection of Archaeological Resources," Code of Federal Regulations, Office of the Federal Register.

43 CFR 10, 2006, "Native American Graves Protection and Repatriation Regulations," Code of Federal Regulations, Office of the Federal Register.

62 FR 224, 1997, "Guidance on Testing Requirements for Mixed Radioactive and Hazardous Waste," Federal Register. 
15 USC $\S 2601$ et seq., 1976, “The Toxic Substances Control Act (TSCA) of 1976,” United States Code.

16 USC $§ 469$ et seq., 1974, “Archeological and Historic Preservation Act,” United States Code.

16 USC § 470 et seq., 1966, "National Historic Preservation Act," United States Code.

16 USC § 470aa-ii, 1979, “Archaeological Resources Protection Act,” United States Code.

25 USC $\S 3001$ et seq., P.L. 101-601, 1990, "Native American Graves Protection and Repatriation Act," United States Code.

42 USC $§ 6901$ et seq., 1976, "Resource Conservation and Recovery Act of 1976 (Solid Waste Disposal Act)," United States Code.

42 USC $§ 7401$ et seq., 1977, “Clean Air Act,” United States Code.

42 USC § 7412 et seq., 1990, "National Emission Standards for Hazardous Air Pollutants (NESHAPs)," United States Code.

DOE G 435.1-1, 1999,"Implementation Guide for Use with DOE M 435.1-1, Radioactive Waste Management Manual," U.S. Department of Energy.

DOE M 435.1-1, 2001, “Radioactive Waste Management Manual,” U.S. Department of Energy.

DOE O 435.1, 2001, "Radioactive Waste Management," U.S. Department of Energy.

DOE O 5400.5, 1993, "Radiation Protection of the Public and the Environment," U.S. Department of Energy.

Executive Order 11593, 1971, "Protection and Enhancement of the Cultural Environment," 36 FR 8921, 3 CFR, May 1971.

Executive Order 11988, 1997, Floodplain Management, 42 FR 26951, 3 CFR, 1977, May 1977.

Executive Order 11990, 1997, Protection of Wetlands, 42 FR 26961, 3 CFR, 1977, May 1977.

Idaho Code, § 39-101 (101 through 130) et seq., 2000, "Idaho Environmental Protection and Health Act." State of Idaho Codes.

Idaho Code, § 39-4401 et seq., 1983, "Hazardous Waste Management Act of 1983," State of Idaho Codes.

Idaho Code, § 39-5801 et seq., 1985, “State Hazardous Waste Facility Siting Act,” State of Idaho Codes.

Idaho Code, $\S 42-238,1998$, “Well-Drillers’ Licenses and Operator Permits,” State of Idaho Codes.

IDAPA 37.03.09, 1993, "Well Construction Standards Rules," Idaho Administrative Procedures Act, Idaho Department of Environmental Quality.

IDAPA 58.01.01, 1994, "Rules for the Control of Air Pollution in Idaho," Idaho Administrative Procedures Act, Idaho Department of Environmental Quality. 
IDAPA 58.01.01.006.90, 1994, "Significant Contribution," Idaho Administrative Procedures Act, Idaho Department of Environmental Quality.

IDAPA 58.01.01.161, 1995, “Toxic Substances,” Idaho Administrative Procedures Act, Idaho Department of Environmental Quality.

IDAPA 58.01.01.210, 1995, "Demonstration of Preconstruction Compliance with Toxic Standards," Idaho Administrative Procedures Act, Idaho Department of Environmental Quality.

IDAPA 58.01.01.210.16, 2000, "Environmental Remediation Source," Idaho Administrative Procedures Act, Idaho Department of Environmental Quality.

IDAPA 58.01.01.577, 1994, “Ambient Air Quality Standards for Specific Air Pollutants,” Idaho Administrative Procedures Act, Idaho Department of Environmental Quality.

IDAPA 58.01.01.585, 1995, “Toxic Air Pollutants Non-Carcinogenic Increments," Idaho Administrative Procedures Act, Idaho Department of Environmental Quality.

IDAPA 58.01.01.586, 2001, “Toxic Air Pollutants Carcinogenic Increments," Idaho Administrative Procedures Act, Idaho Department of Environmental Quality.

IDAPA 58.01.01.625, 2000, "Visible Emissions," Idaho Administrative Procedures Act, Idaho Department of Environmental Quality.

IDAPA 58.01.01.650, 1994, "Rules for Control of Fugitive Dust," Idaho Administrative Procedures Act, Idaho Department of Environmental Quality.

IDAPA 58.01.01.651, 1994, “General Rules," Idaho Administrative Procedures Act, Idaho Department of Environmental Quality.

IDAPA 58.01.05, 1993, "Rules and Standards for Hazardous Waste," Idaho Administrative Procedures Act, Idaho Department of Environmental Quality.

IDAPA 58.01.05.011, 2006, "Land Disposal Restrictions," Idaho Administrative Procedures Act, Idaho Department of Environmental Quality.

IDAPA 58.01.11.200, 1997, “Ground Water Quality Standards,” Idaho Administrative Procedures Act, Idaho Department of Environmental Quality.

Mitchell, T., S. Mitchell, J. Humphrey, D. Kennedy, and T. Funderburg, 2001, 100-Year Floodplain and 25-Year Runoff Analyses for the Radioactive Waste Management Complex Area at the Idaho National Engineering and Environmental Laboratory, INEEL/EXT-02-00093, Idaho National Engineering and Environmental Laboratory. 
B-18 


\section{Appendix C}

\section{Balancing Criteria Detailed Analysis}




$$
\text { C-2 }
$$




\section{CONTENTS}

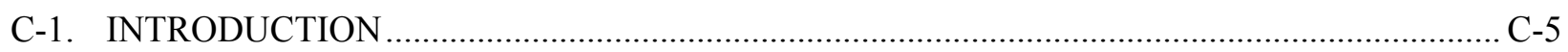

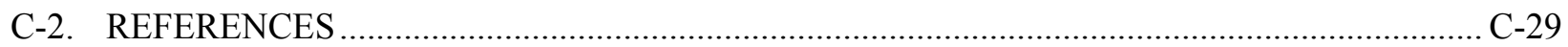

TABLES

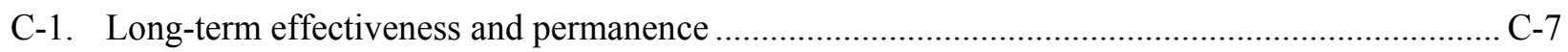

C-2. Reduction of toxicity, mobility, or volume through treatment .............................................. C-12

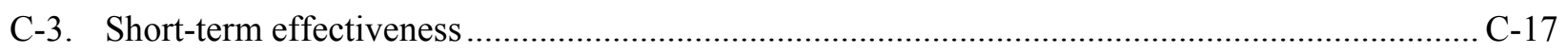

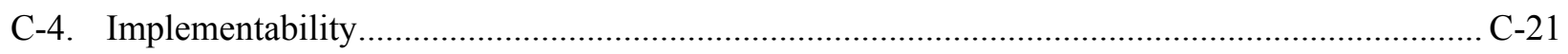

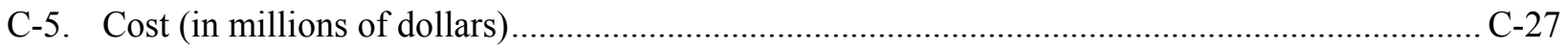


C-4 


\section{Appendix C}

\section{Balancing Criteria Detailed Analysis \\ C-1. INTRODUCTION}

This feasibility study evaluates the expected performance of assembled alternatives against criteria provided in U.S. Environmental Protection Agency guidance (EPA 1988). Nine criteria are subdivided into three types: threshold, balancing, and modifying. Criteria are described in detail in Section 4.1. An alternative must satisfy the two threshold criteria (i.e., overall protection of human health and the environment, and compliance with applicable or relevant and appropriate requirements) to be considered for selection. All alternatives in this feasibility study - except No Action, which is presented as a basis for comparison - satisfy the two threshold criteria. The two modifying criteria (i.e., state acceptance and community acceptance) will be evaluated subsequent to the proposed plan and are not addressed in the feasibility study. Therefore, this appendix focuses on the five balancing criteria:

- $\quad$ Long-term effectiveness and permanence

- $\quad$ Reduction of toxicity, mobility, and volume through treatment

- $\quad$ Short-term effectiveness

- Implementability

- $\quad$ Cost.

This appendix presents five tables; one table for each of the five balancing criteria. Each table contains questions suggested in the U.S. Environmental Protection Agency guidance (EPA 1988) that are organized under topics encompassed by the criterion. Every question is addressed for each of the five assembled alternatives in a side-by-side format to facilitate detailed analysis (see Section 4) and comparative analysis (Section 5). Some questions from the guidance relate to requirements that would not be established until the record of decision; therefore, this analysis addresses anticipated requirements if the alternative is selected. The five assembled alternatives, developed in Section 3 and evaluated in this appendix, are summarized as follows:

- $\quad$ Alternative 1 (No Action)-This alternative evaluates environmental monitoring only, with no mitigative measures to reduce risk.

- $\quad$ Alternative 2 (Surface Barrier)-Two subalternatives are evaluated in detail:

- $\quad$ Alternative 2a (Modified Resource Conservation and Recovery Act [RCRA] Type C Surface Barrier) -is a surface barrier assembled with additional near-surface vapor vacuum extraction; foundation grouting to address subsidence; continued operation of the Organic Contamination in the Vadose Zone (OCVZ) system; and long-term site surveillance, maintenance, monitoring, and institutional controls (ICs). Pad A would be incorporated as-is into the surface barrier.

- $\quad$ Alternative 2b (Evapotranspiration [ET] Surface Barrier)-is a surface barrier with an active gas collection layer, dynamic compaction of pits to address subsidence; continued operation of the OCVZ system; and long-term site surveillance, maintenance, monitoring, and ICs. Pad A waste would be transferred to the Low-Level Waste (LLW) Pit. 
- $\quad$ Alternative 3 (In Situ Grouting [ISG])_involves immobilizing Tc-99 and I-129 in place using high-pressure jet grouting. Relevant waste forms are associated with Idaho National Laboratory Site reactor research and operations. Fully assembled, this alternative includes dynamic compaction of pits to address subsidence; an ET surface barrier with a passive gas collection layer; continued operation of the OCVZ system; and long-term site surveillance, maintenance, monitoring, and ICs. Pad A waste would be retrieved, treated ex situ, and transferred to the LLW Pit.

- $\quad$ Alternative 4 (Partial Retrieval, Treatment, and Disposal [RTD])—includes two subalternatives that are evaluated in detail to facilitate scaling for variable sizes of retrieval areas, as follows:

- $\quad$ Alternative 4a (4-acre Partial RTD) —addresses removal of targeted Rocky Flats Plant waste from pit areas totaling 4 acres. Additional features of this assembled alternative include dynamic compaction of pits to address subsidence; an ET surface barrier with a passive gas collection layer; continued operation of the OCVZ system; and long-term site surveillance, maintenance, monitoring, and ICs. Pad A waste would be removed and sent to the Idaho CERCLA Disposal Facility for treatment and disposal.

- $\quad$ Alternative 4b (2-acre Partial RTD)—addresses removal of targeted Rocky Flats Plant waste from pit areas totaling 2 acres. Additional features of this assembled alternative include proof-rolling of pits to address subsidence; a subsurface slurry wall around the perimeter of the landfill; a passively vented ET surface barrier; continued operation of the OCVZ system; and long-term site surveillance, maintenance, monitoring, and ICs. Pad A would be dynamically compacted and incorporated into the surface barrier.

- $\quad$ Alternative 5 (Full RTD) -includes removal of all buried waste in combination with a simplified ET surface barrier, long-term site surveillance, maintenance, monitoring, and ICs. 
Specific Considerations Alternative
No Action

What is the magnitude of

Cumulative risk for future esidential scenarios woul exceed threshold values

Implementation of this alternative controls greater than or equal to 1 ). COCs to the surface and into the vadose zone and underlying aquifer. In situ grouting of was containing specified Tc- 99 would provide an additional measure of protection by inhibiting release of Tc-99 and collocated contaminants
(e.g., I-129). Combined groundwater and surface (e.g., -1-129). Combined groundwater and surface 1E-04, and the hazard index would be less than 1 (see Section D-3.6). Cons (see Section D-3.6)

Contamination that has already been released to he vadose zone and is untreatable is a primary contributor to associa withe restrean be controlled by construction of a durable surface barrier.

the vadose zone and is untreatable is surface barrier.

The OCVZ treatment system would be operated until remediation goals for $\mathrm{OU} 7-13 / 14$ are achieved. In addition, passive venting of the surface barrier would be required after 列 released to the atmosphere and does not miga is to the underlying vadose zone or aquifer.

Because residual contamination would preclude unrestricted land use, 5-year reviews would be produced until discontinued through the review process.

Risk is associated with postremediation release con

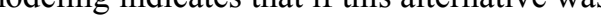
mplemented, both groundwater and surface

Noncarcinogenic risk modeling also indicates that the hazard index, for both groundwater an surface exposure, attributable to postremediation be less than 1 (see Section D-3.6).

The 2 and 4-acre RTD alternatives would leave most of the radiological COCs and a portion of the nonradiological COCs buried in the SDA. addition, the 2-acre RTD alternative (4b) does not remove Pad A waste from the SDA, leaving all nitrate (i.e., a COC with a groundwater

The OCVZ treatment system would be operated alternative removes Pad A waste from the SDA. until remediation goals for OU 7-13/14 are The OCVZ treatment system would be operated achieved. In addition, passive venting of the surface barrier would be required after

conplet 14 in until remediation goals for OU 7-13/14 are achieved. to the underlying vadose zone or aquifer.
Because residual contamination would preclude process anrestricted land use, 5-year reviews would be
Because residual contamination would preclude unrestricted land use, 5-year reviews would be produced until discontinued through the review process.
Risk is associated with postremediation transport of contaminants that have already been released from waste into the vadose zone. Risk modeling indicates that if this alternative was

mplemented, both groundwater and surface exposure carcinogenic risk would be less than

Noncarcinogenic risk modeling also indicates hat the hazard index, for both groundwater an cirface exposure, attibutable to postremediation ve would be less than 1 (see Section D-3.6)

This alternative removes all waste from the buried waste zone; however, some risk will

cemain associated with contaminants that may have already migrated into the vadose zone. The OCVZ treatment system would be operated unt 
Specific Considerations Alternative

\section{Adequacy and reliability of control}

What is the likelihood that Not applicable.

echnologies would meet

required process efficiencies or

performance specifications?
Alternative 2

Alternative 3
In Situ Grouting

Surface barriers are an established technology and have been thoroughly studied for applicatio at the SDA. Preliminary design and field scale testing at the INL Site indicate that performa objectives could be met by more than one surface barrier type or configuration (e.g., RCRA Type $\mathrm{C}$ or alternative). Construction details for a surface barrier would e determined during post-ROD remedia

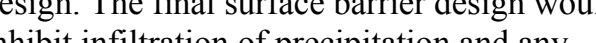
associated contaminant migration to levels sufficient to meet all groundwater objectives. The final design also would incorporate features to prevent unacceptable exposure to biota from soil and inhibit transport of COCs to the surface by plants and animals. Use of grouting for foundation preparation in Subalternative 2a may not fully mitigate surface barrier subsidence, substantial maintenance may be required. Concern over spread of contamination during prepartion may pose administative implementability issues for Subalternative $2 b$.
Experience in the SDA suggests that ISG process efficiencies are adequate to allow treatment of specified areas in trenches and soll vault rows. Performance specifications for ISG would be based on-INL Site-specific process knowledge developed during remedial design Technologies identified for excavation of $\mathrm{P}$ waste are likely to meet required process incincies, howeve, evidence or waste result in delays in waste excavation treetment or relocation within the OU 7-13/14 area of contamination. Ongoing OCVZ operations h been well documented (Housley 2005), and no problems are anticipated in meeting future process efficiencies. Performance of an E surface barrier assuming current conditions in the SDA has been modeled (Mattson et al. 2004), and no problems are anticipated in meeting performance specifications for moisture infltration. Conce over spredof con ming may pose administrative implementability issues.
Alternative 4

Partial Retrieval, Treatment, and Disposal

Partial RTD alternatives include all excavation, contamination control, on-INL Site storage technologies used by the Accelerated Retriev Project. Retrieval of targeted waste from pit areas has been proven to be feasible and

implemented during the Accelerated Retrieva Project. Therefore, the Accelerated Retrieval meeting performance objectives for Alternative 4.

Additional technologies used in thes alternatives include a lateral barrier (e., p. (e.g., ET nngherd surer

barrier, environmental monitoring

(e.g. groundwater and vadose zone), and passive ICs. All of these technologies are industry proven technologies, and the ET surface barrier has been extensively researched at the INL Site. Therefore, these technologies are anticipated to be effective in meeting performance objectives. Concern over spread of contamination during use of dynamic compaction for found preparation may pose administrative

Use of prof tling for found Sube of mitigation of differential subsidence of the overburden soil, and the process may have to modified during remedial design. Use of dynamic compaction for consolidation of aboveground structure, as proposed in Subalternative $4 \mathrm{~b}$ for Pad A, is without precedent in literature, and a demonstratio feasibility may be required prior to field application.
Alternative 5

Full Retrieval, Treatment, and Disposal

The Full RTD alternative includes all storage and disposal, and WIPP storage and disposal technologies used by the Accelerated Retrieval Project. These technologies have bee extensively researched and implemented at the NL Site and, therefore, are anticipated to be Active in Additonal technologies used in this alternative include a surface barrier, surveillance and maintenance of the surface barrier environmental monitoring (e.g., groundwater and vadose zone), and passive ICs. All of these The ET The echnologies are anticipated to be effective in meeting performance objectives.

Technologies with high potential for problems with retrieval and dispocies or performance de nontransuranic waste. This alternative would remove remote-handled nontransuranic waste using the method applied at the

Intermediate-Level Transuranic Storage Facility. This method entails transferring waste from the pit area, using a crane, into a shielded cask. This cask would then be stored within a newly constructed storage facility for remote-handled nontransuranic waste and stored for 20 years, pending placement in a repository that does not currenly exist. Using this mold od within smaller challenges. In addition, the method was used to extract intact remote-handled drums from

belowground vaults. Waste containers buried within SDA pits, trenches, and soil vaults would most likely be deteriorated, creating additional challenges for retrieval. 
Specific Considerations What type and degree of long-term management is required?

Not applicable.

Alternative

The surface barrier must be maintained until disconthued through the 5 -year review proces to prevent surface exposure to primary COCs (100 years of $\mathrm{IC}$ is used as a basis for cost

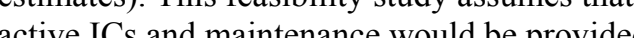
for at least 100 years after completion of the markers) are assumed to remain effective into the indefinite future. Institutional control would be maintained until eliminated through the CERCLA 5-year review processes. $\begin{array}{ll}\text { What are the requirements for } & \text { Long-term monitoring } \\ \text { long-term monitoring? } & \text { requirements likely would }\end{array}$ ong-term monitoring? include aquifer; vadose zone water, and vapor); surface sol, surface water (i.e. runoff), air, perimeter exposure rates, and biological monitoring.

The surface barrier would be visually inspecte periodically to identify any areas affected by perlo community. Standard vadose zone and groundwater monitoring would be continued to verify that the surface barrier sufficiently reduces infiltration and leaching of contam from waste.
Alternative 4

Partial Retrieval, Treatment, and Disposal The surface barrier must be maintained until discorthund through the 5-year review process to prevent surface exposure to primary COCs (lin active ICs and mintenace would be provided for at least 100 years after completion of the markers) are assumed to remain effective into the indefinite future. Institutional control wo be maintained until eliminated through the CERCLA 5-year review processes.

This alternative leaves all waste, treated or untreated, within the OU 7-13/14 area

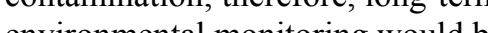

confirm performe of would be required to include sampling and analysis appropriate for both primary and secondary $\mathrm{COCs}$.
Integrity of the surface barrier must be

maintained to prevent surface exposure to $\mathrm{COC}_{s}$ in both the near and long term and to minimize long-term groundwater risk. Active ICs and provided for at least 100 years, and passive controls (e. a lestace barier and associnted perimeter markers) are assumed to remain effective in the indefinite future. Institution control would be maintained until eliminated through the CERCLA 5-year review processes.

Long-term monitoring would include monitoring of groundwater and the vadose zone.

roundwater monitoring is performed to as Monitoring the vadose zone can provide an

warning of moisture infiltration and contaminat migration out of the waste zone. Aquifer monitoring is currently performed at 21 groundwater monitoring wells in and around RWMC on a semiannual basis for the firs 5 years and annually for the next 95 years. Vadose zone monitoring would be performed using 112 lysimeters, 17 vapor port wells, an 100 tensiometers. Each lysimeter would be sampled annually in the late spring. Vapor po would be monitored quarty for 5 yeas and from tensiometers would occur querterly and data reporting annually.
Alternative 5

Full Retrieval, Treatment, and Disposal Integrity of the surface barrier must be maintained to minimize long-term groundwater misk associted with any $\mathrm{COC}$ hat may have migrated into the vadose zone. Active ICs and provided for at least 100 years, and pasive controls (e $g$, surface barrier and associated perimeter markers) are assumed to remain effective in the indefinite future. Institution control would be maintained until eliminated through the CERCLA 5-year review processes.

ong-term monitoring would include monitoring of groundwater and the vadose zone.

Ge Monitoring of the vadose zone can prer.

early warning of moisture infiltration and increased contaminant migration. Aquifer monitoring (using groundwater monitoring wells) and vadose zone monitoring (using lysimeters and vapor port wells and tensiometers) would be performed with the same equipment and on the same frequency bases as described in Alternative 4 
Specific Considerations

What operations and

performed?

Not applicable. (i.e, large subsidence events)

What difficulties and

Not applicable. associated with long-term operations and maintenance?

What technical components

Not applicable.

may require

What is the magnitude of

threats or risk if the remedia

Not applicable. alternative. Uncertainties associated with rate of
Operations and maintenance functions include continued operations, maintenance, and replacement of OCVZ treatment units. Periodic enals of the surface barrier would include he surface barrier if substantial damage occurs

Periodic surveillance activities would include urveys to identify evidence of animal intrusio (e.g., burrows) and to ensure $\mathrm{p}$.

Operation and maintenance of the OCVZ extraction and treatment system would be 7-13/14 remediation goals

Operations and maintenance functions include

No major difficulties are anticipated during long-term operations and maintenance of this diffusion of VOCs from buried waste may Uncertainty associated with failure rates for buried waste containers may extend the risk of surface barrier subsidence beyond 100 years.

Surface barriers would be designed to

accommodate minor subsidence; however,

significant subsidence (e.g., collapse of a large buried container) could require reconstruction of portions of the surface barrier. Periodic repair and replacement of the OCVZ treatment syste is part of this alternative. Any monitoring

equipment and instrumentation

(e.g., tensiometers and well pumps) would also require periodic replacement. Other componen nents, and associch basive vers, as tocive of 1,000 years; replacement is not anticipated. Components of the environmental monitoring system may require replacement.

Short-term risk associated with replacement of monitoring equipment or subsidence repair would be extremely low. Risk for these activities would include average SDA background worlo implementation of the repair. estimate. The ET surface barrier, passive gas would be entremely low. Risk for hese activitic surveillance and repali of he surface banier, a continued operations, maintenance, an replace op of OCVZ treatnent units. Perio reserion the suffece barier if substantial damage occurs (i.e., large subsidence events)

Periodic surveillance activities would include surveys to identify evidence of animal intrus (e.g., burrows) and to ensurn vegetative community.

Operation and maintenance of the OCVZ extraction and treatment system would be contined unilou 7-13/14 rec continued operations, maintenance, and replacement of OCVZ treatment units. Perio epair of the surface barrier would include (i.e., large subsidence events).

Periodic surveillance activities would include surveys to identify evidence of animal intrus healthy vegetative community.

Operation and maintenance of the OCVZ extraction and treatment system would be conthued 作 diffusion of VOCs from buried waste may extend the duration of OCVZ operations. Uncertainty associated with failure rates for buried waste containers may extend the risk surface barrier subsidence beyond 100 years.

In situ grouting of waste containing Tc-99 is assumed to be a one-time action that would not require replacement. Relocation of stabilized
Pad A waste within the OU 7-13/14 area of contamination is assumed to be a one-time action that would not require replacement. Replacement of OCVZ treatment units is included in the operations and maintenance cos vents, and associated perimeter markers are assumed to have effective design lives in excess Components of the environmental monitoring system may require replacement.

Short-term risk associated with replacement of monitoring equipment or subsidence repair would include average SDA background rachol implementation of the repair. long-term operations and maintenance of this alternative. Partial retrieval of VOC-containing waste (e.g., Series 743 sludge) may shorten the duration of OCVZ operations. Uncertainty associated with failure rates for buried waste containers may extend the risk of surface barrier subsidence beyond 100 years.

Future subsidence and associated repair would be anticipated for the 2-acre RTD alternative to reduced foundation stabilization achieved through proof-rolling as opposed to the more effective dynamic compaction performed in the 4-acre RTD alternative. Replacement of OCVZ treatment units is included in the operations a maintenance cost estimate. The ET surface barrier, passive gas vents, and perimeter mark are assumed to have effective design lives excess of 1,00 years, replacement is not

monitoring system may require replacement.

Short-term risk associated with replacement of monitoring equipment or subsidence repair would include average SDA background

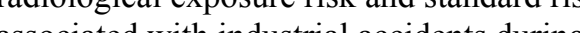
implementation of the repair. would be extremely low. Risk for these activit
Alternative 5 Operations and maintenance functions include surveillance and repair of the surface barrier, continued operations, maintenance, and enceriodic

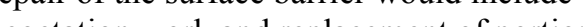
he surface barrier if substantial damage occurs (i.e., large subsidence events).

Periodic surveillance activities would include Per healthy vegetative community.

Operation and maintenance of the OCVZ xtraction and treatment system would be

No major difficulties are anticipated during alternative.

For this alternative, future subsidence is not anticipated due to absence of waste material under the surface barrier. Replacement of OCVZ

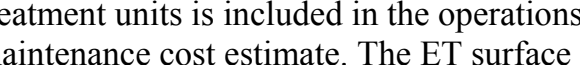
barrier and perimeter markers are assumed to have effective design lives in excess of 1,000 years; replacement is not anticipated. Components of the environmental monitoring system may require replacement.

Short-term risk associated with replacement of monitoring equipment or subsidence repair would be extremely low. Risk for these activities would include standard risk associated with 
Specific Considerations What is the degree of confidence that controls can
adequately handle potential

What are the uncertainties associated with land dispo waste?
Not applicable.

Alternative 1

Not applicable.

with

\section{Long-term monitoring and maintenance would \\ be adequate to identify potential problems. No barriers inhibit routine maintenance and repar. Subsidence repair has been successfully} and repeatedly performed in the SDA for se
years without worker safety issues. A high degree of confidence exists that monitoring and repair activities would adequately address any performance problems encountered with the surface barrier.

Remedial components included in this alternative would not result in generation of treatment residuals that would require land disposal. Removal and relocation of Pad A was within the OU 7 -13/14 area of contantion
Alternative 3

ong-term monitoring and maintenance would be adequate to identify potential problems. No barriers inhibit roune maintenance and repair. and repeatedly performed in the SDA years without worker safety issues. A high degree of confidence exist that monitoring and repair activities would adequately address any performance problems encountered with the surface barrier

Remedial components included in this alternative would not result in generation of treatment residuals that would require lan disposal. However, stabilization of Pad A pirto ploment and require treatment to meet land dispost restrictions, unless a waiver were obtained.

\section{Alternative} Leng antence would be adequate to identify potential problems. No barriers inhibit routine maintenance and repair. and repeatedly perforen sucs years without worker safety issues. A high degree of confidence exist that mon toring and repair activities would adequately address any performance problems encountered with the surface barrier.

Shipments of transuranic waste to WIPP are exempt from specific land disposal restriction Uncertainties recmain for disposal of Pad A waste at ICDF and retieved waste that cannot be
Alternative 5

Full Retrieval, Treatment, and Disposal

Long-term monitoring and maintenance would be adequate to identify potential problems. No barriers inhibit routine maintenance and repair. Subsidence repal has beed

yer seve egree of confidence exist that monitoing repair activities would adequately address any performance problems encountered with the surface barrier.

Shipments of transuranic waste to WIPP are exempt from specific land disposal restrictions. Uncertainties remain for treatost, storage, and disposal facilities outside the INL Site for Pad certified for dispost at WIPP. Curoty

identified disposal path is available for remote-handled nontransuranic waste retrieved from the SDA.
CERCLA $=$ Comprehensive Environmental Response, Compensation, and Liability Act
COC $=$ contaminant of concern $\mathrm{COC}=$ contaminant of con
$\mathrm{ET}=$ evapotranspiration

IC $=$ institutional control

ICDF = Idaho CERCLA Disposal Facility

ISG $=$ in situ grouting
$O C V Z=$ Organic Contamination in the Vadose Zone
$O U=$ oprable unit
RCR $A$ Resource Conservation and Recovery Act
ROD $=$ record of decision

$\mathrm{OCVZ}=$ Organic $\mathrm{C}$

$\mathrm{RCRA}=$ Resource Conse
$\mathrm{ROD}=$ record of decision $\begin{aligned} & \mathrm{RTD}=\text { retrieval, treatment, and disposal } \\ & \mathrm{RWMC}\end{aligned}=$ Radioactive Waste Management Complex

SDA = Subsurface Disposal Area

VOC $=$ volatile organic compound
WIPP $=$ Waste Isolation Pilot Plant 
Specific Considerations Alternative
No Action

\section{Treatment process and remedy}

Does the treatment process hreats?

Not applicable.

process?

Not applicable.

meet OU 7-13/14 remediation goals. Remova

of organic vapors from the vadose zone using
the OCVZ system must meet OU 7-13/14 remediation goals.

pet al. 2006), Alternative 2

Alternative 3

Because source materials containing liquid
or highly mobile materials posing a risk

potential of 1E-03 (EPA 1991) have not been

waste. However, potential risk associated several primary COCs (i.e., VOCs, C-14, Tc-99, and I-129) may exceed OU 7-13/14 Under this alternative, a surface barrier is constructed to (1) reduce migration of water-soluble contaminants into the vadose from the buried waste zone to the ground surface. Removal of soil vapors from ben the surface barrier and vadose zone would minimize gas-phase nigration of VOCs and

In Situ Grouting

Alternative 4

Alternative 5

Full Retrieval, Treatment, and Disposal

Because source materials containing liquid perighly mobile materials posing a risk

potental of HE-03 (EPA 1991) have not been SDA wa SDA Howevot contin principal threat several primary COCs (i.e., VOCs, C-14, Tc-99, and 1 -129) may exceed $\mathrm{OU}$ 7-13/14 Under this alternative, a surface barrier is constructed to (1) reduce migration of water-soluble contaminants into the vadose from the buried waste zone to the groun surface. Removal of soil vapors from benest the surface barrier and vadose zone would minimize gas-phase migration or $\mathrm{VOCs}$ and C-14 to the aquifer. In addition, Alternative would provide an additional measure of

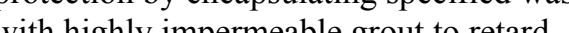
migration of Tc-99 and I-129.

In situ immobilization of Tc-99 and I-129 in source materials is dependent on

dentification of disposal locations for waste

packages containing mobile contaminants.

Once disposal locations are identified,

effectiveness of ISG immobilization is

dependent on completeness of encapsulation

and durability of the resulting waste form.

inferred from review of dispos wond

results of bench-scale treatability studies,

construction process knowledge. Pad A waste

would be treated to meet land disposal

restrictions unless a waiver is obtained.
Because source materials containing liquids or highly mobile materials posing a risk

potential of 1E-03 (EPA 1991)

identified in the SDA (Holdren et al. 2006),

We SDA does not contain principal threat

waste. However, potential risk associated

several primary COCs (i.e., VOCs, C-14,

Tches

Under this alternative, a surface barrier is

constructed to (1) reduce migration of

water-soluble contaminants into the vadose

om the buried waste zone to the ground

he surface barrier and vadose zone would

minimize gas-phase migration of VOCs an

$\mathrm{C}-14$ to the aquifer. In addition, Alternative

would provide an additional measure of

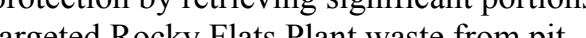
areas.

Targeted waste containing transuranic sotopes must be certified for shipment and disposal at WIPP. Targeted roaster oxides with no transuranic isotopes may require treatment for the characteristic or reactivity or
Because source materials containing liquids porighly mobile materials posing a risk

potential of 1E-03 (EPA 1991) have not been

SDA the SDA (Holdren et al. 2006),

the SDA does not contain principal threat were we cady entered the underlying vadose zone potential risk of exceeding U 7-13/14 remedial action objectives if no ddressed. Under this alternative, a simplified urface barrie i igration of water-soluble contaminants vapors from the vadose zone would minimize quifer.

Waste containing transuranic isotopes must be certified for shipment and disposal at WIPP. Contact-handled waste with no transuran isotopes must be characterized to allow

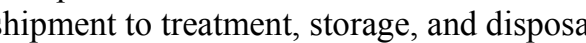
facilities outside the INL Site. Characterization requirements for shipment and disposal of remote-handled established. 
Specific Considerations

Alternative 1

mount of hazardous material destroyed or treated

What portion (mass or volume) Not applicable.

of contaminated material is

destroyed?

What portion (mass or volume) Not applicable. of contaminated material is

treated?
No portion of waste mass or volume is destroyed in situ. A portion of VOCs released from source materials is removed from the vadose zone beneath the surface barrier and thermally oxidized using the $\mathrm{OCVZ}$ treatme system. Operation and maintenance of the OCVZ extraction and trealment system would goals are met.

There is no source treatment activity under this alternative. A portion of VOCs released from source materials is removed from the vadose zone beneath the surface barrier and thermally oxidized using the $O C V Z$ treatne system. Operation and maintenance of the OCVZ extraction and treatment system wo goals are met.
No portion of waste mass or volume is estroyed in situ. A portion of VOCs relea from source materials is removed from the vadose zone beneath the surface barrier and

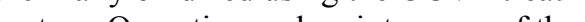
SCVZ Operation and maintenance of the be co extaction and $7-13 / 14$ gols and Specified areas would be treated it In situ grouting treatment areas would immobilize approximately $50 \%$ of the $\mathrm{Tc}-99$ that migh rapidly migrate from source materials (e.g., surface contaminated debris, resins, fuel examination waste). Preconceptual designs assume that approximately 0.2 acres of specified areas would be grouted from the surfecting zone. Approximately $360,000 \mathrm{ft}^{2}$ of waste would be excavated from Pad A, including approximately 11 million pounds of Rocky Flats Plant Series 745 evaporator salts, which represent approximately one-half of total nitrate buried in the SDA. All waste an debris excavated from Pad A would be stabilized with cementitious grout before OU 7-13/14 area of contion.

Alternative 4

Partial Retrieval, Treatment, and Disposal

Alternative 5

Full Retrieval, Treatment, and Disposal

No portion of waste mass or volume is destroyed; however, contaminants are transferred to various treatment and disposal locations. The 2 and 4-acre RTD alternatives retrieve approximately $92,800 \mathrm{fl}$ and $119,200 \mathrm{ft}$ of targeted waste, respectively, either transered to WIPP reatment and disposal. In a dition, Subalternative 4a removes approxim 11 million pounds of nitrate salts from $\mathrm{Pad} A$ and sends them to the ICDF for treatment and disposal. A portion of VOCs released from source materials is removed from the vadose zone beneath the surface barrier and thermally oxidized using the OCVZ treatment system. Operation and maintenance of the OCVZ extraction and treat 7 nt systern would be continued

All waste excavated from the SDA would be sent to either a preexisting on-INL Site off-INL Site facility for treatment and disposal. The 2 and 4-acre RTD alternative remove approximately $92,800 \mathrm{ft}^{3}$ and 119,200 of of targeted waste, respectively, from pit areas within the SDA. This waste either transferred to WIPP or to ICDF for Subater an disposal.

11 milion pounds of nits appoximately and sends them to the ICDF for treatment and disposal.
No portion of waste mass or volume is transferred to various treatment and dispo locations. The full RTD alternative would remove approximately 13 billion $\mathrm{ft}^{3}$ of waste from the SDA. This waste is then transfered to the WIPP for disposal, transferred to the disposal, transferred to an off-INL Site acility, (e. EnergySolutions [formerly Envirocare]) for treatment and disposal, or transferred to a repository for disposal of remote-handled nontransuranic waste. A portion of VOCs released from source materials is removed from the vadose zone beneath the surface barrier and thermally oxidized using the OCVZ treatment system. Operation and maintenance of the OCVZ continued unti OU 7-13/14 im world be

All waste excavated from the SDA, with the exception of remote-handled nontransuranic waste, would be sent to a preexisting on-INL dispor off-INL Site facility for treatme approximately 13 billion $\mathrm{ft}^{3}$ of waste from the DA pit areas. 
Specific Considerations

Alternative 1
No Action Alternative 2

\section{No Action}

Reduction in toxicity, mobility, or volume through treatment

To what extent is the total

Not applicable.

reduced?

Alternative 2 does not reduce the total mass of toxic contaminants through treatment-all contaminants remain in the SDA following remediation.
To what extent is the mobility Not applicable. of toxic contaminants reduced?

To what extent is the volume of toxic contaminants reduced?
Though this alternative does not include treatment of the source term, mobility of all contaminants would be inhibited by overal reduced infiltration afforded by the surface barrier. The surface barrier would (1) reduce migration of water-soluble contaminants into con the ground surface. Active venting of soil vapors from beneath the surface barrier and active removal of soil vapors from the vadose zone using the OCVZ system would minimize migration of volatile COCs to the underlying aquifer.

This alternative does not substantially change the volume of toxic contaminants because waste is left in the SDA. Active extraction of soil vapors using the OCVZ system does no directly reduce the volume of waste
containing VOCs in the buried waste $z$
Alternative 3 does not reduce the total mass of remediation toxic contaminants through treatment—all

Alternative 3

This alternative includes treatment to reduce mobility of a small portion of the source tern In situ grouting would reduce release of Tc-99 nd collocated COCs (i.e., I-129) into moisture that might infiltrate the buried waste zone. Mobility of all contaminants would ifforded by the surface barrier. The ET surface barrier would (1) reduce migration of water-soluble contaminants into the vadose zone and (2) reduce transport of contaminants from the buried waste zone to the ground surface. In addition, ex situ treatment of Pad A waste would not substantially affect contaminant mobility. Passive venting of soil vapors from beneath the surface barrier and active removal of soil vapors from the vadose zone using the OCVZ system would minimize

Remedial components included in Alternative 3 do not reduce the volume of toxic contaminants remaining in the SDA. In situ grouting of buried waste would result in a cohesive waste form several times the volu
of the specified waste disposals. Ex situ of the specified waste disposals. Ex situ
stabilization of Pad A waste would result in stabilization of Pad A waste would result
relocation of approximately 1.5 times relocation of approximately 1.5 times
(assumed 40 to 45 vol\% expansion) the original waste volume to another area within the OU 7-13/14 area of contamination. Active extraction of soil vapors using the OCVZ system does not directly reduce the volume of waste containing VOCs in the buried waste zone.

Alternative 4

Partial Retrieval, Treatment, and Disposal

Alternative 5

Full Retrieval, Treatment, and Disposal

Alternative 4 does not reduce the total mass of toxic contaminants through treatment; however, a portion of the mass is transferr elsewhere following retrieval. The 2 and 4-acre subalternatives remove significan portions of targeted waste from pit areas within the SDA. In addition, the 4-acre 11 million pounds of nitrate salts from Pad and sends them to ICDF for treatment and disposal.

This alternative does not affect the mobility of contaminants, but removes a significant portion of targeted waste from pit areas with he SDA. In addition, a small portion of the argeted waste (i.e. roaster oxides) is sent $t$ he ICDF or an off-INL Site facility for (1) reduce migration contaminants into the vadose zone and

(2) reduce transport of contaminants from the buried waste zone to the ground surface. In addition, passive venting of soil vapors from beneath the surface barrier and active removal of soil vapors from the vadose zone using the DCVZ system would ninimize migration of volatile COCs to the underlying aquifer.

Treatment to reduce volume is not a feature of Treatment to reduce volume is not a primary Alternative 4. However, the 2 and 4-acre RTD feature of Alternative 5. However, this alternatives remove approximately $92,800 \mathrm{ft}^{3} \quad$ alternative would remove all the waste and most of the contaminated media from the

respectively, from pit areas within the SDA. ICDF for is either transferred to WIPP or to ICDF for treatment and disposal. In addition, 11 million pound refoves approximately and sends them to ICDF for tels from Pad $A$ disposal.
Alternative 5 does not reduce the total mass however, most of the mass is transferred val. Alternative 5 would remove all waste from the buried waste

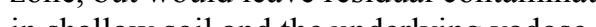

This alternative does not affect the mobility of contaminants, but removes all the waste SDA. The she contaminated media from would reduce transport of contaminants from the basalt interface to the ground surface. 
Specific Considerations

\section{Irreversibility of treatment}

To what extent are the effects Not applicable. of treatment irreversible?

\section{Type and quantity of treatment residual}

\section{What residuals remain? \\ Not applicable}

Not applicable.

characteristics?
Alternative 2 does not include treatment of waste at the SDA; therefore, no treatment residuals are produced. All contaminants, except volatile contaminants removed using the OCVZ system, remain in the SDA.

Alternative 2 does not include treatment of waste at the SDA; therefore, no treetment residuals are produced. All contaminants. except volatile contaminants removed using the OCVZ system, remain in the SDA.
Not applicable.
Because this Alternative 2 does not include treatment of waste at the SDA, there are no
Although this alternative does not include

system would be thermally oxidized, which is an irreversible process.

Though grout stabilization of waste would not preclude subsequent retrieval using egregating encapsulated waste from the cement matrix would be infeasible. A portio of VOCs released from source materials is removed from the vadose zone beneath the hermal oxidation treatment system.

In situ grouting addresses a very small portion (e.g., 0.2 acres) of the total disposal area in the SDA, and little or no treatment residuals of Pad A waste within the SDA would result in a significant increase in waste volume, but ot destroy the underlying contaminants. contaminants would remain in the SDA.

Alternative 3 would produce little or no treatment residuals. In situ treatment of specified disposals containing Tc-99 in would immobilize approximately $75,000 \mathrm{ft}^{3}$ waste and collocated media. Treated waste would be impermeable to moisture infiltra for at least 1,000 years. Ex situ treatment of Pad A waste would result in approximately $725,000 \mathrm{ft}^{3}$ of treated nitrate salts and fines
and $104,000 \mathrm{ft}^{3}$ of treated debris, which woul and ret, contamination. Treated Pad A waste would not be susceptible to subsidence, but would not effectively immobilize nitrate salts.

Alternative 3 would produce little or no risk. In situ treatment of specified fission and activation-product waste disposals would etard diffusion of Tc-99, I-129 and corcted in the future. Ex situ stabilization of Pad $\mathrm{A}$ waste would not retard diffusion of nitrate.
Alternative 4

Alternative 5

Partial Retrieval, Treatment, and Disposal

portion of VOCs released from source beneath the surface barrier using an treatment system.

portion of VOCs released from past source materials is removed from the vadose zone beneath the surface barrier using an $z$ reversible OCVZ thermal oxidation eatment system

Alternative 4 does not include treatment of waste at the SDA; therefore, no treatment residuals are produced. Retrieval of Rocky would remove of a significant portion (a) he SDA.

Alternative 4 does not include treatment of waste at the SDA; therefore, no treatment alternatives would leave most of the radiological COCs and a portion of the 列 4-acre subalternative (4a) would transfer Pad zone will remain beneath the SDA. disposal, re ICDF for treatment and itrate salt mass from the SDA.

Alternative 4 does not include treatment of waste at the SDA; therefore, no treatme residuals are produced that would pose additional risk. Radiological and nonradiological COCs remaining within the DA following targeted waste retrieval or pit
Alternative 5 does not include treatment of waste at the SDA; therefore, no treatment wove all produced. Alternative 5 would

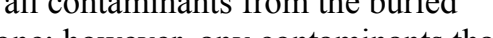
ay have, already migrated into the vadose

Alternative 5 does not include treatment of waste at the SDA : therefore, no zone will remain beneath the SDA.
Alternative 5 does not include treatment of waste at he SDA, therefore, no treatment residuals are produced that would pose all contaminants from the buried waste zone, Iready migrated into the vadose zone will remain beneath the SDA. additional risk. Alternative 5 would remove 
Table C-2. (continued).

\begin{tabular}{|c|c|c|c|c|c|}
\hline Specific Considerations & $\begin{array}{l}\text { Alternative } 1 \\
\text { No Action } \\
\end{array}$ & $\begin{array}{l}\text { Alternative } 2 \\
\text { Surface Barrier }\end{array}$ & $\begin{array}{l}\text { Alternative } 3 \\
\text { In Situ Grouting } \\
\end{array}$ & $\begin{array}{c}\text { Alternative } 4 \\
\text { Partial Retrieval, Treatment, and Disposal } \\
\end{array}$ & $\begin{array}{l}\text { Alternative } 5 \\
\text { Full Retrieval, Treatment, and Disposal }\end{array}$ \\
\hline \multicolumn{6}{|c|}{ Statutory preference for treatment as a principal element } \\
\hline $\begin{array}{l}\text { Are principal threats within the } \\
\text { scope of the action? }\end{array}$ & $\begin{array}{l}\text { Not applicable. Principal threats, } \\
\text { defined as source materials containing } \\
\text { liquids or highly mobile material } \\
\text { posing a risk potential of } 1 \mathrm{E}-03 \text { or } \\
\text { greater (EPA 1991), are not present in } \\
\text { the SDA (Holdren et al. 2006). }\end{array}$ & $\begin{array}{l}\text { Not applicable. Principal threats, defined } \\
\text { as source materials containing liquids or } \\
\text { highly mobile material posing a risk potential } \\
\text { of } 1 \text { E- } 03 \text { or greater (EPA 1991), are not } \\
\text { present in the SDA (Holdren et al. 2006). }\end{array}$ & $\begin{array}{l}\text { Not applicable. Principal threats, defined as } \\
\text { source materials containing liquids or highly } \\
\text { mobile material posing a risk potential of } \\
\text { 1E-03 or greater (EPA 1991), are not present } \\
\text { in the SDA (Holdren et al. 2006). }\end{array}$ & $\begin{array}{l}\text { Not applicable. Principal threats, defined as } \\
\text { source materials containing liquids or highly } \\
\text { mobile material posing a risk potential of } \\
\text { 1E-03 or greater (EPA 1991), are not present } \\
\text { in the SDA (Holdren et al. 2006). }\end{array}$ & $\begin{array}{l}\text { Not applicable. Principal threats, defined as } \\
\text { source materials containing liquids or highly } \\
\text { mobile material posing a risk potential of } \\
\text { 1E-03 or greater (EPA 1991), are not present } \\
\text { in the SDA (Holdren et al. 2006). }\end{array}$ \\
\hline $\begin{array}{l}\text { Is treatment used to reduce } \\
\text { inherent hazards posed by } \\
\text { principal threats at the site? }\end{array}$ & Not applicable. & Not applicable. & Not applicable. & Not applicable. & Not applicable. \\
\hline
\end{tabular}

inherent hazards posed by

$\mathrm{NL}=$ Idaho National Laboratory
$\mathrm{ISG}=$ in situ grouting

ISG $=$ in situ grouting
$\mathrm{OCVZ}=$ Organic $\mathrm{C}$

$\mathrm{OU}=$ operable

RTD $=$ retrieval, treatment, and disposal
SDA $=$ Subsurface Disposal A rea

CERCLA $=$ Comprehensive Environmental Response, Compensation, and Liability Act
$C O C=$ contaminant of concern

$\mathrm{ET}=$ evapotranspiration
$\mathrm{ICDF}=$ Idaho $C E R C L A$ Disposal Facility

$U=$ operable unit

VOC $=$ volatile organic compound
WIPP = Waste Isolation Pilot Plan 
Specific Considerations

\section{Protection of community during remedial actions}

\section{What are the risks to the \\ Not applicable. No remedial}

actions that must be

action is im
alternative.

addressed?
How would risk to the community be addressed an mitigated?

Not applicable. No remedial alternative.

None.

What risk to the community remains that
controlled?
No additional risk would be posed to the community when controls typical of DOE waste management operations are used (Wheldon et al. 2006). Primary concerns for the community would be potential release of cost on that Pad A waste could be excavated, treated, and relocated within the OU 7-13/14 area of contamination with public to significant amounts of hazardous or radioactive contaminants. Approximately one public injury might be incurred in an accident involving transport of construction materials the SDA over public thoroughfares. The possibility that transport of construction materials for this allentive would result in a highly unlikely.

No additional risk would be posed to the community when controls typical of DOE

waste management operations are used

Wheldon et al. 2006). Operating experience in the SDA suggests that ISG could be conducted (1) contaminants Similarly, operating experience gained during the ongoing Accelerated Retriev Project suggests that Pad A waste could be excavated, treated, and relocated within the OU 7-13/14 area of contamination without exposing members of the public to significant amounts of hazardous or radioactive contaminants. Approximately one public injury might be incurred in an accident involving transport of cod over public thoroughfares. The possibility th alterntive would member of the public is highly unlikely.

Community risk is considered to be negligible for this alternative. Developing a stringent traffic control plan would mitigate risk. In addition, appropriate engineering controls and contingency plans would be developed and implemented during surface barrier installatio No contaminated material would be exposed dung installion. Engheered and

(2a), dynamic compaction (2b), and recouting of Pad A (2b) would prevent public exposure to airborne contaminants and penetrating radiation. Delivery schedules would be adjusted to

minimize public exposure to risk associated with transport of construction materials to the SDA.

Neither subalternative presents risk to membe of the public that cannot be readily controlled.
Engineered and administrative controls for ISG and excavation, treatment, and relocation of Pad A waste would prevent public exposure airborne contaminants and penetrating radia Delivery schedules would be adjusted to with transport of construction materials to the SDA.

Alternative 3 presents no risk to members of public that cannot be redily controlled.
Partial Retrieval, Treatment, and Disposal
Overall, both the 2 and 4-acre RTD alternatives would pose very low health risk to the community when controls typical of DOE waste management operations are used Wheldon ex al. 206). Operating experience Project sugest the 4 ith 2 ores of wore could be excavated and shipped off the SDA for treatment and disposal without exposing members of the public to significant amou hazardous or radioactive contaminants. Approximately one public recordable injury might be incurred in accidents involving transport of construction materials to the SDA over public thoroughtares for either alternative. materials for either alternative would result in a transport of waste.

Engineered and administrative controls implemented during waste retrieval and dynamic compaction of Pad A would preven public exposure to airborne contaminants and penetrating radiation. Delivery schedules would be adjusted to minimize public exposure to associated with transs The possibility that transport of construction fatality involving a member of the public is

Overall, this alternative would pose moderate health risk to the community when controls typical of DOE waste management operation are used (Wheldon et al. 2006). Operating Accelerated Retrieval Project suggests th contact-handled waste could be excts that shipped off the SDA for treatment and disposal without exposing members of the public to significant amounts of hazardous or radioactive contaminants. Less than one public recordable injury might be incurred in accidents involving transport of construction materials to the SDA over public thoroughfares for this alternative. The possibility that transport of construction materials for this alternative would result in fatality involving a member of the public is highly unlikely. Substantially more injuries during transport of waste.

Engineered and administrative controls implemented during waste retrieval would prevent public exposure to airborne Delivery schedules would be adjusted to minimize public exposure to risk associated

Neither subalternative presents risk to membe of the public that cannot be readily controlled.
Alternative 5 does not present risk to members of the public that cannot be readily controlled. 
What is the risk to workers that Not applicable. No remedial action is implemented under this implune alternative.
A maximally exposed worker involved included in this alternative that have proximi to contaminated media would incur relatively low risk from penetrating radiation relative to worker involved in routine construction Most radiological risk accrued by a remedi
worker involved in Subalternative $2 \mathrm{~b}$ is worker involved in Subaltenative $2 b$ is relocation of Pad A waste. Chemical risk and hazards for a remediation worker would be negligible. Workers implementing remedial components may incur as many as seven recordable industrial accidents. A worke would be highly unlikely. activities in the SDA (Wheldon et al. 2006).

A maximally exposed worker involved in included in this alternative that have proximity contaminated media would incur a relatively low risk from penetrating radiation relative to a worker involved in routine construction Metivities in the SDA (Wheldon et al. 2006). Most radiological risk accrued by a remediation

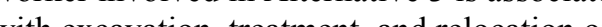
Pad A waste. Chemical risk and hazd for a remediation worker would be negligible. Workers could incur as many as 12 recordable industrial accidents. A worker fatality during mplementation of this alternative would be highly unlikely.

$$
\text { (a) }
$$

Overall, both the 2 and 4-acre RTD subalternatives pose moderate to moderately high risk to a remediation worker. Operating experience gained during the ongoing waste within the SDA pits and Pad A could be waste within the SDA pits and Pad A could treatment and disposal without SDA for remedint arosing administrative dose. Therefore, the bove-mentioned risk values are highly conservative. Remediation workers would be protected from chemical risk and hazards through use of engineering and administrative to the collocated worker from building manageable. Workers implementing remedia components would incur as many as 32 (2-acre RTD) and 56 (4-acre RTD) recordable industring accidents. A worker fatality during implementation
highly unlikely.

What risk to workers remains $\quad$ Not applicable. No remedial that cannot be readily controlled? alternative.

All physical and chemical risk to remediation workers could be readily controlled through use of engineered or administrative controls or use of personal protective equipment.

All physical and chemical risk to remediation workers could be readily controlled through use

All physical and chemical risk to remediation workers could be readily contive controls or use of personal protective equipment.

Risk to remediation workers would be address by (1) maintaining exposure to penetrating radiation as low as reasonably achievable,
(2) using personal protective equipment to lin risk associated with inhalation or dermal adsorption of radionuclides or chemicals, and (3) promoting a safety culture that creates a work environment free from occupational injur or illness.
Risk to remediation workers would be addresse by (1) maintaining exposure to penetrating risk associated with inhalation or dermal adsorption of radionuclides or chemicals, and (3) promoting a safety culture that creates a work environment free from occupational injur or illness. (2)
Risk to remediation workers would be addressed by (1) maintaining exposure to penetrating risk associated with inhalation or dermal adsorption of radionuclides or chemicals, and work environment free from occupational inj or illness. radiation as low as reasonably achievable, (3) promoting a safety culture that creates a
Alternative 5 poses relatively high risk to the remediation worker. Operating experience gained during the ongoing Accelerated Retrieva Project suggests that contact-handled waste within could be excavated and shipped off the SDA for treatment and disposal without exposing remediation workers to the maximum allowable administrative dose. Though the low exposure rates during tect has experienced retrieval activities, risk of exposure to high

doses would increase when removing the buried remote-handled objects and when sizing the oversized items. Therefore, the above-mentioned risk values are only moderately conservative. Radiological and chemical cancer risks to collocated workers from building emissions during waste retrieval are manageable. Workers implementing 616 rial components would incur as many as 616 recordable indus wal accidents. A worker would be highly unlikely.

All physical and chemical risk to remediation workers could be readily controlled through us of engineered or administrative controls or use of personal protective equipment.

Risk to remediation workers would be addressed by (1) maintaining exposure to penetrating

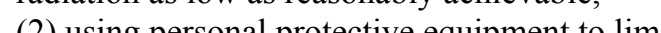
risk associated with inhalation or dermal adsorption of radionuclides or chemicals, (3) promoting a safety culture that creates a work environment free from occupational injury or illness. 
Specific Considerations

\section{Environmental impacts}

What environmental impacts Not applicable. No remedial are expected with construction and implementation of the Iternative?
Minimal or no environmental impacts are construction of the surface barrier. No contaminated media would be exposed during construction of the ET surface barrier; therefore, contamination of adjacent areas is not anticipated. Areas immediately outside the existing SDA perimeter fence would be physically distribed ding surface barrier drainage contours, and vegetation. Cultur resource could be impacted in borrow sites and in areas adjacent to the SDA that are affected by occur during surface barrier construction.

Potentially impacted areas would be screened to What are the available Not applicable. No remedia itigation measures to be used action is implemented under this nhat is their reliability to alternative.

minimize potential impacts?
What are the impacts that cannot be avoided should the
alternative be implemented?
Not applicable. No remedial action is implemented under th alternative. anticipated for relocation of Pad A waste and remedial actions. Fugitive dust releases could

Minimal or no environmental impacts are locations, or excavation, treatment, an relocation of Pad A waste within the OU 7-13/14 area of contamination. No contaminated media would be exposed during construction of the ET surface barrier; therefore, contamination of adjacent areas is not existing SDA perimme fely onside the physically disturbed during surface barrier enstruction, grading to reestablish local drainage contours, and vegetation. Cultural resources could be impacted in borrow sites in areas adjacent to the SDA that are affected by remedial actions. Fugitive dust releases could occur during surface barrier construction

Conventional suppression measure

(e.g., retrieval enclosures, water mist systern minimize fugitive dusts during ISG, relocetion of Pad A waste within the OU 7-13/14 area of contamination, and construction of the ET surface barrier. A mixture of perennial plan species would be used to vegetate the surface activities would be required to ensure construction of new borrow areas do not have suppression measures would be used to minimize fugitive dusts during construction of he surface barrier. A mixture of perennial pla species would be used to vegetate the surface barrier and adjacent areas. Vegetation would mitigate wind or water erosion on the ET surface barrier and is an essential co
optimal surface barrier performance.

All impacts can be readily avoided or mitigated. barrier and adjacent areas. Vegetation wo mitigate wind or water erosion on the ET surface barrier and is an essential compon
optimal surface barrier performance.

ET

All impacts can be readily avoided or mitigated.

Partial Retrieval, Treatment, and Disposal

\section{Alternative 5}

Full Retrieval, Treatment, and Disposal

Minimal or no environmental impacts are anticipated for the partial retrieval alternative No contaminated media would be exposed during proof-rolling, installation of the perimeter slurry cut-off wall, or during construction of the ET surface barrier; howev dynamic compaction of pits and Pad A could result in conn existing SDA perimeter fece would be physically disturbed during surfe barrie construction, grading to reestablish local drainage contours, and vegetation. Cultural resources could be impacted in borrow sites an in areas adjacent to the SDA that are affected by remedial actions. Fugitive dust releases could

Conventional suppression measures

(e.g., retrieval enclosures, water mist system
, and water spray systems) would be used to minimize fugitive dusts during impleme compaction of Pad A, proof-rolling, slury cut-off wall installation, and construction of ET surface barrier. A mixture of perennial plant species would be used to vegetate the surface barrier and adjacent areas. Vegetation would mitigate wind or water erosion on the ET surface barrier and is an essential componen
for optimal surface barrier performance.
Minimal or no environmental impacts are anticipated for full SDA excavation. No contaminated media would be exposed during retrieval or during construction of the ET surface barrier, therefore, contamination of djacent areas is not anticipated. Areas ferimeter fence would be physically disturbed during (eestablish local drainage contours and vestablish local drahage crisurs, and mpacted in borrow sites and in areas adjacent to the SDA that are affected by remedial actions. Fugitive dust releases could occur during surface barrier construction.

Conventional suppression measure

g., retrieval enclosures, water mist system minimize fugitive dusts during SDA retrieva and construction of the ET surface barrier. A mixture of perennial plant species would be used to vegetate the surface barrier and adjacen areas. Vegetation would mitigate wind or water erosion on the ET surface barrier and is an essential component for optimal surface barrier performance.

All impacts can be readily avoided or mitigated 
Specific Considerations Alternative 1 Alternative 3

\section{Time until remedial action objectives are achieved}

How long until protection Protection is not achieved.

against the threats being

addressed by the specific

action is achieved?

How long until any remaining Site threats are not addressed. site threats would be

addressed?

How long until remedial action Remedial action objectives are objectives are achieved? not achieved. goals are met.

Operation and maintenance of the OCVZ
All remedial components included in

Alternative 2, including construction of the

ET surface barrier, would be completed with

$7(2 \mathrm{a})$ to $10(2 \mathrm{~b})$ years of project inception. he surface barrier. Operation cond of the OCVZ extraction and treatment system would continue until OU 7-13/14 remediatio

All remedial components included in Alternative 3 , including construction of the $\mathrm{ET}$ surface barrier, would be completed within 10 years of project inception. In situ grouting of specified waste disposals containing Tc-99 project inception. extraction and treatment system would contin

peration and maintenance of the OCVZ extraction and treatment system wold until OU 7-13/14 remediation goals are met. The passive gas vent layer in the surface barrier would minimize migration of volatile C-14 into the vadose zone for at least 1,000 years.

This alternative would achieve all OU 7-13/14 medial action objectives upon completion of the ET surface barrier. Operation and maintenance of the OCVZ extraction and treatment system would continue until OU 7-3/14 remediation goals are met.
Alternative 4

Partial Retrieval, Treatment, and Disposal

All remedial components of Alternative 4 ,

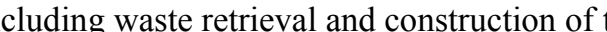
ET surface barrier, would be completed within 12 (4b) to 16 (4a) years of project inception. Altenative ta retrieval and transport operations could be complete as early as 8 years after project inception. Alternative $4 \mathrm{~b}$ waste retrie and transport operations could be complete as

Operation and maintenance of the OCVZ extraction and treatment system would continue until OU 7-13/14 remediation goals are met. The passive gas vent layer in the surface barrie would minimize migration of volatile $\mathrm{C}$ - 14 the vadose zone for at least 1,000 years.

Both partial retrieval subalternatives would achieve all OU 7-13/14 remedial action

barrier Operation and maintenance of surface

OCVZ extraction and trentment system would

continue until OU 7-13/14 remediation goals met.

RTD $=$ retrieval, treatment, and disposa
SDA = Subsurface Disposal Area
Alternative 5

All remedial components of Alternative 5, including waste retrieval and construction of the ET surface barrier, would be completed within 30 years of project inception. Full SDA waste retreval and transport operations are predicted to be complete within 27 years after project

Operation and maintenance of the OCVZ extraction and treatment system would continue until OU 7-13/14 remediation goals are met.

Alternative 5 would achieve all OU 7-13/14 remedial action objectives upon completion of urface barrier. Operation maintenance of the OCVZ extraction and treatment system would continue until 
Specific Considerations

\section{Ability to construct and operate technology (technical feasibility)}

$\begin{array}{ll}\text { What difficulties may be } & \text { Not applicable. No remedial } \\ \text { associated with construction? } & \text { action is implemented under }\end{array}$ action is im
What uncertainties are related Not applicable. No remedial to construction?
Construction techniques are standard practice. Foundation grouting (2a) or dynamic compaction (2b) to minimize subsidence would be moderately difficult to implement. However, deployed to date have been for relatively areas (e.,$<5$ acres) (EPA 2006). For a large area such as the SDA (i.e. 97 acres), signific echnical and administrative implementability issues may arise. Specifically, staged deployn of an asphalt composite layer over a large are would cause interlift boundaries, which would require construction of sealed staggered joints. Because of previous difficulties in constructing hin impermeable layers (Suter, Luxmore, an Smith 1993), rigorous construction quality thin asphalt composite hydra lic barrier (Bowders et al. 2003).

Subgrade stabilization processes (i.e., foundation Exact locations of specified waste disposals grouting and dynamic compaction) have not been used in the SDA and may present difficulties mplementation. Constriction of the surface barrier involves standard earthwork pactices, and few difficulties are anticipated in implementation.
All remedial components included in this alternative are well understood an encapsulation of irradiated beryllium reflector blocks (Lopez et al. 2005). Pad A excavation methods are based on those currently used by the Accelerated Retrieval Project, and may be moderately difficult to implement. Ex situ stabilization of Pad A waste is based on processes currently used at the ICDF and is expected to be readily implementable. Method for construction of the ET surface barrier are
commonly used in civil engineering practice. identified for ISG have not been validated us historical records or geophysical methods. treatment of disposal areas complicated by presence of large dense objects that could res in probe refusal before reaching underlying preparion of surace barrer construction not been used in the SDA and may present difficulties in implementation. previously has been used in the SDA for
All remedial components included in the partia retrieval alternatives are well understood and commercially available. Excavation methods Accelerated Retrieval Project and may be moderately difficult to implement. Methods for construction of the slurry cut-off wall and the ET surface barrier are commonly used in civil engineering practice. Dynamic compaction of Pad A and the SDA waste pits is expected to moderately difficult to implement.

Pe 列 or is also cos sately basis. Targeted waste retrieval is also complicated by undefined disposal

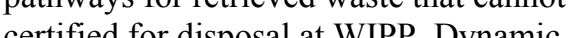
compaction of a landfill in preparation of surface barrier construction has not been used in the SDA and may present difficulties in implementation of Subalternative 4a. For this alternative, uncertainties related to construction pertain to design of the portable retrieval tent structures to allow removal of remote-handled nontransuranic waste from the pit areas and retrieval and sizing of from below grade.
Full Retrieval, Treatment, and Disposal

emedial components associated with retrieva f buried SDA waste (excluding 列 urface barrier are well understood and commercially available. The full excavation method is based on a method currently used by the Accelerated Retrieval Project, combined with a method for retrieval of remote-handled objects used at the Intermediate-Level Transuranic Storage Facility, and is expected to be moderately difficult to implement. Methods commonly used in civil engineering practice.

Retrieval may be complicated by discovery of pyrophoric materials, high-activity radioactive waste forms, or other waste that would compromise the operations safety basis. This alternative is also complicated by undefined disposal pathways for retrieved waste that existing fility. For this alternative, exishg cecilly. For ths allative, allow removal of remote-handled

nontransuranic waste from the pit areas and retrieval and sizing of large objects extracted from below grade.

Retrieval of remote-handled nontransuranic waste entails transferring waste from the pit area into a shielded cask using a crane. Using this method within small mobile retrieval tent structures would present uncertainties pertaining to crane clearance, personnel
shielding, and the crane's ability to retrieve deteriorated containers.

Retrieval of large objects entails either in situ sizing of the objects or hoisting the large objects out of the retrieval area and ex situ sizing. Using this method within small mobile retrieva tent structures would present uncertainties pertaining to crane clearance, sizing equipmen clearance, and packaging. 


\section{Reliability of technology (technical feasibility)}

What is the likelihood that Not applicable. No remedial

technical problems would

alternative.

Construction techniques for surface barriers are

Experience with ISG in the SDA suggests that chedule decte. Technical problems leading to waste is remosed to fility. How surface barer (Alternative 2b), a bw pobblity exists that schedule delays could occur.

erience during the Accelerated Retrieval

Project suggests that excavation of Pad A waste could be complicated by the presence of Rocky Flats Plant roaster oxides, which may contain pyrophoric material. Observation of pyrophoric material could delay Pad A waste excavation an treatment. Large amounts of Rocky Flats Plan Series 745 evaporator salts may present

significant difficulties in mantaning product consistency during ex sit stabilization of waste

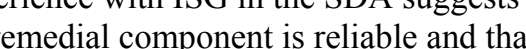
minimal schedule delays are to be anticipated. Experience during the Accelerated Retrieval could be complicated by the presence of Rocky Flats Plant roaster oxides, which may contain pyrophoric material. Observation of pyrophoric material could delay Pad A waste excavation and treatment. Large amounts of Rocky Flats Plant Series 745 evaporator salts may present significant difficulties in maintaining product consistency during ex situ stabilization of waste removed from Pad A.

Tase of undertaking additional remedial action if necessary (technical feasibilty)

What likely future remedial Five-year reviews may show

actions may be anticipted? cause for additional action. S actions may require a second actions, including containment treatment, or removal. Further migration of contaminants to adjacent media should be anticipated and potentially increase any future remediation requirements associated with SDA waste.

How difficult would it be to

This alternative would not

preclude or int would facilitate future maintenance or
No future remedial actions are anticipated.

No future remedial actions are anticipated.

No future remedial actions are anticipated. No future remedial actions are anticipated.
The relative simplicity of the ET surface barrier would facilitate future maintenance of the Transuranic Storage Area). The portions RCRA Type $\mathrm{C}$ surface barrier would be difficult to repair or extend.
The relative simplicity of the ET surface barri

of the Transuranic Storage Area). In situ grouting of specified disposal locations wo not preclude subsequent retrieval using conventional excavation equipment; however, may be infeasible to segregate encapsulated waste from the cemint matix. Stabilizalio Pad A waste should not adversely impact subsequent retrieval or transportation on or of the INL Site.
Experience during the Accelerated Retrieval Project suggests that excavation of SDA wast Flats Plant roaster oxides, which may contain pyrophoric material. Observation of pyrophor ferial could delay targeted waste removal fom pit areas. Full Retrieval, Treatment, and Disposal

ikelihood of schedule delays from technic problems is high. Experience during the Accelerated Retioval Project suggests the excavation of SDA waste delayed by the presence of pyrophoric material. The same typ removal of highly radioactive objects or during sizing of large objects.
The relative simplicity of the ET surface barrier would facilitate future maintenance or

of the Transuranic Storage Area). Following surface barrier completion, remediation of large volumes of barrier material.
This alternative would remove all waste and contaminated media from the SDA, eliminating zone. The relative simplicity of the ET surface barrier would facilitate future maintenance or modification (e.g., extension to include portion of the Transuranic Storage Area). 
Specific Considerations

Do migration or exposure

Migration and exposure pathways

pathways exist that cann

are easily monitored under this

All migration and exposure pathways are

adequately covered by existing environmenta

ir, soil, and briams, including INL Sitewide air, soil, and biotic sampling and SDA-specific dissolved and gas phase).

What risk of exposure exists Exposure risk would be equal to if monitoring is insufficient to those identified in the baseline detect failure?

Risk of exposure associated with any insufficiency of the monitoring program is isignificant because waste sources COCs, exposure pathways, and transport mechanisms are all understood.
well

All migration and exposure pathways are adequately covered by existing environmenta monitoring programs, including INL Sitewide air, soil, and biotic sampling and SDA-specific dissolved and gas phase).

Risk of exposure associated with any insufficiency of the monitoring program is considered insignificant because waste sources, COCs, exposure pathways, and transport mechanisms are adequately characterized and well understood.

\section{This alternative would not require significant} permitting with other agencies. Expansion an development of new borrow areas to obtain necessary surface barrier materials would likely
require modification and approval of an existing require modification and aps

This allernative would not require except to maintain monitoring requirements.

What steps are requir

coordinate
agencies?

What steps are required to set up long-term or future coordination

This alternative would not require coordination with other agencies except to main

Can permits for off-INL Sit activities be obtained if required? No off-INL Site activities are
required under this alternative. coordination among agencies for selection of
The FFA/CO provides framework for coordination among agencies for selection of future remedial actions at the INL Site. Long-term land-use plans, environment applicable to any remedial alternative implemented in the SDA are addressed in the Laboratory Site (Litus and Shea 2005).

The only off-INL Site activities under this alternative would be expansion and developme of borrow sources for surface barrier materials. No problems are anticipated with obtaining the sources is routinely accomplished in the construction industry.
Because this alternative would be implemented as a CERCLA closure activity, no permits are equired. Coordination with the Idaho

Department of Environmental Quality and U.S. Environmental Protection Agency is required
ensure this alternative meets all applicable or elevant and appropriate requirements. It may be necessary to clarify land disposal requirements or obtain a waiver for stabilization and relocation of Pad A waste within the OU 7-13/14 area of contamination.

The FFA/CO provides framework for future remedial actions at the INL Site. Long-term land-use plans, environmenta applicable to any remedial alternative implemented in the SDA are addressed in the Summary of Cleanup at the Idaho National Laboratory Site (Litus and Shea 2005).

This alternative does not include treatment or disposal activities off the INL Site; therefore, dditional permits are not required. $N$ problens are anticipated in complying wit borrows sources. ICDF would depend on compliance with
existing waste acceptance criteria defined existing permit.

All migration and exposure pathways are adequately covered by existing environmen monitoring programs, including INL Sitewid air, soil, and biotic sampling and SDA-sp dissolved and gas phase).

Risk of exposure associated with any is ( well understood.

Because partial retrieval subalternatives woul be implemented as CERCLA closure activities, no permits are required. Coordination with the and U.S. Environmental Protection Agency is aplicable onsure that alternatives meet requirements. While it would be necessar clarify land disposal requirements for waste transferred to the ICDF (performed during the Pad A retrieval activity), no administrative barriers are anticipated.

The FFA/CO provides framework fo coordination among agencies for selection of future remedial actions at the INL Site. Long-term land-use plans, environment applicable to any remedial alternative implemented in the SDA are addressed in the Summary of Cleanup at the Idaho National Laboratory Site (Litus and Shea 2005).

Most retrieved waste is anticipated to meet certification requirements for disposal at WIP under an existing permit for transuranic waste. fowever, disposal pathways remain undefine for
All migration and exposure pathways are adequately covered by existing environmental monitoring programs, including INL Sitewide air, soil, and biotic sampling and SDA-specific dissolved and gas phase).

Risk of exposure associated with any insufficiency of the monitoring program is considered insignificant because waste sources, $\mathrm{COCs}$, exposure pathways, and transport mechanisms are adequately characterized and well understood.

Because this alternative would be implemente S a CERCLA closure activity, no permits a required. Coordination with the Idaho Department of Environmental Quality and U.S. Environmental Protection Agency is applicable or relevant and appropriate requirements. While it would be necessary to clarify land disposal requirements for waste transferred to the ICDF, no administrative barriers are anticipated.

The FFA/CO provides framework for coordination among agencies for selection of future remedial actions at the INL Site. Long-term land-use plans, environmenta applicable to any remedial alternative implemented in the SDA are addressed in the Summary of Cleanup at the Idaho National

Retrieved waste containing transuranics is nticipated to meet certification requirements for disposal at WIPP under an existing permit. for retrieved waste that cannot disposal at WIPP or other facility. Acceptance for disposal at ICDF would depend on compliance with existing waste acceptance criteria defined in the existing permit. Disposa at off-INL facilities (e.g., EnergySolutions or Nevada Test Site) would also be contingent on compliance with permit defined acceptance criteria 
Are adequate treatment, Not applicable. Treatment, storage capacity, and disposal storage, and disposal services are services available? Not applicable. Treatment, storage, and dispo services are not elements of this alternative. Relocation of Pad A within the OU 7-13/14 area storage, or disposal.

This alternative does not require additional treatment, storage, or disposal capacity off the L Site. An on-INL Site treatment capability Pad A waste.

Lack of treatment, storage, or disposal capacity
This alternative does not include treatment, must be developed to llow ex situ treatment of Pad A waste.

Disposal capacity at WIPP is assumed to be sufficient to accommodate targeted WiPP-acceptable waste retrieved under Alternative 4. However, disposal pathways connot be certified for disposal at WIPP. Treatment and disposal capacity at ICDF is assumed to be adequate; however, ICDF is scheduled to be closed in the year 2012 and may become unavailable for both Subalternatives $4 a$ and $4 b$. If the ICDF is unable to accept the relatively small quantity of roaster oxide after 2012, then this waste form woul sent to an off-INL facility where disposal capacity is assuncel to be adequate and dispo costs comparable to ICDF.

Additional treatment and disposal capacity for Alternative 4 may be required, but is assumed to be available in the commercial sector. Disposal capacity at WIPP is assumed to be sufficient to accommodate targeted disp-acceptable waste. It is assumed that disposal pathways will be identified for retrieved waste that cannot be certified for disposal at WIPP. Treatment and disposal year 2012. If the ICDF is unable to accept relatively small quantity of roaster oxide after 2012 , then this waste form would be sent to off-INL facility where disposal capacity is assumed to be adequate and disposal cost comparable to ICDF. on or off the INL Site would not preven
Lack of disposal capacity would not prevent implementation of Alternative 4. Disposal capacily at WIPP is ass WIPP-a be sulficient to retrieved under Alternative 4. It is ass med tha disposal pathways will be identified for retrieved waste that cannot be certified fo disposal at WIPP. Disposal of a relatively sm quantity of roaster oxide at ICDF may become unavailable after the year 2012; however, disposal capacity at an off-INL Site LLW disposal facility (e.g., EnergySolutions) is assumed to be adequate and available throughout the Alternative 4 performance period.
Disposal capacity at WIPP may not be Which to accommodate all WIPP-acceptable waste retrieved under Alternative 5. In additio disposal pathways remain undefined for disposal at WIPP. Treatment and disposal capacity at ICDF is assumed to be adequate for some waste forms; however, ICDF is scheduled o be closed in the year 2012 and may become unavailable for Alternative 5. Treatment and disposal capacity at off-INL Site LLW disposa acilities (e.g., EnergySolutions) is assumed to be available throughout the Alternative 5 performance period. This alternative includes construction of an interim storage facility on the NL Site for remote-handed nontransuranic facility by another program.

Additional treatment and disposal capacity for Alternative 5 may be required, but is assumed to be largely available in the may not be sufficient to accommodate al IIPP-acceptable waste retrieved under Alternative 5. Treatment and disposal at ICDF may become unavailable after the year 201 however, capacity at off-INL Site LLW be (e.g., Enaysolu tons) is assumed to Alternative 5 performance period Alternative 5 assumes permitting and construction of a epository for remote-handled nontransuran radioactive waste.

Lack of disposal capacity would not preven mplementation of Alternative 5. Disposa cacin a WIP retrieved under Alternative 5 . Treat isposal at ICDF may become unavailable afte the year 2012. however, capacity at off-INL Site LLW facilities (e.g., EnergySolutions) is assumed to be adequate and available throughout the Alternative 5 performance period. Alternative 5 assumes permitting and construction of a repository for remote-handled nontransuranic radioactive waste. 
Specific Consideration

Ilternative
No Action

Not applicable.

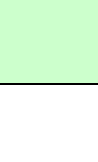

Not applicable.

Alternative 2
Surface Barrie

Alternative 3
In Situ Grouting

Alternative 4
Partial Retrieval, Treatment, and Disposal

that treatment, storage, or disposal capacity

alternative. An on-INL Site treatment cap

must be developed to allow ex situ treatment of

Pad A waste.

Additional provisions may be required

capacity for Alternative 4. Dispost apacity a

WIPP is assumed to be sufficient to

accommodate targeted WIPP-accentable waste What additional provisions are required to ensure are required to ensure

No additional provisions are required to ensure retrieved under Alternative 4. It is assumed th disposal pathways will be identified for retrieved roaster oxide (containing no transuranic isotopes) that cannot be certified for disposal at WIPP. Disposal at ICDF may become unavailable after the year 2012; however, disposal capacity at an off-INL Site assumed to be adequate and available throughout the Alternative 4 performance period.

The Nevada Test Site disposal is scheduled for Management through the year 2027, with possibilities for life extension. The Nevad Site is considered to have unlimited disposal capacity.

\section{Availability of necessary equipment and specialists (availability of services and materials)}

Are the necessary equipment Not applicable.

and specialists available?

Equipment and specialists required for dynamic compaction of pits and construction of an surface barrier are available within the commercial sector. The INL Site resources ar adequate for planning, design, an implementation of Pad A waste excavation and contamination.

What additional equipment Not applicable and specialists are required?

An enclosure and excavator would be required for removal of Pad A waste in the case of Alternative $2 b$. No additional equipment or specialists are required for implementation of this alternative.

Lack of equipment or specialists would no

Does lack of equipment and Not applicable. specialists prevent
implementation?

What additional provisions

Not applicable re required to ensure

equipment and specialists are

available? prevent implementation of the remedial

No additional provisions are required to ensure availability of equipment or specialists required in this alternative.
Equipment and specialists required for ISG of specified waste, dynamic compaction of pits, and construction of an ET surface barrier are available within the commercial sector. INL Site resources are adequate for planning, desig the area of contamination.

An enclosure and excavator would be required for removal of Pad A waste. Treatment of Pad A waste within the SDA would require procurement of a large paddle mixer, box stabilization fixture, and grout mixing plan similar to those used at ICDF. Specialists woul be required to validate performance of generic certich

Lack of equipment or specialists would not prevent implementation of the remedial components included in this alternative.

No additional provisions are required to ensure to ilability of equipment or specialists required in Alternative 3.
INL Site resources are adequate for planning, design, and implementation of targeted was Equevalin pil areas and removal or Pad $\mathrm{A}$. Equipment and specialists required for dy compaction of Pad A and waste pits, available within the commercial sector.

An enclosure, modified excavator, and modifi telehandler would be required for removal of SDA waste. Additional equipment required for retrieval includes waste packaging glove box designed for visual examination, segregation, and packaging of retioved waste. Specialists would be required to visually identify waste construction.

Lack of retrieval and packaging equipment or specialists would not prevent implementation remedial components included in the partial retrieval alternatives.

No additional provisions are required to ensure availability of equipment or specialists required in the partial retrieval alternatives. colf backfill parameters dung antuin slury and
Full Retrieval, Treatment, and Disposal Additional provisions are required to ensure apacity for Alternative 5. Disposl opacity WIPP may not be sufficient to accommodate all WIPP-acceptable waste retrieved under Alternative 5. Treatment and disposal at ICDF may become unavailable after the year 2012; however, capacity at off-INL Site LLW facilities (e.g., EnergySolutions) is assumed to adequate and available throughout the Alternative 5 performance period. Alternative assumes permitting and construction of a radioctive waste.

The Nevada Test Site disposal is scheduled for operations for DOE Office of Environment Management through the year 2027, with Site is considered to have un. Mited

Equirent required for SDA waste retrieval and construction of an ET surface barrier are available from INL Site resources or within the commercial secto

An enclosure, modified excavator, and modifie Alehandler would be required for removal of SDA waste. Additional equipment required for etrieval includes waste packaging glove boxes designed for visual examination, segregation, and packaging of retrieved waste. A crane and shielded transport casks would also be required waste. Specialists would be rectiod to vianc identify waste types during retrieval.

Lack of equipment for retrieval and packaging of remote-handled nontransuranic waste would not prevent implementation of this alternative.

No additional provisions are required to ensure in within this retrieval alternative. 


\section{Availability of prospective technologies (availability of services and materials)}

\section{Are technologies under}

Not applicable

demonstrated for the specific

application?
Necessary technologies are available and are in

common use in the construction industry.

Remedial components in this alternative, including ISG of specified waste disposals

Pad A waste excavation, treatment, and

relocation, dynamic compaction of burial pits, extraction of VOC vapors from the vadose are sufficiently demonstrated at either the INL Site or within the DOE complex and are generally available from the commercial sector.

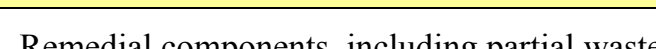
Remedial components, including partial waste excavation, dynamic compaction, proof-rolling
of burial pits, installation of a perimeter slurry of burial pits, installation of a perimeter sluriy cut-off wall, containment using an ET surface vadose zone are sufficiently demonstrated at either the INL Site or within the DOE complex and are generally available from the commercia and are
Remedial components included in this (ypes found in the SDA.

Demonstrations of ISG and dynamic compaction may be required to suppo operational readiness reviews.

Remedial components included in Alternative 3 Remedial components included in the partial are sufficiently developed to allow immediate full-scale use in the SDA.
Remedial components included in partial retrieval activities are sufficiently developed waste types found in the SDA.

A demonstration of dynamic compaction of Pad A waste may be required. retrieval alternatives are sufficiently developed
to allow immediate full-scale use in the SDA. alternative are sufficiently developed to allow
Remedial components, including waste

excavation, containment using an ET surface varrier, and extraction of VOC vapors from the vadose zone are sufficiently demonstrated at ard are generally available from DOEcommercia

This alternative would remove remote-handled nontransuranic waste using the method used at Facility, which extracted intact, remote-hor drums from belowground vaults within open ai and placed the drums in shielded casks. Using this method within smaller retrieval tent structures and on deteriorated drums has not been demonstrated.

The INL Site has decontaminated and demolished several large facility complexes as a component of sitewide closure activities. doing so, the INL Site has sufficiently demonstrated competency in the ability to size large objects extracted from the SDA area

Remedial components included in retrieval activities are sufficiently developed, with exception of retrieval and handling of
remote-handled nontransuranic waste and larg objects, to allow full-scale deployment for emediation of waste types found in the SDA.

Remedial components included in this alternative are sufficiently developed, with exception of retrieval and handling of remote-handled nontransuranic waste and large objects, to allow immediate full-scale use in the

Technologies used for extraction of large objects and remote-handled objects from the SDA would be developed and tested during the remedial design phase and would by
by start of construction activities. 
Specific Consideration

Would more than one vendor Would more than one ven
be available to provide a be available to p
competitive bid?

Multiple vendors are available all aspects of environmenta monitoring.
Alternative 2
Surface Barrie

Multiple vendors are available for all aspects of the work. All aspects of surface barrier areas, hauling, and placement of surface barrier materials, could be accomplished by a number of local construction firms. For the dynamic compaction option, specialized firms with specific geotechnical experience would be

required; however, there are a number of firm available in the U.S. that could provide tha service.
Alternative 3
Situ Groutin

Based on previous responses to reque

for proposal, it is probable that few

provide ISG of specified waste in thould bid to

Similarly, it is probable that few qualified

vendors would bid to provide dynamic

compaction of waste buried in pits in the SDA.

Several commercial firms are anticipated to

respond to requests for proposals for design an

construction of an ET surface barrier.
CERCLA = Comprehensive Environmental Response, Compensation, and Liability A $\mathrm{COC}=$ contaminant of concern
$\mathrm{DOE}=\mathrm{U}$.S. Department of Energy
$\mathrm{NL}=$ Idaho National Laboratory

ISG $=$ in situ grouting
RCRA $=$ Resource C
Alternative 4

Partial Retrieval, Treatment, and Disposal Based on previous responses to requests for pepdors would bid onable that few qualified dynamic compaction. Several commercial firms are anticipated to respond to requests for proposals for design and construction o
cut-off wall and an ET surface barrier.
$E T=$ evapotranspiration
$F F A C O=$ Federal Facility Agreement and Consent Order FFACO $=$ Federal Facility Agreement and
ICDF $=$ Idaho CERCLA Disposal Facility (n) Alternative 2a Alternative $2 b$ $\begin{array}{cc}\text { Alternative } 2 \mathrm{a} & \text { Alternative 2b } \\ \text { Modified RCRA Type C } & \text { Evapotranspiration Surface } \\ \text { Surface Barrier } & \text { Barrier }\end{array}$ Barrier

\begin{tabular}{|c|c|c|c|c|c|c|c|c|c|c|c|c|c|c|}
\hline \multirow[b]{2}{*}{$\begin{array}{c}\text { Specific } \\
\text { Considerations }\end{array}$} & \multicolumn{2}{|c|}{$\begin{array}{c}\text { Alternative } 1 \\
\text { No Action }\end{array}$} & \multicolumn{2}{|c|}{$\begin{array}{c}\text { Alternative 2a } \\
\text { Modified RCRA Type C } \\
\text { Surface Barrier } \\
\end{array}$} & \multicolumn{2}{|c|}{$\begin{array}{c}\text { Alternative } 2 \mathrm{~b} \\
\text { Evapotranspiration Surface } \\
\text { Barrier } \\
\end{array}$} & \multicolumn{2}{|c|}{$\begin{array}{c}\text { Alternative } 3 \\
\text { In Situ Grouting }\end{array}$} & \multicolumn{2}{|c|}{$\begin{array}{c}\text { Alternative 4a } \\
\text { 4-Acre Partial Retrieval, } \\
\text { Treatment, and Disposal }\end{array}$} & \multicolumn{2}{|c|}{$\begin{array}{c}\text { Alternative } 4 \mathrm{~b} \\
\text { 2-Acre Partial Retrieval, } \\
\text { Treatment, and Disposal }\end{array}$} & \multicolumn{2}{|c|}{$\begin{array}{c}\text { Alternative } 5 \\
\text { Full Retrieval, } \\
\text { Treatment, and Disposal } \\
\end{array}$} \\
\hline & $\begin{array}{l}\text { Current } \\
\text { Value }^{\mathrm{a}, \mathrm{b}} \\
(\$ \mathrm{M})\end{array}$ & $\begin{array}{l}\text { Net Present } \\
\text { Value } \mathrm{a}^{\mathrm{a} b} \\
(\$ \mathrm{M})\end{array}$ & $\begin{array}{l}\text { Current } \\
\text { Value, }^{\text {,b }} \\
(\$ M)\end{array}$ & $\begin{array}{l}\text { Net Present } \\
\text { Value } \\
(\$ M)\end{array}$ & $\begin{array}{l}\text { Current } \\
\text { Value, } \\
(\$ M)\end{array}$ & $\begin{array}{l}\text { Net Present } \\
\text { Value }{ }^{\mathrm{a}, \mathrm{b}} \\
(\$ \mathrm{M})\end{array}$ & $\begin{array}{l}\text { Current } \\
\text { Value }{ }^{\mathrm{a}, \mathrm{b}} \\
(\$ \mathrm{M})\end{array}$ & $\begin{array}{l}\text { Net Present } \\
\text { Value }{ }^{\mathrm{a}, \mathrm{b}} \\
(\$ \mathrm{M})\end{array}$ & $\begin{array}{l}\text { Current } \\
\text { Value }{ }^{\mathrm{a}, \mathrm{b}} \\
(\$ \mathrm{M})\end{array}$ & $\begin{array}{l}\text { Net Present } \\
\text { Value }{ }^{\mathrm{a}, \mathrm{b}} \\
(\$ \mathrm{M})\end{array}$ & $\begin{array}{l}\text { Current } \\
\text { Value, } \\
(\$ M)\end{array}$ & $\begin{array}{l}\text { Net Present } \\
\text { Value } \\
(\$ M)\end{array}$ & $\begin{array}{l}\text { Current } \\
\text { Value }{ }^{\mathrm{a}, \mathrm{b}} \\
(\$ \mathrm{M})\end{array}$ & $\begin{array}{l}\text { Net Present } \\
\text { Value }{ }^{\mathrm{a}, \mathrm{b}} \\
(\$ \mathrm{M})\end{array}$ \\
\hline Capital cost & NA & NA & 144.6 & 112.5 & 162.5 & 122.0 & 216.1 & 166.0 & 919.1 & 706.5 & 553.2 & 434.5 & $13,520.2$ & $8,397.0$ \\
\hline $\begin{array}{l}\text { Operations and } \\
\text { maintenance costs }\end{array}$ & 52.3 & 14.8 & 193.9 & 62.5 & 163.6 & 55.8 & 163.6 & 55.8 & 146.7 & 48.2 & 146.7 & 50.2 & 126.0 & 36.6 \\
\hline Periodic costs & 4.7 & 1.0 & 5.2 & 1.1 & 5.2 & 1.0 & 5.2 & 1.0 & 5.2 & 0.8 & 5.2 & 1.0 & 5.2 & 0.6 \\
\hline Total costs & 57.0 & 15.8 & 343.7 & 176.1 & 331.4 & 178.8 & 385.0 & 222.7 & $1,071.0$ & 755.5 & 705.1 & 485.6 & $13,651.4$ & $8,434.2$ \\
\hline $\begin{array}{l}\text { Are cost estimates } \\
\text { within an expected } \\
\text { accuracy of }+50 \text { to } \\
-30 \% \text { ? }\end{array}$ & \multicolumn{2}{|c|}{$\begin{array}{l}\text { Yes. Confidence in estimates is } \\
\text { high. Estimates are based on } \\
\text { actual costs for well-defined, } \\
\text { ongoing monitoring programs. }\end{array}$} & \multicolumn{4}{|c|}{$\begin{array}{l}\text { Yes. Confidence in estimates is high. Estimates are based on } \\
\text { preconceptual designs. Contingency costs were assigned to } \\
\text { individual remedial components based on professional judgment } \\
\text { of process uncertainty. }\end{array}$} & \multicolumn{2}{|c|}{$\begin{array}{l}\text { Yes. Confidence in estimates is } \\
\text { moderate. Estimates are based } \\
\text { on preconceptual designs. } \\
\text { Contingency costs were } \\
\text { assigned to individual remedial } \\
\text { components based on } \\
\text { professional judgment of } \\
\text { process uncertainty. }\end{array}$} & \multicolumn{4}{|c|}{$\begin{array}{l}\text { Yes. Confidence in estimates is high because estimates are based on } \\
\text { preconceptual designs in combination with actual costs for the } \\
\text { Accelerated Retrieval Project. Contingency costs were assigned to } \\
\text { individual remedial components based on professional judgment of } \\
\text { process uncertainty. }\end{array}$} & \multicolumn{2}{|c|}{$\begin{array}{l}\text { Yes. Confidence in estimates is } \\
\text { low. All estimates are based on } \\
\text { preconceptual designs of } \\
\text { processes that may not be well } \\
\text { defined. Large contingency costs } \\
\text { were assigned to individual } \\
\text { remedial components based on } \\
\text { professional judgment of proces } \\
\text { uncertainty. }\end{array}$} \\
\hline
\end{tabular}

Alternative 3 Acre Partial Retrieval,

$\mathrm{DA}=$ Subsurface Disposal Area

Table C-5. Cost (in millions of dollars).

. Cost estimates developed for this feasibility study are for evaluating and comparing alternatives and are not suitable for budgetary, planning, or funding purposes. Estimates have an approximate range of accuracy of +50 to $-30 \%$, in accordance with EPA guidance (EPA 1988 .

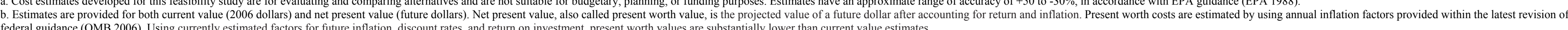
RCRA = Resource Conservation and Recovery Act 



\section{C-2. REFERENCES}

Bowders, John J., J. Erick Loehr, Deepak Neupane, and Abdelmalek Bouassa, 2003, "Construction Quality Control for Asphalt Concrete Hydraulic Barriers," Journal of Geotechnical and Geoenvironmental Engineering, Vol. 129, No. 3, pp. 219-223.

EPA, 1988, Guidance for Conducting Remedial Investigations and Feasibility Studies Under CERCLA, Interim Final, EPA/540/G-89/004, OSWER Directive 9355.3-01, U.S. Environmental Protection Agency.

EPA, 1991, A Guide to Principal Threat and Low Level Threat Wastes, OSWER Directive 9380.3-06FS, U.S. Environmental Protection Agency, Office of Solid Waste and Emergency Response.

EPA, 2006, Remediation Technology Descriptions, Alternative Landfill Cover Project Profiles, U.S. Environmental Protection Agency, Technology Innovation Program, URL: http://cluin.org/products/altcovers/, Web page visited August 14, 2006.

Holdren, K. Jean, Danny L. Anderson, Bruce H. Becker, Nancy L. Hampton, L. Don Koeppen, Swen O. Magnuson, and A. Jeffrey Sondrup, 2006, Remedial Investigation and Baseline Risk Assessment for OU 7-13/14, DOE/ID-11241, U.S. Department of Energy Idaho Operations Office.

Housley, L. Todd, 2005, Environmental and Operational End-Year Data Report for the OU 7-08 Organic Contamination in the Vadose Zone Project-2004, ICP/EXT-05-00779, Rev. 0, Idaho National Laboratory, Idaho Completion Project.

Litus, Marty and Jerry P. Shea, 2005, Summary of Cleanup at the Idaho National Laboratory Site, ICP/EXT-05-00806, Rev. 0, Idaho National Laboratory, Idaho Completion Project.

Lopez, S. L., William H. Landman, Donald E. Sebo, and Vivian G. Schultz, 2005, Summary Report for the OU 7-13/14 Early Actions Beryllium Encapsulation Project, ICP/EXT-04-00646, Rev. 1, Idaho National Laboratory Engineering and Environmental Laboratory, Idaho Completion Project.

Mattson, Earl, Mark Ankeny, Steve Dwyer, Nancy Hampton, Gretchen Matthern, Brenda Pace, Alva Parsons, Mitch Plummer, Steve Reese, and Jody Waugh, 2004, Preliminary Design for an Engineered Surface Barrier at the Subsurface Disposal Area, ICP/EXT-04-00216, Idaho National Engineering and Environmental Laboratory, Idaho Completion Project.

Suter, Glenn W. II, Robert J. Luxmore, and Ellen D. Smith, 1993, "Compacted Soil Barriers at Abandoned Landfill Sites Are Likely to Fail in the Long Term," Journal of Environmental Quality, Vol. 22, No. 2, pp. 217-223.

Wheldon, Nathan M., Gary J. McManus, Jeffrey A. Towers, and David J. Thorne, 2006, Short-Term Risk Assessment for the OU 7-13/14 Feasibility Study, RPT-188, Idaho National Laboratory, Idaho Cleanup Project. 
C-30 
Appendix D

\section{Modeling}


D-2 


\section{CONTENTS}

ACRONYMS

D-9

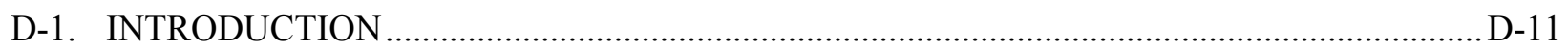

D-2. BASELINE CONCEPTUAL SITE MODEL FOR THE SUBSURFACE DISPOSAL AREA...D-15

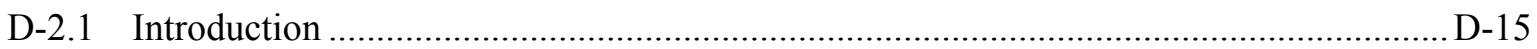

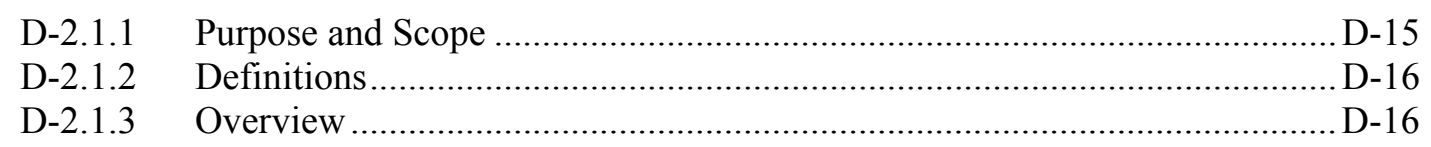

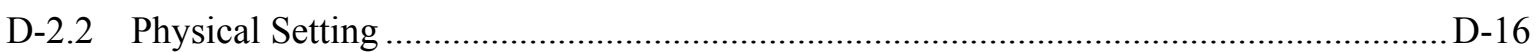

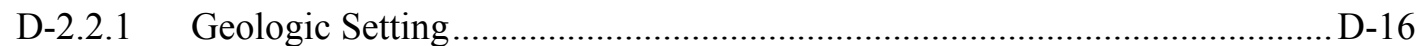

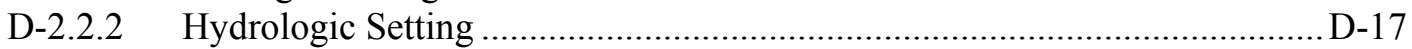

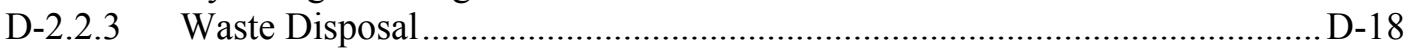

D-2.3 Subsurface Groundwater Pathway …....................................................................... D-19

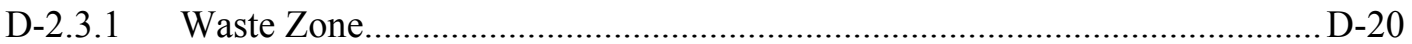

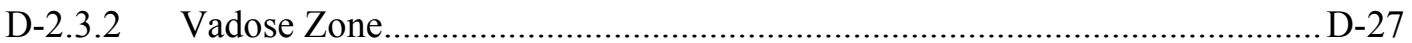

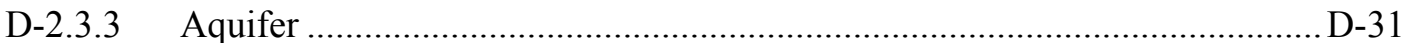

D-2.3.4 Summary of Important Assumptions ...................................................... D-32

D-2.4 Soil Pathway Conceptual Models............................................................................... D-33

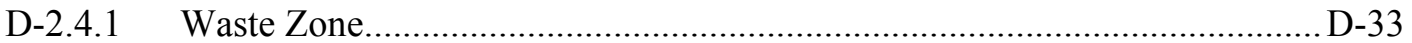

D-2.4.2 Transport of Contaminants from Subsurface to Surface .............................. D-35

D-2.4.3 General Assumptions ................................................................................. D-35

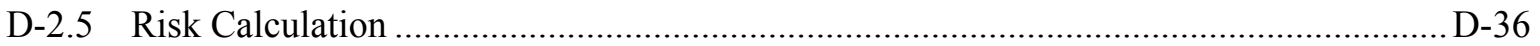

D-2.5.1 Subsurface Water Pathway (Groundwater) .............................................. D-36

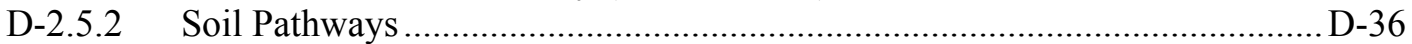

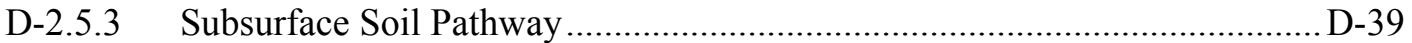

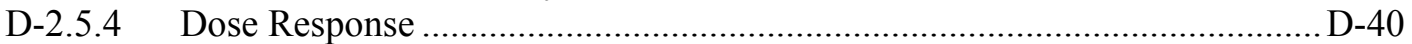

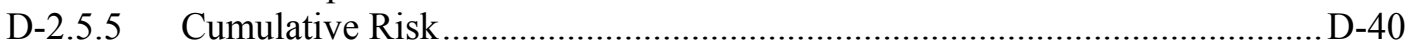

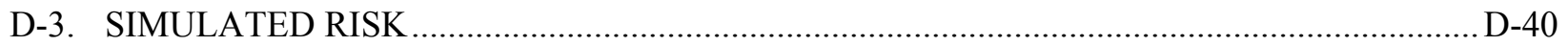

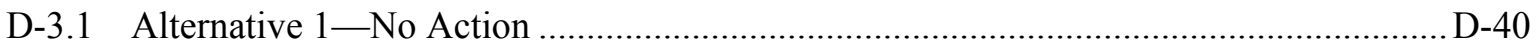

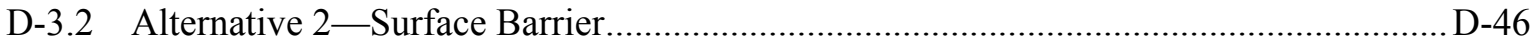

D-3.2.1 Alternative 2a-Modified RCRA Type C Surface Barrier ........................... D-46

D-3.2.2 Alternative 2b-Evapotranspiration Surface Barrier .................................. D-46

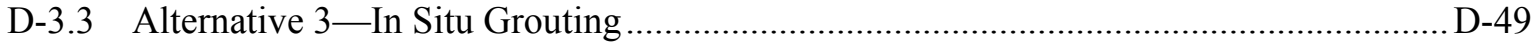


D-3.4 Alternative 4-Partial Retrieval, Treatment, and Disposal ...................................... D-53

D-3.4.1 Alternative 4a-4-Acre Retrieval, Treatment, and Disposal Areas .............. D-53

D-3.4.2 Alternative 4b-2-Acre Retrieval, Treatment, and Disposal ....................... D-54

D-3.5 Alternative 5-Full Retrieval, Treatment, and Disposal ......................................... D-54

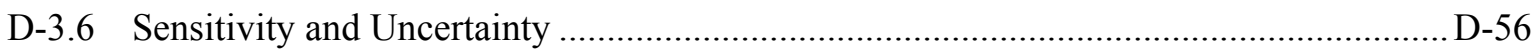

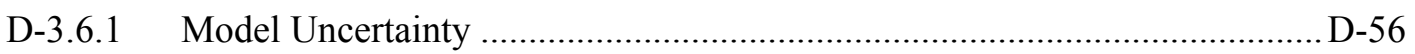

D-3.6.2 Uranium Sensitivity Simulations ……............................................. D-85

D-3.6.3 Evapotranspiration Surface Barrier with Higher Infiltration Rate ................ D-87

D-3.6.4 Full Retrieval with No Surface Barrier .................................................... D-87

D-4. COMPARISON OF SIMULATED GROUNDWATER CONCENTRATIONS TO

MAXIMUM CONTAMINANT LEVELS ........................................................................... D-90

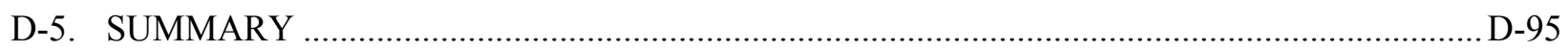

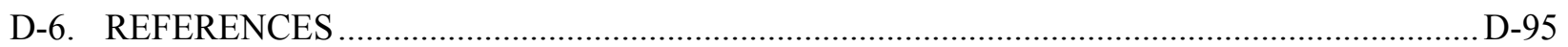

\section{FIGURES}

D-1. Operable Unit 7-13/14 risk modeling modules .................................................................... D-11

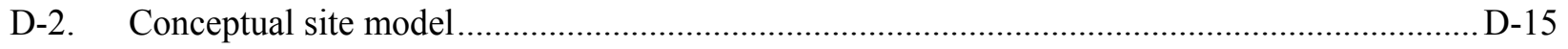

D-3. Zones by which subsurface groundwater pathway conceptual model are discussed................ D-19

D-4. Waste Area Group 7 biotic transport conceptual model ..................................................... D-34

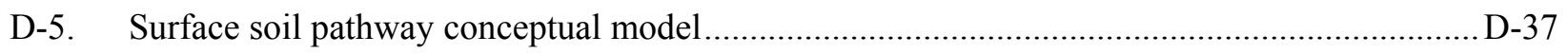

D-6. Subsurface soil pathway conceptual model ..................................................................... D-38

D-7. Cumulative risk for all pathways for Alternative $1-$ No Action .......................................... D-42

D-8. Cumulative hazard index for all pathways for Alternative 1-No Action ............................. D-43

D-9. Comparison of cumulative groundwater ingestion risk for Alternative 1-No Action and the Remedial Investigation and Baseline Risk Assessment base case ................................... D-45

D-10. Comparison of the cumulative groundwater ingestion hazard index for Alternative $1-$ No Action and the Remedial Investigation and Baseline Risk Assessment base case

D-11. Comparison of cumulative groundwater ingestion risk for Alternative 1-No Action and Alternative 2a-Modified RCRA Type C Surface Barrier.

D-12. Comparison of cumulative groundwater ingestion hazard index for Alternative 1No Action and Alternative 2a-Modified RCRA Type C Surface Barrier .... 


\section{FIGURES (continued)}

D-13. Comparison of cumulative groundwater ingestion risk for Alternative 1-No Action, and Alternative $2 \mathrm{~b}$-Evapotranspiration Surface Barrier.

D-14. Comparison of cumulative groundwater ingestion hazard index for Alternative 1No Action, Alternative $2 \mathrm{~b}$-Evapotranspiration Surface Barrier, and Alternative $2 \mathrm{a}-$ Modified RCRA Type C Surface Barrier D-48

D-15. Density of releasable technetium-99 in the Subsurface Disposal Area D-49

D-16. Hypothetical treatment locations for Alternative 3-In Situ Grouting D-50

D-17. Comparison of cumulative groundwater ingestion risk for Alternative 1-No Action; Alternative 3-In Situ Grouting; and Alternative 2b-Evapotranspiration Surface Barrier, using (A) a diffusion model and (B) a surface wash model for Tc-99 and I-129.....

D-18. Hypothetical targeted waste retrieval locations for Alternative 4a-4-Acre Partial Retrieval, Treatment, and Disposal

D-19. Comparison of cumulative groundwater ingestion risk for Alternative 1-No Action; Alternative 4a-4-Acre Retrieval, Treatment, and Disposal; Alternative 4b-2-Acre Retrieval, Treatment, and Disposal; and Alternative 2b-Evapotranspiration Surface Barrier .....

D-20. Hypothetical targeted waste retrieval locations for Alternative 4b-2-Acre Retrieval, Treatment, and Disposal

D-21. Comparison of cumulative groundwater ingestion risk for Alternative 1-No Action; Alternative 5-Full Retrieval, Treatment, and Disposal; Alternative 4a-4-Acre Retrieval, Treatment, and Disposal; Alternative 4b-2-Acre Retrieval, Treatment, and Disposal; and Alternative $2 \mathrm{~b}$-Evapotranspiration Surface Barrier

D-22. Time-history comparison of simulated (red line) and observed (blue diamond symbols) concentrations for nitrate in Lysimeters PA02-L16 and W25-L28 in the 0 to 35-ft depth interval

D-23. Time-history comparison of simulated (red line) and observed (blue diamond symbols) concentrations for nitrate in the lysimeters in the 35 to $250-\mathrm{ft}$ depth interval

D-24. Time-history comparison of simulated (red line) and observed (blue diamond symbols) nitrate (as nitrogen) concentration time histories for aquifer monitoring wells in the vicinity of the Subsurface Disposal Area.....

D-25. Screen intervals for aquifer monitoring wells in relation to vertical aquifer model grid discretization

D-26. Simulated and observed nitrate concentrations superimposed onto monitoring locations in the vicinity of the Radioactive Waste Management Complex 


\section{FIGURES (continued)}

D-27. Horizontal view of vadose zone model grid and cross section of remediation goal zones........ D-66

D-28. Simulated average carbon tetrachloride vapor concentrations in Zones A1, A2, and A3 compared to remediation goals for Alternative 2a-Modified RCRA Type C Surface Barrier.....

D-29. Simulated average carbon tetrachloride vapor concentrations in Zones A1, A2, and A3 compared to remediation goals for Alternative $2 b$-Evapotranspiration Surface Barrier

D-30. Simulated average carbon tetrachloride vapor concentrations in Zones A1, A2, and A3 compared to remediation goals for Alternative 4-Partial Retrieval, Treatment, and Disposal

D-31. Simulated average carbon tetrachloride vapor concentrations in Zones A1, A2, and A3 compared to remediation goals for Alternative 5-Full Retrieval, Treatment, and Disposal

D-32. Maximum predicted carbon tetrachloride concentrations in the aquifer outside the Subsurface Disposal Area for feasibility study alternatives

D-33. Maximum predicted carbon tetrachloride concentrations in the aquifer outside the Subsurface Disposal Area.

D-34. Predicted maximum concentrations in the aquifer $(\mu \mathrm{g} / \mathrm{L})$ outside the Subsurface Disposal Area for volatile organic compounds other than carbon tetrachloride.

D-35. Impact of extended vapor vacuum extraction with treatment operations on maximum predicted carbon tetrachloride concentrations in the aquifer outside the Subsurface Disposal Area for Alternative 2a-Modified RCRA Type C Surface Barrier

D-36. Impact of extended vapor vacuum extraction with treatment operations on maximum predicted carbon tetrachloride concentrations in the aquifer outside the Subsurface Disposal Area for Alternative $2 b$ - Evapotranspiration Surface Barrier .

D-37. Impact of extended vapor vacuum extraction with treatment operations on maximum predicted carbon tetrachloride concentrations in the aquifer outside the Subsurface Disposal Area for Alternative 4-Partial Retrieval, Treatment, and Disposal

D-38. Impact of extended vapor vacuum extraction with treatment operations on maximum predicted carbon tetrachloride concentrations in the aquifer outside the Subsurface Disposal Area for Alternative 5-Full Retrieval, Treatment, and Disposal

D-39. Predicted maximum concentrations $(\mu \mathrm{g} / \mathrm{L})$ in the aquifer outside the Subsurface Disposal Area for volatile organic compounds (Group 11 contaminants) if operation of the Organic Contamination in the Vadose Zone system were extended to year 2110 


\section{FIGURES (continued)}

D-40. Distribution of carbon tetrachloride $(\mu \mathrm{g} / \mathrm{L})$ in the refined portion of the aquifer model for Alternative 2a-Modified RCRA Type C Surface Barrier, in years 2010 and 2110

D-41. Distribution of carbon tetrachloride $(\mu \mathrm{g} / \mathrm{L})$ in the refined portion of the aquifer model for Alternative 2b-Evapotranspiration Surface Barrier, in years 2010 and 2110

D-42. Distribution of carbon tetrachloride $(\mu \mathrm{g} / \mathrm{L})$ in the refined portion of the aquifer model for Alternative 4-Partial Retrieval, Treatment, and Disposal, in years 2010 and 2110

D-43. Distribution of carbon tetrachloride $(\mu \mathrm{g} / \mathrm{L})$ in the refined portion of the aquifer model for Alternative 5-Full Retrieval, Treatment, and Disposal, in years 2010 and 2110

D-44. Time history of measured and simulated carbon tetrachloride concentrations in the aquifer at wells in and around the Subsurface Disposal Area.

D-45. Maximum predicted carbon tetrachloride concentrations in the aquifer outside the Subsurface Disposal Area

D-46. Comparison of uranium-238 groundwater ingestion risk for various solubility limits.

D-47. Comparison of uranium-238 groundwater ingestion risk for different soil-to-water distribution coefficients

D-48. Comparison of cumulative groundwater ingestion risk for the evapotranspiration surface barrier with a higher infiltration rate, Alternative $1-$ No Action, and Alternative $2 b-$ Evapotranspiration Surface Barrier

D-49. Comparison of the cumulative groundwater ingestion hazard index for the evapotranspiration surface barrier with a higher infiltration rate, Alternative 1No Action, and Alternative 2b-Evapotranspiration Surface Barrier

D-50. Comparison of cumulative groundwater ingestion risk for Alternative 1-No Action, Alternative 5-Full Retrieval, Treatment, and Disposal; and the full retrieval without a surface barrier sensitivity case

D-51. Comparison of cumulative groundwater ingestion hazard index for Alternative 1No Action; Alternative 5-Full Retrieval, Treatment, and Disposal; and the full retrieval without a surface barrier sensitivity case

D-52. Comparison of nitrate groundwater concentration with maximum contaminant level

D-53. Comparison of iodine-129 groundwater concentration with maximum contaminant level....... D-91

D-54. Comparison of carbon tetrachloride groundwater concentration with maximum contaminant level

D-55. Comparison of methylene chloride groundwater concentration with maximum contaminant level 


\section{FIGURES (continued)}

D-56. Comparison of tetrachloroethylene groundwater concentration with maximum contaminant level

D-57. Comparison of trichloroethylene groundwater concentration with maximum contaminant level

D-58. Comparison of 1,4-dioxane groundwater concentration with health advisory level

D-93

\section{TABLES}

D-1. Contaminant groups for Operable Unit 7-13/14 simulations ............................................... D-13

D-2. Remedial investigation and feasibility study source-release simulation cases ........................ D-14

D-3. Summary of five assembled alternatives and major components in each............................. D-41

D-4. Peak risk and hazard index for each contaminant of potential concern for Alternative 1No Action

D-5. Summary of simulated Organic Contamination in the Vadose Zone system operation times for feasibility study alternatives

D-6. Predicted maximum concentrations outside the Subsurface Disposal Area for volatile organic compounds (Group 11 contaminants) and feasibility study alternatives 


\section{ACRONYMS}

\begin{tabular}{ll} 
DEQ & (Idaho) Department of Environmental Quality \\
DOE & U.S. Department of Energy \\
EPA & U.S. Environmental Protection Agency \\
ET & evapotranspiration \\
IC & institutional control \\
INL & Idaho National Laboratory \\
ISG & in situ grouting \\
MCL & maximum contaminant level \\
OCVZ & organic contamination in the vadose zone \\
OU & operable unit \\
RCRA & Resource Conservation and Recovery Act \\
RI/BRA & Remedial Investigation and Baseline Risk Assessment \\
RI/FS & remedial investigation and feasibility study \\
RTD & retrieval, treatment, and disposal \\
RWMC & Radioactive Waste Management Complex \\
SDA & Subsurface Disposal Area \\
VOC & volatile organic compound \\
\hline
\end{tabular}


D-10 


\section{Appendix D}

\section{Modeling}

\section{D-1. INTRODUCTION}

This appendix summarizes modeling activities and results that supported development of the Feasibility Study for Operable Unit 7-13/14. Modeling in this feasibility study is a continuation of modeling performed for the Remedial Investigation and Baseline Risk Assessment (RI/BRA) (Holdren et al. 2006), and is essentially the same as modeling implemented in the Ancillary Basis for Risk Analysis (Holdren et al. 2002), but with improvements.

The Radioactive Waste Management Complex (RWMC) at the Idaho National Laboratory (INL) Site is a complicated site. A single model cannot accommodate source release, fate and transport, and risk calculations with sufficient detail to be acceptable to the U.S. Department of Energy (DOE), Idaho Department of Environmental Quality (DEQ), and U.S. Environmental Protection Agency (EPA), (referred to as the Agencies). Therefore, modeling is divided into modules, and separate models or tools that are appropriate for each module are used as described below (see Figure D-1):

- Waste Inventory and Location Database (McKenzie et al. 2005) provides inventory information, in terms of the amount of waste disposed of per year, for each source area

- DUST-MS computes the release of contaminants due to the shallow subsurface

- $\quad$ TETRAD computes contaminant concentration movement in the groundwater and volatile inhalation concentration at the surface

- DOSTOMAN computes biotic uptake concentrations for other surface pathways, including external exposure, crop ingestion, soil ingestion, and dust inhalation

- $\quad$ Risk calculations convert concentrations from TETRAD or DOSTOMAN into a carcinogenic risk or hazard index.

\section{Operable Unit 7-13/14 Modeling Modules}

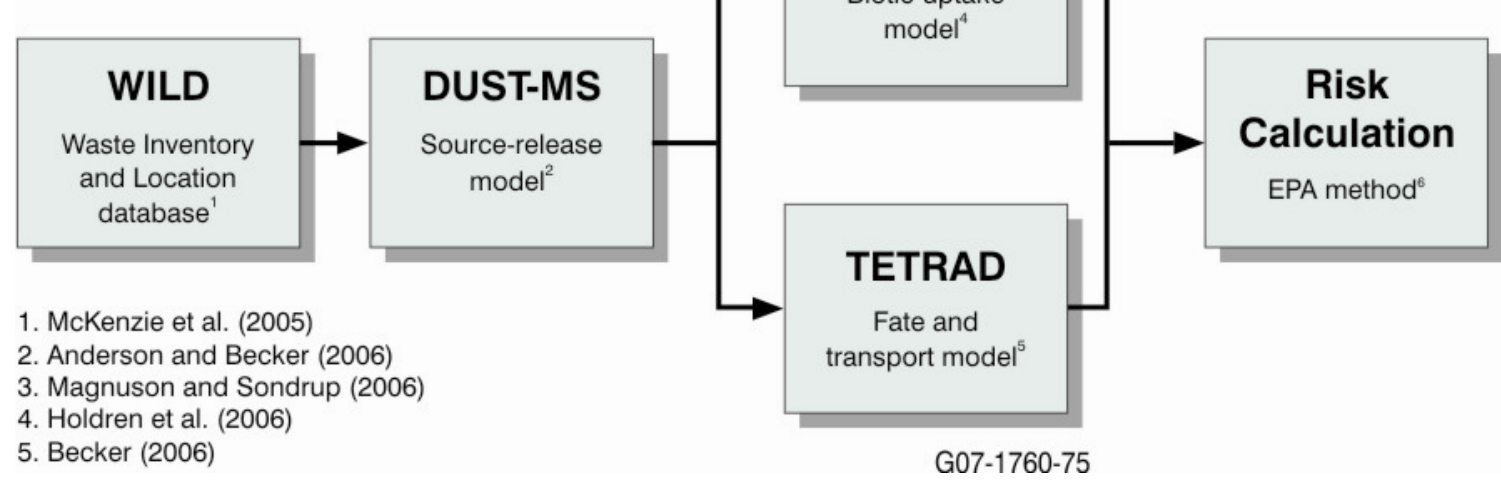

Figure D-1. Operable Unit 7-13/14 risk modeling modules. 
Numerous model runs were used to define a base case and to assess the sensitivity of results to select model parameters and assumptions. Additional runs were used to assess effectiveness of remedial action alternatives. Long-lived progeny were specifically included in simulations because migration can occur over long time periods, and remedial action may slow transport even further; this possibility would allow additional ingrowth and influence risk estimates. Biotic modeling used to assess human health risk for surface exposure pathways also provided the basis for ecological risk assessment. Only a few additional contaminants were simulated for surface exposure for ecological impacts. Contaminants of potential concern, identified in the RI/BRA, were divided among 12 modeling groups based on common decay chain ancestry or on other common chemical or physical characteristics. Table D-1 shows these groups.

Using these modeling groups, 10 simulation cases were run for the RI/BRA, and seven simulation cases were run for the feasibility study. An abbreviated nomenclature was developed to identify the cases without creating overly long labels and file names. Table D-2 identifies the 17 cases and their nomenclature and distinguishes between the RI/BRA cases and the feasibility study cases. Cases with a designator beginning with a "B" are associated with the RI/BRA. Cases with a designator beginning with an " $F$ " are associated with the feasibility study. The following sections briefly describe each case and present the risk results. For details on modeling assumptions, the simulation process, and results expressed in terms of concentrations, refer to associated modeling reports for either source-term release (Anderson and Becker 2006) or fate and transport in the vadose zone and aquifer (Magnuson and Sondrup 2006).

Martian (2007) documents the results of an independent evaluation of the TETRAD version $12.7 \mathrm{~ms}$ simulator to assess its reliability and functionality for use in environmental transport simulation. GeoTrans, under subcontract to EPA, provided verification and benchmark problem descriptions. Problems ranged in complexity from 1-D saturated flow and transport to 3-D multiphase flow and transport in a combined unsaturated and saturated domain. Idaho Cleanup Project staff set up the defined problems, ran the TETRAD simulator, and provided simulation results to GeoTrans. GeoTrans evaluated TETRAD simulation results against analytical solutions and results from other simulators (GeoTrans 2006). Results showed that the TETRAD simulator solves environmental fate and transport problems with reasonable accuracy, excellent stability, and acceptable speed. GeoTrans concluded that TETRAD simulation results agreed well with those produced by other codes (GeoTrans 2006; Martian 2007). 
Table D-1. Contaminant groups for Operable Unit 7-13/14 simulations.

\begin{tabular}{|c|c|c|c|c|}
\hline $\begin{array}{l}\text { Simulation } \\
\text { Group }\end{array}$ & $\begin{array}{l}\text { Group } \\
\text { Name }\end{array}$ & $\begin{array}{l}\text { Contaminants } \\
\text { in Group }^{\mathrm{a}}\end{array}$ & Description & Basis for Group \\
\hline 1 & Am-241 & $\begin{array}{l}\text { Am-241, Np-237, } \\
\text { U-233, and Th-229 }\end{array}$ & $\mathrm{Pu}-241$ decay chain & $\begin{array}{l}\text { Neptunium series beginning at Am-241, } \\
\text { created by weapons production. }\end{array}$ \\
\hline 2 & Am-243 & $\begin{array}{l}\text { Am-243, Pu-239, } \\
\text { U-235, Pa-231, } \\
\text { and Ac-227 }\end{array}$ & $\begin{array}{l}\text { Am-243/Pu-239 } \\
\text { decay chain }\end{array}$ & $\begin{array}{l}\text { Am- } 243 \text { to } \mathrm{Pu}-239 \text {, both created primarily } \\
\text { by weapons production, to actinium series } \\
\text { initiated by } \mathrm{U}-235 \text {. }\end{array}$ \\
\hline 3 & $\mathrm{Pu}-240$ & $\begin{array}{l}\mathrm{Pu}-240, \mathrm{U}-236, \\
\text { Th-232, and Ra-228 }\end{array}$ & $\mathrm{Pu}-240$ decay chain & $\begin{array}{l}\mathrm{Pu}-240 \text { to } \mathrm{U}-236 \text {, created primarily by } \\
\text { weapons production, to thorium series } \\
\text { initiated by } \mathrm{Th}-232 .\end{array}$ \\
\hline $4^{\mathrm{c}}$ & $\mathrm{Pu}-238$ & $\begin{array}{l}\mathrm{Pu}-238, \mathrm{U}-234, \\
\mathrm{Th}-230, \mathrm{Ra}-226 \text {, } \\
\text { and } \mathrm{Pb}-210\end{array}$ & Pu-238 decay chain & $\begin{array}{l}\mathrm{Pu}-238 \text {, created primarily by reactor } \\
\text { operations, to U-234 to mid uranium } \\
\text { series. }\end{array}$ \\
\hline $5^{\mathrm{c}}$ & U-238 & $\begin{array}{l}\mathrm{U}-238, \mathrm{U}-234, \\
\text { Th-230, Ra-226, } \\
\text { and } \mathrm{Pb}-210\end{array}$ & $\begin{array}{l}\text { Uranium decay } \\
\text { chain }\end{array}$ & $\begin{array}{l}\text { Uranium series initiated by U-238, } \\
\text { primarily from weapons production. }\end{array}$ \\
\hline 6 & Tc-99 & $\begin{array}{l}\text { Tc-99, I-129, } \\
\text { and Cl-36 }\end{array}$ & $\begin{array}{l}\text { Mobile activation } \\
\text { products }\end{array}$ & Created by reactor operations. \\
\hline $8^{\mathrm{d}}$ & $\mathrm{C}-14$ & $\mathrm{C}-14$ & $\begin{array}{l}\text { Mobile, dual-phase } \\
\text { activation product }\end{array}$ & $\begin{array}{l}\text { Requires dual-phase simulation. Created } \\
\text { by reactor operations. }\end{array}$ \\
\hline 9 & $\mathrm{Nb}-94$ & $\begin{array}{l}\text { Nb-94, Sr-90, Cs-137, } \\
\text { and Th-228 }\end{array}$ & $\begin{array}{l}\text { Fission and } \\
\text { activation products }\end{array}$ & $\begin{array}{l}\text { Surface pathways only. Created by reactor } \\
\text { operations. }\end{array}$ \\
\hline 10 & Nitrate & $\begin{array}{l}\text { Nitrate (as nitrogen) } \\
\text { and chromium }\end{array}$ & Toxic chemicals & $\begin{array}{l}\text { Nonvolatile (single-phase), } \\
\text { nonradioactive chemicals. Nitrate is } \\
\text { contained primarily in Series } 745 \text { sludge } \\
\text { from Rocky Flats Plant. Mobile with no } \\
\text { decay. Chromium is a possible model } \\
\text { performance indicator. }\end{array}$ \\
\hline 11 & $\begin{array}{l}\text { Volatile } \\
\text { organic } \\
\text { compound }\end{array}$ & $\begin{array}{l}\text { Carbon tetrachloride, } \\
\text { methylene chloride, } \\
\text { tetrachloroethylene, } \\
\text { trichloroethylene, } \\
\text { and 1,4-dioxane }\end{array}$ & $\begin{array}{l}\text { Toxic, dual-phase } \\
\text { chemicals in organic } \\
\text { sludge }\end{array}$ & $\begin{array}{l}\text { Volatile (dual-phase) nonradioactive } \\
\text { chemicals. }\end{array}$ \\
\hline $12^{\mathrm{g}}$ & Tc-99 & Tc-99 and I-129 & $\begin{array}{l}\text { Mobile activation } \\
\text { products }\end{array}$ & Created by reactor operations \\
\hline \multicolumn{5}{|c|}{$\begin{array}{l}\text { a. Simulations include contaminants that are not contaminants of potential concern. These additional contaminants are decay-chain products or } \\
\text { are useful for other reasons (e.g., comparison to performance assessment modeling and interpreting model performance and uncertainty). } \\
\text { b. Groups } 4 \text { and } 5 \text { both contain U-234, Th-230, Ra- } 226 \text {, and } \mathrm{Pb}-210 \text {. } \\
\text { c. Group } 7 \text { was reserved for tritium, which was dropped as a model performance indicator. } \\
\text { d. Dual-phase refers to simultaneous transport in both vapor and liquid phases. } \\
\text { e. Th-232 is not directly created by reactor operations, but is a progeny in two decay chains for isotopes that are produced in a reactor } \\
\text { (i.e., Pu- } 240 \text { and U-232). } \\
\text { f. Simulations for trichloroethylene were added for the feasibility study. } \\
\text { g. Group } 12 \text { is a revised Group } 6 \text {. }\end{array}$} \\
\hline
\end{tabular}


Table D-2. Remedial investigation and feasibility study source-release simulation cases.

\begin{tabular}{|c|c|}
\hline Designator & Simulation Description \\
\hline \multicolumn{2}{|r|}{ Remedial Investigation Simulation Cases } \\
\hline B4ng & $\begin{array}{l}\text { No grout and no retrieval; best-estimate inventory; area-specific infiltration rates; Pit } 4 \\
\text { Accelerated Retrieval Project-targeted inventory not removed and beryllium blocks not } \\
\text { grouted }\end{array}$ \\
\hline $\mathrm{B}$ & $\begin{array}{l}\text { Remedial investigation base case; best-estimate inventory; area-specific infiltration rates; } \\
\text { Pit } 4 \text { Accelerated Retrieval Project-targeted inventory removed and beryllium blocks } \\
\text { grouted (no action case for the feasibility study) }\end{array}$ \\
\hline $\mathrm{Bu}$ & Base case with an upper-bound inventory \\
\hline Bhi & $\begin{array}{l}\text { Base case with area-specific infiltration rates inside the SDA replaced with a high } \\
\text { infiltration rate of } 23 \mathrm{~cm} / \text { year assigned uniformly across the SDA }\end{array}$ \\
\hline Bloi & $\begin{array}{l}\text { Base case with background infiltration (outside SDA) reduced from } 1.0 \mathrm{~cm} / \text { year to } \\
0.1 \mathrm{~cm} / \text { year }\end{array}$ \\
\hline Bnbc & $\begin{array}{l}\text { Base case with no B-C interbed. The B-C interbed is replaced with fractured basalt in the } \\
\text { vadose zone simulation }\end{array}$ \\
\hline $\mathrm{BkU}$ & Uranium $\mathrm{K}_{\mathrm{d}}$ sensitivity case; $\mathrm{K}_{\mathrm{d}}$ reduced from 15.4 to $6 \mathrm{~mL} / \mathrm{g}$ for $\mathrm{U}-234$ and U-238 \\
\hline $\mathrm{BsU}$ & $\begin{array}{l}\text { Uranium solubility-limit sensitivity case } \\
\text { - BsU10 }=10 \times \text { default solubility limit } \\
\text { - BsU100 }=100 \times \text { default solubility limit } \\
\text { - BsUn = no solubility limit (modeled as } 1 \mathrm{E}+06 \text { ) }\end{array}$ \\
\hline $\mathrm{BcP}$ & $\begin{array}{l}\text { Base case where sorption of } \mathrm{Pu}-239 \text { and } \mathrm{Pu}-240 \text { does not occur in the B-C and } \\
\mathrm{C}-\mathrm{D} \text { interbeds }\end{array}$ \\
\hline Bnlk & Base case with no low-permeability zone in the aquifer \\
\hline \multicolumn{2}{|r|}{ Feasibility Study Simulation Cases } \\
\hline FmR & Modified RCRA Type C surface barrier; reduced infiltration, $0.1 \mathrm{~cm} /$ year \\
\hline Fet & ET surface barrier; reduced infiltration, $0.1 \mathrm{~cm} /$ year \\
\hline Feth & ET surface barrier; higher infiltration, $1.0 \mathrm{~cm} /$ year \\
\hline $\mathrm{Fg}$ & ISG; reduced infiltration, $0.1 \mathrm{~cm} /$ year \\
\hline Fpr & Partial RTD; reduced infiltration, $0.1 \mathrm{~cm} /$ year \\
\hline Ffr & Full RTD; reduced infiltration, $0.1 \mathrm{~cm} /$ year \\
\hline Frnc & Full RTD without a surface barrier (no barrier) \\
\hline $\begin{array}{l}\text { ET }=\text { evapotranspira } \\
\text { ISG }=\text { in situ groutin } \\
\text { RCRA = Resource } C \\
\text { RTD = retrieval, trea }\end{array}$ & $\begin{array}{l}\text { vation and Recovery Act } \\
\text { and disposal }\end{array}$ \\
\hline
\end{tabular}




\section{D-2. BASELINE CONCEPTUAL SITE MODEL FOR THE SUBSURFACE DISPOSAL AREA}

\section{D-2.1 Introduction}

\section{D-2.1.1 Purpose and Scope}

This section presents a baseline comprehensive conceptual site model for the OU 7-13/14 remedial investigation and feasibility study (RI/FS). A conceptual site model uses all available information to describe the sources, releases, and movement of contaminants along pathways to receptor locations where exposure point concentrations occur (see Figure D-2). The conceptual site model is implemented in a series of numerical models to estimate concentrations at the exposure point, which then is converted into risk, based on assumed scenarios. Though this section focuses primarily on describing the subsurface groundwater pathway, it also discusses the subsurface soil pathway and the surface soil pathway.

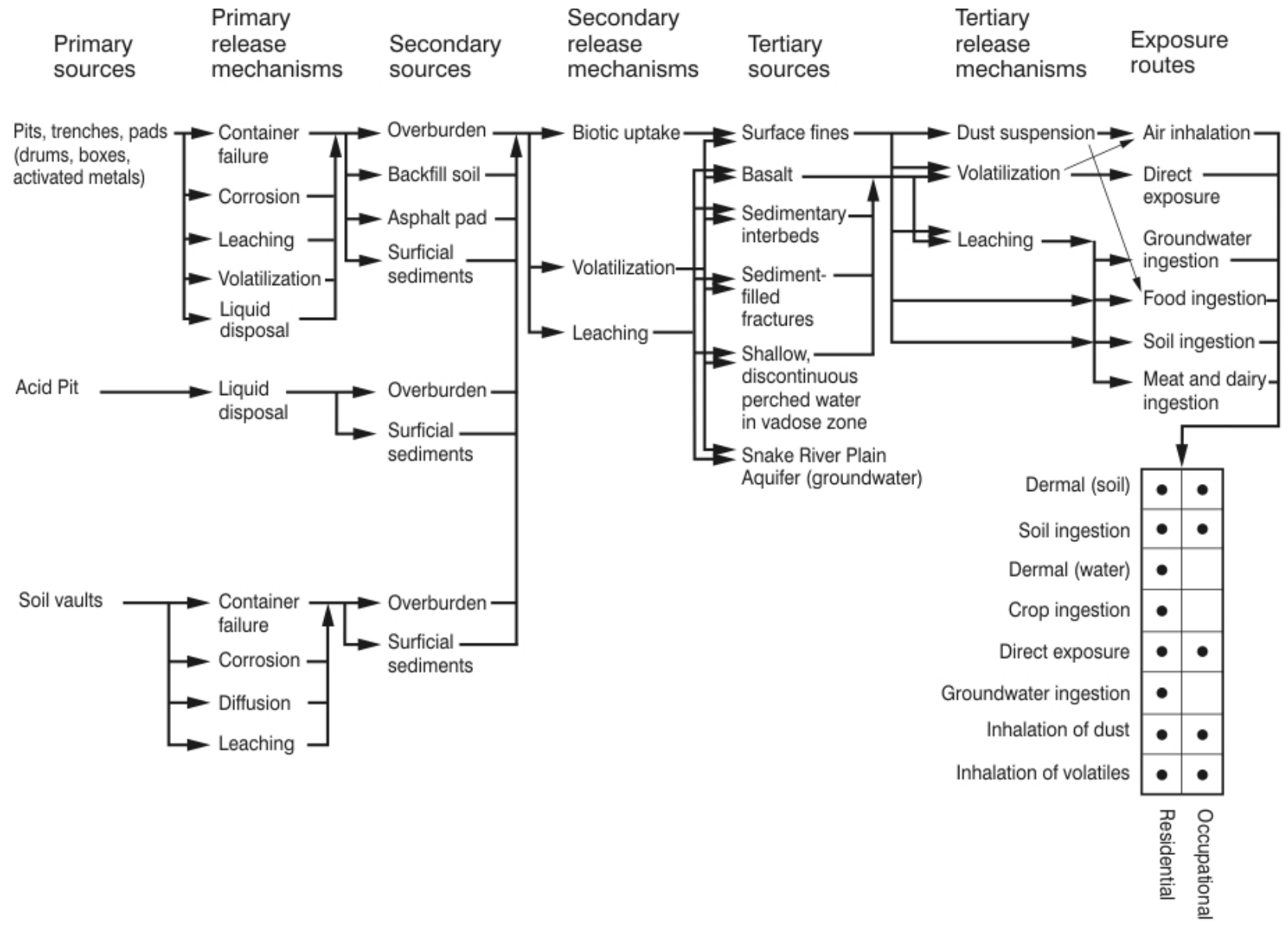

Figure D-2. Conceptual site model.

This subsection provides a comprehensive summary of key components and assumptions included in the conceptual site model. Section D-3 discusses assumptions related to evaluating contaminant movement after potential remedial actions are implemented. 
The conceptual site model is implemented for the OU 7-13/14 RI/FS in numerical models described in Anderson and Becker (2006) and Magnuson and Sondrup (2006). Those documents are the result of a series of model development tasks, each building on results and experience of previous modeling. Though each task contains details of the model implementation, the model sometimes relies on assumptions developed and explained in earlier modeling tasks. This conceptual site model attempts to comprehensively capture all assumptions that contribute to current RI/FS models.

\section{D-2.1.2 Definitions}

Definitions listed below clarify terms used in this subsection.

- Conceptual model-Description of how contaminants enter a system, how they are transported within the system, including the governing physical and chemical processes that control movement; and pathways or routes of exposure to potential receptors.

- Numerical model-Numerical solution to a set of governing equations requiring discretization in time and space. This solution normally is embedded into a computer code and requires input parameters for properties and boundary conditions. Numerical models have been developed for the source release and for contaminant migration in the subsurface.

- Conservatism-Representation of processes and assignment of model parameters to maximize concentrations at an exposure point. Usually conservatism is invoked to address uncertainty.

\section{D-2.1.3 Overview}

Section D-2.2 briefly describes the physical setting, including the geologic framework, the hydrologic framework, and the waste buried at the Subsurface Disposal Area (SDA) within RWMC. Sections D-2.3 and D-2.4 describe pathways that comprise the conceptual site model - the subsurface groundwater pathways and the soil pathways, respectively. Section D-2.5 presents the method by which exposure-point concentrations are converted into individual and cumulative risk from each of these two pathways. This includes assumptions on receptor locations and timeframes for each exposure scenario.

\section{D-2.2 Physical Setting}

Material presented in this section is condensed from Section 2.2 of the RI/BRA (Holdren et al. 2006) and from Magnuson and Sondrup (2006). This information provides context for understanding the conceptual model for the subsurface groundwater pathway.

\section{D-2.2.1 Geologic Setting}

The RWMC lies within a natural topographic depression that primarily has been undergoing soil deposition for the last 10,000 years (Hackett et al. 1995). Undisturbed surficial sediment at RWMC ranges in thickness from 0.6 to $7.0 \mathrm{~m}$ ( 2 to $23 \mathrm{ft}$ ). This shallow sediment rests on a thick sequence of relatively thin basalt flows that are intercalated with thin sedimentary interbeds.

Using the nomenclature of Anderson and Lewis (1989), the three uppermost sedimentary layers are designated the A-B, B-C, and C-D sedimentary interbeds. Of these three uppermost interbeds, the $\mathrm{C}$-D interbed is by far the most continuous. However, each interbed contains known gaps, although gaps in the C-D interbed have been observed only outside the SDA. The A-B interbed is very discontinuous and generally exists beneath only the northern half of the SDA. 
Most of the basalt flows originated from vents in the Arco-Big Southern Butte Volcanic Rift Zone. This northwest-trending vent corridor may have implications for subsurface water movement because near-vent volcanic deposits and fissures probably provide either localized preferential pathways or barriers to groundwater flow (Kuntz et al. 2002).

\section{D-2.2.2 Hydrologic Setting}

Direct precipitation is the primary source of surface water on the SDA. Average annual precipitation at the INL Site is $21.4 \mathrm{~cm}$ (8.44 in.). Rates of precipitation are highest during May and June and lowest in July. Normally, winter snow falls from November through April. Though no permanent surface water features are within the local RWMC basin, the basin tends to hold precipitation and to collect additional run-off from the surrounding slopes. Surface water eventually either evaporates or infiltrates to the vadose zone and the underlying aquifer. Surface water within the local RWMC area does not reach the Big Lost River (Keck 1995). Historically, the SDA has been flooded by local basin run-off three times because of a combination of snowmelt, rain, and warm winds. After each flood, dikes and drainage channels around the perimeter of the SDA either were constructed or improved.

Local run-off from within the SDA from late winter and early spring snowmelt has the greatest potential for infiltration because surface infiltration events occur when evapotranspiration (ET) rates are low. Disturbed soil and sparse vegetation also may contribute to increased infiltration within the SDA. Based on vadose zone instrumentation in the surficial sediment, Laney et al. (1988), McElroy (1993), and Martian (1995) conclude that surface infiltration within the SDA is highly nonuniform and is concentrated in surface depressions. If spring thaw occurs over frozen ground, most melted water is diverted to topographically low areas, increasing infiltration in low areas, while reducing infiltration in higher areas. Intense spring and summer rain storms also can have the same effect.

During localized recharge events, wetting fronts can move through surficial sediment and into underlying basalt in a matter of days (McElroy 1993). Continued downward movement through the basalt is assumed to occur primarily through open or sediment-filled fractures or joints rather than through the basalt matrix. Rapid infiltration through fractured basalt or basalt flow rubble zones can occur. Rapid downward movement of the wetting front through fractures and rubble zones is slowed as moisture is stored in sediment and basalt or is diverted laterally by geologic media with contrasting hydraulic conductivities (e.g., dense basalt layers or sedimentary interbeds).

Perched water is ephemeral beneath the SDA, especially at shallow depths, such as at the base of the surficial sediments. Shallow perched water is usually associated with snowmelt and localized run-off and, periodically, in response to large precipitation events. However, deep perched water has been present for extended periods in several wells. Bodies of perched water have been identified at two depth intervals associated with interbeds beneath the SDA. Perched water typically occurs in fractured basalt above the interbeds.

Lateral underflow from the Big Lost River and the spreading areas within the vadose zone may provide additional sources of water to the SDA subsurface. Rightmire and Lewis (1987) and Hubbell (1990) present evidence suggesting that the spreading areas are a source for perched water in Well USGS-92, located in basalt above the C-D interbed in the western half of the SDA. Water movement from spreading areas to the SDA was documented by the arrival of a tracer in perched water at Well USGS-92, less than 91 days after introducing the tracer into the spreading areas (Nimmo et al. 2002). Investigators hypothesize that water from the spreading areas moves primarily downward, but a portion is diverted laterally by perching above layers having low hydraulic conductivity. 
The Snake River Plain Aquifer underlies RWMC at a depth of approximately $177 \mathrm{~m}$ (580 ft) below land surface. The aquifer is composed of numerous, relatively thin basalt flows. In addition, the aquifer contains sedimentary interbeds that are typically discontinuous. The effective thickness of the aquifer in

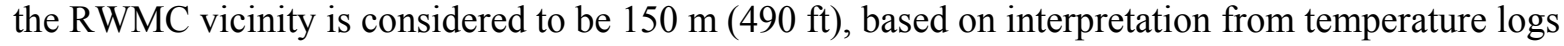
in Well C1A (Smith 2002). The water table gradient in the immediate SDA vicinity is low, and flow directions are variable, with interpreted directions ranging from southwest under the western half of the SDA to southeast under the eastern half of the SDA vicinity (Magnuson and Sondrup 2006). Wood (1989) indicates that the direction of water movement beneath the SDA changed from southerly to easterly as a result of groundwater mounding in the aquifer due to discharges to the spreading areas.

Aquifer permeability is controlled by distribution of highly fractured basalt flow tops, interflow zones, lava tubes, fractures, vesicles, and intergranular pore spaces. The variety and degree of interconnected water-bearing zones complicate direction of groundwater movement locally throughout the aquifer. Permeability of the aquifer varies considerably over short distances, but generally, a series of basalt flows includes several excellent water-bearing zones. Pump test results from RWMC wells show that a region of low permeability is present in the aquifer south and southwest of the SDA (Wylie and Hubbell 1994; Wylie 1996). Additional pump test results conducted in 2003 corroborated the interpretation of permeability to the north and east of the SDA but were inconclusive regarding the low-permeability region (Jolley 2003).

\section{D-2.2.3 Waste Disposal}

The SDA is a radioactive waste landfill with shallow subsurface disposal units consisting of pits, trenches, and soil vaults. Constituents in the landfill include hazardous chemicals; low-level radioactive waste, including remote-handled fission and activation products; and transuranic waste. Construction, operation, and decommissioning of INL Site nuclear reactor testing programs have resulted in large volumes of waste. Various containers were used to ship and dispose of waste, including steel drums, casks, cardboard cartons, and wooden boxes. Larger individual items (e.g., tanks, furniture, process and laboratory equipment, engines, and vehicles) were placed separately as loose trash. Additionally, liquid waste was buried in the SDA, including direct disposal of free liquids to pits and trenches and disposal of solidified liquids in containers (Holdren et al. 2002).

Radioactive waste from off-INL Site sources originated from a variety of facilities, including military and other defense agencies, universities, commercial operations, and the U.S. Atomic Energy Commission. The primary off-INL Site contributor was the Rocky Flats Plant. Shipping of waste to the INL Site from the Rocky Flats Plant began in April 1954 and continued into late 1989. Waste from the Rocky Flats Plant was deposited underground in a series of pits and trenches until 1970, when the U.S. Atomic Energy Commission policy was implemented requiring segregation and retrievable storage of all solid transuranic waste. After 1970, transuranic waste received from the Rocky Flats Plant was placed in aboveground, earthen-covered retrievable storage at the Transuranic Storage Area. Aboveground stored waste was designated as transuranic retrievable waste (Vejvoda 2005).

Beginning in 1952, waste was stacked in pits and trenches. However, beginning in 1963, some waste was dumped directly into pits and trenches to reduce labor costs and minimize radiation exposure of personnel. Current disposal operations require stacking contact-handled waste to maximize disposal capacity of the landfill. Remote-handled waste is placed in concrete vaults. 


\section{D-2.3 Subsurface Groundwater Pathway}

The conceptual model for movement of contaminants in the subsurface either as aqueous- or gaseous-phase contaminants is divided into three zones, as indicated in Figure D-3. These zones are the waste zone, the vadose zone, and the aquifer. The waste zone is composed of surficial sediments and buried waste, including overburden and underburden. The vadose zone is the remainder of the subsurface from contact between the waste zone and the underlying basalt down to the aquifer and consists primarily of fractured basalt with some sedimentary interbeds. The aquifer is the saturated region beneath the vadose zone. Like the vadose zone, the aquifer also consists primarily of fractured basalt and sedimentary interbeds.

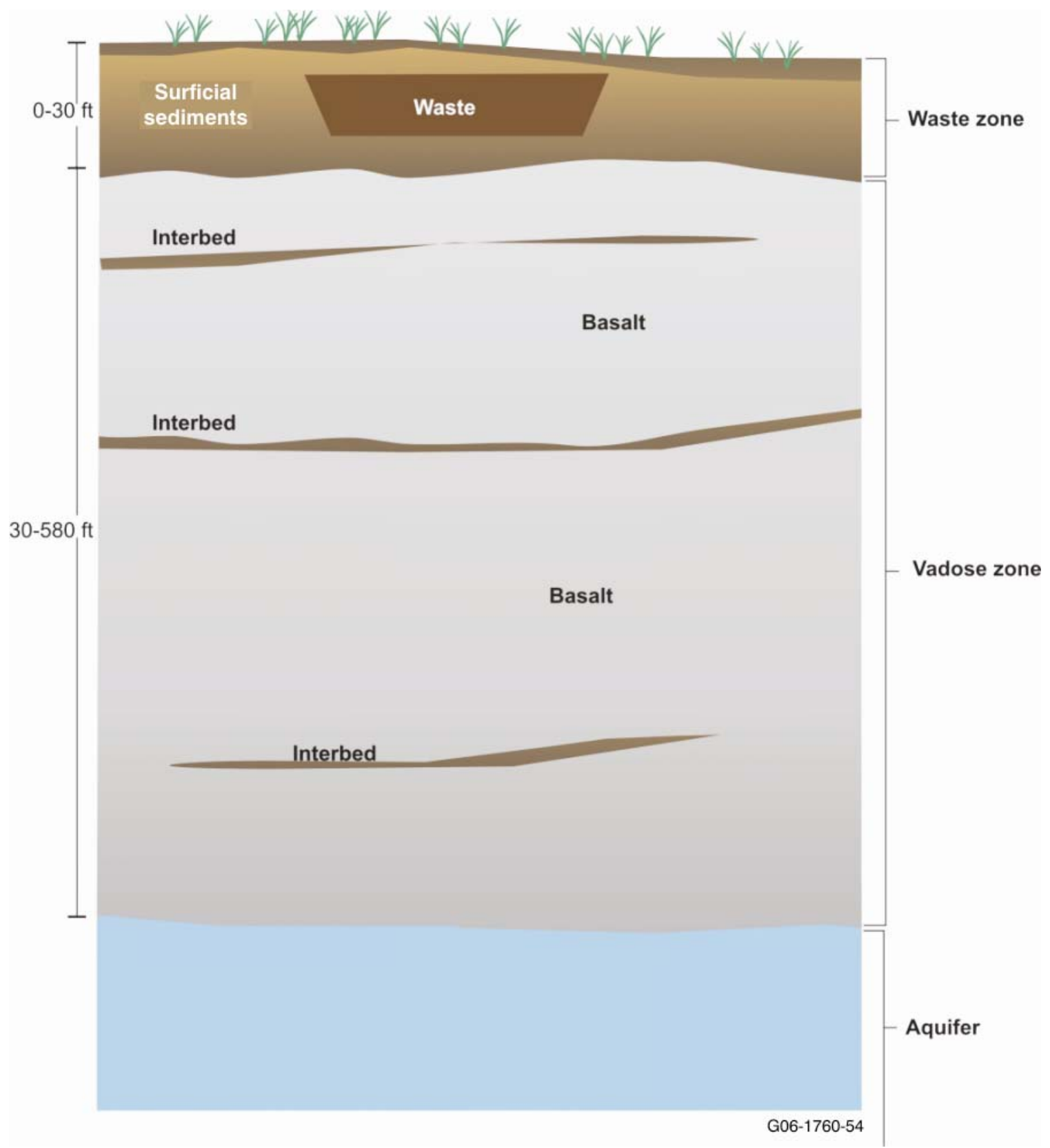

Figure D-3. Zones by which subsurface groundwater pathway conceptual model are discussed. 


\section{D-2.3.1 Waste Zone}

D-2.3.1.1 Water and Air Movement in the Waste Zone. Most contaminants migrate in the subsurface by water movement. Some contaminants also partition into the gaseous phase and migrate within that phase. Water movement in the waste zone is controlled by gravity and capillary forces and is described by variably saturated governing equations, assuming Darcian flow is applicable. Likewise, air movement is considered to be within Reynolds number ranges such that air flow is laminar and Darcian concepts apply. It is assumed that a representative elementary volume (Bear 1972) can be defined that allows this region to be described as a porous medium. Including all possible buried waste forms (e.g., automobiles) obviously violates this assumption, but given the scale of the area being represented in the numerical model (i.e., the entire SDA), to consider the waste as having hydrological properties different from the surface sediments is not practical. This assumption of the waste and sediments having the same properties is supported by excavations that have demonstrated extensive soil mixed with waste (Olson 2004a, 2004b).

Though hydrologic properties within the waste zone certainly vary across the SDA, they are considered to be homogeneous because it is assumed that the contrast in hydrologic properties between the waste zone and underlying basalt is large and has a much greater effect on water movement than variations in properties within the waste zone. As a result of this assumption, preferential movement of water downward due to heterogeneity is neglected. Porosity and permeability for the waste zone are derived from infiltration modeling performed by Martian (1995). Variably saturated properties describing the moisture characteristic curve also are based on an average of site-specific samples of the surficial sediments within the SDA (Baca et al. 1992).

All water sources in the waste zone originate from surface events (e.g., precipitation, snow accumulation and melting, and flooding). A substantial portion of the average annual precipitation can be present in the early spring in the form of a consolidated snowpack (McElroy 1993). Often, the snowpack melts before the ground is thawed, and water redistributes to topographically low areas (e.g., ditches). These low areas then experience more infiltration than more elevated areas (Bishop 1996).

Infiltration of surface water into the waste zone is highly variable across the SDA. Overall, infiltration inside the SDA is considered to be greater than infiltration outside the SDA due to disruption of natural soil layering and less vegetation inside the SDA (Barraclough et al. 1976; McElroy 1993). Background infiltration rates outside the SDA are estimated to be on the order of $1.0 \mathrm{~cm} /$ year (0.4 in./year) (Cecil et al. 1992), though ongoing studies indicate this value may be an order of magnitude too high. Inverse modeling using soil moisture profiles measured with neutron logging coupled with meteorological time histories was used to estimate infiltration at monitoring locations around the SDA (Martian and Magnuson 1994; Martian 1995). These inverse modeling estimates were used in combination with surface topography to assign a distribution of three rates across the SDA (Martian 1995). These three rates are $1 \mathrm{~cm} /$ year (0.4 in./year), which is the same as background infiltration outside the SDA; $3.7 \mathrm{~cm} /$ year (1.5 in./year), representing a medium value; and $10.0 \mathrm{~cm} /$ year (4 in./year), representing a high value. The spatial average of assigned infiltration, across the uniformly sized model grid blocks representing the SDA, is $5.0 \mathrm{~cm} /$ year ( 2 in./year). These rates represent net infiltration, or recharge, because the influence of ET is included in the inverse modeling (Martian 1995). Therefore, this amount of water contacts the waste and continues downward.

Direct observations of infiltration used by Martian (1995) for infiltration estimates are limited in that all are located either between waste pits or away from waste pits and provide no direct measurements within waste. Instrumented probes were installed to measure infiltration directly within waste but had not produced useable results by the time the OU 7-13/14 RI/BRA was initiated. Because estimates of infiltration directly within waste have not been documented, infiltration in the waste is assumed to be 
similar to soil moisture measurements made between or away from the waste. This assumption is at least partly valid because disturbed soil was found in some locations where measurements have been taken.

The numerical model does not account for changes in topography or hydrologic properties due to waste emplacement over time. Modeling assumes that the spatial infiltration pattern estimated in Martian (1995) can be applied back to 1952. Because contaminants are released from the source-release model over time, any additional water added before waste is released is not considered to substantially impact predicted contaminant movement. Similarly, the impact of soil added to the SDA surface during contouring is assumed to be incorporated in the spatially variable infiltration assignment. The model assumes that initial conditions before waste emplacement started in 1952 were in hydrologic equilibrium with the background flux of $1 \mathrm{~cm} /$ year $(0.4 \mathrm{in}$./year).

In addition to being highly variable spatially, infiltration is also highly transient (McElroy 1993; Bishop 1996). Infiltration primarily occurs in the early spring during snowmelt, but also has occurred in response to intense large-magnitude summer rain showers. However, implementation in the numerical model treats infiltration as a steady-state phenomenon, with the exception of the historical floods. Modeling studies have evaluated the impact of transient surface infiltration on contaminant migration and determined that as long as an assumption of equilibrium-reversible sorption is invoked, the influence of transient infiltration lessens with depth in the vadose zone due to sorption in the interbeds (Magnuson and Sondrup 1998).

The conceptual model includes historical flooding of the SDA. The three historical flooding events that occurred in 1962, 1969, and 1982 are imposed at their respective times in the modeling, with water volumes based on Vigil (1988) and an assumed duration of 10 days. The high infiltration rates assigned in the model (spatial average of $5 \mathrm{~cm} /$ year [2 in./year]) are continued into the future and are thought to account for the impact of possible future flooding of the SDA because the assigned infiltration rates represent an additional $4 \mathrm{~cm} /$ year (1.6 in./year) of infiltration above background, and they occur every year.

Overall, the conceptual model assumes that water movement through the waste zone and into underlying fractured basalt is primarily vertical. Lateral migration of water within the waste zone has been observed. Magnesium chloride brine in lysimeters located at a distance from roadways where the brine was applied demonstrates that water moved horizontally at least $12 \mathrm{~m} \mathrm{(40} \mathrm{ft)} \mathrm{(Hull} \mathrm{and}$ Bishop 2003). Also, water was hypothesized to spread laterally at the depleted uranium probing focus area, based on tensiometer responses at depth in the waste zone showing wetting where no wetting was observed at sensors located shallower at the same location (Hubbell et al. 2005). Lastly, ephemeral perched water has been observed in surficial sediments at the SDA in neutron access tubes located between and away from waste. Perching at these locations indicates a local horizontal gradient is established within the sediments above the sediment-basalt contact that could move water laterally. However, because of the presence of high-permeability fractures in the underlying basalt, water is assumed to move only a short distance within the sediments before contacting these fractures which are able to accommodate this water and thereby limit extensive lateral migration. In support of the conceptual model assumption of primarily vertical movement, the maximum observed spacing of vertical fracture joints in basalt is $3 \mathrm{~m}$ (10 ft) at Hell's Half Acre and Box Canyon (Knutson et al. 1992). This spacing is approximately a factor of four less than the minimum horizontal grid block size of $38.1 \mathrm{~m}(125 \mathrm{ft})$ used in the numerical model. Therefore, it is reasonable to assume that at the scale of the smallest grid block in the numerical model, water movement through the waste zone and into the underlying fractured basalt is primarily vertical. 
D-2.3.1.2 Contaminant Inventory, Release, and Transport in the Waste Zone. The rate of contaminant release from the source depends on the volume of water moving through the source, the flux, and the contaminant concentration in the water. The previous subsection discussed water movement. This subsection discusses contaminant inventories, release from disposed waste, and how released contaminants are considered to move in the aqueous and gaseous phases. Information used to calculate release concentrations include source inventory, waste form, solubility, partitioning, and physical transport processes. Within the source-term model, waste within a container is not subject to mobilization. Once the container fails, contaminants can be released from the waste by one of several mechanisms. Contaminants released within the waste zone partition among the aqueous phase, the gaseous phase, and the solid phase on sediments. Contaminants released out the bottom of the waste zone depends on several processes, which, for the numerical model, have been simplified to a few parameters. Contaminants released out the top of the waste zone, likewise, depends on several simplified, but different, processes.

Contaminant inventories estimated for the SDA are based on extensive research of historical shipping records, process knowledge, and material-accountability records. Process knowledge was obtained from interviews with retired staff present when waste was originally generated (Vejvoda 2005; INEL 1995; Abbott et al. 2005). Estimates were developed for mass and activity of waste emplaced annually since 1952. Also, locations of buried waste were input to the Geographic Information System database, enabling production of spatially distributed waste inventories. Decay of parent nuclides and ingrowth of daughter nuclides are part of the source-term simulation. For the source model, release for any given year is based on waste disposal records to that date, including radioactive decay. The source release is implemented by assigning inventories and waste forms to 18 possible subregions (source-release areas) within the SDA. These subregions represent functional groups that might be treated in remedial alternatives currently under evaluation.

Waste is categorized by waste forms and container types. A wide range of containers has been used to dispose of waste at the SDA, including cardboard boxes, plywood boxes, carbon steel drums, and welded stainless steel containers. In addition, the form of waste varies widely and includes solidified sludge, activated metal, and loose laboratory waste packaged in polyethylene bags. Some containers and waste forms provide a barrier to the release of contaminants, and others do not. No credit is taken for containment in cardboard or wooden boxes. Credit for delayed release is taken for waste in drums, comprising primarily Rocky Flats Plant waste. These carbon steel drums fail over time primarily due to corrosion. From historical waste retrieval operations, the mean and variance of the drum failure rate were fit with a Gaussian distribution to determine parameters for drum failure rates. No credit is taken for containment of waste in polyethylene liners within drums, even though some of these liners have been observed to still be intact (Olson 2004a, 2004b). Dumping during emplacement caused some drums to fail immediately; therefore a fixed fraction of the waste containers emplaced between 1965 and 1970 was assumed to fail immediately upon emplacement, and contaminants within those containers were considered to be immediately available for transport within the waste zone.

Credit for delayed release also is taken for Tc-99 and I-129 disposed of in activated stainless steel and thick-walled carbon steel containers. These waste forms are highly resistant to release and are projected to have much longer lives than carbon steel drums and maintain their integrity for a considerable time. The numerical model accounts for all containers in which Tc-99 and I-129 waste was buried. Steel containers were failed with a Gaussian failure distribution, with the mean time to failure equal to the time necessary for the average corrosion rate to corrode half the thickness of the metal. For polyethylene containers, the radiation field associated with the disposal was used to calculate the time to failure. The distribution of radiation field is linear; therefore, a uniform failure rate was used. These assumptions relative to Tc-99 and I-129 release are important because without them, predicted Tc-99 and I-129 concentrations are dramatically overpredicted compared to current observations from the vadose zone and aquifer monitoring network (Holdren et al. 2006). Even with these assumptions, Tc-99 is still 
overpredicted in the aquifer by one to two orders of magnitude compared to observed monitoring results (Magnuson and Sondrup 2006).

Once a container fails and a contaminant is available for release to the subsurface environment, contaminants move from emplaced waste into either the aqueous or gaseous phase where migration can occur by three primary mechanisms: diffusion, corrosion, and surface washoff. Diffusion is used to describe release of volatile organics bound up in sludge. Corrosion is used to describe release of contaminants from activated metals. Specifically, the corrosion mechanism is used to describe release of tritium and C-14 from beryllium blocks and Cl-36 and Tc-99 from activated stainless steel. Surface washoff is used to describe the release of contaminants chemically bound to or otherwise present on surfaces and is used for all other waste forms. Surface washoff is described using a distribution coefficient that assumes equilibrium partitioning between buried waste and pore water around the waste. For all three mechanisms, a maximum is imposed on the source concentration, limited by the calculated solubility of the contaminant. Partitioning coefficients for all contaminants undergoing surface washoff are assumed to be equal to partitioning coefficients for soil. This is a reasonable assumption because soil was added over emplaced waste and filled voids within the waste. Waste excavations have demonstrated extensive soil mixed with waste (Olson 2004a, 2004b). If the waste has a lower partitioning coefficient than soil, then the contaminant will leave the waste and be partitioned onto the surrounding soil. If the waste has a higher partitioning coefficient than soil, then the contaminant will remain on the waste, and the assumption will tend to overestimate release from the waste.

Water within the waste zone influences both the corrosion and surface washoff release mechanisms. Corrosion rates are accelerated due to the presence of water, especially if salts are present in the water. In the past, magnesium chloride salts have been applied to roads inside the SDA as a dust suppressant; therefore, salt concentrations in pore water are elevated, and this was taken into account when assigning corrosion rates in the source-release model.

The amount of infiltrating water also defines the moisture content within the waste zone through the hydrologic parameters defining the nonlinear relationship between soil water tension, moisture content, and unsaturated hydraulic conductivity. Moisture content directly affects the amount of mass released through the surface wash mechanism. Infiltration is assigned spatially on a more refined basis than the 18 subregions into which the source releases are applied. These infiltration rates are averaged for these 18 subregions. This averaging of infiltration for functional groups, instead of assigning it on a one-to-one basis with infiltration for grid blocks, is not thought to impact the results significantly. The greater impact, based on experience in conducting sensitivity studies for the RI/BRA, is the magnitude of water contacting waste in the first place. Stated otherwise, changing the overall amount of infiltration has a greater impact than changing how infiltration is averaged once infiltration is assigned.

Buried waste represents an extremely heterogeneous geochemical environment. A wide range of conditions are possible within the waste that makes it difficult to evaluate source-release parameters. Conditions also will change over time as waste degrades, requiring an assessment of what set of conditions are most applicable for long-term risk assessment. Microbes in the waste will degrade organic matter (e.g., cardboard, cloth, and wood) over time, consume oxygen, and create a reduced environment in the waste. Gas analyses from gas ports installed in waste indicate the presence of hydrogen and methane gases, indicating reduced conditions. Degradation of organic matter also may create organic complexing compounds that may make waste radionuclides more mobile. The $\mathrm{pH}$ of pore waters in the waste could deviate from neutral conditions, depending on waste degradation and buried chemicals in the waste. Solubility of minerals that could control mobility of waste radionuclides may vary significantly, depending on the concentrations of inorganic constituents in the waste or the presence of complexing agents. By considering the waste zone to include backfilled soil and underburden, in addition to buried waste, a simplified geochemical environment could be established for the source-release model. 
Reducing conditions within waste depend on the presence of organic matter (e.g., wood, paper, and cardboard) undergoing microbial decay. Oxygen measurements in the vadose zone around the waste pits, and even gas-phase measurements within the pits themselves, indicate the presence of oxygen gas. Once organic matter is consumed, microbial activity will diminish, and oxygen will diffuse into the waste from the surrounding soil gas phase. This condition will allow the remaining waste to become oxidized and can change the valence state of radionuclides in the waste. Many fission products (e.g., Tc-99 and I-129) and actinides (e.g., uranium and neptunium) are more soluble and mobile under oxidized conditions. Therefore, oxidizing conditions were assumed to be present in the buried waste at all times. This conservatively accelerates short-term mobility of some radionuclides, but is a better assumption of long-term conditions in the waste.

Fermentation of organic waste by microbes under reduced conditions creates dissolved organic compounds (e.g., oxalate, malonate, and lactate) that can form soluble aqueous complexes with radionuclides. A radionuclide complexed in solution is effectively isolated in solution. The complexed radionuclide does not participate in partitioning reactions with soil minerals, and migrates more rapidly than a radionuclide that is not complexed. Such complexing behavior was seen in low-level radioactive waste burial grounds at Maxey Flats, Kentucky, and at Oak Ridge, Tennessee. Therefore, it is reasonable to expect that radionuclides are complexing with organic ligands in reduced conditions at the SDA. No measurements are available for organic ligand concentrations in pore water within the waste zone at the SDA. Even if there were, there is not a good thermodynamic database of equilibrium constants from which solution composition of radionuclide-organic complexes could be calculated. Other solution parameters (e.g., $\mathrm{pH}$ and ionic strength) which would be required to accurately calculate organic complex concentrations, also are not known. Organic ligands in question are not stable in water under oxidized conditions. In the presence of oxygen, microbes use the organic ligands as a source of carbon (food) and destroy the ligands. Once out of reduced conditions within the waste and into the interstitial soil or underburden, organic ligands would not persist. In the short term, while reduced conditions persist in the waste, organic ligands may accelerate the migration of radionuclides from the buried waste, which is reduced, into the surrounding soil or underburden, which is oxidized. Once out of the waste, organic ligands will not be stable and will release the radionuclides. From the perspective of the waste zone, as a whole, radionuclide release from the waste zone will be controlled by the oxidized form of the radionuclides and partitioning to the soil, and will not be controlled by complexing with organic ligands.

Soil at the SDA contains an appreciable fraction of the mineral calcite $\left(\mathrm{CaCO}_{3}\right)$. Calcite can buffer $\mathrm{pH}$ near neutral $\mathrm{pH}$ values by dissolution or precipitation. Because the waste zone includes interstitial soil and underburden, it was assumed that $\mathrm{pH}$ would be near neutral. This assumption precludes large swings in solubility or partitioning of contaminants in the waste zone because of extremes in $\mathrm{pH}$. Within the buried waste, such extremes may occur; however, they are assumed to be damped out within the source zone. Because of the heterogeneity of the buried waste and the difficulty of sampling the buried waste, it might be possible to obtain a few $\mathrm{pH}$ measurements of waste-zone pore water, but it would not be possible to fully characterize the distribution of $\mathrm{pH}$ in the waste.

Oxidizing conditions are assumed to control solubility limits and partitioning of radionuclides in the source zone. This certainly will be the long-term case at the SDA. Solubility under reducing conditions would be lower in the short term, but complexing with organic ligands may increase solubility under reduced conditions. Currently, data are not available to quantitatively evaluate this tradeoff. For contaminants (e.g., uranium) with a large mass inventory present in the SDA, the solubility limit is a sensitive parameter, and this assumption strongly affects groundwater pathway contaminant concentrations (Anderson and Becker 2006).

Once contaminants are released from waste, they exist either in the aqueous phase or, in some cases, also as a gaseous-phase contaminant in equilibrium with the aqueous phase. Volatile organics and C-14 are the two contaminants where gaseous-phase transport is important. Henry's Law defines the 
partitioning behavior between the aqueous and gaseous phases for the volatile organics and also for C-14 when treated as carbon dioxide (Martian 2003). Sufficient organic mass never is released for an oleic phase to be present.

Advection, dispersion, and diffusion control contaminant movement in the aqueous phase. Advection is the movement of contaminants with migrating water. Dispersion results from tortuous pathways of differing lengths causing spreading of a sharp contaminant front. Dispersion is parameterized through a longitudinal and transverse dispersivity, which acts in relation to the water velocity. Transverse dispersion describes movement orthogonally to the direction of water velocity. To conservatively keep dilution to a minimum in the model, dispersivities are assigned values less than conventional wisdom would dictate for the scale of the model. Diffusion, results from random motion on the molecular scale. Aqueous diffusion in a porous medium is described by Fick's first law, which relates the rate of movement to the aqueous concentration gradient and the effective diffusion coefficient. In a porous medium, contaminant molecules must travel longer diffusion paths than in a pure aqueous solution because of the structure of the medium and the reduction in wetted cross-sectional area due to variable saturation. To account for longer diffusion paths, the free water diffusion coefficient is modified by a tortuosity term that accounts for porosity and water saturation. Aqueous-phase diffusion generally has a small impact on contaminant movement compared to advection and dispersion. However, the mechanism is retained in the numerical model because diffusion allows contaminants to enter into lower-permeability regions, where the contaminant remains until it can diffuse back out into regions that have lower concentrations after lower-permeability regions have been swept clean of contaminants.

Contaminants are transported in the gaseous phase through the same three mechanisms that transport aqueous-phase contaminants: advection, dispersion, and diffusion. Within the waste zone, gaseous-phase advection primarily results from atmospheric pressure fluctuations and, to a lesser extent, from changes in pressure introduced deeper in the vadose zone from either positive air pressures during drilling or from operating the Organic Contamination in the Vadose Zone Project (OCVZ) system. Gaseous advection also can occur when gaseous-phase density gradients are present. Elevated density gradients occur when concentrations are high. These are likely to be important only in the waste zone where gaseous-phase concentrations are the highest.

Gaseous-phase diffusion transports contaminants more rapidly than aqueous-phase diffusion. Gaseous-phase tortuosity values for waste zone sediments were estimated based on porosity and moisture content. Gaseous diffusion upward to land surface and into the atmosphere accounts for a large portion of the volatile organic compound (VOC) and C-14 inventory. Contaminant concentrations in the atmosphere are assumed to be maintained at zero. This is a reasonable assumption because most gaseous-phase contamination that reaches land surface will be swept away by winds or will diffuse even more rapidly. Gaseous-phase contamination is also an important aspect of the conceptual model because without this process of losing contaminant mass to the atmosphere, subsurface concentrations of C-14 would be overpredicted.

Sensitivity to gaseous-phase advective loss across the surface caused by atmospheric pressure fluctuations was tested for VOCs and C-14. The test showed that advective loss across the surface was a second-order effect compared to diffusive loss across the surface (Magnuson and Sondrup 2006). Thereafter, fluctuating pressure at land surface was excluded to facilitate modeling efficiency. This also was a conservative assumption because more mass remained in the subsurface because it was not allowed to advect to the atmosphere. The numerical model included gaseous-phase advection resulting from changes in pressure introduced deeper in the vadose zone from either positive air pressure during drilling or from OCVZ system operation.

Once contaminants are present and moving within the aqueous phase, they can undergo transformations that impact their continued movement. These transformations include chemical 
interactions with solids, formation of colloids, radioactive decay and ingrowth, and for organics, degradation. Conceptually, all the chemical reactions - where dissolved-phase contaminants interact chemically with the soil matrix - are lumped together as sorption, which is described by a soil-water distribution coefficient. Reactions contributing to sorption include ion-exchange and surface complexation. Each of these reactions can be reversed and is influenced by numerous geochemical factors. In the numerical model, sorption is treated in the most simplistic fashion, with a linear reversible isotherm establishing a constant ratio between the aqueous-phase and sorbed-phase contaminant. The distribution coefficient is this ratio and significantly impacts mobility of a contaminant. Nonzero distribution coefficients retard contaminant movement and can allow radioactive decay to reduce contaminant activity below a level that would otherwise be of environmental concern. The degree of confidence in distribution coefficients varies. Distribution coefficient values used for the RI/BRA were established in Holdren and Broomfield (2004) and represent best estimates. As implemented in the numerical model, use of distribution coefficients assumes that aqueous-phase concentrations generally are low, competition with other contaminants for sorption sites does not limit sorption, and solid minerals do not precipitate. Though some exceptions are likely in the waste zone-due to extreme chemical variations caused by heterogeneous waste types - distribution coefficients are reasonably representative, given the large surface areas present in loamy soil comprising sediment in the waste zone. Distribution coefficients also are assumed to be distributed uniformly in the waste zone. While it is obvious that soil properties vary spatially, uniform distribution was assumed, contributing to uncertainty.

Two types of colloids are evaluated in this conceptual model. Colloids are small particles, generally less than $10 \mu \mathrm{m}$, that are transported by advective movement of water, with limited or no chemical interaction with the surrounding soil matrix. Transport of colloids in subsurface media has been the subject of intense research for at least two decades. Natural colloids at the SDA are derived from clay-rich soil. Contaminants can sorb onto the natural colloids and undergo enhanced transport. Site-specific studies using SDA soil in laboratory columns have demonstrated this possibility for plutonium, americium, thorium, and neptunium (Fjeld, Coates, and Elzerman 2000). These studies estimated that only a small fraction (i.e., less than 1\%) of these isotopes introduced in the column underwent colloid-facilitated transport. Plutonium-239 and Pu-240 also are thought to have formed intrinsic colloids as a result of going through high-temperature processes at the Rocky Flats Plant production facility (Batcheller and Redden 2004). These intrinsic colloids also migrate without interacting with the soil matrix in the waste zone. Batcheller and Redden (2004) conservatively estimated that $3.7 \%$ of production went through the high-temperature process at Rock Flats Plant. In the numerical source-release model, this $3.7 \%$ of the $\mathrm{Pu}-239$ and $\mathrm{Pu}-240$ inventory is assumed to be in colloidal form and is, therefore, mobile. This is implemented in the numerical model by assigning a distribution coefficient of zero to the colloidal $\mathrm{Pu}-239 / 240$ fraction in the waste zone sediment. The $3.7 \%$ mobile fraction of Pu-239 and $\mathrm{Pu}-240$ (due to intrinsic colloids) is much greater than that attributed to natural colloids by Fjeld, Coates, and Elzerman (2000); thereby, the 3.7\% mobile fraction bounds the effects that might occur through transport by natural colloids for $\mathrm{Pu}-239$ and $\mathrm{Pu}-240$. Enhanced transport that might occur for other contaminants sorbing onto natural colloids is excluded because it was a small fraction (Fjeld, Coates, and Elzerman 2000).

Radioactive decay and ingrowth of daughter products are the most certain aspects of the conceptual model both because this process is known to occur and because the numerical model explicitly accounts for decay and ingrowth. Daughter products are created within the model as the parent decays. Daughter products have separate mobilities based on chemical identity and have different distribution coefficients assigned for them in the numerical model.

Other contaminants likely to have undergone decay or degradation include VOCs. Chloroform is detected routinely in vapor monitoring results, but very little appears in the inventory estimates for disposed waste. Chloroform most likely results from reductive dechlorination of carbon tetrachloride under reducing conditions in the source zone. Organic degradation is not included in the numerical model 
because of uncertainly regarding the mechanism and rate. Neglecting organic degradation is conservative because by-products of carbon tetrachloride degradation (i.e., chloroform, methylene chloride, and chloromethane) have transport properties similar to carbon tetrachloride, but are typically less toxic. Neglecting organic degradation is not thought to affect the overall vadose zone model calibration because that calibration is based on the amount of carbon tetrachloride mass that must have been released from the source zone to mimic the observed contaminant plume in the vadose zone and the aquifer.

Movement of water and contaminants from the waste zone portion of the modeling domain into the vadose zone portion of the modeling domain is accounted for internally in the numerical model. Because both regions are simulated within one numerical model, a mass transfer interface between models is not required. The numerical model represents irregular topography of the contact between waste zone sediments and underlying basalt. As discussed in the previous section, some limited redistribution of water and dissolved-phase contaminants is likely as they migrate downward through the waste zone and contact underlying basalt. This limited movement is not thought to occur on a scale greater than the horizontal dimensions of the numerical model. Therefore, given the parameterization of the underlying basalt as a high-permeability, low-porosity medium (see next subsection) able to accept large volumes of infiltrating water, nothing in the model forces water to redistribute horizontally, and water and contaminants move vertically across this interface.

\section{D-2.3.2 Vadose Zone}

For this conceptual model discussion, the vadose zone is that portion of the subsurface from beneath the surficial sediments and waste zone down to the aquifer. This zone is composed of fractured basalt and sedimentary interbeds.

D-2.3.2.1 Water and Air Movement in Basalt. The fracture network controls water and air movement in basalt portions of the vadose zone. Fractures generally are connected to other fractures, occur frequently, and have apertures large enough to transmit water and air. Because of extensive fracturing in the basalt portions of the subsurface, basalt is treated as an equivalent porous medium with high permeability due to high fracture conductivity and low effective porosity due to the limited volume of the fracture system compared to the basalt matrix. Darcian flow is assumed to occur through this equivalent porous medium. The Large Scale Infiltration Test conducted south of the SDA (Wood and Norrell 1996) demonstrated that on the scale of the SDA, water in the fractured basalt moved primarily downward, was controlled by the fracture network, and could be emulated with an equivalent porous-medium numerical model. Parameterization of the equivalent porous medium for the RI/FS model is based on inverse modeling conducted to emulate the Large Scale Infiltration Test (Magnuson 1995). This parameterization allows rapid movement of water and air vertically through the fracture system. An important aspect of this parameterization was an estimated horizontal-to-vertical permeability ratio of $300: 1$, indicating that water can easily spread in the horizontal direction when downward movement encounters resistance (e.g., an interbed or low-permeability region within the basalt). This high anisotropy ratio aided in comparing simulated and observed spread of the carbon tetrachloride plume beneath the SDA (Magnuson and Sondrup 2006).

In cases involving contaminants that also partition into the gaseous phase, movement of water and air within the basalt matrix is evaluated. This representation uses a dual permeability description in which two separate mathematical continua representing the matrix and the fracture domains are treated as if they occupy the same physical domain (Warren and Root 1963). Samples of the basalt matrix have been characterized hydraulically (Bishop 1991). These results are used to describe the moisture characteristic curve for the basalt matrix. Matrix permeability was derived from inverse modeling to the Large Scale Infiltration Test (Magnuson 1995), and matrix porosity was assigned based on calibration to the carbon tetrachloride plume beneath the SDA (Magnuson and Sondrup 1998). All basalt matrix properties were assumed to be homogeneous. In a dual-permeability representation, interaction between the matrix and 
the fracture is controlled by an interaction term. Physical parameters affecting the interaction are the average or characteristic matrix block length, which is the distance between fractures, the characteristic fracture aperture, and matrix-matrix direct interaction. The characteristic block length was assigned a value of $20 \mathrm{~m}(66 \mathrm{ft})$, which is on the upper end of the range from Knutson et al. (1992). This large value was assigned to improve comparisons between the observed and simulated carbon tetrachloride plumes (Magnuson and Sondrup 2006). The fracture aperture is used to calculate a harmonic effective permeability between fracture and matrix domains. The characteristic fracture aperture was set to zero; this implied the matrix permeability alone controlled water movement from the fracture into the matrix. Matrix-matrix interaction across fractures was set to 0.5 for each orthogonal direction, allowing partial contact between matrix blocks.

The same assumptions used for air movement in the fractured basalt are used for the waste zone, namely, that it is within Reynolds number ranges such that air flow is laminar and Darcian concepts apply. Air movement in the fractured basalt results from changes in pressure introduced in the vadose zone such as positive air pressures during drilling or negative pressures from operating the OCVZ system.

D-2.3.2.2 Water Movement in Interbeds. Only three interbeds are represented in the conceptual and numerical models: A-B, B-C, and C-D interbeds. Though other interbeds are present deeper in the vadose zone, they are neglected because data are sparse and existing data suggest deep interbeds are relatively thin and discontinuous. Topography of the upper surfaces and thicknesses of the three simulated interbeds are estimated through geostatistical techniques (Leecaster 2004) using lithology data collated in Ansley, Helm-Clark, and Magnuson (2004). Leecaster (2004) used spatial variability analysis and standard kriging techniques to interpolate the upper surfaces and thicknesses of the interbeds onto the numerical simulation grid. Kriging estimates produce single-value estimates for each grid block. Because interbed thicknesses are highly variable relative to the model grid, some model grid blocks may encompass more than one data point (i.e., where the B-C interbed may be present in one and absent in another). Kriging is a smooth interpolator, and as a result, the single value estimate for this grid block is nonzero. The uppermost A-B interbed is very discontinuous and is missing in many locations in the southern half of the SDA. The preponderance of locations where the interbed is missing persists through the kriging; as a result, the A-B interbed is absent in that portion of the model. In contrast, the B-C and C-D interbeds are continuous in the model, requiring that water (and contaminants) pass through them before reaching the aquifer. Sensitivity studies were conducted for the OU 7-13/14 RI/BRA to evaluate the effect of this continuity assumption. If the B-C interbed were removed completely, groundwater pathway risks were impacted. If colloidal transport was not truncated through assumed filtration at the B-C and C-D interbeds, groundwater pathway risks were impacted significantly.

Hydrologic properties of the interbeds vary both in the real system and in the conceptual model for the $\mathrm{B}-\mathrm{C}$ and $\mathrm{C}-\mathrm{D}$ interbed. The A-B interbed is considered to be homogeneous and is assigned a low permeability $(4 \mathrm{mD})$ compared to the other interbeds. The $\mathrm{B}-\mathrm{C}$ and $\mathrm{C}-\mathrm{D}$ interbeds have more hydrologic characterization data because they were the target of investigations conducted in 1999 and 2000. Data were sufficient to determine a spatial correlation structure, which was used to krige both the permeability and porosity for both interbeds (Leecaster 2002). Two assumptions were used in this interpolation. One assumption was that hydrologic properties measured on core-sized samples are representative of properties measured at larger scales. This is obviously a poorly supported but necessary assumption and applies to about any subsurface investigation. The second assumption is that flow is primarily perpendicular to the interbed, which allows permeability measurements to be harmonically averaged when more than one measurement is available at a single location. Porosity for these locations was arithmetically averaged. Low permeability of the A-B interbed in the numerical model affects water movement by focusing it toward gaps in the A-B interbed. The assigned low permeability of the A-B interbed results is not from hydrologic data, but from precedent in previous modeling studies. The effect is thought to be conservative because focusing water movement toward gaps reduces the chance of 
sorption in the A-B interbed sediments. Moisture characteristic curve parameters are considered to be the same for all three interbeds.

Transient infiltration events of sufficient magnitude that persist through the waste zone sediments are considered to move rapidly and primarily downward through the fractured basalt. These wetting fronts are considered to dampen as they encounter interbeds and move through the interbed sediment. This aspect of the conceptual model is supported by observations within the SDA at a nested tensiometer site (Hubbell et al. 2002), where a series of early spring infiltration events track downward through the upper vadose zone to the A-B interbed at a depth of $9.4 \mathrm{~m}(31 \mathrm{ft})$, where the wetting front advance was dampened.

D-2.3.2.3 Additional Sources of Water in the Vadose Zone. In addition to surface infiltration, other sources of water can contribute to the hydrological regime in the vadose zone. Some of these are hypothesized to contribute, and others are known to contribute.

Primary sources of additional water within the vadose zone are the spreading areas located west and southwest of the SDA. Rightmire and Lewis (1987) and Hubbell (1990) hypothesized, based on water chemistry and perched water level response, that Big Lost River water discharged to the spreading areas migrated horizontally within the vadose zone to beneath the SDA. A tracer test conducted in 1999 by the U.S. Geological Survey (Nimmo et al. 2002) confirmed spreading area water could travel at least this far within 90 days. This finding led to speculation that water from the Big Lost River channel possibly could spread to the SDA vicinity. Another likely source of water at depth in the vadose zone is enhanced infiltration from the perimeter drainage channel that bounds the southern and eastern side of the SDA. This channel facilitates drainage of the local basin in which the SDA lies. The channel is excavated down through the surficial sediments and collects water, thereby increasing infiltration. The sewage treatment ponds, located south of the Transuranic Storage Area, are not a source of water because they are lined.

The Ancillary Basis for Risk Analysis (Holdren et al. 2002) evaluated sensitivity of predicted transport of additional water sources to the aquifer. The primary result from adding additional water was decreased simulated concentrations in the aquifer due to dilution. This finding applied to relatively long-lived contaminants migrating in the dissolved phase. If any short-lived radionuclides had reached the C-D interbed before additional spreading area water was added, higher concentrations might have been predicted for the groundwater pathway due to faster transport from the C-D interbed to the aquifer with less time for decay. This however was not the case. The inventory of short-lived radionuclides is small, and concentrations in the C-D interbed were small when additional water was added. Thus, the additional water had little effect on increasing transport to the aquifer. Impacts to organics, which also partition into the gaseous phase, were not evaluated. This finding was generalized in the RI/FS because additional water from any source that does not directly contact the emplaced waste and cause additional contaminants to be released is considered to result primarily in dilution for the groundwater pathway and in lower estimated aquifer concentrations. Therefore, it was conservative to not include additional water sources.

D-2.3.2.4 Perched Water in the Vadose Zone. Perched water is observed at depth beneath the SDA in association with the interbeds. The occurrence and behavior of perched water has been studied since it was first encountered in 1972 (Barraclough et al. 1976; Hubbell 1990, 1993a, 1993b, 1995; Cecil et al. 1992). Numerous mechanisms are hypothesized to cause the perched water, including low-permeability regions within the interbeds and infilling of fractures above the interbeds. Perching or saturated conditions develop when downward-moving water encounters reduced permeability. Water then spreads laterally until an adequately large area is wetted to accommodate the infiltrating water, or until the water encounters a gap or higher permeability region in the low-permeability layer. 
Perching is facilitated in the numerical model by means of a low-porosity, low-permeability feature assumed to exist at the top of the B-C and C-D interbeds across the entire vadose zone simulation domain. This low-permeability feature represents either a low-permeability sedimentary feature at the top of the interbeds or, more likely, a low-permeability feature caused by fine sediment infilling of fractures in the basalt immediately above the interbed. The latter would occur from deposition of entrained sediment fines as infiltration continues through fractures in overlying basalt emplaced after the interbeds form. Including this low-porosity, low-permeability feature in the numerical model was necessary to achieve conditions close to saturation that have been observed within the interbeds. It also facilitates spreading of carbon tetrachloride in the vadose zone as part of transport calibration. The low-porosity, low-permeability region works in opposition to the spatially assigned hydrologic properties because it imposes a uniform property across the top of the interbed. This limited the effectiveness of evaluating preferential movement of water and contaminants across the interbed.

To support higher infiltration rates assigned inside the SDA and the low-porosity, low-permeability feature, observed perched water conditions in some wells and generally wetter conditions observed inside the SDA - compared to outside from the deep tensiometer monitoring network - indicate some combination of factors is slowing water movement and causing elevated water saturations associated with the interbeds.

D-2.3.2.5 Transport in the Vadose Zone. When implementing the conceptual and numerical models, transport occurs in the vadose zone region in both aqueous and gaseous phases by advection, dispersion, and diffusion.

An important feature of the conceptual model for transport in the vadose zone is that although the basalt fracture surface is coated - with either fine sediments or alteration products that are good candidates for sorption - the fracture surface area for chemical interaction is so limited that essentially no sorption occurs within the fractured basalt. This is a conservative assumption and is applied universally to both the basalt-fracture and the basalt-matrix domains.

Sorption does occur and is included in the sedimentary interbed features. Distribution coefficients within interbed sediments vary spatially and depend on soil characteristics and pore water chemistry. Attempts have been made to assess this spatial variability for uranium and neptunium (Leecaster and Hull 2004). Because the number of data points was insufficient to identify a spatial correlation structure, median values were used instead. The entire set of distribution coefficients for the interbeds was defined in Holdren and Broomfield (2004). These values are applied uniformly across the interbeds and correspond to an assumption of no preferential pathways across the interbeds. Because gaps are known to exist in the B-C interbed inside the SDA, a bounding sensitivity study was included in the RI/FS modeling whereby the B-C interbed was treated as fractured basalt with no sorption (i.e., the interbed did not exist). Results showed little difference in simulated groundwater pathway concentrations, primarily because the C-D interbed was present everywhere across the vadose zone model domain, and sorption within the $\mathrm{C}-\mathrm{D}$ interbed is a key factor in controlling transport to the aquifer.

Transport of colloids, and contaminants sorbed to them, within the fractured basalt is considered to be relatively rapid. When these entrained colloids encounter sedimentary interbeds, they are considered to be mechanically filtered out (Batcheller and Redden 2004). In the numerical model, this is accomplished by assigning the distribution coefficients in Holdren and Broomfield (2004) to the mobile fraction of plutonium representing colloidal transport. This is an important assumption because it limits further downward migration of plutonium. The assumption appears reasonable because it is supported by observed actinide distributions, which decrease across the B-C interbed in one location where they are confirmed to have migrated to the B-C interbed (Rawson, Walton, and Baca 1991). A sensitivity simulation in the RI/FS modeling showed that if this filtration does not occur in either the B-C or $\mathrm{C}-\mathrm{D}$ interbed, plutonium concentrations in the aquifer are increased. 
For VOCs and C-14, partitioning into the gaseous phase and diffusion into the matrix domain result in a temporary sink. Matrix blocks store the contaminants until they diffuse out of the blocks and continue migrating downward in the aqueous phase. Aqueous-phase diffusion into the matrix blocks is too slow to be significant and, conservatively, is not included.

Contaminants that migrate to the bottom of the vadose zone in a real system enter the aquifer in two ways: (1) aqueous-phase contaminants continue advecting downward into the aquifer, and (2) contaminants within the gaseous phase can partition directly into water in the capillary fringe or the aquifer. In the numerical model, the vadose zone and aquifer are separate models, and only advection of aqueous-phase contaminants is used to transfer contaminant mass from the vadose zone to the aquifer. Therefore, gaseous phase contamination is partitioned into the aqueous phase at the bottom of the vadose zone model domain. This happens because saturated conditions are applied to the bottom of the vadose zone model domain. Thus all VOC contamination exits the bottom of the vadose zone in the aqueous phase.

\section{D-2.3.3 Aquifer}

D-2.3.3.1 Water Movement in the Aquifer. The aquifer is assumed to consist entirely of fractured basalt. Though present within the aquifer, sedimentary interbeds are neglected because they are not well characterized and are assumed to comprise a very small portion of the aquifer volume. Additionally, the hydrologic contrast between the fractured basalt and the sediments would result in water flowing around the sediments, effectively bypassing them.

Regional hydraulic gradients control aquifer flow in the SDA region and are implemented through first-type or prescribed boundaries on the aquifer model domain. Anistropy in the aquifer is conceptually assumed to limit vertical flow such that the primary flow directions are horizontal. However, in the numerical implementation, the aquifer was considered to be isotropic, which allowed slightly more vertical flow. However, because the flow was still predominantly horizontal, this mixing was slight (Magnuson and Sondrup 2006).

Permeability variations within the aquifer affect flow locally. Observed transmissivities from single-well pump tests imply a region of low permeability south-southwest of the SDA (Wylie and Hubbell 1994; Jolley 2003). In the numerical model, this region is implemented as continuous and effectively reduces horizontal velocities through this region. The impact is to reduce dilution that otherwise would occur if larger aquifer water fluxes were present. This is a conservative assumption and has been shown to have a large impact in sensitivity simulations in the RI/FS modeling when the low-permeability zone was not included.

The effective thickness of the aquifer near RWMC is considered to be $150 \mathrm{~m}(490 \mathrm{ft})$, based on interpretation from temperature logs in Well C1A (Smith 2002). The conceptual model uses a uniform thickness of $76 \mathrm{~m}$ (250 ft), based on estimates in Robertson, Schoen, and Barraclough (1974). This smaller thickness is conservative because it reduces the thickness available for dilution.

Transient influences affect water table elevation, including spreading area discharges and regional increases and decreases due to weather patterns. These transient changes conservatively are neglected in the numerical model. These transient influences would change the local velocity field and result in additional dilution beyond what occurs in a steady-state simulation.

D-2.3.3.2 Transport in the Aquifer. Transport occurs in the aquifer through the same dissolved-phase mechanisms that occur in the waste zone and the vadose zone. Obviously, partitioning into the gaseous-phase does not occur because the system is saturated. Partitioning of volatile contaminants that have migrated away from the SDA vicinity back into the gas phase across the water table boundary is likely. This partitioning is conservatively neglected and would serve only to reduce 
simulated aquifer concentrations. Again, sorption is neglected in the aquifer because the aquifer is composed exclusively of fractured basalt in the model.

Though contaminants from upgradient INL Site facilities (relative to the SDA with respect to aquifer flow) may be present in the aquifer near the SDA, the numerical model neglects this possible influence.

Porosity in the aquifer controls water velocity. Porosity is assumed to be uniform throughout the SDA model domain and was assigned a value of 0.06. Currently, no contaminant has been determined to be present in the aquifer that can be attributed strictly to dissolved-phase transport from waste buried in the SDA. The numerical model was not considered calibrated for strictly dissolved-phase flow. Therefore, no attempt has been made to adjust porosity in the aquifer to account for observed transport. An anion anomaly, which has been identified southeast of the SDA, may eventually prove useful for such a calibration.

Dispersion in the aquifer was modeled using longitudinal and transverse dispersivity values. Values are set small, relative to the modeling domain, to conservatively limit the amount of smearing or spreading of contaminant plumes. The longitudinal and transverse dispersivity values used in the numerical model are $9 \mathrm{~m}(29 \mathrm{ft})$ and $4 \mathrm{~m}(13 \mathrm{ft})$, respectively. These are based on the ratio estimated by Arnett, Martineau, and Lehto (1990). The nonzero transverse dispersivity allows dispersive mixing in any direction orthogonal to the primary horizontal velocity. This includes vertical mixing, which might, in reality, be limited by extreme anisotropy. Both the anisotropy and vertical mixing were investigated in the RI/FS modeling and found to have a very small impact, indicating that the assigned values are still appropriate.

\section{D-2.3.4 Summary of Important Assumptions}

The subsurface groundwater pathway conceptual model contains many components. Some components impact the predicted concentrations at receptor concentrations more than others. Based on experience gained through conducting sensitivity simulations, the following list comprises the key components impacting simulated groundwater pathway concentrations:

- Inventory-The initial amount of contaminant emplaced has a direct and obvious impact on simulated groundwater pathway concentrations.

- Release mechanism-Similar to inventory, the rate at which contaminants get released has a direct impact (e.g., C-14 release due to corrosion of activated metal).

- Contaminant partitioning into the gaseous phase and diffusion through land surfaceIncluding gaseous-phase partitioning and allowing gaseous-phase contaminants to diffuse through the land-surface boundary causes marked decreases in groundwater pathway concentrations for $\mathrm{C}-14$. The decreased groundwater-pathway concentrations are appropriate because partitioning and surface diffusion are both realistic and reasonably parameterized processes and boundary conditions.

- Amount of infiltrating water contacting waste-Infiltration directly impacts release and subsequent migration. Estimated infiltration is from monitoring locations between and away from waste. Values are thought to be assigned conservatively given that contouring has improved drainage off the waste pits. 
- Mobility once released-The distribution coefficient in sediment directly impacts simulated groundwater pathway concentrations. For contaminants with long source-release durations or long half-lives relative to the vadose zone transit time, retardation has little impact on peak aquifer concentrations because these concentrations reach a stable, steady-state concentration. However, timing at which the peak concentration is reached is affected. For nuclides with short half-lives or that are released in a short pulse, retardation significantly impacts peak concentrations.

- $\quad$ Continuity of C-D interbed-The C-D interbed is continuous across the vadose zone model domain, forcing all water and contaminants to pass through it and provide an opportunity for sorption for all contaminants with nonzero distribution coefficients.

- Continuous low-permeability zone in aquifer-This is a direct impact that increases simulated aquifer concentrations due to lack of dilution from water that would otherwise be flowing through this portion of the aquifer.

\section{D-2.4 Soil Pathway Conceptual Models}

Because the 1.5-m (5-ft) soil cover on the SDA is not deep enough to prevent burrowing animals and rooting plants from intruding into the waste, contaminants can be redistributed from the subsurface to the surface through biotic transport. The conceptual model for biotic transport addresses movement of contaminants between the surface and waste zone through plant uptake and activities of burrowing animals (see Figure D-4). Modeled compartments include the waste zone, aboveground plant mass, surface soil ( 0 to $0.15 \mathrm{~m}$ [0 to $0.5 \mathrm{ft}]$ ), subsurface soil (between 0.15 and $3.0 \mathrm{~m}[0.5$ and $10 \mathrm{ft}]$ ), and contaminant sink.

Modeled processes include burrowing animal intrusion and burrow collapse, plant uptake and release, radioactive decay, and leaching of contaminants from infiltrating water. Movement of contaminants by plant uptake through each compartment can be simulated (e.g., using the DOSTOMAN code [Root 1981]) for up to eight contaminants in a single run. Figure D-4 illustrates two components of a single decay chain.

\section{D-2.4.1 Waste Zone}

Buried waste is represented by brown boxes at the bottom of Figure D-4. Once mass available for uptake is released from the waste, the mass amount is input into the waste zones. Contaminant inventory, waste form, and release mechanisms (i.e., surface washoff and dissolution release) incorporated in the biotic transport model are discussed in Section D-2.3.1.2. Total contaminant input for the biotic model is the sum of the surface washoff, which is available immediately, and corrosion, which is computed by the source-release model. The inventory released by the surface wash mechanism is immediately available for transport by the biotic pathway. Availability of inventory released by corrosion (e.g., Tc-99) of activated metal is delayed until the contaminant is released from the waste form. Output from the source-release model is used for dissolution release to provide input to the biotic model. To simplify calculating mass available from the surface-wash portion of the inventory, the container failure rate is not used. No credit is taken for the containers. This is conservative because more mass is available sooner, and it simplifies the additional calculations required for input into the biotic model. 


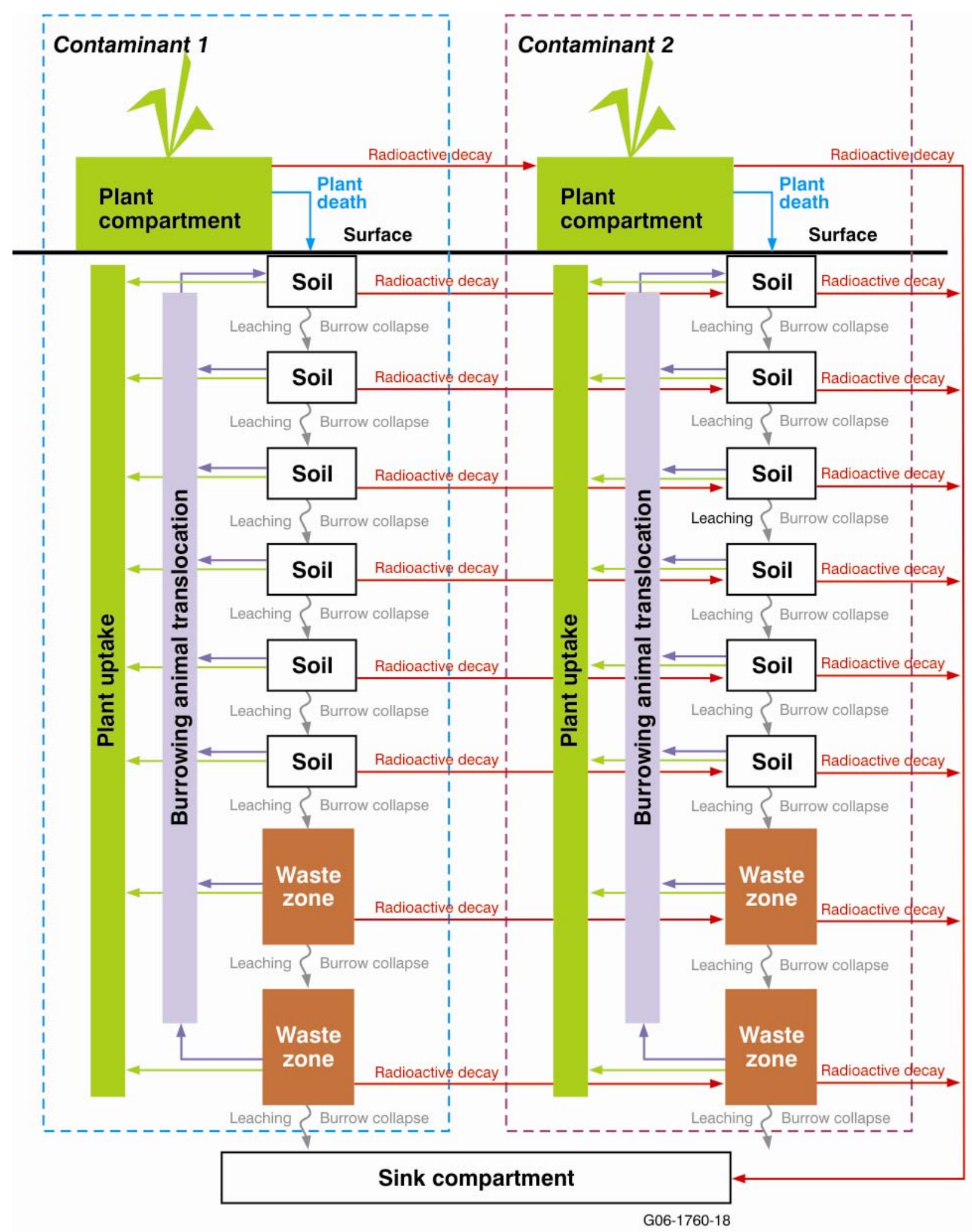

Figure D-4. Waste Area Group 7 biotic transport conceptual model. 


\section{D-2.4.2 Transport of Contaminants from Subsurface to Surface}

At the SDA, subsurface contamination can be moved to the surface and near-surface soil profile by root assimilation and translocation by burrowing animals. Once transferred to aboveground plant structures and soil, contamination may be transported by primary consumers through the food web or it may accumulate in surface soil through plant death and decay. Masses for two example contaminants are contained in the dotted blue and purple boxes in Figure D-4.

In Figure D-4, empty black boxes above the waste zone represent individual soil compartments. The green-shaded box at the upper left corner is the plant compartment. Plants assimilate contaminant mass, which becomes part of the plant compartment and is represented by green lines from the waste zone and individual soil zones to the plant compartment.

Contaminant mass assimilated by plants is released when the plants die. In Figure D-4, plant death is represented by the blue line from the plant compartment to the surface compartment. In reality, plant death contributes contaminant mass to all soil compartments; however, for simplicity, the contaminant is shown as going only to the surface compartment. The model also accounts for changes in plant and animal communities (e.g., species composition, density, and rooting and burrowing depths) and succession over time.

In Figure D-4, contaminant movement is represented by the purple line from individual compartments to the surface compartment. Contaminant mass can be removed from an individual compartment by leaching or burrow collapse, which effectively move mass to the next lower compartment and are represented by gray lines in Figure D-4.

To evaluate possible exposures from soil ingestion and physical contact for human and biotic receptors, the DOSTOMAN code was used to predict the amount of contaminants brought to the surface. Yearly average soil concentrations distributed evenly across the SDA were computed for 18 source zones. Soil concentrations in the 0 to $15-\mathrm{cm}$ (0 to 6-in.) compartment were used to represent the surface soil concentration and to estimate surface exposure for human health and ecological risk calculations. The maximum concentrations calculated in the compartments between 0.15 and $3.0 \mathrm{~m} \mathrm{(0.5}$ and $10 \mathrm{ft})$ represent subsurface concentration levels for ecological risk calculations. Four successive phases were represented that describe transition from the current disturbed setting back to a native vegetation mixture.

\section{D-2.4.3 General Assumptions}

General assumptions used for the biotic transport calculations to support the human health and ecological risk assessments include the following:

- $\quad$ Representative subsurface and surface concentrations are derived from best-estimate waste inventory values

- $\quad$ Average receptor exposures are simulated by distributing waste homogeneously across the SDA

- The vegetation community currently on the SDA is maintained (e.g., measures are taken to control shrub establishment) throughout the simulated 100-year institutional control (IC) period, and succession to a native community occurs within 200 years

- Evaluation of soil loss caused by erosion or surface runoff would result in less conservative concentration estimates. 
Neglecting erosion and surface run-off is conservative because it leads to higher surface concentrations in the SDA. The effect of including erosion would be to remove contaminant mass from the surface and, thereby, reduce the soil concentration to which the receptor would be exposed. The effect would be offset by reduced depth to the waste and enhanced intrusion. However, the erosion scenario is not appropriate because the SDA is a depositional environment (Hackett et al. 1995).

\section{D-2.5 Risk Calculation}

\section{D-2.5.1 Subsurface Water Pathway (Groundwater)}

D-2.5.1.1 Human Health Exposure Model. Contaminant concentrations in groundwater estimated by the model discussed in Section D-2.3 are the basis for evaluating potential human exposures from groundwater ingestion. Groundwater ingestion was assessed only for a residential exposure scenario. Standard EPA exposure factors were used to compute groundwater ingestion for humans.

D-2.5.1.2 Environmental Exposure Model. No natural pathway exists for groundwater to reach the surface of the SDA; therefore, exposure routes for biotic receptors do not exist, and the subsurface water pathway was not evaluated for ecological risk.

\section{D-2.5.2 Soil Pathways}

The conceptual site model combines environmental and contaminant characteristics of the SDA to develop exposure scenarios for assessing risk to human and ecological receptors. Ecological conceptual models for surface-soil (see Figure D-5) and subsurface-soil (see Figure D-6) pathways are presented as detailed components of biotic uptake in the Waste Area Group 7 conceptual site model (see Figure D-2). In Figures D-5 and D-6, physical contact was analyzed only as an external exposure for radionuclide contaminants. The models integrate both direct and indirect (i.e., predation) receptor exposure routes. Soil pathway models account for plants and burrowing animals, including insects, as vectors of both transport and exposure.

\section{D-2.5.2.1 Surface Soil Pathway}

D-2.5.2.1.1 Human Health Exposure Model-Exposures for human receptors, resulting from contaminated soil brought to the surface through biotic transport, were evaluated for current and future workers (i.e., soil ingestion, dermal contact, inhalation, and direct exposure to ionizing radiation) and a future residential scenario (i.e., soil ingestion, crop ingestion, dermal contact, inhalation, and direct exposure to ionizing radiation) (see Figure D-2). Twenty-five-year average concentrations were used to estimate occupational exposures, and 30-year average concentrations were used to evaluate residential exposures. Details of the human health surface exposure models are given in the RI/BRA (Holdren et al. 2006). Dermal exposure is computed only for organic chemicals. For radionuclides, direct gamma exposure is calculated, but the amount of uptake into the body from dermal exposure is not. According to the Risk Assessment Guidance (EPA 1989), "This route can be important for many organic chemicals; however, dermal uptake for radionuclides is generally not an important route of uptake for radionuclides, which have small dermal permeability constants." 


\begin{tabular}{|c|c|c|c|}
\hline $\begin{array}{l}\text { Primary } \\
\text { source }\end{array}$ & $\begin{array}{l}\text { Affected } \\
\text { media }\end{array}$ & $\begin{array}{l}\text { Transport } \\
\text { mechanisms }\end{array}$ & $\begin{array}{l}\text { Secondary } \\
\text { sources }\end{array}$ \\
\hline
\end{tabular}

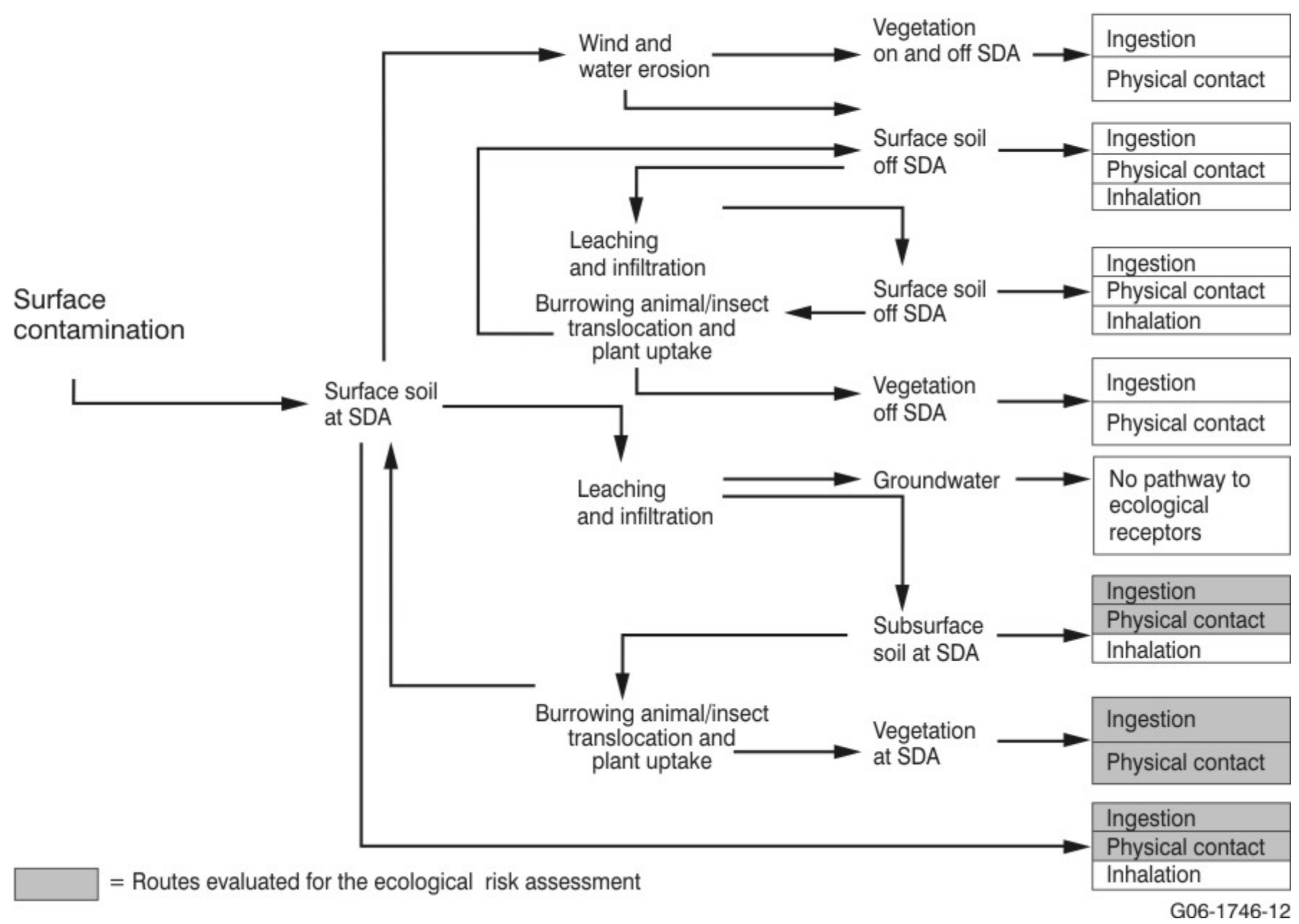

Figure D-5. Surface soil pathway conceptual model. 


\begin{tabular}{|c|c|c|c|}
\hline $\begin{array}{l}\text { Primary } \\
\text { source }\end{array}$ & $\begin{array}{l}\text { Affected } \\
\text { media }\end{array}$ & $\begin{array}{l}\text { Transport } \\
\text { mechanisms }\end{array}$ & $\begin{array}{l}\text { Secondary } \\
\text { sources }\end{array}$ \\
\hline
\end{tabular}

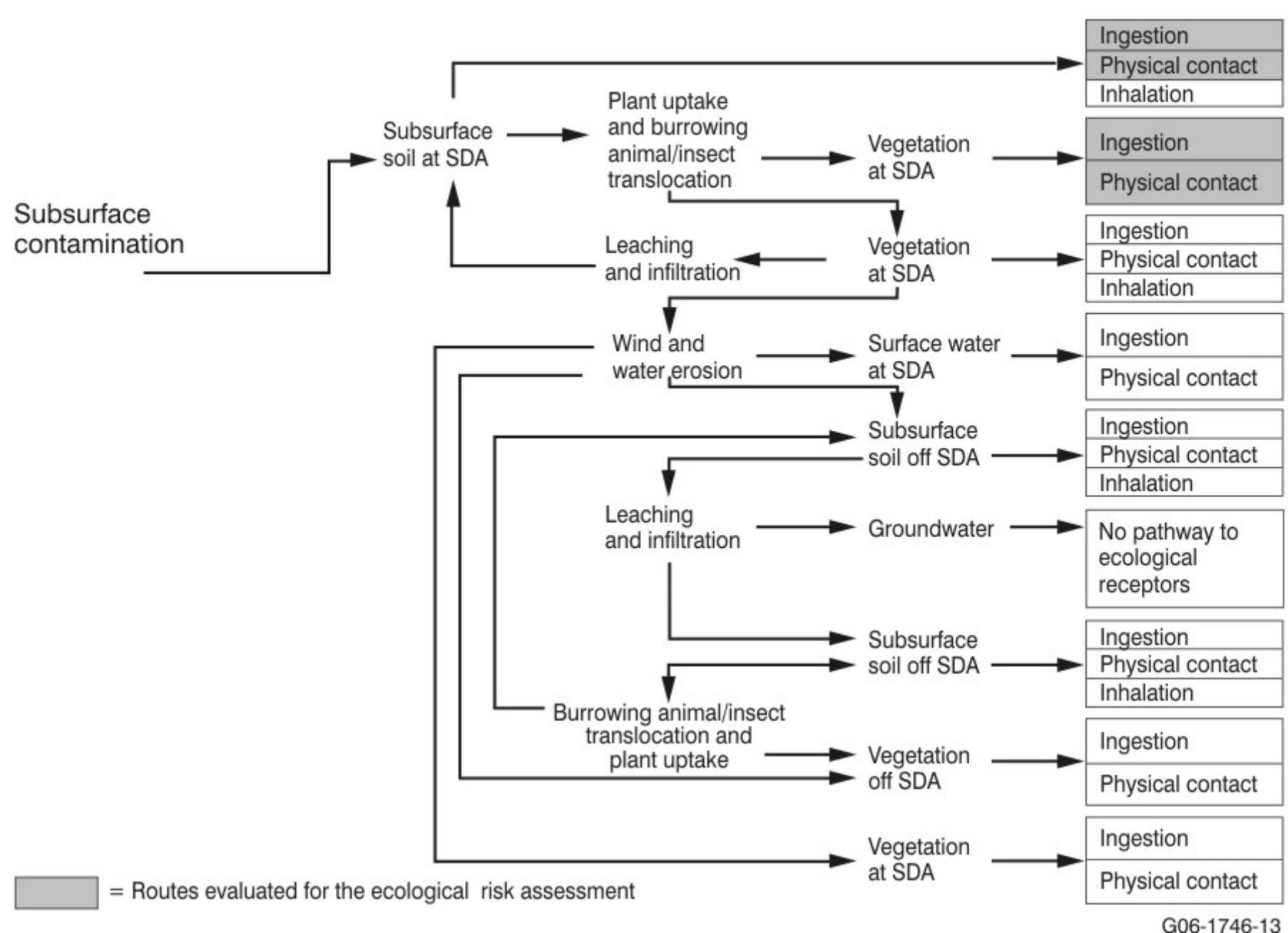

Figure D-6. Subsurface soil pathway conceptual model. 
D-2.5.2.1.2 Environmental Exposure Model-Surface soil is defined as the uppermost $0.15 \mathrm{~m}(0.5 \mathrm{ft})$ for the ecological exposure analysis. The Waste Area Group 7 ecological surface pathway model (see Figure D-4) accounts for internal exposures for nonradiological contaminants, and both internal and external exposures for radionuclides. The model incorporates ingestion of contaminated plants and soil by herbivorous and burrowing animals. Therefore, animals receiving direct exposure are potential sources of indirect exposure when preyed upon by carnivorous receptors. Model input parameters include dietary components (i.e., fraction of soil, plant, and prey ingested) and amount of time spent in contact with contaminated media (i.e., resident versus migratory). Exposures for some receptors (e.g., reptiles and insects) were not evaluated in the risk assessment because toxicity data are not available.

External radiation is modeled as a hemispherical exposure for surface receptors. Though inhalation and dermal contact are important exposure routes, they are not evaluated in the ecological risk assessment because data and models have not been developed for ecological receptors. Details of surface soil exposure analysis for ecological receptors are presented in the RI/BRA (Holdren et al. 2006).

\section{D-2.5.3 Subsurface Soil Pathway}

D-2.5.3.1 Human Health Exposure Model. No exposures to subsurface soil for human receptors were assessed.

D-2.5.3.2 Environmental Exposure Model. Subsurface soil is defined at depths of 0.15 to $3 \mathrm{~m}$ $(0.5$ to $10 \mathrm{ft})$ for the ecological exposure analysis. Contamination depths greater than $3 \mathrm{~m}(10 \mathrm{ft})$ below ground surface are assumed inaccessible to ecological receptors because this depth is generally below the root zone of plants and the burrowing depth of ground-dwelling animals.

As with the surface exposure model, the subsurface soil pathway model accounts for radiological and nonradiological exposures for plants by uptake, and for burrowing animals by ingestion of belowground plant material and soil (see Section D-2.5.2.1.2). Subsurface external radiation exposures are modeled as a sphere (versus hemispherical surface exposures).

D-2.5.3.3 General Assumptions. Primary assumptions for assessing surface and subsurface soil exposures for human health scenarios include:

- $\quad$ Risk from soil exposures for human receptors results from biotic transport of contaminants from the waste zone (e.g., no scenarios include human intrusion into waste)

- Average contaminant concentrations modeled for soil across the SDA represent the maximum potential exposures beyond the SDA fence. include:

Primary assumptions for assessing surface and subsurface soil exposures for ecological receptors

- $\quad$ Off-INL Site surface or subsurface exposures are below maximum modeled exposures for the SDA and were not specifically evaluated

- $\quad$ Potential inhalation and dermal exposures likely are minor compared to ingestion or external radiation exposures. 


\section{D-2.5.4 Dose Response}

D-2.5.4.1 Human Health Effects. Both carcinogenic and noncarcinogenic effects were evaluated for nonradionuclide contaminants of potential concern. Only carcinogenic effects were evaluated for radionuclide contaminants of potential concern. Reference doses and concentrations used to evaluate noncarcinogenic effects and unit risk values and slope factors used to evaluate carcinogenic effects were taken primarily from the Integrated Risk Information System database (EPA 2006) and Health Effects Assessment Summary Tables (EPA 2001).

D-2.5.4.2 Environmental Effects. Exposure effects for ecological receptors were determined using threshold reference values developed from toxicity profiles for individual animal orders and contaminant groups. Ingestion exposures for some receptors (e.g., reptiles and insects) could not be specifically evaluated because toxicity data are not available.

\section{D-2.5.5 Cumulative Risk}

Cumulative risk is the sum of individual risks on a time-consistent basis, and EPA-approved methodology was applied for the human health assessment. Though possible interactions between chemicals within the body could increase or decrease the net effect, the assessment does not address chemical interactions.

\section{D-3. SIMULATED RISK}

This feasibility study evaluates a range of possible remedial actions and produces a set of alternatives to be evaluated quantitatively. Table D-3 lists alternatives evaluated for the OU 7-13/14 feasibility study. The following subsections describe each alternative, how it was modeled, and the risk results. All pathways are evaluated for Alternative 1 (No Action). All other alternatives include a surface barrier, to reduce infiltration, which blocks the pathways for surface exposure. Therefore, only groundwater ingestion risk is calculated for the other alternatives.

\section{D-3.1 Alternative 1-No Action}

Alternative 1 (No Action) is used as the basis for comparing all other alternatives. It presents the risk if no further remediation is performed at the SDA. Normally, results for No Action are synonymous with the baseline risk assessment. However, the RI/BRA concluded with recommendations for additional modeling to refine estimates for several contaminants and to provide a better foundation for the feasibility study. Details are provided in two modeling reports that support the analysis (i.e., Anderson and Becker [2006] for source-release modeling and Magnuson and Sondrup [2006] for transport modeling). This section incorporates those modifications for Alternative 1. Compared to the RI/BRA, differences are slight; the most significant changes are associated with risk estimates for Tc-99 (and collocated I-129) and tetrachloroethylene. Minor changes also were realized for C-14, nitrate, and VOCs. Refinements to the RI/BRA for Alternative 1, are as follows:

1. Overprediction of Tc-99, I-129, and nitrate transport to the aquifer-Source release parameters were modified to account for waste containers (Anderson and Becker 2006).

2. DUST-MS code error-An error was discovered in Version 4 that affected simulations involving dissolved-phase contaminants with a zero distribution coefficient (i.e., T-99, I-129, and nitrate). Source-release results were updated for the OU 7-13/14 feasibility study, using Version 5 to correct surface washoff results for these contaminants. 
Table D-3. Summary of five assembled alternatives and major components in each.

\begin{tabular}{|c|c|c|c|c|c|c|c|}
\hline \multirow[b]{2}{*}{ Component } & \multirow[b]{2}{*}{$\begin{array}{c}1 . \\
\text { No Action }\end{array}$} & \multicolumn{2}{|c|}{ 2. Surface Barrier } & \multirow[b]{2}{*}{$\begin{array}{c}3 . \\
\text { In Situ Grouting }\end{array}$} & \multicolumn{2}{|c|}{ 4. Partial Retrieval, Treatment, and Disposal } & \multirow{2}{*}{$\begin{array}{l}\text { Full Retrieval, } \\
\text { Treatment, and } \\
\text { Disposal }\end{array}$} \\
\hline & & $\begin{array}{c}2 \mathrm{a} . \\
\text { Modified RCRA } \\
\text { Type C } \\
\end{array}$ & $\begin{array}{c}2 \mathrm{~b} . \\
\text { Evapotranspiration }\end{array}$ & & $\begin{array}{c}4 a . \\
4 \text { Acres }\end{array}$ & $\begin{array}{c}4 b . \\
2 \text { Acres }\end{array}$ & \\
\hline Monitoring $^{\mathrm{a}}$ & Monitoring & Monitoring & Monitoring & Monitoring & Monitoring & Monitoring & Monitoring \\
\hline $\begin{array}{l}\text { In situ } \\
\text { treatment }\end{array}$ & None & None & None & $\begin{array}{l}\text { ISG-specified Tc-99 and } \\
\text { I-129 }\end{array}$ & None & None & None \\
\hline Retrieval & None & None & None & None & \begin{tabular}{|l|} 
Retrieve targeted Rocky \\
Flats Plant waste
\end{tabular} & \begin{tabular}{|l|} 
Retrieve targeted \\
Rocky Flats Plant waste
\end{tabular} & $\begin{array}{l}\text { Retrieve all waste in the } \\
\text { SDA }\end{array}$ \\
\hline Pad A & None & $\begin{array}{l}\text { Incorporate Pad A as-is } \\
\text { into cap }\end{array}$ & Relocate to LLW Pit & $\begin{array}{l}\text { Treat ex situ and relocate } \\
\text { to LLW Pit }\end{array}$ & Remove to ICDF & $\begin{array}{l}\text { Dynamically compact } \\
\text { and incorporate into cap }\end{array}$ & $\begin{array}{l}\text { Remove to off-INL Site } \\
\text { disposal facility }\end{array}$ \\
\hline $\begin{array}{l}\text { Subsidence in } \\
\text { pits }\end{array}$ & None & Foundation grouting & Dynamic compaction $^{\mathrm{b}}$ & Dynamic compaction $^{\mathrm{b}}$ & Dynamic compaction $^{b}$ & Proof-roll & None \\
\hline $\begin{array}{l}\text { Surface } \\
\text { barrier }\end{array}$ & None & $\begin{array}{l}\text { Modified RCRA } \\
\text { Type C surface barrier } \\
\text { with biointrusion layer }\end{array}$ & $\begin{array}{l}\text { ET surface barrier with } \\
\text { biointrusion layer }\end{array}$ & $\begin{array}{l}\text { ET surface barrier with } \\
\text { biointrusion layer }\end{array}$ & $\begin{array}{l}\text { ET surface barrier with } \\
\text { biointrusion layer }\end{array}$ & $\begin{array}{l}\text { ET surface barrier with } \\
\text { biointrusion layer and } \\
\text { slurry perimeter wall }\end{array}$ & $\begin{array}{l}\text { ET surface barrier } \\
\text { without biointrusion } \\
\text { barrier }\end{array}$ \\
\hline $\begin{array}{l}\text { Vadose zone } \\
\text { vapor } \\
\text { extraction }\end{array}$ & None & $\begin{array}{l}\text { Add near-surface } \\
\text { extraction wells; } \\
\text { operate OCVZ system }^{c}\end{array}$ & Operate OCVZ system ${ }^{c}$ & Operate OCVZ system ${ }^{c}$ & Operate OCVZ system ${ }^{\mathrm{c}}$ & Operate OCVZ system ${ }^{\mathrm{c}}$ & Operate OCVZ system ${ }^{\mathrm{c}}$ \\
\hline $\begin{array}{l}\text { Surveillance } \\
\text { and } \\
\text { maintenance }\end{array}$ & None & $\begin{array}{l}\text { Until eliminated by a } \\
\text { 5-year review } d\end{array}$ & $\begin{array}{l}\text { Until eliminated by a } \\
\text { 5-year review }{ }^{d}\end{array}$ & $\begin{array}{l}\text { Until eliminated by a } \\
5 \text {-year review }{ }^{d}\end{array}$ & $\begin{array}{l}\text { Until eliminated by a } \\
5 \text {-year review }\end{array}$ & $\begin{array}{l}\text { Until eliminated by a } \\
5 \text {-year review }\end{array}$ & $\begin{array}{l}\text { Until eliminated by a } \\
\text { 5-year review }{ }^{d}\end{array}$ \\
\hline $\begin{array}{l}\text { Institutional } \\
\text { controls }\end{array}$ & None & $\begin{array}{l}\text { Until eliminated by a } \\
5 \text {-year review }{ }^{d}\end{array}$ & $\begin{array}{l}\text { Until eliminated by a } \\
\text { 5-year review }{ }^{d}\end{array}$ & $\begin{array}{l}\text { Until eliminated by a } \\
\text { 5-year review }{ }^{d}\end{array}$ & $\begin{array}{l}\text { Until eliminated by a } \\
\text { 5-year review }{ }^{\mathrm{d}}\end{array}$ & $\begin{array}{l}\text { Until eliminated by a } \\
\text { 5-year review }{ }^{d}\end{array}$ & $\begin{array}{l}\text { Until eliminated by a } \\
\text { 5-year review }\end{array}$ \\
\hline \multicolumn{8}{|c|}{$\begin{array}{l}\text { a. Monitoring comprises surface, vadose zone, and aquifer monitoring. Cost estimates include } 100 \text { years of monitoring for No Action and } 100 \text { years of monitoring after the cap is complete for all action alternatives. } \\
\text { b. Dynamic compaction was identified for analysis because it presents the most short-term risk and highest cost among process options that apply surface treatment to address subsidence; thus, it bounds the analysis. } \\
\text { Other process options (e.g., impact rolling) could be substituted during remedial design. } \\
\text { c. Operation of the OCVZ system would continue until eliminated by a 5-year review after remediation goals for VOCs in the vadose zone are achieved. } \\
\text { d. Estimates include cost for } 100 \text { years of surveillance, maintenance, and institutional control after the cap is complete. }\end{array}$} \\
\hline \multicolumn{3}{|c|}{$\begin{array}{l}\text { ET = evapotranspiration } \\
\text { ICDF = Idaho CERCLA Disposal Facility } \\
\text { ISG }=\text { in situ grouting }\end{array}$} & \multicolumn{2}{|c|}{$\begin{array}{l}\text { INL = Idaho National Laboratory } \\
\text { LLW = low-level waste } \\
\text { OCVZ = Organic Contamination in the Vadose Zone }\end{array}$} & \multicolumn{3}{|c|}{$\begin{array}{l}\text { RCRA }=\text { Resource Conservation and Recovery Act } \\
\text { SDA = Subsurface Disposal Area } \\
\text { VOC = volatile organic compound }\end{array}$} \\
\hline
\end{tabular}


3. Trichloroethylene - This VOC was identified as a contaminant of potential concern late in development of the RI/BRA. Concentrations were estimated based on scaling carbon tetrachloride. Contaminant-specific modeling was completed for the feasibility study.

4. Deep vapor extraction-Extraction of gaseous-phase contaminants from beneath the C-D interbed, beginning in 2007, was included and affected C-14 and volatile organic contaminants.

Figure D-7 presents the residential scenario all pathways cumulative risk for the feasibility study Alternative 1. Figure D-8 presents the residential scenario all pathways cumulative hazard index for the feasibility study Alternative 1 . Table D-4 presents the updated risk and primary exposure routes for the COCs identified in the remedial investigation.

The four refinements listed above impact the groundwater ingestion pathway risk evaluated for the residential scenario. In addition to model refinements, the slope factor for tetrachloroethylene groundwater ingestion applied in the RI/BRA was corrected. This correction, which increased the risk estimate for tetrachloroethylene by a factor of 1,000, overshadows model refinements in overall cumulative risk estimates for groundwater pathways. Figure D-9 compares cumulative groundwater ingestion risk results for the RI/BRA and Alternative 1. Figure D-10 shows the same comparison for the cumulative groundwater ingestion hazard index. Risk within 1,000 years is affected because of operational changes to the OCVZ system and the Tc-99 release. Risk estimates beyond 1,000 years are unchanged because risk is driven by actinide isotopes, which were not affected by any of the refinements.

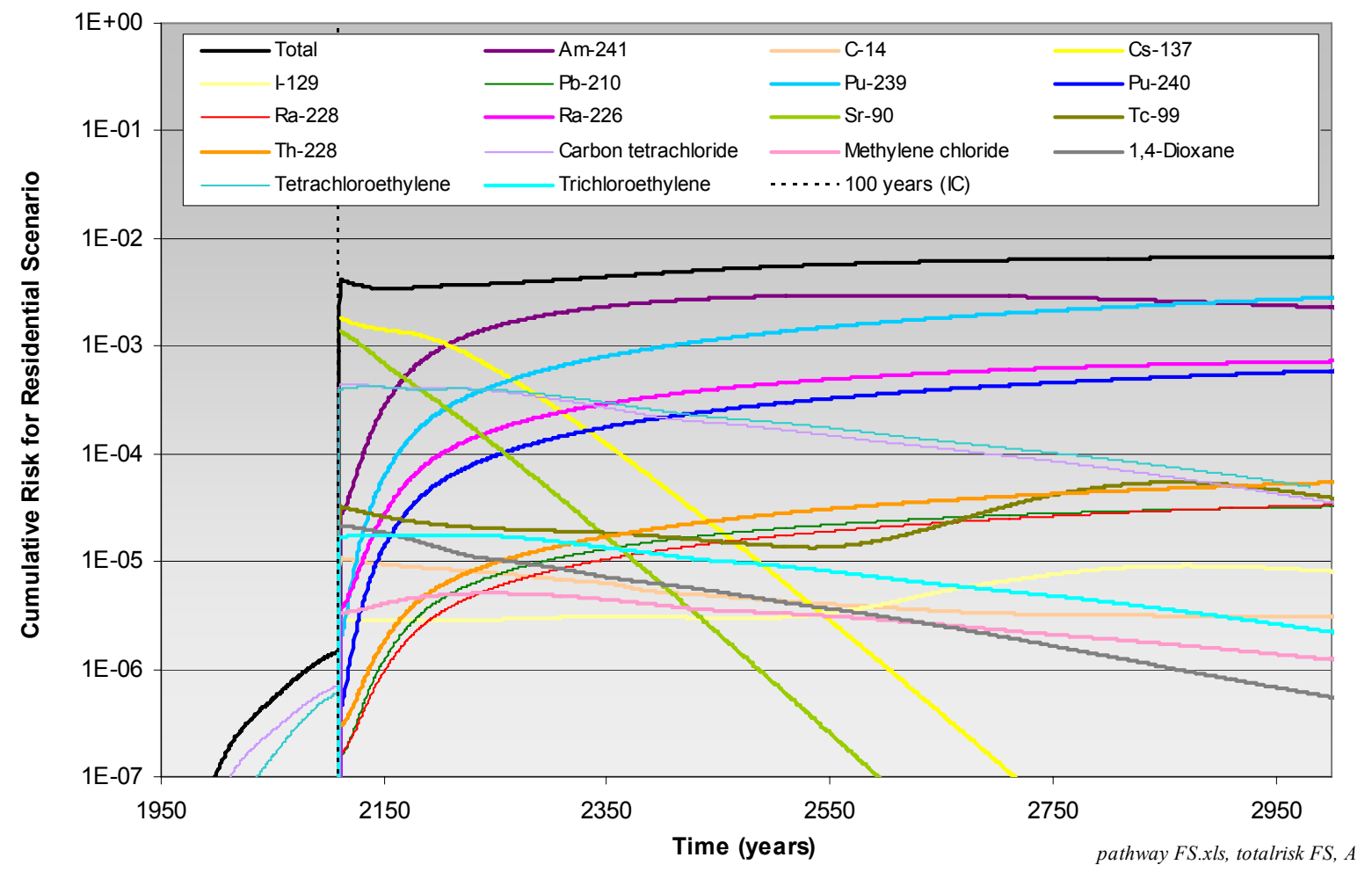

Figure D-7. Cumulative risk for all pathways for Alternative 1-No Action. 


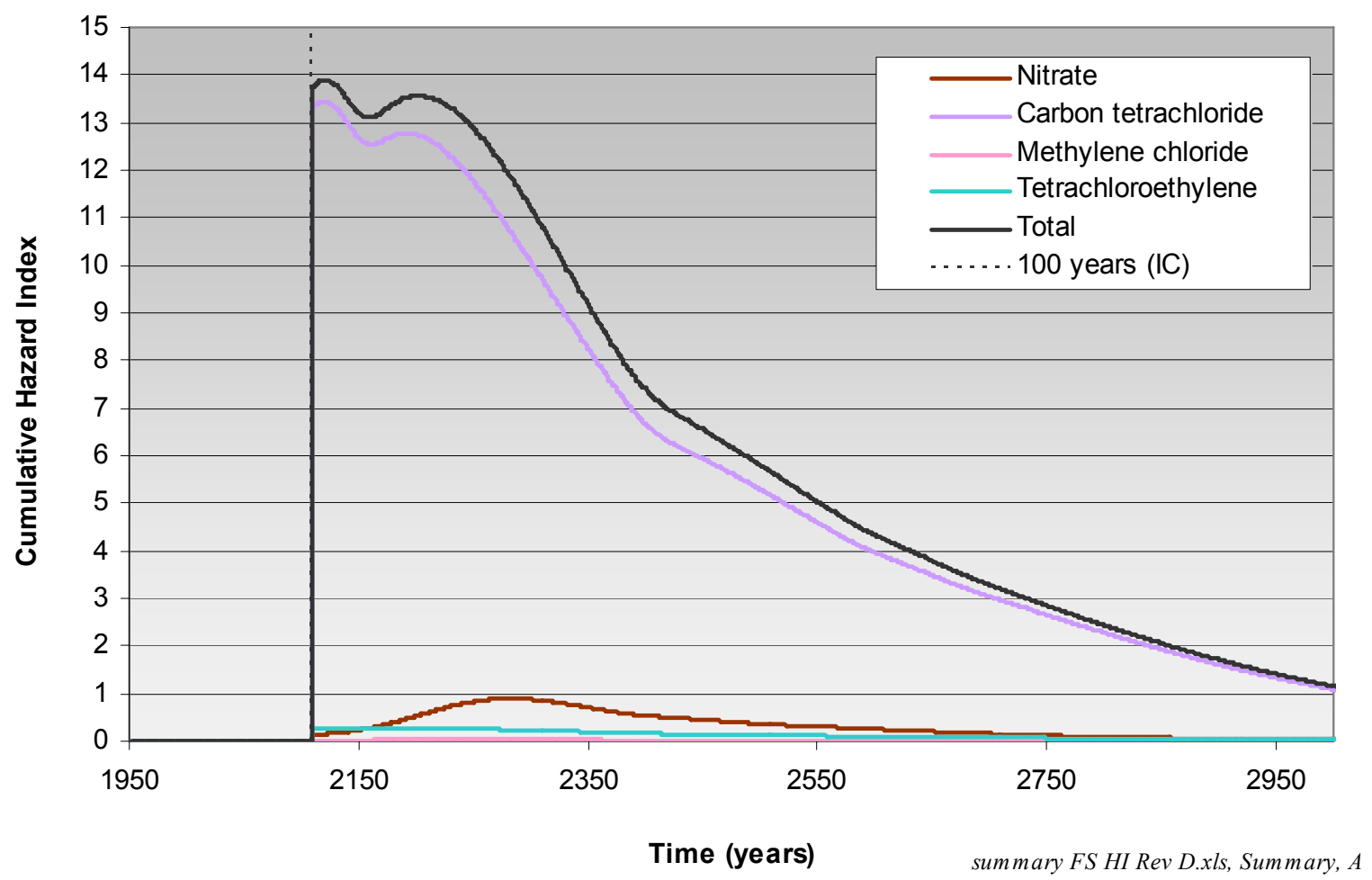

Figure D-8. Cumulative hazard index for all pathways for Alternative $1-$ No Action. 
Table D-4. Peak risk and hazard index for each contaminant of potential concern for Alternative $1-$ No Action.

\begin{tabular}{|c|c|c|c|c|}
\hline Contaminant & $\begin{array}{l}\text { Simulation } \\
\text { Group }\end{array}$ & Peak & $\begin{array}{l}\text { Year of } \\
\text { Peak }\end{array}$ & Primary Exposure Pathway \\
\hline \multicolumn{5}{|c|}{ Risk } \\
\hline Ac-227 & 2 & $5 \mathrm{E}-07$ & 3010 & Groundwater ingestion \\
\hline Am-241 & 1 & $3 \mathrm{E}-03$ & 2594 & $\begin{array}{l}\text { External exposure, soil ingestion, inhalation, and crop } \\
\text { ingestion }\end{array}$ \\
\hline Am-243 & 2 & 1E-07 & 3008 & External exposure \\
\hline $\mathrm{C}-14^{\mathrm{a}}$ & 8 & $1 \mathrm{E}-05$ & 2110 & Groundwater ingestion and inhalation of volatiles \\
\hline $\mathrm{Cl}-36$ & 6 & 2E-06 & 2384 & Groundwater ingestion and crop ingestion \\
\hline Cs-137 & 9 & 2E-03 & 2110 & External exposure and crop ingestion \\
\hline$I-129^{a}$ & 12 & $9 \mathrm{E}-06$ & 2870 & Groundwater ingestion \\
\hline $\mathrm{Nb}-94$ & 9 & 2E-06 & 3010 & External exposure \\
\hline Np-237 & 1 & 7E-06 & 2647 & External exposure \\
\hline $\mathrm{Pa}-231$ & 2 & $3 \mathrm{E}-07$ & 3010 & Groundwater ingestion \\
\hline $\mathrm{Pb}-210$ & 4 and 5 & $3 \mathrm{E}-05$ & 3010 & Crop ingestion and soil ingestion \\
\hline $\mathrm{Pu}-238$ & 4 & $1 \mathrm{E}-06$ & 2262 & Soil ingestion, crop ingestion, and inhalation \\
\hline $\mathrm{Pu}-239$ & 2 & $3 \mathrm{E}-03$ & 3010 & $\begin{array}{l}\text { Soil ingestion, crop ingestion, inhalation, and external } \\
\text { exposure }\end{array}$ \\
\hline $\mathrm{Pu}-240$ & 3 & $6 \mathrm{E}-04$ & 3010 & Soil ingestion, crop ingestion, and inhalation \\
\hline Ra-226 & 4 and 5 & 7E-04 & 3010 & External exposure and crop ingestion \\
\hline $\mathrm{Ra}-228$ & 3 & $3 \mathrm{E}-05$ & 3010 & External exposure \\
\hline Sr-90 & 9 & 1E-03 & 2110 & Crop ingestion, external exposure, and soil ingestion \\
\hline Tc-99 $9^{\mathrm{a}}$ & 12 & $5 \mathrm{E}-05$ & 2858 & Groundwater ingestion and crop ingestion \\
\hline Th-228 & 9 & $5 \mathrm{E}-05$ & 3010 & External exposure \\
\hline Th-229 & 1 & 4E-07 & 3010 & Groundwater ingestion and external exposure \\
\hline Th-230 & 4 and 5 & $1 \mathrm{E}-08$ & 3010 & Crop ingestion, soil ingestion, and inhalation \\
\hline Th-232 & 3 & $3 \mathrm{E}-07$ & 3010 & Crop ingestion, soil ingestion, and inhalation \\
\hline $\mathrm{U}-233$ & 1 & 4E-06 & 3010 & Groundwater ingestion \\
\hline U-234 & 4 and 5 & $6 \mathrm{E}-07$ & 3010 & Groundwater ingestion \\
\hline U-235 & 2 & $2 \mathrm{E}-07$ & 2286 & External exposure and groundwater ingestion \\
\hline U-236 & 3 & 9E-07 & 3010 & Groundwater ingestion \\
\hline $\mathrm{U}-238$ & 5 & $1 \mathrm{E}-06$ & 2284 & External exposure and groundwater ingestion \\
\hline Carbon tetrachloride $^{\mathrm{a}}$ & 11 & 4E-04 & 2117 & Groundwater ingestion and inhalation of volatiles \\
\hline 1,4-Dioxane ${ }^{\mathrm{a}}$ & 11 & $2 \mathrm{E}-05$ & 2110 & Groundwater ingestion \\
\hline Methylene chloride $^{\mathrm{a}}$ & 11 & $5 \mathrm{E}-06$ & 2244 & Groundwater ingestion \\
\hline Tetrachloroethylene $^{\mathrm{a}}$ & 11 & 4E-04 & 2136 & Groundwater ingestion and dermal exposure \\
\hline Trichloroethylene $^{\mathrm{a}}$ & 11 & $2 \mathrm{E}-05$ & 2141 & Groundwater ingestion \\
\hline \multicolumn{5}{|c|}{ Hazard Index } \\
\hline Carbon tetrachloride $^{\mathrm{a}}$ & 11 & $1 \mathrm{E}+01$ & 2119 & Groundwater ingestion and inhalation of volatiles \\
\hline Methylene chloride ${ }^{a}$ & 11 & $3 \mathrm{E}-02$ & 2244 & Groundwater ingestion \\
\hline Nitrate $^{\mathrm{a}}$ & 10 & $9 \mathrm{E}-01$ & 2283 & Groundwater ingestion \\
\hline Tetrachloroethylene $^{\mathrm{a}}$ & 11 & $3 \mathrm{E}-01$ & 2136 & Groundwater ingestion and dermal exposure \\
\hline
\end{tabular}




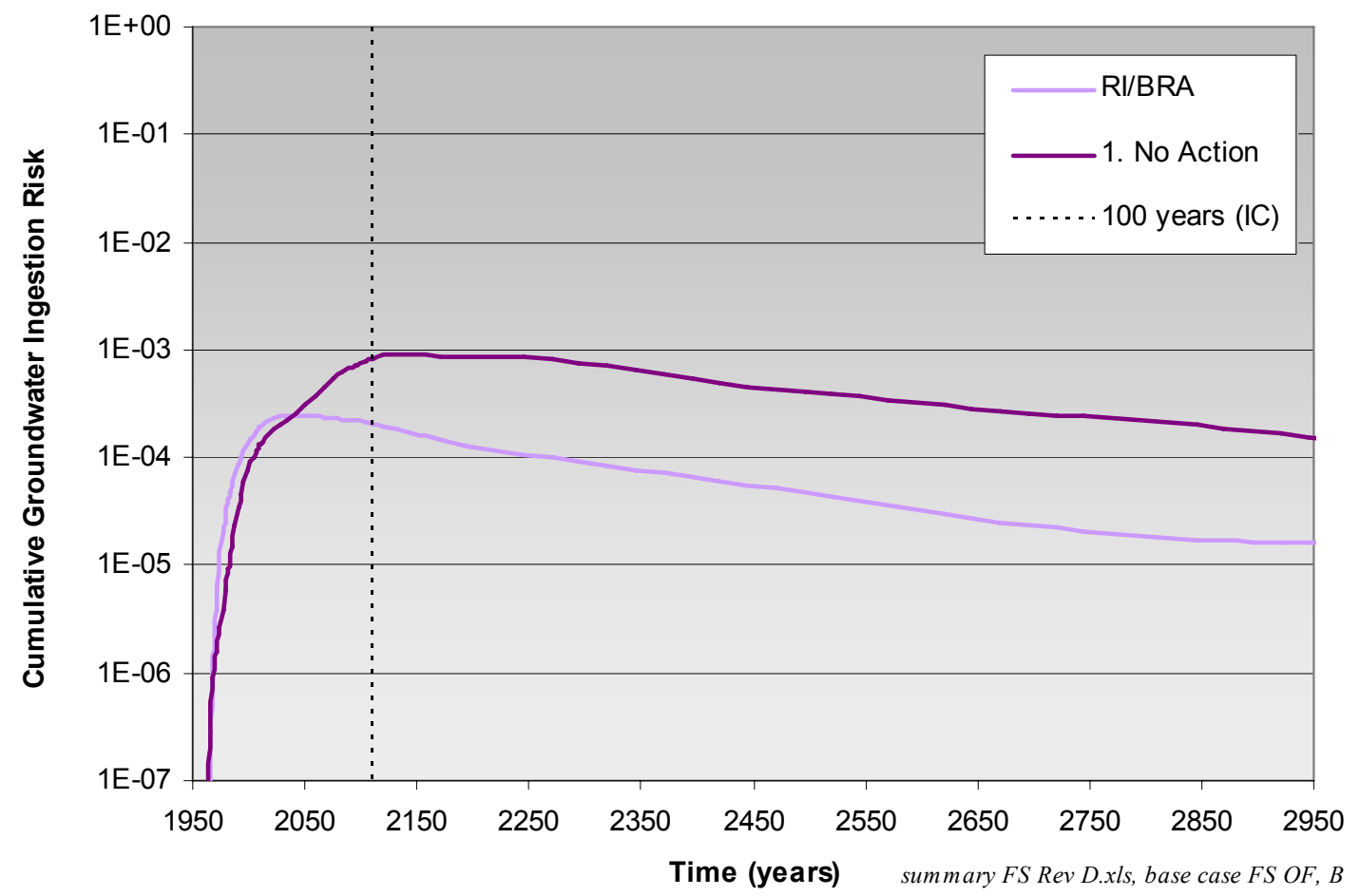

Figure D-9. Comparison of cumulative groundwater ingestion risk for Alternative $1-$ No Action and the Remedial Investigation and Baseline Risk Assessment base case.

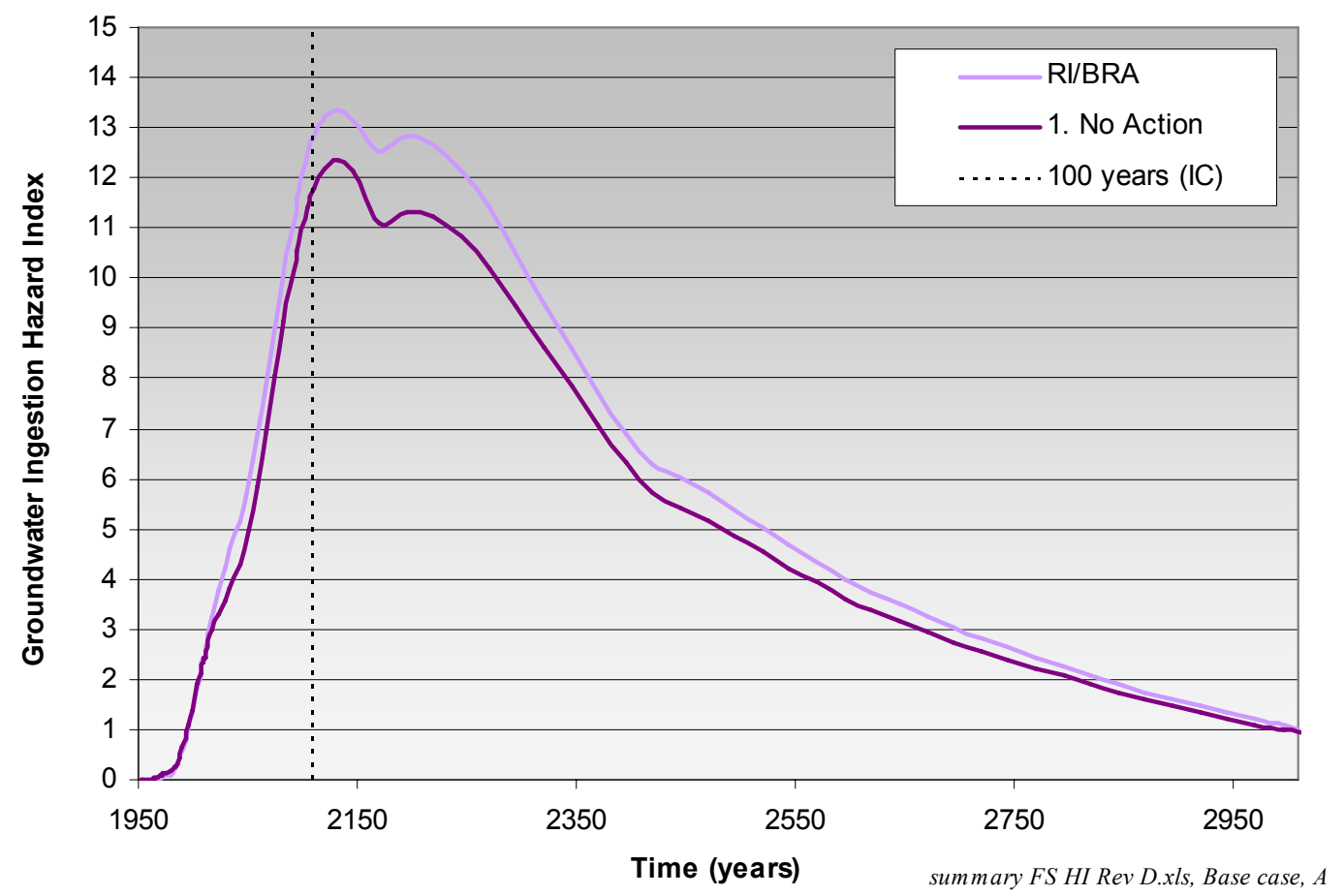

Figure D-10. Comparison of the cumulative groundwater ingestion hazard index for Alternative 1No Action and the Remedial Investigation and Baseline Risk Assessment base case. 


\section{D-3.2 Alternative 2-Surface Barrier}

All alternatives identified for the OU 7-13/14 feasibility study, except Alternative 1 (No Action), include a surface barrier of some sort. The two major barrier types are the modified Resource Conservation and Recovery Act (RCRA) Type C surface barrier and the ET surface barrier. Surface barrier designs are discussed in Sections D-3.2.1 and D-3.2.2. Each surface barrier is designed to collect VOCs and inhibit intrusion by plants and animals, thus mitigating potential risk from surface exposure pathways. Therefore, risk results focus on the groundwater ingestion pathway risk because the surface barrier will preclude surface pathway risk. The following subsections discuss how the different surface barriers were modeled and the impact each surface barrier has on the groundwater ingestion risk.

\section{D-3.2.1 Alternative 2a-Modified RCRA Type C Surface Barrier}

Alternative 2a (Modified RCRA Type C Surface Barrier) uses a series of layers, including man-made materials (e.g., asphalt), to limit net infiltration to $0.1 \mathrm{~cm} /$ year $(0.04 \mathrm{in}$./year). Additional features of this alternative are that Pad A is left in place and near-surface vapor extraction wells will be installed adjacent to VOC source areas and integrated into the existing OU 7-08 OCVZ system. Because the surface barrier has an asphalt layer, vapor does not diffuse through the surface barrier in the model. The near-surface OCVZ extraction system is designed to capture future release of volatile contaminants from the source for the duration of its operation. The complete OCVZ system operates 10 months of each year (i.e., January through October) until remediation goals for carbon tetrachloride are achieved, at which time, the system is shut down completely. Modeling predicts remediation goals for carbon tetrachloride are achieved in year 2075. Magnuson and Sondrup (2006) provide additional modeling details describing Alternative 2a.

Figure D-11 shows the comparison of the cumulative groundwater ingestion risk for Alternatives 1 and 2a. Cumulative risk is below 1E-04 for the entire period after the end of ICs. Figure D-12 shows the comparison of the hazard index for Alternatives 1 and 2a. The cumulative hazard index is 1 at the end of ICs and decreases over time.

\section{D-3.2.2 Alternative 2b-Evapotranspiration Surface Barrier}

Alternative $2 \mathrm{~b}$ (ET Surface Barrier) uses natural soil layering and storage to reduce net infiltration to a design rate of $0.1 \mathrm{~cm} /$ year (0.04 in./year). In Alternative $2 \mathrm{~b}$, Pad A waste is retrieved and transferred to the active Low-Level Waste (LLW) Pit in the SDA without treatment. A biotic barrier and a gas collection layer are included in the design. The gas collection layer is not represented explicitly in the model, but the effect is accounted for by simulating VOCs as if the surface barrier were not present. The OCVZ system operates 7 months of each year in the shallow and intermediate-depth extraction zones and the remaining 5 months of each year in the shallow and deep extraction zones until remediation goals for carbon tetrachloride are achieved. Modeling predicts remediation goals for carbon tetrachloride are achieved in the year 2055, at which time the OCVZ system is shut down.

Figure D-13 shows the comparison of the cumulative groundwater ingestion risk for Alternative $2 b$ (ET Surface Barrier) with Alternative 2a (Modified RCRA Type C Surface Barrier) and Alternative 1 (No Action). Cumulative risk for Alternative $2 b$ is below 1E-04 for the entire period after the end of ICs. The risk becomes lower than the risk from Alternative 2a around year 2300. This reduction is due primarily to the gas collection layer of Alternative $2 b$ allowing vapor to escape to the atmosphere. Alternative 2a has an active near-surface OCVZ system that gets turned off in year 2075. After that time, the $\mathrm{C}-14$ and remaining VOC vapors get trapped under the surface barrier, promoting migration toward the groundwater and increasing the groundwater ingestion risk. Figure D-14 shows the comparison of the cumulative hazard index for Alternative $2 \mathrm{~b}$ with Alternatives 1 and 2a. Again, the cumulative hazard index is less than 1 at the end of ICs and decreases with time. 


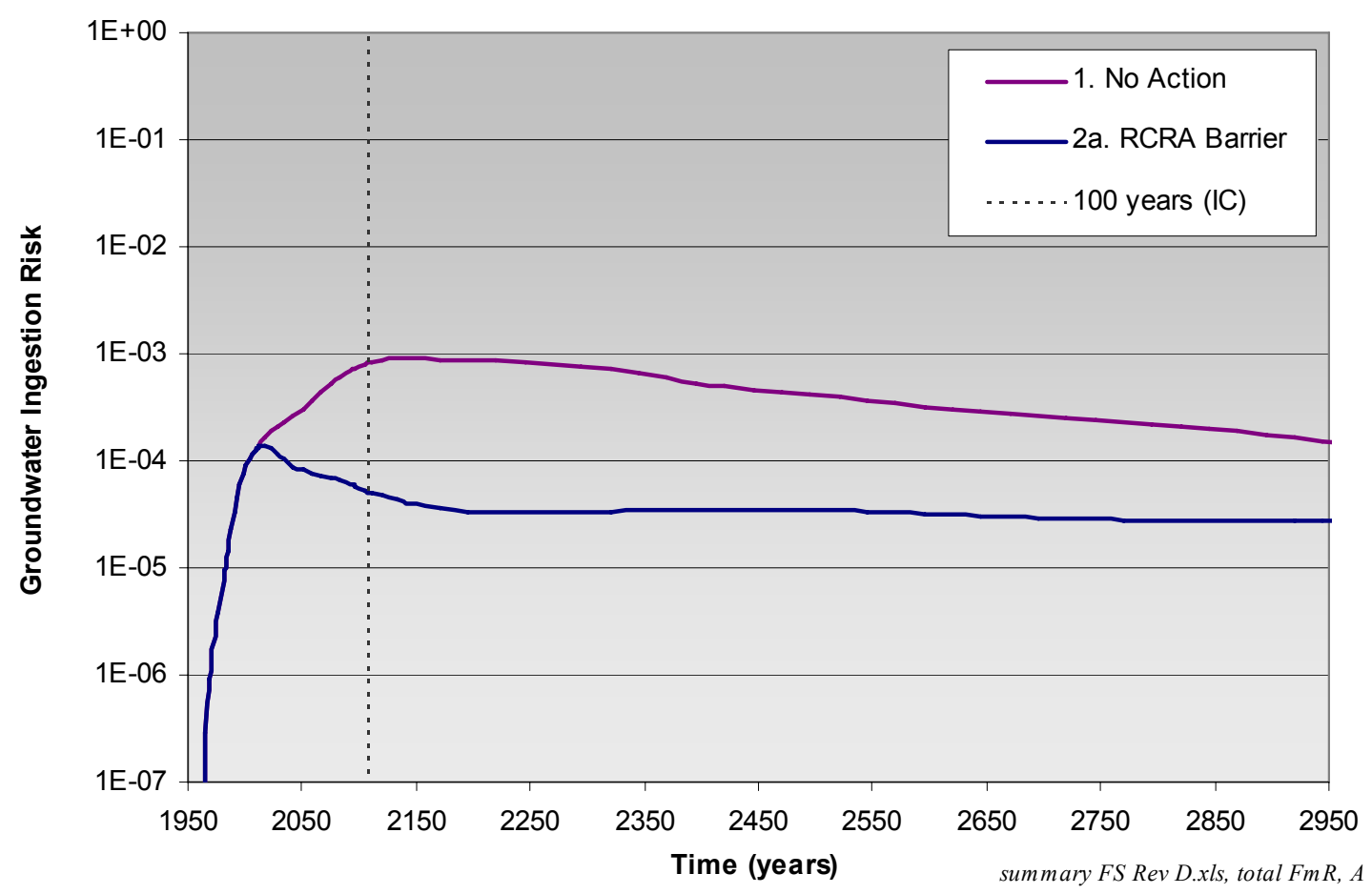

Figure D-11. Comparison of cumulative groundwater ingestion risk for Alternative 1-No Action and Alternative 2a-Modified RCRA Type C Surface Barrier.

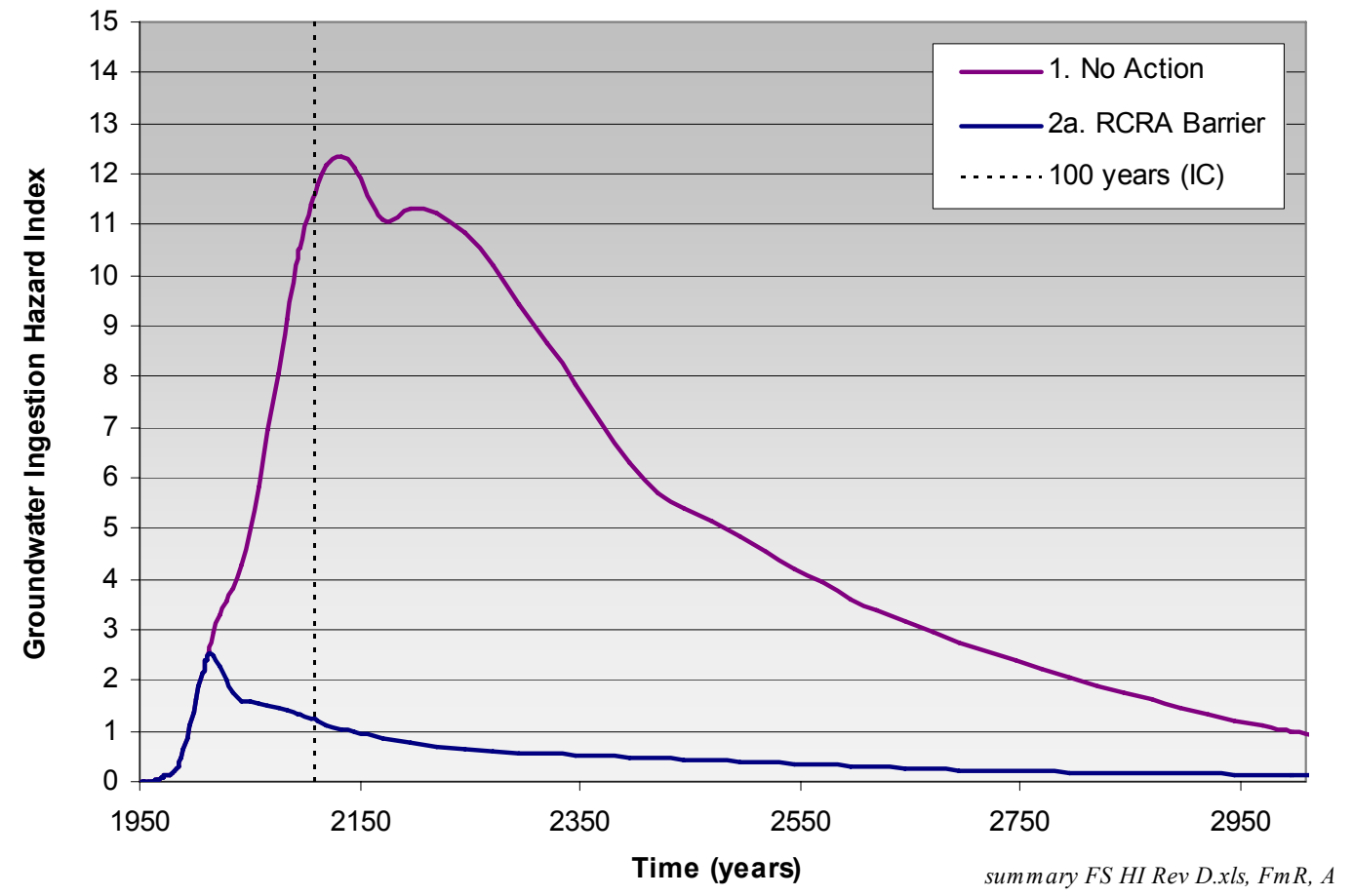

Figure D-12. Comparison of cumulative groundwater ingestion hazard index for Alternative $1-$ No Action and Alternative 2a-Modified RCRA Type C Surface Barrier. 


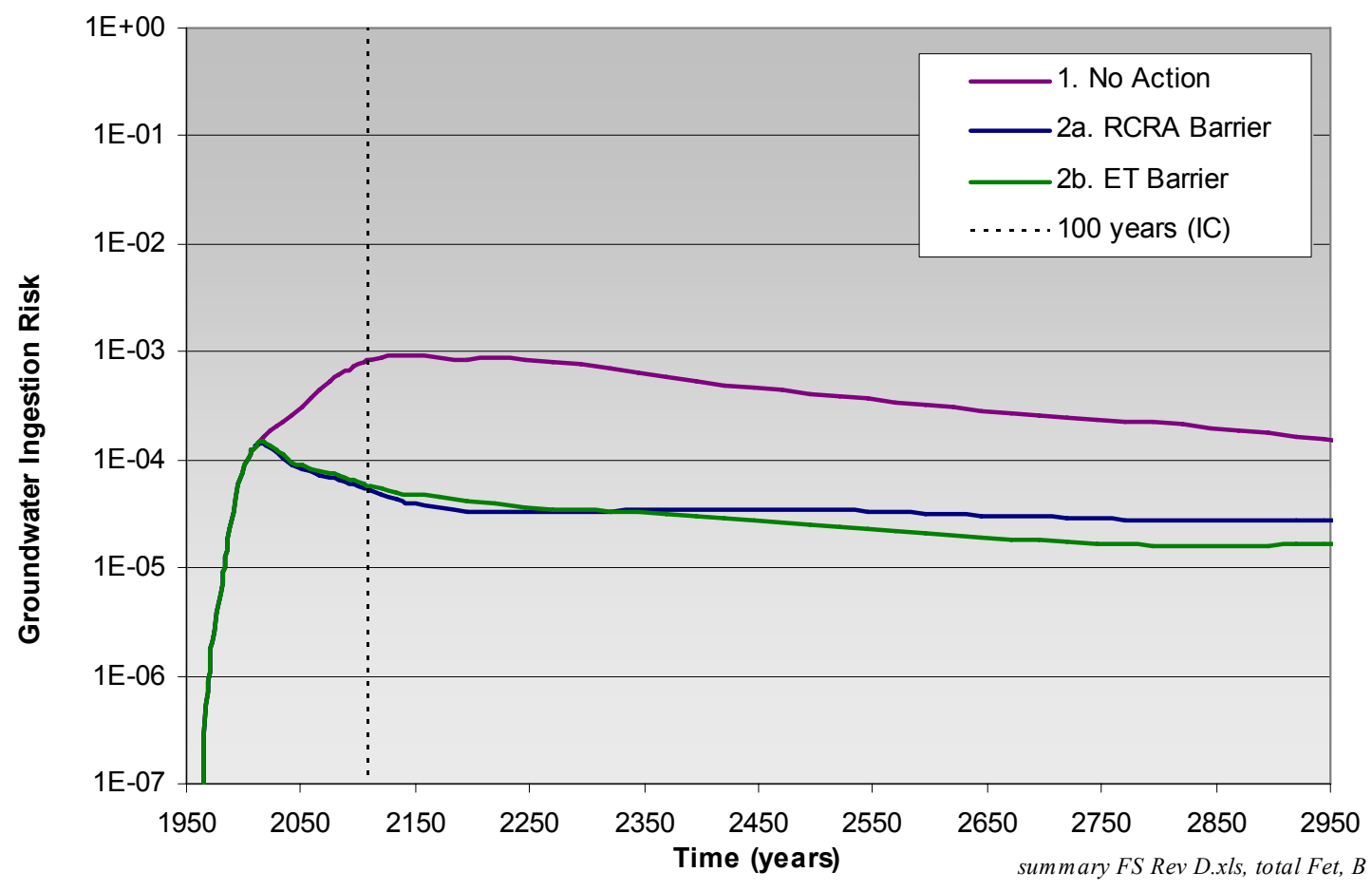

Figure D-13. Comparison of cumulative groundwater ingestion risk for Alternative 1-No Action, and Alternative $2 \mathrm{~b}$-Evapotranspiration Surface Barrier.

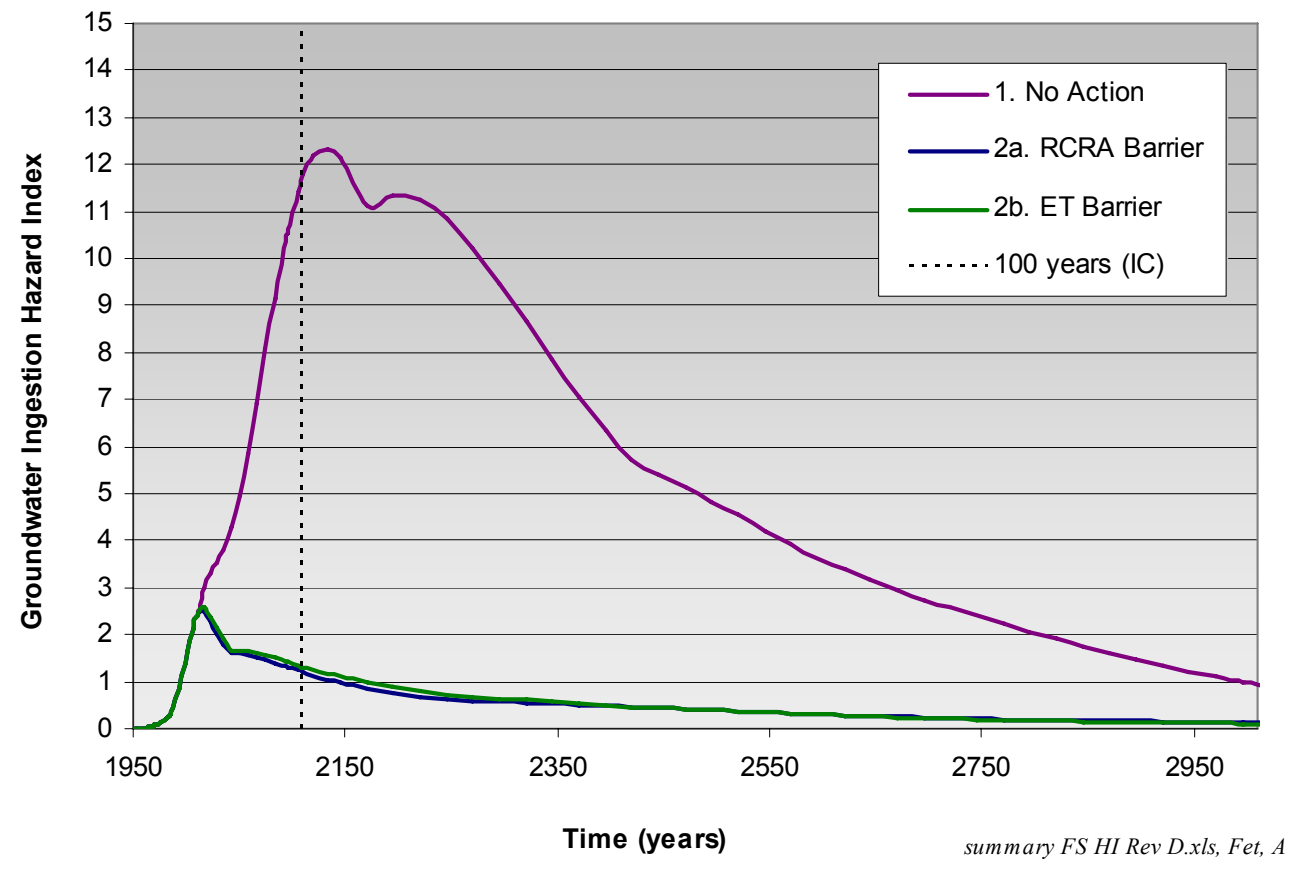

Figure D-14. Comparison of cumulative groundwater ingestion hazard index for Alternative 1-No Action, Alternative $2 \mathrm{~b}$ - Evapotranspiration Surface Barrier, and Alternative 2a-Modified RCRA Type C Surface Barrier. 


\section{D-3.3 Alternative 3-In Situ Grouting}

Alternative 3 (In Situ Grouting [ISG]) simulates the following features:

- $\quad$ Cement-based grout

- $\quad$ Evapotranspiration surface barrier designed to reduce net infiltration rate to $0.1 \mathrm{~cm} / \mathrm{year}$ (0.04 in./year)

- $\quad$ Passive vent layer.

Pad A waste is treated ex situ with a cement-based grout and returned to a pit in the SDA.

However, because of the large amount of nitrate on Pad A, the grout is assumed to physically stabilize the waste, but not reduce release. (Physical stabilization refers to addressing subsidence.) Therefore, nitrate release is the same as for Alternative $2 \mathrm{~b}$ (ET Surface Barrier) and was not affected by ISG. Similarly, VOCs and most radionuclides are not affected by ISG. Risk results from Alternative $2 \mathrm{~b}$ were used to evaluate the effectiveness of Alternative 3 (ISG) for these contaminants. Therefore, only Tc-99 and I-129 releases are simulated in the cement-based grout, and the total risk consists of the sum of these results and the results from Alternative $2 b$ for all other contaminants. Alternative 3 addresses releasable forms of Tc-99 and I-129. Figure D-15 shows the density of releasable Tc-99 and I-129 buried in the SDA. Figure D-16 shows the locations of shipments specified for grouting.

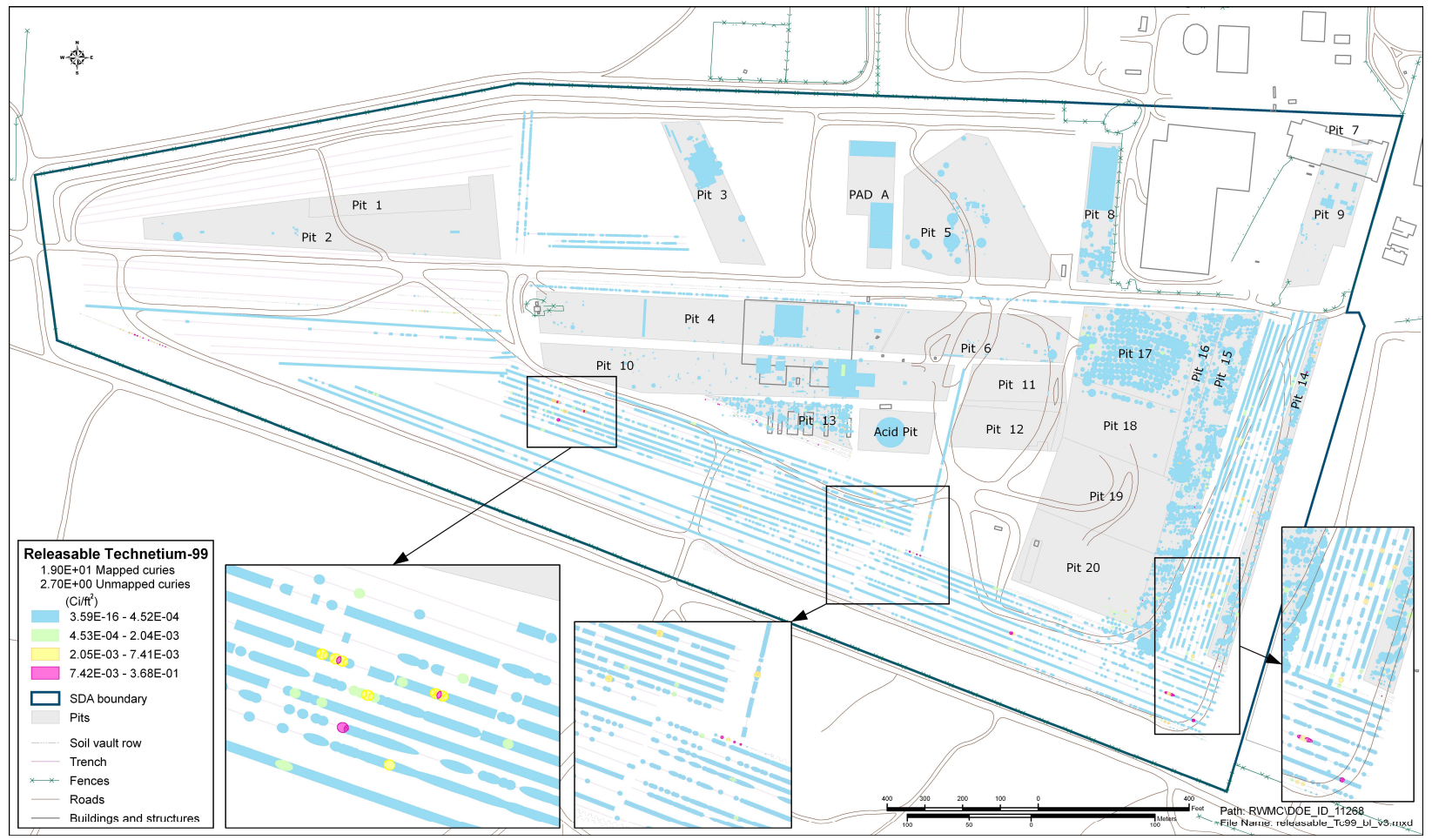

Figure D-15. Density of releasable technetium-99 in the Subsurface Disposal Area. 


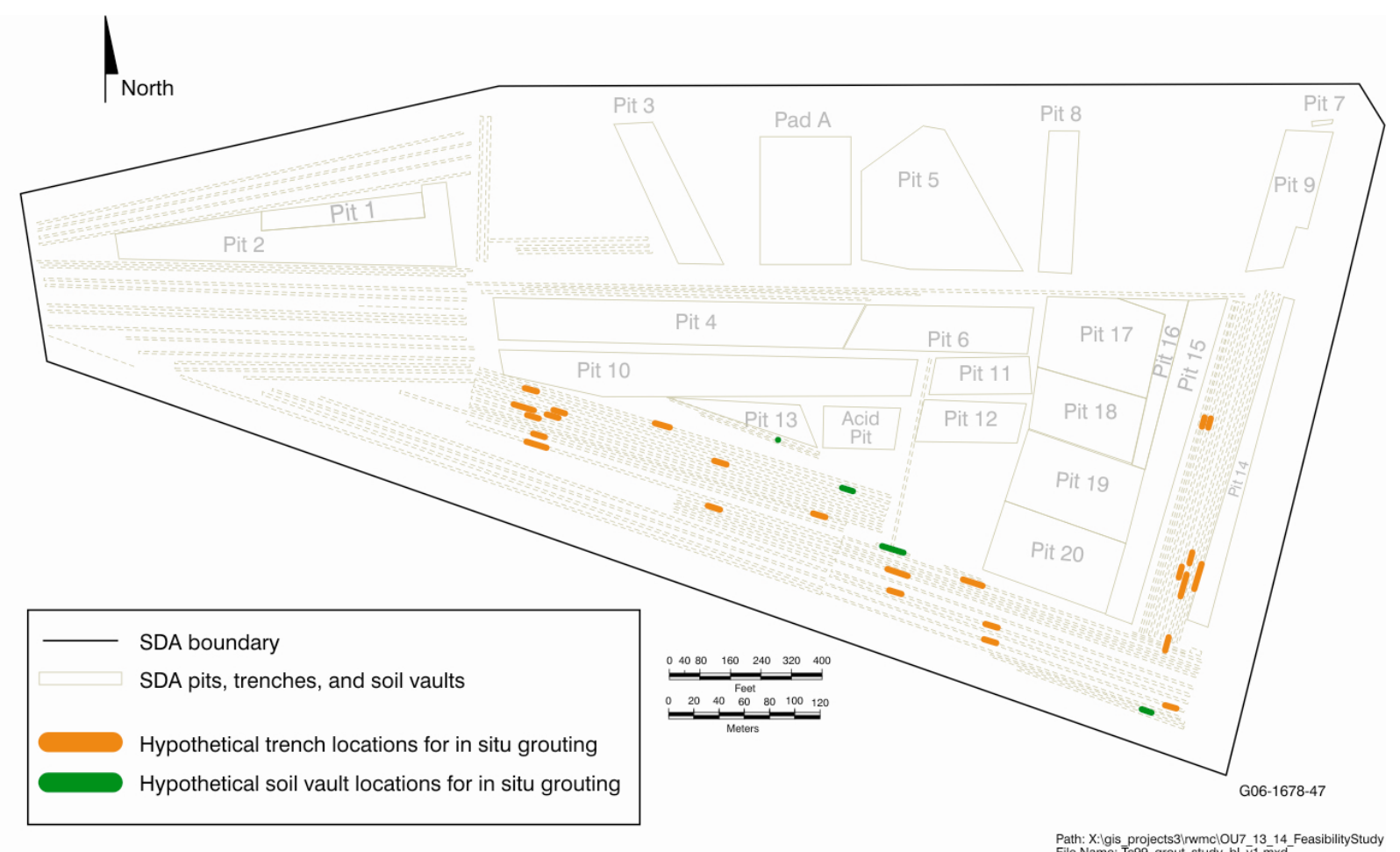

Figure D-16. Hypothetical treatment locations for Alternative 3-In Situ Grouting.

Technetium-99 and I-129 releases from grout were simulated twice using two different models. In both models, parameters for three of the six waste types were adjusted to simulate installation of a cement-based grout: surface wash (i.e., loose contamination), fuel-like materials, and resins. The surface wash waste type should not be confused with the surface wash release mechanism in DUST-MS. The surface wash mechanism can be applied to any of the waste types, not just waste with surface contamination.

The first simulation assumes an immediate failure of waste packaging containers, caused by emplacing grout, for portions of the three specified waste types that are grouted. Data from bench-scale tests (Matthern et al. 2005) were used to estimate the diffusion release from a grout matrix. This diffusion coefficient is used in the DUST-MS diffusion model for both the surface wash and resin waste types, starting in the year 2010, when the grout is emplaced. Using this model, the source release simulation output shows a brief spike at the onset, and the release rate from the grouted waste form is greater than for Alternative 1 (No Action) during the first 100 years; however, the release rate diminishes and is less than Alternative 1 after the first 100 years (Anderson and Becker 2006).

The second simulation releases source from the grout over the 1,000-year period using the surface wash release mechanism for surface-wash and resin waste types. This simulation does not account for any diffusion. In this case, the initial spike is in the source release simulation output, but the release rate from the grouted waste form is still greater than for Alternative 1 (No Action) and for a longer period, lasting 1,000 years, after which it diminishes, falling below the Alternative 1 rate (Anderson and Becker 2006). 
Figure D-17A shows risk results for the diffusion model, and Figure D-17B shows risk results for the surface wash model. For both simulations, the groundwater ingestion risk is lower than Alternative 1, and on a logarithmic scale, risk plots of the two simulations show very little difference. In fact, the peak groundwater ingestion risks are identical when presented with only one or even two significant digits. In either case, grouting reduces the peak risk from $3 \mathrm{E}-05$ to $2 \mathrm{E}-05$. A hybrid simulation using the surface wash model for the resin waste form and using the diffusion model for the surface wash waste form would provide results somewhere between the two current simulations, which are already very similar (i.e., the hybrid result would be bounded by the diffusion and surface wash model results).

In both simulations, all waste packaging is assumed to fail instantaneously during ISG operations (i.e., disrupted by high-pressure grout), though disposal records indicate that these waste types were contained in durable packages (e.g., concrete cask or welded stainless steel can). Furthermore, literature suggests that treating resins with cementitious grouts should have little or no effect on release of Tc-99 (Morgan and Bostick 1992), and though less is known about Tc-99 and I-129 release from fuelexamination waste stabilized in cement grout, it is likely that the most representative groundwater ingestion risk result for Alternative 3 (ISG) would approximate or be less than the result using an ET surface barrier alone. While modeling results do not illustrate reduced groundwater ingestion risk associated with ISG-specified waste, bench-scale tests suggest that grout would retard diffusion of Tc-99 and I-129 (Matthern et al. 2005), and no adverse chemical incompatibilities are anticipated.

Though Alternative 3 (ISG) includes an ET surface barrier, the graphs in Figures D-17A and $\mathrm{D}-17 \mathrm{~B}$ indicate a greater effectiveness, in the first 2,000 years, for Alternative $2 \mathrm{~b}$ (ET Surface Barrier) which does not include ISG. Results after the first 2,000 years seem to indicate an eventual reduction in risk due to the grout. However, by this time, the grout is assumed to have failed and, though release is quicker, much less source is available for release. The risk is lower most likely because most of the source was released early in the simulation period.

To summarize, during the first 2,000 years, the release rate for Alternative 3 (ISG) is simulated to be greater than for Alternative 1 (No Action), and the groundwater ingestion risk for Alternative 3 is estimated to be greater than for Alternative $2 b$ (ET Surface Barrier). However, this result most likely is attributable to overly conservative assumptions developed early in the modeling effort, and it is assumed that ISG would provide some additional degree of protectiveness.

No chemical COCs are specified for grout; therefore, the cumulative hazard index would be identical to Alternative 2b (ET Surface Barrier) hazard index results (see Figure D-14). 


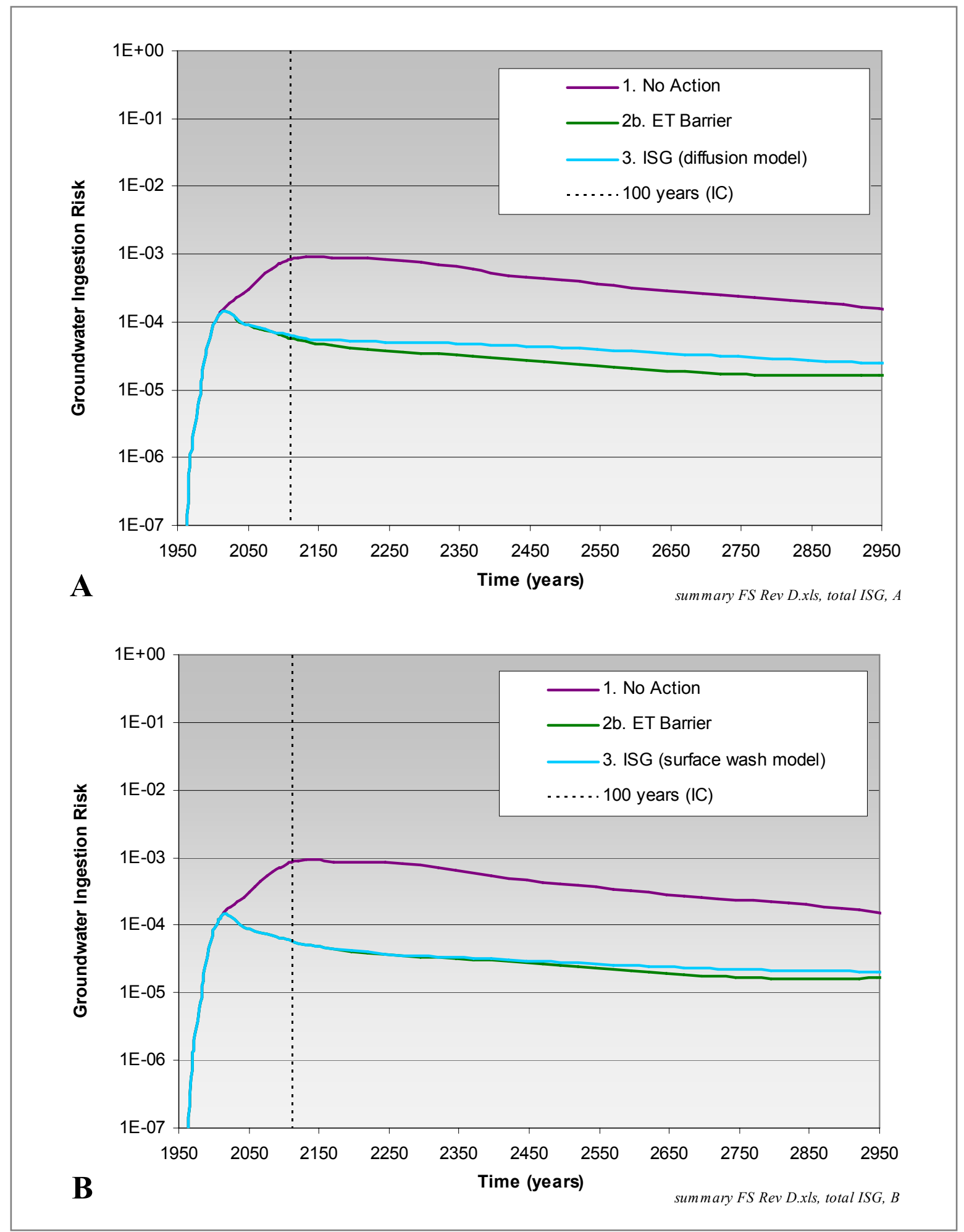

Figure D-17. Comparison of cumulative groundwater ingestion risk for Alternative $1-$ No Action; Alternative 3-In Situ Grouting; and Alternative 2b-Evapotranspiration Surface Barrier, using (A) a diffusion model and (B) a surface wash model for Tc-99 and I-129. 


\section{D-3.4 Alternative 4-Partial Retrieval, Treatment, and Disposal}

Alternative 4 (4-Acre Retrieval, Treatment, and Disposal [RTD]) evaluates targeted waste retrieval from the SDA using methods used by the Accelerated Retrieval Project. Alternative 4a was modeled explicitly. Because the relationship between surface area and source release was assumed to be linear, Alternative $4 \mathrm{~b}$ (2-Acre RTD) was simply scaled from Alternative 4a.

\section{D-3.4.1 Alternative 4a-4-Acre Retrieval, Treatment, and Disposal Areas}

Alternative 4a (4-Acre RTD) hypothetical locations for retrieving targeted waste from pit areas totaling 4 acres, shown in Figure D-18, are in addition to the 0.5 -acre Accelerated Retrieval Project retrieval. As with the Accelerated Retrieval Project retrieval, VOCs, transuranic waste, and uranium waste are targeted. Alternative 4a includes retrieving Pad A waste and disposal at the Idaho CERCLA Disposal Facility. An ET surface barrier with a design net-infiltration rate of $0.1 \mathrm{~cm} /$ year $(0.04$ in./year) is installed after retrieval is complete. The modeling assumed that the visual sorting to identify targeted waste is $80 \%$ effective. Therefore, $20 \%$ of targeted waste in the retrieval area is returned to the pit uncontained. The OCVZ system operates in the same manner as for Alternative 2b (ET Surface Barrier), except remediation goals for carbon tetrachloride are achieved earlier in year 2045.

Figure D-19 shows the comparison of the cumulative groundwater ingestion risk for Alternative 4a (4-acre RTD), Alternative 4b (2-Acre RTD), Alternative 2b (ET Surface Barrier), and Alternative 1 (No Action). Residual risk for Alternative $4 \mathrm{a}$ is nearly identical to residual risk for Alternative $2 \mathrm{~b}$.

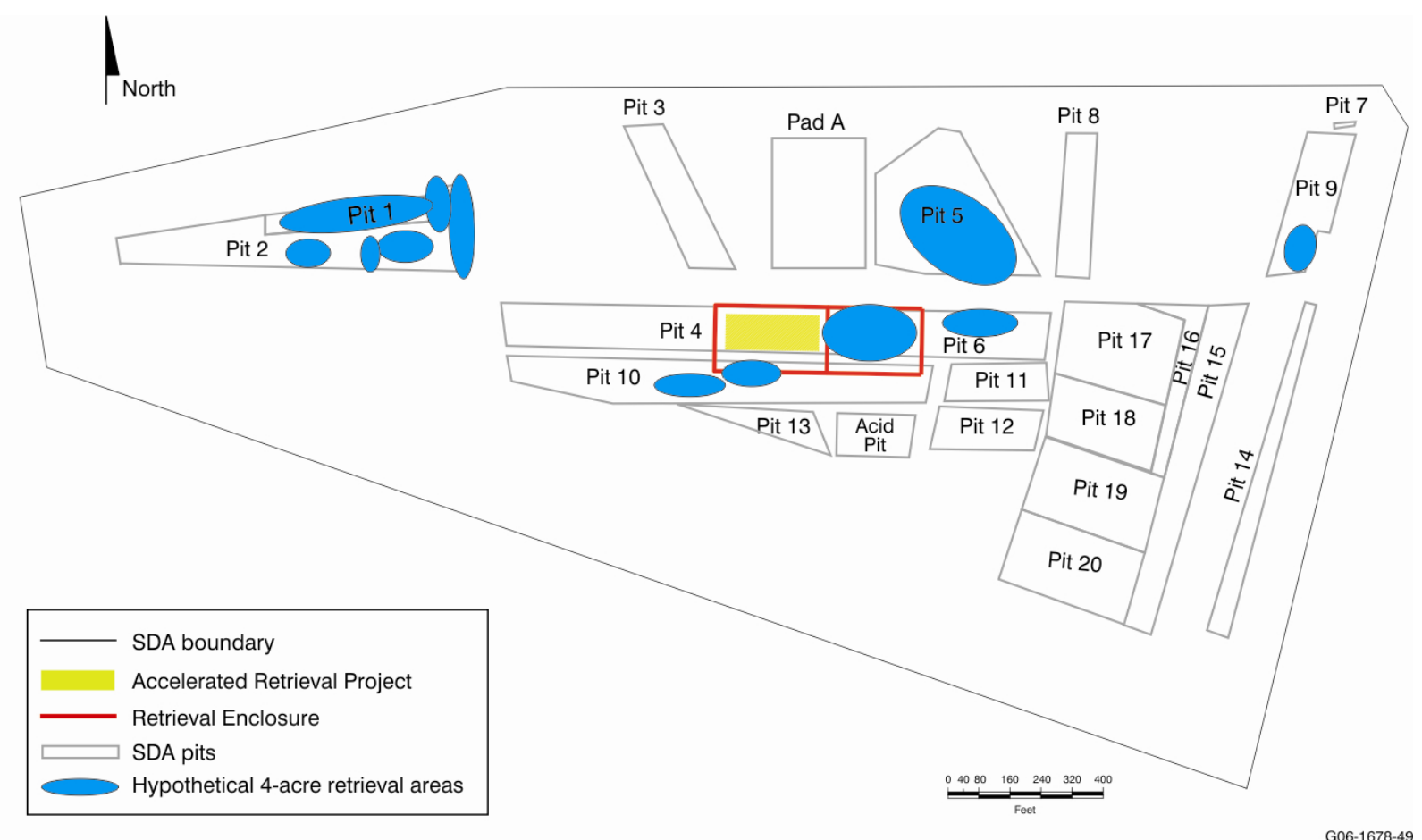

Figure D-18. Hypothetical targeted waste retrieval locations for Alternative 4a-4-Acre Partial Retrieval, Treatment, and Disposal. 


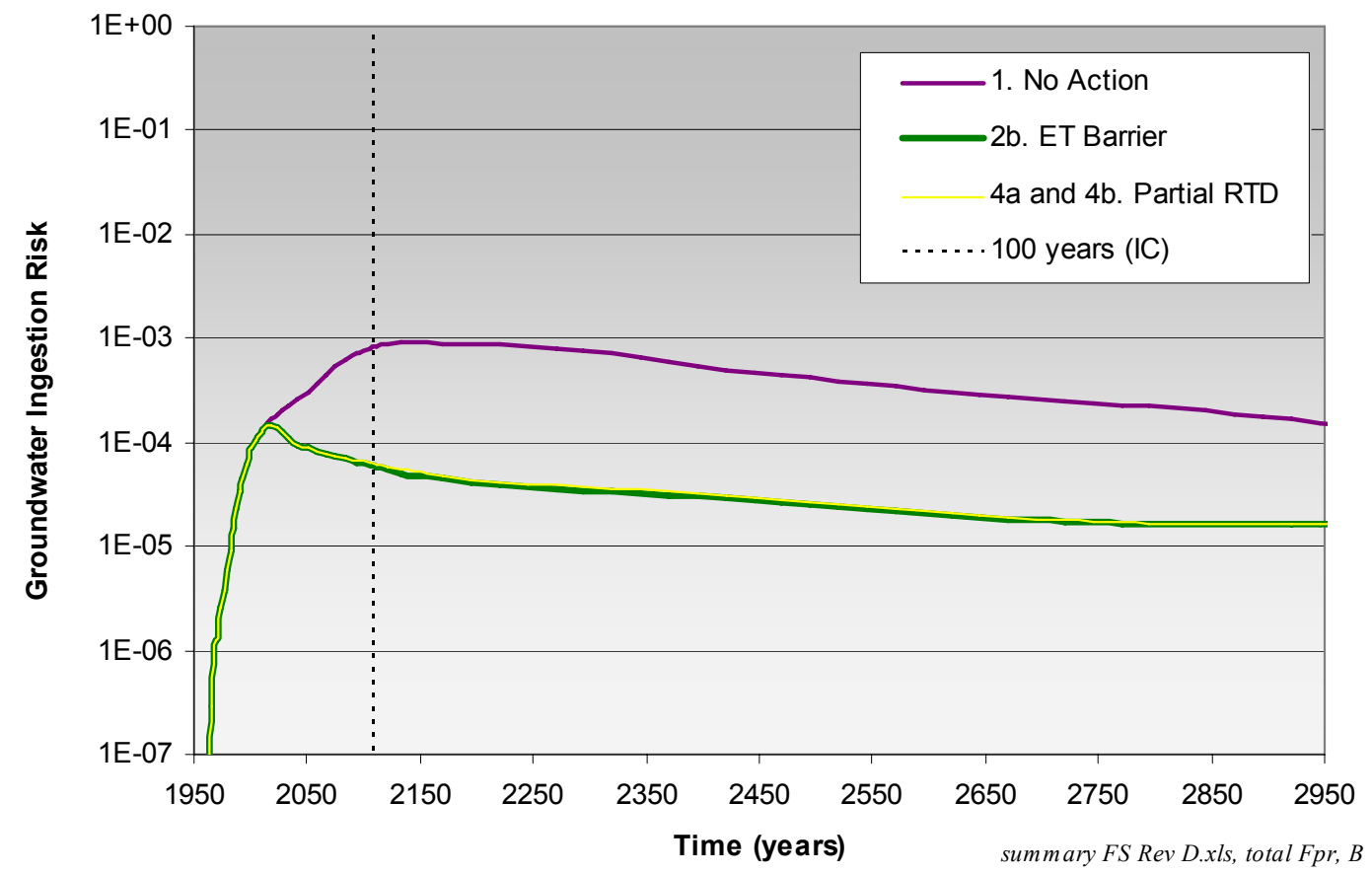

Figure D-19. Comparison of cumulative groundwater ingestion risk for Alternative $1-$ No Action; Alternative 4a-4-Acre Retrieval, Treatment, and Disposal; Alternative 4b-2-Acre Retrieval, Treatment, and Disposal; and Alternative $2 \mathrm{~b}$-Evapotranspiration Surface Barrier.

In the early timeframe, organic contaminants are the key risk drivers. The OCVZ system reduces the mass reaching the aquifer; therefore, the risk is nearly identical for Alternatives 4 and 2 . The primary difference is duration of OCVZ system operations. Similarly, actinide contaminants - primarily uranium - drive risk beyond 1,000 years. The solubility limit controls the release of uranium. Retrieval has little impact on risk because enough mass remains for the simulated release to be solubility limited.

\section{D-3.4.2 Alternative 4b-2-Acre Retrieval, Treatment, and Disposal}

Figure D-20 shows Alternative 4b (2-Acre RTD) hypothetical locations for targeted waste retrieval from pit areas totaling 2 acres. Groundwater ingestion risk for Alternative $4 \mathrm{~b}$ is essentially identical to the groundwater ingestion risk for Alternative $2 \mathrm{~b}$ (ET Surface Barrier) and Alternative 4a (4-Acre RTD) (see Figure D-19).

As with Alternative 4a, the OCVZ system addresses the early risk, and the infiltration rate reduces long-term risk. The duration of OCVZ system operations would be between Alternative $2 \mathrm{~b}$ and Alternative 4a durations.

\section{D-3.5 Alternative 5-Full Retrieval, Treatment, and Disposal}

Alternative 5 (Full RTD) is the bounding case for retrieval, where all waste is removed from the SDA, and an ET surface barrier with a net infiltration rate of $0.1 \mathrm{~cm} /$ year $(0.4 \mathrm{in} /$ year $)$ is installed. The OCVZ system operates until the year 2035, when remediation goals for carbon tetrachloride are achieved. Figure D-21 shows the cumulative groundwater ingestion risk for Alternative 5 compared to Alternative 1 (No Action), Alternative 2b (ET Surface Barrier), and Alternative 4a (4-Acre RTD). 


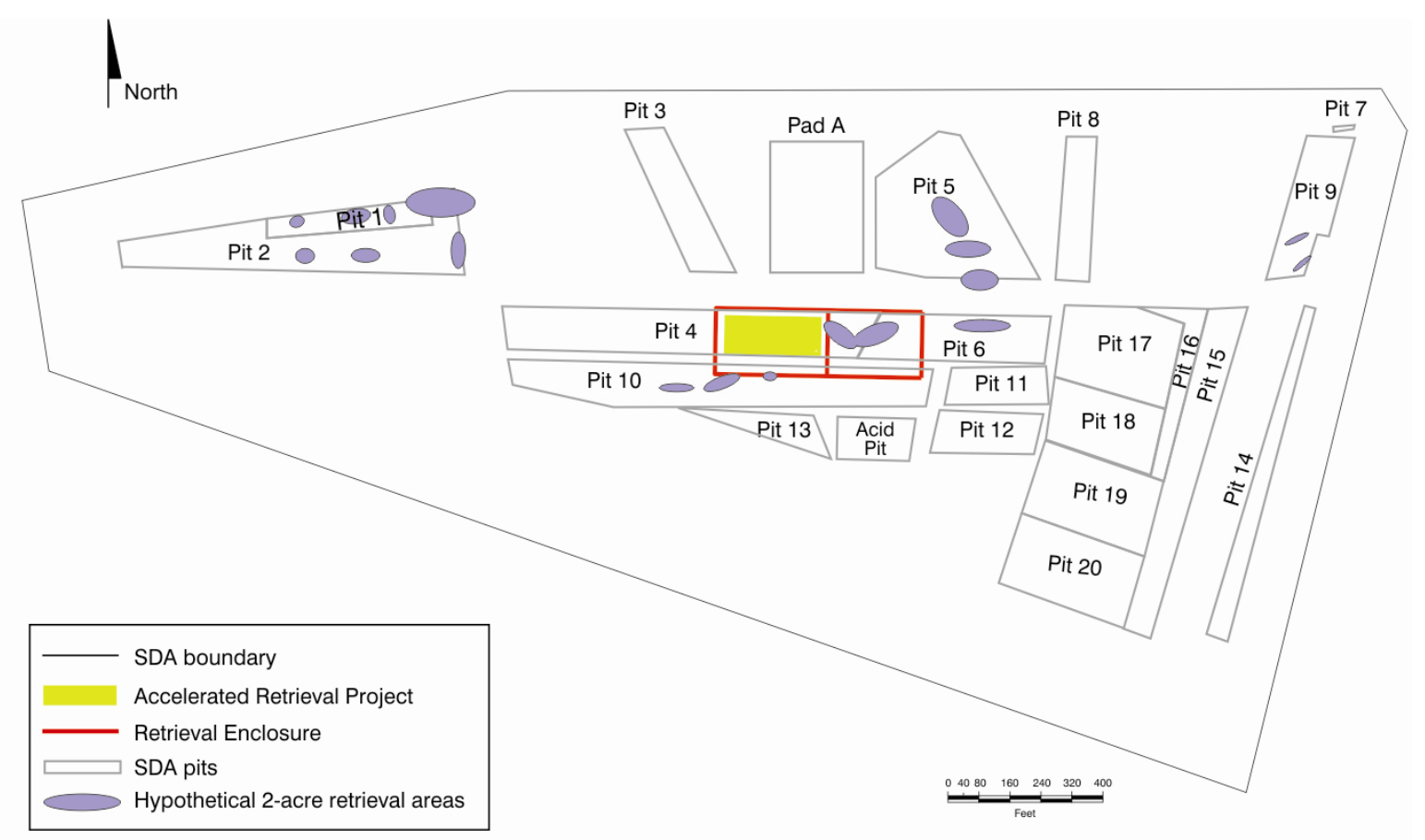

G06-1678-48

Figure D-20. Hypothetical targeted waste retrieval locations for Alternative 4b-2-Acre Retrieval, Treatment, and Disposal.

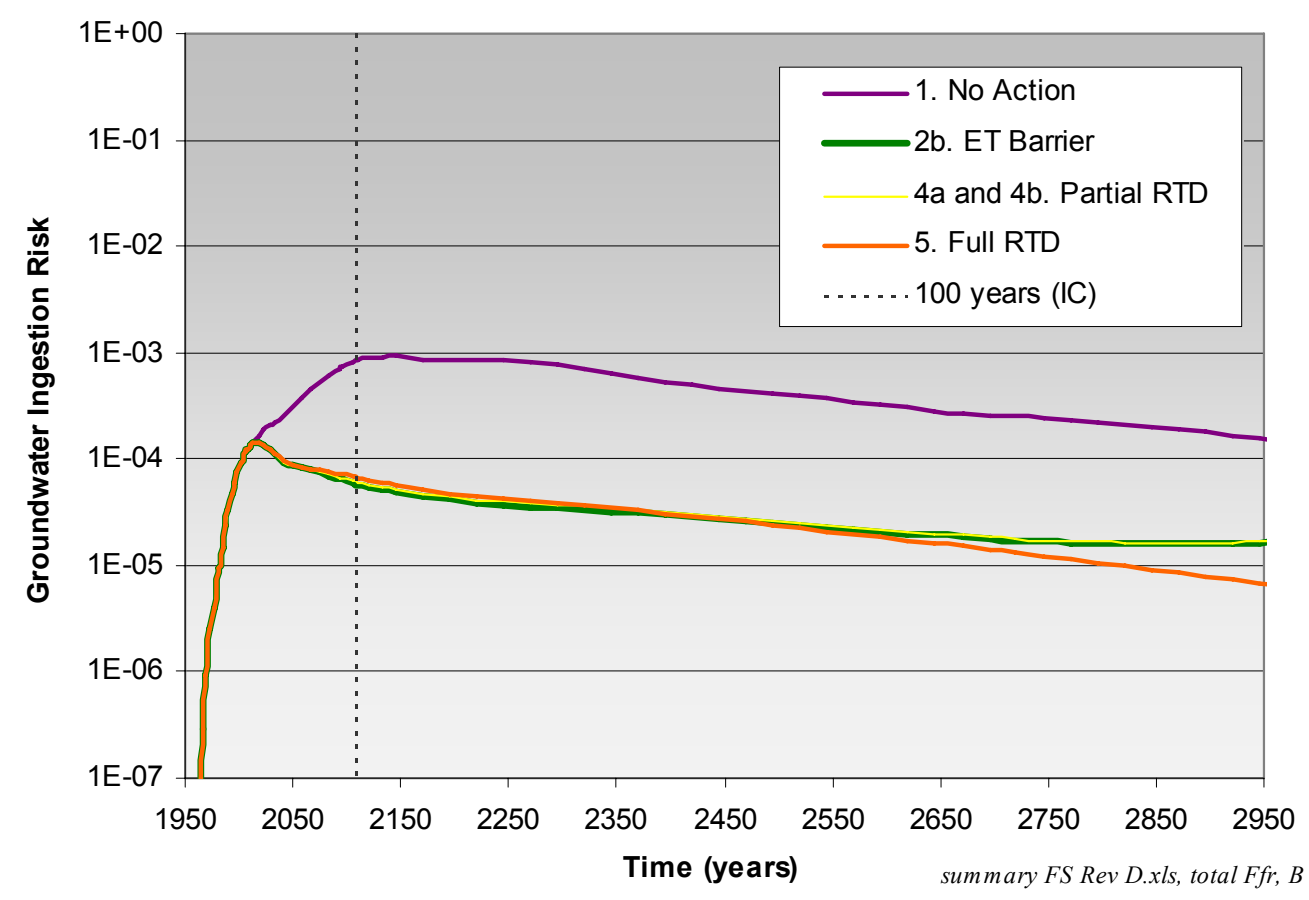

Figure D-21. Comparison of cumulative groundwater ingestion risk for Alternative $1-$ No Action; Alternative 5-Full Retrieval, Treatment, and Disposal; Alternative 4a-4-Acre Retrieval, Treatment, and Disposal; Alternative 4b-2-Acre Retrieval, Treatment, and Disposal; and Alternative 2bEvapotranspiration Surface Barrier. 


\section{D-3.6 Sensitivity and Uncertainty}

Sensitivity of risk results to certain parameters or conditions were modeled to address uncertainty and to provide the Agencies with additional information on which to base decisions. Two sensitivity cases involved uranium because risk from uranium has decreased from the previous risk assessment (Holdren et al. 2002). Risk decreased because new information justified less conservative assumptions than previously used. The sensitivity to infiltration rate through the ET surface barrier and the sensitivity to no surface barrier also were examined.

\section{D-3.6.1 Model Uncertainty}

\section{D-3.6.1.1 Feasibility Study Base Case Nitrate Simulation Compared to Nitrate Monitoring}

Results. The numerical subsurface fate and transport model, comprising a vadose zone representation and an aquifer representation (described in detail in Magnuson and Sondrup [2006]), was used to simulate each contaminant of potential concern for the feasibility study base case. A separate source-release model (Anderson and Becker 2006) provided contaminant inputs to the vadose zone model. This section summarizes material from Magnuson and Sondrup (2006) and compares simulated nitrate results (as elemental nitrogen) with observed concentrations to illustrate transport model conservatism for nitrate. Observed concentrations through Fiscal Year 2004 are used for comparison (Holdren and Broomfield 2004). These comparisons are presented in sequence for the vadose zone (from 0 to $10.7 \mathrm{~m}$ [0 to $35 \mathrm{ft}]$ ); the deeper vadose zone (from 10.7 to $76.2 \mathrm{~m}$ [35 to $250 \mathrm{ft}$ ]), which contains the B-C and C-D interbeds; and the aquifer. Comparisons are shown as time histories of simulation results and monitoring results.

Calibration to observed nitrate concentrations was not attempted for these simulations. Rather, simulations for both the vadose zone and the aquifer were developed based on best-available information. Then, simulations were run once in a time-forward mode to obtain results.

D-3.6.1.1.1 Vadose Zone: $\mathbf{0}$ to $\mathbf{1 0 . 7} \mathrm{m}$ (0 to $\mathbf{3 5} \mathrm{ft}$ )-This section focuses on nitrate simulation results for those locations showing elevated concentrations or trends in the vadose zone at depths less than $10.7 \mathrm{~m}(35 \mathrm{ft})$. In general, this region encompasses the waste zone and surficial sediment down to the first basalt interface. Because each well can have multiple lysimeters at different depths, this section refers to lysimeters, using an identifier that combines the well name and lysimeter number (e.g., I-2S-DL11).

Elevated nitrate concentrations have been observed at lysimeters in Wells PA02 and W25 in the 0 to $10.7-\mathrm{m}$ ( 0 to $35-\mathrm{ft}$ ) zone (see Figure D-22). To show detail in monitoring results, Figure D-22 shows two different vertical concentration scales, though both show the simulated concentration is higher than the observed concentration. Revisions to the source release model since the RI/BRA delay release of nitrate, and thus simulations show nitrate is not present at these locations by year 2005. Underprediction by the refined RI/FS model at these locations is not surprising given the coarse discretization of grid blocks ( $38.1 \mathrm{~m}[125 \mathrm{ft}]$ on a side and approximately $1.8 \mathrm{~m}[6 \mathrm{ft}$ thick]) at the lysimeter locations. These grid blocks are large compared to the volume sampled by a lysimeter. Thus, simulated concentrations are averaged over large volumes and may not represent conditions at point locations.

D-3.6.1.1.2 Vadose Zone: 10.7 to $76.2 \mathrm{~m}$ (35 to $250 \mathrm{ft}$ )—Similar to the shallow vadose zone in the 0 to $10.7-\mathrm{m}$ ( 0 to $35-\mathrm{ft})$ interval, this section compares simulated time histories for those monitoring locations from the 10.7 to $76.2-\mathrm{m}$ ( 35 to 250 -ft) interval that have elevated - even if only slightly - nitrate concentrations. Elevated nitrate concentrations in the 10.7 to $76.2-\mathrm{m}$ (35 to 250-ft) interval were observed at Wells I-2S and I-4S. Figure D-23 shows these simulation results. Lysimeter I-2S-DL11 shows elevated monitoring results for nitrate, similar to those in Well PA02. 

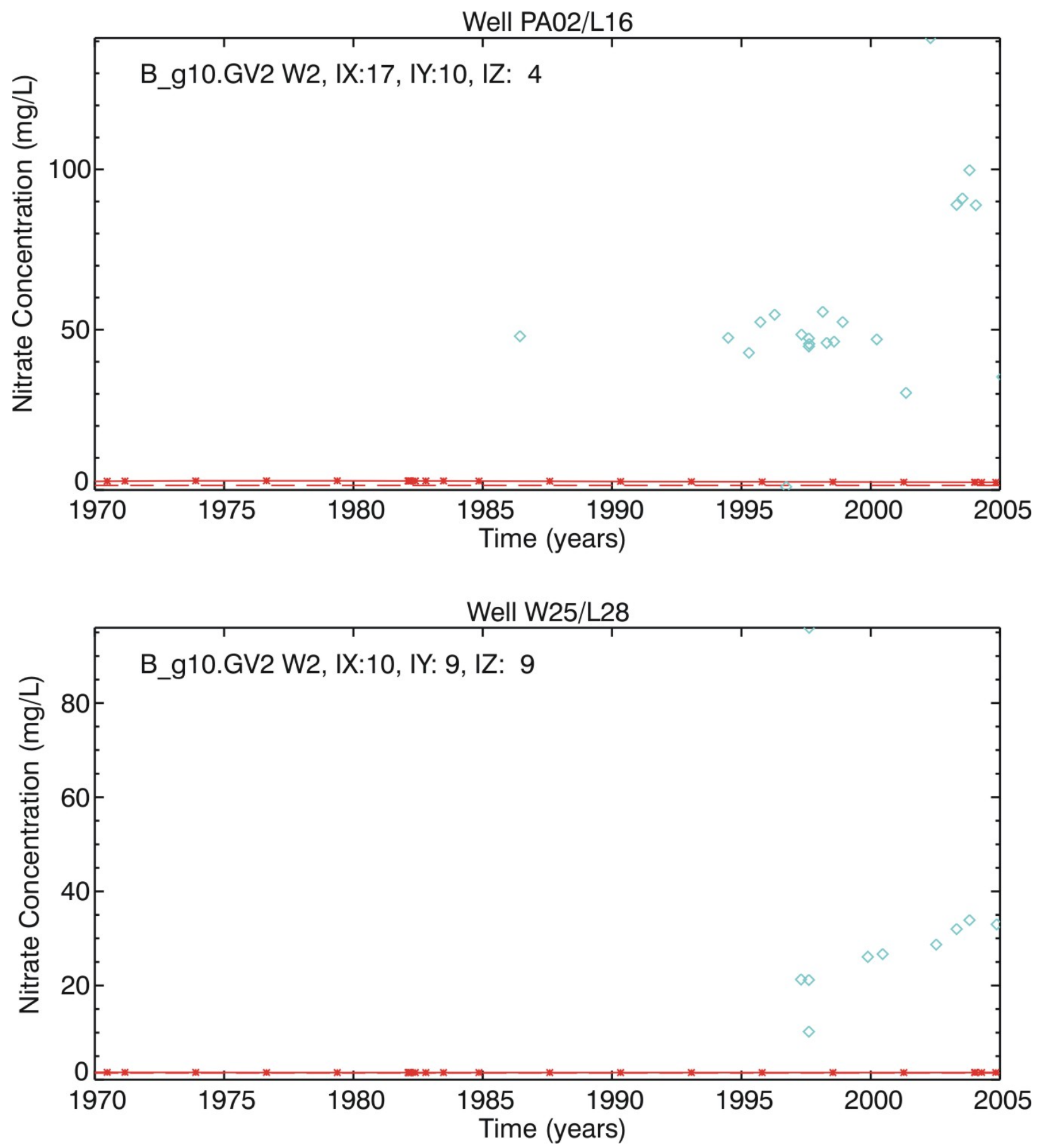

Figure D-22. Time-history comparison of simulated (red line) and observed (blue diamond symbols) concentrations for nitrate in Lysimeters PA02-L16 and W25-L28 in the 0 to 35-ft depth interval. The dashed line indicates vadose zone background concentration. 

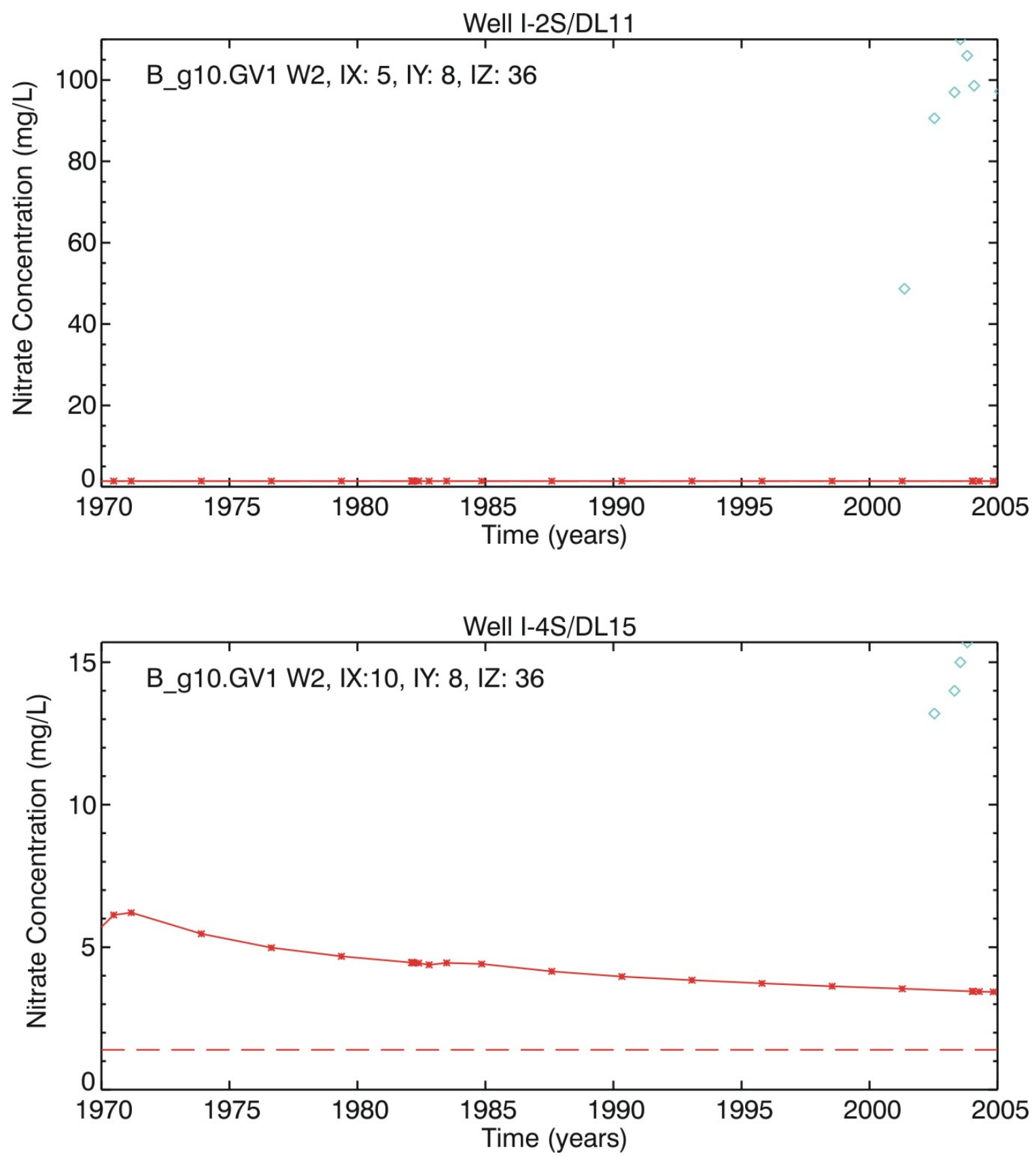

Figure D-23. Time-history comparison of simulated (red line) and observed (blue diamond symbols) concentrations for nitrate in the lysimeters in the 35 to $250-\mathrm{ft}$ depth interval. The dashed line indicates vadose zone background concentration.

Simulation results show no nitrate present. Lysimeter I-4S-DL15 has lower monitoring results and does show the presence of some nitrate mass in the simulation results. This simulated mass is present because this location is close to the Acid Pit source-release location (see Figure 1-6), which has the only substantial mass release before year 2000. The model underprediction at these locations with elevated concentrations is not surprising given the coarse discretization in the vadose zone model. 
D-3.6.1.1.3 Aquifer-Nitrate is a common chemical in groundwater, especially in farming communities. Therefore, background concentrations must be considered when making comparisons, even though for RI/FS modeling, upgradient sources are assumed to not influence contaminant concentrations near the SDA. A background concentration of $1.0 \mathrm{mg} / \mathrm{L}$ was added to simulated values in the simulated aquifer time-history plots shown in Figure D-24. This background concentration appears appropriate for the local RWMC area and is within the range of background concentrations typical for the INL Site (i.e., 0.4 to $5.0 \mathrm{mg} / \mathrm{L}$ ) as presented in Section 4 of the RI/BRA (Holdren et al. 2006). The time-history plots are shown with a consistent time axis and a consistent concentration axis, except for Well M17S, for which the concentration axis is one order of magnitude larger to show simulated results. Simulation results representing all wells, except Well M4D, are taken from the second gridblock down in the aquifer model. Well M4D is unique because it is screened much deeper; therefore, simulated concentrations from deeper in the model are used. The second gridblock extends from 8 to $16 \mathrm{~m} \mathrm{(26} \mathrm{to} 52 \mathrm{ft}$ ) in the aquifer domain and is similar to most of the screened intervals in the monitoring wells (see Figure D-25). As such, simulated concentrations represent concentrations at $12 \mathrm{~m} \mathrm{(39} \mathrm{ft})$ below the water table. Figure D-24 illustrates that nitrate is overpredicted for three locations (i.e., Wells M17S, USGS-119, and USGS-90). Simulation results for all other locations are indiscernible from background concentrations, which vary from 0 to $5 \mathrm{mg} / \mathrm{L}$, with the most common concentration range of 1 to $2 \mathrm{mg} / \mathrm{L}$ (Knobel, Orr, and Cecil 1992). Also, monitoring data show that monitored concentrations vary from the mean local background estimate.

The numerical model predicts movement of water and nitrate to the southeast in both the vadose zone and in the refined portion of the aquifer simulation domain. Figure D-26 shows this predicted movement of nitrate east-southeast within the aquifer model-refined domain. Figure D-26 shows simulated time histories from Figure D-24 in spatial relation to their well locations. Elevated nitrate concentrations are predicted by current time for Wells M17S, USGS-119, USGS-90, and M15S, all of which are either beneath the SDA or south-southeast of the SDA. Wells M6S and M15S would have higher predicted concentrations, but they are outside the refined area; therefore, the predicted concentration is subject to averaging over a much larger gridblock volume, which dilutes the simulated concentration.

Some nitrate patterns can be interpreted by comparing monitoring data to the local aquifer background estimate of $1.0 \mathrm{mg} / \mathrm{L}$. For purposes of comparison, monitoring results are grouped into three classes, as indicated in the upper right corner of each time-history plot. An "L" indicates the monitoring data are mostly less than the background, an "M" indicates the monitoring data are mostly equal to the background, and an "H" indicates the monitoring data are mostly greater than background. Following this grouping, most concentrations at Wells USGS-87, M3S, M7S, M16S, USGS-90, M17S, USGS-117, M4D, and USGS-120 are less than background. Concentrations at Wells M1S and M15S match local background. Concentrations at Wells USGS-119 and USGS-88 are greater than the local background. Concentrations at Well M6S are the highest above the local background estimate. Grouped in this fashion, the monitoring data also show a tendency for elevated nitrate concentrations in several wells south of the SDA, with one group including Wells USGS-119, M15S, and M6S, which are in the direction of predicted local transport to the southeast.

Most of the monitoring data are consistent with the conceptual model and numerical implementation from Magnuson and Sondrup (2006). The aquifer flow system is dominated by a low-permeability region south and southwest of the SDA that directs flow eastward around the low-permeability system. 

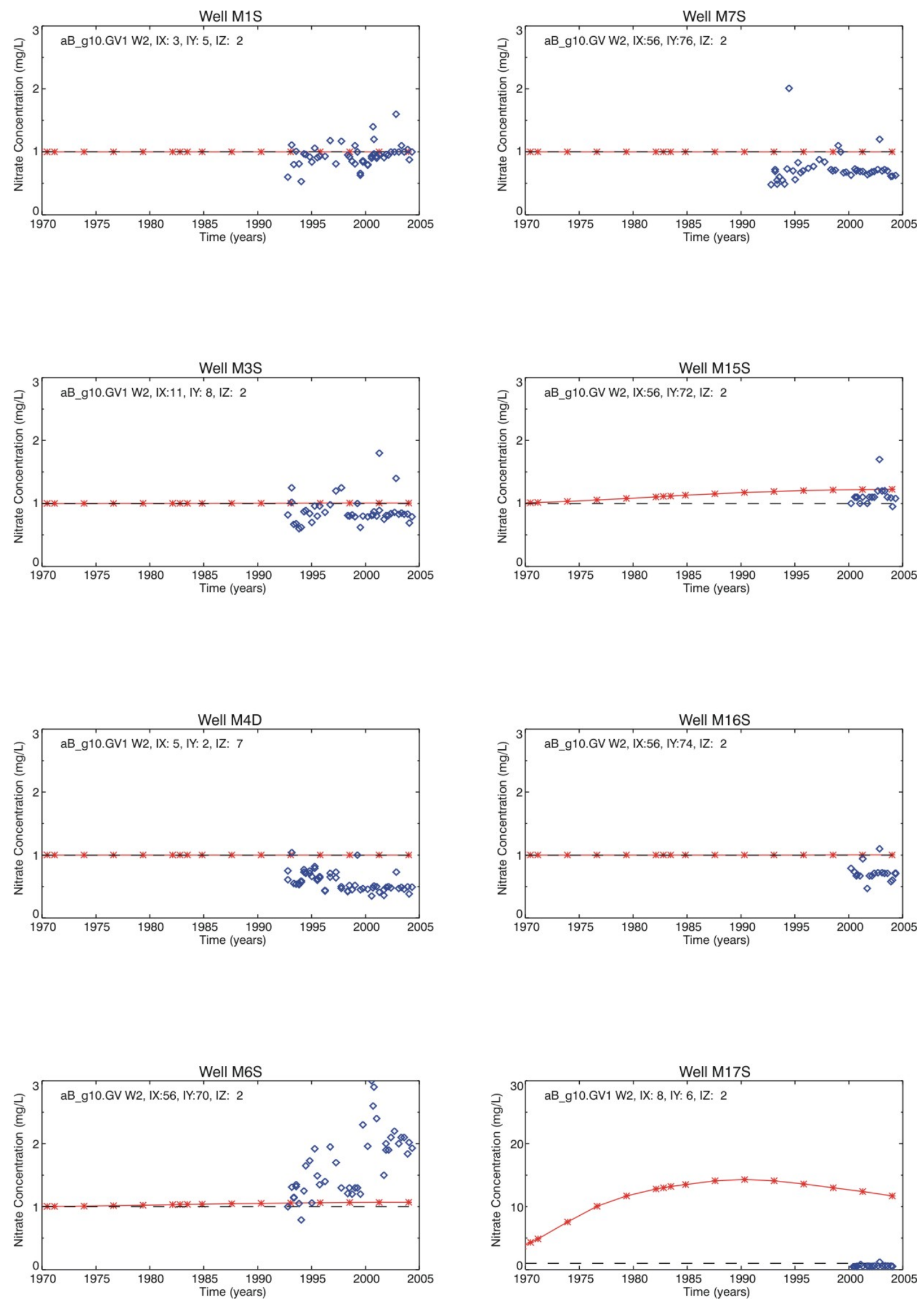

Figure D-24. Time-history comparison of simulated (red line) and observed (blue diamond symbols) nitrate (as nitrogen) concentration time histories for aquifer monitoring wells in the vicinity of the Subsurface Disposal Area. The dashed line indicates background concentration. 
Well A11A31

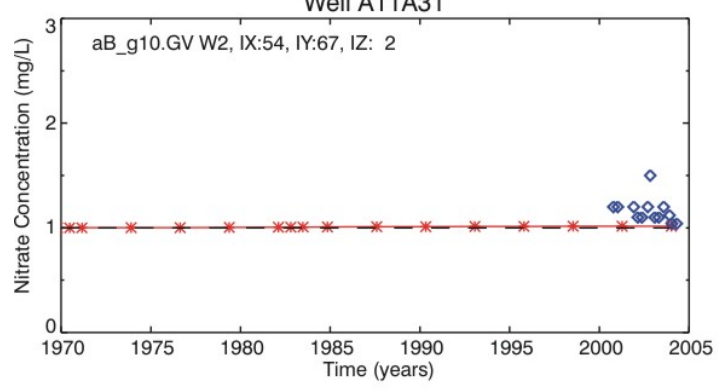

Well USGS-87

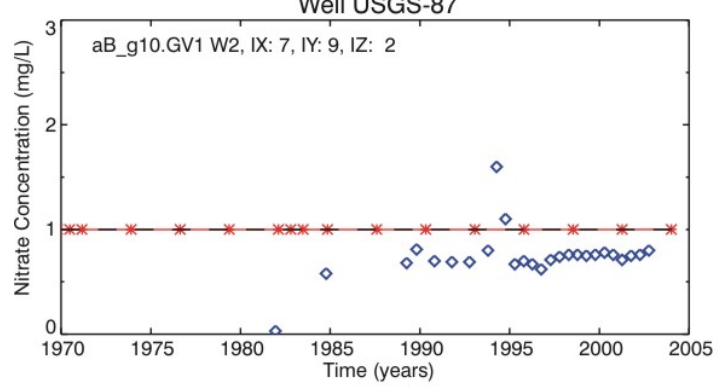

Well USGS-88

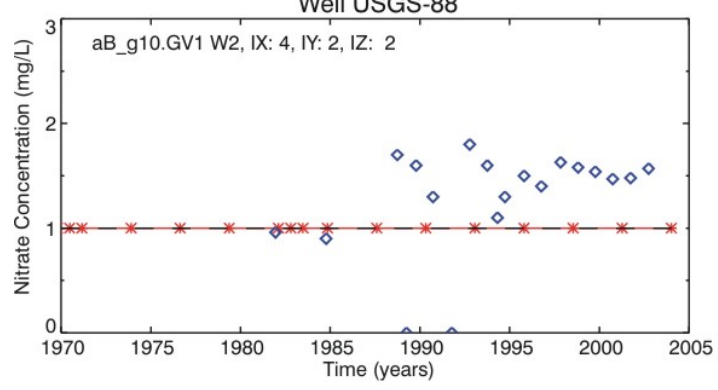

Well USGS-90

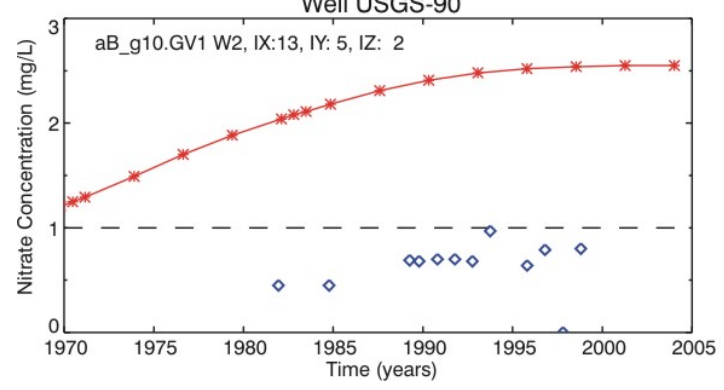

Well USGS-117

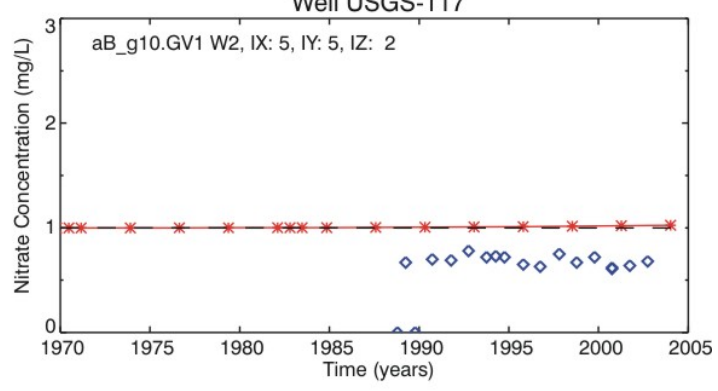

Well USGS-119

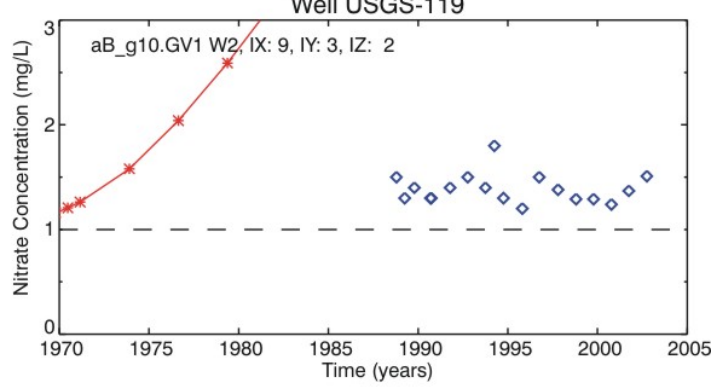

Well USGS-120

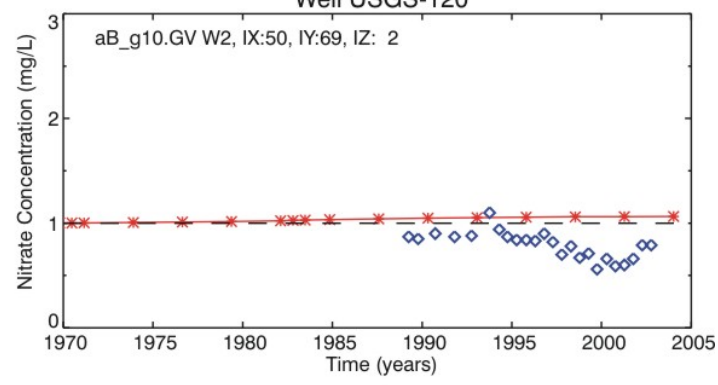

Well RWMC

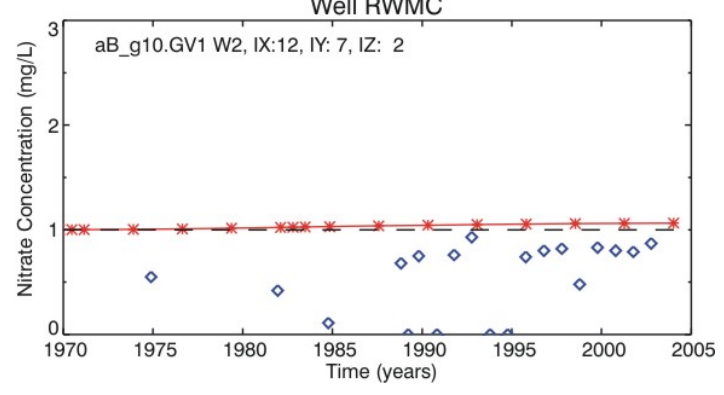

Figure D-24. (continued). 


\section{Aquifer Monitoring Wells in SDA Vicinity}

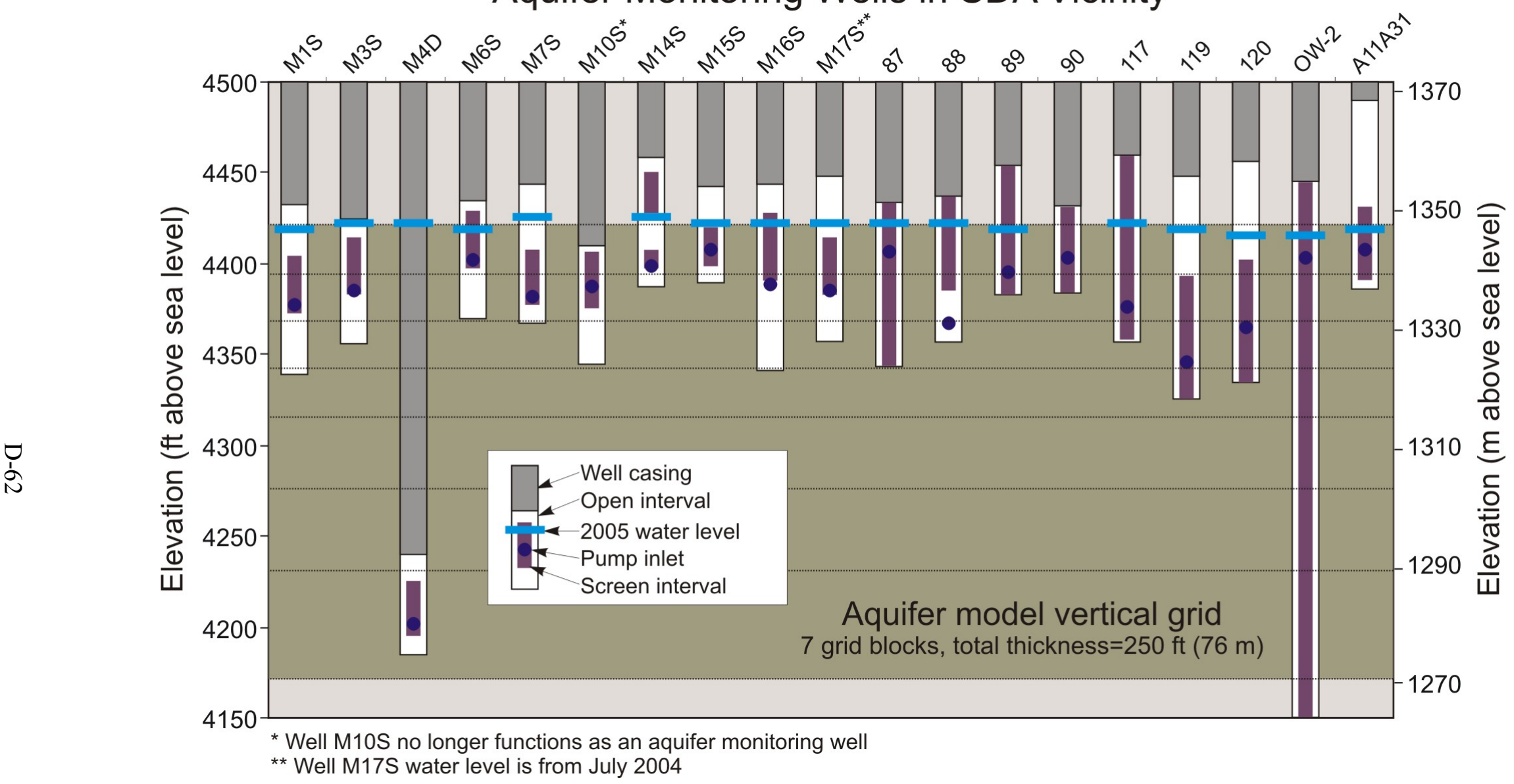

Figure D-25. Screen intervals for aquifer monitoring wells in relation to vertical aquifer model grid discretization. The top of the model grid is placed at the average 2005 water table elevation of wells shown. 


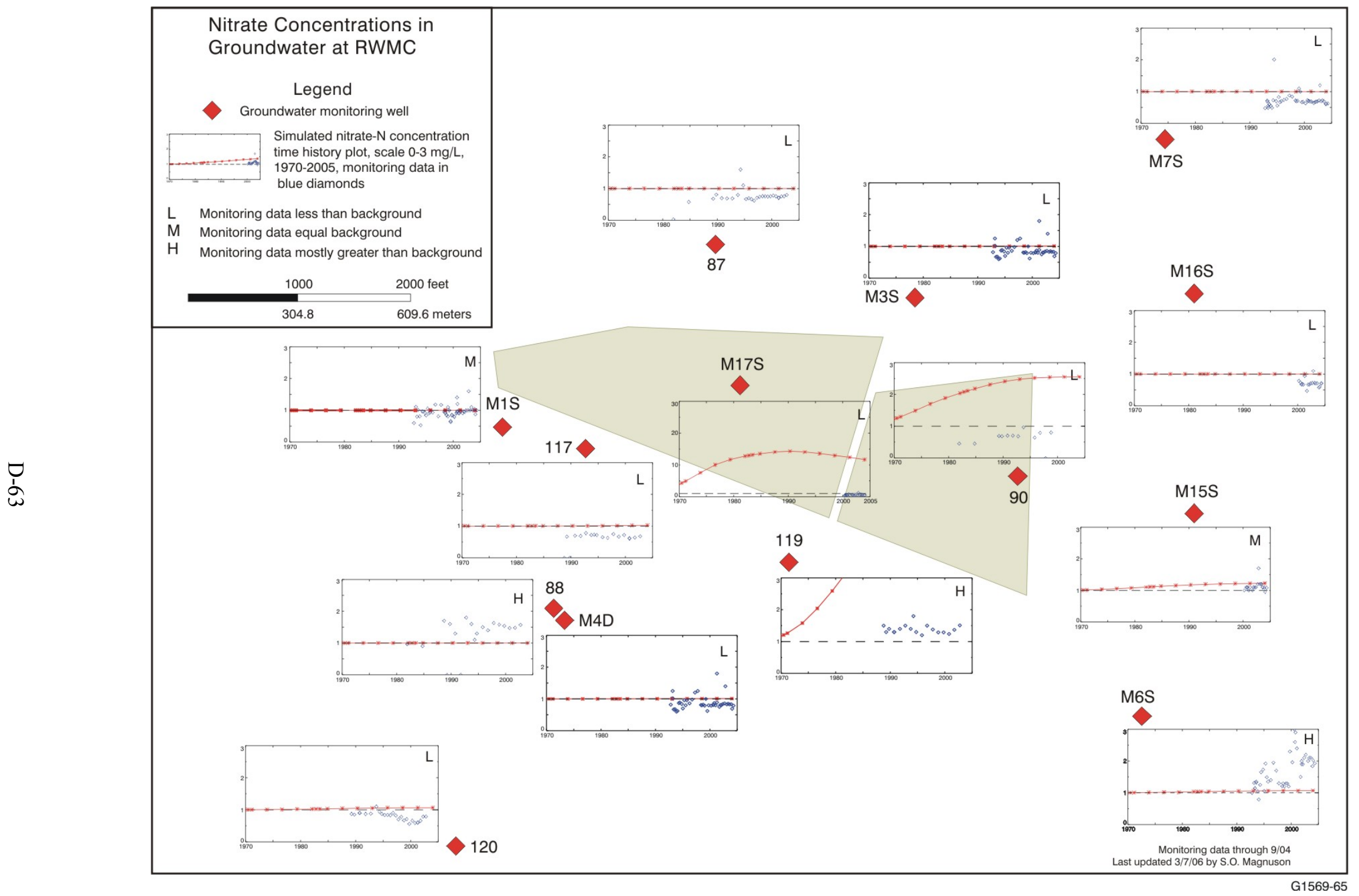

Figure D-26. Simulated and observed nitrate concentrations superimposed onto monitoring locations in the vicinity of the Radioactive Waste Management Complex. Dashed line indicates background concentration. 
In comparing simulation results to monitoring results, concentrations are substantially overpredicted in Well M17S (inside the SDA), Well USGS-119 (immediately south of the SDA), and Well USGS-90 (east of the SDA). Predicted concentrations agree with observed concentrations at Well M15S (east of the Transuranic Storage Area) and underpredict at Well M6S (southeast of the SDA). Simulation results at the grid location corresponding to Well M6S and M15S are subject to additional dilution because the grid location is outside the refined area. Without this dilution, the agreement would be better. The majority of other aquifer locations outside this predicted contaminant plume show no simulated impact above local background concentrations. The overprediction at Wells M17S, USGS-119, and USGS-90 is due to the release of nitrate mass in the Acid Pit source release location (see Figure 1-6). This released mass migrates down through the vadose zone and impacts simulated concentrations at these locations.

D-3.6.1.1.4 Conclusion-Undoubtedly, water and contaminant movement in the vadose zone and aquifer is more complex than has been represented in the numerical model. However, the model provides a foundation for explaining most of the observed behavior and, thus, meets a goal of general representativeness. The numerical model underpredicts observed nitrate concentrations at the few locations in the vadose zone with observed elevated concentrations. The numerical model does, however, produce large overpredictions at Wells M17S, USGS-90, and USGS-117 in the aquifer, demonstrating that the nitrate simulation results are conservative overall to the point of being not credible when compared to monitoring results. This demonstrated conservativeness indicates uncertainty in the model results, especially for nitrate.

Because current aquifer monitoring results for nitrate are either overpredicted at three wells or show no simulated impact and are consistent with background concentrations at the other wells, the RI/FS model indicates that a distributed plume of elevated nitrate is in the vadose zone and aquifer that is not substantiated by monitoring. For example, this unsubstantiated simulated plume was predicted to exceed the nitrate maximum contaminant level (MCL) of $10 \mathrm{mg} / \mathrm{L}$ before 1980 at the Well M17S monitoring location inside the SDA fence, and to approach $10 \mathrm{mg} / \mathrm{L}$ by 2005 at the Well USGS-119 monitoring location. Neither location has ever produced monitoring results that are noticeably different from the regional background concentration of $1 \mathrm{mg} / \mathrm{L}$. The unsubstantiated plume results in future elevated aquifer nitrate concentrations for the feasibility study remedial alternatives that exceed the nitrate MCL of $10 \mathrm{mg} / \mathrm{L}$ (see results in Section D-4). These elevated current and future nitrate concentrations are not credible because they are based on simulated release from the source that has not occurred at predicted levels.

A consequence of the overpredicted nitrate concentrations for the feasibility study is that the model shows a significant mass of nitrate released into the vadose zone that would be beyond the influence of remedial action. In reality, most of this mass is probably still in the buried waste, and a remedial action that limits infiltration would effectively reduce transport to the vadose zone and aquifer and would prevent groundwater concentrations that exceed the nitrate MCL. 


\section{D-3.6.1.2 Modeling of Volatile Organic Compounds}

D-3.6.1.2.1 Remediation Goals-Each feasibility study alternative includes OCVZ system operations for VOCs (Group 11 contaminants). In model simulations, the OCVZ system operates until preliminary remediation goals for carbon tetrachloride in the vadose zone are achieved. Remediation goals for carbon tetrachloride were defined by OU 7-08 (INL 2005) in terms of vapor concentrations for three vertical zones in the vadose zone within the influence of the current OCVZ system. These three vertical zones are labeled A1, A2, and A3 in Figure D-27. The oval-shaped Region A in Figure D-27 is represented in the model by the darker shaded area. Zones A1, A2, and A3 are separated vertically by the B-C and C-D interbeds. Though OU 7-08 remediation goals also were defined for larger zones (i.e., B1, B2, and B3), those larger zones were not considered because they extend outside the influence of the current OCVZ system and are not identified as preliminary remediation goals for OU 7-13/14. Operable Unit 7-08 also developed a second set of remediation goals for each region that were less as a result of using more restrictive assumptions, and those were not used for the feasibility study simulations.

Though each alternative was simulated until remediation goals were achieved in Zones A1, A2, and A3, only remediation goals for Zones A1 and A2 have been adopted by OU 7-13/14 as preliminary remediation goals. Operable Unit 7-13/14 excluded Zone A3 for two reasons: (1) the model overpredicts vapor concentrations in Zone A3 compared to measured data, and (2) the OCVZ project (OU 7-08) has not evaluated the practicability and effectiveness of deep extraction (below C-D interbed). Nevertheless, estimated operation times to achieve remediation goals in all three zones are used for evaluating the alternatives.

From year 2010, when feasibility study remediation alternatives (e.g., surface barriers and retrieval actions) are implemented in the model, OCVZ system operations were simulated in 5-year increments until carbon tetrachloride remediation goals were achieved in Zones A1, A2, and A3. To check against remediation goals, model concentrations from each gridblock within the zone of interest were averaged and compared to the goal. In all cases, modeled concentrations rebounded after the OCVZ system was shut down, primarily due to continued source releases. Therefore, the peak rebound concentration also was considered when comparing against remediation goals. Figures D-28 through D-31 show average carbon tetrachloride vapor concentrations in each zone compared with remediation goals for each alternative. Table D-5 contains the OCVZ system operating times required to achieve remediation goals.

As might be expected, Alternative 5 (Full RTD) requires the least amount of operating time for the OCVZ system to achieve remediation goals. In this alternative, Zones A1 and A2 are cleaned up relatively rapidly, while Zone A3 requires a substantially longer operating time. To increase effectiveness, more extraction capability could be used for the deeper zones so that cleanup in all three zones would occur simultaneously. Alternative 2a (Modified RCRA Type C Surface Barrier) requires the longest amount of time to achieve preliminary remediation goals. This alternative requires more time because the surface barrier does not allow VOCs to escape to the atmosphere. Near-surface extraction wells would effectively capture future source releases, but would not completely offset the vapor-trapping effect of the asphalt layer because the extraction wells would affect a smaller area than would be covered by the barrier. The barrier also would cause a higher rebound concentration after the system is shut down. Another reason more time would be required is that flow used to operate the near-surface extraction wells would be taken from the total OCVZ system flow. Thus, the vadose zone would not be cleaned up as quickly as for other alternatives that apply the entire OCVZ system flow to the vadose zone. 


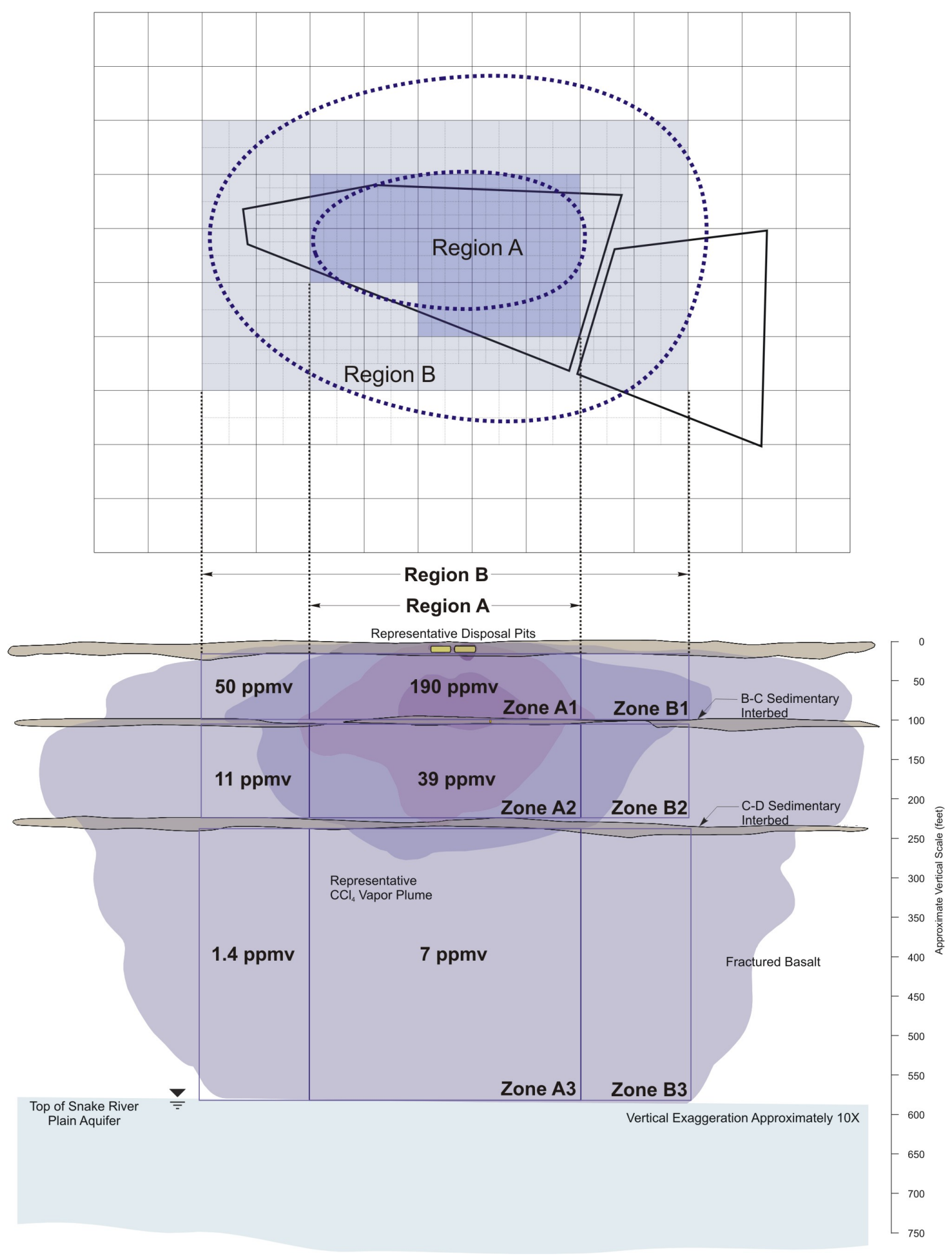

Figure D-27. Horizontal view of vadose zone model grid and cross section of remediation goal zones. Remediation goals are shown in parts-per-million vapor concentrations for carbon tetrachloride. 

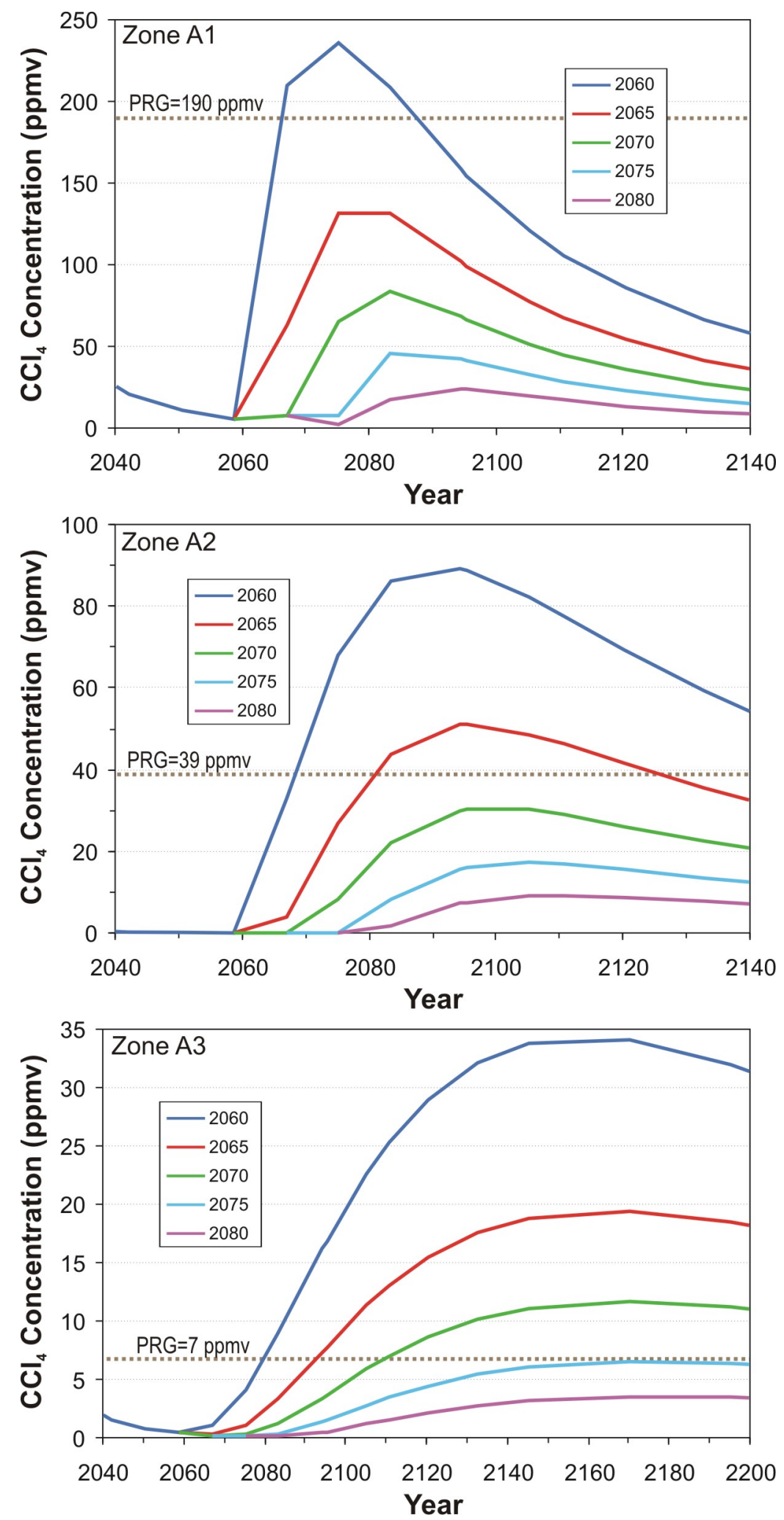

Figure D-28. Simulated average carbon tetrachloride vapor concentrations in Zones A1, A2, and A3 compared to remediation goals for Alternative 2a-Modified RCRA Type C Surface Barrier. The legend indicates the year vapor vacuum extraction with treatment operations cease. 

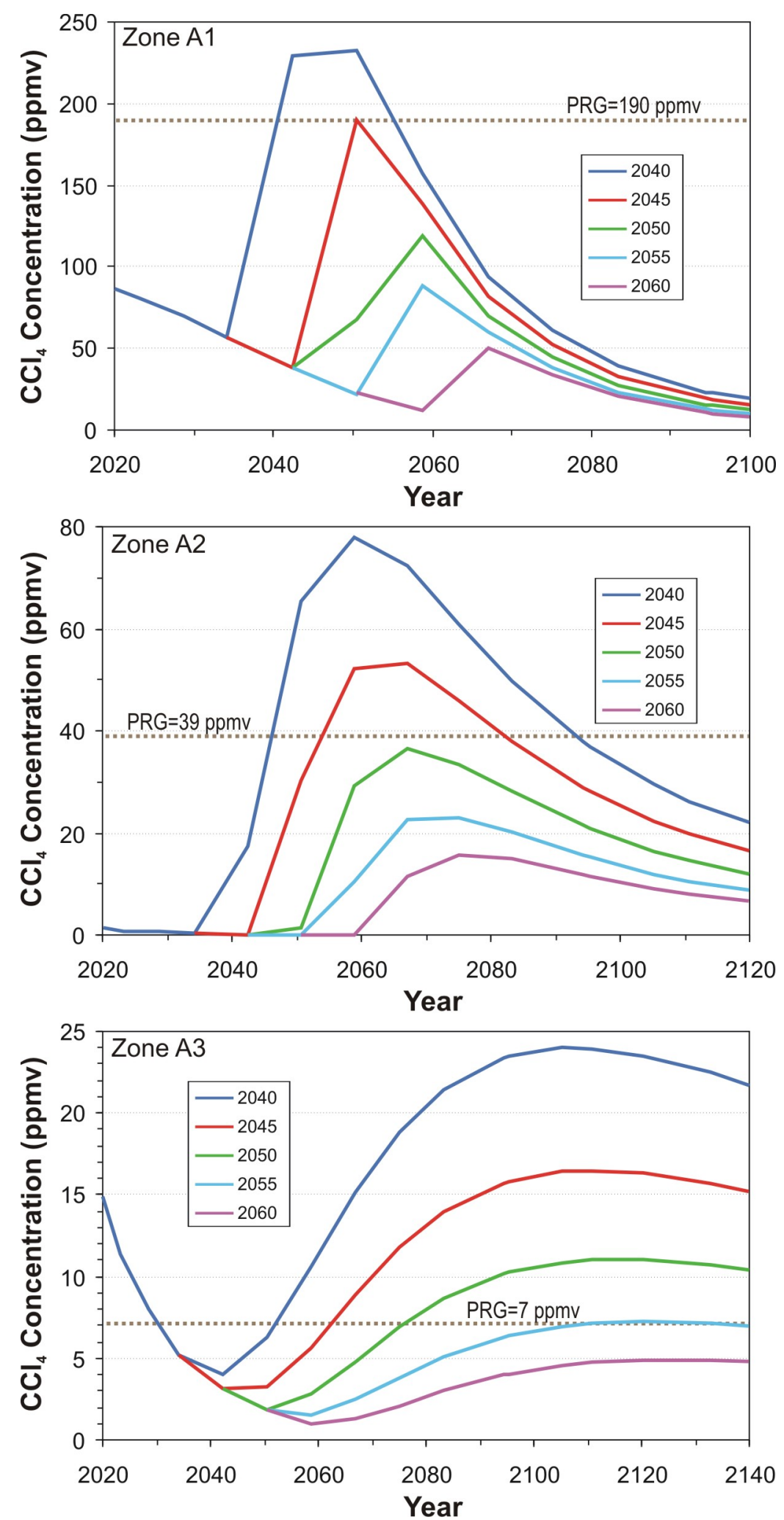

Figure D-29. Simulated average carbon tetrachloride vapor concentrations in Zones A1, A2, and A3 compared to remediation goals for Alternative $2 b-$ Evapotranspiration Surface Barrier. The legend indicates the year vapor vacuum extraction with treatment operations cease. 

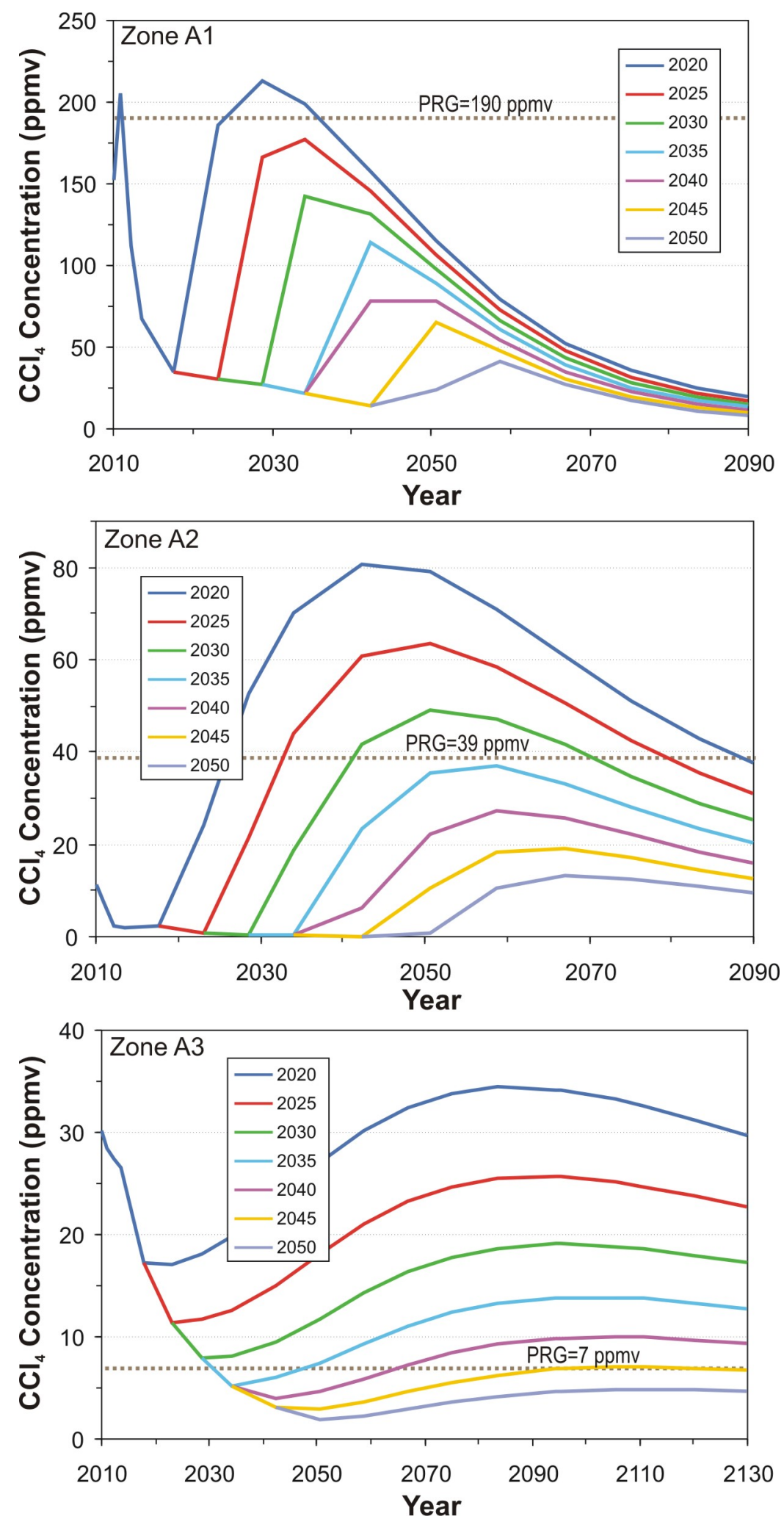

Figure D-30. Simulated average carbon tetrachloride vapor concentrations in Zones A1, A2, and A3 compared to remediation goals for Alternative 4-Partial Retrieval, Treatment, and Disposal. The legend indicates the year vapor vacuum extraction with treatment operations cease. 

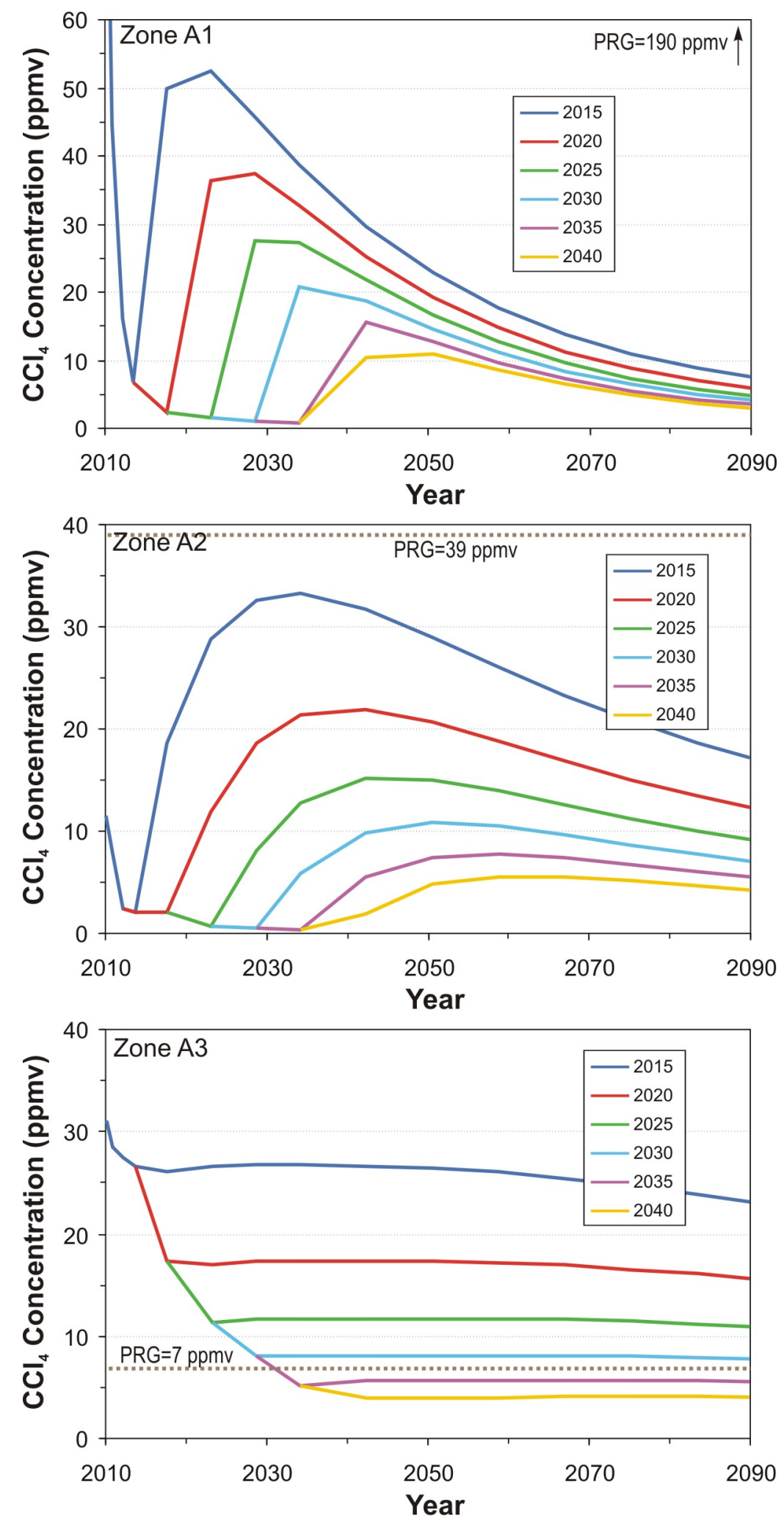

Figure D-31. Simulated average carbon tetrachloride vapor concentrations in Zones A1, A2, and A3 compared to remediation goals for Alternative 5-Full Retrieval, Treatment, and Disposal. The legend indicates the year vapor vacuum extraction with treatment operations cease. 
Table D-5. Summary of simulated Organic Contamination in the Vadose Zone system operation times for feasibility study alternatives.

\begin{tabular}{|c|c|c|c|c|}
\hline & \multirow[b]{2}{*}{ Feasibility Study Alternative } & \multicolumn{3}{|c|}{$\begin{array}{l}\text { Operations Required to this Year } \\
\text { to Achieve Remediation Goals }\end{array}$} \\
\hline & & Zone A1 & Zone A2 & Zone A3 \\
\hline $2 \mathrm{a}$ & Modified RCRA Type C Surface Barrier & 2065 & 2070 & 2075 \\
\hline $2 b$ & ET Surface Barrier & 2045 & 2050 & 2055 \\
\hline 3 & $\mathrm{ISG}^{\mathrm{a}}$ & 2045 & 2050 & 2055 \\
\hline 4 & Partial RTD & 2025 & 2035 & 2045 \\
\hline 5 & Full RTD & 2015 & 2015 & 2035 \\
\hline \multicolumn{5}{|c|}{$\begin{array}{l}\text { a. Alternative } 3 \text { - ISG was not simulated for VOCs because results are the same as for Alternative } 2 \mathrm{~b} \text {. Grouting would no } \\
\text { affect waste that contains VOCs. }\end{array}$} \\
\hline \multicolumn{2}{|r|}{$\begin{array}{l}\text { ET = evapotranspiration } \\
\text { ISG = in situ grouting } \\
\text { RCRA = Resource Conservation and Recovery Act }\end{array}$} & \multicolumn{3}{|c|}{$\begin{array}{l}\mathrm{RTD}=\text { retrieval, treatment }, \text { and disposal } \\
\mathrm{VOC}=\text { volatile organic compound }\end{array}$} \\
\hline
\end{tabular}

\section{D-3.6.1.2.2 Predicted Groundwater Concentrations and Maximum Contaminant}

Levels-Operating the OCVZ system significantly impacts predicted aquifer concentrations.

Figure D-32 shows the predicted maximum carbon tetrachloride concentration in the aquifer outside the SDA boundary for Alternative 1 (No Action) and each feasibility study alternative. Although, according to the model, each feasibility study alternative achieves vadose zone remediation goals for carbon tetrachloride before the end of ICs (i.e., year 2110), maximum carbon tetrachloride concentrations in the aquifer are greater than the MCL of $5 \mu \mathrm{g} / \mathrm{L}$ in year 2110. Figure D-33 shows the same results on a different scale and shows that carbon tetrachloride MCLs are not achieved outside the SDA fence until approximately year 2550 .

Figure D-34 shows the predicted maximum aquifer concentrations for the other four VOCs for the same set of feasibility study simulations. The results show methylene chloride concentrations slightly exceed the MCL $(5 \mu \mathrm{g} / \mathrm{L})$ for each alternative, and trichloroethylene concentrations slightly exceed the MCL ( $5 \mu \mathrm{g} / \mathrm{L})$ for Alternative 4 (Partial RTD) and Alternative 5 (Full RTD). The predicted maximum tetrachloroethylene concentrations are less than the MCL $(5 \mu \mathrm{g} / \mathrm{L})$ for all alternatives. Although no MCL is defined for 1,4-dioxane, predicted concentrations beyond year 2110 are significantly greater than the health-based advisory level for drinking water (i.e., $3 \mu \mathrm{g} / \mathrm{L}$ ). Table D-6 summarizes maximum aquifer concentration results. 


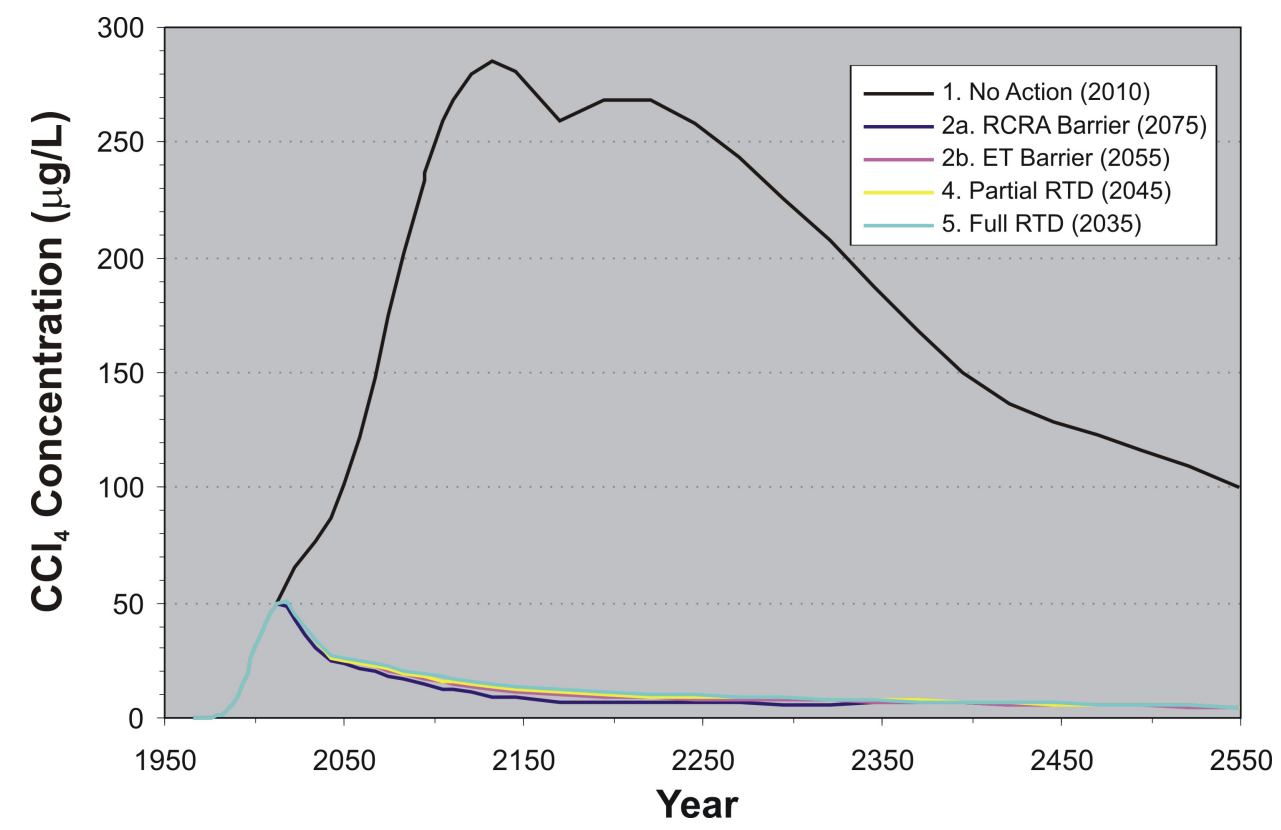

Figure D-32. Maximum predicted carbon tetrachloride concentrations in the aquifer outside the Subsurface Disposal Area for feasibility study alternatives. The legend indicates the year vapor vacuum extraction with treatment operations cease because vadose zone remediation goals are achieved.

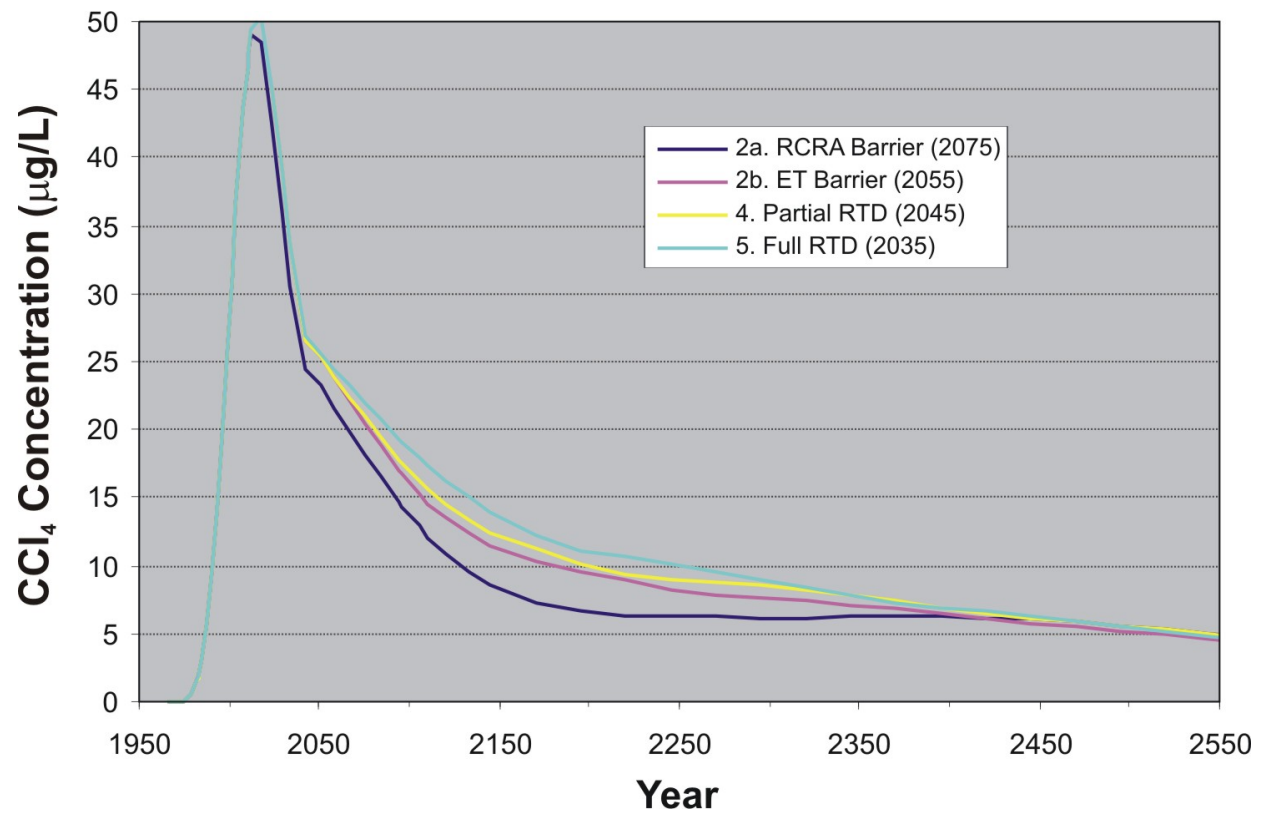

Figure D-33. Maximum predicted carbon tetrachloride concentrations in the aquifer outside the Subsurface Disposal Area. The legend indicates the year vapor vacuum extraction with treatment operations cease because vadose zone remediation goals are achieved. 

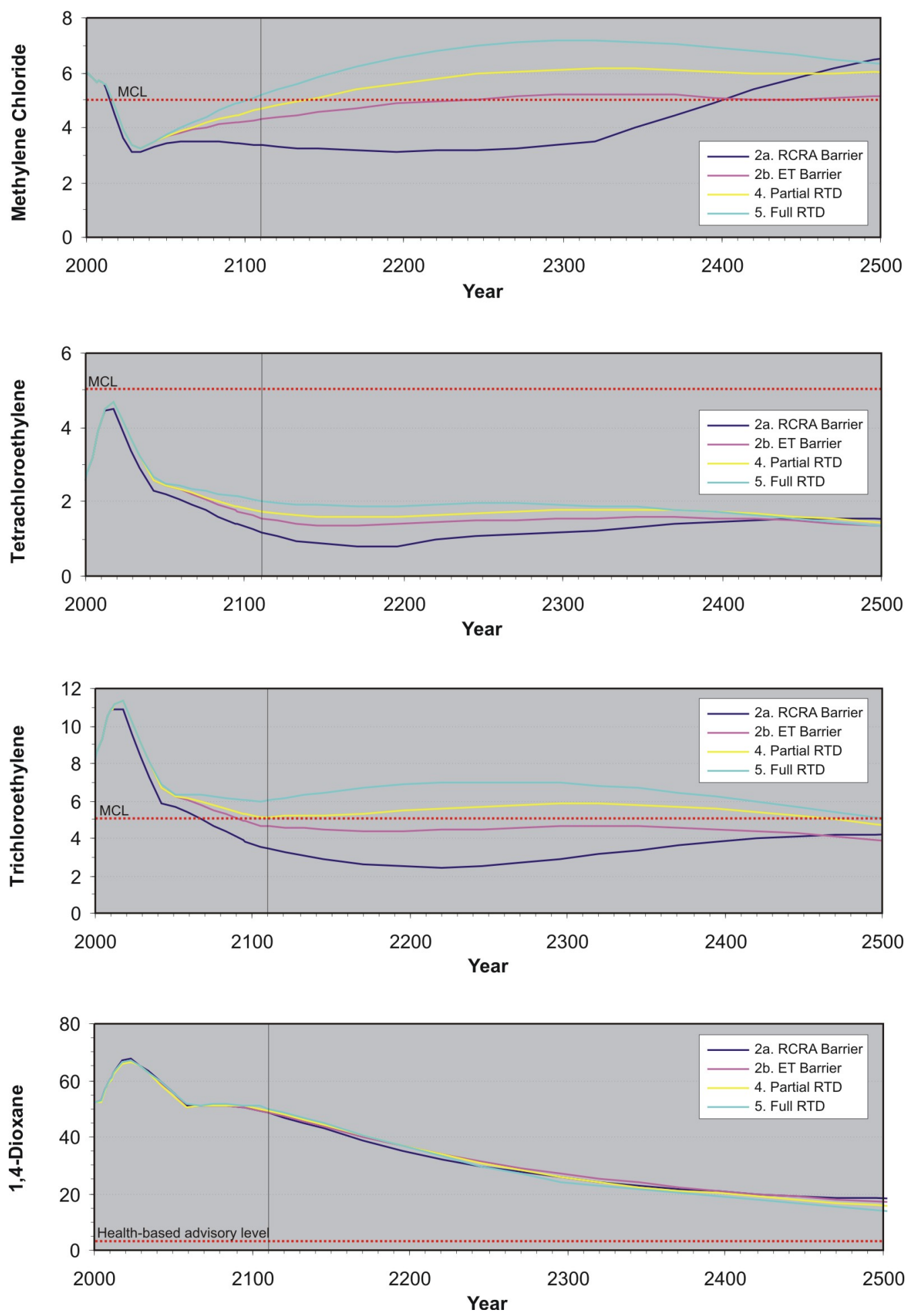

Figure D-34. Predicted maximum concentrations in the aquifer $(\mu \mathrm{g} / \mathrm{L})$ outside the Subsurface Disposal Area for volatile organic compounds other than carbon tetrachloride. 
Table D-6. Predicted maximum concentrations outside the Subsurface Disposal Area for volatile organic compounds (Group 11 contaminants) and feasibility study alternatives.

\begin{tabular}{|c|c|c|c|c|c|c|}
\hline & & \multicolumn{5}{|c|}{$\begin{array}{l}\text { Predicted Maximum Aquifer Concentration beyond Year } 2110 \\
(\mu \mathrm{g} / \mathrm{L})\end{array}$} \\
\hline \multicolumn{2}{|c|}{ Feasibility Study Alternative } & $\begin{array}{c}\text { Carbon } \\
\text { Tetrachloride }\end{array}$ & $\begin{array}{l}\text { Methylene } \\
\text { Chloride }\end{array}$ & $\begin{array}{l}\text { Tetrachloro } \\
\text {-ethylene }\end{array}$ & $\begin{array}{l}\text { Trichloro- } \\
\text { ethylene }\end{array}$ & 1,4-Dioxane \\
\hline $2 \mathrm{a}$ & $\begin{array}{l}\text { Modified RCRA } \\
\text { Type C Surface Barrier }\end{array}$ & 12 & 7.5 & 1.6 & 4.2 & 48 \\
\hline $2 b$ & ET Surface Barrier & 15 & 5.2 & 1.6 & 4.7 & 49 \\
\hline 3 & $\mathrm{ISG}^{\mathrm{a}}$ & 15 & 5.2 & 1.6 & 4.7 & 49 \\
\hline 4 & Partial RTD & 16 & 6.1 & 1.8 & 5.8 & 50 \\
\hline 5 & Full RTD & 17 & 7.2 & 2.0 & 7.0 & 50 \\
\hline
\end{tabular}

a. Alternative 3-ISG was not simulated for VOCs, but the results are the same as Alternative $2 \mathrm{~b}$ because grouting does not affect the VOC source.

$\mathrm{ET}=$ evapotranspiration
$\mathrm{ISG}=$ in situ grouting
$\mathrm{MCL}=$ maximum contaminant level
RCRA $=$ Resource Conservation and Recovery Act

$\mathrm{RTD}=$ retrieval, treatment, and disposal

$\mathrm{VOC}=$ volatile organic compound

Predicted maximum concentration exceeds the MCL. The MCL for each contaminant is $5 \mu \mathrm{g} / \mathrm{L}$, except for 1,4-dioxane. A health-based advisory level for drinking water of $3 \mu \mathrm{g} / \mathrm{L}$ is used for 1,4-dioxane.

It is unusual that methylene chloride and 1,4-dioxane exceed their respective MCLs given that they have the lowest inventory of the VOCs (Group 11 contaminants). The primary reason they do not meet MCLs is their high solubility and corresponding low Henry's constant. A low Henry's constant means the contaminants have an affinity for the aqueous phase and travel primarily downward with the infiltrating water. As a result, less vapor phase is available to diffuse, escape to the atmosphere, or be captured by the OCVZ system. Trichloroethylene has a slightly higher Henry's constant than 1,4-dioxane, which is why it meets MCLs for some alternatives and not for others. Another reason methylene chloride does not meet MCLs is that it comes from a different waste stream. The other VOCs primarily come from Series 743 sludge, which is buried in Pits 4, 5, 6, 9 and 10. A significant portion of the methylene chloride was buried in other pits (e.g., Pits 1, 2 and 3) and is not impacted as much by the OCVZ system, which has extraction wells near Series 743 sludge disposal locations.

Additional simulations were performed to determine whether extended operation of the OCVZ system would achieve MCLs by year 2110. In the simulations, OCVZ system operation was extended in 10 -year increments beyond the time required to achieve vadose zone remediation goals until year 2110. Figures D-35 through D-38 show the impact of extended operations on maximum predicted concentrations of carbon tetrachloride in the aquifer outside the SDA boundary. Although extending OCVZ system operations an additional 10 to 20 years reduces aquifer concentrations slightly, none of the alternatives achieves MCLs by the year 2110. Continued operations beyond the additional 10 to 20 years achieves no further reduction. This failure to reduce aquifer concentrations occurs because the vadose zone is relatively clean by this time, and all that remains is residual contamination that previously entered the aquifer and is caught in the low-permeability zone. The low-permeability zone reduces dilution that would otherwise occur. Section D-3.6.1.2.3.1 shows the impact of not including the low-permeability zone in the simulations. 


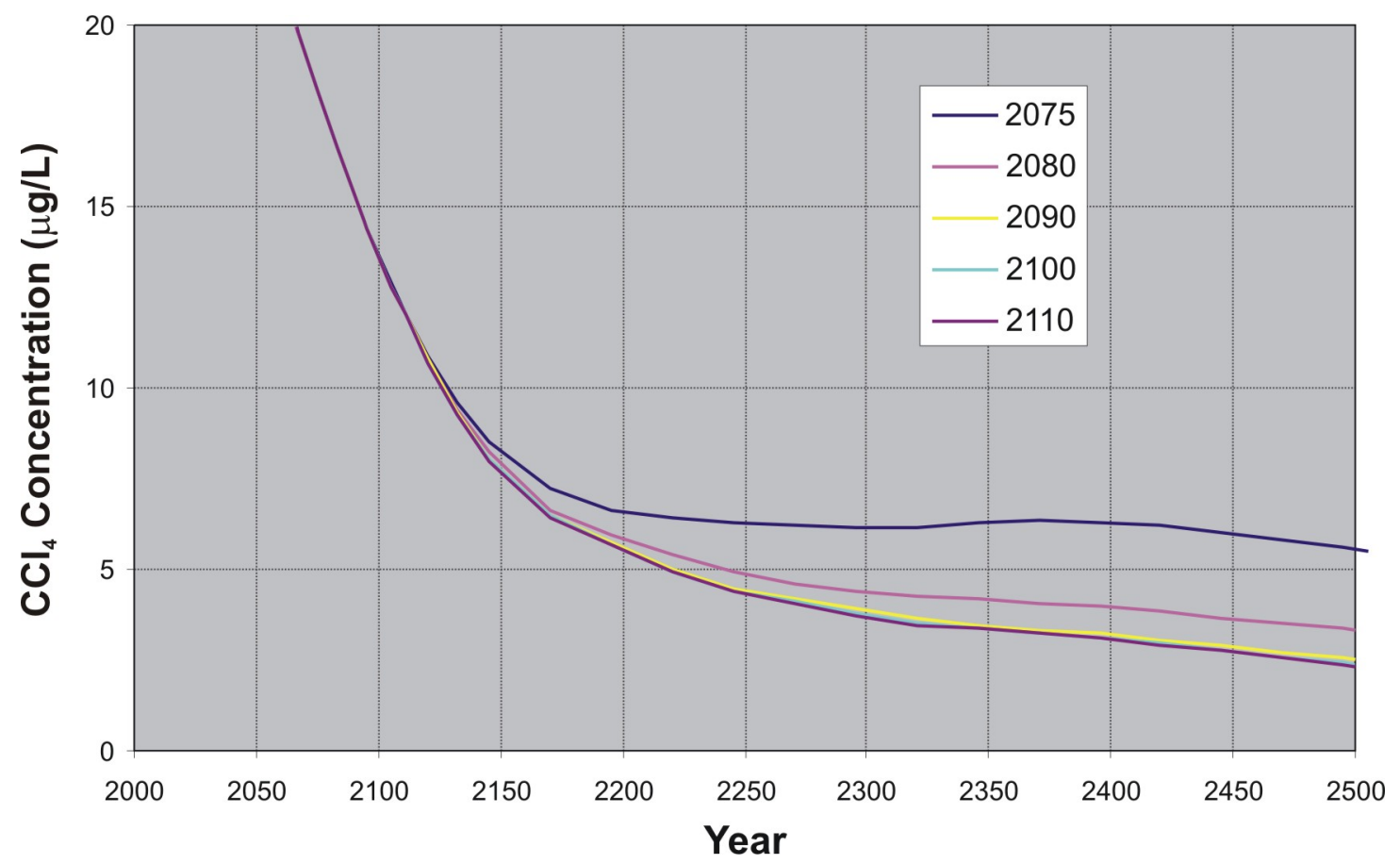

Figure D-35. Impact of extended vapor vacuum extraction with treatment operations on maximum predicted carbon tetrachloride concentrations in the aquifer outside the Subsurface Disposal Area for Alternative 2a-Modified RCRA Type C Surface Barrier. The legend indicates the year vapor vacuum extraction with treatment operations cease.

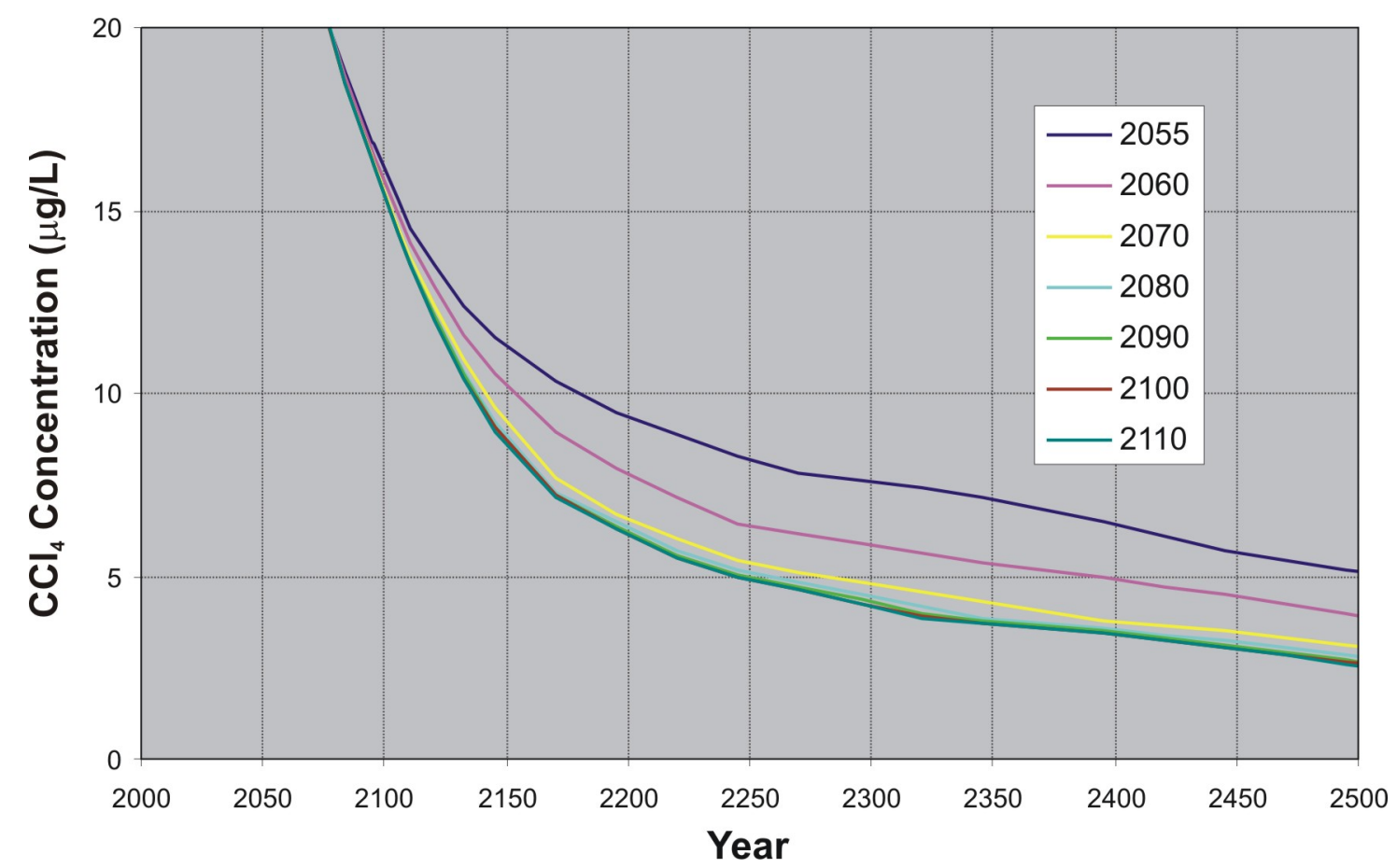

Figure D-36. Impact of extended vapor vacuum extraction with treatment operations on maximum predicted carbon tetrachloride concentrations in the aquifer outside the Subsurface Disposal Area for Alternative $2 b-$ Evapotranspiration Surface Barrier. The legend indicates the year vapor vacuum extraction with treatment operations cease. 


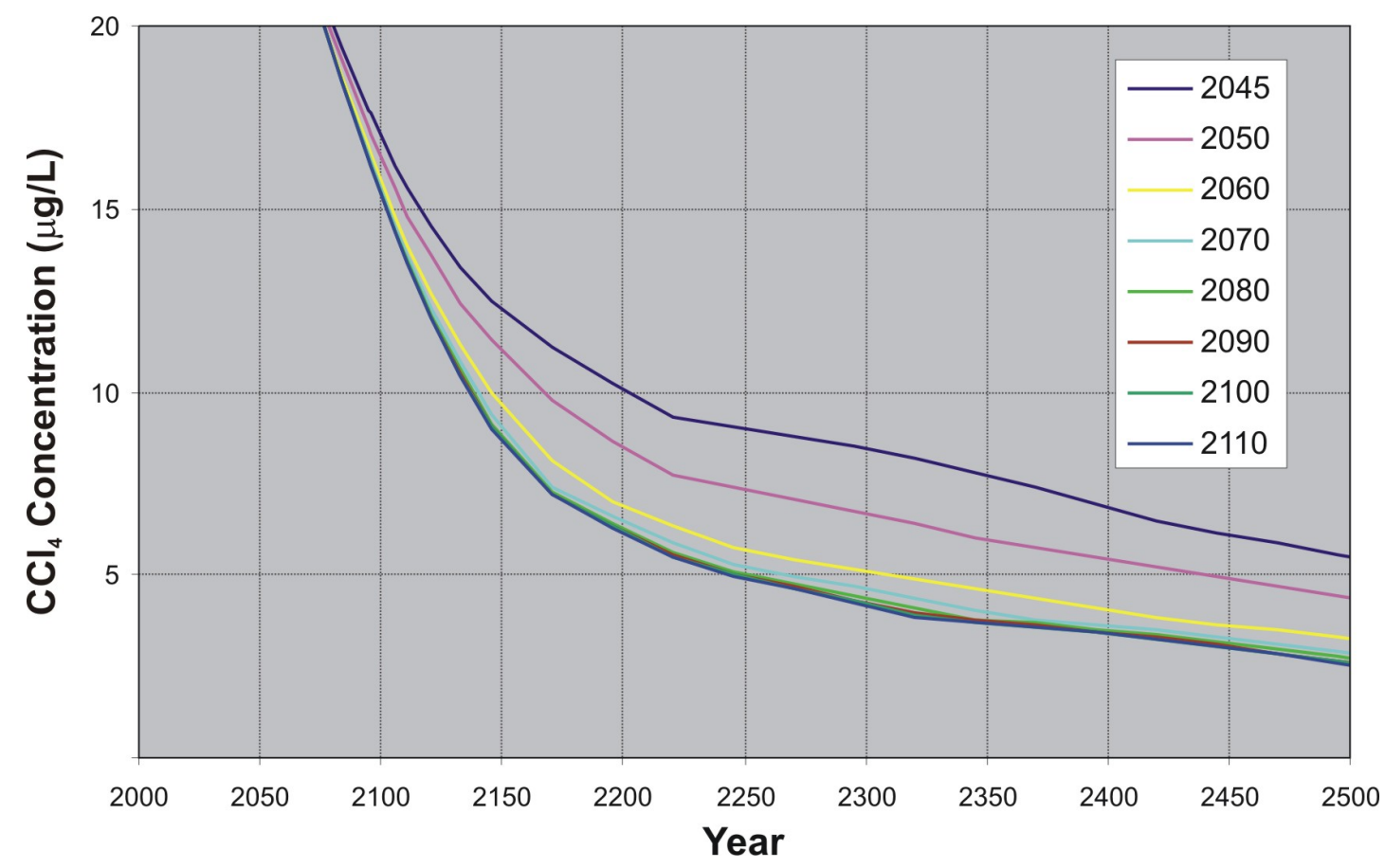

Figure D-37. Impact of extended vapor vacuum extraction with treatment operations on maximum predicted carbon tetrachloride concentrations in the aquifer outside the Subsurface Disposal Area for Alternative 4-Partial Retrieval, Treatment, and Disposal. The legend indicates the year vapor vacuum extraction with treatment operations cease.

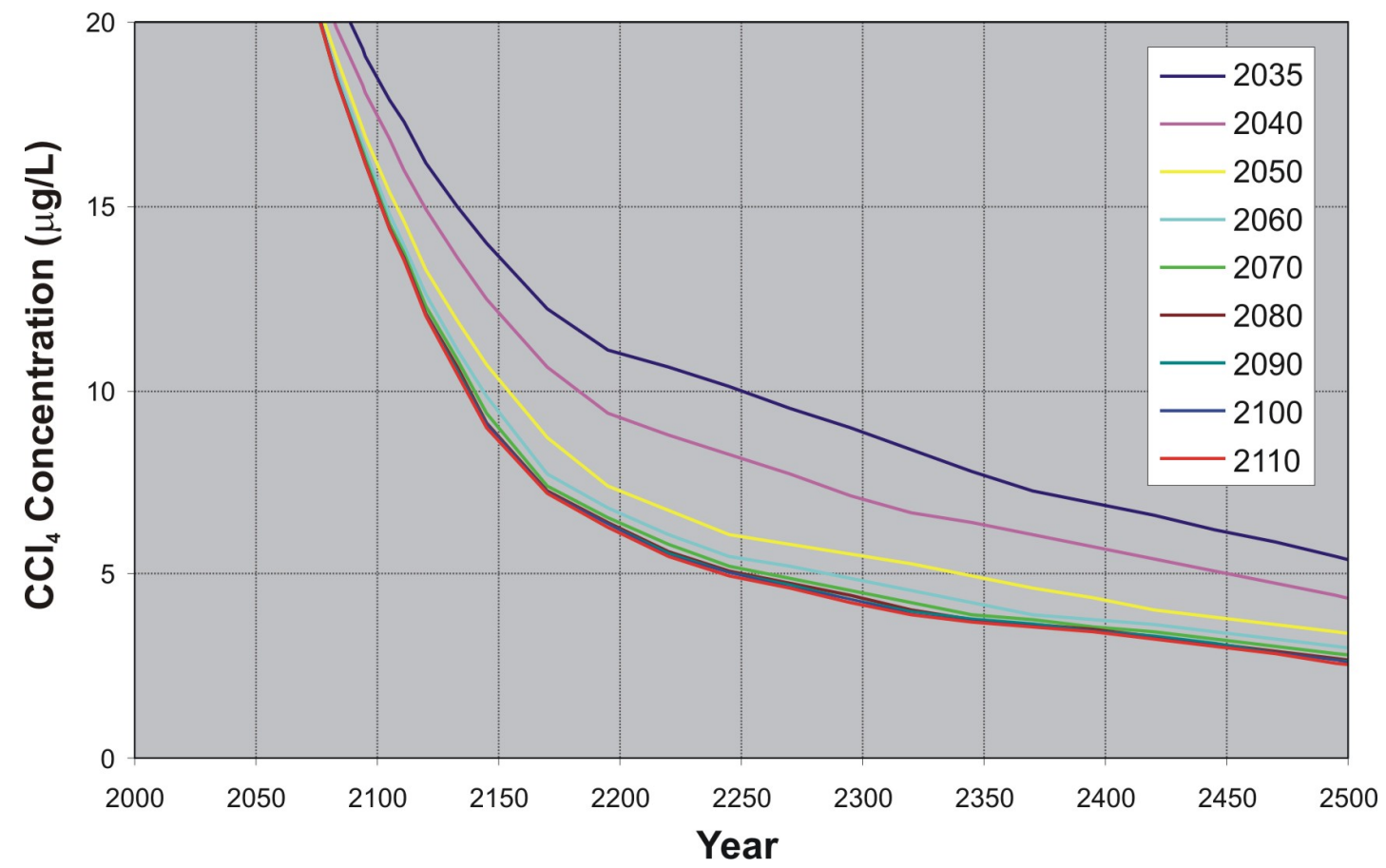

Figure D-38. Impact of extended vapor vacuum extraction with treatment operations on maximum predicted carbon tetrachloride concentrations in the aquifer outside the Subsurface Disposal Area for Alternative 5-Full Retrieval, Treatment, and Disposal. The legend indicates the year vapor vacuum extraction with treatment operations cease. 
Figure D-39 shows the predicted maximum aquifer concentrations for each VOC (Group 11 contaminants) if OCVZ system operation is extended to the year 2110. However, as discussed previously, the results would be the same if operations were extended another 10 to 20 years beyond the time to achieve remediation goals. Because simulations for Alternatives 2b (ET Surface Barrier), 4 (Partial RTD), and 5 (Full RTD) are similar in terms of OCVZ system operations, they appear as the same line on the graphs. In other words, the OCVZ system will have operated so long that the VOCs will have been cleaned or removed from the vadose zone regardless of any previous removal actions. The results show extending operation of the OCVZ system to the year 2110 reduces maximum predicted concentrations after the year 2110 to less than MCLs for methylene chloride and trichloroethylene for each alternative. Tetrachloroethylene was already less than the MCL for each alternative, and the concentrations are even less in this case. Carbon tetrachloride and 1,4-dioxane still exceed the MCL after 2110.

\section{D-3.6.1.2.3 Vadose Zone Remediation Goals versus Maximum Contaminant}

Levels-The primary reason the model meets vadose zone remediation goals for carbon tetrachloride, but does not meet MCLs by year 2110 is that different modeling approaches were used for each. The different approaches and the uncertainty associated with each approach produced similar but different results.

Vadose zone remediation goals for carbon tetrachloride were determined individually for each zone by assigning a uniform carbon tetrachloride vapor concentration to one zone while assigning a zero concentration (i.e., clean region) everywhere outside that zone. The model then was run in a time-forward mode until the maximum concentration in the aquifer outside the SDA was achieved. The limiting vapor concentration for the zone (i.e., remediation goal) then was determined by multiplying the ratio of the MCL to the maximum predicted groundwater concentration for that simulation and the uniform vapor concentration. This can be considered a backward calibration, but only one simulation is necessary because the results are linear and scale accordingly. This procedure was repeated for each zone until a remediation goal for each zone was determined.

The procedure to determine remediation goals differs from the feasibility study modeling in two important ways. First, in the feasibility study modeling, the vadose zone is contaminated outside the remediation goal zone, both vertically and horizontally. Therefore, the cumulative effect on groundwater concentrations based on satisfying vapor phase remediation goals in each zone was not evaluated. For example, when the remediation goal for Zone A2 was established, Zone A1 above, Zone A3 below, and Zones B1, B2, and B3 outside were considered clean (i.e., zero concentration). The feasibility study modeling considers the entire contaminated vadose zone and the total impact on the aquifer. In addition, the feasibility study simulations only achieved remediation goals in Region A and did not consider Region B, which is outside the direct influence of the OCVZ system.

The second important way the modeling approaches differ is how each approach distributes the contamination in the subsurface. The modeling approach to determine remediation goals assumed the zones were contaminated uniformly. This was done primarily for convenience. In feasibility study modeling, the contamination distribution is more conventional and similar to reality in that concentrations are highest below the largest source area (i.e., near the center of the SDA) and decrease exponentially with distance. As a result, most of the mass enters the aquifer near the center of the SDA, rather than more uniformly as with the remediation goal modeling. This results in a similarly uneven contaminant distribution in the aquifer for feasibility study modeling. Figures D-40 through D-43 show simulated carbon tetrachloride concentrations in the aquifer (second gridblock down) for each alternative in years 2010 and 2110. As Figures D-40 through D-43 show, the highest concentrations are in the center of the SDA in year 2010; after 100 years, in year 2110, the maximum concentration is outside the SDA boundary. Though the maximum concentration in year 2110 is still above the MCL of $5 \mu \mathrm{g} / \mathrm{L}$, the 5- $\mu \mathrm{g} / \mathrm{L}$ isopleth is shrinking. This is important if a buffer zone is considered as part of remedial alternatives. 

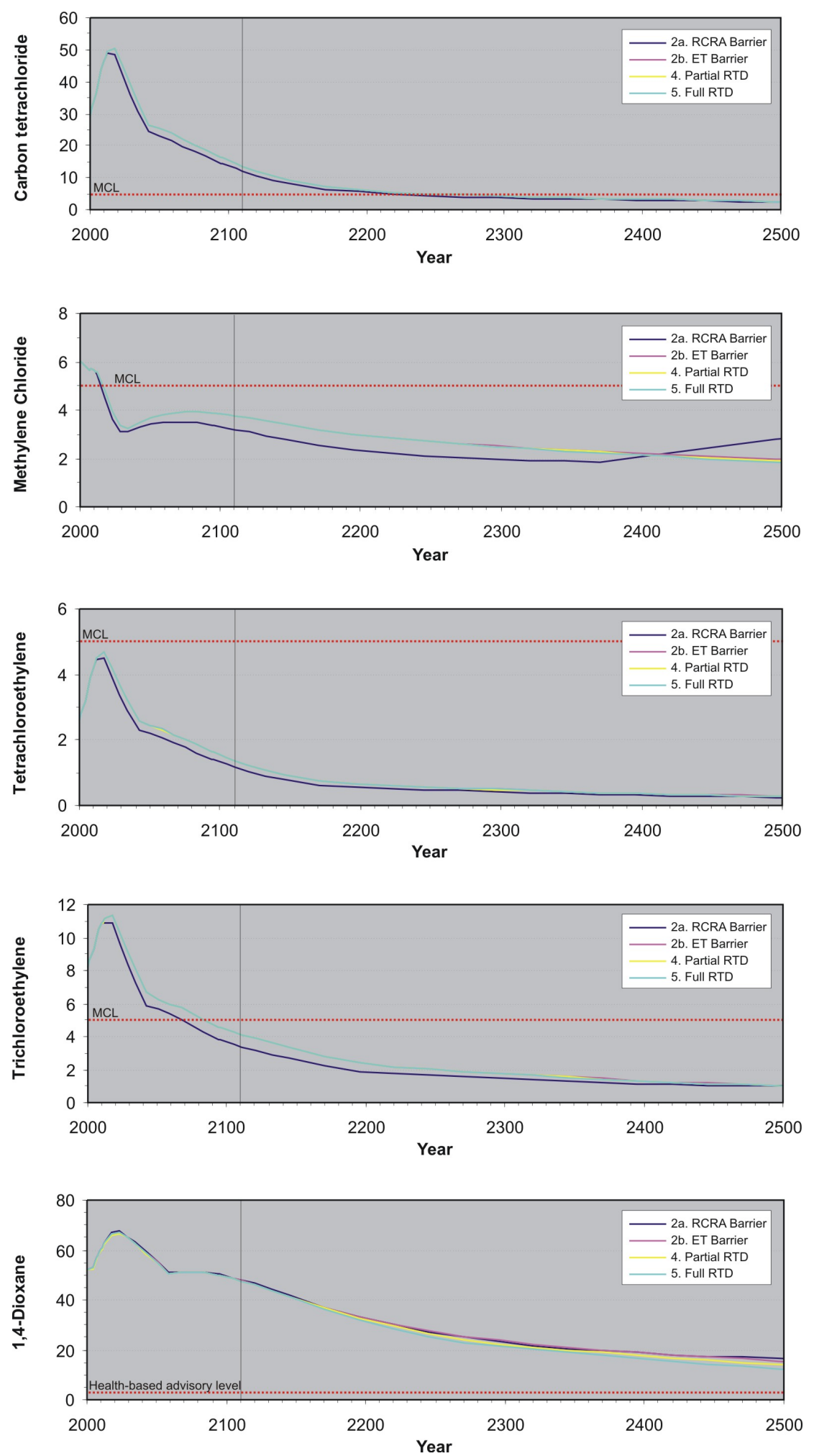

Figure D-39. Predicted maximum concentrations $(\mu \mathrm{g} / \mathrm{L})$ in the aquifer outside the Subsurface Disposal Area for volatile organic compounds (Group 11 contaminants) if operation of the Organic Contamination in the Vadose Zone system were extended to year 2110. 
aFmR_g11.GV1: W3: IZ=1: Year $=2010$

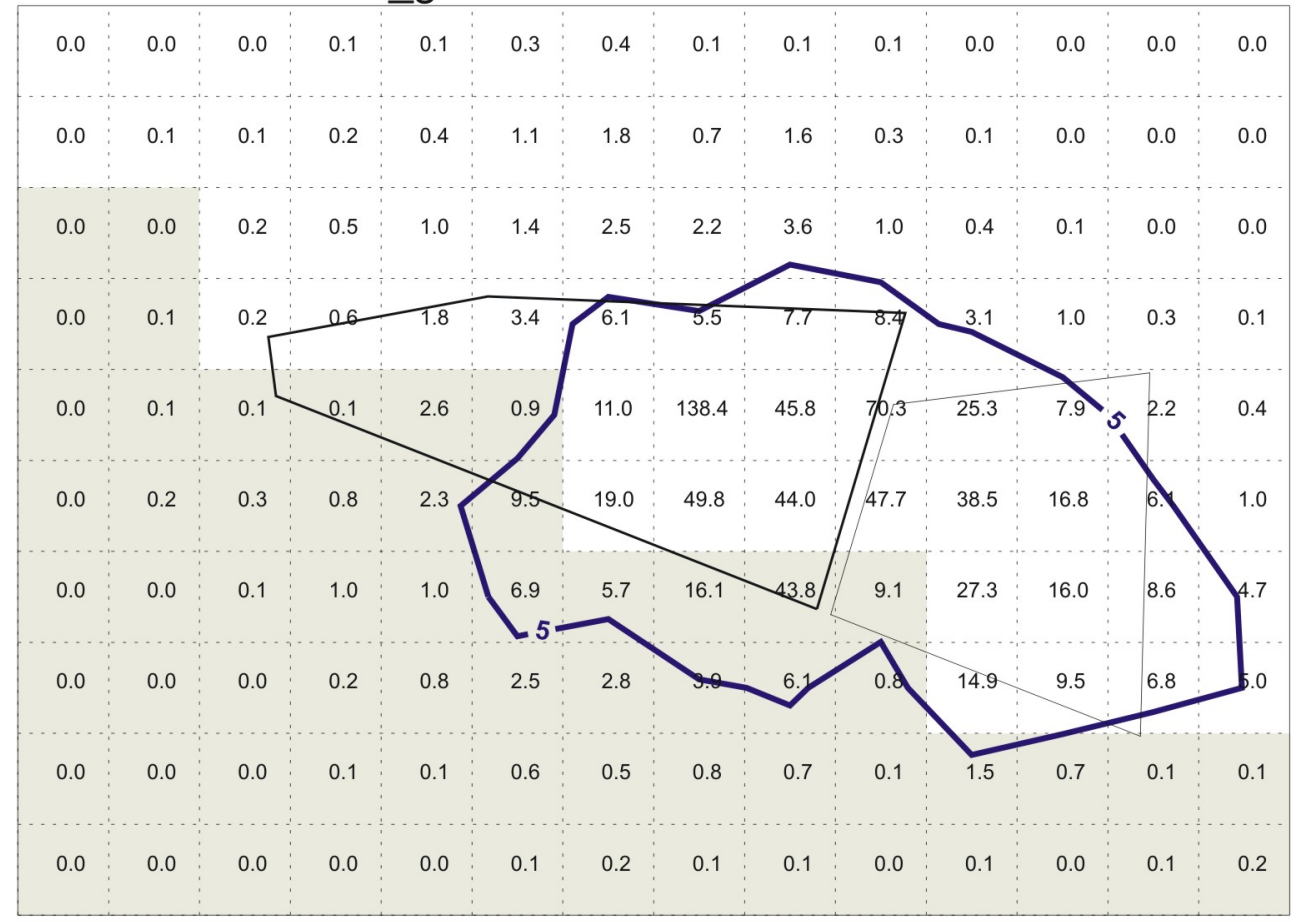

aFmR_g11.GV1: W3: IZ=1: Year $=2110$

\begin{tabular}{|c|c|c|c|c|c|c|c|c|c|c|c|c|c|}
\hline 0.0 & 0.0 & 0.0 & 0.0 & 0.0 & 0.0 & 0.0 & 0.0 & 0.0 & 0.0 & 0.0 & 0.0 & 0.0 & 0.0 \\
\hline 0.1 & 0.1 & 0.1 & 0.0 & 0.0 & 0.0 & 0.0 & 0.0 & 0.0 & 0.0 & 0.0 & 0.0 & 0.0 & 0.0 \\
\hline 0.1 & 0.3 & 0.3 & 0.1 & 0.0 & 0.0 & 0.0 & 0.0 & 0.0 & 0.0 & 0.0 & 0.0 & 0.0 & 0.0 \\
\hline 0.2 & 0.4 & 0.6 & 05 & 0.3 & 0.3 & 0.2 & 0.2 & 0.2 & .4 & 0.1 & 0.0 & 0.0 & 0.0 \\
\hline 0.2 & 0.3 & 0.6 & 0.9 & 2.8 & 2.4 & 0.7 & 2.2 & 0.9 & & 0.4 & 0.2 & 0.1 & 0.0 \\
\hline 0.1 & 0.2 & 0.5 & 1.2 & 3.8 & & & 3.4 & 2.9 & 2.4 & 1.5 & 0.8 & 0.4 & 0.1 \\
\hline 0.1 & 0.2 & 0.4 & 0.6 & 2.7 & & 6.2 & & & & 2.0 & 1.4 & 0.9 & 0.6 \\
\hline 0.0 & 0.1 & 0.2 & 0.5 & 1.1 & 2.6 & & 8.3 & 8.5 & 6.6 & & 3.1 & 1.9 & 1.6 \\
\hline 0.0 & 0.0 & 0.1 & 0.2 & 0.7 & 1.4 & 2.3 & & & & 7.2 & & 1.6 & 0.1 \\
\hline 0.0 & 0.0 & 0.0 & 0.1 & 0.3 & 0.6 & 0.9 & 1.6 & 1.9 & 1.5 & 4.0 & 1.7 & 0.2 & 0.0 \\
\hline
\end{tabular}

Figure D-40. Distribution of carbon tetrachloride $(\mu \mathrm{g} / \mathrm{L})$ in the refined portion of the aquifer model for Alternative 2a-Modified RCRA Type C Surface Barrier, in years 2010 and 2110. The vapor vacuum extraction with treatment system operates until 2075 for this alternative. The shaded area represents the low-permeability aquifer zone in the model. 
aFet_g11.GV1: W3: IZ=1: Year $=2010$

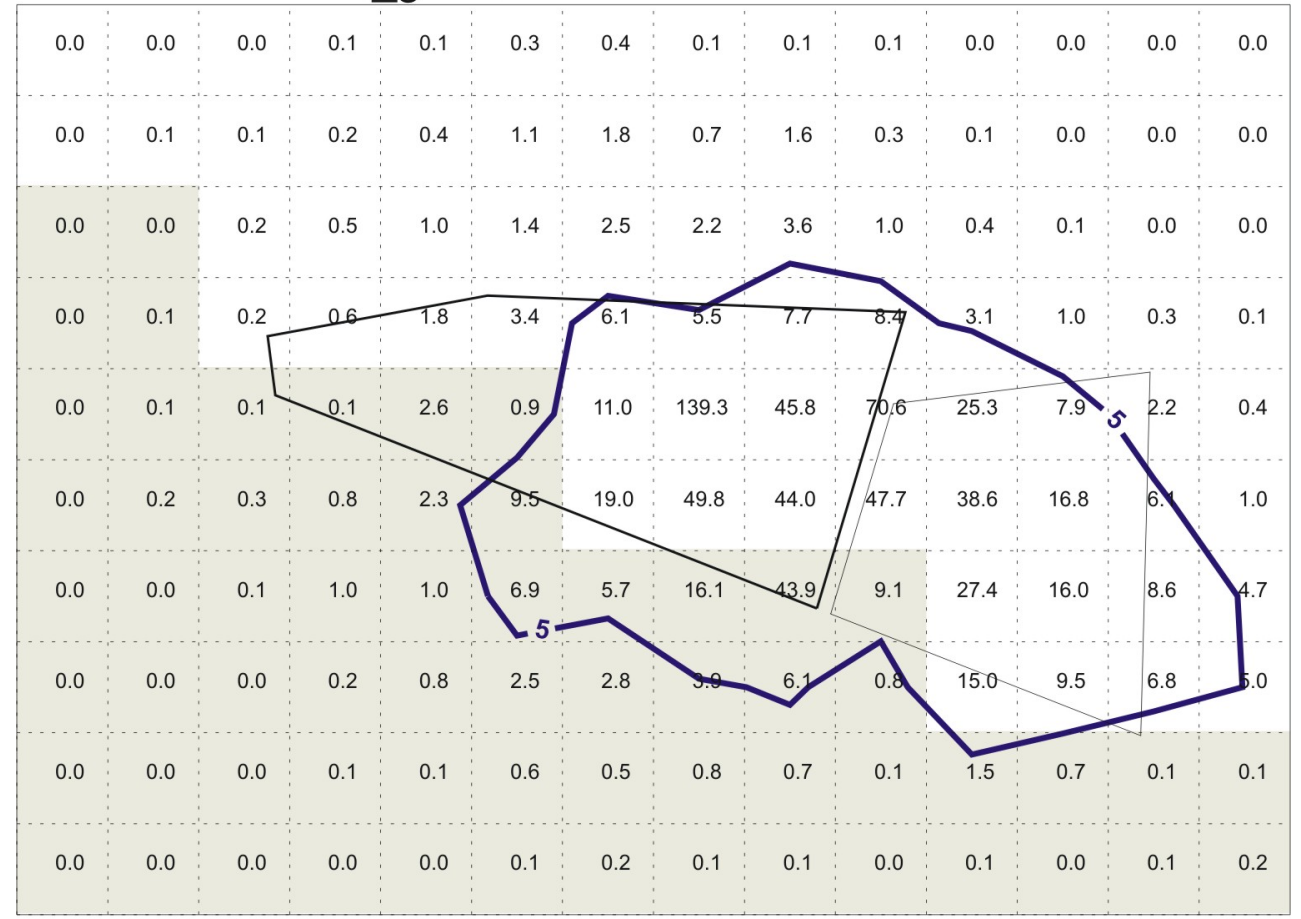

aFet_g11.GV1: W3: IZ= 1: Year $=2110$

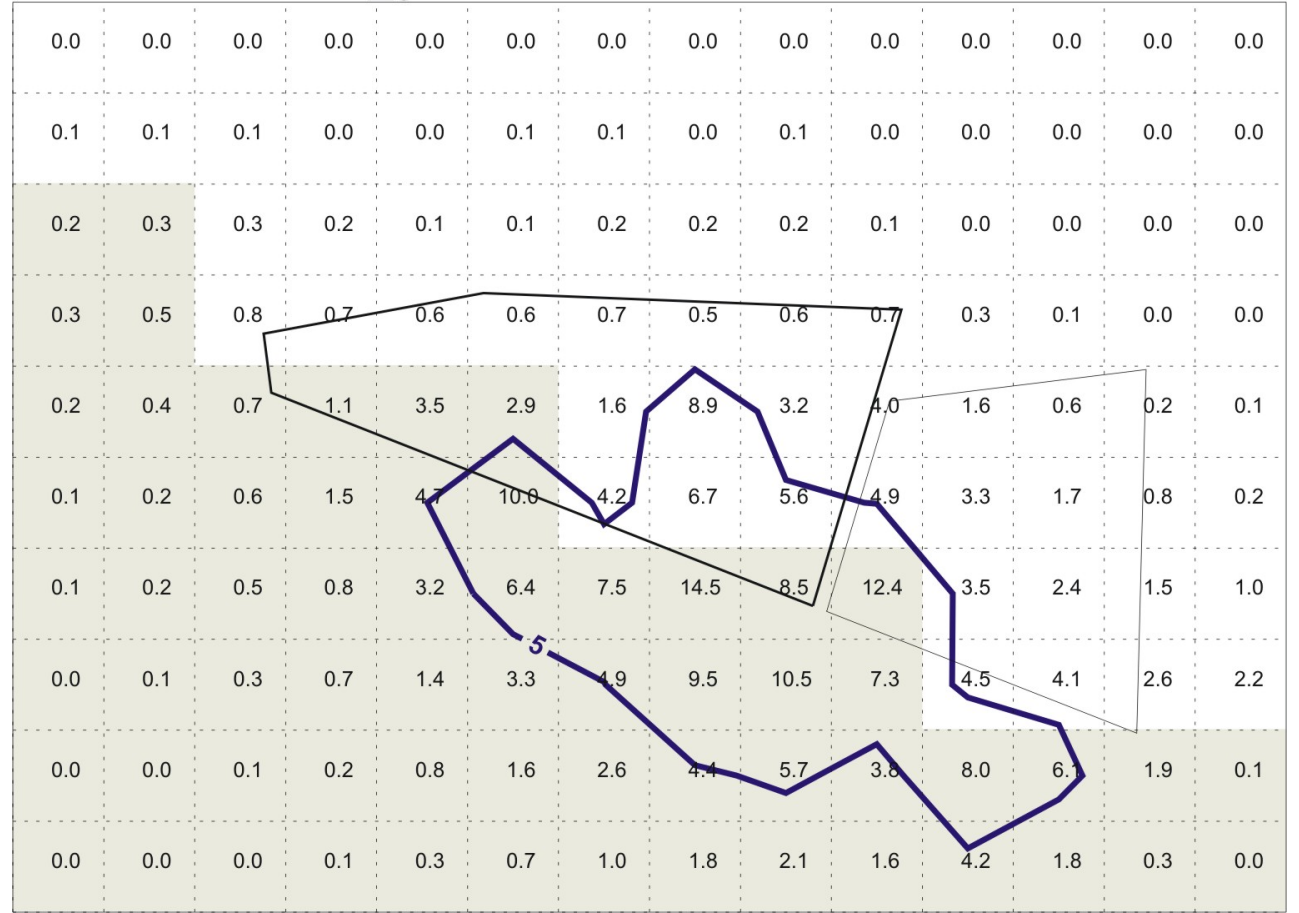

Figure D-41. Distribution of carbon tetrachloride $(\mu \mathrm{g} / \mathrm{L})$ in the refined portion of the aquifer model for Alternative 2b-Evapotranspiration Surface Barrier, in years 2010 and 2110. The vapor vacuum extraction with treatment system operates until year 2055 for this alternative. The shaded area represents the low-permeability aquifer zone in the model. 
aFpr_g11.GV1: W3: IZ=1: Year $=2010$

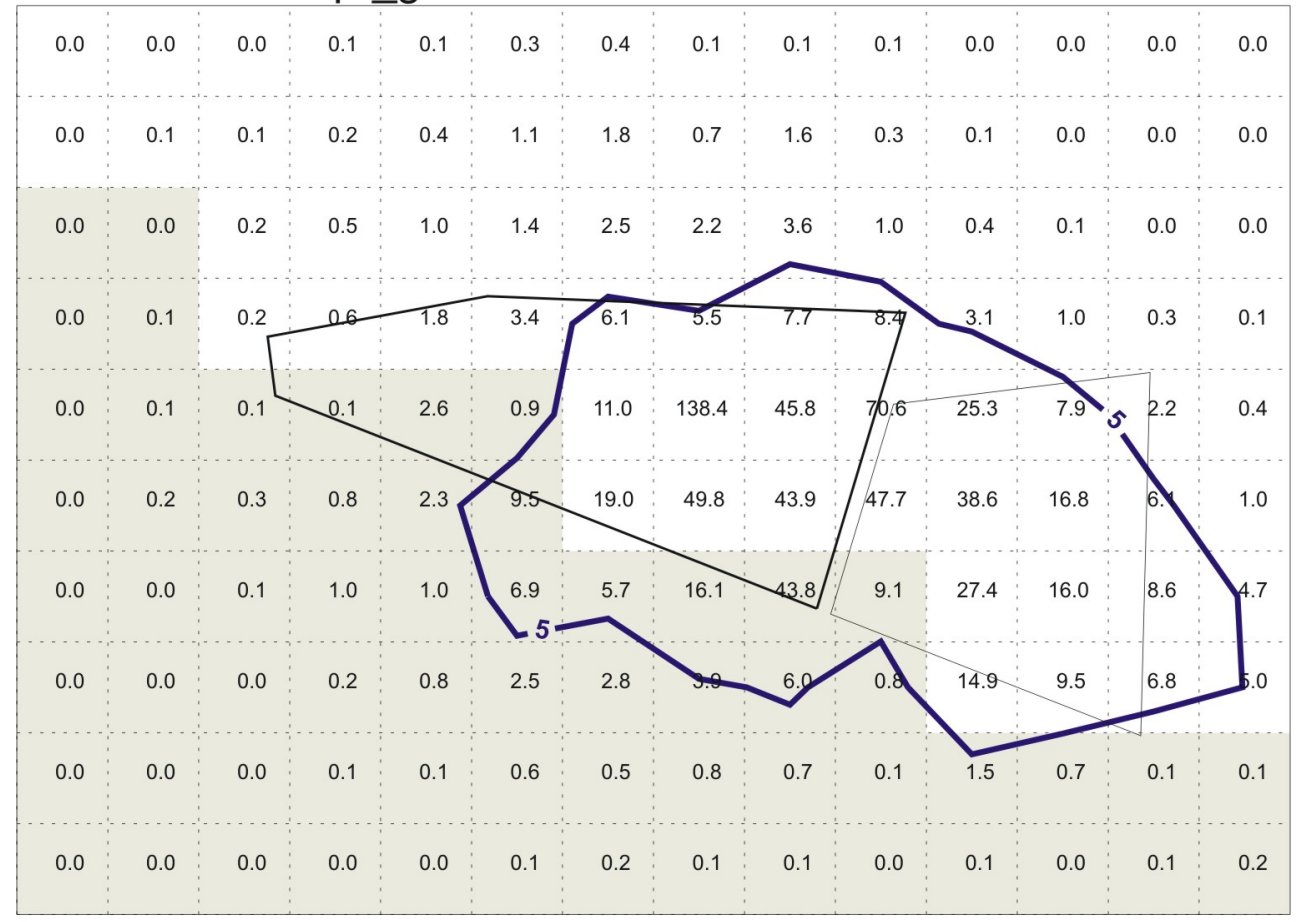

\section{aFpr g11.GV1: W3: IZ=1: Year $=2110$}

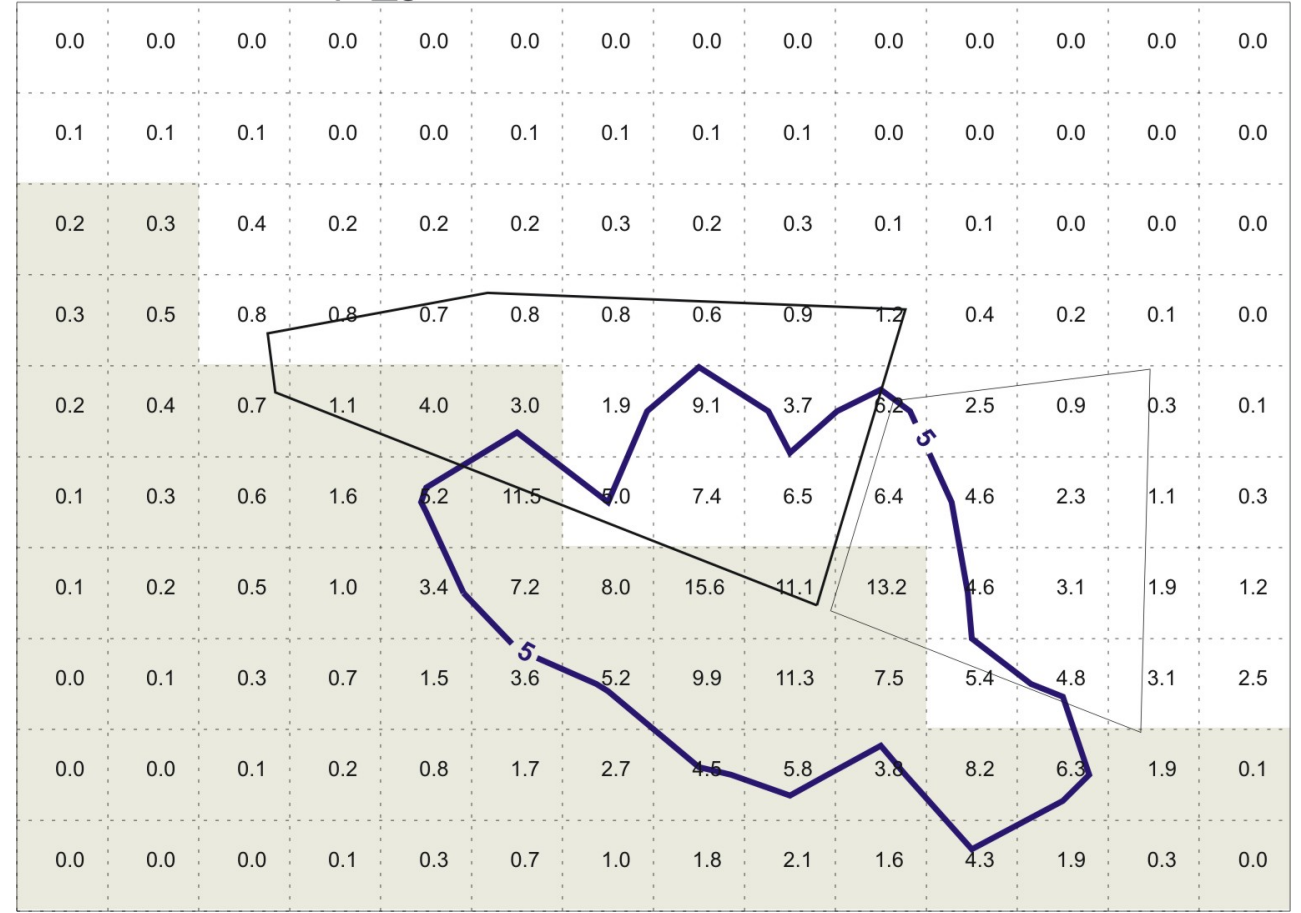

Figure D-42. Distribution of carbon tetrachloride $(\mu \mathrm{g} / \mathrm{L})$ in the refined portion of the aquifer model for Alternative 4-Partial Retrieval, Treatment, and Disposal, in years 2010 and 2110. The vapor vacuum extraction with treatment system operates until year 2045 for this alternative. The shaded area represents the low-permeability aquifer zone in the model. 
aFfr_g11.GV1: W3: IZ=1: Year $=2010$

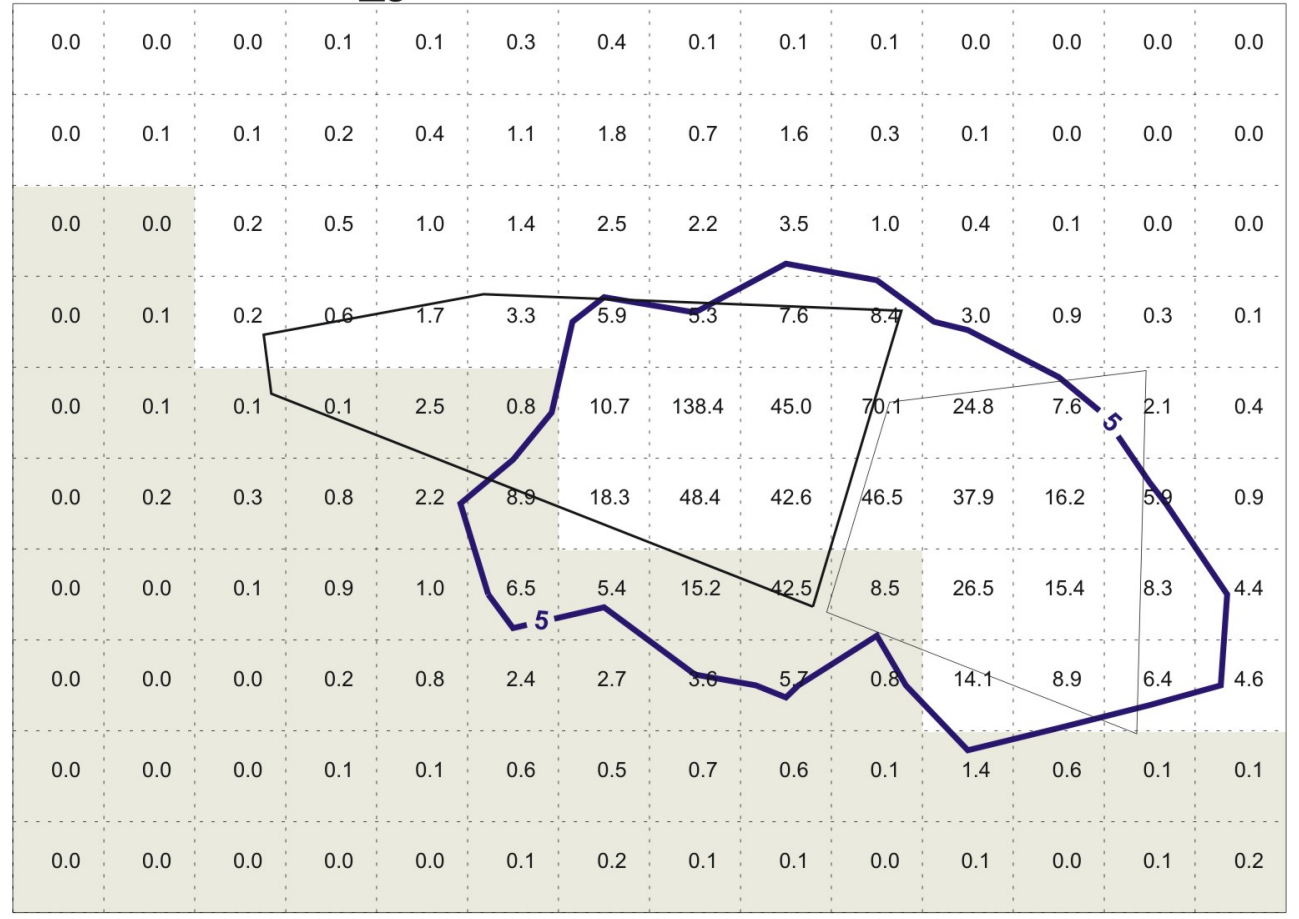

aFfr_g11.GV1: W3: IZ=1: Year $=2110$

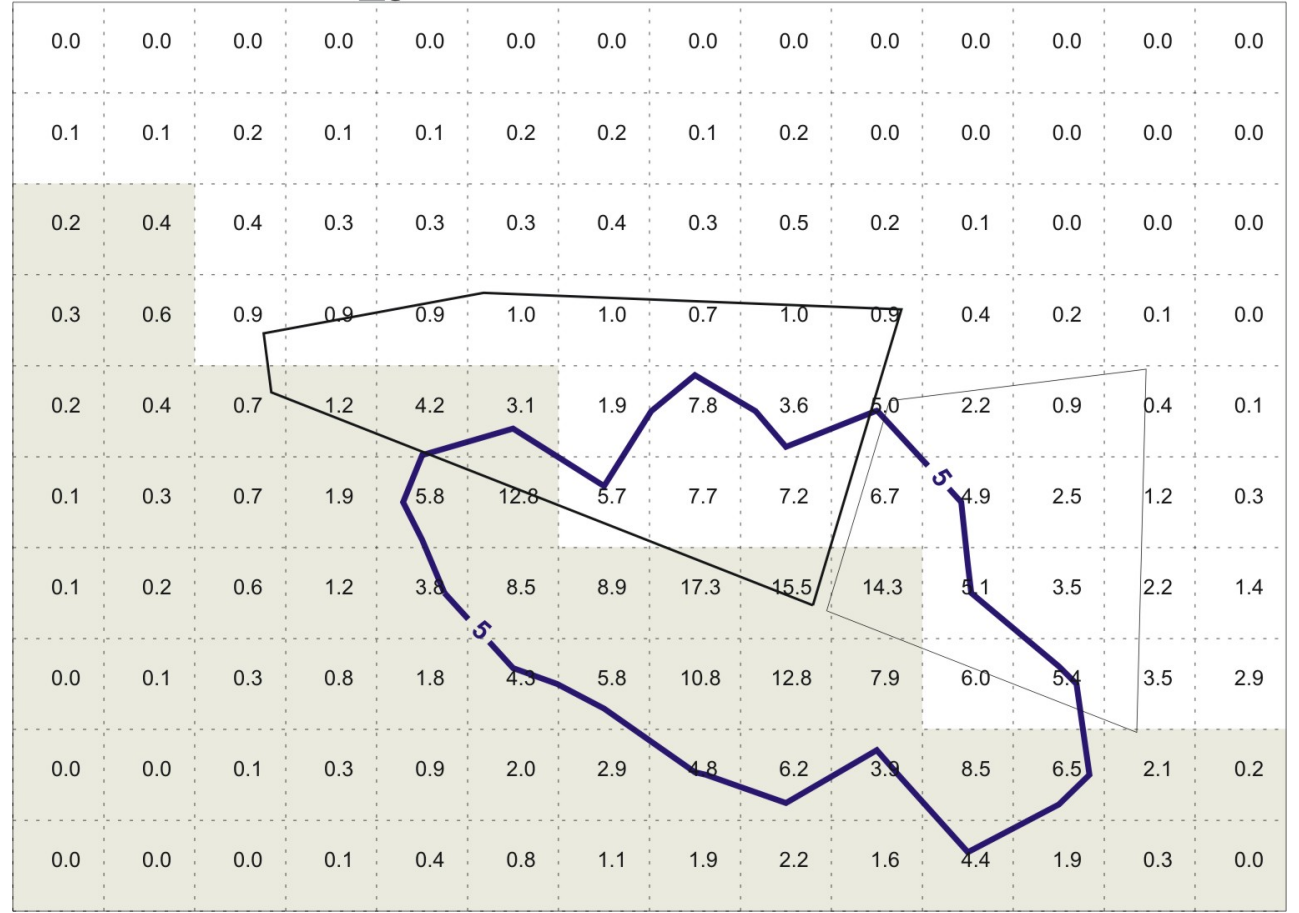

Figure D-43. Distribution of carbon tetrachloride $(\mu \mathrm{g} / \mathrm{L})$ in the refined portion of the aquifer model for Alternative 5-Full Retrieval, Treatment, and Disposal, in years 2010 and 2110. The vapor vacuum extraction with treatment system operates until year 2035 for this alternative. The shaded area represents the low-permeability aquifer zone in the model. 


\section{D-3.6.1.2.3.1 Sources of Model Uncertainty for Volatile Organic Compounds-}

Despite a gap in the two modeling approaches between achieving vadose zone remediation goals and aquifer MCLs, uncertainty is sufficient to conclude that MCLs could be achieved before the year 2110 for each alternative. For example, contaminant distribution in the vadose zone and aquifer is highly variable, and model results are a simplified representation of this distribution. During VOC model calibration, reasonable changes were made to increase contamination spread in the vadose zone to better match aquifer concentrations well outside the SDA. The final result, however, was a tradeoff between matching concentrations near and away from the SDA. The model overpredicted aquifer carbon tetrachloride concentrations near the center of the SDA at Wells USGS-117, USGS-119, and particularly Well M17S, while it underpredicted concentrations at outlying wells (e.g., Wells M6S and M7S) (see Figure D-44). This discrepancy was acknowledged and allowed in order to obtain the best overall match. However, similar to nitrate, by significantly overpredicting concentrations at Well M17S, the model likely will overpredict future concentrations in the aquifer near this location.

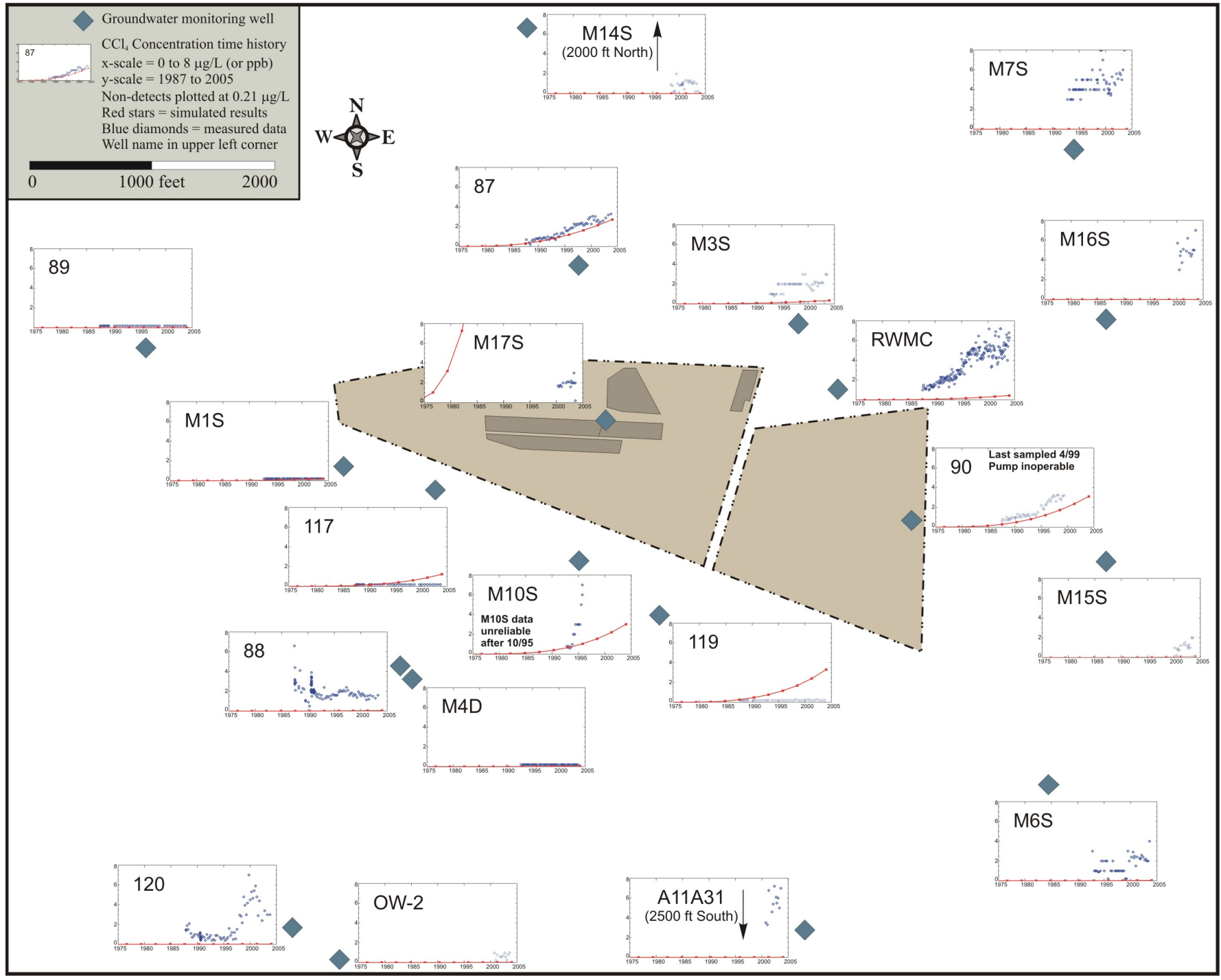

Figure D-44. Time history of measured and simulated carbon tetrachloride concentrations in the aquifer at wells in and around the Subsurface Disposal Area. Model results are for the Remedial Investigation and Baseline Risk Assessment base case. Primary carbon tetrachloride source pits are shaded in the Subsurface Disposal Area. 
While the potential for model overprediction applies to carbon tetrachloride, it may not apply as readily to methylene chloride, tetrachloroethylene, and trichloroethylene. Simulated concentrations of these three VOCs are still greater than, but more in agreement with, measured values. Aquifer samples have not been analyzed specifically for 1,4-dioxane in the past. The November 6, 2006, sampling event is the first time 1,4-dioxane was on the analyte list; it was not detected. The simulated maximum aquifer concentration for 1,4-dioxane is approximately $120 \mu \mathrm{g} / \mathrm{L}$ in year 2006 for Alternative 1 (No Action). Because it was not detected in any of the 15 aquifer monitoring wells sampled November 6, 2006, 1,4-dioxane is probably overpredicted. However, routine monitoring over time will be necessary to further substantiate the conclusion that modeling overpredicts 1,4-dioxane.

Another significant source of uncertainty may be the low-permeability zone in the aquifer. Model simulations were run for each alternative without the low-permeability zone in the aquifer to show the impact. In those simulations, the permeability of the low-permeability zone was made equal to that of the larger region downgradient of the SDA. Figure D-45 shows that without the low-permeability zone, each alternative would achieve MCLs by about the year 2030.

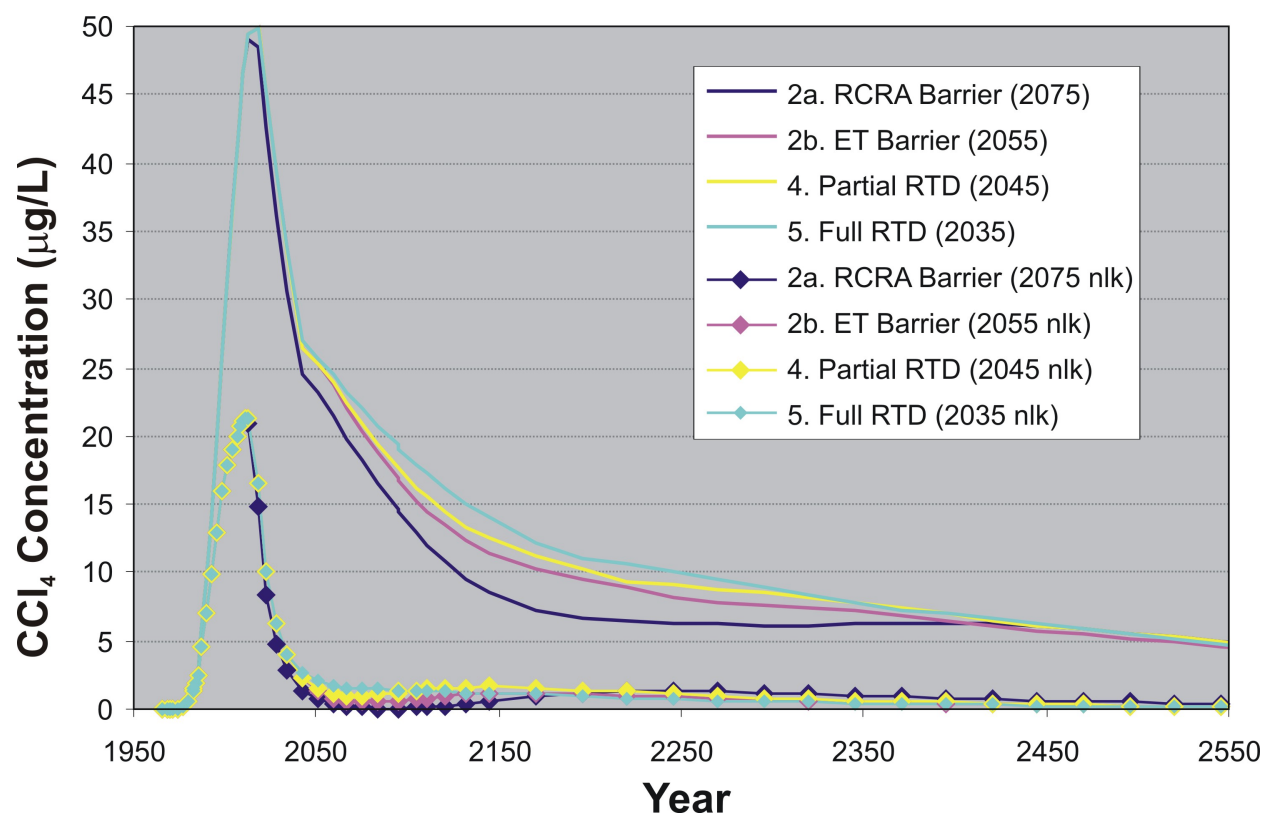

Figure D-45. Maximum predicted carbon tetrachloride concentrations in the aquifer outside the Subsurface Disposal Area. The legend indicates the year vapor vacuum extraction with treatment operations cease because vadose zone remediation goals are achieved. Simulations without the low-permeability zone in the aquifer (nlk) are indicated by lines with diamond symbols.

Future concentrations also may be overpredicted because the model does not account for chemical degradation. Degradation was not included in the RI/BRA modeling due to uncertainty of the degradation rate and mechanism. Neglecting degradation was conservative because by-products of carbon tetrachloride degradation (i.e., chloroform, methylene chloride, and chloromethane) have transport properties similar to carbon tetrachloride, but are less toxic (i.e., have higher risk-based concentrations). The model is also conservative because neglecting degradation could result in overestimating the remaining source. 
Lastly, uncertainty surrounding the inventory and source release model (Anderson and Becker 2006) should be recognized. Modeling of VOCs was conducted assuming that $50 \%$ of the original inventory remained in the pits. This was a median value suggested by Sondrup et al. (2004), who estimated the range to be 25 to $75 \%$. Other uncertain parameters that control VOC release include container failure rate and VOC diffusivity in sludge. Though these parameters are important, uncertainty of the parameters on future aquifer concentrations is lessened because (a) the transport model was calibrated using abundant available data, limiting the possible model outcomes, and (b) the OCVZ system will be operating and capture most of the future releases. The uncertainty will have the largest impact on how long the OCVZ system is required to operate to achieve remediation goals.

\section{D-3.6.1.2.4 Summary of Volatile Organic Compound Modeling Uncertainty and}

Recommendations-Simulation results for the feasibility study alternatives meet vadose zone remediation goals for carbon tetrachloride, but predicted concentrations everywhere outside the SDA are not less than MCLs in the year 2110 for all contaminants and all alternatives. The discrepancy is primarily due to simplifying assumptions used to develop the remediation goals and uncertainties associated with those assumptions. Although the feasibility study model predictions do not achieve MCLs by the year 2110 in all cases, the results are close to MCLs (excluding 1,4-dioxane), and it is reasonable to conclude that MCLs are within the bounds of uncertainty. The overprediction of concentrations at Well M17S suggests that the model also may overpredict future concentrations. In addition, the low-permeability zone as represented in the model dramatically increases future VOC concentrations in the aquifer. Uncertainty about how the model represents the zone suggests that future concentrations may be much less than predicted and less than MCLs.

Though the modeling goal was to achieve vadose zone remediation goals and not MCLs, it is reasonable to expect, based on professional judgment and interpretation of model results, that achieving MCLs is probable. If, however, vadose zone remediation goals are achieved and aquifer concentrations are not less than MCLs, then additional risk management actions could be required to address aquifer concentrations if they continue to exceed MCLs. These could include a buffer zone, expanding the OCVZ system, or an aquifer pump and treat system. At this point, however, expanding the OCVZ system may not be effective because the contamination likely has entered the aquifer and is beyond the influence of the OCVZ system.

If MCLs must be achieved in the model simulations, the VOCs could be remodeled with an expanded OCVZ system in the year 2010. The feasibility study modeling used the existing OCVZ system and was constrained by existing well locations and total flow rate. The modeling could be redone with more wells and a larger total flow rate to meet the MCL. This, however, may not be an efficient use of resources because capital and operating costs may be significantly higher just to reduce concentrations by a few micrograms per liter in a small area. Another possibility, and perhaps more practical alternative, is to remodel and focus on removing more contamination deep in the vadose zone earlier in the simulation before it reaches the aquifer and then gets caught in the low-permeability zone.

\section{D-3.6.2 Uranium Sensitivity Simulations}

Uranium was one of the primary contaminants of potential concern identified in the Ancillary Basis for Risk Analysis (Holdren et al. 2002). Studies by Hull and Pace (2000) and Leecaster and Hull (2004) show that the solubility and mobility used in the Ancillary Basis for Risk Analysis likely were conservative. The Ancillary Basis for Risk Analysis used no solubility limit for uranium, and the chemical models used by Hull and Pace (2000) predict a solubility limit of $1 \mathrm{mg} / \mathrm{L}$. Additional work with SDA sediment material by Leecaster and Hull (2004) resulted in a best-estimate soil-to-water distribution coefficient of $15.4 \mathrm{~mL} / \mathrm{g}$, which is greater than the $6-\mathrm{mL} / \mathrm{g}$ value used in the Ancillary Basis for Risk 
Analysis. Sensitivity to the solubility limit and sensitivity to the distribution coefficient are discussed in the following subsections.

D-3.6.2.1 Solubility Limit. The solubility limit of uranium was increased 10 times and 100 times from the base case value of $1 \mathrm{mg} / \mathrm{L}$ to determine the impact of solubility on risk. Figure D- 46 shows the U-238 groundwater ingestion risk for the various solubility limits. All the simulations used the feasibility study Alternative 1 (No Action) infiltration rate (no surface barrier) and the best-estimate distribution coefficient of $15.4 \mathrm{~mL} / \mathrm{g}$.

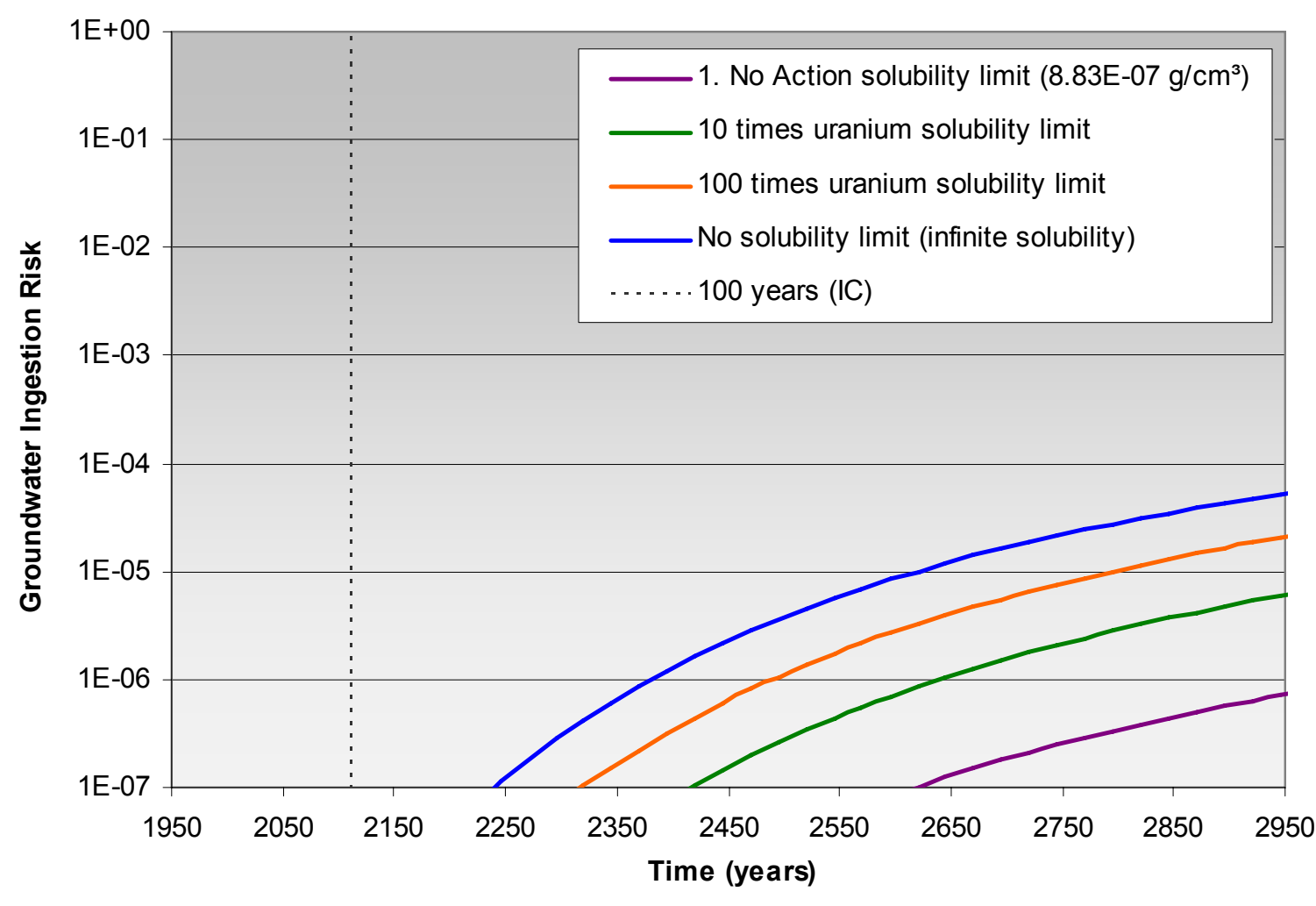

Figure D-46. Comparison of uranium-238 groundwater ingestion risk for various solubility limits.

D-3.6.2.2 Distribution Coefficient. The soil-to-water distribution coefficient affects contaminant mobility and, as a result, the timing and magnitude of peak groundwater ingestion risk. Alternative 1 (No Action) used the best-estimate soil-to-water distribution coefficient of $15.4 \mathrm{~mL} / \mathrm{g}$ (Holdren and Broomfield 2004). The Ancillary Basis for Risk Analysis model (Holdren et al. 2002) used a lower distribution coefficient of $6 \mathrm{~mL} / \mathrm{g}$, which approximated the lower bound of the batch test data from the Clemson studies (Grossman et al. 2001). Figure D-47 compares the groundwater ingestion risk for U-238 for the two different soil-to-water partition coefficients. The Alternative 1 infiltration rate and solubility limit were used for both cases. 


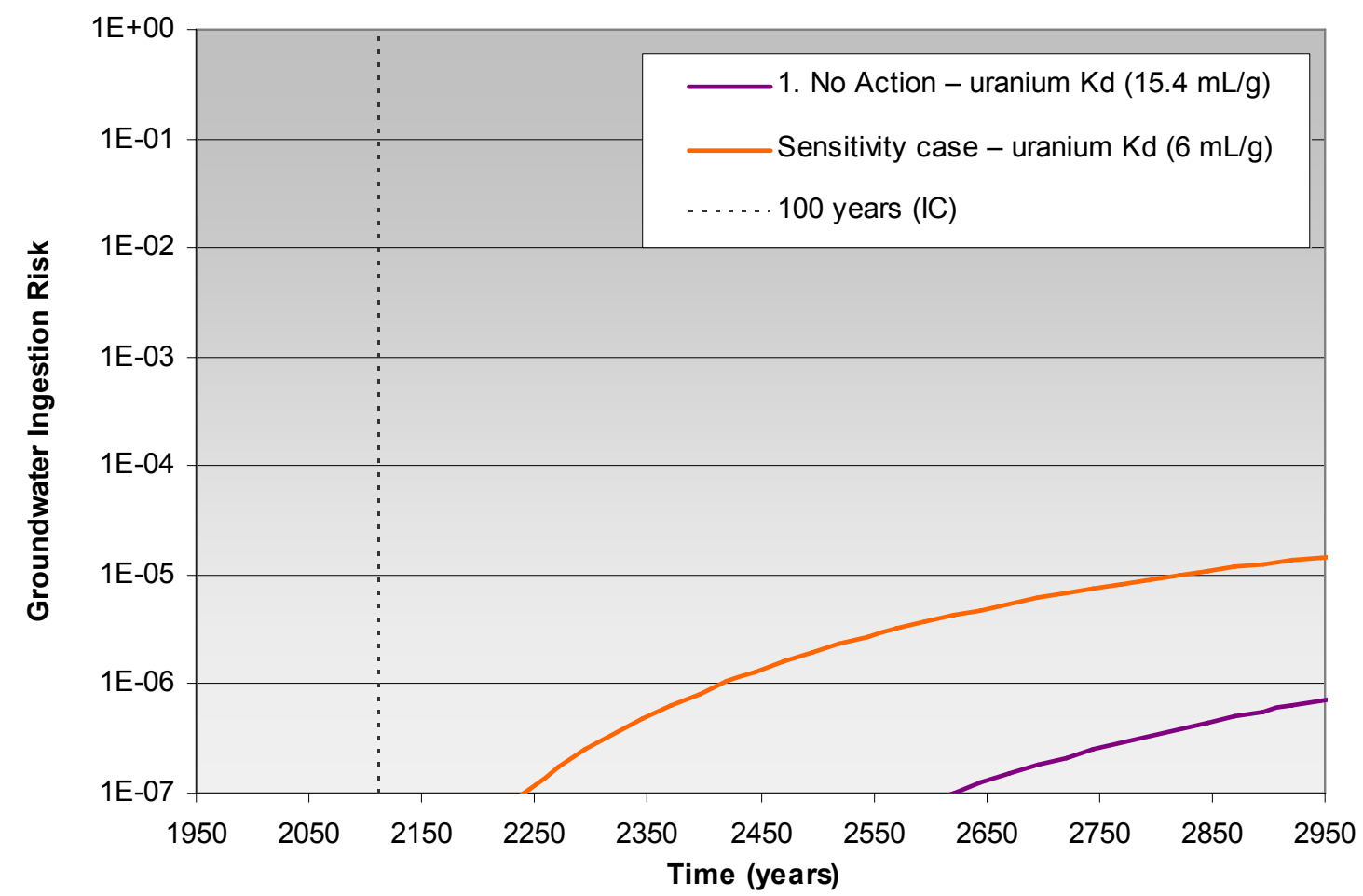

group5OFgroundwater.xls, aBkU_g5.GV1_of_conc, $A$

Figure D-47. Comparison of uranium-238 groundwater ingestion risk for different soil-to-water distribution coefficients.

\section{D-3.6.3 Evapotranspiration Surface Barrier with Higher Infiltration Rate}

The design assumption for both surface barrier designs (Alternative 2a [Modified RCRA Type C Surface Barrier] and Alternative 2b [ET Surface Barrier]) is an infiltration rate of $0.1 \mathrm{~cm} /$ year (0.04 in./year). An additional surface barrier case was simulated with an order-of-magnitude increase in the net infiltration rate to $1.0 \mathrm{~cm} /$ year $(0.4 \mathrm{in}$./year). An infiltration rate of $1 \mathrm{~cm} /$ year rate mimics an engineered barrier that matches the estimated background infiltration rate. Figure D-48 shows the cumulative groundwater ingestion risk for both cases. The cumulative groundwater ingestion risk is below 1E-04 with the higher infiltration rate. Figure D-49 shows the cumulative groundwater ingestion hazard index. The hazard index is less sensitive to infiltration because the hazard index is due primarily to carbon tetrachloride and other volatiles that also migrate as a vapor and are, therefore, less influenced by infiltration.

\section{D-3.6.4 Full Retrieval with No Surface Barrier}

Sensitivity to the presence or absence of a surface barrier for Alternative 5 (Full RTD) was examined by excluding the simulated low-infiltration surface barrier over the SDA. The full RTD with no surface barrier sensitivity case demonstrates that a surface barrier would further reduce residual risk. Figure D-50 compares cumulative groundwater ingestion risk for the full retrieval without a surface barrier sensitivity case to Alternative 1 (No Action) and Alternative 5 (Full RTD). Cumulative groundwater risk is higher than with the surface barrier, but still well below the $10^{-6}$ to $10^{-4}$ remedial action objective. Figure D-51 shows a similar comparison for the cumulative hazard index. Though the cumulative groundwater ingestion hazard index is 2 for full retrieval without the surface barrier; this result is based on overpredicted concentrations of nitrate (see Section D-3.6.1.1). 


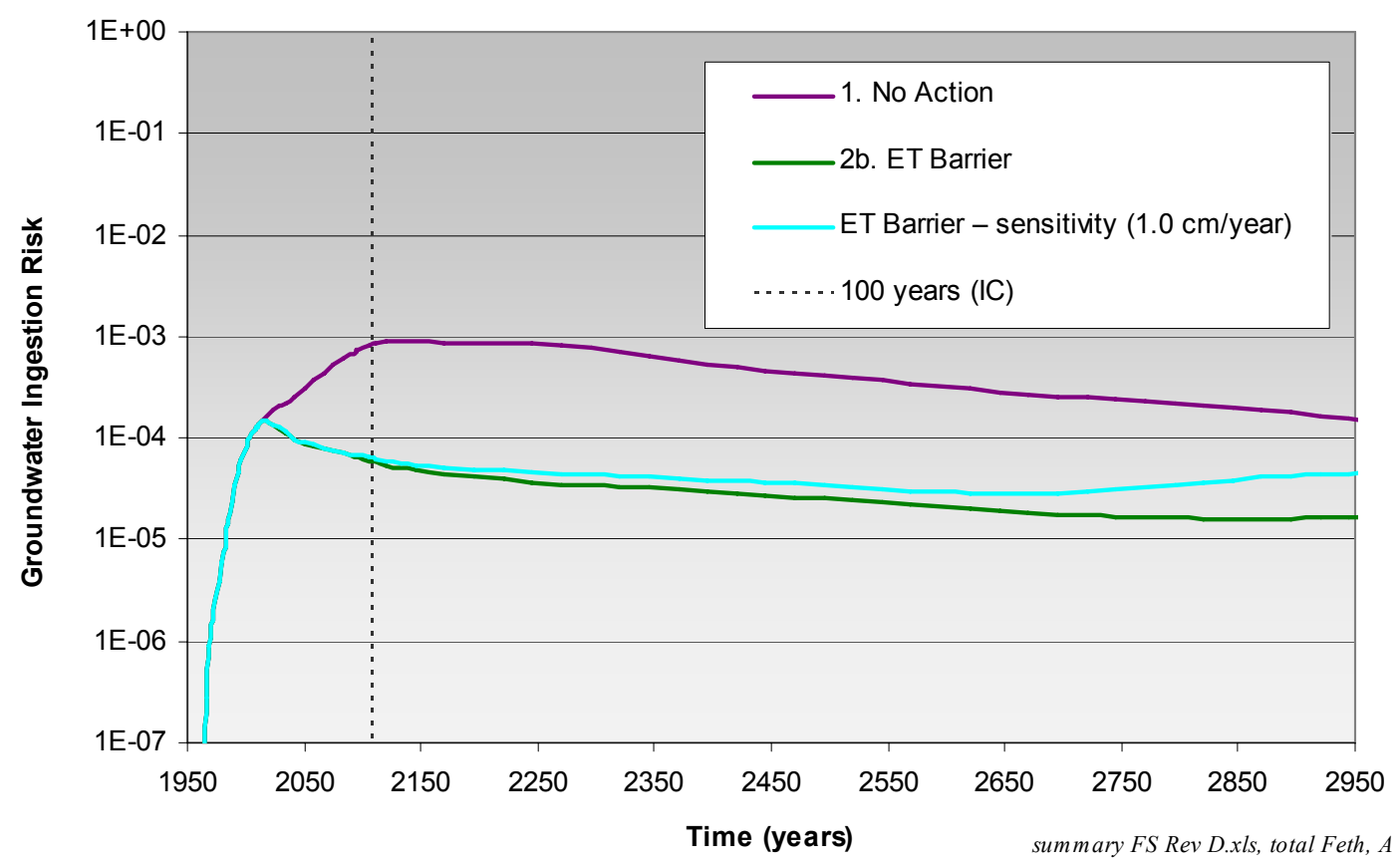

Figure D-48. Comparison of cumulative groundwater ingestion risk for the evapotranspiration surface barrier with a higher infiltration rate, Alternative 1-No Action, and Alternative $2 \mathrm{~b}$-Evapotranspiration Surface Barrier.

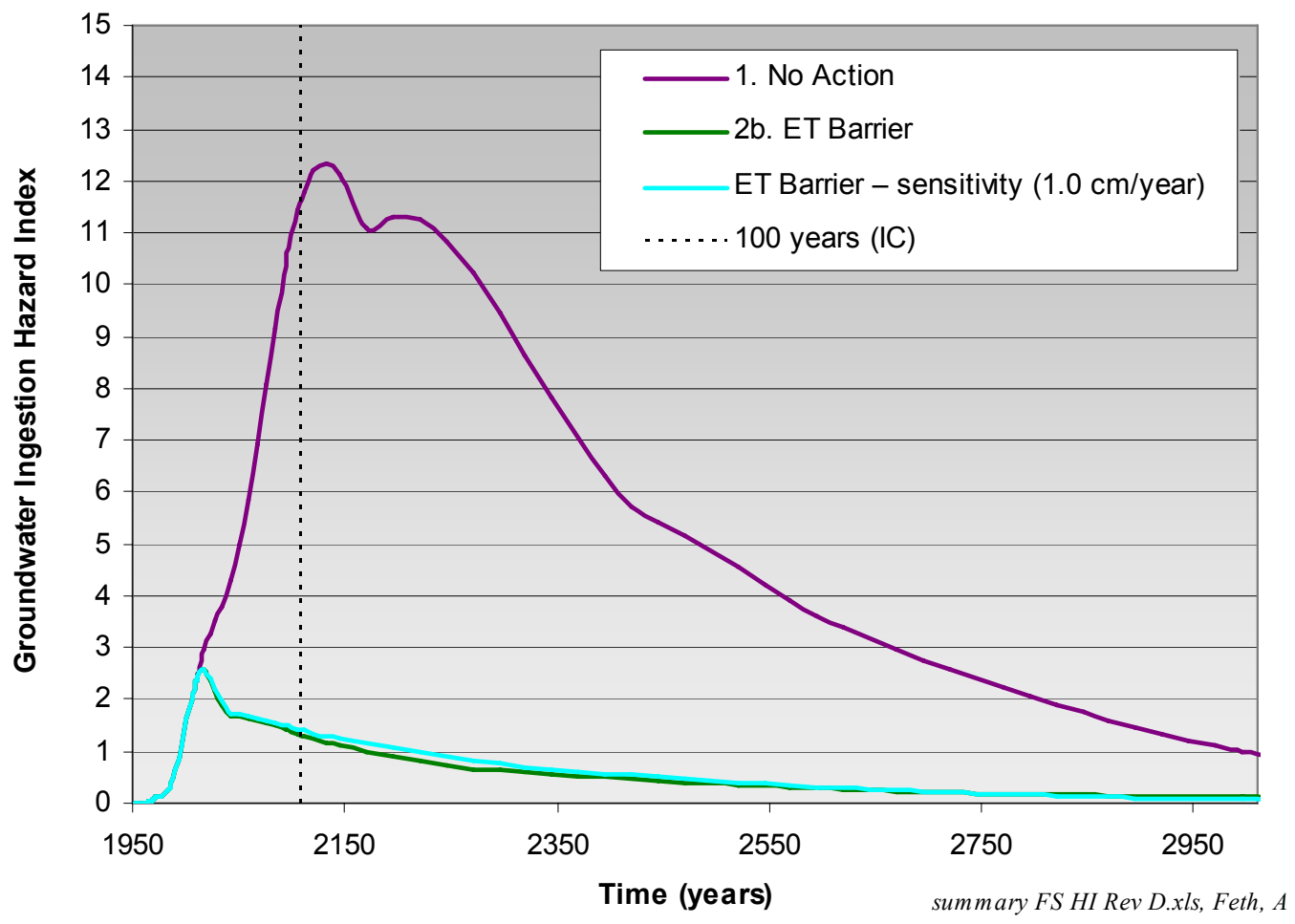

Figure D-49. Comparison of the cumulative groundwater ingestion hazard index for the evapotranspiration surface barrier with a higher infiltration rate, Alternative 1-No Action, and Alternative $2 b-E v a p o t r a n s p i r a t i o n$ Surface Barrier. 


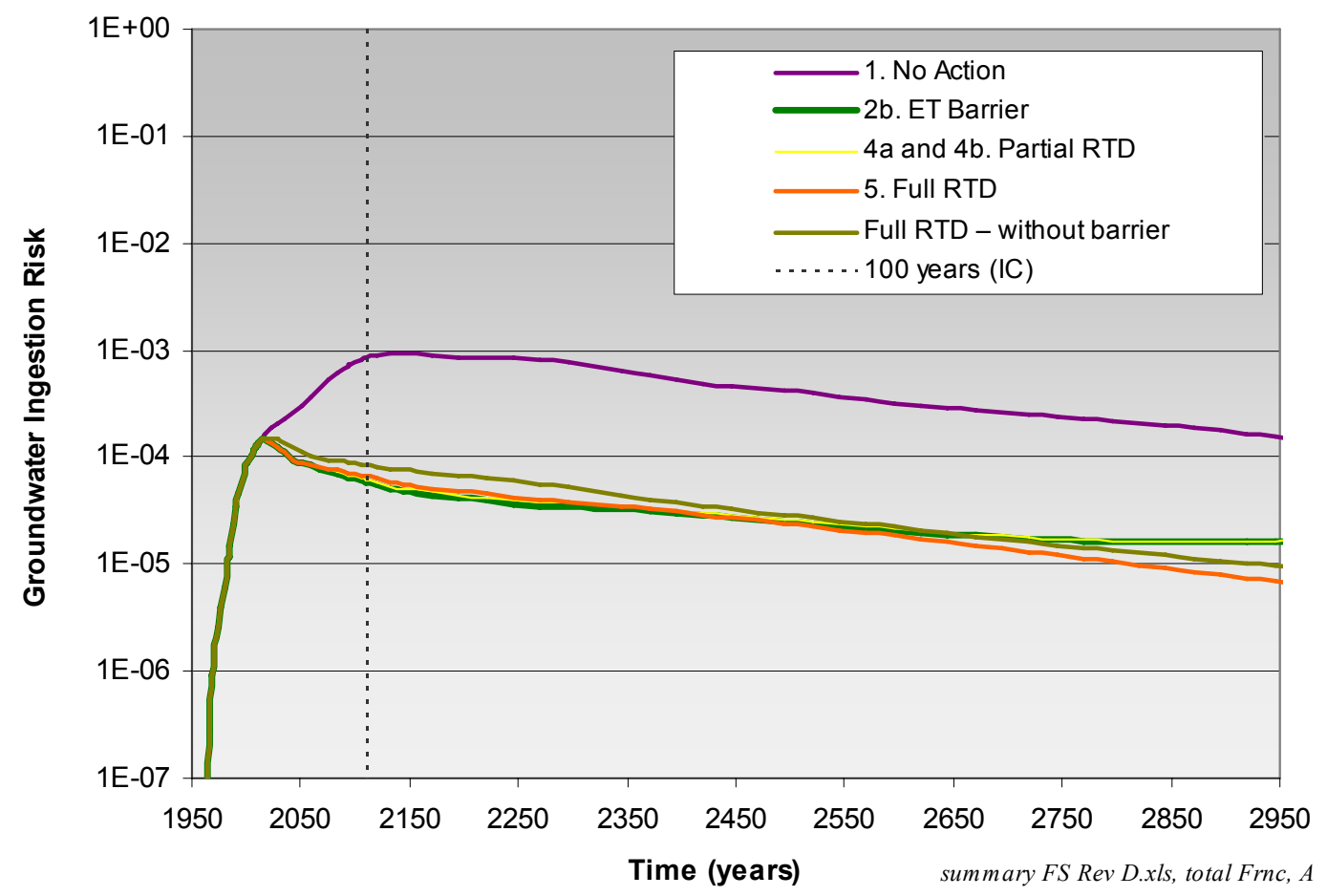

Figure D-50. Comparison of cumulative groundwater ingestion risk for Alternative $1-$ No Action, Alternative 5-Full Retrieval, Treatment, and Disposal; and the full retrieval without a surface barrier sensitivity case.

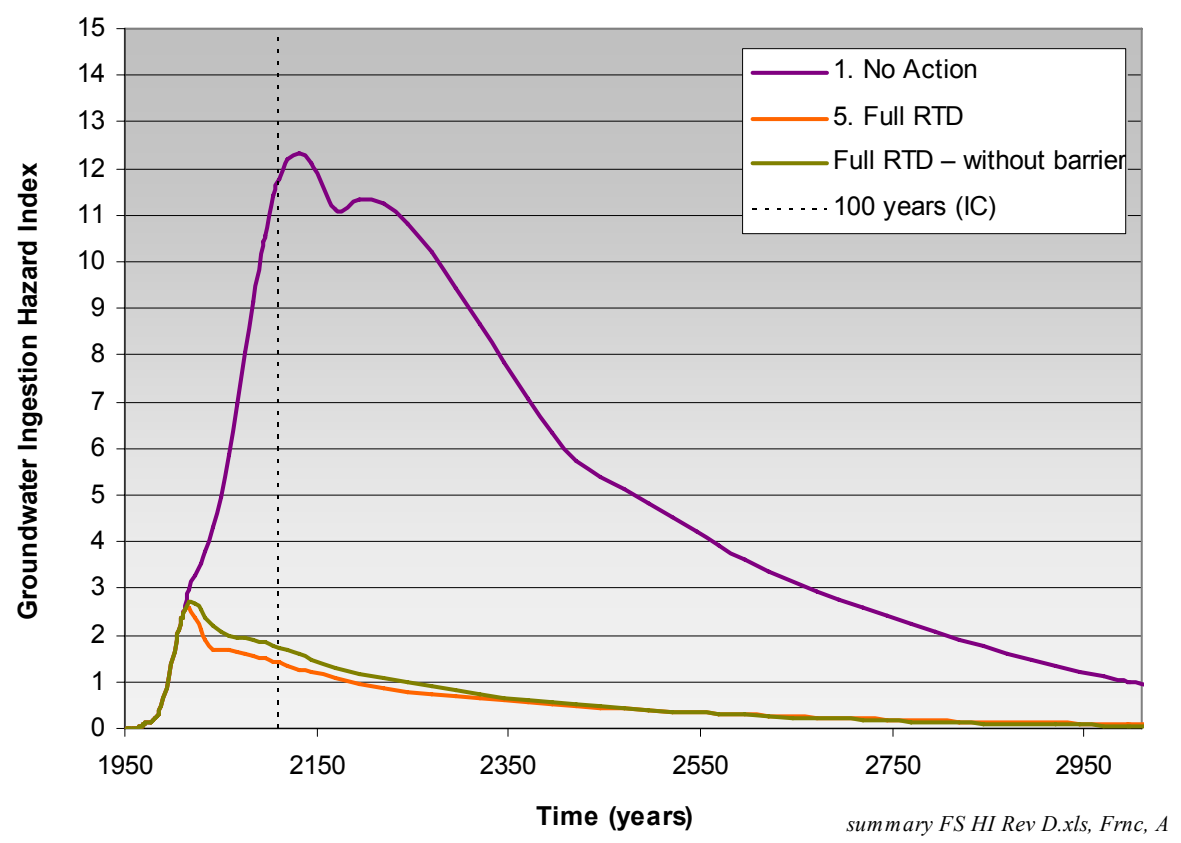

Figure D-51. Comparison of cumulative groundwater ingestion hazard index for Alternative 1-No Action; Alternative 5-Full Retrieval, Treatment, and Disposal; and the full retrieval without a surface barrier sensitivity case. 


\section{D-4. COMPARISON OF SIMULATED GROUNDWATER CONCENTRATIONS TO MAXIMUM CONTAMINANT LEVELS}

Meeting MCLs is a preliminary remediation goal that applies to all feasibility study simulations. This section presents a comparison of maximum simulated aquifer concentrations outside the SDA fence for all feasibility study alternatives for the 1,000-year simulation period ending year 3010 . Simulated concentrations exceed MCLs for some feasibility study alternatives. Simulated contaminant concentrations shown in this section are those that show exceedance in any alternative, including the No Action alternative. Simulated concentrations for those contaminants that do not exceed the MCL are not shown. Lastly, the likelihood of these exceedances actually occurring is discussed.

Six contaminants, primarily the VOCs, are predicted to exceed MCLs at some point between years 2110 and 3010, if no remedial action is taken. These six contaminants are nitrate, I-129, carbon tetrachloride, methylene chloride, tetrachloroethylene, and trichloroethylene. In addition, simulated 1,4-dioxane exceeds its health advisory level. Figures D-52 through D-58 compare simulated groundwater concentrations for each of the remedial action alternatives to MCLs for each of these seven contaminants.

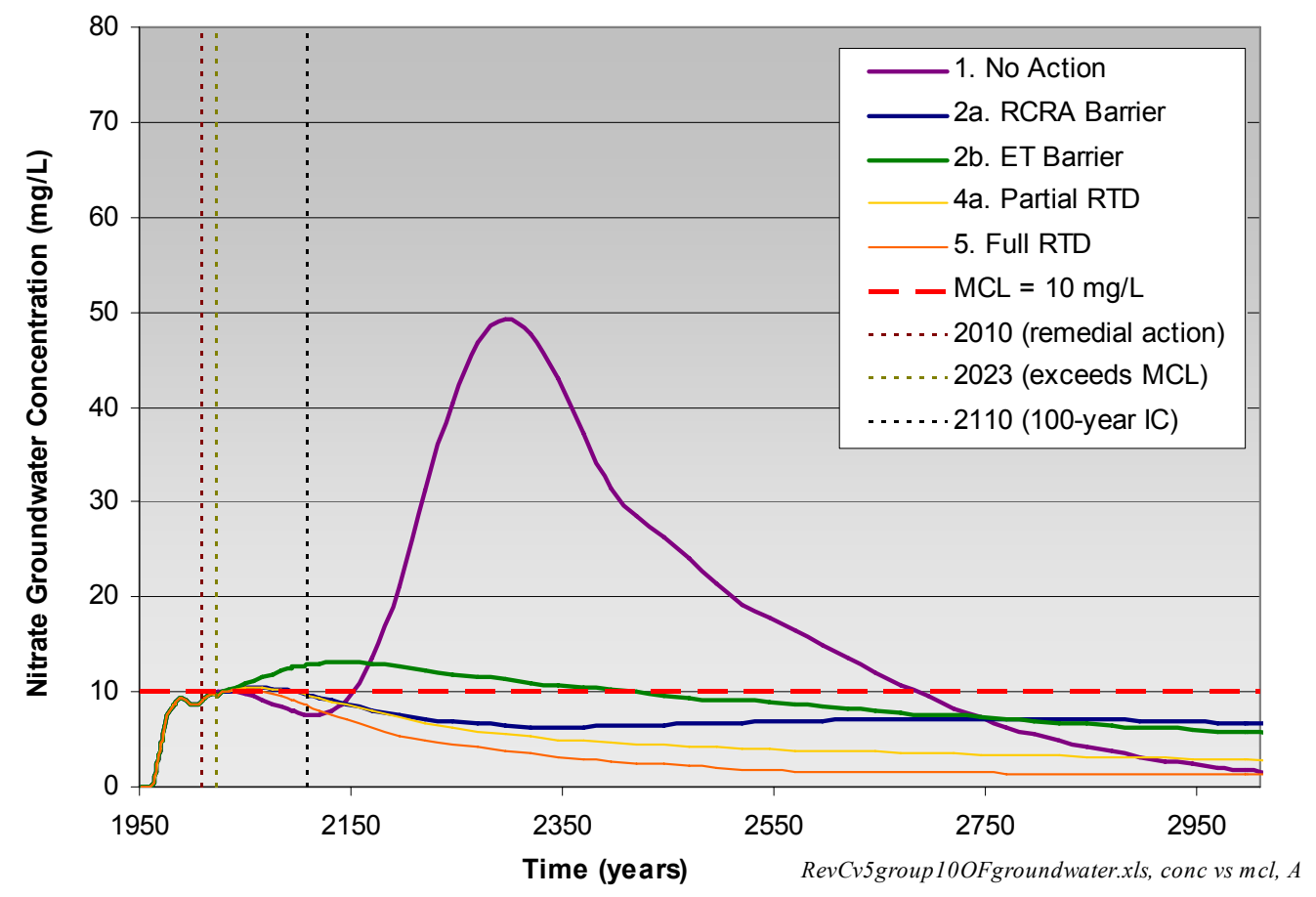

Figure D-52. Comparison of nitrate groundwater concentration with maximum contaminant level. 


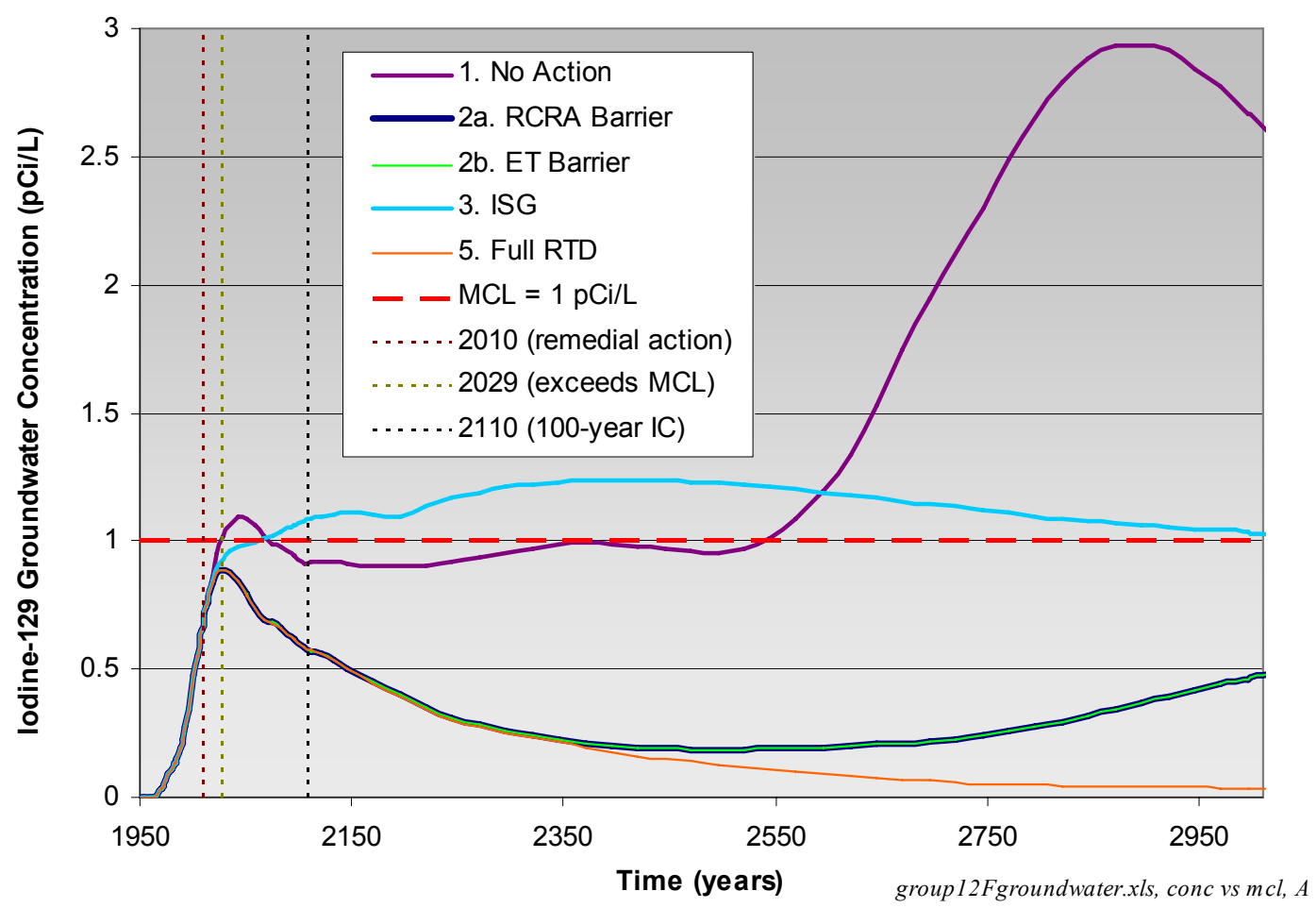

Figure D-53. Comparison of iodine-129 groundwater concentration with maximum contaminant level.

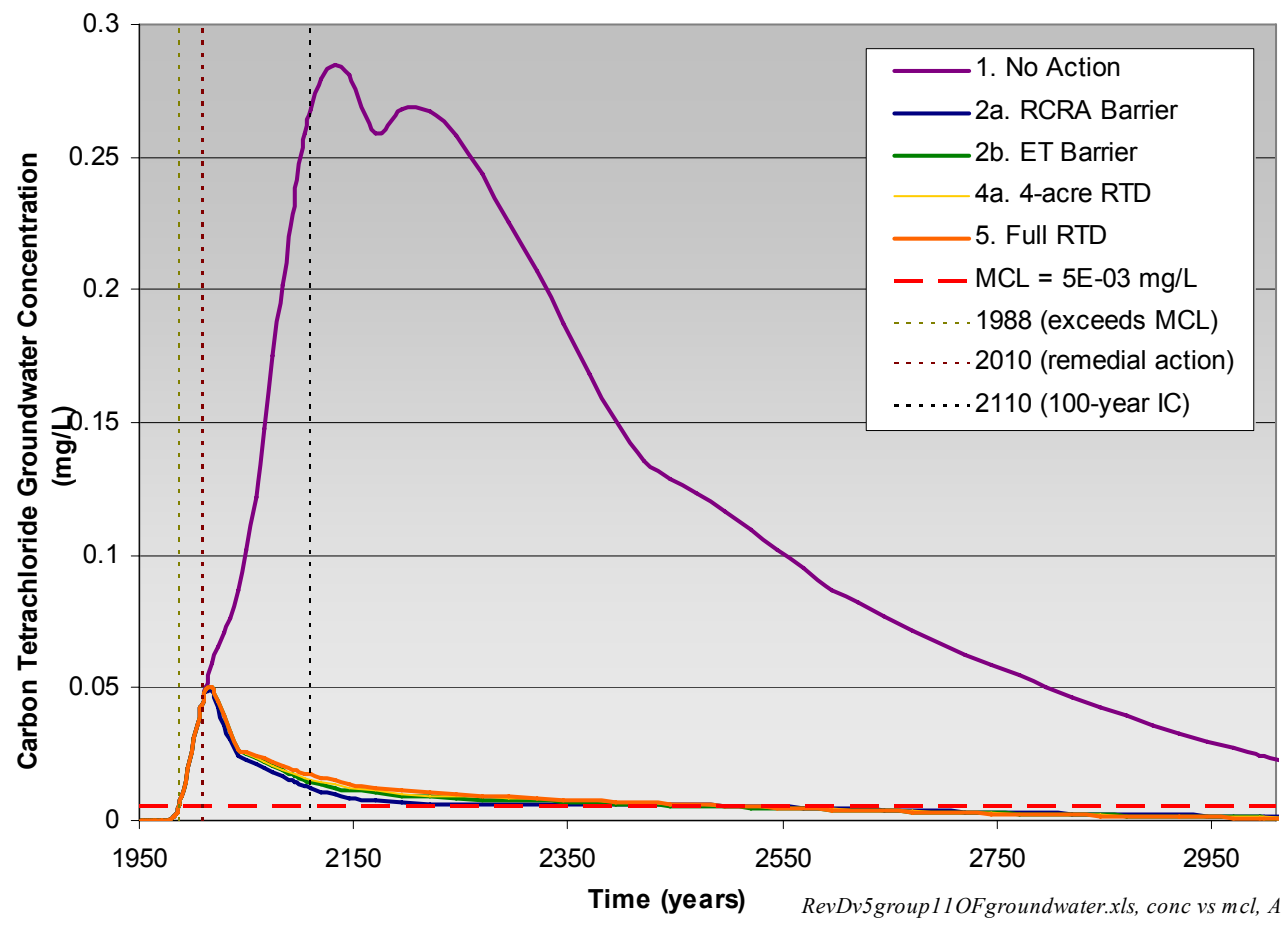

Figure D-54. Comparison of carbon tetrachloride groundwater concentration with maximum contaminant level. 


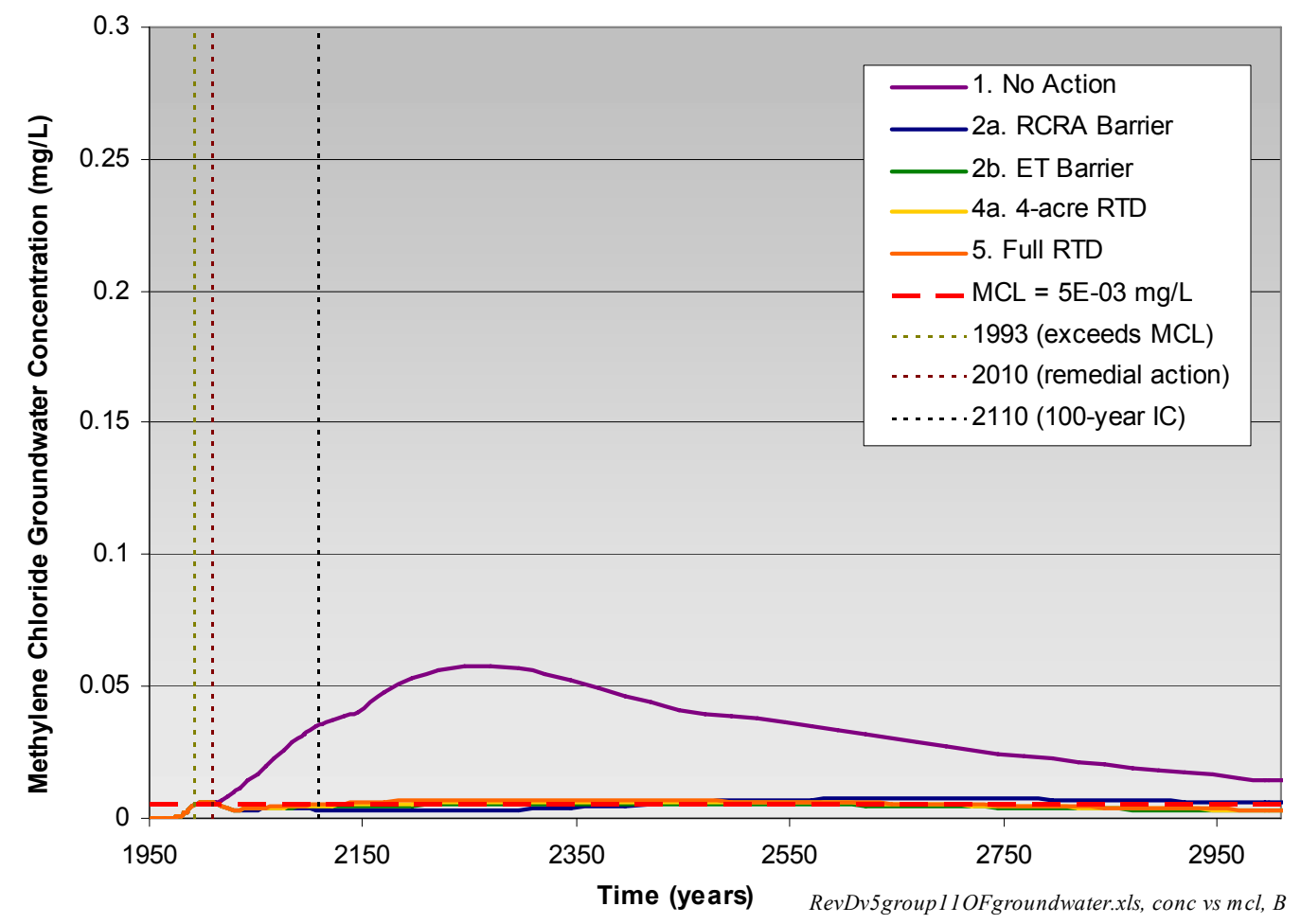

Figure D-55. Comparison of methylene chloride groundwater concentration with maximum contaminant level.

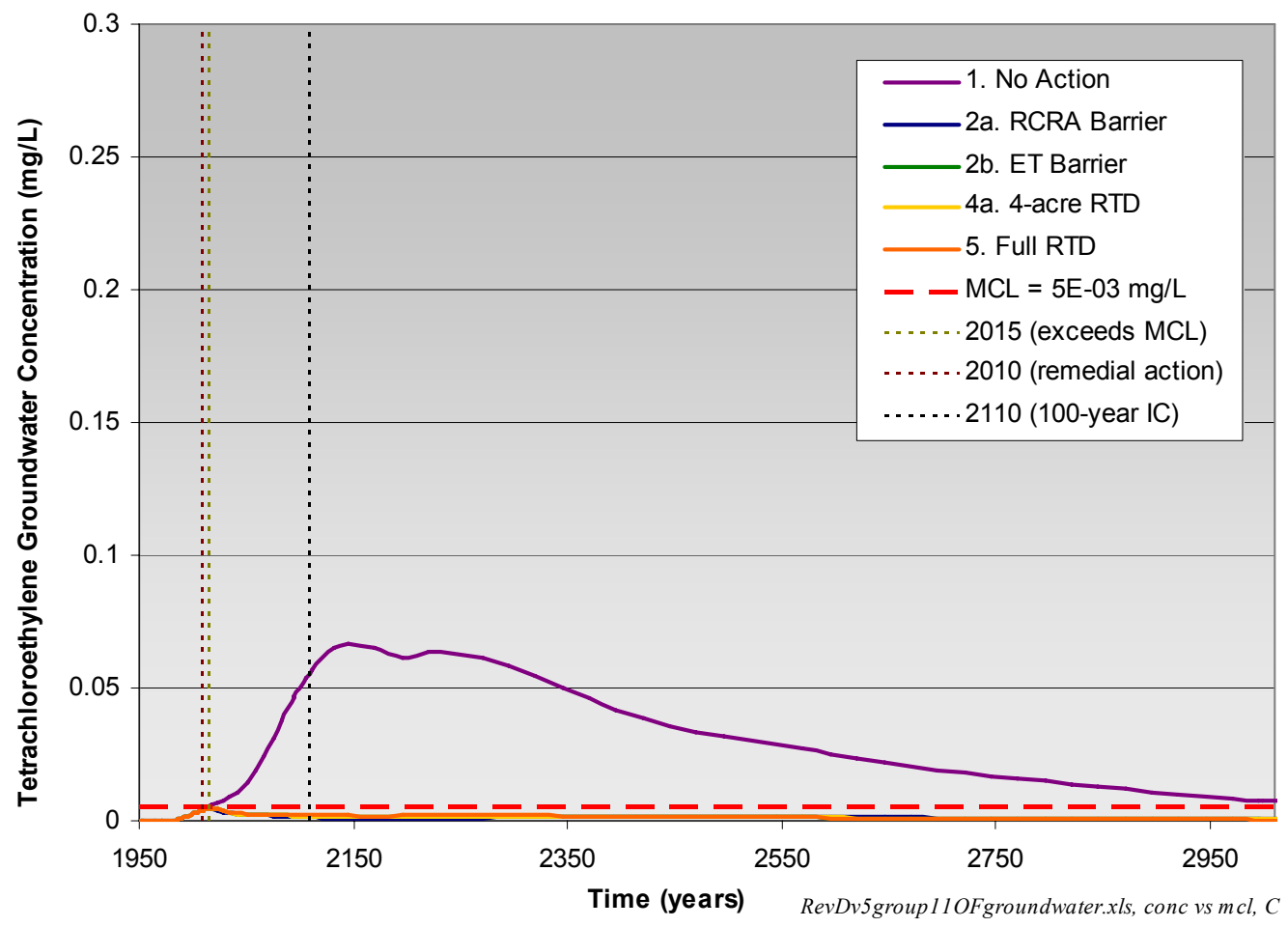

Figure D-56. Comparison of tetrachloroethylene groundwater concentration with maximum contaminant level. 


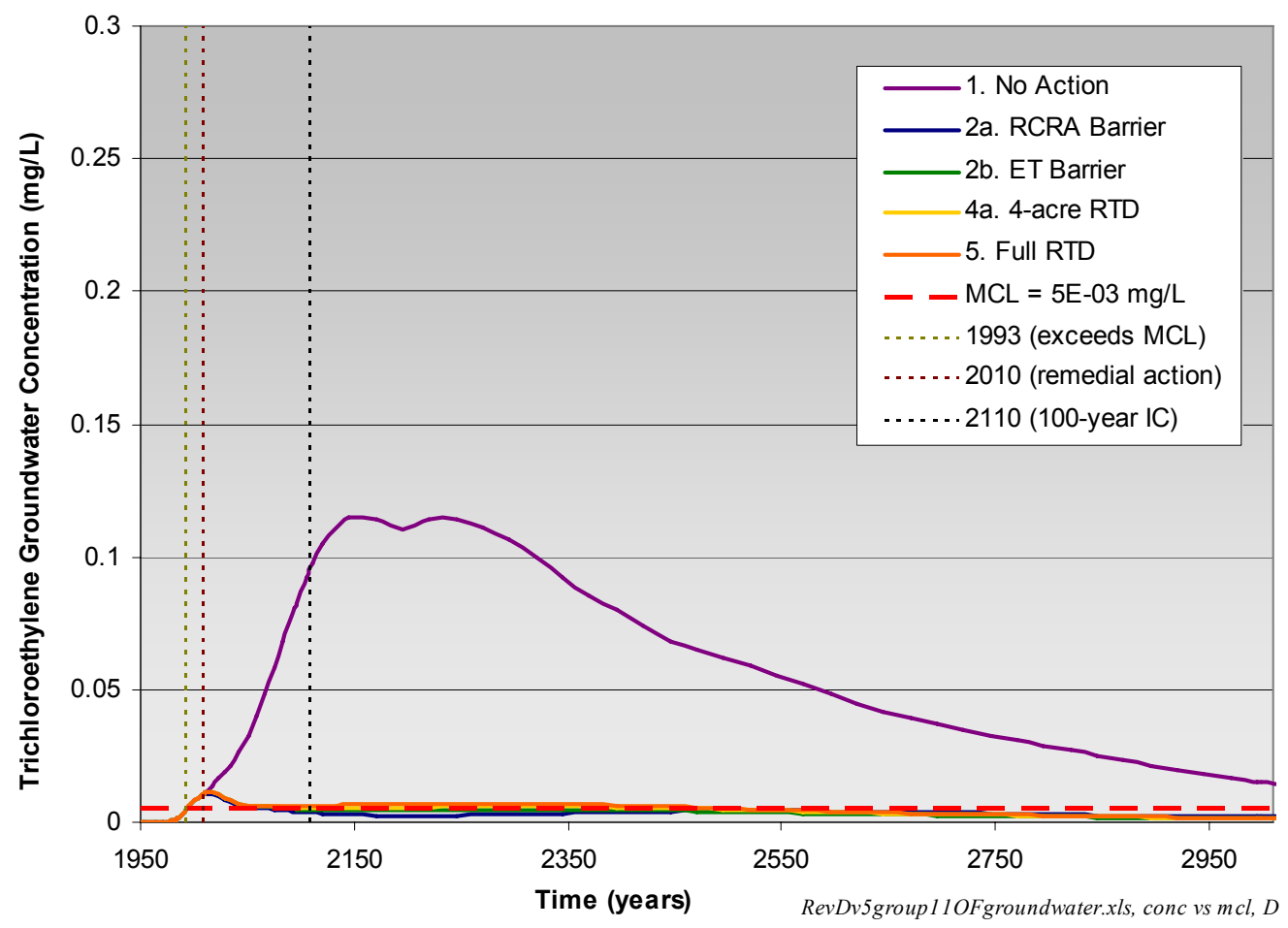

Figure D-57. Comparison of trichloroethylene groundwater concentration with maximum contaminant level.

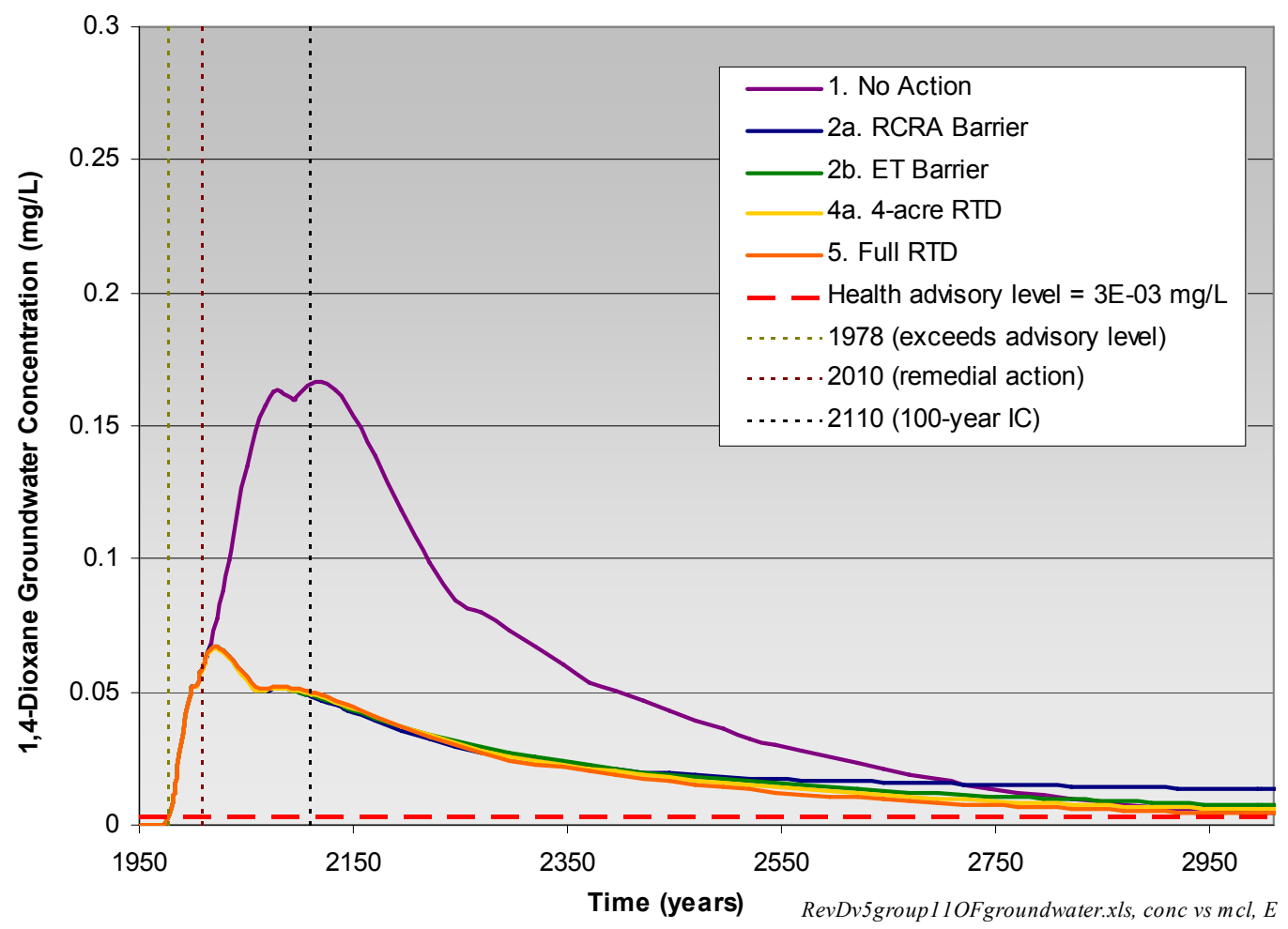

Figure D-58. Comparison of 1,4-dioxane groundwater concentration with health advisory level. 
Simulated nitrate concentrations in Figure D-52 exceed the MCL of $10 \mathrm{mg} / \mathrm{L}$ after ICs for Alternative $2 \mathrm{~b}$ (ET Surface Barrier). The aquifer nitrate concentration for this alternative is predicted to exceed the MCL for approximately 200 years after ICs end. The exceedance for Alternative $2 \mathrm{~b}$ (ET Surface Barrier) is a prospective modeling artifact of how Pad A waste was simulated. As explained in Section D-3.2.2, Pad A waste was simulated as retrieved and transferred to the active LLW Pit in the SDA without treatment. The depth of the LLW Pit is accounted for in the subsurface pathway model (Magnuson and Sondrup, 2006). For Alternative 2b simulations, additional nitrate mass is placed deeper than in the other alternatives; therefore, this additional mass is less impacted by the infiltration-reducing cover. This additional mass continues migrating down to the aquifer and results in higher simulated concentrations than even the Alternative 1 (No Action) case for some time periods. Given uncertainty in the modeling results due to overprediction of groundwater pathway concentrations in Alternative 1 (No Action), and due to the conservative approach of an intact areally extensive low-permeability zone in the aquifer that limits the effect of dilution, the simulated exceedance of the nitrate MCL for Alternative $2 \mathrm{~b}$ (ET Surface Barrier) is likely not representative.

Simulated I-129 concentrations in Figure D-53 exceed the MCL of $1 \mathrm{pCi} / \mathrm{L}$ after ICs for almost 1,000 years for Alternative 3 (ISG). However, as explained in Section D-3.3, these elevated concentrations for I-129 most likely result from overly conservative assumptions adopted by consensus with the Agencies early in the modeling effort, and it is assumed that ISG would provide some additional degree of protectiveness beyond that provided alone by Alternative 2b (ET Surface Barrier).

Simulated carbon tetrachloride concentrations in Figure D-54 exceed the MCL of $0.005 \mathrm{mg} / \mathrm{L}$ by factors of two to three for all alternatives at the end of ICs in 2110 and continue to exceed the MCLs for approximately 250 years, until approximately year 2550 (see Figure D-33) for all alternatives. As discussed in Section D-3.6.1.2.3.1, carbon tetrachloride concentrations in the aquifer, for the feasibility study alternatives, are most likely overpredicted due to several reasons. First, Wells USGS-117, USGS-119, and M17S - located centrally in or near the SDA - are overpredicted in Alternative 1 (No Action) results, and therefore, the feasibility study results are also likely overpredicted. Second, the uncertainty imposed by the conservative approach of the low-permeability region in the aquifer also increases the likelihood of the feasibility study alternatives being overpredicted. Lastly, the subsurface transport model does not account for degradation, which would further reduce predicted concentrations.

Simulated methylene chloride concentrations in Figure D-55 barely exceed the MCL of $0.005 \mathrm{mg} / \mathrm{L}$ for various time periods for all feasibility study alternatives after ICs end in year 2110 . As discussed in Section D-3.6.1.2.3.1, though simulated groundwater methylene chloride concentrations are more in line with observed concentrations and do not, therefore, as readily support a claim of overprediction, the feasibility study results are still probably overpredicted after ICs end in year 2010 because of the low-permeability region in the aquifer and not including degradation.

Simulated tetrachloroethylene concentrations in Figure D-56 only exceed the MCL of $0.005 \mathrm{mg} / \mathrm{L}$ for Alternative 1 (No Action) and never exceed the MCL for any of the feasibility study alternatives.

Similar to methylene chloride, simulated trichloroethylene concentrations shown in Figure D-57 barely exceed the MCL of 5E-3 mg/L for various time periods for the feasibility study Alternative $4 \mathrm{a}$ (Partial RTD) and Alternative 5 (Full RTD) (see Figure D-34) after ICs end in year 2110. As discussed in Section D-3.6.1.2.3.1, though the simulated groundwater trichloroethylene concentrations are more in line with observed concentrations and do not, therefore, as readily support a claim of overprediction, the feasibility study results are still probably overpredicted after ICs end in year 2010 because of the low-permeability region in the aquifer and not including degradation. 
Simulated 1,4-dioxane concentrations in Figure D-58 exceed the health advisory level of $0.003 \mathrm{mg} / \mathrm{L}$ by a factor of approximately 15 as ICs end in year 2110 and stays above this level until the simulation ends in year 3010. As discussed in Section D-3.6.1.2.3.1, monitoring for 1,4-dioxane in the aquifer has begun only recently. Results from 15 aquifer wells sampled in November 6, 2006, were all nondetect for 1,4-dioxane. The simulated maximum aquifer concentration in 2006 was $120 \mathrm{mg} / \mathrm{L}$, indicating the model is most likely overpredicting 1,4-dioxane concentrations. Additional routine monitoring will be necessary to substantiate the conclusion of overprediction. Similar to the other VOC compounds, no degradation of 1,4-dioxane is included; this also would contribute to the simulated aquifer concentrations being overpredicted.

Overall, it is important to note that for each instance of a simulated contaminant concentration exceeding the MCL during the post-IC period, simulated concentrations are only slightly higher than the MCL. These small simulated MCL exceedances are within the qualitative uncertainty in the modeling results. The exceedance of 1,4-dioxane above the health advisory level is most likely an overprediction based on initial aquifer monitoring results for 1,4-dioxane being nondetects compared to higher simulated concentrations.

In addition to the 1,000-year simulation period, contaminants also were evaluated against MCLs for an extended 10,000-year period. Simulated concentrations for two secondary COCs (i.e., Np-237 and U-238) exceed MCLs after 1,000 years (see Table 1-4) for Alternative 1 (No Action). Simulation results for each of the feasibility study alternatives were two or more orders of magnitude beneath the MCL during the entire 10,000-year simulation, even with the conservative continuous low-permeability region in the aquifer limiting the effect of dilution.

\section{D-5. SUMMARY}

The conceptual model of contaminant release and subsequent flow and transport in the SDA subsurface was updated for this feasibility study. This updated model is the most comprehensive and thorough description compiled to date. The conceptual model was represented in a numerical simulator that was used to evaluate cumulative health effects for five remedial alternatives. A series of simulations also was performed to address sensitivity to (a) uranium solubility, (b) uranium distribution coefficient, (c) an increased infiltration rate through the ET surface barrier, and (d) full retrieval with no ET surface barrier. These modeling results provide the means to assess effectiveness of remedial alternatives in protecting human health and the environment.

\section{D-6. REFERENCES}

42 USC $\S 9601$ et seq., 1980, "Comprehensive Environmental Response, Compensation and Liability Act of 1980 (CERCLA/Superfund)," United States Code.

Abbott, Carolyn, Molly Anderson, Margaret Hinman, and Charles Marcinkiewicz, 2005, Historical Background Report for Rocky Flats Plant Waste Shipped to the INEEL and Buried in the SDA from 1954 through 1971, ICP/EXT-04-00248, Rev. 1, Idaho National Laboratory, Idaho Completion Project.

Anderson, Danny L. and Bruce H. Becker, 2006, Source-Release Modeling Report for Operable Unit 7-13/14, ICP/EXT-05-01039, Rev. 1, Idaho National Laboratory, Idaho Cleanup Project. 
Anderson, S. R. and B. D. Lewis, 1989, Stratigraphy of the Unsaturated Zone at the Radioactive Waste Management Complex, Idaho National Engineering Laboratory, Idaho, U.S. Geological Survey Water-Resources Investigations Report 89-4065, U.S. Geological Survey; DOE/ID-22080, U.S. Department of Energy Idaho Operations Office.

Ansley, Shannon L., Catherine M. Helm-Clark, and Swen O. Magnuson, 2004, Updated Stratigraphic Selections for Wells in the Vicinity of the Subsurface Disposal Area, ICP/EXT-04-00207, Rev. 0, Idaho National Engineering and Environmental Laboratory, Idaho Completion Project.

Arnett, R. C., R. C. Martineau, and Michael J. Lehto, 1990, Preliminary Numerical Model of Radionuclide Transport in the Snake River Plain Aquifer Near the Idaho National Engineering Laboratory, EGG-WM-8820, Idaho National Engineering Laboratory.

Baca, R. G., S. O. Magnuson, H. D. Nguyen, and P. Martian, 1992, A Modeling Study of Water Flow in the Vadose Zone Beneath the Radioactive Waste Management Complex, EGG-GEO-10068, Idaho National Engineering Laboratory.

Barraclough, J. T., J. B. Robertson, V. J. Janzer, and L. G. Saindon, 1976, Hydrology of the Solid Waste Burial Ground as Related to the Potential Migration of Radionuclides at the Idaho National Engineering Laboratory, U.S. Geological Survey Open-File Report 76-471, IDO 22056, prepared by the U.S. Geological Survey for the U.S. Energy Research and Development Administration.

Batcheller, Thomas A. and George D. Redden, 2004, Colloidal Plutonium at the OU 7-13/14 Subsurface Disposal Area: Estimate of Inventory and Transport Properties, ICP/EXT-04-00253, Idaho National Engineering and Environmental Laboratory, Idaho Completion Project.

Bear, Jacob, 1972, Dynamics of Fluids in Porous Media, New York: Dover Publications.

Becker, Bruce, 2006, “Operable Unit 7-13/14 Exposure Pathway Calculations,” EDF-7112, Idaho National Laboratory, Idaho Cleanup Project.

Bishop, C. W., 1991, Hydraulic Properties of Vesicular Basalt, M.S. Thesis: University of Arizona, Tucson, Arizona.

Bishop, C. W., 1996, Soil Moisture Monitoring Results at the Radioactive Waste Management Complex of the Idaho National Engineering Laboratory, FY-96, FY-95, and FY-94, INEL-96/297, Idaho National Engineering Laboratory.

Cecil, L. D., J. R. Pittman, T. M. Beasley, R. L. Michel, P. W. Kubik, P. Sharma, U. Fehn, and H. Gove, 1992, "Water Infiltration Rates in the Unsaturated Zone at the Idaho National Engineering Laboratory Estimated from Chlorine-36 and Tritium Profiles, and Neutron Logging," Proceedings of the 7th International Symposium on Water-Rock Interaction, Park City, Utah, WRI-7, Rotterdam: Balkema.

EPA, 1989, Risk Assessment Guidance for Superfund, Vol. I - Human Health Evaluation Manual, Interim Guidance, Part A, EPA/540/1-89/002, U.S. Environmental Protection Agency.

EPA, 2001, Health Effects Assessment Summary Tables, Annual Update, U.S. Environmental Protection Agency. 
EPA, 2006, Integrated Risk Information System, IRIS Database for Risk Assessment, U.S. Environmental Protection Agency, URL: http://www.epa.gov/iriswebp/iris/index.html, updated June 6, 2006, Web page visited February 12, 2007.

Fjeld, Robert J., John T. Coates, and Alan W. Elzerman, 2000, Final Report, Column Tests to Study the Transport of Plutonium and Other Radionuclides in Sedimentary Interbed at INEEL, INEEL/EXT-01-00763, Rev. 0, prepared by the Department of Environmental Engineering and Science, Clemson University, Clemson, South Carolina, for the Idaho National Engineering and Environmental Laboratory.

GeoTrans, 2006, Benchmarking/Verification of TETRAD Simulator, Version 12.7MS, GeoTrans.

Grossman, Christopher J., Robert A. Fjeld, John T. Coates, and Alan W. Elzerman, 2001, The Sorption of Selected Radionuclides in Sedimentary Interbed Soils from the Snake River Plain,

INEEL/EXT-01-01106, Rev. 0, prepared by Clemson University, Clemson, South Carolina, for the Idaho National Engineering and Environmental Laboratory.

Hackett, W. R., J. A. Tullis, R. P. Smith, S. J. Miller, T. V. Dechert, P. A. McDaniel, and A. L. Falen, 1995, Geologic Processes in the RWMC Area, Idaho National Engineering Laboratory:

Implications for Long Term Stability and Soil Erosion at the Radioactive Waste Management Complex, INEL-95/0519, Idaho National Engineering Laboratory.

Holdren, K. Jean and Barbara J. Broomfield, 2004, Second Addendum to the Work Plan for the OU 7-13/14 Waste Area Group 7 Comprehensive Remedial Investigation/Feasibility Study, DOE/ID-11039, Rev. 0, U.S. Department of Energy Idaho Operations Office.

Holdren, K. Jean, Bruce H. Becker, Nancy L. Hampton, L. Don Koeppen, Swen O. Magnuson, T. J. Meyer, Gail L. Olson, and A. Jeffrey Sondrup, 2002, Ancillary Basis for Risk Analysis of the Subsurface Disposal Area, INEEL/EXT-02-01125, Idaho National Engineering and Environmental Laboratory.

Holdren, K. Jean, Danny L. Anderson, Bruce H. Becker, Nancy L. Hampton, L. Don Koeppen, Swen O. Magnuson, and A. Jeffrey Sondrup, 2006, Remedial Investigation and Baseline Risk Assessment for Operable Unit 7-13/14, DOE/ID-11241, U.S. Department of Energy Idaho Operations Office.

Hubbell, J. M., 1990, Perched Ground Water at the Radioactive Waste Management Complex of the Idaho National Engineering Laboratory, EGG-ER-8779, Idaho National Engineering Laboratory.

Hubbell, J. M., 1993a, "Perched Water at the Radioactive Waste Management Complex," ER-VVED-098, Rev. 1, Idaho National Engineering Laboratory.

Hubbell, J. M., 1993b, "Perched Groundwater Monitoring in the Subsurface Disposal Area of the Radioactive Waste Management Complex," ER\&WM-EDF-002293, Idaho National Engineering Laboratory.

Hubbell, J. M., 1995, Perched Groundwater Monitoring in the Subsurface Disposal Area of the Radioactive Waste Management Complex, Idaho, FY-94, INEL-95/149, Idaho National Engineering Laboratory. 
Hubbell, J. M., E. D. Mattson, J. B. Sisson, and D. L. McElroy, 2002, "Water Potential Response in a Fractured Basalt from Infiltration Events," Evaluation and Remediation of Low Permeability and Dual Porosity Environments, ASTM 1415, American Society for Testing and Materials, West Conshohocken, Pennsylvania.

Hubbell, Joel M., Carolyn W. Bishop, Mike J. Rohe, and Vivian G. Schultz, 2005, Moisture-Monitoring Program at the Subsurface Disposal Area for Fiscal Year 2004, ICP/EXT-05-00829, Rev. 0, Idaho National Laboratory, Idaho Cleanup Project.

Hull, Larry C. and Carolyn W. Bishop, 2003, Fate of Magnesium Chloride Brine Applied to Suppress Dust from Unpaved Roads at the INEEL Subsurface Disposal Area, INEEL/EXT-01-01173, Rev. 0, Idaho National Engineering and Environmental Laboratory.

Hull, Laurence and Mary N. Pace, 2000, Solubility Calculations for Contaminants of Potential Concern, OU 7-13/14, INEEL/EXT-2000-00465, Rev. 0, Idaho National Engineering and Environmental Laboratory.

INEL, 1995, A Comprehensive Inventory of Radiological and Nonradiological Contaminants in Waste Buried in the Subsurface Disposal Area of the INEL RWMC During the Years 1952-1983, INEL-95/0310, Rev. 1, Idaho National Engineering Laboratory.

INL, 2005, Data Quality Objectives Summary Report for the Operable Unit 7-08 Post-Record of Decision Sampling, INEEL/EXT-2000-00814, Rev. 2, Idaho National Laboratory, Idaho Cleanup Project.

Jolley, Wendell, 2003, "Fiscal Year 2003 Pumping Test Results from Wells Located at the Radioactive Waste Management Complex," EDF-3777, Rev. 0, Idaho National Engineering and Environmental Laboratory.

Keck, Karen N., 1995, SDA Surface Water Description and Data, INEL-95/119, ER-WAG7-66, Idaho National Engineering Laboratory.

Knobel, L. L., B. R. Orr, and L. D. Cecil, 1992, "Summary of Background Concentrations of Selected Radiochemical and Chemical Constituents in Groundwater from the Snake River Plain Aquifer, Idaho: Estimated from an Analysis of Previously Published Data," Journal of the Idaho Academy of Science, Vol. 28, No. 10.1, pp. 48.

Knutson, C. F., K. A. McCormick, J. C. Crocker, M. A. Glenn, and M. L. Fishel, 1992, 3D RWMC Vadose Zone Modeling (Including FY-89 to FY-90 Basalt Characterization Results), EGG-ERD-10246, Idaho National Engineering Laboratory.

Kuntz, Mel A., Steven R. Anderson, Duane E. Champion, Marvin A. Lanphere, and Daniel J. Grunwald, 2002, "Tension Cracks, Eruptive Fissures, Dikes, and Faults Related to Late Pleistocene-Holocene Basaltic Volcanism and Implications for the Distribution of Hydraulic Conductivity in the Eastern Snake River Plain, Idaho," Special Paper 353: Geology, Hydrogeology, and Environmental Remediation: Idaho National Engineering and Environmental Laboratory, Eastern Snake River Plain, Idaho, Geological Society of America, pp. 111-133, URL: http://www.gsajournals.org/gsaonline/?request=get-abstract\&doi=10.1130\%2F0-8137-23531(2002)353\%3C111:TEAFRT\%3E2.0.CO\%3B2, Web page last visited February 12, 2007. 
Laney, P. T., S. C. Minkin, R. G. Baca, D. L. McElroy, J. M. Hubbell, L. C. Hull, B. F. Russell, G. J. Stormberg, and J. T. Pittman, 1988, Annual Progress Report: FY-1987: Subsurface Investigations Program at the Radioactive Waste Management Complex of the Idaho National Engineering Laboratory, DOE/ID-10183, U.S. Department of Energy Idaho Operations Office.

Leecaster, Molly K., 2002, Geostatistic Modeling of Subsurface Characteristics in the Radioactive Waste Management Complex Region, Operable Unit 7-13/14, INEEL/EXT-02-00029, Rev. 0, Idaho National Engineering and Environmental Laboratory.

Leecaster, Molly K., 2004, Fiscal Year 2004 Geostatistical Modeling of Lithologic Characteristics in the Radioactive Waste Management Complex for OU 7-13/14, ICP/EXT-04-00494, Idaho National Engineering and Environmental Laboratory, Idaho Completion Project.

Leecaster, Molly K. and Larry C. Hull, 2004, Spatial Distribution of Neptunium and Uranium Partition Coefficients $\left(K_{d}\right)$ for Interbed Sediments at a Radioactive Waste Subsurface Disposal Area, ICP/EXT-03-00088, Rev. 0, Idaho National Engineering and Environmental Laboratory, Idaho Completion Project.

Magnuson, S. O., 1995, Inverse Modeling for Field-Scale Hydrologic and Transport Parameters of Fractured Basalt, INEL-95/0637, Idaho National Engineering Laboratory.

Magnuson, S. O. and A. J. Sondrup, 1998, Development, Calibration, and Predictive Results of a Simulator for Subsurface Pathway Fate and Transport of Aqueous- and Gaseous-Phase Contaminants in the Subsurface Disposal Area at the Idaho National Engineering and Environmental Laboratory, INEEL/EXT-97-00609, Idaho National Engineering and Environmental Laboratory.

Magnuson, Swen O. and A. Jeffrey Sondrup, 2006, Subsurface Flow and Transport Model Development for the Operable Unit 7-13/14 Remedial Investigation and Feasibility Study, ICP/EXT-05-01016, Rev. 1, Idaho National Laboratory, Idaho Cleanup Project.

Martian, P., 1995, UNSAT-H Infiltration Model Calibration at the Subsurface Disposal Area, Idaho National Engineering Laboratory, INEL-95/0596, Idaho National Engineering Laboratory.

Martian, Peter, 2003, "Simulation of Carbon-14 Transport in a Mesoscale Experiment," EDF-3394, Rev. 0, Idaho National Engineering and Environmental Laboratory.

Martian, Peter, 2007, Verification and Benchmark Testing of the TETRAD Simulator, Version 12.7ms, RPT-335, Idaho National Laboratory, Idaho Cleanup Project.

Martian, P. and S. O. Magnuson, 1994, A Simulation Study of Infiltration Into Surficial Sediments at the Subsurface Disposal Area, Idaho National Engineering Laboratory, EGG-WM-11250, Idaho National Engineering Laboratory.

Matthern, Gretchen, Neal Yancey, Gregory Hulet, and Peter Shaw, 2005, Preremedial Design Report of Remediation Options for OU 7-13/14, ICP/EXT-04-00330, Rev. 0, Idaho National Laboratory, Idaho Cleanup Project.

McElroy, D. L., 1993, Soil Moisture Monitoring Results at the Radioactive Waste Management Complex of the Idaho National Engineering Laboratory, FY 1993, EGG-WM-11066, Idaho National Engineering Laboratory. 
McKenzie, M. Doug, Donald E. Sebo, Kirk M. Green, and Vivian G. Schultz, 2005, Waste Information and Location Database for the OU 7-13/14 Project, ICP/EXT-04-00271, Rev. 0, Idaho National Laboratory, Idaho Cleanup Project.

Morgan, I. L. and W. D. Bostick, 1992, "Performance Testing of Grout-Based Waste Forms for the Solidification of Anion Exchange Resins," Stabilization and Solidification of Hazardous, Radioactive, and Mixed Wastes, 2nd Volume, STP 1123, ASTM, Philadelphia, pp. 133-145.

Nimmo, John R., Kim S. Perkins, Peter E. Rose, Joseph P. Rousseau, Brennon R. Orr, Brian V. Twining, and Steven R. Anderson, 2002, "Kilometer-Scale Rapid Transport of Naphthalene Sulfonate Tracer in the Unsaturated Zone at the Idaho National Engineering and Environmental Laboratory," Vadose Zone Journal, Vol. 1, No. 1, pp. 89-101.

Olson, Gail, 2004a, OU 7-13/14 Field Representative GEM Logbook, January 20, 2004 -

February 20, 2004, ER-038-2004, Idaho National Engineering and Environmental Laboratory, Idaho Completion Project.

Olson, Gail, 2004b, OU 7-13/14 Field Representative GEM Logbook, December 15, 2003 February 24, 2004, ER-039-3004, Idaho National Engineering and Environmental Laboratory, Idaho Completion Project.

Rawson, S. A., J. C. Walton, and R. G. Baca, 1991, "Migration of Actinides from a Transuranic Waste Disposal Site in the Vadose Zone," Radiochimica Acta, Vol. 52/53, pp. 477-486.

Rightmire, C. T. and B. D. Lewis, 1987, Hydrogeology and Geochemistry of the Unsaturated Zone, Radioactive Waste Management Complex, Idaho National Engineering Laboratory, Idaho, U.S. Geological Survey Water-Resources Investigations Report 87-4198, U.S. Geological Survey; DOE/ID-22073, U.S. Department of Energy Idaho Operations Office.

Robertson, J. B., R. Schoen, and J. T. Barraclough, 1974, The Influence of Liquid Waste Disposal on the Geochemistry of Water at the National Reactor Testing Station, Idaho, 1952-1970, Open-File Report IDO-22053, U.S. Geological Survey.

Root, R. W. Jr., 1981, Documentation and User's Guide for DOSTOMAN-A Pathways Computer Model of Radionuclide Movement, DPST-81-549, Savannah River Laboratory.

Smith, Richard P., 2002, Variability of the Aquifer Thickness Beneath the Idaho National Engineering and Environmental Laboratory (INEEL), INEEL/EXT-02-01022, Idaho National Engineering and Environmental Laboratory.

Sondrup, A. Jeffrey, Eric C. Miller, Edward H. Seabury, and Nick Josten, 2004, Estimating Carbon Tetrachloride and Total Volatile Organic Compound Mass Remaining in Subsurface Disposal Area Pits, ICP/EXT-04-00396, Idaho National Engineering and Environmental Laboratory, Idaho Completion Project.

Vejvoda, Edward, 2005, Summary of Rocky Flats Plant Waste Buried in the Subsurface Disposal Area, ICP/EXT-04-00717, Idaho National Engineering and Environmental Laboratory, Idaho Completion Project.

Vigil, M. J., 1988, "Estimate of Water in Pits during Flooding Events," BWP-12, Idaho National Engineering Laboratory. 
Warren, J. E. and P. J. Root, 1963, “The Behavior of Naturally Fractured Reservoirs,” Transactions Society of Petroleum Engineers, AIME, Vol. 228, pp. 245-255.

Wood, Thomas R., 1989, Preliminary Assessment of the Hydrogeology at the Radioactive Waste Management Complex, Idaho National Engineering Laboratory, EGG-WM-8694, Idaho National Engineering Laboratory.

Wood, Thomas R. and Gregory T. Norrell, 1996, Integrated Large-Scale Aquifer Pumping and Infiltration Tests, Groundwater Pathways OU 7-06, Summary Report, INEL-96/0256, Rev. 0, Idaho National Engineering Laboratory.

Wylie, A. H., 1996, Pumping Test of Pit 9 Production Well, INEL-96/171, Idaho National Engineering Laboratory.

Wylie, A. H. and J. M. Hubbell, 1994, “Aquifer Testing of Wells M1S, M3S, M4D, M6S, M7S, and M10S at the Radioactive Waste Management Complex," ER-WAG7-26, Rev. 1, Idaho National Engineering Laboratory. 
D-102 
Appendix E

Development of Modules 
E-2 


\section{CONTENTS}

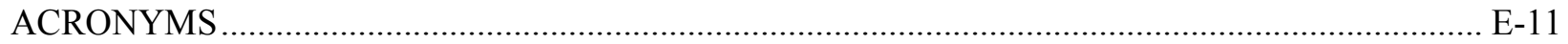

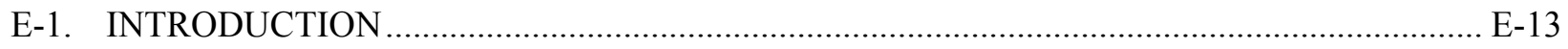

E-2. 2-ACRE RETRIEVAL, TREATMENT, AND DISPOSAL ………......................................... E-20

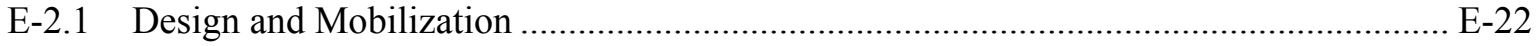

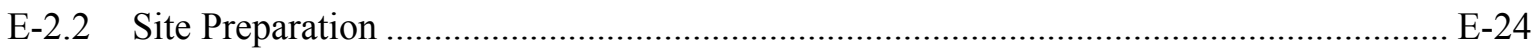

E-2.3 Readiness Demonstration ............................................................................ E-25

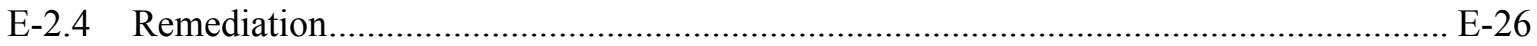

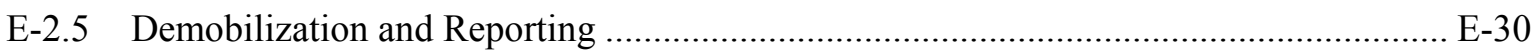

E-3. 4-ACRE RETRIEVAL, TREATMENT, AND DISPOSAL …................................................ E-30

E-4. FULL RETRIEVAL, TREATMENT, AND DISPOSAL ….................................................. E-32

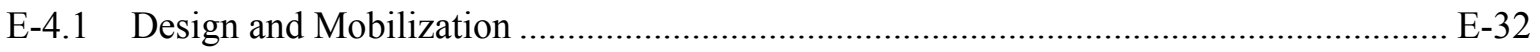

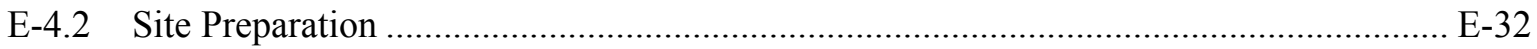

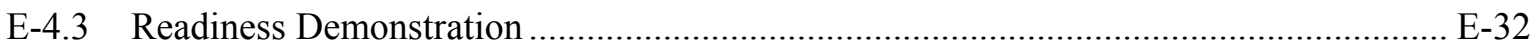

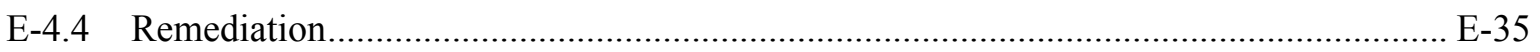

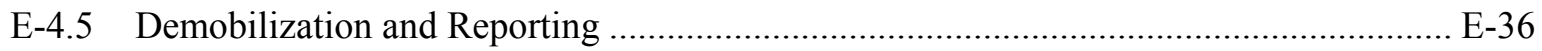

E-5. PAD A RETRIEVAL AND SUBSURFACE DISPOSAL AREA DISPOSAL ........................... E-36

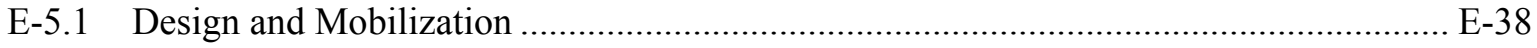

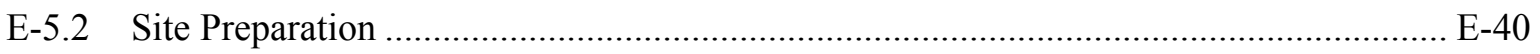

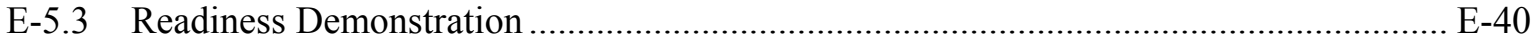

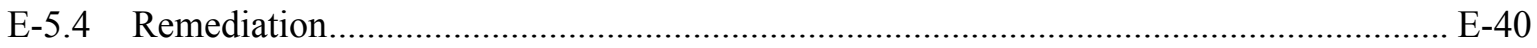

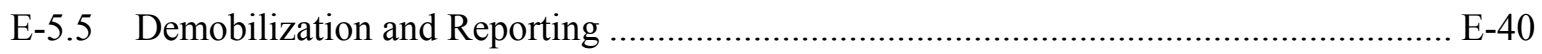

E-6. PAD A RETRIEVAL, EX SITU TREATMENT, AND SUBSURFACE DISPOSAL

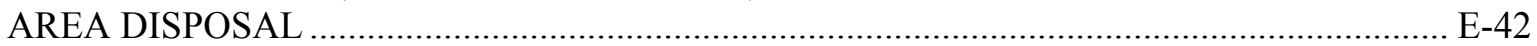

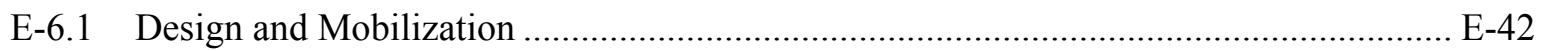

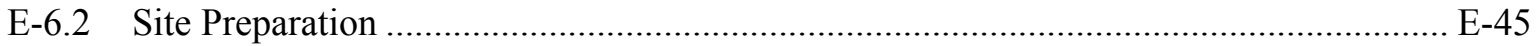

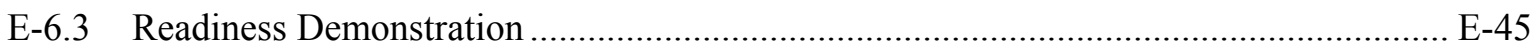




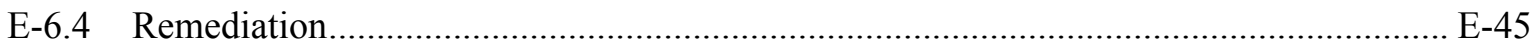

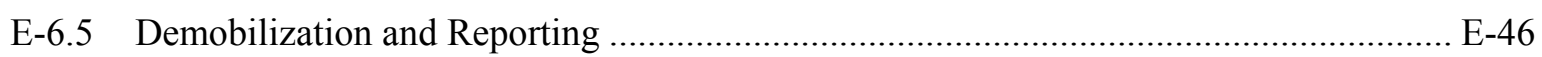

E-7. PAD A RETRIEVAL WITH SHIPMENT TO THE IDAHO CERCLA DISPOSAL

FACILITY FOR TREATMENT AND DISPOSAL …....................................................... E-46

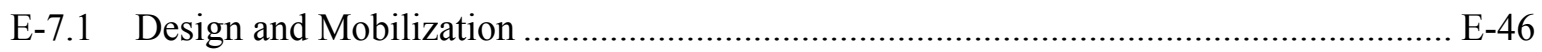

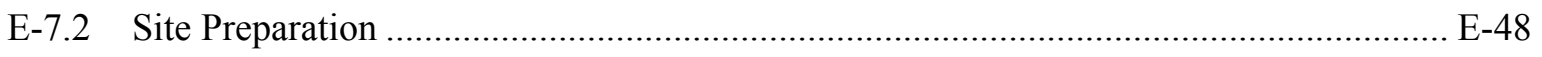

E-7.3 Readiness Demonstration .................................................................................. E-48

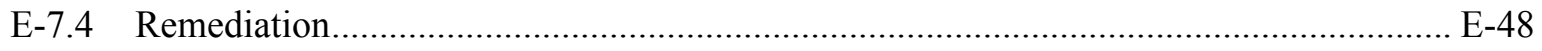

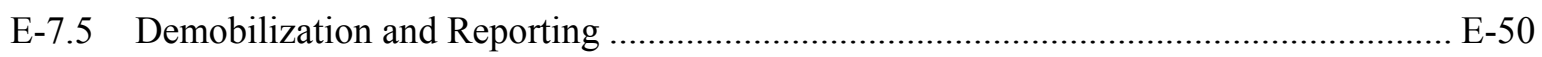

E-8. PAD A RETRIEVAL WITH SHIPMENT OFF THE IDAHO NATIONAL

LABORATORY SITE FOR TREATMENT AND DISPOSAL ............................................. E-50

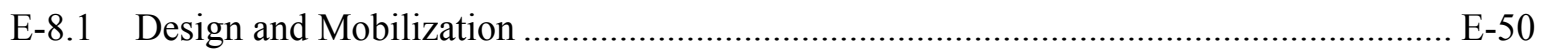

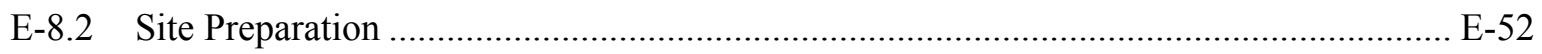

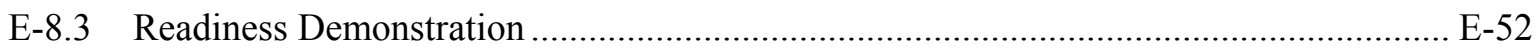

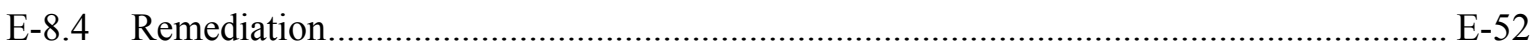

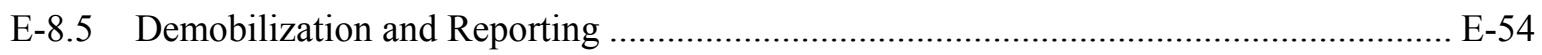

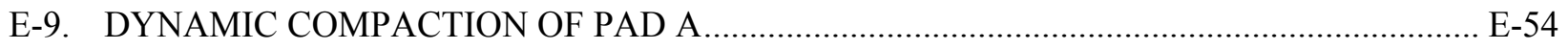

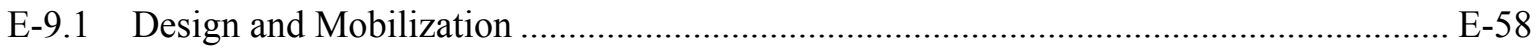

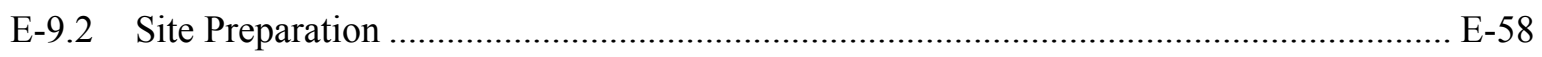

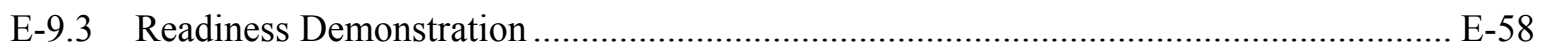

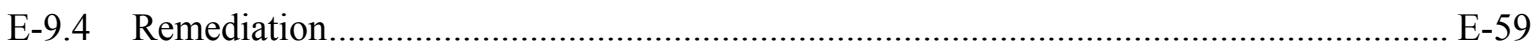

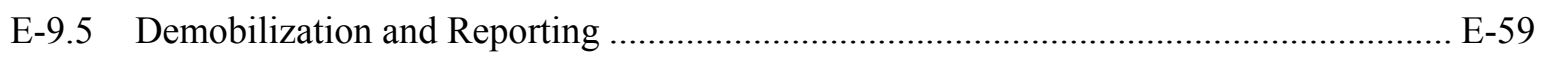

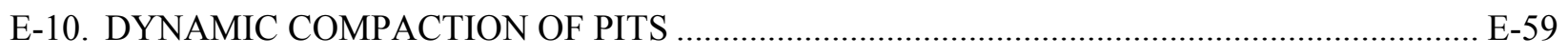

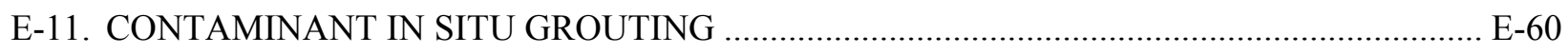

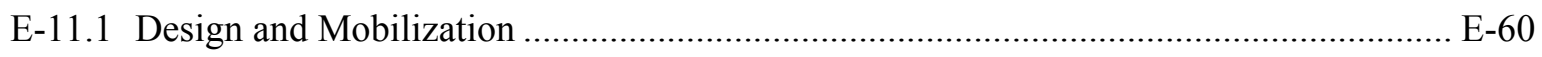

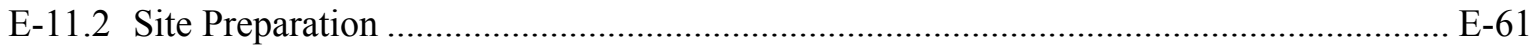

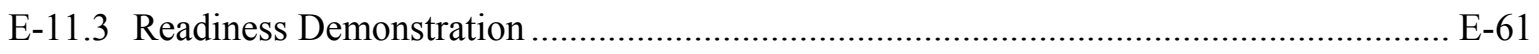

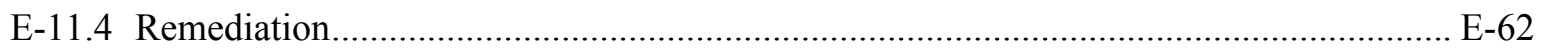

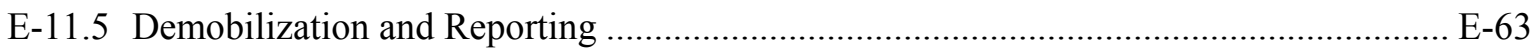




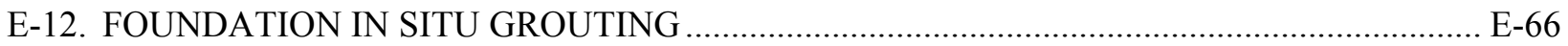

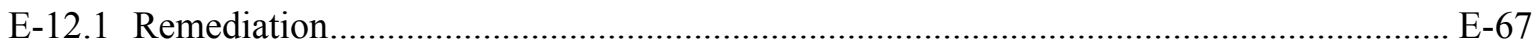

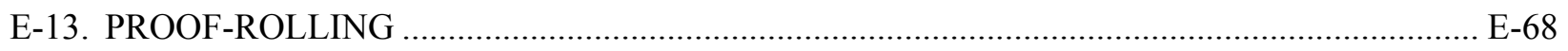

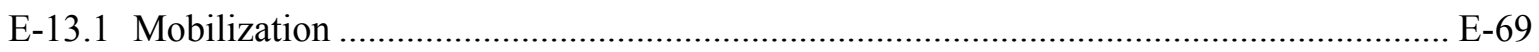

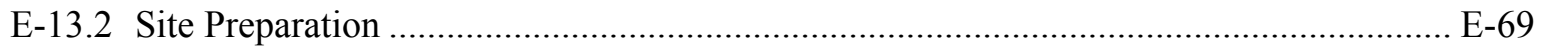

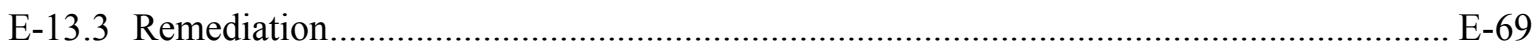

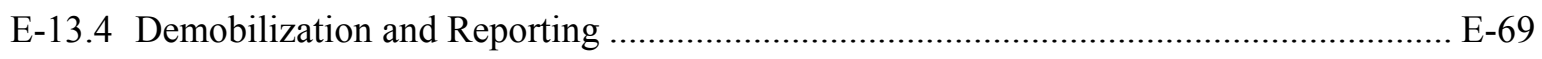

E-14. MODIFIED RESOURCE CONSERVATION AND RECOVERY ACT TYPE C

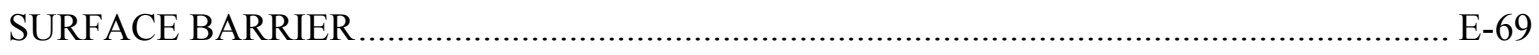

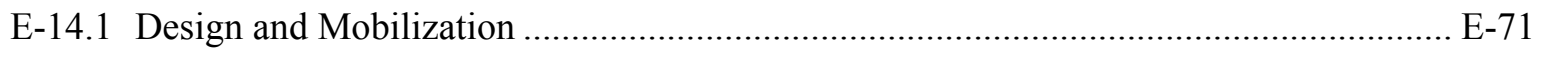

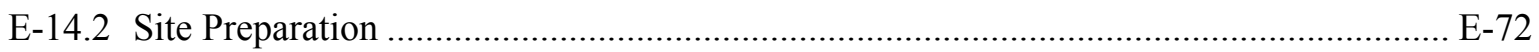

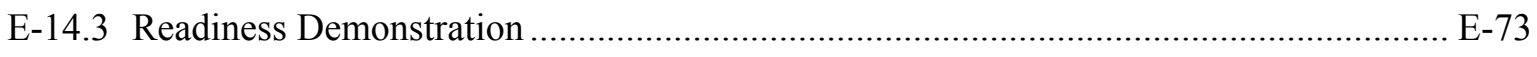

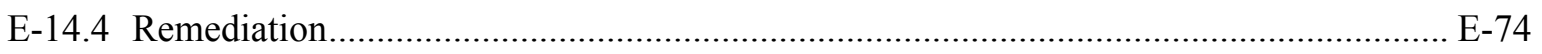

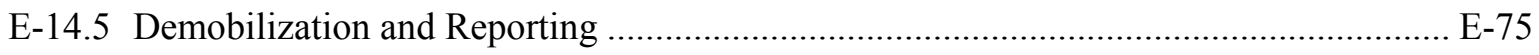

E-14.6 Long-Term Surveillance, Monitoring, and Reporting ….......................................... E-75

E-15. EVAPOTRANSPIRATION SURFACE BARRIER ............................................................ E-76

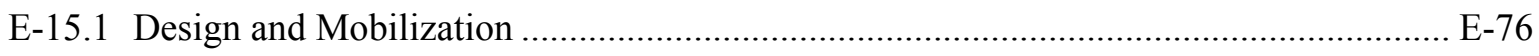

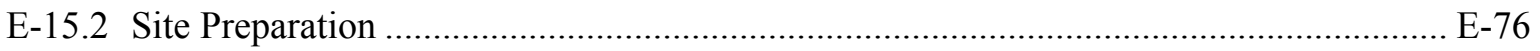

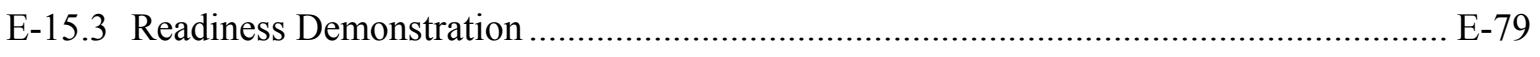

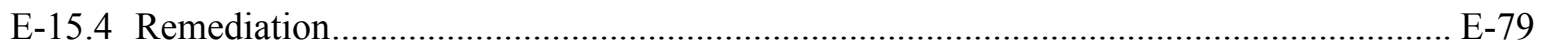

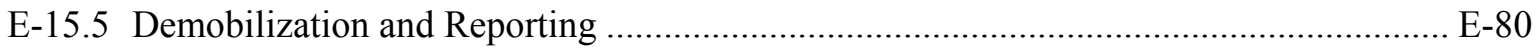

E-15.6 Long-Term Surveillance, Monitoring, and Reporting …......................................... E-80

E-16. SIMPLIFIED EVAPOTRANSPIRATION SURFACE BARRIER WITH NO
BIOINTRUSION AND GAS VENT LAYER .............................................................. E-80

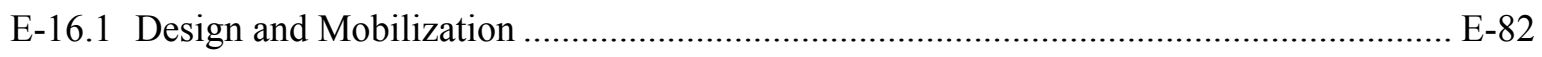

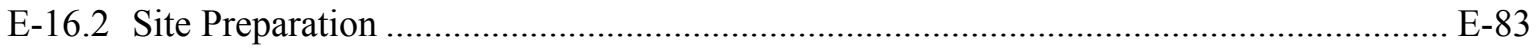

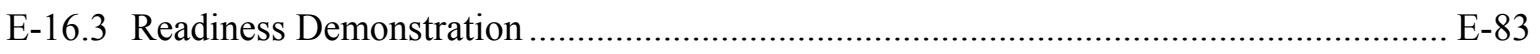

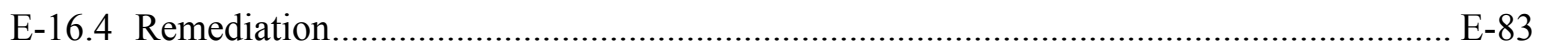




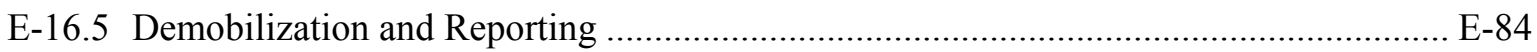

E-16.6 Long-Term Surveillance, Monitoring, and Reporting …........................................... E-84

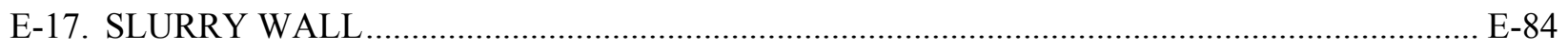

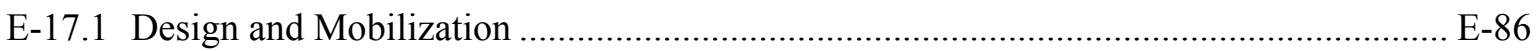

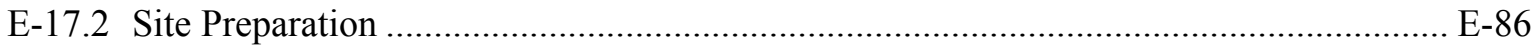

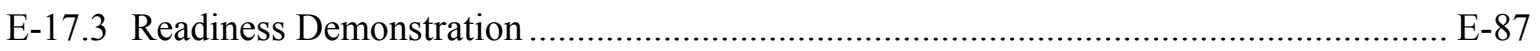

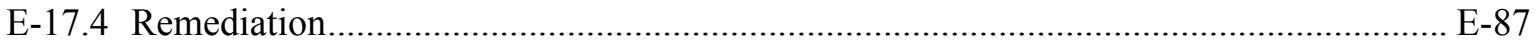

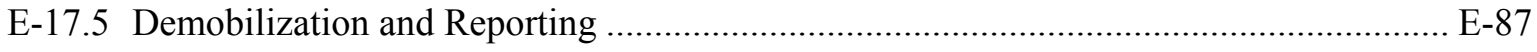

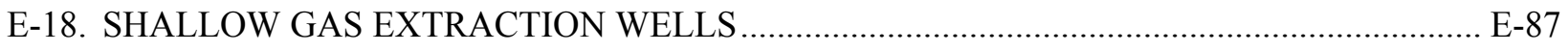

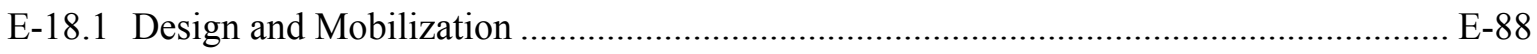

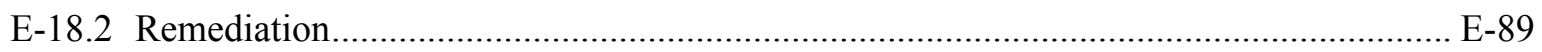

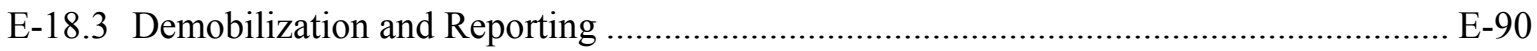

E-19. GAS VENT LAYER EXTRACTION PIPE ….................................................................. E-90

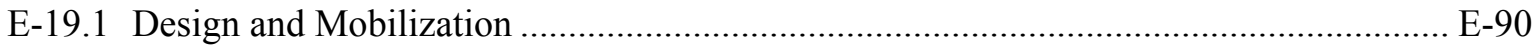

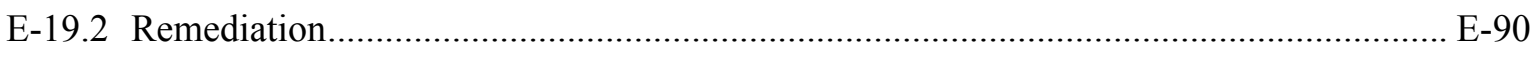

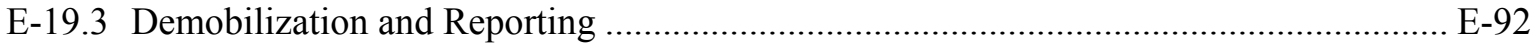

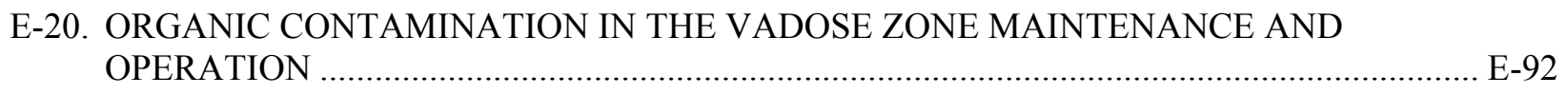

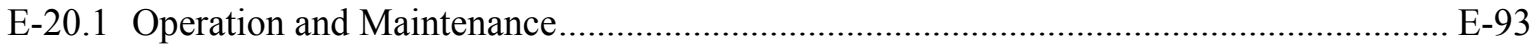

E-20.2 Treatment Unit Replacement................................................................................. E-94

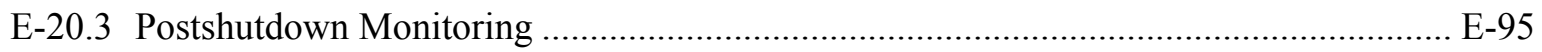

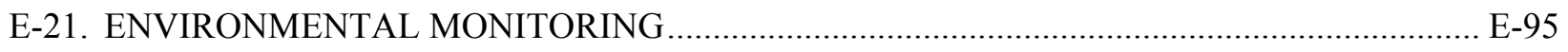

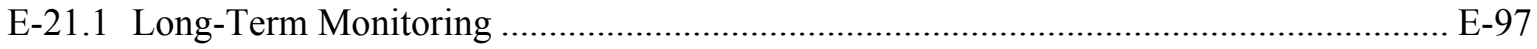

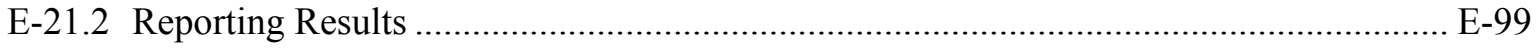

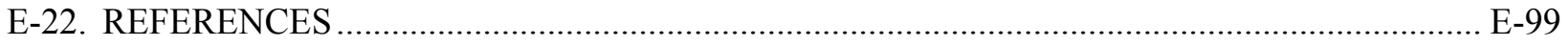




\section{FIGURES}

E-1. Retrieval Enclosure for the Accelerated Retrieval Project E-20

E-2. Modified excavation equipment at the Accelerated Retrieval Project................................... E-20

E-3. Preconceptual process flow diagram for partial retrieval, treatment, and disposal................... E-21

E-4. Hypothetical retrieval locations for retrieval, treatment, and disposal of targeted waste from pit areas totaling 2 acres.

E-5. Drum packaging system within the Accelerated Retrieval Project......................................... E-24

E-6. Modifications to the existing Retrieval Enclosure .................................................................. E-25

E-7. Preconceptual plan view of partial retrieval process in the Subsurface Disposal Area ............. E-26

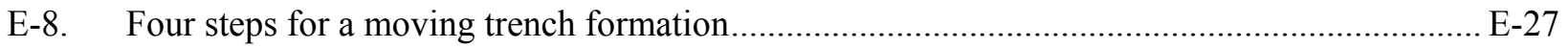

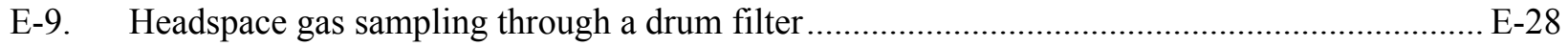

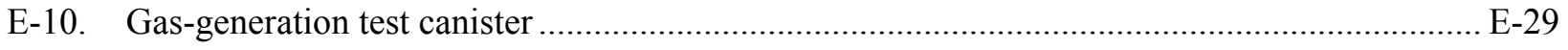

E-11. Hypothetical retrieval locations for retrieving targeted waste from pit areas totaling 4 acres

E-12. Preconceptual process flow diagram for full retrieval, treatment, and disposal ...................... E-33

E-13. Preconceptual plan view of full retrieval process and remote-handled storage in the Subsurface Disposal Area

E-14. Remote-handled drum removal at the Intermediate-Level Transuranic Storage Facility .......... E-36

E-15. Preconceptual process flow diagram for Pad A retrieval and Subsurface Disposal Area disposal

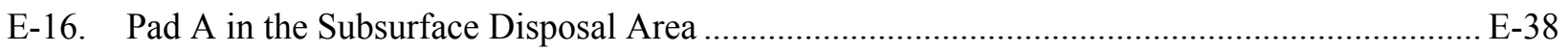

E-17. Pad A cross section covered by retrieval structure …..............................................................

E-18. Preconceptual plan view of the Pad A retrieval and Subsurface Disposal Area disposal.......... E-42

E-19. Preconceptual process flow diagram for Pad A retrieval, ex situ treatment, and Subsurface Disposal Area disposal.

E-20. Preconceptual plan view of Pad A retrieval, ex situ treatment, and Subsurface Disposal Area disposal

E-21. Preconceptual process flow diagram for Pad A retrieval and shipment to the Idaho CERCLA Disposal Facility for treatment and disposal. 


\section{FIGURES (continued)}

E-22. Preconceptual plan view of Pad A retrieval and shipment to the Idaho CERCLA Disposal Facility

E-23. Preconceptual process flow diagram for Pad A retrieval, treatment, and off-Idaho National Laboratory Site disposal

E-24. Preconceptual plan view of Pad A retrieval and shipment to an off-Idaho National Laboratory Site facility

E-25. Dynamic compaction operation at the Savanna River Site E-55

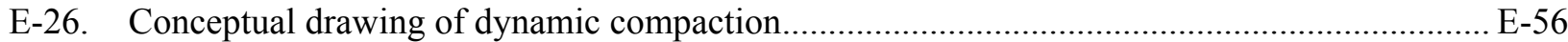

E-27. Preconceptual process flow diagram for dynamic compaction................................................. E-57

E-28. Preconceptual process flow diagram for in situ grouting.................................................... E-60

E-29. Hypothetical locations and spacing for contaminant in situ grouting .................................... E-61

E-30. Trackhoe combined with mast-mounted rotary percussion drill rig ...................................... E-62

E-31. In situ grouting feed system (from Cram 2004) ................................................................. E-64

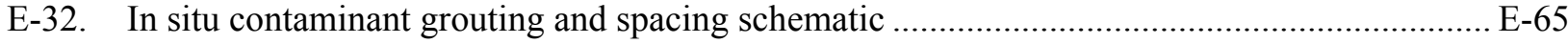

E-33. Hypothetical locations for foundation in situ grouting ….................................................. E-66

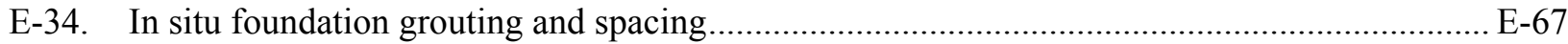

E-35. Preconceptual process flow diagram for proof-rolling ......................................................... E-68

E-36. Preconceptual process flow diagram for a modified RCRA Type C surface barrier................ E-70

E-37. Cross section of the modified RCRA Type C surface barrier.................................................... E-71

E-38. Preconceptual process flow diagram for an evapotranspiration surface barrier ...................... E-77

E-39. Cross section of evapotranspiration surface barrier ................................................................. E-78

E-40. Preconceptual process flow diagram for a simplified evapotranspiration surface barrier with no biointrusion and gas vent layer

E-41. Cross section of a simplified evapotranspiration surface barrier with no biointrusion and gas vent layer E-82

E-42. Preconceptual process flow diagram for a slurry wall ......................................................... E-85

E-43. Plan view and cross section of slurry cut-off wall production.............................................. E-86

E-44. Preconceptual process flow diagram for the shallow gas extraction well installation.............. E-88 


\section{FIGURES (continued)}

E-45. Extraction well cross section and locations E-89

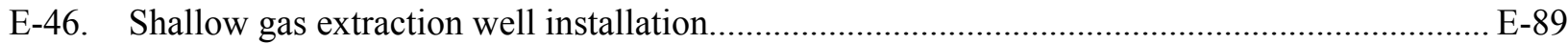

E-47. Preconceptual process flow diagram for the gas vent layer extraction pipe ........................... E-91

E-48. Gas vent layer extraction pipe within evapotranspiration surface barrier cross section ............ E-92

E-49. Preconceptual process flow diagram for operation and maintenance of the Organic Contamination in the Vadose Zone system

E-50. Preconceptual process flow diagram for replacement of Organic Contamination in the Vadose Zone system treatment units

E-51. Lysimeter - a development model using clear plastic instead of stainless steel to show probe internals

E-52. Vapor port — detects and collects gas and vapor samples ................................................. E-96

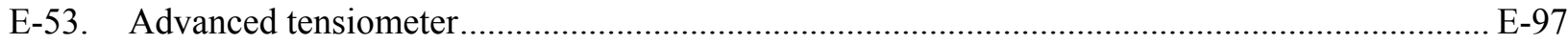

E-54. Preconceptual process flow diagram for Subsurface Disposal Area monitoring only ............... E-98

\section{TABLES}

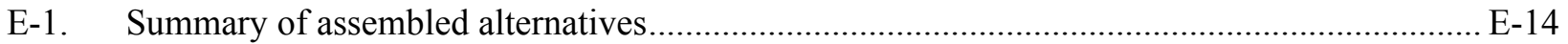

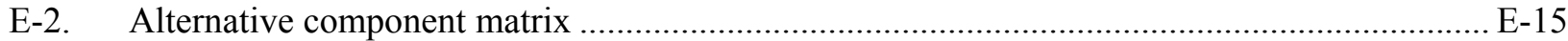

E-3. Waste type volumes for the 2-acre retrieval, treatment, and disposal module........................ E-23

E-4. Disposal locations and quantities for the 2-acre retrieval, treatment, and disposal module ...... E-23

E-5. Waste type volumes for the 4-acre retrieval, treatment, and disposal module........................ E-31

E-6. Disposal locations and quantities for the 4-acre retrieval, treatment, and disposal module ...... E-31

E-7. Waste type volumes for the full retrieval, treatment, and disposal module ............................ E-34

E-8. Disposal locations and quantities for full retrieval, treatment, and disposal............................ E-34

E-9. Waste type volumes for Pad A retrieval and Subsurface Disposal Area disposal .................... E-39

E-10. Waste type volumes for Pad A retrieval, ex situ treatment, and Subsurface Disposal Area disposal. 


\section{TABLES (continued)}

E-11. Waste type volumes for Pad A retrieval with shipment to the Idaho CERCLA Disposal Facility for treatment and disposal.

E-12. Waste type volumes for Pad A retrieval with shipment off the Idaho National Laboratory Site for treatment and disposal E-53

E-13. Description, thickness, and volume of materials that would comprise the modified RCRA Type C surface barrier.

E-14. Description, thickness, and volume of material that would comprise the evapotranspiration surface barrier. E-78

E-15. Design layers, thickness, and volume of a simplified evapotranspiration surface barrier ......... E-82 


\section{ACRONYMS}

CERCLA Comprehensive Environmental Response, Compensation, and Liability Act

COC contaminant of concern

DOE U.S. Department of Energy

ET evapotranspiration

IC institutional control

ICDF Idaho CERCLA Disposal Facility

INL Idaho National Laboratory

ISG in situ grouting

LLW low-level waste

OCVZ Organic Contamination in the Vadose Zone

OU operable unit

RCRA Resource Conservation and Recovery Act

RTD retrieval, treatment, and disposal

RWMC Radioactive Waste Management Complex

SDA Subsurface Disposal Area

VOC volatile organic compound

WIPP Waste Isolation Pilot Plant 
E-12 


\section{Appendix E}

\section{Development of Modules}

\section{E-1. INTRODUCTION}

This appendix to the Feasibility Study for Operable Unit 7-13/14 discusses the five comprehensive remedial alternatives that have been developed to provide decision-makers with a range of options for remedial action at Operable Unit (OU) 7-13/14, in accordance with National Contingency Plan (40 CFR 300) expectations and requirements for developing source control alternatives. These alternatives address remedial action objectives identified in Section 2.1 that were developed by combining representative process options identified in Section 2.3 into distinct technical approaches. Representative process options were assembled to provide general response actions appropriate to waste disposal configurations, waste forms, and environmental conditions in the Subsurface Disposal Area (SDA) within the Radioactive Waste Management Complex (RWMC).

All alternatives, except Alternative 1 (No Action), include surface barrier process options that inhibit infiltration and subsequent transport of contaminants to the vadose zone. Containment process options also include means for managing volatile organic compounds (VOCs) released into the surface barrier or migrating into the underlying vadose zone. One alternative evaluates a surface barrier as the primary means of source control (i.e., Alternative 2-Surface Barrier, scenarios 2a and 2b). One alternative evaluates in situ treatment for immobilization of long-lived radioactive contaminants resulting from Idaho National Laboratory (INL) Site reactor operations (i.e., Alternative 3-In Situ Grouting [ISG]). One alternative evaluates the retrieval of a portion of waste containing transuranic isotopes from described areas within the SDA (i.e., Alternative 4-Partial Retrieval, Treatment, and Disposal [RTD], scenarios $4 \mathrm{a}$ and $4 \mathrm{~b}$ ). A final alternative develops a scenario for removal of all waste (e.g., low-level and remote-handled) from the SDA (i.e., Alternative 5-Full RTD). All alternatives include strategies for integrating Pad A (i.e., a unique abovegrade disposal area with a preexisting record of decision) into the comprehensive remedies. Alternatives were developed to include a full representation of applicable process options. Assigning a particular process option to a specific alternative does not imply a presumption of implementability or effectiveness for either the process option or assembled alternative.

Because a limited number of remedial alternatives would be applicable to SDA conditions and contaminants of concern (COCs), a preliminary screening of alternatives was not necessary, as discussed in U.S. Environmental Protection Agency (EPA) guidance, A Guide to Developing and Documenting Cost Estimates During the Feasibility Study (EPA 2000). These five alternatives were carried directly into the detailed analysis in Section 4, and Table E-1 provides a summary of the five alternatives.

Table E-2 segments the five alternatives into eight component categories. The first six categories are (1) methods for retrieving buried waste and disposing of that waste, (2) actions associated with the unique abovegrade disposal area (i.e., Pad A), (3) any in situ treatment technologies that would be applied, (4) foundation preparation activities applied to the SDA surface to help mitigate future subsidence, (5) type of surface barrier, and (6) method for removing VOCs that build up beneath the surface barrier. The final two categories indicate which alternatives (7) include 100 years of surveillance and monitoring and (8) include institutional controls (ICs). 
Table E-1. Summary of assembled alternatives.

\begin{tabular}{|c|c|}
\hline Alternative & Description $^{\mathrm{a}}$ \\
\hline 1. No Action & $\begin{array}{l}\text { Alternative } 1 \text { evaluates the absence of remedial action to provide a baseline for } \\
\text { comparison with other alternatives. Environmental monitoring is the only activity } \\
\text { evaluated for this alternative. }\end{array}$ \\
\hline 2. Surface Barrier & $\begin{array}{l}\text { Alternative } 2 \text { involves constructing a low-permeability surface barrier to control exposure } \\
\text { to contaminants by suppressing migration and implementing ICs. Two surface barrier } \\
\text { alternatives ( } 2 \text { a and } 2 \text { b) have been developed to support the evaluation of two competing } \\
\text { surface barriers (i.e., a modified RCRA Type C surface barrier with active gas extraction } \\
\text { through shallow wells and an ET surface barrier with active gas extraction from within the } \\
\text { barrier itself). The two surface barrier alternatives differ in foundation stabilization for } \\
\text { barrier support (foundation ISG and dynamic compaction) and disposition of Pad A waste } \\
\text { (leave in place and relocate within the SDA). }\end{array}$ \\
\hline 3. In Situ Grouting & $\begin{array}{l}\text { Alternative } 3 \text { includes deploying ISG to stabilize select areas within the SDA. Select areas } \\
\text { that contain COC-rich waste types (primarily fission products in waste from INL Site } \\
\text { reactor operations) would be stabilized. To address remaining untreated waste, the entire } \\
\text { SDA would also be covered by an ET surface barrier that incorporates passive gas } \\
\text { extraction. Dynamic compaction for foundation support and ex situ grouting of Pad A } \\
\text { waste, before disposal in the SDA, also would be evaluated. }\end{array}$ \\
\hline $\begin{array}{l}\text { 4. Partial Retrieval, } \\
\text { Treatment, and } \\
\text { Disposal }\end{array}$ & $\begin{array}{l}\text { Alternative } 4 \text { evaluates partial removal of buried waste. Select areas that contain } \\
\text { concentrations of Rocky Flats Plant transuranic waste and collocated roaster oxide } \\
\text { (uranium oxide) would be systematically retrieved. Two partial retrieval alternatives } \\
\text { ( } 4 \text { a and } 4 \text { b) have been developed to evaluate retrieval of targeted waste from pit areas } \\
\text { totaling either } 2 \text { or } 4 \text { acres. To address residual waste, the entire SDA would be covered } \\
\text { by an ET surface barrier with passive gas extraction. The two retrieval alternatives differ } \\
\text { in foundation stabilization for barrier support (dynamic compaction and proof-rolling) and } \\
\text { disposition of Pad A waste (relocate to ICDF and dynamically compact in place). } \\
\text { Additionally, a perimeter slurry wall would be incorporated in one of the partial retrieval } \\
\text { alternatives. }\end{array}$ \\
\hline $\begin{array}{l}\text { 5. Full Retrieval, } \\
\text { Treatment, and } \\
\text { Disposal }\end{array}$ & $\begin{array}{l}\text { Alternative } 5 \text { provides for removal of all contaminated waste to the maximum extent } \\
\text { possible. All buried waste would be systematically retrieved. Retrieved waste would be } \\
\text { managed using a combination of short-term staging of contact-handled waste, long-term } \\
\text { storage of remote-handled waste, and disposal at commercial and federal disposal sites. To } \\
\text { reduce moisture infiltration and subsequent transport of contaminants left in the vadose } \\
\text { zone, a surface barrier would cover the entire SDA. Pad A waste would be retrieved and } \\
\text { shipped off the INL Site. }\end{array}$ \\
\hline \multicolumn{2}{|c|}{$\begin{array}{l}\text { a. All assembled alternatives, except Alternative } 1 \text {, include continued operation of the OCVZ system until OU 7-08 remediation goals are } \\
\text { achieved, and long-term surveillance, maintenance, monitoring, and ICs. }\end{array}$} \\
\hline $\begin{array}{l}\mathrm{COC}=\text { contaminant of ce } \\
\mathrm{ET}=\text { evapotranspiration } \\
\text { IC }=\text { institutional control } \\
\text { ICDF = Idaho CERCLA } \\
\text { INL = Idaho National La } \\
\text { ISG = in situ grouting } \\
\text { OCVZ = Organic Contan } \\
\text { OU = operable unit } \\
\text { RCRA = Resource Conse } \\
\text { SDA = Subsurface Dispo }\end{array}$ & $\begin{array}{l}\text { osal Facility } \\
\text { tory } \\
\text { tion in the Vadose Zone } \\
\text { ion and Recovery Act } \\
\text { Area }\end{array}$ \\
\hline
\end{tabular}


Table E-2. Alternative component matrix.

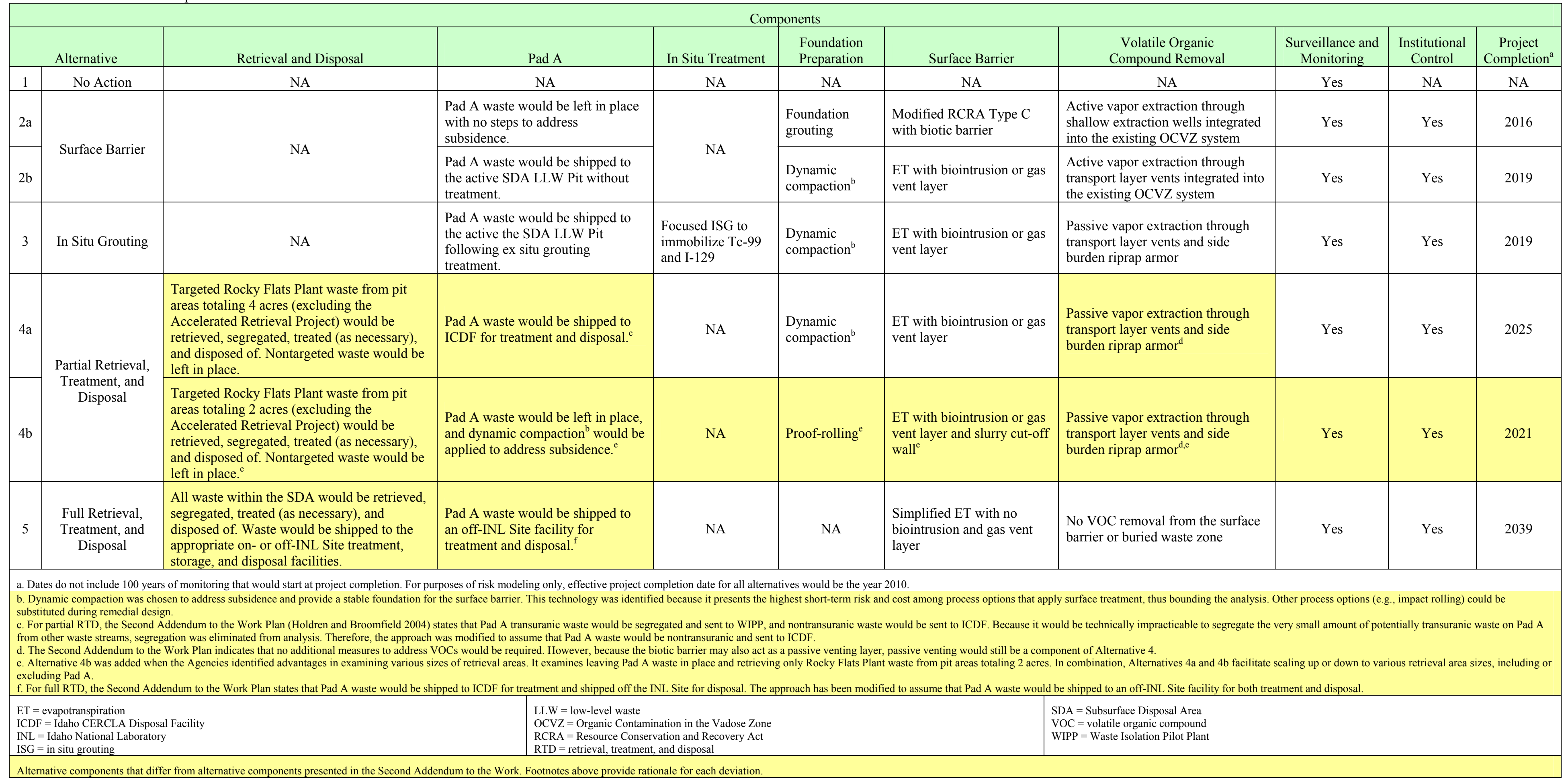



Some alternative components presented in Table E-2 differ from alternative components presented in the Second Addendum to the Work Plan (Holdren and Broomfield 2004). These differing components are highlighted in yellow in Table E-2, and footnotes provide rationale for the deviation.

For cost-estimating purposes, alternative components listed in Table E-2 are grouped into 20 separate modules. These modules provide a means by which construction activities (e.g., mobilization, site preparation, remediation, and demobilization) for each alternative component (e.g., surface barrier construction, slurry cut-off wall installation, dynamic compaction, and ISG) can be defined. Additionally, modularizing the alternative components allows use of identical modules for different alternatives. For example, the evapotranspiration (ET) surface barrier alternative (Alternative 2b), the ISG alternative (Alternative 3), and the 4-acre partial RTD alternative (Alternative 4a) all use dynamic compaction to stabilize the SDA before surface barrier placement. Using the modular method, a single dynamic compaction module may be used for all three alternatives. An added bonus to the modular approach is the ability to estimate costs and schedules for alternatives not listed in Table E-2 through an alternate combination of modules.

Figures, drawings, data, and assumptions provided in this appendix are based on hypothetical preconceptual design features that were generated for the sole purpose of developing cost estimates. Detailed design would occur for alternative component modules following selection of the preferred alternative. The following list provides brief high-level discussions of each module.

\section{- Retrieval and disposal modules}

- $\quad$ 2-Acre partial RTD (Section E-2)-This module consists of retrieving targeted waste from pit areas totaling 2 acres, sorting and packaging waste within a centrally located retrieval enclosure, and transporting waste to either the Waste Isolation Pilot Plant (WIPP) or the Idaho CERCLA Disposal Facility (ICDF), as appropriate.

- $\quad$ 4-Acre partial RTD (Section E-3) - This module consists of retrieving targeted waste from pit areas totaling 4 acres, sorting and packaging waste within a centrally located retrieval enclosure, and transporting waste to either WIPP or ICDF, as appropriate.

- $\quad$ Full RTD (Section E-4)-This module consists of retrieving all waste from the SDA. Remote-handled waste containing no transuranic isotopes would be placed in interim storage. All other waste would be sorted and packaged within a centrally located retrieval enclosure and transported to WIPP, ICDF, or another off-INL Site disposal facility, as appropriate.

\section{- Pad A modules}

- $\quad$ Removing Pad A and disposing of waste in the RWMC Low-Level Waste (LLW) Pit without treatment (Section E-5) - This module consists of contouring the Pad A berm and building an enclosure over the top for retrieving waste from Pad A. Waste would be retrieved, sorted, placed in bulk containers, and transferred to the LLW Pit (or other location in the SDA) without treatment.

- $\quad$ Removing Pad A and disposing of waste in the RWMC LLW Pit following ex situ treatment (Section E-6)-This module consists of contouring the Pad A berm and building an enclosure over the top for retrieving waste from Pad A. Waste would be retrieved, sorted, treated ex situ with grout, placed in waste boxes, and transferred to the LLW Pit (or other location in the SDA). 
- $\quad$ Removing Pad A and disposing of and treating waste at ICDF or similar on-INL Site facility (Section E-7)-This module consists of contouring the Pad A berm and building an enclosure over the top for retrieving waste from Pad A. Waste would be retrieved, sorted, visually examined to satisfy ICDF waste acceptance criteria, placed in waste boxes, and transferred to ICDF (or similar facility) for treatment and disposal.

- $\quad$ Removing Pad A and disposing of and treating waste at EnergySolutions or similar off-INL Site facility (Section E-8) - This module consists of contouring the Pad A berm and building an enclosure over the top for retrieving waste from Pad A. Waste would be retrieved, placed in containers, and transferred to EnergySolutions (formerly Envirocare) by rail for treatment and disposal.

- Dynamic compaction of Pad A (Section E-9) - This module consists of dynamically compacting soil by dropping a heavy weight from a designated height in an engineered pattern. This would prepare the Pad A mound for a surface barrier that would be placed over $\operatorname{Pad}$ A.

\section{- Foundation preparation modules}

- Dynamic compaction of pits (Section E-10) - This module consists of dynamically compacting pit areas by dropping a heavy weight from a designated height in an engineered pattern and is similar to dynamic compaction of Pad A. Dynamic compaction would mitigate subsidence in SDA pit areas to provide a stable base for a surface barrier. Dynamic compaction was identified because it presents the most short-term risk and highest cost among process options that apply surface treatment to address subsidence, thus bounding the analysis. Other process options (e.g., impact rolling) could be substituted during remedial design.

- $\quad$ Foundation grouting (Section E-12)-This module consists of injecting subsurface grout columns at regular intervals using a rotary percussion drill. Foundation grouting would provide a stable base for a cap.

- $\quad$ Proof-rolling (Section E-13) - This module consists of compacting the SDA pit areas using a roller-compactor. The proof-rolling compaction process would be used to test uniformity and stability of foundation for the surface barrier.

- In situ treatment module

Contaminant grouting (Section E-11)-This module consists of installing overlapping subsurface grout columns by injecting grout using a rotary percussion drill. Columns would overlap to fill entire specified areas with grout to encapsulate waste.

\section{- $\quad$ Surface barrier modules}

- Modified Resource Conservation and Recovery Act (RCRA) Type C surface barrier (Section E-14)-This module consists of constructing a modified RCRA Type C cap over the entire SDA. This surface barrier would manage moisture and biotic intrusion by incorporating an impermeable asphalt layer. This module also includes installing and demolishing roads and fences, extending wells, installing wells, contouring the SDA, and 100 years of surveillance, maintenance, monitoring, and ICs. Overall thickness of the cap, coupled with long-term ICs, would preclude inadvertent human intrusion. 
- $\quad$ ET surface barrier (Section E-15) - This module consists of constructing an ET cap, composed of several layers of varying thickness and composition, over the entire SDA. This type of surface barrier would manage moisture through evaporation and transpiration and would include layers to prevent biotic intrusion and collect volatile constituents emitted by buried waste. This module also includes installing and demolishing roads and fences, extending wells, installing wells, contouring the SDA, and 100 years of surveillance, maintenance, monitoring, and ICs. Overall thickness of the cap, coupled with long-term ICs, would preclude inadvertent human intrusion.

- $\quad$ Simplified ET surface barrier with no biointrusion and gas vent layer (Section E 16) This module consists of constructing a simplified ET cap specifically for Alternative 5, where features to address biotic intrusion and gas venting would not be required because all waste would be removed. This module also includes installing and demolishing roads and fences, extending wells, installing wells, contouring the SDA, and 100 years of surveillance, maintenance, monitoring, and ICs. Overall thickness of the cap, coupled with long-term ICs, would preclude inadvertent human intrusion.

- $\quad$ Slurry cut-off wall (Section E-17) - This module consists of installing a subsurface slurry cut-off wall by digging a trench around the SDA and immediately filling it with bentonite slurry. This belowgrade barrier would be placed beneath and incorporated into the toe of a surface barrier.

- Volatile organic compound removal modules:

- $\quad$ Near-surface vapor extraction wells (Section E-18)-This module consists of installing near-surface vapor extraction wells vertically through the modified RCRA Type C surface barrier, between the waste pits, and into the underlying basalt. Following cap completion, protruding wells would be connected to the OCVZ system.

- $\quad$ Gas vent layer extraction pipe (Section E-19)-This module consists of placing sections of horizontal pipe within the ET cap biointrusion and gas vent layer and either connecting the pipe to the OCVZ system or venting the pipe directly to the atmosphere.

- OCVZ system operations and maintenance (Section E-20)-This module consists of operating and maintaining the OCVZ system. Three phases associated with this module are: (1) operating and maintaining OCVZ treatment units for each 5-year period they operate, (2) replacing OCVZ treatment units for each 20 years they are in service, and (3) shutting down the OCVZ system at the end of operation. Because alternatives have different OCVZ system operational timeframes, various combinations of these three phases would be used to estimate cost for each alternative.

- Monitoring module

- Monitoring (Section E-21) - This module comprises only environmental monitoring for the No Action alternative. Unlike surface barrier modules, this module does not involve installing new monitoring equipment as a site-preparation activity. This module includes 100 years of monitoring. 


\section{E-2. 2-ACRE RETRIEVAL, TREATMENT, AND DISPOSAL}

Two-acre retrieval of targeted waste would be performed within a large centrally located retrieval enclosure (see Figure E-1) and within three smaller mobile tent structures using excavators modified for breathing air, dust suppression, and camera optics (see Figure E-2). Targeted waste includes Rocky Flats Plant Series 741 sludge and 743 sludge, filters, graphite, and roaster oxides. Determinations of whether waste is targeted or nontargeted are made at or near the dig face.

Figure E-3 provides a preconceptual process diagram that overviews implementation of this module and was created for cost-estimation purposes. Key tasks identified in Figure E-3 are discussed in the following subsections.

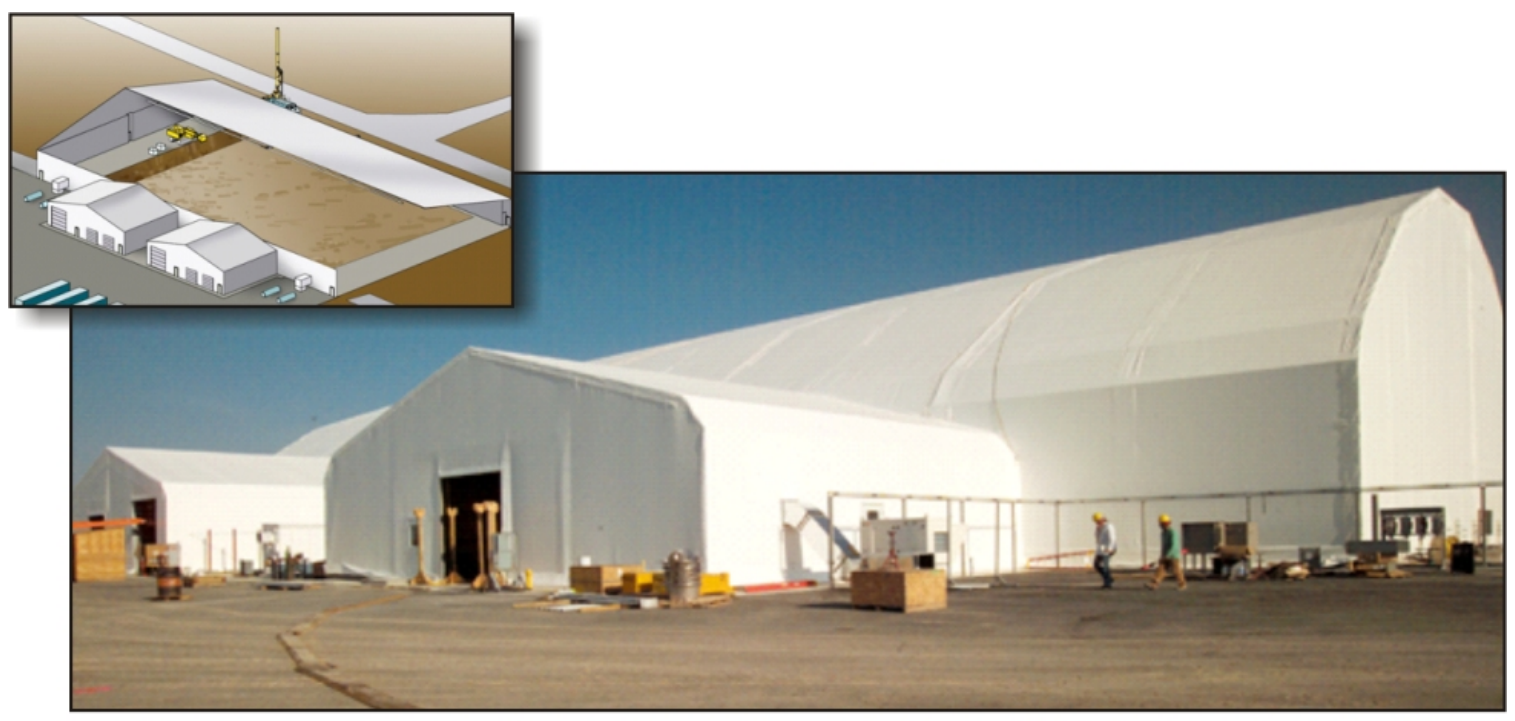

G06-1746-10

Figure E-1. Retrieval Enclosure for the Accelerated Retrieval Project.

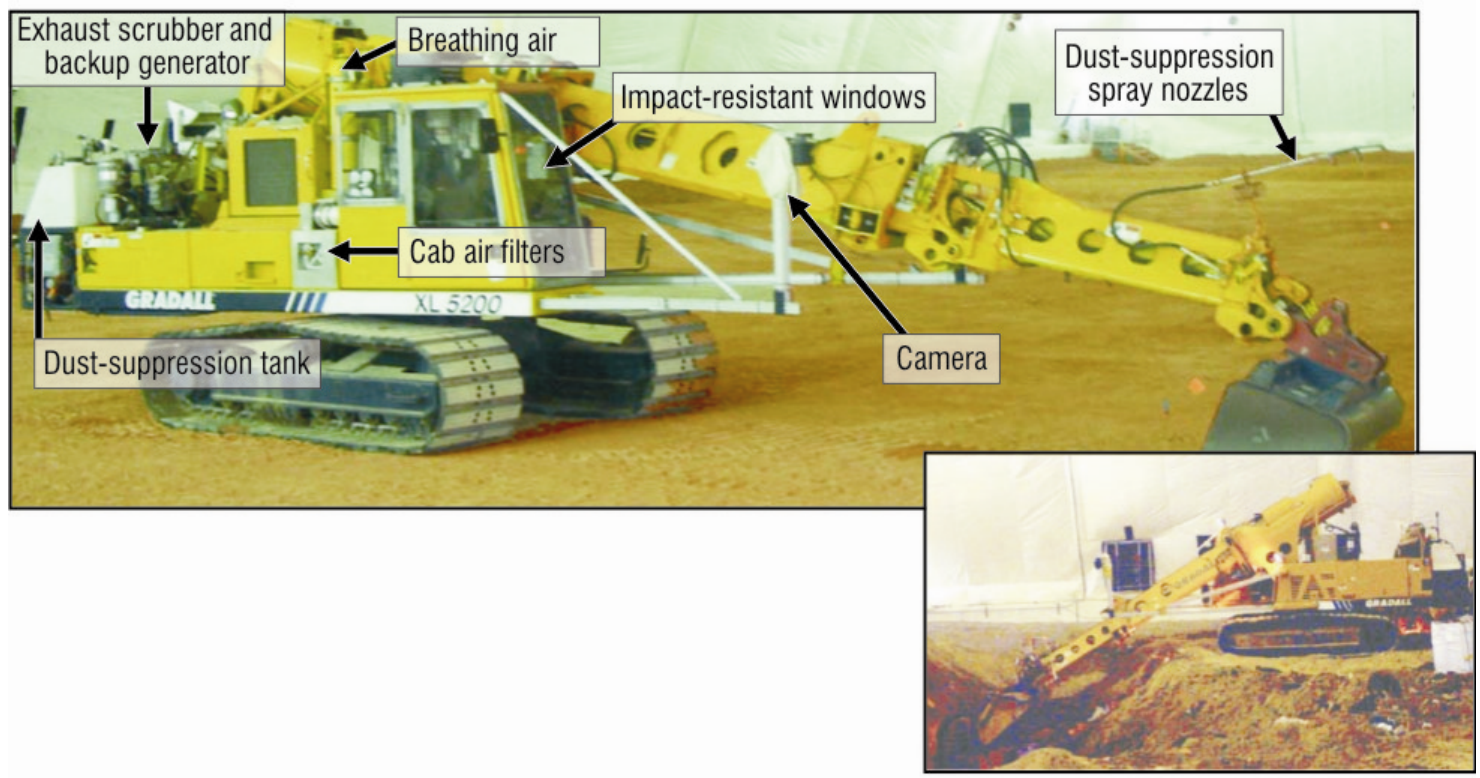

G06-1746-11

Figure E-2. Modified excavation equipment at the Accelerated Retrieval Project. 


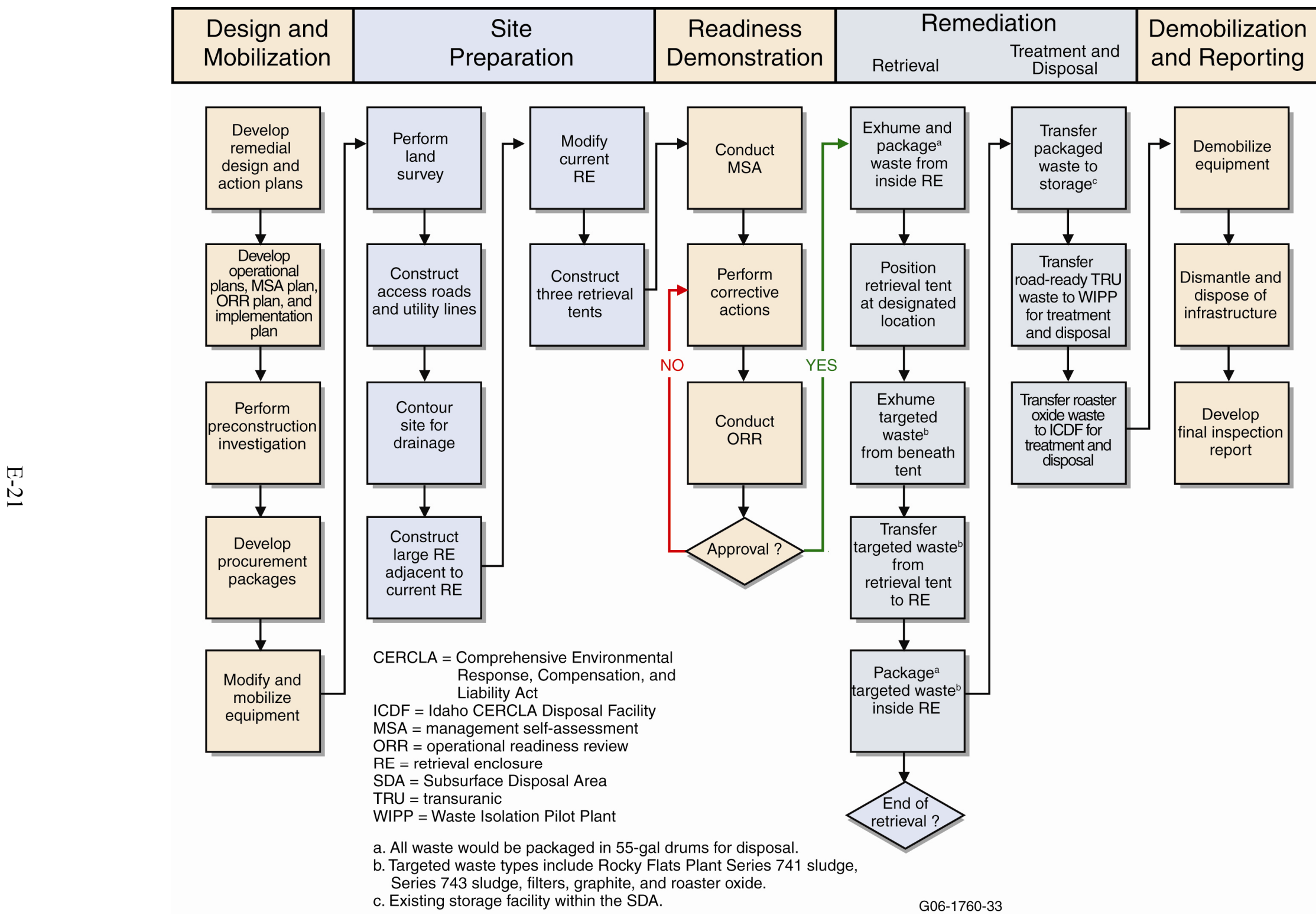

Figure E-3. Preconceptual process flow diagram for partial retrieval, treatment, and disposal. 


\section{E-2.1 Design and Mobilization}

Design and mobilization for retrieving and disposing of targeted waste from SDA pit areas totaling 2 acres, include developing remedial design and remedial action work plans, operational and management self-assessment plans (i.e., generating an operation and layout plan, a radiation monitoring and control plan, an industrial hygiene exposure and sampling plan, a training plan, and a quality control plan), operational readiness review plan of action and implementation plan; developing procurement packages; performing a preconstruction investigation; and mobilizing equipment to the work site.

Developing remedial design and remedial action work plans would include preparing designs and schedules for (a) constructing a centrally located retrieval structure and three smaller mobile retrieval tents; (b) retrieving targeted waste from highlighted areas, as shown on Figure E-4, within the large retrieval structure and mobile retrieval tents; and (c) disposing of those waste forms at WIPP and ICDF. Preliminary designs assume that half the Rocky Flats Plant Series 742 sludge either would be commingled with Series 741 sludge or would be mistakenly identified as Series 741 sludge and retrieved. As presented in Table E-3, volumes of buried waste expand because of waste captured within the angle of repose, commingled soil, waste expansion following retrieval, and the void space left within the final packaged waste drum. Table E-4 provides the quantity of waste sent to various treatment and disposal facilities, both on and off the INL Site

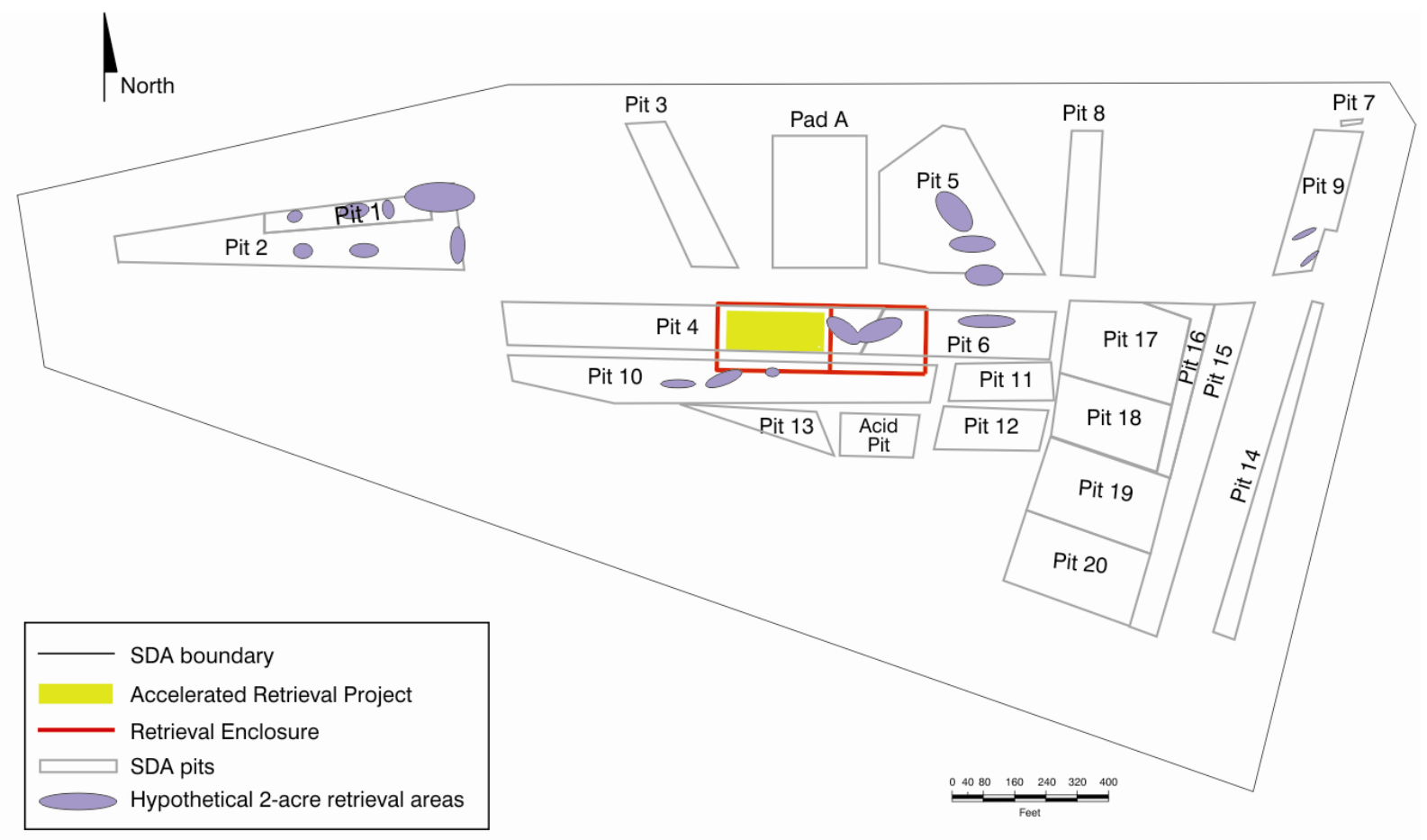

Figure E-4. Hypothetical retrieval locations for retrieval, treatment, and disposal of targeted waste from pit areas totaling 2 acres. 
Table E-3. Waste type volumes for the 2-acre retrieval, treatment, and disposal module.

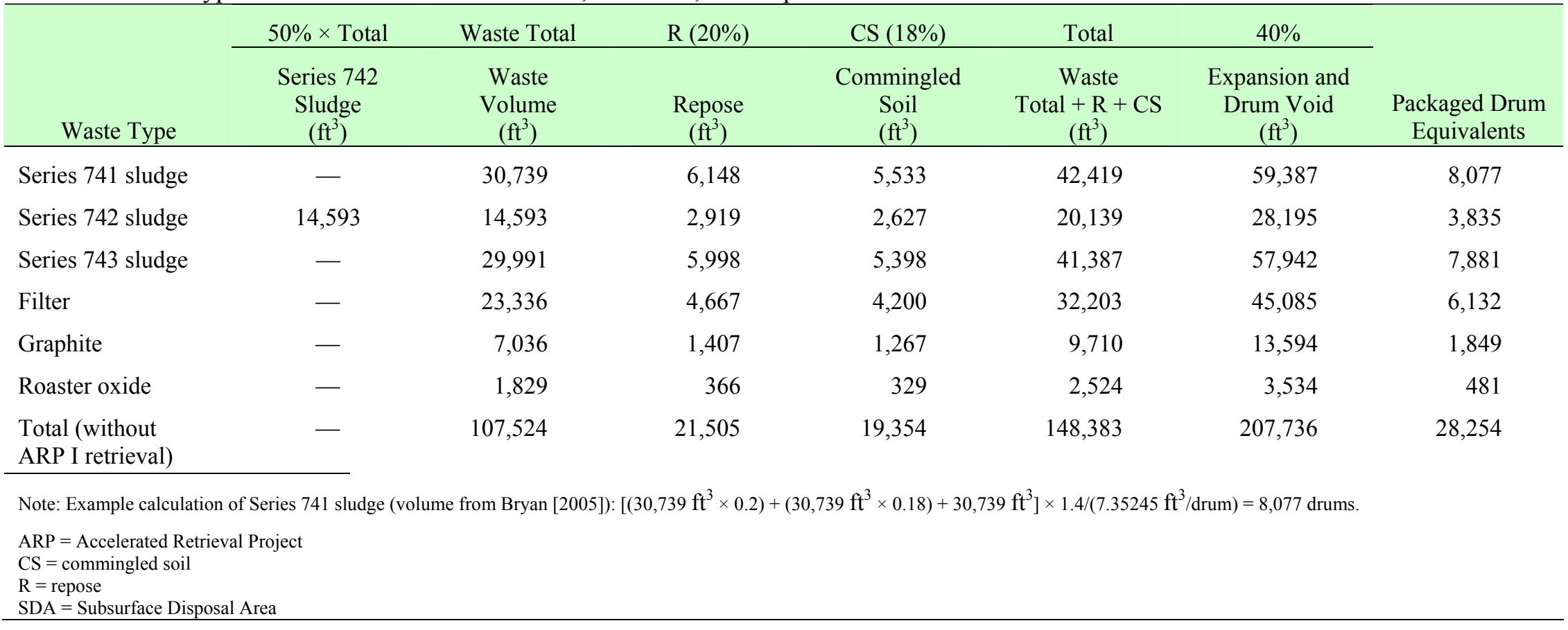

Table E-4. Disposal locations and quantities for the 2-acre retrieval, treatment, and disposal module.

\begin{tabular}{|c|c|c|c|c|}
\hline & Drums & $\mathrm{ft}^{3}$ & $\mathrm{yd}^{3}$ & $\mathrm{~m}^{3}$ \\
\hline WIPP & 27,773 & 204,202 & 7,563 & 5,782 \\
\hline ICDF & 481 & 3,534 & 131 & 100 \\
\hline Total & 28,254 & 207,736 & 7,694 & 5,882 \\
\hline
\end{tabular}


Retrieving targeted waste from pit areas totaling 2 acres would require a management self-assessment, and unlike other modules that do not retrieve belowgrade waste, this module would require an operational readiness review plan (and associated implementation plan) before the start of construction.

\section{E-2.2 Site Preparation}

The SDA is contained within RWMC. The RWMC is a 200 -acre facility where radiological and hazardous materials are routinely handled, stored, characterized, shipped, and disposed of. Radiation engineering, maintenance, utilities, and other support services are available at RWMC. In addition, the Accelerated Retrieval Project has already begun a targeted waste retrieval campaign within Pit 4 of the SDA. This ongoing retrieval campaign entails waste excavation inside a large retrieval enclosure (approximately 65,000 $\mathrm{ft}^{2}$ ) using an excavator modified for breathing air, dust suppression, and camera optics (see Figure E-2). An airlock, housing an equipment maintenance bay, and a second airlock, housing drum packaging stations (as shown in Figure E-5), are attached to this building.

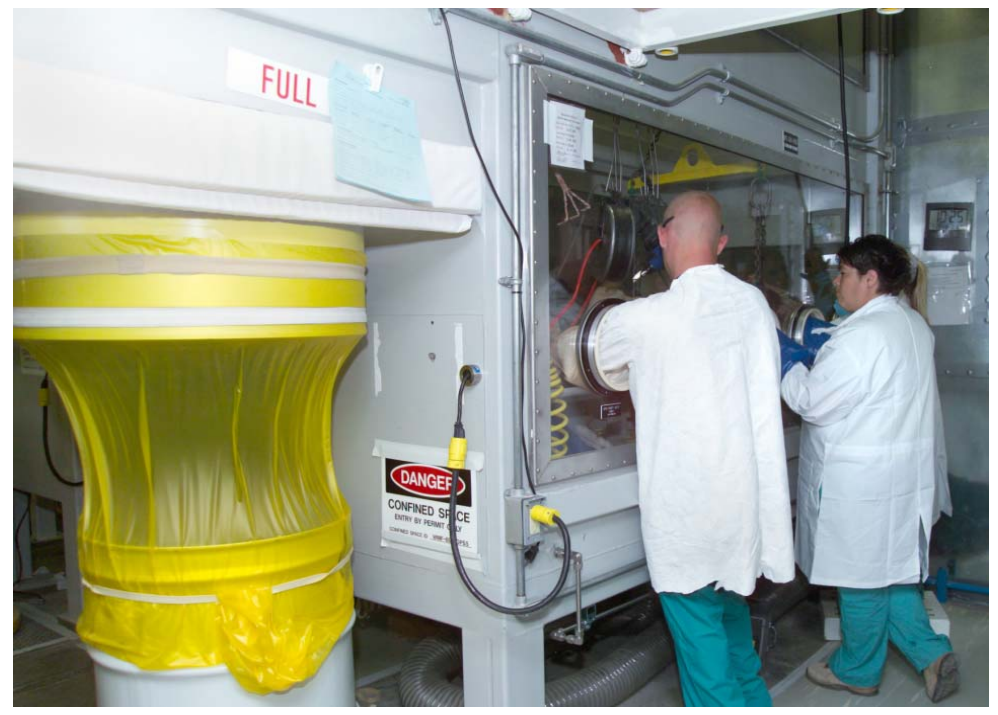

Figure E-5. Drum packaging system within the Accelerated Retrieval Project.

Site preparation for retrieving targeted waste from pit areas totaling 2 acres begins with a land survey of SDA retrieval locations (shown in Figure E-4), followed by construction of access roads and associated ground contouring for site drainage. Utility lines would be installed, and overburden would be removed down to an elevation of $1,527.7 \mathrm{~m}(5,012 \mathrm{ft})$ over a specific SDA footprint to prepare for a $73.2-\mathrm{m}$ (240-ft) extension onto the existing Accelerated Retrieval Project Retrieval Enclosure. This new extension would add an additional filtered exhaust system and attachment capabilities for a mobile radiation control structure, an equipment maintenance structure, and several waste-transport cargo containers. As shown in Figure E-6, modifications to the existing Retrieval Enclosure entail building a new extension onto the east end of the enclosure and removing half of the existing enclosure, including an attached equipment maintenance bay airlock. The adjoining wall between the two enclosures then would be removed to form a single retrieval enclosure with two attached airlocks, housing a total of $11 \mathrm{drum}$ packaging stations. Equipment maintenance activities would be performed within the retrieval enclosure. Utilities to support equipment maintenance (e.g., breathing air, fuel, and dust suppressant) would be supplied from a mobile unit structure attached to the side of the retrieval enclosure. Additional site preparation activities within the enclosure would include cutting ground probes off at ground level and treating the top layer of soil with a polymer to create a durable dust-free surface. 


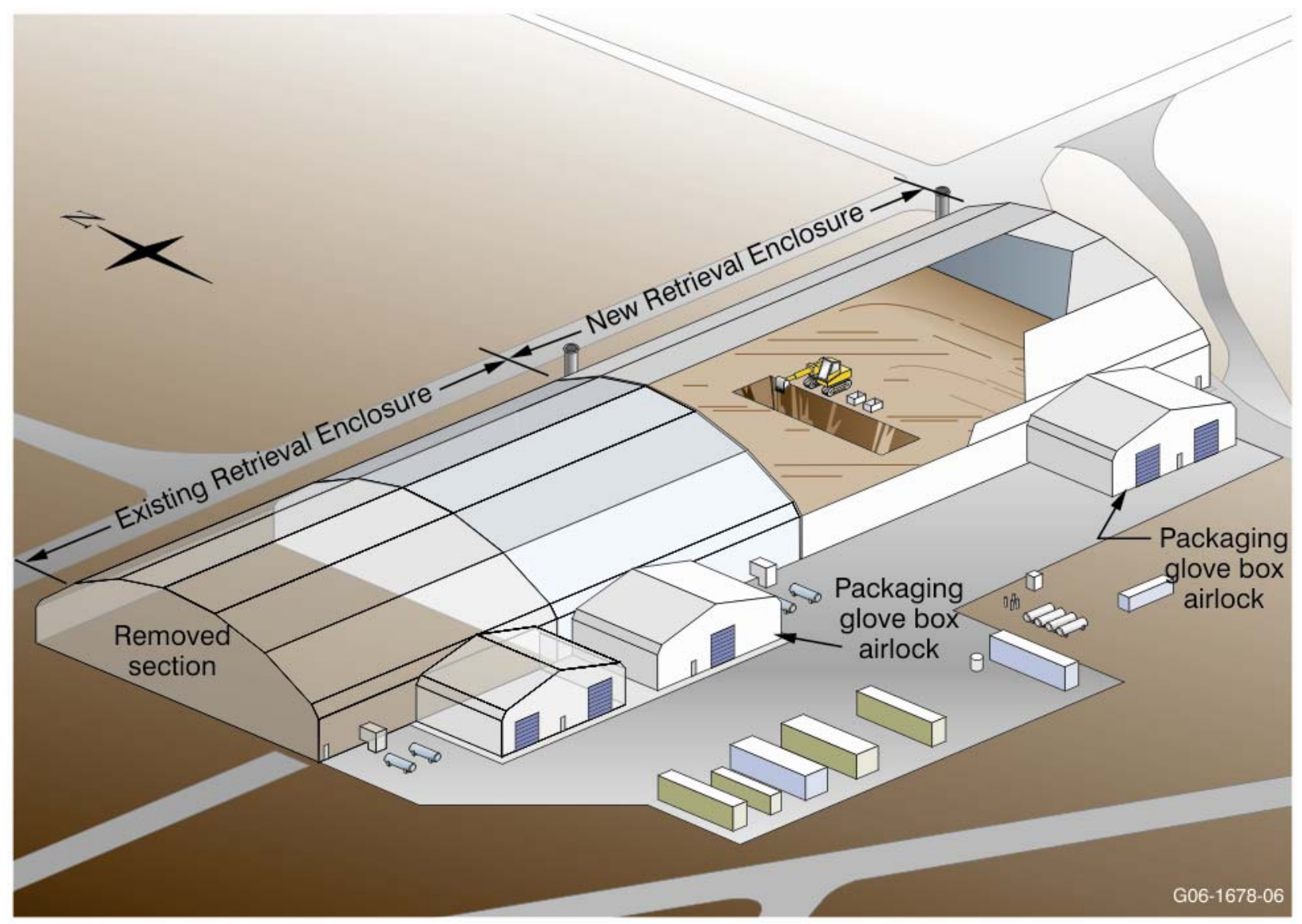

Figure E-6. Modifications to the existing Retrieval Enclosure.

Three smaller retrieval tent enclosures (approximately 11,000 $\mathrm{ft}^{2}$ each) also would be constructed during this period. These smaller tents would be designed to be dragged from location to location. Each tent would include a filtered exhaust system and attachment capabilities for a mobile personnel change room, a mobile mechanical equipment room, and two waste-transport cargo containers.

Site preparation also involves preparing an existing staging area to facilitate moving packaged waste from the Retrieval Enclosure to the final disposal area.

\section{E-2.3 Readiness Demonstration}

Readiness for retrieval and disposal of targeted waste from pit areas totaling 2 acres would be demonstrated by conducting a management self-assessment, followed by an operational readiness review, to ensure that a deliberate and managed approach would be used to perform operations safely. Operations would commence upon approval from the designated startup authority after the project had completed actions associated with the various readiness review processes.

Preparations for readiness would include determining that equipment operability, procedure validity, and personnel knowledge, skills, and performance are adequate for operations. Preparations would involve using surrogate waste to verify equipment operations and operator training and proficiency development. 


\section{E-2.4 Remediation}

This action would permanently remove a targeted waste volume (e.g., Rocky Flats Plant waste Series 741 sludge, Series 743 sludge, filters, graphite, and roaster oxides) and associated contaminants from the SDA and send waste to WIPP or place waste that does not meet WIPP waste acceptance criteria in either ICDF or an off-INL Site facility. As shown in Figure E-7, waste retrieval would be performed within the large centrally located retrieval enclosure and within three smaller mobile tent structures using excavators modified for breathing air, dust suppression, and camera optics (see Figure E-2). Whether a waste is targeted or nontargeted would be determined at or near the dig face. Following waste determination, nontargeted waste would be returned to the exhumation area, while targeted waste would be retrieved.

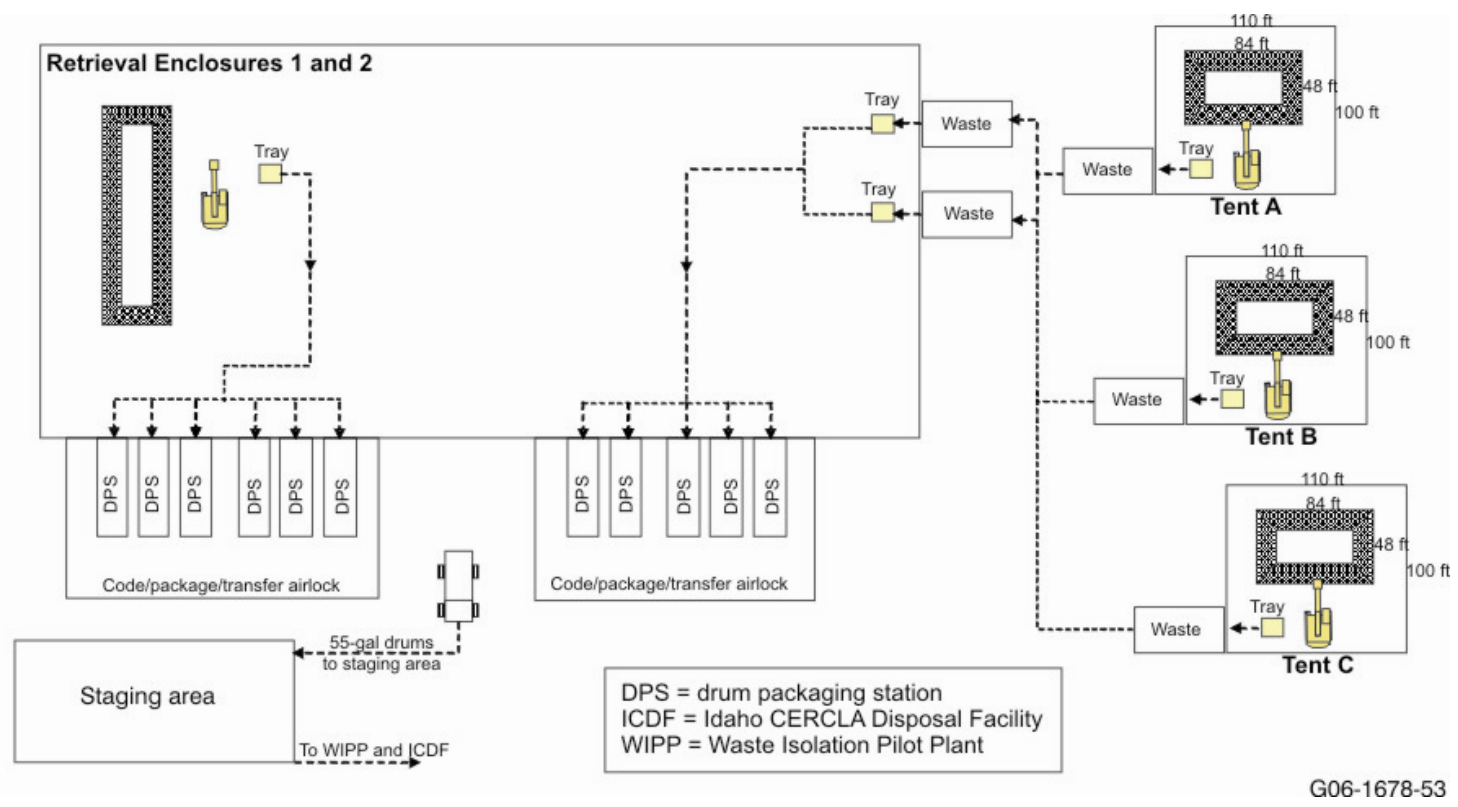

Figure E-7. Preconceptual plan view of partial retrieval process in the Subsurface Disposal Area.

Targeted waste retrieval within the enclosure and smaller mobile tent structures would be performed by first removing a swath of clean soil and stockpiling the soil adjacent to the area of retrieval (within the enclosure). Exposed waste within the area of the swath would be retrieved. Whether the waste is targeted or nontargeted would be determined at or near the dig face. Efforts from this initial retrieval will result in an open waste trench in the enclosure that spans from the surface of excavation down to the depth of either basalt or underburden. While working on this initial waste trench, targeted waste would be loaded onto waste transfer trays and transferred to drum packaging stations (within the central retrieval enclosure), while nontargeted waste would be stockpiled above grade within the enclosure.

Following initial trench formation, targeted waste retrieval would be performed by employing a moving trench method. As depicted in Figure E-8, the moving trench method uses four repeated steps to progress a trench through the retrieval area. The first step retrieves targeted waste from one side of the open trench and places nontargeted waste on the opposite face. After a specified depth of nontargeted waste has been placed on the opposite dig face, the second step would be performed. The second step involves transferring a portion of nontargeted waste, staged inside the enclosure during initial trench formation, onto the newly formed nontargeted waste shelf. The third step retrieves the remaining waste from the dig face, removes the targeted portion, and places the remaining nontargeted waste on the opposite dig face (covering waste returned to the pit during the second step). 

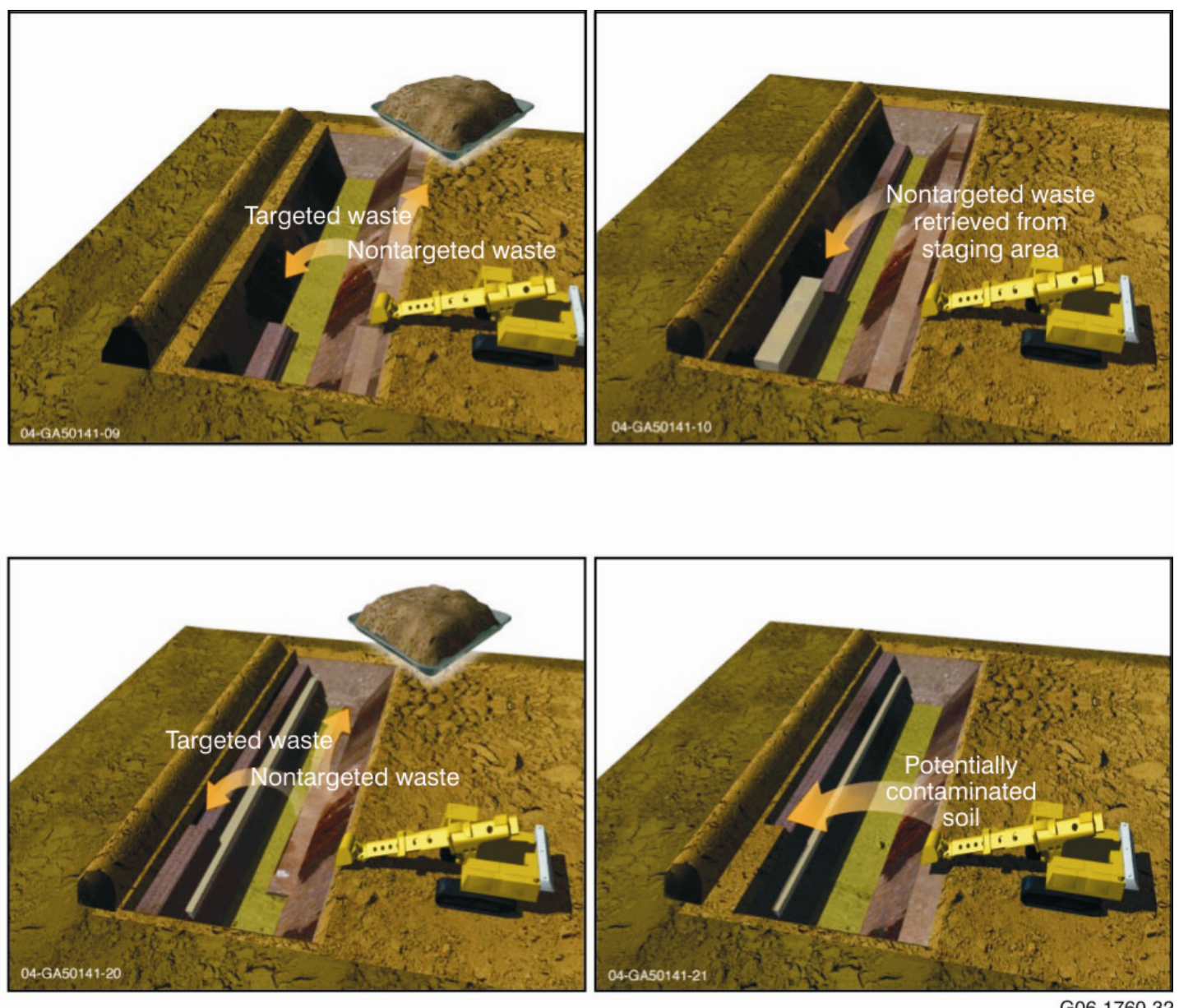

Figure E-8. Four steps for a moving trench formation.

The fourth and final step involves retrieving a layer of potentially contaminated soil adjacent to the working dig face and placing this soil over the nontargeted waste at the opposite trench face. Steps one through four would be repeated until all targeted waste beneath the enclosure is retrieved, leaving an open trench at the opposite end of the retrieval area. This open trench then would be backfilled with clean soil or additional nontargeted waste.

During retrieval operations, if large objects (i.e., objects requiring significant size reduction before handling, such as a large storage tank) or highly radioactive objects are unearthed, they would be left within the retrieval area. Objects of this type may be used as marker shipments. Marker shipments are easily identifiable waste forms that would be used to validate accuracy of disposal locations based on historical records.

At the drum packaging station, operators, assisted by visual examiners, would evaluate and process waste to determine whether it is targeted waste, nontargeted waste, special case waste, OU 7-13/14 items of interest, WIPP-prohibited items, outliers, or incompatible materials. The operations foreman and technical subject matter experts would be consulted, as necessary, to ensure safe waste handling and processing inside the drum packaging station. The waste tray would be assigned a WIPP summary category group number, sampled as necessary, and any WIPP-prohibited items removed. The tray liner then would be hoisted and loaded into a drum. Any waste material samples containing graphites or filters may be counted using a fissile material monitor for criticality safety. The loaded drum then would be 
removed from the area and transported to a fissile material assay system. Each waste drum would be assayed to verify that fissile gram loading is less than 380 fissile gram equivalent. Drums measuring less than 380 fissile gram equivalent would be transported to a staging location on the INL Site for routine waste staging, while drums measuring greater than 380 fissile gram equivalent would require special precautions and staging requirements for criticality safety.

Once targeted waste is packaged, the drums would be sent to a staging area and processed for shipment to WIPP or, in the case of roaster oxide, waste drums would be sent to a staging area to await transport to ICDF.

Processing waste for WIPP disposal would start by assaying waste to ensure WIPP acceptance criterion of $100 \mathrm{nCi} / \mathrm{g}$ transuranic concentration is met. The headspace gas of a WIPP-acceptable waste drum would be sampled through the drum's bung filter (see Figure E-9), and the composition would be analyzed for hydrogen, methane, and volatile organic gases. Results from the headspace gas sampling would be used to verify that concentrations comply with the WIPP Hazardous Waste Facility Permit Waste Analysis Plan (NMED 2004) and the TRUPACT-II Safety Analysis Report for packaging (WIPP 2005a).

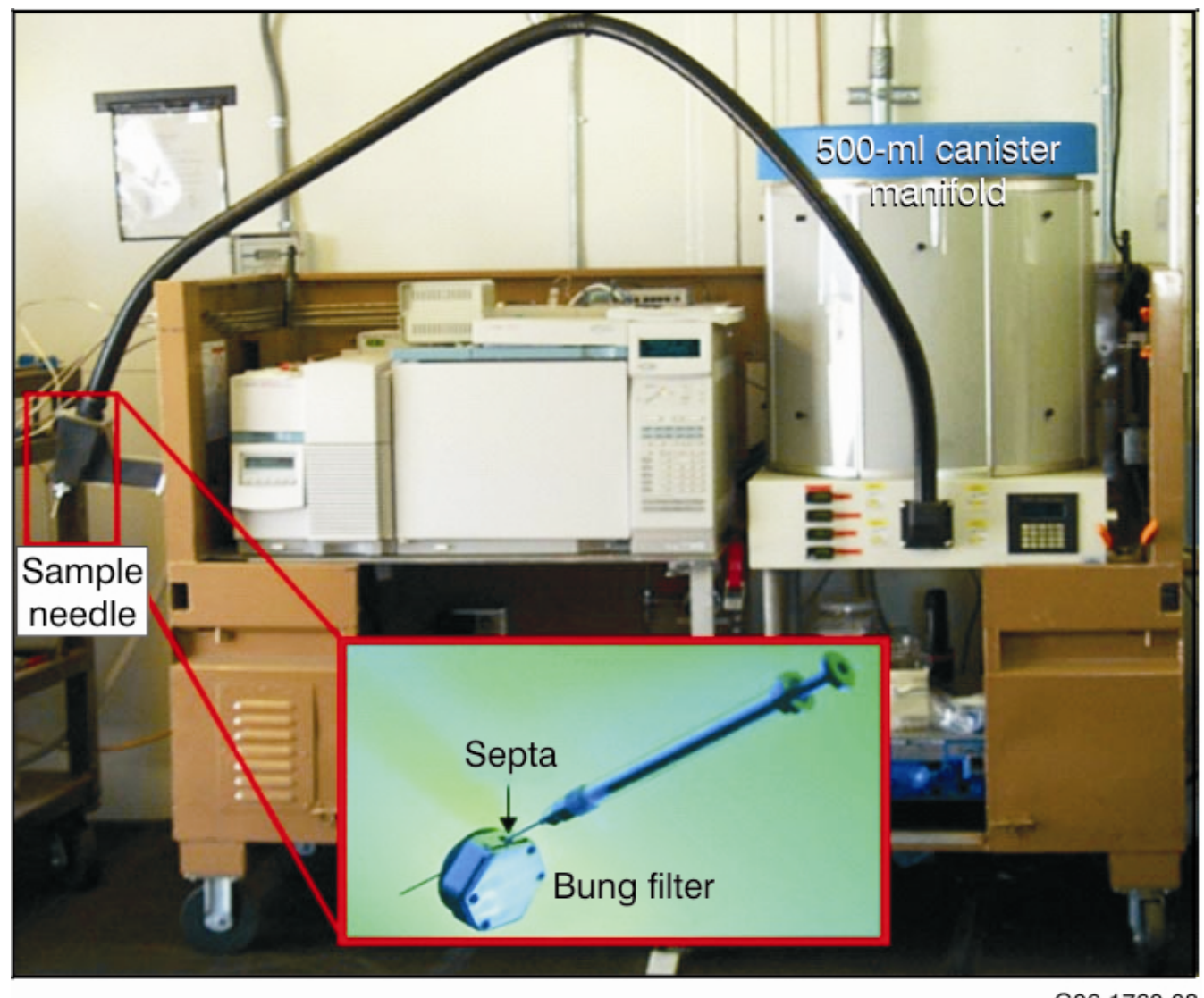

Figure E-9. Headspace gas sampling through a drum filter. 
If results from the assay indicate presence of enough releasable energy to form a flammable concentration of hydrogen (through radiolysis), or if results from headspace gas sampling indicate the presence of flammable VOCs, then a gas-generation test would be required. ${ }^{\mathrm{a}}$ Drum contents comprise another factor in determining whether gas-generation testing should be applied to a waste drum. If the drum contains a significant amount of solidified organic waste (e.g., Rocky Flats Plant Series 743 sludge), the waste would be considered a test category waste (WIPP 2005b) and would require gas-generation testing. Test category waste is a waste type where the hydrogen-generation rate per $100 \mathrm{eV}$ of energy absorbed is unknown (DOE-CBFO 2005).

Gas-generation testing involves placing a vented drum inside the gas-generation test canister (as shown on Figure E-10). Vapor would be driven out of the drum vent and into the annulus between the exterior of the drum and the interior of the gas-generation test canister by heating the exterior canister using a heat blanket. Vapor leaving the annulus through a heated outlet line would be sampled periodically.
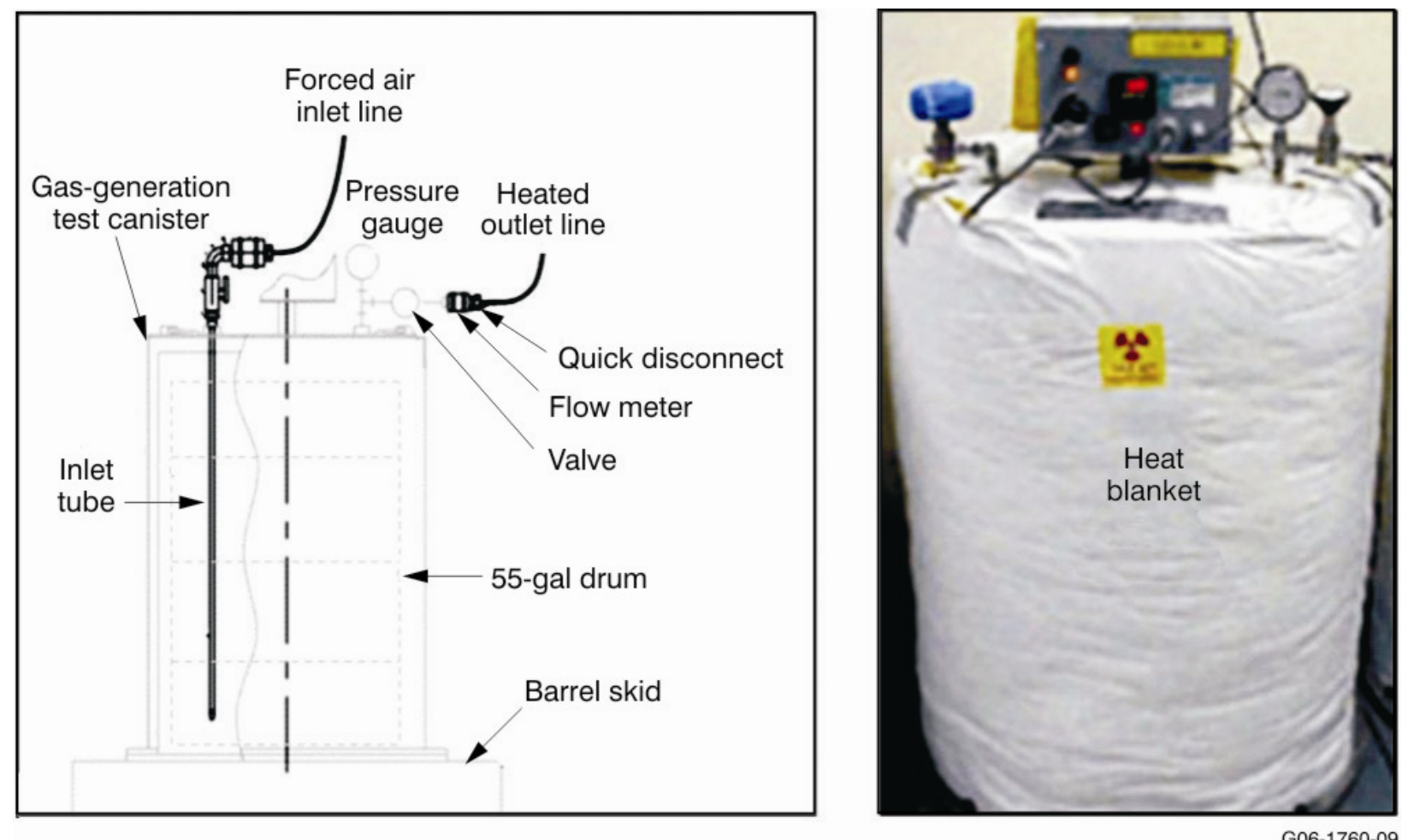

Figure E-10. Gas-generation test canister.

If hydrogen or flammable VOC concentrations that exceed the limits are found, the drum would be removed from the gas-generation test canister and either packaged or treated. This feasibility study assumes, for estimating purposes, that failure of gas-generation testing does not occur.

Following headspace gas sampling, and potentially gas-generation testing, waste drums would be loaded into transuranic package containers and transferred to WIPP.

a. Gas-generation tests determine whether contents of the waste drum comply with WIPP waste acceptance criteria and the TRUPACT-II Safety Analysis Report for packaging. 


\section{E-2.5 Demobilization and Reporting}

After RTD of targeted waste from pit areas totaling 2 acres has been completed, equipment would be demobilized, and the retrieval enclosure, mobile tent structures, and associated infrastructure would be dismantled. Excess equipment would be used or disposed of. The final inspection report for the 2-acre RTD module would be included in the remedial action report for OU 7-13/14.

\section{E-3. 4-ACRE RETRIEVAL, TREATMENT, AND DISPOSAL}

Design, mobilization, site preparation, readiness demonstration, remediation, demobilization, and reporting for the 4-Acre RTD module would be identical to those mentioned in Section E-2.1. Discrepancies between the two modules lie in the area of retrieval. Figure E-11 shows areas of retrieval for the 4-acre RTD module. These areas encompass previously defined regions for the 2-acre RTD module shown in Figure E-4. The 4-acre RTD module was generated to allow estimation of cost and risk for retrieval areas of alternate sizes. Estimating an alternate retrieval area could be performed by scaling data from the 2 and 4-acre RTD modules.

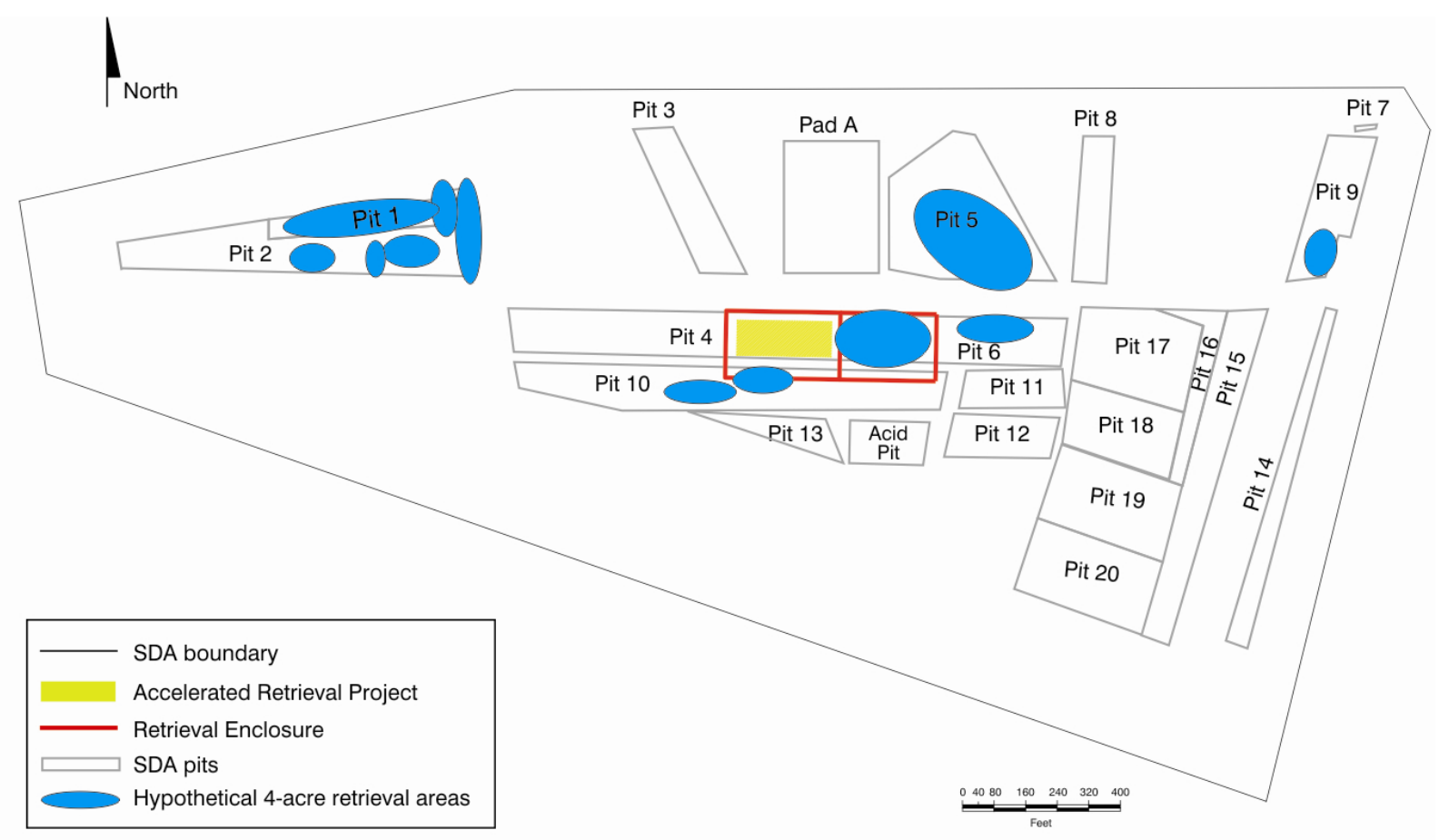

Figure E-11. Hypothetical retrieval locations for retrieving targeted waste from pit areas totaling 4 acres.

Preliminary designs assume that half the Rocky Flats Plant Series 742 sludge either would be commingled with Series 741 sludge or would be mistakenly identified as Series 741 sludge and retrieved. As presented in Table E-5, volumes of buried waste expand due to waste captured within the angle of repose, commingled soil, waste expansion following retrieval, and the void space left within the final packaged waste drum. Table E-6 provides the quantity of waste sent to various treatment and disposal facilities, both on and off the INL Site. 
Table E-5. Waste type volumes for the 4-acre retrieval, treatment, and disposal module.

\begin{tabular}{|c|c|c|c|c|c|c|c|c|}
\hline \multirow{2}{*}{ Waste Type } & Source Total & $50 \% \times$ Total & Waste Total & $\mathrm{R}(20 \%)$ & $\mathrm{CS}(18 \%)$ & Total & $40 \%$ & \multirow[b]{2}{*}{$\begin{array}{l}\text { Packaged } \\
\text { Drum } \\
\text { Equivalents }\end{array}$} \\
\hline & $\begin{array}{c}\text { Source Data } \\
\left(\mathrm{ft}^{3}\right)\end{array}$ & $\begin{array}{l}\text { Series } 742 \\
\text { Sludge } \\
\left(\mathrm{ft}^{3}\right)\end{array}$ & $\begin{array}{l}\text { Waste } \\
\text { Volume } \\
\left(\mathrm{ft}^{3}\right)\end{array}$ & $\begin{array}{c}\text { Repose } \\
\left(\mathrm{ft}^{3}\right)\end{array}$ & $\begin{array}{l}\text { Commingled } \\
\text { Soil } \\
\left(\mathrm{ft}^{3}\right)\end{array}$ & $\begin{array}{c}\text { Waste } \\
\text { Total }+\mathrm{R}+\mathrm{CS} \\
\left(\mathrm{ft}^{3}\right)\end{array}$ & $\begin{array}{c}\text { Expansion and } \\
\text { Drum Void } \\
\left(\mathrm{ft}^{3}\right)\end{array}$ & \\
\hline Series 741 sludge & 35,201 & - & 35,201 & 7,040 & 6,336 & 48,578 & 68,009 & 9,250 \\
\hline Series 742 sludge & 40,973 & 20,486 & 20,486 & 4,097 & 3,688 & 28,271 & 39,580 & 5,383 \\
\hline Series 743 sludge & 33,875 & - & 33,875 & 6,775 & 6,098 & 46,748 & 65,447 & 8,091 \\
\hline Filters & 34,581 & - & 34,581 & 6,916 & 6,225 & 47,271 & 66,810 & 9,087 \\
\hline Graphite & 11,086 & - & 11,086 & 2,217 & 1,995 & 15,298 & 21,418 & 2,913 \\
\hline Roaster oxide & 2,559 & - & 2,559 & 512 & 461 & 3,532 & 4,944 & 672 \\
\hline $\begin{array}{l}\text { Total } \\
\text { (without ARP I } \\
\text { retrieval) }\end{array}$ & 158,275 & 20,486 & 137,789 & 27,558 & 24,802 & 190,149 & 266,208 & 36,207 \\
\hline \multicolumn{9}{|c|}{ Note: Example calculation of Series 741 sludge: $\left[\left(35,201 \mathrm{ft}^{3} \times 0.2\right)+\left(35,201 \mathrm{ft}^{3} \times 0.18\right)+35,201 \mathrm{ft}^{3}\right] \times 1.4 /\left(7.35245 \mathrm{ft}^{3} / \mathrm{drum}\right)=9,250 \mathrm{drums}$. } \\
\hline \multicolumn{9}{|c|}{$\begin{array}{l}\text { ARP }=\text { Accelerated Retrieval Project } \\
\text { CS }=\text { commingled soil } \\
R=\text { repose } \\
\text { SDA = Subsurface Disposal Area }\end{array}$} \\
\hline
\end{tabular}

Table E-6. Disposal locations and quantities for the 4-acre retrieval, treatment, and disposal module.

\begin{tabular}{lrrrr}
\hline \multicolumn{1}{c}{ Waste Type } & Drums & \multicolumn{1}{c}{$\mathrm{ft}^{3}$} & \multicolumn{1}{c}{$\mathrm{yd}^{3}$} & \multicolumn{1}{c}{$\mathrm{m}^{3}$} \\
\hline WIPP & 35,534 & 261,263 & 9,676 & 1,398 \\
ICDF & 672 & 4,944 & 183 & 140 \\
Total & 36,207 & 266,208 & 9,860 & 7,538 \\
\hline ICDF = Idaho CERCLA Disposal Facility & & & \\
WIPP = Waste Isolation Pilot Plant & & & \\
\hline
\end{tabular}




\section{E-4. FULL RETRIEVAL, TREATMENT, AND DISPOSAL}

The full SDA waste retrieval would be performed within a large centrally located retrieval enclosure and within six smaller mobile tent structures using excavators modified for breathing air, dust suppression, and camera optics (see Figure E-2).

Figure E-12 provides a preconceptual process diagram that overviews implementation of this module and was created for cost-estimation purposes. Key tasks identified in Figure E-12 are discussed in the following subsections.

\section{E-4.1 Design and Mobilization}

Design and mobilization for retrieving and disposing of all waste within the SDA footprint would include developing remedial design and remedial action work plans, operational plans (i.e., operations and layout plan, radiation monitoring and control plan, industrial hygiene exposure and sampling plan, training plan, and quality control plan), management self-assessment plans, operational readiness review plan of action and implementation plan, and procurement packages; performing a preconstruction investigation; and mobilizing equipment to the work site.

Developing remedial design and remedial action work plans would include preparing designs and schedules for (a) constructing a centrally located retrieval structure and six smaller mobile retrieval tents, (b) constructing a staging area for waste with no transuranic isotopes and remote-handled waste,

(c) retrieving waste (e.g., LLW, waste containing transuranic isotopes, remote-handled waste, and large objects, such as tanks and trucks) from within the large retrieval structure and mobile retrieval tents, and (d) placing remote-handled waste in a newly constructed interim storage facility and disposing of all other waste at WIPP, ICDF, or an off-INL Site staging area for waste with no transuranic isotopes. Preliminary designs assume that half the Rocky Flats Plant Series 742 sludge either would be commingled with Series 741 sludge or would be mistakenly identified as Series 741 sludge and retrieved. As presented in Table E-7, volumes of buried waste expand due to commingled soil, waste expansion following retrieval, and the void space left within the final packaged waste drum. Table E-8 provides the quantity of waste sent to various treatment and disposal facilities, both on and off the INL Site.

\section{E-4.2 Site Preparation}

Site preparation for full retrieval starts with a land survey of SDA retrieval locations followed by construction of access roads and associated ground contouring for site drainage. As with the 2 and 4-acre RTD modules, utility lines would be installed, probes would be cut off at ground level, surface soil would be treated, and a new 73.2-m (240-ft) extension would be constructed onto the existing Accelerated

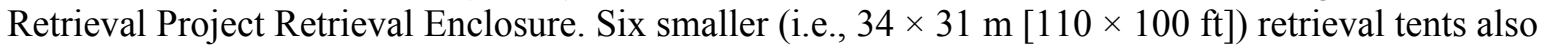
would be constructed during this time period. The large retrieval enclosure extension and small retrieval tent designs would be identical to designs outlined Section E-2.1. An additional staging area for waste with no transuranic isotopes and an additional storage facility for remote-handled waste also would be required. The remote-handled waste facility would be designed to house all remote-handled SDA waste for a period of 20 years.

\section{E-4.3 Readiness Demonstration}

Readiness demonstration is identical to the readiness steps identified in Section E-2.1. 


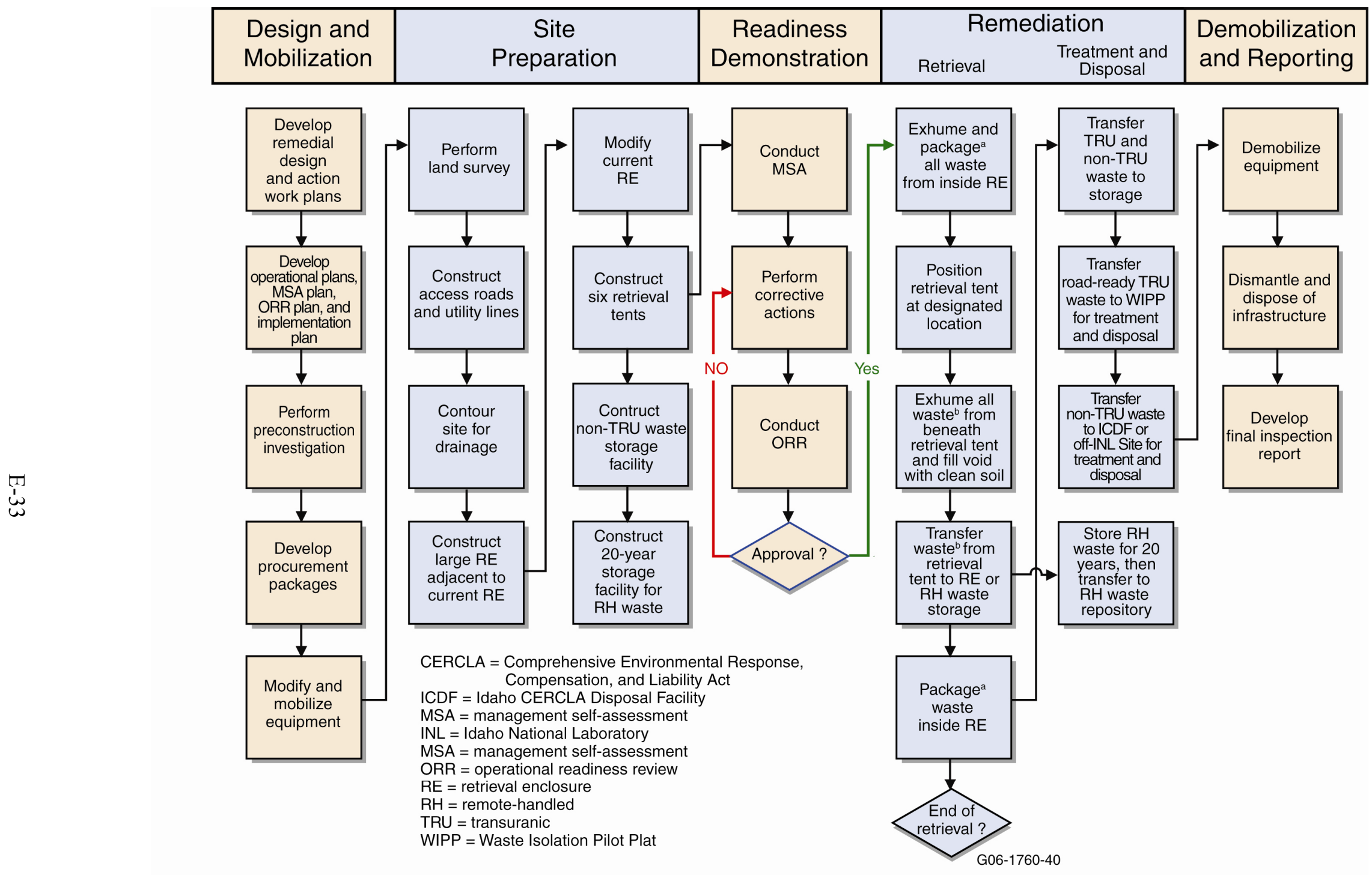

a. All waste packaged in the RE would be placed in 55-gal drums.

b. All waste would be exhumed and transferred to the RE with the exception of RH waste. Within the tents,

RH waste would be placed in shielded casks. Large objects would be sized for transport.

Figure E-12. Preconceptual process flow diagram for full retrieval, treatment, and disposal. 
Table E-7. Waste type volumes for the full retrieval, treatment, and disposal module.

\begin{tabular}{|c|c|c|c|c|c|}
\hline & & Commingled Soil (18\%) & Total & $40 \%$ & \\
\hline Waste Type & $\begin{array}{c}\text { Source Data } \\
\left(\mathrm{ft}^{3}\right)\end{array}$ & $\begin{array}{c}\text { Commingled Soil } \\
\left(\mathrm{ft}^{3}\right)\end{array}$ & $\begin{array}{c}\text { Source }+ \text { Commingled } \\
\text { Soil } \\
\left(\mathrm{ft}^{3}\right)\end{array}$ & $\begin{array}{c}\text { Expansion and } \\
\text { Drum Void } \\
\left(\mathrm{ft}^{3}\right)\end{array}$ & $\begin{array}{l}\text { Packaged Drum } \\
\text { Equivalents }\end{array}$ \\
\hline Series 741 sludge & 64,141 & 11,545 & 75,687 & 105,961 & 14,412 \\
\hline Series 742 sludge & 55,302 & 9,954 & 65,256 & 91,359 & 12,426 \\
\hline Series 743 sludge & 63,756 & 11,476 & 75,232 & 105,325 & 14,325 \\
\hline Filter & 79,764 & 14,357 & 94,121 & 131,770 & 17,922 \\
\hline Graphite & 34,612 & 6,230 & 40,843 & 57,180 & 7,777 \\
\hline Roaster oxide & 166,041 & 29,887 & 195,928 & 274,299 & 37,307 \\
\hline $\begin{array}{l}\text { Other waste with transuranic } \\
\text { isotopes }\end{array}$ & 777,139 & 139,885 & 917,024 & $1,283,833$ & 174,613 \\
\hline $\begin{array}{l}\text { Other waste with no transuranic } \\
\text { isotopes }\end{array}$ & $6,963,571$ & $1,253,443$ & $8,217,014$ & $11,503,820$ & $1,564,624$ \\
\hline Remote-handled & 92,750 & 16,695 & 109,445 & 153,223 & 20,840 \\
\hline Total & $8,297,076$ & $1,493,474$ & $9,790,550$ & $13,706,770$ & $1,864,245$ \\
\hline
\end{tabular}

Table E-8. Disposal locations and quantities for full retrieval, treatment, and disposal.

\begin{tabular}{lrrrr} 
& \multicolumn{1}{c}{ Drums } & \multicolumn{1}{c}{$\mathrm{ft}^{3}$} & $\mathrm{yd}^{3}$ & $\mathrm{~m}^{3}$ \\
\hline WIPP & 241,474 & $1,775,427$ & 65,757 & 50,275 \\
ICDF & 428,463 & $3,150,254$ & 116,676 & 89,206 \\
Off-INL Site facility & $1,173,468$ & $8,627,865$ & 319,551 & 244,315 \\
On-INL Site remote-handled storage & 20,840 & 153,223 & 5,675 & 4,339 \\
Total & $1,864,245$ & $13,706,770$ & 507,658 & 388,135 \\
\hline ICDF = Idaho CERCLA Disposal Facility & & & & \\
INL = Idaho National Laboratory & & & & \\
WIPP = Waste Isolation Pilot Plant & & & & \\
\hline
\end{tabular}




\section{E-4.4 Remediation}

As shown in Figure E-13, waste retrieval would be performed within the large centrally located retrieval enclosure and six smaller mobile tent structures using excavators modified for breathing air, dust suppression, and camera optics (see Figure E-2). Following complete waste retrieval, under a mobile tent, clean backfill (from the T-12 borrow pits) would be placed in the excavated cavity, and the tent would be moved to the next location. Waste retrieved within the mobile tent structures would be transported (inside cargo containers) to the centrally located retrieval enclosure. Within the central retrieval enclosure, waste trays would be loaded into drum packaging stations where a certified visual examination would be performed, and any remaining prohibited items would be segregated. Following visual examination, waste would be loaded into certified drums, using the drum packaging station load-out system, and temporarily staged before shipment. Waste containing transuranic isotopes would be processed for shipment and sent to WIPP for disposal. Roaster oxide and $25 \%$ of other contact-handled waste would be sent to ICDF for treatment and disposal. The remaining contact-handled waste would be sent to a disposal facility off the INL Site.

As shown in Figure E-14, remote-handled waste (when encountered) would be retrieved from the SDA using a crane, shielding blocks, and a cask. Following retrieval, remote-handled waste with no transuranic isotopes would be sent to a new on-INL Site remote-handled storage facility for 20 years, pending future transport to an off-INL Site facility. Highly radioactive waste may be used as marker shipments. Marker shipments are easily identifiable waste forms used to validate accuracy of disposal locations based on historical records.

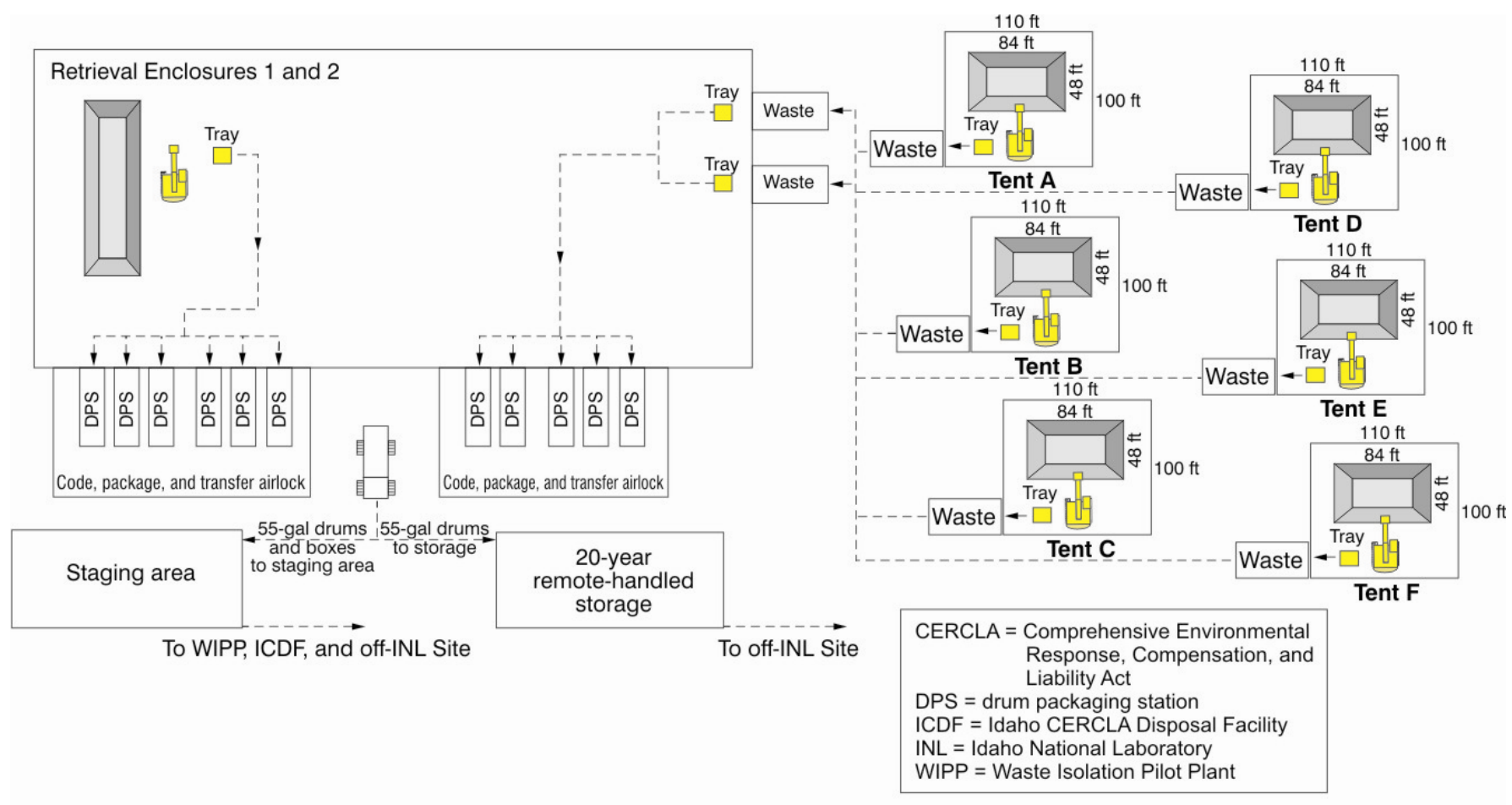

Figure E-13. Preconceptual plan view of full retrieval process and remote-handled storage in the Subsurface Disposal Area. 


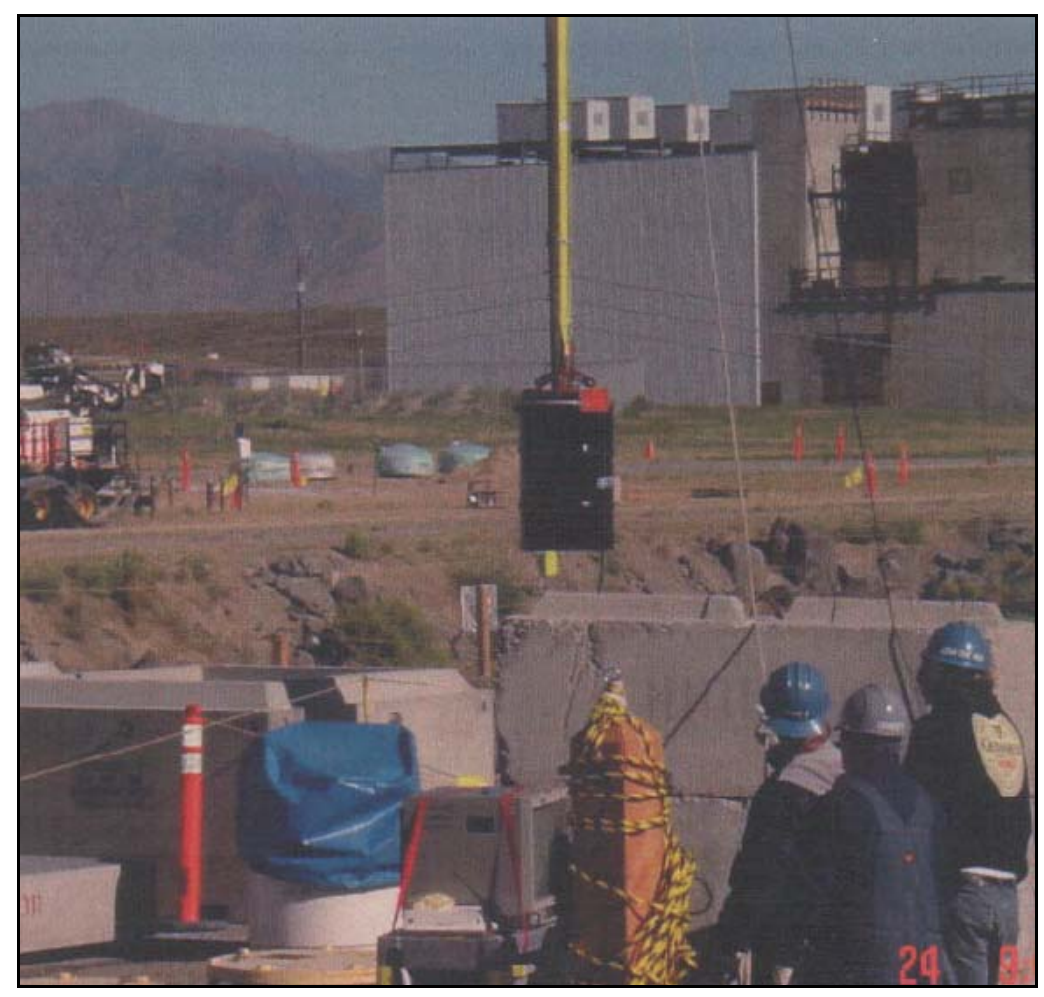

Figure E-14. Remote-handled drum removal at the Intermediate-Level Transuranic Storage Facility.

Large objects (when encountered) would be retrieved from the SDA using heavy lifting equipment. These large objects would require use of additional handling and special equipment. Large objects may be used as marker shipments. Marker shipments are easily identifiable waste forms used to validate the accuracy of disposal locations based on historical records.

\section{E-4.5 Demobilization and Reporting}

After completing the full SDA RTD, equipment would be demobilized, and the retrieval enclosure, mobile tent structures, and associated infrastructure would be dismantled. Excess equipment would be used or disposed of. The final inspection report for the full SDA RTD would be included in the remedial action report for OU 7-13/14.

\section{E-5. PAD A RETRIEVAL AND SUBSURFACE DISPOSAL AREA DISPOSAL}

Figure E-15 provides a preconceptual process diagram that overviews implementation of this module and was created for cost-estimation purposes. Key tasks identified in Figure E-15 are discussed in the following subsections. 


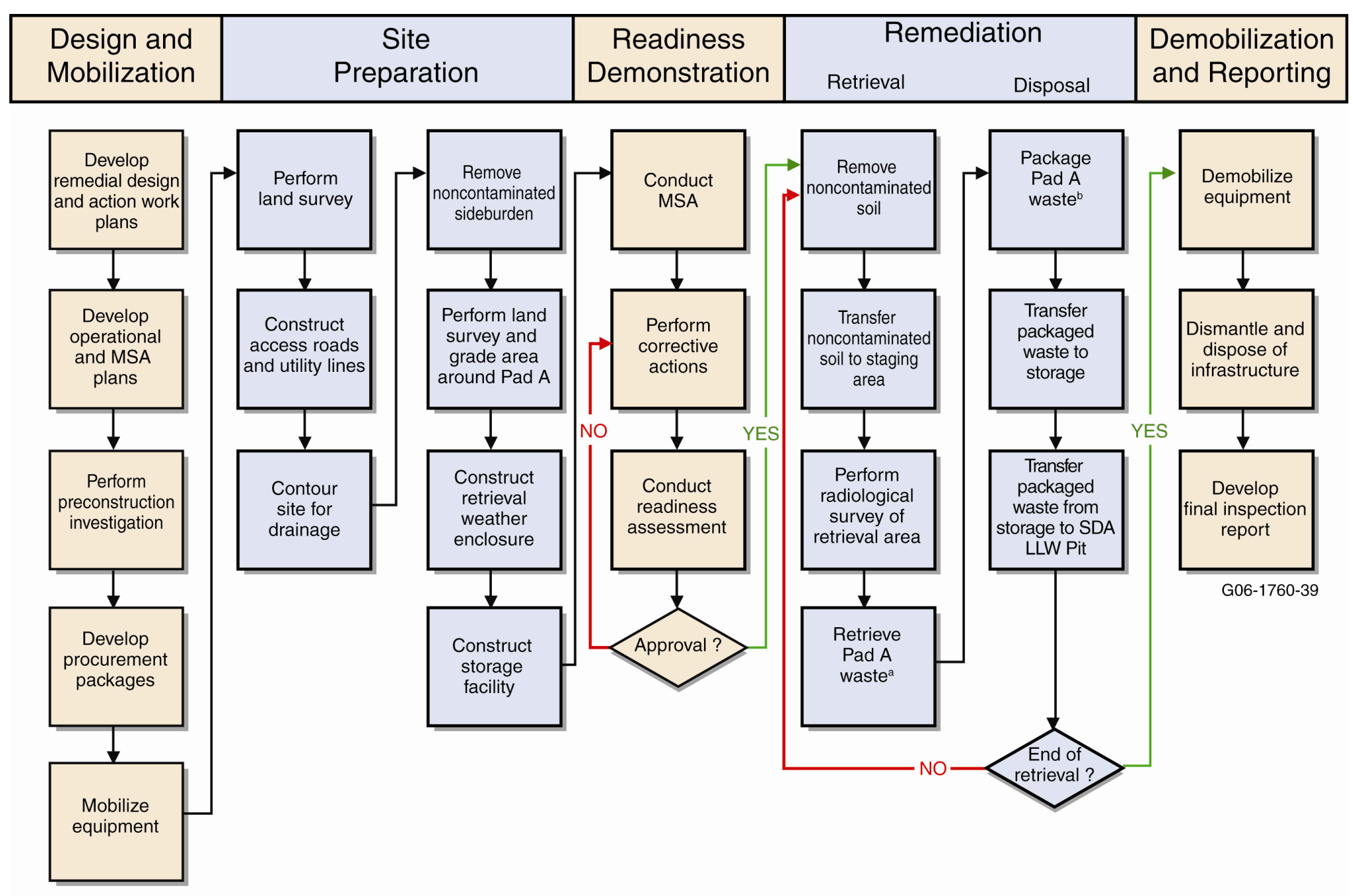

LLW = low-level waste

MSA = management self-assessment

SDA = Subsurface Disposal Area

a. Waste types include waste in drums, waste in plywood boxes, plywood covers, tarp covers, and asphalt pad.

b. All waste would be disposed of in wooden boxes or soft-sided lift liners.

Figure E-15. Preconceptual process flow diagram for Pad A retrieval and Subsurface Disposal Area disposal. 


\section{E-5.1 Design and Mobilization}

Design and mobilization for retrieval of Pad A (shown on Figure E-16) waste, and disposal within the SDA, would include developing remedial design and remedial action work plans, operational plans (i.e., operation and layout plan, radiation monitoring and control plan, industrial hygiene exposure and sampling plan, training plan, and quality control plan), and procurement packages; performing a preconstruction investigation; and mobilizing equipment to the work site.

Developing remedial design and remedial action work plans would include obtaining regulatory approval if the hazardous waste determination classifies Pad A waste as mixed. Preliminary engineering design assumes that most waste containers on Pad A are structurally compromised and that retrieved waste would be commingled during retrieval. Resulting waste are assumed to be identified as alpha-contaminated low-level mixed waste, based on process knowledge, and no additional characterization is assumed to be required. As presented in Table E-9, half of the drums in Pad A are assumed to be intact, and the rest of the drums and boxes are assumed to be loose waste. Intact drums would be placed in boxes for transport, while loose waste would be placed in lift liners for transport. Volumes of this waste will expand, based on box and lift liner packing efficiencies.

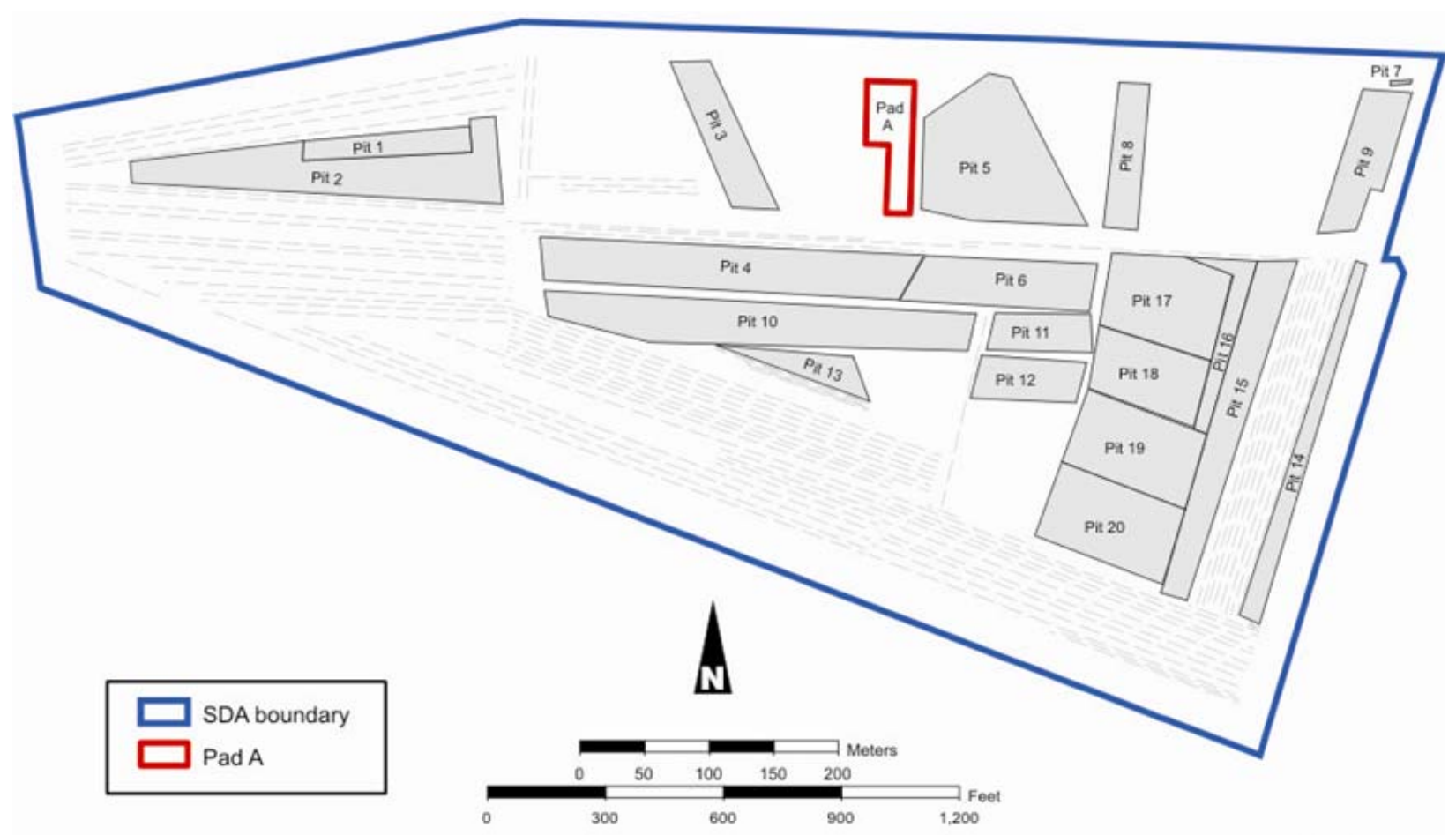

G06-1760-76

Figure E-16. Pad A in the Subsurface Disposal Area. 
Table E-9. Waste type volumes for Pad A retrieval and Subsurface Disposal Area disposal.

\begin{tabular}{|c|c|c|c|c|c|c|c|}
\hline & Total & Conversion & $30 \%$ & $10 \%$ & $30 \%$ & $130 \mathrm{ft}^{3} / \mathrm{box}$ & $216 \mathrm{ft}^{3} /$ liner \\
\hline Waste Type & $\begin{array}{c}\text { Source Data } \\
\text { (quantity) }\end{array}$ & $\begin{array}{c}\text { Source Data } \\
\left(\mathrm{ft}^{3}\right)\end{array}$ & $\begin{array}{c}\text { Contaminated } \\
\text { Overburden and } \\
\text { Sideburden } \\
\left(\mathrm{ft}^{3}\right)\end{array}$ & $\begin{array}{c}\text { Boxed } \\
\text { Volume } \\
\left(\mathrm{ft}^{3}\right)\end{array}$ & $\begin{array}{c}\text { Bagged } \\
\text { Volume } \\
\left(\mathrm{ft}^{3}\right)\end{array}$ & $\begin{array}{c}\text { Number of } \\
\text { Boxes }\end{array}$ & $\begin{array}{l}\text { Number of } \\
\text { Liners }\end{array}$ \\
\hline Intact 55-gal drums & 9,116 & 67,025 & - & 73,727 & - & 567 & - \\
\hline Loose 55-gal drums & 9,116 & 67,025 & - & - & 87,132 & - & 403 \\
\hline Loose $4 \times 4 \times 7$-ft plywood boxes & 2,020 & 226,240 & - & - & 294,112 & - & 1,362 \\
\hline Loose overburden and sideburden & - & 766,474 & 229,942 & - & 298,925 & - & 1,384 \\
\hline Total & 20,252 & $1,126,764$ & 229,942 & 73,727 & 680,169 & 567 & 3,149 \\
\hline
\end{tabular}




\section{E-5.2 Site Preparation}

Site preparation for retrieval of Pad A waste and disposal within the SDA would include performing an initial land survey, constructing access roads and utilities, contouring the SDA to direct surface run-off, partial removal of uncontaminated soil from slopes adjacent to Pad A (see Figure E-17), surveying the Pad A area following slope removal, constructing a high-efficiency particulate air-filtered retrieval enclosure over the contoured Pad A (see Figures E-17 and E-18), and preparing a staging area to facilitate moving packaged waste from the retrieval enclosure to the final disposal area.

\section{E-5.3 Readiness Demonstration}

Readiness for Pad A waste retrieval and disposal within the SDA would be demonstrated by conducting a management self-assessment and completing any resulting corrective actions.

\section{E-5.4 Remediation}

This action would remove waste from Pad A and relocate it within the OU 7-13/14 area of contamination (assumed LLW Pit). This action would not reduce the toxicity, mobility, or volume of Pad A waste. As demonstrated in Figure E-18, Pad A waste would be retrieved using a retrieval enclosure and excavation technologies similar to those for retrieval of waste buried elsewhere in the SDA. Any uncontaminated soil removed at the beginning of retrieval operations would be taken out of the retrieval enclosure and stockpiled elsewhere in the SDA. Waste then would be removed from the side of the Pad A stack using an excavator modified for operation within a contaminated environment. All wooden boxes and $50 \%$ of the drums on Pad A are assumed to be highly degraded and unable to contain waste when exposed using an excavator bucket. Uncontained waste would be placed in $216-\mathrm{ft}^{3}$ lift liners without segregating waste types or separating debris from waste fines and soil. Any drums with structural integrity sufficient to allow retrieval using an excavator bucket would be over-packed using $130-\mathrm{ft}^{3}$ wooden boxes. This retrieval method would not support identification and removal of prohibited items. Full lift liners and boxes would be relocated to an attached airlock before transfer to the staging area. Subsequently, packaged waste would be transferred to the active low-level radioactive waste disposal area (or other subsurface location) within the SDA.

\section{E-5.5 Demobilization and Reporting}

After completing Pad A waste retrieval and disposal within the SDA, equipment would be demobilized and the retrieval enclosure and associated infrastructure would be dismantled. Excess equipment would be used or disposed of. The final inspection report for Pad A waste retrieval and disposal within the SDA would be included in the remedial action report for OU 7-13/14. 
End view

containment structure

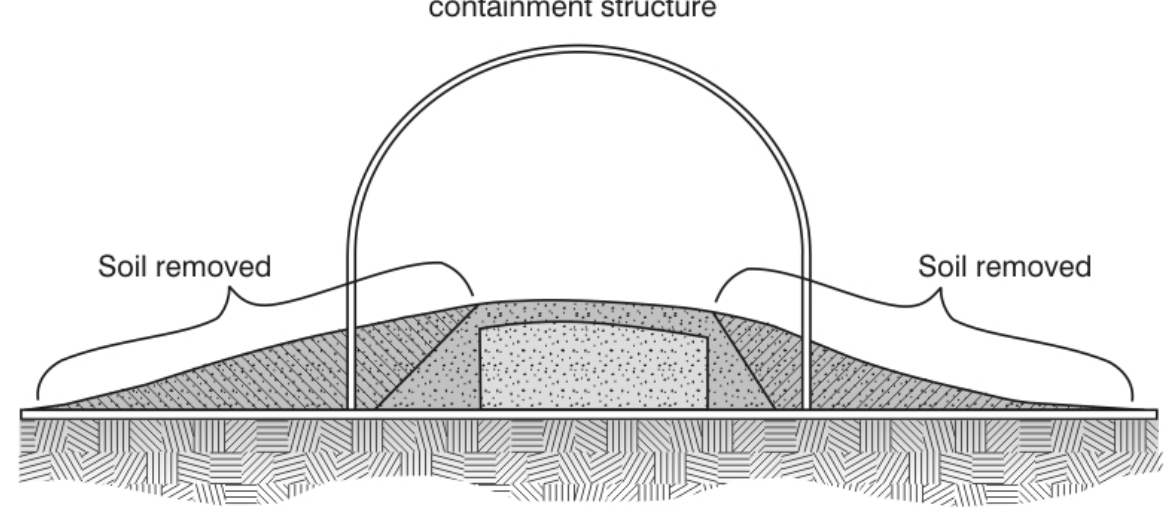

Side view containment structure

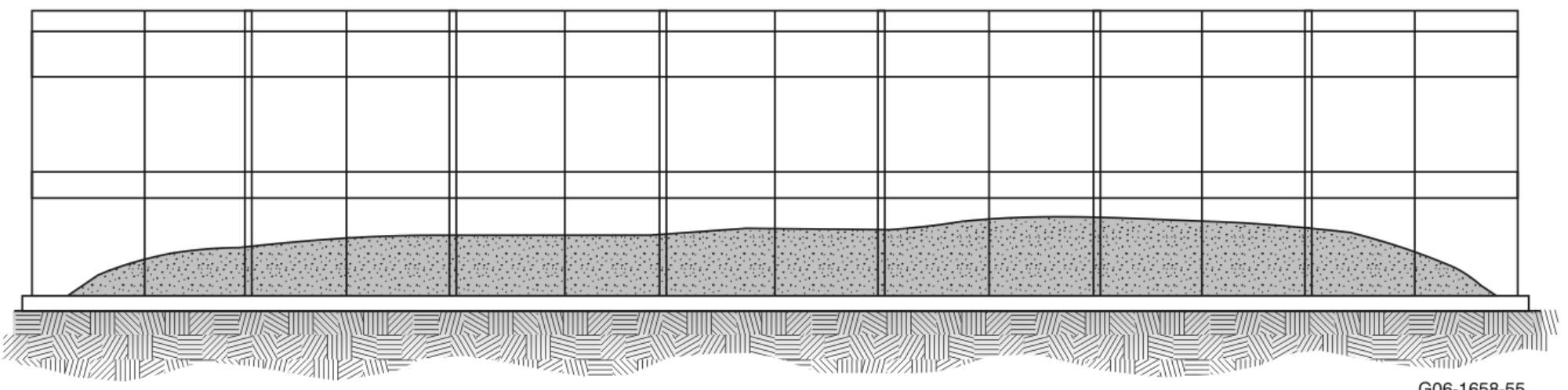

Figure E-17. Pad A cross section covered by retrieval structure. 


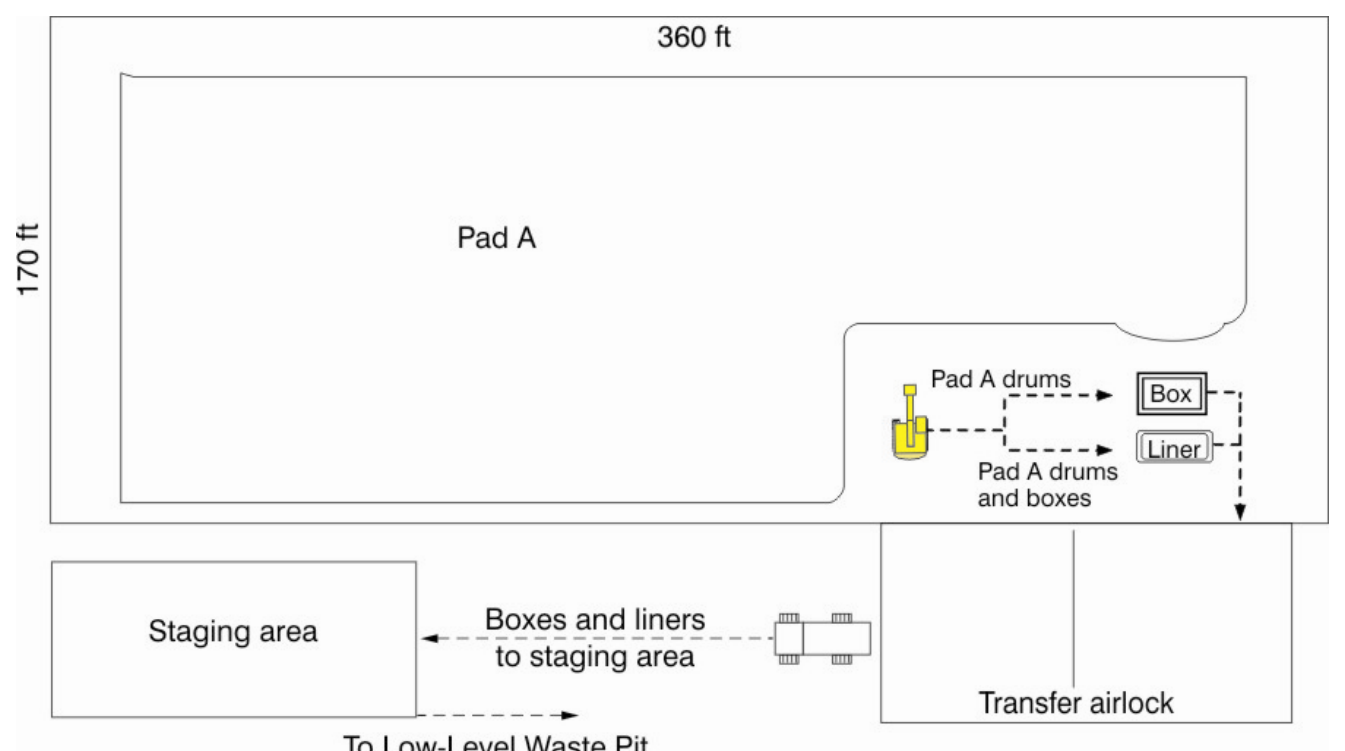

G06-1760-10

Figure E-18. Preconceptual plan view of the Pad A retrieval and Subsurface Disposal Area disposal.

\section{E-6. PAD A RETRIEVAL, EX SITU TREATMENT, AND SUBSURFACE DISPOSAL AREA DISPOSAL}

Figure E-19 provides a preconceptual process diagram that overviews implementation of this module and was created for cost-estimation purposes. Key tasks identified in Figure E-19 are discussed in the following subsections.

\section{E-6.1 Design and Mobilization}

Design and mobilization for Pad A waste retrieval, ex situ treatment, and disposal within the SDA would include developing remedial design and remedial action work plans, operational plans (i.e., operation and layout plan, radiation monitoring and control plan, industrial hygiene exposure and sampling plan, training plan, and quality control plan), and procurement packages; performing a preconstruction investigation; and mobilizing equipment to the work site.

Developing remedial design and remedial action work plans would include completing a hazardous waste determination for Pad A waste and obtaining regulatory approval if the hazardous waste determination classified Pad A waste as mixed waste. Preliminary engineering design assumes that most waste containers on Pad A are structurally compromised and that retrieved waste would be commingled upon retrieval. Resulting waste is assumed to be identified as alpha-contaminated low-level mixed waste, based on process knowledge, and no additional characterization is assumed to be required. As presented in Table E-10, the majority of all buried waste and all contaminated soil (i.e., overburden and sideburden) would be boxed and treated as fines. A hazardous waste determination would be required for treatment of waste retrieved from Pad A, and studies to confirm effectiveness of ex situ treatment of waste fines and debris would be completed during the remedial design phase. The balance of the waste would be boxed and treated as debris. Waste forms expand during excavation, packaging, and treatment. 


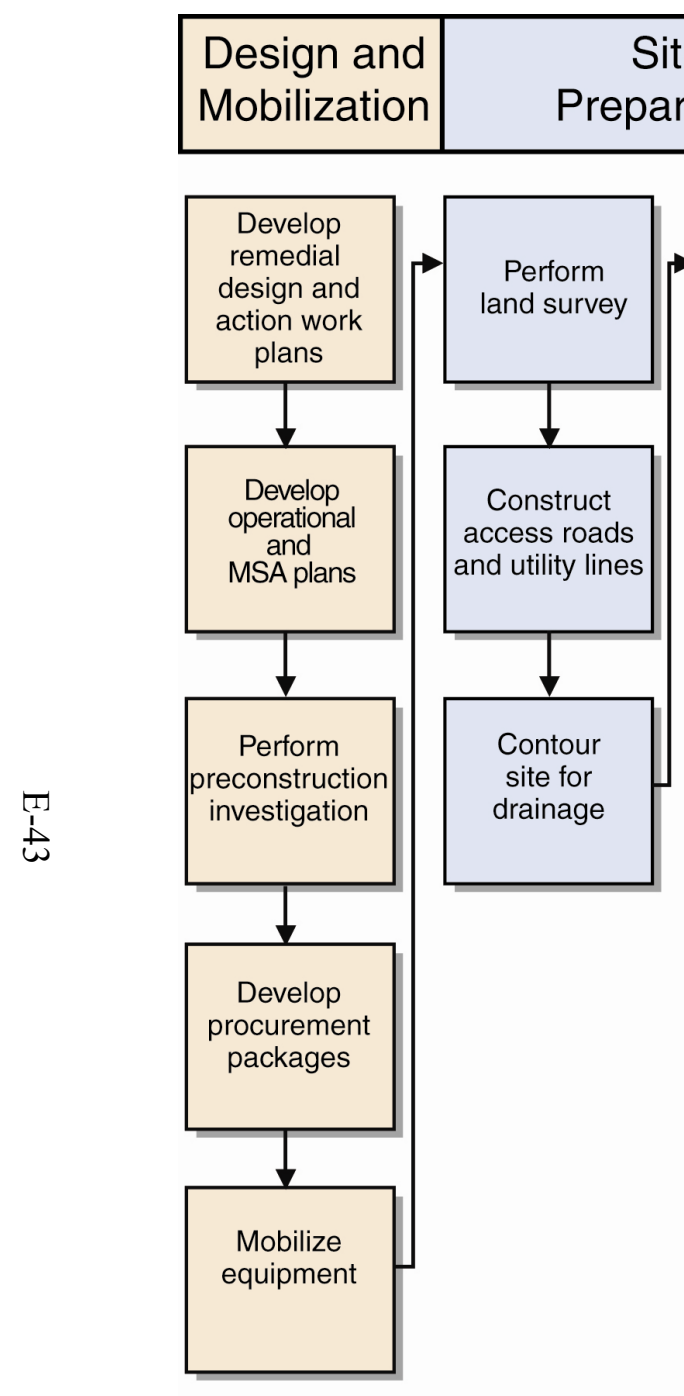

LLW $=$ low-level waste

MSA = management self-assessment

a. Waste types include waste in drums, waste in plywood boxes. plywood covers, tarp covers, and asphalt pad SDA = Subsurface Disposal Area

Figure E-19. Preconceptual process flow diagram for Pad A retrieval, ex situ treatment, and Subsurface Disposal Area disposal. 
Table E-10. Waste type volumes for Pad A retrieval, ex situ treatment, and Subsurface Disposal Area disposal.

\begin{tabular}{|c|c|c|c|c|c|c|c|c|}
\hline & Conversion & $30 \%$ & $80 \%$ & $20 \%$ & $40 \%$ & $45 \%$ & $128 \mathrm{ft}^{3} / \mathrm{box}$ & $128 \mathrm{ft}^{3} / \mathrm{box}$ \\
\hline Waste Type & $\begin{array}{c}\text { Source Data } \\
\left(\mathrm{ft}^{3}\right)\end{array}$ & $\begin{array}{l}\text { Contaminated } \\
\text { Overburden } \\
\text { and } \\
\text { Sideburden } \\
\left(\mathrm{ft}^{3}\right)\end{array}$ & $\begin{array}{l}\text { Fines } \\
\text { Volume } \\
\left(\mathrm{ft}^{3}\right)\end{array}$ & $\begin{array}{c}\text { Debris } \\
\text { Volume } \\
\left(\mathrm{ft}^{3}\right)\end{array}$ & $\begin{array}{c}\text { Fines Boxed } \\
\text { Volume } \\
\left(\mathrm{ft}^{3}\right)\end{array}$ & $\begin{array}{c}\text { Debris } \\
\text { Boxed } \\
\text { Volume } \\
\left(\mathrm{ft}^{3}\right)\end{array}$ & $\begin{array}{c}\text { Number of } \\
4 \times 4 \times 8 \text {-ft } \\
\text { Wooden } \\
\text { Boxes } \\
\text { (fines) }\end{array}$ & $\begin{array}{c}\text { Number of } \\
4 \times 4 \times 8-\mathrm{ft} \\
\text { Wooden } \\
\text { Boxes } \\
\text { (debris) }\end{array}$ \\
\hline INL Site-generated & 517 & - & 414 & 103 & 579 & 150 & 5 & 1 \\
\hline Series 745 sludge & 256,852 & - & 205,482 & 51,370 & 287,674 & 74,487 & 2,247 & 582 \\
\hline Series 995 sludge & 5,158 & - & 4,126 & 1,032 & 5,777 & 1,496 & 45 & 12 \\
\hline $\begin{array}{l}\text { Rocky Flats Plant combustibles } \\
\text { and noncombustibles }\end{array}$ & 96,764 & - & 77,411 & 19,353 & 108,376 & 28,062 & 847 & 219 \\
\hline Roaster oxide & 1,675 & - & 1,340 & 335 & 1,876 & 486 & 15 & 4 \\
\hline Loose overburden and sideburden & 766,474 & 229,942 & - & - & 321,919 & - & 2,515 & - \\
\hline Total & $1,127,440$ & 229,942 & 288,773 & 72,193 & 726,201 & 104,680 & 5,673 & 818 \\
\hline
\end{tabular}




\section{E-6.2 Site Preparation}

Site preparation for Pad A waste retrieval, ex situ treatment, and disposal within the SDA would include the following:

- $\quad$ Perform an initial land survey

- $\quad$ Construct access roads and utilities

- $\quad$ Contour the SDA to direct surface run-off

- $\quad$ Remove part of the uncontaminated soil from slopes adjacent to Pad A

- $\quad$ Survey the Pad A site following slope removal

- $\quad$ Construct the retrieval enclosure

- Install ex situ treatment equipment in an attached airlock

- $\quad$ Prepare a staging area to facilitate moving packaged waste from the ex situ treatment airlock to the final disposal area within the SDA.

\section{E-6.3 Readiness Demonstration}

Readiness for Pad A waste retrieval, ex situ treatment, and disposal within the SDA would be demonstrated by conducting a management self-assessment and completing any resulting corrective actions. Any studies to confirm effectiveness of ex situ treatment approaches for fines and debris would be completed during the remedial design phase.

\section{E-6.4 Remediation}

This action would remove waste from Pad A, treat waste fines and debris with a Portland cement-based grout, and relocate stabilized waste within the OU 7-13/14 area of contamination. This action may reduce mobility of contaminants, but would not reduce the toxicity or volume of Pad A waste. Pad A waste would be retrieved using an enclosure and excavation technologies similar to those for retrieval of waste buried elsewhere in the SDA. Any uncontaminated soil removed at the beginning of retrieval operations would be taken out of the retrieval enclosure and stockpiled elsewhere in the SDA. Waste then would be removed from the side of the Pad A stack using an excavator modified for operation within a contaminated environment. As presented in Figure E-20, retrieved waste would be separated into debris (greater than 15-cm [6-in.] diameter) and fines (less than 15-cm [6-in.] diameter) using fixtures within the retrieval enclosure. Any prohibited items would be removed during waste sorting. It is assumed that disposal paths can be identified for any prohibited items and that contingency estimates would be sufficient to cover any additional disposal costs. Debris and fines would be placed in $128-\mathrm{ft}^{3}$ wooden boxes and transferred to the attached ex situ treatment airlock. Debris and fines would be treated by stabilization with Portland cement-based grout. Waste treatment methods would be analogous to those currently used at ICDF. Waste fines would be dumped from the wooden box into a paddle mixer and combined with a Portland cement-based grout. Treated fines would be poured back into the original waste box. Boxes containing debris would be treated by filling accessible voids with a flowable Portland cement-based grout. Boxes containing treated waste would be closed, decontaminated, and transported to the staging area. Subsequently, treated waste would be transferred to the active low-level radioactive waste disposal pit (or other subsurface location) within the SDA. 


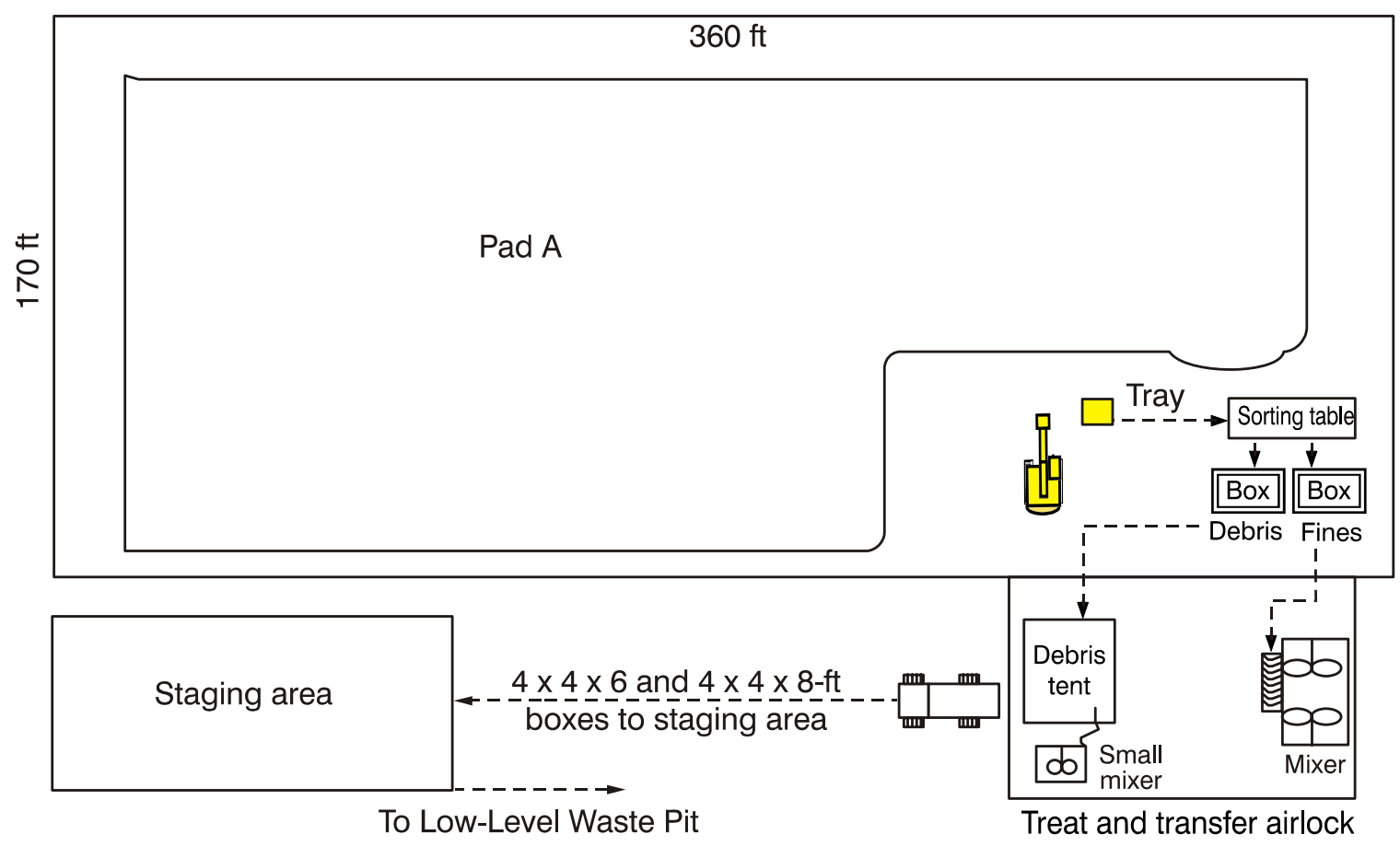

G06-1760-11

Figure E-20. Preconceptual plan view of Pad A retrieval, ex situ treatment, and Subsurface Disposal Area disposal.

\section{E-6.5 Demobilization and Reporting}

After completing Pad A waste retrieval, ex situ treatment, and disposal within the SDA, equipment would be demobilized, and the retrieval enclosure, ex situ treatment equipment, and associated infrastructure would be dismantled. Excess equipment would be used or disposed of. The final inspection report for Pad A waste retrieval, ex situ treatment and disposal within the SDA would be included in the remedial action report for OU 7-13/14.

\section{E-7. PAD A RETRIEVAL WITH SHIPMENT TO THE IDAHO CERCLA DISPOSAL FACILITY FOR TREATMENT AND DISPOSAL}

Figure E-21 provides a preconceptual process diagram that overviews implementation of this module and was created for cost-estimation purposes. Key tasks identified in Figure E-21 are discussed in the following subsections.

\section{E-7.1 Design and Mobilization}

Design and mobilization for Pad A retrieval with shipment to ICDF for treatment and disposal would include developing remedial design and remedial action work plans, operational plans (i.e., operation and layout plan, radiation monitoring and control plan, industrial hygiene exposure and sampling plan, training plan, and quality control plan), and procurement packages; performing a preconstruction investigation; and mobilizing equipment to the field. 


\begin{tabular}{|l|c|c|c|c|}
\hline $\begin{array}{c}\text { Design and } \\
\text { Mobilization }\end{array}$ & $\begin{array}{c}\text { Site } \\
\text { Preparation }\end{array}$ & $\begin{array}{c}\text { Readiness } \\
\text { Demonstration }\end{array}$ & Remediation & Remobilization \\
Retrieval & Treatment and Disposal & $\begin{array}{c}\text { Demol Reporting } \\
\text { and }\end{array}$ \\
\hline
\end{tabular}
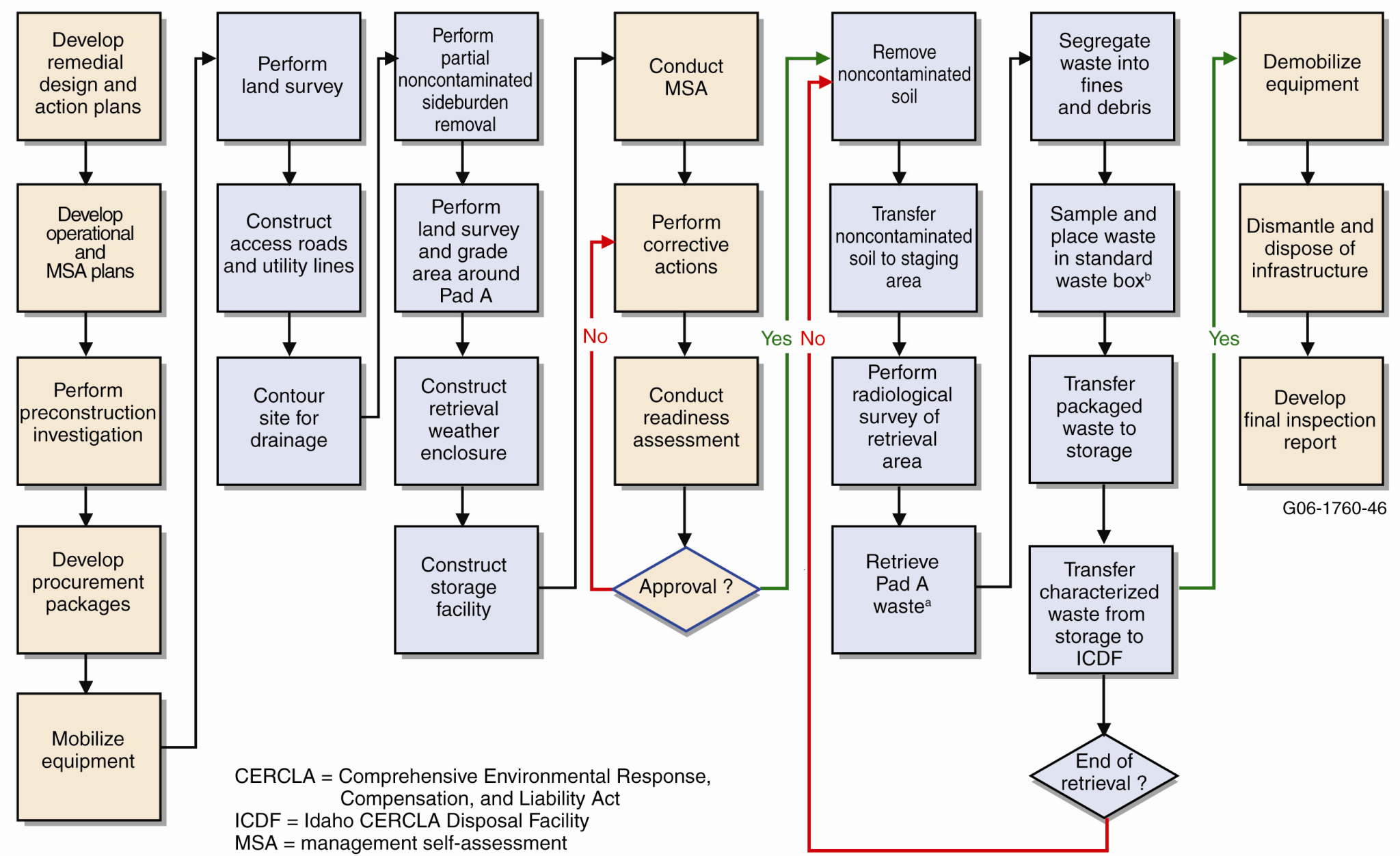

G06-1760-46

CERCLA = Comprehensive Environmental Response, Compensation, and Liability Act

ICDF = Idaho CERCLA Disposal Facility $\mathrm{MSA}=$ management self-assessment

a. Waste types include waste in drums, waste in plywood boxes. plywood covers, tarp covers, and asphalt pad.

b. Fines would be placed in metal $4 \times 4 \times 6$-ft standard waste boxes. Debris would be placed in wooden $4 \times 4 \times 8$-ft standard waste boxes.

Figure E-21. Preconceptual process flow diagram for Pad A retrieval and shipment to the Idaho CERCLA Disposal Facility for treatment and disposal. 
Developing remedial design and remedial action work plans would include completing a hazardous waste determination for Pad A waste and confirming that packaged waste would meet ICDF waste acceptance criteria. Preliminary engineering design assumes that most waste containers on Pad A are structurally compromised and that retrieved waste would be commingled upon retrieval. Resulting waste is assumed to be identified as alpha-contaminated low-level mixed waste, based on process knowledge and statistical sampling of boxed waste. Waste would be packaged in containers currently accepted by ICDF for ex situ treatment of soil and debris. Metal boxes $(n=500)$ would be returned to the SDA for reuse after ex situ treatment of waste fines. Wooden boxes would be disposed of with stabilized debris. As presented in Table E-11, the majority of all buried waste and all contaminated soil (i.e., overburden and side burden) would be boxed and treated as fines. The balance of the waste would be boxed and treated as debris. Waste forms are assumed to expand during excavation, packaging, and treatment.

\section{E-7.2 Site Preparation}

Site preparation would include performing an initial land survey, constructing access roads and utilities, contouring the SDA to direct surface run-off, removing part of the uncontaminated soil from slopes adjacent to Pad A, surveying the Pad A site following slope removal, constructing the retrieval enclosure, installing stations in the waste packaging airlock, and preparing a staging area to facilitate transportation of packaged waste from the SDA to ICDF.

\section{E-7.3 Readiness Demonstration}

Readiness would be demonstrated by conducting a management self-assessment and completing any resulting corrective actions. Any studies to confirm effectiveness of ex situ treatment of fines and debris would be performed by ICDF during the remedial design phase.

\section{E-7.4 Remediation}

This action would permanently remove the Pad A waste volume, and associated contaminants, from the SDA and place it in a lined landfill on the INL Site. Pad A waste would be retrieved using an enclosure and excavation technologies similar to those for retrieval of waste buried elsewhere in the SDA. Any uncontaminated soil removed at the beginning of retrieval operations would be taken out of the retrieval enclosure and stockpiled elsewhere in the SDA. As shown in Figure E-22, waste then would be removed from the side of the Pad A stack using an excavator modified for operation within a contaminated environment. Retrieved waste would be separated into debris (greater than 15-cm [6-in.] diameter) or fines (less than 15-cm [6-in.] diameter) using manned sorting tables within the retrieval enclosure. Any items prohibited by ICDF waste acceptance criteria would be removed at the sorting tables. It is assumed that disposal paths can be identified for any prohibited items and that contingency estimates would be sufficient to cover any additional disposal costs. Sorted waste would be placed on trays and transported to waste packaging stations located in an adjacent airlock. Within the packaging stations, waste sampling would occur, waste codes would be assigned, waste fines would be packaged in $4 \times 4 \times 6$-ft metal boxes, waste debris would be packaged in $4 \times 4 \times 8$ - $\mathrm{ft}$ wooden waste boxes, boxes would be closed, and labeling would be affixed. Labeled waste boxes would be transferred to the staging area where U.S. Department of Transportation oxidizer tests would be performed before shipment to ICDF for treatment and disposal. At ICDF, waste fines and debris would be treated using a Portland cement-based grout. Waste fines would be dumped from the metal transport box into a paddle mixer and combined with grout. The resulting mixture would be disposed of in the ICDF landfill, and the metal box would be returned to the Pad A staging area for reuse. Wooden boxes containing debris would be punctured and accessible voids filled with a flowable grout before disposal in the ICDF landfill. 
Table E-11. Waste type volumes for Pad A retrieval with shipment to the Idaho CERCLA Disposal Facility for treatment and disposal.

\begin{tabular}{|c|c|c|c|c|c|c|c|c|}
\hline & Conversion & $30 \%$ & $80 \%$ & $20 \%$ & $30 \%$ & $45 \%$ & $96 \mathrm{ft}^{3} / \mathrm{box}$ & $128 \mathrm{ft}^{3} / \mathrm{box}$ \\
\hline Waste Type & $\begin{array}{c}\text { Source Data } \\
\left(\mathrm{ft}^{3}\right)\end{array}$ & $\begin{array}{c}\text { Contaminated } \\
\text { Overburden and } \\
\text { Sideburden } \\
\left(\mathrm{ft}^{3}\right)\end{array}$ & $\begin{array}{l}\text { Fines } \\
\text { Volume } \\
\left(\mathrm{ft}^{3}\right)\end{array}$ & $\begin{array}{l}\text { Debris } \\
\text { Volume } \\
\left(\mathrm{ft}^{3}\right)\end{array}$ & $\begin{array}{c}\text { Fines Boxed } \\
\text { Volume } \\
\left(\mathrm{ft}^{3}\right)\end{array}$ & $\begin{array}{c}\text { Debris Boxed } \\
\text { Volume } \\
\left(\mathrm{ft}^{3}\right)\end{array}$ & $\begin{array}{c}\text { Number of } \\
4 \times 4 \times 6-f t \\
\text { Metal Boxes } \\
\text { (fines) }\end{array}$ & $\begin{array}{c}\text { Number of } \\
4 \times 4 \times 8 \text {-ft } \\
\text { Wooden Boxes } \\
\text { (debris) }\end{array}$ \\
\hline INL Site-generated & 517 & - & 414 & 103 & 538 & 150 & 6 & 1 \\
\hline Series 745 sludge & 256,852 & - & 205,482 & 51,370 & 267,126 & 74,487 & 2,783 & 582 \\
\hline Series 995 sludge & 5,158 & - & 4,126 & 1,032 & 5,364 & 1,496 & 56 & 12 \\
\hline $\begin{array}{l}\text { Rocky Flats Plant } \\
\text { combustibles and } \\
\text { noncombustibles }\end{array}$ & 96,764 & - & 77,411 & 19,353 & 100,635 & 28,062 & 1,048 & 219 \\
\hline Roaster oxide & 1,675 & - & 1,340 & 335 & 1,742 & 486 & 18 & 4 \\
\hline $\begin{array}{l}\text { Loose overburden and } \\
\text { sideburden }\end{array}$ & 766,474 & 229,942 & - & - & 298,925 & - & 3,114 & - \\
\hline Total & $1,127,440$ & 229,942 & 288,773 & 72,193 & 674,330 & 104,680 & 7,024 & 818 \\
\hline
\end{tabular}




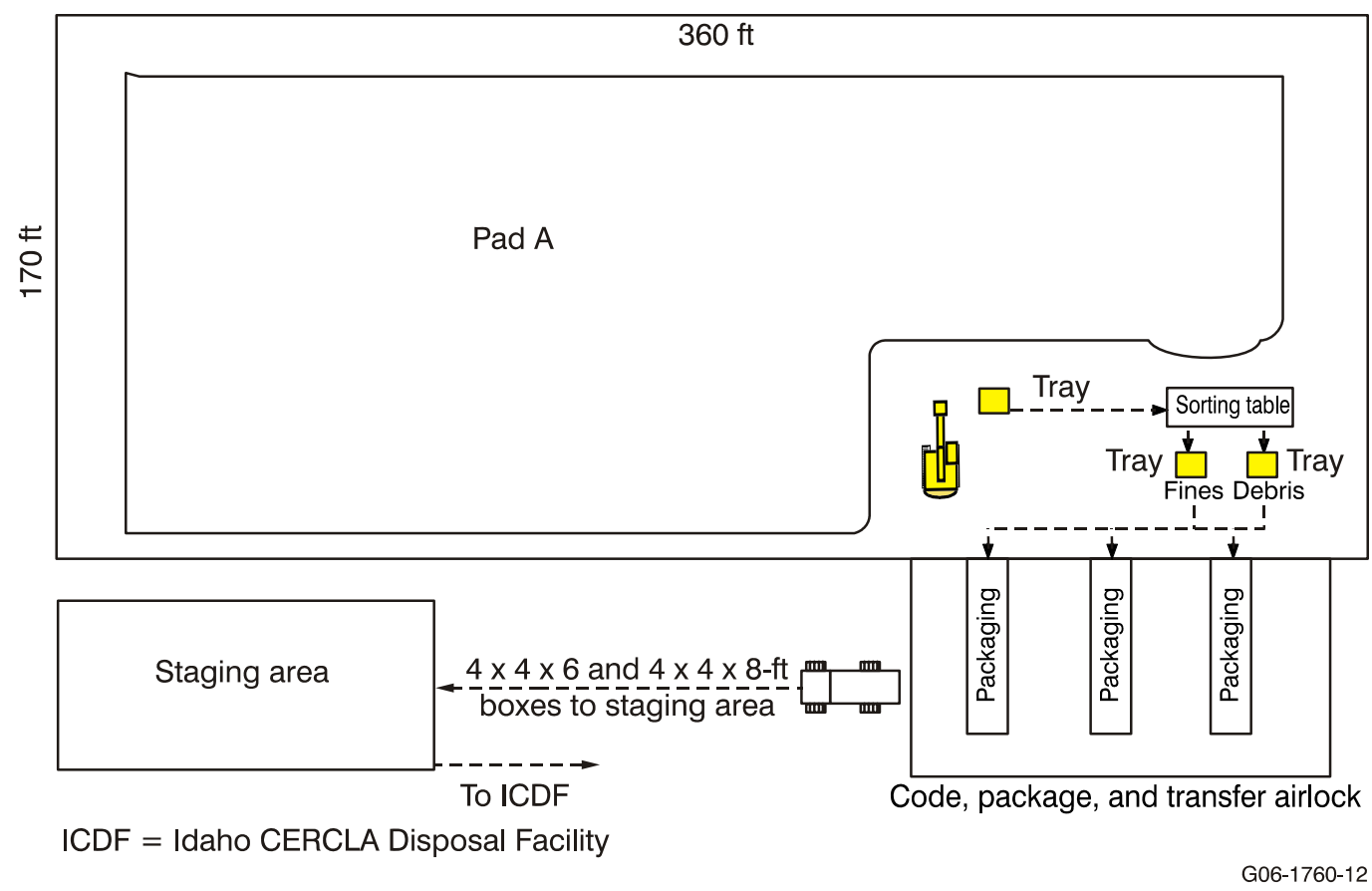

Figure E-22. Preconceptual plan view of Pad A retrieval and shipment to the Idaho CERCLA Disposal Facility.

\section{E-7.5 Demobilization and Reporting}

Upon completion of Pad A retrieval with shipment to ICDF for treatment and disposal, equipment would be demobilized and the retrieval enclosure, waste packaging stations, and associated infrastructure would be dismantled. Excess equipment would be used or disposed of. The final inspection report for Pad A retrieval with shipment to ICDF for treatment and disposal would be included in the remedial action report for OU 7-13/14.

\section{E-8. PAD A RETRIEVAL WITH SHIPMENT OFF THE IDAHO NATIONAL LABORATORY SITE FOR TREATMENT AND DISPOSAL}

Figure E-23 provides a preconceptual process diagram that overviews implementation of this module and was created for cost-estimation purposes. Key tasks identified in Figure E-23 are discussed in the following subsections.

\section{E-8.1 Design and Mobilization}

Design and mobilization for Pad A retrieval with shipment off the INL Site for treatment and disposal would include developing remedial design and remedial action work plans, operational plans (i.e., operation and layout plan, radiation monitoring and control plan, industrial hygiene exposure and sampling plan, training plan, and quality control plan), and procurement packages; performing a preconstruction investigation; and mobilizing equipment to the work site. 


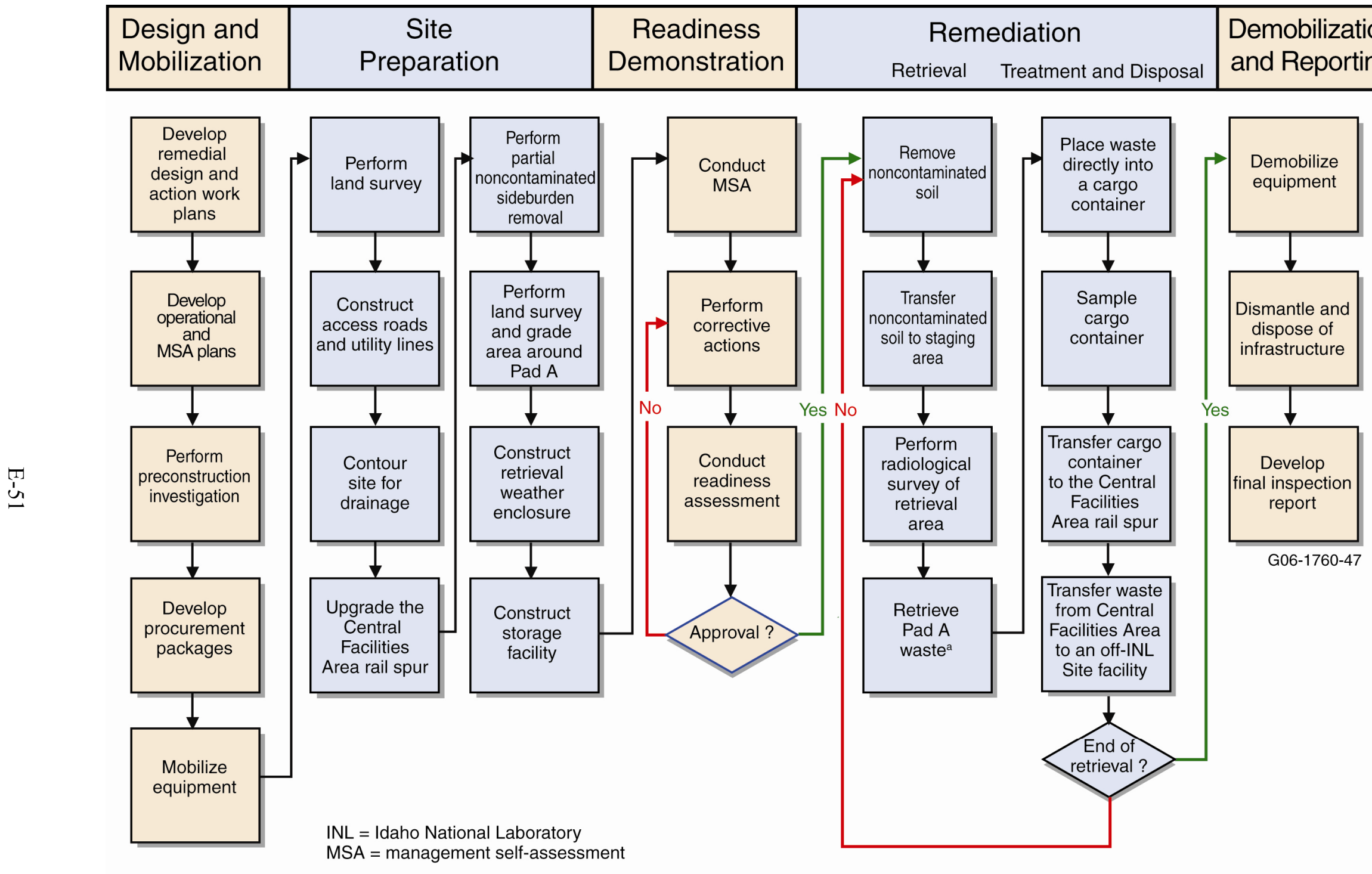

a. Waste types include waste in drums, waste in plywood boxes. plywood covers, tarp covers, and asphalt pad.

Figure E-23. Preconceptual process flow diagram for Pad A retrieval, treatment, and off-Idaho National Laboratory Site disposal. 
Developing remedial design and remedial action work plans would include completing a hazardous waste determination for Pad A waste and confirming that packaged waste would meet U.S. Department of Transportation requirements for public transport and waste acceptance criteria for commercial disposal (e.g., EnergySolutions). Preliminary engineering design assumes that most waste containers on Pad A are structurally compromised, that retrieved waste would be commingled upon retrieval, and that segregating various waste types would be technically impracticable. Resulting waste is assumed to be identified as alpha-contaminated low-level mixed waste, based on process knowledge and statistical sampling of packaged waste. Waste would be packaged in lined $8 \times 8.5 \times 20$-ft cargo containers. As presented in Table E-12, all buried waste and all contaminated soil (i.e., overburden and sideburden) would be placed into cargo containers. Waste forms are assumed to expand during excavation and packaging.

\section{E-8.2 Site Preparation}

Site preparation for Pad A retrieval with shipment off the INL Site for treatment and disposal would include performing an initial land survey, constructing access roads and utilities, contouring the SDA to direct surface run-off, removing part of the uncontaminated soil from slopes adjacent to Pad A, resurveying the Pad A site following slope removal, constructing the retrieval enclosure, installing an enclosed load-out chute from the retrieval enclosure to the transfer airlock, and preparing a staging area to facilitate transporting full cargo containers from the SDA to the rail loading crane at the Central Facilities Area.

\section{E-8.3 Readiness Demonstration}

Readiness for Pad A retrieval with shipment off the INL Site for treatment and disposal would be demonstrated by conducting a management self-assessment and completing any resulting corrective actions. Any studies to confirm compliance of bulk-loaded Pad A waste with U.S. Department of Transportation requirements would be performed during the remedial design phase.

\section{E-8.4 Remediation}

This action would permanently remove Pad A waste volume, and associated contaminants, from the SDA and the INL Site. Pad A waste would be retrieved using an enclosure and excavation technologies similar to those for retrieval of waste buried elsewhere in the SDA. Any uncontaminated soil removed at the beginning of retrieval operations would be taken out of the retrieval enclosure and stockpiled elsewhere in the SDA. Waste then would be removed from the side of the Pad A stack using a conventional loader modified for operation within a contaminated environment. Retrieved waste would be dropped into an enclosed chute that would unload into a lined $8 \times 8.5 \times 20$-ft cargo container staged within an attached airlock. Any waste segregation or examination (for prohibited items) is assumed to occur at the receiving treatment, storage, and disposal facility. Waste characterization would be statistical, with one composite sample collected for every two cargo containers. Full cargo containers would be closed, decontaminated, and transferred to the Pad A staging area where U.S. Department of Transportation oxidizer tests would be performed before shipment. Full cargo containers then would be transported to the Central Facilities Area for loading onto intermodal rail cars. Intermodal rail cars, with containerized Pad A waste, would be transported to a commercial facility (e.g., EnergySolutions) for treatment and disposal (see Figure E-24). Treatment at EnergySolutions is assumed to consist of encapsulating debris. 
Table E-12. Waste type volumes for Pad A retrieval with shipment off the Idaho National Laboratory Site for treatment and disposal.

\begin{tabular}{|c|c|c|c|c|}
\hline \multirow{2}{*}{ Waste Type } & \multirow[b]{2}{*}{$\begin{array}{c}\text { Source Data } \\
\left(\mathrm{ft}^{3}\right)\end{array}$} & $30 \%$ & $30 \%$ & $1,360 \mathrm{ft}^{3} /$ container \\
\hline & & $\begin{array}{c}\text { Contaminated } \\
\text { Overburden and } \\
\text { Sideburden } \\
\left(\mathrm{ft}^{3}\right)\end{array}$ & $\begin{array}{l}\text { Expansion and } \\
\text { Packing Void } \\
\left(\mathrm{ft}^{3}\right)\end{array}$ & $\begin{array}{l}\text { Number of Cargo } \\
\text { Containers }\end{array}$ \\
\hline INL Site-generated & 517 & - & 672 & 0 \\
\hline Series 745 sludge & 256,852 & - & 333,908 & 246 \\
\hline Series 995 sludge & 5,158 & - & 6,705 & 5 \\
\hline $\begin{array}{l}\text { Rocky Flats Plant combustibles } \\
\text { and noncombustibles }\end{array}$ & 96,764 & - & 125,793 & 92 \\
\hline Roaster oxide & 1,675 & - & 2,178 & 2 \\
\hline Loose overburden and sideburden & 766,474 & 229,942 & 298,925 & 220 \\
\hline Total & $1,127,440$ & 229,942 & 768,181 & 565 \\
\hline
\end{tabular}




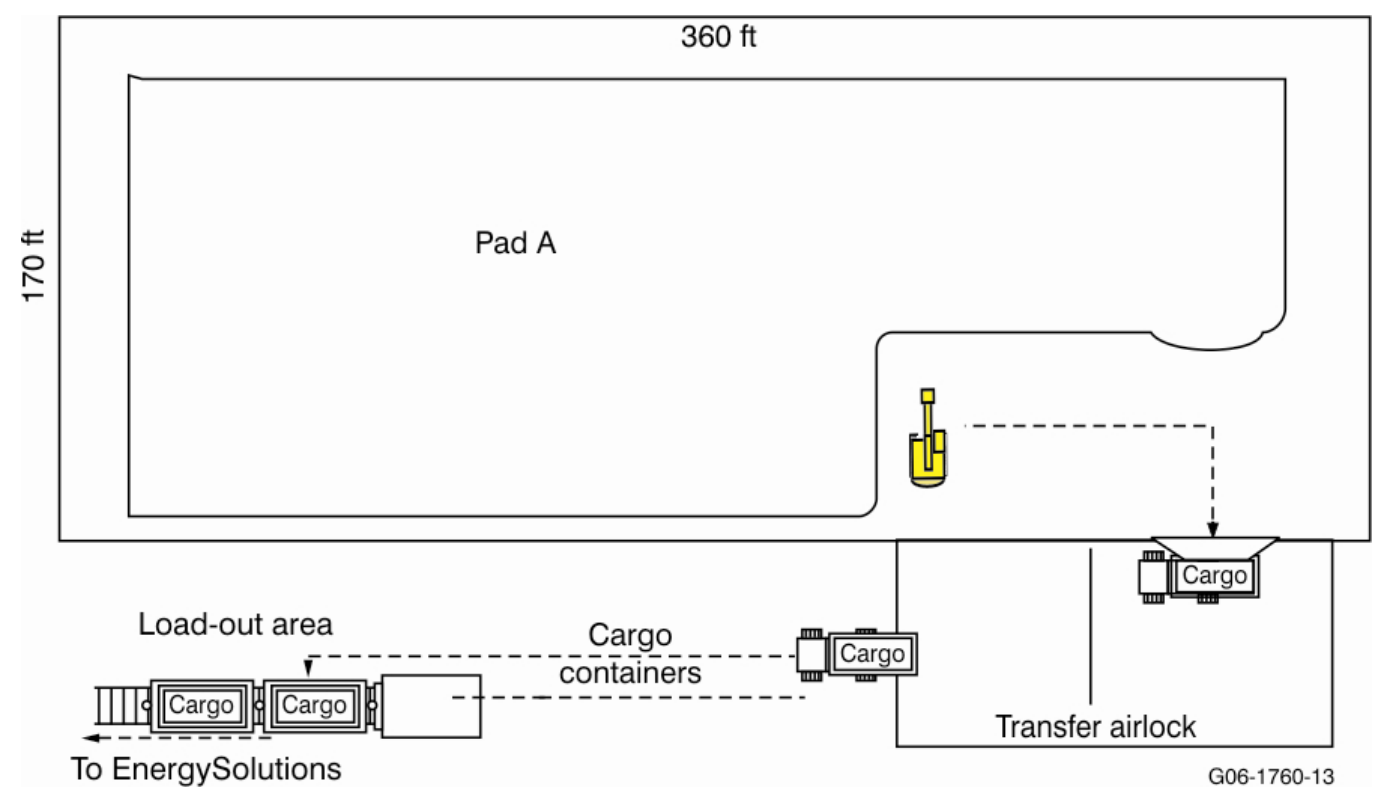

Figure E-24. Preconceptual plan view of Pad A retrieval and shipment to an off-Idaho National Laboratory Site facility.

\section{E-8.5 Demobilization and Reporting}

Upon completion of Pad A retrieval, with shipment off the INL Site for treatment and disposal, equipment would be demobilized, and the retrieval enclosure and associated infrastructure would be dismantled. Excess equipment would be used or disposed of. The final inspection report for Pad A retrieval with shipment off the INL Site for treatment and disposal would be included in the remedial action report for OU 7-13/14.

\section{E-9. DYNAMIC COMPACTION OF PAD A}

Void reduction would decrease the probability of local soil subsidence, thus improving long-term integrity of a surface barrier. Dynamic compaction has been used successfully to reduce voids in buried waste in municipal landfills and U.S. Department of Energy (DOE) burial sites where conditions are similar to the SDA. Figure E-25 provides a photograph of dynamic compaction being performed at the Savanna River Site.

The U.S. Department of Energy uses the Savannah River Site in Aiken, SC for disposal of low-level radioactive waste. The waste is buried in trenches approximately 25 feet deep. Uncontaminated soil fill was used in the upper six feet of the trenches as a buffer between the contaminated waste and the site workers. Prior to close-out of the trenches and placement of a liner system, dynamic compaction was used to compact the waste material.

Due to the nature of the radioactive waste, a detailed safety protocol was used. Radioactive testing was continuously performed to prevent exposure of on-Site personnel. If wind velocities greater than $15 \mathrm{mph}$ were recorded, compaction operations ceased for the day. 
At the Savanna River Site, an eight foot diameter 20 ton weight was used to perform dynamic compaction. The project lasted for over a year. Following completion of the dynamic compaction program, a synthetic liner was placed over the landfill (TerraSystems 2006).

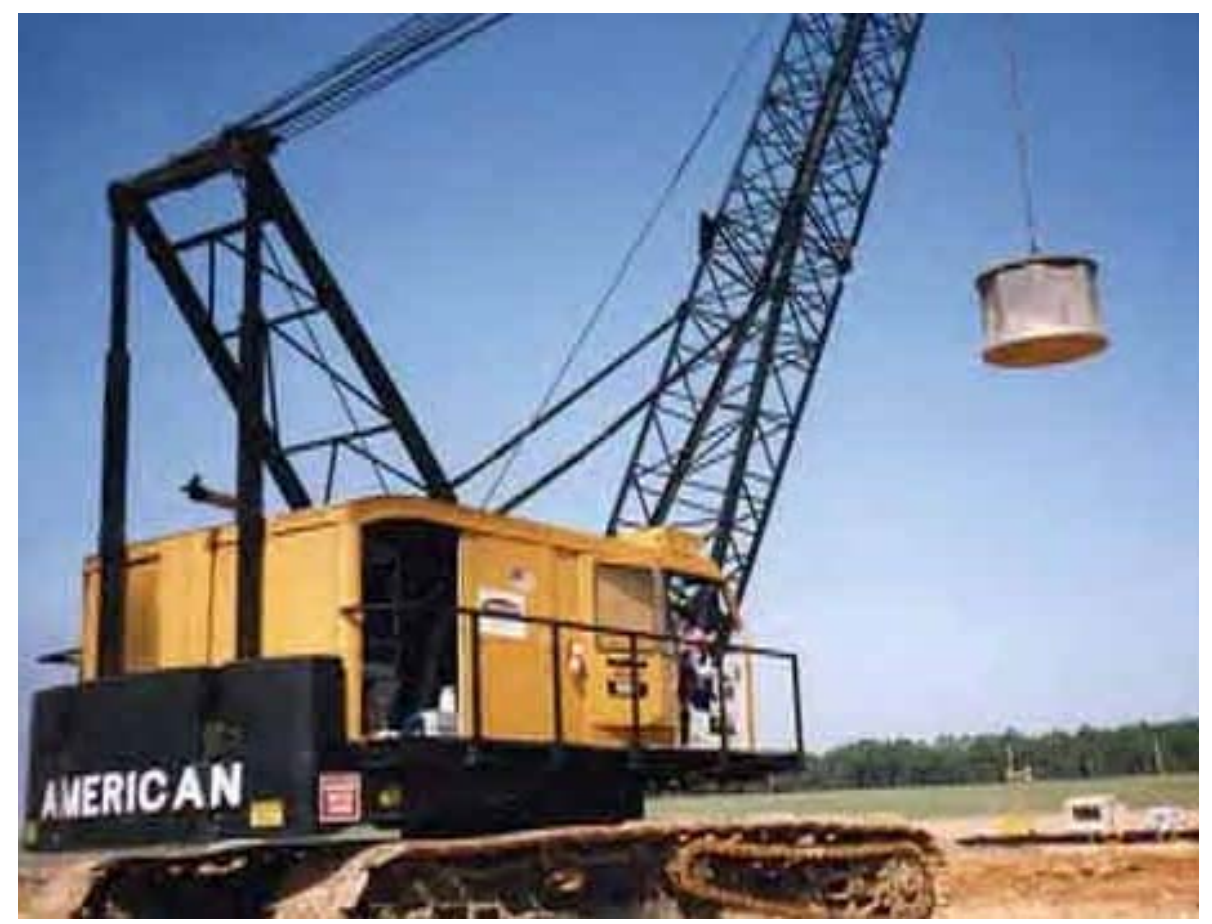

Figure E-25. Dynamic compaction operation at the Savanna River Site.

Dynamic compaction is a ground improvement process for compacting and strengthening loose or soft soil. As shown in Figure E-26, the method involves systematic dropping of heavy weights, typically 10 to 20 tons, in a pattern designed to reduce void space in Pad A. Drop heights vary from 9.1 to $24.4 \mathrm{~m}$ (30 to $80 \mathrm{ft}$ ). A crater would be formed at the impact point that could be up to $2 \mathrm{~m}(6.6 \mathrm{ft})$ deep. Craters would be backfilled by end-dumping fill into the craters. Several phases or passes of tamping may be required across Pad A, depending on the level of improvement required. After completing the "high-energy" tamping, a low-energy, or "ironing," phase would be performed to compact material in the craters and in the upper $1.5 \mathrm{~m}(5 \mathrm{ft})$ of the formation. The ironing phase consists of dropping weight from a drop height of 3 to $7.6 \mathrm{~m}$ (10 to $25 \mathrm{ft}$ ) on close centers (Richins and Hurst 2004).

The soil improvement depth would be proportional to the energy per drop (i.e., drop weight $\times$ drop height) and configuration of the weight. Published correlations are available to economically establish the appropriate weight and drop height for the zone of soil to be improved. Experience data from landfills, other DOE buried waste sites, and test data specific to Pad A would be required to accurately assess the degree of void reduction for waste buried in Pad A. The effect of ground vibrations on nearby structures can be estimated from drop weight and drop height. Using sample values of a 15-ton drop weight and 15.2-m (50-ft) drop height, a conservative estimate of maintaining a 39.6-m (130-ft) minimum distance from any vibration-sensitive structure was calculated for dynamic compaction in the SDA. 


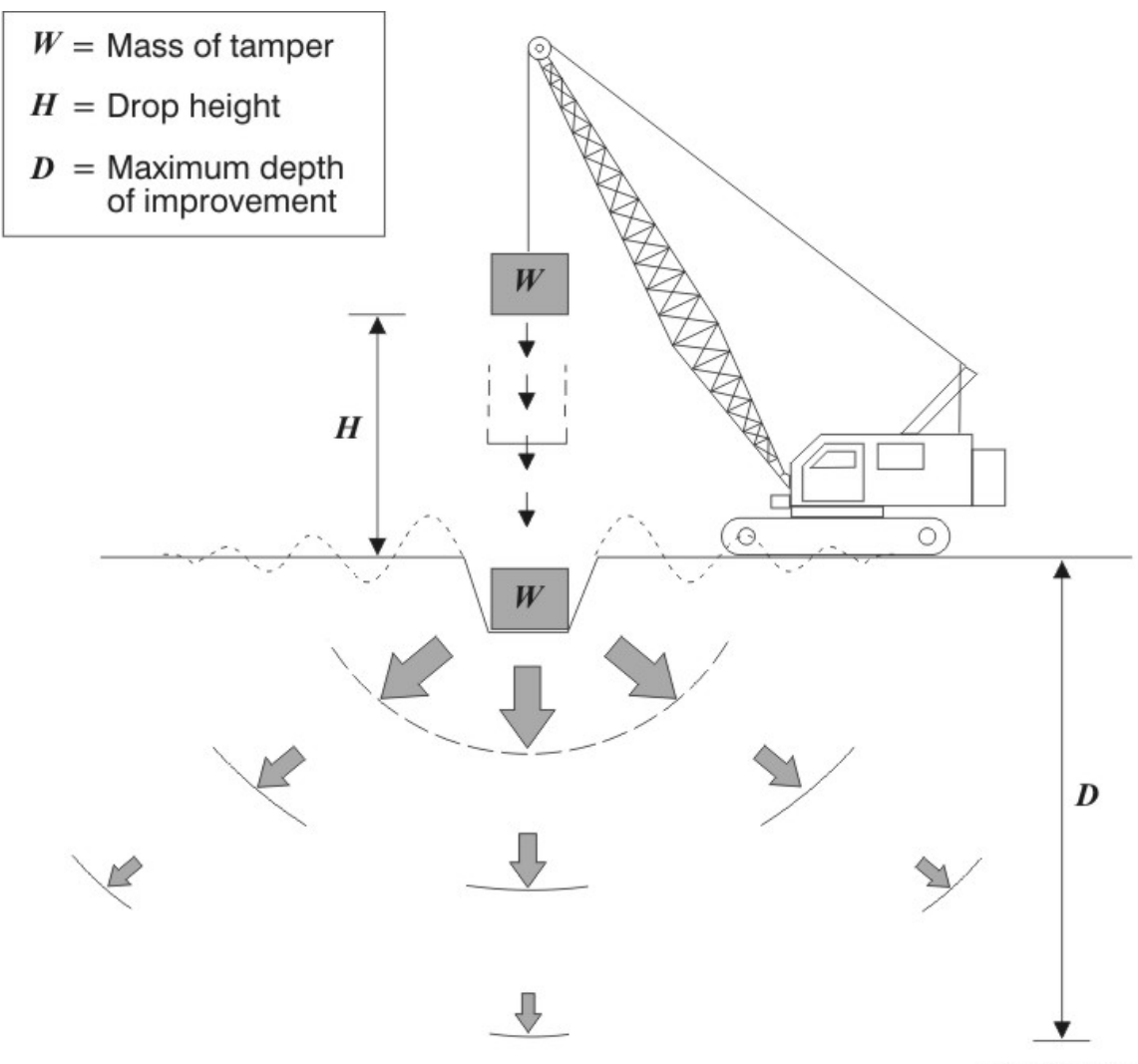

G07-1760-73

Figure E-26. Conceptual drawing of dynamic compaction.

A test demonstration of dynamic compaction in the SDA, with surrogate waste, is recommended to accurately determine drop weight and height required to obtain the required depth of improvement. In addition, formulas for estimating depth of improvement are for soil improvement only and may not be applicable to void reduction.

Effective operations require proper equipment, appropriate safety systems, and experienced operators and contractors. Typically, dynamic compaction would be carried out using large crawler friction-type cranes specifically modified for dynamic compaction operations. Unmodified cranes are not recommended because they may suffer damage from stresses that result from quick release of heavy weights. Radiological control and dust-suppression systems also must be in place before operations commence. A geophysical monitoring system to measure ground vibrations must be in place before initiating dynamic compaction.

Figure E-27 provides a preconceptual process diagram that overviews implementation of this module and was created for cost-estimation purposes. Key tasks identified in Figure E-27 are discussed in the following subsections. 


\begin{tabular}{|c|cc|c|c|c|}
\hline $\begin{array}{c}\text { Design and } \\
\text { Mobilization }\end{array}$ & $\begin{array}{c}\text { Site Preparation } \\
\text { Mockup Testing }\end{array}$ & $\begin{array}{c}\text { Readiness } \\
\text { Demonstration }\end{array}$ & $\begin{array}{c}\text { Remediation } \\
\text { Dynamic Compaction }\end{array}$ & $\begin{array}{c}\text { Demobilization } \\
\text { and Reporting }\end{array}$ \\
\hline
\end{tabular}
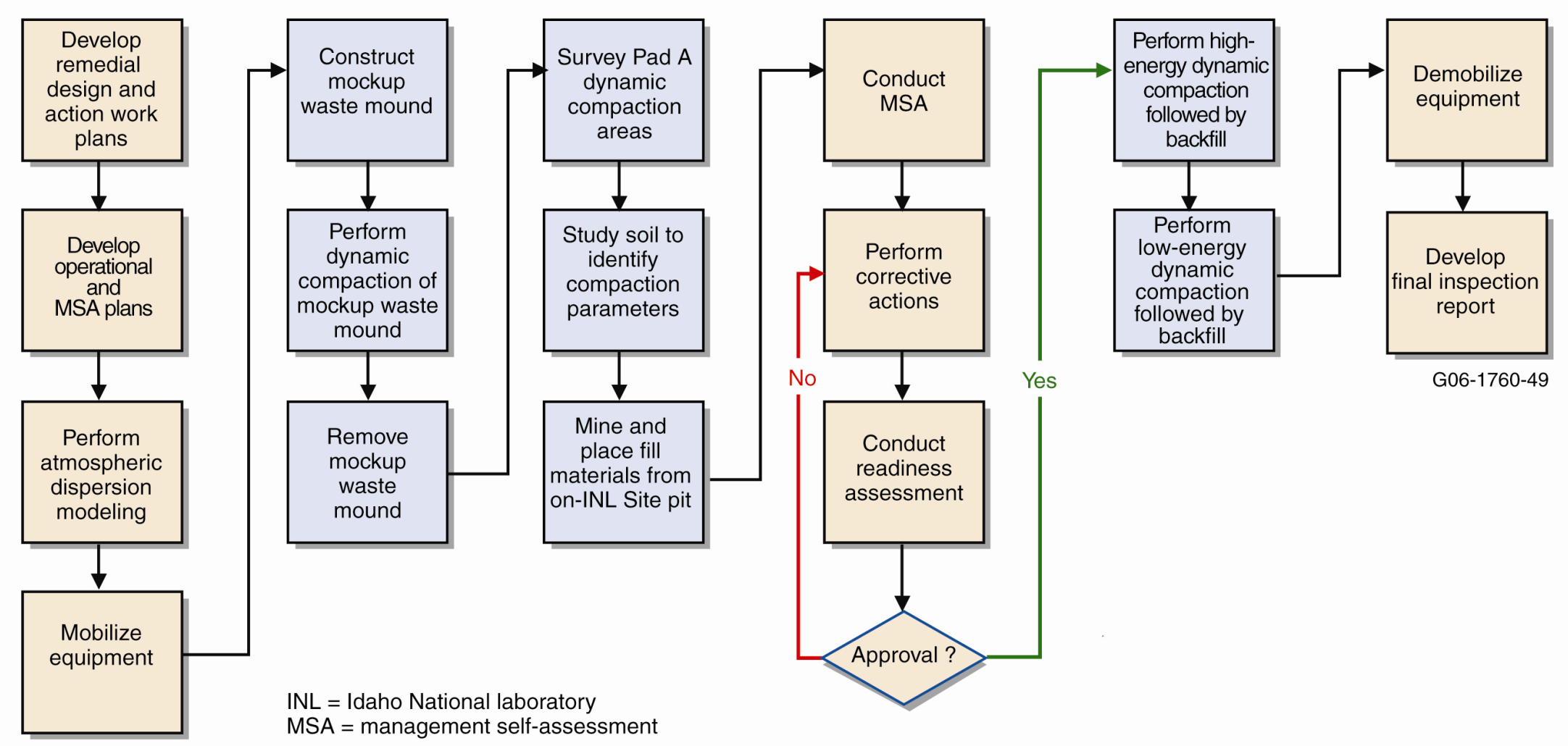

Figure E-27. Preconceptual process flow diagram for dynamic compaction. 


\section{E-9.1 Design and Mobilization}

Design and mobilization for dynamically compacting Pad A would include developing remedial design and remedial action work plans, operational plans (i.e., operations and layout plan, radiation monitoring and control plan, industrial hygiene exposure and sampling plan, and quality control plan), management self-assessment plans, and procurement packages; performing atmospheric dispersion modeling; and mobilizing equipment to the work site.

Developing remedial design and remedial action work plans would include preparing designs and schedules for preliminary soil studies, determining compaction parameters (e.g., drop weight and height, drop pattern, and number of passes), installing geophysical monitoring systems, mining and importing fill material, and performing dynamic compaction of Pad A.

An atmospheric dispersion model would be generated to predict what airborne concentrations of contaminants would be generated during dynamic compaction. Modeling results would determine highest concentration receptor locations and optimal weather conditions.

\section{E-9.2 Site Preparation}

Before dynamic compaction of Pad A, the impact of ground vibrations on buried waste, resulting in potential container breaches or release of contaminants to the air, is a valid concern that must be thoroughly evaluated. This feasibility study addresses these concerns through mockup testing and monitoring. A mockup of Pad A would be fabricated, and dynamic compaction would be applied. Results from mockup testing would indicate what would be required (e.g., soil cover thickness and drop height) to dynamically compact the mound safely. Finally, during dynamic compaction of Pad A, results from atmospheric modeling would indicate ideal atmospheric conditions for dynamic compaction, based on initial dispersion modeling results.

A detailed site investigation would be required to ensure that dynamic compaction would be a safe and effective process for Pad A. This investigation includes surveying the area precisely to identify the boundary of the area to be compacted. Soil studies would be required to analyze ground vibrations resulting from the compaction process. Vibration-sensitive facilities and equipment (e.g., extraction wells for OCVZ Unit F, on-going retrievals in the SDA, monitoring wells, and equipment) should be identified, and a minimum distance from impacts that result from the drop should be determined. Questions concerning deflagration of nitrate salts contained in Pad A during dynamic compaction would have to be fully addressed. Note that detonation tests with nitrate or cellulosic mixtures conducted for the Pit 9 drilling project found the mixtures to be insensitive to impact or friction at transient temperatures below $150^{\circ} \mathrm{C}$ and containing more than $5 \%$ moisture by weight (Thompson et al. 2000).

Before commencing compaction, a 0.3-m (12-in.) blanket of fill would be placed over the treatment area, if sufficient fill is not already above the waste zone. This fill would aid in dust control and containment of contaminants if buried containers rupture during compaction.

\section{E-9.3 Readiness Demonstration}

Readiness for Pad A waste compaction would be demonstrated by conducting a management self-assessment, completing any resulting corrective actions, and successfully completing a final readiness review. DOE approval is assumed to be required before initiating any waste compaction activity. 


\section{E-9.4 Remediation}

Remediation involves placing additional soil fill over Pad A to mitigate potential release of contaminants to the air and provide fill for subsidence areas. Dynamic compacting Pad A would be performed. Dynamic compaction would entail dropping a weight, typically 10 to 30 tons, from a specified height, typically 15.2 to $30.5 \mathrm{~m}$ (50 to $100 \mathrm{ft})$, for a given number of times at impact points in a grid pattern. The appropriate impact footprint also must be chosen to ensure the desired effect would be achieved. On the first pass, the deepest layers would be compacted. After completing each pass, the compaction area would be backfilled and graded. Subsequent passes would compact successively shallower layers; then the compaction area would be graded.

After completing the high-energy "tamping" phase, a low-energy, or "ironing" phase, would be performed with lower compaction energy to compact material in the craters and in the upper $1.5 \mathrm{~m}(5 \mathrm{ft})$ of the formation. The ironing phase would consist of dropping the weight from a lower drop height, typically $6 \mathrm{~m}(20 \mathrm{ft})$, on close centers. Resulting craters would be backfilled, and roller compaction would be applied to fill material.

Radiological and chemical releases would be controlled throughout dynamic compaction operations. Releases would be controlled through (a) placing additional soil over the area to be compacted, (b) preventing compaction during adverse atmospheric conditions (as determined through modeling), and (c) mitigating dust generation through use of water spray provided by water trucks. Geophysical monitoring of vibrations generated during dynamic compaction operations also would be required.

\section{E-9.5 Demobilization and Reporting}

After completing Pad A waste compaction, equipment would be demobilized. Excess equipment would be used or disposed of. The final inspection report for Pad A waste compaction would be included in the remedial action report for OU 7-13/14.

\section{E-10. DYNAMIC COMPACTION OF PITS}

The OU 7-13/14 ISG Project Foundation Grouting Study (Stephens 2004) (using the finite element analysis computer program) determined spacing requirements for placing in situ foundation grout columns in potential subsidence areas of the SDA. This study concluded the following in regards to foundation stabilization: "The analysis results indicate that if a minimum of $0.5 \mathrm{~m}(1.5 \mathrm{ft})$ of grading fill is provided in the area occupied by Trenches 1 through 10, no grouted columns are required in this area." (Stephens 2004)

Based on results from this study, foundation stabilization, including dynamic compaction, is assumed not to be required within SDA trenches or vaults. Therefore, areas of the SDA targeted for foundation stabilization in the form of dynamic compaction only include Pits 1 through 6 and 8 through 16 . Pit 7 is too small to realize any benefit from stabilization.

Design and mobilization, site preparation, readiness demonstration, remediation, demobilization, and reporting for dynamic compaction of the SDA pit areas are nearly identical to those mentioned in Section E-9. Discrepancies between the two modules lie in the mockup testing. Release of contaminants into the air during dynamic compaction of a subgrade pit is assumed to be less probable than release of contaminants during compaction of an abovegrade mound (as described in Section E-9). Therefore, mockup testing would not be required for this module. 


\section{E-11. CONTAMINANT IN SITU GROUTING}

Figure E-28 provides a preconceptual process diagram that overviews implementation of this module and was created for cost-estimation purposes. Key tasks identified in Figure E-28 are discussed in the following subsections.

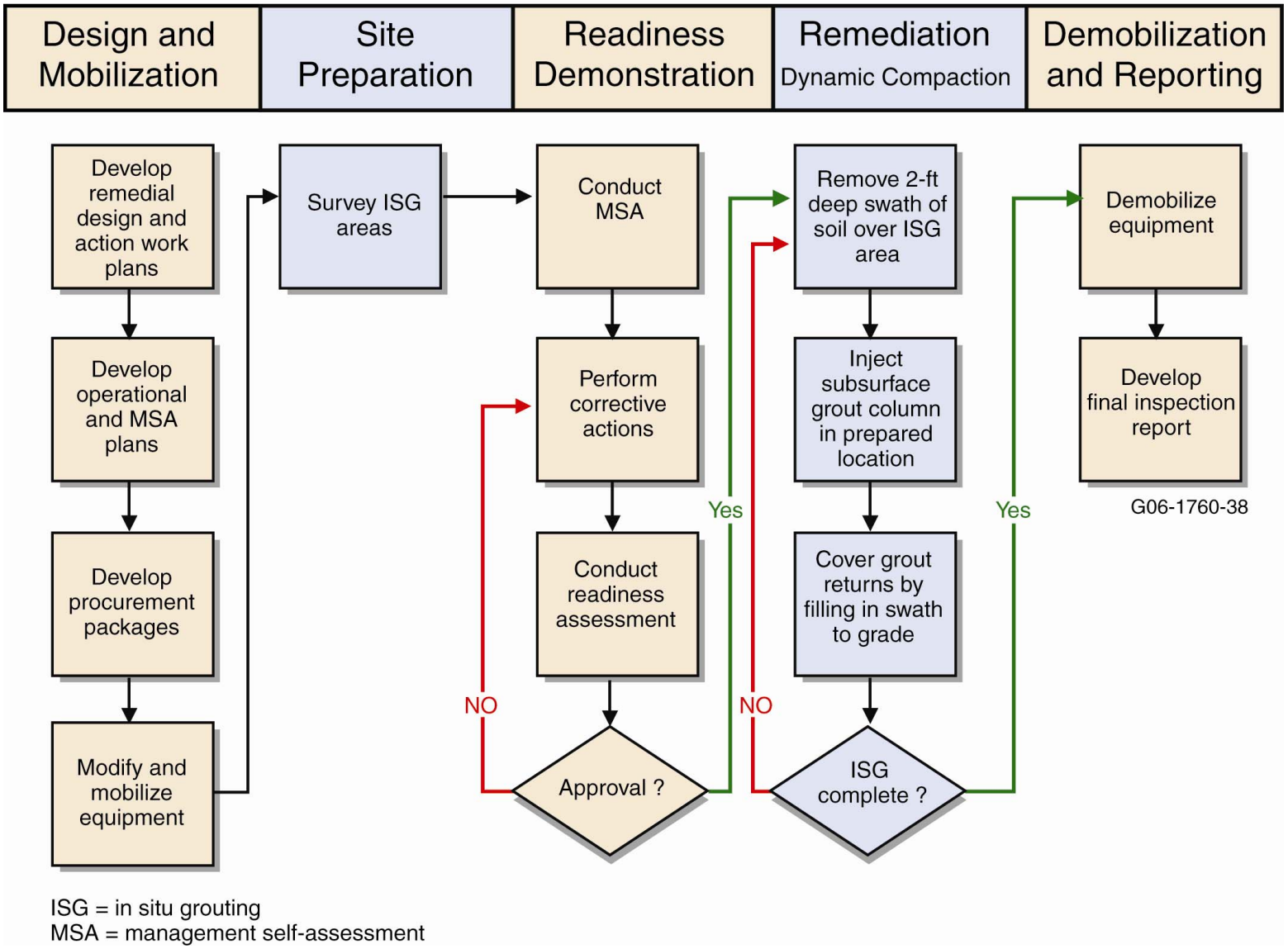

Figure E-28. Preconceptual process flow diagram for in situ grouting.

\section{E-11.1 Design and Mobilization}

Design and mobilization for in situ treatment of specified waste types within the SDA, using high-pressure jet grouting, would include developing remedial design and remedial action work plans, operational plans (i.e., operations and layout plan, radiation monitoring and control plan, industrial hygiene exposure and sampling plan, training plan, and quality control plan), a management self-assessment plan, and procurement packages, and modifying and mobilizing equipment.

Developing remedial design and remedial action work plans would include identifying COCs for in situ treatment, waste types containing COCs subject to rapid release, and disposal locations for specified waste types using the Waste Identification and Location Database and corroborating geophysical or probe information to identify areas requiring treatment by ISG. In situ contaminant grouting services will procured from a specialty vendor, the specialty vendor will modify a conventional tracked excavator to deploy a rotopercussion drill for injecting grout into the buried waste, and grout formulation used for 
contaminant grouting will consist of Portland cement and blast furnace slag. Field demonstration of implementability and effectiveness of vendor procedures would be required before commencing operations within the SDA.

In situ treatment of specified waste types within the SDA, using high-pressure jet grouting, would focus on immobilizing long-lived fission and activation products in waste types where rapid contaminant release is anticipated. Potential waste types for in situ treatment, using high-pressure jet grouting, include INL Site reactor and fuel development waste containing readily releasable Tc-99, I-129, or C-14. Disposal locations for specified waste types would be identified using the Waste Identification and Location Database and corroborating geophysical or probe information. Figure E-29 provides hypothetical contaminant grouting locations used to develop costs for this module.

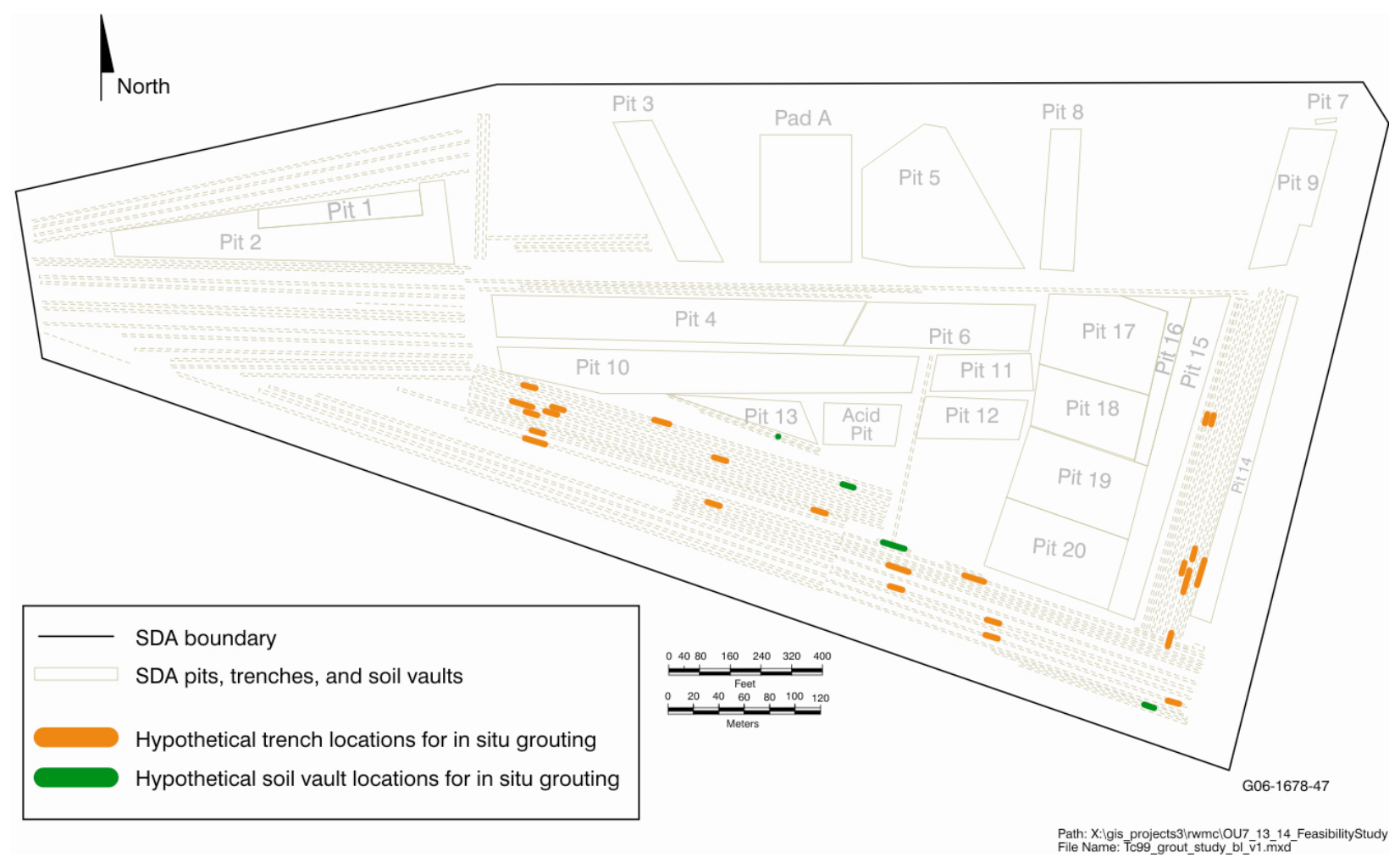

Figure E-29. Hypothetical locations and spacing for contaminant in situ grouting.

\section{E-11.2 Site Preparation}

Site preparation for in situ treatment of specified waste types within the SDA, using high-pressure jet grouting, would include a land survey to identify positions for grout injection.

\section{E-11.3 Readiness Demonstration}

Readiness for in situ treatment of specified waste types within the SDA, using high-pressure jet grouting, would be demonstrated by conducting a management self-assessment and completing any resulting corrective actions. Grouting operations in the SDA would commence following approval of the final readiness assessment. Field demonstrations of the implementability and effectiveness of vendor procedures for ISG, using high-pressure jet grouting, would be required before commencing operations in the SDA. 


\section{E-11.4 Remediation}

Studies to date have indicated that the ISG process could include use of a large, 90,000-lb class, hydraulic commercial trackhoe combined with a mast-mounted rotary percussion drill rig configured for drilling or driving a high-pressure grout injection drill string. The drill rig replaces the normal bucket on the end of the trackhoe stick. As shown in Figure E-30, the drill rig includes a mast-mounted rotary percussion drill rig capable of impact and rotary drilling and grout injection. Raivo (2004) provides detailed trackhoe and injection information.

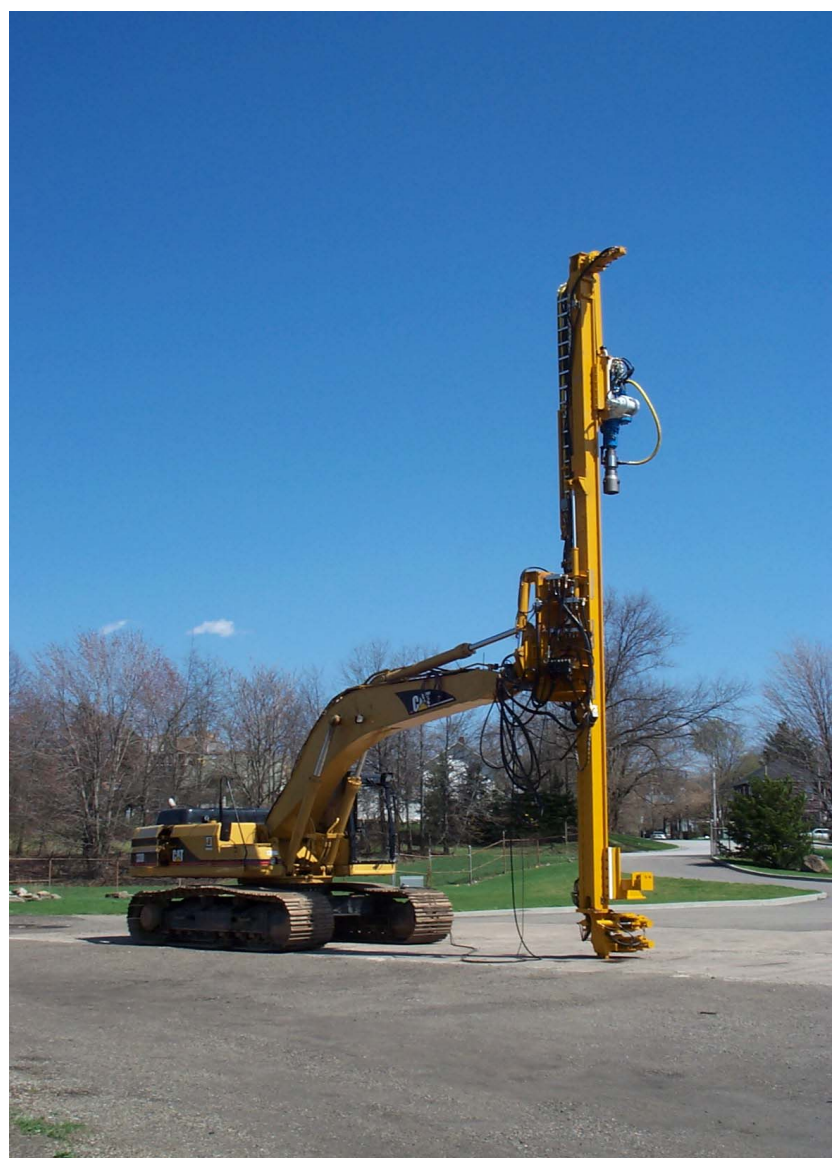

Figure E-30. Trackhoe combined with mast-mounted rotary percussion drill rig.

The anticipated normal operating scenario includes the equipment operator, located inside the trackhoe cab, performing the following tasks:

1. Position drill string point at a preselected location using trackhoe tracks for gross movement

2. Use trackhoe chassis pivot for horizontal angular setup

3. Use boom, stick, and bucket motion controls to achieve vertical positioning for precision hole location setup.

The drill string design uses one drill pipe of sufficient length to enable single-pass drilling and single-fluid grout injection. High-pressure grout fluid would be delivered to the drill pipe at approximately $8,000 \mathrm{lb} / \mathrm{in}^{2}$ by way of a swivel located on the drill head. The drill head and mast assembly would have sufficient mass to supply necessary vertical force to advance the drill (no additional 
down force would be required from the trackhoe boom and stick). Torque jaws, located on the bottom of the drill mast, are designed to break the drill stem should the stem become lodged in the injection point.

Main components of the grout delivery subsystem (Cram 2004) are:

- $\quad$ Grout receiving hopper

- $\quad$ Low-pressure pump

- $\quad$ Low-pressure piping to high-pressure pump

- $\quad$ High-pressure grout pump

- $\quad$ High-pressure piping

- $\quad$ Hoses to drill-string swivel.

As presented in Figure E-31, the hopper and low-pressure pump could be mounted on a lowboy trailer located inside the SDA, with the high-pressure grout pump located on another lowboy trailer. Ready-mix grout trucks would deliver grout to the receiving hopper, from which a low-pressure pump would feed a high-pressure pump with the required flow rate. The high-pressure pump would deliver grout at high pressure to the drill string by way of a high-pressure $\left(10,000 \mathrm{lb} / \mathrm{in} .^{2}\right)$ hose. The delivery side of the grouting system would be self-contained with engine-driven generators.

Remediation would be achieved by removing approximately $0.6 \mathrm{~m}(2 \mathrm{ft})$ of overburden from identified treatment areas to form depressions to retain any contaminated grout that might be displaced to the ground surface. The drill point then would be driven down to the basalt layer or the point of drill-stem refusal, then slowly raised in small incremental steps while simultaneously injecting a generic Portland cement-based grout mixture. The drill stem would be raised to the elevation that coincides with the waste and overburden interface. Then high-pressure grouting would be discontinued for that hole (see Figure E-32).

Testing has shown that grout would continue to weep (pumped at low pressure) while the drill would be extracted and moved to a new location. Grout columns, nominally $0.6 \mathrm{~m}(2 \mathrm{ft})$ in diameter, would be installed throughout the prepared treatment area on $0.5-\mathrm{m}(20$-in.) triangular centers (as shown in the upper left of Figure E-32). The buffer area would extend $3 \mathrm{~m} \mathrm{(10} \mathrm{ft)} \mathrm{beyond} \mathrm{the} \mathrm{specified} \mathrm{waste}$ disposal area to compensate for uncertainty in documented disposal locations. The resulting stabilized waste monoliths would be highly impermeable to any infiltrating water and would provide a stable foundation for any future construction activities above the treatment area. Immediately following completion of grout injection, the in situ treatment area would be covered with clean soil.

\section{E-11.5 Demobilization and Reporting}

After completing in situ treatment of specified waste types in the SDA, using high-pressure jet grouting, vendor equipment would be decontaminated and removed from the SDA. Any excess equipment would be used or disposed of. The final inspection report for in situ treatment of specified waste types in the SDA, using high-pressure jet grouting, would be included in the remedial action report for OU 7-13/14. 


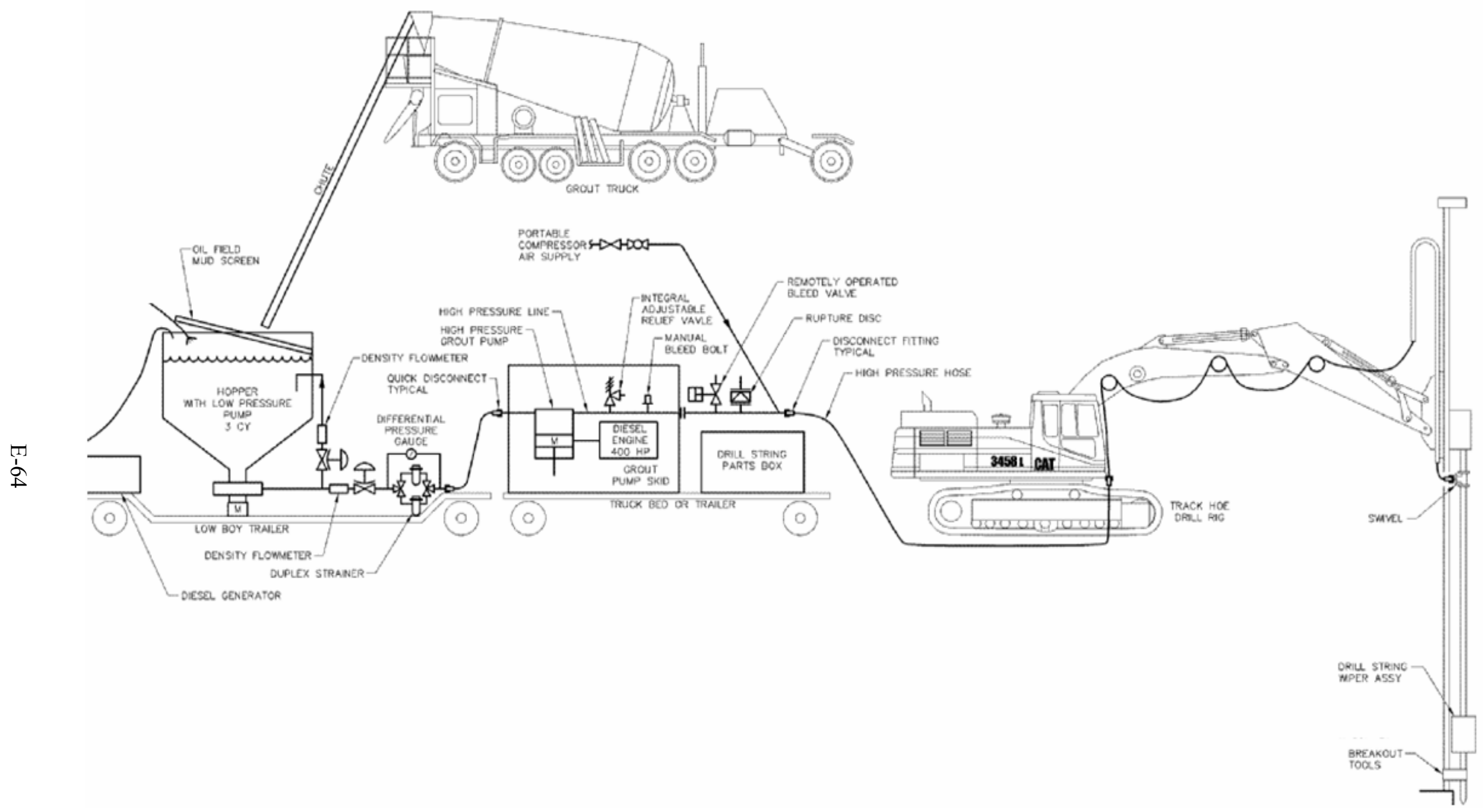

Figure E-31. In situ grouting feed system (from Cram 2004). 
Grout column spacing

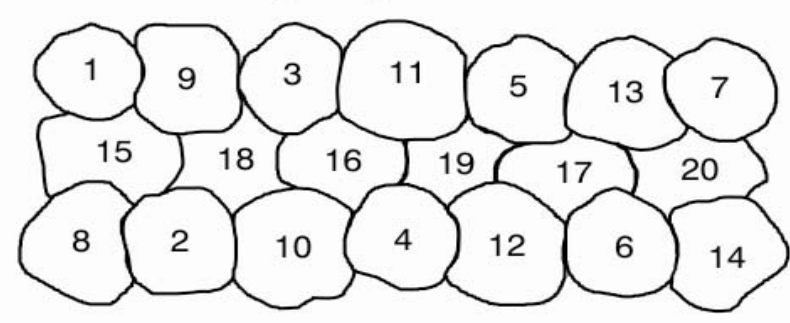

(Numbers indicate order of injection)

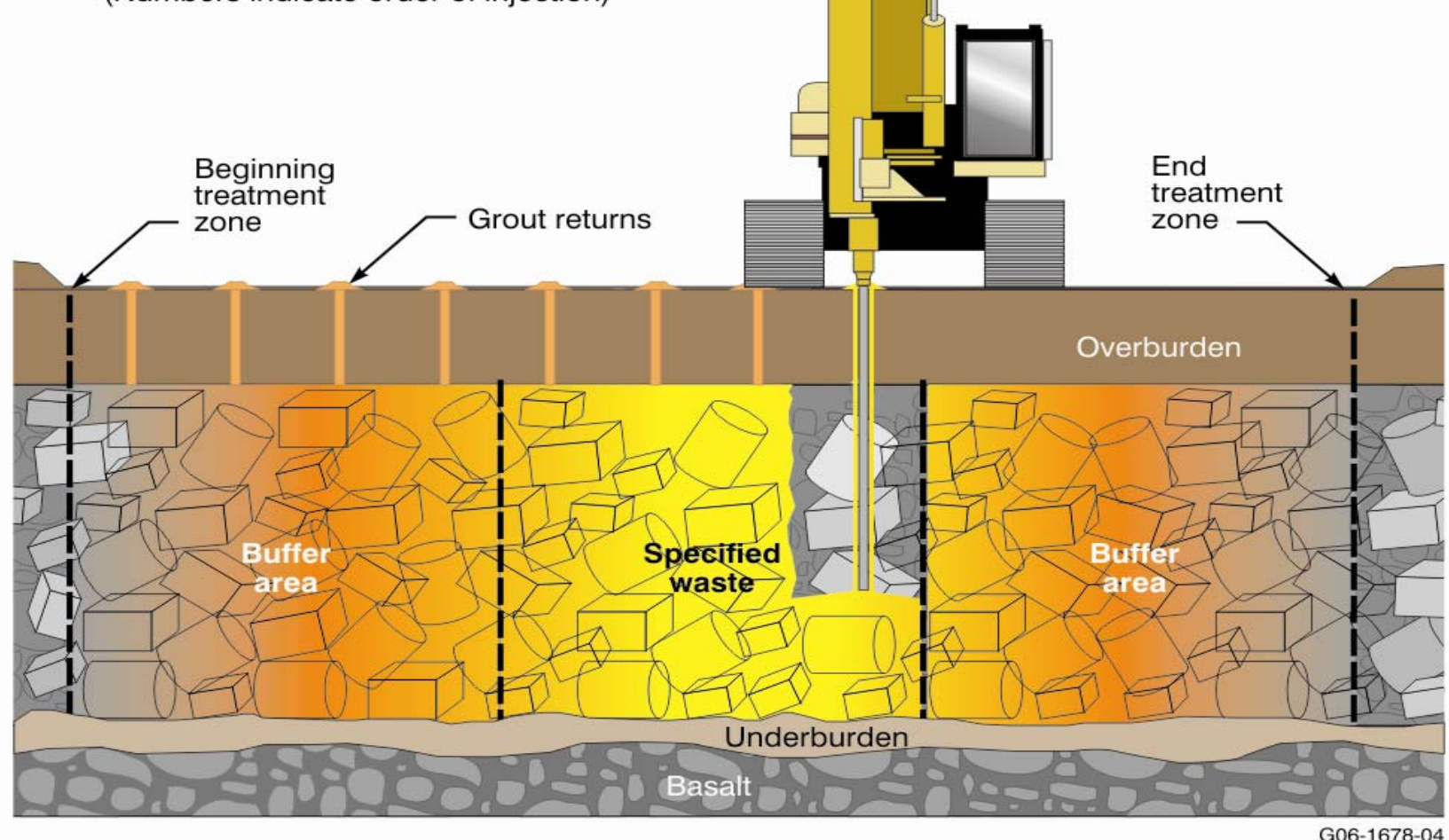

Figure E-32. In situ contaminant grouting and spacing schematic. 


\section{E-12. FOUNDATION IN SITU GROUTING}

Design and mobilization, site preparation, readiness demonstration, demobilization, and reporting for foundation ISG would be identical to those mentioned in Section E-11.

Unlike contaminant ISG, foundation stabilization using ISG does not focus on locations of specific waste types. Instead, foundation grouting focuses on stabilizing all SDA pits (as shown in Figure E-33) by emplacing free-standing ISG columns with compressive strengths adequate to support an overlying surface barrier. Foundation construction using ISG would be used in-pit disposal areas, but not trench or soil vault areas.

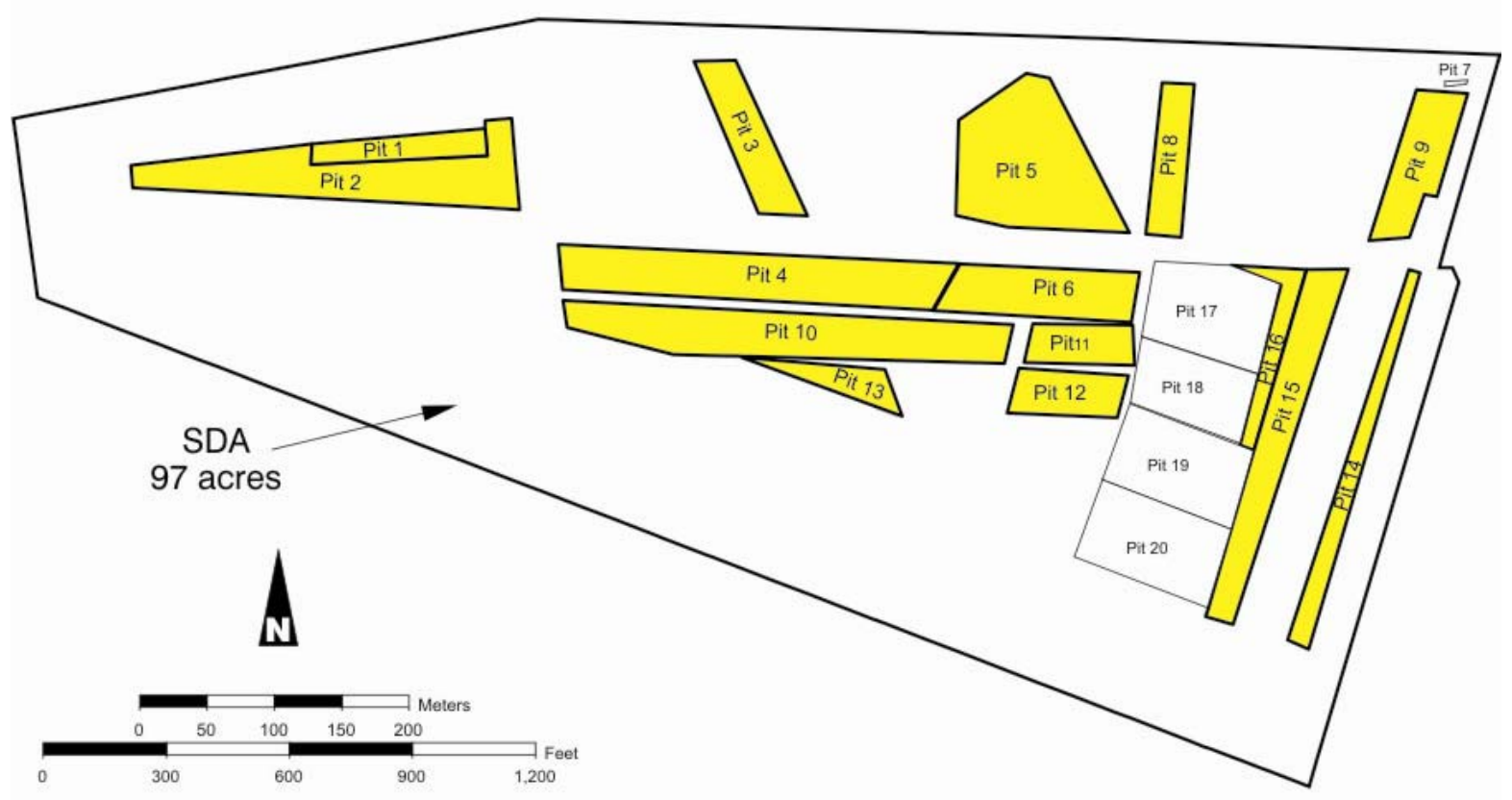

G06-1760-77

Figure E-33. Hypothetical locations for foundation in situ grouting.

The OU 7-13/14 ISG Project Foundation Grouting Study (Stephens 2004) study used the finite element analysis computer program to determine spacing requirements for placing in situ foundation grout columns in potential subsidence areas of the SDA. This study concluded the following in regards to foundation stabilization: "The analysis results indicate that if a minimum of $1.5 \mathrm{ft}$ of grading fill is provided in the area occupied by Trenches 1 through 10, no grouted columns are required in this area." (Stephens 2004)

Based on results from this study, foundation grouting is assumed not to be required within SDA trenches or soil vaults. Therefore, areas of the SDA targeted for foundation stabilization in the form of grout columns include only Pits 1 through 6 and 8 through 16. Pit 7 is too small to realize any benefit from stabilization. 


\section{E-12.1 Remediation}

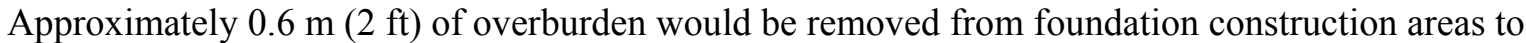
form depressions to retain any contaminated grout that may be displaced to the ground surface. A generic Portland cement-based grout would be used for foundation construction. Grout columns, nominally $0.6 \mathrm{~m}$ ( $2 \mathrm{ft}$ ) in diameter, would be installed on 3.7-m (12-ft) triangular centers (see Figure E-34). Grout columns would extend from the underlying basalt, through the buried waste zone, and $0.3 \mathrm{~m}(1 \mathrm{ft})$ into the overburden. The resulting free-standing columns would have a minimum compressive strength of $1,200 \mathrm{lb} / \mathrm{in}^{2}$. Foundation construction using ISG would provide a stable base for any future construction activities in the SDA (e.g., surface barrier).

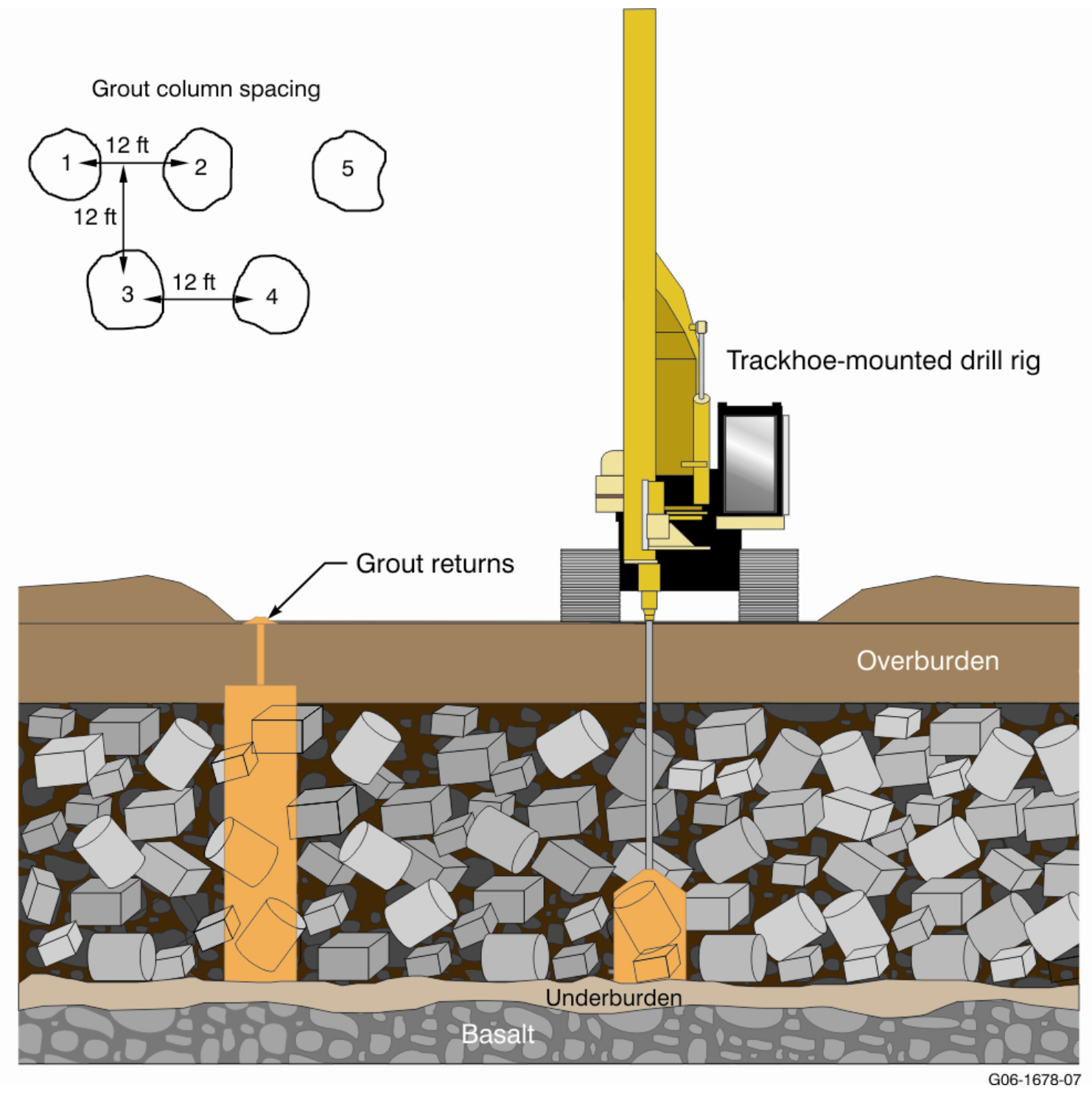

Figure E-34. In situ foundation grouting and spacing. 


\section{E-13. PROOF-ROLLING}

Proof-rolling, in this context, would be performed to test uniformity and stability of foundation compaction to allow surface barrier placement. Maximum allowable rutting or elastic movement of compacted soil would be based on the specified density required. Specified weight, tire pressure, vibratory capability, and applying the specified number of passes would be essential to achieve this density.

Figure E-35 provides a preconceptual process diagram that overviews implementation of this module and was created for cost-estimation purposes. Key tasks identified in Figure E-35 are discussed in the following subsections.

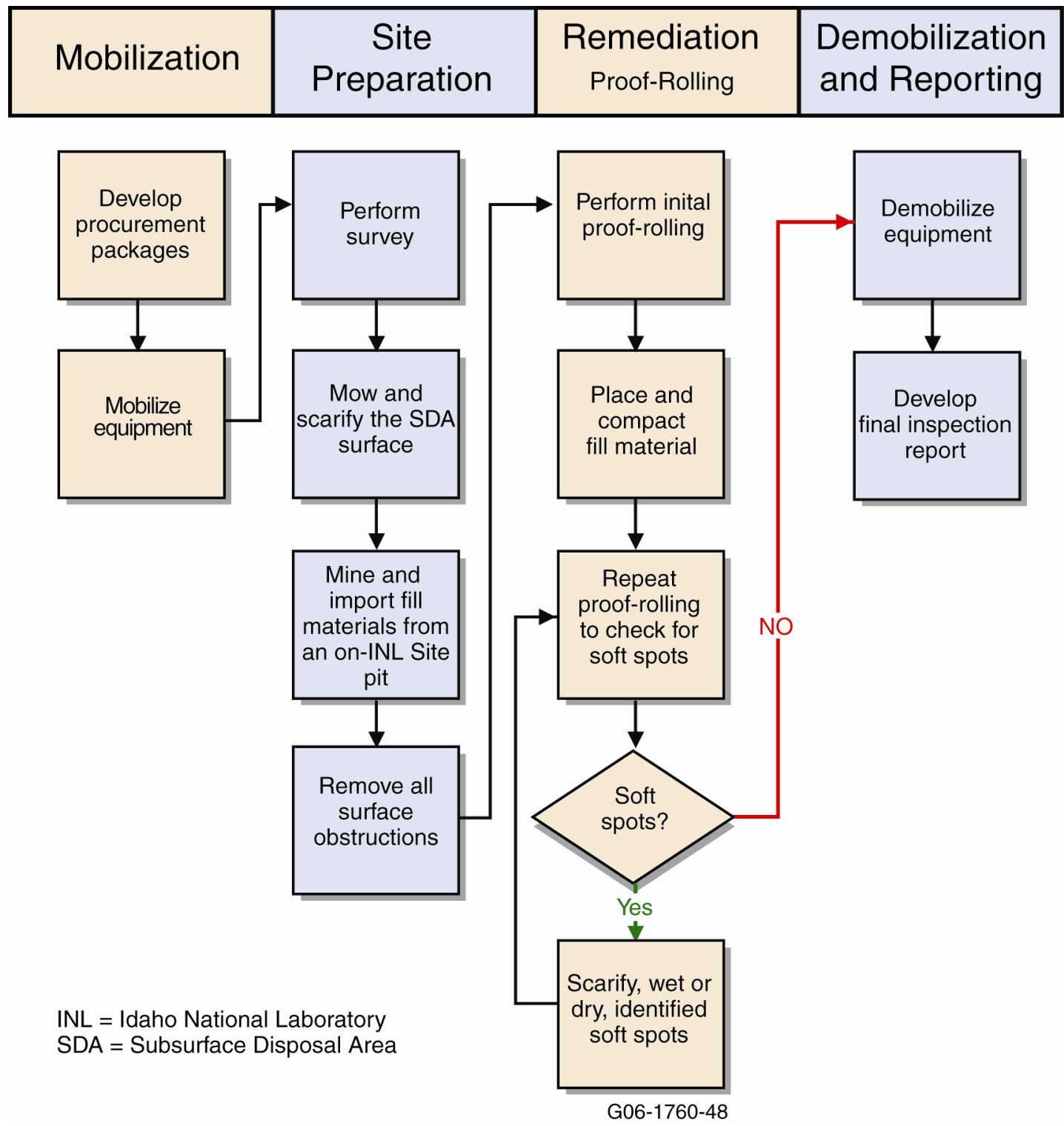

Figure E-35. Preconceptual process flow diagram for proof-rolling. 


\section{E-13.1 Mobilization}

Design and mobilization for proof-rolling would include developing procurement packages and mobilizing equipment to the work site. Proof-rolling would be included in initial surface barrier placement activities. Therefore, surface barrier modules would include design activities, including developing remedial design and remedial action work plans and operational plans (i.e., operations and layout plan, radiation monitoring and control plan, industrial hygiene exposure and sampling plan, and quality control plan), and management self-assessment plans).

\section{E-13.2 Site Preparation}

Site preparation includes surveying the area to be compacted. Ground surface would be mowed and scarified. Scarification (i.e., breakup of the soil) enables better compaction, and engineering and administrative controls would be required to control the depth of scarification. Fill material would be procured, mined, and imported from a local borrow area, as needed. Fill materials would be placed on the surface to be compacted using appropriate equipment to obtain the required density. Moisture content of the fill must be optimized for compaction. Any depressions in the surface able to hold water would be eliminated. All surface obstructions would be identified and removed, if necessary.

\section{E-13.3 Remediation}

Proof-rolling consists of applying test loads over the compacted surface using a heavy pneumatic-tired roller, or other vehicle of specified design, to locate and permit timely correction of deficiencies likely to adversely affect performance of the foundation. Densification may be enhanced by using vibratory features of the equipment and using equipment that imparts the most energy per unit of area. Proof-rolling identifies any soft spots in the foundation surface and minimizes the likelihood of future subsidence.

Assuming sufficient clean fill exists above the waste zone, the trench or pit area would be rolled repetitively to expose soft spots and potential areas of subsidence. Past records showing subsidence would be of particular interest during this phase for special consideration during rolling. Previously staged fill material then would be used to fill subsidence areas. After initial compaction and fill placement, the surface would be proof-rolled again, and the soil would be tested to determine whether sufficient compaction had been obtained. Any areas found to be weak or failing the test would be ripped, scarified, wetted, or dried, if necessary, and compacted to meet requirements for density and moisture.

\section{E-13.4 Demobilization and Reporting}

After proof-rolling compaction is complete, equipment would be demobilized. Excess equipment would be used or disposed of. The final inspection report for proof-rolling compaction would be included in the remedial action report for OU 7-13/14.

\section{E-14. MODIFIED RESOURCE CONSERVATION AND RECOVERY ACT TYPE C SURFACE BARRIER}

Figure E-36 provides a preconceptual process diagram that overviews implementation of this module and was created for cost-estimation purposes. Key tasks identified in Figure E-36 are discussed in the following subsections. 


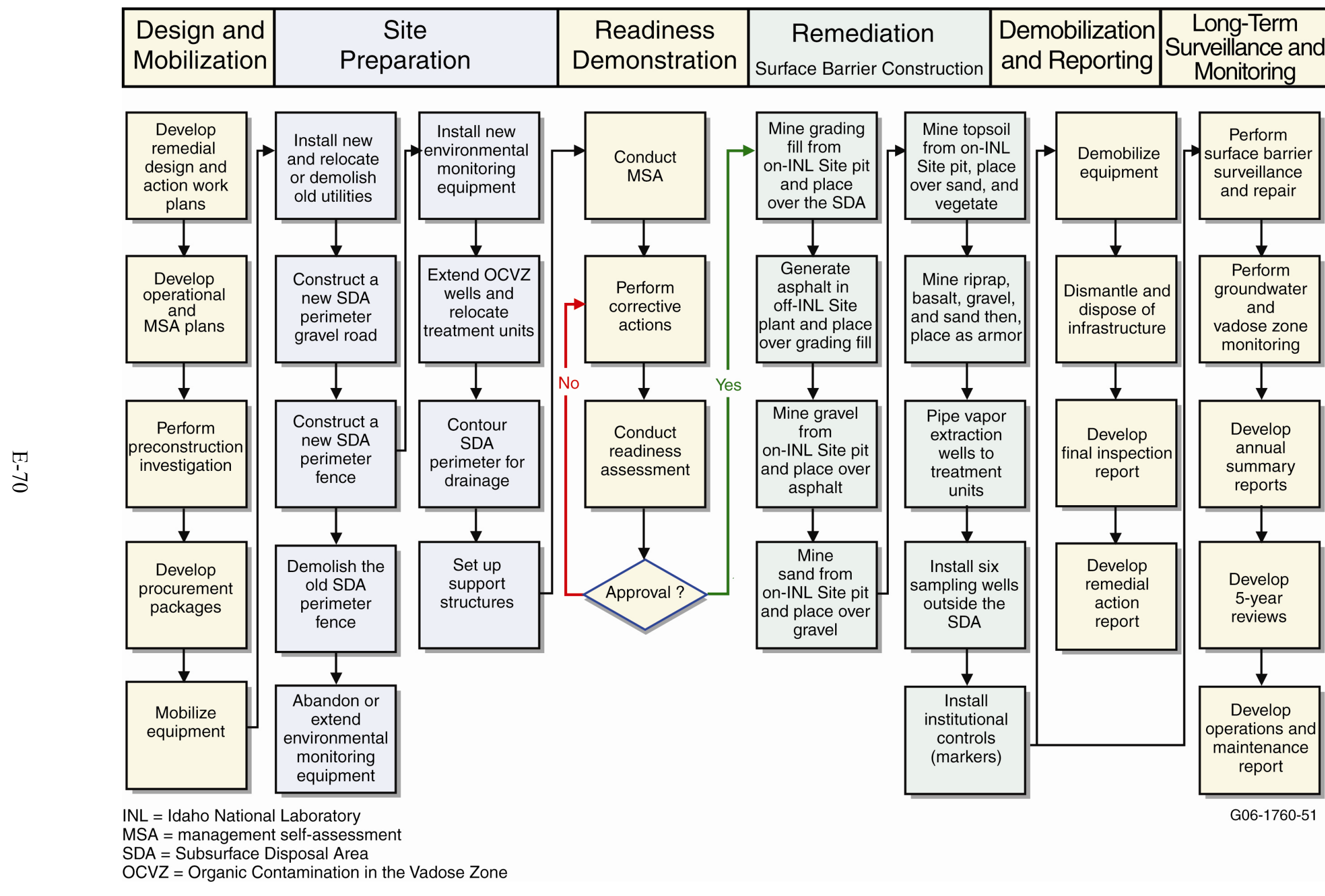

Figure E-36. Preconceptual process flow diagram for a modified RCRA Type C surface barrier. 


\section{E-14.1 Design and Mobilization}

Design and mobilization for installing a RCRA Type C surface barrier over the SDA would include developing remedial design and remedial action work plans, operational plans (i.e., operations and layout plan, radiation monitoring and control plan, industrial hygiene exposure and sampling plan, training plan, and quality control plan), a management self-assessment plan, and procurement packages; applying preconstruction investigations (e.g., surveying); and modifying and mobilizing equipment.

The remedial design work plan would include design documents (e.g., drawings, specifications, and engineering analysis), air emissions reports, waste management plans, characterization plans (e.g., plans for field sampling, secondary waste characterization, sampling and analysis, and emissions monitoring), health and safety plans, and an operations and maintenance plan. Detailed construction schedules and cost estimates also would be developed in the remedial action work plan.

For purposes of developing the feasibility study cost estimate, a preconceptual surface barrier design has been completed. Figure E-37 provides a cross-section schematic of the surface barrier. The primary component of the modified RCRA Type $\mathrm{C}$ surface barrier would be an asphalt drainage layer that serves to divert infiltrating water to the edges of the surface barrier. For purposes of the feasibility study cost estimate, the modified RCRA Type $\mathrm{C}$ surface barrier design would be identical to that presented in Figure 2-18 of Mattson et al. (2004), except for the gravel gas-collection layer. For purposes of the feasibility study, gas collection under the modified RCRA Type $C$ surface barrier is assumed to be accomplished by installing vertical venting wells just below the basalt outcrop depth (details of this collection system are provided in Section E-19). Therefore, a gravel gas-collection layer beneath the asphalt layer would not be required. Table E-13 provides estimated material types, quantities, and sources for constructing the surface barrier.

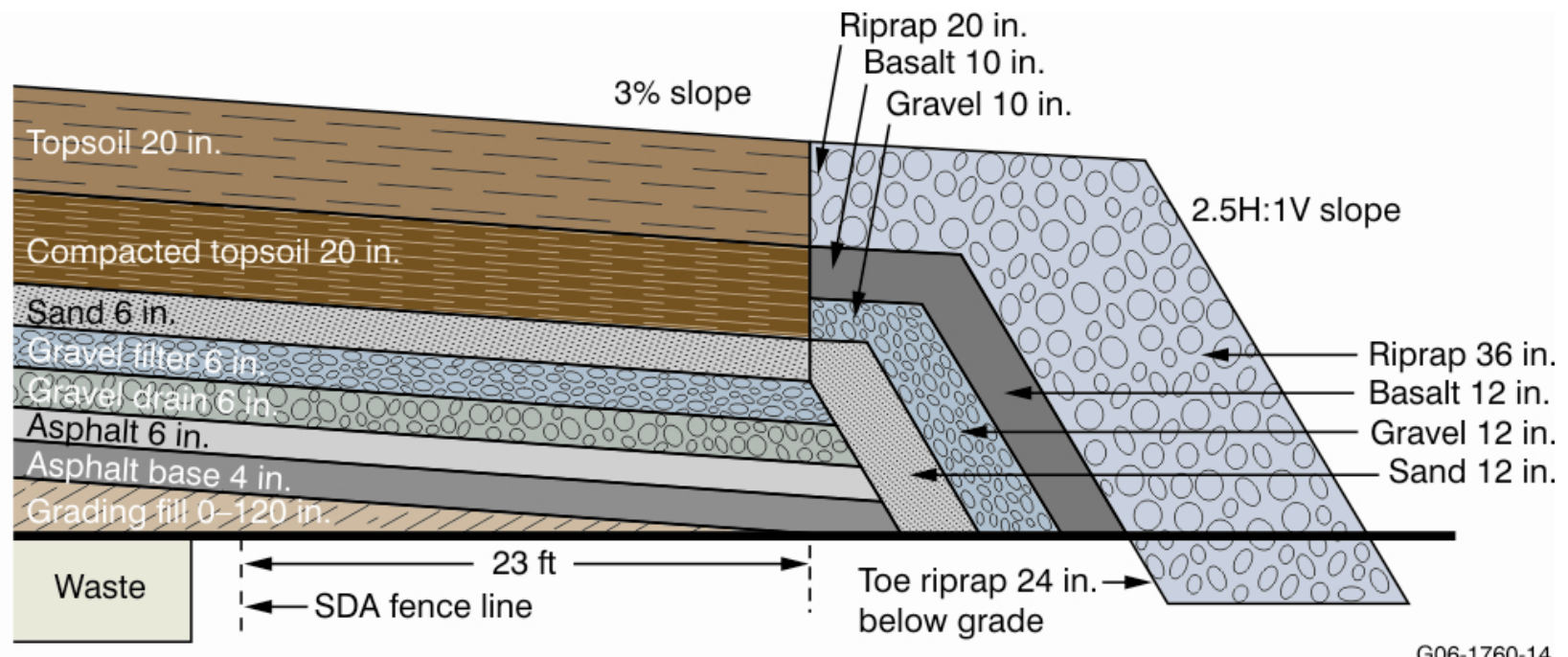

Figure E-37. Cross section of the modified RCRA Type C surface barrier. 
Table E-13. Description, thickness, and volume of materials that would comprise the modified RCRA Type $\mathrm{C}$ surface barrier.

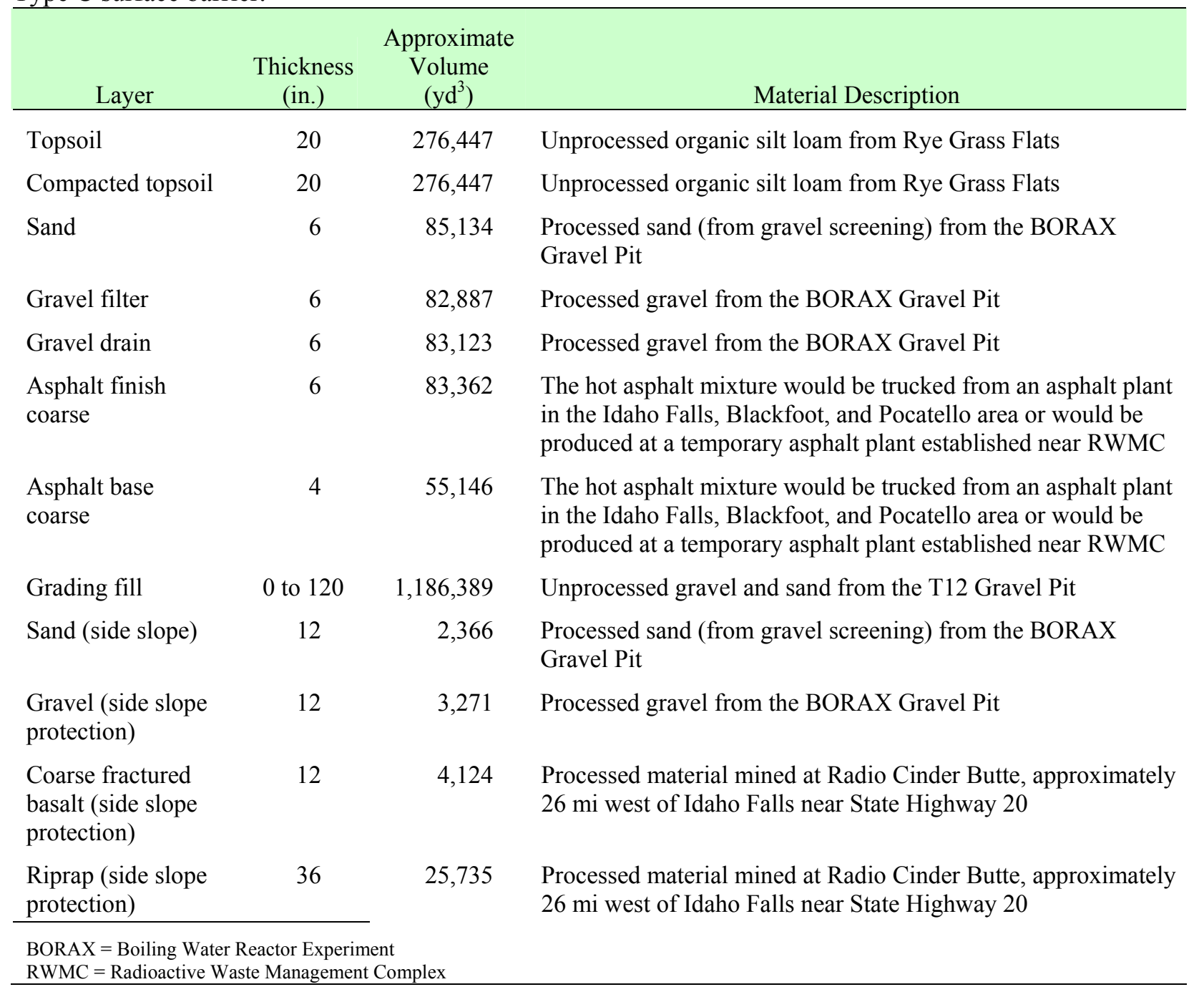

Final identification of materials and quantities for constructing the surface barrier would be developed in the remedial design. Key design considerations would include control of water flux through the surface barrier and long-term performance of the surface barrier.

\section{E-14.2 Site Preparation}

Site preparation would entail a number of construction activities to be completed before commencing surface barrier construction. Examples of preconstruction activities include:

- Installing temporary utilities in the SDA, including power and water-Temporary power would be provided on the east side of the SDA. Any temporary power required at any of the borrow sources would be provided by portable generators. A water supply would be located within $152 \mathrm{~m}$ $(500 \mathrm{ft})$ of the SDA and would be designed to provide enough capacity to ensure required water would be available. A temporary-fill storage tank also would be installed to assist with filling of water equipment during peak use. 
- Relocating or demolishing utilities-Existing structures currently on the SDA surface would be removed. (For purposes of costing this module in the feasibility study, buildings associated with OU 7-10 and the Accelerated Retrieval Project are assumed to be removed or demolished before start of construction of the surface barrier.) Rubble from demolition of the OU 7-10 treatment building may be used as grading fill in the SDA.) An existing pole line, incorporating 13.7-m (45-ft) poles and \#2 aluminum steel conductor wire, would be removed.

- Constructing a new access road at the SDA perimeter-The unpaved access road would be approximately 3,048 $\mathrm{m}$ long, $6 \mathrm{~m}$ wide, and $0.6 \mathrm{~m}$ deep (10,000 ft long, $20 \mathrm{ft}$ wide, and $2 \mathrm{ft}$ deep). The road would be located beyond the perimeter of the future surface barrier.

- Installing a new perimeter fence-The perimeter fence would be approximately $3 \mathrm{~km}(10,000 \mathrm{ft})$ of $1.8-\mathrm{m}(6-\mathrm{ft})$-high chain link. The new perimeter fence would be constructed approximately $20 \mathrm{~m}(65.6 \mathrm{ft})$ outside the existing fence line to accommodate construction of the armored surface barrier toe.

- Demolishing the existing perimeter fence-Following construction of the new perimeter fence, the old SDA perimeter fence and fence surrounding the SDA LLW Pit would be demolished.

- $\quad$ Abandoning or extending environmental monitoring equipment-Approximately 25 monitoring wells would be abandoned and another 25 wells extended to the final surface barrier grade. Fifty advanced tensiometers would be extended by placing extensions on the casing.

- Installing new environmental monitoring equipment-Approximately 50 new advanced tensiometers would be installed by drilling a $0.3-\mathrm{m}$ (12-in.) hole to the basalt, placing a $0.2-\mathrm{m}$ (8-in.) casing in the hole, and filling the annulus with concrete; drilling to an additional depth inside the casing; installing tensiometers; and placing extensions on the casing and tensiometers vertically upward so the ends would protrude through the final surface barrier.

- $\quad$ Reconfiguring the OCVZ system-Eighteen existing OCVZ wells would be extended in height. The three OCVZ treatment units would be relocated outside the footprint of the surface barrier.

- $\quad$ Other site preparation activities-The south and east sides of the SDA would be contoured for drainage; a $152.4 \times 6 \times 3$-m $(500 \times 20 \times 10$-ft $)$-deep area would be drilled and blasted for drainage. Administrative and equipment buildings or trailers also would be set up to support operational controls, radiation controls, and personnel facilities.

In addition to routine construction preparation activities, constructing the modified RCRA Type C surface barrier would follow foundation stabilization of the SDA. These activities are described in other modules, including dynamic compaction (Section E-9), foundation ISG (Section E-12), and proof-rolling (Section E-13). Specific modules and process options are assembled in the feasibility study.

\section{E-14.3 Readiness Demonstration}

Readiness for surface barrier construction would be demonstrated by conducting a management self-assessment and completing any resulting corrective actions. Encountering waste material while constructing the surface barrier is not anticipated; therefore, constructing the surface barrier would not require an operational readiness review assessment. 


\section{E-14.4 Remediation}

The Modified RCRA Type C Surface Barrier module entails using well-established technology, and conventional earthwork equipment and methods of construction. Based on the preconceptual design, the surface barrier would cover 105 acres. This surface barrier system would be constructed of consecutive layers of natural and man-made materials, including grading fill, asphalt base, asphalt, gravel drain, gravel filter, sand, compacted topsoil, and topsoil layers with perimeter armor protection. Because of the continuous multilayered design, this surface barrier would be installed across the SDA in a sequential approach. Each layer of the surface barrier would be constructed in a continuous fashion across the SDA.

The first layer of the surface barrier is referred to as grading fill. Grading fill quantity is estimated to be $1,186,389 \mathrm{yd}^{3}$. Grading fill would be obtained by leveling the existing SDA perimeter berm, using demolition rubble from nearby structures, and mining and importing fill materials from the T12 borrow source. Grading fill material would be placed and compacted on a 3\% slope (in accordance with EPA [2000] guidance), starting $6 \mathrm{~m}$ (20 ft) outside the existing SDA fence line.

Layers 2 and 3 would comprise a 10-cm (4-in.) -thick asphalt base and a 15-cm (6-in.) -thick asphalt top. These layers serve to control both drainage and biotic intrusion. Approximately 55,146 $\mathrm{yd}^{3}$ of asphalt base and 83,362 $\mathrm{yd}^{3}$ of asphalt finish would be required. Asphalt would be trucked from a plant in the local region or would be produced at a temporary asphalt plant established near RWMC.

Layers 4, 5, and 6 would comprise gravel and sand produced at the INL Adams Pit. These layers serve as a lateral drainage layer to allow run-off of water collected over the asphalt layer. It is anticipated that $83,123 \mathrm{yd}^{3}$ of gravel would be required for a drain layer, $82,887 \mathrm{yd}^{3}$ of gravel required for a filter layer, and $85,134 \mathrm{yd}^{3}$ of sand would be required for a filter layer. The 15-cm (6-in.) -thick gravel drain layer would be placed and compacted over the asphalt finish layer. The 15-cm (6-in.) -thick gravel filter layer would be placed and compacted over the gravel drain layer. The 15-cm (6-in.) -thick sand layer would be placed and compacted over the gravel filter layer.

Layers 7 and 8 would serve to establish and maintain a vegetative community, which is expected to minimize surface erosion. Topsoil layers would be mined and imported from Rye Grass Flats. Approximately $276,447 \mathrm{yd}^{3}$ of topsoil would be required for the $0.5-\mathrm{m}$ (20-in.) -thick compacted layer, and $276,447 \mathrm{yd}^{3}$ of topsoil would be required for the $0.5-\mathrm{m}$ (20-in.) -thick noncompacted top layer.

Cost estimates in Appendix F assume that topsoil material would be available on the INL Site (e.g., Rye Grass Flats). If not available on the INL Site, topsoil would be purchased from a vendor. Additional expense associated with procuring soil from off the INL Site would be captured within the surface barrier contingency.

Edges of the surface barrier would be armored by layers of sand, gravel, and basalt riprap to protect against erosion. Sand and gravel would be mined and imported from the Adams Pit, and 2,366 $\mathrm{yd}^{3}$ of sand $^{\circ}$ armor would be required. A $0.3-\mathrm{m}$ (12-in.) -thick sand layer would be placed on edge of the surface barrier and mated to the surface barrier's sand layer. About 3,271 $\mathrm{yd}^{3}$ of gravel armor would be required to construct a $0.3-\mathrm{m}(12$-in.) -thick gravel armor layer. The gravel armor would be placed over the sand armor layer to prevent sand from migrating out through the larger basalt and riprap armor layers. Both sand and gravel would be placed on a $2.5 \mathrm{H}: 1 \mathrm{~V}$ slope. The final armor layer would comprise basalt and riprap mined and imported from Radio Cinder Butte. About 4,124 $\mathrm{yd}^{3}$ of basalt would be overlain by approximately $25,735 \mathrm{yd}^{3}$ of riprap armor. 
Construction equipment for mining, hauling, and placement of surface barrier material would include standard equipment, including excavators, dozers, graders, compactors, dump trucks, scrapers, and water trucks. Because of weight restrictions in the SDA, scrapers would only be allowed to carry 33.5 bank $\mathrm{yd}^{3}$ per load.

After surface barrier construction, the OCVZ system would be reconstructed; additional monitoring wells would be installed beyond the perimeter of the cover, as necessary; and ICs would be established. The OCVZ system reconstruction consists of piping the OCVZ probes (extending up through the surface barrier surface) to the relocated OCVZ treatment units. Six new groundwater monitoring wells are estimated to be installed outside the SDA following surface barrier construction. Placement of active ICs would include installing permanent markers surrounding the SDA to delineate contamination. Permanent markers would be made of concrete and would contain information about the type of contamination. Twelve permanent markers are estimated to be required, based on the size of the SDA.

After construction activities on the surface barrier are completed, the surface would be seeded with native grasses to provide vegetative cover. Because of the arid climate of the INL Site, an extended period of time would be required to establish a permanent vegetative cover. Erosion of the uppermost layers of the surface barrier during snowmelt would be expected during the years immediately following construction, requiring routine additional repairs and reseeding.

\section{E-14.5 Demobilization and Reporting}

After completing remedial activities, construction support infrastructure (e.g., trailers, offices, and utilities) would be decontaminated and removed from the SDA. Any excess equipment would be used or disposed of. The final inspection report for the surface barrier, along with all inspection reports generated before surface barrier completion, would be captured in the remedial action report for OU 7-13/14.

\section{E-14.6 Long-Term Surveillance, Monitoring, and Reporting}

Surveillance and monitoring activities would continue for a 100-year period following completion of the surface barrier.

Surveillance activities would include biological surveillance and vegetation surveillance. Biological and vegetation surveillance would include annual surveys to identify evidence of animal intrusion (e.g., burrows) and vegetation inspections to ensure presence of a healthy vegetative community. Additional surveillance activities include subsidence identification. Surveillance would be performed in the fall of every year for the first 5 years and less frequently thereafter.

Based on results from surveillance activities, maintenance of the surface barrier may be required after construction is complete. Frequent maintenance would be anticipated during the years immediately following construction to repair damage from erosion and to establish a permanent vegetative cover. In addition, the added weight of the surface barrier would be expected to result in increased settlement

during the initial years following construction. Some areas of the surface barrier would require ongoing maintenance to repair damage resulting from settlement. Annual maintenance and repairs would be anticipated to be required during the first 5 years following construction and less frequently thereafter.

Monitoring activities would include groundwater monitoring and vadose zone monitoring. Groundwater and vadose zone monitoring activities are described in detail in Section E-21. 
Results from surveillance and monitoring activities would be reported in an annual data report, which would present and summarize data for each media sampled. This data report would be prepared annually for the first 5 years, and then would be evaluated to determine the reporting frequency after the initial 5-year period. An annual review of these data, including techniques, analytes, and data interpretation, would be held after the review of the annual report.

Five-year reviews would be held subsequent to the initial 5-year period, which would mimic the annual review. These 5-year reviews would take place until the end of the 100-year monitoring period. At the end of the 100-year monitoring period, a final operations and maintenance report would be prepared, documenting effectiveness of the remedial action and recommendations on further monitoring requirements.

\section{E-15. EVAPOTRANSPIRATION SURFACE BARRIER}

Figure E-38 provides a preconceptual process diagram that overviews implementation of this module and was created for cost-estimation purposes. Key tasks identified in Figure E-38 are discussed in the following subsections.

\section{E-15.1 Design and Mobilization}

Design and mobilization for installing an ET surface barrier over the SDA would include developing remedial design and remedial action work plans (reports included in these two plans would be identical to those stated in Section E-14.1), operational plans (i.e., operations and layout plan, radiation monitoring and control plan, industrial hygiene exposure and sampling plan, training plan, and quality control plan), a management self-assessment plan, and procurement packages; applying preconstruction investigations (e.g., surveying); and modifying and mobilizing equipment.

For purposes of developing the feasibility study cost estimate, a preconceptual surface barrier design has been completed. Figure E-39 provides a cross-section schematic of the ET surface barrier. Primary components of the ET surface barrier would be a thick fine-soil layer used for water storage and release, and an underlying coarse rock (e.g., cobble) layer used for collecting gas and preventing biotic intrusion. For purposes of the feasibility study cost estimate, the ET surface barrier design would be identical to that recommended in Mattson et al. (2004). Table E-14 provides estimated material types, quantities, and sources for constructing the surface barrier.

Final identification of materials and quantities for construction of the surface barrier would be developed in the remedial design. Key design considerations would include control of water flux through the surface barrier and long-term performance of the surface barrier.

\section{E-15.2 Site Preparation}

Site preparation for the ET surface barrier would entail a number of construction activities to be completed before commencement of surface barrier construction. These activities would be identical to those described in Section E-14.2. 


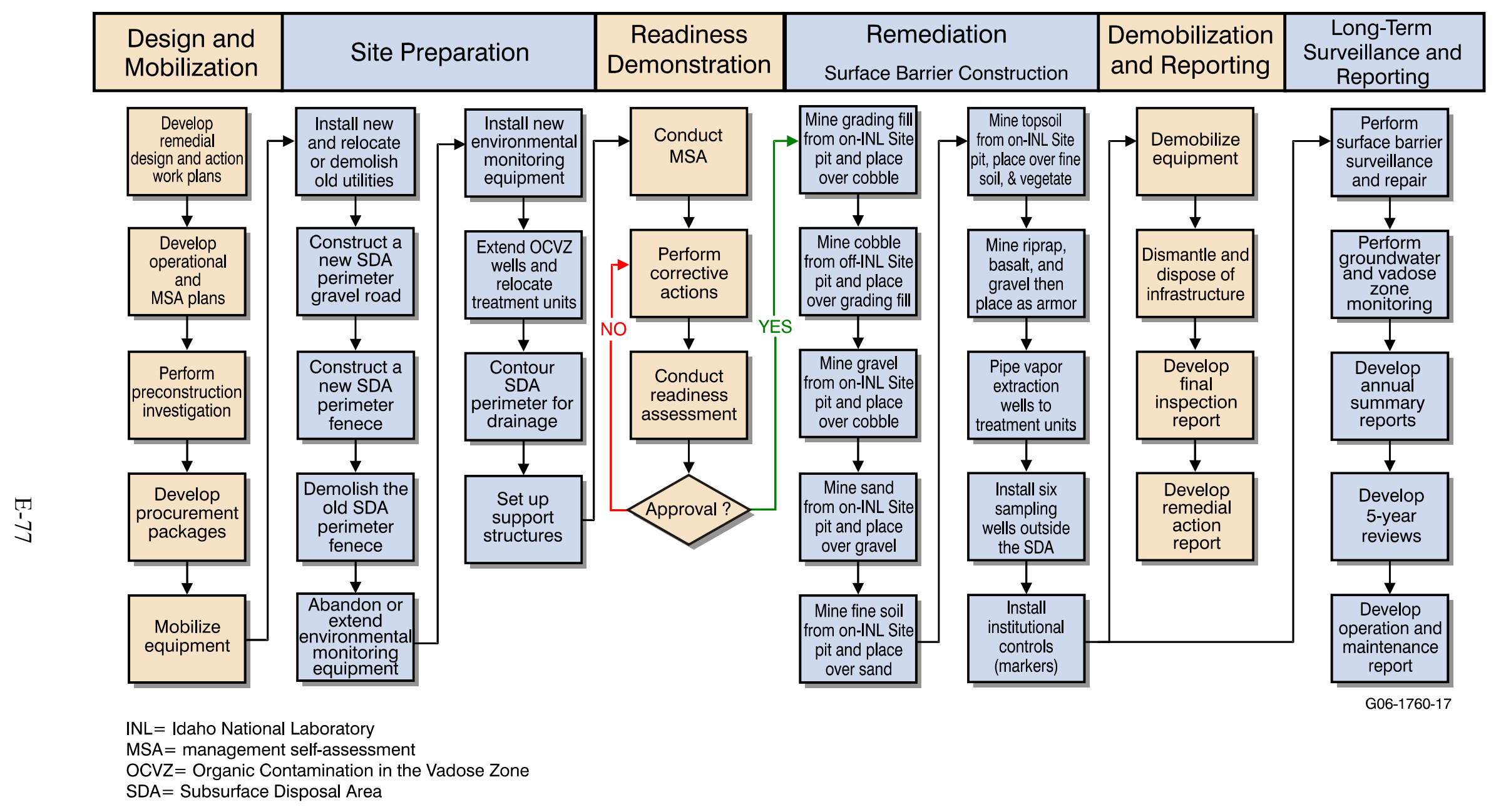

Figure E-38. Preconceptual process flow diagram for an evapotranspiration surface barrier. 


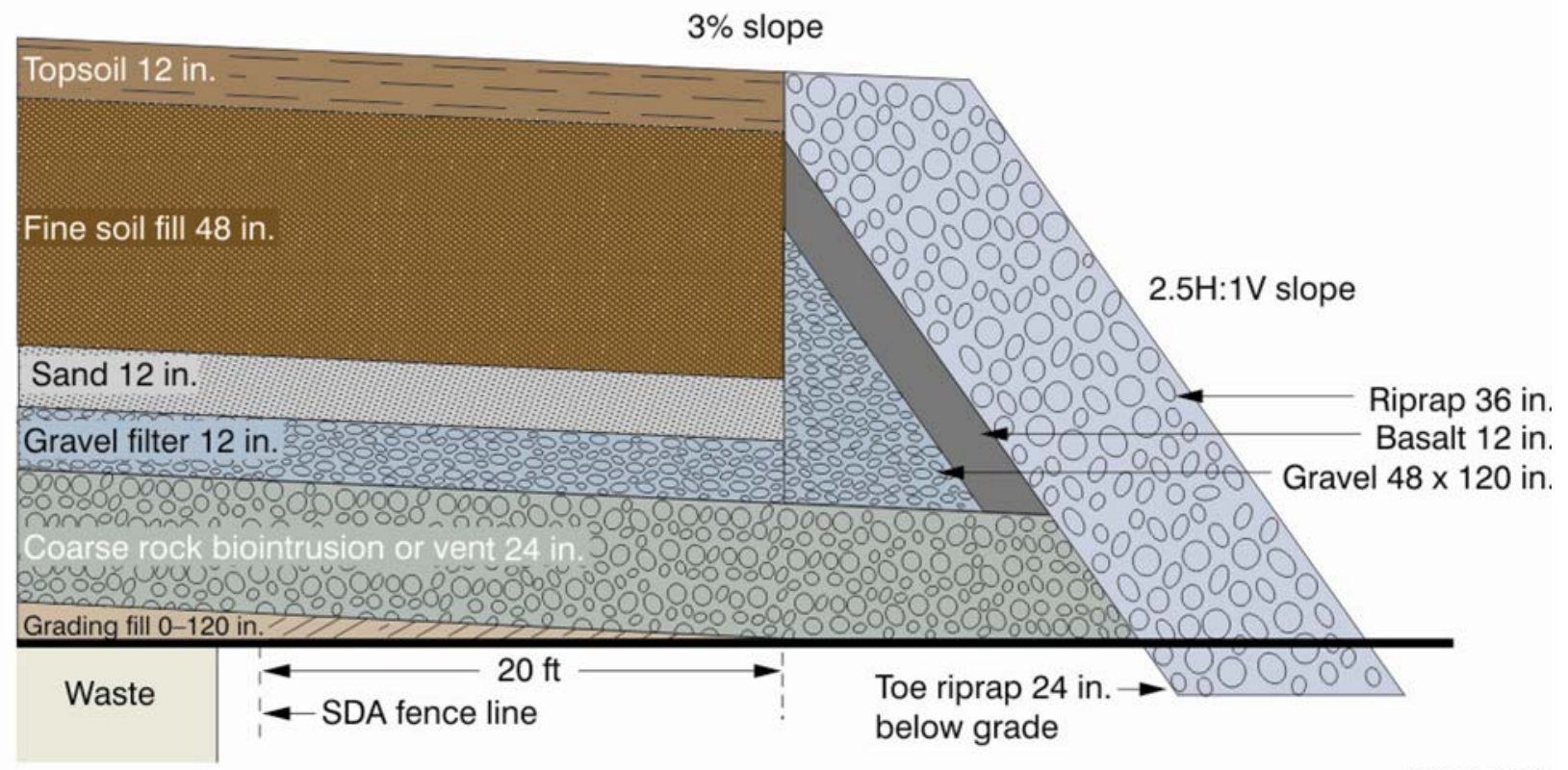

Figure E-39. Cross section of evapotranspiration surface barrier.

Table E-14. Description, thickness, and volume of material that would comprise the evapotranspiration surface barrier.

\begin{tabular}{|c|c|c|c|}
\hline Layer & $\begin{array}{l}\text { Thickness } \\
\text { (in.) }\end{array}$ & $\begin{array}{l}\text { Approximate } \\
\text { Volume } \\
\left(\mathrm{yd}^{3}\right)\end{array}$ & Material Description \\
\hline Topsoil & 12 & 165,632 & Unprocessed organic silt loam from Rye Grass Flats \\
\hline Fine soil fill & 48 & 662,147 & Unprocessed silt loam from Rye Grass Flats \\
\hline Sand & 12 & 165,537 & $\begin{array}{l}\text { Processed sand (from gravel screening) from the } \\
\text { BORAX Gravel Pit }\end{array}$ \\
\hline Gravel filter & 12 & 165,537 & Processed gravel from the BORAX Gravel Pit \\
\hline Coarse rock & 24 & 342,093 & $\begin{array}{l}\text { Processed material transported to the Idaho National } \\
\text { Laboratory Site from the Idaho Falls area }\end{array}$ \\
\hline Grading fill & 0 to 120 & $1,186,389$ & $\begin{array}{l}\text { Unprocessed gravel and sand from the T12 Gravel } \\
\text { Pit }\end{array}$ \\
\hline $\begin{array}{l}\text { Gravel (side slope } \\
\text { protection) }\end{array}$ & $48 \times 120$ & 11,862 & Processed gravel from the BORAX Gravel Pit \\
\hline $\begin{array}{l}\text { Coarse fractured basalt } \\
\text { (side slope protection) }\end{array}$ & 12 & 5,230 & $\begin{array}{l}\text { Processed material mined at the Radio Cinder Butte, } \\
\text { approximately } 26 \text { mi west of Idaho Falls, near State } \\
\text { Highway } 20\end{array}$ \\
\hline $\begin{array}{l}\text { Riprap (side slope } \\
\text { protection) }\end{array}$ & 36 & 29,102 & $\begin{array}{l}\text { Processed material mined at the Radio Cinder Butte, } \\
\text { approximately } 26 \text { mi west of Idaho Falls, near State } \\
\text { Highway } 20\end{array}$ \\
\hline
\end{tabular}




\section{E-15.3 Readiness Demonstration}

Readiness for surface barrier construction would be demonstrated by conducting a management self-assessment and completing any resulting corrective actions. Encountering waste material while constructing the surface barrier is not anticipated; therefore, constructing the surface barrier would not require an operational readiness review assessment.

\section{E-15.4 Remediation}

The ET surface barrier module entails use of well-established technology and conventional earthwork equipment and methods of construction. Based on preconceptual design, the surface barrier would cover 105 acres. This surface barrier system would be constructed of consecutive layers of natural materials, including grading fill, coarse rock, gravel, sand, fine-grained soil fill, and topsoil with perimeter armor protection. Because of the monolithic design of the ET surface barrier, it could be installed in phases across the SDA to accommodate ongoing operations. The first layer of the surface barrier to be constructed would be referred to as grading fill. Grading fill quantity is estimated to be $1,186,389 \mathrm{yd}^{3}$. Grading fill would be obtained by leveling the existing SDA perimeter berm, using demolition rubble from nearby structures, and using mining and import fill materials from the T12 borrow source. Grading fill material would be placed and compacted on a 3\% slope (as per guidance stated in EPA 2000) starting $6 \mathrm{~m}(20 \mathrm{ft})$ outside the existing SDA fence line.

The second layer would comprise coarse rock mined from a new pit located along the Snake River bed in Madison, Jefferson, or Bingham county. This layer serves as both a biointrusion barrier and a gas-collection layer. The biointrusion component prevents plant roots or burrowing animals from migrating through the surface barrier and into the waste zone. The gas collection component aids in removing gas, emitted by buried waste, before gas can reach and subsequently hamper growth of the vegetative community in upper layers of the surface barrier. An estimated 342,093 $\mathrm{yd}^{3}$ of material would be required to create a $0.6-\mathrm{m}$ (24-in.) -thick layer over the entire SDA. The coarse rock layer would be placed directly on the compacted grading fill layer.

Layers 3 and 4 would comprise $0.3-\mathrm{m}$ (12-in.) -thick layer of gravel and a $0.3-\mathrm{m}$ (12-in.) -thick layer of sand, respectively. These two layers prevent the upper fine-soil layer (i.e., Layer 5) from migrating through the coarse rock layer below. Gravel and sand would be produced and hauled from the Adams Pit. Approximately $165,537 \mathrm{yd}^{3}$ of gravel and $165,537 \mathrm{yd}^{3}$ of sand would be required.

Layers 5 and 6 serve to establish and maintain vegetative community to minimize surface erosion and contribute to water balance of the surface barrier. Layer 5 would consist of fine soil and topsoil imported from Rye Grass Flats. This layer would be approximately $1.2 \mathrm{~m}$ (48 in.) thick to provide optimum water balance. Approximately $662,147 \mathrm{yd}^{3}$ of fine soil fill would be required. Soil fill would be placed and compacted directly on the sand layer. Layer 6 would be constructed of $0.3 \mathrm{~m}$ (12 in.) of topsoil imported from Rye Grass Flats. Approximately 165,632 $\mathrm{yd}^{3}$ of topsoil fill would be required.

Cost estimates in Appendix F assume that topsoil material would be available on the INL Site (e.g., Rye Grass Flats). If not available on the INL Site, topsoil would be purchased from a vendor. Additional expense associated with procuring soil from off the INL Site would be captured within the surface barrier contingency.

Edges of the surface barrier would be armored by layers of sand, gravel, and basalt riprap to protect against erosion. Sand and gravel would be mined and imported from the Adams Pit. Approximately $11,862 \mathrm{yd}^{3}$ of gravel fill would be required. Gravel would be placed on a $2.5 \mathrm{H}: 1 \mathrm{~V}$ slope. The final armor layer would comprise basalt and riprap mined and imported from the Radio Cinder Butte. Approximately 
$5,230 \mathrm{yd}^{3}$ of basalt fill would be overlain by approximately $29,102 \mathrm{yd}^{3}$ of riprap armor. The $0.9-\mathrm{m}$ (36-in.) -thick riprap layer would be placed and compacted over the basalt armor layer.

Construction equipment for mining, hauling, and placing the surface barrier materials would include standard equipment (e.g., excavators, dozers, graders, compactors, dump trucks, scrapers, and water trucks). Because of weight restrictions on the SDA, scrapers would only be allowed to carry 33.5 bank yd $^{3}$ per load.

Following construction of the surface barrier, the OCVZ system would be reconstructed; additional monitoring wells would be installed beyond the perimeter of the cover, as necessary; and ICs would be established. The OCVZ system reconstruction consists of piping the OCVZ probes (extending up through the top of the surface barrier) to the relocated OCVZ treatment units. Six new groundwater monitoring wells are estimated to be installed outside the SDA following surface barrier construction. Placement of active ICs would include installing permanent markers surrounding the SDA to delineate contamination. Permanent markers would be made of concrete and would contain information about the type of contamination. Twelve permanent markers are estimated to be required, based on the size of the SDA.

After construction activities on the surface barrier are completed, the surface would be seeded with native grasses to provide vegetative cover. Because of the arid climate of the INL Site, an extended period of time would be required to establish a permanent vegetative cover. Erosion of the uppermost layers of the surface barrier during snowmelt would be expected during the years immediately following construction, requiring routine additional repairs and reseeding.

\section{E-15.5 Demobilization and Reporting}

Upon completion of remedial activities, construction support infrastructure (e.g., trailers, offices, and utilities) would be decontaminated and removed from the SDA. Any excess equipment would be used or disposed of. The final inspection report for the surface barrier, along with all inspection reports generated before surface barrier completion, would be captured in the remedial action report.

\section{E-15.6 Long-Term Surveillance, Monitoring, and Reporting}

Long-term surveillance, monitoring, and reporting of the ET surface barrier would entail a number of activities to be completed following surface barrier construction. These activities would be identical to those described in Section E-14.6.

\section{E-16. SIMPLIFIED EVAPOTRANSPIRATION SURFACE BARRIER WITH NO BIOINTRUSION AND GAS VENT LAYER}

Figure E-40 provides a preconceptual process diagram that overviews implementation of this module and was created for cost-estimation purposes. Key tasks identified in Figure E-40 are discussed in the following subsections. 


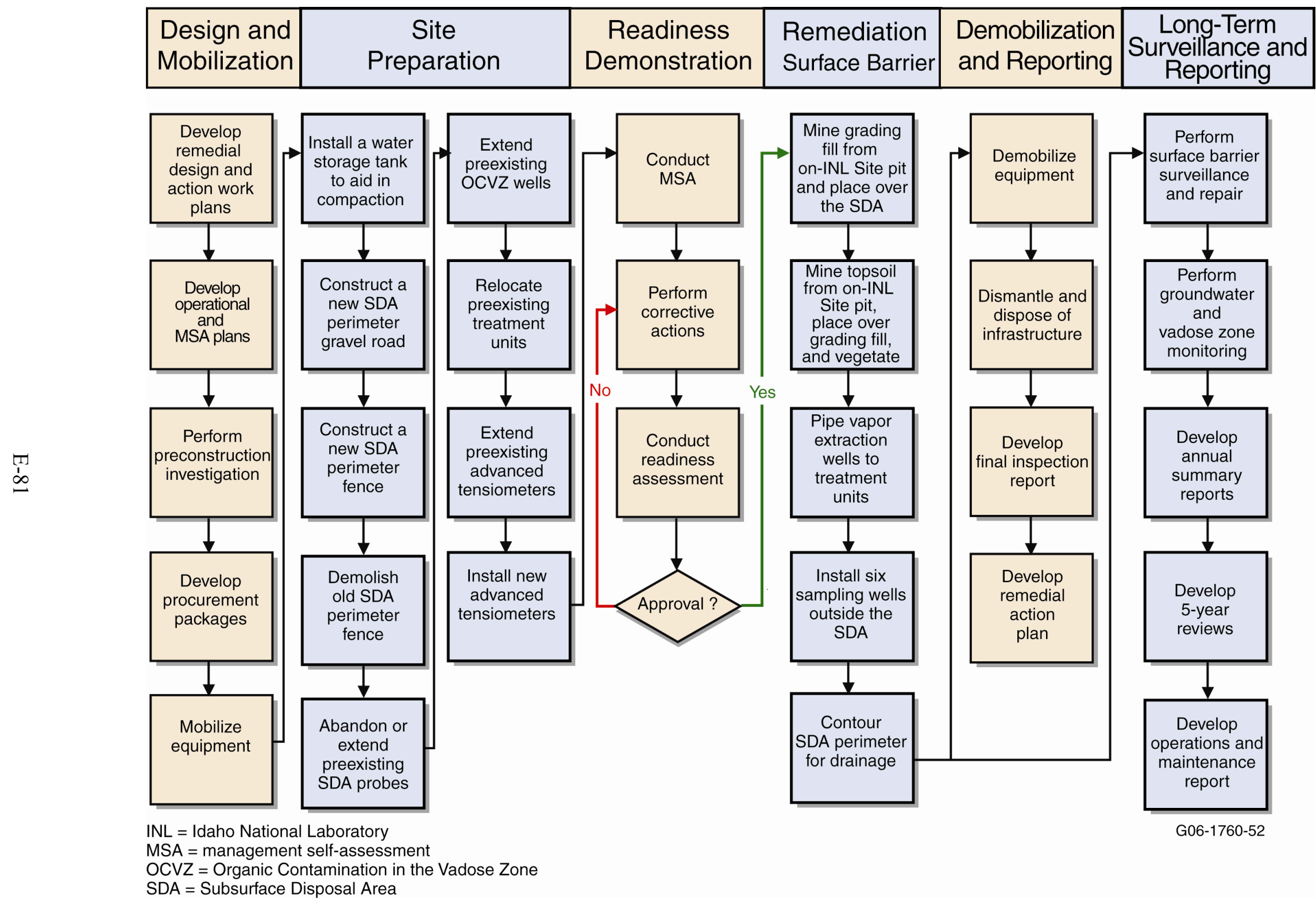

Figure E-40. Preconceptual process flow diagram for a simplified evapotranspiration surface barrier with no biointrusion and gas vent layer. 


\section{E-16.1 Design and Mobilization}

Design and mobilization for installing a simplified ET surface barrier with no biointrusion and gas vent layer would include developing remedial design and remedial action work plans, operational plans (i.e., operations and layout plan, radiation monitoring and control plan, industrial hygiene exposure and sampling plan, training plan, and quality control plan), a management self-assessment plan, and procurement packages; applying preconstruction investigations (e.g., surveying); and modifying and mobilizing equipment to the work site.

This surface barrier would comprise a $0.3-\mathrm{m}$ (12-in.) -thick topsoil layer placed on a bed of grading fill. The topsoil layer would be contoured to achieve an approximately $3 \%$ slope to facilitate run-off (see Figure E-41). Table E-15 provides estimated material types, quantities, and sources for construction of the surface barrier.

The simplified ET surface barrier would be used only in combination with the full retrieval module. Design requirements for the surface barrier would be significantly reduced compared to the ET barrier in Section E-15 because all buried waste would be removed and the area backfilled with clean material before construction of the surface barrier. This preliminary design is based on the following assumptions:

- $\quad$ Primary contaminant sources would have been removed

- $\quad$ Backfilled SDA soil, coupled with grading fill, would act as an ET layer by retaining water during the wet season and releasing stored water through evaporation and transpiration during the dry season (this ET layer would limit transport of contaminants that may have migrated beneath the first basalt interface)

- Contaminants beneath the first basalt interface would not pose a significant terrestrial risk or compromise the vigor of surface vegetation established within the topsoil layer.

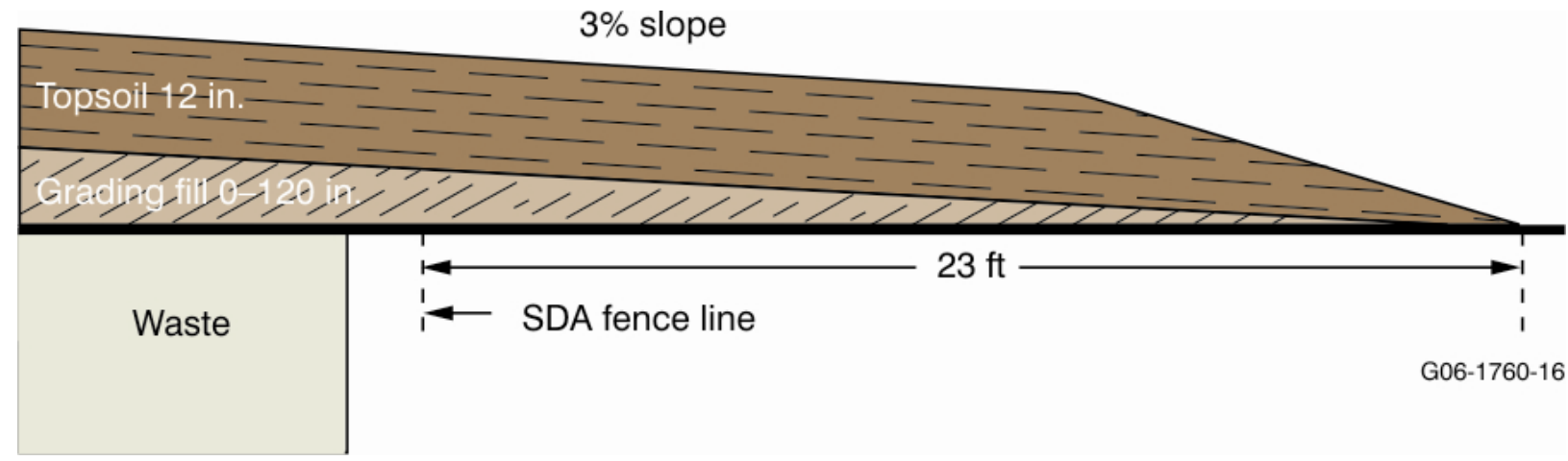

Figure E-41. Cross section of a simplified evapotranspiration surface barrier with no biointrusion and gas vent layer.

Table E-15. Design layers, thickness, and volume of a simplified evapotranspiration surface barrier.

\begin{tabular}{lccl}
\hline \multicolumn{1}{c}{ Layer } & $\begin{array}{c}\text { Thickness } \\
\text { (in.) }\end{array}$ & $\begin{array}{c}\text { Approximate Volume } \\
\left(\mathrm{yd}^{3}\right)\end{array}$ & Material Description \\
\hline Topsoil & 12 & 165,632 & Unprocessed organic silt loam from Rye Grass Flats \\
Grading fill & 0 to 120 & $1,186,389$ & Unprocessed gravel and sand from the T12 Gravel Pit \\
\hline
\end{tabular}


This design differs from the ET surface barrier design of Section E-15 and presented in Mattson et al. (2004) in that the coarse rock biointrusion layer, overlying gravel and sand layers, the fine soil layer, and armament are not required. In the Mattson et al. (2004) ET surface barrier design, the coarse rock layer served as a biointrusion layer to reduce intrusion of plants and burrowing animals; it also served as a gas-collection layer. Design requirements for the simplified ET surface barrier would not include biointrusion control and gas collection; therefore, the coarse rock layer would not be required. In the Mattson et al. (2004) ET surface barrier design, gravel and sand layers prevented overlaying fine soil from filtering down into the coarse rock. Because coarse rock would not be present in the simplified ET surface barrier design, gravel and sand layers would not be required. The 1.2-m (4-ft) -thick fine soil layer of the ET surface barrier described in Section E-15.4 provided a moisture storage capacity until evaporation and transpiration removed the water. Because SDA pits and trenches would be backfilled with clean soil, this soil would provide the moisture storage capacity required to make evaporation and transpiration possible. Therefore, an additional fine soil layer would not be required in the surface barrier design. In the Mattson et al. (2004) ET surface barrier design, armament was required to prevent erosion on the relatively steep-sloped sides of the surface barrier $(2.5 \mathrm{H}: 1 \mathrm{~V}$ slope). Because the simplified ET surface barrier would not be as thick, the new perimeter slope would match the grading fill slope (3\% slope); therefore, the need for side slope armor was removed.

Final identification of materials and quantities for construction of the surface barrier would be developed in the remedial design. Key design considerations would include control of water flux through the surface barrier and long-term performance of the surface barrier.

\section{E-16.2 Site Preparation}

Site preparation for the simplified ET surface barrier would require a number of construction activities to be completed before commencement of surface barrier construction. These activities would be identical to those described in Section E-2.15.2.

\section{E-16.3 Readiness Demonstration}

Readiness for surface barrier construction would be demonstrated by conducting a management self-assessment and completing any resulting corrective actions. Construction of the surface barrier is not anticipated to encounter any waste materials, and, as such, would not require an operational readiness review assessment.

\section{E-16.4 Remediation}

The first layer of the surface barrier to be constructed would be referred to as grading fill. Grading fill quantity is estimated to be $1,186,389 \mathrm{yd}^{3}$. Grading fill would be obtained by leveling the existing SDA perimeter berm, using demolition rubble from nearby structures, and using mining and import fill materials from the T12 borrow source. Grading fill material would be placed and compacted on a $3 \%$ slope starting $6 \mathrm{~m}(20 \mathrm{ft})$ outside the existing SDA fence line.

The second and final layer of this surface barrier would comprise unprocessed organic silt loam from Rye Grass Flats. This layer would serve to establish and maintain the vegetative community to minimize surface erosion. Topsoil is anticipated to be approximately $0.3 \mathrm{~m}(1 \mathrm{ft})$ thick, requiring $165,632 \mathrm{yd}^{3}$. The topsoil layer would be placed and compacted over the grading fill layer. 
Cost estimates in Appendix F assume that topsoil material would be available on the INL Site (e.g., Rye Grass Flats). If not available on the INL Site, topsoil would be purchased from a vendor. Additional expense associated with procuring soil from off the INL Site would be captured within the surface barrier contingency.

Construction equipment for mining, hauling, and placement of surface barrier materials would include standard equipment (e.g., excavators, dozers, graders, compactors, dump trucks, scrapers, and water trucks). Because of weight restrictions in the SDA, scrapers would be allowed to carry only 33.5 bank $\mathrm{yd}^{3}$ per load.

Following construction of the surface barrier, the OCVZ system would be reconstructed; additional monitoring wells would be installed beyond the perimeter of the surface barrier, as necessary; and ICs would be established. The OCVZ system reconstruction consists of piping the OCVZ probes (i.e., extending up through top of the surface barrier) to the relocated OCVZ treatment units. Six new groundwater monitoring wells are estimated to be installed outside of the SDA following surface barrier construction. Placement of active ICs would include installing permanent markers surrounding the SDA to delineate contamination. Permanent markers would be made of concrete and would contain information about the type of contamination. Twelve permanent markers would be required, based on the size of the SDA.

After construction activities on the surface barrier are complete, the surface would be seeded with native grasses to provide vegetative cover. Because of the arid climate of the INL Site, an extended period of time would be required to establish a permanent vegetative cover. Erosion of the uppermost layers of the surface barrier during snowmelt would be expected during the years immediately following construction, requiring routine additional repairs and reseeding.

\section{E-16.5 Demobilization and Reporting}

After completing remedial activities, construction support infrastructure (e.g., trailers, offices, and utilities) would be decontaminated and removed from the SDA. Any excess equipment would be used or disposed of. The final inspection report for the surface barrier, along with all inspection reports generated before surface barrier completion, would be captured in the remedial action report.

\section{E-16.6 Long-Term Surveillance, Monitoring, and Reporting}

Long-term surveillance, monitoring, and reporting of this surface barrier would entail of a number of activities to be completed following surface barrier construction. These activities would be identical to those described in Section E-14.6.

\section{E-17. SLURRY WALL}

The belowground soil-bentonite slurry wall would be a secondary defense against surface run-off migrating laterally into waste. The primary defense would be grading, drainage controls, and toe associated with the surface barrier. Additionally, the slurry wall could function as a partial foundation for the surface barrier.

The most common subsurface barrier is a slurry wall. In general, the slurry wall would be constructed $6.1 \mathrm{~m}(20 \mathrm{ft})$ outside the SDA fence line in a two-step process. First, a 0.6 to $0.9-\mathrm{m}$ ( 2 to 3 -ft) -wide vertical trench would be excavated to basalt, using conventional or customized excavation equipment capable of excavating to the required depth, while bentonite slurry would be 
pumped into the trench to maintain trench stability. Once the trench has been excavated to the designed depth and width, soil removed from excavating the trench would be mixed with trench slurry and dozed back into the trench. The slurry backfill has a low permeability, forming a hydraulic barrier. A 0.9 to $1.2-\mathrm{m}$ ( 3 to $4-\mathrm{ft}$ ) bridging layer of soil then would be compacted over the trench before surface barrier placement or access across the trench. The slurry wall would be integrated into the toe of the covering surface barrier.

Figure E-42 provides a preconceptual process diagram that overviews implementation of a slurry wall and was created for cost-estimation purposes. Key tasks identified in Figure E-42 are discussed in the following subsections.

\begin{tabular}{|c|c|c|c|c|}
\hline $\begin{array}{c}\text { Design and } \\
\text { Mobilization }\end{array}$ & $\begin{array}{c}\text { Site } \\
\text { Preparation }\end{array}$ & $\begin{array}{c}\text { Readiness } \\
\text { Demonstration }\end{array}$ & $\begin{array}{c}\text { Remediation } \\
\text { Slurry Wall Installation }\end{array}$ & $\begin{array}{c}\text { Demobilization } \\
\text { and Reporting }\end{array}$ \\
\hline
\end{tabular}

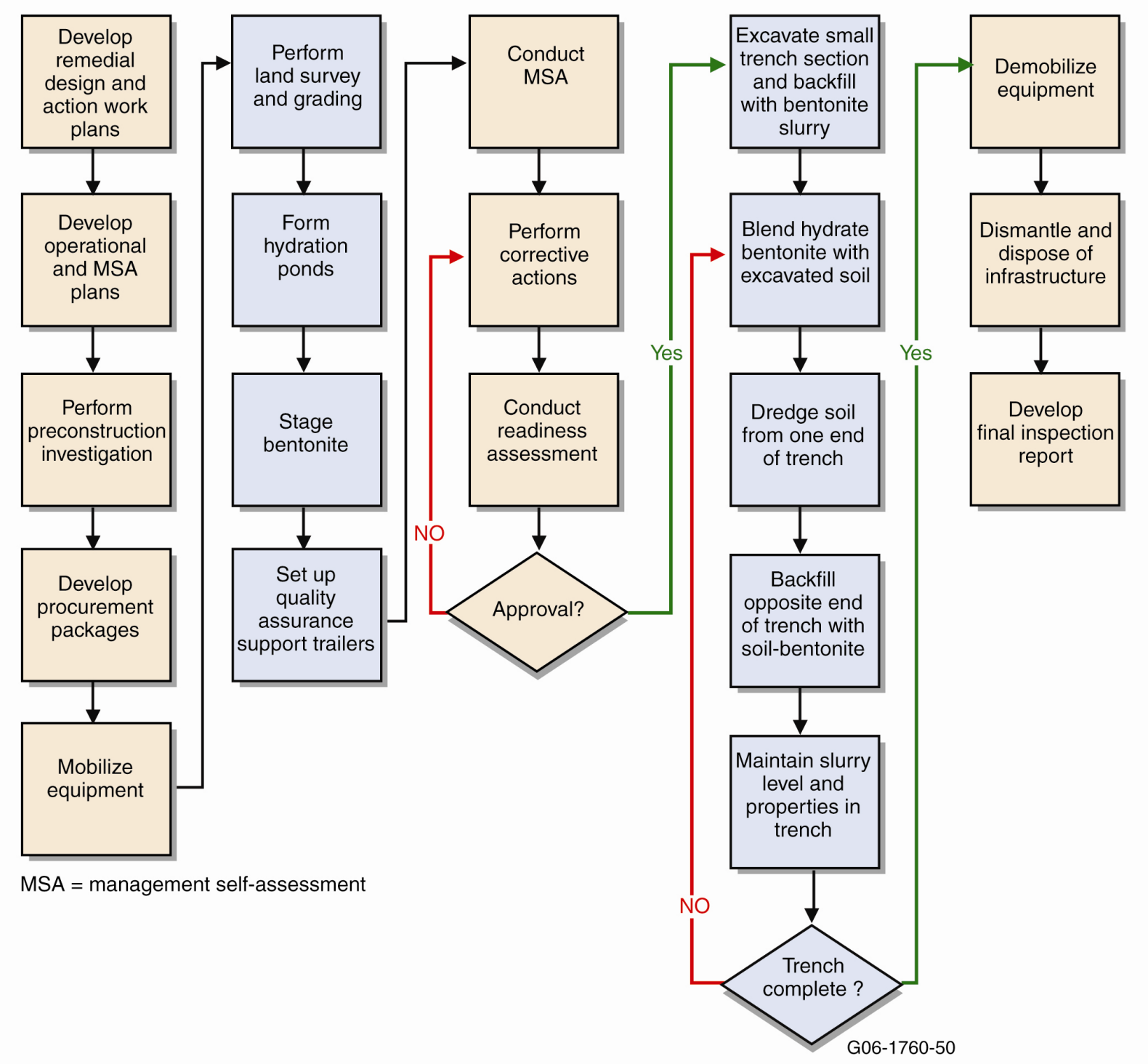

Figure E-42. Preconceptual process flow diagram for a slurry wall. 


\section{E-17.1 Design and Mobilization}

Need for this slurry wall may be determined by provisions in the record of decision. Design and mobilization for installing a bentonite slurry wall around the SDA perimeter would include developing remedial design and remedial action work plans, operational plans (i.e., operations and layout plan, industrial hygiene exposure and sampling plan, and quality control plan), a management self-assessment plan, and procurement packages; mobilizing equipment; and performing a preconstruction investigation.

As part of remedial design, design studies of trench stability would be conducted to ensure proper determination of slurry parameters, geotechnical properties of the soil, and other construction constraints. Design evaluation would establish weight, viscosity, and filtrate-loss requirements for the slurry. Backfill design would specify criteria for unit weight, slump (e.g., backfill should typically have an approximate 10 to $15-\mathrm{cm}$ [4 to 6-in.] slump), gradation, and permeability to prevent hydrofracturing of the slurry wall under high stress. Laboratory studies of backfill permeability would be conducted during the design phase to ensure that performance criteria can be met.

Preconstruction investigations would include a thorough evaluation of site conditions, including (a) site geology and hydrogeology, (b) nature and extent of contamination, and (c) geotechnical properties of subsurface materials. Soil borings would be drilled along the potential alignment route, or routes, and samples would be collected for geotechnical, physical, and contaminant analyses. Surface water modeling also may be necessary.

\section{E-17.2 Site Preparation}

Soil-bentonite barriers can generally be constructed only where surface grades are less than $1 \%$. Because slurry would flow, excavating down a slope would result in lower slurry levels within the upslope portion of the trench, reducing trench stability. A land survey of the line of excavation and potentially a site grading adjustment would be required before beginning trench construction.

Bentonite slurry should be fully hydrated before being placed in the trench, typically for 12 to 24 hours. Therefore, bentonite staging areas and temporary hydration ponds would be required near the slurry wall. A centrally located quality assurance trailer also would be required to analyze slurry properties at the ponds and dig face. Figure E-43 illustrates a typical slurry wall construction site.

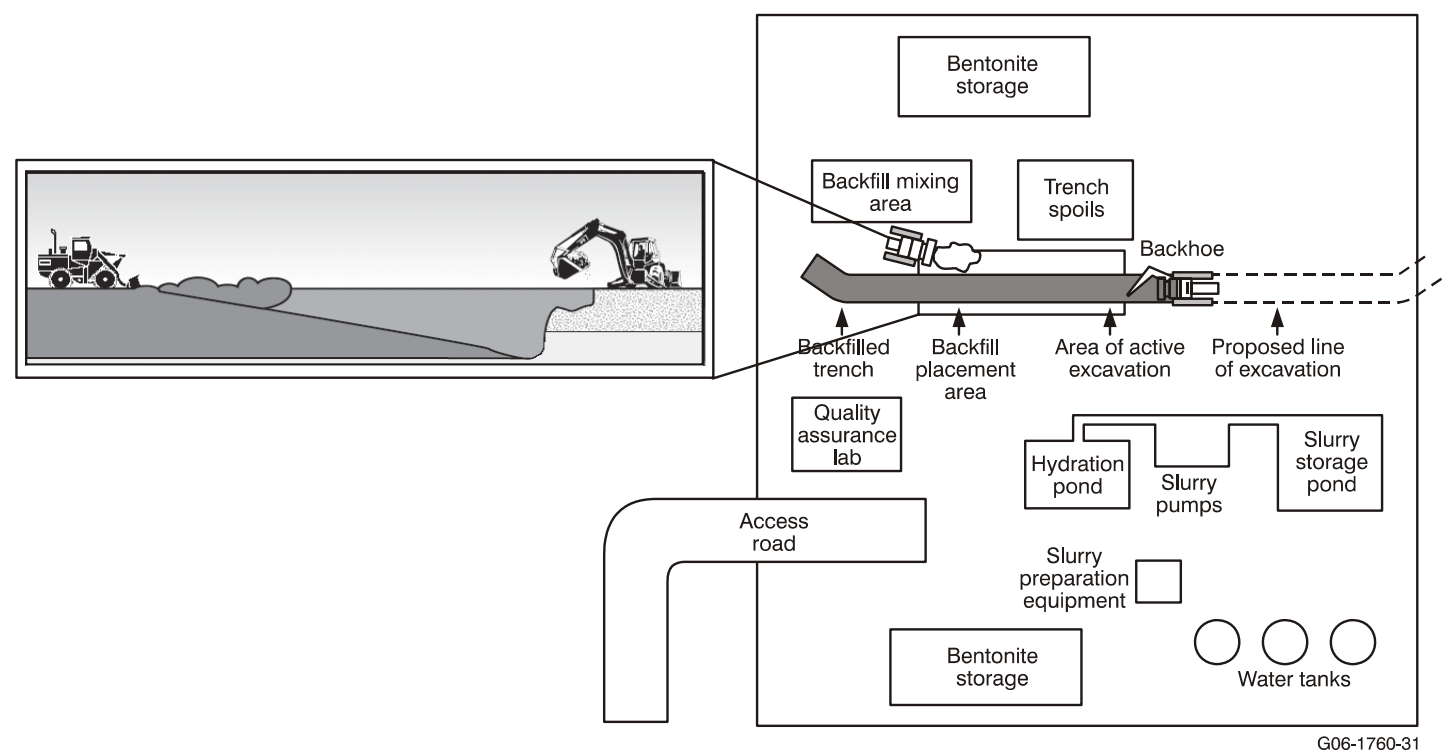

Figure E-43. Plan view and cross section of slurry cut-off wall production. 


\section{E-17.3 Readiness Demonstration}

Readiness for slurry wall fabrication would be demonstrated by conducting a management self-assessment, completing any resulting corrective actions, and successfully completing a final readiness review. Approval by DOE is assumed to be required before initiating any fabrication activity.

\section{E-17.4 Remediation}

As shown in Figure E-43, applying a soil-bentonite slurry wall involves dredging soil from one end of a slurry-filled trench while adding a low-permeability backfill to the other end of the trench. Slurry within the trench would comprise 30-mesh bentonite and water (typically 1 to $5 \%$ bentonite). The slurry mixture would be maintained within the trench to support the trench side walls by overcoming active earth pressures in the soil adjacent to the trench and forming a filter cake along trench walls. The slurry level in the trench would be maintained at or near the top of the trench and above the surrounding groundwater table. Before being placed in the trench, slurry would be sampled and tested for unit weight, viscosity, and filtrate loss to ensure that these parameters meet design requirements. Slurry also may be tested for $\mathrm{pH}$, sand content, and gel strength. Slurry samples also would be collected from the trench during excavation and tested again for unit weight, viscosity, and filtrate loss.

The low-permeability backfill is prepared by mixing bentonite slurry (from the hydration ponds) with dredged native soil. Before placement in the trench, the backfill would be sampled and tested for unit weight, slump, gradation, and permeability to ensure that it meets design requirements. Backfill unit weight would be tested to ensure it is at least $15 \mathrm{lb} / \mathrm{ft}^{3}$ greater than the slurry weight. This density gradation would be required to enable slurry displacement during backfill placement. Backfill samples then would be collected on a frequent and regular basis during backfill placement. When the barrier is completed, backfill samples would be collected at regular intervals and tested for permeability. This test would establish whether the completed barrier meets design criteria. Typically a 0.9 to $1.2-\mathrm{m}$ ( 3 to $4-\mathrm{ft}$ ) -thick soil layer would be placed over the trench to allow equipment crossing and to act as a foundation for final surface barrier placement.

\section{E-17.5 Demobilization and Reporting}

After completing the slurry wall, vendor equipment would be decontaminated and removed from the SDA. Any excess equipment would be used or disposed of. The final inspection report for the slurry wall would be included in the remedial action report for OU 7-13/14.

\section{E-18. SHALLOW GAS EXTRACTION WELLS}

The shallow gas extraction wells module involves installing shallow (i.e., approximately $12.2 \mathrm{~m}$ [40 ft]) extraction wells to provide a means for removing volatile organic contaminants from the shallow subsurface near the SDA. Extraction wells would be installed in tandem with the landfill surface barrier to ensure vapor accumulation associated with the surface barrier would be mitigated and to support active extraction of vapors from the shallow subsurface. Operation and replacement of the OCVZ system is addressed under a separate module. Figure E-44 provides a preconceptual process diagram that overviews installation of shallow extraction wells and was created for cost-estimation purposes. Key tasks identified in Figure E-44 are discussed in the following subsections. 


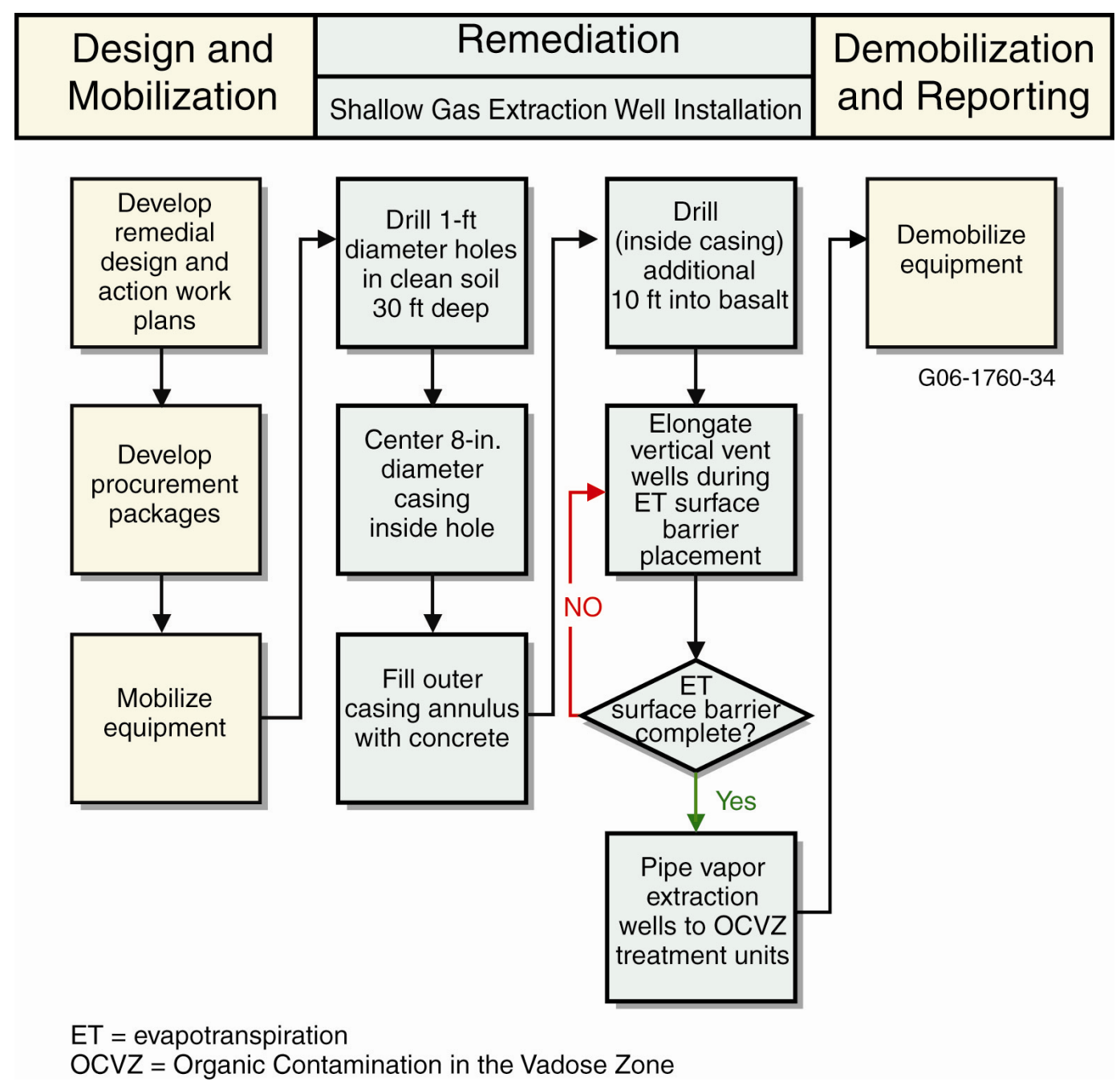

Figure E-44. Preconceptual process flow diagram for the shallow gas extraction well installation.

\section{E-18.1 Design and Mobilization}

Design and mobilization activities involve completing required remedial design plans and remedial action work plans that outline the work scope and associated regulatory and operational requirements. Procurement activities involve generating a bid package and acquiring a qualified subcontractor to install wells and additional supporting systems (e.g., required well extensions [for the surface barrier] and piping connection to the OCVZ system). Mobilization consists of the subcontractor mobilizing necessary drilling and other equipment to the SDA. As part of mobilization, the subcontractor would conduct various site preparation functions (e.g., a site survey to locate required extraction wells).

Eight extraction wells would be located near the waste pits with the highest potential VOC mass. Figure E-45 identifies conceptual well locations. Wells would be installed in clean soil adjacent to waste pits. 


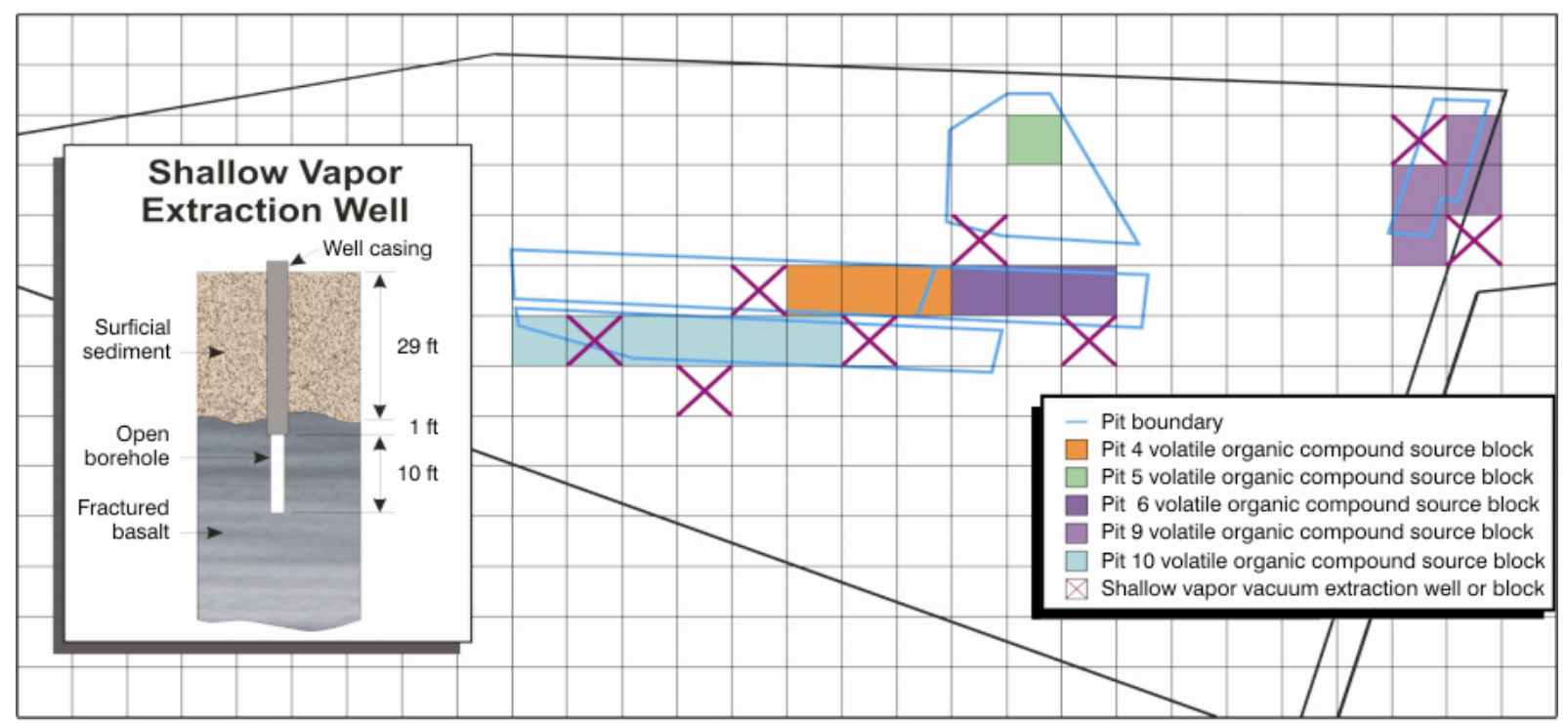

G06-1760-30

Figure E-45. Extraction well cross section and locations.

\section{E-18.2 Remediation}

The remediation or well installation component involves drilling eight shallow gas extraction wells into the basalt layer in the SDA. As Figure E-46 illustrates, the module assumes installation of a 0.3-m (12-in.) -diameter borehole into the subsurface to a depth of approximately $9.1 \mathrm{~m}(30 \mathrm{ft})$. This borehole then would be cased with a 0.2-m (8-in.) -diameter casing, and the annulus between the casing and 0.3-m (12-in.) borehole would be grouted. A smaller hole then would be drilled inside the grouted casing an additional $3 \mathrm{~m} \mathrm{(10} \mathrm{ft)} \mathrm{into} \mathrm{the} \mathrm{underlying} \mathrm{basalt} \mathrm{layer.} \mathrm{This} \mathrm{uncased} \mathrm{section} \mathrm{of} \mathrm{the} \mathrm{borehole} \mathrm{into} \mathrm{the}$ relatively permeable basalt layer would enable extraction of surrounding VOC-contaminated vapors near the borehole. Wells would be established in clean soil adjacent to waste pits, thus greatly simplifying controls during well installation.

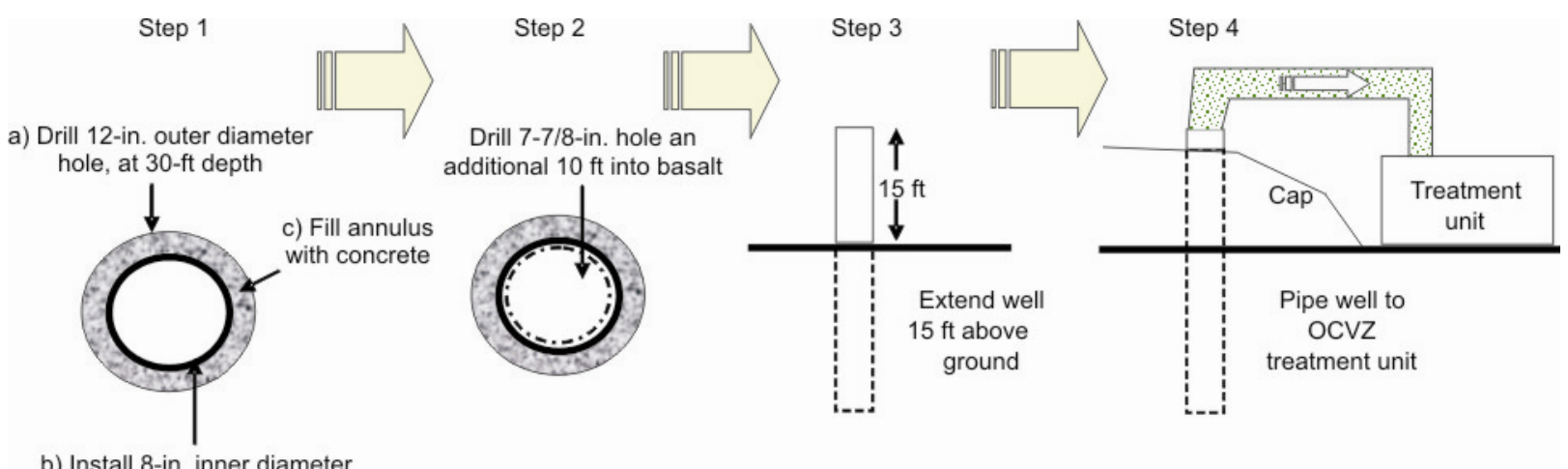

$$
\text { casing, at } 30-\mathrm{ft} \text { depth }
$$

Figure E-46. Shallow gas extraction well installation. 
Each of the newly established shallow extraction wells would require vertical extension of the

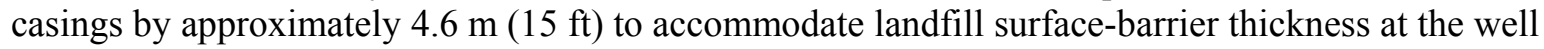
location. After the landfill cover has been completed, extraction piping for each well would be connected to a 1,200 -standard- $\mathrm{ft}^{3} /$ minute manifold system that conveys extracted vapors to the OCVZ system units for treatment.

\section{E-18.3 Demobilization and Reporting}

Demobilization essentially involves removing drill rigs and construction support equipment from RWMC. Reporting would be performed as required by the Comprehensive Environmental Response, Compensation, and Liability Act (CERCLA) (42 USC § 9601 et seq., 1980).

\section{E-19. GAS VENT LAYER EXTRACTION PIPE}

The gas vent layer extraction pipe module involves installing horizontal and vertical piping within the landfill surface barrier to support active or passive venting of the surface barrier. Piping would be installed during surface barrier construction and would ensure that the surface barrier does not limit vapor transport to the atmosphere (i.e., confining vapors could lead to increased transport of vapors into the subsurface) and to ensure that vapor concentrations do not increase to levels that could damage vegetation on the surface of the barrier. The gas vent layer extraction pipe can function as a passive vent system or can be connected to the OCVZ system in such a way that active vapor extraction can be performed. Figure E-47 provides a preconceptual process diagram that overviews implementation of this module and was created for cost-estimation purposes. Key tasks identified in Figure E-47 are discussed in the following subsections.

\section{E-19.1 Design and Mobilization}

Design and mobilization activities involve completing required remedial design plans and remedial action work plans that outline work scope and associated regulatory and operational requirements. Procurement activities involve generating a bid package and acquiring a qualified subcontractor to install the vent system and connect to the OCVZ system (if required). Mobilization consists of the subcontractor delivering necessary equipment to the SDA site location to support construction of the venting system. As part of mobilization, the subcontractor would conduct various site-preparation functions (e.g., conducting a site survey).

\section{E-19.2 Remediation}

Remediation entails constructing and installing a vent system. As noted in Figure E-47, vent system installation would be integrated with construction of the ET surface barrier. A horizontal perforated pipe (i.e., 3,600 linear ft of 12-in. pipe) would be installed in the combined gas venting and biotic layer that is part of the surface barrier design. Horizontal vent pipes would be installed near the apex of the surface barrier. Thirty-seven 4.6-m (15-ft) -tall vertical risers (12-in. pipe) would be connected along the horizontal pipe every $30.5 \mathrm{~m}(100 \mathrm{ft})$. Alternative $2 \mathrm{~b}$ includes six vertical vent pipes protruding from the surface barrier that would be routed to a manifold. As shown in the left side of Figure E-48, these effluent lines then would be piped to the OCVZ treatment units (located outside the surface barrier perimeter) for treatment. For Alternative 3 and Alternatives $4 \mathrm{a}$ and $4 \mathrm{~b}$, effluent from vertical vent pipes would be released directly to the atmosphere (see right side of Figure E-48). 


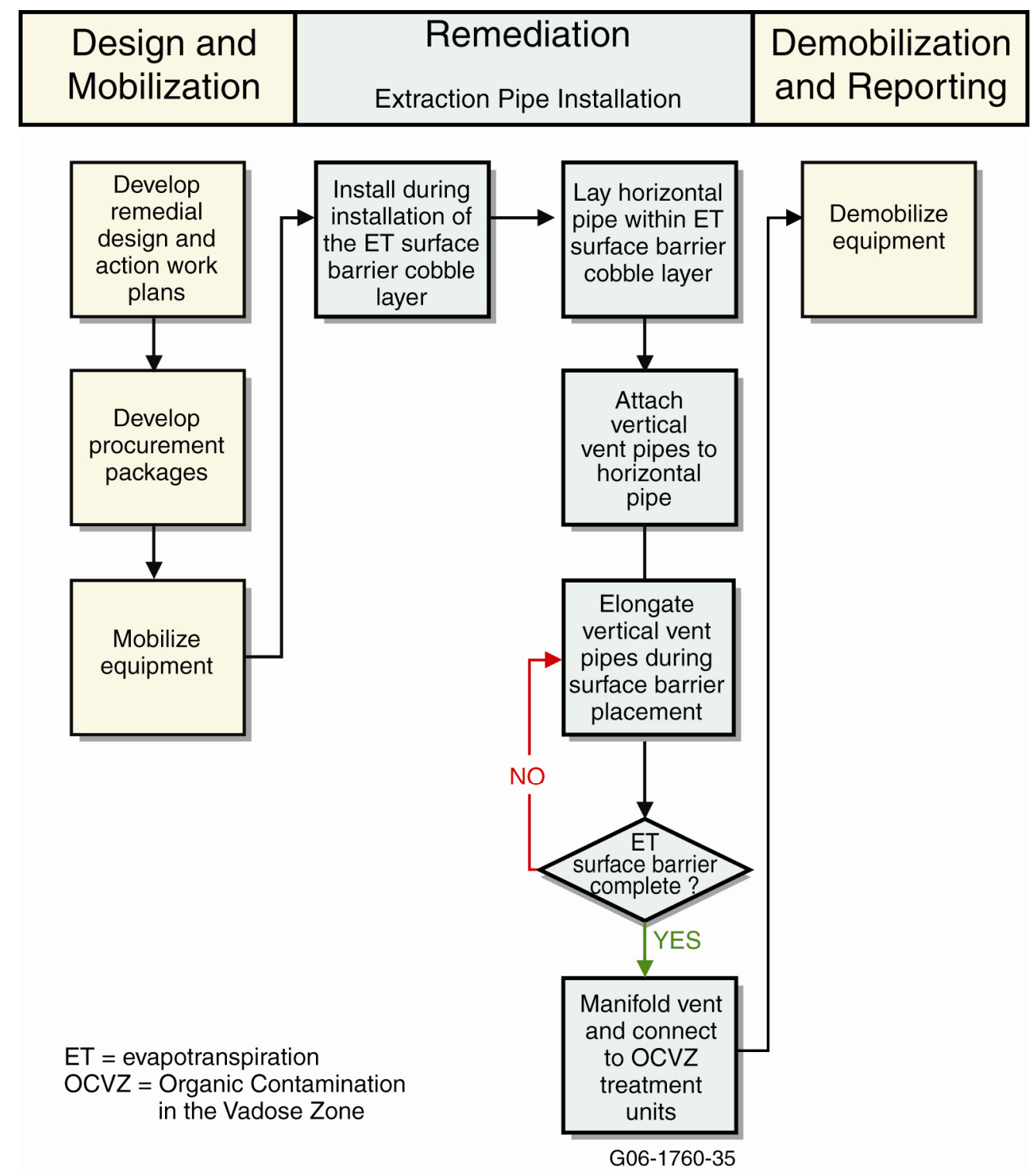

Figure E-47. Preconceptual process flow diagram for the gas vent layer extraction pipe. 

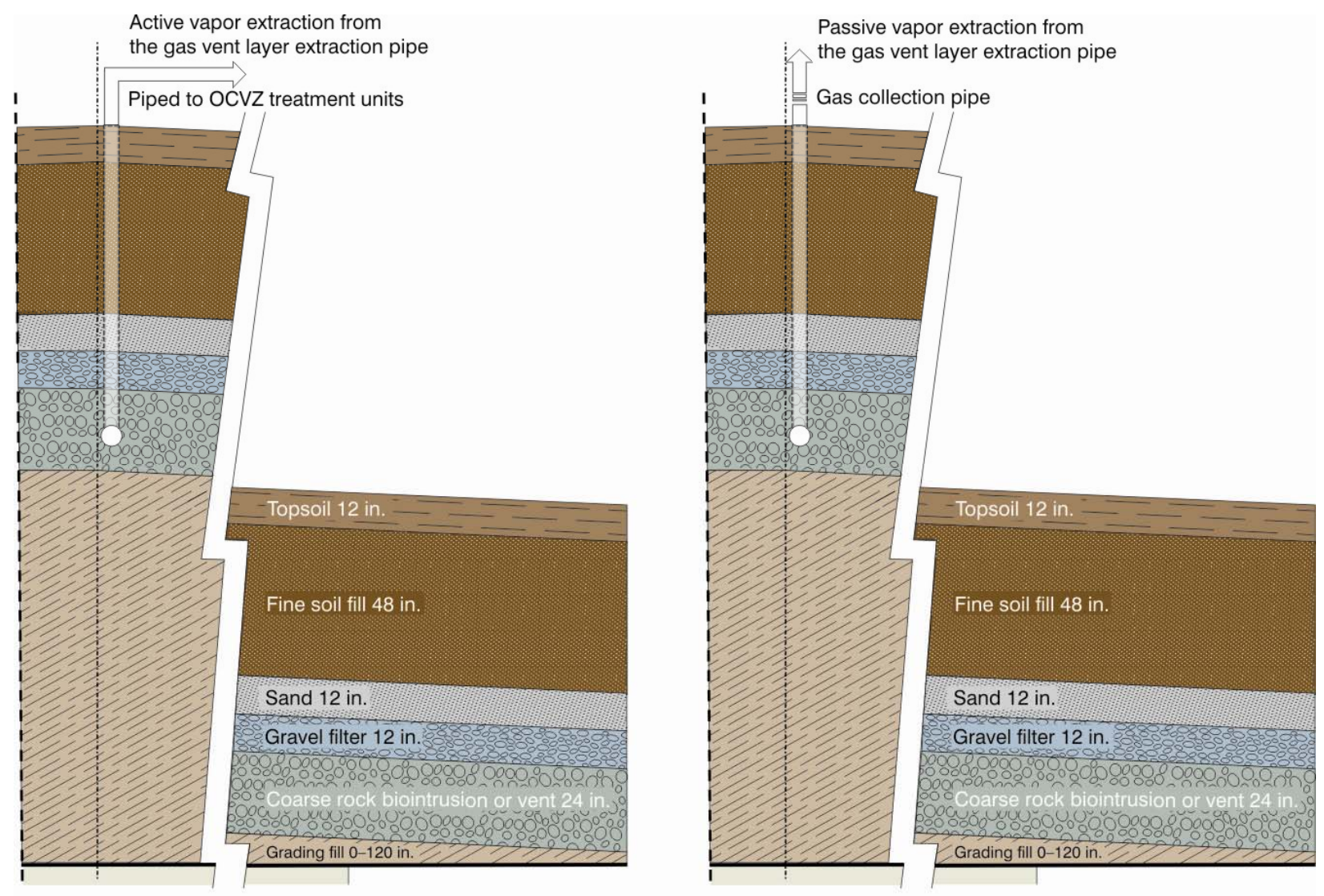

G06-1760-28

Figure E-48. Gas vent layer extraction pipe within evapotranspiration surface barrier cross section.

\section{E-19.3 Demobilization and Reporting}

No significant demobilization activities would be involved because piping installation does not involve significant equipment or support systems for construction. Reporting would be performed as part of the overall OU 7-13/14 remedial action report preparation (i.e., no stand-alone reports would be required).

\section{E-20. ORGANIC CONTAMINATION IN THE VADOSE ZONE MAINTENANCE AND OPERATION}

Groundwater modeling estimates predict that a relatively long-term extraction of VOCs from the vadose zone would be necessary to achieve subsurface remediation goals. The actual timeframe would depend on the remedial alternative implemented (e.g., increased waste retrieval shortens required timeframe) and continued effectiveness at meeting remediation goals; however, modeling predicts an operational timeframe in the range of 10 to 65 years. Therefore, this module provides a scope and cost basis for supporting the likely need for long-term OCVZ system operations, treatment unit replacement every 20 years, and a final 1-year monitoring effort of vadose zone wells following retirement of treatment unit operations.

The following subsections discuss ongoing operation of the OCVZ system, replacing the system to support the long-term operational timeframe, and performing postshutdown monitoring activities. 


\section{E-20.1 Operation and Maintenance}

Figure E-49 provides a preconceptual process diagram that overviews operation and maintenance of the OCVZ system and was created for cost-estimation purposes. Key tasks identified in Figure E-49 are discussed in the following paragraphs.

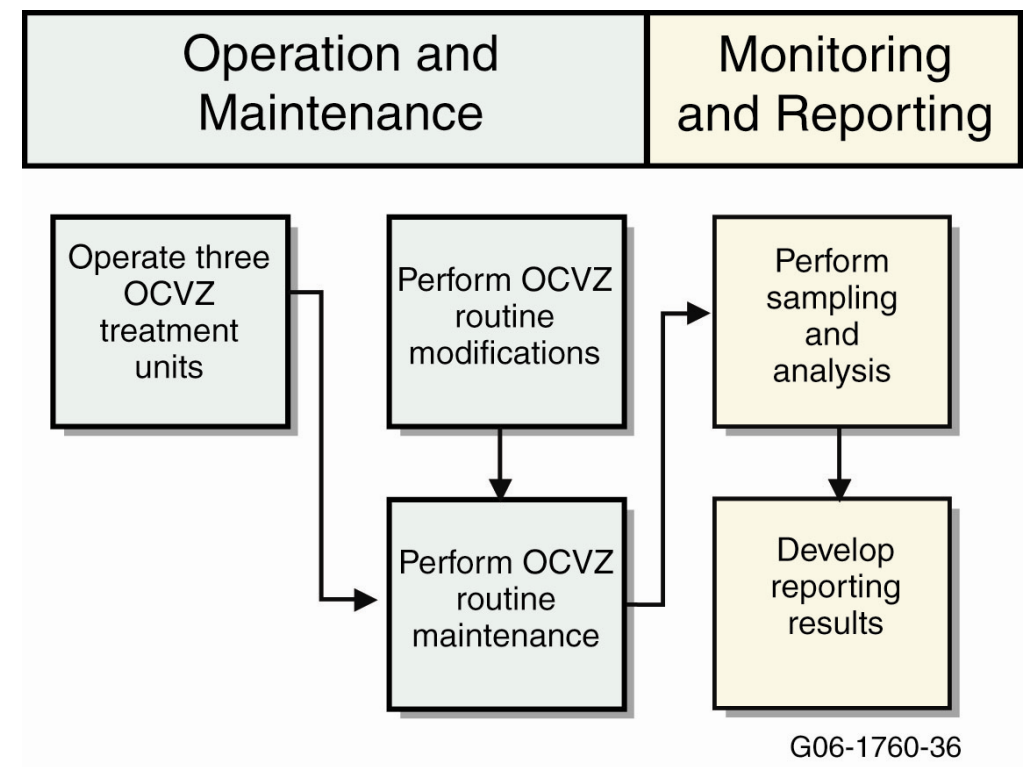

OCVZ = Organic Contamination in the Vadose Zone

Figure E-49. Preconceptual process flow diagram for operation and maintenance of the Organic Contamination in the Vadose Zone system.

The OCVZ system operations and maintenance portion of this module scope involves operating the OCVZ treatment units and sampling (including analysis) vapor ports for a period of 5 years. For cost-estimating purposes, a 5-year timeframe was chosen to allow multiple applications of this module within different alternatives requiring various OCVZ treatment periods. Long-term operation of the OCVZ system ensures that VOCs, which have been identified as COCs, would be extracted from the subsurface and treated. Operations involve continued use of three electrically heated catalytic oxidization systems to perform soil vapor extraction of VOCs from various wells located in the SDA and gas sample extraction from those wells for analysis. The process consists of four basic operations: (1) pretreatment, (2) catalytic oxidation, (3) stack release of oxidizer exhaust gas, and (4) sampling of well and header vapor ports. The function of pretreatment equipment would be to collect extracted VOC vapor into a header using a vacuum blower. The VOC vapor then would be withdrawn from the wellhead and carried (through insulated piping) to one of three skid-mounted catalytic oxidation systems. The catalytic oxidation systems elevate vapor temperature by an external source to the set point temperature of the process. At this temperature, halogenated compounds would be destroyed in a catalytic reaction. Oxidation products would be exhausted from treatment units through an exhaust stack. The function of well vapor port sampling and analysis would be to determine the concentration of VOCs in the vadose zone. The function of header vapor port sampling would be to determine the concentration of VOCs that are extracted and sent to the oxidation treatment unit. These sampling results would be used for weekly organic mass destruction calculations, which would be reported on a weekly and annual basis.

Equipment replacement during the 5-year life span includes standard consumables associated with system operation (e.g., catalyst materials). 


\section{E-20.2 Treatment Unit Replacement}

Figure E-50 provides a preconceptual process diagram that overviews replacement of an OCVZ treatment unit and was created for cost-estimation purposes. Key tasks identified in Figure E-50 are discussed in the following paragraphs.

The treatment unit replacement module includes scope to replace a catalytic oxidation OCVZ treatment unit after the 20-year operational life of the unit.

Design and mobilization for OCVZ treatment unit replacement involves preparing remedial design and remedial action work plans for CERCLA compliance, updating or developing operational plans (i.e., operations and layout plan, radiation monitoring and control plan, industrial hygiene exposure and sampling plan, and quality control plan), performing required procurement processes to obtain and review vendor information on the treatment process, and allowing for shipment of the unit to the project site. Subcontractor mobilization activities would involve setting up support facilities in the SDA to install, test, and inspect the new system. A management self-assessment will require performance to verify readiness to demobilize the old system and implement operation of the new unit.

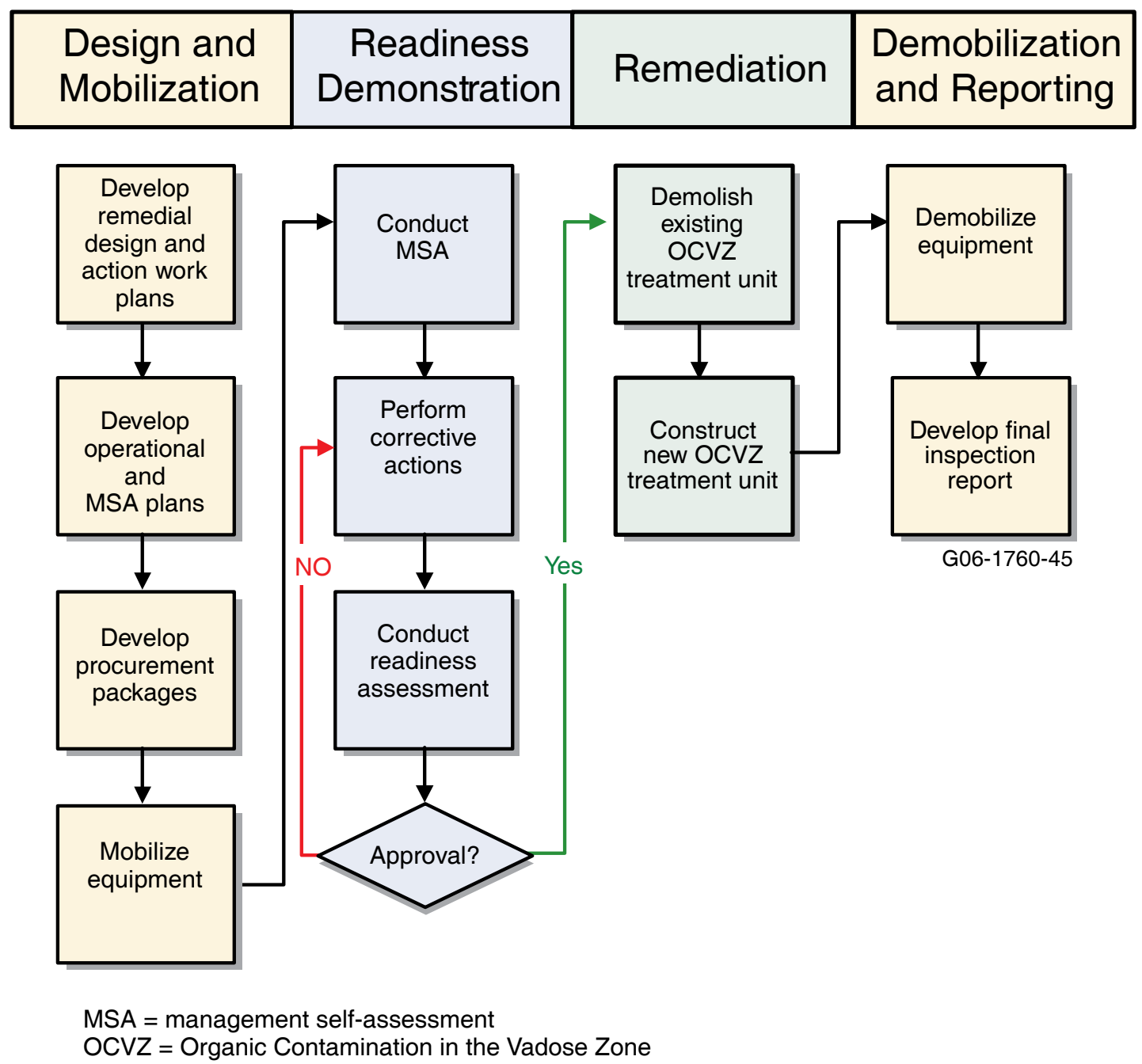

Figure E-50. Preconceptual process flow diagram for replacement of Organic Contamination in the Vadose Zone system treatment units. 
Remediation involves demolishing and removing the existing OCVZ treatment unit and installing, testing, and inspecting the new treatment unit. The demolition component would require integration with reinstallation work to ensure that systems are retained, as necessary, and replacement systems are compatible with the required system configuration. Obsolete system components would generally be disposed of at on-INL Site landfills or recycled as scrap material, to the extent possible. Placement of the new unit would be accomplished with a crane and a man lift.

Demobilization and reporting involves the subcontractor removing support structures and equipment from the project site and preparing necessary documentation to demonstrate that the system works as designed, is operational, and has satisfied all required inspection criteria. In addition, the subcontractor will prepare a final inspection report following installing the treatment unit.

\section{E-20.3 Postshutdown Monitoring}

Postshutdown monitoring includes sampling 50 vadose zone vapor ports for 1 year following closure of OCVZ system operations. Following sample collection, samples would be shipped to an off-INL Site analytical laboratory for analysis. Sampling results would be used to validate the decision to shut down OCVZ treatment units. Samples would be pulled monthly and would focus on a suite of VOCs, as defined in project sampling and analysis plans, to be prepared to guide continuing efforts.

\section{E-21. ENVIRONMENTAL MONITORING}

Long-term monitoring would include monitoring of groundwater and the vadose zone. Groundwater monitoring would be performed to assess migration of contaminants to the aquifer. Monitoring of the vadose zone can provide an early warning of surface water infiltration and contaminant migration out of the waste zone. Vadose zone monitoring would include using lysimeters, vapor ports, and tensiometers. Monitoring must be robust enough to distinguish sporadic detections from contaminant trends. In a preliminary assessment, the existing monitoring network was determined to be sufficiently robust for long-term monitoring. Final design of the monitoring network would be detailed in remedial design documentation.

Contaminant concentrations would be routinely monitored within and around RWMC to determine whether waste buried in the SDA is impacting the environment. Samples would be taken periodically from both groundwater and the vadose zone (i.e., unsaturated region between land surface and an underlying aquifer or water table) and analyzed for a variety of radionuclide, inorganic, and organic contaminants.

Recent studies (Holdren et al. 2006; Olson et al. 2003; Koeppen et al. 2004, 2005) have summarized data from monitoring activities in and around RWMC. Results show that organic contaminants in the vadose zone are declining because of ongoing vapor vacuum extraction efforts; however, other contaminants are leaching and ultimately may impact groundwater quality. Contaminants to be monitored would be prioritized and would include characteristic leaching procedure metal, nitrate and nitrite, VOCs, semi-VOCs, gross alpha and beta, Sr-90, Tc-99, U-234, U-235/236, U-238, Am-241, gamma isotopes, C-14, and I-129. Turbidity, total suspended solids, total dissolved solids, and $\mathrm{pH}$ also would be monitored in groundwater samples.

Aquifer monitoring is currently performed at 21 groundwater monitoring wells in and around the RWMC on a semiannual basis. The groundwater monitoring program currently consists of semiannual monitoring of more than 88 chemical and radioactive constituents (ICP 2005). Data from aquifer monitoring are used to determine whether contaminants buried in the SDA are migrating and affecting water quality of the aquifer. 
Soil-moisture samples would be collected on a quarterly basis using suction lysimeters (see Figure E-51) throughout the waste and vadose zones of the SDA. Data collected from lysimeter samples would be used to determine whether contaminants are migrating from buried waste to the surrounding soil; and if so, the data would be used to characterize the spatial extent of contamination.

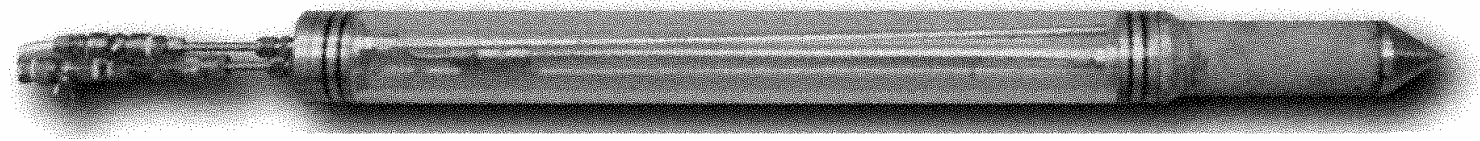

Figure E-51. Lysimeter - a development model using clear plastic instead of stainless steel to show probe internals.

To collect the liquid lysimeter sample, a partial vacuum would be applied on the porous section of the lysimeter (porous stainless steel with a $0.2-\mu$ pore size) that is in contact with the soil, and soil moisture would be drawn into the lysimeter body. The sample liquid would be removed from the lysimeter by applying positive pressure to the lysimeter; this pressure pushes the collected liquid up a tube to the surface and into a sample container.

The current vadose zone monitoring network includes 63 lysimeters inside and outside the SDA, 12 additional lysimeters in the LLW Pit, and 37 additional lysimeters in the waste zone of the SDA for a total of 112 lysimeters that are currently in operation at RWMC. Lysimeter samples can be limited in volume (i.e., from only a few milliliters up to approximately $900 \mathrm{~mL}$ per sampling event) due to arid conditions at the INL Site.

Soil-gas samples using vapor ports (see Figure E-52) would be collected routinely from the SDA subsurface for analysis of VOCs at depths down to $7.6 \mathrm{~m}(25 \mathrm{ft})$. Other soil-gas samples would be collected near buried beryllium reflector blocks to determine the extent of C-14 and tritium releases. Vapor ports would be constructed of 3/8-in. stainless steel tubing that has been perforated near the bottom of the tubing. Soil-gas samples would be collected by applying a vacuum to the vapor port line. There are five vapor port wells with 11 vapor ports inside the SDA and 12 vapor ports wells with 13 vapor ports in the LLW Pit.

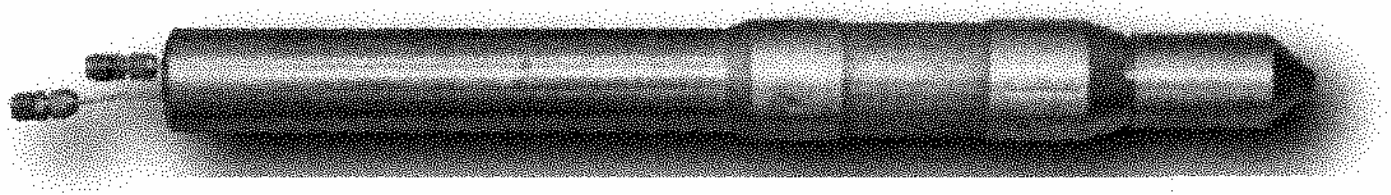

Figure E-52. Vapor port—detects and collects gas and vapor samples.

Tensiometers are instruments that measure water potential. As presented in Figure E-53, a volume of water would be placed in the polyvinyl chloride pipe extending to the surface to fill a porous cup. Water in the porous cup would move into or out of the soil until pressure in the cup is equal to water pressure in the surrounding soil. A pressure transducer measurement of this partial vacuum is a direct measure of soil-water potential. When analyzing the response of a tensiometer, the higher (or less negative) the water-potential measurement, the greater the wetness of that medium. Increasing water potentials over time indicate wetting of the medium, and conversely, decreasing water potentials indicate drying of the medium over time. Tensiometers are placed to provide data on the variability of moisture in the soil, quantify the amount and timing of moisture infiltration, and define the presence and extent of saturated conditions. These data can be used to determine movement of water, and therefore, potential leaching and possible transport of contaminants in the subsurface. 
Currently, 43 Type B tensiometers and 66 advanced tensiometers are in use in the SDA. Type B

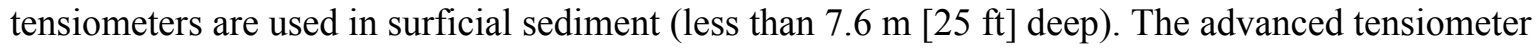
design enables placement at any depth, and these instruments are placed from 2.7 to $117.3 \mathrm{~m}$ (9 to $385 \mathrm{ft}$ ) deep.

Data generated by tensiometers would be collected on data loggers, typically taking measurements at 2-hour intervals. Data would be downloaded from the data loggers at periodic intervals for analysis.

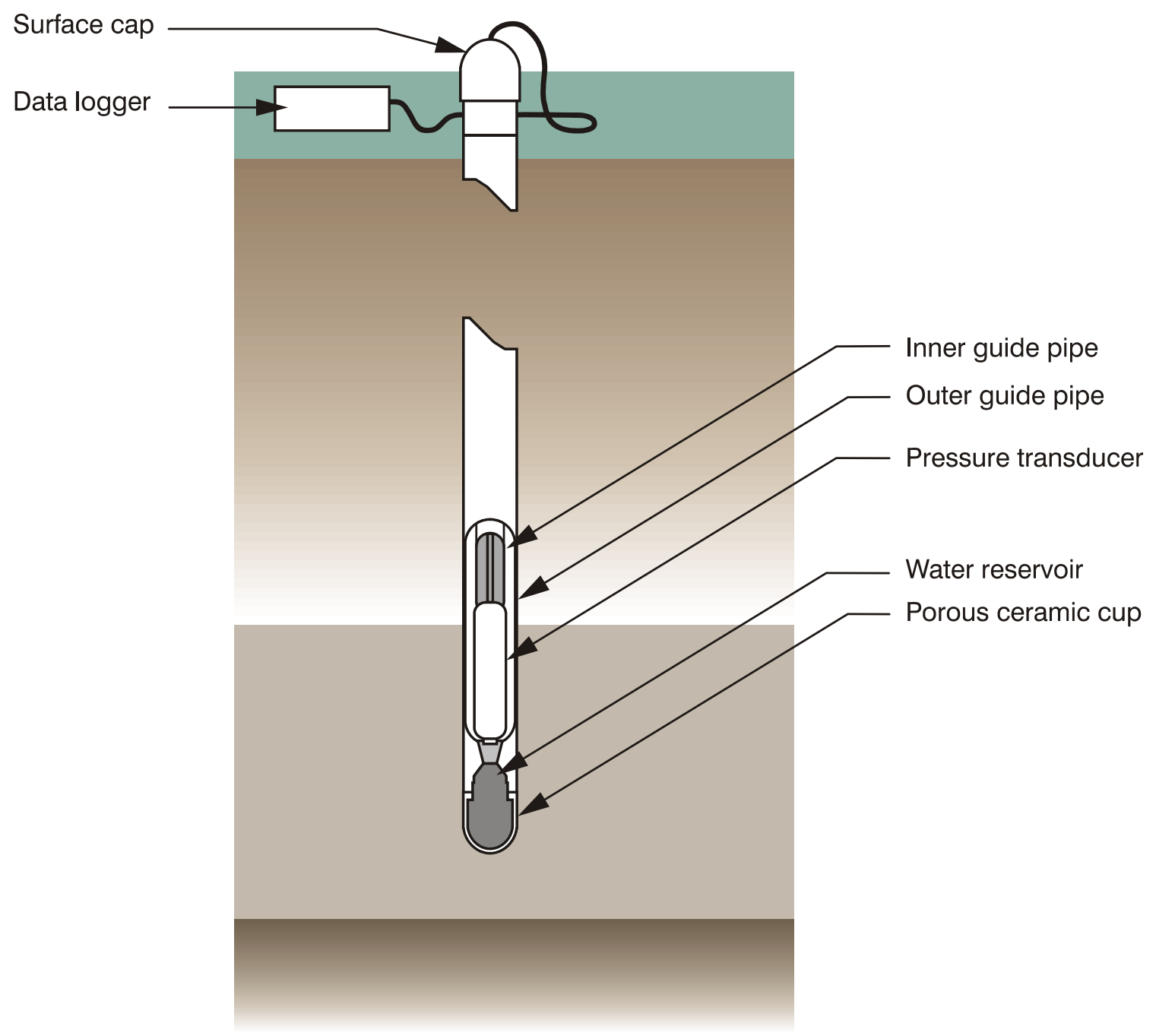

G07-1760-72

Figure E-53. Advanced tensiometer.

\section{E-21.1 Long-Term Monitoring}

Long-term monitoring entails using the existing monitoring organization, sampling and reporting procedures, and monitoring equipment present at RWMC to observe contaminant migration beneath the surface. The timeframe for long-term monitoring would be 100 years. Long-term monitoring does not include ICs, waste remediation, or additional monitoring equipment. Figure E-54 provides a preconceptual process diagram that overviews implementation of this module and was created for cost-estimation purposes. Key tasks identified in Figure E-54 are discussed in the following paragraphs. 


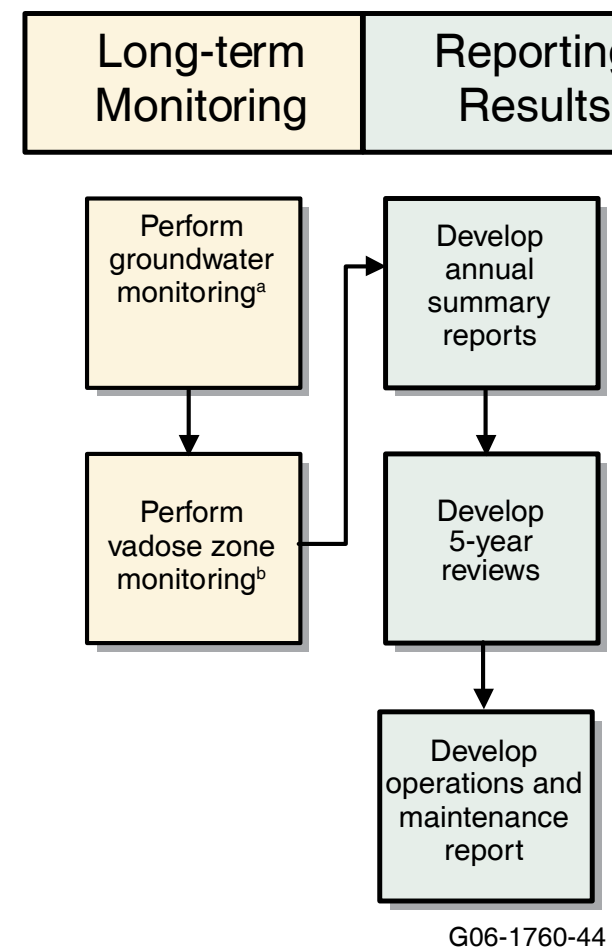

a. Monitoring for contaminants in the aquifer. b. Monitoring for soil moisture, soil gas, soil water potential, and contaminants within the soil water.

Figure E-54. Preconceptual process flow diagram for Subsurface Disposal Area monitoring only.

Long-term groundwater monitoring would consist of 21 monitoring wells, with a maximum depth screened interval of $183 \mathrm{~m}(600 \mathrm{ft})$. Groundwater would be monitored semiannually for the first 5 years and annually for the next 95 years. Four quality assurance or quality control samples would be collected per event. The primary objective for groundwater monitoring and analysis is to determine whether waste buried in the SDA is impacting the Snake River Plain Aquifer.

One hundred lysimeters would be monitored annually in the late spring for 100 years. Thirty-five percent of the lysimeters are assumed to yield adequate sample volume for analysis, and one additional quality assurance or quality control sample would be available. Samples would be prioritized for the same analytes as groundwater monitoring. The objective would be to determine whether contaminants have migrated from the waste zone of the SDA to surrounding soil and perched water layers and to collect data on the spatial extent of contamination.

Twenty vapor ports would be monitored quarterly for 5 years and annually for the next 95 years. Vapor port samples would be analyzed for C-14 and tritium. Volatile organic compound monitoring would be sampled and analyzed through the OCVZ system. Carbon-14 in the SDA results primarily from disposal of activated metal, including beryllium reflector blocks. ${ }^{\mathrm{b}}$ Carbon-14 and tritium monitoring would be used to monitor effectiveness of the non-time-critical removal action performed in the summer of 2004 to encapsulate beryllium reflectors in wax-based grout (Lopez et al. 2005). Also, because tritium is a mobile contaminant that often co-occurs with activation products that are of concern, tritium monitoring can provide trend detection and early warning of migrating contaminants.

b. Beryllium reflector blocks are estimated to contain $90 \%$ of mobile C-14 buried in the SDA. Tritium also is released from irradiated beryllium, by corrosion, as gas or water vapor into the surrounding soil. 
Local surface water infiltration would be monitored using 50 advanced tensiometers. The advanced tensiometers would be connected to continuous data loggers. Resulting data would be evaluated quarterly and reported annually. These data would be used to identify moisture infiltration into the soil that may cause contaminant leaching and to determine movement of water and possible transport of contaminants in the subsurface.

\section{E-21.2 Reporting Results}

Four major media would be sampled and analyzed at different frequencies. These results would be reported in an annual data report that would present and summarize data for each media sampled. This data report would be prepared annually for the first 5 years and then would be evaluated to determine the reporting frequency after the initial 5-year period. An annual review of these data, including techniques, analytes, and data interpretation, would be held after review of the annual report.

Five-year reviews, which would mimic the annual review, would be held subsequent to the initial 5-year period. These 5-year reviews would take place until the end of the 100-year monitoring period. At the end of the 100-year monitoring period, a final operations and maintenance report would be prepared, documenting effectiveness of the remedial action and listing recommendations on further monitoring requirements.

\section{E-22. REFERENCES}

40 CFR 300, 2006, "National Oil and Hazardous Substances Pollution Contingency Plan," Code of Federal Regulations, Office of the Federal Register.

42 USC $\S 9601$ et seq., 1980, "Comprehensive Environmental Response, Compensation and Liability Act of 1980 (CERCLA/Superfund)," United States Code.

Bryan, Jeffrey D., 2005, "Preliminary Evaluation of Buried Waste Inventory in Waste Area Group 7 Exhumation Areas,” EDF-5978, Rev. 1, Idaho National Laboratory, Idaho Cleanup Project.

Cram, Al, 2004, “OU 7-13/14 In Situ Grouting Project Grout Delivery System,” EDF-5102, Rev. 0, Idaho National Engineering and Environmental Laboratory, Idaho Completion Project.

DOE-CBFO, 2005, Contact-Handled Transuranic Waste Acceptance Criteria for the Waste Isolation Pilot Plant, DOE/WIPP-02-3122, Rev. 3, U.S. Department of Energy Carlsbad Field Office.

EPA, 2000, A Guide to Developing and Documenting Cost Estimates During the Feasibility Study, EPA 540-R-00-002 OSWER 9355.0-75, U.S. Environmental Protection Agency, Office of Emergency and Remedial Response; U.S. Army Corps of Engineers.

Holdren, K. Jean and Barbara J. Broomfield, 2004, Second Addendum to the Work Plan for the OU 7-13/14 Waste Area Group 7 Comprehensive Remedial Investigation/Feasibility Study, DOE/ID-11039, Rev. 0, U.S. Department of Energy Idaho Operations Office.

Holdren, K. Jean, Bruce H. Becker, Nancy L. Hampton, L. Don Koeppen, Swen O. Magnuson, T. J. Meyer, Gail L. Olson, and A. Jeffrey Sondrup, 2002, Ancillary Basis for Risk Analysis of the Subsurface Disposal Area, INEEL/EXT-02-01125, Idaho National Engineering and Environmental Laboratory. 
ICP, 2005, Field Sampling Plan for Aquifer Groundwater Monitoring of OU 7-14/14, INEEL/EXT-2000-00029, Rev. 3, Idaho National Laboratory, Idaho Cleanup Project.

Koeppen, L. Don, Alva M. Parsons, A. Jeffrey Sondrup, Paul D. Ritter, and Gail L. Olson, 2004, Fiscal Year 2003 Environmental Monitoring Report for the Radioactive Waste Management Complex, ICP/EXT-04-00259, Rev. 1, Idaho National Engineering and Environmental Laboratory, Idaho Completion Project.

Koeppen, L. Don, Gail L. Olson, Alva M. Parsons, Mitch A. Plummer, Paul D. Ritter, and A. Jeffrey Sondrup, 2005, Fiscal Year 2004 Operable Unit 7-13/14 Environmental Monitoring Report for the Radioactive Waste Management Complex, ICP/EXT-05-00795, Idaho National Laboratory, Idaho Cleanup Project.

Lopez, S. L., William H. Landman, Donald E. Sebo, and Vivian G. Schultz, 2005, Summary Report for the OU 7-13/14 Early Actions Beryllium Encapsulation Project, ICP/EXT-04-00646, Rev. 1, Idaho National Engineering and Environmental Laboratory, Idaho Completion Project.

Mattson, Earl, Mark Ankeny, Steve Dwyer, Nancy Hampton, Gretchen Matthern, Brenda Pace, Alva Parsons, Mitch Plummer, Steve Reese, and Jody Waugh, 2004, Preliminary Design for an Engineered Surface Barrier at the Subsurface Disposal Area, ICP/EXT-04-00216, Rev. 0, Idaho National Engineering and Environmental Laboratory, Idaho Completion Project.

NMED, 2004, Hazardous Waste Facility Permit Issued to Waste Isolation Pilot Plant, Attachment B, Waste Analysis Plans, EPA No. NM4890139088, New Mexico Environment Department, http://www.wipp.energy.gov/library/rcrapermit/rcrapermit.htm, Web page visited January 26, 2007.

Olson, Gail L., L. Don Koeppen, Alva M. Parsons, Paul D. Ritter, and A. Jeffrey Sondrup, 2003, FY 2002 Environmental Monitoring Report for the Radioactive Waste Management Complex, INEEL/EXT-03-00055, Rev. 0, Idaho National Engineering and Environmental Laboratory.

Raivo, Brian D., 2004, "OU 7-13/14 In Situ Grouting Project Hydraulic Excavator and Drill-Injection Rig,” EDF-5153, Rev. 0, Idaho National Engineering and Environmental Laboratory, Idaho Completion Project.

Richins, W. D. and C. J. Hurst, 2004, “Assessment of Dynamic Soil Compaction at SDA,” EDF-4909, Rev. 0, Idaho National Engineering and Environmental Laboratory, Idaho Completion Project.

Stephens, David L., 2004, “OU 7-13/14 In Situ Grouting Project Foundation Grouting Study,” EDF-5028, Rev. 0, Idaho National Engineering and Environmental Laboratory, Idaho Completion Project.

TerraSystems, 2006, TerraSystems Website, Savannah River Site, Terra Systems, URL: http://www.terrasystems-inc.com/dcpn.htm/, Web page visited January 26, 2007.

Thompson, Hugh L. Jr., John A. Auxier, James H. Clarke, Michael D. Coburn, and B. John Garrick, 2000, Independent Technical Review of Proposed Drilling Activities for Operable Unit 7-10 Staged Interaction (Alternative Pit 9 Project), INEEL/EXT-2000-00185, EDF-ER-143, Idaho National Engineering and Environmental Laboratory. 
WIPP, 2005a, TRUPACT-II Safety Analysis Report, Rev. 21, URL: http://www.wipp.energy.gov/library/CHsar/Documents/TRUPACT-II\%20SAR.pdf, Web page visited January 26, 2007.

WIPP, 2005b, CH-TRAMPAC, Rev. 2, URL: http://www.wipp.energy.gov/library/rhdsa/CHsar/Documents/CH-TRAMPAC.pdf, Web page visited January 15, 2007. 
E-102 


\section{Appendix F}

Module Cost Estimates

General Information 
F-2 


\section{CONTENTS}

ACRONYMS

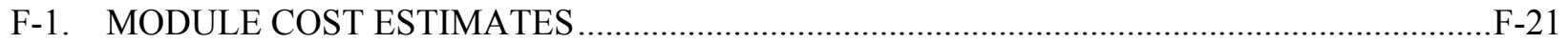

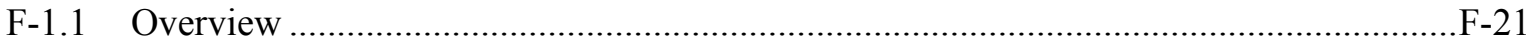

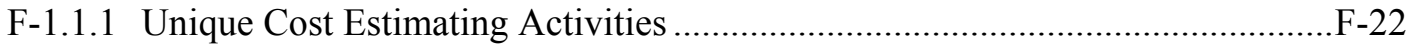

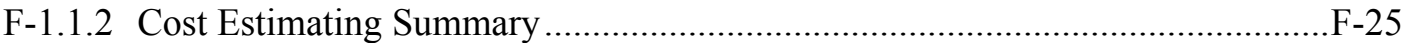

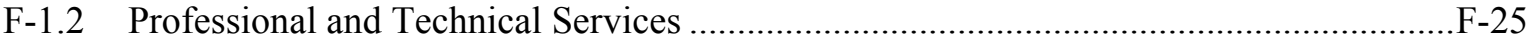

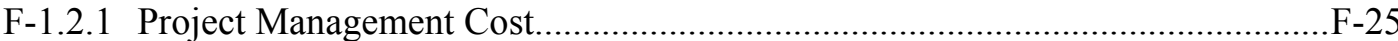

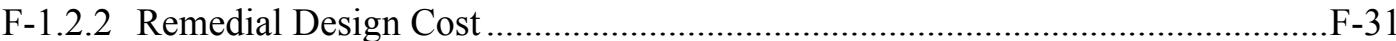

F-1.2.3 Construction Management Cost ................................................................F-31

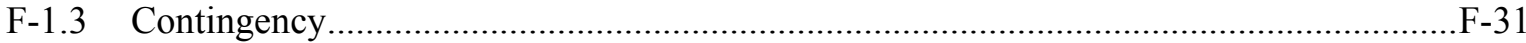

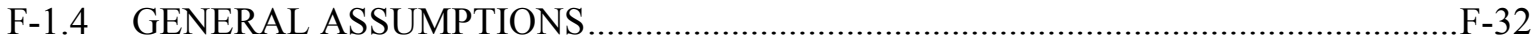

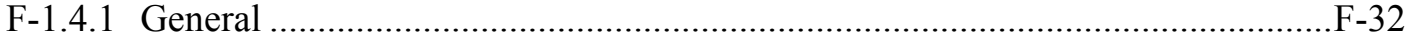

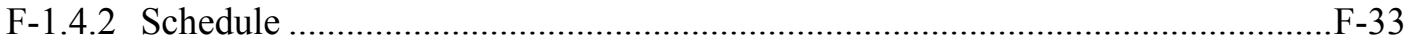

F-1.4.3 Mobilization and Demobilization ............................................................

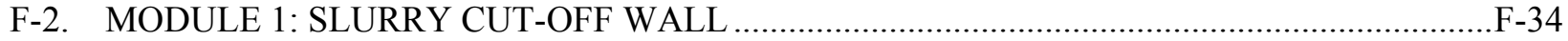

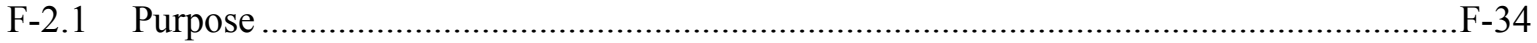

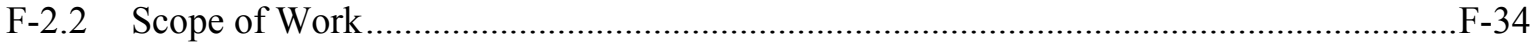

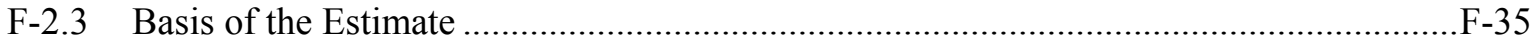

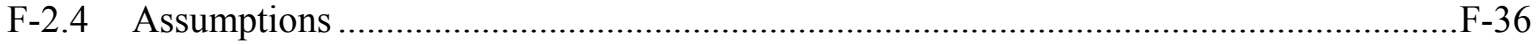

F-2.5 Contingency Guideline Implementation...................................................................

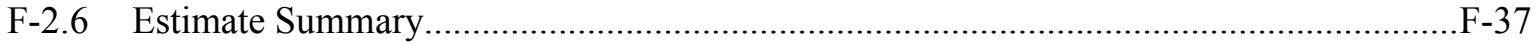

F-2.7 Other Comments or Concerns Specific to the Estimate ..................................................

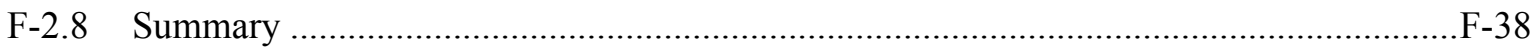

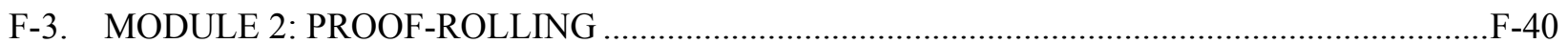

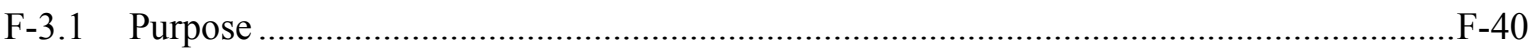

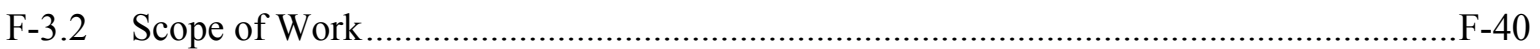

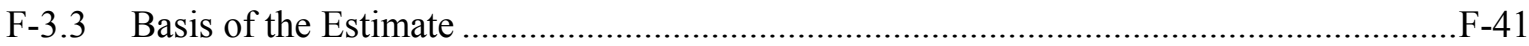

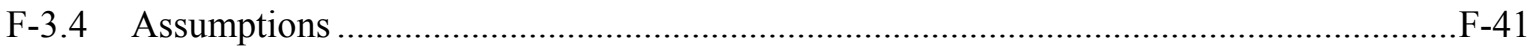


F-3.5 Contingency Guideline Implementation..............................................................F-43

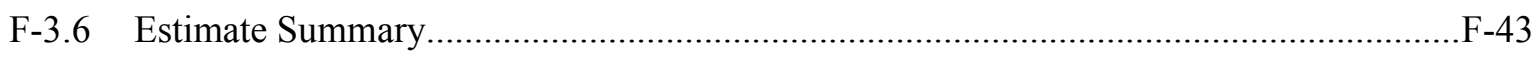

F-3.7 Other Comments or Concerns Specific to the Estimate ............................................... -43

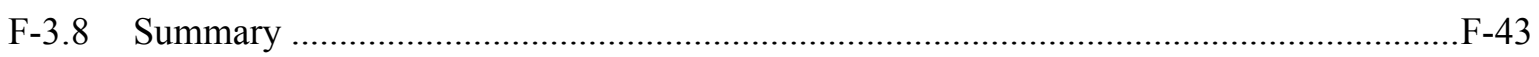

F-4. MODULE 3: EVAPOTRANSPIRATION CAP ….....................................................................

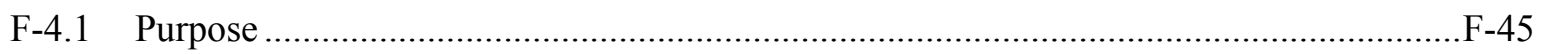

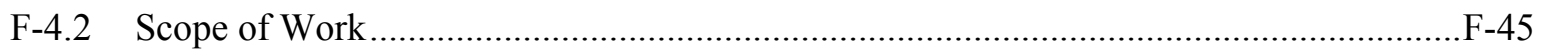

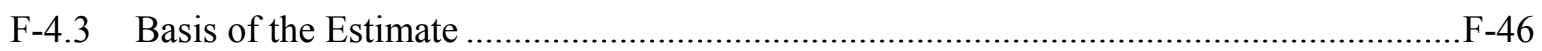

F-4.4 Assumptions ................................................................................................... 48

F-4.5 Contingency Guideline Implementation................................................................. -57

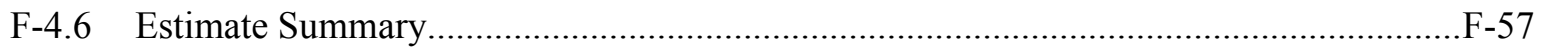

F-4.7 Other Comments or Concerns Specific to the Estimate ...............................................F-57

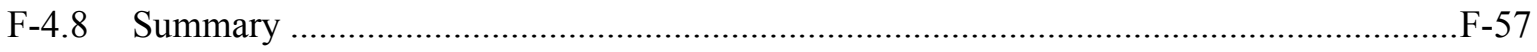

F-5. MODULE 4: SIMPLIFIED EVAPOTRANSPIRATION SURFACE BARRIER WITH NO BIOINTRUSION AND GAS VENT LAYER …..............................................................6-61

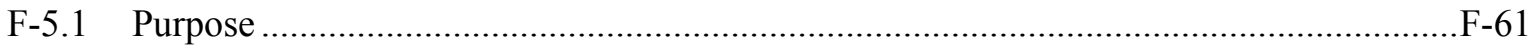

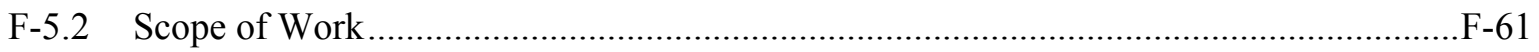

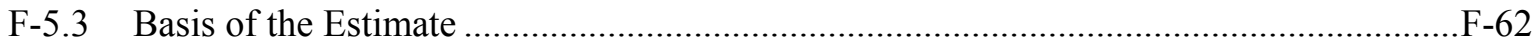

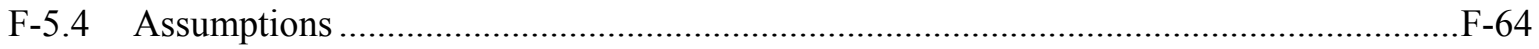

F-5.5 Contingency Guideline Implementation...................................................................

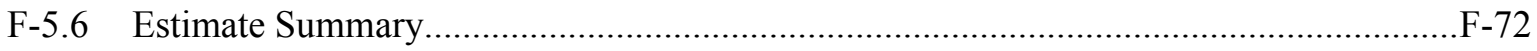

F-5.7 Other Comments or Concerns Specific to the Estimate …...........................................72

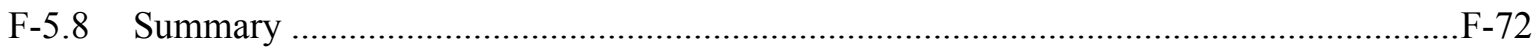

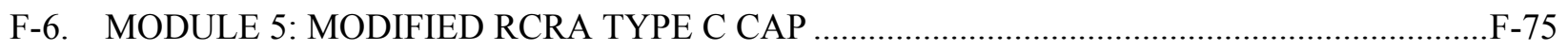

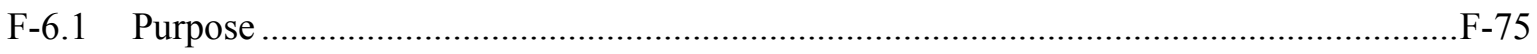

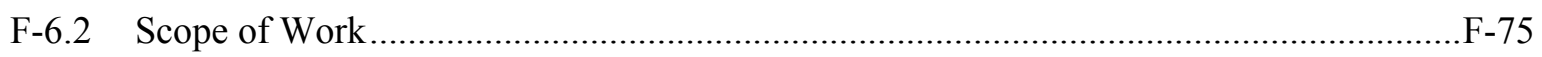

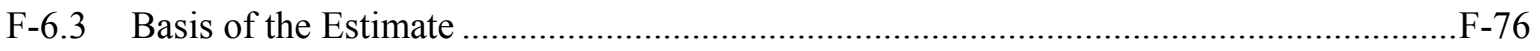




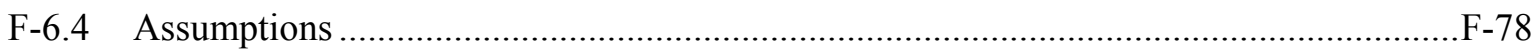

F-6.5 Contingency Guideline Implementation............................................................. -85

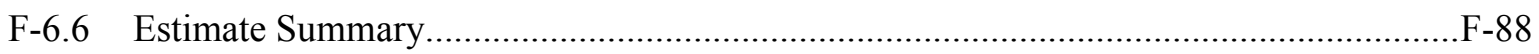

F-6.7 Other Comments or Concerns Specific to the Estimate …........................................... -8 -8

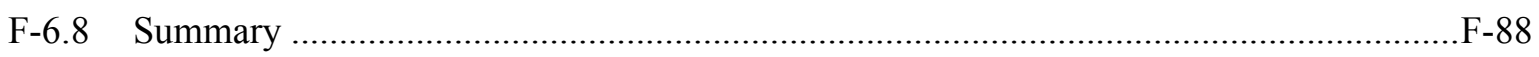

F-7. MODULE 6: GAS VENT LAYER EXTRACTION PIPE ….....................................................

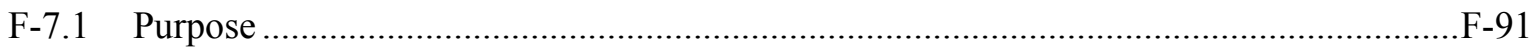

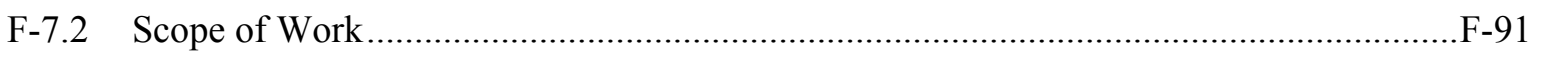

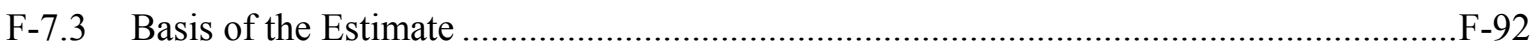

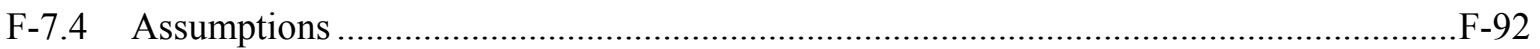

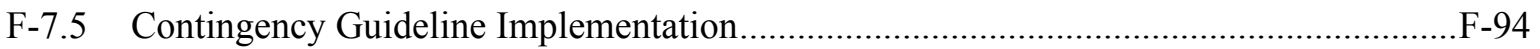

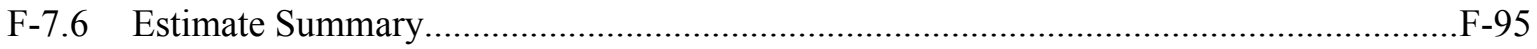

F-7.7 Other Comments or Concerns Specific to the Estimate ...............................................95

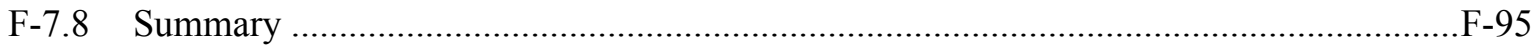

F-8. MODULE 7: SHALLOW GAS EXTRACTION WELL .............................................................98

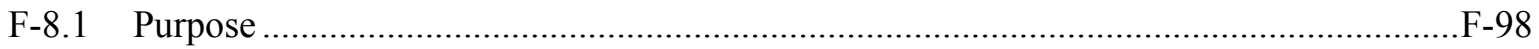

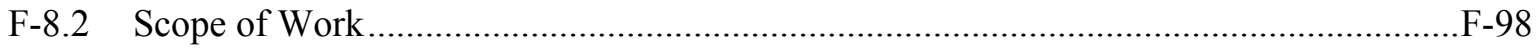

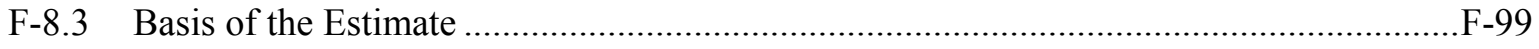

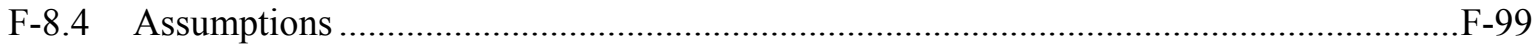

F-8.5 Contingency Guideline Implementation ...........................................................F-102

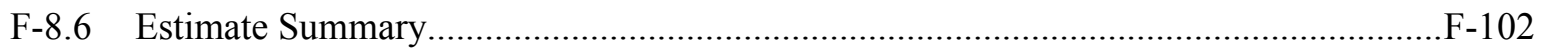

F-8.7 Other Comments or Concerns Specific to the Estimate …........................................F-102

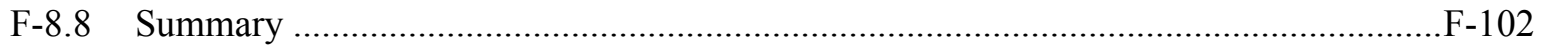

F-9. MODULE 8: DYNAMIC COMPACTION OF THE SUBSURFACE DISPOSAL

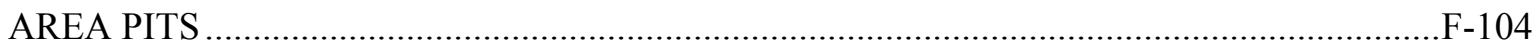

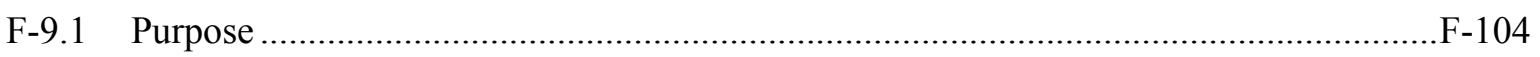

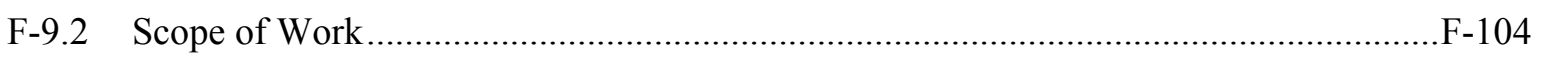




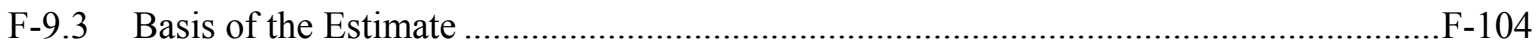

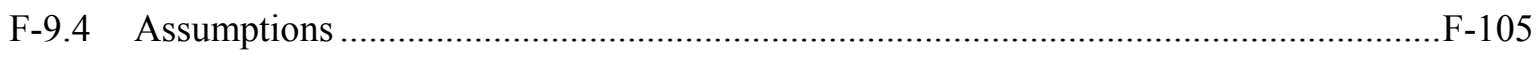

F-9.5 Contingency Guideline Implementation...........................................................F-10

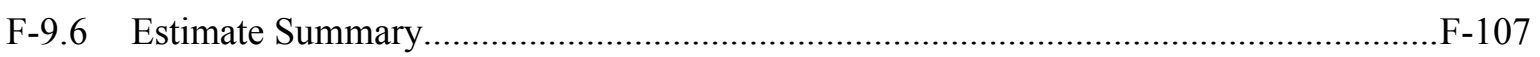

F-9.7 Other Comments or Concerns Specific to the Estimate …............................................

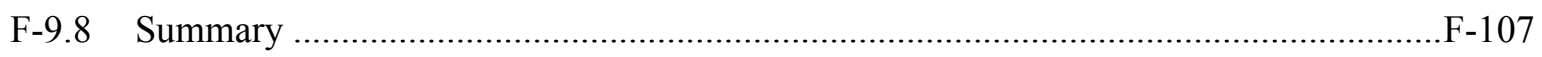

F-10. MODULE 9: DYNAMIC COMPACTION OF PAD A.............................................................

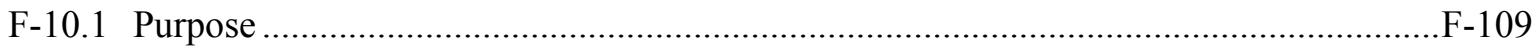

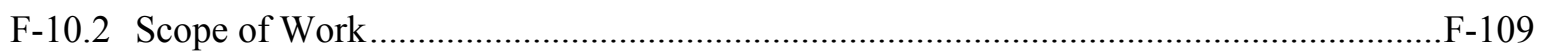

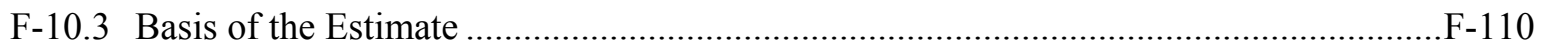

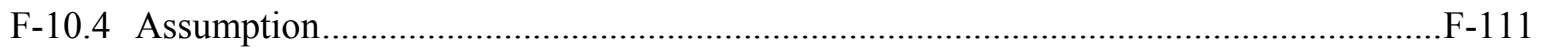

F-10.5 Contingency Guideline Implementation..................................................................

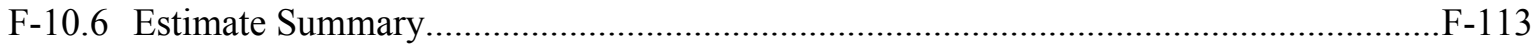

F-10.7 Other Comments or Concerns Specific to the Estimate …........................................... -113

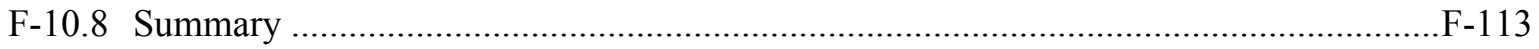

F-11. MODULE 10: FOUNDATION GROUTING …................................................................

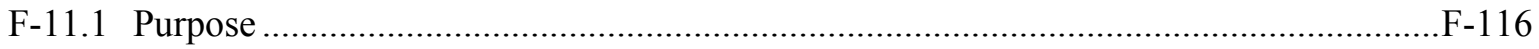

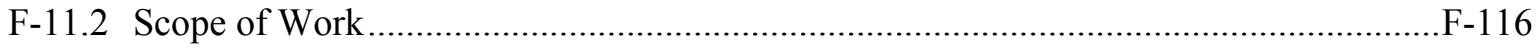

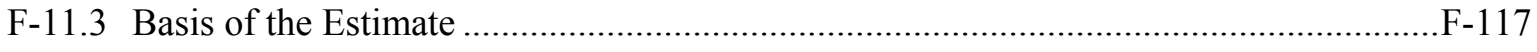

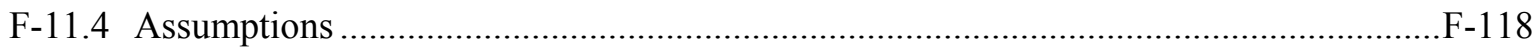

F-11.5 Contingency Guideline Implementation...........................................................F-119

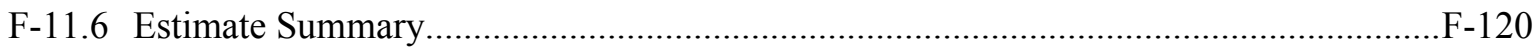

F-11.7 Other Comments or Concerns Specific to the Estimate ….......................................F-120

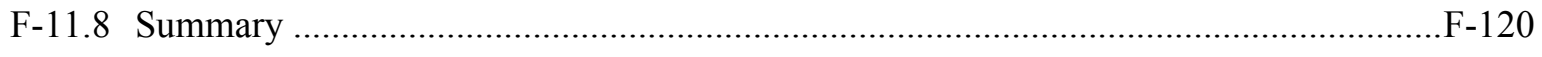

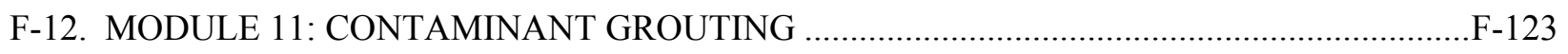

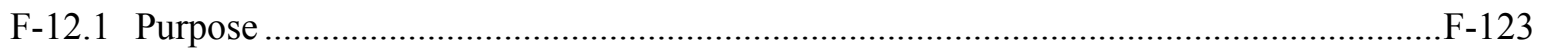




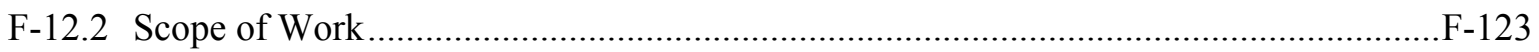

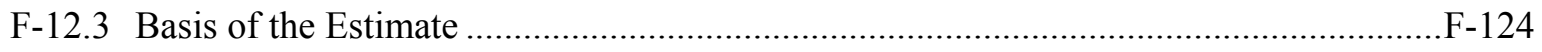

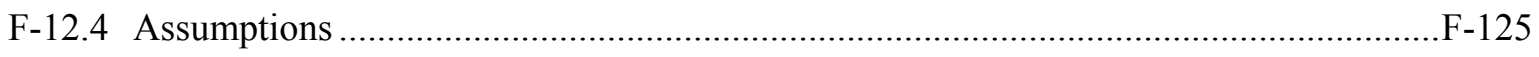

F-12.5 Contingency Guideline Implementation............................................................

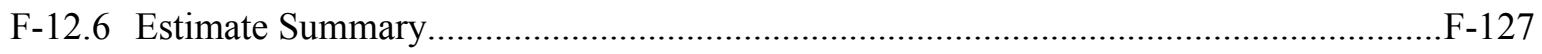

F-12.7 Other Comments or Concerns Specific to the Estimate …........................................F-127

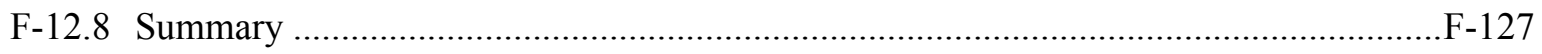

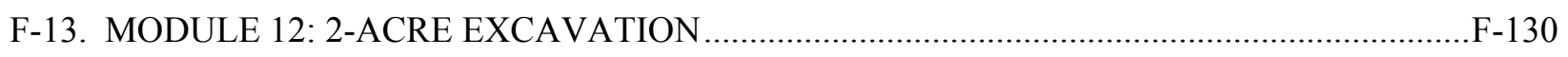

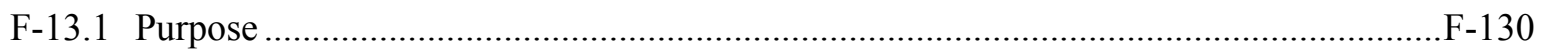

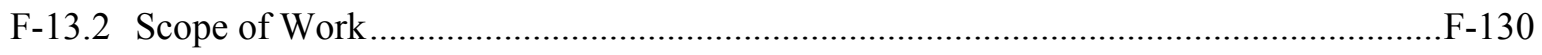

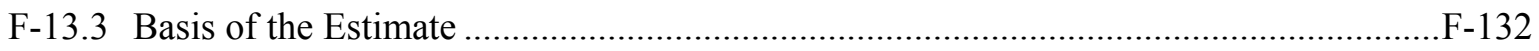

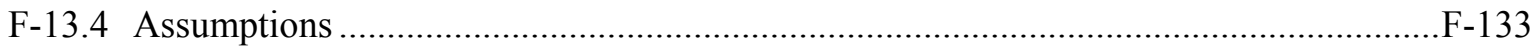

F-13.5 Contingency Guideline Implementation...........................................................F-135

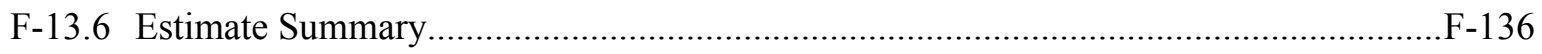

F-13.7 Other Comments or Concerns Specific to the Estimate …........................................F-136

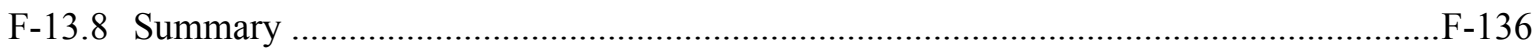

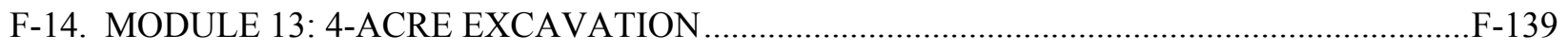

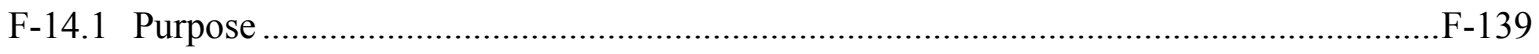

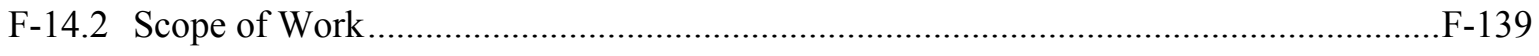

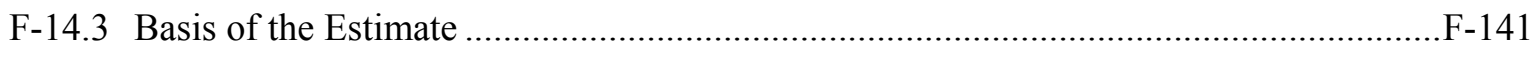

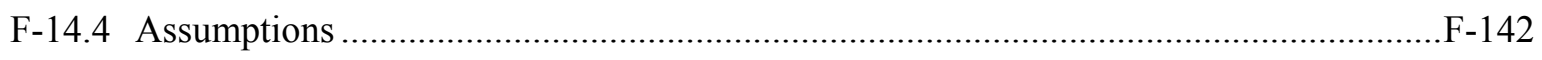

F-14.5 Contingency Guideline Implementation.............................................................

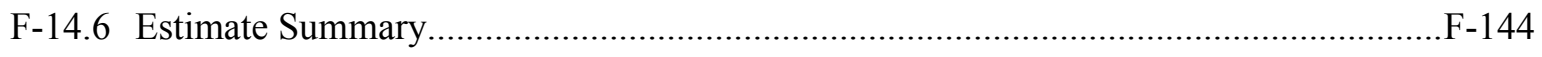

F-14.7 Other Comments or Concerns Specific to the Estimate …........................................F-144

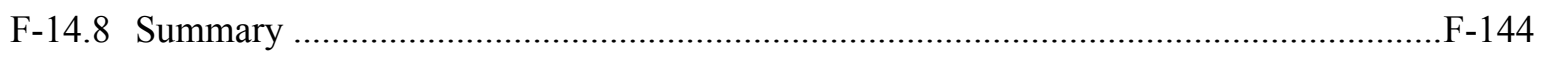




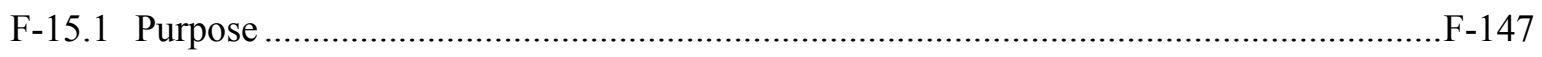

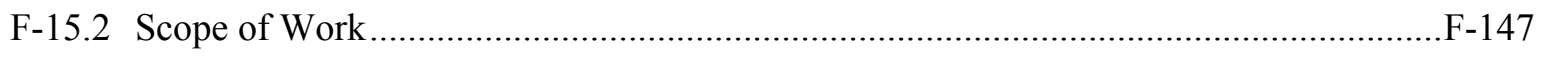

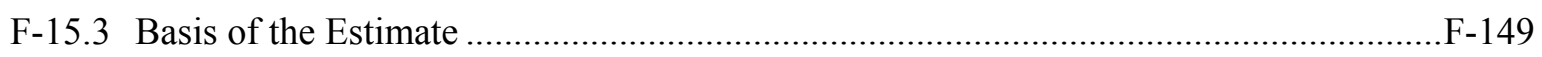

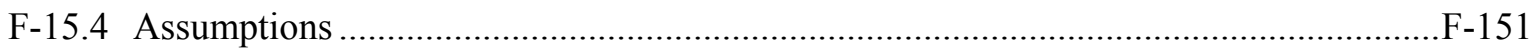

F-15.5 Contingency Guideline Implementation..............................................................

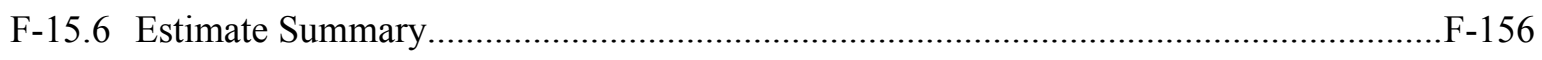

F-15.7 Other Comments or Concerns Specific to the Estimate ….......................................F-156

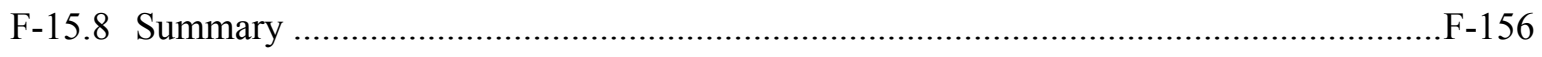

F-16. MODULE 15: PAD A REMOVAL WITHOUT TREATMENT AND SHIPPED TO

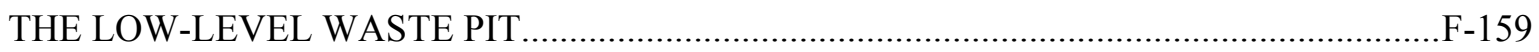

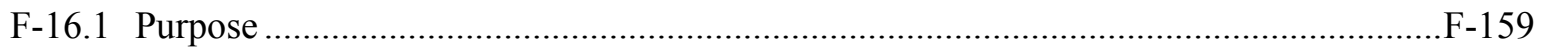

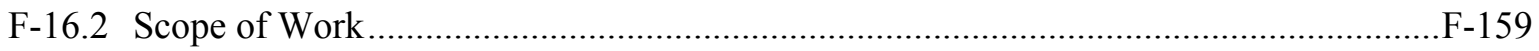

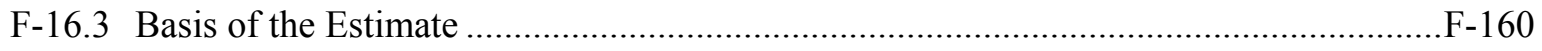

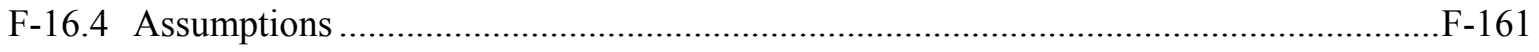

F-16.5 Contingency Guideline Implementation...........................................................

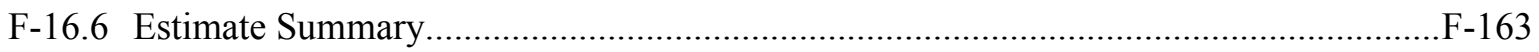

F-16.7 Other Comments or Concerns Specific to the Estimate …...........................................163

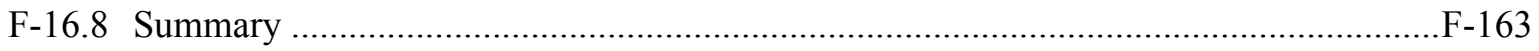

F-17. MODULE 16: PAD A REMOVED AND SHIPPED TO ON-IDAHO NATIONAL LABORATORY SITE FACILITY FOR TREATMENT AND DISPOSAL ...............................167

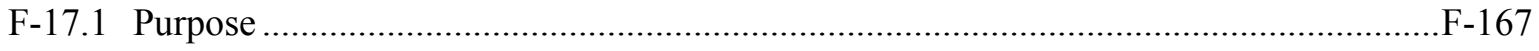

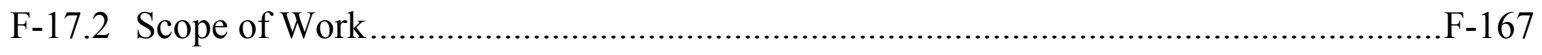

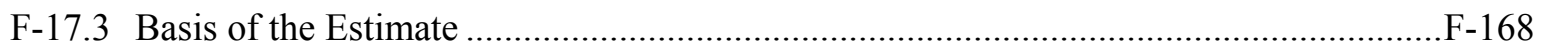

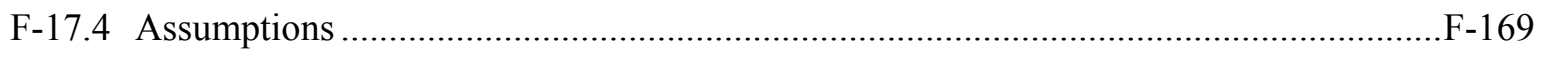

F-17.5 Contingency Guideline Implementation .............................................................171

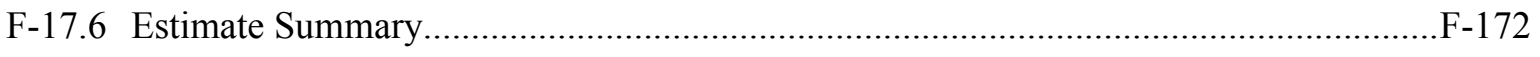


F-17.7 Other Comments or Concerns Specific to the Estimate

F-17.8 Summary

F-18. MODULE 17: PAD A REMOVED AND SHIPPED TO OFF-IDAHO NATIONAL LABORATORY SITE FACILITY FOR TREATMENT AND DISPOSAL ..............................F-175

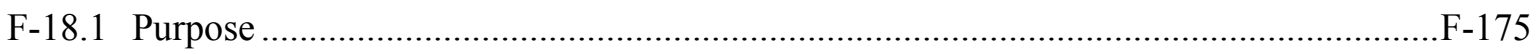

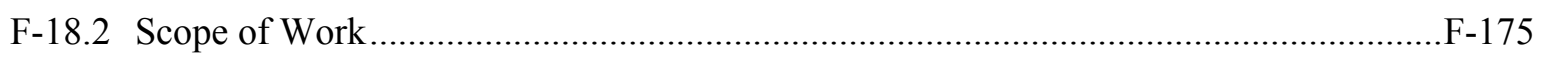

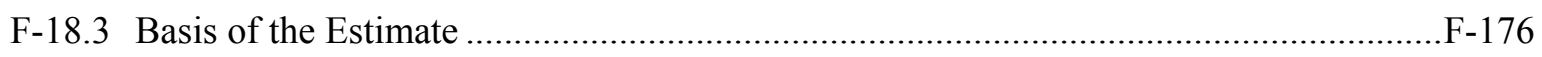

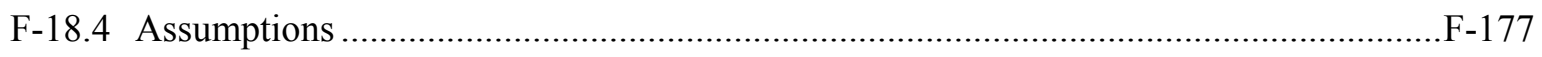

F-18.5 Contingency Guideline Implementation............................................................F-179

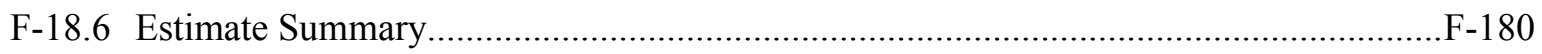

F-18.7 Other Comments or Concerns Specific to the Estimate ….......................................... 180

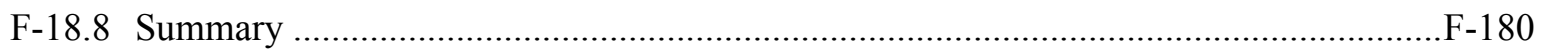

F-19. MODULE 18: PAD A REMOVED WITH TREATMENT AND SHIPPED TO

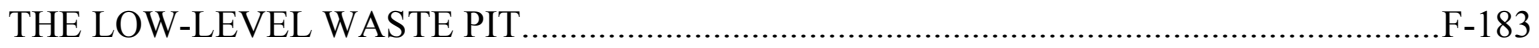

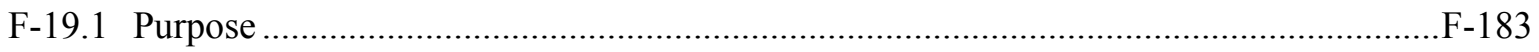

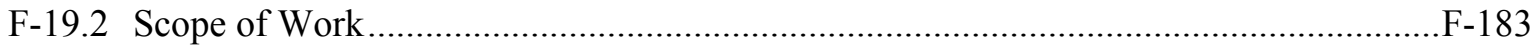

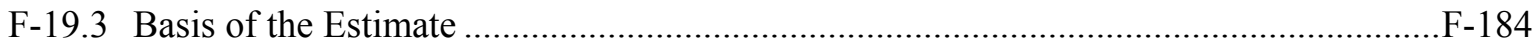

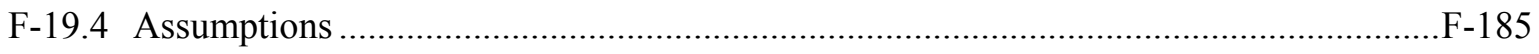

F-19.5 Contingency Guideline Implementation..............................................................187

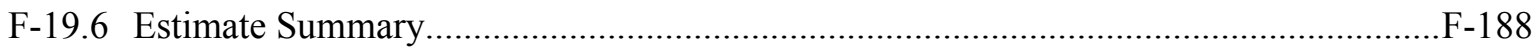

F-19.7 Other Comments or Concerns Specific to the Estimate ….......................................F-188

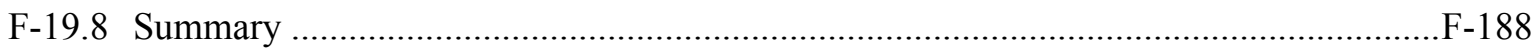

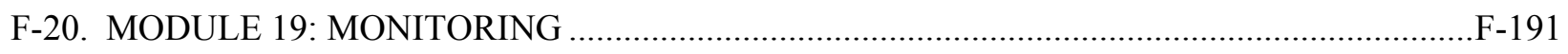

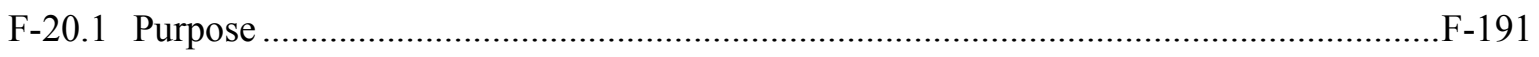

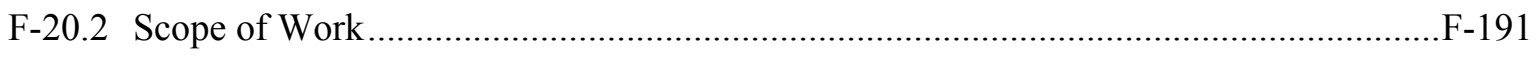

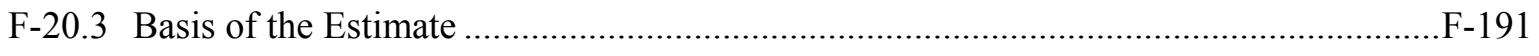

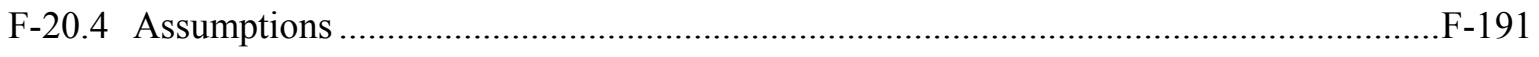


F-20.5 Contingency Guideline Implementation.................................................................

F-20.6 Estimate Summary...........................................................................................F-194

F-20.7 Other Comments or Concerns Specific to the Estimate ….........................................F-194

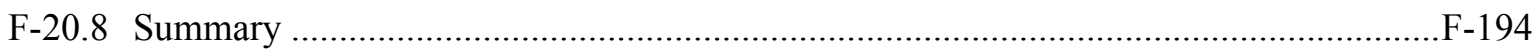

F-21. MODULE 20A: ORGANIC CONTAMINATION IN THE VADOSE ZONE PROJECT 5-YEAR OPERATIONS AND MONITORING .....................................................................F-197

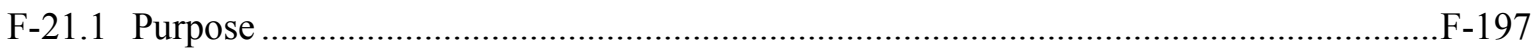

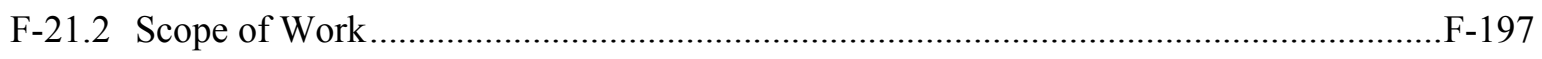

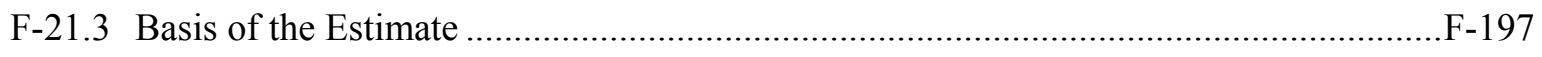

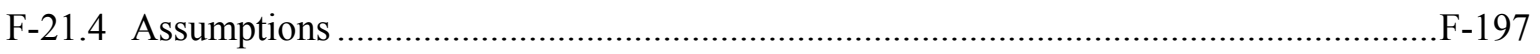

F-21.5 Contingency Guideline Implementation...............................................................F-199

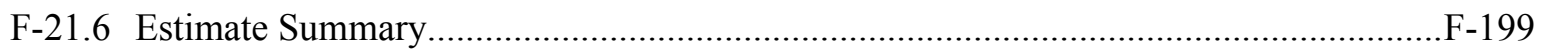

F-21.7 Other Comments or Concerns Specific to the Estimate .................................................199

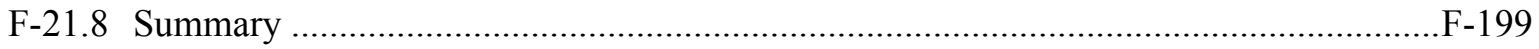

F-22. MODULE 20B: ORGANIC CONTAMINATION IN THE VADOSE ZONE PROJECT 20-YEAR TREATMENT UNIT REPLACEMENT …..............................................................2-201

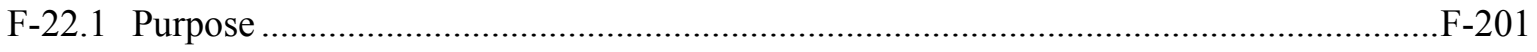

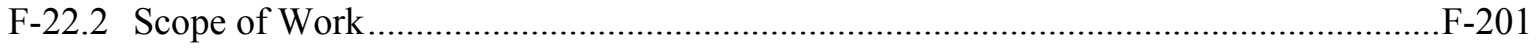

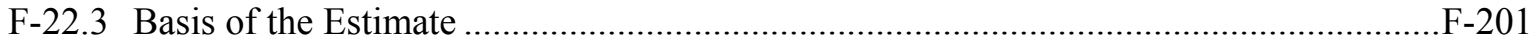

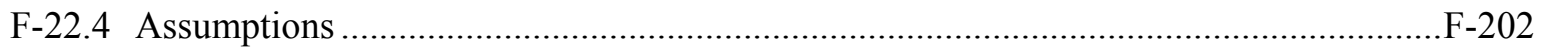

F-22.5 Contingency Guideline Implementation.................................................................

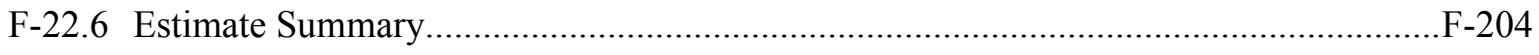

F-22.7 Other Comments or Concerns Specific to the Estimate …........................................F-204

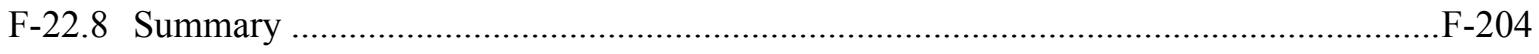

F-23. MODULE 20C: ORGANIC CONTAMINATION IN THE VADOSE ZONE PROJECT

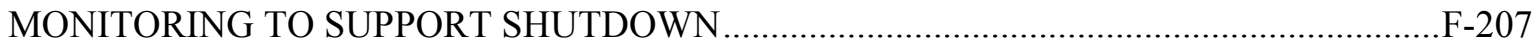

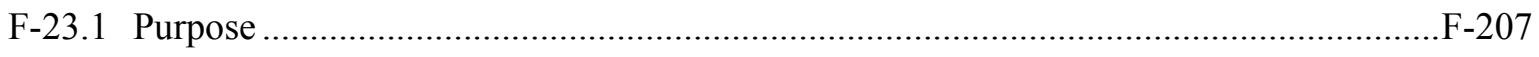

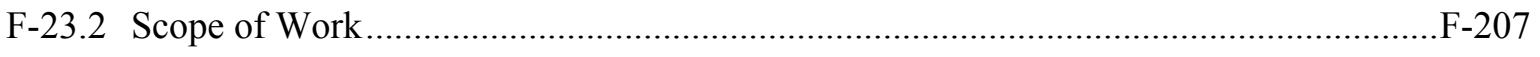


F-23.3 Basis of the Estimate

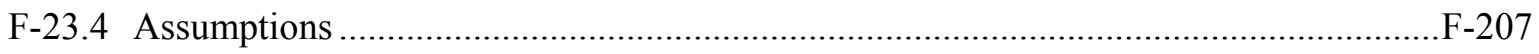

F-23.5 Contingency Guideline Implementation............................................................F-209

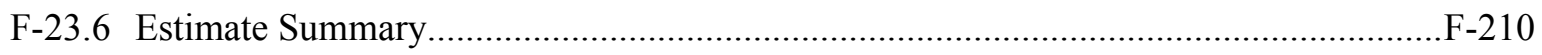

F-23.7 Other Comments or Concerns Specific to the Estimate …........................................ -210

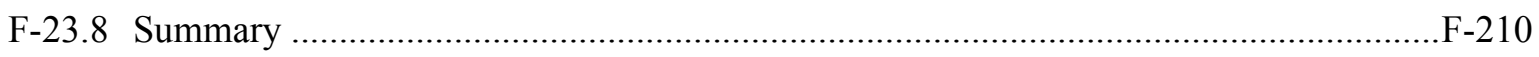

F-24. PERCENTAGES FOR MODULE TECHNICAL SERVICES AND MODULE

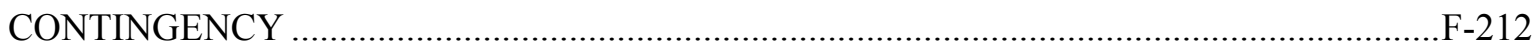

F-25. ALTERNATIVE NET PRESENT VALUE COST ANALYSIS BY MODULE .......................F-219

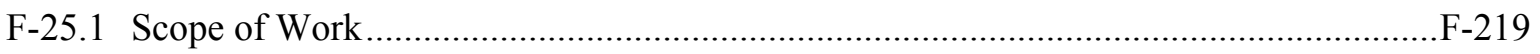

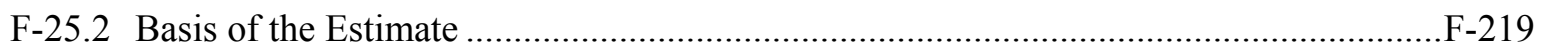

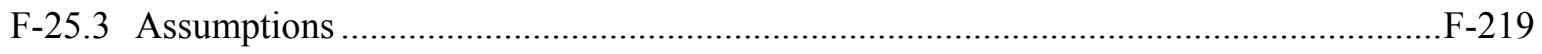

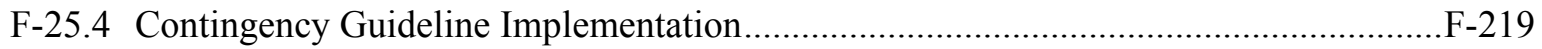

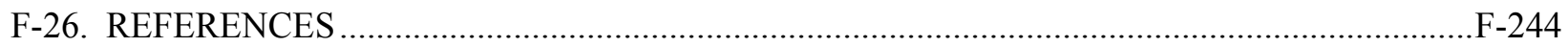

\section{FIGURES}

F-1. Module 1 design and construction schedule for slurry cut-off wall..................................... F-36

F-2. Module 2 design and construction schedule for preloading compaction .............................. F-42

F-3. Module 3 design, construction, and surveillance schedule for evapotranspiration

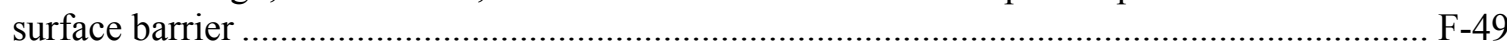

F-4. Module 4 design, construction, and surveillance schedule for simplified evapotranspiration surface barrier with no biointrusion gas vent layer .............................................................. F-65

F-5. Module 5 design, construction, and surveillance schedule for a modified RCRA Type C

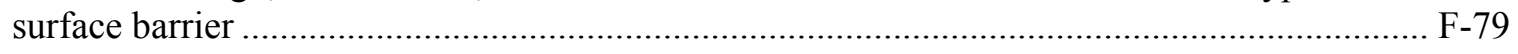

F-6. Module 6 design, construction, and surveillance schedule for the active gas vent layer

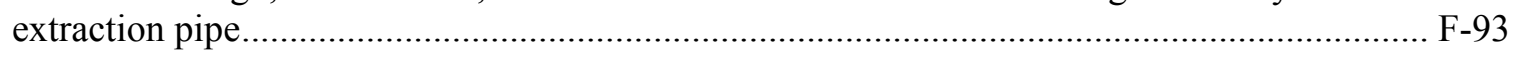

F-7. Module 6 design, construction, and surveillance schedule for the passive gas vent layer

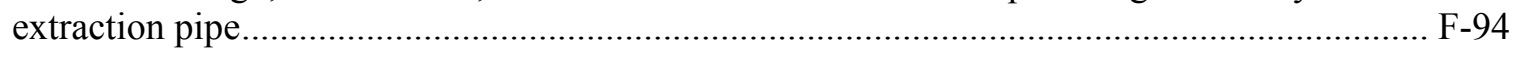

F-8. Module 7 design and construction schedule for installation of the shallow extraction well ... F-101 


\section{FIGURES (continued)}

F-9. Module 8 design and construction schedule for dynamic compaction of the Subsurface Disposal Area pits.... F-106

F-10. Module 9 design and construction schedule for dynamic compaction of Pad A F-111

F-11. Module 10 design and construction schedule for foundation grouting of the Subsurface Disposal Area pits

F-12. Module 11 design and construction schedule for contaminant grouting within the Subsurface Disposal Area pits

F-13. Module 12 design and construction schedule for a 2-acre partial retrieval within the Subsurface Disposal Area

F-14. Module 13 design and construction schedule for 4-acre alternative within the Subsurface Disposal Area.

F-15. Module 14 design and construction schedule for retrieval of the entire Subsurface Disposal Area

F-16. Module 15 design and construction schedule for removing Pad A and transferring it to the LLW Pit without treatment

F-17. Module 16 design and construction schedule for removing Pad A waste and transferring it to the Idaho CERCLA Disposal Facility for treatment and disposal

F-18. Module 17 design and construction schedule for removing Pad A waste and transferring it off-Idaho National Laboratory Site for treatment and disposal

F-19. Module 18 design and construction schedule for removing Pad A waste, treating Pad A waste, and transferring it to the LLW Pit

F-20. Module 19 monitoring only schedule

F-21. Module 20a 5-year Organic Contamination in the Vadose Zone Project operations and maintenance schedule

F-22. Module 20b design and construction schedule for replacement of the Organic Contamination in the Vadose Zone Project treatment unit

F-23. Module 20c operations and maintenance schedule for monitoring the vadose zone following shutdown of the OCVZ Project treatment unit 


\section{TABLES}

F-1. Feasibility study alternative component matrix …............................................................. F-23

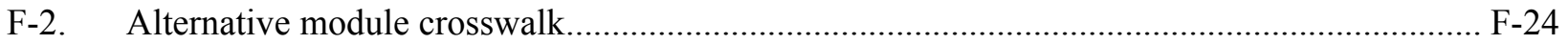

F-3. Cost estimate summaries for Alternatives 1 through 5 of the Operable Unit 7-13/14

Feasibility Study

F-4. Rough order of magnitude allocations of the methodologies used to develop the cost estimate for Module 1

F-5. Capital costs for Module 1: Operable Unit 7-13/14 Feasibility Study-Slurry Cut-Off Wall, Project Number: 5992-0.

F-6. Rough order of magnitude allocations of the methodologies used to develop the cost estimate for Module 2

F-7. Capital costs for Module 2: Operable Unit 7-13/14 Feasibility Study—Preloading

Compaction, Project Number: 5992-P F-44

F-8. Distances and sources of borrow materials for the cap or cover system for Module 3 ............ F-52

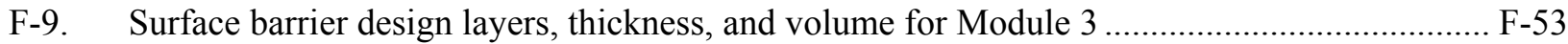

F-10. Module 3 estimated long-term monitoring program ....................................................... F-55

F-11. Module 3 estimated long-term surveillance program …...................................................... F-55

F-12. Module 3 estimated analytical requirements .................................................................... F-56

F-13. Rough order of magnitude allocations of the methodologies used to develop the cost estimate for Module 3

F-14. Capital costs for Module 3: Operable Unit 7-13/14 Feasibility Study—Evapotranspiration Cap, Project Number: 5992.

F-15. Summary operations and maintenance costs for Module 3: Operable Unit 7-13/14

Feasibility Study_Evapotranspiration Cap, Project Number: 5992.

F-16. Summary periodic costs for Module 3: Operable Unit 7-13/14 Feasibility Study-

Evapotranspiration Cap, Project Number: 5992

F-17. Summary total costs for Module 3: Operable Unit 7-13/14 Feasibility Study-

Evapotranspiration Cap, Project Number: 5992

F-18. Module 4 distances and sources of borrow materials for the cap or cover system F-68

F-19. Module 4 surface barrier design layers, thickness, and volume F-68

F-20. Module 4 estimated long-term monitoring program. F-70 


\section{TABLES (continued)}

F-21. Module 4 estimated long-term surveillance program ….................................................... F-70

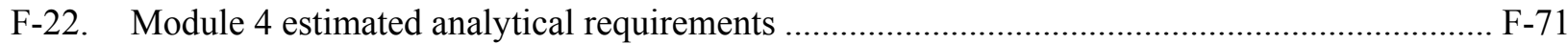

F-23. Rough order of magnitude allocations of the methodologies used to develop the cost

estimate for Module 4

F-24. Capital costs for Module 4: Operable Unit 7-13/14 Feasibility Study—Simplified

Evapotranspiration Surface Barrier with No Biointrusion Gas Vent Layer, Project

Number: 5992-A

F-25. Operational and maintenance costs for Module 4: Operable Unit 7-13/14 Feasibility StudySimplified Evapotranspiration Surface Barrier with No Biointrusion Gas Vent Layer, Project Number: 5992-A

F-26. Periodic costs for Module 4: Operable Unit 7-13/14 Feasibility Study— Simplified

Evapotranspiration Surface Barrier with No Biointrusion Gas Vent Layer,

Project Number: 5992-A

F-27. Total costs for Module 4: Operable Unit 7-13/14 Feasibility Study—Simplified

Evapotranspiration Surface Barrier with No Biointrusion Gas Vent Layer, Project

Number: 5992-A

F-28. Module 5 distances and sources of borrow materials for the cap/cover system ...................... F-82

F-29. Module 5 surface barrier design layers, thickness, and volume ............................................ F-83

F-30. Module 5 estimated long-term monitoring program....................................................... F-86

F-31. Module 5 estimated long-term surveillance program …................................................... F-86

F-32. Module 5 estimated analytical requirements .................................................................... F-87

F-33. Rough order of magnitude allocations of methodologies used to develop the cost estimate for Module 5

F-34. Capital costs for Module 5: Operable Unit 7-13/14 Feasibility Study-RCRA Type C

Cap, Project Number: 5992-B.

F-35. Operational and maintenance costs for Module 5: Operable Unit 7-13/14 Feasibility

Study-RCRA Type C Cap, Project Number: 5992-B...

F-36. Periodic costs for Module 5: Operable Unit 7-13/14 Feasibility Study-RCRA Type C

Cap, Project Number: 5992-B.

F-37. Total costs for Module 5: Operable Unit 7-13/14 Feasibility Study-RCRA Type C Cap, Project Number: 5992-B 


\section{TABLES (continued)}

F-38. Rough order of magnitude allocations of methodologies used to develop the cost estimate for Module 6

F-39. Capital costs for Module 6: Operable Unit 7-13/14 Feasibility Study-Gas Vent Layer Extraction Pipe (Active), Project Number: 5992-C

F-40. Module 6: Operable Unit 7-13/14 Feasibility Study—Gas Vent Layer Extraction Pipe (Passive), Project Number: 5992-C

F-41. Rough order of magnitude allocations of methodologies used to develop the cost estimate for Module 7

F-42. Capital costs for Module 7: Operable Unit 7-13/14 Feasibility Study—Shallow Extraction well, Project Number: 5992-D

F-43. Rough order of magnitude allocations of methodologies used to develop the cost estimate for Module 8

F-44. Capital costs for Module 8: Operable Unit 7-13/14 Feasibility Study-Dynamic Compaction Module Pits, Project Number: 5992-E

F-45. Rough order of magnitude allocations of methodologies used to develop the cost estimate or Module 9

F-46. Capital costs for Module 9: Operable Unit 7-13/14 Feasibility Study—Dynamic Compaction Pad A, Project Number: 5992-Q

F-47. Rough order of magnitude allocations of methodologies used to develop the cost estimate for Module 10

F-48. Capital costs for Module 10: Operable Unit 7-13/14 Feasibility Study-Foundation Grouting, Project Number: 5992-F

F-49. Rough order of magnitude allocations of the methodologies used to develop the cost estimate for Module 11

F-50. Capital costs for Module 11: Operable Unit 7-13/14 Feasibility Study-Contaminant Grouting, Project Number: 5992-G

F-51. Rough order of magnitude allocations of the methodologies used to develop the cost estimate for Module 12

F-52. Capital costs for Module 12: Operable Unit 7-13/14 Feasibility Study-2-Acre Excavation, Project Number: 5992-H

F-53. Rough order of magnitude allocations of the methodologies used to develop the cost estimate for Module 13 


\section{TABLES (continued)}

F-54. Capital costs for Module 13: Operable Unit 7-13/14 Feasibility Study-4-Acre

Excavation, Project Number: 5992-I

F-145

F-55. Rough order of magnitude allocations of the methodologies used to develop the cost estimate for Module 14

F-56. Capital costs for Module 14: Operable Unit 7-13/14 Feasibility Study-Full Excavation, Project Number: 5992-J

F-57. Rough order of magnitude allocations of the methodologies used to develop the cost estimate for Module 15

F-58. Capital costs for Module 15: Operable Unit 7-13/14 Feasibility Study-Pad A Removal without Treatment and Shipped to the Low-Level Waste Pit, Project Number: 5992-K

F-59. Rough order of magnitude allocations of the methodologies used to develop the cost estimate for Module 16

F-60. Capital costs for Module 16-Operable Unit 7-13/14 Feasibility Study-Pad A Removed and Shipped to Idaho CERCLA Disposal Facility for Treatment and Disposal, Project Number: 5992-L

F-61. Rough order of magnitude allocations of the methodologies used to develop the cost estimate for Module 17

F-62. Capital costs for Module 17: Operable Unit 7-13/14 Feasibility Study-Pad A Removed and Shipped Off-Idaho National Laboratory Site for Treatment and Disposal, Project Number: 5992-M

F-63. Rough order of magnitude allocations of the methodologies used to develop the cost estimate for Module 18

F-64. Capital costs for Module 18-Operable Unit 7-13/14 Feasibility Study-Pad A Ex Situ Grouting, Project Number: 5992-N

F-65. Rough order of magnitude allocations of the methodologies used to develop the cost estimate for Module 19

F-66. Capital costs for Module 19: Operable Unit 7-13/14 Feasibility Study-Monitoring, Project Number: 5992-R

F-67. Periodic cost information for Module 19: Operable Unit 7-13/14 Feasibility StudyMonitoring, Project Number: 5992-R

F-68. Total cost information for Module 19: Operable Unit 7-13/14 Feasibility StudyMonitoring, Project Number: 5992-R

F-69. Rough order of magnitude allocations of the methodologies used to develop the cost estimate for Module 20a 


\section{TABLES (continued)}

F-70. Capital costs for Module 20a: Operable Unit 7-13/14 Feasibility Study-Organic Contamination in the Vadose Zone Maintenance and Operations (5 years),

Project Number: 5992-S

F-71. Rough order of magnitude allocations of the methodologies used to develop the cost estimate for Module 20b

F-72. Capital costs for Module 20b: Operable Unit 7-13/14 Feasibility Study-Organic Contamination in the Vadose Zone Maintenance and Operations (Unit Replacement), Project Number: 5992-T

F-73. Module 20c estimated monitoring program ...................................................................... F-209

F-74. Module 20c estimated analytical costs................................................................................. F-209

F-75. Rough order of magnitude allocations of the methodologies used to develop the cost estimate for Module 20c

F-76. Operations and maintenance cost information for Module 20c: Operable Unit 7-13/14 Feasibility Study-Organic Contamination in the Vadose Zone Maintenance and Operations (Shutdown), Project Number: 5992-U 
F-18 


\section{ACRONYMS}

CERCLA Comprehensive Environmental Response, Compensation, and Liability Act

$\mathrm{CM} \quad$ construction management

DC dynamic compaction

DEQ (Idaho) Department of Environmental Quality

EPA U.S. Environmental Protection Agency

ET evapotranspiration

IC institutional control

ICDF Idaho CERCLA Disposal Facility

ICP Idaho Cleanup Project

INL Idaho National Laboratory

ISG in situ grouting

LLW low-level waste

$\mathrm{M} \& \mathrm{O} \quad$ maintenance and operations

MSA management self-assessments

OCVZ Organic Contamination in the Vadose Zone

RCRA Resource Conservation and Recovery Act

ROD $\quad$ record of decision

RTD retrieval, treatment, and disposal

RWMC Radioactive Waste Management Complex

SDA Subsurface Disposal Area

TFR technical and functional requirements

TRU transuranic

VOC volatile organic compound

WAC waste acceptance criteria

WIPP Waste Isolation Pilot Plant 


\section{Appendix F}

\section{Module Cost Estimates General Information}

Appendix F presents current value module-specific cost estimates (see Sections F-2 through F-23), rationale for percentage values chosen to represent technical services and contingency (see Section F-24), and the net present value alternative-specific cost estimates and calculations (see Section F-25).

The term "transuranic" (TRU) in this appendix is loosely applied to waste containing any amount of transuranic radionuclides. Transuranic or TRU in this appendix does not mean that the waste contains a TRU concentration greater than $100 \mathrm{nCi} / \mathrm{g}$.

\section{F-1. MODULE COST ESTIMATES}

\section{F-1.1 Overview}

Five comprehensive remedial alternatives were developed to provide decision-makers with a range of remedial action options for Operable Unit 7-13/14 at the Idaho National Laboratory (INL) Site Radioactive Waste Management Complex (RWMC). Alternative 1 (No Action) evaluates the absence of remedial action to provide a baseline for comparison of other alternatives. Environmental monitoring is the only activity evaluated for this alternative. Alternative 2 (Surface Barrier) evaluates containment as the primary means of source control. Alternative 3 (In Situ Grouting [ISG]) evaluates ISG for immobilization of long-lived radioactive contaminants resulting from INL Site reactor operations. Alternative 4 (Partial Retrieval) evaluates retrieval of a portion of TRU-contaminated waste from described areas within the Subsurface Disposal Area (SDA) at RWMC. Alternative 5 (Full Retrieval) develops a scenario for removing all low-level waste (LLW), TRU waste, and remote-handled waste from the SDA. All alternatives include strategies for integrating Pad A- a unique abovegrade disposal area with a preexisting record of decision (ROD) (DOE-ID 1994) - into the comprehensive remedies. All action alternatives (i.e., this excludes Alternative 1) include a surface barrier to inhibit infiltration and subsequent transport of contaminants to the vadose zone. Additional common elements between action alternatives include methods to manage volatile organic compounds (VOCs) that have been released into the surface barrier or have migrated into the underlying vadose zone.

Table F-1 segments the five alternatives into eight component categories. These eight categories are:

1. Methods for retrieving buried waste and disposing of that waste

2. Actions associated with the unique abovegrade disposal area (i.e., Pad A)

3. Any in situ treatment technologies that are evaluated

4. Foundation preparation activities to mitigate future subsidence

5. Type of surface barrier

6. Methods for removing VOCs that build up beneath the surface barrier

7. 100 years of surveillance, maintenance, and monitoring

8. Alternatives that include institutional controls (ICs). 
For cost-estimating purposes, alternative components listed in Table F-1 are separated into 20 modules. Table F-2 provides a crosswalk between the alternative components listed in Table F-1 and the 20 cost estimating modules. These modules provide a means by which construction activities ${ }^{\mathrm{a}}$ for each alternative component (e.g., cap construction, slurry cut-off wall installation, dynamic compaction, and ISG) can be detailed and estimated. In addition, modularizing the alternative components allows use of identical modules for different alternatives. For example, Alternative 2b (Evapotranspiration [ET] Surface Barrier), Alternative 3 (ISG), and Alternative 4a (4-Acre Partial Retrieval) all use dynamic compaction as a means of stabilizing the SDA before surface barrier placement. Using the modular method, a single dynamic compaction module may be used for all three alternatives. An added bonus to the modular approach is the ability to estimate costs and schedules for alternatives not listed in Table F-1 through an alternate combination of modules.

Sections within this appendix are ordered by increasing module number and labeled in accordance with terminology provided in Table F-2.

\section{F-1.1.1 Unique Cost Estimating Activities}

Each alternative includes 100 years of groundwater and vadose zone monitoring. Alternatives 2 through 5 have an additional surface barrier repair and periodic cost (summary reports and reviews) during this 100-year period. For this reason, a separate cost estimating module for monitoring alone (Module 19) was generated for Alternative 1, and the cost for 100 years of monitoring, surface barrier repair, and periodic cost was added onto each of the surface barrier modules (Modules 3, 4, and 5) included within Alternatives 2 through 5 (see Table F-1).

For Alternatives 2 through 5, the Organic Contamination in the Vadose Zone (OCVZ) Project vapor vacuum extraction with treatment system would operate until concentration based remediation goals are achieved. The time required to meet these remediation goals are dependent on the surface barrier configuration and remedial actions such as waste removal. To minimize the quantity of OCVZ cost estimates and provide flexibility for estimating vapor extraction system durations for alternatives not listed in Table F-1, the OCVZ vapor extraction with treatment system cost is decomposed into three common elements. These elements are:

1. 5-year maintenance and operation cost associated with running and maintaining the treatment units, extracting and analyzing samples, and reporting results. (Module 20a)

2. 20-year unit replacement cost associated with replacement of the OCVZ thermal oxidation treatment units every 20 years. (Module 20b)

3. 1-year monitoring cost associated with monitoring the gas extraction wells for 1 year following shutdown of the treatment units. (Module 20c)

a. Construction activities typically consist of mobilization, site preparation, remediation, and demobilization. 
Table F-1. Feasibility study alternative component matrix.

\begin{tabular}{|c|c|c|c|c|c|c|c|c|c|}
\hline \multicolumn{10}{|c|}{ Components } \\
\hline \multicolumn{2}{|r|}{ Alternative } & \multirow[t]{2}{*}{ Retrieval and Disposal } & \multirow[t]{2}{*}{ Pad A } & \multirow{2}{*}{$\begin{array}{l}\text { In Situ Treatment } \\
\text { NA }\end{array}$} & \multirow{2}{*}{$\begin{array}{r}\text { Foundation } \\
\text { Preparation } \\
\text { NA } \\
\end{array}$} & \multirow[t]{2}{*}{ Surface Barrier } & \multirow{2}{*}{$\begin{array}{l}\begin{array}{c}\text { Volatile Organic Compound } \\
\text { Removal }\end{array} \\
\text { NA }\end{array}$} & \multirow{2}{*}{$\begin{array}{l}\text { Surveillance and } \\
\text { Monitoring } \\
\text { Yes }\end{array}$} & \multirow{2}{*}{$\begin{array}{c}\begin{array}{c}\text { Institutional } \\
\text { Control }\end{array} \\
\text { NA } \\
\end{array}$} \\
\hline 1 & No Action & & & & & & & & \\
\hline $2 \mathrm{a}$ & \multirow[t]{2}{*}{ Surface Barrier } & \multirow[t]{2}{*}{ NA } & $\begin{array}{l}\text { Pad A waste would be left in place } \\
\text { with no steps to address subsidence. }\end{array}$ & \multirow[t]{2}{*}{ NA } & $\begin{array}{l}\text { Foundation } \\
\text { grouting }\end{array}$ & $\begin{array}{l}\text { Modified RCRA Type C } \\
\text { with biotic barrier }\end{array}$ & $\begin{array}{l}\text { Active vapor extraction through } \\
\text { shallow extraction wells integrated } \\
\text { into the existing OCVZ system }\end{array}$ & Yes & Yes \\
\hline $2 \mathrm{~b}$ & & & $\begin{array}{l}\text { Pad A waste would be shipped to } \\
\text { the active SDA LLW Pit without } \\
\text { treatment. }\end{array}$ & & $\begin{array}{l}\text { Dynamic } \\
\text { compaction }\end{array}$ & $\begin{array}{l}\text { ET with biointrusion or gas } \\
\text { vent layer }\end{array}$ & $\begin{array}{l}\text { Active vapor extraction through } \\
\text { transport layer vents integrated into } \\
\text { the existing OCVZ system }\end{array}$ & Yes & Yes \\
\hline 3 & ISG & NA & $\begin{array}{l}\text { Pad A waste would be shipped to } \\
\text { the active the SDA LLW Pit } \\
\text { following ex situ grouting } \\
\text { treatment. }\end{array}$ & $\begin{array}{l}\text { Focused ISG to } \\
\text { immobilize Tc-99 } \\
\text { and I-129 }\end{array}$ & $\begin{array}{l}\text { Dynamic } \\
\text { compaction }\end{array}$ & $\begin{array}{l}\text { ET with biointrusion or gas } \\
\text { vent layer }\end{array}$ & $\begin{array}{l}\text { Passive vapor extraction through } \\
\text { transport layer vents and side } \\
\text { burden rip-rap armor }\end{array}$ & Yes & Yes \\
\hline 4a & \multirow[t]{2}{*}{ Partial RTD } & $\begin{array}{l}\text { Targeted Rocky Flats Plant TRU waste from } \\
\text { pit areas totaling } 4 \text { acres (excluding the } \\
\text { Accelerated Retrieval Project) would be } \\
\text { retrieved, segregated, treated (as necessary), } \\
\text { and disposed of. Targeted TRU waste would } \\
\text { be shipped to WIPP, and nontargeted waste } \\
\text { would be left in place. }\end{array}$ & $\begin{array}{l}\text { Pad A waste would be shipped to } \\
\text { the Idaho CERCLA Disposal } \\
\text { Facility for treatment and disposal. }\end{array}$ & $\mathrm{NA}$ & $\begin{array}{l}\text { Dynamic } \\
\text { compaction }\end{array}$ & $\begin{array}{l}\text { ET with biointrusion or gas } \\
\text { vent layer }\end{array}$ & $\begin{array}{l}\text { Passive vapor extraction through } \\
\text { transport layer vents and side } \\
\text { burden rip-rap armor }\end{array}$ & Yes & Yes \\
\hline $4 \mathrm{~b}$ & & $\begin{array}{l}\text { Targeted Rocky Flats Plant TRU waste from } \\
\text { pit areas totaling } 2 \text { acres (excluding the } \\
\text { Accelerated Retrieval Project) would be } \\
\text { retrieved, segregated, treated (as necessary), } \\
\text { and disposed of. Targeted TRU waste would } \\
\text { be shipped to WIPP, and nontargeted waste } \\
\text { would be left in place. }\end{array}$ & $\begin{array}{l}\text { Pad A waste would be left in place, } \\
\text { and dynamic compaction would be } \\
\text { applied to address subsidence. }\end{array}$ & $\mathrm{NA}$ & Proof-rolling & $\begin{array}{l}\text { ET with biointrusion or gas } \\
\text { vent layer and slurry cut-off } \\
\text { wall }\end{array}$ & $\begin{array}{l}\text { Passive vapor extraction through } \\
\text { transport layer vents and side } \\
\text { burden rip-rap armor }\end{array}$ & Yes & Yes \\
\hline 5 & Full RTD & $\begin{array}{l}\text { All waste within the SDA would be retrieved, } \\
\text { segregated, treated, as necessary, and disposed } \\
\text { of. Transuranic waste would be shipped to } \\
\text { WIPP, and non-TRU waste would be shipped } \\
\text { to the appropriate on-INL Site or off-INL Site } \\
\text { treatment, storage, and disposal facilities. }\end{array}$ & $\begin{array}{l}\text { Pad A waste would be shipped to an } \\
\text { off-INL Site facility for treatment } \\
\text { and disposal. }\end{array}$ & $\mathrm{NA}$ & $\mathrm{NA}$ & $\begin{array}{l}\text { ET without biointrusion or } \\
\text { gas vent layer }\end{array}$ & $\begin{array}{l}\text { No volatile organic compound } \\
\text { removal from the surface barrier or } \\
\text { buried waste zone }\end{array}$ & Yes & Yes \\
\hline \multicolumn{10}{|c|}{$\begin{array}{l}\text { CERCLA = Comprehensive Environmental Response, Compensation, and Liability Act } \\
\text { ET = evapotranspiration } \\
\text { IN = Idaho National Laboratory } \\
\text { ISG = in situ grouting } \\
\text { LLW = low-level waste } \\
\text { OCVZ = Organic Contamination in the Vadose Zone } \\
\text { RCRA = Resource Conservation and Recovery Act } \\
\text { RTD = retrieval, treatment, and disposal } \\
\text { SDA = Subsurface Disposal Area } \\
\text { TRU = transuranic } \\
\text { WIPP = Waste Isolation Pilot Plant }\end{array}$} \\
\hline
\end{tabular}


Table F-2. Alternative module crosswalk.

\begin{tabular}{|c|c|}
\hline \multicolumn{2}{|r|}{ Modules } \\
\hline No. & Title \\
\hline 1 & Slurry cut-off wall \\
\hline 2 & Proof-rolling \\
\hline 3 & ET Surface Barrier \\
\hline 4 & Simplified ET Surface Barrier \\
\hline 5 & Modified RCRA Type C Surface Barrier \\
\hline 6 & Gas Vent Layer Extraction Pipe \\
\hline 7 & Shallow Extraction Wells \\
\hline 8 & Dynamic Compaction: Pits \\
\hline 9 & Dynamic Compaction: Pad A \\
\hline 10 & Foundation Grouting \\
\hline 11 & Contaminant Grouting \\
\hline 12 & 2-Acre Excavation \\
\hline 13 & 4-Acre Excavation \\
\hline 14 & Full Excavation \\
\hline 15 & $\begin{array}{l}\text { Pad A Removed without Treatment and Ship to } \\
\text { LLW Pit }\end{array}$ \\
\hline 16 & $\begin{array}{l}\text { Pad A Removed and Ship to on-INL Facility for } \\
\text { Treatment and Disposal }\end{array}$ \\
\hline 17 & $\begin{array}{l}\text { Pad A Removed and Ship to Off-INL Facility for } \\
\text { Treatment and Disposal }\end{array}$ \\
\hline 18 & $\begin{array}{l}\text { Pad A Removed with Treatment and Ship to } \\
\text { LLW Pit }\end{array}$ \\
\hline 19 & Monitoring \\
\hline 20a & $\begin{array}{l}\text { OCVZ Management and Operations } \\
\text { (5-year management and operations) }\end{array}$ \\
\hline $20 \mathrm{~b}$ & $\begin{array}{l}\text { OCVZ Management and Operations (20-year } \\
\text { treatment unit replacement) }\end{array}$ \\
\hline $20 \mathrm{c}$ & $\begin{array}{l}\text { OCVZ Management and Operations (monitoring } \\
\text { to support shutdown) }\end{array}$ \\
\hline
\end{tabular}

\begin{tabular}{|c|c|c|c|c|c|c|c|c|c|}
\hline \multicolumn{2}{|c|}{ Alternative } & \multirow{2}{*}{$\begin{array}{c}\text { Retrieval and } \\
\text { Disposal } \\
\end{array}$} & \multirow[b]{2}{*}{ Pad A } & \multirow{2}{*}{$\begin{array}{c}\text { In Situ } \\
\text { Treatment }\end{array}$} & \multirow{2}{*}{$\begin{array}{l}\text { Foundation } \\
\text { Preparation } \\
\end{array}$} & \multirow{2}{*}{$\begin{array}{c}\text { Containment } \\
\text { Barrier }\end{array}$} & \multirow{2}{*}{$\begin{array}{c}\text { Shallow Volatile } \\
\text { Organic } \\
\text { Compound } \\
\text { Removal } \\
\end{array}$} & \multirow{2}{*}{$\begin{array}{l}\text { Surveillance and } \\
\text { Monitoring }\end{array}$} & \multirow{2}{*}{$\begin{array}{c}\text { Institutional } \\
\text { Controls }\end{array}$} \\
\hline No. & Title & & & & & & & & \\
\hline 1 & No Action & NA & NA & NA & NA & NA & NA & 19 & NA \\
\hline $2 a$ & \multirow{2}{*}{ Surface Barrier } & \multirow{2}{*}{ NA } & $\begin{array}{l}\text { Pad A waste left } \\
\text { in place with no } \\
\text { steps to address } \\
\text { subsidence }\end{array}$ & \multirow{2}{*}{ NA } & 10 & 5 & 7 & \multicolumn{2}{|c|}{5 and 20} \\
\hline $2 b$ & & & 15 & & 8 & 3 & 6 & \multicolumn{2}{|c|}{3 and 20} \\
\hline 3 & In Situ Grouting & NA & 18 & 11 & 8 & 3 & 6 & 3 an & \\
\hline $4 a$ & \multirow{2}{*}{$\begin{array}{l}\text { Partial Retrieval, } \\
\text { Treatment, and } \\
\text { Disposal }\end{array}$} & 13 & 16 & NA & 8 & 3 & 6 & \multicolumn{2}{|c|}{3 and 20} \\
\hline $4 \mathrm{~b}$ & & 12 & 9 & NA & 2 & 3 and 1 & 6 & \multicolumn{2}{|c|}{3 and 20} \\
\hline 5 & $\begin{array}{l}\text { Full Retrieval, } \\
\text { Treatment, and } \\
\text { Disposal }\end{array}$ & 14 & 17 & NA & NA & 4 & $\begin{array}{l}\text { No VOC removal } \\
\text { from the surface } \\
\text { barrier or buried } \\
\text { waste zone }\end{array}$ & \multicolumn{2}{|c|}{4 and 20} \\
\hline $\begin{array}{l}\text { INL }=\text { Id } \\
\text { LLW }=1 \\
\text { OCVZ }= \\
\text { RCRA }=\end{array}$ & $\begin{array}{l}1 \text { Laboratory } \\
\text { ste } \\
\text { otamination in the V } \\
\text { Conservation and Rec }\end{array}$ & & & & & & & & \\
\hline
\end{tabular}


From these three cost elements an OCVZ vapor extraction with treatment system cost can be obtained for any treatment duration. Equation $(\mathrm{F}-1)$ is used to calculate the alternative OCVZ system cost:

OCVZMonitoringCost $=\left(\frac{\text { Years }}{5}\right) \times($ Module $20 a)+\left(20 y r_{-}\right.$Re placements $) \times($Module $20 b)+($ Module $20 c)$.

"Years" in Equation (F-1) above denotes the number of years the OCVZ system is required to run in order to meet the concentration based remediation goals. "20yr_Replacements" in Equation (F-1) above denotes the number of 20 -year increments within the OCVZ operational timeframe. For example, there would be three "20yr_Replacements" during 65 years of OCVZ operation (e.g., years 20, 40, and 60). All three components of Module 20 are shown on the alternative time lines presented in Section F-3.

\section{F-1.1.2 Cost Estimating Summary}

Table F-3 provides separate cost estimate summaries for Alternatives 1 through 5 of the Operable Unit 7-13/14 Feasibility Study. Capital, operations and maintenance, and periodic costs are provided as current value and net present value (i.e., cumulative worth of all costs from the beginning of the first year of activities using discount rates that account for pretax return on investment and future inflation). Net present value costs are estimated by using annual inflation factors provided within the latest revision of Appendix C of OMB Circular A-94 (OMB 2006). The current value cost in Fiscal Year 2006 dollars is the cost of performing all the work in 2006 without any inflation of costs for future work or return on investment for dollars invested in 2006.

Present value analysis is a method to evaluate expenditures, either capital or operations and maintenance, that occur over different time periods. This standard methodology allows for cost comparisons of different remedial alternatives on the basis of a single cost figure for each alternative. This single number, referred to as the present value, is the amount needed to be set aside at the initial point in time (base year of 2006) to ensure that funds will be available in the future as they are needed, assuming certain economic conditions.

\section{F-1.2 Professional and Technical Services}

Professional and technical services are incorporated into every module. These services account for costs associated with project management, remedial design, and construction management. In accordance with Exhibit 5-8 of the U.S. Environmental Protection Agency (EPA) guidance (EPA 2000), each of these cost elements is calculated based on a percentage of the module's capital cost.

\section{F-1.2.1 Project Management Cost}

Project management includes oversight, generating a safety analysis report addendum and RWMC interface agreement, generating bid package and contract documentation, issuing requests for proposals, and evaluating, selecting, and awarding the bid.

Exhibit 5-8 of the EPA guidance (EPA 2000) provides examples of project management costs as a percentage of total capital costs (i.e., capital costs plus scope and bid contingencies). The percentages range from $10 \%$ for projects with capital costs less than $\$ 100,000$ to $5 \%$ for projects with capital costs greater than $\$ 10$ million. The EPA guidance states that these values may be adjusted up for more complex projects or down for less complex projects, based on engineering judgment. Section F-23 provides a list of the chosen percentages of capital cost and rationale for those chosen percentages. 
F-26 
Table F-3. Cost estimate summaries for Alternatives 1 through 5 of the Operable Unit 7-13/14 Feasibility Study.

Alternative \#1: PRESENT VALUE ANALYSIS SUMMARY SHEET
Project: WAG 7 Feasibility Study

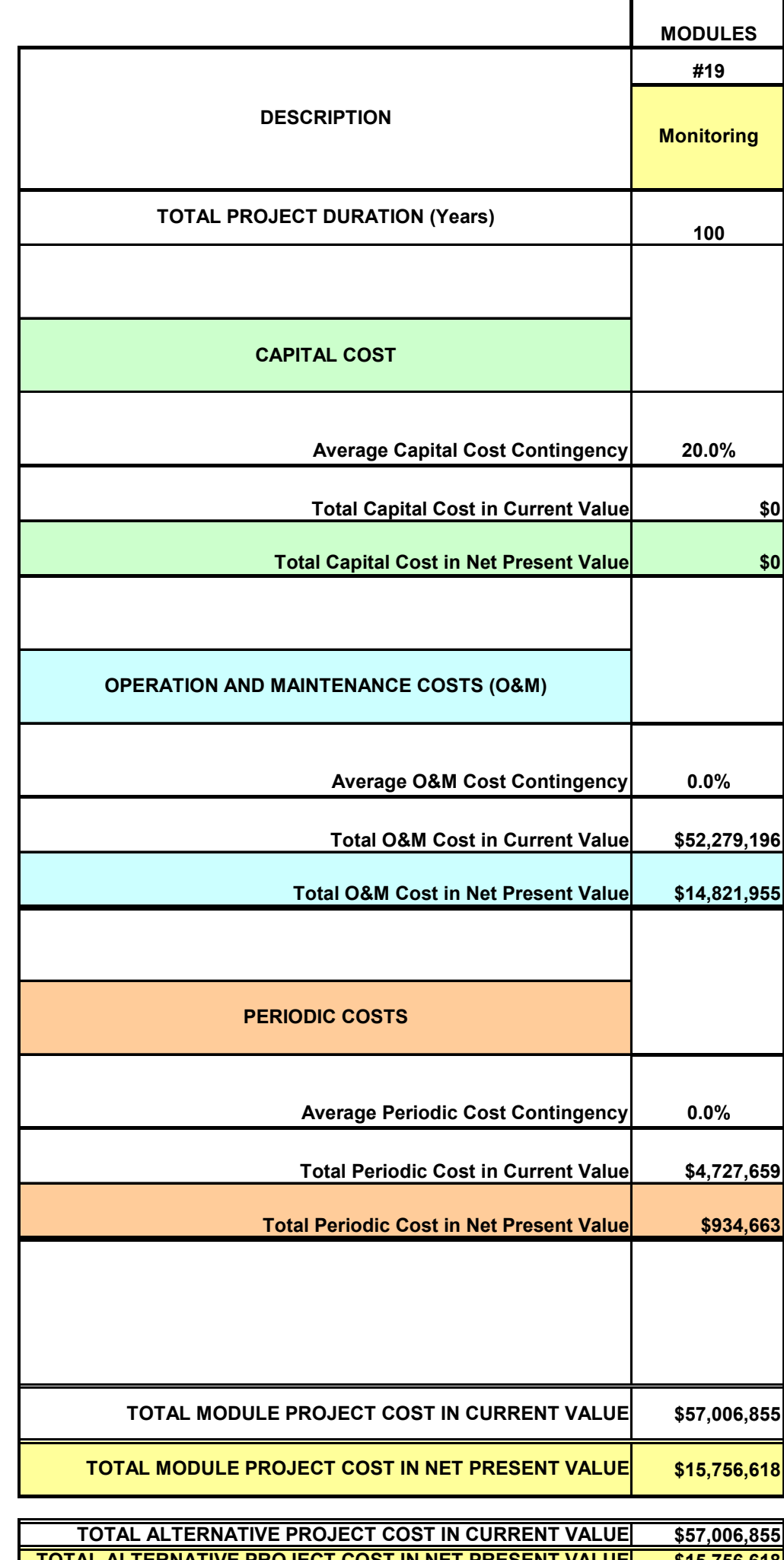

Alternative \#2a: PRESENT VALUE ANALYYIS SUMMARY SHEET

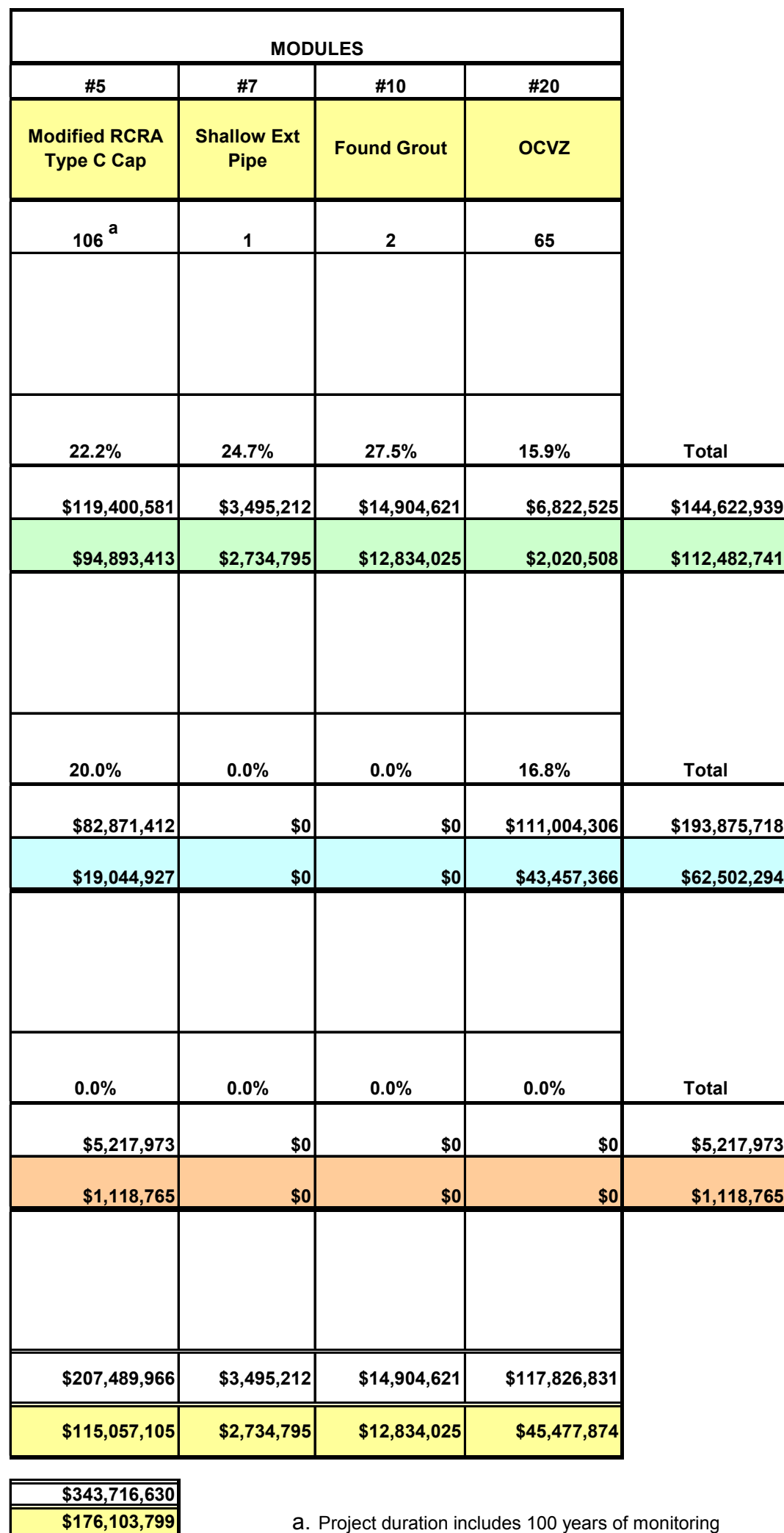

Alternative \#2b: PRESENT VALUE ANALYSIS SUMMARY SHEET

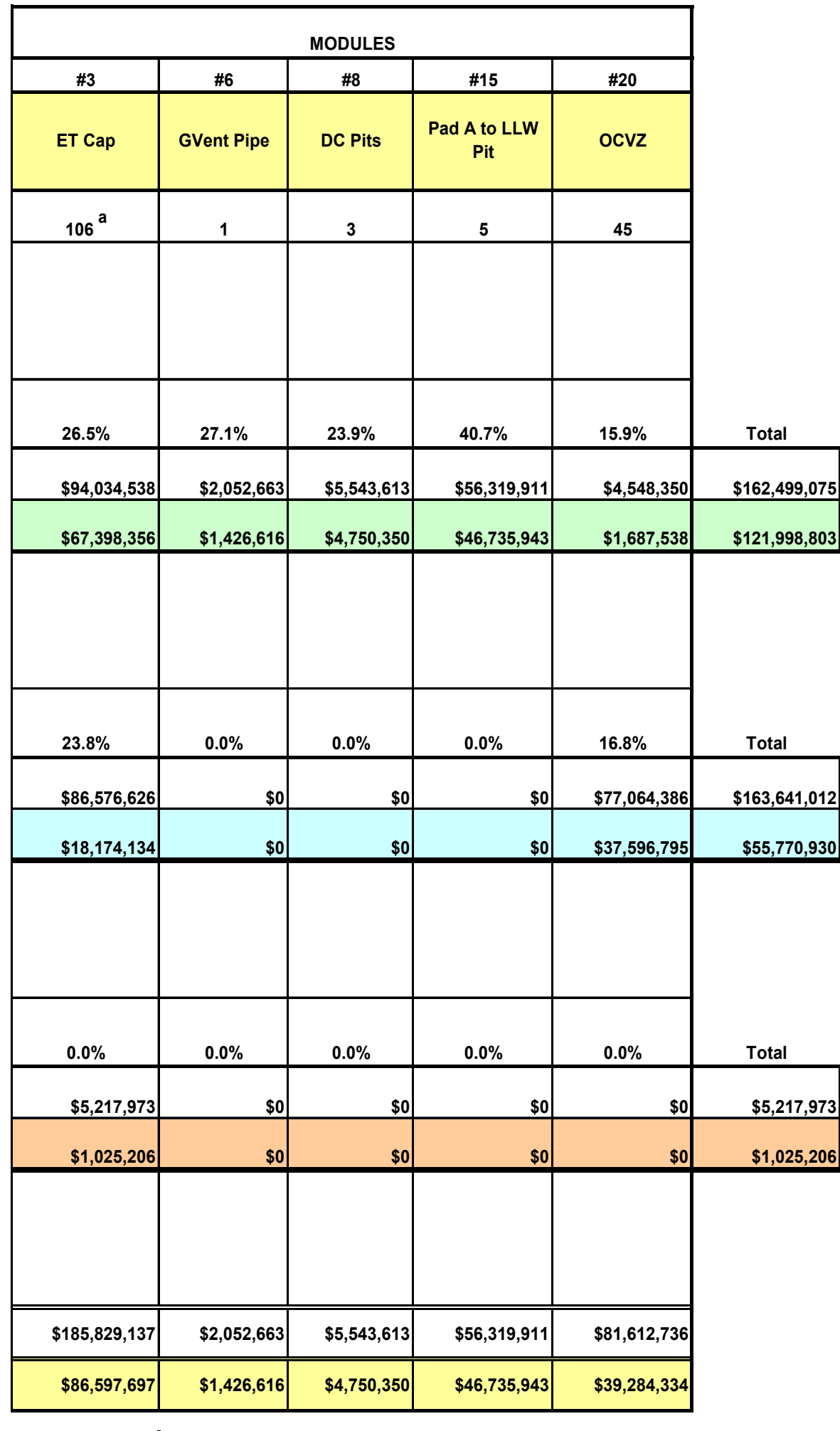

\begin{tabular}{|r|}
\hline$\$ 331,358,060$ \\
\hline \hline$\$ 178,794,939$ \\
\hline
\end{tabular}

a. Project duration includes 100 years of monitoring 
Table F-3. (continued).

Project: WAG 7 Feasibility Study

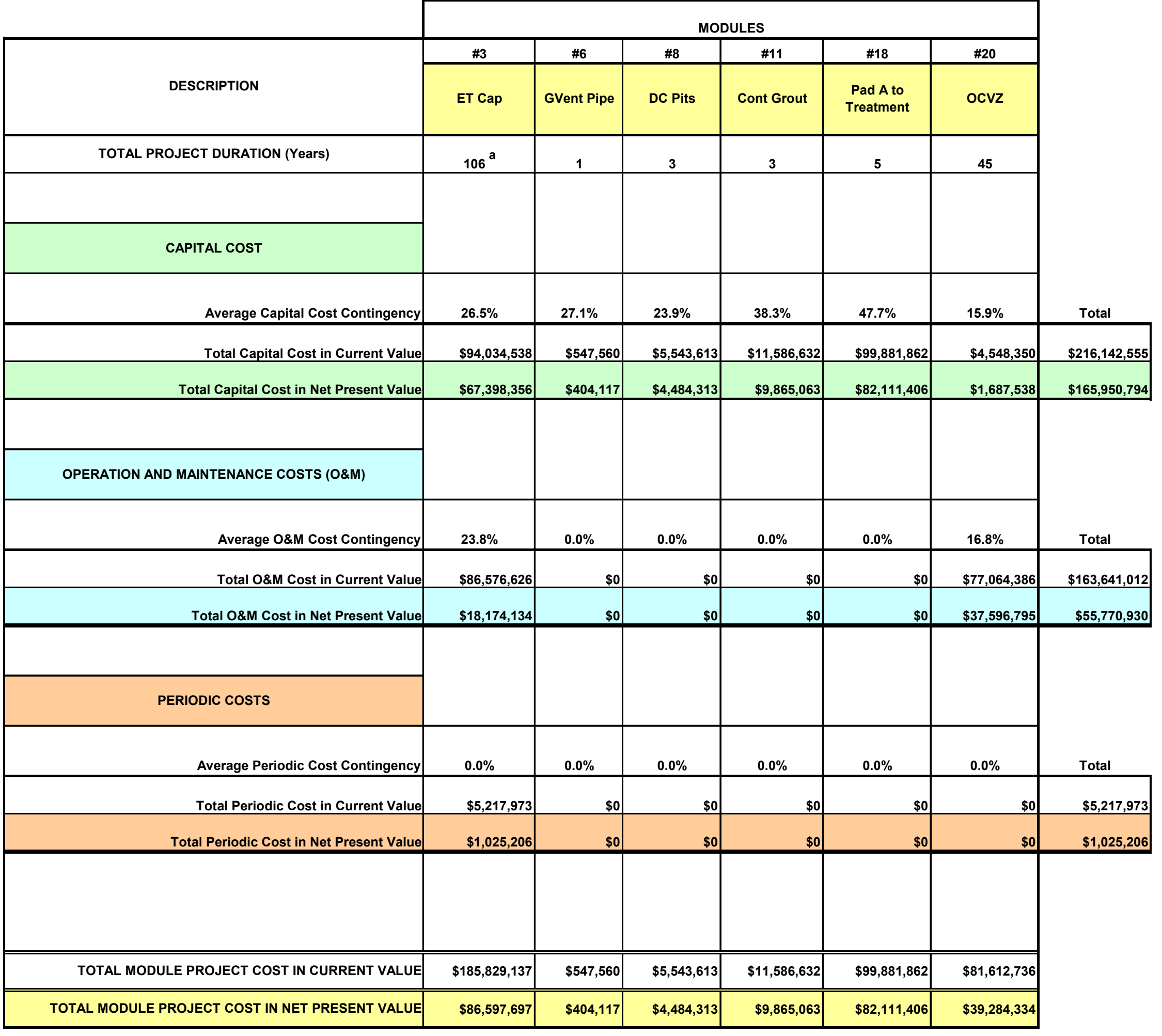

TOTAL ALTERNATIVE PROJECT COST IN CURRENT VALUE] $\$ 385,001,54$

\begin{tabular}{|l|l|l|}
\hline TOTAL ALTERNATIVE PROJECT COST IN NET PRES ENT VALUE & $\$ 222,746,930$ \\
\hline
\end{tabular}

a. Project duration includes 100 years of monitoring
Alternative \#4a: PRESENT VALUE ANALYSIS SUMMARY SHEET

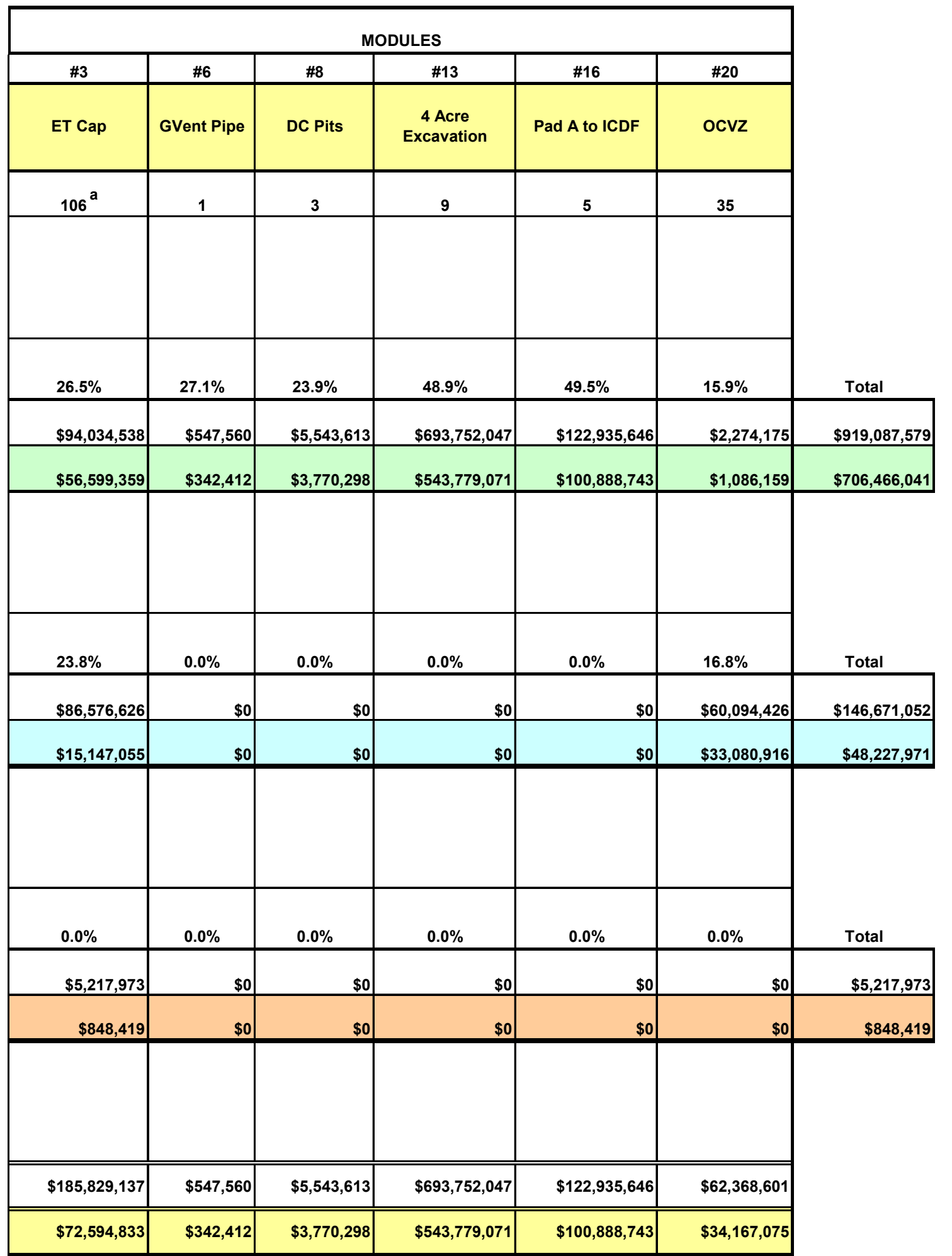

$\$ 1,070,976,604$

\$755,542,432 $\quad$ a. Project duration includes 100 years of monitoring 
Project: WAG 7 Feasibility Study

\begin{tabular}{|c|c|c|c|c|c|c|c|c|}
\hline & \multicolumn{7}{|c|}{ MODULES } & \multirow[b]{6}{*}{ Total } \\
\hline \multirow[b]{2}{*}{ DESCRIPTION } & $\# 1$ & $\# 2$ & $\# 3$ & $\# 6$ & \#9 & $\# 12$ & $\# 20$ & \\
\hline & Cut-Off Wall & $\begin{array}{l}\text { Preload } \\
\text { Comp }\end{array}$ & ET Cap & GVent Pipe & DC Pad A & $\begin{array}{l}2 \text { Acre } \\
\text { Excavation }\end{array}$ & ocvz & \\
\hline TOTAL PROJECT DURATION (Years) & 1 & 1 & $106^{a}$ & 1 & 2 & 7 & 35 & \\
\hline \multicolumn{8}{|l|}{ CAPITAL COST } & \\
\hline Average Capital Cost Contingency & $19.4 \%$ & $8.7 \%$ & $26.5 \%$ & $27.1 \%$ & $23.1 \%$ & $48.9 \%$ & $15.9 \%$ & \\
\hline Total Capital Cost in Current Value & $\$ 1,861,432$ & $\$ 1,980,941$ & $\$ 94,034,538$ & $\$ 547,560$ & $\$ 3,287,463$ & $\$ 449,246,946$ & $\$ 2,274,175$ & $\$ 553,233,055$ \\
\hline Total Capital Cost in Net Present Value & $\$ 1,373,798$ & $\$ 1,462,000$ & $\$ 63,753,331$ & $\$ 382,403$ & $\$ 2,872,532$ & $\$ 363,548,653$ & $\$ 1,086,159$ & $\$ 434,478,875$ \\
\hline \multicolumn{9}{|l|}{ OPERATION AND MAINTENANCE COSTS (O\&M) } \\
\hline Average O\&M Cost Contingency & $0.0 \%$ & $0.0 \%$ & $23.8 \%$ & $0.0 \%$ & $0.0 \%$ & $0.0 \%$ & $16.8 \%$ & Total \\
\hline Total O\&M Cost in Current Value & $\$ 0$ & $\$ 0$ & $\$ 86,576,626$ & $\$ 0$ & \$0 & $\$ 0$ & $\$ 60,094,426$ & $\$ 146,671,052$ \\
\hline Total O\&M Cost in Net Present Value & $\$ 0$ & $\$ 0$ & $\$ 17,102,421$ & so & sol & sol & $\$ 33,080,916$ & $\$ 50,183,337$ \\
\hline \multicolumn{9}{|l|}{ PERIODIC COSTS } \\
\hline Average Periodic Cost Contingency & $0.0 \%$ & $0.0 \%$ & $0.0 \%$ & $0.0 \%$ & $0.0 \%$ & $0.0 \%$ & $0.0 \%$ & Total \\
\hline Total Periodic Cost in Current Value & $\$ 0$ & $\$ 0$ & $\$ 5,217,973$ & so & so & $\$ 0$ & so & $\$ 5,217,973$ \\
\hline Total Periodic Cost in Net Present Value & sol & so & $\$ 965,767$ & so & so & so & so & $\$ 965,767$ \\
\hline TOTAL MODULE PROJECT COST IN CURRENT VALUE & $\$ 1,861,432$ & $\$ 1,980,941$ & $\$ 185,829,137$ & $\$ 547,560$ & $\$ 3,287,463$ & $\$ 449,246,946$ & $\$ 62,368,601$ & \\
\hline TOTAL MODULE PROJECT COST IN NET PRESENT VALUE & $\$ 1,373,798$ & $\$ 1,462,000$ & $\$ 81,821,519$ & $\$ 382,403$ & $\$ 2,872,532$ & $\$ 363,548,653$ & $\$ 34,167,075$ & \\
\hline $\begin{array}{l}\text { TOTAL ALTERNATIVE PROJECT COST IN CURRENT VALUE } \\
\text { TOTAL ALTERNATIVE PROJECT COST IN NET PRESENT VALUE }\end{array}$ & $\begin{array}{l}\$ 705,122,080 \\
\$ 485,627,980 \\
\end{array}$ & & Project durati & on includes 1 & 100 years o & monitoring & & \\
\hline
\end{tabular}

Alternative \#5: PRESENT VALUE ANALYSIS SUMMARY SHEET

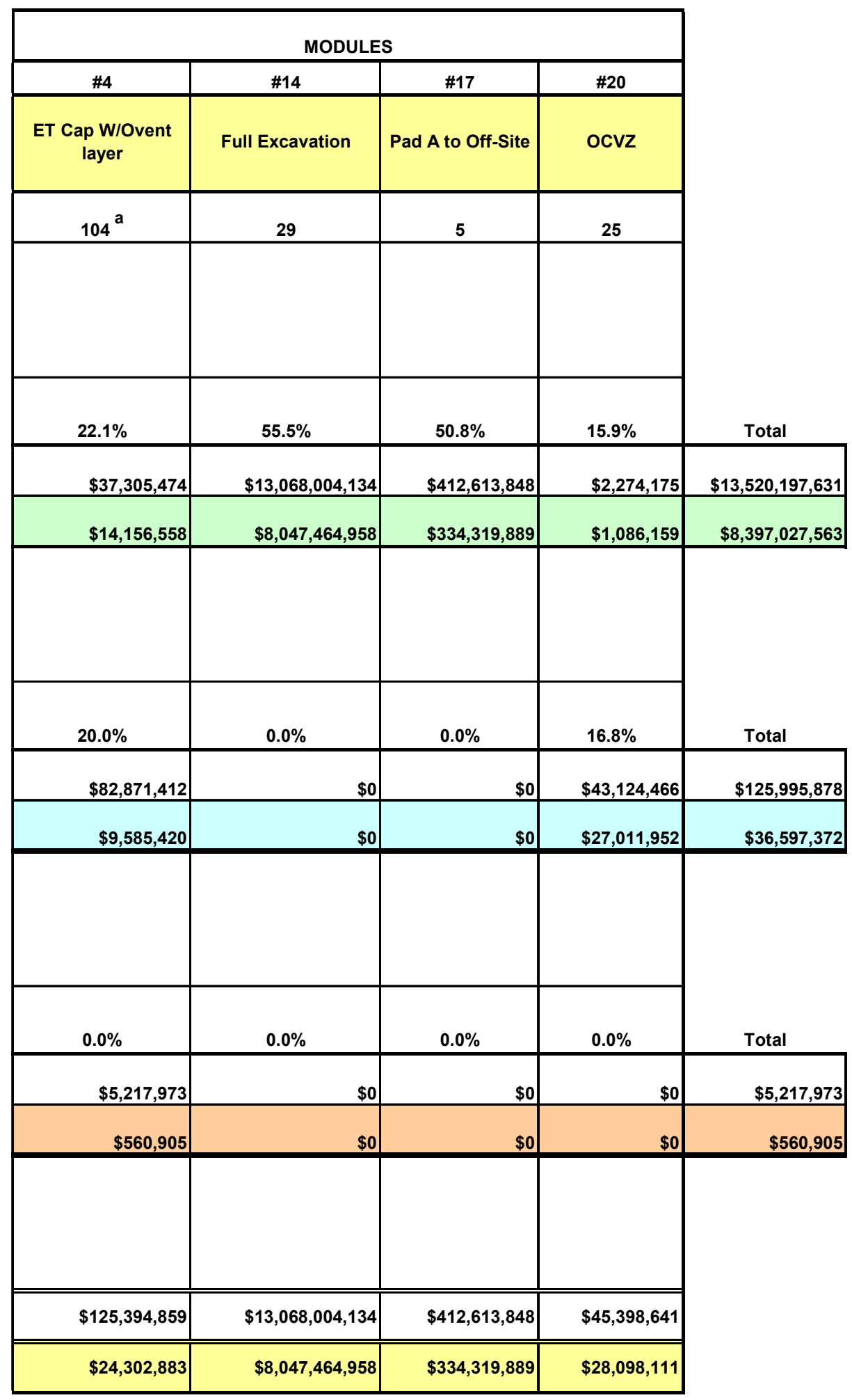

$\$ 13,651,411,48$

185,84 



\section{F-1.2.2 Remedial Design Cost}

Remedial design within this feasibility study refers to preparation, acceptance, and finalization of (1) the remedial design and (2) the remedial action work plan. Remedial design includes design documents (e.g., drawings, specifications, and engineering analysis), air emissions reports, waste management plans, characterization plans (e.g., plans for field sampling, secondary waste characterization, sampling and analysis, and emissions monitoring), health and safety plans, and an operations and maintenance plan. The remedial action work plan refers to preparation, acceptance, and finalization of construction schedules and cost estimates.

Exhibit 5-8 of the EPA guidance provides examples of remedial design costs as a percentage of total capital costs (i.e., capital plus scope and bid contingencies). The percentages range from $20 \%$ for projects with capital costs less than $\$ 100,000$ to $6 \%$ for projects with capital costs greater than $\$ 10$ million. The EPA guidance states that these values may be adjusted up for more complex projects or down for less complex projects, based on engineering judgment. Section F-23 provides a list of the chosen percentages of capital cost and rationale for those chosen percentages.

\section{F-1.2.3 Construction Management Cost}

Construction management applies to capital costs and includes activities to manage construction or installation of the remedial action. Activities include vendor data approvals, revision of preexisting technical and functional requirements, process acceptance testing at the subcontractor's facility, acceptance testing at the SDA (to verify procedures, training, equipment performance, and operational competence), field support and oversight, a prefinal inspection, a management self-assessment, and possibly operational readiness reviews.

Exhibit 5-8 of the EPA guidance provides examples of construction management costs as a percentage of total capital costs (i.e., capital plus scope and bid contingencies). The percentages range from $15 \%$ for projects with capital costs less than $\$ 100,000$ to $6 \%$ for projects with capital costs greater than $\$ 10$ million. The EPA guidance states that these values may be adjusted up for more complex projects or down for less complex projects, based on engineering judgment. Section F-23 provides a list of the chosen percentages of capital cost and rationale for those chosen percentages.

\section{F-1.3 Contingency}

Contingency is incorporated into every module. Contingency accounts for both scope risk and bid risk. In accordance with Exhibit 5-8 of the EPA guidance (EPA 2000), both scope and bid contingency are calculated based off a percentage of the module's capital cost.

Scope contingency represents project risks associated with an incomplete design and includes contributing factors such as limited experience with technologies, additional requirements because of regulatory or policy changes, and inaccuracies in defining quantities or characteristics. This type of contingency represents costs, unforeseeable at the time of estimate preparation, that are likely to become known as the remedial design proceeds. For this reason, scope contingency is sometimes referred to as "design" contingency. Some examples of factors that affect scope (design) contingency are:

1. Introduction of a new technology

2. A change in the surface area requiring treatment

3. A change in the design that affects the amount of raw materials required. 
EPA guidance states that scope contingencies should be added to construction costs. Exhibit 5-6 of the EPA guidance provides examples of scope contingencies for specific remedial technologies.

Bid contingency represents costs, unforeseeable at the time of estimate preparation, that are likely to become known as the remedial action construction or operations and maintenance proceeds. For this reason, bid contingency is sometimes referred to as "construction" contingency. Bid contingencies represent reserves for quantity overruns, modifications, change orders, and claims during construction. Some examples of factors that affect bid (construction) contingency are:

1. Impacts from weather

2. Unexpected radiological contamination

3. Raw material supply shortages

4. Unexpected subsidence

5. Equipment damage.

The EPA guidance states that bid contingencies should be added to construction costs and should range from 10 to $20 \%$. Section F-23 provides a list of the chosen scope and bid percentages of capital cost and rationale for those chosen percentages.

\section{F-1.4 GENERAL ASSUMPTIONS}

The following is a list of general assumptions that are applied to every module cost estimate. Module specific assumptions are located within each module section (see Sections F-2 through F-23).

\section{F-1.4.1 General}

A. Sufficient funding will be available in a manner that allows optimum use of that funding as estimated and scheduled.

B. Based on discussions with the project team, the design and construction of each module (e.g., cut-off wall, dynamic compaction, and ET cap) will be subcontracted. Subcontractor tasks include generating all required plans, performing all site preparation and remediation work, placing all ICs, writing all reports, and performing all long-term operations and maintenance activities. Idaho Cleanup Project (ICP) tasks include project management oversight (e.g., interface agreements, contract awards, and oversight) and construction management oversight (e.g., vendor data acceptance, preexisting technical procedure revisions, acceptance testing, management self-assessments, and possibly operational readiness reviews).

C. The subcontractor will be responsible for surveying.

D. The INL Site resources (i.e., Central Facilities Area, medical facilities, geotechnical laboratory, fire department, security, and utilities in the SDA) will be available for the duration of the project.

E. No fire water, potable water, buried power, propane, sewer, or storm drain utilities will be encountered or required to be removed or relocated.

F. Utilities and structures supporting current projects at the SDA will be completely removed by those projects before the start of this project and at no cost to this project. 
G. If remedial action obstructs an OCVZ project well, the obstructed well will be capped. Following remedial action, the capped well will be reconnected to the appropriate treatment unit. Costs associated with capping and reconnection are accounted for within the scope contingency for each of the cap estimates (i.e., Estimate Numbers 5922, 5922A, and 5922B).

H. No equipment flaggers or traffic control will be needed; once the field work begins, the subcontractor will have complete control of the area.

I. ICP personnel will have access to existing RWMC buildings that can be used as temporary offices during this work.

\section{F-1.4.2 Schedule}

A. Work activities will be performed during the $4 \times 10$ work schedule (i.e., working 4 days per week and 10 hours per day)

B. No unexpected delays will occur because of changes to the unreviewed safety question and safety analysis report process.

\section{F-1.4.3 Mobilization and Demobilization}

A. Equipment and personnel entering and exiting the SDA will not be required to survey in or out or stop for security access. As they travel through the gates, personnel will only be required to flash their identification to personnel manning those gates. The estimates assume free and easy access at the gates for all construction personnel and equipment.

B. Administrative and equipment buildings or trailers will be installed at the SDA to support operational controls, radiation controls, and personnel facilities.

C. ICP personnel will have access to existing RWMC buildings that can be used as temporary offices during this work. 


\section{F-2. MODULE 1: SLURRY CUT-OFF WALL \\ F-2.1 Purpose}

SDA.

This estimate will be used as a cost-comparative tool to examine different options regarding the

\section{F-2.2 Scope of Work}

The scope of work consists of an underground grout curtain that will be placed around the perimeter of the entire SDA. Excavation under a slurry-filled trench provides stability and prevents the trench from collapsing. A soil-bentonite slurry wall has been chosen for this scope.

Application of a soil-bentonite slurry wall involves dredging soil from one end of a bentonite slurry-filled trench while adding a low-permeability backfill to the other end of the trench. Low-permeability backfill (i.e., hydraulic barrier) is prepared by mixing bentonite slurry with dredged native soil. Varying composition of the backfill can alter properties of the barrier to obtain desired strength or permeability. The backfilled curtain will then be capped with a soil-bentonite mixture.

During excavation, bentonite-water slurry, typically consisting of 1 to $5 \%$ bentonite, is placed in the trench to support the sides of the trench. To support the trench, slurry overcomes the active earth pressures in the soil adjacent to the trench and forms a filter cake along the trench walls. Bentonite slurry should be fully hydrated, typically 12 to 24 hours, before being placed in the trench. Therefore, temporary ponds or tanks are necessary for hydration and storage of slurry. The slurry level in the trench is maintained at or near the top of the trench and above the surrounding groundwater table.

Soil excavated from the trench may be used for trench backfill unless physical or contaminant characteristics render it unsuitable. Bentonite-water slurry then is mixed into the soil to form a mixture of soil-bentonite backfill, with a slump of approximately 10 to $15 \mathrm{~cm}$ (4 to $6 \mathrm{in}$.). Backfill then is placed into the trench so that it flows down a shallow slope. Predesign investigations include (1) site geology and hydrogeology, (2) nature and extent of contamination, and (3) geotechnical properties of subsurface materials.

The ICP will perform project management by generating the bid package and choosing the appropriate subcontractor (see Section F-2.4 for details). The subcontractor then will generate all implementation documents (captured under Section F-2.4), mobilize and demobilize equipment, construct all appropriate facilities (captured under Section F-2.4), and perform all remediation activities. During construction and remediation phases of the project, ICP construction management will review vendor data and perform acceptance testing and reviews (see Section F-2.4 for details). In addition, ICP construction management will provide general oversight.

Subcontractor mobilization consists of the following:

- $\quad$ Generate operational plans (see Section F-2.4 for details)

- Generate a management self-assessment plan

- $\quad$ Mobilize equipment (costs captured in Section F-2.4). 
Subcontractor demobilization consists of the following:

- $\quad$ Shut down or demobilize equipment

- Generate a final inspection report.

Site preparation consists of the following:

- Conduct procurement activities

- $\quad$ Survey site locations

- Construct hydration ponds.

Remediation consists of the following:

- $\quad$ Dredge soil from one end of a bentonite slurry-filled trench

- $\quad$ Mix dredged soil with bentonite from the slurry pond

- $\quad$ Add a low-permeability soil-bentonite backfill to the other end of the trench

- $\quad$ Cap the backfilled curtain with a soil-bentonite mixture.

\section{F-2.3 Basis of the Estimate}

The following sequential process, rationale, and estimating methodologies were used to define activities, quantities, and resources that were used to prepare this cost estimate.

A. The INEEL Environmental Restoration Cost Estimating/Cost Engineering Guide (DOE-ID 2000) and the "Idaho National Engineering and Environmental Laboratory Detailed Work Plan Development Process Guidance" (GDE-112) were used to define estimating requirements.

B. The estimate development method was established using a detailed bottoms-up quantifiable technique. Resources, costs, and productions are derived from these individual detailed item quantities.

C. The estimate scope was defined in the scope of work provided by the requester.

D. The estimate was based on drawings and specifications provided by the requester.

E. Costs were developed, using the Success $\odot$ estimating software by U.S. Cost, to a level of detail consistent with available documents and information.

F. Standard material pricing was based on the R. S. Means and Richardson Estimating Manuals.

G. Labor rates were based on the R. S. Means and Richardson Estimating Manuals. All labor rates were factored considering working conditions and requirements at the INL Site.

H. Project cost elements were based on estimate File Number 5432, "Subsurface Disposal Area (SDA) Cap and Cover-Life-cycle Baseline Estimate for FY 2006-2012," prepared July 14, 2005.

I. Security costs were based on "Pit 4 Life-cycle Cost Estimate," File Number 5432. Appropriate general contractor markups for overhead, profit, and bond were applied to costs extracted from this previous estimate. 
J. Submittal and implementation costs were based on costs extracted from estimate File Number 5987, "ISG Project FY 2005-FY 2011," dated August 3, 2004. Appropriate general contractor markups for overhead, profit, and bond were applied to costs extracted from this previous estimate.

K. Final inspection report costs were based on the Preliminary Evaluation of Remedial Alternatives for the SDA (Zitnik et al. 2002).

\section{F-2.4 Assumptions}

\section{A. Schedule}

Figure F-1 presents the project schedule for Module 1.

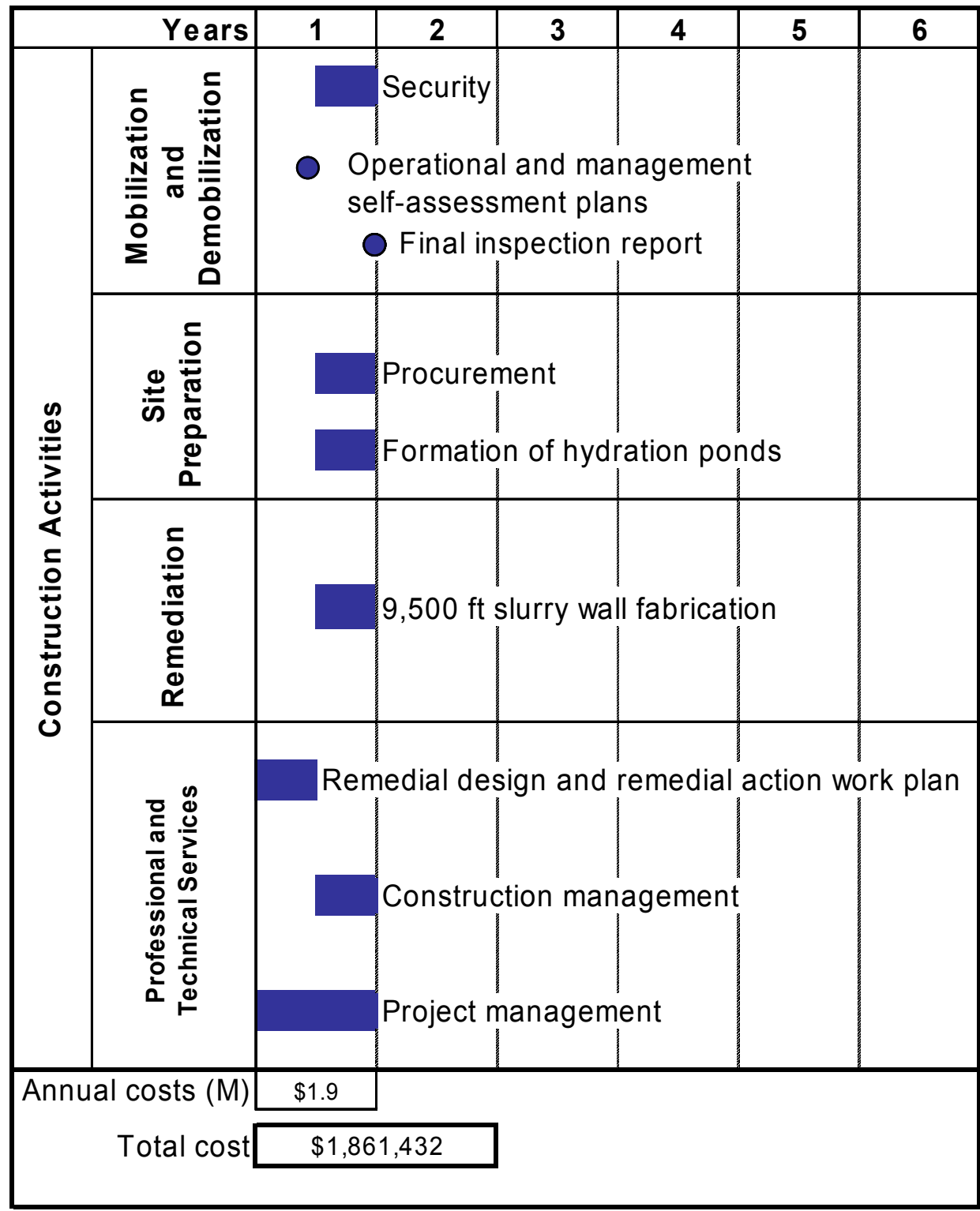

Figure F-1. Module 1 design and construction schedule for slurry cut-off wall. 


\section{B. Mobilization and demobilization (capital costs)}

Mobilization and demobilization costs are captured within the remediation section of this cost estimate.

\section{Site preparation (capital costs)}

A land survey will be required before start of the slurry cut-off wall. Costs for formation of hydration ponds are included within the remediation section of this cost estimate.

\section{Remediation (capital costs)}

1. The depth of the slurry wall around the SDA varies from 10 to 25 feet, depending on the depth of the basalt. On average, 1 cubic yard of fill is required for every 2 square feet of slurry wall surface area.

2. A general subcontractor will perform installation of the slurry cut-off wall. This subcontractor will be experienced with this type of work and will be selected through the bid and award process.

3. This project will not impact Accelerated Retrieval Project excavation.

4. Radioactive and hazardous materials will not be encountered during this project.

5. No release of radioactive materials will be caused by excavation for the slurry cut-off wall.

\section{F-2.5 Contingency Guideline Implementation}

Total capital cost contingency for the slurry cut-off wall is $19.36 \%$. This contingency is the average contingency of construction activities (i.e., 25\%) and professional and technical services (i.e., $0 \%$ ).

\section{F-2.6 Estimate Summary}

Table F-4 provides rough order of magnitude allocations of the methodologies used to develop the cost estimate for Module 1.

Table F-4. Rough order of magnitude allocations of the methodologies used to develop the cost estimate for Module 1.

\begin{tabular}{lc} 
Estimate Methodology & $\begin{array}{c}\text { Rough Order of Magnitude } \\
(\%)\end{array}$ \\
\hline Project team & 50 \\
Recorded actuals & 0 \\
Parametric & 0 \\
Vendor quotes & 20 \\
Other & 30 \\
Total & $\mathbf{1 0 0}$ \\
\hline
\end{tabular}




\section{F-2.7 Other Comments or Concerns Specific to the Estimate}
A. Activities have not been escalated.
B. Subcontractor labor costs reflect INL Site Stabilization Agreement craft labor rates.
C. $\mathrm{CH} 2 \mathrm{M}-\mathrm{WG}$ Idaho labor rates reflect fully burdened present day rates.

\section{F-2.8 Summary}

Table F-5 presents the summary of capital costs for Module 1. 
Table F-5. Capital costs for Module 1: Operable Unit 7-13/14 Feasibility Study—Slurry Cut-Off Wall, Project Number: 5992-0.

\begin{tabular}{|c|c|c|c|c|c|}
\hline Level & Description & $\begin{array}{c}\text { Subtotals }^{\mathrm{a}} \\
(\$)\end{array}$ & $\begin{array}{c}\text { Estimate }^{\mathrm{a}} \\
(\$)\end{array}$ & $\begin{array}{c}\text { Contingency }{ }^{\mathrm{a}, \mathrm{b}} \\
(\$)\end{array}$ & $\begin{array}{c}\text { Total }^{\mathrm{a}, \mathrm{c}} \\
(\$)\end{array}$ \\
\hline 1.1 & Construction activities & $1,208,000$ & - & - & - \\
\hline 1.1 .1 & Mobilization and demobilization & 372,000 & - & - & - \\
\hline 1.1.1.2 & Submittals and implementation plans & 247,000 & - & - & - \\
\hline 1.1.1.2.1 & Operations and layout plan & - & 38,000 & 9,000 & 47,000 \\
\hline 1.1.1.2.3 & Industrial hygiene exposure and sampling plan & - & 56,000 & 14,000 & 69,000 \\
\hline 1.1.1.2.4 & Management self-assessment plan & - & 41,000 & 10,000 & 52,000 \\
\hline 1.1.1.2.8 & Quality control plan & - & 50,000 & 13,000 & 63,000 \\
\hline 1.1.1.2.9 & Final inspection report & - & 63,000 & 16,000 & 78,000 \\
\hline 1.1.1.6 & Security at construction site access gates & - & 125,000 & 31,000 & 156,000 \\
\hline 1.1 .3 & Remediation & 836,000 & - & - & - \\
\hline 1.1.3.1 & Install cut-off wall around the SDA & 836,000 & - & - & - \\
\hline 1.1.3.1.1 & General conditions & - & 44,000 & 11,000 & 55,000 \\
\hline 1.1.3.1.2 & Mobilization and demobilization & 10,000 & - & - & - \\
\hline 1.1.3.1.2.1 & Construction equipment & - & 10,000 & 3,000 & 13,000 \\
\hline 1.1.3.1.3 & Site work & - & 782,000 & 195,000 & 977,000 \\
\hline 1.2 & Professional and technical services & 352,000 & - & - & - \\
\hline 1.2 .1 & Project management & - & 91,000 & - & 91,000 \\
\hline 1.2 .2 & Remedial design and remedial action work plan & 156,000 & - & - & - \\
\hline 1.2.2.1 & Remedial design & - & 117,000 & - & 117,000 \\
\hline 1.2.2.2 & Remedial action work plan & - & 39,000 & - & 39,000 \\
\hline \multirow[t]{3}{*}{1.2 .3} & Construction management & - & 106,000 & - & 106,000 \\
\hline & Total capital cost $^{\mathrm{c}}$ & - & $1,560,000$ & 302,000 & $1,861,000$ \\
\hline & \multicolumn{5}{|c|}{$\begin{array}{l}\text { a. Values are rounded to the nearest } \$ 1,000 \text {. } \\
\text { b. Capital cost contingency is } 19.4 \% \text { of the estimate. } \\
\text { c. Totals were derived for the summation of nonrounded subcomponent values. Therefore, totals are not equal to the summation of the rounded subcomponent values } \\
\text { shown above. See Table } \mathrm{F}-3 \text { for nonrounded totals. }\end{array}$} \\
\hline
\end{tabular}




\section{F-3. MODULE 2: PROOF-ROLLING}

\section{F-3.1 Purpose}

SDA.

This estimate will be used as a cost-comparative tool to examine different options regarding the

\section{F-3.2 Scope of Work}

The scope of work consists of placing a layer of fill material over the entire SDA. This material will be leveled to grade and will be compacted. Compaction is intended to help mitigate subsidence during cap construction. This layer also will serve as the grade base for installation of the final cap.

The ICP will perform project management by generating the bid package and choosing the appropriate subcontractor (see Section F-3.4 for details). The subcontractor will then generate all implementation documents (captured under Section F-3.4), mobilize and demobilize equipment, construct all appropriate facilities (captured under Section F-3.4), and perform all remediation activities. During the construction and remediation phase of the project, ICP construction management will review vendor data and perform acceptance testing and reviews (see Section F-3.4 for details). In addition, ICP construction management will provide general oversight.

Subcontractor mobilization consists of the following:

- $\quad$ Generate operational plans (see Section F-3.4 for details)

- Generate a management self-assessment plan

- $\quad$ Mobilize equipment (costs captured in Section F-3.4).

Subcontractor demobilization consists of the following:

- $\quad$ Shut down or demobilize equipment

- Generate final inspection report.

Site preparation consists of the following:

- $\quad$ Conduct procurement activities

- $\quad$ Mine and import fill materials from the T12 Gravel Pit

- $\quad$ Mow and scarify the SDA.

Remediation consists of the following:

- $\quad$ Place and compact fill materials

- $\quad$ Preload compact the entire SDA for stability. 


\section{F-3.3 Basis of the Estimate}

The following sequential process, rationale, and estimating methodologies were used to define activities, quantities, and resources that were used in preparation of this cost estimate.

A. The INEEL Environmental Restoration Cost Estimating/Cost Engineering Guide (DOE-ID 2000) and the "Idaho National Engineering and Environmental Laboratory Detailed Work Plan Development Process Guidance" (GDE-112) were used to define estimating requirements.

B. The estimate development method was established using a detailed bottoms-up quantifiable technique. Resources, costs, and productions are derived from these individual, detailed item quantities.

C. The estimate scope was defined in the scope of work provided by the requester.

D. The estimate was based on drawings and specifications provided by the requester.

E. Costs were developed, using the Success estimating software by U.S. Cost, to a level of detail consistent with available documents and information.

F. Standard material pricing was based on the R. S. Means and Richardson Estimating Manuals.

G. Labor rates were based on the R. S. Means and Richardson Estimating Manuals. All labor rates were factored considering working conditions and requirements at the INL Site.

H. Project cost elements were based on Estimate File Number 5432, "Subsurface Disposal Area (SDA) Cap and Cover-Life-cycle Baseline Estimate for FY 2006-2012,” prepared July 14, 2005. Appropriate general contractor markups for overhead, profit, and bond were applied to costs extracted from this previous estimate.

I. Submittal and implementation costs were based on costs extracted from Estimate File Number 5987, "ISG Project FY 2005-FY 2011," dated August 3, 2004. Appropriate general contractor markups for overhead, profit, and bond were applied to costs extracted from this previous estimate.

J. Final inspection report costs were based on the Preliminary Evaluation of Remedial Alternatives for the SDA (Zitnik et al. 2002).

K. $\quad$ Security costs were based on Estimate File Number 5432, "Pit 4 Life-cycle Cost Estimate." Appropriate general contractor markups for overhead, profit, and bond were applied to costs extracted from this previous estimate.

\section{F-3.4 Assumptions}

\section{A. General assumptions}

Predesign investigations will be complete before issuing the subcontract for preloading compaction. The subcontractor will be responsible for performing a site survey. 


\section{B. Schedule}

Figure F-2 presents the project schedule for Module 2.

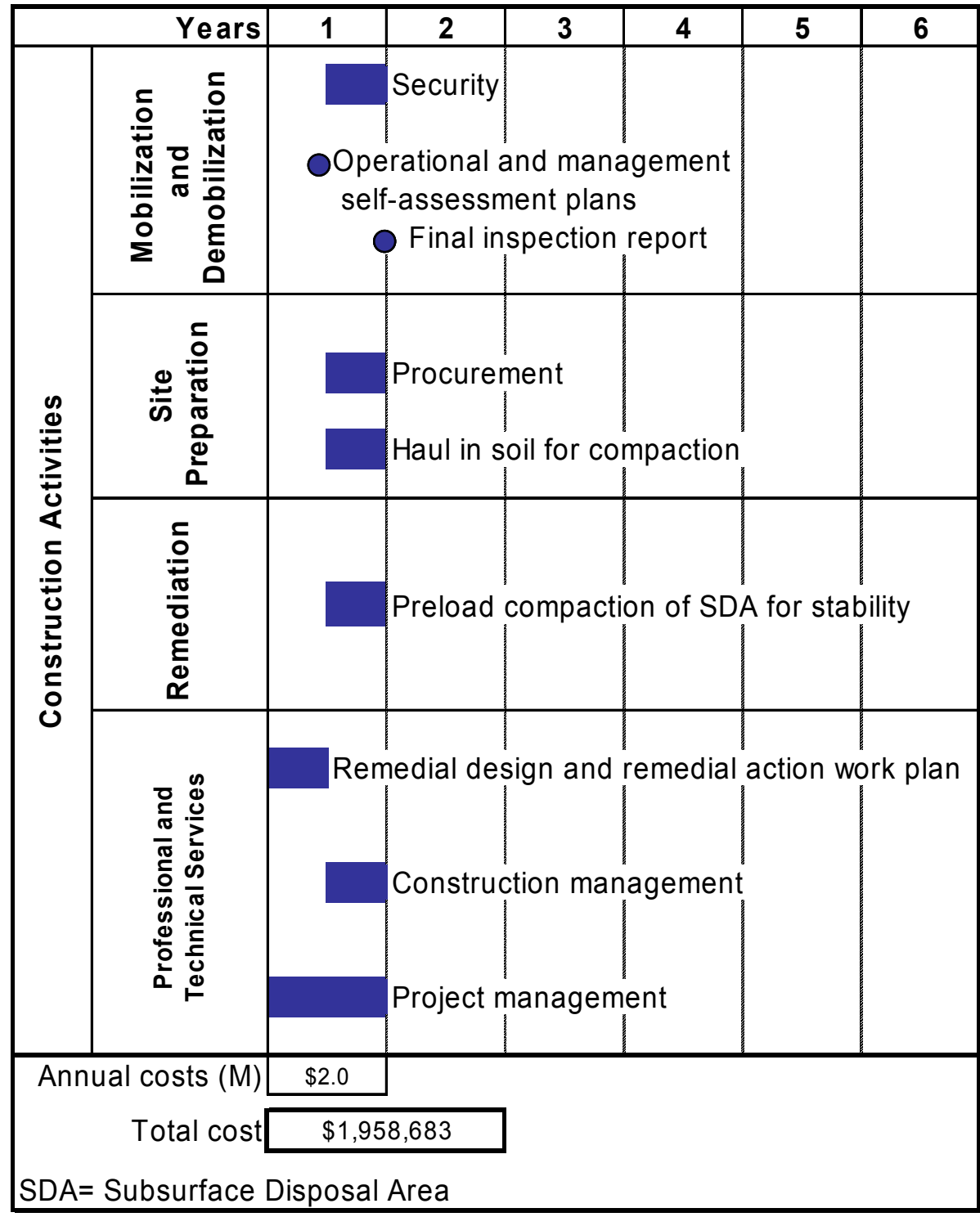

Figure F-2. Module 2 design and construction schedule for preloading compaction.

\section{Mobilization and demobilization (capital costs)}

Mobilization and demobilization costs are captured within the remediation section of this cost estimate.

\section{Site preparation (capital costs)}

Mining and importation of fill material from the T12 Gravel Pit ( $0.6 \mathrm{~km}$ [0.4 mi] away) will be required. 


\section{E. Remediation (capital costs)}

1. A general subcontractor will perform preloading compaction. This subcontractor will be experienced with this type of work and will be selected through the bid and award process.

2. This project will not impact the Accelerated Retrieval Project excavation.

3. Radioactive and hazardous materials will not be encountered during this project.

4. No release of radioactive materials will be caused by subsidence during preloading.

\section{F-3.5 Contingency Guideline Implementation}

Total capital cost contingency for preloading compaction is $8.74 \%$. This contingency is the average contingency of the construction activities (i.e., 15\%) and professional and technical services (i.e., $0 \%$ ).

\section{F-3.6 Estimate Summary}

Table F-6 presents rough order of magnitude allocations of the methodologies used to develop the cost estimate for Module 2.

Table F-6. Rough order of magnitude allocations of the methodologies used to develop the cost estimate for Module 2.

\begin{tabular}{lc}
\hline Estimate Methodology & $\begin{array}{c}\text { Rough Order of Magnitude } \\
(\%)\end{array}$ \\
\hline Project team & 50 \\
Recorded actuals & 0 \\
Parametric & 0 \\
Vendor quotes & 0 \\
Other & 50 \\
Total & $\mathbf{1 0 0}$ \\
\hline
\end{tabular}

\section{F-3.7 Other Comments or Concerns Specific to the Estimate}

A. Activities have not been escalated.

B. Subcontractor labor costs reflect INL Site Stabilization Agreement craft labor rates.

C. CH2M-WG Idaho labor rates reflect fully burdened present day rates.

\section{F-3.8 Summary}

Table F-7 provides the capital cost summary for Module 2. 
Table F-7. Capital costs for Module 2: Operable Unit 7-13/14 Feasibility Study_Preloading Compaction, Project Number: 5992-P.

\begin{tabular}{|c|c|c|c|c|c|}
\hline Level & Description & $\begin{array}{c}\text { Subtotals }^{\mathrm{a}} \\
(\$)\end{array}$ & $\begin{array}{c}\text { Estimate }^{a} \\
(\$)\end{array}$ & $\begin{array}{c}\text { Contingency }^{\mathrm{a}, \mathrm{b}} \\
(\$)\end{array}$ & $\begin{array}{c}\text { Total }^{\mathrm{a}, \mathrm{c}} \\
(\$)\end{array}$ \\
\hline 1.1 & Construction activities & $1,062,000$ & - & - & - \\
\hline 1.1.1 & Mobilization and demobilization & 247,000 & - & - & - \\
\hline 1.1.1.1 & Construction equipment & - & 59,000 & 9,000 & 68,000 \\
\hline 1.1.1.2 & Submittals and implementation plans & 63,000 & - & - & - \\
\hline 1.1.1.2.9 & Final inspection report & - & 63,000 & 9,000 & 72,000 \\
\hline 1.1.1.6 & Security at construction site access gates & - & 125,000 & 19,000 & 144,000 \\
\hline 1.1.2 & Remediation & 815,000 & - & - & - \\
\hline 1.1.2.1 & Preloading compaction & 815,000 & - & - & - \\
\hline 1.1.2.1.1 & General conditions & - & 14,000 & 2,000 & 17,000 \\
\hline 1.1.2.1.2 & Site work & - & 801,000 & 120,000 & 921,000 \\
\hline 1.2 & Professional and technical services & 760,000 & - & - & - \\
\hline 1.2 .1 & Project management & - & 120,000 & - & 120,000 \\
\hline 1.2 .2 & Remedial design and remedial action work plan & 340,000 & - & - & - \\
\hline 1.2.2.1 & Remedial design & - & 232,000 & - & 232,000 \\
\hline 1.2.2.2 & Remedial action work plan & - & 108,000 & - & 108,000 \\
\hline \multirow[t]{3}{*}{1.2 .3} & Construction management & - & 300,000 & - & 300,000 \\
\hline & Total capital cost ${ }^{\mathrm{c}}$ & - & $1,822,000$ & 159,000 & $1,981,000$ \\
\hline & \multicolumn{5}{|c|}{$\begin{array}{l}\text { a. Values are rounded to the nearest } \$ 1,000 \text {. } \\
\text { b. Capital cost contingency is } 8.7 \% \text { of the estimate. } \\
\text { c. Totals were derived for the summation of nonrounded subcomponent values. Therefore, totals are not equal to the summation of the rounded subcomponent } \\
\text { values shown above. See Table F-3 for nonrounded totals. }\end{array}$} \\
\hline
\end{tabular}




\section{F-4. MODULE 3: EVAPOTRANSPIRATION CAP \\ F-4.1 Purpose}

SDA.

This estimate will be used as a cost-comparative tool to examine different options regarding the

\section{F-4.2 Scope of Work}

The objective of this project is to construct an ET surface barrier (i.e., cap) at the SDA. This barrier will cover approximately 105 acres.

Subcontractor mobilization consists of the following:

- Generate operational plans

- Generate a management self-assessment plan

- $\quad$ Mobilize temporary facilities and equipment.

Subcontractor demobilization consists of the following:

- Demobilize temporary facilities and equipment

- Generate a final inspection report following completion of cap construction.

Subcontractor site preparation consists of the following:

- Install a temporary water storage tank at the SDA to be used for compaction

- $\quad$ Relocate, extend, or demolish specified utilities and environmental monitoring equipment

- $\quad$ Contour the south and east sides of the SDA for drainage

- Install a new perimeter fence

- $\quad$ Demolish existing perimeter fence

- $\quad$ Abandon, in place, 25 of 50 existing monitoring wells and probes at the SDA

- $\quad$ Extend 25 of 50 existing monitoring wells and probes

- $\quad$ Extend 18 existing OCVZ system wells above the cap elevation and relocate three treatment units beyond the cap perimeter

- $\quad$ Extend 50 existing advanced tensiometers and install 50 new advanced tensiometers

- $\quad$ Construct a new access road at the perimeter of the SDA.

Subcontractor remediation consists of the following:

- $\quad$ Construct an ET surface barrier, consisting of grading fill, coarse rock layer, gravel filter, sand, fine-soil fill, and topsoil layers with perimeter armor protection

- $\quad$ Install OCVZ system piping from $18 \mathrm{OCVZ}$ system wells to three relocated OCVZ system treatment units

- Install six sampling wells outside the SDA following cap construction

- $\quad$ Conduct placement of ICs. 
Long-term monitoring and operations and maintenance activities include the following:

- $\quad$ Groundwater monitoring

- $\quad$ Vadose zone monitoring

- Biological surveillance

- Vegetation surveillance.

Subcontractor periodic costs include:

- Remedial action report following cap completion

- $\quad$ Annual summary reports during operations and maintenance period

- $\quad$ Five-year reviews during operations and maintenance period

- $\quad$ Operations and maintenance report following operations and maintenance period.

\section{F-4.3 Basis of the Estimate}

The following sequential process, rationale, and estimating methodologies were used to define activities, quantities, and resources that were used in preparation of this cost estimate.

A. Project scope and methodologies for this estimate were prepared from a project visit and discussions with the project team.

B. Costs were developed, using the Success $(\subset$ estimating software by U.S. Cost, to a level of detail consistent with available documents and information.

C. Initial information about the cap was obtained from the Preliminary Design for an Engineering Surface Barrier at the SDA (Mattson et al. 2004).

D. A revised drawing of the cap, a recapitulation template, contingency input, and costs and percentages for submittals, implementation plans, professional and technical services (e.g., project management, design, and construction management), and long-term operational and maintenance work were provided.

E. Engineering provided most of the estimated excavation and fill quantities.

F. Engineering provided the estimate of a grading-fill quantity of 1,186,389 in-place cubic yards.

G. ICP construction management provided material properties.

H. Cost-estimating judgment, coupled with on-INL Site unrecorded experiences and field observations of projects constructed and demolished at the INL Site, was used to establish rationale for structuring the work.

I. Estimate development was established using a detailed bottoms-up quantifiable technique. Activity descriptions, costs, and productions are based on these individual detailed item quantities.

J. New perimeter fencing costs were based on Estimate File Number 2448-G, "ICDF Complex Perimeter 6' Chain Link Fence and Gates," dated March 19, 2003. Appropriate general contractor markups for overhead, profit, and bond were applied to costs extracted from this previous estimate. 
K. Submittal and implementation plan costs and professional and technical periodic costs were based on costs extracted from Estimate File Number 5987, "ISG Project FY 2005FY 2011," dated August 3, 2004. Appropriate general subcontractor markups for overhead, profit, and bond were applied to costs extracted from this previous estimate.

L. Security costs are based on CH2M-WG Idaho Estimate File Number 5432. Appropriate general subcontractor markups for overhead, profit, and bond were applied to costs extracted from this previous estimate.

M. Costs for land-use restrictions, operations and maintenance activities, and cap maintenance were extracted from Zitnik et al. (2002). Appropriate general subcontractor markups for overhead, profit, and bond were applied to costs extracted from this previous estimate.

N. The following drawings were used to help define the scope of work and assumptions used to bound the estimate with quantities:

1. "Radioactive Waste Management Complex Diagram," Drawing Number 416511

2. "Basalt Topo Elevation," provided by geographical information system analyst

3. "Radioactive Waste Management Complex Area Map," Drawing Number 175603

4. "Radioactive Waste Management Complex Site Plan,” Drawing Number 175604

5. "RWMC Telephone/Communication Site Plan,” Drawing Number 175606.

O. Costs for relocation of OCVZ units were based on Estimate File Number 5989-G, "AR ProjectOCVZ Unit E Relocation Subcontract." Appropriate general subcontractor markups for overhead, profit, and bond were applied to costs extracted from this previous estimate.

P. Equipment rates are based on monthly rates for that particular piece of equipment, as published in 2005 Rental Rate Blue Book, published by PRIMEDIA Business Magazines and Media, Inc. These rates have been adjusted for use in Idaho and for a 50-hour week (216.67 optimum hours per month).

Q. The following resources were used to determine equipment and crew makeup, production rates, and production-adjustment factors:

1. 2005 Rental Rate Blue Book

2. 2005 RS Means Facilities Construction Cost Data

3. Caterpillar (CAT) Performance Handbook, Edition 30

4. Caterpillar (CAT) Performance Handbook, Edition 35

5. Construction Equipment Ownership and Operating Expense Schedule, U.S. Army Corps of Engineers, July 2003

6. Construction Planning, Equipment, and Methods, Fourth Edition, McGraw-Hill, 1985

7. EP 1110, U.S. Army Corps of Engineers, July 2003

8. Excavation and Materials Handling, Geology Engineering 465, University of Idaho, Spring 2005

9. Field Manual (FM) 5-434, U.S. Department of the Army, June 2000 
10. Interviews with local equipment vendors

11. Process Plant Cost Estimating Standards, Richardsons Engineering Services, Inc., 1995 Edition.

R. This estimate is based on the following adjustment factors:

1. Normal job site efficiency factor of $83 \%$

2. Overtime factor of $91.25 \%$

3. Machine shutdown periods, safety walk-downs, and personnel breaks of $97.50 \%$

4. Machine warm-up periods and plan of the day meetings of $95 \%$.

S. Fiscal Year 2006 INL Site Stabilization Agreement craft wage rates were used in this estimate.

\section{F-4.4 Assumptions}

\section{A. Schedule}

1. Figure F-3 illustrates the project schedule.

2. Construction operations will be performed for 9 to 10 months a year without weather impacts. Construction will be performed during this time, working one 10-hour shift per day, with a back shift that performs maintenance.

3. Field crews will demobilize equipment during a 2-month winter shutdown period each year to refurbish and replace equipment.

4. Durations are based on estimated crew productivity, regulatory reviews and approvals, and weather constraints inherent to the INL Site.

\section{B. Mobilization and demobilization (capital cost)}

1. ICP personnel will not require move monies.

2. Mobilization and demobilization costs for heavy earthwork equipment are captured in the remediation section of this cost estimate.

\section{Site preparation (capital cost)}

1. A perimeter fence will be installed around the SDA (3 $\mathrm{km}[10,000 \mathrm{ft}])$ and will be replaced once in 100 years.

2. Piping to connect OCVZ system probes to relocated OCVZ treatment units will not be installed until completion of cap construction (i.e., probes will not be operational during cap construction). 


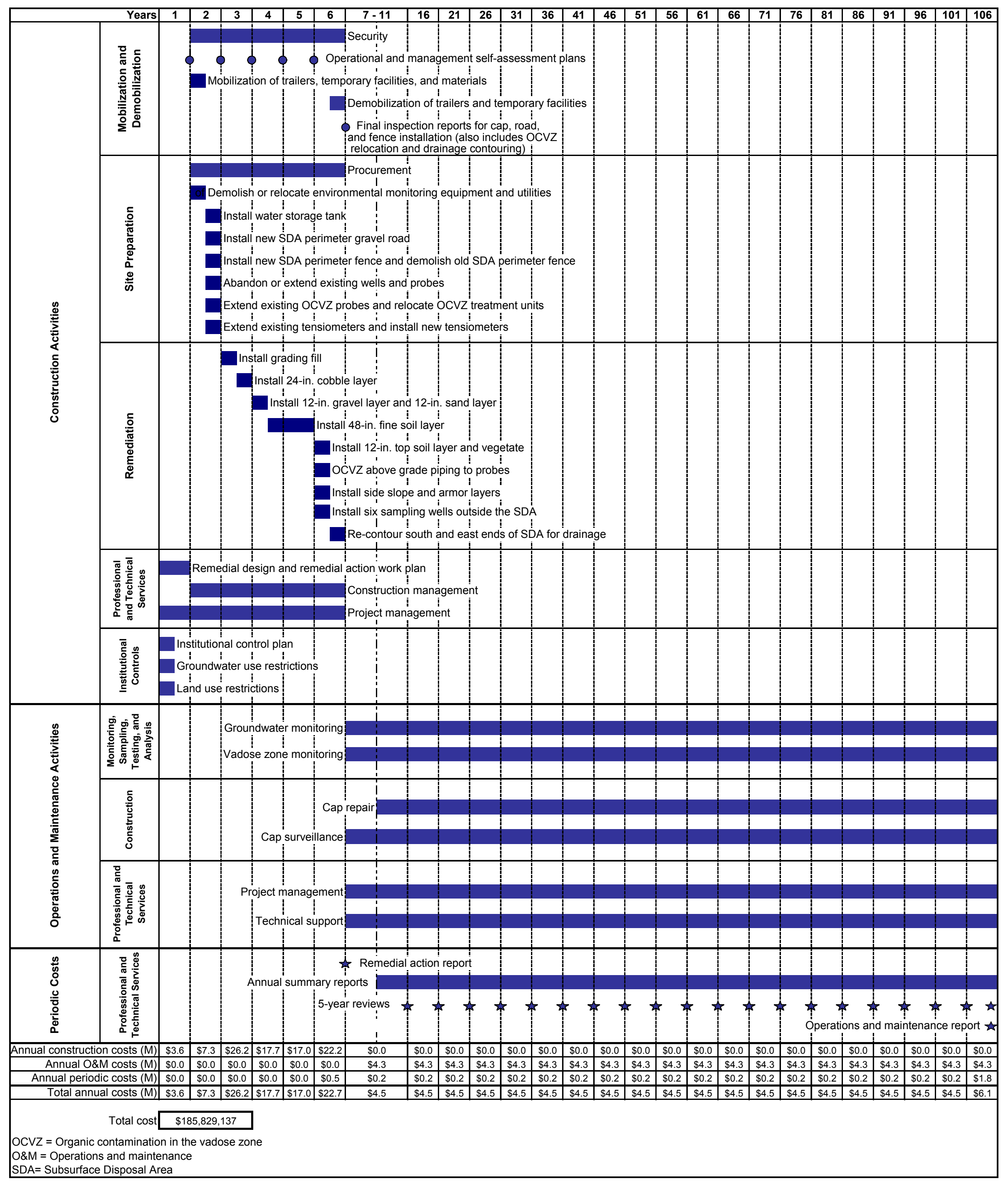

Figure F-3. Module 3 design, construction, and surveillance schedule for evapotranspiration surface barrier. 


\section{Remediation-ET surface barrier (capital cost)}

1. Soil removed from the existing SDA perimeter berm will be allowed for use as cut-to-fill materials.

2. All existing soil piles inside the SDA will be gone at the time of this project and, therefore, cannot be claimed as credit for use as fill material for this work.

3. INL Site Stabilization Agreement wages will apply, and no overtime (other than monies needed to work five 10-hour days) or shift differential is considered for this estimate.

4. Employee plan-of-the-day meetings will take place during equipment warm-up periods. No additional monies were included beyond that time period.

5. Borrow sources for fill materials are indicated in Table F-8.

6. Cap layer composition and thickness are indicated in Table F-9.

7. Borrow pits will not experience flooding.

8. A water supply (government-furnished equipment at no cost to this project) will be located within $152 \mathrm{~m}(500 \mathrm{ft})$ of the SDA and will provide enough gallons per minute to ensure required water is available. To help support the supply of water, a temporary storage tank will be needed to assist with filling of water equipment during peak-use times.

9. Temporary power will be provided east of the SDA at no cost to this project. Temporary power required at any of the borrow sources will be provided by the subcontractor using portable generators.

10. No rock will be encountered during excavation work at the SDA.

11. Utilities to be removed will not be required to be relocated or replaced at the end of this work. Other than existing electrical lines to the Advanced Mixed Waste Treatment Project Facility, all utilities listed in the detail sheets to be demolished are no longer needed.

12. No radiological or hazardous material will be encountered at any time during this project.

13. No secondary waste will be generated during construction of this project.

14. Equipment rates for this project have been estimated at Fiscal Year 2005 rates for new equipment. New rates will compensate for any machine breakdowns.

15. Optimum equipment use will be required to meet the construction schedule.

16. Because of maximum weight restrictions, scrapers will only be allowed to carry 33.5 bank cubic yards per load. 
Table F-8. Distances and sources of borrow materials for the cap or cover system for Module 3.

\begin{tabular}{|c|c|c|c|}
\hline Material & Issue & $\begin{array}{l}\text { One-Way } \\
\text { Haul Distance } \\
(\mathrm{mi})\end{array}$ & Source \\
\hline Topsoil & $\begin{array}{l}\text { This material would consist of organic silt loam and would } \\
\text { be used to construct a topsoil layer to support vegetation } \\
\text { on top of the surface barrier. }\end{array}$ & 13.7 & $\begin{array}{l}\text { This material would be unprocessed organic silt loam } \\
\text { from Rye Grass Flats. }\end{array}$ \\
\hline Compacted topsoil & $\begin{array}{l}\text { This material would consist of organic silt loam placed } \\
\text { below the topsoil layer. }\end{array}$ & 13.7 & $\begin{array}{l}\text { This material would be unprocessed organic silt loam } \\
\text { from Rye Grass Flats. }\end{array}$ \\
\hline Fine soil fill & $\begin{array}{l}\text { This material would be used to construct a compacted } \\
\text { engineered earth fill layer within the cap. }\end{array}$ & 13.7 & $\begin{array}{l}\text { This material would be unprocessed silt loam from } \\
\text { Rye Grass Flats. }\end{array}$ \\
\hline Sand & $\begin{array}{l}\text { This material would be used for the fine filter layer within } \\
\text { the cap. No identified bank run borrow areas are available } \\
\text { within the INL Site boundary. }\end{array}$ & 4 & $\begin{array}{l}\text { This material would be processed sand (from gravel } \\
\text { screening) from the Borax Gravel Pit. }\end{array}$ \\
\hline Gravel & $\begin{array}{l}\text { This material would be used for a coarse filter layer within } \\
\text { the cap and for surface barrier side-slope protection. A } \\
\text { sufficient quantity of good structural gravel is available } \\
\text { (crushing required). }\end{array}$ & 4 & $\begin{array}{l}\text { This material would be processed gravel from the } \\
\text { Borax Gravel Pit. }\end{array}$ \\
\hline Cobbles & $\begin{array}{l}\text { This material would be used as biotic barrier material if } \\
\text { coarse fractured basalt is not available or is not allowed for } \\
\text { such use. No borrow areas are identified within the INL } \\
\text { Site boundary. }\end{array}$ & 60 & $\begin{array}{l}\text { This material would be processed material transported } \\
\text { to the INL Site from the Idaho Falls area. }\end{array}$ \\
\hline Grading fill & $\begin{array}{l}\text { This material would be used for the first layer of the cap } \\
\text { (and for filling the Subsurface Disposal Area), which is } \\
\text { assumed to begin at elevation 5,012.0 ft. }\end{array}$ & 1.9 & $\begin{array}{l}\text { This material would be unprocessed gravel and sand } \\
\text { from the T12 Gravel Pit. }\end{array}$ \\
\hline $\begin{array}{l}\text { Coarse fractured } \\
\text { basalt }\end{array}$ & $\begin{array}{l}\text { This material would be used for surface barrier side-slope } \\
\text { protection. The majority of the mined coarse fractured } \\
\text { basalt material at the INL Site has been used for other } \\
\text { remedial actions at the INL Site. }\end{array}$ & 35 & $\begin{array}{l}\text { This material would be processed material mined at } \\
\text { Radio Cinder Butte, approximately } 26 \text { mi west of } \\
\text { Idaho Falls, near State Highway } 20 \text {. }\end{array}$ \\
\hline Rip-rap & $\begin{array}{l}\text { Rip-rap would be used for erosion control around the } \\
\text { perimeter of the cap. The majority of the mined rip-rap } \\
\text { material at the INL Site has been used for other remedial } \\
\text { actions at the INL Site. }\end{array}$ & 35 & $\begin{array}{l}\text { This material would be processed material mined at } \\
\text { Radio Cinder Butte, approximately } 26 \text { mi west of } \\
\text { Idaho Falls, near State Highway } 20 \text {. }\end{array}$ \\
\hline
\end{tabular}


Table F-9. Surface barrier design layers, thickness, and volume for Module 3.

\begin{tabular}{|c|c|c|c|}
\hline Layer & $\begin{array}{l}\text { Thickness } \\
\text { (in.) }\end{array}$ & $\begin{array}{l}\text { Approximate } \\
\text { Volume } \\
\left(\mathrm{yd}^{3}\right)\end{array}$ & Material Description \\
\hline Topsoil & 12 & 165,632 & $\begin{array}{l}\text { Unprocessed organic silt loam from } \\
\text { Rye Grass Flats }\end{array}$ \\
\hline Fine soil fill & 48 & 662,147 & Unprocessed silt loam from Rye Grass Flats \\
\hline Sand & 12 & 165,537 & $\begin{array}{l}\text { Processed sand (from gravel screening) from } \\
\text { the Borax Gravel Pit }\end{array}$ \\
\hline Gravel filter & 12 & 165,537 & Processed gravel from the Borax Gravel Pit \\
\hline Cobbles & 24 & 342,093 & $\begin{array}{l}\text { Processed material transported to the Idaho } \\
\text { National Laboratory Site from the Idaho Falls } \\
\text { area }\end{array}$ \\
\hline Grading fill & $0-120$ & $1,186,389$ & $\begin{array}{l}\text { Unprocessed gravel and sand from the } \\
\text { T12 Gravel Pit }\end{array}$ \\
\hline Gravel (side-slope protection) & $48 \times 120$ & 11,862 & Processed gravel from the Borax Gravel Pit \\
\hline $\begin{array}{l}\text { Coarse fractured basalt } \\
\text { (side-slope protection) }\end{array}$ & 12 & 5,230 & $\begin{array}{l}\text { Processed material mined at Radio Cinder } \\
\text { Butte, approximately } 26 \text { mi west of Idaho Falls, } \\
\text { near State Highway } 20\end{array}$ \\
\hline Rip-rap (side-slope protection) & 36 & 29,102 & $\begin{array}{l}\text { Processed material mined at Radio Cinder } \\
\text { Butte, approximately } 26 \text { mi west of Idaho Falls, } \\
\text { near State Highway } 20\end{array}$ \\
\hline
\end{tabular}

\section{E. Institutional controls (capital cost)}

1. Placement of ICs will include generation of an IC plan, restrictions on groundwater use, and restrictions on land use.

2. Groundwater-use restrictions will include limitations or restrictions on well drilling in the affected area or buffer zone.

3. Land-use restrictions will include repairing and replacing perimeter signs and installing permanent markers surrounding the SDA to delineate contamination. Permanent markers will be made of concrete and contain information about the type of contamination. The number of permanent markers is 12 , based on the large size of the SDA.

\section{F. Long-term operating and maintenance and monitoring (operations and maintenance cost)}

1. Operations and maintenance activities will continue after the surface barrier is complete. Operations and maintenance activities will include groundwater monitoring, vadose zone monitoring, biological surveillance, and vegetation surveillance.

2. Operable Unit 7-13/14 will fund groundwater and vadose zone monitoring for the first 5 years following project completion (costs are included in this estimate).

3. The INL Sitewide Monitoring Program will fund groundwater and vadose zone monitoring from Year 6 to the end of the IC period (costs are included in this estimate). 
4. Air monitoring of suspended contaminants, biological monitoring of animal tissue, soil monitoring for biotic transported contaminants, and monitoring of surface water runoff are captured within the contingency of this cost estimate module. Therefore, costs are not included within this estimate.

5. After topsoil has been placed as the final layer on the surface barrier, it will be seeded to provide vegetative cover that will reduce erosion. However, because of the arid climate of the INL Site, an extended period of time will be required to establish a permanent vegetative cover. Erosion of the uppermost layers of the surface barrier during snowmelt will occur during the years immediately following construction; therefore, repairs and reseeding will be required.

6. Ongoing maintenance of the surface barrier will be required in perpetuity after construction is completed. Frequent maintenance will be required during years immediately following construction to repair damage from erosion and to establish a permanent vegetative cover. In addition, the added weight of the surface barrier is expected to result in increased settlement during the initial years following construction. Some areas of the surface barrier will require ongoing maintenance to repair damage resulting from settlement. Annual maintenance and repairs will be required during the first 5 years following construction. Ongoing maintenance and repairs will continue every 5 years concurrent with the 5 -year review process.

7. Environmental monitoring will continue for 100 years following issuance of the ROD. Estimated monitoring requirements and the projected labor effort are summarized in Table F-10. Estimated surveillance requirements and the projected labor effort are summarized in Table F-11. Estimated costs of the required laboratory analyses are provided in Table F-12.

8. This estimate does not include costs to maintain and operate the OCVZ system treatment units or costs to sample and analyze OCVZ vapor ports for volatile organics.

9. A 10\% allocation is included for replacement parts and equipment for existing wells and lysimeters.

10. Reports will be prepared annually, summarizing analytical and field data.

11. Contingency percentage (i.e., scope plus bid) for the operations and maintenance program uses the same contingency percentages used for capital costs.

12. Project management for the operations and maintenance program is $5 \%$ of overall operations and maintenance cost, plus contingency.

13. Technical support for the operations and maintenance program is $15 \%$ of overall operations and maintenance cost, plus contingency.

\section{G. Periodic costs}

Reviews will be conducted once every 5 years for 100 years. Five-year reviews will not result in additions or modifications of the remedy. No cost is included in the estimate for remedy additions or modifications. 
Table F-10. Module 3 estimated long-term monitoring program.

\begin{tabular}{|c|c|c|c|c|}
\hline Media & Monitoring Stations & Monitoring Frequency & $\begin{array}{l}\text { Estimated Labor } \\
\text { (hours per event) }\end{array}$ & Other Assumptions \\
\hline Groundwater & 21 monitoring wells & $\begin{array}{l}\text { Semiannually for } 5 \text { years; } \\
\text { annually for } 95 \text { years }\end{array}$ & $\begin{array}{l}\text { Two and one-half personnel (staff) for } \\
10.5 \text { days }=262 \text { hours }\end{array}$ & $\begin{array}{l}\text { Maximum depth of screened interval is } 600 \mathrm{ft} \text {; } \\
\text { four quality assurance and quality control samples } \\
\text { per event. Analyses include characteristic leaching } \\
\text { procedures for metals, nitrate/nitrite, VOCs, } \\
\text { semi-VOCs, gross alpha and beta, Sr-90, Tc-99, } \\
\text { U-234, U-235/236, U-238, Am-241, gamma } \\
\text { isotopes, C-14, I-129, pH, turbidity, total } \\
\text { suspended solids, and total dissolved solids. }\end{array}$ \\
\hline \multirow[t]{3}{*}{ Vadose zone } & 100 lysimeters & Annually for 100 years & $\begin{array}{l}\text { Four personnel for } 4 \text { days and } \\
\text { six personnel for } 2.5 \text { days }=310 \text { hours }\end{array}$ & $\begin{array}{l}\text { Lysimeters will be sampled in late spring. Assume } \\
35 \% \text { of lysimeters yield adequate liquid for } \\
\text { analysis. Assume one additional quality assurance } \\
\text { and quality control sample. Samples will be } \\
\text { prioritized for groundwater analytes. }\end{array}$ \\
\hline & 20 vapor ports & $\begin{array}{l}\text { Quarterly for } 5 \text { years; } \\
\text { annually for } 95 \text { years }\end{array}$ & Three personnel for 2 days $=60$ hours & $\begin{array}{l}\text { Vapor port samples analyzed for C-14 and tritium } \\
\text { only. }\end{array}$ \\
\hline & 100 tensiometers & Continuous data logger & $\begin{array}{l}\text { Maintenance }=200 \text { hours } \\
\text { Data evaluation }=100 \text { hours } \\
\text { Data reporting }=160 \text { hours }\end{array}$ & $\begin{array}{l}\text { Local surface water infiltration will be monitored } \\
\text { using tensiometers installed in either undisturbed } \\
\text { surficial soil or water-storage layers within the } \\
\text { engineered surface barrier. Maintenance and data } \\
\text { evaluation occur quarterly, and data reporting } \\
\text { occurs annually. }\end{array}$ \\
\hline
\end{tabular}

$\mathrm{VOC}=$ volatile organic compound

Table F-11. Module 3 estimated long-term surveillance program.

\begin{tabular}{|c|c|c|c|c|}
\hline Media & Monitoring Stations & Monitoring Frequency & $\begin{array}{l}\text { Estimated Labor } \\
\text { (hours per event) }\end{array}$ & Other Assumptions \\
\hline Biological & Animal intrusion & Annually for 100 years & $\begin{array}{l}\text { Two personnel (staff) for } \\
1 \text { day }=20 \text { hours }\end{array}$ & Requires two staff once per year. \\
\hline Vegetation & Entire cap surface & $\begin{array}{l}\text { Annually for } 5 \text { years; } \\
\text { every } 5 \text { years for } \\
95 \text { years }\end{array}$ & $\begin{array}{l}\text { Two personnel (staff) for } \\
1 \text { day }=20 \text { hours }\end{array}$ & $\begin{array}{l}\text { Perform one inspection per year in early fall for } \\
5 \text { years. Reseed } 10 \text { acres each year for } 5 \text { years } \\
\text { ( } 50 \text { acres total). Perform one inspection every } \\
5 \text { years in early fall; thereafter, for } 95 \text { years. } \\
\text { Reseed } 10 \text { acres every } 5 \text { years for } 95 \text { years. }\end{array}$ \\
\hline
\end{tabular}


Table F-12. Module 3 estimated analytical requirements.

Vadose Zone Event

\begin{tabular}{|c|c|c|c|c|}
\hline \multirow[b]{2}{*}{ Target Analyte } & \multirow[b]{2}{*}{$\begin{array}{l}\text { Unit Cost } \\
\text { (\$) }\end{array}$} & \multirow[b]{2}{*}{$\begin{array}{l}\text { Groundwater Event } \\
\text { (25 samples) } \\
(\$)\end{array}$} & \multicolumn{2}{|c|}{ Vadose Zone Event } \\
\hline & & & $\begin{array}{l}\text { Lysimeter Event } \\
\text { (36 samples) } \\
\text { (\$) }\end{array}$ & $\begin{array}{c}\text { Vapor Port Event } \\
\text { (20 samples) } \\
(\$)\end{array}$ \\
\hline Volatile organics & 169 & 4,221 & 6,078 & - \\
\hline Semivolatile organics & 211 & 5,276 & 7,598 & - \\
\hline Metals & 169 & 4,221 & 6,078 & - \\
\hline Nitrate/nitrite & 15 & 386 & 555 & - \\
\hline Gross alpha and beta & 66.64 & 1,666 & 2,399 & - \\
\hline Sr-90 & 128.20 & 3,205 & 4,615 & - \\
\hline Tc-99 & 89.35 & 2,234 & 3,217 & - \\
\hline U-234, $-235 / 236$, and -238 & 180.65 & 4,516 & 6,503 & - \\
\hline Am-241 & 180.65 & 4,516 & 6,503 & - \\
\hline $\mathrm{C}-14$ & 93.24 & 2,331 & 3,357 & 1,865 \\
\hline $\mathrm{I}-129$ & 93.24 & 2,331 & 3,357 & - \\
\hline Tritium & 46.27 & 1,157 & 1,666 & 925 \\
\hline Gamma isotopes & 128.21 & 3,205 & 4,616 & - \\
\hline Analytical subtotal & - & 39,265 & 56,542 & 2,790 \\
\hline Procurement (12\%) & - & 4,712 & 6,785 & 335 \\
\hline Project adder ${ }^{\mathrm{a}}$ & - & 1,543 & 2,221 & 1,234 \\
\hline Validation procurement $\mathrm{t}^{\mathrm{a}}$ & 一 & 2,072 & 2,984 & 1,658 \\
\hline Total $^{b}$ & - & 47,592 & 68,532 & 6,017 \\
\hline \multicolumn{5}{|l|}{ Assumptions: } \\
\hline \multicolumn{5}{|c|}{$\begin{array}{l}\text { 1. Two task order statements for entire project, samples are batched to maximize efficiency for analysis, shipping } \\
5-10 \text { samples per shipment, all shipments for a sampling event sent within a 2-week period. Normal turn around time } \\
\text { (i.e., } 35 \text { days). } \\
\text { 2. Metals: contract laboratory program metals, nitrate as nitrogen through EPA } 353.1 . \\
\text { 3. Semivolatile-organic analysis: Priority Pollutant List SW-846 8270C. } \\
\text { 4. Volatile-organic analysis: Priority Pollutant List SW-846 8260B. }\end{array}$} \\
\hline \multicolumn{5}{|c|}{$\begin{array}{l}\text { a. Adder costs included task order statement, sampling and analysis plan table, data review, data tracking, data entry (Energy } \\
\text { Research Information System) upload, invoicing, and validation. } \\
\text { b. Listed within the "Other" column in the cost estimate. }\end{array}$} \\
\hline
\end{tabular}




\section{F-4.5 Contingency Guideline Implementation}

The total capital cost contingency for Module 3 is $26.50 \%$. This contingency is the average contingency of construction activities (i.e., $30 \%$ ) and professional and technical services (i.e., $0 \%$ ).

The total operations and maintenance cost contingency for Module 3 is $23.81 \%$. This contingency is the average contingency of the monitoring, sampling, and testing activities (i.e., 30\%); construction activities (i.e., 30\%); and professional and technical services (i.e., $0 \%$ ).

The total periodic cost contingency for Module 3 is $0 \%$ (the contingency for the professional and technical services).

\section{F-4.6 Estimate Summary}

Table F-13 provides rough order of magnitude allocations of the methodologies used to develop the cost estimate for Module 3.

Table F-13. Rough order of magnitude allocations of the methodologies used to develop the cost estimate for Module 3.

\begin{tabular}{lc} 
Estimate Methodology & $\begin{array}{c}\text { Rough Order of Magnitude } \\
(\%)\end{array}$ \\
\hline Project team & 65 \\
Recorded actuals & 0 \\
Parametric & 0 \\
Vendor quotes & 0 \\
Other (estimating manuals) & 35 \\
Total & $\mathbf{1 0 0}$ \\
\hline
\end{tabular}

\section{F-4.7 Other Comments or Concerns Specific to the Estimate}

A. All costs reflect present day costs. No escalation is included in the estimate.

B. Costs for Idaho state sales tax $(5 \%)$ on material purchases are included in the estimate, where applicable.

C. Because work activities identified in this estimate will not begin until after September 30, 2005, no ICP general and administrative costs have been included in this estimate in accordance with recent direction received by Estimating Services.

\section{F-4.8 Summary}

Tables F-14 through F-17 present the summary costs for Module 3. 
F-58 
Table F-14. Capital costs for Module 3: Operable Unit 7-13/14 Feasibility Study—Evapotranspiration Cap, Project Number: 5992.

\begin{tabular}{|c|c|c|c|c|c|}
\hline Level & Description & $\begin{array}{l}\text { Subtotals }^{\mathrm{a}} \\
(\$)\end{array}$ & $\begin{array}{l}\text { Estimate }^{a} \\
(\$)\end{array}$ & $\begin{array}{l}\text { Contingency } y^{\mathrm{a}, \mathrm{b}} \\
\text { (\$) }\end{array}$ & $\begin{array}{c}\text { Total }^{\mathrm{a}, \mathrm{c}} \\
(\$)\end{array}$ \\
\hline 1.1 & Construction activities & $65,666,000$ & - & - & - \\
\hline 1.1 .1 & Mobilization and demobilization & $4,592,000$ & - & - & - \\
\hline 1.1.1.1 & Mobilization of temporary facilities and materials & - & 129,000 & 39,000 & 168,000 \\
\hline 1.1 .1 .2 & Submittals and implementation plans & $1,159,000$ & - & - & - \\
\hline 1.1.1.2.1 & Operational and layout plan & - & 242,000 & 73,000 & 315,000 \\
\hline 1.1.1.2.2 & Remedial action, monitoring, and control plan & - & 42,000 & 13,000 & 55,000 \\
\hline 1.1.1.2.3 & Industrial hygiene exposure and sample plan & - & 36,000 & 11,000 & 47,000 \\
\hline 1.1.1.2.4 & Management self-assessment plan & - & 266,000 & 80,000 & 346,000 \\
\hline 1.1 .1 .2 .5 & Well abandonment plan & - & 186,000 & 56,000 & 242,000 \\
\hline 1.1.1.2.6 & Quality control plan & - & 65,000 & 19,000 & 84,000 \\
\hline 1.1.1.2.7 & Final inspection report & - & 323,000 & 97,000 & 419,000 \\
\hline 1.1.1.3 & Security at construction site access gates & - & $3,226,000$ & 968,000 & $4,193,000$ \\
\hline 1.1.1.4 & Demobilization of temporary facilities & - & 77,000 & 23,000 & 101,000 \\
\hline 1.1.2 & Site preparation work & $3,897,000$ & - & - & - \\
\hline 1.1.2.1 & Cap or cover & $3,897,000$ & - & - & - \\
\hline 1.1.2.1.1 & Install temporary water fill station storage tank for compaction & - & 65,000 & 19,000 & 84,000 \\
\hline 1.1 .2 .1 .2 & $\begin{array}{l}\text { Relocate and demolish utilities and environmental monitoring } \\
\text { equipment }\end{array}$ & - & 677,000 & 203,000 & 881,000 \\
\hline 1.1.2.1.3 & Construct new SDA perimeter gravel road & - & 354,000 & 106,000 & 460,000 \\
\hline 1.1.2.1.4 & Install new perimeter fence and gates & - & 774,000 & 232,000 & $1,006,000$ \\
\hline 1.1 .2 .1 .5 & Demolition of existing perimeter fence and LLW Pit fence & - & 93,000 & 28,000 & 121,000 \\
\hline 1.1.2.1.6 & Abandon or extend existing wells and probes & - & 376,000 & 113,000 & 489,000 \\
\hline 1.1.2.1.7 & Extend existing OCVZ system probes and relocate treatment units & 580,000 & - & - & - \\
\hline 1.1.2.1.7.1 & Extend 18 existing OCVZ system probes & - & 225,000 & 67,000 & 292,000 \\
\hline $1.1 .2 \cdot 1.7 .2$ & Relocate treatment Unit D & - & 118,000 & 36,000 & 154,000 \\
\hline 1.1.2.1.7.3 & Relocate treatment Unit E & - & 118,000 & 36,000 & 154,000 \\
\hline 1.1.2.1.7.4 & Relocate treatment Unit F & - & 118,000 & 36,000 & 154,000 \\
\hline 1.1.2.1.8 & $\begin{array}{l}\text { Extend existing advanced tensiometers and install new advanced } \\
\text { tensiometers }\end{array}$ & 978,000 & - & - & - \\
\hline 1.1.2.1.8.1 & Maintain and extend 50 existing advanced tensiometers & - & 16,000 & 5,000 & 21,000 \\
\hline 1.1.2.1.8.2 & Install 50 new advanced tensiometers & - & 639,000 & 192,000 & 830,000 \\
\hline 1.1.2.1.8.3 & Well completion & - & 100,000 & 30,000 & 130,000 \\
\hline 1.1.2.1.8.4 & Probe cost for installation of new advanced tensiometers & - & 97,000 & 29,000 & 126,000 \\
\hline 1.1 .2 .1 .8 .5 & Logger cost for installation of new advanced tensiometers & - & 65,000 & 19,000 & 84,000 \\
\hline 1.1.2.1.8.6 & $\begin{array}{l}\text { Network design cost for installation of new advanced } \\
\text { tensiometers }\end{array}$ & - & 62,000 & 19,000 & 81,000 \\
\hline 1.1 .3 & Remediation & $57,177,000$ & - & - & - \\
\hline 1.1 .3 .1 & Cap or cover & $57,177,000$ & - & - & - \\
\hline 1.1.3.1.1 & Construct ET surface barrier & $56,105,000$ & - & - & - \\
\hline 1.1.3.1.1.1 & Install grading fill—layer one & - & $9,214,000$ & $2,764,000$ & $11,979,000$ \\
\hline 1.1.3.1.1.2 & Install cobble for biointrusion and gas venting - layer two & - & 521,000 & 156,000 & 677,000 \\
\hline 1.1.3.1.1.3 & Install gravel filter-layer three & - & $3,588,000$ & $1,076,000$ & $4,664,000$ \\
\hline 1.1.3.1.1.4 & Install sand-layer four & - & $1,806,000$ & 542,000 & $2,348,000$ \\
\hline 1.1.3.1.1.5 & Install fine soil fill-layer five & - & $9,315,000$ & $2,795,000$ & $12,110,000$ \\
\hline 1.1.3.1.1.6 & Install topsoil-layer six & - & $4,241,000$ & $1,272,000$ & $5,514,000$ \\
\hline 1.1.3.1.1.7 & Install side-slope gravel & - & $2,053,000$ & 616,000 & $2,668,000$ \\
\hline 1.1.3.1.1.8 & Install side-slope basalt & - & $17,148,000$ & $5,144,000$ & $22,292,000$ \\
\hline 1.1.3.1.1.9 & Install side-slope rip-rap & - & $4,219,000$ & $1,266,000$ & $5,485,000$ \\
\hline 1.1.3.1.1.10 & Vegetate cap and construction area & - & 302,000 & 91,000 & 393,000 \\
\hline 1.1.3.1.1.11 & Install OCVZ abovegrade piping to probes & - & 561,000 & 168,000 & 730,000 \\
\hline $1.1 .3 \cdot 1.1 .12$ & Install six sampling wells outside the SDA & - & $3,135,000$ & 941,000 & $4,076,000$ \\
\hline 1.1.3.1.2 & Contour south and east ends outside the SDA for drainage & - & $1,072,000$ & 322,000 & $1,394,000$ \\
\hline 1.2 & Professional and technical services & $\mathbf{8 , 5 3 7 , 0 0 0}$ & - & - & - \\
\hline 1.2 .1 & Project management & - & $4,268,000$ & - & $4,268,000$ \\
\hline 1.2 .2 & Remedial design and remedial action work plan & $2,561,000$ & - & - & - \\
\hline 1.2 .2 .1 & Remedial design & - & $1,707,000$ & - & $1,707,000$ \\
\hline 1.2 .2 .2 & Remedial action work plan & - & 854,000 & - & 854,000 \\
\hline 1.2 .3 & Construction management & - & $1,707,000$ & - & $1,707,000$ \\
\hline 1.3 & Institutional controls & 133,000 & - & - & - \\
\hline 1.3 .1 & Institutional controls plan & - & 17,000 & - & 17,000 \\
\hline 1.3 .2 & Groundwater use restrictions & - & 26,000 & - & 26,000 \\
\hline 1.3 .3 & Land use restrictions & 90,000 & - & - & - \\
\hline 1.3 .3 .1 & Perimeter markers & - & 77,000 & - & 77,000 \\
\hline \multirow[t]{3}{*}{1.3 .3 .2} & Repair and replace perimeter signs & - & 13,000 & - & 13,000 \\
\hline & Total capital cost ${ }^{\mathrm{c}}$ & - & $74,335,000$ & $19,700,000$ & $94,035,000$ \\
\hline & $\begin{array}{l}\text { a. Values are rounded to the nearess } \$ 1,000 . \\
\text { b. Capital cost contingency is } 26.5 \% \text { of the estimate. } \\
\text { c. Totals were derived for the summation of nonrounded subcomponent values. Therefore, tot } \\
\text { See Table F-3 for nonrounded totals. } \\
\text { LLW = low-level waste } \\
\text { OCVZ = Organic Contamination in the Vadose Zone } \\
\text { SDA = Subsurface Disposal Area }\end{array}$ & not equal to t & nmation of the & led subcomponent & ues shown above. \\
\hline
\end{tabular}


Table F-15. Summary operations and maintenance costs for Module 3: Operable Unit 7-13/14 Feasibility Study_Evapotranspiration Cap, Project Number: 5992.

\begin{tabular}{|c|c|c|c|c|c|}
\hline Level & Description & $\begin{array}{l}\text { Subtotals }{ }^{\mathrm{a}} \\
(\$)\end{array}$ & $\begin{array}{c}\text { Estimate }^{\mathrm{a}} \\
(\$)\end{array}$ & $\begin{array}{c}\text { Contingency }^{\mathrm{a}, \mathrm{b}} \\
(\$)\end{array}$ & $\begin{array}{c}\text { Total }^{\mathrm{a}} \\
(\$)\end{array}$ \\
\hline 2.1 & Monitoring, sampling, testing, and analysis & $45,292,000$ & - & - & - \\
\hline 2.1 .1 & Groundwater monitoring & $9,967,000$ & - & - & - \\
\hline 2.1.1.1 & $\begin{array}{l}\text { Groundwater monitoring, semiannually for } 5 \text { years } \\
\text { (10 sampling events) }\end{array}$ & - & 813,000 & 244,000 & $1,057,000$ \\
\hline 2.1.1.2 & $\begin{array}{l}\text { Groundwater monitoring, annually for } 95 \text { years } \\
\text { (95 sampling events) }\end{array}$ & - & $7,723,000$ & $2,317,000$ & $10,039,000$ \\
\hline 2.1.1.3 & $\begin{array}{l}\text { Replacement parts and equipment costs (assume } 10 \% \text { of total } \\
\text { groundwater monitoring costs) }\end{array}$ & - & $1,432,000$ & 430,000 & $1,861,000$ \\
\hline 2.1 .2 & Vadose zone monitoring & $35,325,000$ & - & - & - \\
\hline 2.1.2.1 & Sample 100 lysimeters, one time per year, in late spring & - & $11,172,000$ & $3,352,000$ & $14,523,000$ \\
\hline 2.1.2.2 & $\begin{array}{l}\text { Sample and analyze } 20 \text { vapor ports four times per year for } \\
5 \text { years }\end{array}$ & - & 266,000 & 80,000 & 346,000 \\
\hline 2.1.2.3 & $\begin{array}{l}\text { Sample and analyze } 20 \text { vapor ports, one time per year } \\
\text { thereafter for } 95 \text { years }\end{array}$ & - & $1,265,000$ & 379,000 & $1,644,000$ \\
\hline 2.1.2.4 & Analyze 100 advanced tensiometers & $17,548,000$ & - & 一 & - \\
\hline 2.1.2.4.1 & $\begin{array}{l}\text { Maintenance of advanced tensiometers four times per year } \\
\text { for } 100 \text { years }\end{array}$ & - & $10,322,000$ & $3,097,000$ & $13,419,000$ \\
\hline 2.1.2.4.2 & $\begin{array}{l}\text { Data evaluation of advanced tensiometers four times per } \\
\text { year for } 100 \text { years }\end{array}$ & - & $5,161,000$ & $1,548,000$ & $6,710,000$ \\
\hline 2.1.2.4.3 & $\begin{array}{l}\text { Data reporting of advanced tensiometers one time per year } \\
\text { for } 100 \text { years }\end{array}$ & - & $2,064,000$ & 619,000 & $2,684,000$ \\
\hline 2.1.2.5 & $\begin{array}{l}\text { Replacement parts and equipment costs (assume 10\% of total } \\
\text { vadose zone monitoring costs) }\end{array}$ & - & $5,074,000$ & $1,522,000$ & $6,596,000$ \\
\hline 2.2 & Construction activities & $10,206,000$ & - & - & - \\
\hline 2.2 .1 & Remedy failure or replacement & $9,677,000$ & - & - & - \\
\hline 2.2.1.1 & Cap or cover maintenance and repairs & - & $9,677,000$ & $2,903,000$ & $12,580,000$ \\
\hline 2.2 .2 & Cap surveillance & 528,000 & - & - & - \\
\hline 2.2.2.1 & Biological surveillance & 30,000 & 一 & 一 & 一 \\
\hline 2.2.2.1.1 & $\begin{array}{l}\text { Intrusion surveillance with two people two times the first } \\
5 \text { years }\end{array}$ & - & 3,000 & 1,000 & 4,000 \\
\hline 2.2.2.1.2 & $\begin{array}{l}\text { Intrusion surveillance with two people one time every } \\
5 \text { years, thereafter for } 95 \text { years }\end{array}$ & - & 27,000 & 8,000 & 35,000 \\
\hline 2.2.2.2 & Vegetation surveillance & 499,000 & 一 & 一 & 一 \\
\hline 2.2.2.2.1 & Perform one inspection per year in early fall for 5 years & - & 7,000 & 2,000 & 9,000 \\
\hline 2.2.2.2.2 & Reseed 10 acres each year for 5 years ( 50 acres total) & - & 97,000 & 29,000 & 126,000 \\
\hline 2.2.2.2.3 & $\begin{array}{l}\text { Perform one inspection in early fall every } 5 \text { years thereafter } \\
\text { for } 95 \text { years }\end{array}$ & - & 27,000 & 8,000 & 35,000 \\
\hline 2.2.2.2.4 & Reseed 10 acres every 5 years for 95 years & - & 368,000 & 110,000 & 478,000 \\
\hline 2.3 & Professional and technical services & $14,429,000$ & - & 一 & - \\
\hline 2.3 .1 & Project management & - & $3,607,000$ & - & $3,607,000$ \\
\hline \multirow[t]{3}{*}{2.3 .2} & Technical support & - & $10,822,000$ & - & $10,822,000$ \\
\hline & Total operational and maintenance $\operatorname{cost}^{\mathrm{c}}$ & - & $69,927,000$ & $69,927,000$ & $16,649,000$ \\
\hline & \multicolumn{5}{|c|}{$\begin{array}{l}\text { a. Values are rounded to the nearest } \$ 1,000 \text {. } \\
\text { b. Operational and maintenance cost contingency is } 23.8 \% \text { of the estimate. } \\
\text { c. Totals were derived for the summation of nonrounded subcomponent values. Therefore, totals are not equal to the summation of the rounded subcomponent values shown above. } \\
\text { See Table F-3 for nonrounded totals. }\end{array}$} \\
\hline
\end{tabular}

Table F-16. Summary periodic costs for Module 3: Operable Unit 7-13/14 Feasibility Study_Evapotranspiration Cap, Project Number: 5992.

\begin{tabular}{|c|c|c|c|c|c|}
\hline Level & Description & $\begin{array}{c}\text { Subtotals } \\
(\$)\end{array}$ & $\begin{array}{c}\text { Estimate } \\
(\$)\end{array}$ & $\begin{array}{c}\text { Contingency }^{\mathrm{a}, \mathrm{b}} \\
(\$)\end{array}$ & $\begin{array}{c}\text { Total }^{\mathrm{a}, \mathrm{c}} \\
(\$)\end{array}$ \\
\hline 3.1 & Professional and technical services (periodic) & $5,218,000$ & - & - & - \\
\hline 3.1 .2 & Annual summary reports & - & $1,935,000$ & - & $1,935,000$ \\
\hline 3.1 .3 & 5-year reviews & - & $1,161,000$ & - & $1,161,000$ \\
\hline 3.1 .4 & \multicolumn{5}{|c|}{$\begin{array}{l}\text { a. Values are rounded to the nearest } \$ 1,000 \text {. } \\
\text { b. Periodic cost contingency is } 0.0 \% \text { of the estimate. } \\
\text { c. Totals were derived for the summation of nonrounded subcomponent values. Therefore, totals are not equal to the summation of the rounded subcomponent values } \\
\text { shown above. See Table F-3 for nonrounded totals. }\end{array}$} \\
\hline
\end{tabular}

Table F-17. Summary total costs for Module 3: Operable Unit 7-13/14 Feasibility Study_Evapotranspiration Cap, Project Number: 5992.

\begin{tabular}{|c|c|c|c|}
\hline & $\begin{array}{c}\text { Estimate } \\
(\$)\end{array}$ & $\begin{array}{c}\text { Contingency }^{\mathrm{a}} \\
(\$)\end{array}$ & $\begin{array}{c}\text { Total } \\
(\$)\end{array}$ \\
\hline Total cost for evapotranspiration cap & $149,480,000$ & $36,349,000$ & $185,829,000$ \\
\hline
\end{tabular}




\section{F-5. MODULE 4: SIMPLIFIED EVAPOTRANSPIRATION SURFACE BARRIER WITH NO BIOINTRUSION AND GAS VENT LAYER \\ F-5.1 Purpose}

This estimate will be used as a cost-comparative tool to examine different options regarding the SDA.

\section{F-5.2 Scope of Work}

The objective of this project is to construct an ET surface barrier without gas vent layers in the SDA. This barrier will cover approximately 105 acres in the SDA.

Subcontractor mobilization consists of the following:

- Generate operational plans

- Generate a management self-assessment plan

- Mobilize temporary facilities and equipment.

Subcontractor demobilization consists of the following:

- Demobilize temporary facilities and equipment

- Generate a final inspection report following completion of cap construction.

Subcontractor site preparation consists of the following:

- Install a temporary water storage tank in the SDA to be used for compaction

- $\quad$ Relocate, extend, or demolish specified utilities and environmental monitoring equipment

- $\quad$ Contour south and east ends outside the SDA area for drainage

- Install a new perimeter fence

- Demolish existing perimeter fence

- $\quad$ Abandon, in-place, 25 of 50 existing SDA monitoring wells and probes

- $\quad$ Extend 25 of 50 existing monitoring wells and probes

- $\quad$ Extend 18 existing OCVZ system wells above cap elevation and relocate three OCVZ system treatment units beyond cap perimeter

- $\quad$ Extend 50 existing advanced tensiometers and install 50 new advanced tensiometers

- $\quad$ Construct a new access road at the SDA perimeter.

Subcontractor remediation consists of the following:

- $\quad$ Construct an ET surface barrier without gas vent layers, consisting of grading fill and topsoil layers with no perimeter armor protection

- Install OCVZ system piping from 18 OCVZ system wells to three relocated OCVZ system treatment units 
- Install six sampling wells outside the SDA following cap construction

- $\quad$ Conduct placement of ICs

- Work scope excludes installation of gas-collection piping (Option 2b) and costs for related impacts to the cap construction.

Long-term monitoring and operations and maintenance activities include the following:

- $\quad$ Groundwater monitoring

- $\quad$ Vadose zone monitoring

- Biological surveillance

- Vegetation surveillance.

Subcontractor periodic costs include:

- Remedial action report following cap completion

- $\quad$ Annual summary reports during operations and maintenance period

- $\quad$ Five-year reviews during operations and maintenance period

- $\quad$ Operations and maintenance report following operations and maintenance period.

\section{F-5.3 Basis of the Estimate}

The following sequential process, rationale, and estimating methodologies were used to define activities, quantities, and resources that were used in preparation of this cost estimate.

A. Project scope and methodologies for this estimate were prepared from a project visit and discussions with the project team.

B. Costs were developed, using the Success $₫$ estimating software by U.S. Cost, to a level of detail consistent with available documents and information.

C. Initial information about the cap was obtained from the Preliminary Design for an Engineering Surface Barrier at the SDA (Mattson et al. 2004).

D. A revised drawing of the cap, a recapitulation template, contingency input, and costs and percentages for submittals, implementation plans, professional and technical services (e.g., project management, design, and construction management), and long-term operational and maintenance work were provided.

E. Engineering provided most of the estimated excavation and fill quantities.

F. Engineering provided the estimate of a grading fill quantity of 1,186,389 in-place cubic yards.

G. ICP construction management provided material properties.

H. Cost estimating judgment, coupled with on-INL Site unrecorded experiences and field observations of projects constructed and demolished at the INL Site, was used to establish rationale for structuring of the work. 
I. Estimate development was established using a detailed bottoms-up quantifiable technique. Activity descriptions, costs, and productions are based on these individual detailed item quantities.

J. New perimeter fencing costs were based on Estimate File Number 2448-G, "ICDF Complex Perimeter 6' Chain Link Fence and Gates," dated March 19, 2003. Appropriate general contractor markups for overhead, profit, and bond were applied to costs extracted from this previous estimate.

K. Submittal and implementation plan costs and professional and technical periodic costs were based on costs extracted from Estimate File Number 5987, "ISG Project FY 2005-FY 2011," dated August 3, 2004. Appropriate general contractor markups for overhead, profit, and bond were applied to costs extracted from this previous estimate.

L. Security costs are based on Estimate File Number 5432. Appropriate general contractor markups for overhead, profit, and bond were applied to costs extracted from this previous estimate.

M. Costs for land use restrictions, operations and maintenance activities, and cap maintenance were extracted from Zitnik et al. (2002). Appropriate general contractor markups for overhead, profit, and bond were applied to costs extracted from this previous estimate.

N. The following drawings were used to help define the scope of work and assumptions used to bound the estimate with quantities:

1. “Radioactive Waste Management Complex Diagram," Drawing Number 416511

2. "Basalt Topo Elevation," provided by geographical information system analyst

3. "Radioactive Waste Management Complex Area Map," Drawing Number 175603

4. Radioactive Waste Management Complex Site Plan,” Drawing Number 175604

5. “RWMC Telephone/Communication Site Plan,” Drawing Number 175606.

O. Costs for relocation of OCVZ units were based on Estimate File Number 5989-G, "AR ProjectOCVZ Unit E Relocation Subcontract." Appropriate general subcontractor markups for overhead, profit, and bond were applied to costs extracted from this previous estimate.

P. Equipment rates are based on monthly rates for that particular piece of equipment as published in 2005 Rental Rate Blue Book, PRIMEDIA Business Magazines and Media, Inc. These rates have been adjusted for use in Idaho and for a 50-hour week (216.67 optimum hours per month).

Q. The following resources were used to determine equipment and crew makeup, production rates, and production adjustment factors:

1. 2005 Rental Rate Blue Book

2. 2005 RS Means Facilities Construction Cost Data

3. Caterpillar (CAT) Performance Handbook, Edition 30

4. Caterpillar (CAT) Performance Handbook, Edition 35

5. "Construction Equipment Ownership and Operating Expense Schedule," U.S. Army Corps of Engineers, July 2003

6. Construction Planning, Equipment, and Methods, Fourth Edition, McGraw-Hill, 1985

7. EP 1110, U.S. Army Corps of Engineers, July 2003 
8. Excavation and Materials Handling, Geology Engineering 465, University of Idaho, Spring 2005

9. FM 5-434, U.S. Department of the Army, June 2000

10. Interviews with local equipment vendors

11. Process Plant Cost Estimating Standards, Richardsons Engineering Services, Inc., 1995 Edition.

R. This estimate is based on the following adjustment factors:

1. Normal job-site efficiency factor of $83 \%$

2. Overtime factor of $91.25 \%$

3. Machine shutdown periods, safety walk downs, and personnel breaks of $97.50 \%$

4. Machine warm-up periods and plan of the day meetings of $95 \%$.

S. Fiscal Year 2006 INL Site Stabilization Agreement craft wage rates were used in the estimate.

\section{F-5.4 Assumptions}

\section{A. Schedule}

1. Figure F-4 illustrates the project schedule.

2. Construction operations will be performed for 9 to 10 months a year without weather impacts. Construction will be performed during this time, working one 10-hour shift per day, with a back shift that performs maintenance.

3. Field crews will demobilize equipment during a 2-month winter shutdown period each year to refurbish and replace equipment.

4. Durations are based on estimated crew productivity, regulatory reviews and approvals, and weather constraints inherent to the INL Site.

\section{B. Mobilization and demobilization (capital costs)}

1. ICP personnel will not require move monies.

2. Heavy earthwork equipment mobilization and demobilization costs are captured in the remediation section of this cost estimate.

\section{Site preparation (capital costs)}

1. A perimeter fence would be installed around the SDA (3 km $[10,000 \mathrm{ft}])$ and would be replaced once in 100 years.

2. Piping to connect OCVZ system probes to relocated OCVZ treatment units will not be installed until completion of cap construction (i.e., probes will not be operational during cap construction). 


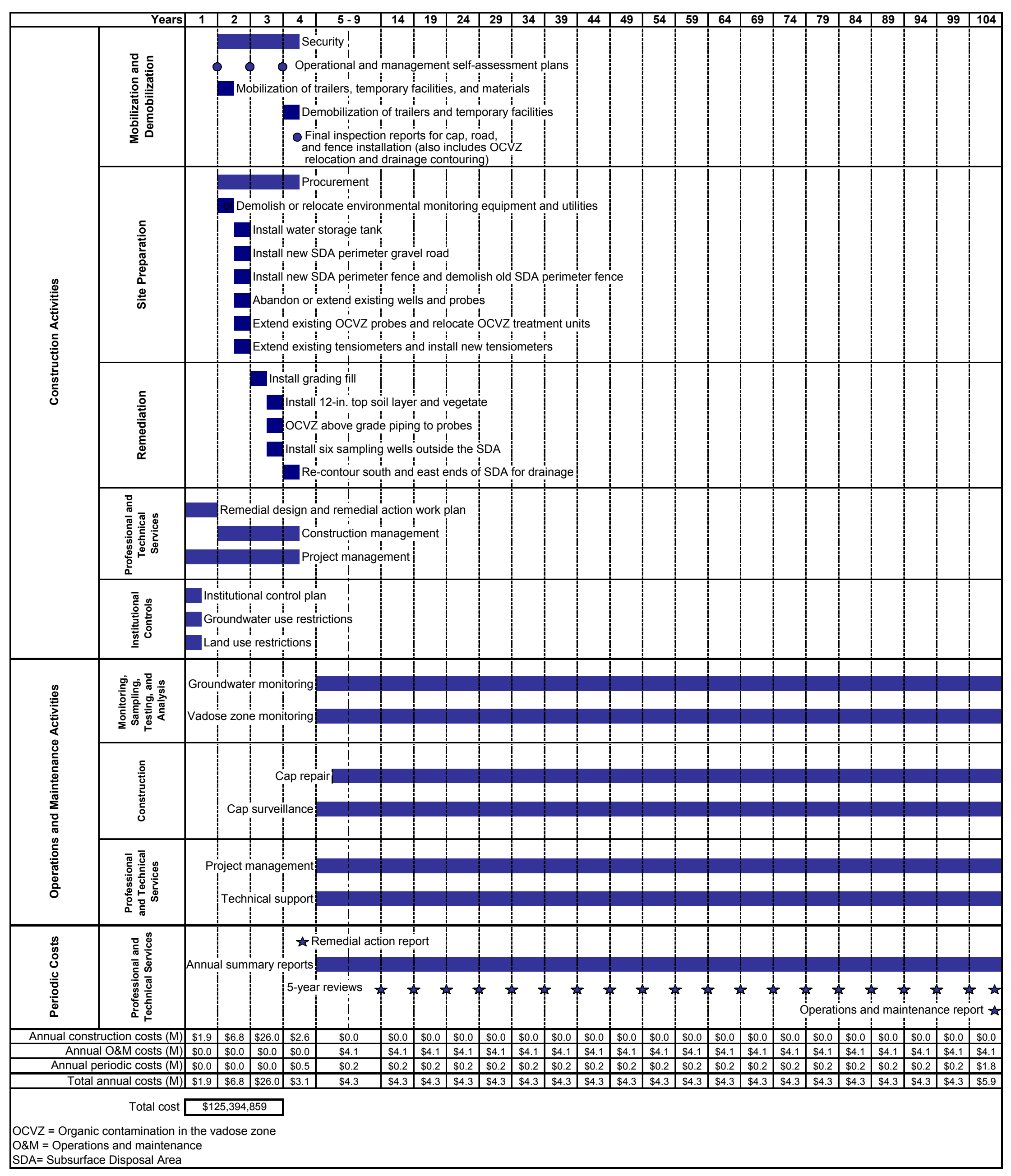

Figure F-4. Module 4 design, construction, and surveillance schedule for simplified evapotranspiration surface barrier with no biointrusion gas vent layer. 


\section{Remediation-ET surface barrier without a gas vent layer (capital costs)}

1. Soil removed from the existing SDA perimeter berm will be allowed to be used for cut-to-fill materials.

2. All existing soil piles inside the SDA will be gone at the time of this project and, therefore, cannot be claimed as credit for use as fill materials for this work.

3. INL Site Stabilization Agreement wages will apply, and no overtime (other than the monies needed to work five 10-hour days) or shift differential has been considered for this estimate.

4. Employee plan of the day meetings will take place during equipment warm-up periods. No additional monies were included beyond that time period.

5. Borrow sources for fill materials are indicated in Table F-18.

6. Cap layer composition and thickness are indicated in Table F-19.

7. Borrow pits will not experience flooding.

8. A water supply (government-furnished equipment at no cost to this project) will be located within $152 \mathrm{~m}(500 \mathrm{ft})$ of the SDA and will provide enough gallons per minute to ensure required water is available. To help support the water supply, a temporary fill storage tank will be needed to assist with filling of water equipment during peak use times.

9. Temporary power will be provided east of the SDA at no cost to this project. Temporary power required at any of the borrow sources will be provided by the subcontractor through use of portable generators.

10. No rock will be encountered during excavation work in the SDA.

11. Utilities to be removed will not be required to be relocated or replaced at the end of this work. Other than existing electrical lines to the Advanced Mixed Waste Treatment Project Facility, all utilities listed in the detail sheets to be demolished are no longer needed.

12. No radiological or hazardous materials will be encountered at any time during this project.

13. No secondary waste will be generated during construction of this project.

14. Equipment rates for this project have been estimated at Fiscal Year 2005 rates for new equipment and have not been adjusted for machine mechanical availability. New rates will compensate for any machine breakdowns.

15. Optimum equipment use will be required to meet the construction schedule.

16. Due to maximum weight restrictions, scrapers will only be allowed to carry 33.5 bank cubic yards per load.

17. The project team will direct the design team so that the toe of the grading fill material will begin at the cut-off wall. 
Table F-18. Module 4 distances and sources of borrow materials for the cap or cover system.

\begin{tabular}{|c|c|c|c|}
\hline Material & Issue & $\begin{array}{l}\text { One-Way Haul } \\
\text { Distance } \\
(\mathrm{mi})\end{array}$ & Source \\
\hline Topsoil & $\begin{array}{l}\text { This material would consist of organic } \\
\text { silt loam and would be used to construct } \\
\text { a topsoil layer to support vegetation on } \\
\text { top of the surface barrier. }\end{array}$ & 13.7 & $\begin{array}{l}\text { This material would be } \\
\text { unprocessed organic silt loam from } \\
\text { Rye Grass Flats. }\end{array}$ \\
\hline Grading fill & $\begin{array}{l}\text { This material would be used for the first } \\
\text { layer of the cap (and for filling the } \\
\text { Subsurface Disposal Area pit), which is } \\
\text { assumed to begin at elevation } 5,012.0 \mathrm{ft} \text {. }\end{array}$ & 1.9 & $\begin{array}{l}\text { This material would be } \\
\text { unprocessed gravel and sand from } \\
\text { the T12 Gravel Pit. }\end{array}$ \\
\hline
\end{tabular}

Table F-19. Module 4 surface barrier design layers, thickness, and volume.

\begin{tabular}{lccc}
\hline Layer & $\begin{array}{c}\text { Thickness } \\
\text { (in.) }\end{array}$ & $\begin{array}{c}\text { Approximate } \\
\text { Volume } \\
\left(\mathrm{yd}^{3}\right)\end{array}$ & Material Description \\
\hline Topsoil & 12 & 165,632 & Unprocessed organic silt loam from Rye Grass Flats. \\
Grading fill & $0-120$ & $1,186,389$ & Unprocessed gravel and sand from the T12 Gravel Pit. \\
\hline
\end{tabular}

\section{E. Institutional controls (capital costs)}

1. Placement of ICs will include generation of an IC plan, restrictions on groundwater use, and restrictions on land use.

2. Groundwater use restrictions will include limitations or restrictions on well drilling in the affected area or buffer zone.

3. Land-use restrictions will include repairing and replacing perimeter signs and installing permanent markers that surround the SDA to delineate contamination. Permanent markers will be made of concrete and contain information about the type of contamination. The number of permanent markers is 12 , based on the large size of the SDA.

\section{F. Long-term operating and maintenance and monitoring (operations and maintenance costs)}

1. Operations and maintenance activities will continue following completion of the surface barrier. Operations and maintenance activities will include groundwater monitoring, vadose zone monitoring, biological surveillance, and vegetation surveillance.

2. Operable Unit 7-13/14 will fund groundwater and vadose zone monitoring for the first 5 years following project completion (costs are included in this estimate).

3. The INL Sitewide Monitoring Program will fund groundwater and vadose zone monitoring from Year 6 to the end of the IC period (costs are included in this estimate). 
4. Air monitoring of suspended contaminants, biological monitoring of animal tissue, soil monitoring for biotic transported contaminants, and monitoring of surface water runoff are captured within the contingency of this cost estimate module. Therefore, costs are not included within this estimate.

5. After topsoil has been placed as the final layer on the surface barrier, it will be seeded to provide vegetative cover that will reduce erosion. However, because of the arid climate of the INL Site, an extended period of time will be required to establish a permanent vegetative cover. Erosion of the uppermost layers of the surface barrier during snowmelt will occur during the years immediately following construction; therefore, repairs and reseeding will be required.

6. Ongoing maintenance of the surface barrier will be required in perpetuity after construction is completed. Frequent maintenance will be required during the years immediately following construction to repair damage from erosion and to establish a permanent vegetative cover. In addition, the added weight of the surface barrier is expected to result in increased settlement during the initial years following construction. Some areas of the surface barrier will require ongoing maintenance to repair damage resulting from settlement. Annual maintenance and repairs will be required during the first 5 years following construction. Ongoing maintenance and repairs will continue every 5 years concurrent with the 5 -year review process.

7. Environmental monitoring will continue for 100 years following issuance of the ROD.

Estimated monitoring requirements and projected labor effort are summarized in Table F- 20 . Estimated surveillance requirements and projected labor effort are summarized in Table F-21. Estimated costs of the required laboratory analyses are provided in Table F- 22 .

8. This estimate does not include costs to maintain and operate OCVZ system treatment units or costs to sample and analyze OCVZ vapor ports for volatile organics.

9. A $10 \%$ allocation has been included for replacement parts and equipment for existing wells and lysimeters.

10. Reports will be prepared annually summarizing analytical and field data.

11. Contingency percentage (i.e., scope plus bid) for the operations and maintenance program uses the same contingency percentages used for capital costs.

12. Project management for the operations and maintenance program is $5 \%$ of overall operations and maintenance costs plus contingency.

13. Technical support for the operations and maintenance program is $15 \%$ of overall operations and maintenance costs plus contingency.

\section{G. Periodic costs}

Reviews will be conducted once every 5 years for 100 years. Five-year reviews will not result in additions or modifications of the remedy. No costs are included in the estimate for remedy additions or modifications. 
Table F-20. Module 4 estimated long-term monitoring program.

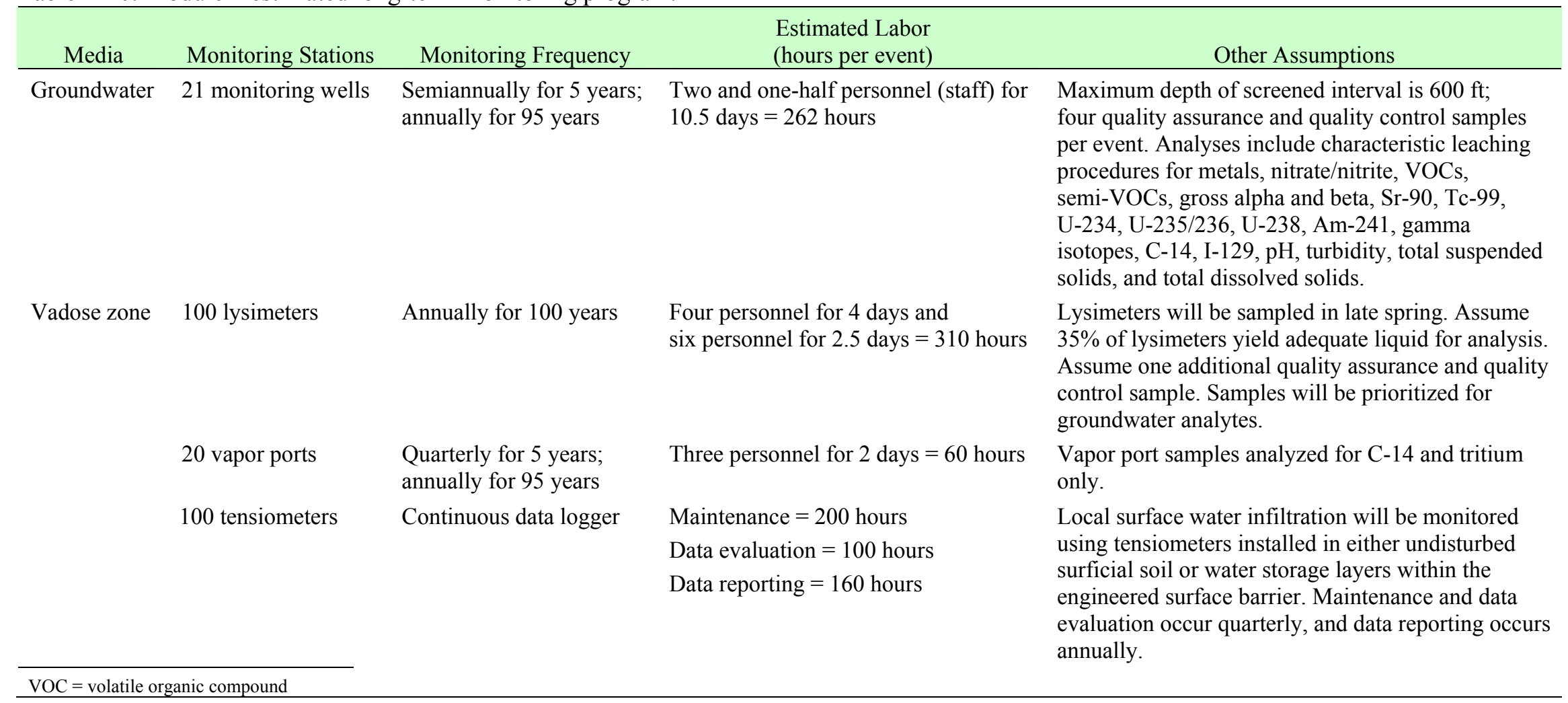

Table F-21. Module 4 estimated long-term surveillance program.

\begin{tabular}{|c|c|c|c|c|}
\hline Media & Monitoring Stations & Monitoring Frequency & $\begin{array}{l}\text { Estimated Labor } \\
\text { (hours per event) }\end{array}$ & Other Assumptions \\
\hline Biological & Animal intrusion & Annually for 100 years & $\begin{array}{l}\text { Two personnel (staff) for } \\
1 \text { day }=20 \text { hours }\end{array}$ & Requires two staff once per year. \\
\hline Vegetation & Entire cap surface & $\begin{array}{l}\text { Annually for } 5 \text { years; } \\
\text { every } 5 \text { years for } 95 \text { years }\end{array}$ & $\begin{array}{l}\text { Two personnel (staff) for } \\
1 \text { day }=20 \text { hours }\end{array}$ & $\begin{array}{l}\text { Perform one inspection per year in early fall for } \\
5 \text { years. Reseed } 10 \text { acres each year for } 5 \text { years } \\
\text { ( } 50 \text { acres total). Perform one inspection every } \\
5 \text { years in early fall; thereafter, for } 95 \text { years. } \\
\text { Reseed } 10 \text { acres every } 5 \text { years for } 95 \text { years. }\end{array}$ \\
\hline
\end{tabular}


Table F-22. Module 4 estimated analytical requirements.

\begin{tabular}{|c|c|c|c|c|}
\hline \multirow[b]{2}{*}{ Target Analyte } & \multirow[b]{2}{*}{$\begin{array}{l}\text { Unit Cost } \\
(\$)\end{array}$} & \multirow[b]{2}{*}{$\begin{array}{l}\text { Groundwater Event } \\
\text { (25 samples) } \\
(\$)\end{array}$} & \multicolumn{2}{|c|}{ Vadose Zone Event } \\
\hline & & & $\begin{array}{l}\text { Lysimeter Event } \\
\text { (36 samples) } \\
\text { (\$) }\end{array}$ & $\begin{array}{c}\text { Vapor Port Event } \\
\text { (20 samples) } \\
(\$)\end{array}$ \\
\hline Volatile organics & 169 & 4,221 & 6,078 & - \\
\hline Semivolatile organics & 211 & 5,276 & 7,598 & - \\
\hline Metals & 169 & 4,221 & 6,078 & - \\
\hline Nitrate/nitrite & 15 & 386 & 555 & - \\
\hline Gross alpha and beta & 66.64 & 1,666 & 2,399 & - \\
\hline Sr-90 & 128.20 & 3,205 & 4,615 & - \\
\hline Tc-99 & 89.35 & 2,234 & 3,217 & - \\
\hline U-234, $-235 / 236$, and -238 & 180.65 & 4,516 & 6,503 & - \\
\hline Am-241 & 180.65 & 4,516 & 6,503 & - \\
\hline $\mathrm{C}-14$ & 93.24 & 2,331 & 3,357 & 1,865 \\
\hline I-129 & 93.24 & 2,331 & 3,357 & - \\
\hline Tritium & 46.27 & 1,157 & 1,666 & 925 \\
\hline Gamma isotopes & 128.21 & 3,205 & 4,616 & - \\
\hline Analytical subtotal & - & 39,265 & 56,542 & 2,790 \\
\hline Procurement (12\%) & - & 4,712 & 6,785 & 335 \\
\hline Project adder ${ }^{\mathrm{a}}$ & - & 1,543 & 2,221 & 1,234 \\
\hline Validation procurement ${ }^{\mathrm{a}}$ & - & 2,072 & 2,984 & 1,658 \\
\hline Total $^{\text {b }}$ & - & 47,592 & 68,532 & 6,017 \\
\hline \multicolumn{5}{|c|}{$\begin{array}{l}\text { Assumptions: } \\
\text { 1. Two task order statements for entire project, samples are batched to maximize efficiency for analysis, shipping } 5-10 \\
\text { samples per shipment, all shipments for a sampling event sent within a 2-week period. Normal turn around time (i.e., } 35 \text { days). } \\
\text { 2. Metals: contract laboratory program metals, nitrate as nitrogen through EPA 353.1. } \\
\text { 3. Semivolatile-organic analysis: Priority Pollutant List SW-846 8270C. } \\
\text { 4. Volatile-organic analysis: Priority Pollutant List SW-846 8260B. }\end{array}$} \\
\hline \multicolumn{5}{|c|}{$\begin{array}{l}\text { a. Adder costs included task order statement, sampling and analysis plan table, data review, data tracking, data entry (Energy } \\
\text { Research Information System) upload, invoicing, and validation. } \\
\text { b. Listed within the "Other" column in the cost estimate. }\end{array}$} \\
\hline
\end{tabular}




\section{F-5.5 Contingency Guideline Implementation}

Total capital cost contingency for Module 4 is $22.13 \%$. This contingency is the average contingency of construction activities (i.e., $25 \%$ ) and professional and technical services (i.e., $0 \%$ ).

Total operations and maintenance cost contingency for Module 4 is $20 \%$. This contingency is the average contingency of monitoring, sampling, and testing activities (i.e., 25\%); construction activities (i.e., 25\%); and professional and technical services (i.e., $0 \%$ ).

Total periodic cost contingency for Module 4 is $0 \%$ (contingency for professional and technical services).

\section{F-5.6 Estimate Summary}

Table F-23 presents rough order of magnitude allocations of the methodologies used to develop the cost estimate for Module 4.

Table F-23. Rough order of magnitude allocations of the methodologies used to develop the cost estimate for Module 4.

\begin{tabular}{lc}
\hline Estimate Methodology & $\begin{array}{c}\text { Rough Order of Magnitude } \\
(\%)\end{array}$ \\
\hline Project team & 65 \\
Recorded actuals & 0 \\
Parametric & 0 \\
Vendor quotes & 0 \\
Other (estimating manuals) & 35 \\
Total & $\mathbf{1 0 0}$ \\
\hline
\end{tabular}

\section{F-5.7 Other Comments or Concerns Specific to the Estimate}

A. All costs reflect present day costs. No escalation is included in the estimate.

B. Costs for Idaho state sales tax $(5 \%)$ on material purchases are included in the estimate, where applicable.

C. Because work activities identified in this estimate will not begin until after September 30, 2005, no CH2M-WG Idaho general and administrative costs have been included in this estimate per recent direction received by Estimating Services.

\section{F-5.8 Summary}

Tables F-24 through F-27 provide summary cost information for Module 4. 
Table F-24. Capital costs for Module 4: Operable Unit 7-13/14 Feasibility Study—Simplified Evapotranspiration Surface Barrier with No Biointrusion Gas Vent Layer, Project Number: 5992-A.

\begin{tabular}{|c|c|c|c|c|c|}
\hline Level & Description & $\begin{array}{l}\text { Subtotals }{ }^{\mathrm{a}} \\
\quad(\$)\end{array}$ & $\begin{array}{l}\text { Estimate }^{\mathrm{a}} \\
(\$)\end{array}$ & $\begin{array}{l}\text { Contingency } \\
(\$)\end{array}$ & $\begin{array}{c}\text { Total }^{\mathrm{a}, \mathrm{c}} \\
(\$)\end{array}$ \\
\hline 1.1 & Construction activities & $27,035,000$ & - & - & - \\
\hline 1.1 .1 & Mobilization and demobilization & $2,717,000$ & - & - & - \\
\hline 1.1 .1 .1 & Mobilization of temporary facilities and materials & - & 129,000 & 32,000 & 161,000 \\
\hline 1.1.1.2 & Submittals and implementation plans & 898,000 & - & - & - \\
\hline 1.1.1.2.1 & Operational and layout plan & - & 145,000 & 36,000 & 182,000 \\
\hline 1.1.1.2.2 & Remedial action, monitoring, and control plan & - & 25,000 & 6,000 & 32,000 \\
\hline 1.1.1.2.3 & Industrial hygiene exposure and sample plan & - & 22,000 & 5,000 & 27,000 \\
\hline 1.1.1.2.4 & Management self-assessment plan & - & 160,000 & 40,000 & 199,000 \\
\hline 1.1 .1 .2 .5 & Well abandonment plan & - & 159,000 & 40,000 & 198,000 \\
\hline 1.1.1.2.6 & Quality control plan & - & 65,000 & 16,000 & 81,000 \\
\hline 1.1.1.2.7 & Final inspection report & - & 323,000 & 81,000 & 403,000 \\
\hline 1.1.1.6 & Security at construction site access gates & - & $1,613,000$ & 403,000 & $2,016,000$ \\
\hline 1.1.1.7 & Demobilization of temporary facilities & - & 77,000 & 19,000 & 97,000 \\
\hline 1.1 .2 & Site preparation work & $3,897,000$ & - & - & - \\
\hline 1.1.2.1 & Cap or cover & $3,897,000$ & - & - & - \\
\hline 1.1.2.1.1 & Install temporary water fill station storage tank for compaction & - & 65,000 & 16,000 & 81,000 \\
\hline 1.1.2.1.2 & $\begin{array}{l}\text { Relocate and demolish utilities and environmental monitoring } \\
\text { equipment }\end{array}$ & - & 677,000 & 169,000 & 847,000 \\
\hline 1.1.2.1.3 & Construct new SDA perimeter gravel road & - & 354,000 & 88,000 & 442,000 \\
\hline 1.1.2.1.4 & Install new perimeter fence and gates & - & 774,000 & 194,000 & 968,000 \\
\hline 1.1.2.1.5 & Demolition of existing perimeter fence and LLW Pit fence & - & 93,000 & 23,000 & 117,000 \\
\hline 1.1.2.1.6 & Abandon or extend existing wells and probes & - & 376,000 & 94,000 & 470,000 \\
\hline 1.1.2.1.7 & $\begin{array}{l}\text { Extend existing OCVZ system probes and relocate treatment } \\
\text { units }\end{array}$ & 580,000 & - & - & - \\
\hline 1.1.2.1.7.1 & Extend 18 existing OCVZ system probes & - & 225,000 & 56,000 & 281,000 \\
\hline 1.1.2.1.7.2 & Relocate treatment Unit D & - & 118,000 & 30,000 & 148,000 \\
\hline 1.1.2.1.7.3 & Relocate treatment Unit E & - & 118,000 & 30,000 & 148,000 \\
\hline 1.1.2.1.7.4 & Relocate treatment Unit F & - & 118,000 & 30,000 & 148,000 \\
\hline 1.1.2.1.8 & $\begin{array}{l}\text { Extend existing advanced tensiometers and install new } \\
\text { advanced tensiometers }\end{array}$ & 978,000 & - & - & - \\
\hline 1.1.2.1.8.1 & Maintain and extend 50 existing advanced tensiometers & - & 16,000 & 4,000 & 20,000 \\
\hline 1.1.2.1.8.2 & Install 50 new advanced tensiometers & - & 639,000 & 160,000 & 798,000 \\
\hline 1.1.2.1.8.3 & Well completion & - & 100,000 & 25,000 & 125,000 \\
\hline 1.1.2.1.8.4 & Probe cost for installation of new advanced tensiometers & - & 97,000 & 24,000 & 121,000 \\
\hline 1.1.2.1.8.5 & Logger cost for installation of new advanced tensiometers & - & 65,000 & 16,000 & 81,000 \\
\hline 1.1.2.1.8.6 & $\begin{array}{l}\text { Network design cost for installation of new advanced } \\
\text { tensiometers }\end{array}$ & - & 62,000 & 15,000 & 77,000 \\
\hline 1.1 .3 & Remediation & $20,421,000$ & - & - & - \\
\hline 1.1 .3 .1 & Cap or cover & $20,421,000$ & - & - & - \\
\hline 1.1.3.1.1 & Construct ET surface barrier without gas vent layer & $19,349,000$ & - & - & - \\
\hline 1.1.3.1.1.1 & Install grading fill-layer one & - & $9,214,000$ & $2,304,000$ & $11,518,000$ \\
\hline 1.1.3.1.1.2 & Install topsoil-layer two & - & $4,219,000$ & $1,055,000$ & $5,274,000$ \\
\hline 1.1.3.1.1.3 & Vegetate cap and construction area & - & 521,000 & 130,000 & 651,000 \\
\hline 1.1.3.1.1.4 & Install OCVZ abovegrade piping to probes & - & $3,588,000$ & 897,000 & $4,485,000$ \\
\hline 1.1.3.1.1.5 & Install six sampling wells outside the SDA & - & $1,806,000$ & 452,000 & $2,258,000$ \\
\hline 1.1.3.1.2 & Contour south and east ends outside the SDA for drainage & - & $1,072,000$ & 268,000 & $1,340,000$ \\
\hline 1.2 & Professional and technical services & $3,379,000$ & - & - & - \\
\hline 1.2 .1 & Project management & - & $1,690,000$ & 0 & $1,690,000$ \\
\hline 1.2 .2 & Remedial design and remedial action work plan & $1,014,000$ & - & - & - \\
\hline 1.2.2.1 & Remedial design & - & 676,000 & 0 & 676,000 \\
\hline 1.2.2.2 & Remedial action work plan & - & 338,000 & 0 & 338,000 \\
\hline 1.2 .3 & Construction management & - & 676,000 & 0 & 676,000 \\
\hline 1.3 & Institutional controls & 133,000 & - & - & - \\
\hline 1.3 .1 & Institutional controls plan & - & 17,000 & 0 & 17,000 \\
\hline 1.3 .2 & Groundwater use restrictions & - & 26,000 & 0 & 26,000 \\
\hline 1.3 .3 & Land use restrictions & 90,000 & - & - & - \\
\hline 1.3.3.1 & Perimeter markers & - & 77,000 & 0 & 77,000 \\
\hline \multirow[t]{3}{*}{ 1.3.3.2 } & Repair and replace perimeter signs & - & 13,000 & 0 & 13,000 \\
\hline & Total capital cost $\mathrm{t}^{\mathrm{c}}$ & - & $30,547,000$ & $6,759,000$ & $37,305,000$ \\
\hline & \multicolumn{5}{|c|}{$\begin{array}{l}\text { a. Values are rounded to the nearest } \$ 1,000 . \\
\text { b. Capital cost contingency is } 22.1 \% \text { of the estimate. } \\
\text { c. Totals were derived for the summation of nonrounded subcomponent values. Therefore, totals are not equal to the summation of the rounded subcomponent values shown } \\
\text { above. See Table F-3 for nonrounded totals. } \\
\text { ET = evapotranspiration } \\
\text { LLW = low-level waste } \\
\text { OCVZ = Organic Contamination in the Vadose Zone } \\
\text { SDA = Subsurface Disposal Area }\end{array}$} \\
\hline
\end{tabular}


Table F-25. Operational and maintenance costs for Module 4: Operable Unit 7-13/14 Feasibility Study-Simplified Evapotranspiration Surface Barrier with No Biointrusion Gas Vent Layer, Project Number: 5992-A.

\begin{tabular}{|c|c|c|c|c|c|}
\hline Level & Description & $\begin{array}{l}\text { Subtotals }^{\mathrm{a}} \\
(\$)\end{array}$ & $\begin{array}{l}\text { Estimate }^{\mathrm{a}} \\
(\$)\end{array}$ & $\begin{array}{c}\text { Contingency } \\
(\$)\end{array}$ & $\begin{array}{c}\text { Total }^{\mathrm{a}, \mathrm{c}} \\
(\$)\end{array}$ \\
\hline 2.1 & Monitoring, sampling, testing, and analysis & $45,042,000$ & - & - & - \\
\hline 2.1 .1 & Groundwater monitoring & $9,912,000$ & - & - & - \\
\hline 2.1.1.1 & $\begin{array}{l}\text { Groundwater monitoring semiannually for } 5 \text { years } \\
\text { (10 sampling events) }\end{array}$ & - & 813,000 & 203,000 & $1,016,000$ \\
\hline 2.1.1.2 & $\begin{array}{l}\text { Groundwater monitoring annually for } 95 \text { years (95 sampling } \\
\text { events) }\end{array}$ & - & $7,723,000$ & $1,931,000$ & $9,653,000$ \\
\hline 2.1.1.3 & $\begin{array}{l}\text { Replacement parts and equipment costs (assume } 10 \% \text { total } \\
\text { groundwater monitoring costs) }\end{array}$ & - & $1,377,000$ & 344,000 & $1,721,000$ \\
\hline 2.1 .2 & Vadose zone monitoring & $35,130,000$ & - & - & - \\
\hline 2.1.2.1 & Sample 100 lysimeters one time per year in late spring & - & $11,172,000$ & $2,793,000$ & $13,965,000$ \\
\hline 2.1.2.2 & $\begin{array}{l}\text { Sample and analyze } 20 \text { vapor ports four times per year for } \\
5 \text { years }\end{array}$ & - & 266,000 & 67,000 & 333,000 \\
\hline 2.1.2.3 & $\begin{array}{l}\text { Sample and analyze } 20 \text { vapor ports one time per year } \\
\text { thereafter for } 95 \text { years }\end{array}$ & - & $1,265,000$ & 316,000 & $1,581,000$ \\
\hline 2.1.2.4 & Analyze 100 advanced tensiometers & $17,548,000$ & - & - & - \\
\hline 2.1.2.4.1 & $\begin{array}{l}\text { Maintenance of advanced tensiometers four times per } \\
\text { year for } 100 \text { years }\end{array}$ & - & $10,322,000$ & $2,581,000$ & $12,903,000$ \\
\hline 2.1.2.4.2 & $\begin{array}{l}\text { Data evaluation of advanced tensiometers four times per } \\
\text { year for } 100 \text { years }\end{array}$ & - & $5,161,000$ & $1,290,000$ & $6,452,000$ \\
\hline 2.1.2.4.3 & $\begin{array}{l}\text { Data reporting of advanced tensiometers one time per } \\
\text { year for } 100 \text { years }\end{array}$ & - & $2,064,000$ & 516,000 & $2,581,000$ \\
\hline 2.1.2.5 & $\begin{array}{l}\text { Replacement parts and equipment costs (assume 10\% of total } \\
\text { vadose zone monitoring costs) }\end{array}$ & - & $4,879,000$ & $1,220,000$ & $6,099,000$ \\
\hline 2.2 & Construction activities & $\mathbf{1 0 , 2 0 6 , 0 0 0}$ & - & - & - \\
\hline 2.2 .1 & Remedy failure or replacement & $9,677,000$ & - & - & - \\
\hline 2.2.1.1 & Cap or cover maintenance and repairs & - & $9,677,000$ & $2,419,000$ & $12,097,000$ \\
\hline 2.2 .2 & Cap surveillance & 528,000 & - & - & - \\
\hline 2.2.2.1 & Biological surveillance & 30,000 & - & - & - \\
\hline 2.2.2.1.1 & $\begin{array}{l}\text { Intrusion surveillance with two people two times the first } \\
5 \text { years }\end{array}$ & - & 3,000 & 1,000 & 4,000 \\
\hline 2.2.2.1.2 & $\begin{array}{l}\text { Intrusion surveillance with two people one time every } \\
5 \text { years thereafter for } 95 \text { years }\end{array}$ & - & 27,000 & 7,000 & 34,000 \\
\hline 2.2.2.2 & Vegetation surveillance & 499,000 & - & - & - \\
\hline 2.2.2.2.1 & Perform one inspection per year in early fall for 5 years & - & 7,000 & 2,000 & 9,000 \\
\hline 2.2.2.2.2 & Reseed 10 acres each year for 5 years (50 acres total) & - & 97,000 & 24,000 & 121,000 \\
\hline 2.2.2.2.3 & $\begin{array}{l}\text { Perform one inspection in early fall every } 5 \text { years } \\
\text { thereafter for } 95 \text { years }\end{array}$ & - & 27,000 & 7,000 & 34,000 \\
\hline 2.2.2.2.4 & Reseed 10 acres every 5 years for 95 years & - & 368,000 & 92,000 & 460,000 \\
\hline 2.3 & Professional and technical services & $13,812,000$ & - & - & - \\
\hline 2.3 .1 & Project management & - & $3,453,000$ & 0 & $3,453,000$ \\
\hline \multirow[t]{3}{*}{2.3 .2} & Technical support & - & $10,359,000$ & 0 & $10,359,000$ \\
\hline & \multicolumn{2}{|c|}{ Total operational and maintenance $\operatorname{cost}^{\mathrm{c}} \quad$ - } & $69,060,000$ & $13,812,000$ & $82,871,000$ \\
\hline & \multicolumn{5}{|c|}{$\begin{array}{l}\text { a. Values are rounded to the nearest } \$ 1,000 \text {. } \\
\text { b. Operational and maintenance cost contingency is } 20.0 \% \text { of the estimate. } \\
\text { c. Totals were derived for the summation of nonrounded subcomponent values. Therefore, totals are not equal to the summation of the rounded subcomponent values shown } \\
\text { above. See Table F-3 for nonrounded totals. }\end{array}$} \\
\hline
\end{tabular}

Table F-26. Periodic costs for Module 4: Operable Unit 7-13/14 Feasibility Study— Simplified Evapotranspiration Surface Barrier with No Biointrusion Gas Vent Layer, Project Number: 5992-A.

\begin{tabular}{|c|c|c|c|c|c|}
\hline Level & Description & \multirow{2}{*}{$\begin{array}{c}\begin{array}{c}\text { Subtotals }^{\mathrm{a}} \\
(\$)\end{array} \\
\mathbf{5 , 2 1 8 , 0 0 0}\end{array}$} & \multirow{2}{*}{$\begin{array}{c}\text { Estimate }^{\mathrm{a}} \\
(\$) \\
-\end{array}$} & \multirow{2}{*}{$\begin{array}{c}\begin{array}{c}\text { Contingency } \\
(\$)\end{array} \\
-\end{array}$} & \multirow{2}{*}{$\begin{array}{c}\text { Total }^{\mathrm{a}, \mathrm{c}} \\
(\$) \\
-\end{array}$} \\
\hline 3.1 & Professional and technical services & & & & \\
\hline 3.1 .1 & Remedial action report & - & 490,000 & 0 & 490,000 \\
\hline 3.1 .3 & 5-year reviews & - & $1,161,000$ & 0 & $1,161,000$ \\
\hline \multirow[t]{2}{*}{3.1 .4} & Operation and maintenance report & - & $1,631,000$ & 0 & $1,631,000$ \\
\hline & Total periodic cost ${ }^{\mathrm{c}}$ & - & $5,218,000$ & - & $5,218,000$ \\
\hline
\end{tabular}

Table F-27. Total costs for Module 4: Operable Unit 7-13/14 Feasibility Study— Simplified Evapotranspiration Surface Barrier with No Biointrusion Gas Vent Layer, Project Number: 5992-A.

\begin{tabular}{|c|c|c|c|}
\hline & $\begin{array}{c}\text { Estimate }^{\mathrm{a}} \\
(\$)\end{array}$ & $\begin{array}{c}\text { Contingency }{ }^{\mathrm{a}, \mathrm{b}} \\
(\$)\end{array}$ & $\begin{array}{c}\text { Total }^{\mathrm{a}} \\
(\$)\end{array}$ \\
\hline $\begin{array}{l}\text { Total cost for simplified evapotranspiration surface barrier with } \\
\text { no biointrusion gas vent layer) }\end{array}$ & $104,824,000$ & $20,571,000$ & $125,395,000$ \\
\hline
\end{tabular}




\section{F-6. MODULE 5: MODIFIED RCRA TYPE C CAP \\ F-6.1 Purpose}

SDA.

This estimate will be used as a cost-comparative tool to examine different options regarding the

\section{F-6.2 Scope of Work}

The objective of this project is to construct a modified Resource Conservation and Recovery Act (RCRA) (42 USC $\S 6901$ et seq., 1976) Type C surface barrier (i.e., cap) in the SDA. This surface barrier will cover approximately 105 acres in the SDA.

Subcontractor mobilization consists of the following:

- Generate operational plans

- Generate a management self-assessment plan

- Mobilize temporary facilities and equipment.

Subcontractor demobilization consists of the following:

- Demobilize temporary facilities and equipment

- $\quad$ Generate a final inspection report following completion of cap construction.

Subcontractor site preparation consists of the following:

- Install a temporary water storage tank in the SDA to be used for compaction

- $\quad$ Relocate, extend, or demolish specified utilities and environmental monitoring equipment

- Contour the south and east sides of the SDA for drainage

- Install a new perimeter fence

- $\quad$ Demolish existing perimeter fence

- Abandon, in-place, 25 of 50 existing monitoring wells and probes in the SDA

- $\quad$ Extend 25 of 50 existing monitoring wells and probes

- $\quad$ Extend 18 of existing OCVZ system wells above cap elevation and relocate three OCVZ system treatment units beyond the cap perimeter

- $\quad$ Extend 50 existing advanced tensiometers and install 50 new advanced tensiometers

- $\quad$ Construct a new access road at the perimeter of the SDA.

Subcontractor remediation consists of the following steps:

- $\quad$ Construct a modified RCRA Type C surface barrier consisting of grading fill, asphalt base, asphalt, gravel drain, gravel filter, sand, compacted topsoil, and topsoil layers with perimeter armor protection

- Install OCVZ system piping from the $18 \mathrm{OCVZ}$ system wells to the three relocated OCVZ system treatment units 
- Install six sampling wells outside the SDA following cap construction

- $\quad$ Conduct placement of ICs.

Long-term monitoring and operations and maintenance activities include the following:

- $\quad$ Groundwater monitoring

- $\quad$ Vadose zone monitoring

- Biological surveillance

- Vegetation surveillance.

Subcontractor periodic costs include:

- Remedial action report following cap completion

- Annual summary reports during the operations and maintenance period

- $\quad$ Five-year reviews during the operations and maintenance period

- $\quad$ Operations and maintenance report following the operations and maintenance period.

\section{F-6.3 Basis of the Estimate}

The following sequential process, rationale, and estimating methodologies were used to define activities, quantities, and resources that were used in preparation of this cost estimate.

A. Project scope and methodologies for this estimate were prepared from a project visit and from discussions with the project team.

B. Costs were developed, using the Success $\bigodot$ estimating software by U.S. Cost, to a level of detail consistent with available documents and information.

C. Initial information about the cap was obtained from the Preliminary Design for an Engineering Surface Barrier at the SDA (Mattson et al. 2004).

D. A revised drawing of the cap, a recapitulation template, contingency input, and costs and percentages for submittals and implementation plans, professional and technical services (e.g., project management, design, construction management), and long-term operational and maintenance work were provided.

E. Engineering provided most of the estimated excavation and fill quantities.

F. Engineering provided the estimate of a grading fill quantity of $1,186,389$ in-place cubic yards.

G. ICP construction management provided material properties.

H. Cost-estimating judgment, coupled with on-INL Site unrecorded experiences and field observations of projects constructed and demolished at the INL Site, was used to establish the rationale for structuring of the work.

I. Estimate development was established using a detailed bottoms-up quantifiable technique. Activity descriptions, costs, and productions are based on these individual detailed item quantities. 
J. New perimeter fencing costs were based on the "ICDF Complex Perimeter 6' Chain Link Fence and Gates," cost estimate, File Number 2448-G, dated March 19, 2003. Appropriate general contractor markups for overhead, profit, and bond were applied to the costs extracted from this previous estimate.

K. Submittal and implementation plan costs and professional and technical periodic costs were based upon costs extracted from the "ISG Project FY 2005-FY 2011," cost estimate, File Number 5987, dated August 3, 2004. Appropriate general contractor markups for overhead, profit, and bond were applied to the costs extracted from this previous estimate.

L. Security costs are based on CH2M-WG Idaho Cost Estimate Number 5432. Appropriate general contractor markups for overhead, profit, and bond were applied to the costs extracted from this previous estimate.

M. Costs for land-use restrictions, operations and maintenance activities, and cap maintenance were extracted from Zitnik et al. (2002). Appropriate general contractor markups for overhead, profit, and bond were applied to the costs extracted from this previous estimate.

N. The following drawings were used to help define the scope of work and the assumptions used to bind the estimate with quantities.

1. "Radioactive Waste Management Complex Diagram," Drawing Number 416511

2. "Basalt Topo Elevation," provided by geographical information system analyst

3. "Radioactive Waste Management Complex Area Map," Drawing Number 175603

4. "Radioactive Waste Management Complex Site Plan," Drawing Number 175604

5. “RWMC Telephone/Communication Site Plan,” Drawing Number 175606.

O. Unit costs for relocation of the OCVZ were based on the "AR Project - OCVZ Unit E Relocation Subcontract," cost estimate, File Number 5989-G. Appropriate general contractor markups for overhead, profit, and bond were applied to the costs extracted from this previous estimate.

P. Equipment rates are based on the monthly rates for that particular piece of equipment, as published in 2005 Rental Rate Blue Book, PRIMEDIA Business Magazines and Media, Inc. These rates have been adjusted for use in Idaho and for a 50-hour week (216.67 optimum hours per month) use.

Q. The following resources were used to determine equipment and crew makeup, production rates, and production-adjustment factors.

1. 2005 Rental Rate Blue Book

2. 2005 RS Means Facilities Construction Cost Data

3. Caterpillar (CAT) Performance Handbook, Edition 30

4. Caterpillar (CAT) Performance Handbook, Edition 35

5. Construction Equipment Ownership and Operating Expense Schedule, U.S. Army Corps of Engineers, July 2003

6. Construction Planning, Equipment, and Methods, Fourth Edition, McGraw-Hill, 1985

7. EP 1110, U.S. Army Corps of Engineers, July 2003 
8. Excavation and Materials Handling, Geology Engineering 465, University of Idaho, Spring 2005

9. FM 5-434, U.S. Department of the Army, June 2000

10. Interviews with local equipment vendors

11. Process Plant Cost Estimating Standards, Richardsons Engineering Services, Inc., 1995 Edition.

R. This estimate is based on the following adjustment factors:

1. Normal job-site efficiency factor of $83 \%$

2. Overtime factor of $91.25 \%$

3. Machine shutdown periods, safety walk-downs, and personnel breaks of $97.50 \%$

4. Machine warm-up periods and plan of the day meetings of $95 \%$.

S. Fiscal Year 2006 INL Site Stabilization Agreement craft wage rates were used in the estimate.

\section{F-6.4 Assumptions}

\section{A. Schedule}

1. Figure F-5 illustrates the project schedule.

2. Construction operations will be performed for 9 to 10 months a year without weather impacts. Construction will be performed during this time working one 10-hour shift per day, with a back shift that performs maintenance.

3. Field crews will demobilize the equipment during a 2-month winter shutdown period each year to refurbish and replace equipment.

4. The following activities comprise the remedial design and remedial action portion of the modified RCRA Type $\mathrm{C}$ surface barrier module. Corresponding durations are based on estimated crew productivity, regulatory reviews and approvals, and weather constraints inherent to the INL Site.

\section{B. Mobilization and demobilization (capital costs)}

1. ICP personnel will not require move monies.

2. Heavy earthwork equipment mobilization and demobilization costs are captured within the remediation section of this cost estimate.

\section{Site preparation (capital costs)}

1. A perimeter fence will be installed around the SDA (3 $\mathrm{km}[10,000 \mathrm{ft}])$ and will be replaced once in 100 years.

2. Piping to connect the OCVZ system probes to the relocated OCVZ treatment units will not be installed until completion of cap construction (i.e., the probes will not be operational during cap construction). 


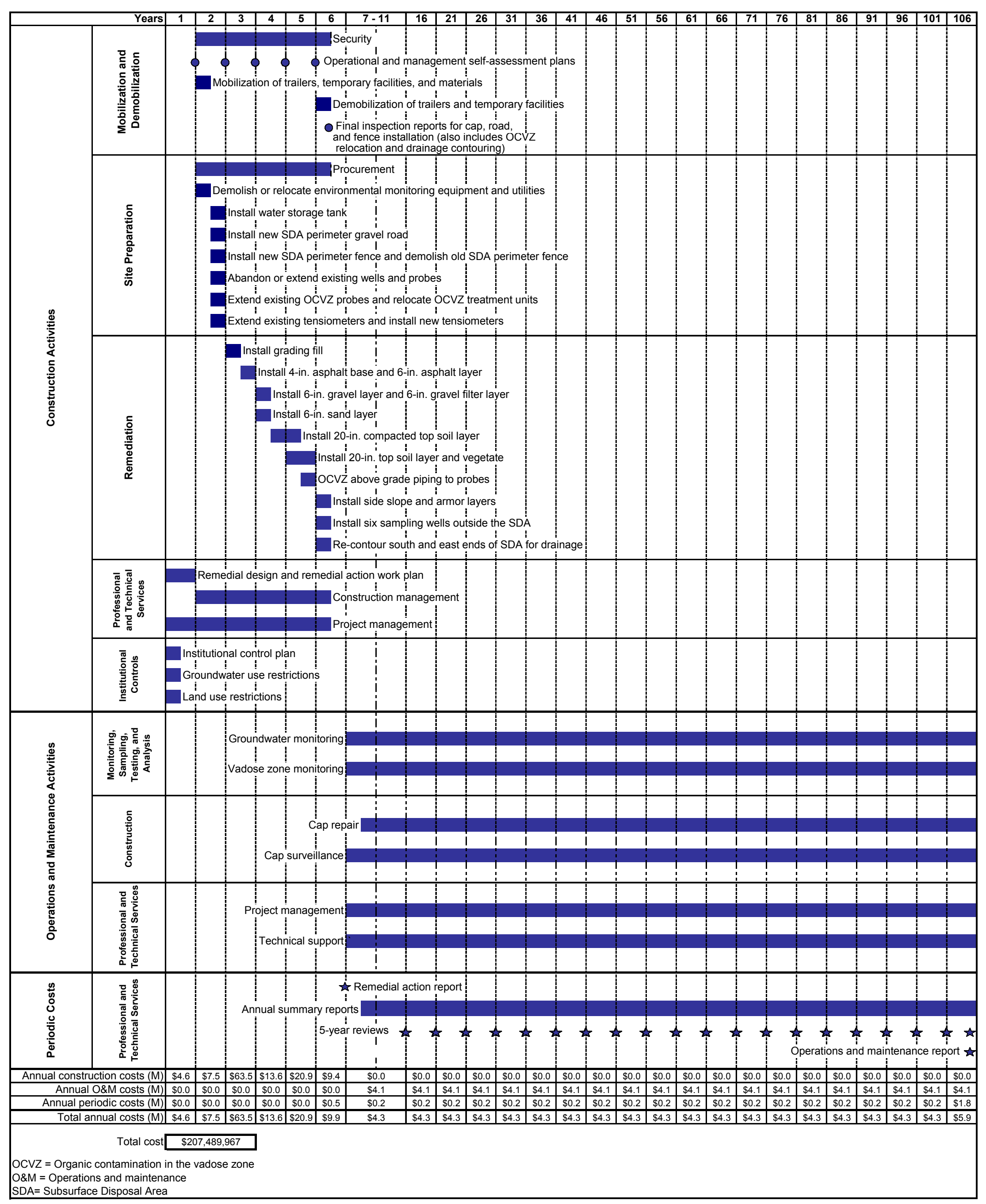

Figure F-5. Module 5 design, construction, and surveillance schedule for a modified RCRA Type C surface barrier. 


\section{Remediation modified RCRA Type C surface barrier (capital costs)}

1. Cuts into the existing SDA perimeter berms will be allowed for use as cut-to-fill materials.

2. All existing soil piles inside of the SDA will be gone at the time of this project and, therefore, cannot be claimed as credit for use as fill material for this work.

3. No hazardous or contaminated materials will be encountered during this work.

4. INL Site Stabilization Agreement wages will apply, and no overtime (other than the monies needed to work five 10-hour days) or shift differential has been considered for this estimate.

5. Employee plan of the day meetings will take place during the equipment warm-up periods. No additional monies were included beyond that time period.

6. Borrow sources for fill materials are indicated in Table F-28.

7. Cap layer composition and thickness are indicated in Table F-29.

8. Borrow pits will not experience any flooding.

9. A water supply (government-furnished equipment at no cost to this project) will be located within $152 \mathrm{~m}(500 \mathrm{ft})$ of the SDA and will provide enough gallons per minute to ensure required water is available. To help support this, a temporary fill storage tank will be needed to assist with the filling of water equipment during peak use times so as not to create stacking of equipment.

10. Temporary power will be provided on the east of the SDA at no cost to this project. Any temporary power required at any of the borrow sources will be provided by the subcontractor by the use of portable generators.

11. No rock will be encountered during excavation work at the SDA.

12. Utilities to be removed will not be required to be relocated or replaced at the end of this work. Other than the existing electrical lines to the Advanced Mixed Waste Treatment Project Facility, all utilities listed in the detail sheets to be demolished are no longer needed.

13. No radiological or hazardous material will be encountered at any time during this project.

14. No secondary waste will be generated during the construction of this project.

15. Equipment rates for this project have been estimated at Fiscal Year 2005 rates for new equipment and have not been adjusted for machine mechanical availability. New rates will compensate for any machine breakdowns.

16. Optimum equipment use will be required to meet the proposed construction schedule.

17. Because of maximum weight restrictions, scrapers will only be allowed to carry 33.5 bank cubic yards per load.

18. The project team will direct the design so that the toe of the grading fill material will begin at the cut-off wall. 
Table F-28. Module 5 distances and sources of borrow materials for the cap/cover system.

\begin{tabular}{ccc} 
& One-Way \\
Material & Haul Distance \\
(mi) & Source & \\
\hline
\end{tabular}

Topsoil This material would consist of organic silt loam and would be used to construct a topsoil layer to support vegetation on top of the surface barrier.

Compacted topsoil This material would consist of organic silt loam placed below the topsoil layer.

Sand

Gravel

Asphalt

Grading fill

Coarse fractured

basalt

Rip-rap
This material would be used for the fine filter layer bank run borrow areas are available within the INL Site boundary

This material would be used for the coarse filter and drain layers within the cap and for surface barrier side slope protection. A sufficient quantity of good structural gravel is available (crushing required).

Asphalt base course and finish course layers would be placed between the grading fill and gravel drain layers.

This material would be used for the first layer of the cap (and for filling the Subsurface Disposal Area),

This material would be used for surface barrier side slope protection. The majority of the mined coarse fractured basalt material at the INL Site has been used for other remedial actions at the INL Site.

Rip-rap would be used for erosion control around the perimeter of the cap. The majority of the mined rip-rap material at the INL Site has been used for other remedial actions at the INL Site. within the cap and along the side slope. No identified which is assumed to begin at elevation $5,012.0 \mathrm{ft}$.
13.7 This material would be unprocessed organic silt loam from Rye Grass Flats.

13.7 This material would be unprocessed organic silt loam from Rye Grass Flats.

$4 \quad$ This material would be processed sand (from gravel screening) from the Borax Gravel Pit.

This material would be processed gravel from the Borax Gravel Pit.

1-60 The hot asphalt mixture would be trucked from an asphalt plant in the Idaho Falls, Blackfoot, and Pocatello areas, or would be produced at a temporary asphalt plant established near the Radioactive Waste Management Complex.

1.9 This material would be unprocessed gravel and sand from the T12 Gravel Pit.

35 This material would be processed material mined at Radio Cinder Butte, approximately 26 mi west of Idaho Falls, near State Highway 20.

This material would be processed material mined at Radio Cinder Butte, approximately 26 mi west of Idaho Falls, near State Highway 20. 
Table F-29. Module 5 surface barrier design layers, thickness, and volume.

\begin{tabular}{|c|c|c|c|}
\hline Layer & $\begin{array}{l}\text { Thickness } \\
\text { (in.) }\end{array}$ & $\begin{array}{l}\text { Approximate } \\
\text { Volume } \\
\left(\mathrm{yd}^{3}\right)\end{array}$ & Material Description \\
\hline Topsoil & 20 & 276,447 & Unprocessed organic silt loam from Rye Grass Flats. \\
\hline Compacted topsoil & 20 & 276,447 & Unprocessed organic silt loam from Rye Grass Flats. \\
\hline Sand & 6 & 85,134 & Processed sand (from gravel screening) from the Borax Gravel Pit. \\
\hline Gravel filter & 6 & 82,887 & Processed gravel from the Borax Gravel Pit. \\
\hline Gravel drain & 6 & 83,123 & Processed gravel from the Borax Gravel Pit. \\
\hline Asphalt finish course & 6 & 83,362 & $\begin{array}{l}\text { Hot asphalt mixture would be trucked from an asphalt plant in Idaho Falls, Blackfoot, } \\
\text { or Pocatello or would be produced at a temporary asphalt plant established near } \\
\text { RWMC. }\end{array}$ \\
\hline Asphalt base course & 4 & 55,146 & $\begin{array}{l}\text { Hot asphalt mixture would be trucked from an asphalt plant in Idaho Falls, Blackfoot, } \\
\text { or Pocatello or would be produced at a temporary asphalt plant established near } \\
\text { RWMC. }\end{array}$ \\
\hline Grading fill & $0-120$ & $1,186,389$ & Unprocessed gravel and sand from the T12 Gravel Pit. \\
\hline Sand (side-slope) & 12 & 2,366 & Processed sand (from gravel screening) from the Borax Gravel Pit. \\
\hline Gravel (side-slope protection) & 12 & 3,271 & Processed gravel from the Borax Gravel Pit. \\
\hline $\begin{array}{l}\text { Coarse fractured basalt } \\
\text { (side-slope protection) }\end{array}$ & 12 & 4,124 & $\begin{array}{l}\text { Processed material mined at Radio Cinder Butte, approximately } 26 \text { mi west of } \\
\text { Idaho Falls, near State Highway } 20 .\end{array}$ \\
\hline Rip-rap (side-slope protection) & 36 & 25,735 & $\begin{array}{l}\text { Processed material mined at Radio Cinder Butte, approximately } 26 \text { mi west of } \\
\text { Idaho Falls, near State Highway } 20 .\end{array}$ \\
\hline
\end{tabular}




\section{E. Institutional controls (capital costs)}

1. Placement of ICs will include generation of an IC plan, restrictions on groundwater use, and restrictions on land use.

2. Groundwater-use restrictions will include limitations or restrictions on well drilling in the affected area or buffer zone.

3. Land use restrictions will include repairing and replacing perimeter signs and installing permanent markers surrounding the SDA to delineate contamination. Permanent markers will be made of concrete and contain information about the type of contamination. The number of permanent markers is 12 , based on the large size of the SDA.

\section{F. Long-term operating and maintenance and monitoring (operations and maintenance costs)}

1. Operations and maintenance activities will continue following completion of the surface barrier. Operations and maintenance activities will include groundwater monitoring, vadose zone monitoring, biological surveillance, and vegetation surveillance.

2. Operable Unit 7-13/14 will fund groundwater and vadose zone monitoring for the first 5 years following project completion (costs are included in this estimate).

3. The INL Sitewide Monitoring Program will fund groundwater and vadose zone monitoring from Year 6 to the end of the IC period (costs are included in this estimate).

4. Air monitoring of suspended contaminants, biological monitoring of animal tissue, soil monitoring for biotic transported contaminants, and monitoring of surface water runoff are captured within the contingency of this cost estimate module. Therefore, costs are not included within this estimate.

5. After topsoil has been placed as the final layer on the surface barrier, it will be seeded to provide vegetative cover that will reduce erosion. However, because of the arid climate of the INL Site, an extended period of time will be required to establish a permanent vegetative cover. Erosion of the uppermost layers of the surface barrier during snowmelt will occur during the years immediately following construction, and repairs and reseeding will be required.

6. Ongoing maintenance of the surface barrier will be required in perpetuity after construction is completed. Frequent maintenance will be required during the years immediately following construction to repair damage from erosion and to establish a permanent vegetative cover. In addition, the added weight of the surface barrier is expected to result in increased settlement during the initial years following construction. Some areas of the surface barrier will require ongoing maintenance to repair damage resulting from settlement. Annual maintenance and repairs will be required during the first 5 years following construction. Ongoing maintenance and repairs will continue every 5 years concurrent with the 5 -year review process.

7. Environmental monitoring will continue for 100 years following issuance of the ROD. Estimated monitoring requirements and the projected labor effort are summarized in Table F-30. Estimated surveillance requirements and the projected labor effort are summarized in Table F-31. The estimated costs of the required laboratory analyses are provided in Table F-32. 
8. This estimate does not include costs to maintain and operate the OCVZ system treatment units or costs to sample and analyze OCVZ vapor ports for volatile organics. These costs are captured in Estimate Number 5992-S (Module 20a).

9. A $10 \%$ allocation is included for replacement parts and equipment for the existing wells and lysimeters.

10. Reports will be prepared annually summarizing analytical and field data.

11. Contingency percentage (scope plus bid) for the operations and maintenance program uses the same contingency percentages used for the capital costs.

12. Project management for the operations and maintenance program is $5 \%$ of the overall operations and maintenance costs plus contingency.

13. Technical support for the operations and maintenance program is $15 \%$ of the overall operations and maintenance costs plus contingency.

\section{G. Periodic costs}

Reviews will be conducted once every 5 years for 100 years. Five-year reviews will not result in additions or modifications of the remedy. No costs are included in the estimate for remedy additions or modifications.

\section{F-6.5 Contingency Guideline Implementation}

The total capital cost contingency for Module 5 is $22.19 \%$. This contingency is the average contingency of the construction activities (i.e., 25\%) and professional and technical services (i.e., $0 \%$ ).

The total operations and maintenance cost contingency for Module 5 is $20 \%$. This contingency is the average contingency of the monitoring, sampling, and testing activities (i.e., 25\%); construction activities (i.e., 25\%); and professional and technical services (i.e., $0 \%$ ).

The total periodic cost contingency for Module 5 is $0 \%$ (the contingency for the professional and technical services). 
Table F-30. Module 5 estimated long-term monitoring program.

\begin{tabular}{|c|c|c|c|c|}
\hline Media & Monitoring Stations & Monitoring Frequency & $\begin{array}{l}\text { Estimated Labor } \\
\text { (hours per event) }\end{array}$ & Other Assumptions \\
\hline Groundwater & 21 monitoring wells & $\begin{array}{l}\text { Semiannually for } 5 \text { years; } \\
\text { annually for } 95 \text { years }\end{array}$ & $\begin{array}{l}\text { Two and one-half personnel } \\
\text { (staff) for } 10.5 \text { days }=262 \text { hours }\end{array}$ & $\begin{array}{l}\text { Maximum depth of screened interval is } 600 \mathrm{ft} \text {; four } \\
\text { quality assurance and quality control samples per } \\
\text { event. Analyses include characteristic leaching } \\
\text { procedures for metals, nitrate/nitrite, VOCs, } \\
\text { semi-VOCs, gross alpha and beta, Sr-90, Tc-99, } \\
\text { U-234, U-235/236, U-238, Am-241, gamma isotopes, } \\
\text { C-14, I-129, pH, turbidity, total suspended solids, and } \\
\text { total dissolved solids. }\end{array}$ \\
\hline \multirow[t]{3}{*}{ Vadose zone } & 100 lysimeters & Annually for 100 years & $\begin{array}{l}\text { Four personnel for } 4 \text { days and } \\
\text { six personnel for } \\
2.5 \text { days }=310 \text { hours }\end{array}$ & $\begin{array}{l}\text { Lysimeters will be sampled in late spring. Assume } \\
35 \% \text { of lysimeters yield adequate liquid for analysis. } \\
\text { Assume one additional quality assurance and quality } \\
\text { control sample. Samples will be prioritized for } \\
\text { groundwater analytes. }\end{array}$ \\
\hline & 20 vapor ports & $\begin{array}{l}\text { Quarterly for } 5 \text { years; } \\
\text { annually for } 95 \text { years }\end{array}$ & $\begin{array}{l}\text { Three personnel for } \\
2 \text { days }=60 \text { hours }\end{array}$ & $\begin{array}{l}\text { Vapor port samples analyzed for C-14 and tritium } \\
\text { only. }\end{array}$ \\
\hline & 100 tensiometers & Continuous data logger & $\begin{array}{l}\text { Maintenance }=200 \text { hours } \\
\text { Data evaluation }=100 \text { hours } \\
\text { Data reporting }=160 \text { hours }\end{array}$ & $\begin{array}{l}\text { Local surface water infiltration will be monitored } \\
\text { using tensiometers installed in either undisturbed } \\
\text { surficial soil or water storage layers within the } \\
\text { engineered surface barrier. Maintenance and data } \\
\text { evaluation occur quarterly, and data reporting occurs } \\
\text { annually. }\end{array}$ \\
\hline
\end{tabular}

Table F-31. Module 5 estimated long-term surveillance program.

\begin{tabular}{|c|c|c|c|c|}
\hline Media & Monitoring Stations & Monitoring Frequency & $\begin{array}{l}\text { Estimated Labor } \\
\text { (hours per event) }\end{array}$ & Other Assumptions \\
\hline Biological & Animal intrusion & Annually for 100 years & $\begin{array}{l}\text { Two personnel (staff) for } \\
1 \text { day }=20 \text { hours }\end{array}$ & Requires two staff once per year. \\
\hline Vegetation & Entire cap surface & $\begin{array}{l}\text { Annually for } 5 \text { years, } \\
\text { every } 5 \text { years for } 95 \text { years }\end{array}$ & $\begin{array}{l}\text { Two personnel (staff) for } \\
1 \text { day }=20 \text { hours }\end{array}$ & $\begin{array}{l}\text { Perform one inspection per year in early fall for } \\
5 \text { years. Reseed } 10 \text { acres each year for } 5 \text { years } \\
\text { ( } 50 \text { acres total). Perform one inspection every } 5 \text { years } \\
\text { in early fall; thereafter, for } 95 \text { years. Reseed } 10 \text { acres } \\
\text { every } 5 \text { years for } 95 \text { years. }\end{array}$ \\
\hline
\end{tabular}


Table F-32. Module 5 estimated analytical requirements.

\begin{tabular}{|c|c|c|c|c|}
\hline \multirow[b]{2}{*}{ Target Analyte } & \multirow[b]{2}{*}{$\begin{array}{l}\text { Unit Cost } \\
(\$)\end{array}$} & \multirow[b]{2}{*}{$\begin{array}{l}\text { Groundwater Event } \\
\quad(25 \text { samples }) \\
\quad(\$)\end{array}$} & \multicolumn{2}{|c|}{ Vadose Zone Event } \\
\hline & & & $\begin{array}{l}\text { Lysimeter Event } \\
\text { (36 samples) } \\
\text { (\$) }\end{array}$ & $\begin{array}{c}\text { Vapor Port Event } \\
\text { (20 samples) } \\
(\$)\end{array}$ \\
\hline Volatile organics & 169 & 4,221 & 6,078 & - \\
\hline Semivolatile organics & 211 & 5,276 & 7,598 & - \\
\hline Metals & 169 & 4,221 & 6,078 & - \\
\hline Nitrate/nitrite & 15 & 386 & 555 & - \\
\hline Gross alpha and beta & 66.64 & 1,666 & 2,399 & - \\
\hline Sr-90 & 128.20 & 3,205 & 4,615 & - \\
\hline Tc-99 & 89.35 & 2,234 & 3,217 & - \\
\hline U-234, -235/236, -238 & 180.65 & 4,516 & 6,503 & - \\
\hline Am-241 & 180.65 & 4,516 & 6,503 & - \\
\hline $\mathrm{C}-14$ & 93.24 & 2,331 & 3,357 & 1,865 \\
\hline $\mathrm{I}-129$ & 93.24 & 2,331 & 3,357 & - \\
\hline Tritium & 46.27 & 1,157 & 1,666 & 925 \\
\hline Gamma isotopes & 128.21 & 3,205 & 4,616 & - \\
\hline Analytical subtotal & - & 39,265 & 56,542 & 2,790 \\
\hline Procurement (12\%) & - & 4,712 & 6,785 & 335 \\
\hline Project adder $^{\mathrm{a}}$ & - & 1,543 & 2,221 & 1,234 \\
\hline Validation procurement ${ }^{\mathrm{a}}$ & - & 2,072 & 2,984 & 1,658 \\
\hline Total $^{\text {b }}$ & - & 47,592 & 68,532 & 6,017 \\
\hline \multicolumn{5}{|c|}{$\begin{array}{l}\text { Assumptions: } \\
\text { 1. Two task order statements for entire project, samples are batched to maximize efficiency for analysis, shipping 5-10 samples per } \\
\text { shipment, all shipments for a sampling event sent within a 2-week period. Normal turn around time (i.e., } 35 \text { days). } \\
\text { 2. Metals: contract laboratory program metals, nitrate as nitrogen through EPA } 353.1 \text {. } \\
\text { 3. Semivolatile-organic analysis: Priority Pollutant List SW-846 8270C. } \\
\text { 4. Volatile-organic analysis: Priority Pollutant List SW-846 8260B. }\end{array}$} \\
\hline \multicolumn{5}{|c|}{$\begin{array}{l}\text { a. Adder costs included task order statement, sampling and analysis plan table, data review, data tracking, data entry (Energy Research } \\
\text { Information System) upload, invoicing, and validation. } \\
\text { b. Listed within the "Other" column in the cost estimate. }\end{array}$} \\
\hline
\end{tabular}




\section{F-6.6 Estimate Summary}

Table F-33 shows the rough order of magnitude allocations of methodologies used to develop the cost estimate for Module 5.

Table F-33. Rough order of magnitude allocations of methodologies used to develop the cost estimate for Module 5.

\begin{tabular}{lc}
\hline Estimate Methodology & $\begin{array}{c}\text { Rough Order of Magnitude } \\
(\%)\end{array}$ \\
\hline Project team & 65 \\
Recorded actuals & 0 \\
Parametric & 0 \\
Vendor quotes & 0 \\
Other (estimating manuals) & 35 \\
Total & $\mathbf{1 0 0}$ \\
\hline
\end{tabular}

\section{F-6.7 Other Comments or Concerns Specific to the Estimate}

A. All costs reflect present day costs. No escalation is included in the estimate.

B. Costs for Idaho state sales tax (5\%) on material purchases are included in the estimate, where applicable.

C. Because work activities identified in this estimate will not begin until after September 30, 2005, no ICP general and administrative costs have been included in this estimate, in accordance with recent direction received by Estimating Services.

\section{F-6.8 Summary}

Tables F-34 through F-37 provide summary cost information for Module 5. 
Table F-34. Capital costs for Module 5: Operable Unit 7-13/14 Feasibility Study-RCRA Type C Cap, Project Number: 5992-B.

\begin{tabular}{|c|c|c|c|c|c|}
\hline Level & Description & $\begin{array}{l}\text { Subtotals } \\
\text { (\$) }\end{array}$ & $\begin{array}{l}\text { Estimate }^{\mathrm{a}} \\
\quad(\$)\end{array}$ & $\begin{array}{l}\text { Contingency } \\
(\$)\end{array}$ & $\begin{array}{c}\text { Total }^{\mathrm{a}, \mathrm{c}} \\
(\$)\end{array}$ \\
\hline 1.1 & Construction activities & $86,740,000$ & - & - & - \\
\hline 1.1 .1 & Mobilization and demobilization & $4,269,000$ & - & - & - \\
\hline 1.1 .1 .1 & Mobilization of temporary facilities and materials & - & 129,000 & 32,000 & 161,000 \\
\hline 1.1.1.2 & Submittals and implementation plans & $1,159,000$ & - & - & - \\
\hline 1.1.1.2.1 & Operational and layout plan & - & 242,000 & 61,000 & 303,000 \\
\hline 1.1.1.2.2 & Remedial action, monitoring, and control plan & - & 42,000 & 11,000 & 53,000 \\
\hline 1.1.1.2.3 & Industrial hygiene exposure and sample plan & - & 36,000 & 9,000 & 45,000 \\
\hline 1.1.1.2.4 & Management self-assessment plan & - & 266,000 & 66,000 & 332,000 \\
\hline 1.1.1.2.5 & Well abandonment plan & - & 186,000 & 46,000 & 232,000 \\
\hline 1.1.1.2.6 & Quality control plan & - & 65,000 & 16,000 & 81,000 \\
\hline 1.1.1.2.7 & Final inspection report & - & 323,000 & 81,000 & 403,000 \\
\hline 1.1 .1 .3 & Security at construction site access gates & - & $2,903,000$ & 726,000 & $3,629,000$ \\
\hline 1.1.1.4 & Demobilization of temporary facilities & - & 77,000 & 19,000 & 97,000 \\
\hline 1.1 .2 & Site preparation work & $3,897,000$ & - & - & - \\
\hline 1.1.2.4 & Cap or cover & $3,897,000$ & - & - & - \\
\hline 1.1.2.1.1 & Install temporary water fill station storage tank for compaction & - & 65,000 & 16,000 & 81,000 \\
\hline 1.1.2.1.2 & $\begin{array}{l}\text { Relocate and demolish utilities and environmental monitoring } \\
\text { equipment }\end{array}$ & - & 677,000 & 169,000 & 847,000 \\
\hline 1.1.2.1.3 & Construct new Subsurface Disposal Area perimeter gravel road & - & 354,000 & 88,000 & 442,000 \\
\hline 1.1.2.1.4 & Install new perimeter fence and gates & - & 774,000 & 194,000 & 968,000 \\
\hline 1.1.2.1.5 & Demolish existing perimeter fence and LLW Pit fence & - & 93,000 & 23,000 & 117,000 \\
\hline 1.1.2.1.6 & Abandon or extend existing wells and probes & - & 376,000 & 94,000 & 470,000 \\
\hline 1.1.2.1.7 & $\begin{array}{l}\text { Extend existing OCVZ system probes and relocate treatment } \\
\text { units }\end{array}$ & 580,000 & - & - & - \\
\hline 1.1.2.1.7.1 & Extend 18 existing OCVZ system probes & - & 225,000 & 56,000 & 281,000 \\
\hline 1.1.2.1.7.2 & Relocate treatment Unit D & - & 118,000 & 30,000 & 148,000 \\
\hline 1.1.2.1.7.3 & Relocate treatment Unit E & - & 118,000 & 30,000 & 148,000 \\
\hline 1.1.2.1.7.4 & Relocate treatment Unit F & - & 118,000 & 30,000 & 148,000 \\
\hline 1.1.2.1.8 & $\begin{array}{l}\text { Extend existing advanced tensiometers and install new advanced } \\
\text { tensiometers }\end{array}$ & 978,000 & - & - & - \\
\hline 1.1.2.1.8.1 & Maintain and extend 50 existing advanced tensiometers & - & 16,000 & 4,000 & 20,000 \\
\hline 1.1.2.1.8.2 & Install 50 new advanced tensiometers & - & 639,000 & 160,000 & 798,000 \\
\hline 1.1.2.1.8.3 & Well completion & - & 100,000 & 25,000 & 125,000 \\
\hline 1.1.2.1.8.4 & Probe cost for installation of new advanced tensiometers & - & 97,000 & 24,000 & 121,000 \\
\hline 1.1.2.1.8.5 & Logger cost for installation of new advanced tensiometers & - & 65,000 & 16,000 & 81,000 \\
\hline 1.1.2.1.8.6 & $\begin{array}{l}\text { Network design cost for installation of new advanced } \\
\text { tensiometers }\end{array}$ & - & 62,000 & 15,000 & 77,000 \\
\hline 1.1 .3 & Remediation & $78,574,000$ & - & - & - \\
\hline 1.1.3.1 & Cap or cover & $78,574,000$ & - & - & - \\
\hline 1.1.3.1.1 & Construct Resource Conservation and Recovery Act Type C cap & $77,508,000$ & - & - & - \\
\hline 1.1.3.1.1.1 & Install grading fill-layer one & - & $9,214,000$ & $2,304,000$ & $11,518,000$ \\
\hline 1.1 .3 .1 .1 .2 & Install 4-in. asphalt base-layer two & - & $14,999,000$ & $3,750,000$ & $18,748,000$ \\
\hline 1.1.3.1.1.3 & Install 6-in. asphalt-layer three & - & $24,562,000$ & $6,141,000$ & $30,703,000$ \\
\hline 1.1.3.1.1.4 & Install gravel drain-layer four & - & $2,124,000$ & 531,000 & $2,655,000$ \\
\hline 1.1 .3 .1 .1 .5 & Install gravel filter-layer five & - & $2,061,000$ & 515,000 & $2,577,000$ \\
\hline 1.1.3.1.1.6 & Install sand-layer six & - & $1,088,000$ & 272,000 & $1,360,000$ \\
\hline 1.1.3.1.1.7 & Install compacted topsoil-layer seven & - & $7,169,000$ & $1,792,000$ & $8,961,000$ \\
\hline 1.1.3.1.1.8 & Install topsoil--layer eight & - & $7,041,000$ & $1,760,000$ & $8,802,000$ \\
\hline 1.1.3.1.1.9 & Install side-slope sand & - & 37,000 & 9,000 & 47,000 \\
\hline 1.1.3.1.1.10 & Install side-slope gravel & - & 84,000 & 21,000 & 105,000 \\
\hline 1.1.3.1.1.11 & Install side-slope basalt & - & 443,000 & 111,000 & 554,000 \\
\hline 1.1.3.1.1.12 & Install side-slope rip-rap & - & $2,770,000$ & 693,000 & $3,463,000$ \\
\hline 1.1.3.1.1.13 & Vegetate cap and construction area & - & 521,000 & 130,000 & 651,000 \\
\hline 1.1.3.1.1.14 & Install OCVZ abovegrade piping to probes & - & $3,588,000$ & 897,000 & $4,485,000$ \\
\hline 1.1.3.1.1.15 & Install six sampling wells outside the SDA & - & $1,806,000$ & 452,000 & $2,258,000$ \\
\hline 1.1.3.1.2 & Contour south and east ends outside the SDA for drainage & - & $1,066,000$ & 267,000 & $1,333,000$ \\
\hline 1.2 & Professional and technical services & $\mathbf{1 0 , 8 4 3 , 0 0 0}$ & - & - & - \\
\hline 1.2 .1 & Project management & - & $5,421,000$ & - & $5,421,000$ \\
\hline 1.2 .2 & Remedial design and remedial action work plan & $3,253,000$ & - & - & - \\
\hline 1.2 .2 .1 & Remedial design & - & $2,169,000$ & - & $2,169,000$ \\
\hline 1.2 .2 .2 & Remedial action work plan & - & $1,084,000$ & - & $1,084,000$ \\
\hline 1.2 .3 & Construction management & - & $2,169,000$ & - & $2,169,000$ \\
\hline 1.3 & Institutional controls & $\mathbf{1 3 3 , 0 0 0}$ & - & - & - \\
\hline 1.3 .1 & Institutional controls plan & - & 17,000 & - & 17,000 \\
\hline 1.3 .2 & Groundwater use restrictions & - & 26,000 & - & 26,000 \\
\hline 1.3 .3 & Land use restrictions & 90,000 & - & - & - \\
\hline 1.3 .3 .1 & Perimeter markers & - & 77,000 & - & 77,000 \\
\hline \multirow[t]{3}{*}{ 1.3.3.2 } & Repair and replace perimeter signs & - & 13,000 & - & 13,000 \\
\hline & Total capital cost ${ }^{\mathrm{c}}$ & - & $97,716,000$ & $21,685,000$ & $119,401,000$ \\
\hline & \multicolumn{5}{|c|}{$\begin{array}{l}\text { a. Values are rounded to the nearest } \$ 1,000 . \\
\text { b. Capital cost contingency is } 22.2 \% \text { of the estimate. } \\
\text { c. Totals were derived for the summation of nonrounded subcomponent values. Therefore, totals are not equal to the summation of the rounded subcomponent values shown } \\
\text { above. See Table F-3 for nonrounded totals. } \\
\text { LLW }=\text { low-level waste } \\
\text { OCVZ = Organic Contamination in the Vadose Zone } \\
\text { SDA = Subsurface Disposal Area }\end{array}$} \\
\hline
\end{tabular}


Table F-35. Operational and maintenance costs for Module 5: Operable Unit 7-13/14 Feasibility Study—RCRA Type C Cap, Project Number: 5992-B.

\begin{tabular}{|c|c|c|c|c|c|}
\hline Level & Description & $\begin{array}{c}\text { Subtotals }^{\mathrm{a}} \\
(\$)\end{array}$ & $\begin{array}{c}\text { Estimate }^{\mathrm{a}} \\
(\$)\end{array}$ & $\begin{array}{c}\text { Contingency }{ }^{\mathrm{a}, \mathrm{b}} \\
(\$)\end{array}$ & $\begin{array}{c}\text { Total }^{\mathrm{a}, \mathrm{c}} \\
(\$)\end{array}$ \\
\hline 2.1 & Monitoring, sampling, testing, and analysis & $45,042,000$ & - & - & - \\
\hline 2.1.1 & Groundwater monitoring & $9,912,000$ & - & - & - \\
\hline 2.1.1.1 & $\begin{array}{l}\text { Groundwater monitoring semiannually for } 5 \text { years (10 sampling } \\
\text { events) }\end{array}$ & - & 813,000 & 203,000 & $1,016,000$ \\
\hline 2.1.1.2 & $\begin{array}{l}\text { Groundwater monitoring annually for } 95 \text { years (95 sampling } \\
\text { events) }\end{array}$ & - & $7,723,000$ & $1,931,000$ & $9,653,000$ \\
\hline 2.1.1.3 & $\begin{array}{l}\text { Replacement parts and equipment costs (assume } 10 \% \text { of total } \\
\text { groundwater monitoring costs) }\end{array}$ & - & $1,377,000$ & 344,000 & $1,721,000$ \\
\hline 2.1 .2 & Vadose zone monitoring & $35,130,000$ & - & - & - \\
\hline 2.1.2.1 & Sample 100 lysimeters one time per year in late spring & - & $11,172,000$ & $2,793,000$ & $13,965,000$ \\
\hline 2.1.2.2 & Sample and analyze 20 vapor ports four times per year for 5 years & - & 266,000 & 67,000 & 333,000 \\
\hline 2.1.2.3 & $\begin{array}{l}\text { Sample and analyze } 20 \text { vapor ports one time per year thereafter for } \\
95 \text { years }\end{array}$ & - & $1,265,000$ & 316,000 & $1,581,000$ \\
\hline 2.1.2.4 & Analyze 100 advanced tensiometers & $17,548,000$ & 一 & - & - \\
\hline 2.1.2.4.1 & $\begin{array}{l}\text { Maintenance of advanced tensiometers four times per year for } \\
100 \text { years }\end{array}$ & - & $10,322,000$ & $2,581,000$ & $12,903,000$ \\
\hline 2.1.2.4.2 & $\begin{array}{l}\text { Data evaluation of advanced tensiometers four times per year } \\
\text { for } 100 \text { years }\end{array}$ & - & $5,161,000$ & $1,290,000$ & $6,452,000$ \\
\hline 2.1.2.4.3 & $\begin{array}{l}\text { Data reporting of advanced tensiometers one time per year for } \\
100 \text { years }\end{array}$ & - & $2,064,000$ & 516,000 & $2,581,000$ \\
\hline 2.1.2.5 & $\begin{array}{l}\text { Replacement parts and equipment costs (assume 10\% of total } \\
\text { vadose zone monitoring costs) }\end{array}$ & - & $4,879,000$ & $1,220,000$ & $6,099,000$ \\
\hline 2.2 & Construction activities & $10,206,000$ & - & - & - \\
\hline 2.2 .1 & Remedy failure or replacement & $9,677,000$ & - & - & - \\
\hline 2.2.1.1 & Cap or cover maintenance and repairs & - & $9,677,000$ & $2,419,000$ & $12,097,000$ \\
\hline 2.2 .2 & Cap surveillance & 528,000 & - & - & - \\
\hline 2.2.2.1 & Biological surveillance & 30,000 & - & - & - \\
\hline 2.2.2.1.1 & $\begin{array}{l}\text { Intrusion surveillance with two people two times the first } \\
5 \text { years }\end{array}$ & - & 3,000 & 1,000 & 4,000 \\
\hline 2.2.2.1.2 & $\begin{array}{l}\text { Intrusion surveillance with two people one time every } 5 \text { years } \\
\text { thereafter for } 95 \text { years }\end{array}$ & - & 27,000 & 7,000 & 34,000 \\
\hline 2.2.2.2 & Vegetation surveillance & 499,000 & - & - & - \\
\hline 2.2.2.2.1 & Perform one inspection per year in early fall for 5 years & - & 7,000 & 2,000 & 9,000 \\
\hline 2.2.2.2.2 & Reseed 10 acres each year for 5 years ( 50 acres total) & - & 97,000 & 24,000 & 121,000 \\
\hline 2.2.2.2.3 & $\begin{array}{l}\text { Perform one inspection in early fall every } 5 \text { years thereafter } \\
\text { for } 95 \text { years }\end{array}$ & - & 27,000 & 7,000 & 34,000 \\
\hline 2.2.2.2.4 & Reseed 10 acres every 5 years for 95 years & - & 368,000 & 92,000 & 460,000 \\
\hline 2.3 & Professional and technical services & $13,812,000$ & - & - & - \\
\hline 2.3 .1 & Project management & - & $3,453,000$ & - & $3,453,000$ \\
\hline \multirow[t]{3}{*}{2.3 .2} & Technical support & - & $10,359,000$ & - & $10,359,000$ \\
\hline & Total operational and maintenance $\operatorname{cost}^{\mathrm{c}}$ & - & $69,060,000$ & $13,812,000$ & $82,871,000$ \\
\hline & \multicolumn{5}{|c|}{$\begin{array}{l}\text { a. Values are rounded to the nearest } \$ 1,000 \text {. } \\
\text { b. Operational and maintenance cost contingency is } 20.0 \% \text { of the estimate. } \\
\text { c. Totals were derived for the summation of nonrounded subcomponent values. Therefore, totals are not equal to the summation of the rounded subcomponent values shown } \\
\text { above. See Table F-3 for nonrounded totals. }\end{array}$} \\
\hline
\end{tabular}

Table F-36. Periodic costs for Module 5: Operable Unit 7-13/14 Feasibility Study—RCRA Type C Cap, Project Number: 5992-B

\begin{tabular}{|c|c|c|c|c|c|}
\hline Level & Description & $\begin{array}{l}\text { Subtotals } \mathrm{s}^{\mathrm{a}} \\
\text { (\$) }\end{array}$ & $\begin{array}{l}\text { Estimate }^{\mathrm{a}} \\
(\$)\end{array}$ & $\begin{array}{l}\text { Contingency } \\
\text { (\$) }\end{array}$ & $\begin{array}{c}\text { Total }^{\mathrm{a}, \mathrm{c}} \\
(\$)\end{array}$ \\
\hline 3.1 & Professional and technical services (periodic) & $5,218,000$ & - & - & - \\
\hline 3.1 .1 & Remedial action report & - & 490,000 & - & 490,000 \\
\hline 3.1 .2 & Annual summary reports & - & $1,935,000$ & - & $1,935,000$ \\
\hline 3.1 .3 & 5-year reviews & - & $1,161,000$ & - & $1,161,000$ \\
\hline \multirow[t]{3}{*}{3.1 .4} & Operation and maintenance report & - & $1,631,000$ & - & $1,631,000$ \\
\hline & Total periodic cost ${ }^{\mathrm{c}}$ & - & $5,218,000$ & - & $5,218,000$ \\
\hline & \multicolumn{5}{|c|}{$\begin{array}{l}\text { a. Values are rounded to the nearest } \$ 1,000 \text {. } \\
\text { b. Periodic cost contingency is } 0.0 \% \text { of the estimate. } \\
\text { c. Totals were derived for the summation of nonrounded subcomponent values. Therefore, totals are not equal to the summation of the rounded subcomponent values shown } \\
\text { above. See Table F- } 3 \text { for nonrounded totals. }\end{array}$} \\
\hline
\end{tabular}

Table F-37. Total costs for Module 5: Operable Unit 7-13/14 Feasibility Study-RCRA Type C Cap, Project Number: 5992-B.

\begin{tabular}{|c|c|c|c|}
\hline & $\begin{array}{c}\text { Estimate }^{\mathrm{a}} \\
(\$)\end{array}$ & $\begin{array}{c}\text { Contingency }{ }^{\mathrm{a}, \mathrm{b}} \\
(\$)\end{array}$ & $\begin{array}{c}\text { Total }^{\mathrm{a}} \\
(\$)\end{array}$ \\
\hline Total cost for Resource Conservation and Recovery Act Type $C$ cap & $171,993,000$ & $35,497,000$ & $207,490,000$ \\
\hline
\end{tabular}




\section{F-7. MODULE 6: GAS VENT LAYER EXTRACTION PIPE \\ F-7.1 Purpose}

SDA.

This estimate will be used as a cost-comparative tool to examine different options regarding the

\section{F-7.2 Scope of Work}

The scope of work consists of installing 1,097.3 m (3,600 ft) of horizontal 12-in. pipe, with 37 each, 12-in. vertical risers. Each riser will be $4.6 \mathrm{~m}$ (15 ft) long and installed in $0.6-\mathrm{m}(2-\mathrm{ft})$ sections. Costs for both active and passive gas extraction are captured within this estimate. For active gas extraction the vertical risers are tied into the three pre-existing OCVZ extraction treatment units following completion of the surface barrier. These treatment units actively extract gas from the surface barrier's gas collection layer and treat the gas through thermal oxidation prior to release. For passive gas extraction, the vertical risers are allowed to passively vent directly into the atmosphere without connections to the OCVZ system treatment units.

Costs for mobilization of security are captured within the cost estimate for the ET surface barrier (see Section D-3).

Site preparation consists of the following:

- $\quad$ Conduct procurement activities

- $\quad$ Survey site locations.

Remediation consists of the following:

- Install 1,097.3 m (3,600 linear $\mathrm{ft})$ of 30.5-cm (12-in.) pipe within the crown of the ET surface barrier gas vent layer.

- Install 37 risers (4.6 m [15 ft] long). Risers will be installed in 0.6-m (2-ft) sections as fill material is placed.

- $\quad$ Following completion of the cap, group (by manifold) six sets of risers (five sets of six risers and one set of seven risers) into six outlet ducts.

- $\quad$ Pipe these ducts to OCVZ system treatment units (active gas extraction option).

Costs for project plans (i.e., operation and layout plan, radiological monitoring and control plan, industrial hygiene exposure and sample plan, management self-assessment plan, and quality control plan), vendor data, and final inspection report will be included in the cost estimate for the ET surface barrier (see Section D-3). 


\section{F-7.3 Basis of the Estimate}

The following sequential process, rationale, and estimating methodologies were used to define activities, quantities, and resources that were used in preparation of this cost estimate.

A. The INEEL Environmental Restoration Cost Estimating/Cost Engineering Guide (DOE-ID 2000) and the "Idaho National Engineering and Environmental Laboratory Detailed Work Plan Development Process Guidance" (GDE-112) were used to define estimating requirements.

B. The estimate development method was established using a detailed bottoms-up quantifiable technique. Resources, costs, and productions are derived from these individual, detailed item quantities.

C. The estimate scope is defined in the scope of work provided by the requester.

D. The estimate is based on drawings and specifications provided by the requester.

E. Costs were developed, using the Success $@$ estimating software by U.S. Cost, to a level of detail consistent with available documents and information.

F. Standard material pricing is based on the R. S. Means and Richardson Estimating Manuals.

G. Labor rates are based on the R. S. Means and Richardson Estimating Manuals. All labor rates are factored considering working conditions and requirements at the INL Site.

H. Project scope and methodologies were prepared from discussions with the requester and project team.

\section{F-7.4 Assumptions}

\section{A. General assumptions}

This project will be performed concurrently with cap construction; therefore, it does not include costs for the operation and layout plan, radiological monitoring and control plan, industrial hygiene exposure and sample plan, management self-assessment plan, quality control plan, and final inspection report. Costs for these activities are included in the estimate to construct the cap (see Section D-3).

\section{B. Schedule}

1. Active extraction

a. The cap will be completed 2 years following installation of the extraction pipe. At this time, extraction pipe exhaust will be piped to OCVZ system treatment units.

b. The project schedule for active gas extraction will be as presented in Figure F-6.

2. Passive extraction

a. The project schedule for passive gas extraction will be as presented in Figure F-7. 


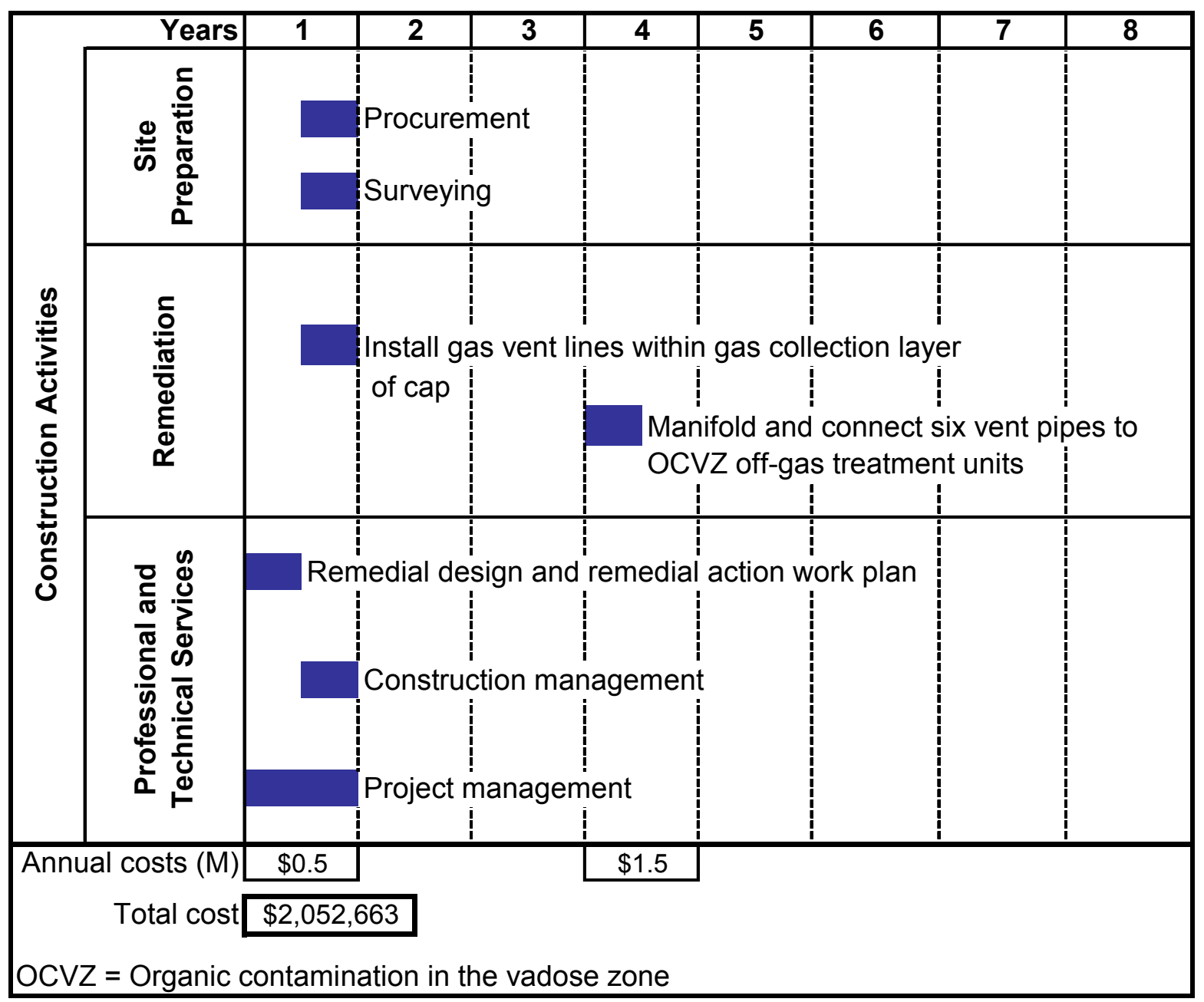

Figure F-6. Module 6 design, construction, and surveillance schedule for the active gas vent layer extraction pipe. 


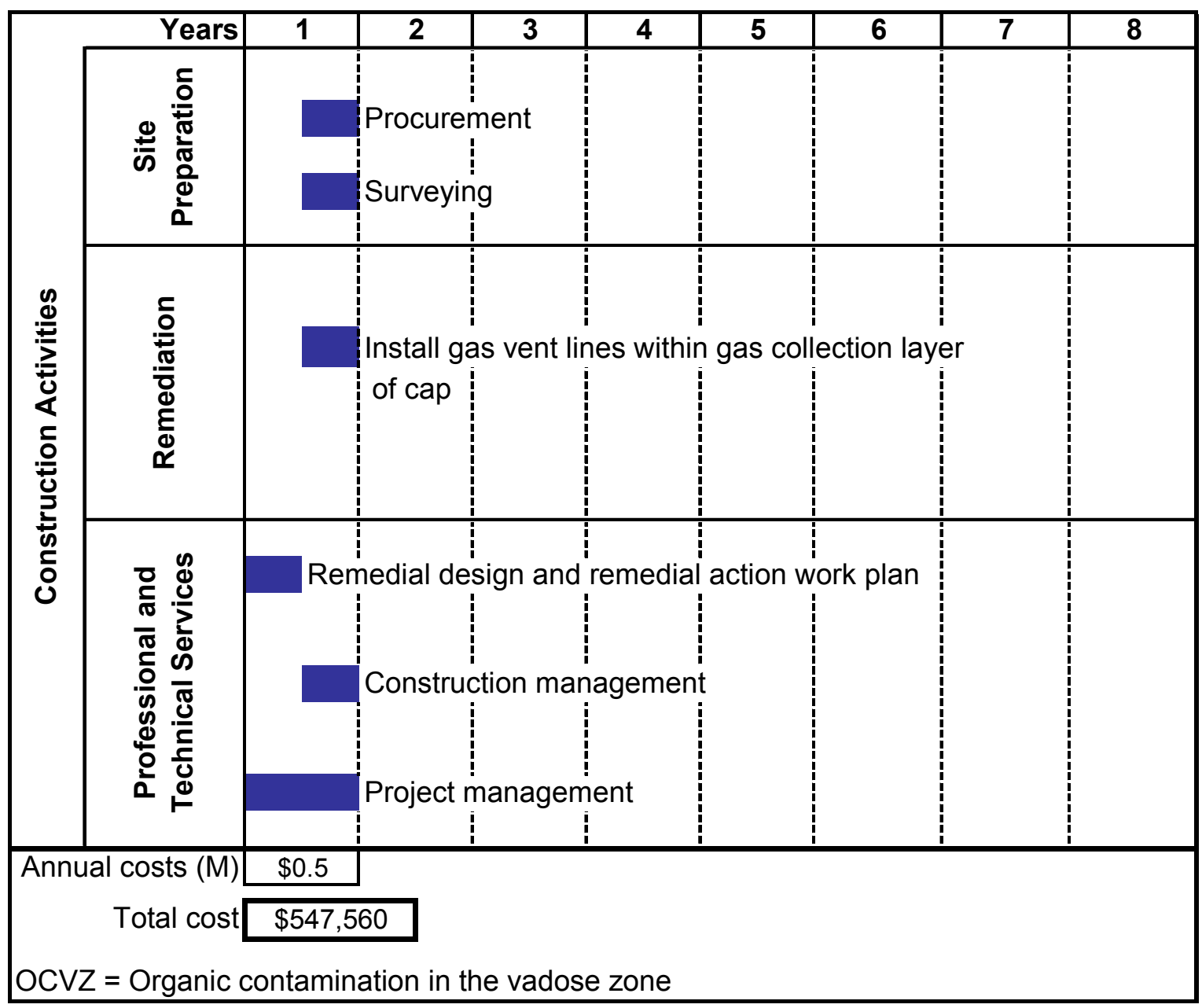

Figure F-7. Module 6 design, construction, and surveillance schedule for the passive gas vent layer extraction pipe.

\section{Mobilization and demobilization (capital costs)}

1. ICP personnel will not require move monies.

2. Mobilization and demobilization costs are captured within the remediation section of the cost estimate.

\section{Site preparation (capital costs)}

A land survey will be required before the start of installing the gas vent layer extraction piping.

\section{F-7.5 Contingency Guideline Implementation}

Total capital cost contingency for Module 6 is $27.9 \%$. This contingency is the average contingency of construction activities (i.e., 30\%) and professional and technical services (i.e., $0 \%$ ). 


\section{F-7.6 Estimate Summary}

Table F-38 provides rough order of magnitude allocations of methodologies used to develop the cost estimate for Module 6.

Table F-38. Rough order of magnitude allocations of methodologies used to develop the cost estimate for Module 6.

\begin{tabular}{lc}
\hline Estimate Methodology & $\begin{array}{c}\text { Rough Order of Magnitude } \\
(\%)\end{array}$ \\
\hline Project team & 50 \\
Recorded actuals & 0 \\
Parametric & 0 \\
Vendor quotes & 40 \\
Other & 10 \\
Total & $\mathbf{1 0 0}$ \\
\hline
\end{tabular}

\section{F-7.7 Other Comments or Concerns Specific to the Estimate}

A. No escalation is included in the cost estimate.

B. Subcontractor labor costs reflect INL Site Stabilization Agreement craft labor rates.

C. $\mathrm{CH} 2 \mathrm{M}-\mathrm{WG}$ Idaho labor rates reflect fully burdened present day rates.

\section{F-7.8 Summary}

Table F-39 provides capital cost information for Module 6 (active) while Table F-40 provides capital cost information for Module 6 (passive). 
Table F-39. Capital costs for Module 6: Operable Unit 7-13/14 Feasibility Study—Gas Vent Layer Extraction Pipe (Active), Project Number: 5992-C.

\begin{tabular}{|c|c|c|c|c|c|}
\hline Level & Description & $\begin{array}{l}\text { Subtotals }{ }^{\mathrm{a}} \\
(\$)\end{array}$ & $\begin{array}{c}\text { Estimate }^{a} \\
(\$)\end{array}$ & $\begin{array}{c}\text { Contingency } \\
(\$)\end{array}$ & $\begin{array}{c}\text { Total }^{\mathrm{a}, \mathrm{c}} \\
(\$)\end{array}$ \\
\hline 1.1 & Construction activities & $1,484,000$ & - & - & - \\
\hline 1.1 .1 & Mobilization and demobilization & 6,000 & - & - & - \\
\hline 1.1.1.1 & Land survey & - & 6,000 & 4,000 & 10,000 \\
\hline 1.1 .2 & Remediation & $1,478,000$ & - & - & - \\
\hline 1.1.2.1 & Gas vent layer extraction pipe & - & 320,000 & 96,000 & 417,000 \\
\hline 1.1.2.2 & Install OCVZ abovegrade piping to extraction pipes & - & 895,000 & 268,000 & $1,163,000$ \\
\hline 1.1.2.3 & Install OCVZ abovegrade electrical to extraction pipes & - & 263,000 & 79,000 & 342,000 \\
\hline 1.2 & Professional and technical services & 121,000 & - & - & - \\
\hline 1.2 .1 & Project management & - & 27,000 & - & 27,000 \\
\hline 1.2 .2 & Remedial design and remedial action work plan & 56,000 & - & - & - \\
\hline 1.2.2.1 & Remedial design & - & 42,000 & - & 42,000 \\
\hline 1.2 .2 .2 & Remedial action work plan & - & 14,000 & - & 14,000 \\
\hline \multirow[t]{3}{*}{1.2 .3} & Construction management & - & 38,000 & - & 38,000 \\
\hline & \multicolumn{2}{|l|}{ Total capital cost $\mathrm{c}^{\mathrm{c}}$} & $1,605,000$ & 448,000 & $2,053,000$ \\
\hline & \multicolumn{5}{|c|}{$\begin{array}{l}\text { a. Values are rounded to the nearest } \$ 1,000 \text {. } \\
\text { b. Capital cost contingency is } 27.9 \% \text { of the estimate. } \\
\text { c. Totals were derived for the summation of nonrounded subcomponent values. Therefore, totals are not equal to the summation of the rounded subcomponent } \\
\text { values shown above. See Table F-3 for nonrounded totals. } \\
\text { OCVZ = Organic Contamination in the Vadose Zone }\end{array}$} \\
\hline
\end{tabular}


Table F-40. Module 6: Operable Unit 7-13/14 Feasibility Study—Gas Vent Layer Extraction Pipe (Passive), Project Number: 5992-C.

\begin{tabular}{|c|c|c|c|c|c|}
\hline Level & Description & $\begin{array}{c}\text { Subtotals }^{\mathrm{a}} \\
(\$)\end{array}$ & $\begin{array}{c}\text { Estimate }^{\mathrm{a}} \\
(\$)\end{array}$ & $\begin{array}{c}\text { Contingency } \\
(\$)\end{array}$ & $\begin{array}{c}\text { Total }^{\mathrm{a}, \mathrm{c}} \\
(\$)\end{array}$ \\
\hline 1.1 & Construction activities & $1,484,000$ & - & - & - \\
\hline 1.1 .1 & Mobilization and demobilization & 6,000 & - & - & - \\
\hline 1.1.1.1 & Land survey & - & 6,000 & 4,000 & 10,000 \\
\hline 1.1.2 & Remediation & $1,478,000$ & - & - & - \\
\hline 1.1.2.1 & Gas vent layer extraction pipe & - & 320,000 & 96,000 & 417,000 \\
\hline 1.2 & Professional and technical services & 121,000 & - & - & - \\
\hline 1.2 .1 & Project management & - & 27,000 & - & 27,000 \\
\hline 1.2 .2 & Remedial design and remedial action work plan & 56,000 & - & - & - \\
\hline 1.2.2.1 & Remedial design & - & 42,000 & - & 42,000 \\
\hline 1.2.2.2 & Remedial action work plan & - & 14,000 & - & 14,000 \\
\hline \multirow[t]{3}{*}{1.2 .3} & Construction management & - & 38,000 & - & 38,000 \\
\hline & Total capital cost $\mathrm{c}^{\mathrm{c}}$ & - & 447,000 & 100,000 & 548,000 \\
\hline & \multicolumn{5}{|c|}{$\begin{array}{l}\text { a. Values are rounded to the nearest } \$ 1,000 \text {. } \\
\text { b. Capital cost contingency is } 27.9 \% \text { of the estimate. } \\
\text { c. Totals were derived for the summation of nonrounded subcomponent values. Therefore, totals are not equal to the summation of the rounded subcomponent } \\
\text { values shown above. See Table F-3 for nonrounded totals. }\end{array}$} \\
\hline
\end{tabular}




\section{F-8. MODULE 7: SHALLOW GAS EXTRACTION WELL \\ F-8.1 Purpose}

SDA.

This estimate will be used as a cost-comparative tool to examine different options regarding the

\section{F-8.2 Scope of Work}

The scope of work consists of drilling eight shallow gas extraction wells into the basalt layer in the SDA. These extraction wells will then be extended to match the cap surface elevation. Effluent from these extraction wells will then be channeled to OCVZ system treatment units following completion of cap construction.

Subcontractor mobilization consists of the following:

- $\quad$ Mobilize equipment (costs captured in Section F-8.4)

- $\quad$ Mobilize security.

Subcontractor demobilization consists of the following:

- $\quad$ Shut down or demobilize equipment.

Site preparation consists of the following:

- $\quad$ Conduct procurement activities

- $\quad$ Survey site for extraction well locations.

Remediation consists of the following:

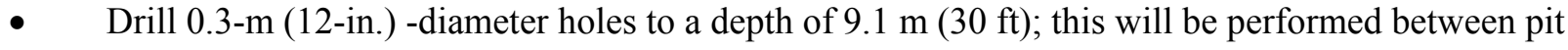
locations in clean soil.

- Install 0.2-m (8-in.) -diameter casings within full length of the drill holes.

- $\quad$ Fill the annulus between the 0.2-m (8-in.) casing and 0.3-m (12-in.) hole with concrete.

- Drill an additional $3 \mathrm{~m}(10 \mathrm{ft})$ deep into the basalt within each 0.2-m (8-in.) casing.

- $\quad$ Extend casing $4.6 \mathrm{~m}(15 \mathrm{ft})$ vertically upward at each location.

- Following completion of the cap (estimated time 5 years), connect the abovegrade extraction well for each well to OCVZ system treatment units.

Costs for project plans (i.e., operation and layout plan, radiological monitoring and control plan, industrial hygiene exposure and sample plan, management self-assessment plan, and quality control plan), vendor data, and final inspection report will be included in the cost estimate for the ET surface barrier (see Section D-3). 


\section{F-8.3 Basis of the Estimate}

The following sequential process, rationale, and estimating methodologies were used to define activities, quantities, and resources that were used in preparation of this cost estimate.

A. The INEEL Environmental Restoration Cost Estimating/Cost Engineering Guide (DOE-ID 2000) and the "Idaho National Engineering and Environmental Laboratory Detailed Work Plan Development Process Guidance" (GDE-112) were used to define estimating requirements.

B. The estimate development method was established using a detailed bottoms-up quantifiable technique. Resources, costs, and productions are derived from these individual, detailed item quantities.

C. Estimate scope is defined in the scope of work provided by the requester.

D. Costs were developed, using the Success $\bigodot$ estimating software by U.S. Cost, to a level of detail consistent with available documents and information.

E. Standard material pricing is based on the R. S. Means and Richardson Estimating Manuals.

F. The project scope and methodologies were prepared from discussions with the requester and project team.

G. Security costs are based on Estimate File Number 5432, "Pit 4 Life-cycle Cost Estimate."

H. Cost allowance for well installation was provided by the Modeling and Measurement division of Battelle Energy Alliance, LLC.

I. Replacement costs for instrumentation refurbishment were based on Estimate File Number 5984-II and the bottoms-up estimating technique for a typical system upgrade during unit replacement.

\section{F-8.4 Assumptions}

\section{A. General assumptions}

1. This project will be performed concurrently with cap construction; therefore, it does not include costs for the operation and layout plan, radiological monitoring and control plan, industrial hygiene exposure and sample plan, management self-assessment plan, quality control plan, and final inspection report. Costs for these activities are included in the estimate to construct the cap (see Section D-3).

2. Based on discussions with the project team, design and construction of this project will be subcontracted. Subcontractor tasks will include generating all required plans, performing all site preparation and remediation work, placing all ICs, and writing all reports. The ICP tasks will include project management oversight (e.g., interface agreements, contract awards, and oversight) and construction management oversight (e.g., vendor data acceptance, preexisting technical procedure revisions, acceptance testing, management self-assessments, and possibly operational readiness reviews). 
3. The INL Site resources (i.e., Central Facilities Area, medical facilities, geotechnical laboratory, fire department, security, and utilities at the SDA) will be available for the duration of the project.

4. No fire water, potable water, buried power, propane, sewer, or storm drain utilities will be encountered or will require removal or relocation.

5. Utilities and structures supporting current projects in the SDA will be completely removed by those projects before the start of this project and at no cost to this project.

6. No equipment flaggers or traffic control will be needed. Once the field work begins, the subcontractor will have complete control of the area.

7. If remedial action obstructs an OCVZ well, the obstructed well will be capped. Following remedial action, the capped well will be reconnected to the appropriate treatment unit. Costs associated with capping and reconnection are accounted for within the scope contingency for each of the cap estimates (i.e., Estimate Numbers 5922, 5922A, and 5922B).

\section{B. Schedule}

1. Figure F-8 illustrates the project schedule.

2. Work activities will be performed during the $4 \times 10$ work schedule.

3. The remedial design and remedial action schedule assumes that no unexpected delays will occur because of changes to the unreviewed safety question and safety analysis report process.

\section{Mobilization and demobilization (capital costs)}

1. Administrative and equipment buildings or trailers will be installed in the SDA to support operational controls, radiation controls, and personnel facilities.

2. Equipment and personnel entering and exiting the SDA will not be required to survey in or out, or stop for security access. As they travel through the gates, personnel will only be required to flash their identification to the personnel manning those gates. This estimate assumes free and easy access at the gates for all construction personnel and equipment.

3. ICP personnel will have access to existing RWMC buildings that can be used as temporary offices during this work.

4. ICP personnel will not require move monies.

5. Mobilization and demobilization costs are captured within the remediation section of this cost estimate.

\section{Site preparation (capital costs)}

A land survey will be required before the start of installing the shallow extraction piping. 


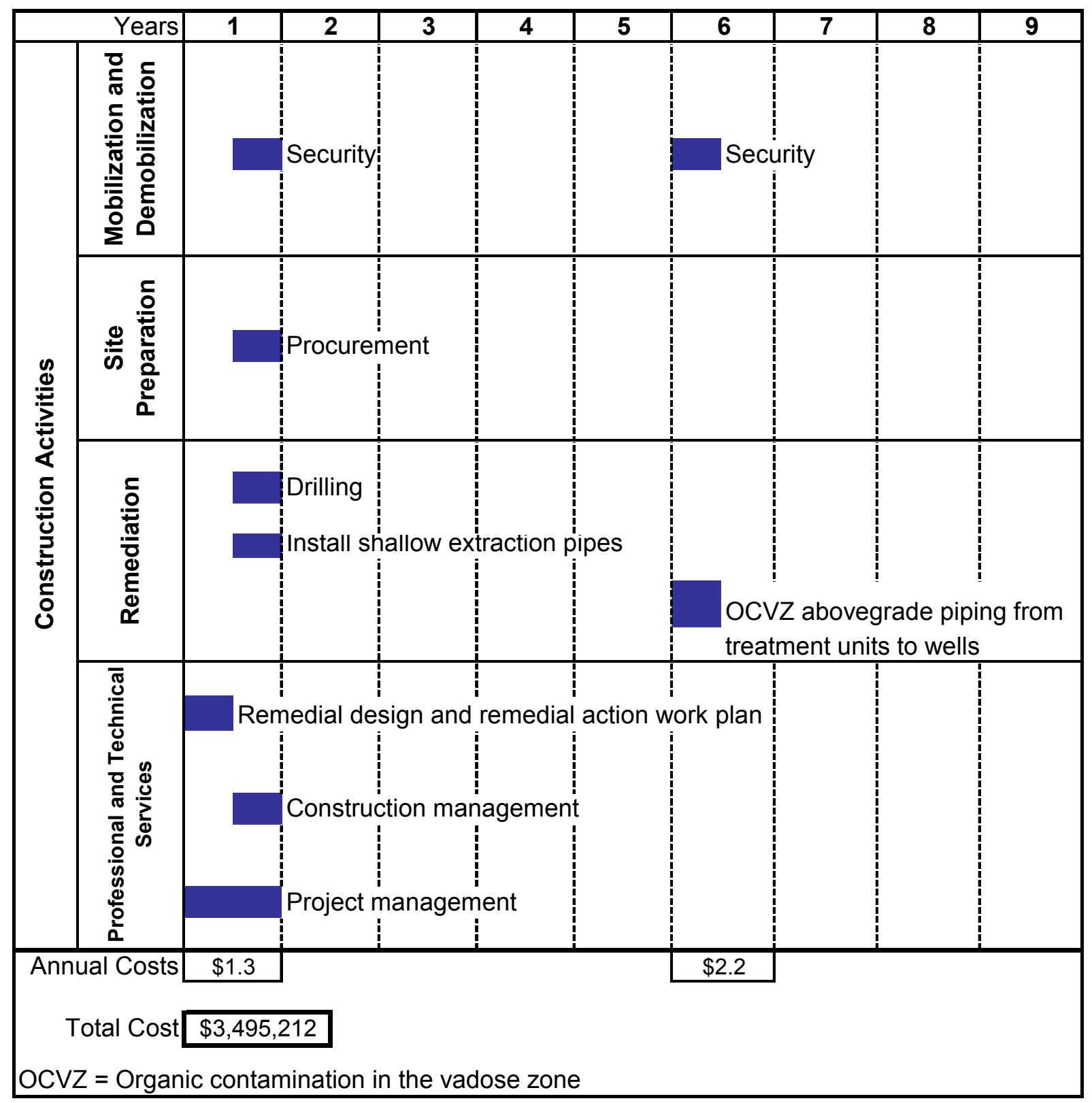

Figure F-8. Module 7 design and construction schedule for installation of the shallow extraction well.

\section{E. Remediation (capital costs)}

1. A subcontractor will install the shallow extraction piping as a stand-alone subcontract.

2. This project will not impact the Accelerated Retrieval Project excavation.

3. Radioactive and hazardous materials will not be encountered during this project. 


\section{F-8.5 Contingency Guideline Implementation}

Total capital cost contingency for Module 7 is $35.79 \%$. This contingency is the average contingency of construction activities (i.e., $35 \%$ ) and professional and technical services (i.e., $0 \%$ ).

\section{F-8.6 Estimate Summary}

Table F-41 presents rough order of magnitude allocations of the methodologies used to develop the cost estimate for Module 7.

Table F-41. Rough order of magnitude allocations of methodologies used to develop the cost estimate for Module 7.

\begin{tabular}{lc}
\hline Estimate Methodology & $\begin{array}{c}\text { Rough Order of Magnitude } \\
(\%)\end{array}$ \\
\hline Project team & 50 \\
Recorded actuals & 0 \\
Parametric & 0 \\
Vendor quotes & 0 \\
Other & 50 \\
Total & $\mathbf{1 0 0}$ \\
\hline
\end{tabular}

\section{F-8.7 Other Comments or Concerns Specific to the Estimate}

A. No escalation is included in the cost estimate.

B. Subcontractor labor costs reflect INL Site Stabilization Agreement craft labor rates.

C. $\mathrm{CH} 2 \mathrm{M}-\mathrm{WG}$ Idaho labor rates reflect fully burdened present day rates.

\section{F-8.8 Summary}

Table F-42 provides capital cost information for Module 7. 
Table F-42. Capital costs for Module 7: Operable Unit 7-13/14 Feasibility Study—Shallow Extraction well, Project Number: 5992-D.

\begin{tabular}{|c|c|c|c|c|c|}
\hline Level & Description & $\begin{array}{c}\text { Subtotals }^{\mathrm{a}} \\
(\$)\end{array}$ & $\begin{array}{c}\text { Estimate }^{\mathrm{a}} \\
(\$)\end{array}$ & $\begin{array}{c}\text { Contingency } \\
(\$)\end{array}$ & $\begin{array}{c}\text { Total }^{\mathrm{a}, \mathrm{c}} \\
(\$) \\
\end{array}$ \\
\hline 1.1 & Construction activities & $1,976,000$ & - & - & - \\
\hline 1.1 .1 & Mobilization and demobilization & 79,000 & - & - & - \\
\hline 1.1.1.1 & Mobilize and demobilize construction equipment & - & 11,000 & 4,000 & 15,000 \\
\hline 1.1.1.2 & Temporary facilities & - & 5,000 & 2,000 & 7,000 \\
\hline 1.1.1.3 & Security at construction site access gates & - & 63,000 & 22,000 & 84,000 \\
\hline 1.1 .2 & Site preparation work & 6,000 & - & - & - \\
\hline 1.1.2.1 & Land survey & - & 6,000 & 2,000 & 8,000 \\
\hline 1.1.3 & Remediation & $1,892,000$ & - & - & - \\
\hline 1.1.3.1 & Drilling & - & 155,000 & 54,000 & 209,000 \\
\hline 1.1.3.2 & Install eight shallow extraction wells & - & 143,000 & 50,000 & 194,000 \\
\hline 1.1 .3 .3 & Install OCVZ abovegrade piping to probes & - & $1,343,000$ & 470,000 & $1,813,000$ \\
\hline 1.1.3.4 & Install OCVZ abovegrade electrical to probes & - & 251,000 & 88,000 & 339,000 \\
\hline 1.2 & Professional and technical services & 827,000 & - & - & - \\
\hline 1.2 .1 & Project management & - & 213,000 & - & 213,000 \\
\hline 1.2 .2 & Remedial design and remedial action work plan & 320,000 & - & - & - \\
\hline 1.2.2.1 & Remedial design & - & 267,000 & - & 267,000 \\
\hline 1.2 .2 .2 & Remedial action work plan & - & 53,000 & - & 53,000 \\
\hline 1.2 .3 & Construction management & - & 293,000 & - & 293,000 \\
\hline & Total capital $\operatorname{cost}^{\mathrm{c}}$ & - & $2,803,000$ & 692,000 & $3,495,000$ \\
\hline & $\begin{array}{l}\text { a. Values are rounded to the nearest } \$ 1,000 \text {. } \\
\text { b. Capital cost contingency is } 35.8 \% \text { of the estimate. } \\
\text { c. Totals were derived for the summation of nonrounded subcompone } \\
\text { shown above. See Table F-3 for nonrounded totals. }\end{array}$ & e, totals are no & 1 to the summ & n of the rounded su & component values \\
\hline
\end{tabular}




\section{F-9. MODULE 8: DYNAMIC COMPACTION OF THE SUBSURFACE DISPOSAL AREA PITS}

\section{F-9.1 Purpose}

This estimate will be used as a cost-comparative tool to examine different options regarding the SDA.

\section{F-9.2 Scope of Work}

The scope of work consists of dynamic compacting 18.7 acres of the SDA. following:

The scope of work to achieve the objective for this project includes, but is not limited to, the

- Mobilization and demobilization activities.

- $\quad$ Site preparation.

- $\quad$ Remediation (cap or cover).

- Dynamic compaction of designated areas in the SDA. Dynamic compaction is the process when soil is compacted by dropping a heavy weight (approximately 15 tons) from a designated height

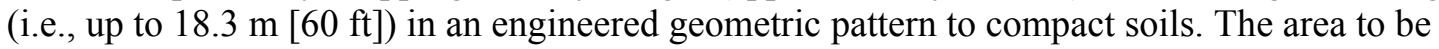
dynamically compacted will also include haul fill, level, and roller compaction.

- $\quad$ Project management.

- Remedial design and remedial action work plan.

- Construction management.

- $\quad$ Applicable contingency.

\section{F-9.3 Basis of the Estimate}

The following sequential process, rationale, and estimating methodologies were used to define activities, quantities, and resources that were used in preparation of this cost estimate.

A. The INEEL Environmental Restoration Cost Estimating/Cost Engineering Guide (DOE-ID 2000) and the "Idaho National Engineering and Environmental Laboratory Detailed Work Plan Development Process Guidance" (GDE-112) were used to define estimating requirements.

B. The estimate development method was established using a detailed bottoms-up quantifiable technique. Resources, costs, and productions are derived from these individual, detailed item quantities.

C. Estimate scope was defined in the scope of work provided by the requester.

D. The estimate was based on drawings and specifications provided by the requester.

E. Costs were developed, using the Success $@$ estimating software by U.S. Cost, to a level of detail consistent with available documents and information. 
F. Standard material pricing was based on the R. S. Means and Richardson Estimating Manuals.

G. Labor rates were based on the R. S. Means and Richardson Estimating Manuals. All labor rates were factored considering working conditions and requirements at the INL Site.

H. Project cost elements were based on Estimate File Number 5405, "Dynamic Compaction Feasibility Study for the SDA," prepared May 24, 2004. Subcontract costs were provided by Hayward Baker Company, Tukwila, Washington.

I. Project scope and methodologies were prepared from a project visit and from discussions with the requester and project team.

J. Submittal and implementation costs were based on costs extracted from Estimate File Number 5987, "ISG Project FY 2005-FY 2011," dated August 3, 2004. Appropriate general contractor markups for overhead, profit, and bond were applied to costs extracted from this previous estimate.

\section{F-9.4 Assumptions}

\section{A. Schedule}

Figure F-9 illustrates the project schedule.

\section{B. Mobilization and demobilization (capital costs)}

ICP personnel will not require move monies.

\section{Site preparation (capital costs)}

A land survey will be required before the start of dynamic compaction.

\section{Remediation (capital costs)}

1. A specialty subcontractor will perform dynamic compaction. This subcontractor will be experienced with this type of work and will be selected through the bid and award process.

2. Twelve inches of fill will be placed over the compaction area before start of compaction. This fill assists with dust control and helps ensure effectiveness of dynamic compaction.

3. No revegetation of the compacted area will be required.

4. Only pit areas will receive dynamic compaction (approximately 18.7 acres [814,600 $\left.\mathrm{ft}^{2}\right]$ ).

5. Dynamic compaction will be complete before any required column grouting or grouting stabilization activities.

6. This project will not impact the Accelerated Retrieval Project excavation.

7. After initial dynamic compaction, the subcontractor will perform an ironing compaction. After the ironing is complete, the area will be roughly leveled and compacted using a scraper and roller.

8. Radioactive and hazardous materials will not be encountered during this project.

9. No release of radioactive materials will be caused by dynamic compaction.

10. No venting of the compacted area will be required. 


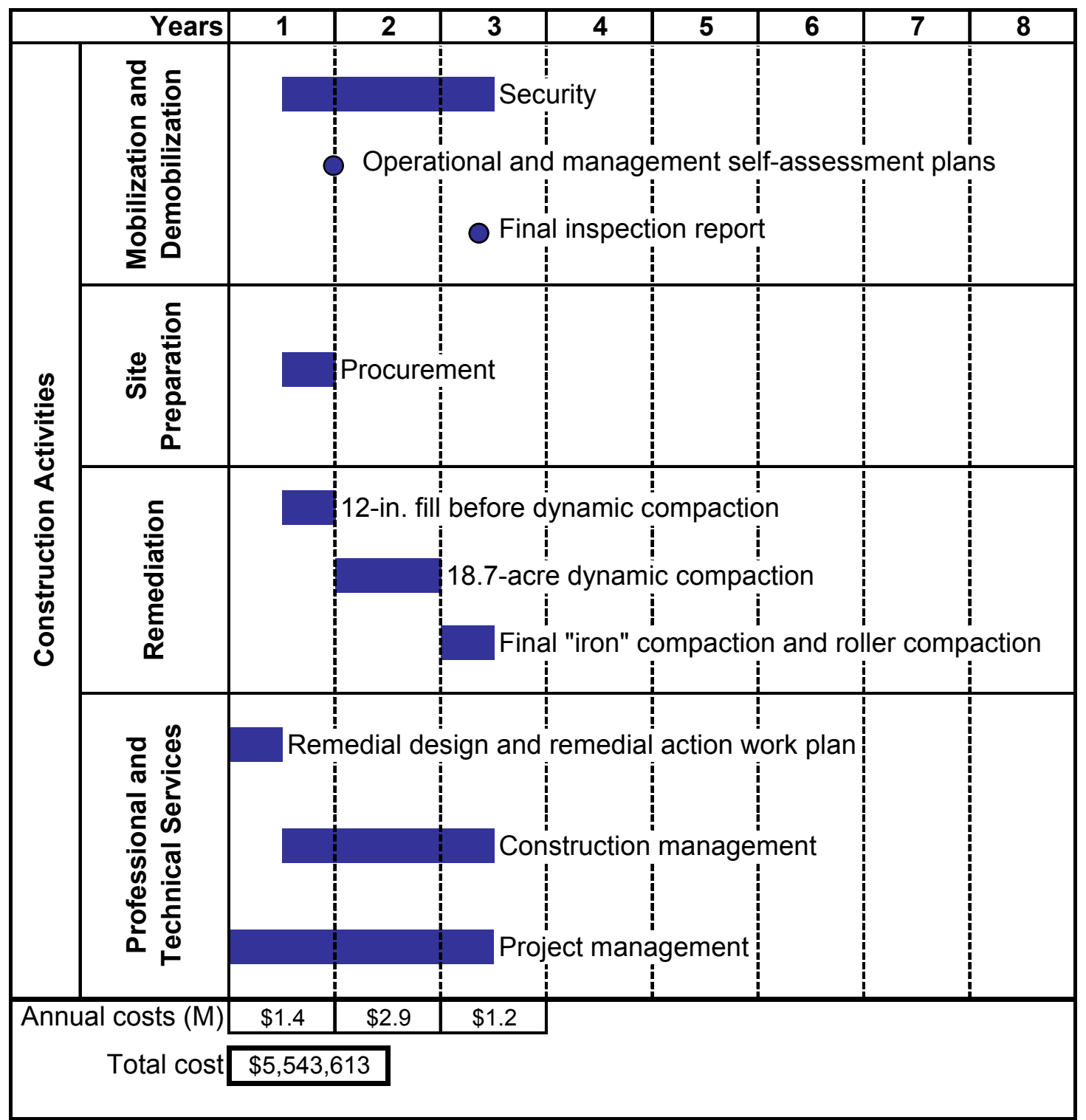

Figure F-9. Module 8 design and construction schedule for dynamic compaction of the Subsurface Disposal Area pits. 


\section{F-9.5 Contingency Guideline Implementation}

Total capital cost contingency for Module 8 is $23.87 \%$. This contingency is the average contingency of construction activities (i.e., 30\%) and professional and technical services (i.e., $0 \%$ ).

\section{F-9.6 Estimate Summary}

Table F-43 provides rough-order-of-magnitude allocations of methodologies used to develop the cost estimate for Module 8 .

Table F-43. Rough order of magnitude allocations of methodologies used to develop the cost estimate for Module 8.

\begin{tabular}{lc}
\hline Estimate Methodology & $\begin{array}{c}\text { Rough Order of Magnitude } \\
(\%)\end{array}$ \\
\hline Project team & 50 \\
Recorded actuals & 0 \\
Parametric & 0 \\
Vendor quotes & 40 \\
Other & 10 \\
Total & $\mathbf{1 0 0}$ \\
\hline
\end{tabular}

\section{F-9.7 Other Comments or Concerns Specific to the Estimate}

A. No escalation is included in the cost estimate.

B. Subcontractor labor costs reflect INL Site Stabilization Agreement craft labor rates.

C. $\mathrm{CH} 2 \mathrm{M}-\mathrm{WG}$ Idaho labor rates reflect fully burdened present day rates.

\section{F-9.8 Summary}

Table F-44 provides capital cost information for Module 8. 
Table F-44. Capital costs for Module 8: Operable Unit 7-13/14 Feasibility Study_Dynamic Compaction Module Pits, Project Number: 5992-E.

\begin{tabular}{|c|c|c|c|c|c|}
\hline Level & Description & $\begin{array}{l}\text { Subtotals } \\
(\$)\end{array}$ & $\begin{array}{c}\text { Estimate }^{a} \\
(\$)\end{array}$ & $\begin{array}{l}\text { Contingency } \\
(\$)\end{array}$ & $\begin{array}{c}\text { Total }^{\mathrm{a}, \mathrm{c}} \\
(\$)\end{array}$ \\
\hline 1.1 & Construction activities & $3,561,000$ & - & - & - \\
\hline 1.1 .1 & Mobilization and demobilization & $1,431,000$ & - & - & - \\
\hline 1.1.1.1 & Submittals and implementation plans & 391,000 & - & - & - \\
\hline 1.1.1.1.1 & Operational plans & - & 38,000 & 11,000 & 49,000 \\
\hline 1.1.1.1.2 & Remedial action and monitoring plan & - & 7,000 & 2,000 & 8,000 \\
\hline 1.1.1.1.3 & Industrial hygiene exposure and sampling plan & - & 6,000 & 2,000 & 7,000 \\
\hline 1.1.1.1.4 & Management self-assessment plan & - & 41,000 & 12,000 & 54,000 \\
\hline 1.1.1.1.5 & Quality control plan & - & 50,000 & 15,000 & 65,000 \\
\hline 1.1.1.1.6 & Final inspection report & - & 250,000 & 75,000 & 325,000 \\
\hline 1.1.1.2 & Temporary facilities & - & 40,000 & 12,000 & 52,000 \\
\hline 1.1.1.3 & Security at construction site access gates & - & $1,000,000$ & 300,000 & $1,300,000$ \\
\hline 1.1 .2 & Site preparation work & 239,000 & - & - & - \\
\hline 1.1.2.1 & Land survey & - & 6,000 & 2,000 & 7,000 \\
\hline 1.1.2.2 & $\begin{array}{l}\text { Place } 12 \text { in. layer of engineered fill prior to dynamic } \\
\text { compaction }\end{array}$ & - & 234,000 & 70,000 & 304,000 \\
\hline 1.1 .3 & Remediation & $1,891,000$ & - & - & - \\
\hline 1.1.3.1 & Dynamic compaction & $1,891,000$ & - & - & - \\
\hline 1.1 .3 .1 .1 & Dynamic compaction of pits-18.7 acres & - & $1,043,000$ & 313,000 & $1,356,000$ \\
\hline 1.1.3.1.2 & $\begin{array}{l}\text { Level, compact and grade pits after dynamic } \\
\text { compaction }\end{array}$ & - & 336,000 & 101,000 & 437,000 \\
\hline 1.1.3.1.3 & Labor support during pit dynamic compaction & - & 512,000 & 153,000 & 665,000 \\
\hline 1.2 & Professional and technical services & 914,000 & - & - & - \\
\hline 1.2 .1 & Project management & - & 231,000 & - & 231,000 \\
\hline 1.2 .2 & Remedial design and remedial action work plan & 358,000 & - & - & - \\
\hline 1.2.2.1 & Remedial design & - & 239,000 & - & 239,000 \\
\hline 1.2 .2 .2 & Remedial action work plan & - & 119,000 & - & 119,000 \\
\hline \multirow[t]{3}{*}{1.2 .3} & Construction management & - & 324,000 & - & 324,000 \\
\hline & Total capital cost ${ }^{\mathrm{c}}$ & - & $4,475,000$ & $1,068,000$ & $5,544,000$ \\
\hline & \multicolumn{5}{|c|}{$\begin{array}{l}\text { a. Values are rounded to the nearest } \$ 1,000 \text {. } \\
\text { b. Capital cost contingency is } 23.9 \% \text { of the estimate. } \\
\text { c. Totals were derived for the summation of nonrounded subcomponent values. Therefore, totals are not equal to the summation of the rounded subcomponent values shown } \\
\text { above. See Table F-3 for nonrounded totals. }\end{array}$} \\
\hline
\end{tabular}




\section{F-10. MODULE 9: DYNAMIC COMPACTION OF PAD A}

\section{F-10.1 Purpose}

This estimate will be used as a cost-comparative tool to examine different options regarding Pad A.

\section{F-10.2 Scope of Work}

The scope of work consists of dynamic compacting 0.8 acres of Pad A.

Dynamic compaction is the process where soil is compacted by dropping a heavy weight

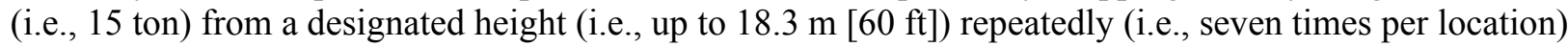
in a predetermined geometric pattern (i.e., $3-\mathrm{m}$ [10-ft] centers) to compact soil. Compaction is carried out in two passes, using a modified large crawler friction-type crane. Following compaction, the compacted areas are leveled with a scraper and compacted with a roller to increase the density of the upper soil layers. Soil fill will be required before compaction operations commence. This fill will be placed directly over the Pad A area to ensure that a minimum of a 5-foot-thick layer is present. ${ }^{b}$ This depth of surface soil is required to ensure that the waste will not project vertically up through the Pad A surface during compaction. An additional foot of preplaced fill will be used to fill up subsidence areas that form during compaction.

This cost estimate addresses concerns pertaining to release of contaminants into the air. Concerns are addressed through modeling, mockup testing, and monitoring. First, an atmospheric dispersion model would be generated to predict what the airborne concentrations of contaminants would be at receptor locations under optimal weather conditions. Next, a mockup of Pad A would be fabricated and dynamic compaction would be applied. Results from the mockup testing would indicate what soil cover thickness, drop height, etc., are required to safely dynamically compact the mound. Finally, during dynamic compaction of Pad A, atmospheric monitoring will indicate ideal conditions for dynamic compaction based on the initial dispersion modeling results.

Subcontractor mobilization consists of the following:

- $\quad$ Generate operational plans

- Generate a management self-assessment plan

- $\quad$ Mobilize equipment

- $\quad$ Perform atmospheric dispersion modeling of airborne waste.

Subcontractor demobilization consists of the following:

- $\quad$ Shut down or demobilize equipment

- Generate a final inspection report following completion of dynamic compaction.

Site preparation consists of the following:

- $\quad$ Conduct procurement activities

- $\quad$ Survey the Pad A area to lay out the appropriate compaction grid

- $\quad$ Construct surrogate mockup waste mound

b. Average depth of overburden for the SDA pit area is $1.5 \mathrm{~m}(5 \mathrm{ft})$. 
- $\quad$ Dynamically compact mockup waste mound

- $\quad$ Remove the mockup waste mound after dynamic compaction testing

- Haul and place approximately $2 \mathrm{ft}$ of fill materials (from T-12 pit) over the Pad A area in an effort to insure that the total soil thickness over Pad A is a minimum of $5 \mathrm{ft}$ thick

- $\quad$ Haul and place $1 \mathrm{ft}$ of engineered fill to fill in subsidence areas.

Remediation consists of the following:

- In two passes, dynamically compact the Pad A area in the previously marked geometric pattern

- $\quad$ Scrape preplaced soil into subsidence areas and compact with roller.

\section{F-10.3 Basis of the Estimate}

The following sequential process, rationale, and estimating methodologies were used to define activities, quantities, and resources that were used in preparation of this cost estimate.

A. The INEEL Environmental Restoration Cost Estimating/Cost Engineering Guide (DOE-ID 2000) and the "Idaho National Engineering and Environmental Laboratory Detailed Work Plan Development Process Guidance" (GDE-112) were used to define estimating requirements.

B. The estimate development method was established using a detailed bottoms-up quantifiable technique. Resources, costs, and productions are derived from these individual, detailed item quantities.

C. Estimate scope was defined in the scope of work provided by the requester.

D. The estimate was based on drawings and specifications provided by the requester.

E. Costs were developed, using the Success $@$ estimating software by U.S. Cost, to a level of detail consistent with available documents and information.

F. Standard material pricing was based on the R. S. Means and Richardson Estimating Manuals.

G. Labor rates were based on the R. S. Means and Richardson Estimating Manuals. All labor rates were factored considering working conditions and requirements at the INL Site.

H. Project cost elements were based on Estimate File Number 5405, "Dynamic Compaction Feasibility Study for the SDA," prepared May 24, 2004. Subcontract costs were provided by Hayward Baker Company, Tukwila, WA.

I. Project scope and methodologies were prepared from a project visit and discussions with the requester and the project team.

J. Submittal and implementation costs were based on costs extracted from Estimate File Number 5987, "ISG Project FY 2005-FY 2011," dated August 3, 2004. Appropriate general contractor markups for overhead, profit, and bond were applied to costs extracted from this previous estimate.

K. Security costs were based on Estimate File Number 5432, "Pit 4 Life-cycle Cost Estimate." Appropriate general contractor markups for overhead, profit, and bond were applied to costs extracted from this previous estimate. 
L. Final inspection report costs were based on the Preliminary Evaluation of Remedial Alternatives for the Subsurface Disposal Area (Zitnik et al. 2002). Appropriate general contractor markups for overhead, profit, and bond were applied to costs extracted from this previous estimate.

M. Dispersion modeling costs were based on man hours estimated for radiological safety analysis computer (RSAC) calculations on TAN 607. Estimate file \# 6374 "TAN 607 downgrade estimate."

\section{F-10.4 Assumption}

\section{A. Schedule}

Figure F-10 illustrates the project schedule.

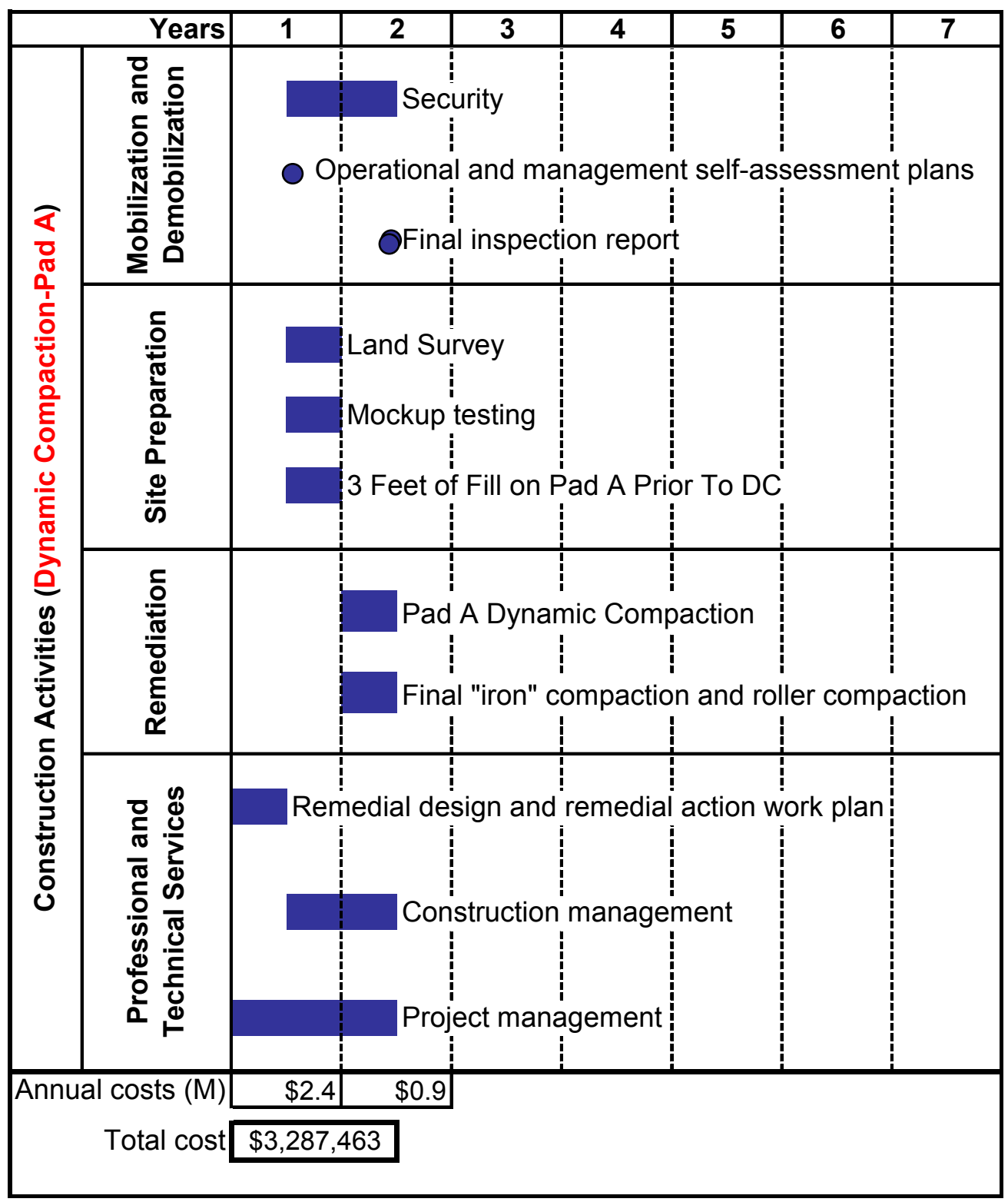

Figure F-10. Module 9 design and construction schedule for dynamic compaction of Pad A. 


\section{B. Mobilization and demobilization (capital costs)}

1. Administrative and equipment buildings or trailers will be installed during mockup testing and during dynamic compaction of 0.8 acres of Pad A.

2. ICP personnel will not require move monies.

3. Mobilization and demobilization costs are captured within the remediation section of this cost estimate.

\section{Site preparation (capital costs)}

1. A land survey will be required to identify appropriate areas for compaction before the start of dynamic compaction.

2. Assume the cold test will be performed at the existing Cold Test North area. Assume a $50 / 50$ mixture $4 \times 4 \times 8$-ft wood boxes and 55-gal drums filled with miscellaneous material and debris (e.g., wood chips, sludge, cloth, coal, and gravel) will be placed on an asphalt pad approximately $40 \mathrm{ft}^{2}$ in area. The boxes and drums will be stacked approximately $22 \mathrm{ft}$ high. A mound of pit-run gravel (assume availability from the T-12 Pit - no costs are included in the estimate for constructing a haul road) will be placed around and over the boxes and drums to an elevation of $4 \mathrm{ft}, 0 \mathrm{in}$. above them. The pit run gravel will be sloped at approximately $4: 1$ on three sides and at 2-1/2:1 on one side. Then, a 12-in.-thick layer of engineered fill will be placed over the $40 \mathrm{ft}^{2}$ area at the top of the pit-run gravel prior to dynamic compaction. Costs have been included in the estimate for removing the asphalt, fill, boxes, and drums.

\section{Remediation (capital costs)}

1. A specialty subcontractor will perform dynamic compaction. This subcontractor will be experienced with this type of work and will be selected through the bid and award process.

2. A total of $2 \mathrm{ft}$ of fill will be placed over the buried pad area plus an additional $10 \mathrm{ft}$ beyond the pad perimeter (assumed 0.95 acres).

3. One foot of engineered fill material will be placed over the area to be compacted (assumed area 0.8 acres).

4. Atmospheric monitoring will require two technicians equipped with standard atmospheric monitoring equipment.

5. No revegetation of the compacted area will be required.

6. For this cost estimate, only Pad A will receive dynamic compaction (approximately 0.8 acres $\left.\left[34,850 \mathrm{ft}^{2}\right]\right)$.

7. No dynamic compaction will occur in undisturbed soil areas.

8. Dynamic compaction will be complete before any required column grouting or grouting stabilization activities. 
9. This project will not impact the Accelerated Retrieval Project excavation.

10. After initial dynamic compaction, the subcontractor will perform an ironing compaction. After the ironing is complete, the area will be roughly leveled and compacted using a scraper and roller.

11. Radioactive and hazardous materials will not be encountered during this project.

12. No release of radioactive materials will be caused by dynamic compaction.

13. No venting of the compacted area will be required.

\section{F-10.5 Contingency Guideline Implementation}

Total capital cost contingency for dynamic compaction is $23.12 \%$. This contingency is the average contingency of construction activities (i.e., $35 \%$ ) and professional and technical services (i.e., $0 \%$ ).

\section{F-10.6 Estimate Summary}

Table F-45 provides rough order of magnitude allocations of the methodologies used to develop the cost estimate for Module 9.

Table F-45. Rough order of magnitude allocations of methodologies used to develop the cost estimate or Module 9.

\begin{tabular}{lc} 
Estimate Methodology & $\begin{array}{c}\text { Rough Order of Magnitude } \\
(\%)\end{array}$ \\
\hline Project team & 50 \\
Recorded actuals & 0 \\
Parametric & 0 \\
Vendor quotes & 40 \\
Other & 10 \\
Total & $\mathbf{1 0 0}$ \\
\hline
\end{tabular}

\section{F-10.7 Other Comments or Concerns Specific to the Estimate}

A. No escalation is included in the cost estimate.

B. Subcontractor labor costs reflect INL Site Stabilization Agreement craft labor rates.

C. $\mathrm{CH} 2 \mathrm{M}-\mathrm{WG}$ Idaho labor rates reflect fully burdened present day rates.

\section{F-10.8 Summary}

Table F-46 provides capital cost summary information for Module 9. 
Table F-46. Capital costs for Module 9: Operable Unit 7-13/14 Feasibility Study_Dynamic Compaction Pad A, Project Number: 5992-Q.

\begin{tabular}{|c|c|c|c|c|c|}
\hline Level & Description & $\begin{array}{c}\text { Subtotals } \mathrm{a}^{\mathrm{a}} \\
(\$)\end{array}$ & $\begin{array}{c}\text { Estimate }^{\mathrm{a}} \\
(\$)\end{array}$ & $\begin{array}{c}\text { Contingency }^{\text {a.b }} \\
(\$)\end{array}$ & $\begin{array}{c}\text { Total }^{\mathrm{a}, \mathrm{c}} \\
(\$)\end{array}$ \\
\hline 1.1 & Construction activities & $1,764,000$ & - & - & - \\
\hline 1.1 .1 & Mobilization and demobilization & 661,000 & - & - & - \\
\hline 1.1.1.1 & Submittals and implementation plans & 401,000 & - & - & - \\
\hline 1.1.1.1.1 & Operational plans & - & 38,000 & 13,000 & 51,000 \\
\hline 1.1.1.1.2 & Remedial action and monitoring plan & - & 7,000 & 2,000 & 9,000 \\
\hline 1.1.1.1.3 & Industrial hygiene exposure and sampling plan & - & 6,000 & 2,000 & 8,000 \\
\hline 1.1.1.1.4 & Management self-assessment plan & - & 41,000 & 14,000 & 56,000 \\
\hline 1.1.1.1.5 & Quality control plan & - & 50,000 & 18,000 & 68,000 \\
\hline 1.1.1.1.6 & Dispersion modeling of airborne waste & - & 10,000 & 4,000 & 14,000 \\
\hline 1.1.1.1.7 & Final inspection report & - & 250,000 & 88,000 & 338,000 \\
\hline 1.1.1.2 & Temporary facilities & - & 10,000 & 4,000 & 14,000 \\
\hline 1.1.1.3 & Security at construction site access gates & - & 250,000 & 88,000 & 338,000 \\
\hline 1.1 .2 & Site preparation work & $1,000,000$ & - & - & - \\
\hline 1.1.2.1 & Land survey & - & 6,000 & 2,000 & 8,000 \\
\hline 1.1.2.2 & Cold test on surrogate waste mound & - & - & - & - \\
\hline 1.1.2.2.1 & Construction of surrogate waste mound & - & 700,000 & 245,000 & 945,000 \\
\hline 1.1.2.2.2 & Dynamic compaction on surrogate waste mound & - & 4,000 & 1,000 & 5,000 \\
\hline 1.1.2.2.3 & $\begin{array}{l}\text { Removal of surrogate waste mound after dynamic } \\
\text { compaction }\end{array}$ & - & 240,000 & 84,000 & 323,000 \\
\hline 1.1.2.3 & Pad A preparation & - & - & - & - \\
\hline 1.1.2.3.1 & Place fill from T-12 pit over Pad A to resist uplift & - & 37,000 & 13,000 & 49,000 \\
\hline 1.1.2.3.2 & Place 12-in. layer of engineered fill over Pad A & - & 14,000 & 5,000 & 19,000 \\
\hline 1.1 .3 & Remediation & 103,000 & - & - & - \\
\hline 1.1.3.1 & Dynamic compaction & 103,000 & - & - & - \\
\hline 1.1.3.1.1 & Dynamic compaction at $\mathrm{Pad} \mathrm{A}-0.8$ acres & - & 56,000 & 19,000 & 75,000 \\
\hline 1.1.3.1.2 & Level, compact, and grade Pad A after dynamic compaction & - & 19,000 & 6,000 & 25,000 \\
\hline 1.1.3.1.3 & Labor support during Pad A dynamic compaction & - & 29,000 & 10,000 & 39,000 \\
\hline
\end{tabular}


Table F-46. (continued)

\begin{tabular}{|c|c|c|c|c|c|}
\hline Level & Description & $\begin{array}{l}\text { Subtotals }^{\mathrm{a}} \\
(\$)\end{array}$ & $\begin{array}{c}\text { Estimate }^{\mathrm{a}} \\
(\$)\end{array}$ & $\begin{array}{c}\text { Contingency }{ }^{\text {a.b }} \\
(\$)\end{array}$ & $\begin{array}{c}\text { Total }^{\mathrm{a}, \mathrm{c}} \\
(\$)\end{array}$ \\
\hline 1.2 & Professional and technical services & 906,000 & - & - & - \\
\hline 1.2 .1 & Project management & - & 190,000 & - & 190,000 \\
\hline 1.2 .2 & Remedial design and remedial action work plan & 430,000 & - & - & - \\
\hline 1.2.2.1 & Remedial design & - & 369,000 & - & 369,000 \\
\hline 1.2.2.2 & Remedial action work plan & - & 61,000 & - & 61,000 \\
\hline \multirow[t]{3}{*}{1.2 .3} & Construction management & - & 286,000 & - & 286,000 \\
\hline & Total capital cost $^{\mathrm{c}}$ & - & $2,670,000$ & 617,000 & $3,287,000$ \\
\hline & \multicolumn{5}{|c|}{$\begin{array}{l}\text { a. Values are rounded to the nearest } \$ 1,000 \text {. } \\
\text { b. Capital cost contingency is } 23.1 \% \text { of the estimate. } \\
\text { c. Totals were derived for the summation of nonrounded subcomponent values. Therefore, totals are not equal to the summation of the rounded subcomponent values shown } \\
\text { above. See Table F-3 for nonrounded totals. }\end{array}$} \\
\hline
\end{tabular}




\section{F-11. MODULE 10: FOUNDATION GROUTING}

\section{F-11.1 Purpose}

SDA.

This estimate will be used as a cost-comparative tool to examine different options regarding the

\section{F-11.2 Scope of Work}

The scope of work includes jet grouting 18.7 acres (i.e., total area of the SDA pits) to provide ground stability for future placement of a cap. Jet-grouted columns will be constructed at nominal 3.7-m (12-ft) centers within the pits. Most of these columns will be constructed in pits containing TRU waste.

Jet-grouting operations and grout delivery will be procured services provided by a specialty vendor. A conceptual design, developed in Fiscal Year 2004, provides the technical basis to scope the project, pending award of the subcontract. The conceptual design envisions that the grouting process will use conventional large hydraulic-tracked excavators. These excavators will be modified to deploy a rotopercussion drill rig to inject grout into the waste.

Grout will be supplied to the jet-grouting systems by ready-mix trucks. Each grout-injection system will feature a self-contained high-pressure pump, which will provide the pressure required for jet-fluid grouting.

Grout returns are managed by moving $0.6 \mathrm{~m}(2 \mathrm{ft})$ of soil in the region of injection before foundation grouting, injecting foundation grout, and then backfilling the region of injection (i.e., covering returns with $0.6 \mathrm{~m}[2 \mathrm{ft}]$ of soil).

Subcontractor mobilization consists of the following:

- $\quad$ Generate operational plans

- Generate a management self-assessment plan

- $\quad$ Mobilize equipment.

Subcontractor demobilization consists of the following:

- $\quad$ Shut down or demobilize equipment

- Generate a final inspection report following completion of foundation grouting.

Site preparation consists of the following:

- $\quad$ Conduct procurement activities

- $\quad$ Mate a hydraulic commercial trackhoe to a mast-mounted rotopercussion drill. 
Remediation consists of the following:

- A ready-mix truck delivers the foundation grout to a low-pressure hopper (mounted on a low-boy trailer).

- $\quad$ The grout mixture is pumped at low pressure from the low-boy hopper to a high-pressure pump mounted on a separate trailer.

- $\quad$ The high-pressure pump pumps high-pressure grout (through a lanyard hose) to the trackhoe drill.

- The drill is driven to the bottom of the waste and grout is injected as the drill is withdrawn.

- $\quad$ Cap grout returns.

\section{F-11.3 Basis of the Estimate}

The following sequential process, rationale, and estimating methodologies were used to define activities, quantities, and resources that were used in preparation of this cost estimate.

A. The INEEL Environmental Restoration Cost Estimating/Cost Engineering Guide (DOE-ID 2000) and the "Idaho National Engineering and Environmental Laboratory Detailed Work Plan Development Process Guidance" (GDE-112) were used to define estimating requirements.

B. The estimate development method was established using a detailed bottoms-up quantifiable technique. Resources, costs, and productions are derived from these individual, detailed item quantities.

C. Estimate scope was defined in the scope of work provided by the requester.

D. The estimate was based on drawings and specifications provided by the requester.

E. Costs were developed, using the Success $\subset$ estimating software by U.S. Cost, to a level of detail consistent with available documents and information.

F. Standard material pricing was based on the R. S. Means and Richardson Estimating Manuals.

G. Labor rates were based on the R. S. Means and Richardson Estimating Manuals. All labor rates were factored considering working conditions and requirements at the INL Site.

H. Project cost elements were based on Estimate File Number 5432, "Subsurface Disposal Area (SDA) Cap and Cover-Life-cycle Baseline Estimate for FY 2006-2012,” prepared July 14, 2005. Appropriate general contractor markups for overhead, profit, and bond were applied to costs extracted from this previous estimate.

I. Submittal and implementation costs were based on costs extracted from Estimate File Number 5987, "ISG Project FY 2005-FY 2011," dated August 3, 2004. Appropriate general contractor markups for overhead, profit, and bond were applied to costs extracted from this previous estimate.

J. Security costs were based on Estimate File Number 5432 "Pit 4 Life-cycle Cost Estimate." Appropriate general contractor markups for overhead, profit, and bond were applied to costs extracted from this previous estimate.

K. Final inspection report costs were based on the Preliminary Evaluation of Remedial Alternatives for the Subsurface Disposal Area (Zitnik et al. 2002). 


\section{F-11.4 Assumptions}

\section{A. Schedule}

1. Figure F-11 illustrates the project schedule.

2. Work activities are planned to be performed using two trackhoe drills, during the $4 \times 10$ work schedule, with 5 effective work hours per day and 26 work weeks per year.

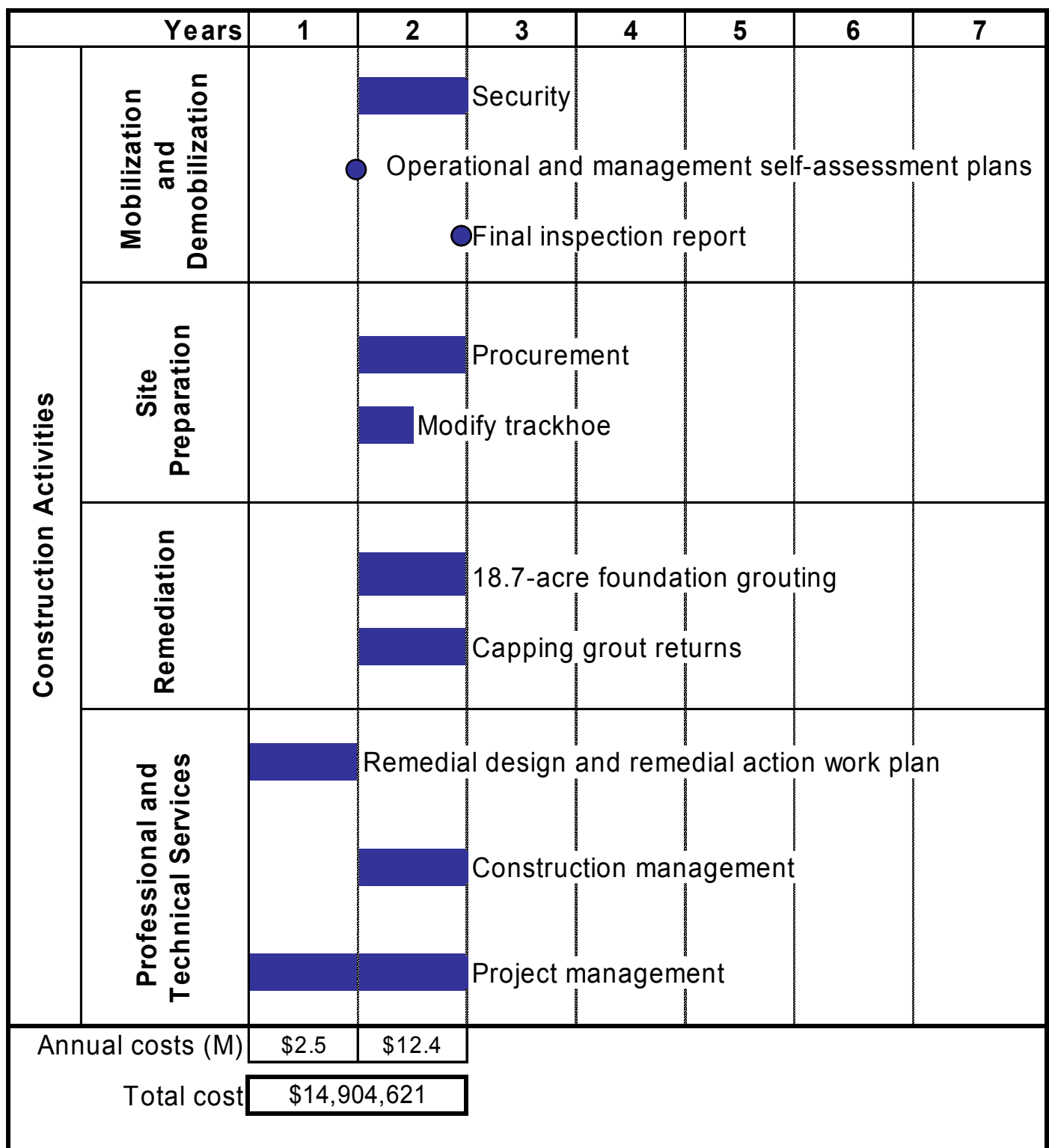

Figure F-11. Module 10 design and construction schedule for foundation grouting of the Subsurface Disposal Area pits. 


\section{B. Mobilization and demobilization (capital costs)}

1. ICP personnel will not require move monies.

2. Mobilization and demobilization costs are captured within the remediation section of this cost estimate.

\section{Site preparation (capital costs)}

A land survey will be required before the start of foundation grouting. Track modifications (i.e., mating a rotopercussion drill to a trackhoe) are captured within the remediation section of this cost estimate.

\section{Remediation (capital costs)}

1. A specialty subcontractor will perform foundation grouting. This subcontractor will be experienced with this type of work and will be selected through the bid and award process.

2. Only designated pit areas (i.e., 18.7 acres $\left[814,600 \mathrm{ft}^{2}\right]$ ) will receive foundation grouting.

3. Foundation grouting will consist of injecting 0.6-m (2-ft) -diameter grout columns (190 gal of grout per column), spaced $3.7 \mathrm{~m}(12 \mathrm{ft})$ apart, for a period of 8 minutes per hole.

4. No foundation grouting will occur in undisturbed soil areas.

5. This project will not impact the Accelerated Retrieval Project excavation.

6. No release of radioactive materials will be caused by foundation grouting.

7. A survey of the area to be grouted will be performed before startup of grouting operations. The subcontractor will be responsible for surveying grout column locations.

8. Before injection grouting, a $1.2 \times 1.2 \times 0.6-\mathrm{m}(4 \times 4 \times 2-\mathrm{ft})$ area, centered at each injection location, will be excavated. Once grouting is complete, the grout returns will be covered with excavated soil and filled to grade.

9. Grout formulation used for foundation grouting is Portland cement.

\section{F-11.5 Contingency Guideline Implementation}

Total capital cost contingency for foundation grouting is $27.46 \%$. This contingency is the average contingency of construction activities (i.e., 35\%) and professional and technical services (i.e., $0 \%$ ). 


\section{F-11.6 Estimate Summary}

Table F-47 provides a rough order of magnitude allocations of methodologies used to develop the cost estimate for Module 10.

Table F-47. Rough order of magnitude allocations of methodologies used to develop the cost estimate for Module 10.

\begin{tabular}{lc}
\hline Estimate Methodology & $\begin{array}{c}\text { Rough Order of Magnitude } \\
(\%)\end{array}$ \\
\hline Project team & 50 \\
Recorded actuals & 0 \\
Parametric & 0 \\
Vendor quotes & 40 \\
Other & 10 \\
Total & $\mathbf{1 0 0}$ \\
\hline
\end{tabular}

\section{F-11.7 Other Comments or Concerns Specific to the Estimate}
A. Activities have not been escalated.
B. Subcontractor labor costs reflect INL Site Stabilization Agreement craft labor rates.
C. CH2M-WG Idaho labor rates reflect fully burdened present day rates.

\section{F-11.8 Summary}

Table F-48 provides capital cost information for Module 10. 
Table F-48. Capital costs for Module 10: Operable Unit 7-13/14 Feasibility Study-Foundation Grouting, Project Number: 5992-F.

\begin{tabular}{|c|c|c|c|c|c|}
\hline Level & Description & $\begin{array}{c}\text { Subtotals }^{\mathrm{a}} \\
(\$)\end{array}$ & $\begin{array}{c}\text { Estimate }^{a} \\
(\$)\end{array}$ & $\begin{array}{c}\text { Contingency } \\
(\$)\end{array}$ & $\begin{array}{c}\text { Total }^{\text {a.c }} \\
(\$)\end{array}$ \\
\hline 1.1 & Construction activities & $\mathbf{9 , 1 7 6 , 0 0 0}$ & - & - & - \\
\hline 1.1 .1 & Mobilization and demobilization & $1,033,000$ & - & - & - \\
\hline 1.1.1.2 & Submittals and implementation plans & 191,000 & - & - & - \\
\hline 1.1.1.2.1 & Operational plans & - & 38,000 & 13,000 & 51,000 \\
\hline 1.1.1.2.2 & Remedial action and monitoring plan & - & 7,000 & 2,000 & 9,000 \\
\hline 1.1.1.2.3 & Industrial hygiene exposure and sampling plan & - & 6,000 & 2,000 & 8,000 \\
\hline 1.1.1.2.4 & Management self-assessment plan & - & 41,000 & 14,000 & 56,000 \\
\hline 1.1.1.2.5 & Training plan & - & 50,000 & 18,000 & 68,000 \\
\hline 1.1.1.2.6 & Quality control plan & - & 50,000 & 18,000 & 68,000 \\
\hline 1.1.1.3 & Temporary facilities & - & 20,000 & 7,000 & 27,000 \\
\hline 1.1.1.4 & Security at construction site access gates & - & 500,000 & 175,000 & 675,000 \\
\hline 1.1.1.5 & Final inspection report & - & 323,000 & 113,000 & 435,000 \\
\hline 1.1 .2 & Site preparation work & 6,000 & - & - & - \\
\hline 1.1.2.1 & Land survey & - & 6,000 & 2,000 & 8,000 \\
\hline 1.1 .3 & Remediation & $8,137,000$ & - & - & - \\
\hline 1.1.3.1 & Foundation grouting -18.7 acres & $8,137,000$ & - & - & - \\
\hline 1.1.3.1.1 & General conditions & - & 138,000 & 48,000 & 186,000 \\
\hline 1.1.3.1.2 & Purchase track drill & - & $3,323,000$ & $1,163,000$ & $4,487,000$ \\
\hline 1.1.3.1.3 & Mobilize and demobilize construction equipment & - & 10,000 & 4,000 & 14,000 \\
\hline 1.1.3.1.4 & Site work & $4,666,000$ & - & - & - \\
\hline 1.1.3.1.4.1 & Cold test & - & 23,000 & 8,000 & 32,000 \\
\hline 1.1.3.1.4.2 & Excavate and recess grout area for grout return & - & 32,000 & 11,000 & 43,000 \\
\hline 1.1.3.1.4.3 & Grout placement-18.7 acres & - & $2,826,000$ & 989,000 & $3,816,000$ \\
\hline 1.1.3.1.4.4 & Cover grout returns -18.7 acres & - & 44,000 & 15,000 & 59,000 \\
\hline 1.1.3.1.4.5 & Equipment maintenance and spare parts & - & $1,740,000$ & 609,000 & $2,349,000$ \\
\hline
\end{tabular}


Table F-48. (continued)

\begin{tabular}{|c|c|c|c|c|c|}
\hline Level & Description & $\begin{array}{c}\text { Subtotals }^{\mathrm{a}} \\
(\$)\end{array}$ & $\begin{array}{c}\text { Estimate }^{a} \\
(\$)\end{array}$ & $\begin{array}{c}\text { Contingency }^{\text {a.b }} \\
(\$)\end{array}$ & $\begin{array}{c}\text { Total }^{\text {a.c }} \\
(\$)\end{array}$ \\
\hline 1.2 & Professional and technical services & $2,517,000$ & - & - & - \\
\hline 1.2 .1 & Project management & - & 619,000 & - & 619,000 \\
\hline 1.2 .2 & Remedial design and remedial action work plan & $1,279,000$ & - & - & - \\
\hline 1.2.2.1 & Remedial design & - & 959,000 & - & 959,000 \\
\hline 1.2.2.2 & Remedial action work plan & - & 320,000 & - & 320,000 \\
\hline \multirow[t]{3}{*}{1.2 .3} & Construction management & - & 619,000 & - & 619,000 \\
\hline & Total capital cost ${ }^{\mathrm{c}}$ & - & $11,693,000$ & $3,212,000$ & $14,905,000$ \\
\hline & \multicolumn{5}{|c|}{$\begin{array}{l}\text { a. Values are rounded to the nearest } \$ 1,000 \text {. } \\
\text { b. Capital cost contingency is } 27.5 \% \text { of the estimate. } \\
\text { c. Totals were derived for the summation of nonrounded subcomponent values. Therefore, totals are not equal to the summation of the rounded subcomponent } \\
\text { values shown above. See Table F-3 for nonrounded totals. }\end{array}$} \\
\hline
\end{tabular}




\section{F-12. MODULE 11: CONTAMINANT GROUTING \\ F-12.1 Purpose}

SDA.

This estimate will be used as a cost-comparative tool to examine different options regarding the

\section{F-12.2 Scope of Work}

The scope of work includes jet grouting 0.2 acres of pits to provide grout monoliths that will encapsulate contaminants. Jet-grouted, $0.6-\mathrm{m}(2-\mathrm{ft})$-diameter columns will be constructed on $0.5-\mathrm{m}$ (20-in.) centers to ensure complete encapsulation of all contaminants.

Jet-grouting operations and grout delivery will be procured services provided by a specialty vendor. A conceptual design developed in Fiscal Year 2004 provides the technical basis to scope the project, pending award of the subcontract. The conceptual design envisions the grouting process will use conventional large hydraulic tracked excavators. These excavators will be modified to deploy a rotopercussion drill rig to inject grout into the waste.

Grout will be supplied to jet-grouting systems by ready-mix trucks. Each grout injection system will feature a self-contained, high-pressure pump, which will provide pressure required for jet fluid grouting.

Grout returns are managed by removing a $0.6-\mathrm{m}$ (2-ft)-deep swath of soil in the region of injection before contaminant grouting, injecting contaminant grout, and then backfilling the region of injection (i.e., covering returns with $0.6 \mathrm{~m}[2 \mathrm{ft}]$ of soil).

Subcontractor mobilization consists of the following:

- $\quad$ Generate operational plans

- Generate a management self-assessment plan

- $\quad$ Mobilize equipment.

Subcontractor demobilization consists of the following:

- $\quad$ Shut down or demobilize equipment

- Generate a final inspection report following completion of contaminant grouting.

Site preparation consists of the following:

- $\quad$ Conduct procurement activities

- Mate a hydraulic commercial trackhoe to a mast-mounted rotopercussion drill. 
Remediation consists of the following:

- $\quad$ Ready-mix trucks deliver the contaminant grout to a low-pressure hopper (mounted on a low-boy trailer).

- $\quad$ The grout mixture is pumped at low pressure from the low-boy hopper to a high-pressure pump mounted on a separate trailer.

- $\quad$ The high-pressure pump pumps high-pressure grout (through a lanyard hose) to the trackhoe drill.

- The drill is driven to the bottom of the waste and grout is injected as the drill is withdrawn.

- $\quad$ Cap grout returns.

\section{F-12.3 Basis of the Estimate}

The following sequential process, rationale, and estimating methodologies were used to define activities, quantities, and resources that were used in preparation of this cost estimate.

A. The INEEL Environmental Restoration Cost Estimating/Cost Engineering Guide (DOE-ID 2000) and the "Idaho National Engineering and Environmental Laboratory Detailed Work Plan Development Process Guidance" (GDE-112) were used to define estimating requirements.

B. The estimate development method was established using a detailed bottoms-up quantifiable technique. Resources, costs, and productions are derived from these individual, detailed item quantities.

C. Estimate scope was defined in the scope of work provided by the requester.

D. The estimate was based on drawings and specifications provided by the requester.

E. Costs were developed, using the Success $\odot$ estimating software by U.S. Cost, to a level of detail consistent with available documents and information.

F. Standard material pricing was based on the R. S. Means and Richardson Estimating Manuals.

G. Labor rates were based on the R. S. Means and Richardson Estimating Manuals. All labor rates were factored considering working conditions and requirements at the INL Site.

H. Project cost elements were based on Estimate File Number 5432, "Subsurface Disposal Area (SDA) Cap and Cover-Life-cycle Baseline Estimate for FY 2006-2012," prepared July 14, 2005.

I. Submittal and implementation costs were based on costs extracted from Estimate File Number 5987, "ISG Project FY 2005-FY 2011," dated August 3, 2004. Appropriate general contractor markups for overhead, profit, and bond were applied to costs extracted from this previous estimate. 


\section{F-12.4 Assumptions}

\section{A. Schedule}

1. Figure F-12 illustrates the project schedule.

2. Work activities are performed using two trackhoe drills during the $4 \times 10$ work schedule, with 5 effective work hours a day, and 26 work weeks per year.

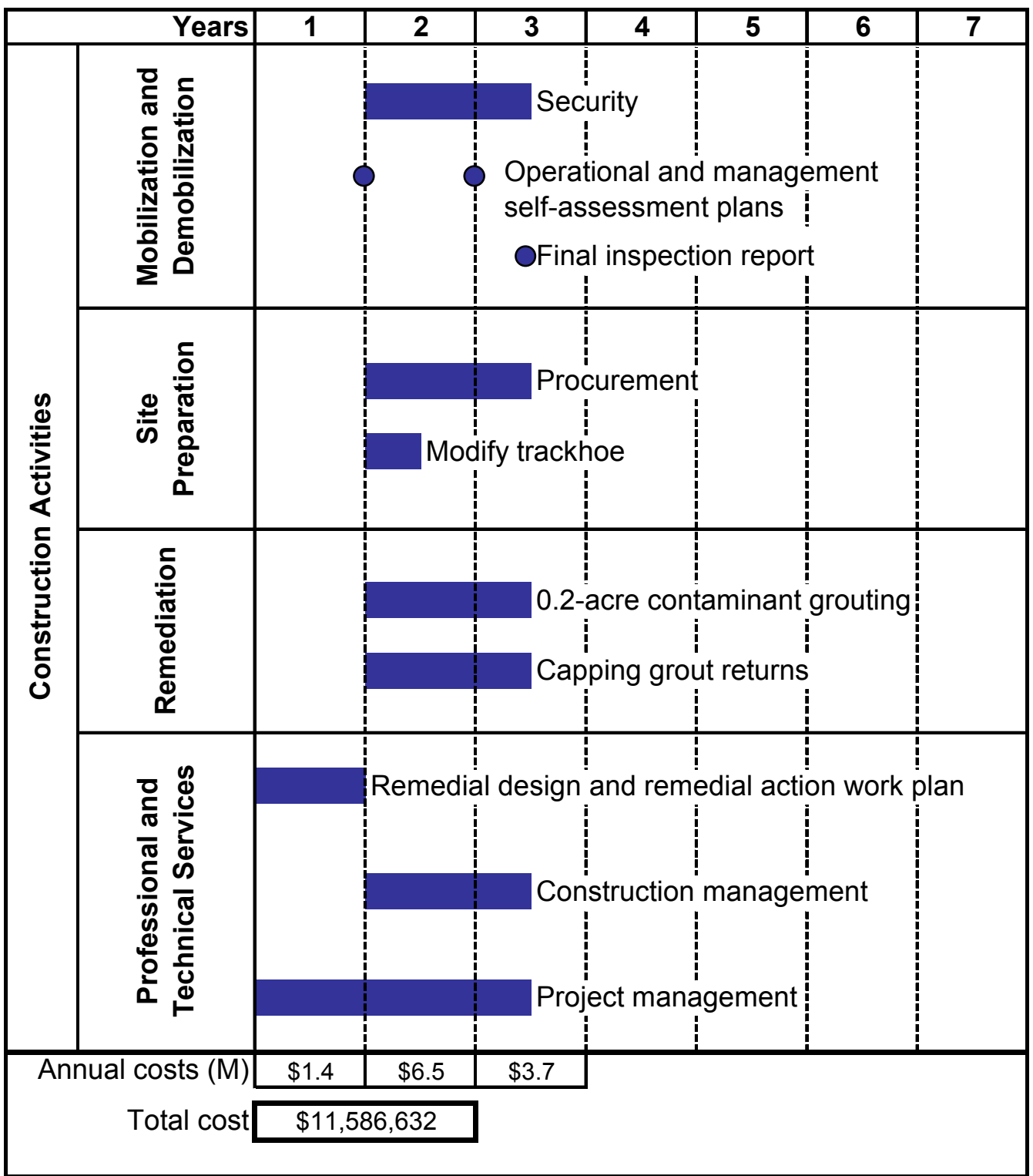

Figure F-12. Module 11 design and construction schedule for contaminant grouting within the Subsurface Disposal Area pits. 


\section{B. Mobilization and demobilization (capital costs)}

1. Administrative and equipment buildings or trailers will be installed in the SDA to support operational controls, radiation controls, and personnel facilities.

2. Equipment and personnel entering and exiting the SDA will not be required to survey in or out, or stop for security access. As they travel through the gates, personnel will only be required to flash their identification to personnel manning those gates. This estimate assumes free and easy access at the gates for all construction personnel and equipment.

3. ICP personnel will have access to existing RWMC buildings that can be used as temporary offices during this work.

4. ICP personnel will not require move monies.

5. Mobilization and demobilization costs are captured within the remediation section of this cost estimate.

\section{Site preparation (capital costs)}

A land survey will be required before the start of contaminant grouting. Track modifications are captured in the remediation section of this cost estimate.

\section{Remediation (capital costs)}

1. A specialty subcontractor will perform contaminant grouting. This subcontractor will be experienced with this type of work and will be selected through the bid and award process.

2. Only designated pit and trench areas will receive contaminant grouting ( 0.2 acres $\left.\left[8,712 \mathrm{ft}^{2}\right]\right)$.

3. Contaminant grouting will consist of injecting 0.6-m (2-ft) -diameter grout columns (177 gal of grout per column, based on $13.6 \mathrm{gal} / \mathrm{ft}$ and $13-\mathrm{ft}$ depths), spaced $0.5 \mathrm{~m}$ (20 in.) apart, for a period of 8 minutes per hole.

4. This project will not impact the Accelerated Retrieval Project excavation.

5. No release of radioactive materials will be caused by contaminant grouting.

6. A survey of the area to be grouted will be performed before startup of grouting operations. The subcontractor will be responsible for surveying grout column locations.

7. Before injection grouting, a 0.24 -acre area ( 0.2 acres plus $20 \%)$, encompassing injection points, will be excavated to a depth of $0.6 \mathrm{~m}(2 \mathrm{ft})$. Once grouting is complete, the grout returns will be covered with excavated soil and filled to grade.

8. Grout formulation used for contaminant grouting consists of Portland cement and blast furnace slag. 


\section{F-12.5 Contingency Guideline Implementation}

Total capital cost contingency for contaminant grouting is $38.32 \%$. This contingency is the average contingency of construction activities (i.e., $50 \%$ ) and professional and technical services (i.e., $0 \%$ ).

\section{F-12.6 Estimate Summary}

Table F-49 provides rough order of magnitude allocations of the methodologies used to develop the cost estimate for Module 11.

Table F-49. Rough order of magnitude allocations of the methodologies used to develop the cost estimate for Module 11.

\begin{tabular}{lc}
\hline Estimate Methodology & $\begin{array}{c}\text { Rough Order of Magnitude } \\
(\%)\end{array}$ \\
\hline Project team & 50 \\
Recorded actuals & 0 \\
Parametric & 0 \\
Vendor quotes & 40 \\
Other & 10 \\
Total & $\mathbf{1 0 0}$ \\
\hline
\end{tabular}

\section{F-12.7 Other Comments or Concerns Specific to the Estimate}

A. Activities have not been escalated.

B. Subcontractor labor costs reflect INL Site Stabilization Agreement craft labor rates.

C. $\mathrm{CH} 2 \mathrm{M}-\mathrm{WG}$ Idaho labor rates reflect fully burdened present day rates.

\section{F-12.8 Summary}

Table F-50 provides capital cost information for Module 11. 
Table F-50. Capital costs for Module 11: Operable Unit 7-13/14 Feasibility Study—Contaminant Grouting, Project Number: 5992-G.

\begin{tabular}{|c|c|c|c|c|c|}
\hline Level & Description & $\begin{array}{c}\text { Subtotals }^{\mathrm{a}} \\
(\$)\end{array}$ & $\begin{array}{c}\text { Estimate }^{\mathrm{a}} \\
(\$)\end{array}$ & $\begin{array}{c}\text { Contingency }^{\mathrm{a}, \mathrm{b}} \\
(\$)\end{array}$ & $\begin{array}{c}\text { Total }^{\mathrm{a}, \mathrm{c}} \\
(\$)\end{array}$ \\
\hline 1.1 & Construction activities & $6,420,000$ & - & - & - \\
\hline 1.1 .1 & Mobilization and demobilization & 829,000 & - & - & - \\
\hline 1.1.1.1 & Submittals and implementation plans & 276,000 & - & - & - \\
\hline 1.1.1.1.1 & Operational plans & - & 75,000 & 38,000 & 113,000 \\
\hline 1.1.1.1.2 & Remedial action and monitoring plan & - & 13,000 & 7,000 & 20,000 \\
\hline 1.1.1.1.3 & Industrial hygiene exposure and sampling plan & - & 6,000 & 3,000 & 8,000 \\
\hline 1.1.1.1.4 & Management self-assessment plan & - & 82,000 & 41,000 & 124,000 \\
\hline 1.1.1.1.5 & Training plan & - & 50,000 & 25,000 & 75,000 \\
\hline 1.1.1.1.6 & Quality control plan & - & 50,000 & 25,000 & 75,000 \\
\hline 1.1.1.3 & Temporary facilities & - & 40,000 & 20,000 & 60,000 \\
\hline 1.1.1.4 & Security at construction site access gates & - & 190,000 & 95,000 & 285,000 \\
\hline 1.1.1.5 & Final inspection report & - & 323,000 & 161,000 & 484,000 \\
\hline 1.1 .2 & Site preparation work & 13,000 & - & - & - \\
\hline 1.1.2.1 & Land survey & - & 13,000 & 7,000 & 20,000 \\
\hline 1.1.3 & Remediation & $5,578,000$ & - & - & - \\
\hline 1.1.3.3 & Contaminant grouting & $5,578,000$ & - & - & - \\
\hline 1.1.3.3.1 & General conditions & - & 125,000 & 62,000 & 187,000 \\
\hline 1.1.3.3.2 & Purchase track drill & - & $3,335,000$ & $1,667,000$ & $5,002,000$ \\
\hline 1.1.3.3.3 & Mobilize and demobilize of construction equipment & - & 10,000 & 5,000 & 15,000 \\
\hline 1.1.3.3.4 & Site work & $2,108,000$ & - & - & - \\
\hline 1.1.3.3.4.1 & Cold test & - & 25,000 & 13,000 & 38,000 \\
\hline 1.1.3.3.4.2 & Excavate and recess grout area for grout return & - & 10,000 & 5,000 & 15,000 \\
\hline 1.1.3.3.4.3 & Grout placement 0.7 acres & - & $1,478,000$ & 739,000 & $2,217,000$ \\
\hline 1.1.3.3.4.4 & Cover grout returns & - & 16,000 & 8,000 & 23,000 \\
\hline 1.1.3.3.4.5 & Equipment maintenance and spare parts & - & 580,000 & 290,000 & 870,000 \\
\hline
\end{tabular}


Table F-50. (continued)

\begin{tabular}{|c|c|c|c|c|c|}
\hline Level & Description & $\begin{array}{c}\text { Subtotals }{ }^{\mathrm{a}} \\
(\$)\end{array}$ & $\begin{array}{c}\text { Estimate }^{a} \\
(\$)\end{array}$ & $\begin{array}{c}\text { Contingency }{ }^{\mathrm{a}, \mathrm{b}} \\
(\$)\end{array}$ & $\begin{array}{c}\text { Total }{ }^{\mathrm{a}, \mathrm{c}} \\
(\$)\end{array}$ \\
\hline 1.2 & Professional and technical services & $\mathbf{1 , 9 5 7 , 0 0 0}$ & - & - & - \\
\hline 1.2 .1 & Project management & - & 481,000 & - & 481,000 \\
\hline 1.2 .2 & Remedial design and remedial action work plan & 994,000 & - & - & - \\
\hline 1.2.2.1 & Remedial design & - & 746,000 & - & 746,000 \\
\hline 1.2.2.2 & Remedial action work plan & - & 249,000 & - & 249,000 \\
\hline \multirow[t]{3}{*}{1.2 .3} & Construction management & - & 481,000 & - & 481,000 \\
\hline & Total capital $\operatorname{cost}^{\mathrm{c}}$ & - & $8,377,000$ & $3,210,000$ & $11,587,000$ \\
\hline & \multicolumn{5}{|c|}{$\begin{array}{l}\text { a. Values are rounded to the nearest } \$ 1,000 \text {. } \\
\text { b. Capital cost contingency is } 38.3 \% \text { of the estimate. } \\
\text { c. Totals were derived for the summation of nonrounded subcomponent values. Therefore, totals are not equal to the summation of the rounded subcomponent } \\
\text { values shown above. See Table F-3 for nonrounded totals. }\end{array}$} \\
\hline
\end{tabular}




\section{F-13. MODULE 12: 2-ACRE EXCAVATION \\ F-13.1 Purpose}

SDA.

This estimate will be used as a cost-comparative tool to examine different options regarding the

\section{F-13.2 Scope of Work}

The scope of work consists of engineering, procuring, constructing, and operating a facility that will excavate and package 2 acres of buried waste in the SDA.

Subcontractor mobilization consists of the following:

- $\quad$ Generate operational plans (see Section F-13.4 for details)

- $\quad$ Generate a management self-assessment plan

- $\quad$ Generate an operational readiness review plan of action and an operational readiness review implementation plan

- $\quad$ Mobilize equipment (costs captured in Section F-13.4).

Subcontractor demobilization consists of the following:

- $\quad$ Shut down or demobilize equipment

- Generate a final inspection report following completion of retrieval within each retrieval enclosure.

Subcontractor site preparation consists of the following:

- Construct one Accelerated Retrieval Project II style Retrieval Enclosure that is $51.8 \times 73.2 \mathrm{~m}$ $(170 \times 240 \mathrm{ft})$

- $\quad$ One airlock, each contains drum packaging systems

- $\quad$ One airlock-type system, using cargo containers for radiological control, maintenance equipment, and personnel entry services

- $\quad$ One nonremote excavator

- $\quad$ One nonremote telehandler

- $\quad$ Emissions monitoring systems

- Heating, ventilation, and filtration systems

- $\quad$ Electrical and controls systems

- Video equipment systems

- $\quad$ Radiological equipment

- $\quad$ Fire detection systems

- Drum packaging stations

- $\quad$ Sorting tables. 
- $\quad$ Construct three retrieval tents $30.5 \times 33.5 \mathrm{~m}(100 \times 110 \mathrm{ft})$

- $\quad$ Cargo containers attachments for waste trays, radiological control equipment, and maintenance equipment

- $\quad$ One nonremote excavator per three tents

- $\quad$ One nonremote telehandler per three tents

- $\quad$ Emissions monitoring systems

- Heating, ventilation, and filtration systems

- $\quad$ Electrical and controls systems

- $\quad$ Radiological equipment.

Subcontractor remediation consists of the following:

- $\quad$ Remove clean overburden from the Accelerated Retrieval Project II area.

- $\quad$ Construct a retrieval enclosure over the Accelerated Retrieval Project II excavation area and connect the structure end-to-end with the Accelerated Retrieval Project I retrieval enclosure.

- $\quad$ Remove the Accelerated Retrieval Projects I and II adjoining wall and selectively excavate targeted waste material beneath the wall and beneath the Accelerated Retrieval Project II Retrieval Enclosure while leaving nontargeted waste in the pit.

- $\quad$ Remove clean overburden from selected retrieval tent areas.

- Construct three retrieval tents (smaller than the retrieval enclosure) over chosen excavation areas.

- $\quad$ Selectively excavate targeted waste material beneath the retrieval tents while leaving nontargeted waste in the pit.

- $\quad$ Transfer (within the attached cargo container) waste from smaller retrieval tents to the larger Accelerated Retrieval Projects I and II combined retrieval enclosure.

- $\quad$ Perform random sampling of waste at the dig face.

- $\quad$ Visually examine to satisfy Idaho CERCLA Disposal Facility (ICDF) waste acceptance criteria and package targeted waste in containers (e.g., 55-gal drums) within the Accelerated Retrieval Projects I and II combined retrieval enclosure drum packaging stations.

- $\quad$ Temporarily store TRU waste drums (packaged out of the drum packaging stations) until they are processed for shipment to the Waste Isolation Pilot Plant (WIPP).

- $\quad$ Temporarily store non-TRU waste drums (packaged out of the drum packaging stations) until they are processed for shipment to the ICDF.

- $\quad$ Ship non-TRU waste drums to the ICDF for treatment and disposal. 
- $\quad$ Prepare TRU waste drums for shipment to the WIPP by

- $\quad$ Assaying waste drums

- $\quad$ Performing headspace gas sampling on TRU and load-managed drums

- $\quad$ Performing gas-generation testing on drums that exceed the allowable headspace gas sampling thermal wattage limit or drums that contain test category waste

- $\quad$ Performing limited VOCs treatment of drums that failed gas-generation testing.

- $\quad$ Containerize (i.e., TRU package containers) TRU drums for WIPP shipment.

- Dismantle retrieval enclosure and restart retrieval process over a new retrieval area.

- $\quad$ Following retrieval of the area totaling 2 acres, ensure the two retrieval enclosures (one preexisting plus one fabricated by the subcontractor) and the three smaller tents are decontaminated, decommissioned, and buried in the SDA.

\section{F-13.3 Basis of the Estimate}

The following sequential process, rationale, and estimating methodologies were used to define activities, quantities, and resources that were used in preparation of this cost estimate.

A. Waste retrievals were based on cost information provided by the Planning and Integration Project team and the life-cycle baseline for the Targeted Waste Removal and Disposition Project. Appropriate general contractor markups for overhead, profit, and bond were applied to costs extracted from this previous estimate.

B. Procurement and construction of tents and retrieval equipment were based on costs information provided by the Project Planning and Integration Project team and the life-cycle baseline for the Targeted Waste Removal and Disposition Project. Appropriate general contractor markups for overhead, profit, and bond were applied to costs extracted from this previous estimate.

C. Procurement and construction of the Accelerated Retrieval Project II Retrieval Enclosure, enclosure support equipment (not including excavator, telehandler, drum packaging stations, and sorting tables), and ICDF treatment and disposal cost elements were based on Estimate File Number 5989-D, “ARP-2 EE/CA Estimate,” prepared March 1, 2005. Appropriate general contractor markups for overhead, profit, and bond were applied to costs extracted from this previous estimate.

D. Where applicable (e.g., excavator and telehandler), material pricing was based on information provided by procurement from previous Accelerated Retrieval Project purchases. Appropriate general contractor markups for overhead, profit, and bond were applied to costs extracted from this previous estimate.

E. Drum packaging station costs were based on the actual subcontract from the Accelerated Retrieval Project I facility. Appropriate general contractor markups for overhead, profit, and bond were applied to costs extracted from this previous estimate.

F. Sorting table costs were based on preliminary design information provided by the Accelerated Retrieval Project II. Appropriate general contractor markups for overhead, profit, and bond were applied to costs extracted from this previous estimate. 
G. Transuranic waste disposition cost and remote-handled waste disposal costs were based on the August 8, 2005, COBRA run for the Contact-Handled Transuranic Waste Disposition Project, minus escalation allowances. Appropriate general contractor markups for overhead, profit, and bond were applied to costs extracted from this previous estimate.

H. Non-TRU waste disposition cost (i.e., ICDF) was based on information provided by a Waste Generator Services e-mail dated December 20, 2004. Appropriate general contractor markups for overhead, profit, and bond were applied to costs extracted from this previous estimate.

I. Submittal and implementation costs were based on costs extracted from Estimate File Number 5987, "ISG Project FY 2005-FY 2011," dated August 3, 2004. Appropriate general contractor markups for overhead, profit, and bond were applied to costs extracted from this previous estimate.

J. Security costs were based on Estimate File Number 5432. Appropriate general contractor markups for overhead, profit, and bond were applied to costs extracted from this previous estimate.

K. Costs were developed, using the Success $@$ estimating software by U.S. Cost, to a level of detail consistent with available documents and information.

L. Airlock construction costs were based on information provided by the construction management group, using force account personnel. Appropriate general contractor markups for overhead, profit, and bond were applied to costs extracted from this previous estimate.

M. Airlock procurement costs were based on budgetary information provided by a building manufacturer of this type. Appropriate general contractor markups for overhead, profit, and bond were applied to costs extracted from this previous estimate.

N. Project scope and methodologies were prepared from discussions with the requester and project team.

O. Experiences of the Operable Unit 7-10 Glovebox Excavator Method Project (Pit 9) and Accelerated Retrieval Projects I and II were used for the design elements associated with this cost estimate.

P. Final inspection costs were based on the "Preliminary Evaluation of Remedial Alternatives for the Subsurface Disposal Area" (Zitnik et al. 2002).

\section{F-13.4 Assumptions}

\section{A. General assumptions}

1. Structures obstructing retrieval in the SDA will be completely removed by those projects before the start of this project and at no cost to this project.

2. If the use of sorting tables, treatment units, or an interim storage facility may be interpreted as "placement" of waste, a waiver or variance will be obtained from the Idaho Department of Environmental Quality (DEQ) that will preclude imposition of RCRA land disposal restriction requirements.

3. Two modified excavators and telehandlers will be purchased for retrieval of the waste. The previously purchased Accelerated Retrieval Project I excavator will be available for use. 


\section{B. Schedule}

Figure F-13 illustrates the project schedule.

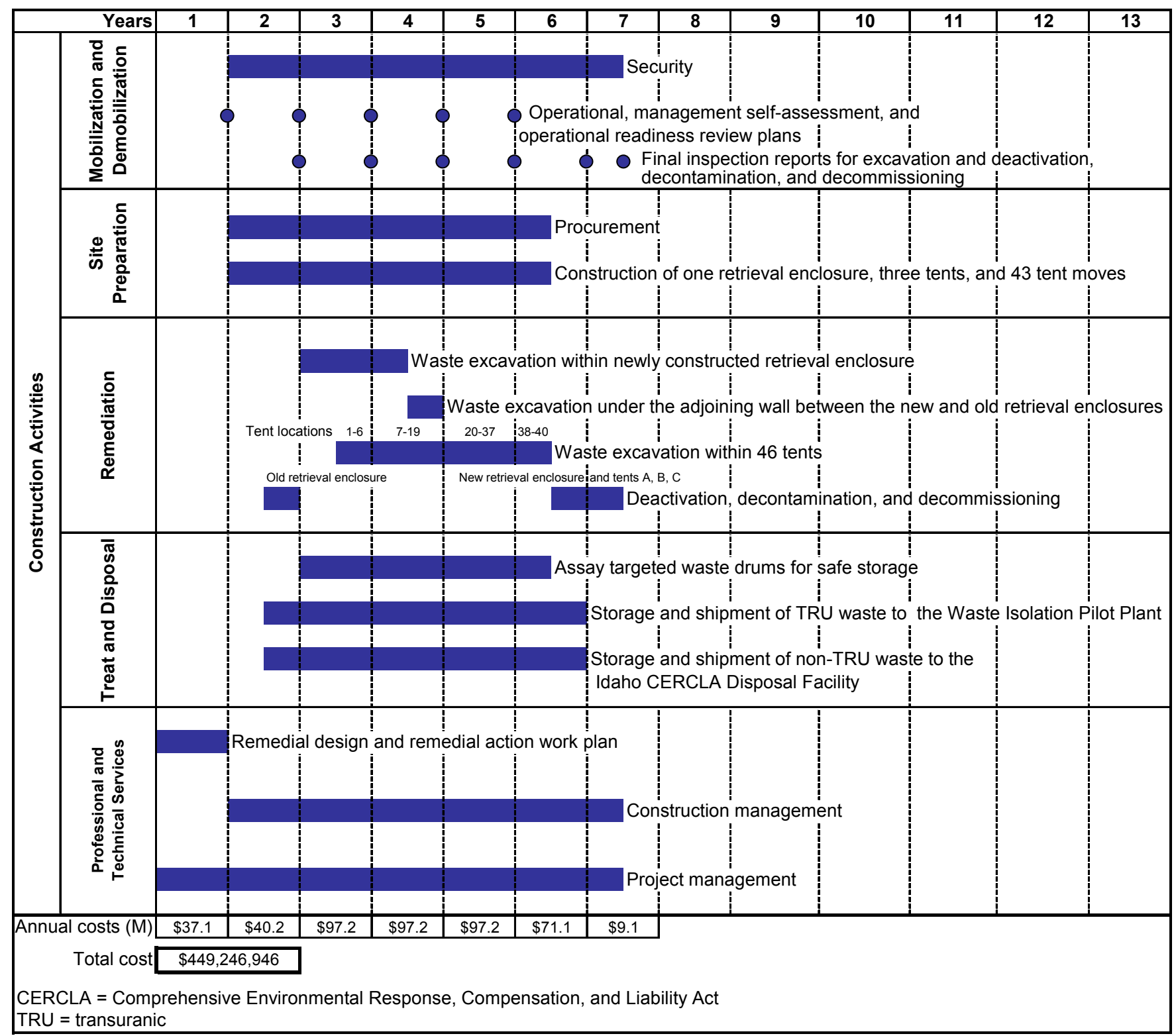

Figure F-13. Module 12 design and construction schedule for a 2-acre partial retrieval within the Subsurface Disposal Area.

\section{Mobilization and demobilization (capital costs)}

1. ICP personnel will not require move monies.

2. Equipment, mobilization, and demobilization costs are captured within the remediation section of this cost estimate. 


\section{Site preparation (capital costs)}

1. This module requires one complete Accelerated Retrieval Project II-type retrieval enclosure.

2. This module will require three complete pullable retrieval tents as identified in the life-cycle baseline.

\section{E. Remediation (capital costs)}

1. Tents will require relocation by dragging 37 times. In addition, two of the three tents will require total disassembly and reassembly at distant satellite locations.

2. A specialty subcontractor will perform waste excavation. This subcontractor will be experienced with this type of work and will be selected through the bid and award process.

3. No revegetation of the excavated area will be required.

4. Only designated pit areas will be excavated (approximately 2.0 acres).

5. All nontargeted waste will be placed back into the pit areas.

6. This project will not impact the current Accelerated Retrieval Project excavation activities.

7. A survey of the proposed excavated area has already been performed. No allowance for surveying is included.

8. Remote-handled materials will not be encountered during this project.

9. If large objects are encountered, they will be left in the pit.

\section{F-13.5 Contingency Guideline Implementation}

Total capital cost contingency for the 2 -acre retrieval, treatment, and disposal (RTD) is $48.85 \%$. This contingency is the average contingency of construction activities (i.e., 65\%) and professional and technical services (i.e., $0 \%$ ). 


\section{F-13.6 Estimate Summary}

Table F-51 provides rough order of magnitude allocations of the methodologies used to develop the cost estimate for Module 12.

Table F-51. Rough order of magnitude allocations of the methodologies used to develop the cost estimate for Module 12.

\begin{tabular}{lc} 
Estimate Methodology & $\begin{array}{c}\text { Rough Order of Magnitude } \\
(\%)\end{array}$ \\
\hline Project team & 30 \\
Recorded actuals & 0 \\
Parametric & 20 \\
Vendor quotes & 20 \\
Other & 30 \\
Total & $\mathbf{1 0 0}$ \\
\hline
\end{tabular}

\section{F-13.7 Other Comments or Concerns Specific to the Estimate}
A. Activities have not been escalated to the activity midpoint.
B. Subcontractor labor costs reflect INL Site Stabilization Agreement craft labor rates.
C. CH2M-WG Idaho labor rates reflect fully burdened present day rates.

\section{F-13.8 Summary}

Table F-52 provides capital cost information for Module 12. 
Table F-52. Capital costs for Module 12: Operable Unit 7-13/14 Feasibility Study-2-Acre Excavation, Project Number: 5992-H.

\begin{tabular}{|c|c|c|c|c|c|}
\hline Level & Description & $\begin{array}{l}\text { Subtotals }^{\mathrm{a}} \\
(\$)\end{array}$ & $\begin{array}{c}\text { Estimate }^{\mathrm{a}} \\
(\$)\end{array}$ & $\begin{array}{l}\text { Contingency } \\
(\$)\end{array}$ & $\begin{array}{c}\text { Total }^{\mathrm{a}, \mathrm{c}} \\
(\$)\end{array}$ \\
\hline 1.1 & Construction activities & $226,832,000$ & - & - & - \\
\hline 1.1 .1 & Mobilization and demobilization & $5,753,000$ & - & - & - \\
\hline 1.1 .1 .2 & Submittals and implementation plans & $1,560,000$ & - & - & - \\
\hline 1.1 .1 .2 .1 & Operational plans & - & 546,000 & 355,000 & 900,000 \\
\hline 1.1 .1 .2 .2 & Management self-assessment plan & - & 346,000 & 225,000 & 571,000 \\
\hline 1.1 .1 .2 .3 & $\begin{array}{l}\text { Operational readiness review, plan of action, and implementation plan } \\
\text { (retrieval only) }\end{array}$ & - & 346,000 & 225,000 & 571,000 \\
\hline 1.1.1.2.4 & Final inspection report & - & 323,000 & 210,000 & 532,000 \\
\hline 1.1.1.3 & Security at construction site access gates & - & $4,193,000$ & $2,726,000$ & $6,919,000$ \\
\hline 1.1 .2 & Site preparation work & $42,518,000$ & - & - & - \\
\hline 1.1.2.1 & Procurement & $32,784,000$ & - & - & - \\
\hline 1.1.2.1.1 & Procurement (from life-cycle baseline) & $24,682,000$ & - & - & - \\
\hline 1.1.2.1.1.1 & Procurement - assay waste for storage & - & $7,328,000$ & $4,763,000$ & $12,091,000$ \\
\hline 1.1.2.1.1.2 & Procurement-ops consumables & - & $6,145,000$ & $3,994,000$ & $10,139,000$ \\
\hline 1.1.2.1.1.3 & Procurement-equipment & - & $3,264,000$ & $2,122,000$ & $5,386,000$ \\
\hline 1.1.2.1.1.4 & Procurement-movable tent structures & - & $7,143,000$ & $4,643,000$ & $11,787,000$ \\
\hline 1.1.2.1.1.5 & Procurement-procurement support & - & 802,000 & 521,000 & $1,323,000$ \\
\hline 1.1.2.1.2 & Procurement (from Accelerated Retrieval Project II) & $8,102,000$ & - & - & - \\
\hline 1.1.2.1.2.1 & Procurement-Retrieval Enclosure Accelerated Retrieval Project II & - & $2,049,000$ & $1,332,000$ & $3,380,000$ \\
\hline 1.1.2.1.2.2 & Procurement—airlock structure & - & 369,000 & 240,000 & 609,000 \\
\hline 1.1.2.1.2.3 & Procurement-emissions monitoring & - & 289,000 & 188,000 & 476,000 \\
\hline 1.1.2.1.2.4 & Procurement-heating and ventilation (retrieval structure) & - & 434,000 & 282,000 & 715,000 \\
\hline 1.1.2.1.2.5 & Procurement-electrical distribution & - & 495,000 & 322,000 & 817,000 \\
\hline 1.1.2.1.2.6 & Video (closed-circuit television) & 154,000 & - & - & - \\
\hline 1.1.2.1.2.6.1 & Dig face video & - & 23,000 & 15,000 & 37,000 \\
\hline 1.1.2.1.2.6.2 & General area video & - & 131,000 & 85,000 & 217,000 \\
\hline 1.1.2.1.2.7 & Radiological and industrial hygiene equipment & 803,000 & - & - & - \\
\hline 1.1.2.1.2.7.1 & RadCon equipment & - & 789,000 & 513,000 & $1,302,000$ \\
\hline 1.1.2.1.2.7.2 & Industrial hygiene equipment & - & 14,000 & 9,000 & 22,000 \\
\hline 1.1.2.1.2.8 & Procurement-nonremote excavator (Gradall) & - & $1,123,000$ & 730,000 & $1,853,000$ \\
\hline 1.1.2.1.2.9 & Procurement_-telehandler (forklift) & - & 501,000 & 326,000 & 827,000 \\
\hline 1.1.2.1.2.10 & Procurement-foundation materials & - & 273,000 & 178,000 & 451,000 \\
\hline 1.1.2.1.2.11 & Drum packaging station stations (five each) & $1,278,000$ & - & - & - \\
\hline 1.1.2.1.2.11.1 & Drum packaging station stations (drum only) & - & 612,000 & 398,000 & $1,010,000$ \\
\hline 1.1.2.1.2.11.2 & Drum packaging station stations (standard waste box and drum) & - & 230,000 & 149,000 & 379,000 \\
\hline 1.1.2.1.2.11.3 & Procurement for drum packaging station units & - & 436,000 & 283,000 & 719,000 \\
\hline 1.1.2.1.2.12 & Power generator & - & 48,000 & 31,000 & 80,000 \\
\hline 1.1.2.1.2.13 & Fire detection & 95,000 & - & - & - \\
\hline 1.1.2.1.2.13.1 & Fire protection-alarm systems & - & 74,000 & 48,000 & 122,000 \\
\hline 1.1 .2 .1 .2 .13 .2 & Fire protection-portable equipment & - & 12,000 & 8,000 & 19,000 \\
\hline 1.1.2.1.2.13.3 & Fire protection-fixed equipment & - & 9,000 & 6,000 & 16,000 \\
\hline 1.1.2.1.2.14 & Fire protection modification-procurement & 102,000 & - & - & - \\
\hline 1.1.2.1.2.14.1 & Procurement-high sensitivity smoke detection & - & 15,000 & 10,000 & 24,000 \\
\hline 1.1.2.1.2.14.2 & Procurement - thermal imaging cameras & - & 87,000 & 57,000 & 144,000 \\
\hline 1.1 .2 .1 .2 .15 & Support trailers (lease extension) & - & 90,000 & 59,000 & 149,000 \\
\hline 1.1.2.2 & Facility construction & $9,734,000$ & - & - & - \\
\hline 1.1.2.2.1 & Construction (from life-cycle baseline) & $4,720,000$ & - & - & - \\
\hline 1.1 .2 .2 .1 .1 & DD\&D of Retrieval Enclosure 1 & - & 406,000 & 264,000 & 671,000 \\
\hline 1.1.2.2.1.2 & Construction and relocation of tents & - & $3,559,000$ & $2,313,000$ & $5,872,000$ \\
\hline 1.1.2.2.1.3 & Mechanical and electrical for Airlock 3 & - & 755,000 & 491,000 & $1,246,000$ \\
\hline 1.1.2.2.2 & Facility construction Accelerated Retrieval Project II & $5,014,000$ & - & - & - \\
\hline 1.1.2.2.2.1 & Retrieval structure erection Accelerated Retrieval Project II & - & $1,548,000$ & $1,006,000$ & $2,554,000$ \\
\hline 1.1 .2 .2 .2 .2 & Airlock structure erection & - & 315,000 & 205,000 & 520,000 \\
\hline 1.1.2.2.2.3 & Access roadway & - & 88,000 & 57,000 & 145,000 \\
\hline 1.1.2.2.2.4 & Site drainage & - & 41,000 & 27,000 & 68,000 \\
\hline 1.1.2.2.2.5 & Fire protection modification-Subpart K & 60,000 & - & - & - \\
\hline 1.1 .2 .2 .2 .5 .1 & Construction-high sensitivity smoke detection & 19,000 & - & - & - \\
\hline 1.1.2.2.2.5.1.1 & Electrical & 19,000 & - & - & - \\
\hline 1.1.2.2.2.5.1.1.1 & Electrical-general conditions & - & 3,000 & 2,000 & 4,000 \\
\hline 1.1.2.2.2.5.1.1.2 & Electrical-sample tubes, raceways, and enclosures & - & 11,000 & 7,000 & 18,000 \\
\hline 1.1.2.2.2.5.1.1.3 & Electrical-power and electronic panels & - & 3,000 & 2,000 & 5,000 \\
\hline 1.1.2.2.2.5.1.1.4 & Electrical—conductors and grounding & - & 1,000 & 1,000 & 2,000 \\
\hline 1.1.2.2.2.5.1.1.5 & Electrical一testing & - & 1,000 & 1,000 & 2,000 \\
\hline 1.1 .2 .2 .2 .5 .2 & Construction - thermal imaging cameras & 10,000 & - & - & - \\
\hline 1.1.2.2.2.5.2.1 & Electrical & 10,000 & - & - & - \\
\hline 1.1 .2 .2 .2 .5 .2 .1 .1 & Electrical-general conditions & - & 3,000 & 2,000 & 4,000 \\
\hline $1.1 .2 .2 \cdot 2.5 .2 .1 .2$ & Electrical—camera assembly & - & 1,000 & 1,000 & 2,000 \\
\hline 1.1.2.2.2.5.2.1.3 & Electrical- power, enclosures, and conductors & - & 6,000 & 4,000 & 9,000 \\
\hline $1.1 .2 .2 \cdot 2 \cdot 5 \cdot 2 \cdot 1.4$ & Electrical-testing & - & 0 & 0 & 1,000 \\
\hline 1.1.2.2.2.5.3 & Field design change fire protection & 31,000 & - & - & - \\
\hline $1.1 \cdot 2 \cdot 2 \cdot 2 \cdot 5 \cdot 3.1$ & Electrical & 31,000 & - & - & - \\
\hline 1.1 .2 .2 .2 .5 .3 .1 .1 & Fire protection-one raceways, enclosures & - & 25,000 & 16,000 & 42,000 \\
\hline $1.1 .2 .2 \cdot 2 \cdot 5.3 .1 .2$ & Fire protection-one conductors & - & 5,000 & 3,000 & 9,000 \\
\hline $1.1 .2 .2 \cdot 2 \cdot 5.3 .1 .3$ & Fire protection-one testing & - & 0 & 0 & 1,000 \\
\hline 1.1.2.2.2.6 & Retrieval enclosure mechanical & - & 755,000 & 490,000 & $1,245,000$ \\
\hline 1.1.2.2.2.7 & Retrieval enclosure electrical & - & 714,000 & 464,000 & $1,178,000$ \\
\hline 1.1.2.2.2.8 & Cargo container RadCon and equipment support & - & 738,000 & 480,000 & $1,218,000$ \\
\hline 1.1.2.2.2.9 & Electrical distribution & - & 754,000 & 490,000 & $1,245,000$ \\
\hline
\end{tabular}


Table F-52. (continued).

\begin{tabular}{|c|c|c|c|c|c|}
\hline Level & Description & $\begin{array}{c}\text { Subtotals }^{\mathrm{a}} \\
(\$)\end{array}$ & $\begin{array}{c}\text { Estimate }^{\mathrm{a}} \\
(\$)\end{array}$ & $\begin{array}{c}\text { Contingency }{ }^{\mathrm{a}, \mathrm{b}} \\
(\$)\end{array}$ & $\begin{array}{c}\text { Total }^{\mathrm{a}, \mathrm{c}} \\
(\$)\end{array}$ \\
\hline 1.1 .3 & Remediation & $104,182,000$ & - & - & - \\
\hline 1.1.3.1 & Facility operations (from life-cycle baseline) & $95,201,000$ & - & - & - \\
\hline 1.1.3.1.1 & Facility maintenance & - & $4,156,000$ & $2,701,000$ & $6,857,000$ \\
\hline 1.1 .3 .1 .2 & Operations management & - & $6,421,000$ & $4,173,000$ & $10,594,000$ \\
\hline 1.1 .3 .1 .3 & Waste packaging & - & $38,591,000$ & $25,084,000$ & $63,675,000$ \\
\hline 1.1.3.1.4 & Retrieval Enclosure 1 DD\&D preparation & - & $1,245,000$ & 809,000 & $2,054,000$ \\
\hline 1.1.3.1.5 & Relocation of tents & - & 546,000 & 355,000 & 902,000 \\
\hline 1.1 .3 .1 .6 & Waste retrieval operations & - & $41,550,000$ & $27,007,000$ & $68,557,000$ \\
\hline 1.1.3.1.7 & Waste sampling & - & $1,290,000$ & 839,000 & $2,129,000$ \\
\hline 1.1.3.1.8 & Operations training & - & $1,403,000$ & 912,000 & $2,315,000$ \\
\hline 1.1.3.2 & Demolition and removal & - & $8,980,000$ & $5,837,000$ & $14,818,000$ \\
\hline 1.1 .4 & Treatment and disposal & $74,379,000$ & - & - & - \\
\hline 1.1.4.1 & On- treatment/disposal & $1,095,000$ & - & - & - \\
\hline 1.1.4.1.1 & Non-TRU waste disposition & - & $1,095,000$ & 712,000 & $1,807,000$ \\
\hline 1.1 .4 .2 & Off-INL treatment/disposal & $73,284,000$ & - & - & - \\
\hline 1.1.4.2.1 & TRU waste disposition & - & $73,284,000$ & $47,634,000$ & $120,918,000$ \\
\hline 1.2 & Professional and technical services & $74,975,000$ & - & - & - \\
\hline 1.2 .1 & Project management & - & $18,714,000$ & - & $18,714,000$ \\
\hline 1.2 .2 & Remedial design and remedial action work plan & $33,805,000$ & & - & \\
\hline 1.2.2.1 & Remedial design & - & $24,146,000$ & - & $24,146,000$ \\
\hline 1.2 .2 .2 & Remedial action work plan & - & $9,658,000$ & - & $9,658,000$ \\
\hline 1.2 .3 & Construction management & - & $22,456,000$ & - & $22,456,000$ \\
\hline & \multirow{2}{*}{\multicolumn{5}{|c|}{$\begin{array}{l}\text { Total capital cost }{ }^{\mathrm{c}} \\
\text { a. Values are rounded to the nearest } \$ 1,000 . \\
\text { b. Capital cost contingency is } 48.9 \% \text { of the estimate. } \\
\text { c. Totals were derived for the summation of nonrounded subcomponent values. Therefore, totals are not equal to the summation of the rounded subcomponent values shown above. } \\
\text { See Table } \mathrm{F}-3 \text { for nonrounded totals. }\end{array}$}} \\
\hline & & & & & \\
\hline
\end{tabular}




\section{F-14. MODULE 13: 4-ACRE EXCAVATION \\ F-14.1 Purpose}

SDA.

This estimate will be used as a cost-comparative tool to examine different options regarding the

\section{F-14.2 Scope of Work}

The scope of work consists of engineering, procuring, constructing, and operating a facility that will excavate and package 4.0 acres of buried waste within the SDA.

Subcontractor mobilization consists of the following:

- Generate operational plans

- Generate a management self-assessment plan

- Generate an operational readiness review plan of action and an operational readiness

review implementation plan

- $\quad$ Mobilize equipment.

Subcontractor demobilization consists of the following:

- $\quad$ Shut down or demobilize equipment

- Generate a final inspection report following completion of retrieval within each retrieval enclosure.

Subcontractor site preparation consists of the following:

- $\quad$ Construct one Accelerated Retrieval Project II-style retrieval enclosure that is $51.8 \times 73.2 \mathrm{~m}$ $(170 \times 240 \mathrm{ft})$

- $\quad$ One airlock, each contains drum packaging systems

- $\quad$ One airlock-type system, using cargo containers for radiological control, maintenance equipment, and personnel entry services

- $\quad$ One nonremote excavator

- $\quad$ One nonremote telehandler

- $\quad$ Emissions monitoring systems

- Heating, ventilation, and filtration systems

- $\quad$ Electrical and controls systems

- Video equipment systems

- $\quad$ Radiological equipment

- $\quad$ Fire detection systems

- Drum packaging stations

- $\quad$ Sorting tables. 
- $\quad$ Construct six retrieval tents $30.5 \times 33.5 \mathrm{~m}(100 \times 110 \mathrm{ft})$

- Cargo container attachments for waste trays, radiological control equipment, and maintenance equipment

- $\quad$ One nonremote excavator per three tents

- $\quad$ One nonremote telehandler per three tents

- $\quad$ Emissions monitoring systems

- Heating, ventilation, and filtration systems

- $\quad$ Electrical and controls systems

- $\quad$ Radiological equipment.

Subcontractor remediation consists of the following:

- $\quad$ Remove clean overburden from the Accelerated Retrieval Project II area.

- $\quad$ Construct a retrieval enclosure over the Accelerated Retrieval Project II excavation area and connect structure end-to-end with the Accelerated Retrieval Project I retrieval enclosure.

- $\quad$ Remove the Accelerated Retrieval Projects I and II adjoining wall and selectively excavate targeted waste material beneath the wall and beneath the Accelerated Retrieval Project II Retrieval Enclosure, while leaving nontargeted waste in the pit.

- Remove clean overburden from selected retrieval tent areas.

- Construct six retrieval tents (smaller than the retrieval enclosure) over the chosen excavation areas.

- $\quad$ Selectively excavate targeted waste material beneath the retrieval tents while leaving nontargeted waste in the pit.

- Transfer (within the attached cargo container) targeted waste from smaller retrieval tents to the larger Accelerated Retrieval Projects I and II combined retrieval enclosure.

- $\quad$ Perform random sampling of excavated waste at the dig face.

- $\quad$ Visually examine to satisfy ICDF waste acceptance criteria and package targeted waste in containers (e.g., 55-gal drum) in the Accelerated Retrieval Projects I and II combined retrieval enclosure drum packaging stations.

- $\quad$ Temporarily store TRU waste drums (packaged out of the drum packaging stations) until they are processed for shipment to the WIPP.

- $\quad$ Temporarily store non-TRU waste drums (packaged out of the drum packaging station) until they are processed for shipment to ICDF.

- $\quad$ Ship non-TRU waste drums to ICDF for treatment and disposal.

- $\quad$ Prepare TRU waste drums for shipment to the WIPP by:

- $\quad$ Assaying waste drums

- $\quad$ Performing headspace gas sampling on TRU and load-managed drums

- $\quad$ Performing gas-generation testing on drums that exceed the allowable headspace gas sampling thermal wattage limit or drums that contain test category waste

- $\quad$ Performing limited VOCs treatment of drums that failed gas-generation testing. 
- $\quad$ Containerize (i.e., TRU package containers) TRU drums for shipment to the WIPP.

- Dismantle retrieval tents and restart retrieval process over a new retrieval area.

- $\quad$ Following retrieval of the pit area totaling 4 acres, ensure the two retrieval enclosures (i.e., one preexisting and one fabricated by the subcontractor) and the smaller six tents will be deactivated, decontaminated, and decommissioned and buried in the SDA.

\section{F-14.3 Basis of the Estimate}

The following sequential process, rationale, and estimating methodologies were used to define activities, quantities, and resources that were used in preparation of this cost estimate:

A. Waste retrievals were based on cost information provided by the Planning and Integration Project team and the life-cycle baseline for the Targeted Waste Removal and Disposition Project. Appropriate general contractor markups for overhead, profit, and bond were applied to costs extracted from this previous estimate.

B. Procurement and construction of tents and retrieval equipment were based on costs information provided by the Project Planning and Integration Project team and the life-cycle baseline for the Targeted Waste Removal and Disposition Project. Appropriate general contractor markups for overhead, profit, and bond were applied to costs extracted from this previous estimate.

C. Procurement and construction of the Accelerated Retrieval Project II Retrieval Enclosure, enclosure support equipment (not including excavator, telehandler, drum packaging stations, and sorting tables), and ICDF treatment and disposal cost elements were based on Estimate File Number 5989-D, “ARP-2 EE/CA Estimate," prepared March 1, 2005. Appropriate general contractor markups for overhead, profit, and bond were applied to costs extracted from this previous estimate.

D. Where applicable (e.g., excavator and telehandler), material pricing was based on information provided by procurement from previous Accelerated Retrieval Project purchases. Appropriate general contractor markups for overhead, profit, and bond were applied to costs extracted from this previous estimate.

E. Drum packaging station costs were based on the actual subcontract from the Accelerated Retrieval Project I facility. Appropriate general contractor markups for overhead, profit, and bond were applied to costs extracted from this previous estimate.

F. Sorting table costs were based on preliminary design information provided by the Accelerated Retrieval Project II. Appropriate general contractor markups for overhead, profit, and bond were applied to costs extracted from this previous estimate.

G. The TRU waste disposition cost and remote-handled waste disposal costs were based on the August 8, 2005, COBRA run for the Contact-Handled Transuranic Waste Disposition Project, minus escalation allowances. Appropriate general contractor markups for overhead, profit, and bond were applied to costs extracted from this previous estimate.

H. Non-TRU waste disposition cost (i.e., ICDF) was based on information provided by a Waste Generator Services e-mail dated December 20, 2004. Appropriate general contractor markups for overhead, profit, and bond were applied to costs extracted from this previous estimate. 
I. Submittal and implementation costs were based on costs extracted from Estimate File Number 5987, "ISG Project, FY 2005-FY 2011," dated August 3, 2004. Appropriate general contractor markups for overhead, profit, and bond were applied to costs extracted from this previous estimate.

J. Security costs were based on Estimate File Number 5432. Appropriate general contractor markups for overhead, profit, and bond were applied to costs extracted from this previous estimate.

K. Costs were developed, using the Success $\bigodot$ estimating software by U.S. Cost, to a level of detail consistent with available documents and information.

L. Airlock construction costs were based on information provided by the construction management group, using force account personnel. Appropriate general contractor markups for overhead, profit, and bond were applied to costs extracted from this previous estimate.

M. Airlock procurement costs were based on budgetary information provided by a building manufacturer of this type. Appropriate general contractor markups for overhead, profit, and bond were applied to costs extracted from this previous estimate.

N. Project scope and methodologies were prepared from discussions with the requester and project team.

O. Experiences of the Operable Unit 7-10 Glovebox Excavator Method Project (Pit 9) and the Accelerated Retrieval Projects I and II were used for the design elements associated with this cost evaluation.

P. Final inspection costs were based on the "Preliminary Evaluation of Remedial Alternatives for the Subsurface Disposal Area" (Zitnik et al. 2002).

\section{F-14.4 Assumptions}

\section{A. General assumptions}

1. If the use of sorting tables, treatment units, or an interim storage facility may be interpreted as "placement" of waste, a waiver or variance will be obtained from DEQ that will preclude imposition of RCRA land disposal restriction requirements.

2. Two modified excavators and telehandlers will be purchased for retrieval of the waste. The previously purchased Accelerated Retrieval Project I excavator will be available for use.

\section{B. Schedule}

Figure F-14 illustrates the project schedule.

\section{Mobilization and demobilization (capital costs)}

1. ICP personnel will not require move monies.

2. Equipment, mobilization, and demobilization costs are captured within the remediation section of this cost estimate. 


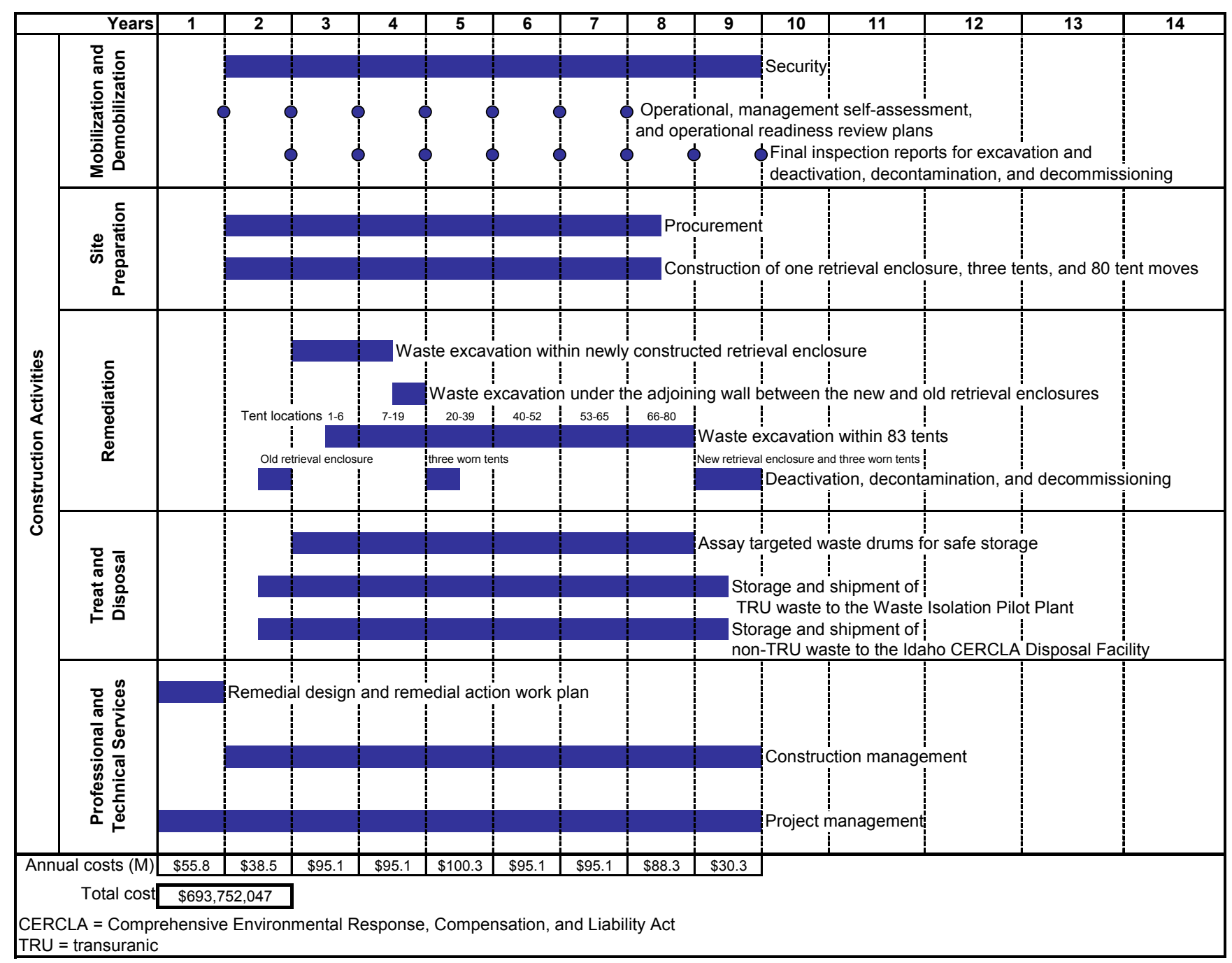

Figure F-14. Module 13 design and construction schedule for 4-acre alternative within the Subsurface Disposal Area.

\section{Site preparation (capital costs)}

1. One complete Accelerated Retrieval Project II-type retrieval enclosure required.

2. This module will require an initial three complete pullable retrieval tents as identified in the life-cycle baseline.

\section{E. Remediation (capital costs)}

1. Three replacement tents will be required halfway through retrieval. Tents will require relocation by dragging to predetermined locations for a total of 77 times. In addition, two of the three tents will require total disassembly and reassembly at distant satellite locations.

2. A specialty subcontractor will perform waste excavation. This subcontractor will be experienced with this type of work and will be selected through the bid and award process. 
3. No revegetation of the excavated area will be required.

4. Only designated trench and pit areas will be excavated (approximately 4.0 acres).

5. All nontargeted waste will be placed back in the pit areas.

6. This project will not impact the current Accelerated Retrieval Project excavation.

7. A survey of the proposed excavated area has already been performed. No allowance for surveying is included.

8. Remote-handled materials will not be encountered during this project.

9. If large objects are encountered, they will be left in the pit.

\section{F-14.5 Contingency Guideline Implementation}

Total capital cost contingency for the 4 -acre RTD is $48.85 \%$. This contingency is the average contingency of construction activities (i.e., $65 \%$ ) and professional and technical services (i.e., $0 \%$ ).

\section{F-14.6 Estimate Summary}

Table F-53 provides rough order of magnitude allocations of the methodologies used to develop the cost estimate for Module 13.

Table F-53. Rough order of magnitude allocations of the methodologies used to develop the cost estimate for Module 13.

\begin{tabular}{lc} 
Estimate Methodology & $\begin{array}{c}\text { Rough Order of Magnitude } \\
(\%)\end{array}$ \\
\hline Project team & 30 \\
Recorded actuals & 0 \\
Parametric & 20 \\
Vendor quotes & 20 \\
Other & 30 \\
Total & $\mathbf{1 0 0}$ \\
\hline
\end{tabular}

\section{F-14.7 Other Comments or Concerns Specific to the Estimate}
A. Activities have not been escalated to the activity midpoint.
B. Subcontractor labor costs reflect INL Stabilization Agreement craft labor rates.
C. $\mathrm{CH} 2 \mathrm{M}-\mathrm{WG}$ Idaho labor rates reflect fully burdened present day rates.

\section{F-14.8 Summary}

Table F-54 provides capital cost information for Module 13. 
Table F-54. Capital costs for Module 13: Operable Unit 7-13/14 Feasibility Study-4-Acre Excavation, Project Number: 5992-I.

\begin{tabular}{|c|c|c|c|c|c|}
\hline Level & Description & $\begin{array}{l}\text { Subtotals }^{\mathrm{a}} \\
(\$)\end{array}$ & $\begin{array}{l}\text { Estimate }^{\mathrm{a}} \\
(\$)\end{array}$ & $\begin{array}{l}\text { Contingency } \\
(\$)\end{array}$ & $\begin{array}{c}\text { Total }^{\mathrm{a}, \mathrm{c}} \\
(\$)\end{array}$ \\
\hline 1.1 & Construction activities & $350,286,000$ & - & - & - \\
\hline 1.1 .1 & Mobilization and demobilization & $7,792,000$ & - & - & - \\
\hline 1.1.1.2 & Submittals and implementation plans & $1,986,000$ & - & - & - \\
\hline 1.1.1.2.1 & Operational plans & - & 706,000 & 459,000 & $1,164,000$ \\
\hline 1.1.1.2.2 & Management self-assessment plan & - & 479,000 & 311,000 & 790,000 \\
\hline 1.1.1.2.3 & $\begin{array}{l}\text { Operational readiness review, plan of action, and implementation plan } \\
\text { (retrieval only) }\end{array}$ & - & 479,000 & 311,000 & 790,000 \\
\hline 1.1.1.2.4 & Final inspection report & - & 323,000 & 210,000 & 532,000 \\
\hline 1.1.1.3 & Security at construction site access gates & - & $5,806,000$ & $3,774,000$ & $9,580,000$ \\
\hline 1.1 .2 & Site preparation work & $67,813,000$ & - & - & - \\
\hline 1.1.2.1 & Procurement & $56,496,000$ & - & - & - \\
\hline 1.1.2.1.1 & Procurement (from life-cycle baseline) & $46,524,000$ & - & - & - \\
\hline 1.1.2.1.1.1 & Procurement—assay waste for storage & - & $16,854,000$ & $10,955,000$ & $27,809,000$ \\
\hline 1.1.2.1.1.2 & Procurement-ops consumables & - & $10,382,000$ & $6,748,000$ & $17,131,000$ \\
\hline 1.1.2.1.1.3 & Procurement-equipment & - & $5,262,000$ & $3,420,000$ & $8,682,000$ \\
\hline 1.1.2.1.1.4 & Procurement-movable tent structures & - & $12,423,000$ & $8,075,000$ & $20,498,000$ \\
\hline 1.1.2.1.1.5 & Procurement-procurement support & - & $1,603,000$ & $1,042,000$ & $2,645,000$ \\
\hline 1.1.2.1.2 & Procurement Accelerated Retrieval Project II & $7,913,000$ & - & - & - \\
\hline 1.1.2.1.2.1 & Procurement-Retrieval Enclosure Accelerated Retrieval Project II & - & $2,049,000$ & $1,332,000$ & $3,380,000$ \\
\hline 1.1.2.1.2.2 & Procurement—airlock structure & - & 369,000 & 240,000 & 609,000 \\
\hline 1.1.2.1.2.3 & Procurement-emissions monitoring & - & 289,000 & 188,000 & 476,000 \\
\hline 1.1.2.1.2.4 & Procurement — heating and ventilation (retrieval structure) & - & 434,000 & 282,000 & 715,000 \\
\hline 1.1.2.1.2.5 & Procurement—electrical distribution & - & 495,000 & 322,000 & 817,000 \\
\hline 1.1.2.1.2.6 & Video (closed-circuit television) & 154,000 & - & - & - \\
\hline 1.1.2.1.2.6.1 & Dig face video & - & 23,000 & 15,000 & 37,000 \\
\hline 1.1.2.1.2.6.2 & General area video & - & 131,000 & 85,000 & 217,000 \\
\hline 1.1.2.1.2.7 & Radiological and industrial hygiene equipment & 803,000 & - & - & - \\
\hline 1.1.2.1.2.7.1 & RadCon equipment & - & 789,000 & 513,000 & $1,302,000$ \\
\hline 1.1.2.1.2.7.2 & Industrial hygiene equipment & - & 14,000 & 9,000 & 22,000 \\
\hline 1.1.2.1.2.8 & Procurement - nonremote excavator (Gradall) & - & $1,123,000$ & 730,000 & $1,853,000$ \\
\hline 1.1.2.1.2.9 & Procurement-Telehandler (forklift) & - & 501,000 & 326,000 & 827,000 \\
\hline 1.1.2.1.2.10 & Procurement-foundation materials & - & 273,000 & 178,000 & 451,000 \\
\hline 1.1.2.1.2.11 & Drum packaging station stations (five each) & $1,088,000$ & - & - & - \\
\hline 1.1.2.1.2.11.1 & Drum packaging station stations (drum only) & - & 475,000 & 308,000 & 783,000 \\
\hline 1.1.2.1.2.11.2 & Drum packaging station stations (standard waste box and drum) & - & 178,000 & 116,000 & 294,000 \\
\hline 1.1.2.1.2.11.3 & Procurement for drum packaging station units & - & 436,000 & 283,000 & 719,000 \\
\hline 1.1.2.1.2.12 & Power generator & - & 48,000 & 31,000 & 80,000 \\
\hline 1.1.2.1.2.13 & Fire detection & 95,000 & - & - & - \\
\hline 1.1.2.1.2.13.1 & Fire protection—alarm systems & - & 74,000 & 48,000 & 122,000 \\
\hline 1.1.2.1.2.13.2 & Fire protection-portable equipment & - & 12,000 & 8,000 & 19,000 \\
\hline 1.1.2.1.2.13.3 & Fire protection-fixed equipment & - & 9,000 & 6,000 & 16,000 \\
\hline 1.1.2.1.2.14 & Fire protection modification-procurement & 102,000 & - & - & - \\
\hline 1.1.2.1.2.14.1 & Procurement--high sensitivity smoke detection & - & 15,000 & 10,000 & 24,000 \\
\hline 1.1.2.1.2.14.2 & Procurement- - thermal imaging cameras & - & 87,000 & 57,000 & 144,000 \\
\hline 1.1.2.1.2.15 & Support trailers (lease extension) & - & 90,000 & 59,000 & 149,000 \\
\hline 1.1.2.1.3 & Procurement- - periodic equipment replacement & $2,058,000$ & - & - & - \\
\hline 1.1.2.1.3.1 & Video (closed-circuit television) 5 years & 332,000 & - & - & - \\
\hline 1.1.2.1.3.1.1 & Dig face video ( 5 years $)$ & - & 23,000 & 15,000 & 37,000 \\
\hline 1.1.2.1.3.1.2 & General area video (5 years) & - & 310,000 & 201,000 & 511,000 \\
\hline 1.1.2.1.3.2 & Procurement- - nonremote excavator (5 years) & - & $1,123,000$ & 730,000 & $1,853,000$ \\
\hline 1.1.2.1.3.3 & Procurement-Telehandler (forklift) 5 years & - & 501,000 & 326,000 & 827,000 \\
\hline 1.1.2.1.3.4 & Fire protection modification-procurement ( 5 years) & 102,000 & - & - & - \\
\hline 1.1.2.1.3.4.1 & Procurement- - high sensitivity smoke detection (5 years) & - & 15,000 & 10,000 & 24,000 \\
\hline 1.1.2.1.3.4.2 & Procurement- - thermal imaging cameras (5 years) & - & 87,000 & 57,000 & 144,000 \\
\hline 1.1.2.2 & Facility construction & $11,318,000$ & - & - & - \\
\hline 1.1.2.2.1 & Construction (from life-cycle baseline) & $6,304,000$ & - & - & - \\
\hline 1.1.2.2.1.1 & Construction-Retrieval Enclosure 1 DD\&D & - & 406,000 & 264,000 & 671,000 \\
\hline 1.1.2.2.1.2 & Construction and relocation of tents & - & $5,142,000$ & $3,343,000$ & $8,485,000$ \\
\hline 1.1.2.2.1.3 & Mechanical and electrical for Airlock 3 & - & 755,000 & 491,000 & $1,246,000$ \\
\hline 1.1.2.2.2 & Facility construction Accelerated Retrieval Project II & $5,014,000$ & - & - & - \\
\hline 1.1.2.2.2.1 & Retrieval structure erection Accelerated Retrieval Project II & - & $1,548,000$ & $1,006,000$ & $2,554,000$ \\
\hline 1.1.2.2.2.2 & Airlock structure erection & - & 315,000 & 205,000 & 520,000 \\
\hline 1.1.2.2.2.3 & Access roadway & - & 88,000 & 57,000 & 145,000 \\
\hline 1.1.2.2.2.4 & Site drainage & - & 41,000 & 27,000 & 68,000 \\
\hline
\end{tabular}


Table F-54. (continued).

\begin{tabular}{|c|c|c|c|c|c|}
\hline Level & Description & $\begin{array}{c}\text { Subtotals }^{a} \\
(\$)\end{array}$ & $\begin{array}{c}\text { Estimate }^{\mathrm{a}} \\
(\$)\end{array}$ & $\begin{array}{c}\text { Contingency } y^{\mathrm{a}, \mathrm{b}} \\
(\$)\end{array}$ & $\begin{array}{c}\text { Total }^{\mathrm{a}, \mathrm{c}} \\
(\$)\end{array}$ \\
\hline 1.1.2.2.2.5 & Fire protection modification-Subpart K & 60,000 & - & - & - \\
\hline 1.1.2.2.2.5.1 & Construction-high sensitivity smoke detection & 19,000 & - & - & - \\
\hline 1.1.2.2.2.5.1.1 & Electrical & 19,000 & - & - & - \\
\hline 1.1.2.2.2.5.1.1.1 & Electrical-general conditions & - & 3,000 & 2,000 & 4,000 \\
\hline 1.1.2.2.2.5.1.1.2 & Electrical—sample tubes, raceways, and enclosures & - & 11,000 & 7,000 & 18,000 \\
\hline $1 \cdot 1 \cdot 2 \cdot 2 \cdot 2 \cdot 5 \cdot 1 \cdot 1 \cdot 3$ & Electrical—power and electronic panels & - & 3,000 & 2,000 & 5,000 \\
\hline 1.1.2.2.2.5.1.1.4 & Electrical—conductors and grounding & - & 1,000 & 1,000 & 2,000 \\
\hline $1.1 \cdot 2 \cdot 2 \cdot 2 \cdot 5 \cdot 1 \cdot 1.5$ & Electrical—testing & - & 1,000 & 1,000 & 2,000 \\
\hline 1.1.2.2.2.5.2 & Construction-thermal imaging cameras & 10,000 & - & - & - \\
\hline 1.1.2.2.2.5.2.1 & Electrical & 10,000 & - & - & - \\
\hline 1.1.2.2.2.5.2.1.1 & Electrical—general conditions & - & 3,000 & 2,000 & 4,000 \\
\hline 1.1.2.2.2.5.2.1.2 & Electrical—camera assembly & - & 1,000 & 1,000 & 2,000 \\
\hline $1.1 \cdot 2 \cdot 2 \cdot 2 \cdot 5 \cdot 2 \cdot 1 \cdot 3$ & Electrical-power, enclosures, and conductors & - & 6,000 & 4,000 & 9,000 \\
\hline 1.1.2.2.2.5.2.1.4 & Electrical-testing & - & 0 & 0 & 1,000 \\
\hline $1.1 \cdot 2 \cdot 2 \cdot 2 \cdot 5 \cdot 3$ & Field design change fire protection & 31,000 & - & - & - \\
\hline 1.1.2.2.2.5.3.1 & Electrical & 31,000 & - & - & - \\
\hline 1.1.2.2.2.5.3.1.1 & Fire protection—one raceways, enclosures & - & 25,000 & 16,000 & 42,000 \\
\hline 1.1.2.2.2.5.3.1.2 & Fire protection—one conductors & - & 5,000 & 3,000 & 9,000 \\
\hline 1.1.2.2.2.5.2.1.3 & Fire protection-one testing & - & 0 & 0 & 1,000 \\
\hline 1.1.2.2.2.6 & Retrieval enclosure mechanical & - & 755,000 & 490,000 & $1,245,000$ \\
\hline 1.1.2.2.2.7 & Retrieval enclosure electrical & - & 714,000 & 464,000 & $1,178,000$ \\
\hline 1.1.2.2.2.8 & Cargo container RadCon and equipment support & - & 738,000 & 480,000 & $1,218,000$ \\
\hline 1.1.2.2.2.9 & Electrical distribution & - & 754,000 & 490,000 & $1,245,000$ \\
\hline 1.1.3 & Remediation & $179,389,000$ & - & - & - \\
\hline 1.1.3.1 & Facility operations (from life-cycle baseline) & $166,947,000$ & - & - & - \\
\hline 1.1.3.1.1 & Facility maintenance & - & $8,311,000$ & $5,402,000$ & $13,714,000$ \\
\hline 1.1.3.1.2 & Operations management & - & $12,841,000$ & $8,347,000$ & $21,188,000$ \\
\hline 1.1.3.1.3 & Waste packaging & - & $77,181,000$ & $50,168,000$ & $127,349,000$ \\
\hline 1.1.3.1.4 & Retrieval Enclosure 1 DD\&D preparation & - & $1,245,000$ & 809,000 & $2,054,000$ \\
\hline 1.1.3.1.5 & Relocation of tents & - & $1,093,000$ & 710,000 & $1,803,000$ \\
\hline 1.1.3.1.6 & Waste retrieval operations & - & $62,292,000$ & $40,490,000$ & $102,781,000$ \\
\hline 1.1.3.1.7 & Waste sampling & - & $2,580,000$ & $1,677,000$ & $4,257,000$ \\
\hline 1.1 .3 .1 .8 & Operations training & - & $1,403,000$ & 912,000 & $2,315,000$ \\
\hline 1.1.3.2 & Demolition and removal & - & $12,442,000$ & $8,087,000$ & $20,529,000$ \\
\hline 1.1.4 & Treatment and disposal & $95,292,000$ & - & - & - \\
\hline 1.1.4.1 & On-INL Site treatment/disposal & $1,530,000$ & - & - & - \\
\hline 1.1.4.1.1 & Non-TRU waste disposition & - & $1,530,000$ & 994,000 & $2,524,000$ \\
\hline 1.1.4.2 & Off-INL Site treatment/disposal & $93,762,000$ & - & - & - \\
\hline 1.1.4.2.1 & TRU waste disposition & - & $93,762,000$ & $60,945,000$ & $154,708,000$ \\
\hline 1.2 & Professional and technical services & $115,780,000$ & - & - & - \\
\hline 1.2 .1 & Project management & - & $28,899,000$ & - & $28,899,000$ \\
\hline 1.2 .2 & Remedial design and remedial action work plan & $52,203,000$ & - & - & - \\
\hline 1.2.2.1 & Remedial design & - & $37,288,000$ & - & $37,288,000$ \\
\hline 1.2 .2 .2 & Remedial action work plan & - & $14,915,000$ & - & $14,915,000$ \\
\hline \multirow[t]{3}{*}{1.2 .3} & Construction management & - & $34,678,000$ & - & $34,678,000$ \\
\hline & Total capital $\operatorname{cost}^{\mathrm{c}}$ & - & $466,066,000$ & $227,686,000$ & $693,752,000$ \\
\hline & \multicolumn{5}{|c|}{$\begin{array}{l}\text { a. Values are rounded to the nearest } \$ 1,000 . \\
\text { b. Capital cost contingency is } 48.9 \% \text { of the estimate. } \\
\text { c. Totals were derived for the summation of nonrounded subcomponent values. Therefore, totals are not equal to the summation of the rounded subcomponent values shown above. See } \\
\text { Table } \mathrm{F}-3 \text { for nonrounded totals. } \\
\text { DD\&D = deactivation, decontamination, and disposal } \\
\text { INL = Idaho National Laboratory } \\
\text { TRU = transuranic }\end{array}$} \\
\hline
\end{tabular}




\section{F-15. MODULE 14: FULL SUBSURFACE DISPOSAL AREA EXCAVATION}

\section{F-15.1 Purpose}

This estimate will be used as a cost-comparative tool to examine different options regarding the SDA.

\section{F-15.2 Scope of Work}

The scope of work consists of engineering, procuring, constructing, and operating a facility that will excavate and package all buried waste in the SDA at RWMC.

Subcontractor mobilization consists of the following:

- $\quad$ Generate operational plans (see Section F-15.4 for details)

- Generate a management self-assessment plan

- Generate an operational readiness review plan of action and an operational readiness review implementation plan

- $\quad$ Mobilize equipment (costs captured in Section F-15.4).

Subcontractor demobilization consists of the following:

- $\quad$ Shut down or demobilize equipment

- Generate a final inspection report following completion of retrieval within each retrieval enclosure.

Subcontractor site preparation consists of the following:

- $\quad$ Construct one Accelerated Retrieval Project II-style retrieval enclosure that is $51.8 \times 73.2 \mathrm{~m}$ $(170 \times 240 \mathrm{ft})$

- $\quad$ One airlock, each contains drum packaging systems

- $\quad$ One airlock-type system, using cargo containers for radiological control, maintenance equipment, and personnel entry services

- One nonremote excavator

- $\quad$ One nonremote telehandler

- $\quad$ Emissions monitoring systems

- Heating, ventilation, and filtration systems

- $\quad$ Electrical and controls systems

- Video equipment systems

- $\quad$ Radiological equipment

- $\quad$ Fire detection systems

- Drum packaging stations

- $\quad$ Sorting tables. 
- $\quad$ Construct six retrieval tents $30.5 \times 33.5 \mathrm{~m}(100 \times 110 \mathrm{ft})$

- Cargo containers attachments for waste trays, radiological control equipment, and maintenance equipment

- $\quad$ One nonremote excavator per six tents

- $\quad$ One nonremote telehandler per six tents

- $\quad$ Emissions monitoring systems

- Heating, ventilation, and filtration systems

- $\quad$ Electrical and controls systems

- Radiological equipment.

- $\quad$ Construct one lag storage facility to house waste that will eventually be sent to ICDF or EnergySolutions, LLC (previously Envirocare), or equivalent

- $\quad$ Construct one remote-handled waste storage facility to house remote-handled waste for 20 years.

Subcontractor remediation consists of the following:

- Remove clean overburden

- Construct retrieval enclosures over the excavation areas

- Excavate waste materials beneath the retrieval enclosure and transfer that material to sorting tables

- Excavate high radiological items

- $\quad$ Excavate large objects

- Transfer (within the attached cargo container) waste from smaller retrieval tents to the larger Accelerated Retrieval Projects I and II combined Retrieval Enclosure

- $\quad$ Perform random sampling of excavated waste at the dig face

- Visually examine to satisfy ICDF waste acceptance criteria and package (e.g., 55-gal drum) waste in drum packaging stations attached to the Retrieval Enclosure

- $\quad$ Size and package large item waste

- $\quad$ Temporarily store TRU waste drums (packaged out of the drum packaging stations) until they are processed for shipment to the WIPP

- $\quad$ Temporarily store non-TRU waste drums (packaged out of the drum packaging station) until they are processed for shipment to ICDF

- $\quad$ Store remote-handled waste

- $\quad$ Ship non-TRU waste drums to ICDF for treatment and disposal

- $\quad$ Ship non-TRU waste drums to EnergySolutions, or equivalent, for treatment and disposal

- $\quad$ Prepare TRU waste drums for shipment to the WIPP by:

- $\quad$ Assaying waste drums

- $\quad$ Performing headspace gas sampling on TRU and load-managed drums 
- $\quad$ Performing gas-generation testing on drums that exceed the allowable headspace gas sampling thermal wattage limit or drums that contain test category waste

- $\quad$ Performing limited VOCs treatment of drums that failed gas-generation testing.

- $\quad$ Containerize (i.e., TRU package containers) TRU drums for shipment to the WIPP

- $\quad$ Dismantle Retrieval Enclosure and restart retrieval process over a new retrieval area

- If a new retrieval area is directly adjacent to an existing enclosure, ensure the two enclosures are joined end-to-end and the adjoining wall is removed to enable excavation beneath the wall

- Following full retrieval of the SDA, ensure the six retrieval enclosures will be deactivated, decontaminated, and decommissioned and disposed of at a facility outside the SDA

- $\quad$ Store remote-handled waste for 20 years

- $\quad$ After 20 years, ship remote-handled waste to an acceptable federal facility.

\section{F-15.3 Basis of the Estimate}

The following sequential process, rationale, and estimating methodologies were used to define activities, quantities, and resources that were used in preparation of this cost estimate.

A. Waste retrievals were based on cost information provided by the Planning and Integration Project team and the life-cycle baseline for the Targeted Waste Removal and Disposition Project. Appropriate general contractor markups for overhead, profit, and bond were applied to costs extracted from this previous estimate.

B. Procurement and construction of tents and retrieval equipment were based on costs information provided by the Project Planning and Integration Project team and the life-cycle baseline for the Targeted Waste Removal and Disposition Project. Appropriate general contractor markups for overhead, profit, and bond were applied to costs extracted from this previous estimate.

C. Procurement and construction of the Accelerated Retrieval Project II Retrieval Enclosure, enclosure support equipment (not including excavator, telehandler, drum packaging stations, and sorting tables), and ICDF treatment and disposal cost elements were based on Estimate File Number 5989-D, “ARP-2 EE/CA Estimate,” prepared March 1, 2005. Appropriate general contractor markups for overhead, profit, and bond were applied to costs extracted from this previous estimate.

D. Where applicable (e.g., excavator and telehandler), material pricing was based on information provided by procurement from previous Accelerated Retrieval Project purchases. Appropriate general contractor markups for overhead, profit, and bond were applied to costs extracted from this previous estimate.

E. Drum packaging station costs were based on the actual subcontract from the Accelerated Retrieval Project I facility. Appropriate general contractor markups for overhead, profit, and bond were applied to costs extracted from this previous estimate.

F. Sorting table costs were based on preliminary design information provided by the Accelerated Retrieval Project II. Appropriate general contractor markups for overhead, profit, and bond were applied to costs extracted from this previous estimate. 
G. Transuranic waste disposition cost and remote-handled waste disposal costs were based on the August 8, 2005, COBRA run for the Contact-Handled Transuranic Waste Disposition Project, minus escalation allowances. Appropriate general contractor markups for overhead, profit, and bond were applied to costs extracted from this previous estimate.

H. Non-TRU waste disposition cost (i.e., the ICDF) was based on information provided by a Waste Generator Services e-mail dated December 20, 2004. Appropriate general contractor markups for overhead, profit, and bond were applied to costs extracted from this previous estimate.

I. Submittal and implementation costs were based on costs extracted from Estimate File Number 5987, "ISG Project FY 2005-FY 2011," dated August 3, 2004. Appropriate general contractor markups for overhead, profit, and bond were applied to costs extracted from this previous estimate.

J. Security costs were based on Estimate File Number 5432. Appropriate general contractor markups for overhead, profit, and bond were applied to costs extracted from this previous estimate.

K. Costs were developed, using the Success $@$ estimating software by U.S. Cost, to a level of detail consistent with available documents and information.

L. Airlock construction costs were based on information provided by the construction management group, using force account personnel. Appropriate general contractor markups for overhead, profit, and bond were applied to costs extracted from this previous estimate.

M. Airlock procurement costs were based on budgetary information provided by a building manufacturer of this type. Appropriate general contractor markups for overhead, profit, and bond were applied to costs extracted from this previous estimate.

N. Project scope and methodologies were prepared from discussions with the requester and project team.

O. Experiences of the Operable Unit 7-10 Glovebox Excavator Method Project (Pit 9) and the Accelerated Retrieval Projects I and II were used for the design elements associated with this cost estimate.

P. The final inspection costs were based on the "Preliminary Evaluation of Remedial Alternatives for the Subsurface Disposal Area" (Zitnik et al. 2002).

Q. Lag storage building costs for non-TRU waste were based on Estimate File Number 5984-Y. Appropriate general contractor markups for overhead, profit, and bond were applied to costs extracted from this previous estimate.

R. Cost allowance for the remote-handled storage building were based on Estimate File Number 2593-B "HLW-SBW Direct Vitrification Interim Storage Facility-SBW and Two Vaults." Appropriate general contractor markups for overhead, profit, and bond were applied to costs extracted from this previous estimate.

S. Costs for off-INL Site treatment and disposal of non-TRU waste were based on information provided by EnergySolutions (Envirocare) Contract No. 500051. Appropriate general contractor markups for overhead, profit, and bond were applied to costs extracted from this previous estimate. 


\section{F-15.4 Assumptions}

\section{A. General assumptions}

If the use of sorting tables, treatment units, or an interim storage facility may be interpreted as "placement" of waste, a waiver or variance will be obtained from DEQ that will preclude imposition of RCRA land disposal restriction requirements.

\section{B. Schedule}

1. Figure F-15 illustrates the project schedule.

2. Remote-handled waste storage begins at the start of waste retrieval.

\section{Mobilization and demobilization (capital costs)}

1. ICP personnel will not require move monies.

2. Equipment, mobilization, and demobilization costs are captured within the remediation section of this cost estimate.

\section{Site preparation (capital costs)}

1. This module requires one complete Accelerated Retrieval Project II-type retrieval enclosure.

2. This module will require an initial six complete pullable retrieval tents as identified in the life-cycle baseline.

3. Transuranic waste lag storage will use an existing SDA building.

4. A new lag storage facility that houses non-TRU waste will be required. The cost for this facility is based on the Accelerated Retrieval Project I storage facility.

5. A new lag storage facility that houses remote-handled waste for 20 years will be required. The costs for this facility were scaled off a previous remote-handled storage facility estimate. 
F-152 


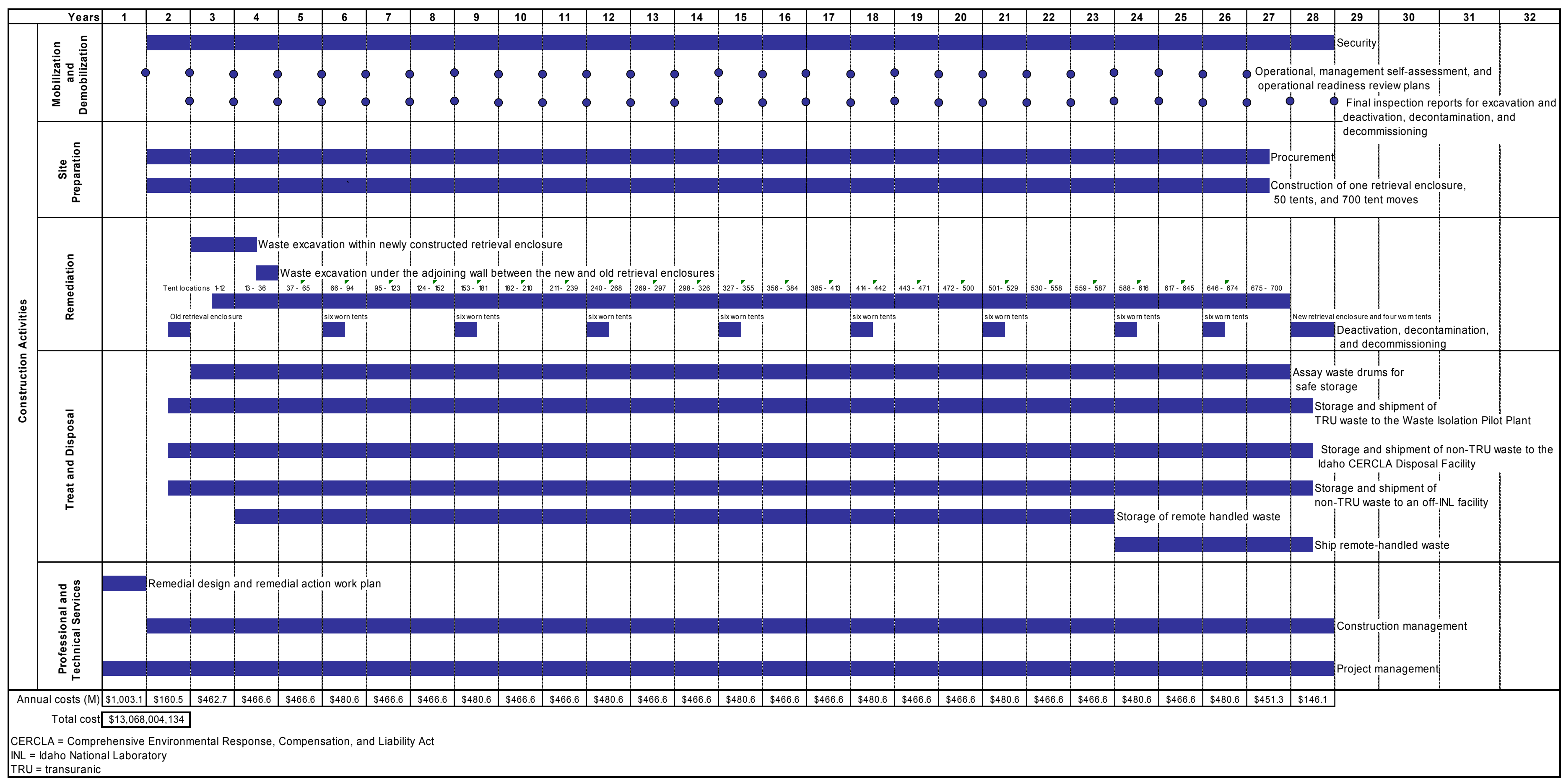

Figure F-15. Module 14 design and construction schedule for retrieval of the entire Subsurface Disposal Area. 



\section{E. Remediation (capital costs)}

1. Two modified excavators and telehandlers will be purchased for retrieval of the waste. The previously purchased Accelerated Retrieval Project I excavator will be available for use.

2. Forty-three replacement tents will be required at intervals throughout retrieval. These tents will require relocation by dragging to predetermined locations for a total of 693 times. In addition, four of the six tents will require total disassembly and reassembly at distant satellite locations.

3. Remote-handled waste will be stored in a new remote-handled storage facility, pending development of a national facility that will be capable of accepting the waste. At the end of the 20 -year period, the remote-handled waste will be shipped to the national facility.

4. Remote-handled shipment preparation costs are equal to WIPP shipment preparation costs.

5. A specialty subcontractor will perform waste excavation. This subcontractor will be experienced with this type of work and will be selected through the bid and award process.

6. No revegetation of the excavated area will be required.

7. Only designated trench and pit areas will be excavated (approximately 64.8 acres).

8. This project will not impact the current Accelerated Retrieval Project excavation activities.

9. A survey of the proposed excavated area has already been performed. No allowance for surveying is included.

10. Removal of remote-handled waste and removal of large objects from the SDA pits and trenches will require specialized equipment and processes. Costs associated with (1) remote removal, (2) sizing, and (3) design are accounted for within the bid and scope contingencies in Section F-15.5.

11. Operations costs for retrieving high-radiation items are developed from the Intermediate-Level Transuranic Storage Facility project. The Intermediate-Level Transuranic Storage Facility total project costs per cubic foot will be increased by $25 \%$ to account for loose waste excavation versus pulling intact drums from a belowgrade vault (Intermediate-Level Transuranic Storage Facility method). This ratio is then multiplied by the total cubic feet of high radiological waste within the total SDA.

12. Costs per cubic foot for retrieving large objects are derived by dividing the life-cycle baseline waste retrieval operations costs by the cubic feet of waste excavated (i.e., 64.8 acre at $3.7-\mathrm{m}[12-\mathrm{ft}]$ depth). This ratio is then multiplied by the total cubic feet of "large objects and debris" (assumed 10\% of 64.8 acres $\times 3.7-\mathrm{m}$ depth) within the total SDA area.

\section{F-15.5 Contingency Guideline Implementation}

Total capital cost contingency for full SDA RTD is $55.53 \%$. This contingency is the average contingency of construction activities (i.e., 75\%) and professional and technical services (i.e., $0 \%$ ). 


\section{F-15.6 Estimate Summary}

Table F-55 provides rough order of magnitude allocations of the methodologies used to develop the cost estimate for Module 14.

Table F-55. Rough order of magnitude allocations of the methodologies used to develop the cost estimate for Module 14.

\begin{tabular}{lc} 
Estimate Methodology & $\begin{array}{c}\text { Rough Order of Magnitude } \\
(\%)\end{array}$ \\
\hline Project team & 30 \\
Recorded actuals & 0 \\
Parametric & 20 \\
Vendor quotes & 20 \\
Other & 30 \\
Total & $\mathbf{1 0 0}$ \\
\hline
\end{tabular}

\section{F-15.7 Other Comments or Concerns Specific to the Estimate}
A. Activities have not been escalated to the activity midpoint.
B. Subcontractor labor costs reflect INL Site Stabilization Agreement craft labor rates.
C. CH2M-WG Idaho labor rates reflect fully burdened present day rates.

\section{F-15.8 Summary}

Table F-56 provides capital cost information for Module 14. 
Table F-56. Capital costs for Module 14: Operable Unit 7-13/14 Feasibility Study-Full Excavation, Project Number: 5992-J.

\begin{tabular}{|c|c|c|c|c|c|}
\hline Level & Description & $\begin{array}{c}\text { Subtotals }^{\mathrm{a}} \\
(\$)\end{array}$ & $\begin{array}{c}\text { Estimate }^{\mathrm{a}} \\
(\$)\end{array}$ & $\begin{array}{c}\text { Contingency } y^{\mathrm{a}, \mathrm{b}} \\
(\$)\end{array}$ & $\begin{array}{c}\text { Total }^{\mathrm{a}, \mathrm{c}} \\
(\$)\end{array}$ \\
\hline 1.1 & Construction activities & $6,221,195,000$ & - & - & - \\
\hline 1.1 .1 & Mobilization and demobilization & $23,289,000$ & - & - & - \\
\hline 1.1.1.2 & Submittals and implementation plans & $5,225,000$ & - & - & - \\
\hline 1.1.1.2.1 & Operational plans & - & $1,923,000$ & $1,442,000$ & $3,366,000$ \\
\hline 1.1.1.2.2 & Management self-assessment plan & - & $1,490,000$ & $1,117,000$ & $2,607,000$ \\
\hline 1.1.1.2.3 & $\begin{array}{l}\text { Operational readiness review, plan of action, and } \\
\text { implementation plan (retrieval only) }\end{array}$ & - & $1,490,000$ & $1,117,000$ & $2,607,000$ \\
\hline 1.1.1.2.4 & Final inspection report & - & 323,000 & 242,000 & 565,000 \\
\hline 1.1.1.3 & Security at construction site access gates & - & $18,064,000$ & $13,548,000$ & $31,612,000$ \\
\hline 1.1 .2 & Site preparation work & $572,843,000$ & - & - & - \\
\hline 1.1.2.1 & Procurement & $448,682,000$ & - & - & - \\
\hline 1.1.2.1.1 & Procurement (from life-cycle baseline) & $427,109,000$ & - & - & - \\
\hline 1.1.2.1.1.1 & Procurement-assay waste for storage & - & $134,831,000$ & $101,124,000$ & $235,955,000$ \\
\hline 1.1.2.1.1.2 & Procurement- ops consumables & - & $139,195,000$ & $104,396,000$ & $243,592,000$ \\
\hline 1.1.2.1.1.3 & Procurement-equipment & - & $8,628,000$ & $6,471,000$ & $15,100,000$ \\
\hline 1.1.2.1.1.4 & Procurement- - movable tent structures & - & $118,484,000$ & $88,863,000$ & $207,347,000$ \\
\hline 1.1.2.1.1.5 & Procurement-procurement support & - & $25,970,000$ & $19,477,000$ & $45,447,000$ \\
\hline 1.1.2.1.2 & Procurement (from Accelerated Retrieval Project II) & $7,913,000$ & - & - & - \\
\hline 1.1.2.1.2.1 & $\begin{array}{l}\text { Procurement—retrieval structure Accelerated Retrieval } \\
\text { Project II }\end{array}$ & - & $2,049,000$ & $1,537,000$ & $3,585,000$ \\
\hline 1.1.2.1.2.2 & Procurement—airlock structure & - & 369,000 & 277,000 & 646,000 \\
\hline 1.1.2.1.2.3 & Procurement-emissions monitoring & - & 289,000 & 216,000 & 505,000 \\
\hline 1.1.2.1.2.4 & Procurement - heating and ventilation (retrieval structure) & - & 434,000 & 325,000 & 759,000 \\
\hline 1.1 .2 .1 .2 .5 & Procurement-electrical distribution & - & 495,000 & 371,000 & 866,000 \\
\hline 1.1.2.1.2.6 & Video (closed-circuit television) & 154,000 & - & - & - \\
\hline 1.1.2.1.2.6.1 & Dig face video & - & 23,000 & 17,000 & 39,000 \\
\hline 1.1.2.1.2.6.2 & General area video & - & 131,000 & 99,000 & 230,000 \\
\hline 1.1.2.1.2.7 & Radiological and industrial hygiene equipment & 803,000 & - & - & - \\
\hline 1.1.2.1.2.7.1 & Radiological control equipment & - & 789,000 & 592,000 & $1,381,000$ \\
\hline 1.1.2.1.2.7.2 & Industrial hygiene equipment & - & 14,000 & 10,000 & 24,000 \\
\hline 1.1.2.1.2.8 & Procurement-nonremote excavator (Gradall) & - & $1,123,000$ & 842,000 & $1,966,000$ \\
\hline 1.1.2.1.2.9 & Procurement-Telehandler (forklift) & - & 501,000 & 376,000 & 877,000 \\
\hline 1.1 .2 .1 .2 .10 & Procurement-foundation materials & - & 273,000 & 205,000 & 478,000 \\
\hline 1.1.2.1.2.11 & Drum packaging stations (five each) & $1,088,000$ & - & - & - \\
\hline 1.1.2.1.2.11.1 & Drum packaging stations (drum only) & - & 475,000 & 356,000 & 831,000 \\
\hline 1.1.2.1.2.11.2 & $\begin{array}{l}\text { Drum packaging stations (standard waste box and } \\
\text { drum) }\end{array}$ & - & 178,000 & 133,000 & 311,000 \\
\hline 1.1.2.1.2.11.3 & Procurement for drum packaging station units & - & 436,000 & 327,000 & 763,000 \\
\hline 1.1.2.1.2.12 & Power generator & - & 48,000 & 36,000 & 85,000 \\
\hline 1.1.2.1.2.13 & Fire detection & 95,000 & - & - & - \\
\hline 1.1.2.1.2.13.1 & Fire protection—alarm systems & - & 74,000 & 55,000 & 129,000 \\
\hline 1.1 .2 .1 .2 .13 .2 & Fire protection-portable equipment & - & 12,000 & 9,000 & 20,000 \\
\hline 1.1 .2 .1 .2 .13 .3 & Fire protection-fixed equipment & - & 9,000 & 7,000 & 17,000 \\
\hline 1.1.2.1.2.14 & Fire protection modification-procurement & 102,000 & - & - & - \\
\hline 1.1.2.1.2.14.1 & Procurement--high-sensitivity smoke detection & - & 15,000 & 11,000 & 26,000 \\
\hline 1.1 .2 .1 .2 .14 .2 & Procurement- - thermal imaging cameras & - & 87,000 & 65,000 & 152,000 \\
\hline 1.1.2.1.2.15 & Support trailers (lease extension) & - & 90,000 & 68,000 & 158,000 \\
\hline 1.1.2.1.3 & Procurement-periodic equipment replacement & $13,661,000$ & - & - & - \\
\hline 1.1.2.1.3.1 & Procurement-emissions monitoring (15 years) & - & 289,000 & 216,000 & 505,000 \\
\hline 1.1.2.1.3.2 & Video (closed-circuit television) 5 years & 769,000 & - & - & - \\
\hline 1.1.2.1.3.2.1 & Dig face video ( 5 years $)$ & - & 113,000 & 84,000 & 197,000 \\
\hline 1.1.2.1.3.2.2 & General area video (5 years) & - & 657,000 & 493,000 & $1,149,000$ \\
\hline 1.1.2.1.3.3 & Radiological and industrial hygiene equipment (10 years) & $1,605,000$ & - & - & - \\
\hline 1.1 .2 .1 .3 .3 .1 & Radiological control equipment ( 10 years) & - & $1,578,000$ & $1,184,000$ & $2,762,000$ \\
\hline $1.1 .2 .1 \cdot 3.3 .2$ & Industrial hygiene equipment (10 years) & - & 27,000 & 20,000 & 47,000 \\
\hline 1.1.2.1.3.4 & Procurement- - nonremote excavator (5 years) & - & $5,616,000$ & $4,212,000$ & $9,829,000$ \\
\hline 1.1.2.1.3.5 & Procurement-telehandler (forklift) 5 years & - & $2,506,000$ & $1,880,000$ & $4,386,000$ \\
\hline 1.1.2.1.3.6 & Five drum packaging stations (10 years) & $2,177,000$ & - & - & - \\
\hline 1.1.2.1.3.6.1 & Drum packaging stations (drum only) 10 years & - & 949,000 & 712,000 & $1,661,000$ \\
\hline 1.1.2.1.3.6.2 & $\begin{array}{l}\text { Drum packaging stations (standard waste box and drum) } \\
10 \text { years }\end{array}$ & - & 356,000 & 267,000 & 623,000 \\
\hline 1.1.2.1.3.6.3 & Procurement for drum packaging station units (10 years) & - & 872,000 & 654,000 & $1,525,000$ \\
\hline 1.1.2.1.3.7 & Fire detection (10 years) & 190,000 & - & - & - \\
\hline 1.1.2.1.3.7.1 & Fire protection-alarm systems (10 years) & - & 148,000 & 111,000 & 258,000 \\
\hline 1.1.2.1.3.7.2 & Fire protection-portable equipment ( 10 years) & - & 23,000 & 17,000 & 41,000 \\
\hline 1.1.2.1.3.7.3 & Fire protection-fixed equipment (10 years) & - & 19,000 & 14,000 & 33,000 \\
\hline 1.1.2.1.3.8 & Fire protection modification-procurement (5 years) & 508,000 & - & - & - \\
\hline 1.1.2.1.3.8.1 & Procurement-high-sensitivity smoke detection (5 year) & - & 73,000 & 55,000 & 128,000 \\
\hline 1.1.2.1.3.8.2 & Procurement - - thermal imaging cameras (5 years) & - & 435,000 & 326,000 & 761,000 \\
\hline 1.1.2.2 & Facility construction & $124,161,000$ & - & - & - \\
\hline 1.1 .2 .2 .1 & Construction (from life-cycle baseline) & $35,411,000$ & - & - & - \\
\hline 1.1.2.2.1.1 & Construction-Retrieval Enclosure 1 DD\&D & - & 406,000 & 305,000 & 711,000 \\
\hline 1.1.2.2.1.2 & Construction and relocation of tents & - & $34,250,000$ & $25,687,000$ & $59,937,000$ \\
\hline 1.1.2.2.1.3 & Mechanical and electrical for Airlock 3 & - & 755,000 & 566,000 & $1,322,000$ \\
\hline 1.1.2.2.2 & Facility construction (from Accelerated Retrieval Project II) & $5,014,000$ & - & - & - \\
\hline 1.1.2.2.2.1 & $\begin{array}{l}\text { Retrieval structure erection Accelerated Retrieval } \\
\text { Project II }\end{array}$ & - & $1,548,000$ & $1,161,000$ & $2,709,000$ \\
\hline 1.1.2.2.2.2 & Airlock structure erection & - & 315,000 & 236,000 & 552,000 \\
\hline 1.1.2.2.2.3 & Access roadway & - & 88,000 & 66,000 & 154,000 \\
\hline 1.1.2.2.2.4 & Site drainage & - & 41,000 & 31,000 & 72,000 \\
\hline
\end{tabular}




\section{F-16. MODULE 15: PAD A REMOVAL WITHOUT TREATMENT AND SHIPPED TO THE LOW-LEVEL WASTE PIT \\ F-16.1 Purpose}

SDA.

This estimate will be used as a cost-comparative tool to examine different options regarding the

\section{F-16.2 Scope of Work}

The scope of work consists of engineering, procuring, constructing, and operating a facility that will excavate and package buried waste in the Pad A area. The packaged waste is then stored at the lag storage facility in the SDA. The waste will then be transferred to the LLW Pit for direct disposal.

Subcontractor mobilization consists of the following:

- $\quad$ Generate operational plans (see Section F-16.4 for details)

- Generate a management self-assessment plan

- $\quad$ Mobilize equipment.

Subcontractor demobilization consists of the following:

- $\quad$ Shut down or demobilize equipment

- Generate a final inspection report following completion of retrieval.

Subcontractor site preparation consists of the following:

- Contour the Pad A berm before construction of the retrieval enclosure.

- $\quad$ Construct one Accelerated Retrieval Project II-style retrieval enclosure that is $51.8 \times 109.7 \mathrm{~m}$ $(170 \times 360 \mathrm{ft})$

- One transfer airlock for the transfer of waste from inside to outside the facility for disposal at the LLW Pit

- $\quad$ One nonremote excavator or loader

- $\quad$ One nonremote all terrain forklift

- $\quad$ Emissions monitoring systems

- $\quad$ Heating, ventilation, and filtration systems

- $\quad$ Electrical and controls systems

- $\quad$ Radiological equipment

- $\quad$ Fire detection systems.

- $\quad$ Construct one lag storage facility to house waste that will eventually be sent to the LLW Pit. 
Subcontractor remediation consists of the following:

- $\quad$ The remaining clean, contoured overburden will be removed from the building during the retrieval process and will be spread over the SDA.

- $\quad$ Working from the side of the waste mound, an excavator or loader will place loose waste in liners and intact waste (including sections of the asphalt pad) in wooden waste boxes.

- $\quad$ All waste lift liners and wooden boxes will be transferred to a temporary storage facility.

- $\quad$ Stored waste will be transferred to the LLW Pit for direct burial.

\section{F-16.3 Basis of the Estimate}

The following sequential process, rationale, and estimating methodologies were used to define activities, quantities, and resources that were used in preparation of this cost estimate.

A. Procurement and construction of the Accelerated Retrieval Project II Retrieval Enclosure and enclosure support equipment cost elements were based on Estimate File Number 5989-D, “ARP-2 EE/CA Estimate," prepared March 1, 2005.

B. Electrical systems for the storage building were based on Estimate File Number 5991, "T-RAD Project," August 1, 2005.

C. Waste removal support personnel effort was based on a typical crew derived from the Accelerated Retrieval Project I, modified for the retrieval operation of Module 15.

D. Submittal and implementation costs were based on costs extracted from Estimate File Number 5987, "ISG Project FY 2005-FY 2011," dated August 3, 2004.

E. Security costs were based on life-cycle baseline File Number 5432.

F. The R. S. Means and Richardson Estimating Manuals were used during the development of this estimate.

G. Estimates were developed, using Success $\bigodot$ estimating software by U.S. Cost, to a level of detail consistent with available documents and information.

H. Transfer airlock construction costs were based on information provided by the construction management group, using force account personnel.

I. Transfer airlock procurement costs were based on budgetary information provided by a building manufacturer of this type.

J. Project scope and methodologies were prepared from discussions with the requester and project team.

K. Experiences of the Operable Unit 7-10 Glovebox Excavator Method Project (Pit 9) and the Accelerated Retrieval Projects I and II were used for the design elements associated with this cost estimate.

L. Final inspection costs were based on the "Preliminary Evaluation of Remedial Alternatives for the Subsurface Disposal Area" (Zitnik et al. 2002). 
M. Where applicable (e.g., excavator and telehandler forklift), material pricing was based on information provided by the procurement from previous Accelerated Retrieval Project purchases. The appropriate general contractor markups for overhead, profit, and bond were applied to the costs extracted from this previous estimate

\section{F-16.4 Assumptions}

\section{A. General assumptions}

1. No additional costs will be incurred for all waste being buried in the LLW Pit, with the exception of transferring waste to the pit.

2. A representative from Waste Generator Services will determine, based on characterization data, that the waste will not require treatment before shipment to the LLW Pit.

3. A waiver to the 2005 INL waste acceptance criteria will be obtained to allow Pad A CERCLA (42 USC $\S 9601$ et seq., 1980) waste disposal within the SDA.

4. Sampling and characterization will not be required for disposal within the SDA.

5. Pad A waste is alpha low-level, non-TRU waste.

\section{B. Schedule}

Figure F-16 illustrates the project schedule.

\section{Mobilization and demobilization (capital costs)}

1. Administrative and equipment buildings or trailers will be installed in the SDA to support operational controls, radiation controls, and personnel facilities.

2. ICP personnel will have access to existing RWMC buildings that can be used as temporary offices during this work.

\section{Site preparation (capital costs)}

This module requires one complete Accelerated Retrieval Project I-type retrieval enclosure.

\section{E. Remediation (capital costs)}

1. A specialty subcontractor will perform waste excavation. This subcontractor will be experienced with this type of work and will be selected through the bid and award process.

2. No revegetation of the excavated area will be required.

3. Only the designated Pad A area will be excavated.

4. A survey of the proposed excavated area has already been performed. No allowance for surveying is included.

5. Remote-handled materials will not be encountered during this project.

6. Boxes and liners will not be reused.

7. Pad A waste will not be segregated based on waste type (e.g., roster oxide and nitrate salt). 


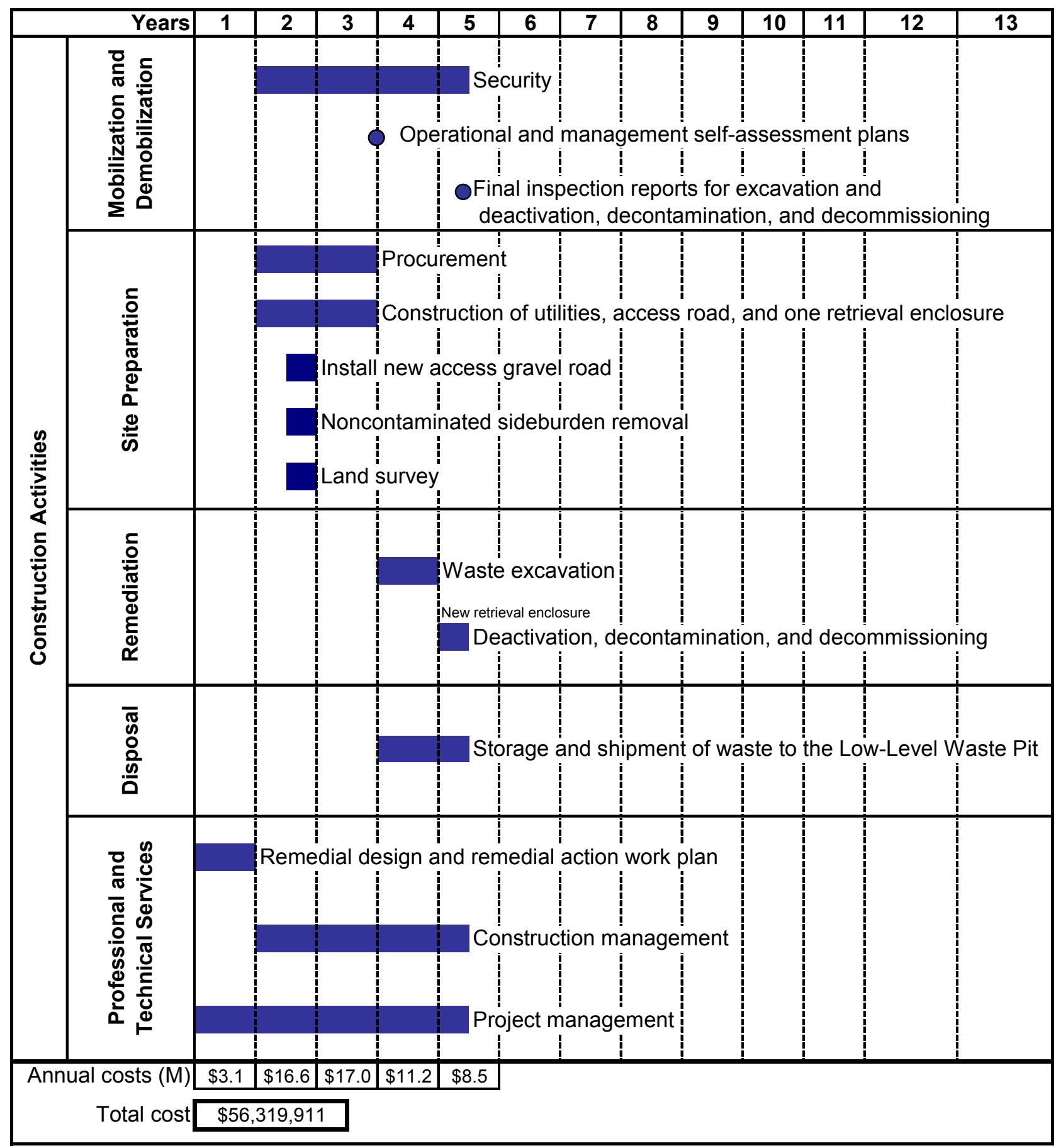

Figure F-16. Module 15 design and construction schedule for removing Pad A and transferring it to the LLW Pit without treatment. 


\section{F-16.5 Contingency Guideline Implementation}

Total capital cost contingency for Module 15 is $40.74 \%$. This contingency is the average contingency of construction activities (i.e., 50\%) and professional and technical services (i.e., $0 \%$ ).

\section{F-16.6 Estimate Summary}

Table F-57 provides rough order of magnitude allocations of the methodologies used to develop the cost estimate for Module 15.

Table F-57. Rough order of magnitude allocations of the methodologies used to develop the cost estimate for Module 15.

\begin{tabular}{lc}
\hline Estimate Methodology & $\begin{array}{c}\text { Rough Order of Magnitude } \\
(\%)\end{array}$ \\
\hline Project team & 30 \\
Recorded actuals & 0 \\
Parametric & 20 \\
Vendor quotes & 20 \\
Other & 30 \\
Total & $\mathbf{1 0 0}$ \\
\hline
\end{tabular}

\section{F-16.7 Other Comments or Concerns Specific to the Estimate}

A. Activities have not been escalated to the activity midpoint.

B. Subcontractor labor costs reflect INL Site Stabilization Agreement craft labor rates.

C. $\mathrm{CH} 2 \mathrm{M}-\mathrm{WG}$ Idaho labor rates reflect fully burdened present day rates.

\section{F-16.8 Summary}

Table F-58 provides capital cost information for Module 15. 
F-164 
Table F-58. Capital costs for Module 15: Operable Unit 7-13/14 Feasibility Study—Pad A Removal without Treatment and Shipped to the Low-Level Waste Pit, Project Number: 5992-K.

\begin{tabular}{|c|c|c|c|c|c|}
\hline Level & Description & $\begin{array}{c}\text { Subtotals }{ }^{\mathrm{a}} \\
(\$)\end{array}$ & $\begin{array}{c}\text { Estimate }^{\mathrm{a}} \\
(\$)\end{array}$ & $\begin{array}{c}\text { Contingency }{ }^{\mathrm{a}, \mathrm{b}} \\
(\$)\end{array}$ & $\begin{array}{c}\text { Total }^{\mathrm{a}, \mathrm{c}} \\
(\$)^{2}\end{array}$ \\
\hline 1.1 & Construction activities & $32,604,000$ & - & - & - \\
\hline 1.1 .1 & Mobilization and demobilization & $2,897,000$ & - & - & - \\
\hline 1.1.1.1 & Construction equipment & - & 70,000 & 35,000 & 105,000 \\
\hline 1.1.1.2 & Submittals and implementation plans & 569,000 & - & - & - \\
\hline 1.1.1.2.1 & Operational plans & - & 193,000 & 97,000 & 290,000 \\
\hline 1.1.1.2.2 & Management self-assessment plan & - & 53,000 & 27,000 & 80,000 \\
\hline 1.1.1.2.4 & Final inspection report & - & 323,000 & 161,000 & 484,000 \\
\hline 1.1.1.6 & Security at construction site access gate & - & $2,258,000$ & $1,129,000$ & $3,387,000$ \\
\hline 1.1 .2 & Site preparation work & $19,114,000$ & - & - & - \\
\hline 1.1 .2 .1 & Procurement & $11,706,000$ & - & - & - \\
\hline 1.1.2.1.2 & Procurement_- building Pad A & $11,049,000$ & - & - & - \\
\hline 1.1.2.1.2.1 & Procurement-retrieval structure & - & $2,950,000$ & $1,475,000$ & $4,425,000$ \\
\hline 1.1.2.1.2.2 & Procurement-airlock structure & - & 369,000 & 185,000 & 554,000 \\
\hline 1.1.2.1.2.3 & Procurement—emissions monitoring & - & 289,000 & 144,000 & 433,000 \\
\hline 1.1.2.1.2.4 & Procurement - heating and ventilation (retrieval structure) & - & 687,000 & 343,000 & $1,030,000$ \\
\hline 1.1.2.1.2.5 & Procurement-electrical distribution & - & 495,000 & 248,000 & 743,000 \\
\hline 1.1.2.1.2.7 & Procurement-radiological equipment & - & 851,000 & 425,000 & $1,276,000$ \\
\hline 1.1.2.1.2.8 & Procurement-fire detection equipment & - & 208,000 & 104,000 & 313,000 \\
\hline 1.1.2.1.2.9 & Procurement-excavation equipment & - & $1,123,000$ & 562,000 & $1,685,000$ \\
\hline 1.1.2.1.2.10 & Procurement-forklift & - & 203,000 & 102,000 & 305,000 \\
\hline 1.1.2.1.2.11 & Procurement—-foundation materials & - & 345,000 & 172,000 & 517,000 \\
\hline 1.1.2.1.2.12 & Procurement-support trailers & - & 122,000 & 61,000 & 183,000 \\
\hline 1.1.2.2.4.3 & Consumables & - & $3,406,000$ & $1,703,000$ & $5,109,000$ \\
\hline 1.1.2.1.3 & Procurement—-storage building & 657,000 & - & - & - \\
\hline 1.1.2.1.3.1 & Procurement—-storage building & - & 539,000 & 269,000 & 808,000 \\
\hline 1.1.2.1.3.2 & Procurement—-storage building ventilation equipment & - & 31,000 & 16,000 & 47,000 \\
\hline 1.1.2.1.3.3 & Procurement-miscellaneous materials & - & 88,000 & 44,000 & 131,000 \\
\hline 1.1 .2 .2 & Facility construction & $7,408,000$ & - & - & - \\
\hline 1.1 .2 .2 .2 & Construct building Pad A & $6,400,000$ & - & - & - \\
\hline 1.1.2.2.2.1 & Land survey & - & 17,000 & 9,000 & 26,000 \\
\hline 1.1.2.2.2.2 & Contour Pad A site & - & 25,000 & 13,000 & 38,000 \\
\hline 1.1.2.2.2.3 & Retrieval structure erection & - & $2,229,000$ & $1,115,000$ & $3,344,000$ \\
\hline 1.1.2.2.2.4 & Airlock structure erection & - & 315,000 & 158,000 & 473,000 \\
\hline 1.1.2.2.2.5 & Access roadway & - & 88,000 & 44,000 & 132,000 \\
\hline 1.1.2.2.2.6 & Site drainage & - & 41,000 & 21,000 & 62,000 \\
\hline 1.1.2.2.2.7 & Fire detection & - & 76,000 & 38,000 & 114,000 \\
\hline 1.1.2.2.2.8 & Retrieval enclosure mechanical & - & $1,087,000$ & 543,000 & $1,630,000$ \\
\hline 1.1.2.2.2.9 & Retrieval enclosure electrical & - & $1,028,000$ & 514,000 & $1,542,000$ \\
\hline 1.1.2.2.2.10 & Airlock mechanical, electrical, and interior walls & - & 738,000 & 369,000 & $1,107,000$ \\
\hline 1.1.2.2.2.11 & Electrical distribution & - & 754,000 & 377,000 & $1,132,000$ \\
\hline 1.1.2.2.3 & Construct storage building & 575,000 & - & - & - \\
\hline 1.1.2.2.3.1 & Construction-storage enclosure & 355,000 & - & - & - \\
\hline 1.1.2.2.3.1.1 & Construction-storage building concrete & - & 59,000 & 30,000 & 89,000 \\
\hline 1.1.2.2.3.1.2 & Construction-storage building structural & - & 117,000 & 58,000 & 175,000 \\
\hline 1.1.2.2.3.1.3 & Construction - storage building exterior fabric and liner & - & 128,000 & 64,000 & 192,000 \\
\hline 1.1.2.2.3.1.4 & Construction—-storage building punch list & - & 15,000 & 7,000 & 22,000 \\
\hline 1.1.2.2.3.1.5 & Construction-storage building equipment & - & 36,000 & 18,000 & 54,000 \\
\hline 1.1 .2 .2 .3 .2 & Mechanical (storage) & 38,000 & - & - & - \\
\hline 1.1.2.2.3.2.1 & General costs mechanical & - & 3,000 & 1,000 & 4,000 \\
\hline 1.1.2.2.3.2.2 & Install ventilation equipment & - & 19,000 & 9,000 & 28,000 \\
\hline 1.1.2.2.3.2.3 & Water storage tank & - & 17,000 & 9,000 & 26,000 \\
\hline 1.1.2.2.3.3 & Electrical (storage) & 181,000 & - & - & - \\
\hline 1.1.2.2.2.3.1 & Electrical details & - & 181,000 & 91,000 & 272,000 \\
\hline 1.1.2.2.4 & Facility and equipment maintenance & - & 434,000 & 217,000 & 651,000 \\
\hline 1.1 .3 & Remediation & $10,592,000$ & - & - & - \\
\hline 1.1 .3 .1 & Waste excavation & $5,996,000$ & - & - & - \\
\hline 1.1 .3 .1 .1 & Waste retrieval $(\mathrm{Pad} \mathrm{A})$ & - & $5,637,000$ & $2,819,000$ & $8,456,000$ \\
\hline 1.1.3.1.1.2 & Waste retrieval equipment $(\mathrm{Pad} \mathrm{A})$ & - & 329,000 & 165,000 & 494,000 \\
\hline 1.1.4.3 & Move waste boxes to low level waste pit & - & 29,000 & 15,000 & 44,000 \\
\hline 1.1.3.2 & Demolition and removal & - & $4,597,000$ & $2,298,000$ & $6,895,000$ \\
\hline 1.2 & Professional and technical services & $7,415,000$ & - & - & - \\
\hline 1.2 .1 & Project management & - & $2,445,000$ & - & $2,445,000$ \\
\hline 1.2 .2 & Remedial design and remedial action work plan & $2,524,000$ & - & - & - \\
\hline 1.2 .2 .1 & Remedial design & - & $1,893,000$ & - & $1,893,000$ \\
\hline 1.2 .2 .2 & Remedial action work plan & - & 631,000 & - & 631,000 \\
\hline \multirow[t]{3}{*}{1.2 .3} & Construction management & - & $2,445,000$ & - & $2,445,000$ \\
\hline & Total capital cost $\mathrm{t}^{\mathrm{c}}$ & - & $40,018,000$ & $16,302,000$ & $56,320,000$ \\
\hline & \multicolumn{5}{|c|}{$\begin{array}{l}\text { a. Values are rounded to the nearest } \$ 1,000 \text {. } \\
\text { b. Capital cost contingency is } 40.7 \% \text { of the estimate. } \\
\text { c. Totals were derived for the summation of nonrounded subcomponent values. Therefore, totals are not equal to the summation of the rounded subcomponent values shown above. } \\
\text { See Table F-3 for nonrounded totals. }\end{array}$} \\
\hline
\end{tabular}




\section{F-17. MODULE 16: PAD A REMOVED AND SHIPPED TO ON-IDAHO NATIONAL LABORATORY SITE FACILITY FOR TREATMENT AND DISPOSAL}

\section{F-17.1 Purpose}

SDA.

This estimate will be used as a cost-comparative tool to examine different options regarding the

\section{F-17.2 Scope of Work}

The scope of work consists of engineering, procuring, constructing, and operating a facility that will excavate and package the buried waste at the Pad A area. The packaged waste is then stored at the lag storage facility in the SDA. The waste will then be transferred to ICDF for treatment and disposal. The ICDF has been used throughout this estimate for cost-estimating purposes only.

Subcontractor mobilization consists of the following:

- $\quad$ Generate operational plans

- Generate a management self-assessment plan

- $\quad$ Mobilize equipment.

Subcontractor demobilization consists of the following:

- $\quad$ Shut down or demobilize equipment

- Generate a final inspection report following completion of retrieval.

Subcontractor site preparation consists of the following:

- $\quad$ Contour the Pad A berm before construction of the retrieval enclosure.

- $\quad$ Construct one Accelerated Retrieval Project II-style retrieval enclosure that is $51.8 \times 109.7 \mathrm{~m}$

$(170 \times 360 \mathrm{ft})$

- $\quad$ One transfer airlock for the transfer of waste from inside to outside the facility for disposal at ICDF

- One nonremote excavator or loader

- One nonremote all terrain forklift

- $\quad$ Emissions monitoring systems

- Heating, ventilation, and filtration systems

- $\quad$ Electrical and controls systems

- $\quad$ Radiological equipment

- $\quad$ Fire detection systems.

- $\quad$ Construct one lag storage facility to house waste that will eventually be sent to the ICDF. 
Subcontractor remediation consists of the following:

- $\quad$ The remaining clean, contoured overburden will be removed from the building during the retrieval process and will be spread over the SDA.

- $\quad$ Working from the side of the waste mound, an excavator or loader will place the waste (including sections of the asphalt pad) on trays that are later transferred to a sorting table.

- $\quad$ At the sorting tables, any intact boxes and drums would be opened and waste segregated into fines and debris.

- $\quad$ After leaving the sorting tables, the fines and debris will be sent to the standard waste box packaging system for assignment of waste codes, labeling, and placement into a $1.2 \times 1.2 \times 1.8-\mathrm{m}$ $(4 \times 4 \times 6$-ft $)$ metal waste box or a $1.2 \times 1.2 \times 2.4-\mathrm{m}(4 \times 4 \times 8-\mathrm{ft})$ wooden box, respectively.

- $\quad$ All standard waste boxes will then be transferred to the storage facility.

- $\quad$ From storage, the standard waste boxes will be transferred to the ICDF for treatment and disposal in a lined landfill.

\section{F-17.3 Basis of the Estimate}

The following sequential process, rationale, and estimating methodologies were used to define activities, quantities, and resources that were used in preparation of this cost estimate.

A. Procurement and construction of the Accelerated Retrieval Project II Retrieval Enclosure and enclosure support equipment cost elements were based on Estimate File Number 5989-D, "ARP-2 EE/CA Estimate," prepared March 1, 2005. Appropriate general subcontractor markups for overhead, profit, and bond were applied to costs extracted from this previous estimate.

B. Electrical systems for the storage building were based on Estimate File Number 5991, "T RAD Project," August 1, 2005. Appropriate general subcontractor markups for overhead, profit, and bond were applied to costs extracted from this previous estimate.

C. Waste removal support personnel effort was based on a typical crew derived from the Accelerated Retrieval Project I, modified for the retrieval operation of Module 16.

D. Submittal and implementation costs are based on costs extracted from Estimate File Number 5987, "ISG Project FY 2005-FY 2011," dated August 3, 2004. Appropriate general contractor markups for overhead, profit, and bond were applied to costs extracted from this previous estimate.

E. Security costs were based on life-cycle baseline File Number 5432. Appropriate general subcontractor markups for overhead, profit, and bond were applied to costs extracted from this previous estimate.

F. The R. S. Means and Richardson Estimating Manuals were used during development of this estimate.

G. Estimates were developed, using Success@ estimating software by U.S. Cost, to a level of detail consistent with available documents and information.

H. Transfer airlock construction costs are based on information provided by the construction management group, using force account personnel. 
I. Transfer airlock procurement costs are based on budgetary information provided by a building manufacturer of this type.

J. Project scope and methodologies were prepared from discussions with the requester and project team.

K. Experiences of the Operable Unit 7-10 Glovebox Excavator Method Project (Pit 9) and the Accelerated Retrieval Projects I and II were used for the design elements associated with this cost estimate.

L. Final inspection costs were based on the "Preliminary Evaluation of Remedial Alternatives for the Subsurface Disposal Area" (Zitnik et al. 2002).

M. The standard waste box packaging system costs were based on the drum packaging system costs from an actual subcontract from the Accelerated Retrieval Project I facility.

N. Sorting table costs were based on preliminary design information provided by the Accelerated Retrieval Project II.

O. Where applicable (e.g., excavator and telehandler forklift), material pricing was based on information provided by the procurement from previous Accelerated Retrieval Project purchases. The appropriate general contractor markups for overhead, profit, and bond were applied to the costs extracted from this previous estimate

\section{F-17.4 Assumptions}

\section{A. General assumptions}

1. A representative from Waste Generator Services will determine, based on characterization data, that the waste will require treatment before burial within the ICDF.

2. Pad A waste is alpha low-level non-TRU waste.

3. If the use of sorting tables, treatment units, or an interim storage facility may be interpreted as "placement" of waste, a waiver or variance will be obtained from the DEQ that will preclude imposition of RCRA land disposal restriction requirements.

\section{B. Schedule}

Figure F-17 illustrates the project schedule. 


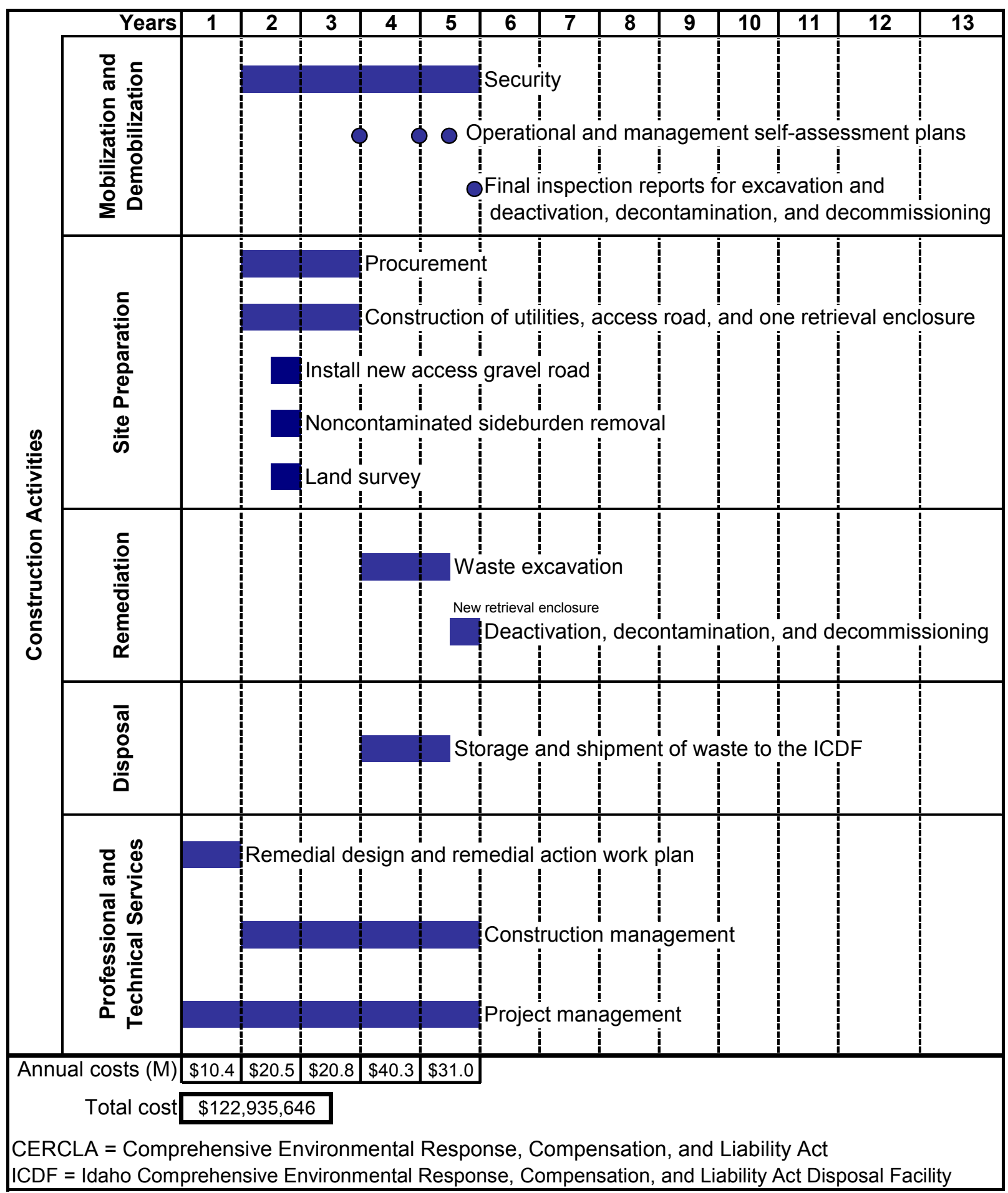

Figure F-17. Module 16 design and construction schedule for removing Pad A waste and transferring it to the Idaho CERCLA Disposal Facility for treatment and disposal. 


\section{Mobilization and demobilization (capital costs)}

1. Administrative and equipment buildings or trailers will be installed in the SDA to support operational controls, radiation controls, and personnel facilities.

2. Equipment and personnel entering and exiting the SDA will not be required to survey in or out, or stop for security access. As they travel through the gates, personnel will only be required to flash their identification to the personnel manning those gates. This estimate assumes free and easy access at the gates for all construction personnel and equipment.

3. ICP personnel will have access to existing RWMC buildings that can be used as temporary offices during this work.

\section{Site preparation (capital costs)}

This module requires one complete Accelerated Retrieval Project II-type retrieval enclosure.

\section{E. Remediation (capital costs)}

1. A specialty subcontractor will perform waste excavation. This subcontractor will be experienced with this type of work and will be selected through the bid and award process.

2. No revegetation of the excavated area will be required.

3. Only the designated Pad A area will be excavated.

4. A survey of the proposed excavated area has already been performed. No allowance for surveying is included.

5. Remote-handled materials will not be encountered during this project.

6. Wooden boxes will not be reused.

7. Waste will be treated for disposal at the ICDF.

8. Costs for treatment and disposal of any ICDF prohibited items discovered during waste segregations will be covered by contingency.

9. Pad A waste will not be segregated based on waste type (e.g., roster oxide and nitrate salt).

\section{F-17.5 Contingency Guideline Implementation}

Total capital cost contingency for Module 16 is $49.47 \%$. This contingency is the average contingency of construction activities (i.e., $65 \%$ ) and professional and technical services (i.e., $0 \%$ ). 


\section{F-17.6 Estimate Summary}

Table F-59 provides rough order of magnitude allocations of the methodologies used to develop the cost estimate for Module 16.

Table F-59. Rough order of magnitude allocations of the methodologies used to develop the cost estimate for Module 16.

\begin{tabular}{lc} 
Estimate Methodology & $\begin{array}{c}\text { Rough Order of Magnitude } \\
(\%)\end{array}$ \\
\hline Project team & 30 \\
Recorded actuals & 0 \\
Parametric & 20 \\
Vendor quotes & 20 \\
Other & 30 \\
Total & $\mathbf{1 0 0}$ \\
\hline
\end{tabular}

\section{F-17.7 Other Comments or Concerns Specific to the Estimate}
A. Activities have not been escalated to the activity midpoint.
B. Subcontractor labor costs reflect INL Site Stabilization Agreement craft labor rates.
C. CH2M-WG Idaho labor rates reflect fully burdened present day rates.

\section{F-17.8 Summary}

Table F-60 provides capital cost information for Module 16. 
Table F-60. Capital costs for Module 16-Operable Unit 7-13/14 Feasibility Study_Pad A Removed and Shipped to Idaho CERCLA Disposal Facility for Treatment and Disposal, Project Number: 5992-L.

\begin{tabular}{|c|c|c|c|c|c|}
\hline Level & Description & $\begin{array}{c}\text { Subtotals }{ }^{\mathrm{a}} \\
(\$)\end{array}$ & $\begin{array}{c}\text { Estimate }^{a} \\
(\$)\end{array}$ & $\begin{array}{c}\text { Contingency }{ }^{\mathrm{a}, \mathrm{b}} \\
(\$)\end{array}$ & $\begin{array}{c}\text { Total }^{\mathrm{a}, \mathrm{c}} \\
(\$)\end{array}$ \\
\hline 1.1 & Construction activities & $62,594,000$ & - & - & - \\
\hline 1.1 .1 & Mobilization and demobilization & $3,589,000$ & - & - & - \\
\hline 1.1.1.1 & Construction equipment & - & 70,000 & 46,000 & 116,000 \\
\hline 1.1.1.2 & Submittals and implementation plans & 938,000 & - & - & - \\
\hline 1.1.1.2.1 & Operational plans & - & 483,000 & 314,000 & 797,000 \\
\hline 1.1.1.2.2 & Management self-assessment plan & - & 133,000 & 86,000 & 219,000 \\
\hline 1.1.1.2.4 & Final inspection report & - & 323,000 & 210,000 & 532,000 \\
\hline 1.1 .1 .6 & Security at construction site access gates & - & $2,581,000$ & $1,677,000$ & $4,258,000$ \\
\hline 1.1 .2 & Site preparation work & $20,719,000$ & - & - & - \\
\hline 1.1 .2 .1 & Procurement & $13,310,000$ & - & - & - \\
\hline 1.1 .2 .1 .2 & Procurement—-building Pad A & $12,653,000$ & - & - & - \\
\hline 1.1.2.1.2.1 & Procurement-retrieval structure & - & $2,950,000$ & $1,918,000$ & $4,868,000$ \\
\hline 1.1.2.1.2.2 & Procurement-airlock structure & - & 369,000 & 240,000 & 609,000 \\
\hline 1.1.2.1.2.3 & Procurement-emissions monitoring & - & 289,000 & 188,000 & 476,000 \\
\hline 1.1.2.1.2.4 & Procurement-heating and ventilation (retrieval structure) & - & 687,000 & 446,000 & $1,133,000$ \\
\hline 1.1.2.1.2.5 & Procurement-electrical distribution & - & 495,000 & 322,000 & 817,000 \\
\hline 1.1.2.1.2.7 & Procurement-radiological equipment & - & 851,000 & 553,000 & $1,404,000$ \\
\hline 1.1.2.1.2.8 & Procurement-fire detection equip & - & 208,000 & 135,000 & 344,000 \\
\hline 1.1.2.1.2.9 & Procurement-excavation equipment & - & $1,123,000$ & 730,000 & $1,853,000$ \\
\hline 1.1.2.1.2.10 & Procurement—-forklift & - & 203,000 & 132,000 & 335,000 \\
\hline 1.1.2.1.2.11 & Procurement-foundation materials & - & 345,000 & 224,000 & 569,000 \\
\hline 1.1.2.1.2.12 & Procurement—-support trailers & - & 122,000 & 79,000 & 201,000 \\
\hline 1.1.2.2.4.13 & Consumables & - & $3,406,000$ & $2,214,000$ & $5,620,000$ \\
\hline 1.1.2.1.2.12 & Drum packaging stations & $1,088,000$ & - & - & - \\
\hline 1.1 .2 .1 .2 .12 .1 & Drum packaging stations (drum only) & - & 475,000 & 308,000 & 783,000 \\
\hline 1.1 .2 .1 .2 .12 .2 & Drum packaging stations (standard waste box and drum) & - & 178,000 & 116,000 & 294,000 \\
\hline 1.1.2.1.2.12.3 & Procurement- - for drum packaging station units & - & 436,000 & 283,000 & 719,000 \\
\hline 1.1.2.1.2.13 & Sorting tables - offsite fabrication & 516,000 & - & - & - \\
\hline 1.1.2.1.2.13.1 & Sorting table- - general costs & - & 33,000 & 21,000 & 54,000 \\
\hline 1.1.2.1.2.13.2 & Sorting table structure & - & 210,000 & 136,000 & 346,000 \\
\hline 1.1.2.1.2.13.3 & Sorting table utilities & 21,000 & - & - & - \\
\hline 1.1.2.1.2.13.3.1 & Sorting table-compressed air utility piping & - & 7,000 & 5,000 & 12,000 \\
\hline 1.1.2.1.2.13.3.2 & Sorting table - electrical power utility & - & 13,000 & 9,000 & 22,000 \\
\hline 1.1.2.1.2.13.4 & Sorting table — exhaust system & - & 177,000 & 115,000 & 292,000 \\
\hline 1.1 .2 .1 .2 .13 .4 & Sorting table - miscellaneous & - & 76,000 & 49,000 & 125,000 \\
\hline 1.1.2.1.3 & Procurement- $—$ storage building & 657,000 & - & - & - \\
\hline 1.1.2.1.3.1 & Procurement—storage building & - & 539,000 & 350,000 & 889,000 \\
\hline 1.1.2.1.3.2 & Procurement — storage building ventilation equipment & - & 31,000 & 20,000 & 52,000 \\
\hline 1.1.2.1.3.3 & Procurement- - miscellaneous materials & - & 88,000 & 57,000 & 144,000 \\
\hline 1.1 .2 .2 & Facility construction & $7,408,000$ & - & - & - \\
\hline 1.1.2.2.2 & Construct building Pad A & $6,400,000$ & - & - & - \\
\hline 1.1.2.2.2.1 & Land survey & - & 17,000 & 11,000 & 29,000 \\
\hline 1.1.2.2.2.2 & Contour Pad A site & - & 25,000 & 17,000 & 42,000 \\
\hline 1.1.2.2.2.3 & Retrieval structure erection & - & $2,229,000$ & $1,449,000$ & $3,678,000$ \\
\hline 1.1.2.2.2.4 & Airlock structure erection & - & 315,000 & 205,000 & 520,000 \\
\hline 1.1.2.2.2.5 & Access roadway & - & 88,000 & 57,000 & 145,000 \\
\hline 1.1.2.2.2.6 & Site drainage & - & 41,000 & 27,000 & 68,000 \\
\hline 1.1.2.2.2.7 & Fire detection & - & 76,000 & 49,000 & 126,000 \\
\hline 1.1.2.2.2.8 & Retrieval enclosure mechanical & - & $1,087,000$ & 706,000 & $1,793,000$ \\
\hline 1.1.2.2.2.9 & Retrieval enclosure electrical & - & $1,028,000$ & 668,000 & $1,696,000$ \\
\hline 1.1 .2 .2 .2 .10 & Airlock mechanical, electrical, and interior walls & - & 738,000 & 480,000 & $1,218,000$ \\
\hline 1.1.2.2.2.11 & Electrical distribution & - & 754,000 & 490,000 & $1,245,000$ \\
\hline 1.1.2.2.3 & Construction—-storage building & 575,000 & - & - & - \\
\hline 1.1.2.2.3.1 & Construction-storage enclosure & 355,000 & - & - & - \\
\hline 1.1.2.2.3.1.1 & Construction - storage building concrete & - & 59,000 & 39,000 & 98,000 \\
\hline 1.1.2.2.3.1.2 & Construction - storage building structural & - & 117,000 & 76,000 & 193,000 \\
\hline 1.1.2.2.3.1.3 & Construction - storage building exterior fabric and liner & - & 128,000 & 83,000 & 211,000 \\
\hline 1.1.2.2.3.1.4 & Construction-storage building punchlist & - & 15,000 & 10,000 & 24,000 \\
\hline 1.1.2.2.3.1.5 & Construction-storage building equipment & - & 36,000 & 23,000 & 59,000 \\
\hline 1.1.2.2.3.2 & Mechanical (storage) & 38,000 & - & - & - \\
\hline 1.1.2.2.3.2.1 & General costs mechanical & - & 3,000 & 2,000 & 5,000 \\
\hline 1.1.2.2.3.2.2 & Install ventilation equipment & - & 19,000 & 12,000 & 31,000 \\
\hline $1.1 .2 \cdot 2 \cdot 3 \cdot 2.3$ & Water storage tank & - & 17,000 & 11,000 & 28,000 \\
\hline 1.1.2.2.3.3 & Electrical (storage) & 181,000 & - & - & - \\
\hline 1.1.2.2.3.3.1 & Electrical details & - & 181,000 & 118,000 & 299,000 \\
\hline 1.1.2.2.4 & Facility and equipment maintenance & - & 434,000 & 282,000 & 716,000 \\
\hline 1.1 .3 & Remediation & $33,017,000$ & - & - & - \\
\hline 1.1.3.1 & Waste excavation Pad A & $27,905,000$ & - & - & - \\
\hline 1.1 .3 .1 .1 & Support personal for waste retrieval (Pad A) & - & $5,637,000$ & $3,664,000$ & $9,301,000$ \\
\hline 1.1.3.1.2 & Waste retrieval equipment $(\mathrm{Pad} \mathrm{A})$ & - & $18,326,000$ & $11,912,000$ & $30,237,000$ \\
\hline 1.1.3.1.3 & Move waste boxes to ICDF & - & $3,942,000$ & $2,562,000$ & $6,504,000$ \\
\hline 1.1 .3 .2 & Demolition and removal & - & $5,113,000$ & $3,323,000$ & $8,436,000$ \\
\hline 1.1 .4 & On-INL Site disposal (ICDF pit) & $5,269,000$ & - & - & - \\
\hline 1.1.4.1 & ICDF charges & - & $5,269,000$ & $3,425,000$ & $8,693,000$ \\
\hline 1.2 & Professional and technical services & $19,656,000$ & - & - & - \\
\hline 1.2 .1 & Project management & - & $5,164,000$ & - & $5,164,000$ \\
\hline 1.2 .2 & Remedial design and remedial action work plan & $9,328,000$ & - & - & - \\
\hline 1.2 .2 .1 & Remedial design & - & $5,330,000$ & - & $5,330,000$ \\
\hline 1.2 .2 .2 & Remedial action work plan & - & $3,998,000$ & - & $3,998,000$ \\
\hline \multirow{3}{*}{1.2 .3} & Construction management & - & $5,164,000$ & - & $5,164,000$ \\
\hline & Total capital cost ${ }^{\mathrm{c}}$ & - & $82,250,000$ & $40,686,000$ & $122,936,000$ \\
\hline & $\begin{array}{l}\text { a. Values are rounded to the nearest } \$ 1,000 . \\
\text { b. Capital cost contingency is } 49.5 \% \text { of the estimate } \\
\text { c. Totals were derived for the summation of nonrounded subcomponent values. } \\
\text { See Table F-3 for nonrounded totals. }\end{array}$ & 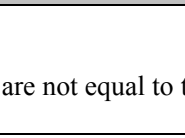 & & & un above \\
\hline
\end{tabular}




\section{F-18. MODULE 17: PAD A REMOVED AND SHIPPED TO OFF-IDAHO NATIONAL LABORATORY SITE FACILITY FOR TREATMENT AND DISPOSAL}

\section{F-18.1 Purpose}

SDA.

This estimate will be used as a cost-comparative tool to examine different options regarding the

\section{F-18.2 Scope of Work}

The scope of work consists of engineering, procuring, constructing, and operating a facility that will excavate and package the buried Pad A waste in the SDA. The waste will be packaged in lined Sea-Land containers and shipped to an off-INL Site destination for treatment and disposal.

Subcontractor mobilization consists of the following:

- $\quad$ Generate operational plans

- Generate a management self-assessment plan

- Generate an operational readiness review plan of action and an operational readiness review implementation plan

- $\quad$ Mobilize equipment.

Subcontractor demobilization consists of the following:

- $\quad$ Shut down or demobilize equipment

- Generate a final inspection report following completion of retrieval.

Subcontractor site preparation consists of the following:

- $\quad$ Accelerated Retrieval Project II-style retrieval enclosure that is $51.8 \times 109.7 \mathrm{~m}(170 \times 360 \mathrm{ft})$

- $\quad$ One transfer airlock for the transfer of waste from inside the facility to the outside for placement into Sea-Land containers

- $\quad$ Tractors and trailers for the transfer of waste to the Central Facilities Area rail spur for loading onto flatcars for off-INL Site shipment

- $\quad$ One 250-ton crane at the Central Facilities Area rail spur

- $\quad$ Emissions monitoring systems

- Heating, ventilation, and filtration systems

- $\quad$ Electrical and controls systems

- $\quad$ Radiological equipment

- $\quad$ Fire detection systems.

- $\quad$ Contour the Pad A berm before construction of the retrieval enclosure. 
Subcontractor remediation consists of the following:

- Working from the side of the waste mound, an excavator or loader will place loose waste (including sections of the asphalt pad) into a lined Sea-Land shipping container via a loading chute.

- $\quad$ Fines and debris will not be segregated.

- $\quad$ Sea-Land containers will be transported to the Central Facilities Area rail spur and loaded onto flatcars for shipment to an off-INL Site treatment facility.

- $\quad$ The remaining clean contoured overburden will be removed from the building after the retrieval process and will be spread over the SDA.

\section{F-18.3 Basis of the Estimate}

The following sequential process, rationale, and estimating methodologies were used to define the activities, quantities, and resources that were used in the preparation of this cost estimate.

A. Procurement and construction of the Accelerated Retrieval Project II Retrieval Enclosure and enclosure support equipment cost elements were based on Estimate Number 5989-D, “ARP-2 EE/CA Estimate,” prepared March 1, 2005.

B. Submittal and implementation costs were based on costs extracted from estimate File Number 5987, "ISG Project FY 2005-FY 2011," dated August 3, 2004. Appropriate general contractor markups for overhead, profit, and bond were applied to the costs extracted from this previous estimate.

C. Security costs were based on life-cycle baseline File Number 5432.

D. The R. S. Means and Richardson estimating manuals were used during the development of this estimate.

E. Estimates were developed, using Success $(\subset)$ estimating software by U.S. Cost, to a level of detail consistent with the available documents and information.

F. Transfer airlock construction costs are based on information provided by the construction management group, using force account personnel.

G. Transfer airlock procurement costs are based on budgetary information provided by a building manufacturer of this type.

H. The project scope and methodologies were prepared from discussions with the requester and the project team.

I. Experiences of the Operable Unit 7-10 Glovebox Excavator Method Project (Pit 9) and the Accelerated Retrieval Projects I and II were used for the design elements associated with this cost estimate.

J. The final inspection costs were based on the Preliminary Evaluation of Remedial Alternatives for the Subsurface Disposal Area (Zitnik et al. 2002).

K. Pricing for treatment and disposal of waste at EnergySolutions was based on values extracted from INL Contract No. 500051. 


\section{F-18.4 Assumptions}

\section{A. General assumptions}

1. Major rework of an existing rail spur at the Central Facilities Area will be required.

2. Structures obstructing retrieval in the SDA will be completely removed by those projects before the start of this project and at no cost to this project.

3. No additional costs will be incurred for all waste being buried in the off-INL Site location.

\section{B. Schedule}

Figure F-18 illustrates the project schedule.

\section{Mobilization and demobilization (capital costs)}

1. Administrative and equipment buildings or trailers will be installed in the SDA to support operational controls, radiation controls, and personnel facilities.

2. Equipment and personnel entering and exiting the SDA will not be required to survey in or out, or stop for security access. As they travel through the gates, personnel will only be required to flash their identification to the personnel manning those gates. This estimate assumes free and easy access at the gates for all construction personnel and equipment.

3. ICP personnel will have access to existing RWMC buildings that can be used as temporary offices during this work.

4. ICP personnel will not require move monies.

5. Equipment, mobilization, and demobilization costs are captured within the remediation section of this cost estimate.

\section{Site preparation (capital costs)}

This module requires one complete Accelerated Retrieval Project II-type retrieval enclosure. 


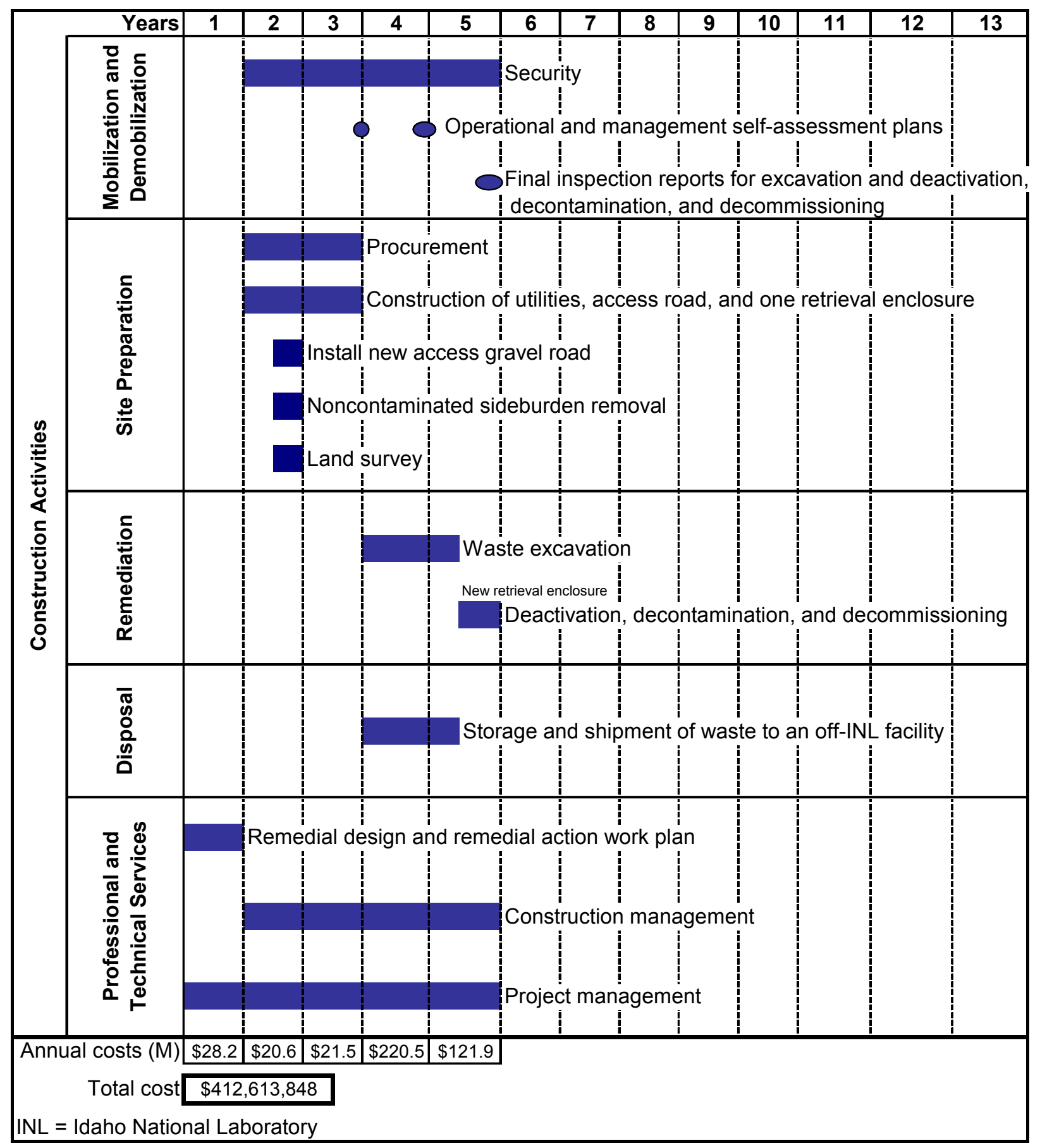

Figure F-18. Module 17 design and construction schedule for removing Pad A waste and transferring it off-Idaho National Laboratory Site for treatment and disposal. 


\section{E. Remediation (capital costs)}

1. A specialty subcontractor will perform the waste excavation. This subcontractor will be experienced with this type of work and will be selected through the bid and award process.

2. No revegetation of the excavated area will be required.

3. Only the designated Pad A area will be excavated.

4. Remote-handled materials will not be encountered during this project.

5. The waste is compliant with land disposal restrictions and requires debris encapsulation treatment before disposal.

6. The radioactive component of the waste is uniformly distributed throughout the waste, and the concentration of radionuclides from one shipping container to the next is essentially the same.

7. The radioactive component of the waste is classified as LLW.

8. The waste is not a polychlorinated biphenyl, Toxic Substances Control Act waste and requires no treatment for polychlorinated biphenyls.

9. The waste does not contain prohibited items as specified in Section 3.3 of the EnergySolutions Waste Acceptance Criteria.

10. Adequate characterization data exist to support chemical, physical, and radiological characterization.

\section{F-18.5 Contingency Guideline Implementation}

The total capital cost contingency for Module 17 is $50.76 \%$. This contingency is the average contingency of the construction activities (i.e., 65\%) and the professional and technical services (i.e., $0 \%$ ). 


\section{F-18.6 Estimate Summary}

Table F-61 provides rough order of magnitude allocations of the methodologies used to develop the cost estimate for Module 17.

Table F-61. Rough order of magnitude allocations of the methodologies used to develop the cost estimate for Module 17.

\begin{tabular}{lc} 
Estimate Methodology & $\begin{array}{c}\text { Rough Order of Magnitude } \\
(\%)\end{array}$ \\
\hline Project team & 30 \\
Recorded actuals & 0 \\
Parametric & 20 \\
Vendor quotes & 20 \\
Other & 30 \\
Total & $\mathbf{1 0 0}$ \\
\hline
\end{tabular}

\section{F-18.7 Other Comments or Concerns Specific to the Estimate}
A. Activities have not been escalated to the activity midpoint.
B. Subcontractor labor costs reflect INL Site Stabilization Agreement craft labor rates.
C. CH2M-WG Idaho labor rates reflect fully burdened present day rates.

\section{F-18.8 Summary}

Table F-62 provides capital cost information for Module 17. 
Table F-62. Capital costs for Module 17: Operable Unit 7-13/14 Feasibility Study_Pad A Removed and Shipped Off-Idaho National Laboratory Site for Treatment and Disposal, Project Number: 5992-M.

\begin{tabular}{|c|c|c|c|c|c|}
\hline Level & Description & $\begin{array}{l}\text { Subtotals }^{\mathrm{a}} \\
(\$)\end{array}$ & $\begin{array}{c}\text { Estimate }^{\mathrm{a}} \\
(\$)\end{array}$ & $\begin{array}{l}\text { Contingency } \\
(\$)\end{array}$ & $\begin{array}{c}\text { Total }^{\mathrm{a}, \mathrm{c}} \\
(\$)\end{array}$ \\
\hline 1.1 & Construction activities & $213,734,000$ & - & - & 一 \\
\hline 1.1 .1 & Mobilization and demobilization & $4,384,000$ & - & - & - \\
\hline 1.1.1.1 & Construction equipment & - & 50,000 & 33,000 & 83,000 \\
\hline 1.1.1.2 & Submittals/implementation plans & $1,431,000$ & - & - & - \\
\hline 1.1.1.2.1 & Operational plans & - & 869,000 & 565,000 & $1,434,000$ \\
\hline 1.1.1.2.2 & Management self-assessment plan & - & 239,000 & 156,000 & 395,000 \\
\hline 1.1.1.2.3 & Final inspection report & - & 323,000 & 210,000 & 532,000 \\
\hline 1.1.1.3 & Security at construction site access gate & - & $2,903,000$ & $1,887,000$ & $4,790,000$ \\
\hline 1.1.2 & Site preparation work & $13,827,000$ & - & - & - \\
\hline 1.1.2.1 & Procurement & $6,316,000$ & - & - & - \\
\hline 1.1.2.1.1 & Procurement—-building Pad A & $6,316,000$ & - & - & - \\
\hline 1.1.2.1.1.1 & Procurement—retrieval structure & $2,950,000$ & $2,950,000$ & $1,918,000$ & $4,868,000$ \\
\hline 1.1.2.1.1.2 & Procurement_-airlock structure & - & 369,000 & 240,000 & 609,000 \\
\hline 1.1.2.1.1.3 & Procurement-emissions monitoring & - & 289,000 & 188,000 & 476,000 \\
\hline 1.1.2.1.1.4 & $\begin{array}{l}\text { Procurement-heating and ventilation (retrieval enclosure } \\
\text { structure) }\end{array}$ & - & 687,000 & 446,000 & $1,133,000$ \\
\hline 1.1.2.1.1.5 & Procurement - electrical distribution & - & 495,000 & 322,000 & 817,000 \\
\hline 1.1.2.1.1.7 & Procurement_radiological equipment & - & 851,000 & 553,000 & $1,404,000$ \\
\hline 1.1.2.1.1.8 & Procurement-fire detection equipment & - & 208,000 & 135,000 & 344,000 \\
\hline 1.1.2.1.1.9 & Procurement-foundation materials & - & 345,000 & 224,000 & 569,000 \\
\hline 1.1.2.1.1.10 & Procurement—support trailers & - & 122,000 & 79,000 & 201,000 \\
\hline 1.1.2.2 & Facility construction & $7,511,000$ & - & - & - \\
\hline 1.1.2.2.2 & Construct building Pad A & $6,400,000$ & - & - & - \\
\hline 1.1.2.2.2.1 & Land survey & - & 17,000 & 11,000 & 29,000 \\
\hline 1.1.2.2.2.2 & Contour Pad A site & - & 25,000 & 17,000 & 42,000 \\
\hline 1.1.2.2.2.3 & Retrieval structure erection & - & $2,229,000$ & $1,449,000$ & $3,678,000$ \\
\hline 1.1.2.2.2.4 & Airlock structure erection & - & 315,000 & 205,000 & 520,000 \\
\hline 1.1.2.2.2.5 & Access roadway & - & 88,000 & 57,000 & 145,000 \\
\hline 1.1.2.2.2.6 & Site drainage & - & 41,000 & 27,000 & 68,000 \\
\hline 1.1.2.2.2.7 & Fire detection & - & 76,000 & 49,000 & 126,000 \\
\hline 1.1.2.2.2.8 & Retrieval enclosure mechanical & - & $1,087,000$ & 706,000 & $1,793,000$ \\
\hline 1.1.2.2.2.9 & Retrieval enclosure electrical & - & $1,028,000$ & 668,000 & $1,696,000$ \\
\hline 1.1.2.2.2.10 & Airlock mechanical, electrical, \& interior walls & - & 738,000 & 480,000 & $1,218,000$ \\
\hline 1.1.2.2.2.11 & Electrical distribution & - & 754,000 & 490,000 & $1,245,000$ \\
\hline 1.1.2.2.3 & Central facilities area rail spur and access road upgrade & 710,000 & - & - & - \\
\hline 1.1.2.2.3.1 & Central facilities area rail spur upgrade & - & 645,000 & 419,000 & $1,064,000$ \\
\hline 1.1.2.2.3.2 & Central facilities area rail spur access road upgrade & - & 65,000 & 42,000 & 106,000 \\
\hline 1.1.2.2.4 & Facility and equipment maintenance & - & 402,000 & 261,000 & 663,000 \\
\hline 1.1 .3 & Remediation & $195,523,000$ & - & - & - \\
\hline 1.1.3.1 & Waste retrieval & $5,617,000$ & - & - & - \\
\hline 1.1.3.1.2 & Waste retrieval and excavation & $4,991,000$ & - & - & - \\
\hline 1.1.3.1.2.1 & Waste retrieval, support personal & - & $4,318,000$ & $2,807,000$ & $7,124,000$ \\
\hline 1.1.3.1.2.2 & Waste retrieval and excavation & - & 674,000 & 438,000 & $1,112,000$ \\
\hline 1.1.3.1.3 & Haul and load sea-land containers & - & 625,000 & 406,000 & $1,031,000$ \\
\hline 1.1.3.2 & Off site treatment & $185,632,000$ & - & - & - \\
\hline 1.1.3.2.1 & Shipment offsite & - & $2,183,000$ & $1,419,000$ & $3,602,000$ \\
\hline 1.1.3.2.2 & Off site treatment & - & $183,449,000$ & $119,242,000$ & $302,690,000$ \\
\hline 1.1.3.3 & Facility demolition and removal & - & $4,275,000$ & $2,779,000$ & $7,054,000$ \\
\hline 1.2 & Professional and technical services & $59,952,000$ & - & - & - \\
\hline 1.2 .1 & Project management & - & $17,633,000$ & - & $17,633,000$ \\
\hline 1.2 .2 & Remedial design and remedial action work plan & $24,686,000$ & - & - & - \\
\hline 1.2.2.1 & Remedial design & - & $17,633,000$ & - & $17,633,000$ \\
\hline 1.2.2.2 & Remedial action work plan & - & $7,053,000$ & - & $7,053,000$ \\
\hline \multirow[t]{3}{*}{1.2 .3} & Construction management & - & $17,633,000$ & - & $17,633,000$ \\
\hline & \multicolumn{2}{|l|}{ Total capital cost ${ }^{\mathrm{c}}$} & $273,687,000$ & $138,927,000$ & $412,614,000$ \\
\hline & \multicolumn{5}{|c|}{$\begin{array}{l}\text { a. Values are rounded to the nearest } \$ 1,000 \text {. } \\
\text { b. Capital cost contingency is } 50.8 \% \text { of the estimate. } \\
\text { c. Totals were derived for the summation of nonrounded subcomponent values. Therefore, totals are not equal to the summation of the rounded subcomponent values shown } \\
\text { above. See Table F-3 for nonrounded totals. }\end{array}$} \\
\hline
\end{tabular}




\section{F-19. MODULE 18: PAD A REMOVED WITH TREATMENT AND SHIPPED TO THE LOW-LEVEL WASTE PIT}

\section{F-19.1 Purpose}

This estimate will be used as a cost-comparative tool to examine the different options regarding the SDA.

\section{F-19.2 Scope of Work}

The scope of work consists of engineering, procuring, constructing, and operating a facility that will excavate, grout, and package the buried waste at the Pad A area in the SDA. Packaged waste will be buried in the LLW Pit in the SDA.

Subcontractor mobilization consists of the following:

- $\quad$ Generate operational plans (see Section F-19.4 for details)

- Generate a management self-assessment plan

- Generate an operational readiness review plan of action and a operational readiness review implementation plan

- $\quad$ Mobilize equipment (costs captured in Section F-19.4).

Subcontractor demobilization consists of the following:

- $\quad$ Shut down or demobilize equipment

- Generation of a final inspection report following completion of retrieval within each retrieval enclosure.

Subcontractor site preparation consists of the following:

- $\quad$ Construct one Accelerated Retrieval Project II-style retrieval enclosure that is $51.8 \times 109.7 \mathrm{~m}$ $(170 \times 360 \mathrm{ft})$

- $\quad$ One transfer airlock for the transfer of waste from inside the facility to the outside for disposal at the LLW Pit

- $\quad$ One nonremote excavator or loader

- $\quad$ One nonremote all terrain forklift

- $\quad$ Emissions monitoring systems

- Heating, ventilation, and filtration systems

- $\quad$ Electrical and control systems

- $\quad$ Radiological equipment

- $\quad$ Fire detection systems.

- $\quad$ Construct one lag storage facility to house waste that will eventually be sent to the LLW Pit

- Contour the Pad A berm before construction of the retrieval enclosure. 
Subcontractor remediation consists of the following:

- Working from the side of the waste mound, an excavator or loader will place loose waste on a tray. Waste will be sorted and boxed as debris or fines.

- $\quad$ Debris (including sections of the asphalt pad) will be boxed, and grout will be mixed and placed in the waste box to fill the voids and create a waste monolith.

- $\quad$ Fines will be mixed with grout and placed in waste boxes; the grouted fines will create a friable mixture and will be boxed waste.

- $\quad$ The grouted fines waste will be randomly sampled.

- $\quad$ The debris monolith and boxed and grouted fines will be transferred to a temporary storage facility.

- $\quad$ Stored waste will be transferred to the LLW Pit for direct burial.

- $\quad$ The remaining clean contoured overburden will be removed from the building after the retrieval process and will be spread over the SDA.

\section{F-19.3 Basis of the Estimate}

The following sequential process, rationale, and estimating methodologies were used to define the activities, quantities, and resources that were used in the preparation of this cost estimate.

A. Procurement and construction of the Accelerated Retrieval Project II Retrieval Enclosure and enclosure support equipment cost elements were based on Estimate Number 5989-D, “ARP-2 EE/CA Estimate," prepared March 1, 2005.

B. Submittal and implementation costs were based on costs extracted from estimate File Number 5987, "ISG Project FY 2005-FY 2011," dated August 3, 2004. Appropriate general contractor markups for overhead, profit, and bond were applied to the costs extracted from this previous estimate.

C. Security costs were based on life-cycle baseline File Number 5432.

D. The R. S. Means and Richardson estimating manuals were used during the development of this estimate.

E. Estimated costs for grouting equipment were based on costs extracted from estimate File Number 2959-G, "AFC Estimate for the SSSTF Facility."

F. Estimates were developed, using Success $\odot$ estimating software by U.S. Cost, to a level of detail consistent with the available documents and information.

G. Transfer airlock construction costs were based on information provided by the construction management group, using force account personnel.

H. Transfer airlock procurement costs were based on budgetary information provided by a building manufacturer of this type.

I. The project scope and methodologies were prepared from discussions with the requester and the project team. 
J. Experiences were engaged with the Operable Unit 7-10 Glovebox Excavator Method Project (Pit 9) and the Accelerated Retrieval Projects I and II were used for the design elements associated with this cost estimate.

K. The final inspection costs were based on the "Preliminary Evaluation of Remedial Alternatives for the Subsurface Disposal Area" (Zitnik et al. 2002).

L. Where applicable (e.g., excavator and telehandler forklift), material pricing was based on information provided by the procurement from previous Accelerated Retrieval Project purchases. The appropriate general contractor markups for overhead, profit, and bond were applied to the costs extracted from this previous estimate.

\section{F-19.4 Assumptions}

\section{A. General assumptions}

1. Based on discussions with the project team, the design and construction of this project will be subcontracted. Subcontractor tasks include generating all required plans, performing all site preparation and remediation work, placing all ICs, and writing all reports. The ICP tasks include project management oversight (e.g., interface agreements, contract awards, and oversight) and construction management oversight (e.g., vendor data acceptance, preexisting technical procedure revisions, acceptance testing, and management self-assessments).

2. The INL Site resources (i.e., Central Facilities Area, medical facilities, geotechnical laboratory, fire department, security, utilities at the SDA) will be available for the duration of the project.

3. No fire water, potable water, buried power, propane, sewer, or storm drain utilities will be encountered or required to be removed or relocated.

4. Structures obstructing retrieval in the SDA will be completely removed by those projects before the start of this project and at no cost to this project.

5. No equipment flaggers or traffic control will be needed. Once the field work begins, the subcontractor will have complete control of the area.

6. The cost estimate does not consider or address funding restrictions. Sufficient funding will be available in a manner that allows optimum usage of that funding as estimated and scheduled.

7. No additional costs will be incurred for all waste being buried in the LLW Pit, with the exception of transferring waste to the pit.

8. If the use of sorting tables, treatment units, or an interim storage facility may be interpreted as placement of waste, a waiver or variance will be obtained from the DEQ that will preclude imposition of RCRA land disposal restriction requirements. 


\section{B. Schedule}

Figure F-19 illustrates the project schedule.

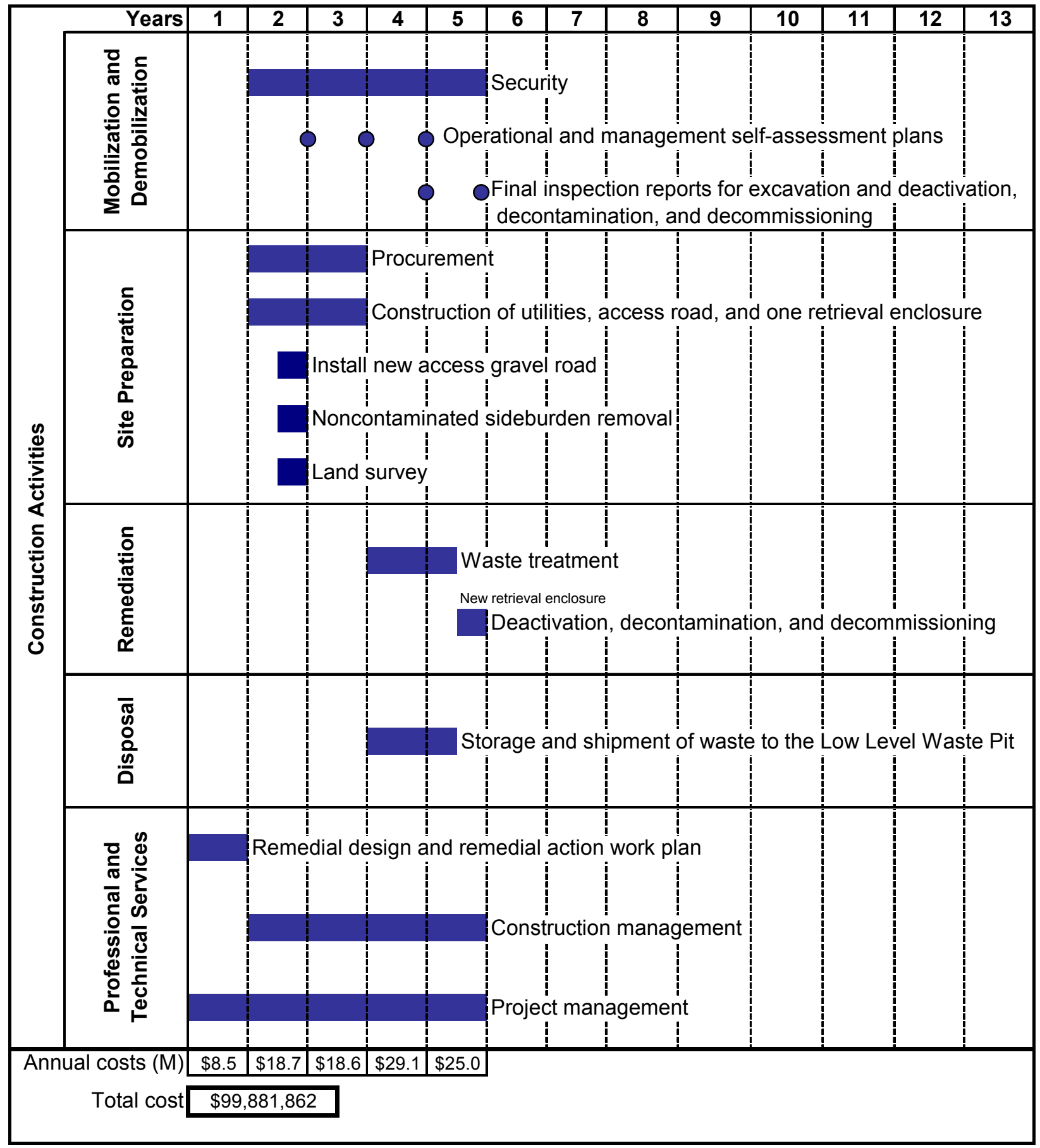

Figure F-19. Module 18 design and construction schedule for removing Pad A waste, treating Pad A waste, and transferring it to the LLW Pit. 


\section{Mobilization and demobilization (capital costs)}

1. Administrative and equipment buildings or trailers will be installed in the SDA to support operational controls, radiation controls, and personnel facilities.

2. Equipment and personnel entering and exiting the SDA will not be required to survey in or out, or stop for security access. As they travel through the gates, personnel will only be required to flash their identification to the personnel manning those gates. This estimate assumes free and easy access at the gates for all construction personnel and equipment.

3. ICP personnel will have access to existing RWMC buildings that can be used as temporary offices during this work.

4. ICP personnel will not require move monies.

5. Equipment, mobilization, and demobilization costs are captured within the remediation section of this cost estimate.

\section{Site preparation (capital costs)}

This module requires one complete Accelerated Retrieval Project II-type retrieval enclosure.

\section{E. Remediation (capital costs)}

1. A specialty subcontractor will perform the waste excavation. This subcontractor will be experienced with this type of work and will be selected through the bid and award process.

2. No revegetation of the excavated area will be required.

3. Only the designated Pad A area will be excavated.

4. Remote-handled materials will not be encountered during this project.

\section{F-19.5 Contingency Guideline Implementation}

The total capital cost contingency for Module 18 is $47.73 \%$. This contingency is the average contingency of the construction activities (i.e., $65 \%$ ) and the professional and technical services (i.e., $0 \%$ ). 


\section{F-19.6 Estimate Summary}

Table F-63 provides rough order of magnitude allocations of the methodologies used to develop the cost estimate for Module 18.

Table F-63. Rough order of magnitude allocations of the methodologies used to develop the cost estimate for Module 18.

\begin{tabular}{lc} 
Estimate Methodology & $\begin{array}{c}\text { Rough Order of Magnitude } \\
(\%)\end{array}$ \\
\hline Project team & 30 \\
Recorded actuals & 0 \\
Parametric & 20 \\
Vendor quotes & 20 \\
Other & 30 \\
Total & $\mathbf{1 0 0}$ \\
\hline
\end{tabular}

\section{F-19.7 Other Comments or Concerns Specific to the Estimate}
A. Activities have not been escalated to the activity midpoint
B. Subcontractor labor costs reflect INL Site Stabilization Agreement craft labor rates
C. $\mathrm{CH} 2 \mathrm{M}-\mathrm{WG}$ Idaho labor rates reflect fully burdened present day rates.

\section{F-19.8 Summary}

Table F-64 provides capital cost information for Module 18. 
Table F-64. Capital costs for Module 18 - Operable Unit 7-13/14 Feasibility Study-Pad A Ex Situ Grouting, Project Number: 5992-N.

\begin{tabular}{|c|c|c|c|c|c|}
\hline Level & Description & $\begin{array}{c}\text { Subtotals }{ }^{\mathrm{a}} \\
(\$)\end{array}$ & $\begin{array}{c}\text { Estimate }^{\mathrm{a}} \\
(\$)\end{array}$ & $\begin{array}{c}\text { Contingency } \\
(\$)\end{array}$ & $\begin{array}{c}\text { Total }^{\mathrm{a}, \mathrm{c}} \\
(\$)\end{array}$ \\
\hline 1.1 & Construction activities & $49,645,000$ & - & - & - \\
\hline 1.1 .1 & Mobilization and demobilization & $3,692,000$ & - & - & - \\
\hline 1.1.1.1 & Construction equipment & - & 50,000 & 33,000 & 83,000 \\
\hline 1.1.1.2 & Submittals and implementation plans & $1,061,000$ & - & - & - \\
\hline 1.1.1.2.1 & Operational plans & - & 579,000 & 377,000 & 956,000 \\
\hline 1.1.1.2.2 & Management self-assessment plan & - & 160,000 & 104,000 & 263,000 \\
\hline 1.1.1.2.4 & Final inspection report & - & 323,000 & 210,000 & 532,000 \\
\hline 1.1.1.3 & Security at construction site access gates & - & $2,581,000$ & $1,677,000$ & $4,258,000$ \\
\hline 1.1 .2 & Site preparation work & $17,946,000$ & - & - & - \\
\hline 1.1.2.1 & Procurement & $10,570,000$ & - & - & - \\
\hline 1.1.2.1.1 & Procurement_-building Pad A & $9,912,000$ & - & - & - \\
\hline 1.1.2.1.1.1 & Procurement-retrieval structure & - & $2,950,000$ & $1,918,000$ & $4,868,000$ \\
\hline 1.1.2.1.1.2 & Procurement-airlock structure & - & 369,000 & 240,000 & 609,000 \\
\hline 1.1.2.1.1.3 & Procurement-emissions monitoring & - & 289,000 & 188,000 & 476,000 \\
\hline 1.1.2.1.1.4 & Procurement- - heating and ventilation (retrieval structure) & - & 687,000 & 446,000 & $1,133,000$ \\
\hline 1.1.2.1.1.5 & Procurement—electrical distribution & - & 495,000 & 322,000 & 817,000 \\
\hline 1.1.2.1.1.7 & Procurement-radiological equipment & - & 851,000 & 553,000 & $1,404,000$ \\
\hline 1.1.2.1.1.8 & Procurement-fire detection equipment & - & 208,000 & 135,000 & 344,000 \\
\hline 1.1.2.1.1.9 & Procurement-excavation equipment & - & $1,123,000$ & 730,000 & $1,853,000$ \\
\hline 1.1.2.1.1.10 & Procurement—-forklift & - & 203,000 & 132,000 & 335,000 \\
\hline 1.1.2.1.1.11 & Procurement—foundation materials & - & 345,000 & 224,000 & 569,000 \\
\hline 1.1.2.1.1.12 & Procurement—support trailers & - & 122,000 & 79,000 & 201,000 \\
\hline 1.1.2.1.1.13 & Sorting tables - offsite fabrication (4 each) & 516,000 & - & - & - \\
\hline 1.1.2.1.1.13.1 & Sorting table-general costs & - & 33,000 & 21,000 & 54,000 \\
\hline 1.1.2.1.1.13.2 & Sorting table-structure & - & 210,000 & 136,000 & 346,000 \\
\hline 1.1.2.1.1.13.3 & Sorting tables-utilities & 21,000 & 一 & 一 & - \\
\hline 1.1.2.1.1.13.3.1 & Sort table - compressed air utility piping & - & 7,000 & 5,000 & 12,000 \\
\hline 1.1.2.1.1.13.3.2 & Sort table-electrical power utility & - & 13,000 & 9,000 & 22,000 \\
\hline 1.1.2.1.1.13.4 & Sorting table-exhaust system & - & 177,000 & 115,000 & 292,000 \\
\hline 1.1.2.1.1.13.5 & Sorting table-miscellaneous & - & 76,000 & 49,000 & 125,000 \\
\hline 1.1.2.1.1.13 & Specialty equipment & $1,754,000$ & - & - & - \\
\hline 1.1.2.2.4.3.1 & Debris grouting equipment & - & 757,000 & 492,000 & $1,250,000$ \\
\hline 1.1.2.2.4.3.2 & Finis grouting equipment & - & 851,000 & 553,000 & $1,404,000$ \\
\hline 1.1.2.2.4.3.3 & Grout water supply tank & - & 17,000 & 11,000 & 28,000 \\
\hline 1.1.2.2.4.3.4 & Grout waste box support frames & - & 129,000 & 84,000 & 213,000 \\
\hline 1.1.2.1.2 & Procurement_—storage building & 657,000 & - & - & - \\
\hline 1.1.2.1.2.1 & Procurement- $—$ storage building & - & 539,000 & 350,000 & 889,000 \\
\hline 1.1.2.1.2.2 & Procurement-storage building ventilation equipment & - & 31,000 & 20,000 & 52,000 \\
\hline 1.1.2.1.2.3 & Procurement—miscellaneous materials & - & 88,000 & 57,000 & 144,000 \\
\hline 1.1.2.2 & Facility construction & $7,376,000$ & - & - & - \\
\hline 1.1.2.2.1 & Construct building Pad A & $6,400,000$ & - & - & - \\
\hline 1.1.2.2.1.1 & Land survey & - & 17,000 & 11,000 & 29,000 \\
\hline 1.1.2.2.1.2 & Contour Pad A site & - & 25,000 & 17,000 & 42,000 \\
\hline 1.1.2.2.1.3 & Retrieval structure erection & - & $2,229,000$ & $1,449,000$ & $3,678,000$ \\
\hline 1.1.2.2.1.4 & Airlock structure erection & - & 315,000 & 205,000 & 520,000 \\
\hline 1.1.2.2.1.5 & Access roadway & - & 88,000 & 57,000 & 145,000 \\
\hline 1.1.2.2.1.6 & Site drainage & - & 41,000 & 27,000 & 68,000 \\
\hline 1.1.2.2.1.7 & Fire detection & - & 76,000 & 49,000 & 126,000 \\
\hline 1.1.2.2.1.8 & Retrieval enclosure mechanical & - & $1,087,000$ & 706,000 & $1,793,000$ \\
\hline 1.1.2.2.1.9 & Retrieval enclosure electrical & - & $1,028,000$ & 668,000 & $1,696,000$ \\
\hline 1.1.2.2.1.10 & Airlock mechanical, electrical, and interior walls & - & 738,000 & 480,000 & $1,218,000$ \\
\hline 1.1.2.2.1.11 & Electrical distribution & - & 754,000 & 490,000 & $1,245,000$ \\
\hline 1.1.2.2.2 & Construction—-storage building & 575,000 & - & - & - \\
\hline 1.1.2.2.2.1 & Construction — storage enclosure & 355,000 & - & - & - \\
\hline 1.1.2.2.2.1.1 & Construction-storage building concrete & - & 59,000 & 39,000 & 98,000 \\
\hline 1.1.2.2.2.1.2 & Construction—-storage building structural & - & 117,000 & 76,000 & 193,000 \\
\hline 1.1.2.2.2.1.3 & Construction-storage building exterior fabric and liner & - & 128,000 & 83,000 & 211,000 \\
\hline 1.1.2.2.2.1.5 & Construction-storage building punch list & - & 15,000 & 10,000 & 24,000 \\
\hline 1.1.2.2.2.1.6 & Construction-storage building equipment & - & 36,000 & 23,000 & 59,000 \\
\hline 1.1.2.2.2.2 & Mechanical & 38,000 & - & - & - \\
\hline 1.1.2.2.2.2.1 & General costs-mechanical & - & 3,000 & 2,000 & 5,000 \\
\hline 1.1.2.2.2.2.2 & Install ventilation equipment & - & 19,000 & 12,000 & 31,000 \\
\hline 1.1.2.2.2.2.3 & Water storage tank & - & 17,000 & 11,000 & 28,000 \\
\hline 1.1.2.2.2.3 & Electrical & 181,000 & - & - & - \\
\hline 1.1.2.2.2.3.1 & Electrical details & - & 181,000 & 118,000 & 299,000 \\
\hline 1.1.2.2.3 & Facility and equipment maintenance & - & 402,000 & 261,000 & 663,000 \\
\hline
\end{tabular}


Table F-64. (continued).

\begin{tabular}{|c|c|c|c|c|c|}
\hline Level & Description & $\begin{array}{l}\text { Subtotals }^{\mathrm{a}} \\
(\$)\end{array}$ & $\begin{array}{c}\text { Estimate }^{a} \\
(\$)\end{array}$ & $\begin{array}{c}\text { Contingency } \\
(\$)\end{array}$ & $\begin{array}{c}\text { Total }^{\mathrm{a}, \mathrm{c}} \\
(\$)\end{array}$ \\
\hline 1.1 .4 & Remediation & $28,007,000$ & - & - & - \\
\hline 1.1.4.1 & Pad A excavation & $9,315,000$ & - & - & - \\
\hline 1.1.4.1.1 & Waste retrieval $(\mathrm{Pad} \mathrm{A})$ & $9,315,000$ & - & - & - \\
\hline 1.1.4.1.1.1 & Support personal for waste retrieval ( $\mathrm{Pad} \mathrm{A})$ & - & $8,464,000$ & $5,501,000$ & $13,965,000$ \\
\hline 1.1.4.1.1.2 & Waste retrieval equipment $(\operatorname{Pad} \mathrm{A})$ & - & 851,000 & 553,000 & $1,404,000$ \\
\hline 1.1.4.2 & Grouting & $12,796,000$ & - & - & - \\
\hline 1.1.4.2.1 & Debris grouting & - & $1,426,000$ & 927,000 & $2,352,000$ \\
\hline 1.1.4.2.2 & Fines grouting & - & $11,370,000$ & $7,391,000$ & $18,761,000$ \\
\hline 1.1.4.3 & Move waste boxes to low level waste pit & - & 569,000 & 370,000 & 939,000 \\
\hline 1.1.4.4 & Demolition and removal & - & $5,327,000$ & $3,463,000$ & $8,790,000$ \\
\hline 1.2 & Professional and technical services & $17,968,000$ & - & - & - \\
\hline 1.2 .1 & Project management & - & $5,285,000$ & - & $5,285,000$ \\
\hline 1.2 .2 & Remedial design and remedial action work plan & $7,399,000$ & - & - & - \\
\hline 1.2.2.1 & Remedial design & - & $5,285,000$ & - & $5,285,000$ \\
\hline 1.2.2.2 & Remedial action work plan & - & $2,114,000$ & - & $2,114,000$ \\
\hline \multirow[t]{3}{*}{1.2 .3} & Construction management & - & $5,285,000$ & - & $5,285,000$ \\
\hline & \multicolumn{2}{|l|}{ Total capital cost ${ }^{\mathrm{c}}$} & $67,613,000$ & $32,269,000$ & $99,882,000$ \\
\hline & \multicolumn{5}{|c|}{$\begin{array}{l}\text { a. Values are rounded to the nearest } \$ 1,000 \text {. } \\
\text { b. Capital cost contingency is } 47.7 \% \text { of the estimate. } \\
\text { c. Totals were derived for the summation of nonrounded subcomponent values. Therefore, totals are not equal to the summation of the rounded subcomponent values shown } \\
\text { above. See Table F-3 for nonrounded totals. }\end{array}$} \\
\hline
\end{tabular}




\section{F-20. MODULE 19: MONITORING}

\section{F-20.1 Purpose}

This estimate will be used as a cost-comparative tool to examine the different options regarding the SDA.

\section{F-20.2 Scope of Work}

The scope of work consists of installing passive ICs and providing surveillance and monitoring of the SDA for a period of 100 years.

Long-term operations and monitoring activities include the following:

- $\quad$ Groundwater monitoring

- $\quad$ Vadose zone monitoring.

Subcontractor periodic costs include:

- $\quad$ Annual summary reports during the operations and monitoring period

- $\quad 5$-year reviews during the operations and monitoring period

- $\quad$ Operations and monitoring report following the operations and monitoring period.

\section{F-20.3 Basis of the Estimate}

A. Costs for operations and monitoring activities were extracted from the Preliminary Evaluation of Remedial Alternatives for the Subsurface Disposal Area (Zitnik et al. 2002). Appropriate general subcontractor markups for overhead, profit, and bond were applied to the costs extracted from this previous estimate.

B. Periodic costs were based on costs extracted from the "ISG Project FY 2005-FY 2011" cost estimate, File Number 5987, dated August 3, 2004. Appropriate general subcontractor markups for overhead, profit, and bond were applied to the costs extracted from this previous estimate.

\section{F-20.4 Assumptions}

\section{A. Schedule}

Figure F-20 illustrates the project schedule. 


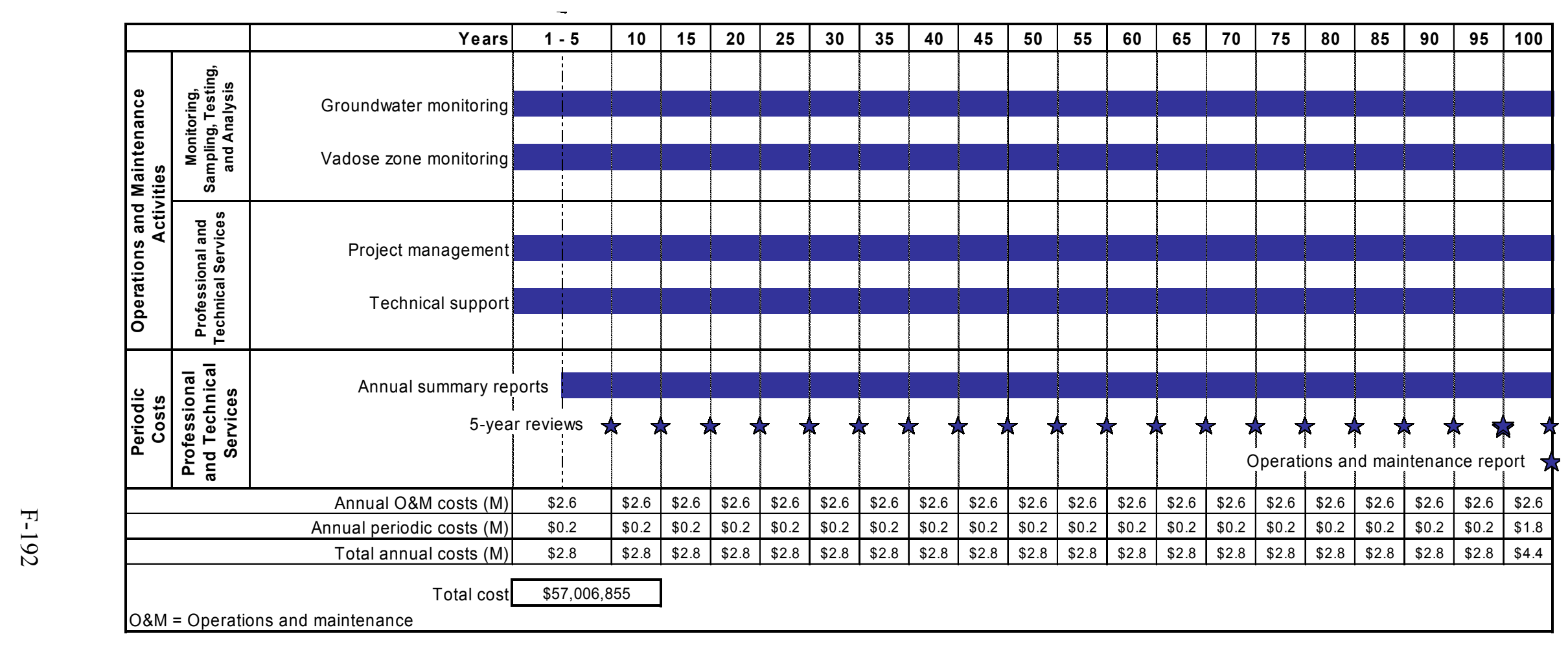

Figure F-20. Module 19 monitoring only schedule. 


\section{B. Long-term operating and monitoring (operations and monitoring costs)}

1. Operations and monitoring activities will include groundwater and vadose zone monitoring.

2. Operable Unit 7-13/14 will fund groundwater and vadose zone monitoring for the first 5 years following project completion (costs are included in this estimate).

3. The INL Sitewide Monitoring Program will fund groundwater and vadose zone monitoring from the sixth year to the end of the IC period (costs are included in this estimate).

4. The INL Sitewide Monitoring Program will provide any required perimeter radiological survey for the SDA and adjacent areas throughout the IC period (costs are not included in this estimate).

5. The INL Sitewide Monitoring Program will provide any required surface water and air monitoring for the SDA and adjacent areas throughout the IC period (costs are not included in this estimate).

6. The INL Sitewide Monitoring Program will provide any required biotic monitoring for the SDA and adjacent areas throughout the IC period (costs are not included in this estimate).

7. Environmental monitoring will continue for 100 years following issuance of the ROD. Estimated monitoring requirements and projected labor efforts are summarized in surface barrier estimates. Estimated costs of required laboratory analyses are summarized in surface barrier estimates.

8. This estimate does not include costs for maintaining and operating the OCVZ system treatment units or costs for sampling and analyzing OCVZ vapor ports for volatile organics. These costs are captured in Estimate Number 5992-S (Module 20a).

9. A $10 \%$ allocation has been included for replacement parts and equipment for existing wells and lysimeters.

10. Reports will be prepared annually, summarizing analytical and field data.

11. Project management for the operations and monitoring program is $5 \%$ of the overall operations and monitoring costs plus contingency.

\section{Periodic Costs}

Reviews will be conducted once every 5 years for 100 years. Five-year reviews will not result in additions or modifications to the remedy. No costs are included in the estimate for remedy additions or modifications. 


\section{F-20.5 Contingency Guideline Implementation}

The total operations and monitoring cost contingency for Module 19 is $20 \%$. This contingency is the average contingency of the monitoring, sampling, and testing activities (i.e., 25\%) and the professional and technical services (i.e., $0 \%$ ).

The total periodic cost contingency for Module 19 is $0 \%$ (i.e., the contingency for the professional and technical services).

\section{F-20.6 Estimate Summary}

Table F-65 provides rough order of magnitude allocations of the methodologies used to develop the cost estimate for Module 19.

Table F-65. Rough order of magnitude allocations of the methodologies used to develop the cost estimate for Module 19.

\begin{tabular}{lc}
\hline Estimate Methodology & $\begin{array}{c}\text { Rough Order of Magnitude } \\
(\%)\end{array}$ \\
\hline Project team & 65 \\
Recorded actuals & 0 \\
Parametric & 0 \\
Vendor quotes & 0 \\
Other (estimating manuals) & 35 \\
Total & $\mathbf{1 0 0}$ \\
\hline
\end{tabular}

\section{F-20.7 Other Comments or Concerns Specific to the Estimate}

A. All costs reflect present day costs. No escalation has been included in the estimate.

B. Costs for Idaho state sales tax $(5 \%)$ on material purchases are not applicable to the estimate.

C. Because the work activities identified in this estimate will not begin until after September 30, 2005, no $\mathrm{CH} 2 \mathrm{M}-\mathrm{WG}$ Idaho general and administrative costs have been included in this estimate according to the recent direction received by Estimating Services.

\section{F-20.8 Summary}

Tables F-66 through F-68 provide summary cost information for Module 19. 
Table F-66. Capital costs for Module 19: Operable Unit 7-13/14 Feasibility Study—Monitoring, Project Number: 5992-R.

\begin{tabular}{|c|c|c|c|c|c|}
\hline Level & $\begin{array}{r}\text { Description } \\
\end{array}$ & $\begin{array}{c}\text { Subtotals }{ }^{\mathrm{a}} \\
(\$)\end{array}$ & $\begin{array}{c}\text { Estimate }^{\mathrm{a}} \\
(\$)\end{array}$ & $\begin{array}{c}\text { Contingency } \\
(\$)\end{array}$ & $\begin{array}{c}\text { Total }^{\mathrm{a}, \mathrm{c}} \\
(\$)\end{array}$ \\
\hline 1.1 & Monitoring, sampling, testing, and analysis & $34,853,000$ & - & - & - \\
\hline 1.1 .1 & Mobilization and demobilization & $9,912,000$ & - & - & - \\
\hline 1.1.1.1 & $\begin{array}{l}\text { Groundwater monitoring semiannually for } 5 \text { years } \\
\text { (10 sampling events) }\end{array}$ & - & 813,000 & 203,000 & $1,016,000$ \\
\hline 1.1.1.2 & Groundwater monitoring annually for 95 years ( 95 sampling events) & - & $7,723,000$ & $1,931,000$ & $9,653,000$ \\
\hline 1.1.1.3 & $\begin{array}{l}\text { Replacement parts and equipment costs } \\
\text { (assume } 10 \% \text { of total groundwater monitoring costs) }\end{array}$ & - & $1,377,000$ & 344,000 & $1,721,000$ \\
\hline 1.1 .2 & Vadose zone monitoring & $24,941,000$ & - & - & - \\
\hline 1.1.2.1 & Sample 100 lysimeters one time per year in late spring & - & $11,172,000$ & $2,793,000$ & $13,965,000$ \\
\hline 1.1.2.2 & Sample and analyze 20 vapor ports four times per year for 5 years & - & 266,000 & 67,000 & 333,000 \\
\hline 1.1.2.3 & $\begin{array}{l}\text { Sample and analyze } 20 \text { vapor ports one time per year thereafter for } \\
95 \text { years }\end{array}$ & - & $1,265,000$ & 316,000 & $1,581,000$ \\
\hline 1.1.2.4 & Analyze 50 advanced tensiometers & $8,774,000$ & - & - & - \\
\hline 1.1.2.4.1 & $\begin{array}{l}\text { Maintenance of advanced tensiometers four times per year for } \\
100 \text { years }\end{array}$ & - & $5,161,000$ & $1,290,000$ & $6,452,000$ \\
\hline 1.1.2.4.2 & $\begin{array}{l}\text { Data evaluation of advanced tensiometers four times per year for } \\
100 \text { years }\end{array}$ & - & $2,581,000$ & 645,000 & $3,226,000$ \\
\hline 1.1.2.4.3 & $\begin{array}{l}\text { Data reporting of advanced tensiometers one time per year for } \\
100 \text { years }\end{array}$ & - & $1,032,000$ & 258,000 & $1,290,000$ \\
\hline 1.1.2.5 & $\begin{array}{l}\text { Replacement parts and equipment costs } \\
\text { (assume } 10 \% \text { of total vadose zone monitoring costs) }\end{array}$ & - & $3,464,000$ & 866,000 & $4,330,000$ \\
\hline 1.2 & Professional and technical services & $8,713,000$ & - & - & - \\
\hline 1.2 .1 & Project management & - & $2,178,000$ & - & $2,178,000$ \\
\hline \multirow[t]{3}{*}{1.2 .2} & Technical support & - & $6,535,000$ & - & $6,535,000$ \\
\hline & Total operations and maintenance $\operatorname{cost}^{\mathrm{c}}$ & - & $43,566,000$ & $8,713,000$ & $52,279,000$ \\
\hline & \multicolumn{5}{|c|}{$\begin{array}{l}\text { a. Values are rounded to the nearest } \$ 1,000 \text {. } \\
\text { b. Operations and maintenance cost contingency is } 20.0 \% \text { of the estimate. } \\
\text { c. Totals were derived for the summation of nonrounded subcomponent values. Therefore, totals are not equal to the summation of the rounded subcomponent values shown } \\
\text { above. See Table F-3 for nonrounded totals. }\end{array}$} \\
\hline
\end{tabular}


Table F-67. Periodic cost information for Module 19: Operable Unit 7-13/14 Feasibility Study—Monitoring, Project Number: 5992-R.

\begin{tabular}{|c|c|c|c|c|c|}
\hline Level & Description & $\begin{array}{c}\text { Subtotals }^{\mathrm{a}} \\
(\$)\end{array}$ & $\begin{array}{c}\text { Estimate }^{a} \\
(\$)\end{array}$ & $\begin{array}{c}\text { Contingency }{ }^{\mathrm{a}, \mathrm{b}} \\
(\$)\end{array}$ & $\begin{array}{c}\text { Total }^{\mathrm{a}, \mathrm{c}} \\
(\$)\end{array}$ \\
\hline 2.1 & Professional and technical services (periodic) & $4,728,000$ & - & - & - \\
\hline 2.1 .1 & Annual summary reports & - & $1,935,000$ & - & $1,935,000$ \\
\hline 2.1.2 & 5-year reviews & - & $1,161,000$ & - & $1,161,000$ \\
\hline \multirow[t]{3}{*}{2.1 .3} & Operations and maintenance report & - & $1,631,000$ & - & $1,631,000$ \\
\hline & Total periodic cost $^{\mathrm{c}}$ & - & $4,728,000$ & - & $4,728,000$ \\
\hline & \multicolumn{5}{|c|}{$\begin{array}{l}\text { a. Values are rounded to the nearest } \$ 1,000 \text {. } \\
\text { b. Periodic cost contingency is } 0.0 \% \text { of the estimate. } \\
\text { c. Totals were derived for the summation of nonrounded subcomponent values. Therefore, totals are not equal to the summation of the rounded subcomponent values } \\
\text { shown above. See Table F-3 for nonrounded totals. }\end{array}$} \\
\hline
\end{tabular}

Table F-68. Total cost information for Module 19: Operable Unit 7-13/14 Feasibility Study-Monitoring, Project Number: 5992-R.

\begin{tabular}{|c|c|c|c|}
\hline & $\begin{array}{c}\text { Estimate }^{\mathrm{a}} \\
(\$)\end{array}$ & $\begin{array}{c}\text { Contingency } \\
(\$)\end{array}$ & $\begin{array}{c}\text { Total }^{\mathrm{a}, \mathrm{c}} \\
(\$)\end{array}$ \\
\hline Total cost for monitoring only ${ }^{\mathrm{c}}$ & $48,294,000$ & $8,713,000$ & $57,007,000$ \\
\hline
\end{tabular}




\section{F-21. MODULE 20A: ORGANIC CONTAMINATION IN THE VADOSE ZONE PROJECT 5-YEAR OPERATIONS AND MONITORING}

\section{F-21.1 Purpose}

This estimate will be used as a cost-comparative tool to examine the different options regarding the SDA.

\section{F-21.2 Scope of Work} period.

The scope of work consists of operating and maintaining the OCVZ operation throughout a 5-year

Subcontractor remediation consists of the following:

- $\quad$ OCVZ vapor port sampling and subsequent analysis of those samples

- $\quad$ Reporting results from the vapor port sampling

- $\quad$ Periodic maintenance of the OCVZ system treatment units

- "Modification planning and implementation" pertaining to the replacement of system components subject to failure within a 5-year period.

\section{F-21.3 Basis of the Estimate}

The following sequential process, rationale, and estimating methodologies were used to define the activities, quantities, and resources that were used in the preparation of this cost estimate.

A. Estimates were developed, using Success@ estimating software by U.S. Cost, to a level of detail consistent with the available documents and information.

B. Project scope and methodologies were prepared from discussions with the requester and the project team.

C. Cost information pertaining to "modification planning and implementation" and "maintenance" was extracted from the OCVZ life-cycle baseline Fiscal Year 2006 through Fiscal Year 2012. Values from the life-cycle baseline were scaled to reflect a 5-year period. Appropriate general contractor markups for overhead, profit, and bond were applied to the costs extracted from this previous estimate.

\section{F-21.4 Assumptions}

\section{A. General assumptions}

1. Based on discussions with the project team, the design and construction of this project will be subcontracted. Subcontractor tasks include performing all periodic maintenance and equipment replacement (e.g., catalyst replacement) and writing the remedial design and remedial action work plan. The ICP tasks include project management oversight (e.g., interface agreements, contract awards, and oversight). Construction management is not required for this maintenance and operational period. 
2. The INL Site resources (i.e., Central Facilities Area, medical facilities, geotechnical laboratory, fire department, security, utilities at the SDA) will be available for the duration of the project.

3. No fire water, potable water, buried power, propane, sewer, or storm drain utilities will be encountered or required to be removed or relocated.

4. The cost estimate does not consider or address funding restrictions. Sufficient funding will be available in a manner that allows optimum usage of that funding as estimated and scheduled.

\section{B. Schedule}

Figure F-21 illustrates the project schedule.

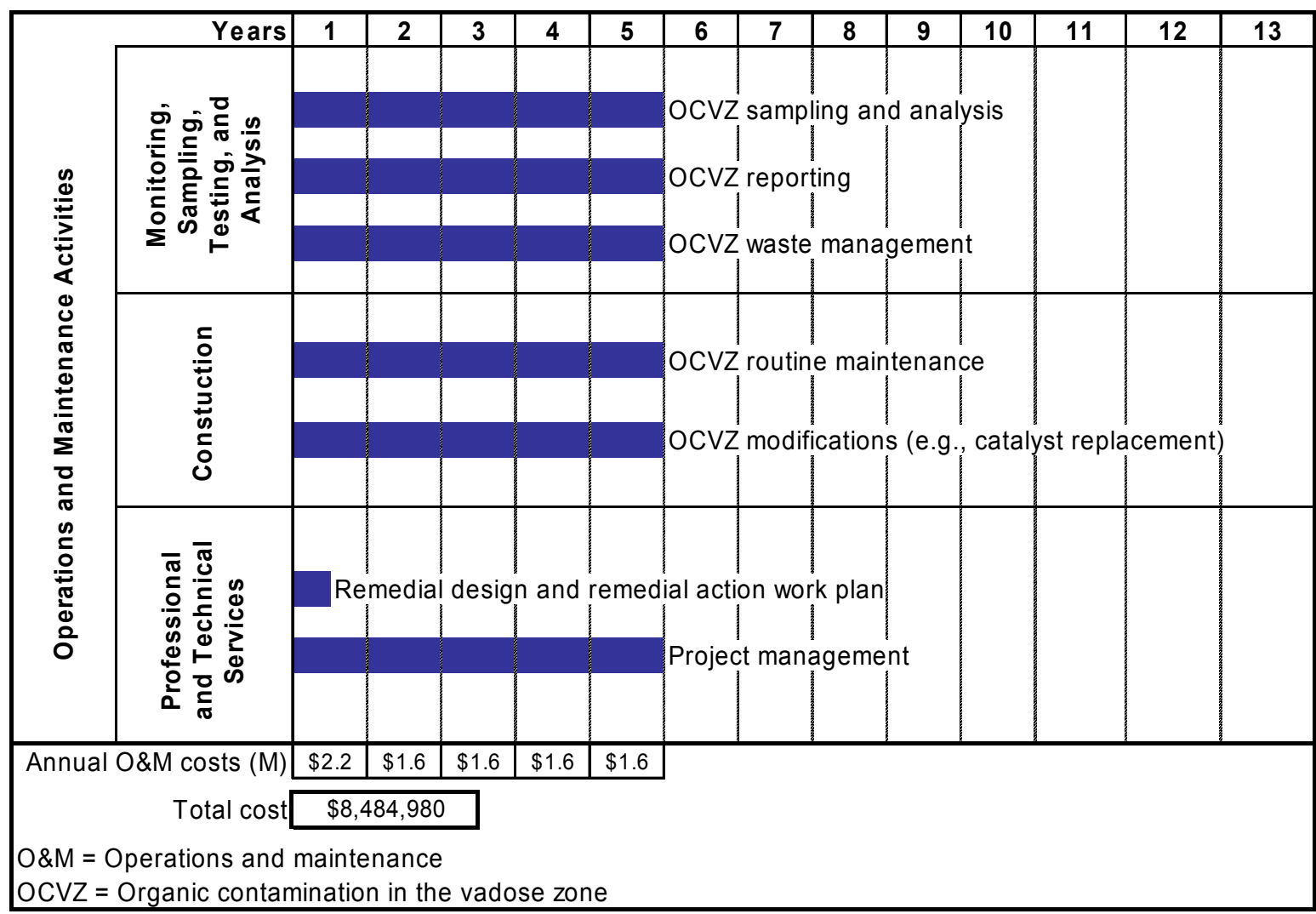

Figure F-21. Module 20a 5-year Organic Contamination in the Vadose Zone Project operations and maintenance schedule.

\section{Remediation (capital costs)}

1. Cost allowances are based on a 5-year maintenance schedule.

2. Equipment replacements during this 5-year life span are standard type consumables, such as catalyst materials. 


\section{F-21.5 Contingency Guideline Implementation}

The total capital cost contingency for Module 20a is $17.35 \%$. This contingency is the average contingency of the construction activities (i.e., 20\%) and the professional and technical services (i.e., $0 \%$ ).

\section{F-21.6 Estimate Summary}

Table F-69 provides rough order of magnitude allocations of the methodologies used to develop the cost estimate for Module 20a.

Table F-69. Rough order of magnitude allocations of the methodologies used to develop the cost estimate for Module 20a.

\begin{tabular}{lc}
\hline Estimate Methodology & $\begin{array}{c}\text { Rough Order of Magnitude } \\
(\%)\end{array}$ \\
\hline Project team & 20 \\
Recorded actuals & 0 \\
Parametric & 0 \\
Vendor quotes & 0 \\
Other & 80 \\
Total & $\mathbf{1 0 0}$ \\
\hline
\end{tabular}

\section{F-21.7 Other Comments or Concerns Specific to the Estimate}

A. Activities have not been escalated to the activity midpoint

B. Subcontractor labor costs reflect INL Site Stabilization Agreement craft labor rates

C. $\mathrm{CH} 2 \mathrm{M}-\mathrm{WG}$ Idaho labor rates reflect fully burdened present day rates.

\section{F-21.8 Summary}

Table F-70 provides capital cost information for Module 20a. 
Table F-70. Capital costs for Module 20a: Operable Unit 7-13/14 Feasibility Study_Organic Contamination in the Vadose Zone Maintenance and Operations (5 years), Project Number: 5992-S.

\begin{tabular}{|c|c|c|c|c|c|}
\hline Level & Description & $\begin{array}{c}\text { Subtotals }^{\mathrm{a}} \\
(\$)\end{array}$ & $\begin{array}{c}\text { Estimate }^{\mathrm{a}} \\
(\$)\end{array}$ & $\begin{array}{c}\text { Contingency }^{\mathrm{a}, \mathrm{b}} \\
(\$)\end{array}$ & $\begin{array}{c}\text { Total }^{\mathrm{a}, \mathrm{c}} \\
(\$) \\
\end{array}$ \\
\hline 1.1 & OCVZ operation and maintenance & $6,272,000$ & - & - & - \\
\hline 1.1.1 & Mobilization and demobilization & $2,525,000$ & - & - & - \\
\hline 1.1.1.1 & OCVZ sampling and analysis & - & 989,000 & 198,000 & $1,187,000$ \\
\hline 1.1.1.2 & OCVZ reporting & - & $1,485,000$ & 297,000 & $1,782,000$ \\
\hline 1.1.1.3 & OCVZ waste management & - & 50,000 & 10,000 & 60,000 \\
\hline 1.1.1.2 & OCVZ construction & $3,747,000$ & - & - & - \\
\hline 1.1.1.2.1 & OCVZ maintenance & - & $2,627,000$ & 525,000 & $3,152,000$ \\
\hline 1.1.1.2.2 & OCVZ modification planning and implementation & - & $1,120,000$ & 224,000 & $1,344,000$ \\
\hline 1.2 & Professional and technical services & 959,000 & - & - & - \\
\hline 1.2 .1 & Project management & - & 376,000 & - & 376,000 \\
\hline 1.2 .2 & Remedial design and remedial action work plan & 583,000 & - & - & - \\
\hline 1.2.2.1 & Remedial design & - & 388,000 & - & 388,000 \\
\hline 1.2.2.2 & Remedial action work plan & - & 194,000 & - & 194,000 \\
\hline & Total capital cost ${ }^{\mathrm{c}}$ & - & $7,231,000$ & $1,254,000$ & $8,485,000$ \\
\hline & $\begin{array}{l}\text { a. Values are rounded to the nearest } \$ 1,000 \text {. } \\
\text { b. Capital cost contingency is } 17.4 \% \text { of the estimate. } \\
\text { c. Totals were derived for the summation of nonrounded subcomponent values. The } \\
\text { above. See Table F-3 for nonrounded totals. } \\
\text { OCVZ = Organic Contamination in the Vadose Zone }\end{array}$ & totals are not ec & the summation & rounded subcomp & t values shown \\
\hline
\end{tabular}




\section{F-22. MODULE 20B: ORGANIC CONTAMINATION IN THE VADOSE ZONE PROJECT 20-YEAR TREATMENT UNIT REPLACEMENT \\ F-22.1 Purpose}

SDA.

This estimate will be used as a cost-comparative tool to examine the different options regarding the

\section{F-22.2 Scope of Work}

The scope of work consists of engineering, procuring, and replacing an existing OCVZ unit in the SDA at RWMC.

Subcontractor mobilization consists of the following:

- $\quad$ Generate operational plans (see Section F-22.4 for details)

- Generate a management self-assessment plan

- $\quad$ Mobilize equipment.

Subcontractor demobilization consists of the following:

- $\quad$ Shut down or demobilize equipment

- Generate a final inspection report following completion of treatment unit installation.

Subcontractor site preparation consists of the following:

- $\quad$ Replace an existing OCVZ unit, including associated controls and conductors as needed.

Subcontractor remediation consists of the following:

- $\quad$ Dispose of the existing OCVZ unit.

\section{F-22.3 Basis of the Estimate}

The following sequential process, rationale, and estimating methodologies were used to define the activities, quantities, and resources that were used in the preparation of this cost estimate.

A. Submittal and implementation costs were based on costs extracted from estimate File No. 5987, "ISG Project FY 2005-FY 2011," dated August 3, 2004. Appropriate general contractor markups for overhead, profit, and bond were applied to the costs extracted from this previous estimate.

B. Security costs were based on "Pit 4 Life-cycle Cost Estimate," File No. 5432. Appropriate general contractor markups for overhead, profit, and bond were applied to the costs extracted from this previous estimate.

C. Costs were developed, using the Success $@$ estimating software by U.S. Cost, to a level of detail consistent with the available documents and information.

D. The project scope and methodologies were prepared from discussions with the requester and the project team. 
E. The final inspection costs were based on the "Preliminary Evaluation of Remedial Alternatives for the Subsurface Disposal Area" (Zitnik et al. 2002). Appropriate general contractor markups for overhead, profit, and bond were applied to the costs extracted from this previous estimate.

F. Cost information for procurement of the new OCVZ units was provided by the OCVZ project manager that originally installed these units. Appropriate general contractor markups for overhead, profit, and bond were applied to the costs extracted from this previous estimate.

G. Replacement costs for "instrumentation refurbishment" were based on Estimate No. 5984-II and the bottoms-up estimating technique for a typical system upgrade during unit replacement.

\section{F-22.4 Assumptions}

\section{A. General assumptions}

1. Based on discussions with the project team, the design and construction of this project will be subcontracted. Subcontractor tasks include generating all required plans, performing all site preparation and remediation work, placing all ICs, and writing all reports. The ICP tasks include project management oversight (e.g., interface agreements, contract awards, and oversight) and construction management oversight (e.g., vendor data acceptance, preexisting technical procedure revisions, acceptance testing, and management self-assessments).

2. The INL Site resources (i.e., Central Facilities Area, medical facilities, geotechnical laboratory, fire department, security, utilities in the SDA) will be available for the duration of the project.

3. No fire water, potable water, buried power, propane, sewer, or storm drain utilities will be encountered or required to be removed or relocated.

4. Structures obstructing unit replacement in the SDA will be completely removed by those projects before the start of this project and at no cost to this project.

5. No equipment flaggers or traffic control will be needed. Once the field work begins, the subcontractor will have complete control of the area.

6. The cost estimate does not consider or address funding restrictions. Sufficient funding will be available in a manner that allows optimum usage of that funding as estimated and scheduled. 


\section{B. Schedule}

Figure F-22 illustrates the project schedule.

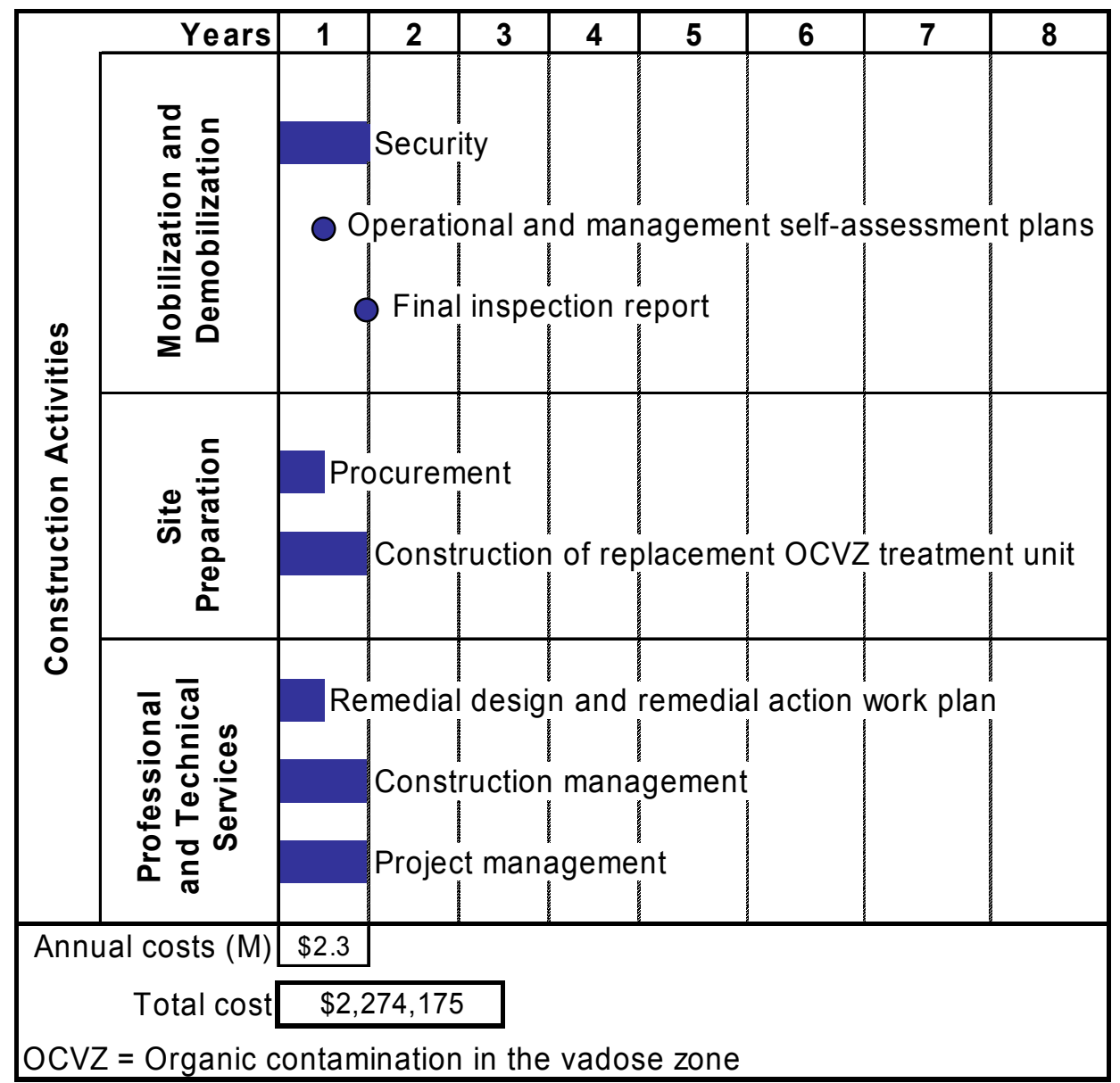

Figure F-22. Module 20b design and construction schedule for replacement of the Organic Contamination in the Vadose Zone Project treatment unit.

\section{Mobilization and demobilization (capital costs)}

1. Equipment and personnel entering and exiting the SDA will not be required to survey in or out, or stop for security access. As they travel through the gates, personnel will only be required to flash their identification to the personnel manning those gates. This estimate assumes free and easy access at the gates for all construction personnel and equipment.

2. ICP personnel will have access to existing RWMC buildings that can be used as temporary offices during this work.

\section{Site preparation (capital costs)}

The replacement unit will have the same configurations as the existing unit. 


\section{E. Remediation (capital costs)}

Costs for demolition and removal of the worn out OCVZ unit are $25 \%$ of the purchase costs of the replacement unit.

\section{F-22.5 Contingency Guideline Implementation}

The total capital cost contingency for contaminant grouting is $15.93 \%$. This contingency is the average contingency of the construction activities (i.e., 20\%) and the professional and technical services (i.e., $0 \%$ ).

\section{F-22.6 Estimate Summary}

Table F-71 provides rough order of magnitude allocations of the methodologies used to develop the cost estimate for Module 20b.

Table F-71. Rough order of magnitude allocations of the methodologies used to develop the cost estimate for Module 20b.

\begin{tabular}{lc}
\hline Estimate Methodology & $\begin{array}{c}\text { Rough Order of Magnitude } \\
(\%)\end{array}$ \\
\hline Project team & 30 \\
Recorded actuals & 0 \\
Parametric & 20 \\
Vendor quotes & 20 \\
Other & 30 \\
Total & $\mathbf{1 0 0}$ \\
\hline
\end{tabular}

\section{F-22.7 Other Comments or Concerns Specific to the Estimate}

A. Activities have not been escalated to the activity midpoint.

B. Subcontractor labor costs reflect INL Site Stabilization Agreement craft labor rates.

C. $\mathrm{CH} 2 \mathrm{M}-\mathrm{WG}$ Idaho labor rates reflect fully burdened present day rates.

\section{F-22.8 Summary}

Table F-72 provides capital cost information for Module 20b. 
Table F-72. Capital costs for Module 20b: Operable Unit 7-13/14 Feasibility Study-Organic Contamination in the Vadose Zone Maintenance and Operations (Unit Replacement), Project Number: 5992-T.

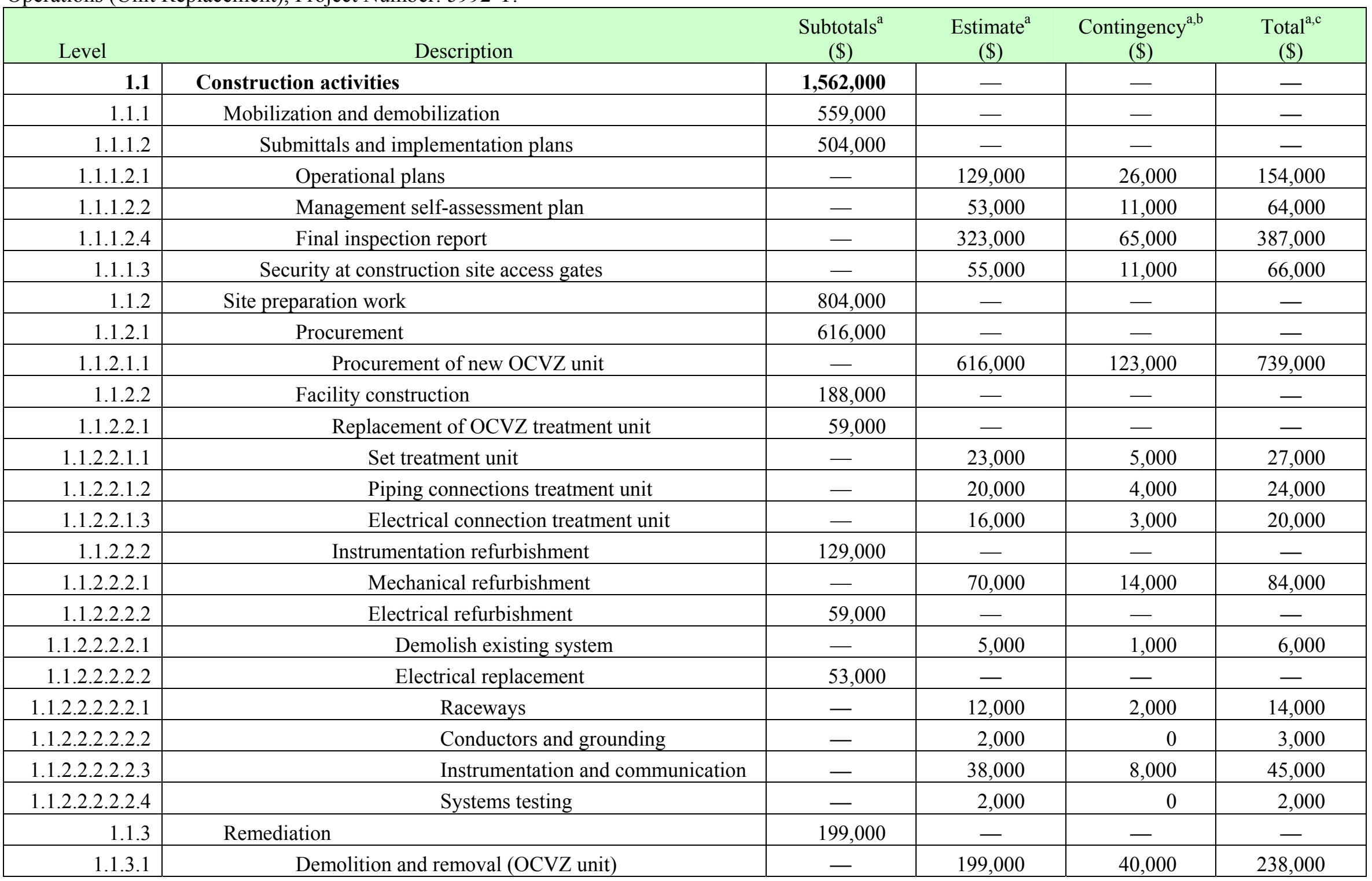


Table F-72. (continued).

\begin{tabular}{|c|c|c|c|c|c|}
\hline Level & Description & $\begin{array}{c}\text { Subtotals }^{\mathrm{a}} \\
(\$)\end{array}$ & $\begin{array}{c}\text { Estimate }^{\mathrm{a}} \\
(\$)\end{array}$ & $\begin{array}{c}\text { Contingency }^{\mathrm{a}, \mathrm{b}} \\
(\$)\end{array}$ & $\begin{array}{c}\text { Total }^{\mathrm{a}, \mathrm{c}} \\
(\$)\end{array}$ \\
\hline 1.2 & Professional and technical services & 400,000 & - & - & - \\
\hline 1.2 .1 & Project management & - & 94,000 & - & 94,000 \\
\hline 1.2 .2 & Remedial design and remedial action work plan & 193,000 & - & - & - \\
\hline 1.2.2.1 & Remedial design & - & 145,000 & - & 145,000 \\
\hline 1.2.2.2 & Remedial action work plan & - & 48,000 & - & 48,000 \\
\hline \multirow[t]{3}{*}{1.2 .3} & Construction management & - & 112,000 & - & 112,000 \\
\hline & Total capital cost ${ }^{\mathrm{c}}$ & - & $1,962,000$ & 312,000 & $2,274,000$ \\
\hline & \multicolumn{5}{|c|}{$\begin{array}{l}\text { a. Values are rounded to the nearest } \$ 1,000 \text {. } \\
\text { b. Capital cost contingency is } 15.9 \% \text { of the estimate. } \\
\text { c. Totals were derived for the summation of nonrounded subcomponent values. Therefore, totals are not equal to the summation of the rounded subcomponent values shown } \\
\text { above. See Table F-3 for nonrounded totals. } \\
\text { OCVZ = Organic Contamination in the Vadose Zone }\end{array}$} \\
\hline
\end{tabular}




\section{F-23. MODULE 20C: ORGANIC CONTAMINATION IN THE VADOSE ZONE PROJECT MONITORING TO SUPPORT SHUTDOWN}

\section{F-23.1 Purpose}

SDA.

This estimate will be used as a cost-comparative tool to examine the different options regarding the

\section{F-23.2 Scope of Work}

The scope of work includes sampling 30 vadose zone vapor ports for 1 year following closure of the OCVZ system treatment units. An off-INL Site laboratory performs analysis of the vapor samples. The sampling results are used to validate the decision to shutdown the OCVZ units.

\section{F-23.3 Basis of the Estimate}

The following sequential process, rationale, and estimating methodologies were used to define the activities, quantities, and the resources that were used in the preparation of this cost estimate.

A. The project scope and methodologies were prepared from discussions with the project team.

B. Costs were developed, using the Success $@$ estimating software by U.S. Cost, to a level of detail consistent with the available documents and information.

C. Appropriate general subcontractor markups for overhead, profit, and bond were applied to the costs extracted from a previous estimate.

D. The Fiscal Year 2006 INL Site Stabilization Agreement craft wage rates were used in the estimate.

E. The hours estimated for sample extraction were provided by the ICP CERCLA remediation group.

F. The hours estimated for sample analysis were provided by the ICP environmental services group.

\section{F-23.4 Assumptions}

\section{A. General assumptions}

1. Based on discussions with the project team, the design and construction of this project will be subcontracted. Subcontractor tasks include vadose zone sampling and analysis on a quarterly basis for 1 year. The ICP tasks include project management oversight (e.g., interface agreements, contract awards, and oversight).

2. The INL Site resources (i.e., Central Facilities Area, medical facilities, geotechnical laboratory, fire department, security, utilities at the SDA) will be available for the duration of the project.

3. No fire water, potable water, buried power, propane, sewer, or storm drain utilities will be encountered or required to be removed or relocated. 


\section{B. Schedule}

1. Figure F-23 illustrates the project schedule.

2. Work activities are planned to be performed during the 10 hours per day, 5 days per week work schedule.

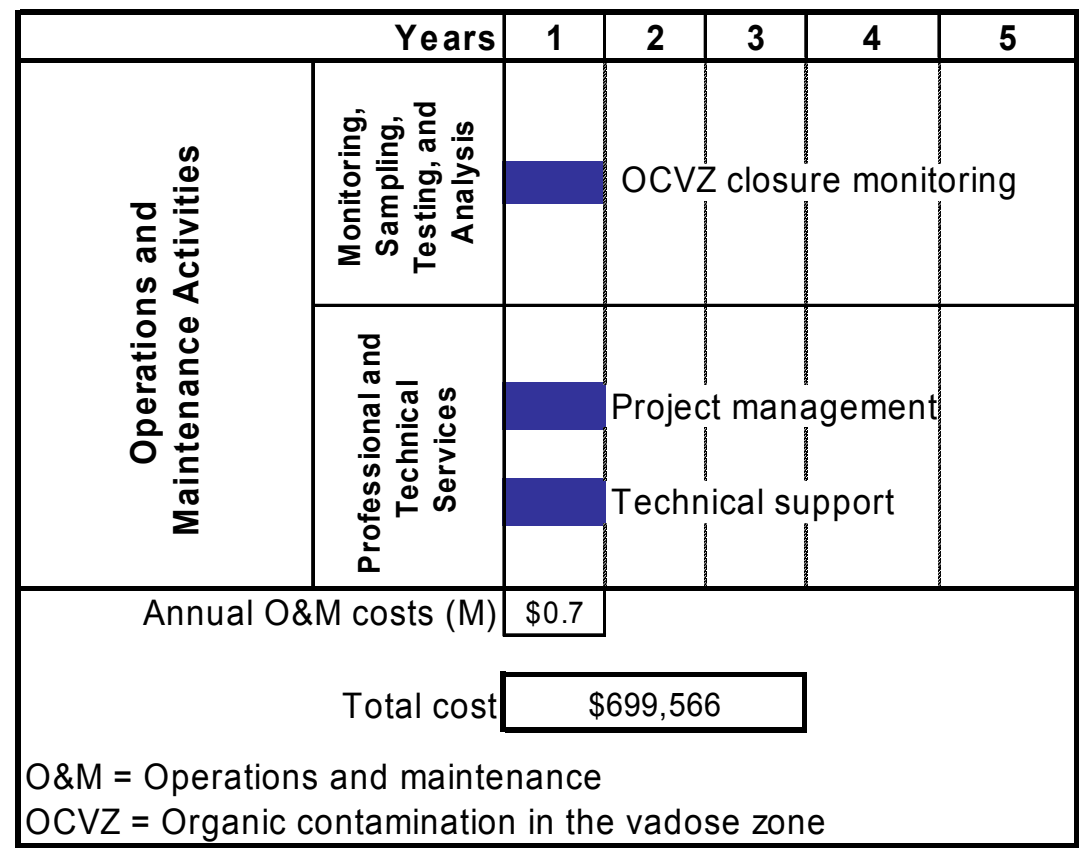

Figure F-23. Module 20c operations and maintenance schedule for monitoring the vadose zone following shutdown of the OCVZ Project treatment unit.

\section{Long-term operating and maintenance and monitoring (operation and maintenance costs)}

1. Operations and maintenance activities will include vadose zone monitoring.

2. Vadose zone monitoring will continue for 1 year following the shutdown of the OCVZ system treatment units. The estimated monitoring requirements and the projected labor effort (see Table F-73) is provided in the surface barrier estimates. Estimated costs of the required laboratory analyses are summarized within the surface barrier estimates.

3. This estimate does not include costs to maintain and operate the OCVZ system treatment units. These costs are captured in Estimate No. 5992-S, Module 20a.

4. A $10 \%$ allocation has been included for replacement parts and equipment for the existing wells and lysimeters.

5. Project management for the operations and maintenance program is $5 \%$ of the overall operations and maintenance costs plus contingency.

6. Technical support for the operations and maintenance program is $15 \%$ of the overall operations and maintenance costs plus contingency. 
7. The number and frequency of OCVZ monitoring events will be renegotiated if Operable Unit 7-08 is subsumed into Operable Unit 7-13/14.

8. The OCVZ decision to shut down will be documented in a 5-year review report; a separate remedial action report will not be required if Operable Unit 7-08 is subsumed into Operable Unit 7-13/14.

9. The costs for reporting the results (i.e., annual review, 5-year review, and final operations and maintenance report) are captured in the periodic costs provided in the cap estimates (File No. 5992) (see Table F-74).

Table F-73. Module 20c estimated monitoring program.

\begin{tabular}{ccccc}
\hline Media & $\begin{array}{c}\text { Monitoring } \\
\text { Stations }\end{array}$ & $\begin{array}{c}\text { Monitoring } \\
\text { Frequency }\end{array}$ & $\begin{array}{c}\text { Estimated Labor } \\
\text { Hours per Event }\end{array}$ & Other Assumptions \\
\hline Vadose zone & 50 vapor ports & $\begin{array}{l}\text { Monthly for } \\
\text { 1 year }\end{array}$ & $\begin{array}{l}3 \text { personnel for } \\
2 \text { days }=60 \text { hours }\end{array}$ & $\begin{array}{l}50 \% \text { of the existing monitoring ports } \\
\text { will be sampled per period } \\
\text { (i.e., 50 samples) }\end{array}$ \\
\hline
\end{tabular}

Table F-74. Module 20c estimated analytical costs.

\begin{tabular}{lcc}
\hline & Target Analyte & $\begin{array}{c}\text { Vadose Zone Event } \\
\text { Vapor Ports Event } \\
\text { (50 samples) } \\
(\$)\end{array}$ \\
\hline Volatile organics & $\begin{array}{c}\text { Unit Cost } \\
\text { Analytical subtotal }\end{array}$ & 20,000 \\
\hline $\begin{array}{l}\text { Procurement (12\%) } \\
\text { Project adder }\end{array}$ & -00 & $\mathbf{2 0 , 0 0 0}$ \\
\hline $\begin{array}{l}\text { Totals } \\
\text { (listed in the "Other" column in the cost estimate) }\end{array}$ & - & 2,400 \\
\hline $\begin{array}{l}\text { a. Adder costs included task order statement, sampling and analysis plan table, data review, data tracking, data entry (i.e., Energy Research } \\
\text { Information System) upload, invoicing, and validation. }\end{array}$ & 2,000 \\
\hline
\end{tabular}

\section{F-23.5 Contingency Guideline Implementation}

The total operations and maintenance cost contingency is $16.13 \%$. This contingency is the average contingency of the monitoring, sampling, and testing activities (i.e., 20\%) and the professional and technical services (i.e., $0 \%$ ). 


\section{F-23.6 Estimate Summary}

Table F-75 provides rough order of magnitude allocations of the methodologies used to develop the cost estimate for Module 20c.

Table F-75. Rough order of magnitude allocations of the methodologies used to develop the cost estimate for Module 20c.

\begin{tabular}{lc}
\hline Estimate Methodology & $\begin{array}{r}\text { Rough Order of Magnitude } \\
(\%)\end{array}$ \\
\hline Project team & 100 \\
Recorded actuals & 0 \\
Parametric & 0 \\
Vendor quotes & 0 \\
Other (estimating manuals) & 0 \\
Total & $\mathbf{1 0 0}$ \\
\hline
\end{tabular}

\section{F-23.7 Other Comments or Concerns Specific to the Estimate}

A. All costs reflect present day costs. No escalation has been included in the estimate.

B. Costs for Idaho state sales tax $(5 \%)$ on material purchases have not been included.

C. Because work activities identified in this estimate will not begin until after September 30, 2005, no CH2M-WG Idaho general and administrative costs have been included in this estimate according to recent direction received by Estimating Services.

\section{F-23.8 Summary}

Table F-76 provides operations and maintenance cost information for Module 20c. 
Table F-76. Operations and maintenance cost information for Module 20c: Operable Unit 7-13/14 Feasibility Study-Organic Contamination in the Vadose Zone Maintenance and Operations (Shutdown), Project Number: 5992-U.

\begin{tabular}{|c|c|c|c|c|c|}
\hline Level & Description & $\begin{array}{l}\text { Subtotals }{ }^{\mathrm{a}} \\
(\$)\end{array}$ & $\begin{array}{l}\text { Estimate }^{\mathrm{a}} \\
\quad(\$)\end{array}$ & $\begin{array}{c}\text { Contingency }^{\mathrm{a}, \mathrm{b}} \\
(\$)\end{array}$ & $\begin{array}{c}\text { Total }^{\mathrm{a}, \mathrm{c}} \\
(\$)\end{array}$ \\
\hline 2.1 & Monitoring, sampling, testing, and analysis & 486,000 & - & - & - \\
\hline 2.1.1 & Mobilization and demobilization & 486,000 & - & - & - \\
\hline 2.1.1.1 & Sample and analyze 50 vapor ports two times per year for 1 year & - & 430,000 & 86,000 & 516,000 \\
\hline 2.1.1.2 & $\begin{array}{l}\text { Replacement parts and equipment costs } \\
\text { (assume } 10 \% \text { of total vadose zone monitoring costs) }\end{array}$ & - & 56,000 & 11,000 & 67,000 \\
\hline 2.2 & Professional and technical services & 117,000 & - & - & - \\
\hline 2.2.1 & Project management & - & 29,000 & - & 29,000 \\
\hline \multirow[t]{3}{*}{ 2.2.2 } & Technical support & - & 87,000 & - & 87,000 \\
\hline & Total operational and maintenance cost ${ }^{\mathrm{c}}$ & - & 602,000 & 97,000 & 700,000 \\
\hline & \multicolumn{5}{|c|}{$\begin{array}{l}\text { a. Values are rounded to the nearest } \$ 1,000 \text {. } \\
\text { b. Operational and maintenance cost contingency is } 16.1 \% \text { of the estimate. } \\
\text { c. Totals were derived for the summation of nonrounded subcomponent values. Therefore, totals are not equal to the summation of the rounded subcomponent values shown } \\
\text { above. See Table F-3 for nonrounded totals. }\end{array}$} \\
\hline
\end{tabular}




\section{F-24. PERCENTAGES FOR MODULE TECHNICAL SERVICES AND MODULE CONTINGENCY \\ Percentages: Professional and Technical Services}

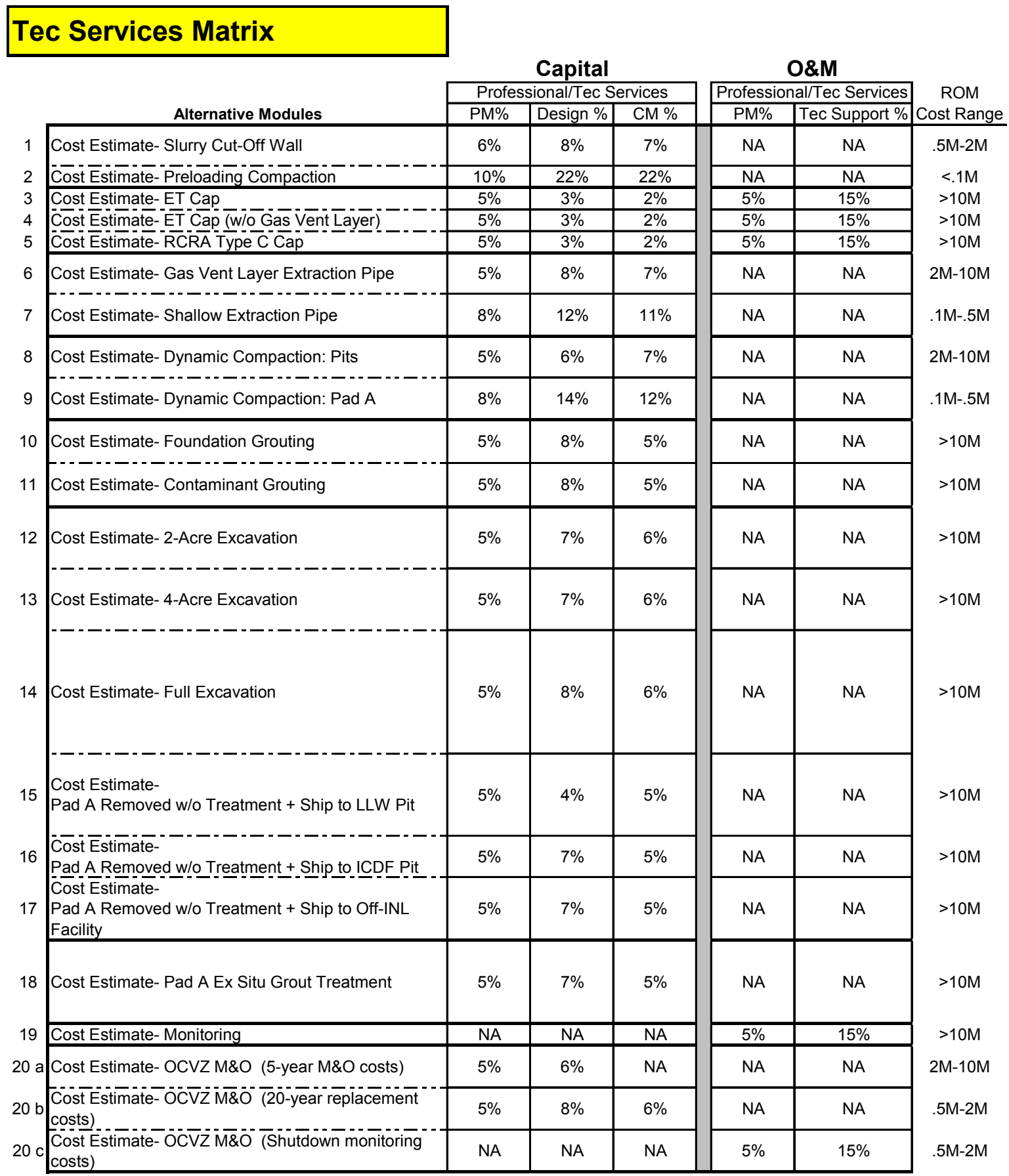

Assumption 1: PM includes work required to issue RFP and award the bid. Therefore, the percentage of capital cost for PM does not change with complexity of the module. Use values out of EPA guidance Exhibit 5-8.

Assumption 2: O\&M activities includes long-term monitoring of remedial action (example: subsidence monitoring and repair) and is only accounted for in

the cost estimates for the surface barrier modules and monitoring modules.

Assumption 3: O\&M prof/tec services PM percentage is identical to the associated capital value PM percentage. 
Design \% Rationale esign \%: Percentage of construction capital (with contingency). Design includes drawings, specs, emissions reports, waste management plan, safety plans, characterization plan, O\&M plan

ROM

Cost Range

$.5 \mathrm{M}-2 \mathrm{M}$

$<1 \mathrm{M}$

$>10 \mathrm{M}$

$>10 \mathrm{M}$

$>10 \mathrm{M}$

$2 \mathrm{M}-10 \mathrm{M}$

$1 \mathrm{M}-.5 \mathrm{M}$

$2 \mathrm{M}-10 \mathrm{M}$

$1 \mathrm{M}-.5 \mathrm{M}$

$>10 \mathrm{M}$

$>10 \mathrm{M}$

$>10 \mathrm{M}$

$>10 \mathrm{M}$

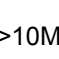

$>10 \mathrm{M}$

$>10 \mathrm{M}$

Cost Estimate- OCVZ M\&O

-year replacement

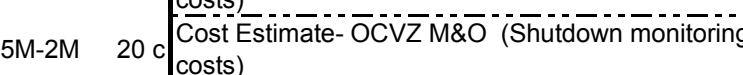

Alternative Modules

Cost Estimate- Slurry Cut-Off Wall

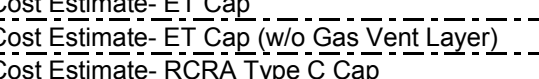

Cost Estimate- Shallow Extraction Pipe

Cost Estimate- Dynamic Compaction: Pad A
Cost Estimate- ET Cap

Cost Estimate- Gas Vent Layer Extraction Pipe

Cost Estimate- Dynamic Compaction: Pits

\begin{tabular}{|c|c|c|}
\hline $\begin{array}{c}\text { Design \% } \\
\text { Range }\end{array}$ & $\begin{array}{c}\text { Design } \\
\%\end{array}$ & Complexity \\
\hline
\end{tabular}

Raw

Rationale

Low number and complexity of design drawings (location and width of slurry wall). This module has the same complexity level as the cap

Low number and complexity of design drawings (perimeter line, slope, and width of each layer). Additional design documents: Safety Plan, O\&M Plan

Moderate number and complexity of design drawings (protected belowground manifold with protected vertical exhaust pipes). Additional design document(s): Safety Plan \begin{tabular}{l} 
with protected vertical exhaust pipes). Additional design document(s): Safety Plan \\
\hline Low number and complexity of design drawings (extraction pipe "probe" grid locations).
\end{tabular} Additional design document: Safety Plan Low number and complexity of design drawings (DC grid locations). Additional design
document: Safety Plan

Low number and complexity of design drawings (DC grid locations). Additional design documents: Safety Plan, Waste Management Plan

High number and complexity of design drawings (standard track hoe modified with sonic drill). Additional design documents: Safety Plan, Waste Management Plan, Emissions Reports, Characterization Plan

High number and complexity of design drawings (enclosures, glove boxes, modified excavator, etc.). Credit can be taken for the INL T-rad designs that have been produced to date. Additional work will be required to finalize design. Additional design documents: Safety Plan, Waste Management Plan, Emissions Reports, Characterization Plan

High number and complexity of design drawings (enclosures, glove boxes, modified excavator, etc.). Full excavation uses T-Rad style excavation but a large amount of additional design work required in removing and sizing large objects, removing highly contaminated objects, and alternate packaging and characterization for a variety of shipping locations. Additional design documents: Safety Plan, Waste Management Plan

Emissions Reports, Characterization Plan be taken for the INL ARP designs that have been produced up to date. Additional design documents: Safety Plan, Waste Management Plan, Emissions Reports, Characterization Plan

High number and complexity of design drawings (enclosure, glove boxes, equipment, etc.). Credit can be taken for the INL ARP designs that have been produced up to date. Additional complexity added from characterization of waste for off SDA shipment. Additional design documents: Safety Plan, Waste Management Plan, Emissions Reports, Characterization Plan

High number and complexity of design drawings (grout treatment equipment, delivery \& extraction systems for equipment, etc.). Modification of existing equipment is not anlipaled. Addilonal design documents: Safety Plan, wh Emissions Reports, Characterization Plan Design not required for this module

\begin{tabular}{l|l|l|l} 
NA & NA & NA & Design not required for this module \\
\hline & & & Low complexity, maintenance and periodic replacement of consumables does no
\end{tabular}

\begin{tabular}{|c|c|c|l|l|}
$6 \%-12 \%$ & $6 \%$ & Low & $\begin{array}{l}\text { Low complexity, maintenance and periodic replacem } \\
\text { require design drawings but will require a work plan }\end{array}$ \\
\hline
\end{tabular}

\begin{tabular}{|c|c|c|c|c|}
\hline $8 \%-15 \%$ & $8 \%$ & Low & Low number and complexity of design drawings due to assumed replacement of same- \\
\hline
\end{tabular}
for-same components as components wear out

\begin{tabular}{l|l|l|l|l} 
NA & NA & NA & Design not required for this module
\end{tabular}

\section{CM \% Rationale}

ROM

Cost Range

$5 \mathrm{M}-2 \mathrm{M}$

$<.1 \mathrm{M}$

$>10 \mathrm{M}$

$>10 \mathrm{M}$

$>10 \mathrm{M}$

$1 \mathrm{M}-.5 \mathrm{M}$

$2 \mathrm{M}-10 \mathrm{M}$

$.1 \mathrm{M}-5 \mathrm{M}$

$>10 \mathrm{M}$

$>10 \mathrm{M}$

$>10 \mathrm{M}$

$>10 \mathrm{M}$

$>10 \mathrm{M}$

$>10 \mathrm{M}$

$>10 \mathrm{M}$

$>10 \mathrm{M}$

Alternative Modules

Construction Management \%: Percentage of construction capital (with contingency). CM includes vendor data review, security plan, TFR revisions, pro

EPA Guidance Exhibit 5-8 Complexity: Low - Med Low - Med - Med High - High

\begin{tabular}{|c|c|c|c|c|}
\hline Alternative Modules & $\begin{array}{l}\text { CM \% } \\
\text { Range }\end{array}$ & CM \% & Complexity & Rationale \\
\hline Cost Estimate- Slurry Cut-Off Wall & $6 \%-10 \%$ & $7 \%$ & Med Low & $\begin{array}{l}\text { CM includes: vendor data review, site security plan, TFR revisions, prefinal inspections, } \\
\text { conducting an MSA, and oversight. }\end{array}$ \\
\hline Cost Éstimate- Preloading Compaction & $15 \%-30 \%$ & $22 \%$ & Med Low & This module has the same complexity level as the cap \\
\hline Cost Estimate- ET Cap & $1 \%-6 \%$ & $2 \%$ & ed Low & \multirow{3}{*}{$\begin{array}{l}\text { CM includes: vendor data review, site security plan, TFR revisions, prefinal inspections, } \\
\text { conducting an MSA, and oversight. }\end{array}$} \\
\hline Cost Estimate-ETCap (w/o Gas Vent Layer) & $1 \%-6 \%$ & $2 \%$ & Med Low & \\
\hline Cost Estimate-RCRA Type C Cap & $1 \%-6 \%$ & $2 \%$ & Med Low & \\
\hline $\begin{array}{l}\text { Cost Estimate- Gas Vent Layer Extraction Pipe } \\
\text { Cost Estimate- Shallow Extraction Pipe }\end{array}$ & $\begin{array}{ll}6 \%-8 \% \\
8 \%-15 \% \\
\end{array}$ & $\begin{array}{cl}7 \% \\
11 \%\end{array}$ & $\begin{array}{ll}\text { Med Low } \\
\text { Med Low }\end{array}$ & $\begin{array}{l}\text { CM includes: vendor data review, site security plan, TFR revisions, prefinal inspections, } \\
\text { conducting an MSA, and oversight. }\end{array}$ \\
\hline Cost Estimate- Dynamic Compaction: Pits & $6 \%-8 \%$ & $7 \%$ & Med & \multirow{2}{*}{$\begin{array}{l}\text { CM includes: vendor data review, site security plan, TFR revisions, prefinal inspections, } \\
\text { conducting an MSA, and oversight. Additional CM activities include: off-INL acceptance } \\
\text { testing and demonstration of DC crane. }\end{array}$} \\
\hline Cost Estimate- Dynamic Compaction: Pad A & $8 \%-15 \%$ & $12 \%$ & Med & \\
\hline Cost Estimate- Foundation Grouting & $1 \%-6 \%$ & $5 \%$ & Med High & \multirow{2}{*}{$\begin{array}{l}\text { CM includes: vendor data review, site security plan, TFR revisions, prefinal inspections, } \\
\text { conducting an MSA, and oversight. Additional CM activities include: off-INL acceptance } \\
\text { testing and demonstration of equipment, on-INL acceptance testing of grout } \\
\text { characteristics within native soil and simulated waste, on-INL acceptance of procedures. }\end{array}$} \\
\hline Cost Estimate- Contaminant Grouting & $1 \%-6 \%$ & $5 \%$ & Med High & \\
\hline Cost Estimate- 2-Acre Excavation & & & & \multirow{3}{*}{$\begin{array}{l}\text { CM includes: vendor data review, site security plan, TFR revisions, prefinal inspections, } \\
\text { conducting an MSA, and oversight. Additional CM activities include: on and off-INL } \\
\text { acceptance testing (excavator), on-INL acceptance of operational procedures, } \\
\text { conducting an ORR. }\end{array}$} \\
\hline Cost Estimate- 4-Acre Excavation & $7 \%-6 \%$ & $6 \%$ & High & \\
\hline Cost Estimate- Full Excavation & $1 \%-6 \%$ & $6 \%$ & High & \\
\hline $\begin{array}{l}\text { Cost Estimate- } \\
\text { Pad A Removed w/o Treatment + Ship to LLW Pit }\end{array}$ & $1 \%-6 \%$ & $5 \%$ & Med High & \multirow{3}{*}{$\begin{array}{l}\text { CM includes: vendor data review, site security plan, TFR revisions, prefinal inspections, } \\
\text { conducting an MSA, and oversight. Additional CM activities include: on-INL acceptance } \\
\text { of operational procedures. }\end{array}$} \\
\hline $\begin{array}{l}\text { Cost Estimate- } \\
\text { Pad A Removed w/o Treatment + Ship to ICDF Pit }\end{array}$ & $1 \%-6 \%$ & $5 \%$ & Med High & \\
\hline $\begin{array}{l}\text { Cost Estimate- } \\
\text { Pad A Removed w/o Treatment + Ship to Off-INL } \\
\text { Facility }\end{array}$ & $1 \%-6 \%$ & $5 \%$ & Med High & \\
\hline Cost Estimate- Pad A Ex Situ Grout Treatment & $1 \%-6 \%$ & $5 \%$ & Med High & $\begin{array}{l}\text { CM includes: vendor data review, site security plan, TFR revisions, prefinal inspections, } \\
\text { conducting an MSA, and oversight. Additional CM activities include: on and off-INL } \\
\text { acceptance testing (ex situ grout treatment system) and on-INL acceptance of } \\
\text { operational procedures. }\end{array}$ \\
\hline Cost Estimate- Monitoring & NA & $\mathrm{NA}$ & $\mathrm{NA}$ & Construction management not required for this module \\
\hline \multirow{2}{*}{ 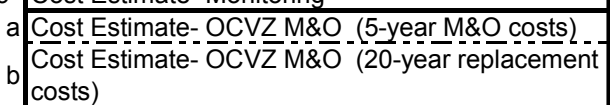 } & $\mathrm{NA}$ & $\mathrm{NA}$ & $\mathrm{NA}$ & \multirow{2}{*}{\begin{tabular}{|l|} 
Maintenance and periodic replacement of consumables does not require construction \\
Low number and complexity of design drawings due to assumed replacement of same- \\
for-same components as components wear out.
\end{tabular}} \\
\hline & $6 \%-10 \%$ & $6 \%$ & Low & \\
\hline $\begin{array}{l}\text { Cost Estimate- OCVZ M\&O (Shutdown monitoring } \\
\text { costs) }\end{array}$ & NA & NA & NA & Construction management not required for this module. \\
\hline
\end{tabular}

O\&M Tec Support \% Rationale Technical Support: Monitor, evaluate, and report progress of remedial action (ground water, vadose zone, surface water, air perimeter radiological, biological, and vegetation monitoring)

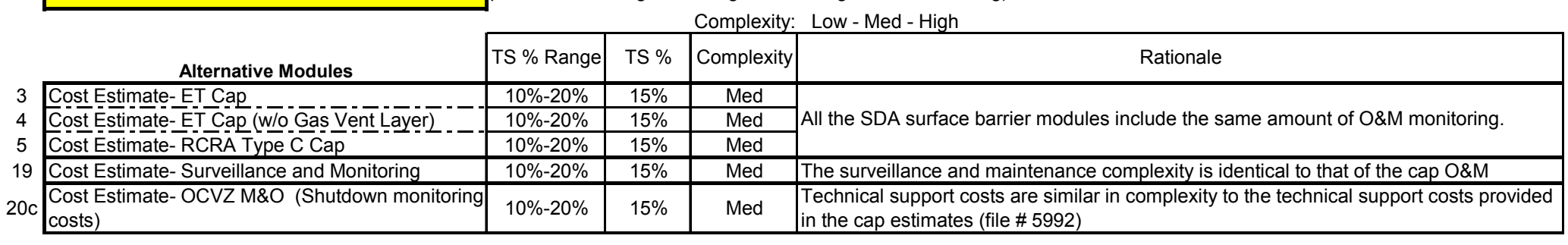




\section{Percentages: Contingency}

\section{Contingency Matrix}

\begin{tabular}{|c|c|c|c|c|c|c|c|}
\hline \multirow{3}{*}{\multicolumn{2}{|c|}{ Alternative Modules }} & \multirow{2}{*}{\multicolumn{3}{|c|}{$\frac{\text { Capital }}{\text { Contingency }}$}} & \multirow{2}{*}{\multicolumn{3}{|c|}{$\frac{\text { O\&M }}{\text { Contingency }}$}} \\
\hline & & & & & & & \\
\hline & & Scope \% & Bid \% & cope $\%+$ Bid $\%$ & Scope \% & Bid \% & scope $\%+$ Bid $\%$ \\
\hline 1 & Cost Estimate- Slurry Cut-Off Wall & $15 \%$ & $10 \%$ & $25 \%$ & NA & NA & NA \\
\hline 2 & Cost Estimate- Preloading Compaction & $5 \%$ & $10 \%$ & $15 \%$ & NA & NA & NA \\
\hline 3 & Cost Estimate- ET Cap & $10 \%$ & $20 \%$ & $30 \%$ & $10 \%$ & $20 \%$ & $30 \%$ \\
\hline 4 & Cost Estimate- ET Cap (w/o Gas Vent Layer) & $10 \%$ & $15 \%$ & $25 \%$ & $10 \%$ & $15 \%$ & $25 \%$ \\
\hline 5 & Cost Estimate- RCRA Type C Cap & $10 \%$ & $15 \%$ & $25 \%$ & $10 \%$ & $15 \%$ & $25 \%$ \\
\hline 6 & Cost Estimate- Gas Vent Layer Extraction Pipe & $15 \%$ & $15 \%$ & $30 \%$ & NA & NA & NA \\
\hline 7 & Cost Estimate- Shallow Extraction Pipe & $20 \%$ & $15 \%$ & $35 \%$ & NA & NA & NA \\
\hline 8 & Cost Estimate- Dynamic Compaction: Pits & $15 \%$ & $15 \%$ & $30 \%$ & NA & NA & NA \\
\hline 9 & Cost Estimate- Dynamic Compaction: Pad A & $15 \%$ & $20 \%$ & $35 \%$ & NA & NA & NA \\
\hline 10 & Cost Estimate- Foundation Grouting & $20 \%$ & $15 \%$ & $35 \%$ & NA & NA & NA \\
\hline 11 & Cost Estimate- Contaminant Grouting & $30 \%$ & $20 \%$ & $50 \%$ & NA & NA & NA \\
\hline 12 & Cost Estimate- 2-Acre Excavation & $45 \%$ & $20 \%$ & $65 \%$ & NA & NA & NA \\
\hline 13 & Cost Estimate- 4-Acre Excavation & $45 \%$ & $20 \%$ & $65 \%$ & NA & NA & NA \\
\hline 14 & Cost Estimate- Full Excavation & $55 \%$ & $20 \%$ & $75 \%$ & NA & NA & NA \\
\hline 15 & $\begin{array}{l}\text { Cost Estimate- } \\
\text { Pad A Removed w/o Treatment + Ship to LLW Pit }\end{array}$ & $35 \%$ & $15 \%$ & $50 \%$ & NA & NA & NA \\
\hline 16 & $\begin{array}{l}\text { Cost Estimate- } \\
\text { Pad A Removed w/o Treatment + Ship to ICDF Pit }\end{array}$ & $45 \%$ & $20 \%$ & $65 \%$ & NA & NA & NA \\
\hline 17 & $\begin{array}{l}\text { Cost Estimate- } \\
\text { Pad A Removed w/o Treatment + Ship to Off-INL } \\
\text { Facility }\end{array}$ & $45 \%$ & $20 \%$ & $65 \%$ & NA & NA & NA \\
\hline 18 & Cost Estimate- Pad A Ex Situ Grout Treatment & $45 \%$ & $20 \%$ & $65 \%$ & NA & NA & NA \\
\hline 19 & Cost Estimate- Monitoring & NA & NA & NA & $10 \%$ & $15 \%$ & $25 \%$ \\
\hline $20 \mathrm{a}$ & Cost Estimate- OCVZ M\&O (5-year M\&O costs) & $10 \%$ & $10 \%$ & $20 \%$ & NA & NA & NA \\
\hline $20 \mathrm{~b}$ & $\begin{array}{l}\text { Cost Estimate- OCVZ M\&O (20-year replacement } \\
\text { costs) }\end{array}$ & $10 \%$ & $10 \%$ & $20 \%$ & NA & NA & NA \\
\hline $20 \mathrm{c}$ & $\begin{array}{l}\text { Cost Estimate- OCVZ M\&O (Shutdown monitoring } \\
\text { costs) }\end{array}$ & $10 \%$ & $10 \%$ & $20 \%$ & NA & NA & NA \\
\hline
\end{tabular}

Assumption: O\&M Contingency scope and bid percentages for the cap modules are identical to the associated capital value scope and bid percentages.

Assumption: Monitoring Contingency scope and bid percentages for the Monitoring module are identical to the lowest percentages for O\&M applied to the cap module. 
F-216 
Scope \% Rationale Design contingency: Risk of scope change during design (example: new technology, change in surface area for

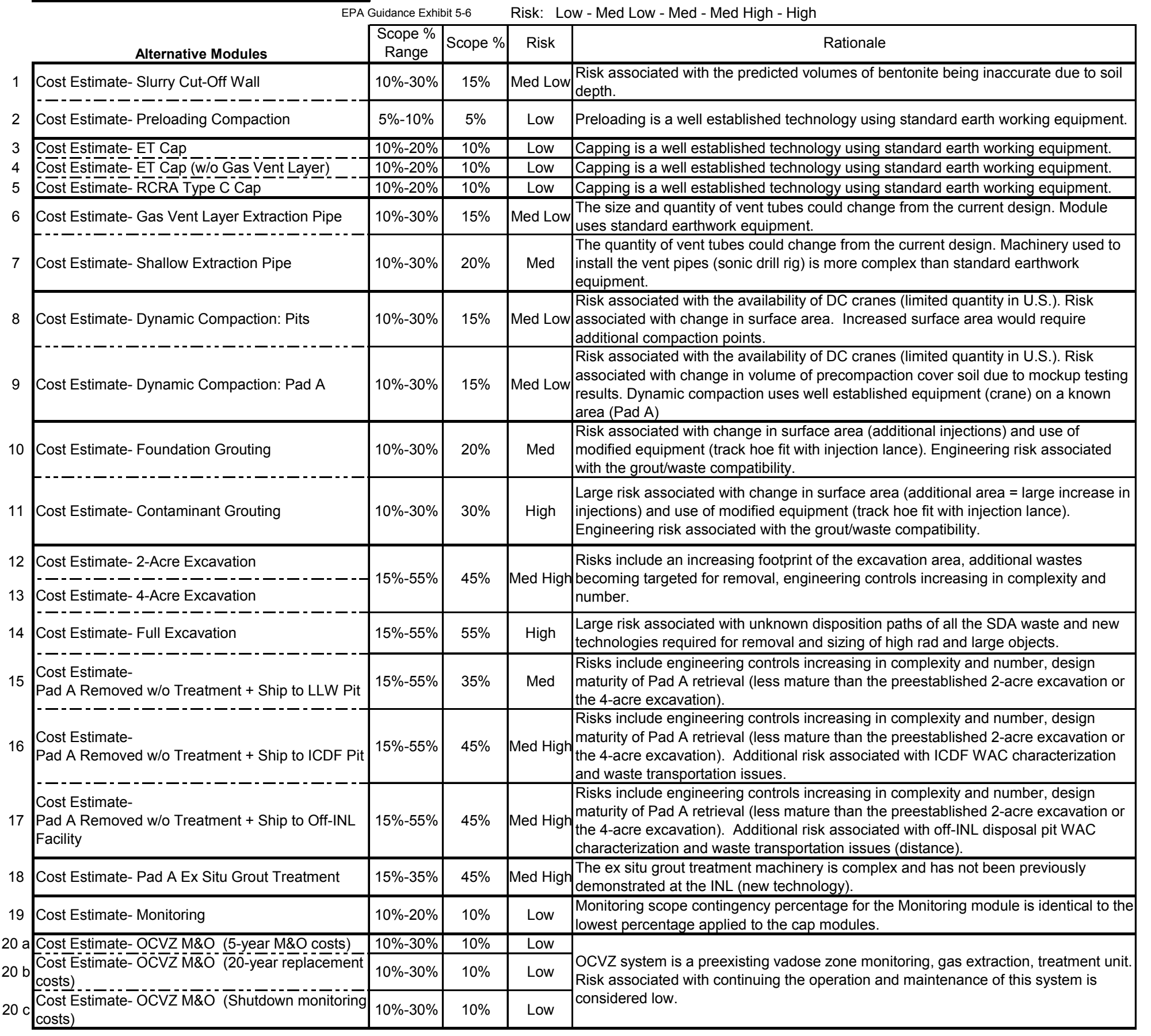

Construction contingency: Risk of change after bid award (example: weather impacts, unexpected rad contamination

Bid \% Rationale

Construction contingency: Risk of change after bid award (example: w
levels, raw material supply shortage, subsidence, equipment damage)

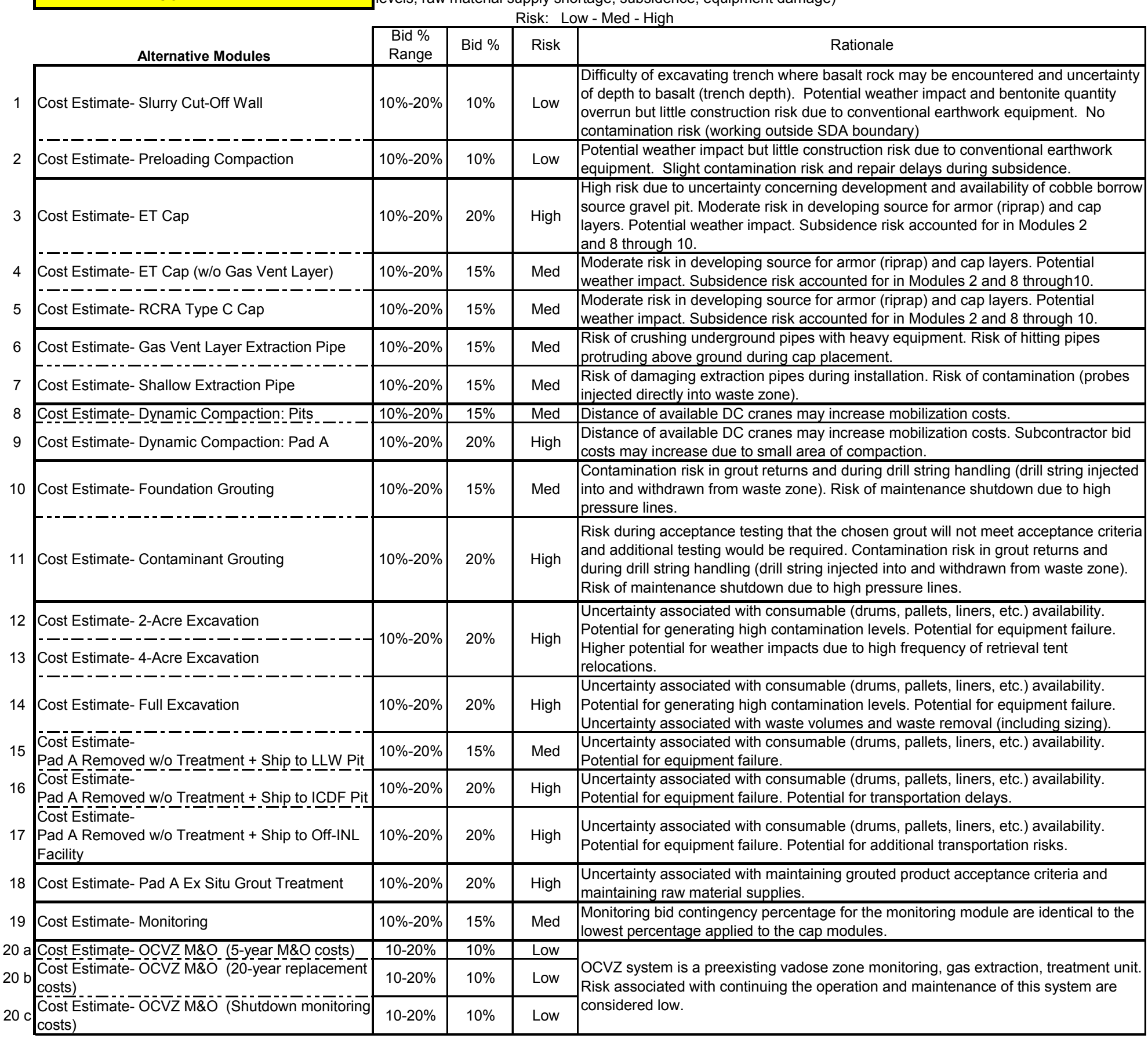




\section{F-25. ALTERNATIVE NET PRESENT VALUE COST ANALYSIS BY MODULE}

This present value evaluation will be used as a cost-comparative tool to examine the different options regarding the SDA.

\section{F-25.1 Scope of Work}

The scope of work includes development of the present values for each of 23 modules addressed in the Waste Area Group 7 feasibility study. Preparation of the values will conform to requirements identified in A Guide to Developing and Documenting Cost Estimates During the Feasibility Study (EPA 2000).

\section{F-25.2 Basis of the Estimate}

A. The project support estimates prepared by CH2M-WG Idaho Estimating Services for the 23 modules provide the basis for all unescalated Fiscal Year 2006 values used in the present value spreadsheets. A breakdown of the costs was provided by Estimating Services in a timeline format that identified the total estimated cost for both the amount and the year each would be expended. This breakdown also identified the separate amounts required for capital construction, operations and maintenance, and periodic costs.

B. Guidance for present value analysis preparation as identified in Chapter 4 of $A$ Guide to Developing and Documenting Cost Estimates During the Feasibility Study (EPA 2000).

C. The Office of Management and Budget Circular A-94, Appendix C, January 2006 revision provides the basis of estimate for the real discount rate used in the estimate.

\section{F-25.3 Assumptions}

A. Several modules require multiple year capital construction costs; therefore, to provide consistency for all modules, regardless of multiple year or single year timeframes, counting year No. 1 has been used as the beginning of all evaluations.

B. Counting year No. 1 has been associated with the year 2006 for convenience of evaluation. It is expected that 2006 will provide the beginning timeframe for the work identified in these modules.

C. The EPA guidance recommends use of real discount rates as provided in the latest revision of OMB Circular A-94 Appendix C. The 20-year discount rate identified in this circular has been applied to counting year No. 20 and beyond.

D. Unescalated values are used for all costs in the evaluation.

\section{F-25.4 Contingency Guideline Implementation}

Contingency, as appropriate and in accordance with guidance provided in A Guide to Developing and Documenting Cost Estimates During the Feasibility Study (EPA 2000), was included with the project estimates that provided the costs for this present value evaluation. No additional contingency is included in this evaluation. 
F-220 


\section{Alternative 1: Monitoring Only}
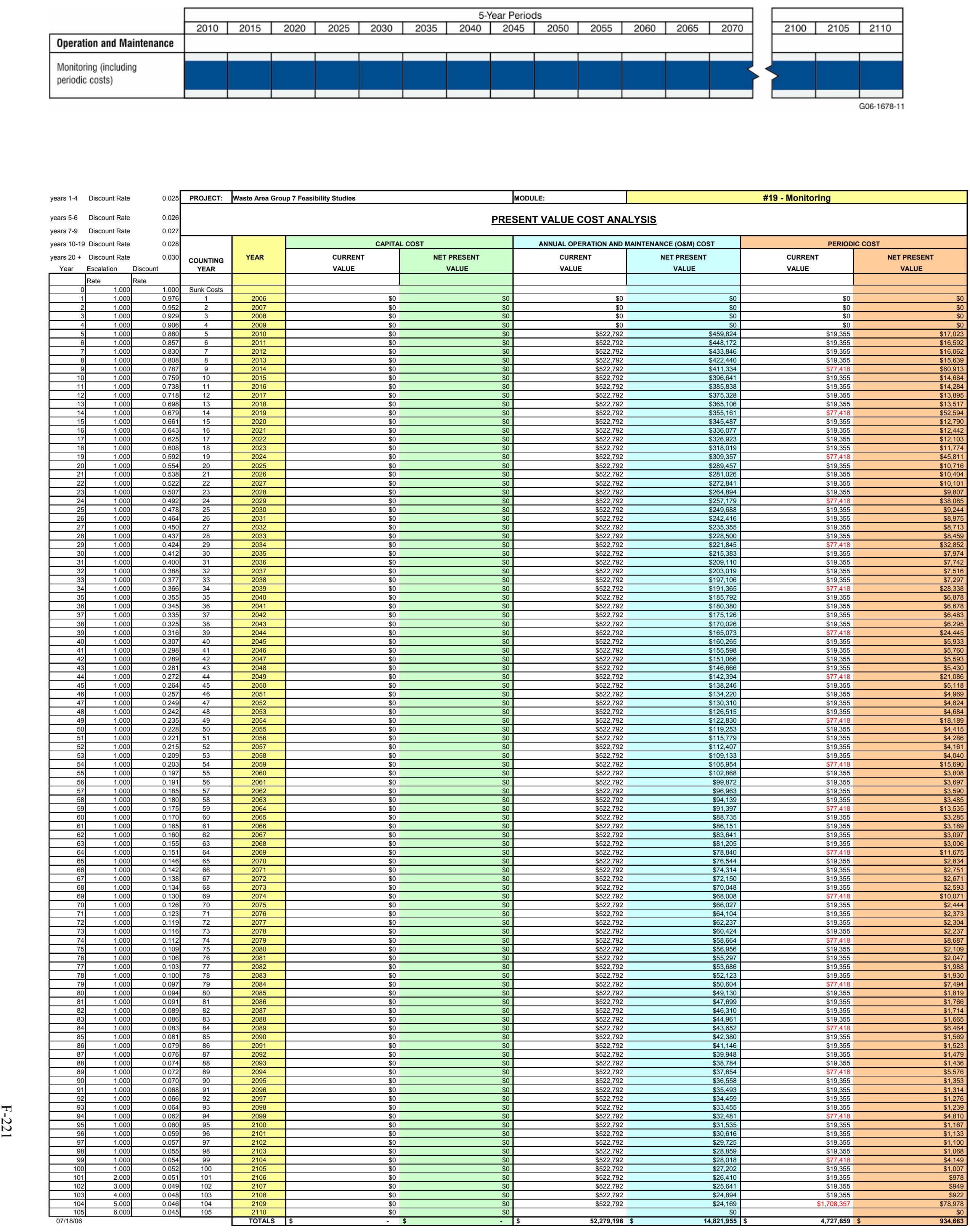


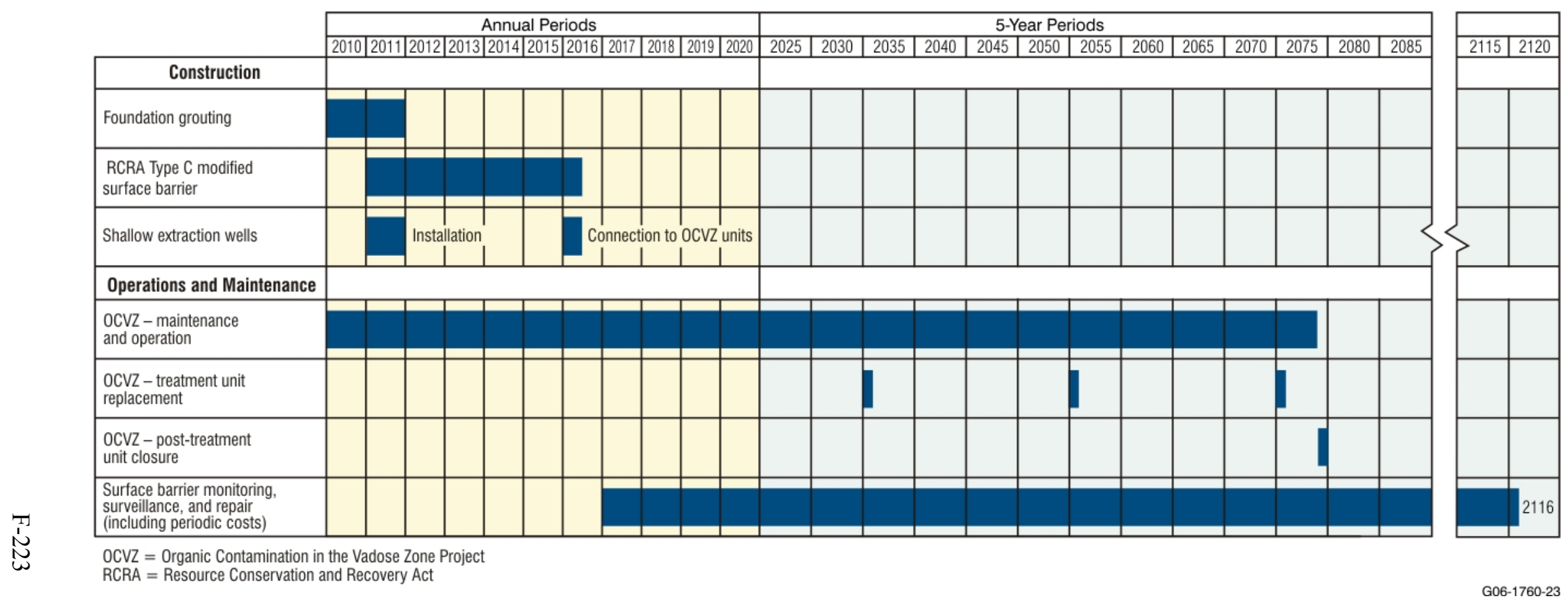

\section{Alternative 2a: Surface Barrier (RCRA Type C)}

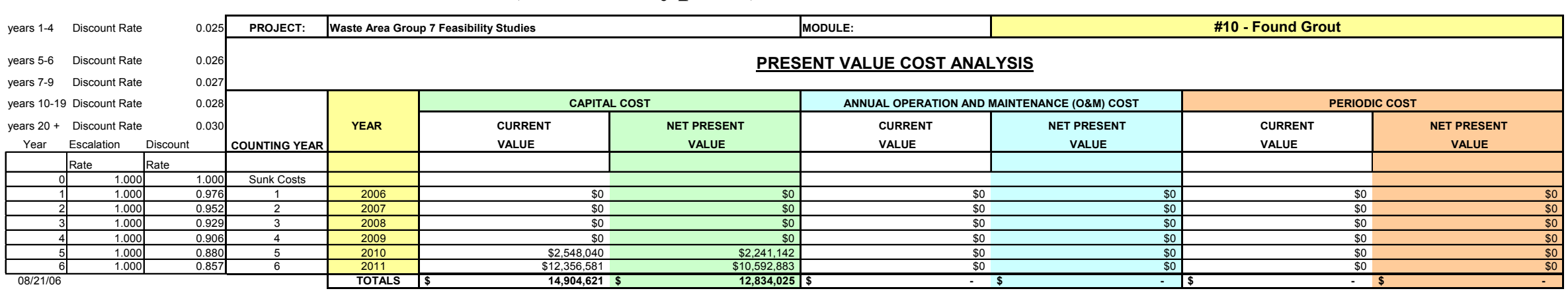











This present value analysis utilizes the real discount rates provided in the Officic of Management and Budget (OMB) Circular A-94, Appendix C, January 2006 revision.
The values identified under the Current Value headings represent unescalated dollars. 
Alternative 2b: Surface Barrier (Evapotranspiration)
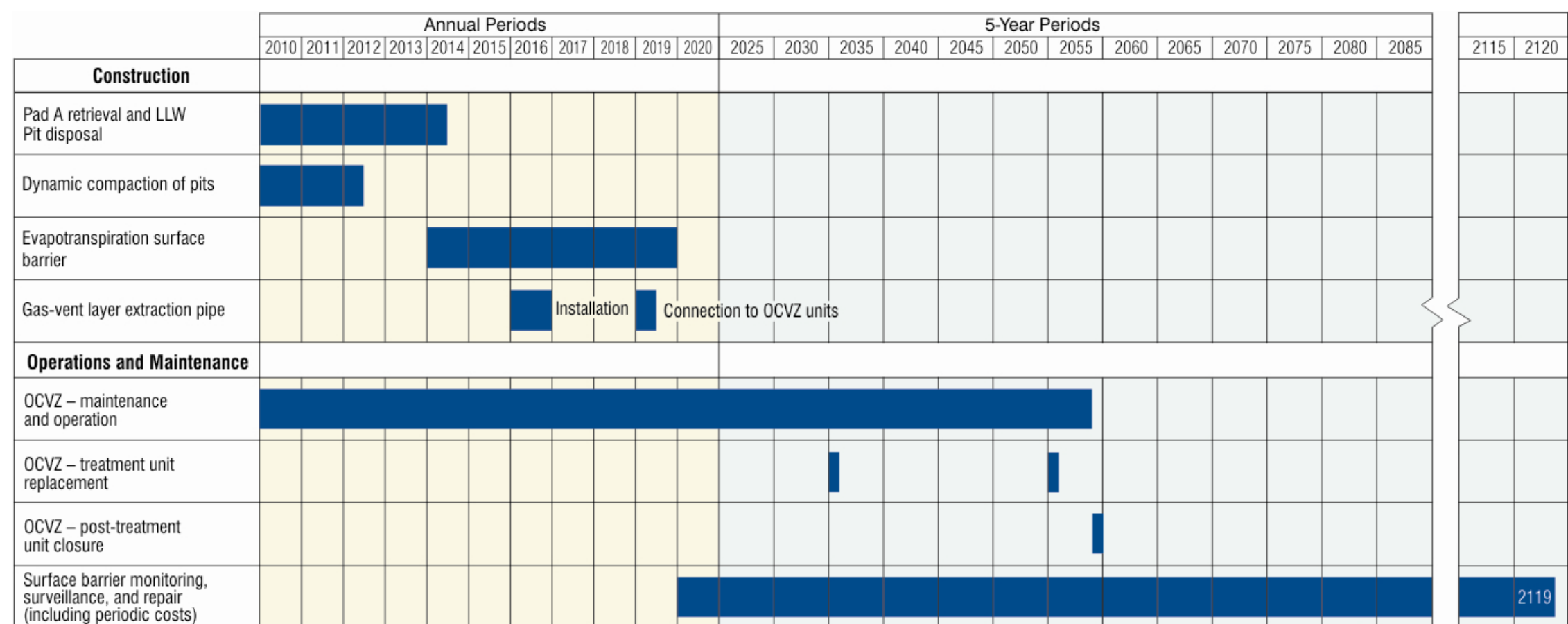

$\lfloor L W=$ low-level waste
$0 \mathrm{CVZ}=$ Organic Contamination in the Vadose Zone Project

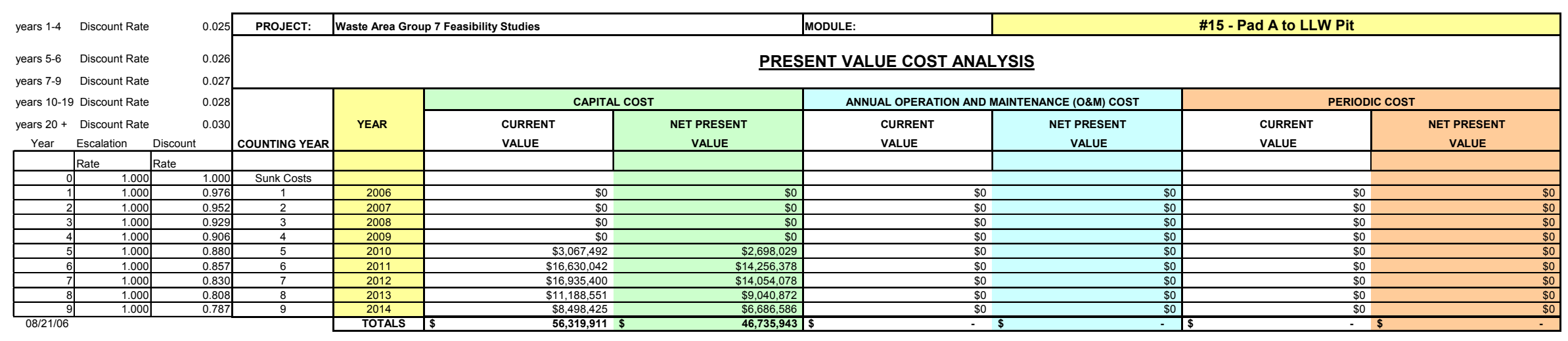

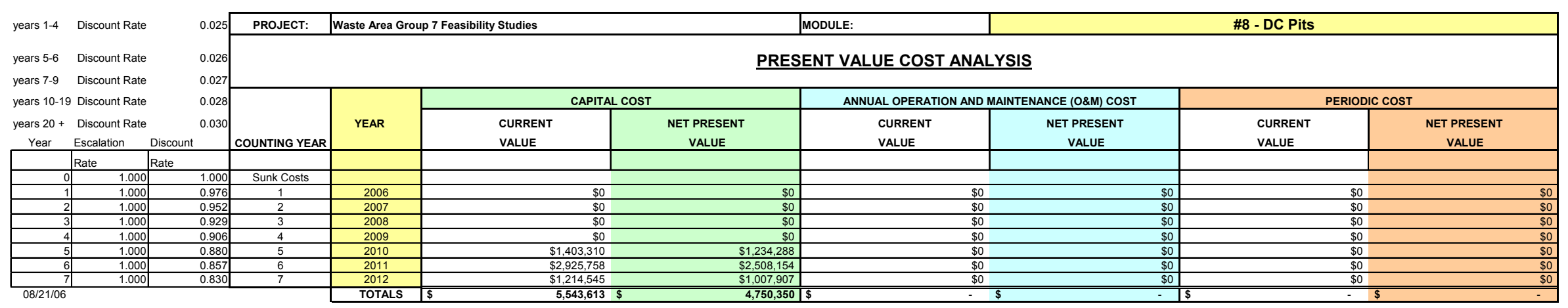



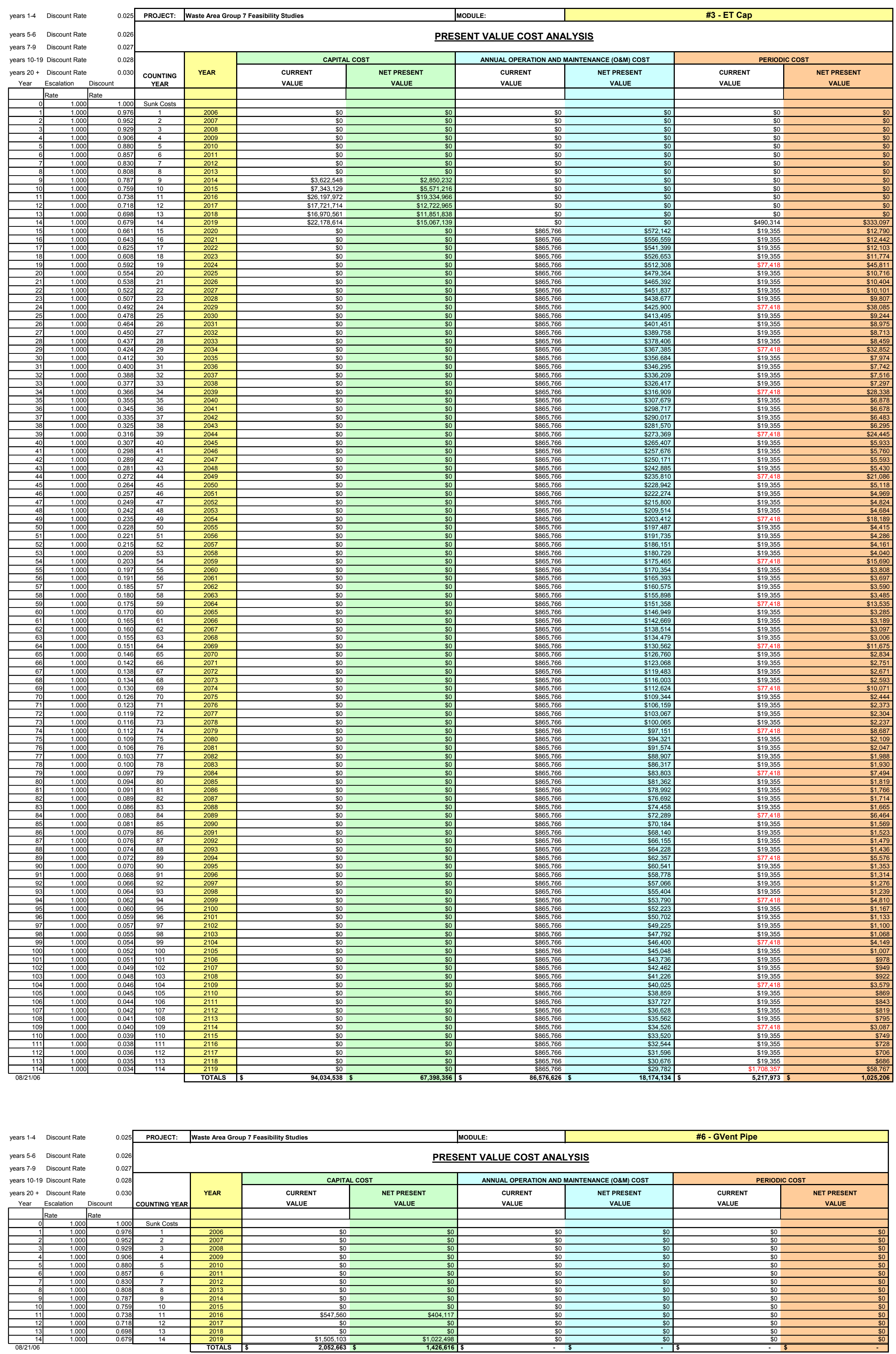


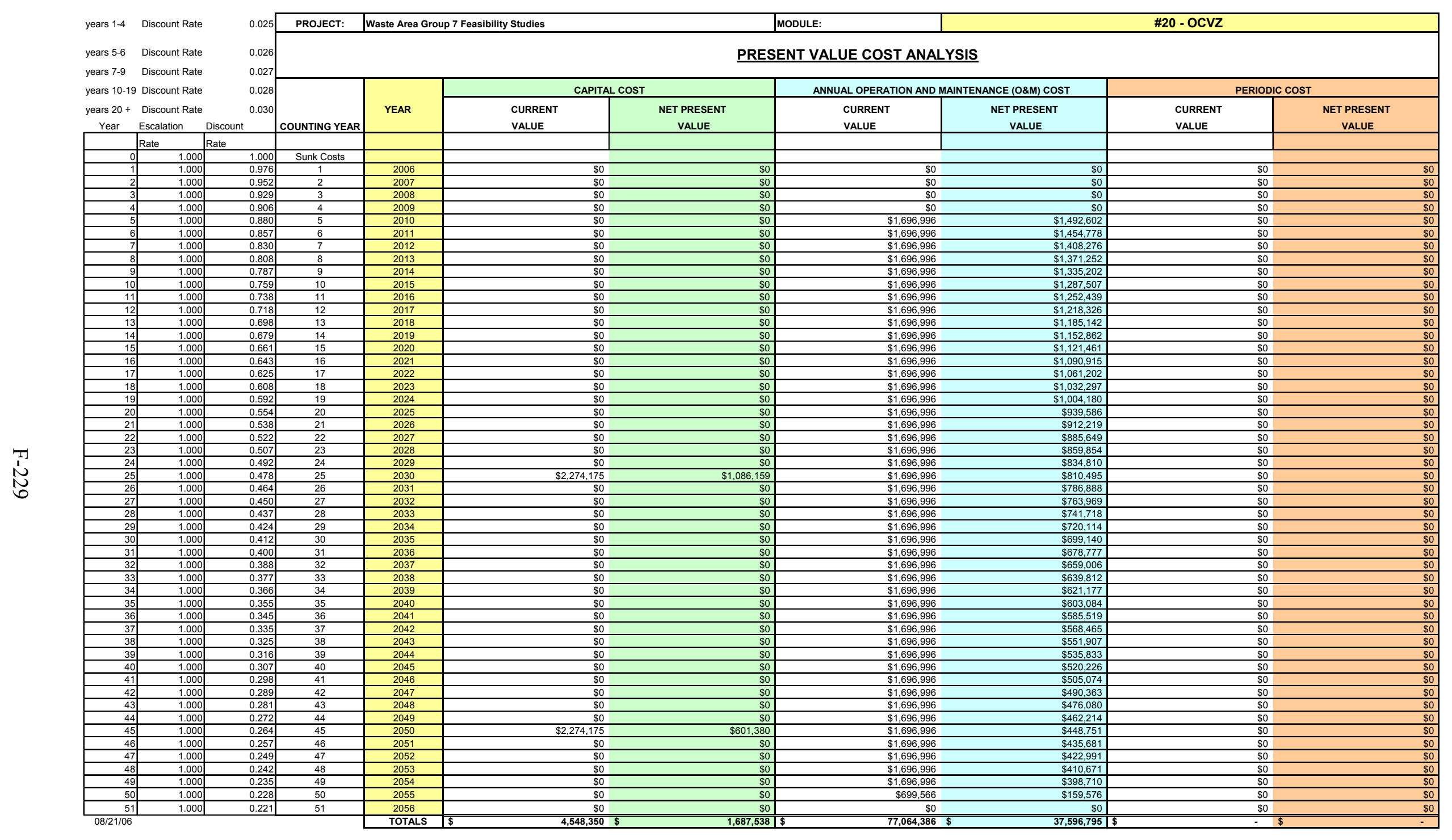

This present value analysis utilizes the real discount rates provided in the Office of Management and Budget (OMB) Circular A-94, Appendix C, January 2006 revision. The values identified under the Current Value headings represent unescalated dollars. 
莣 


\section{Alternative 3: In Situ Grouting}
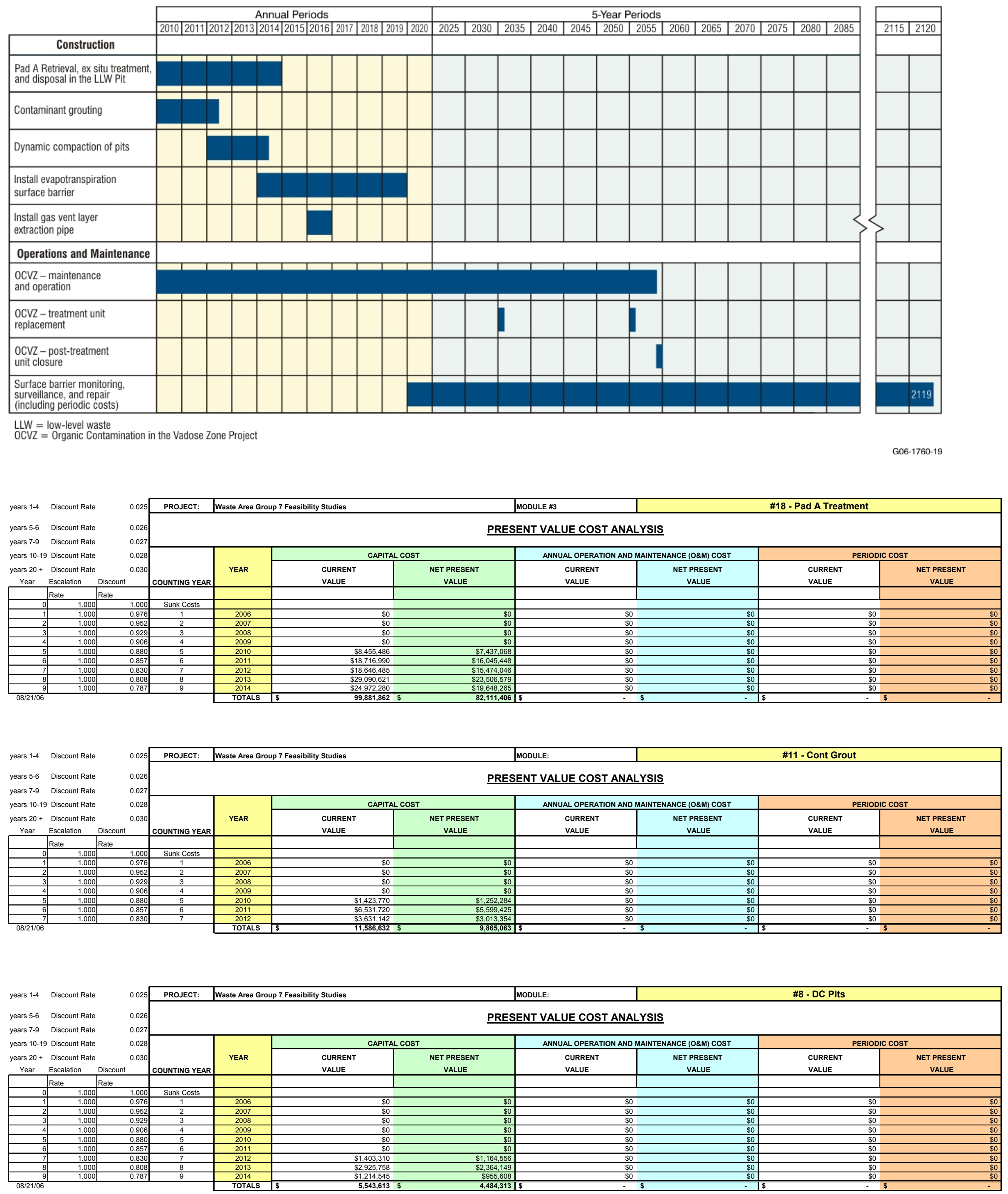

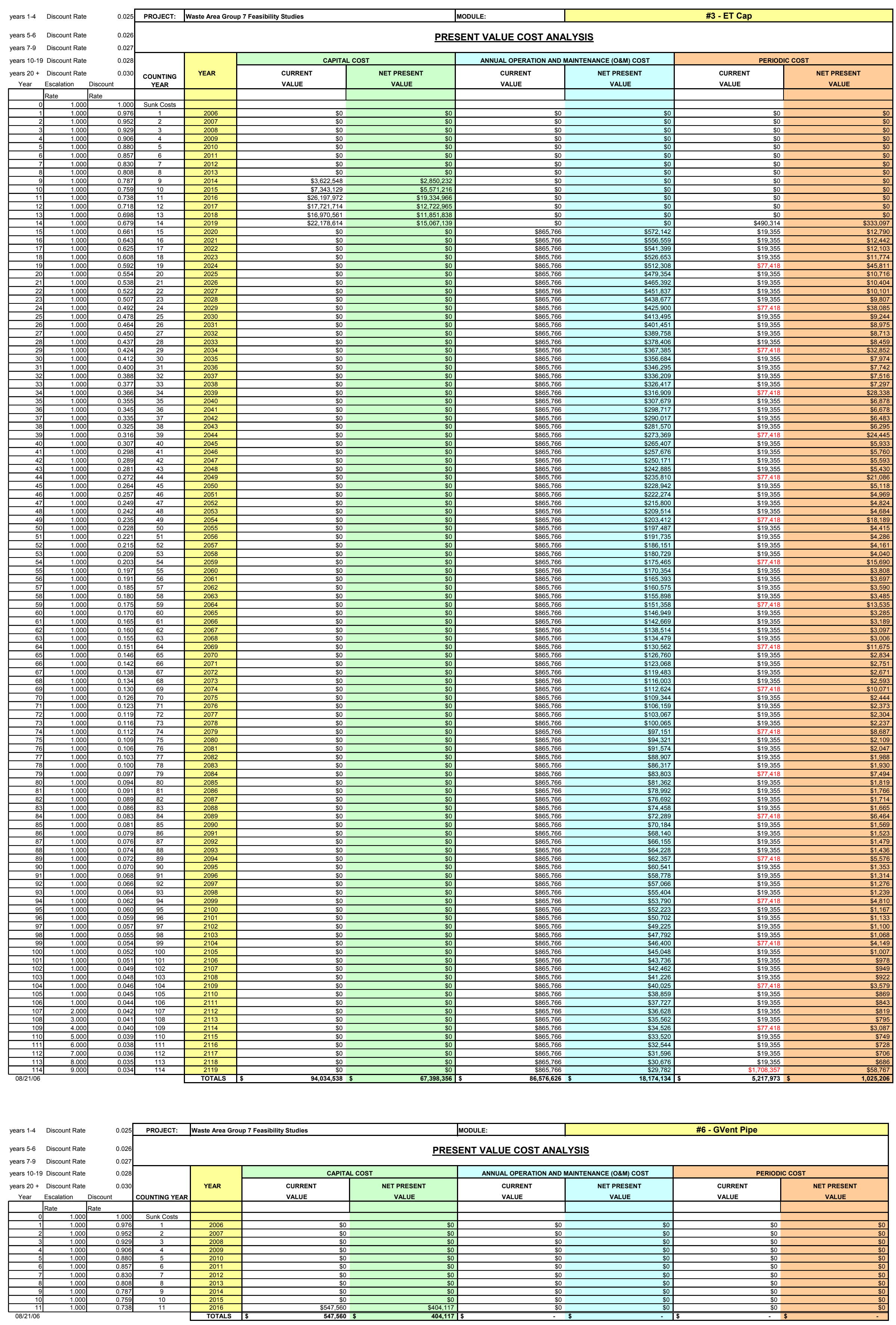


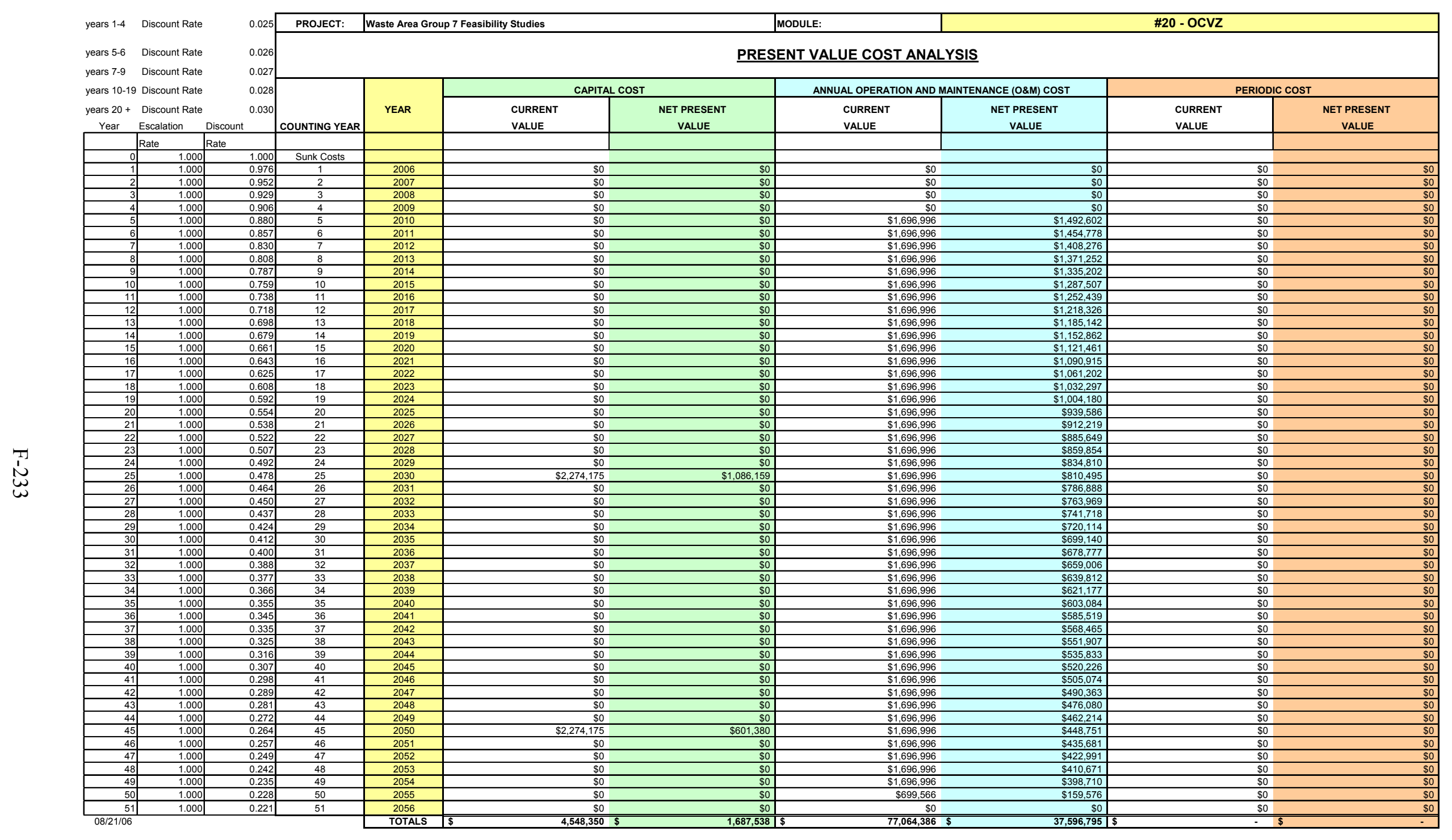

This present value analysis utilizes the real discount rates provided in the Office of Management and Budget (OMB) Circular A-94, Appendix C, January 2006 revision. The values identified under the Current Value headings represent unescalated dollars. 
N 


\section{Alternative 4a: Partial Retrieval (4 Acres)}
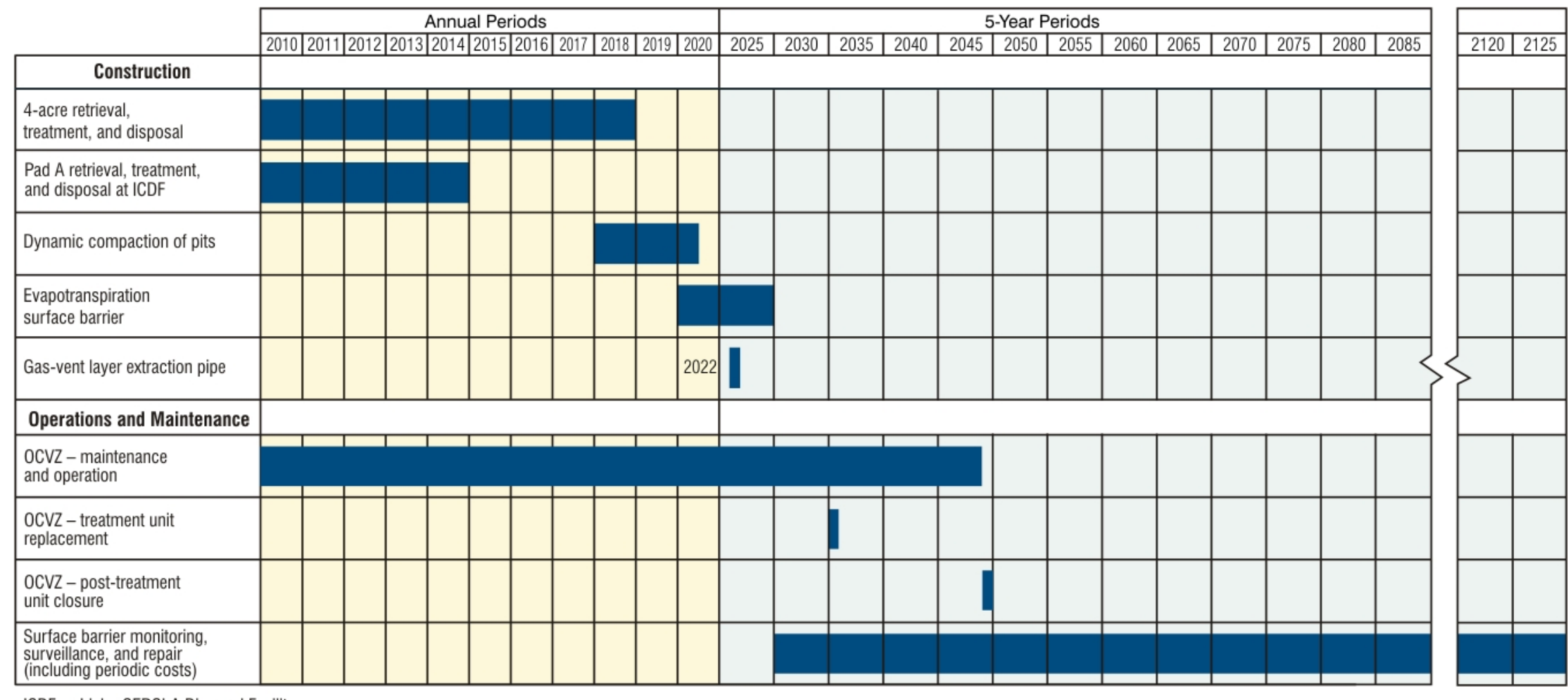

ICDF $=$ Idaho CERCLA Disposal Facility
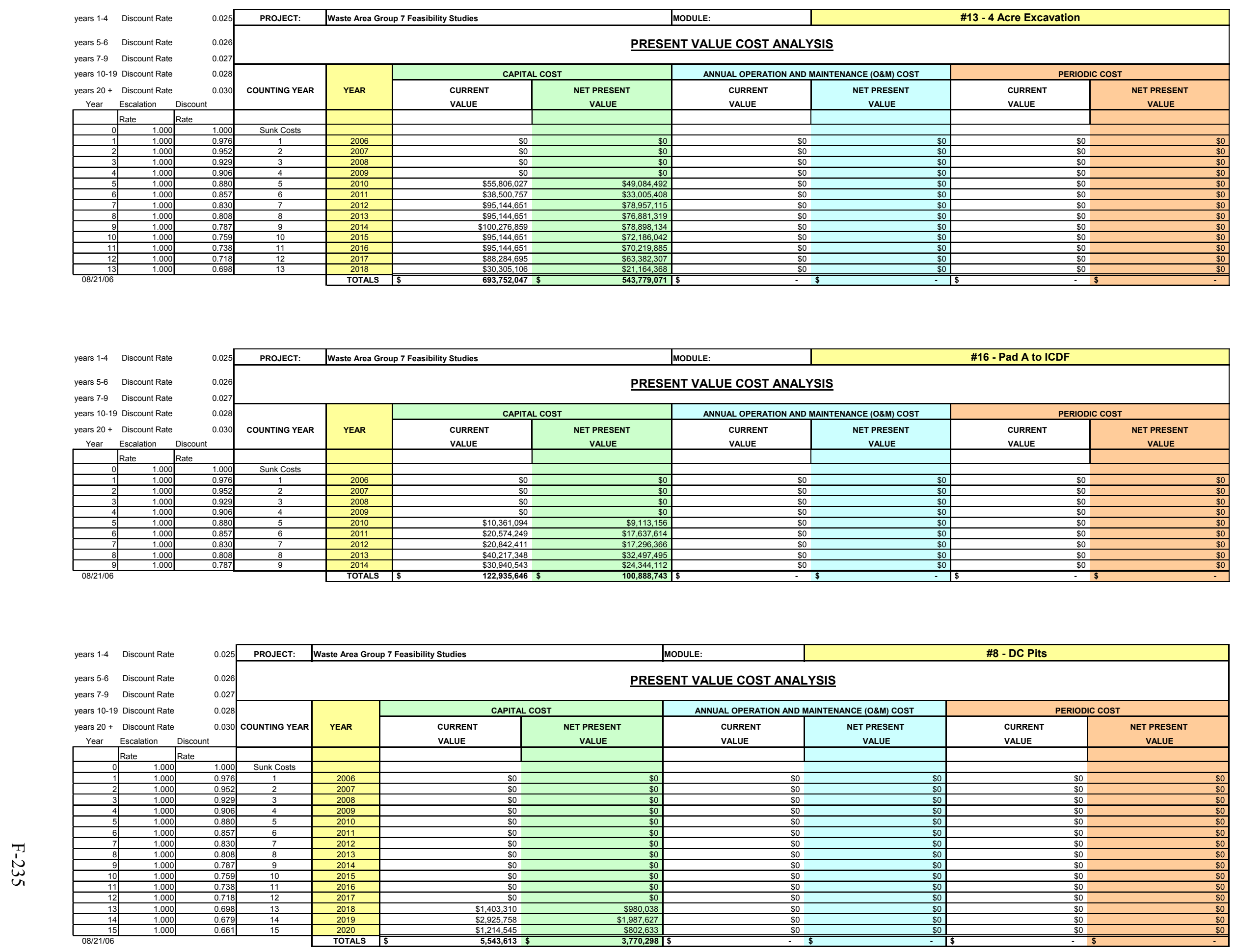


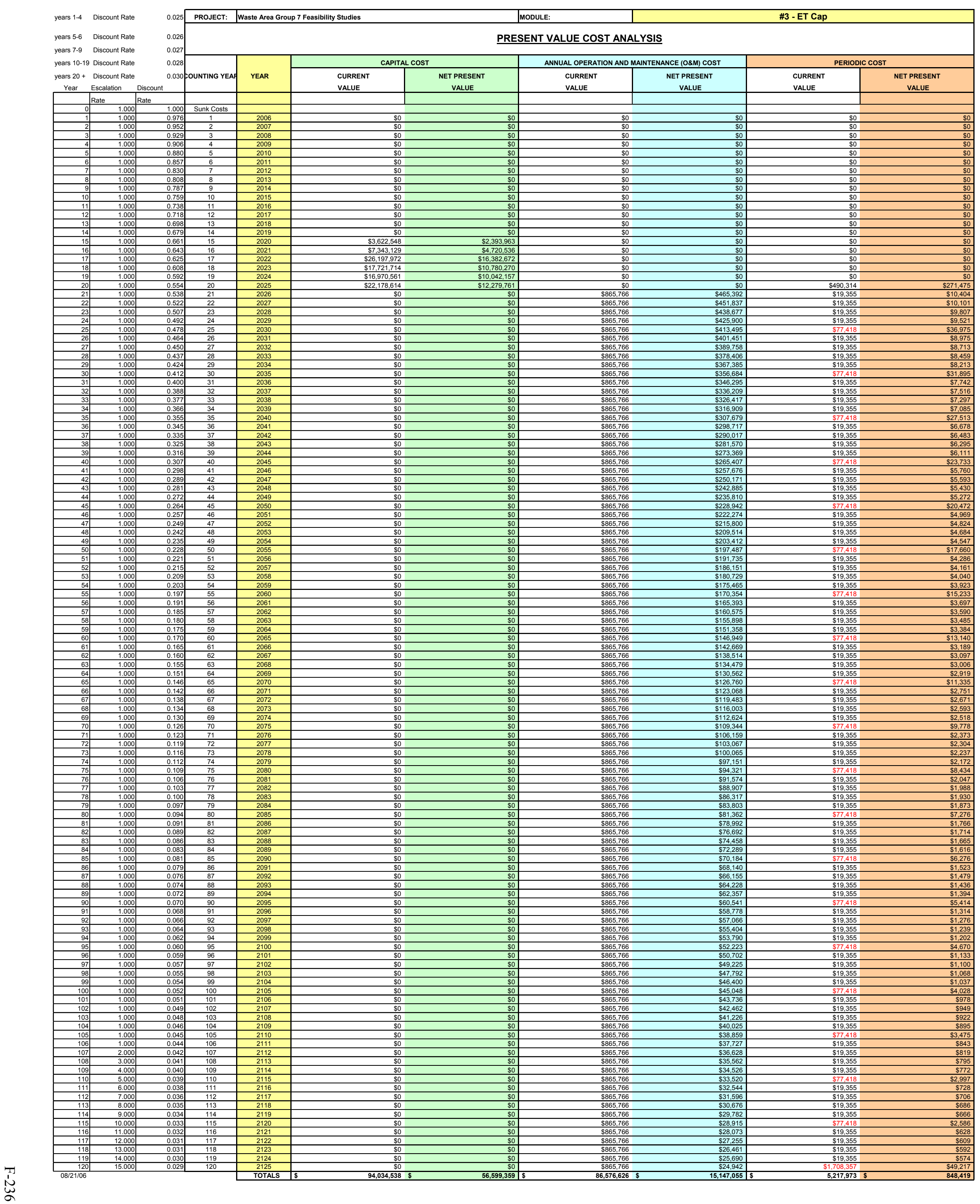



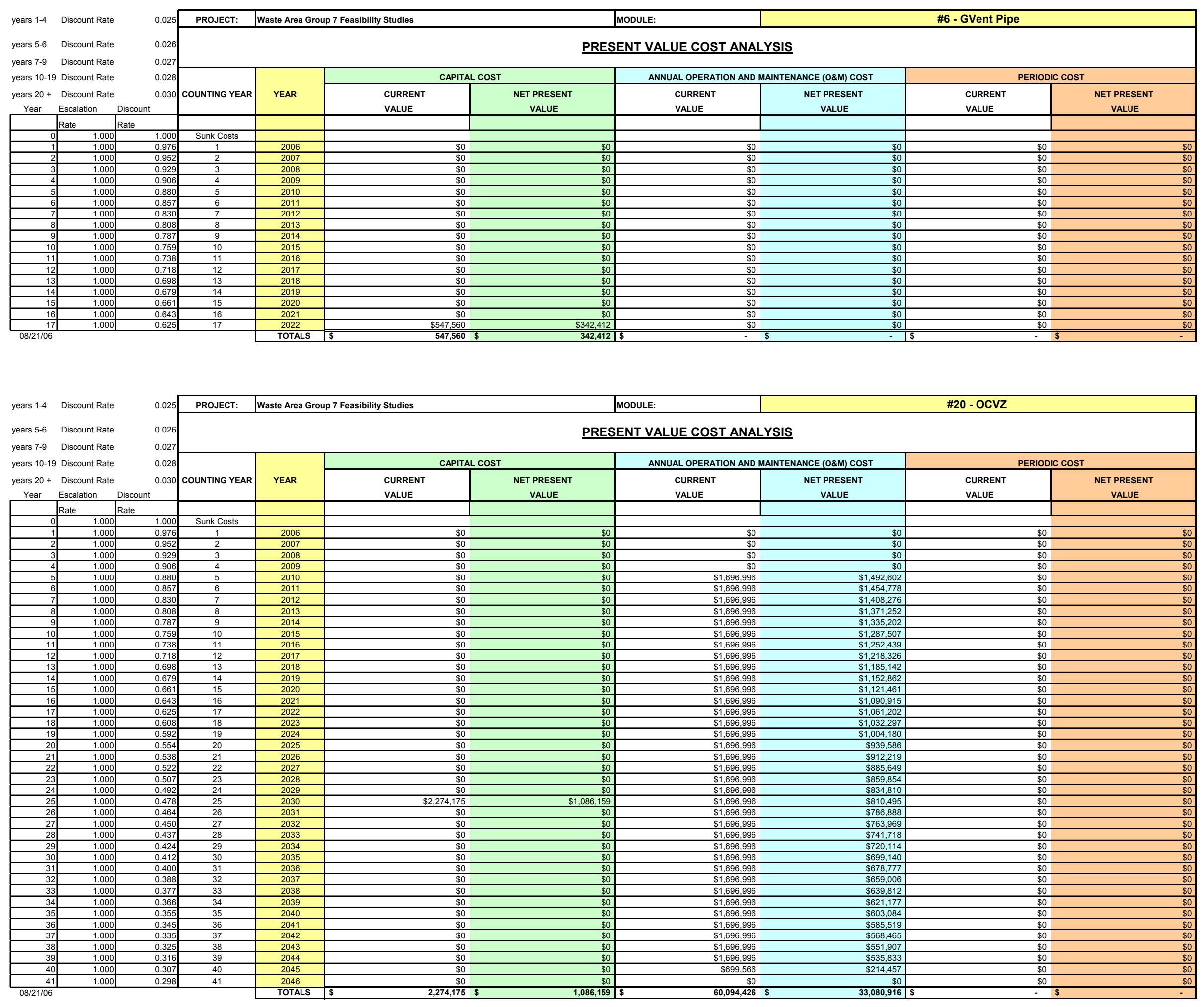

This present value analysis utilizes the real discount rates provided in the office of Management and Budget (OMB) Circular A-94, Appendix C, January 2006 revision.
The values identified under the Current Value headings represent unescalated dollars. 


\section{Alternative 4b: Partial Retrieval (2 Acres)}

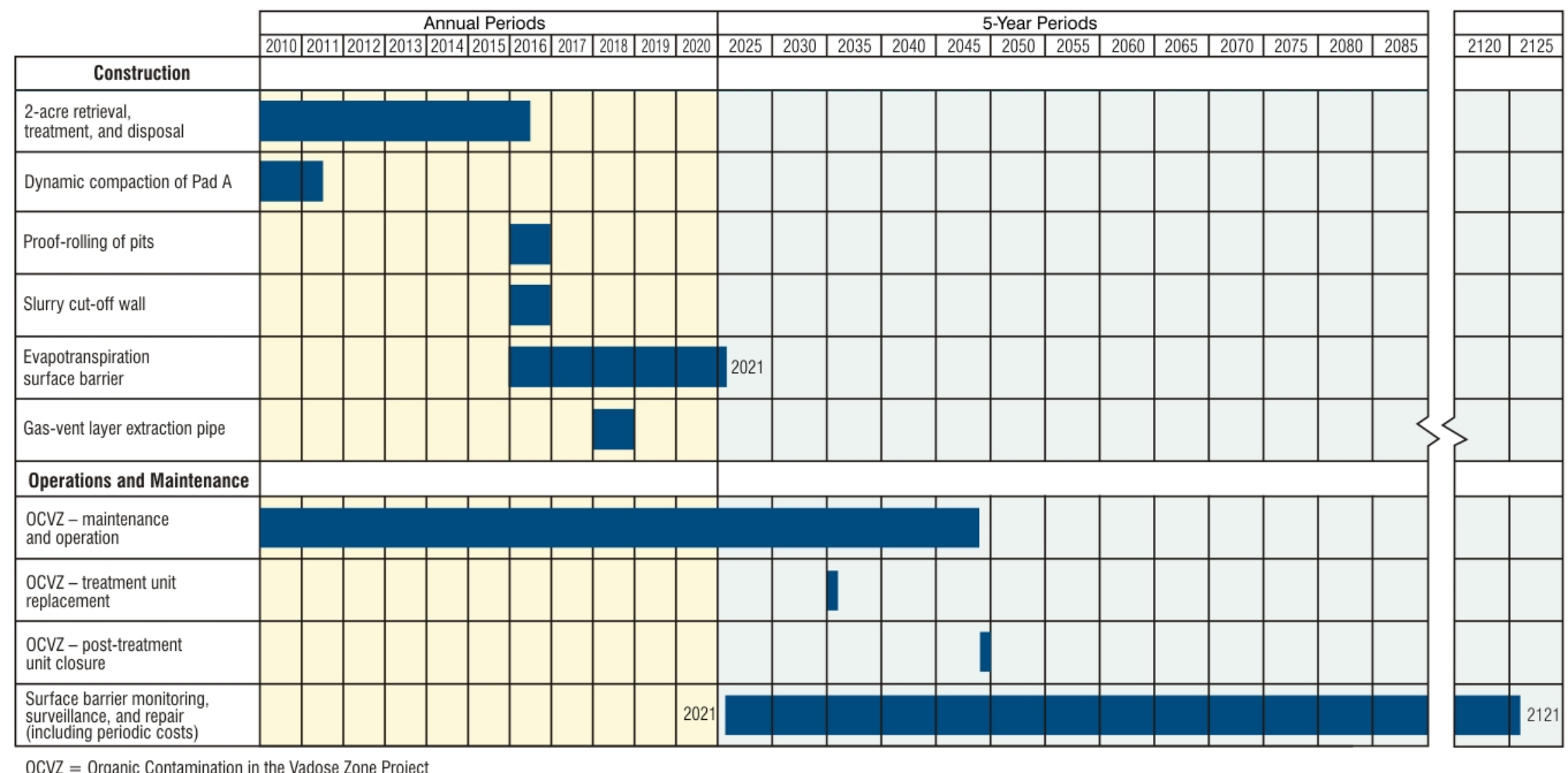

OCVZ = Organic Contamination in the Vadose Zone Project
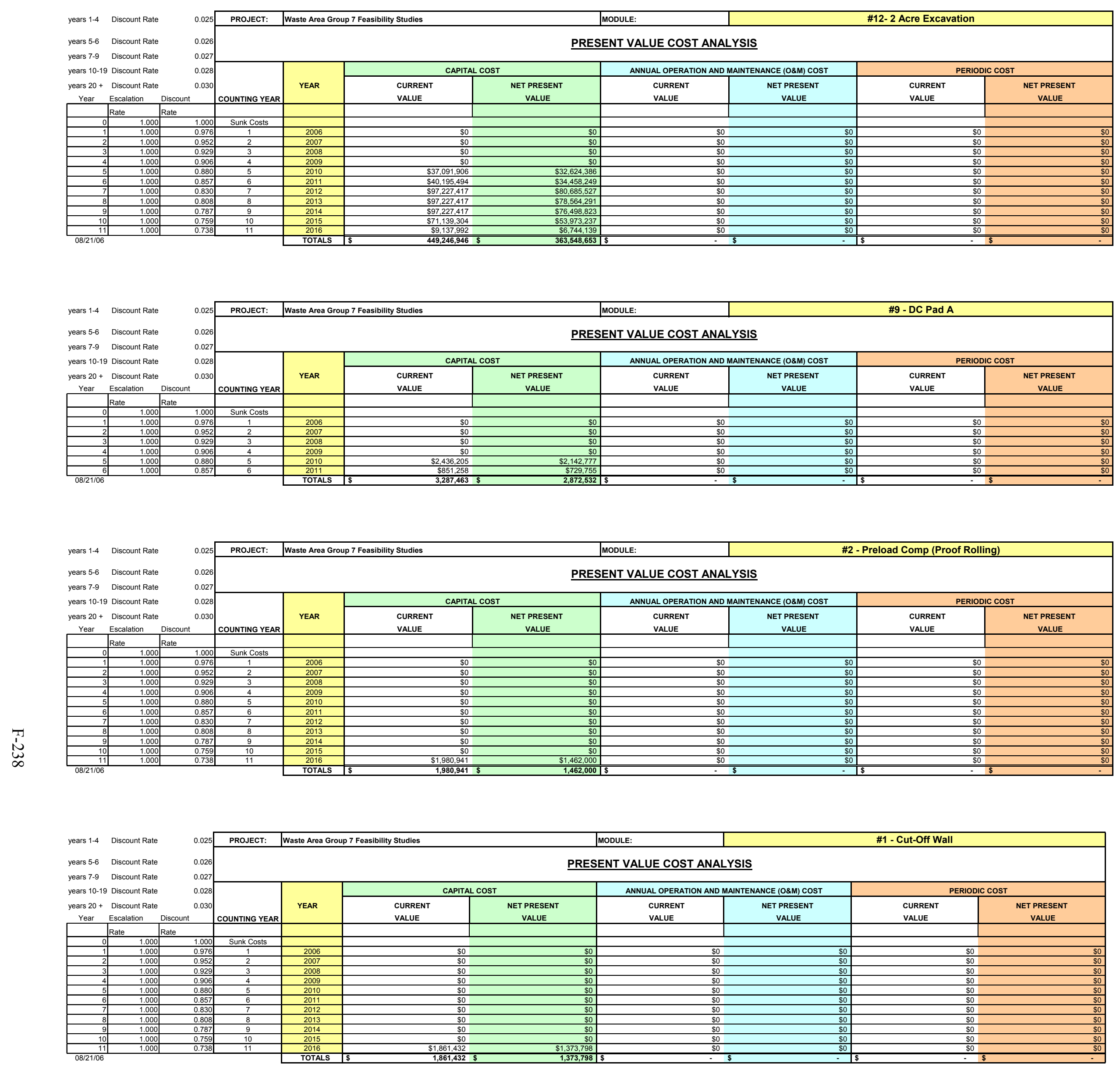

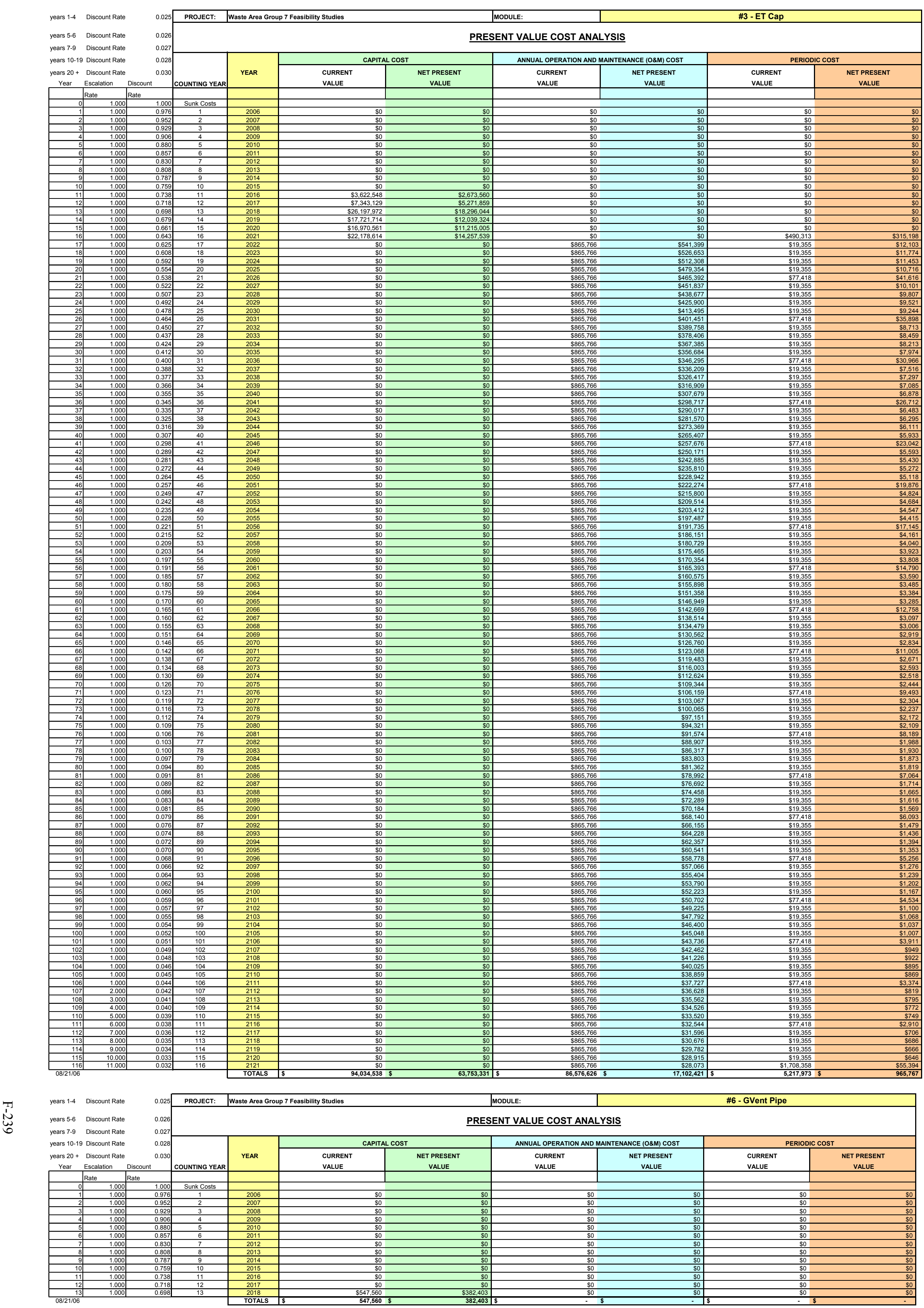


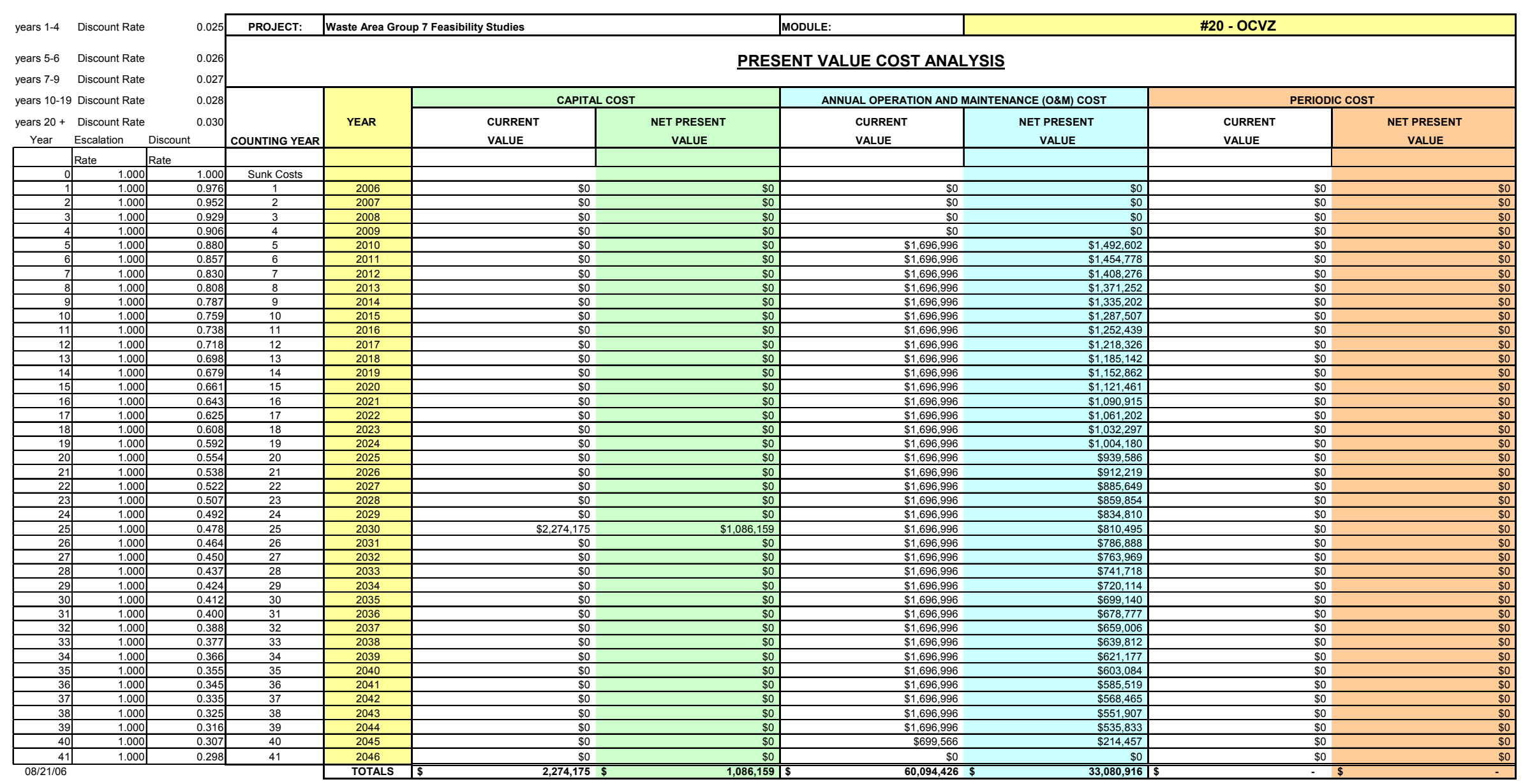

This present value analysis utilizes the real discount rates provided in the Officice of Management and Budget (OMB) Circular A-94, Appendix C, January 2006 revision.
The values identified under the Current Value headings represent unescalated dollars. 


\section{Alternative 5: Full Retrieval}

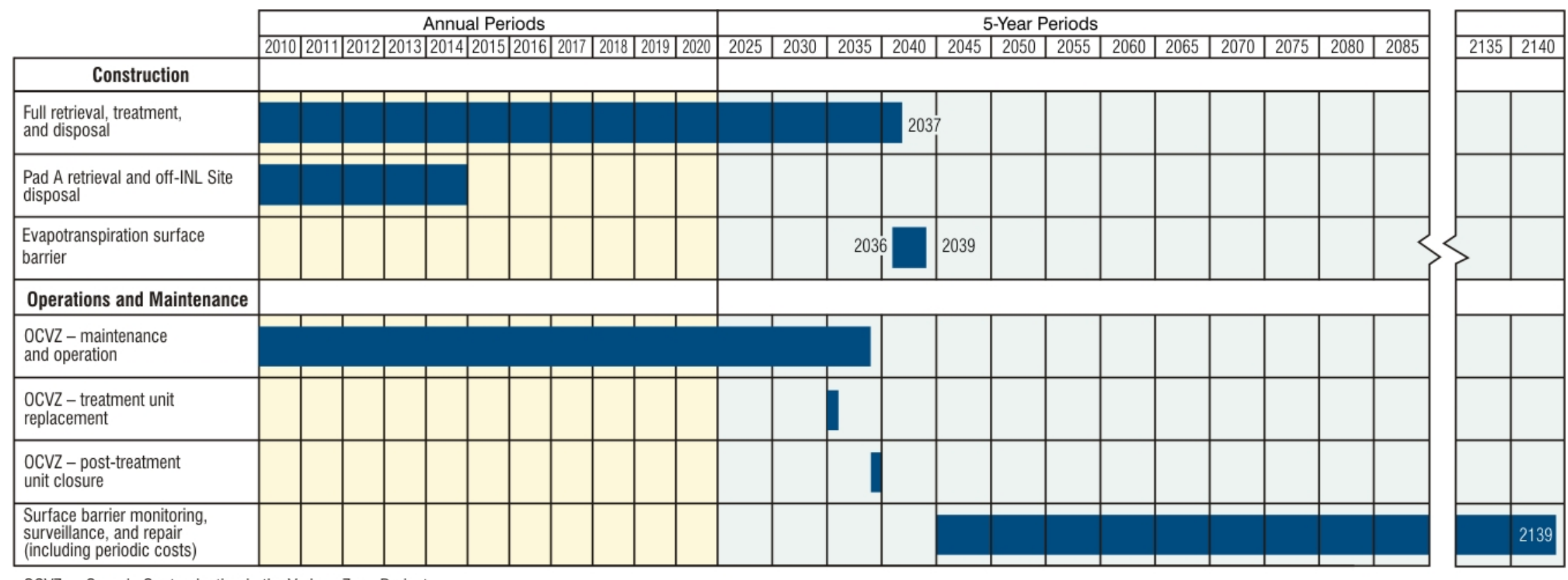

OCVZ = Organic Contamination in the Vadose Zone Project
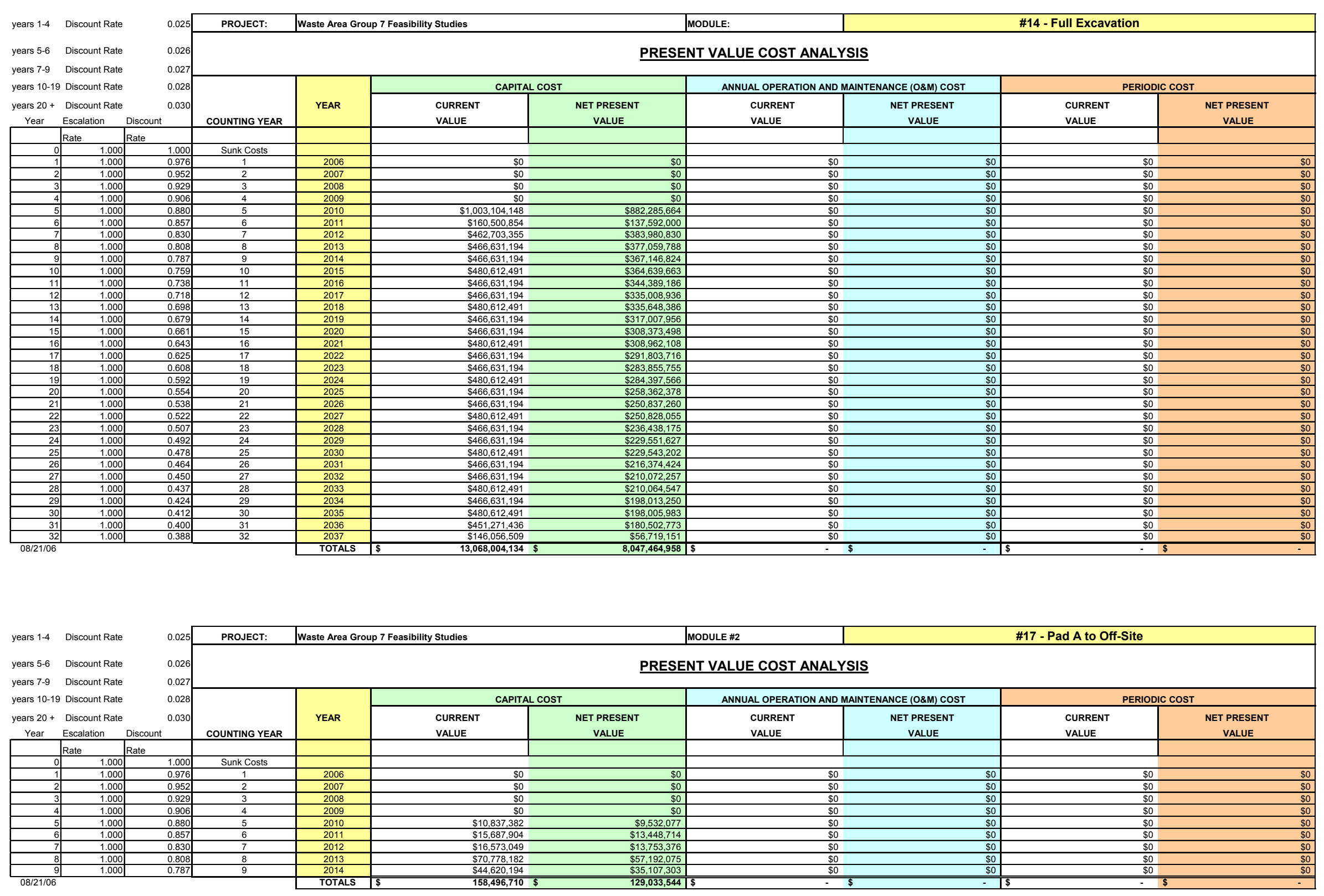


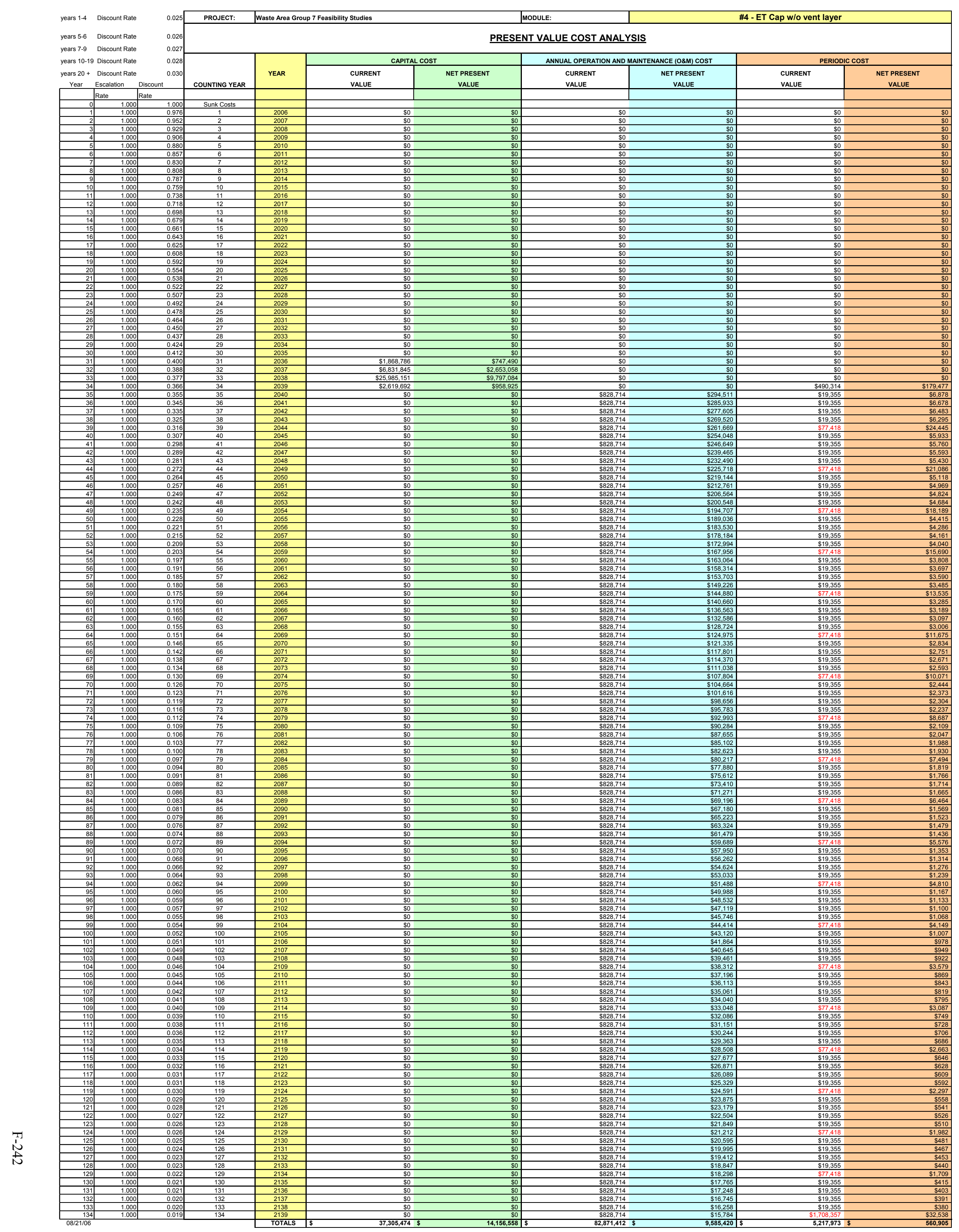




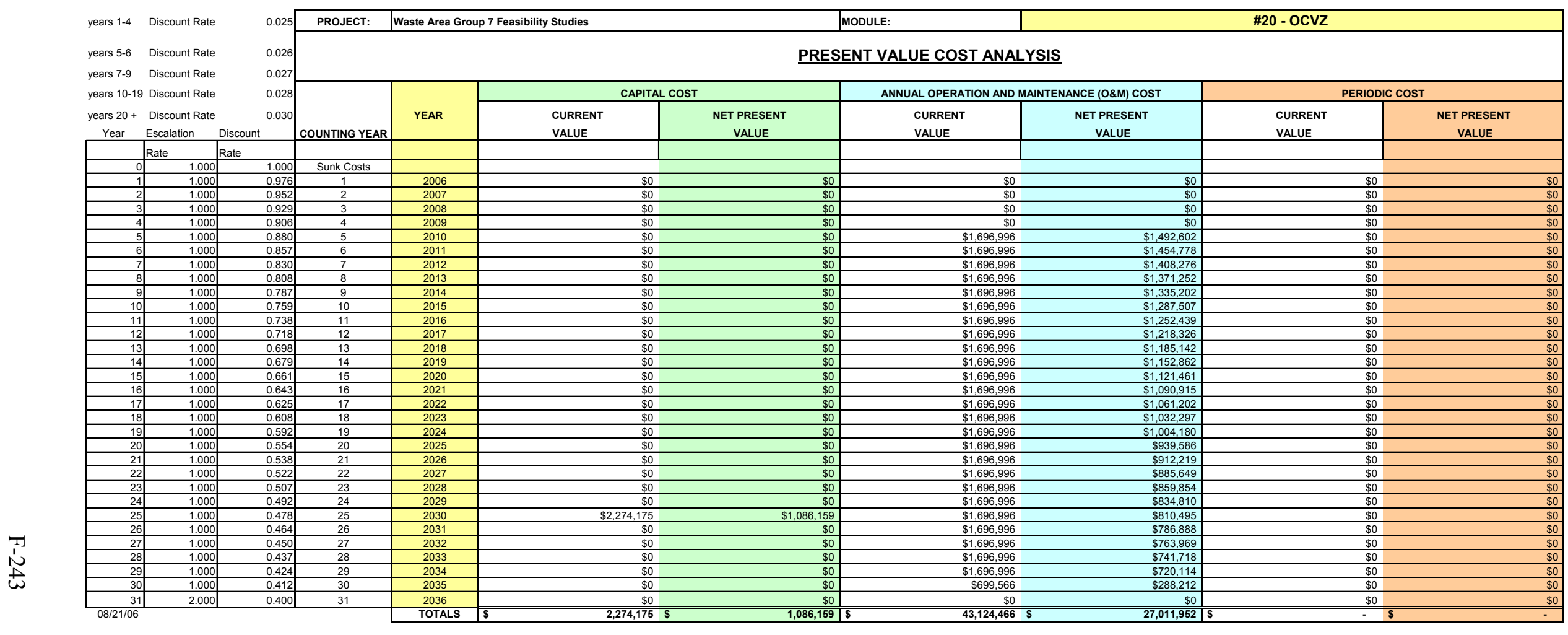

This present value analysis utilizes the real discount rates provided in the Office of Management and Budget (OMB) Circular A-94, Appendix C, January 2006 revision. 


\section{F-26. REFERENCES}

42 USC $\S 6901$ et seq., 1976, "Resource Conservation and Recovery Act of 1976 (Solid Waste Disposal Act)," United States Code, October 21, 1976.

42 USC § 9601 et seq., 1980, "Comprehensive Environmental Response, Compensation and Liability Act of 1980," United States Code, December 11, 1980.

DOE-ID, 1994, Record of Decision: Declaration for Pad A at the Radioactive Waste Management Complex Subsurface Disposal Area at the Idaho National Engineering Laboratory, Administrative Record No. 5632, U.S. Department of Energy Idaho Operations Office; U.S. Environmental Protection Agency, Region 10; Idaho Department of Health and Welfare.

DOE-ID, 2000, INEEL Environmental Restoration Cost Estimating/Cost Engineering Guide, DOE/ID-10473, Rev. 2, U.S. Department of Energy Idaho Operations Office.

EPA, 2000, A Guide to Developing and Documenting Cost Estimates During the Feasibility Study, EPA 540-R-00-002, OSWER 9355.0-75, U.S. Environmental Protection Agency, Office of Emergency and Remedial Response; U.S. Army Corps of Engineers.

GDE-112, 2004, Idaho National Engineering and Environmental Laboratory Detailed Work Plan Development Process Guidance,” Rev. 4, Idaho Cleanup Project.

Mattson, Earl, Mark Ankeny, Steve Dwyer, Nancy Hampton, Gretchen Matthern, Brenda Pace, Alva Parsons, Mitch Plummer, Steve Reese, and Jody Waugh, 2004, Preliminary Design for an Engineered Surface Barrier at the Subsurface Disposal Area, ICP/EXT-04-00216, Idaho Completion Project.

OMB, 2006, OMB Circular A-94, Office of Management and Budget.

Zitnik, James F., Aran T. Armstrong, Brian K. Corb, Mark H. Edens, Douglas B. Holsten, Patricia M. O'Flaherty, Janet Rodriguez, Tamara N. Thomas, Russell L. Treat, Wayne Schofield, and Kira L. Sykes, 2002, Preliminary Evaluation of Remedial Alternatives for the Subsurface Disposal Area, INEEL/EXT-02-01258, Rev. 0, prepared by CH2MHILL for the Idaho National Engineering and Environmental Laboratory. 